Prepared for the U.S. Department of Energy

under Contract DE-AC05-76RL01830

\title{
Evaluation of Representative Smart Grid Investment Grant Project Technologies: Distributed Generation
}

\author{
R Singh \\ B Vyakaranam
}

February 2012

\section{Pacific Northwest}

NATIONAL LABORATORY

Proudly Operated by Battelle Since 1965 


\title{
DISCLAIMER
}

This report was prepared as an account of work sponsored by an agency of the United States Government. Neither the United States Government nor any agency thereof, nor Battelle Memorial Institute, nor any of their employees, makes any warranty, express or implied, or assumes any legal liability or responsibility for the accuracy, completeness, or usefulness of any information, apparatus, product, or process disclosed, or represents that its use would not infringe privately owned rights. Reference herein to any specific commercial product, process, or service by trade name, trademark, manufacturer, or otherwise does not necessarily constitute or imply its endorsement, recommendation, or favoring by the United States Government or any agency thereof, or Battelle Memorial Institute. The views and opinions of authors expressed herein do not necessarily state or reflect those of the United States Government or any agency thereof.

\author{
PACIFIC NORTHWEST NATIONAL LABORATORY \\ operated by \\ BATTELLE \\ for the \\ UNITED STATES DEPARTMENT OF ENERGY \\ under Contract DE-AC05-76RL01830
}

Printed in the United States of America
Available to DOE and DOE contractors from the Office of Scientific and Technical Information,
P.O. Box 62, Oak Ridge, TN 37831-0062;
ph: (865) 576-8401
fax: $(865)$ 576-5728
email: reports@adonis.osti.gov

\begin{abstract}
Available to the public from the National Technical Information Service, U.S. Department of Commerce, 5285 Port Royal Rd., Springfield, VA 22161 ph: (800) 553-6847 fax: $(703) 605-6900$ email: orders@ntis.fedworld.gov online ordering: http://www.ntis.gov/ordering.htm
\end{abstract}

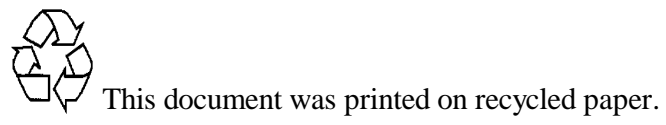




\title{
Evaluation of Smart Grid Investment Grant Project Technologies: Distributed Generation
}

\author{
R Singh \\ B Vyakaranam
}

February 2012

Prepared for the U.S. Department of Energy under Contract DE-AC05-76RL01830

Pacific Northwest National Laboratory Richland, Washington 99352 


\section{$\underline{\text { Table of Contents }}$}

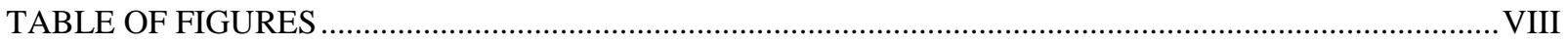

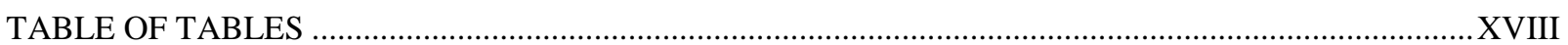

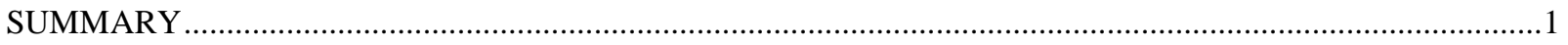

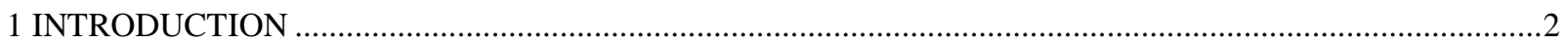

1.1 REPORT SCOPE

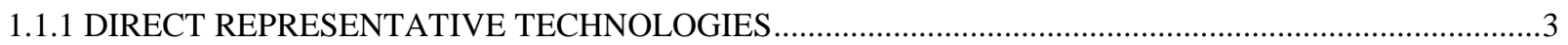

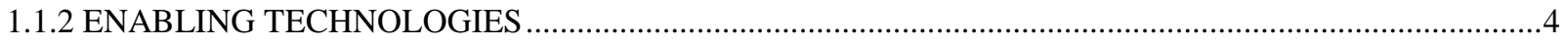

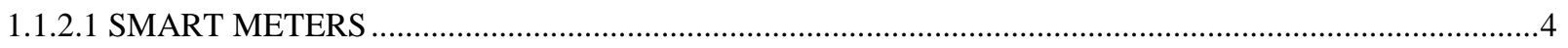

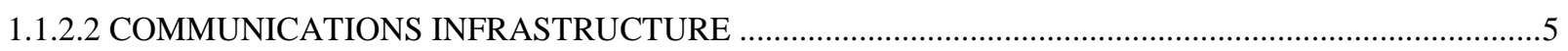

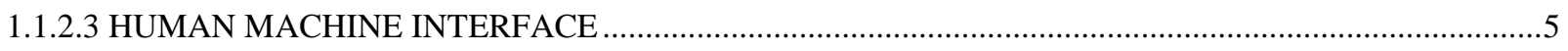

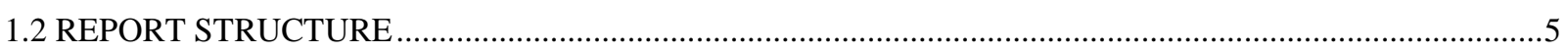

2 DISTRIBUTED GENERATION TECHNOLOGY AREAS.

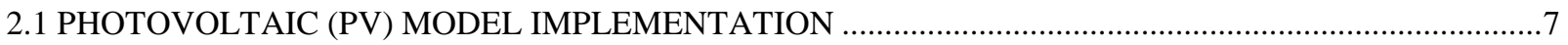

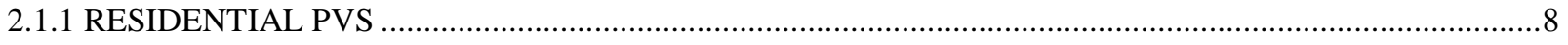

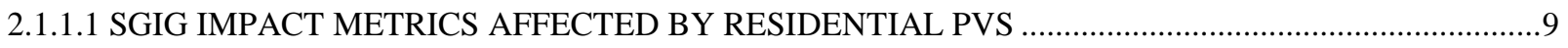

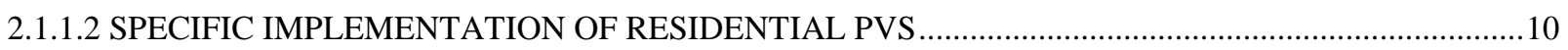

2.1.1.3 OVERALL RESIDENTIAL PVS SIMULATION RESULTS ............................................................... 11

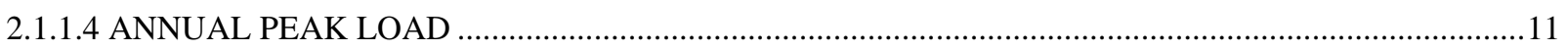

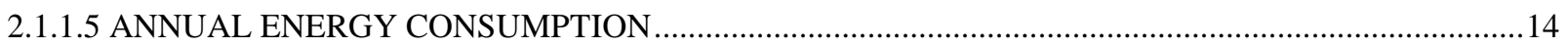

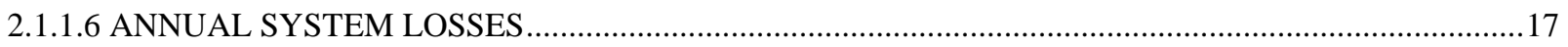

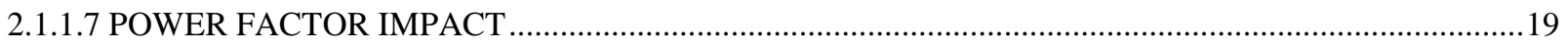

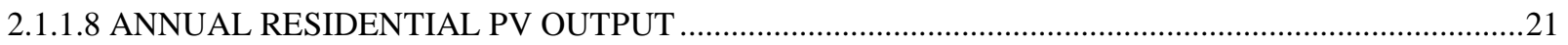

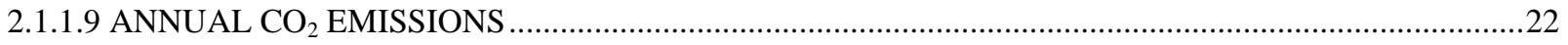

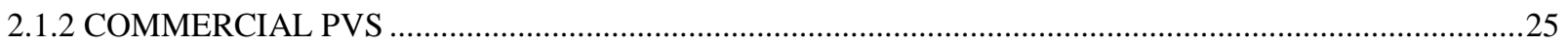

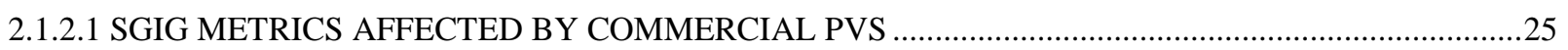

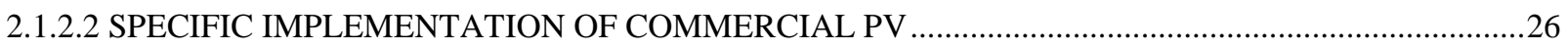

2.1.2.3 HIGH LEVEL COMMERCIAL PV SIMULATION RESULTS ...............................................................26

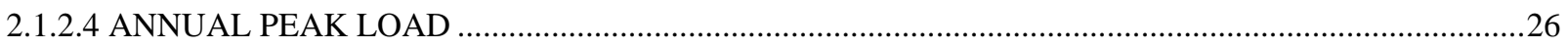

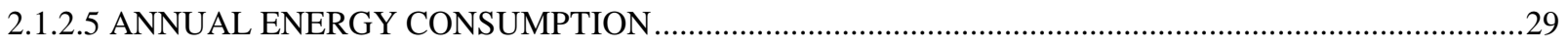

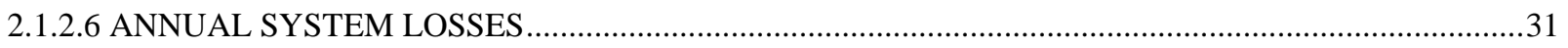

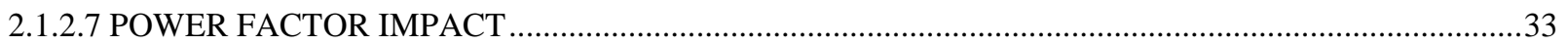

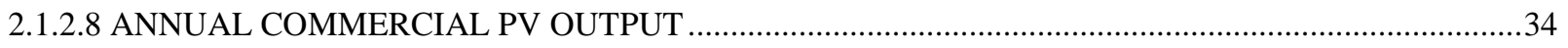

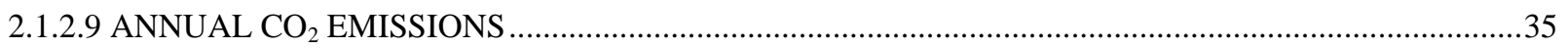

2.1.3 ADDITION OF BOTH COMMERCIAL AND RESIDENTIAL (COMBINED) PVS...................................37

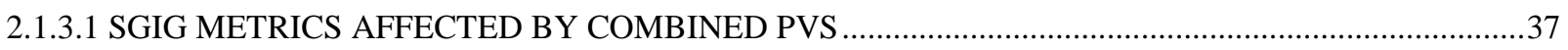

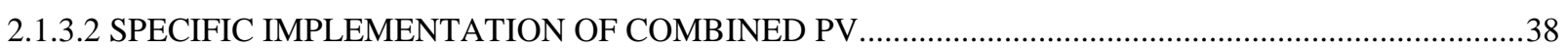

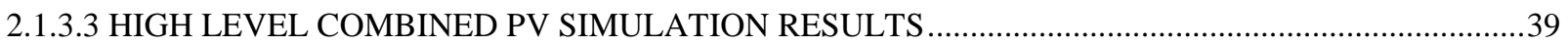

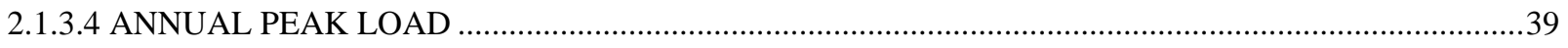

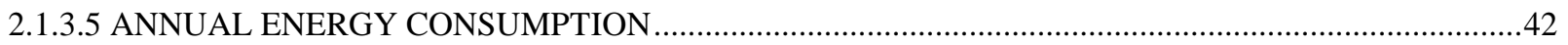

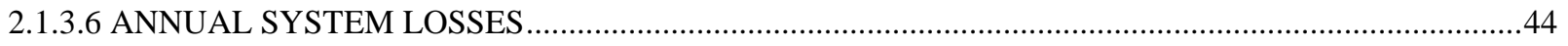

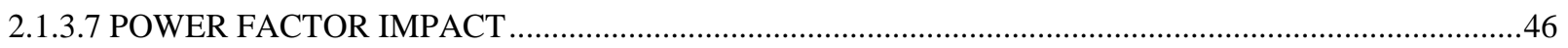

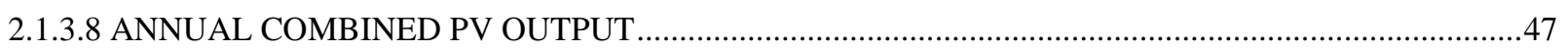




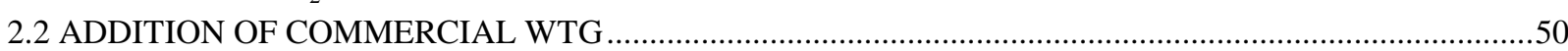

2.2.1 SGIG METRICS AFFECTED BY COMMERCIAL WTG …….....................................................................51

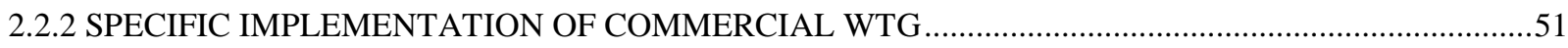

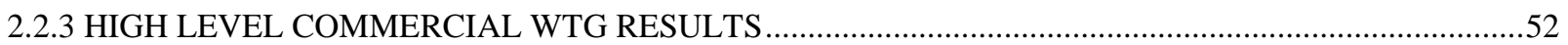

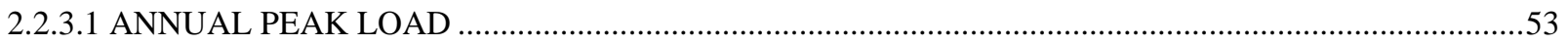

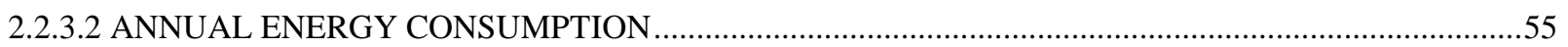

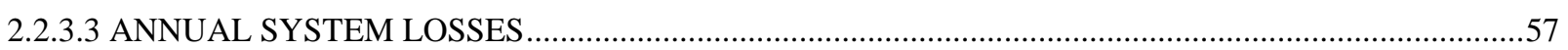

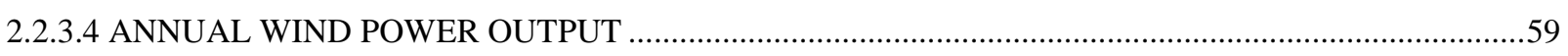

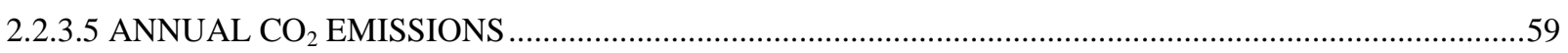

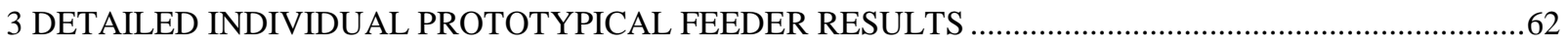

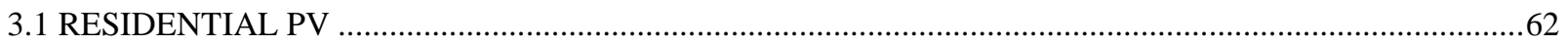

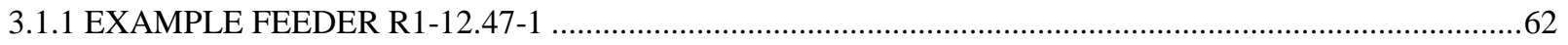

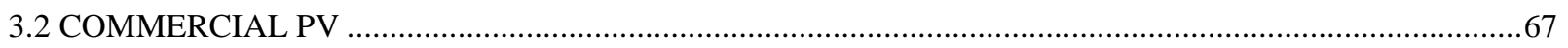

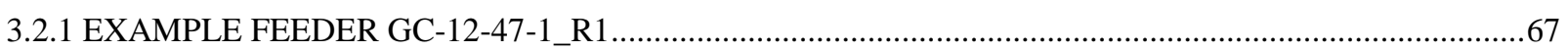

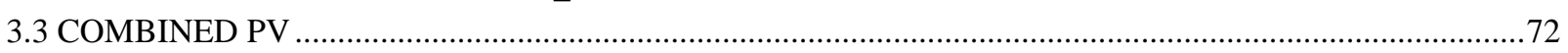

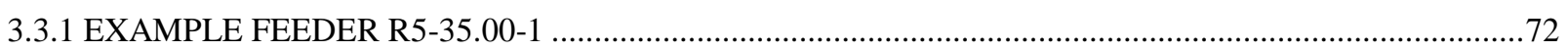

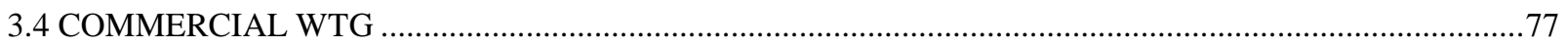

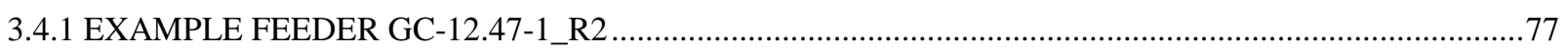

4 SGIG IMPACT METRIC VALUES …

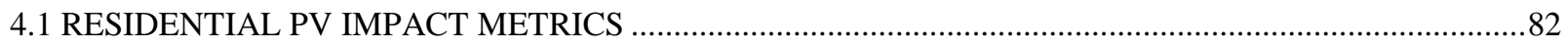

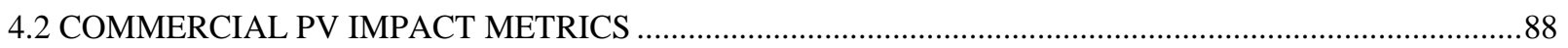

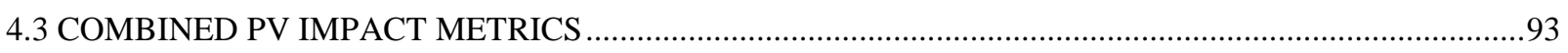

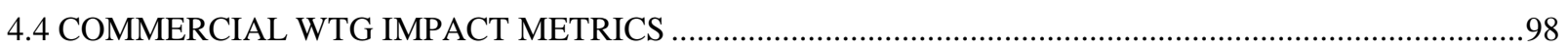

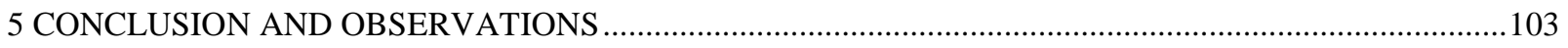

5.1 DISTRIBUTED GENERATION OBSERVATIONS AND CONCLUSIONS ……....................................103

5.2 DISTRIBUTED GENERATION OBSERVATIONS AND CONCLUSIONS SUMMARY ..........................104

5.2.1 OBSERVATIONS AND CONCLUSIONS SUMMARY FOR PV INTEGRATION.................................105

5.2.2 OBSERVATIONS AND CONCLUSIONS SUMMARY FOR WTG INTEGRATION ............................106

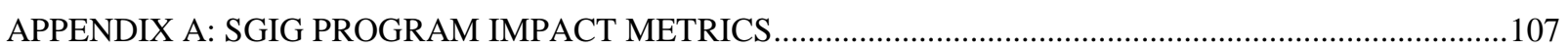

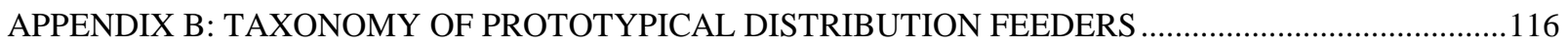

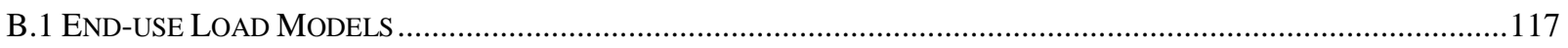

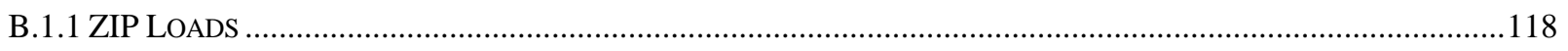

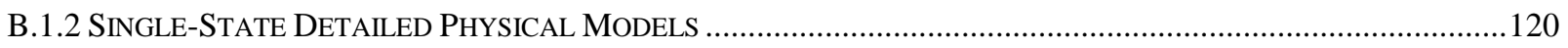

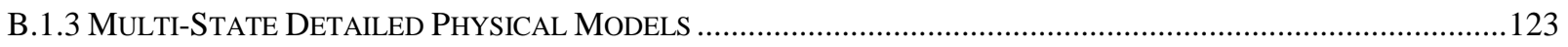

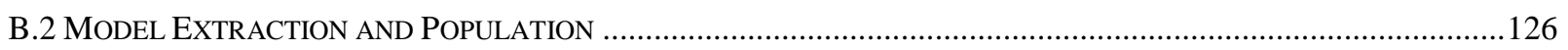

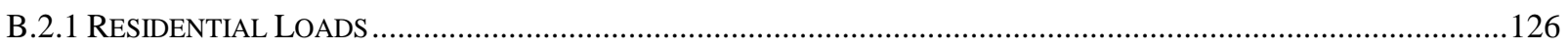

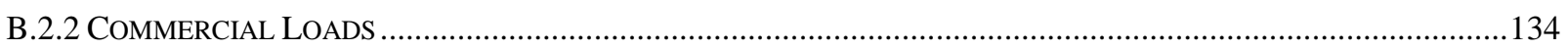

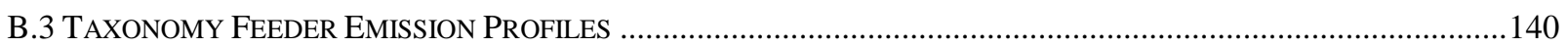

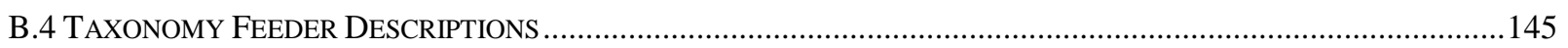

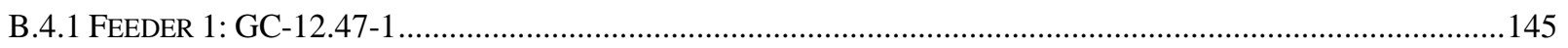

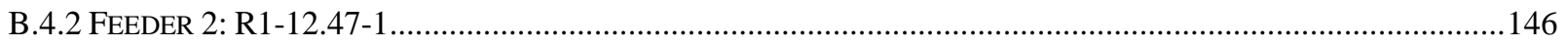

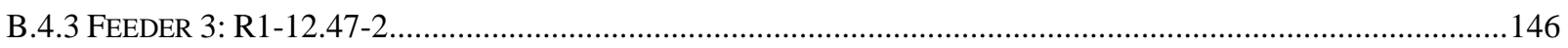




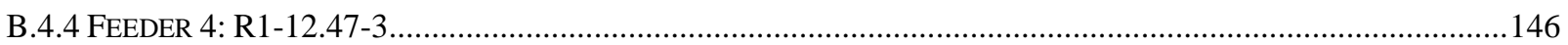

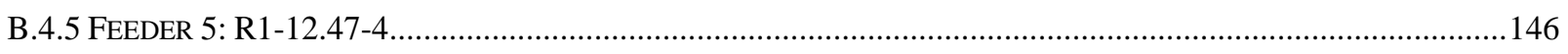

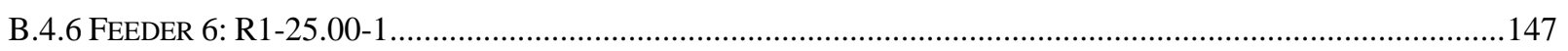

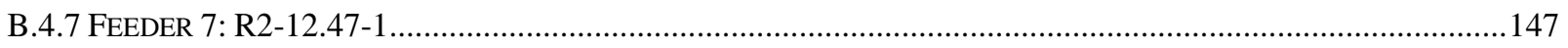

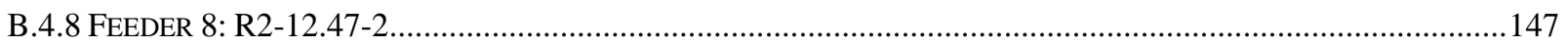

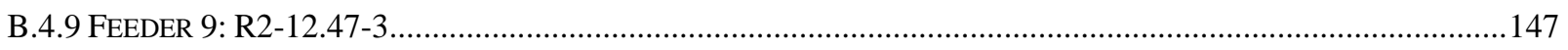

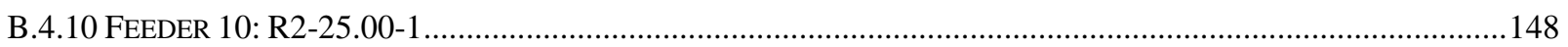

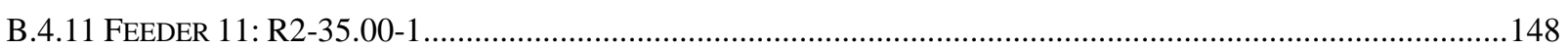

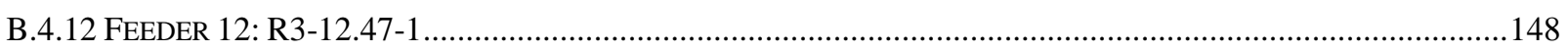

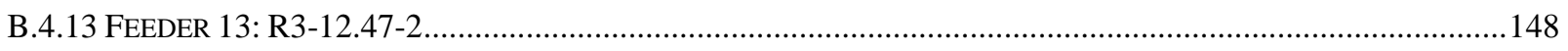

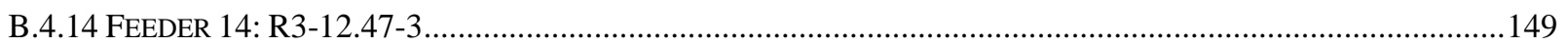

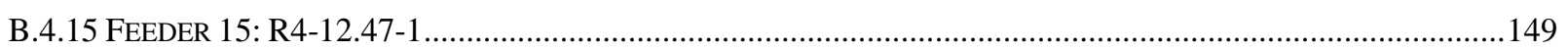

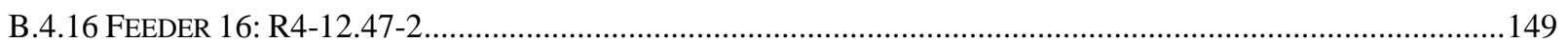

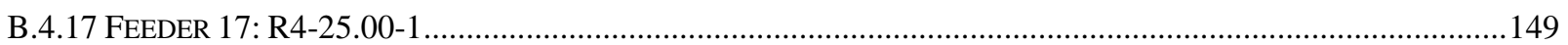

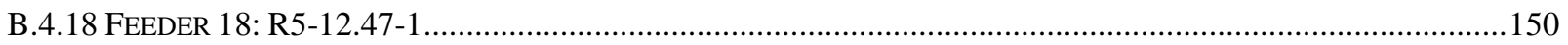

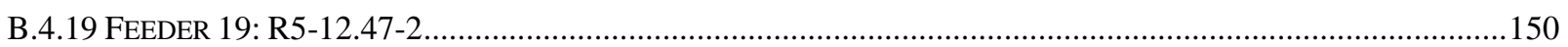

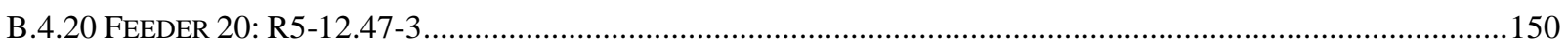

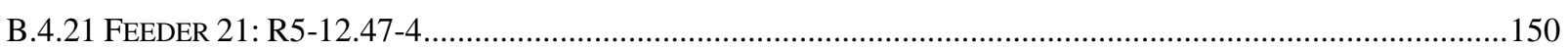

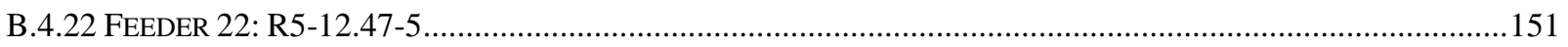

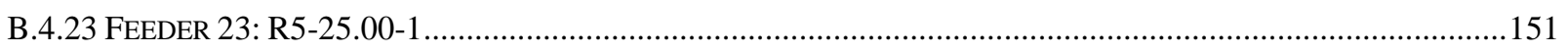

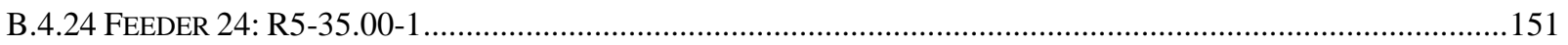

APPENDIX C: SIMULATION TECHNOLOGY AND METHODOLOGY ......................................................

APPENDIX D: PLOTS FOR INDIVIDUAL FEEDER RESULTS ................................................................. 155

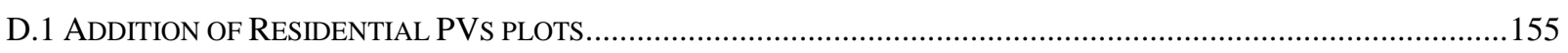

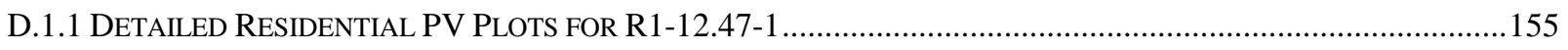

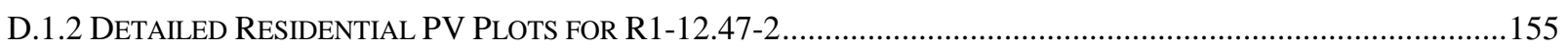

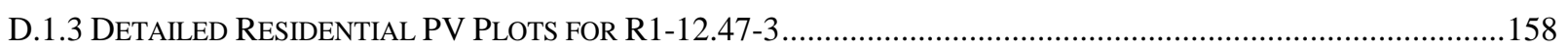

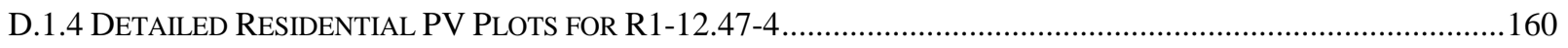

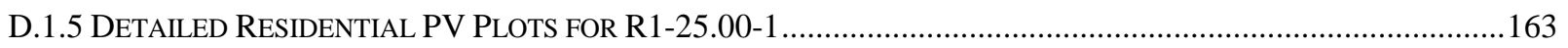

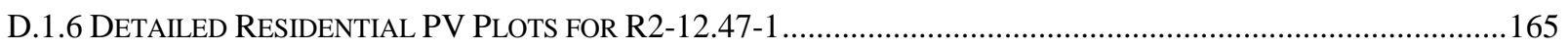

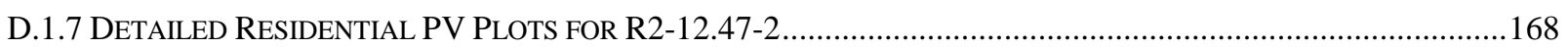

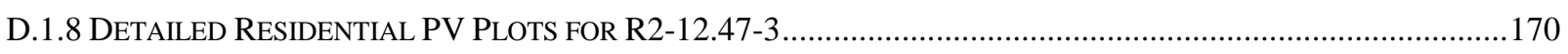

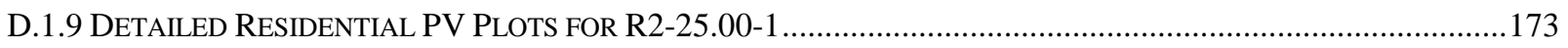

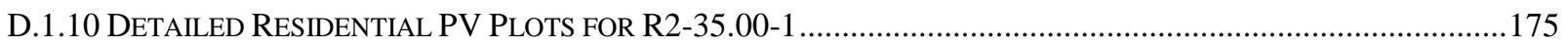

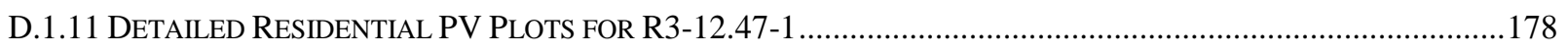

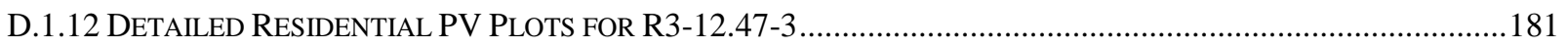

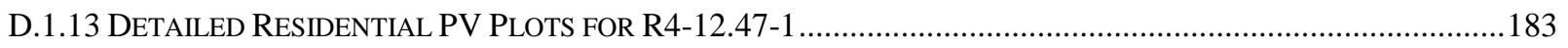

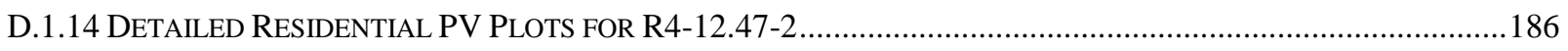

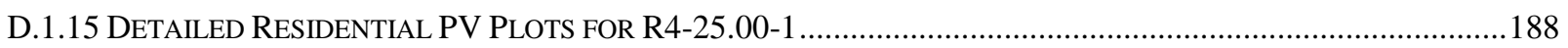

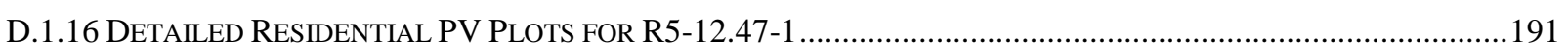

D.1.17 DETAILED RESIDENTIAL PV PLOTS FOR R5-12.47-2 _............................................................................194

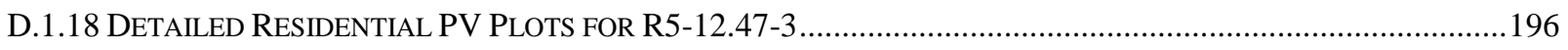

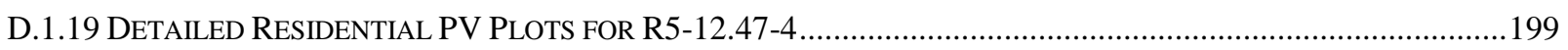

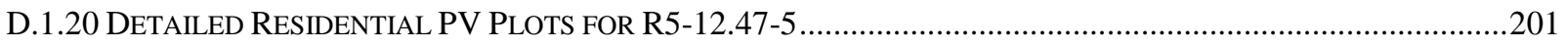

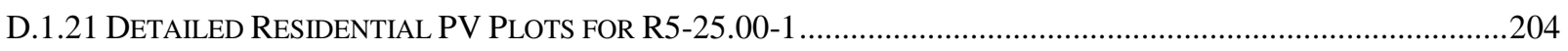

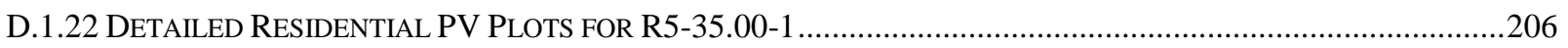




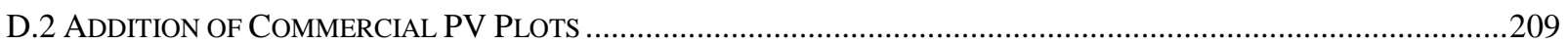

D.2.1 DETAILED COMMERCIAL PV PLOTS FOR GC-12.47-1_R1 ….................................................................209

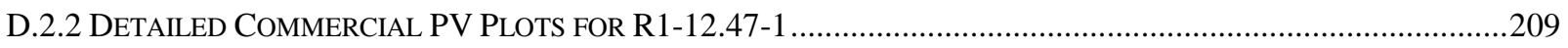

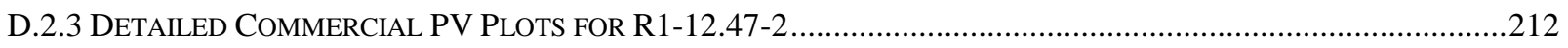

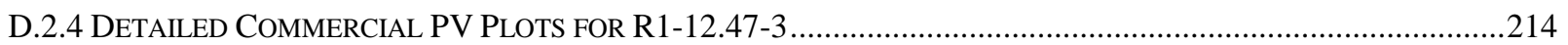

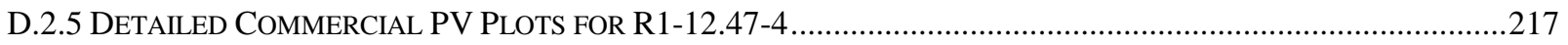

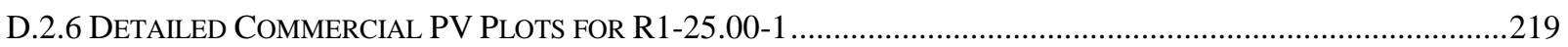

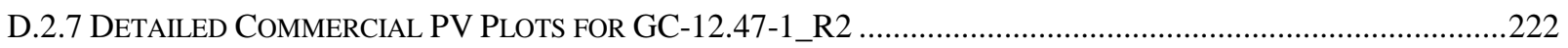

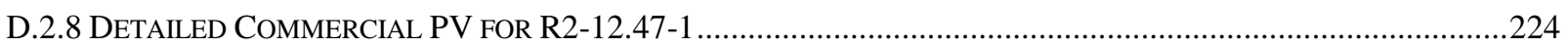

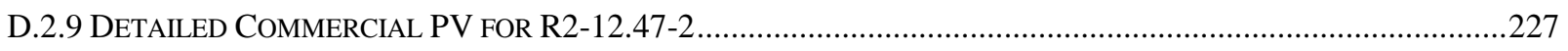

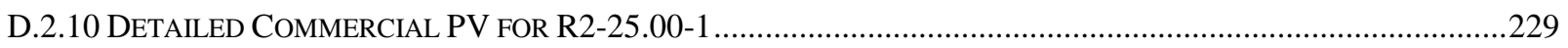

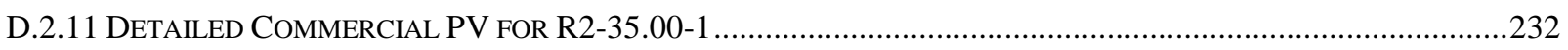

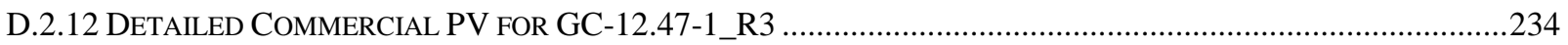

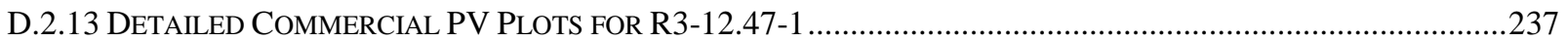

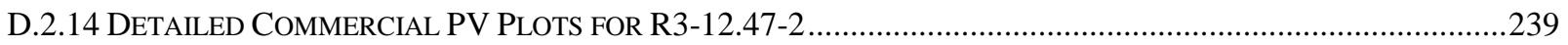

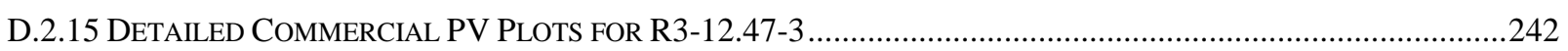

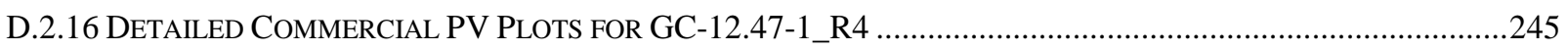

D.2.17 DETAILED COMMERCIAL PV PLOTS FOR R4-12.47-1 ........................................................................247

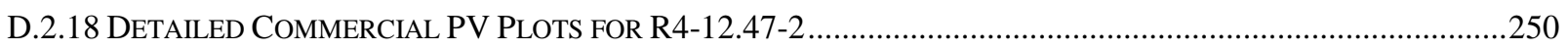

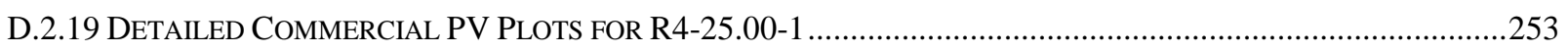

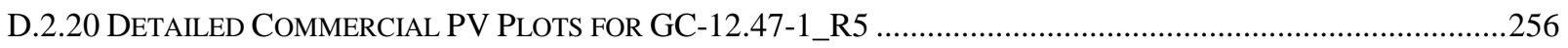

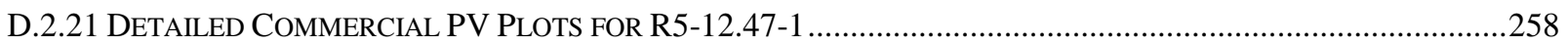

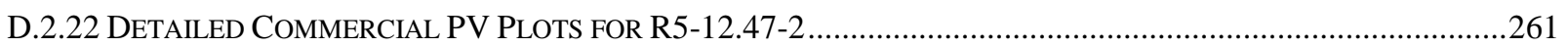

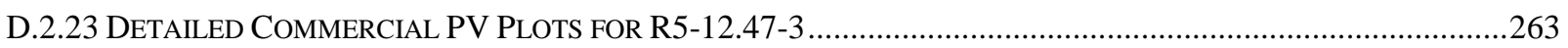

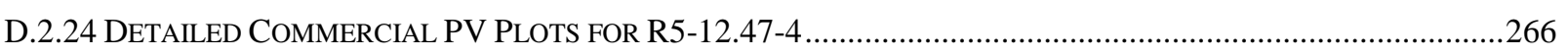

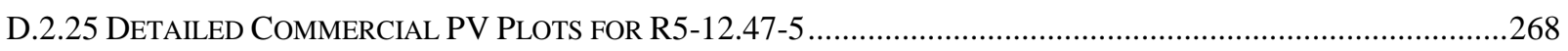

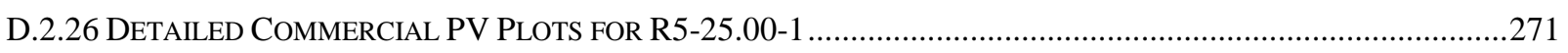

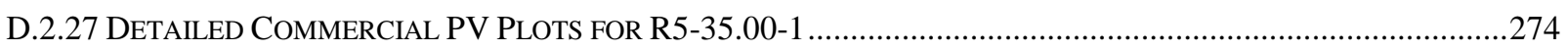

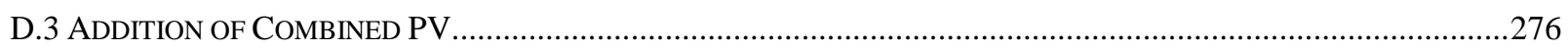

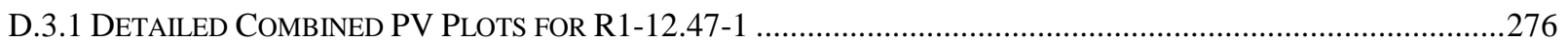

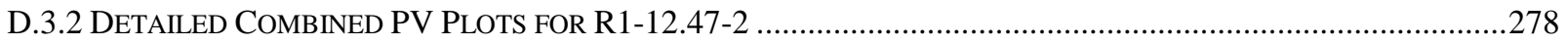

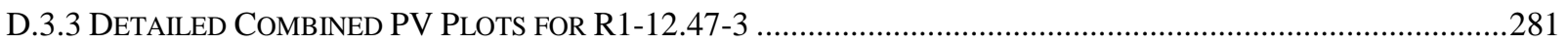

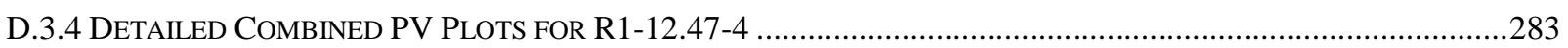

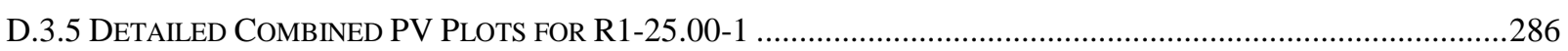

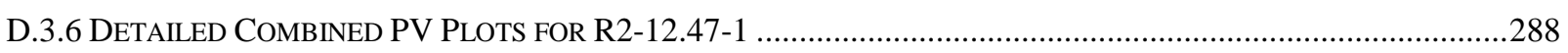

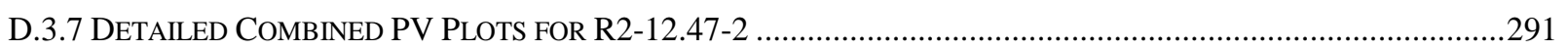

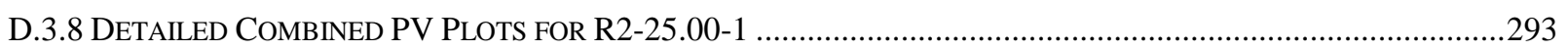

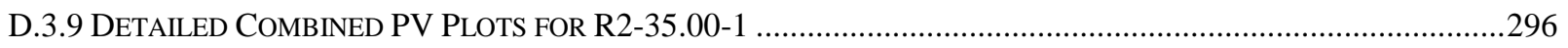

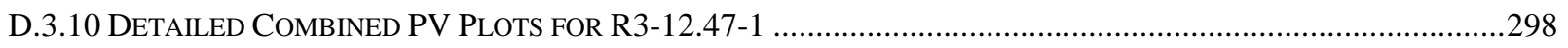

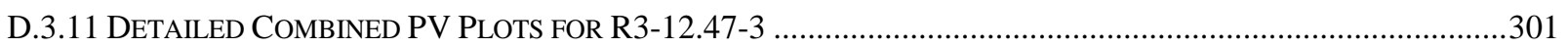

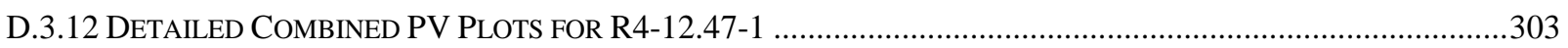

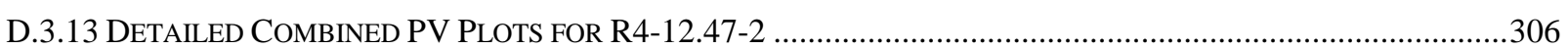

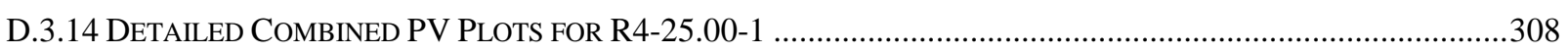

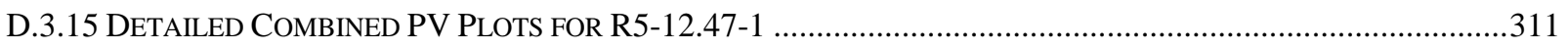

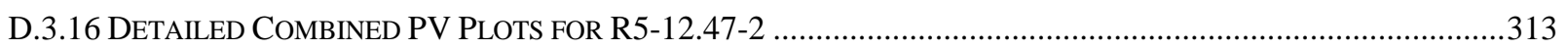

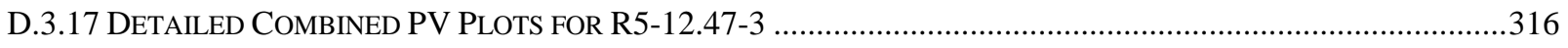

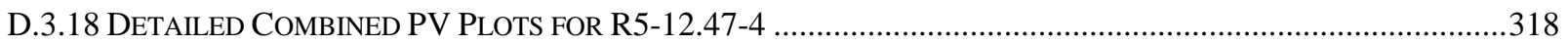

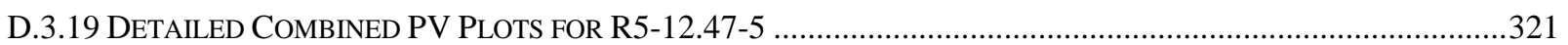




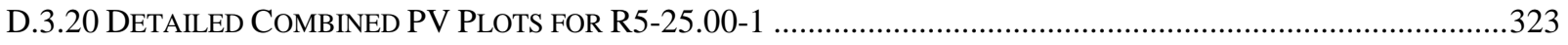

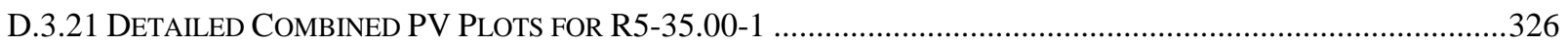

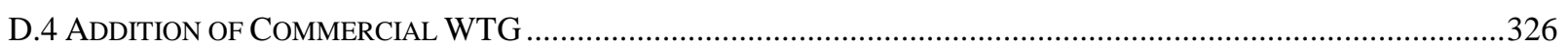

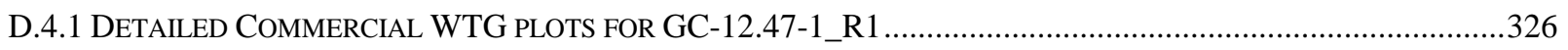

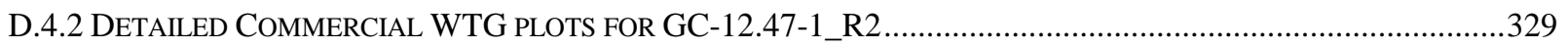

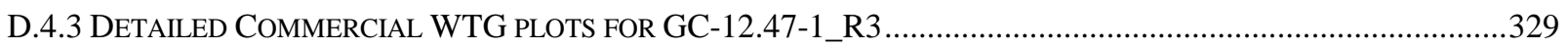

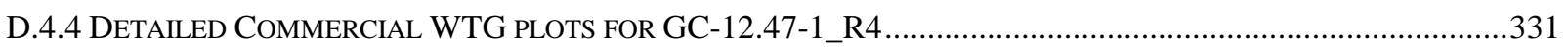

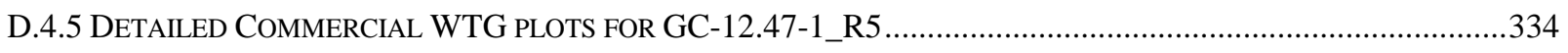

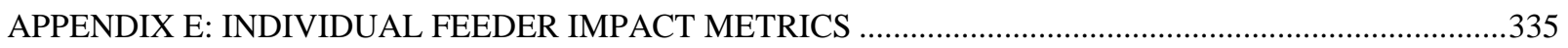

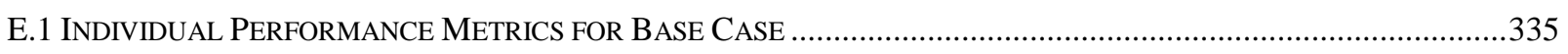

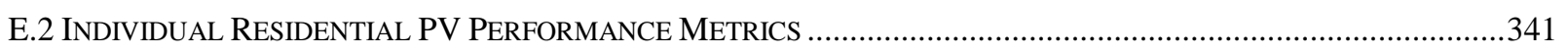

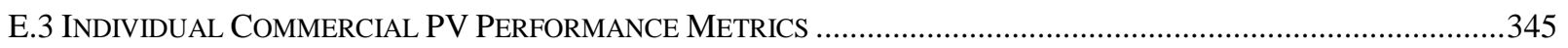

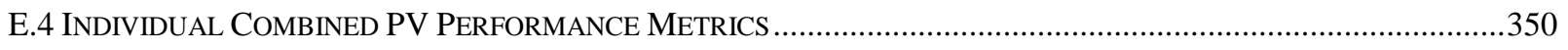

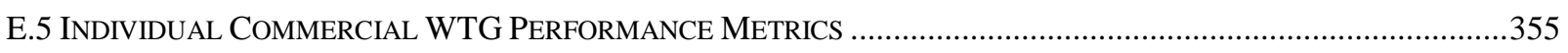

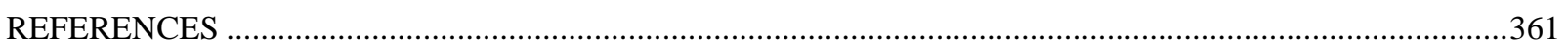




\section{$\underline{\text { Table of Figures }}$}

Figure 2.1. Climate Zones Used for Development of Prototypical Feeders.......................................................10

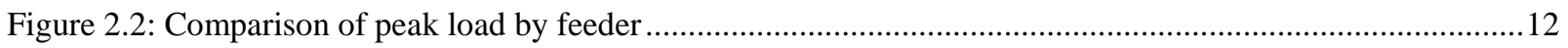

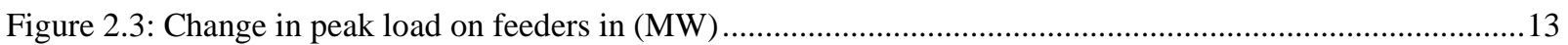

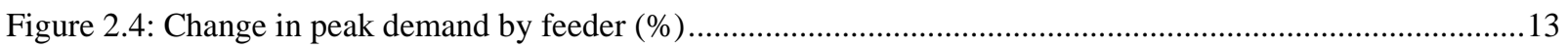

Figure 2.5: Comparison of annual energy consumption by feeder ......................................................................15

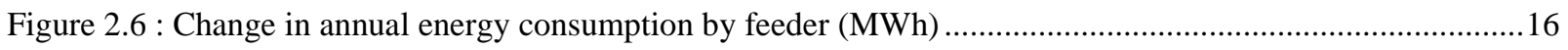

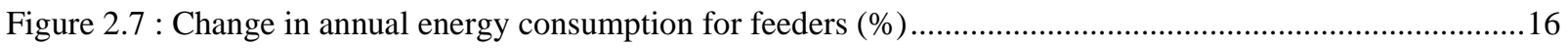

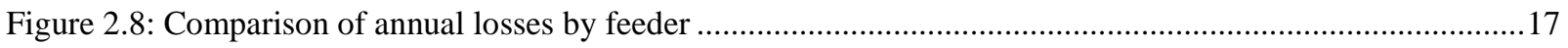

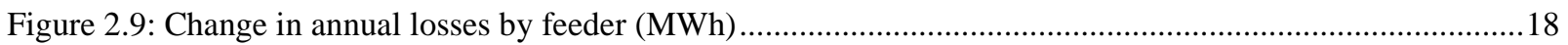

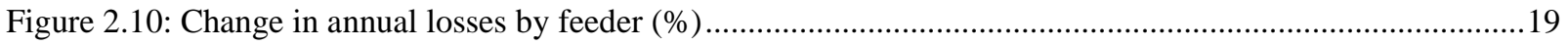

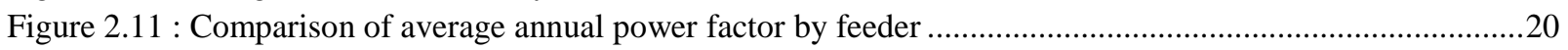

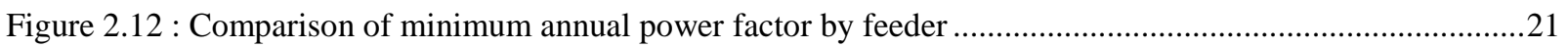

Figure 2.13: Annual residential PV power output by feeder.........................................................................22

Figure 2.14: Comparison of total annual $\mathrm{CO}_{2}$ emission by feeder.....................................................................23

Figure 2.15: Change in total annual $\mathrm{CO}_{2}$ emissions by feeder (tons) .............................................................24

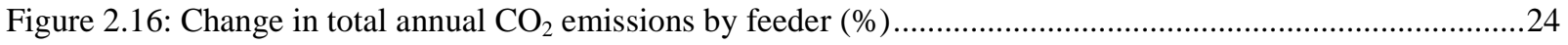

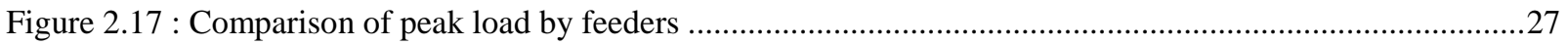

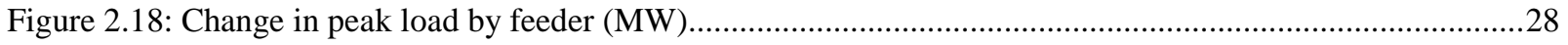

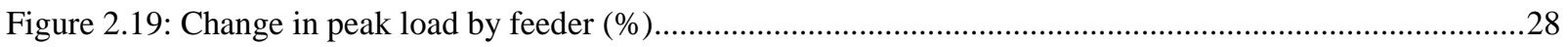

Figure 2.20 : Comparison of annual energy consumption by feeder (MWh) ......................................................29

Figure 2.21 : Change in annual energy consumption by feeder $(\mathrm{GWh})$.............................................................30

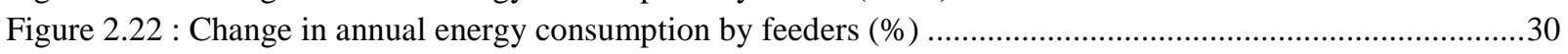

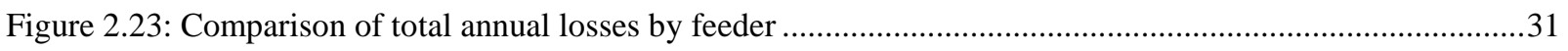

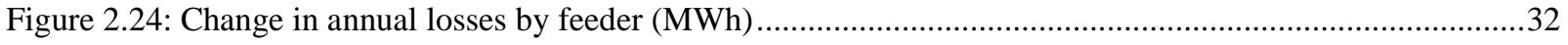

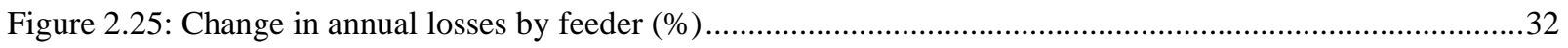

Figure 2.26: Comparison of average annual power factor by feeder ..............................................................33

Figure 2.27: Comparison of minimum annual power factor by feeders.............................................................

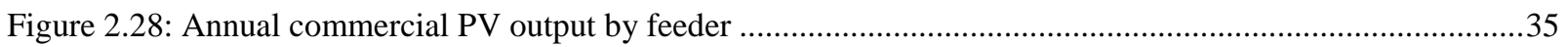

Figure 2.29 : Change in total annual $\mathrm{CO}_{2}$ emissions by feeder (kilotons) ……...............................................36

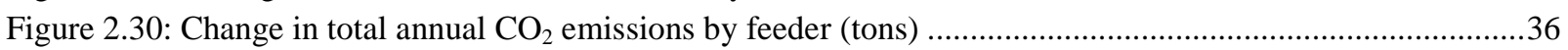

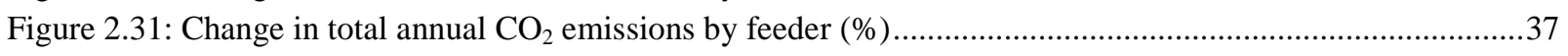

Figure 2.32 Climate Zones Used for Development of Prototypical Feeders...........................................................39

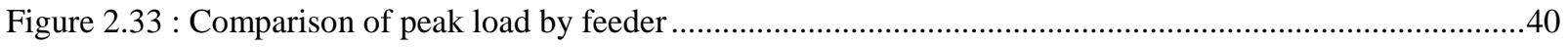

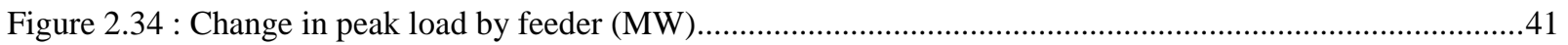

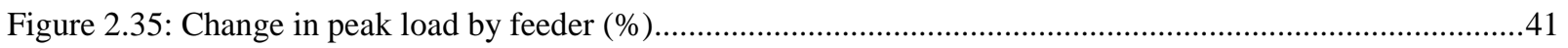

Figure 2.36: Comparison of annual energy consumption by feeder $(\mathrm{GWh})$......................................................42

Figure 2.37: Change in annual energy consumption by feeder (GWh) ..................................................................43

Figure 2.38: Change in annual energy consumption by feeder $(\%)$..................................................................4

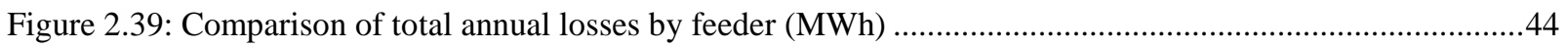

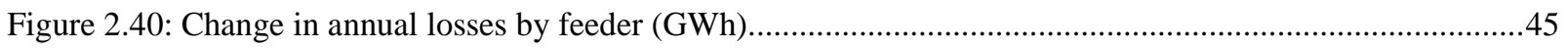

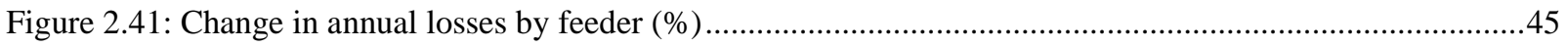

Figure 2.42 : Comparison of annual average power factor by feeder ................................................................

Figure 2.43: Comparison of minimum annual power factor by feeder .............................................................4

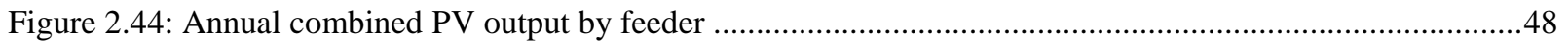

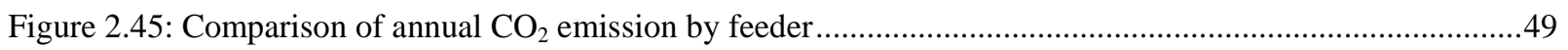

Figure 2.46: Change in annual $\mathrm{CO}_{2}$ emission by feeder (kilotons) ................................................................. 


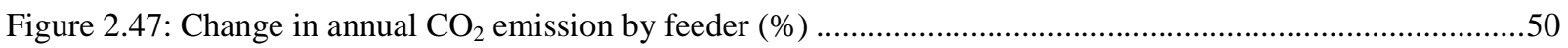

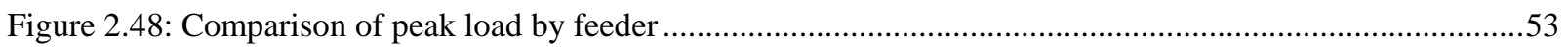

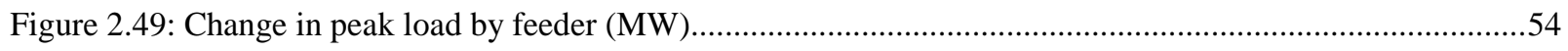

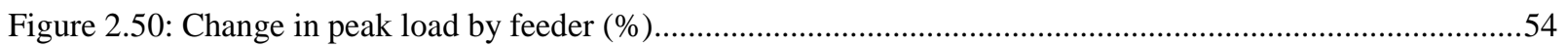

Figure 2.51: Comparison of annual energy consumption by feeder $(\mathrm{GWh})$........................................................5

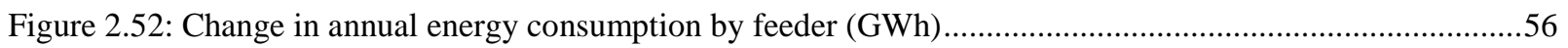

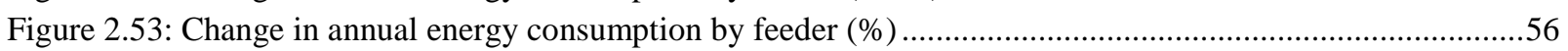

Figure 2.54: Comparison of total annual losses by feeder ...............................................................................57

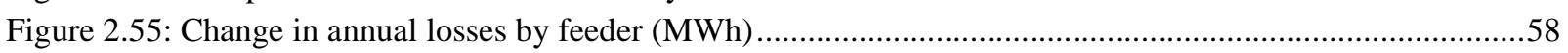

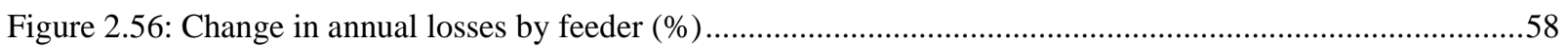

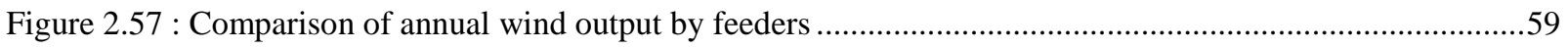

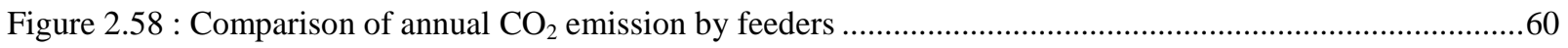

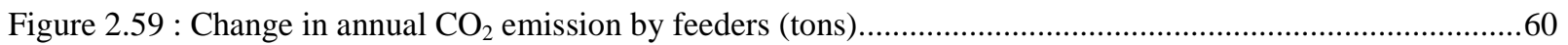

Figure 2.60 : Change in annual $\mathrm{CO}_{2}$ emission by feeders $(\%)$......................................................................61

Figure 3.1: Comparison of peak load by month for R1-12.47-1 .....................................................................63

Figure 3.2: Comparison of energy consumption by month for R1-12.47-1 .....................................................64

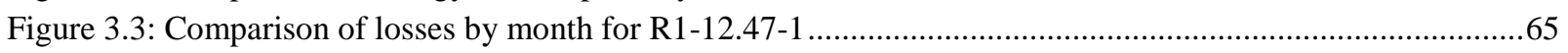

Figure 3.4: Comparison of PV output by month for R1-12.47-1 ...............................................................66

Figure 3.5: Comparison of $\mathrm{CO}_{2}$ emissions by month for R1-12.47-1 ...........................................................67

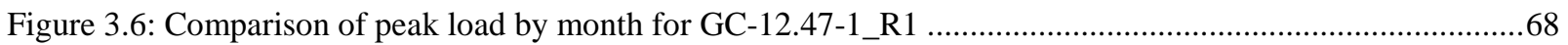

Figure 3.7: Comparison of energy consumption by month for GC-12.47-1_R1 …………………………......69

Figure 3.8: Comparison of losses by month for GC-12.47-1_R1 ..............................................................

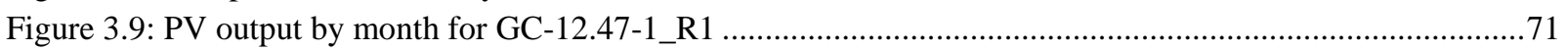

Figure 3.10: Comparison of $\mathrm{CO}_{2}$ emissions by month for GC-12.47-R1 ...........................................................71

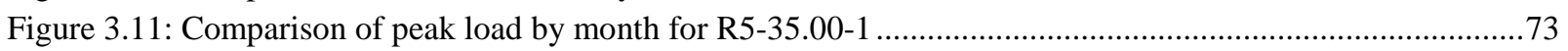

Figure 3.12: Comparison of energy consumption by month for R5-35.00-1 .........................................................74

Figure 3.13: Comparison of losses by month for R5-35.00-1 …................................................................75

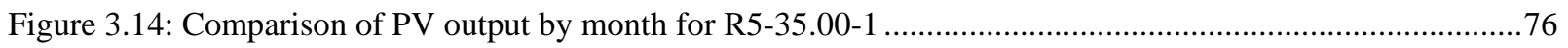

Figure 3.15: Comparison of $\mathrm{CO}_{2}$ emissions by month for R5-35.00-1 ….....................................................

Figure 3.16: Comparison of peak load by month for GC-12.47-1_R2 ...........................................................

Figure 3.17: Comparison of energy consumption by month for GC-12.47-1_R2 ……………........................78

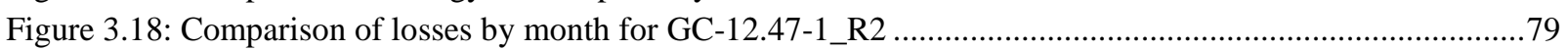

Figure 3.19: Comparison of WTG output by month for GC-12.47-1_R2 ..........................................................8

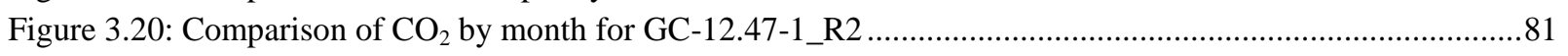

Figure B.1: Climate Zones Used for Development of Prototypical Feeders......................................................116

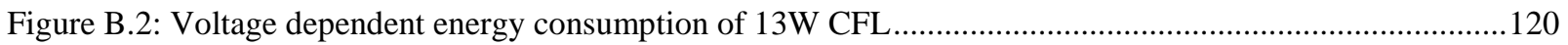

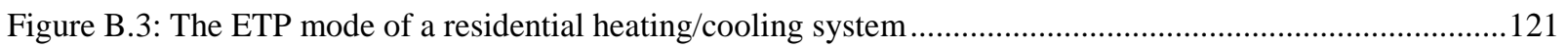

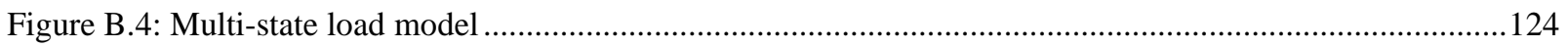

Figure B.5: Exemplary cooling set points diversified with time and daytime and nighttime offsets....................131

Figure B.6: Average cooling set points of entire population of R1-12.47-2 ..................................................131

Figure B.7: Average energy consumption of responsive loads ....................................................................133

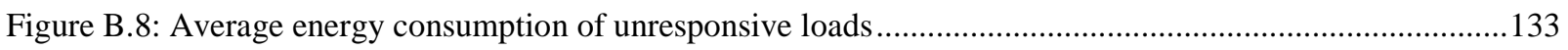

Figure B.9: Office zonal floor plan representing 1 of 3 identical floors .........................................................135

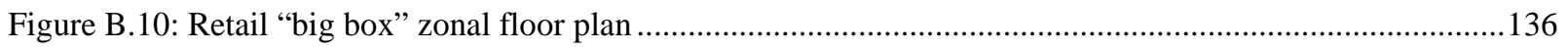

Figure B.11: Retail strip mall zonal floor plan with $\mathrm{N}$ zones depending upon scaling factor..............................137

Figure B.12: Average office end-use load shape (weekday)............................................................................138 
Figure B.13: Average office end-use load shape (weekend).......................................................................138

Figure B.14: Average big box and strip mall end-use load shape (weekday) ..................................................139

Figure B.15: Average big box and strip mall end-use load shape (weekend) ..................................................139

Figure B.16: 15-minute interval comparing fuel dispatch for the peak load versus the base case load versus a

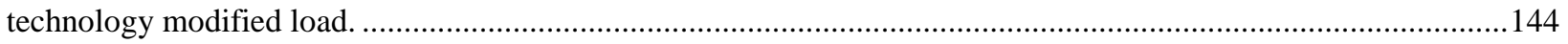

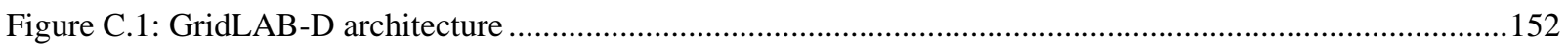

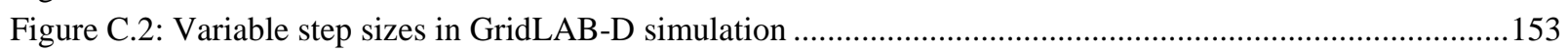

Figure D.1: Comparison of peak load by month for R1-12.47-2 …...........................................................155

Figure D.2: Comparison of energy consumption by month for R1-12.47-2 …..............................................156

Figure D.3: Comparison of losses by month for R1-12.47-2 ….................................................................156

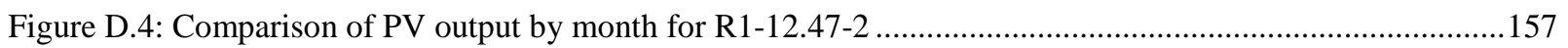

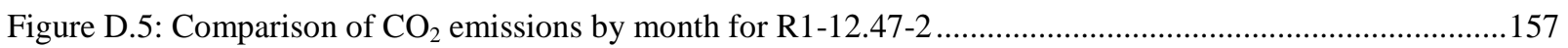

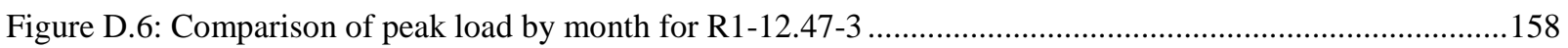

Figure D.7: Comparison of energy consumption by month for R1-12.47-3 ......................................................158

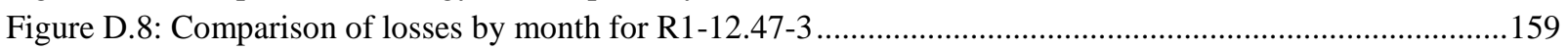

Figure D.9: Comparison of PV output by month for R1-12.47-3 .................................................................159

Figure D.10: Comparison of $\mathrm{CO}_{2}$ emissions by month for R1-12.47-3 ........................................................160

Figure D.11: Comparison of peak load by month for R1-12.47 .....................................................................160

Figure D.12: Comparison of energy consumption by month for R1-12.47-4 ...................................................161

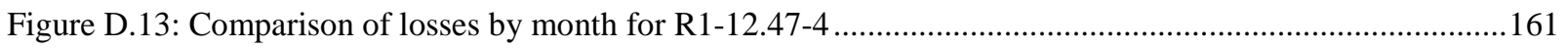

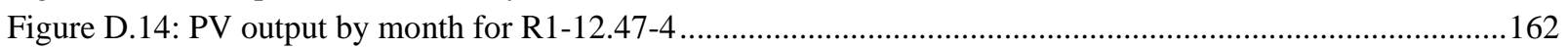

Figure D.15: Comparison of $\mathrm{CO}_{2}$ emissions by month for R1-12.47-4 ….........................................................162

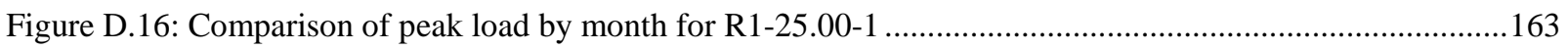

Figure D.17: Comparison of energy consumption by month for R1-25.00-1 ......................................................163

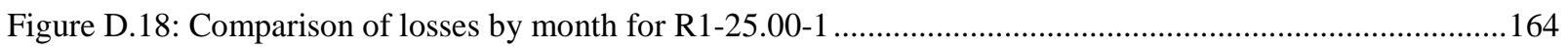

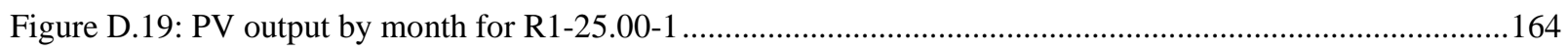

Figure D.20: Comparison of $\mathrm{CO}_{2}$ emissions by month for R1-25.00-1 …........................................................165

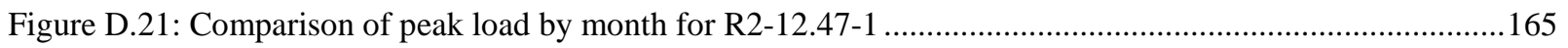

Figure D.22: Comparison of energy consumption by month for R2-12.47-1 ....................................................166

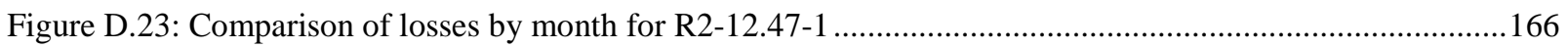

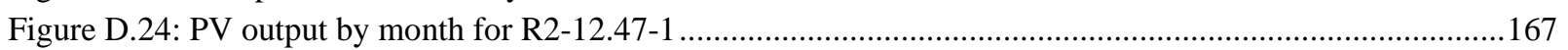

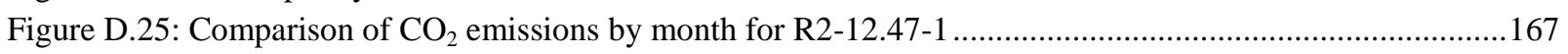

Figure D.26: Comparison of peak load by month for R2-12.47-2 .............................................................. 168

Figure D.27: Comparison of energy consumption by month for R2-12.47-2 ...............................................168

Figure D.28: Comparison of losses by month for R2-12.47-2 …..........................................................169

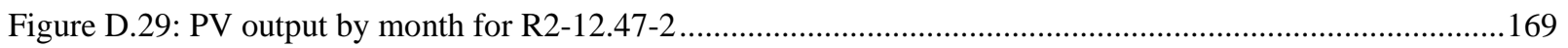

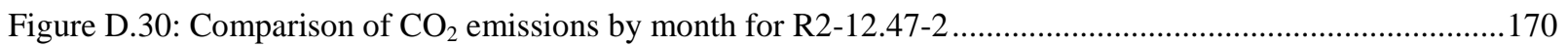

Figure D.31: Comparison of peak load by month for R2-12.47-3 ............................................................170

Figure D.32: Comparison of energy consumption by month for R2-12.47-3 …................................................171

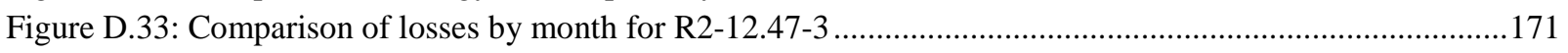

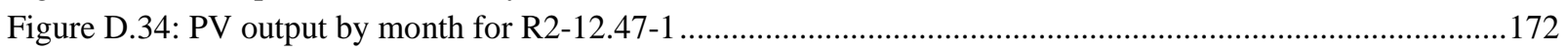

Figure D.35: Comparison of $\mathrm{CO}_{2}$ emissions by month for R2-12.47-3 …..............................................172

Figure D.36: Comparison of peak load by month for R2-25.00-1 ..............................................................173

Figure D.37: Comparison of energy consumption by month for R2-25.00-1 …................................................173

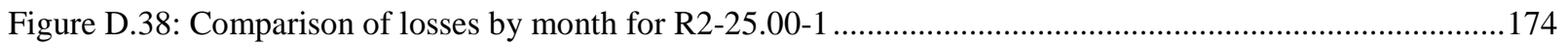

Figure D.39: PV output by month for R2-25.00-1 ..................................................................................174 


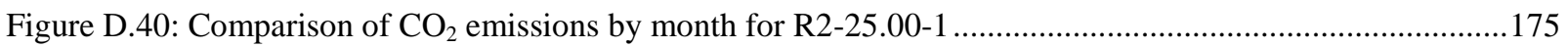

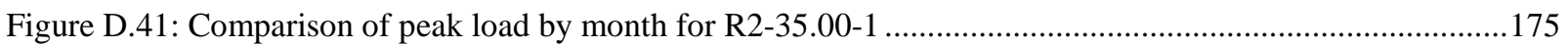

Figure D.42: Comparison of energy consumption by month for R2-35.00-1 ...................................................176

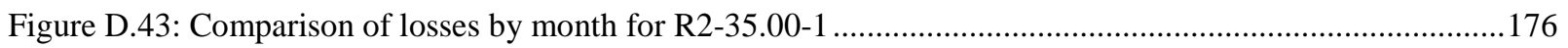

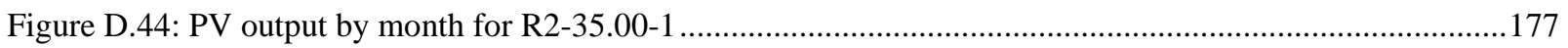

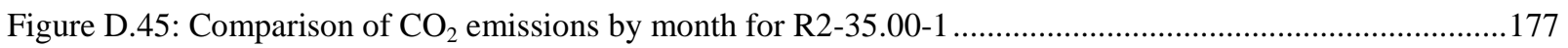

Figure D.46: Comparison of peak load by month for R3-12.47-1 ..................................................................178

Figure D.47: Comparison of energy consumption by month for R3-12.47-1 ....................................................179

Figure D.48: Comparison of losses by month for R3-12.47-1 ......................................................................179

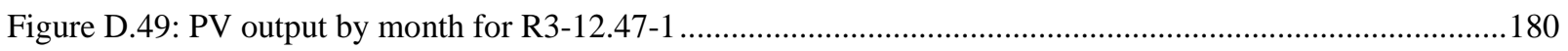

Figure D.50: Comparison of $\mathrm{CO}_{2}$ emissions by month for R3-12.47-1 ....................................................... 180

Figure D.51: Comparison of peak load by month for R3-12.47-3 …............................................................ 181

Figure D.52: Comparison of energy consumption by month for R3-12.47-3 …................................................181

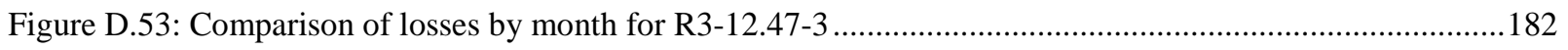

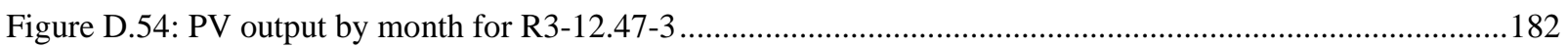

Figure D.55: Comparison of $\mathrm{CO}_{2}$ emissions by month for R3-12.47-3 .............................................................. 183

Figure D.56: Comparison of peak load by month for R4-12.47-1 .............................................................183

Figure D.57: Comparison of energy consumption by month for R4-12.47-1 …..............................................184

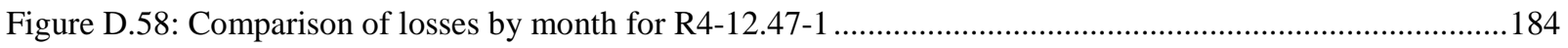

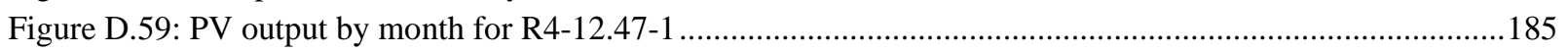

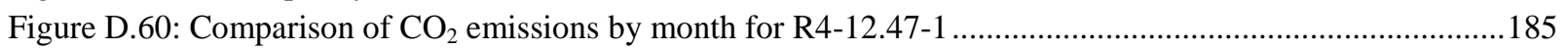

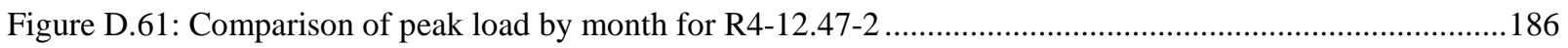

Figure D.62: Comparison of energy consumption by month for R4-12.47-2 …............................................186

Figure D.63: Comparison of losses by month for R4-12.47-2 …...................................................................187

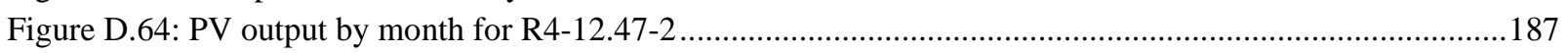

Figure D.65: Comparison of $\mathrm{CO}_{2}$ emissions by month for R3-12.47-1 ...........................................................188

Figure D.66: Comparison of peak load by month for R4-25.00-1 ....................................................................188

Figure D.67: Comparison of energy consumption by month for R4-25.00-1 …..............................................189

Figure D.68: Comparison of losses by month for R4-25.00-1 …...................................................................189

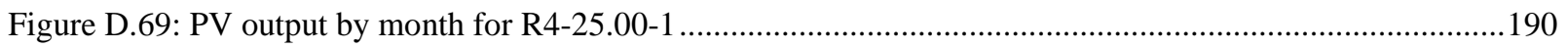

Figure D.70: Comparison of $\mathrm{CO}_{2}$ emissions by month for R4-25.00-1 …........................................................190

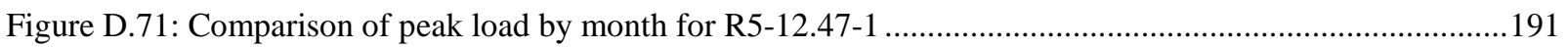

Figure D.72: Comparison of energy consumption by month for R5-12.47-1 …..................................................192

Figure D.73: Comparison of losses by month for R5-12.47-1 …...............................................................192

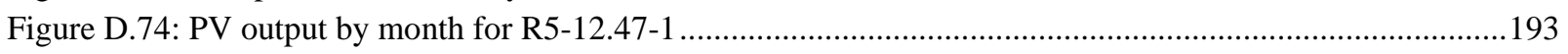

Figure D.75: Comparison of $\mathrm{CO}_{2}$ emissions by month for R5-12.47-1 ....................................................193

Figure D.76: Comparison of peak load by month for R5-12.47-2 ….........................................................194

Figure D.77: Comparison of energy consumption by month for R5-12.47-2 …............................................194

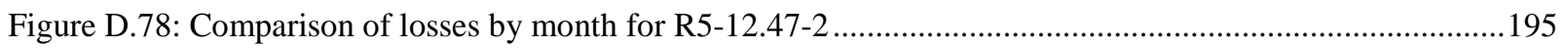

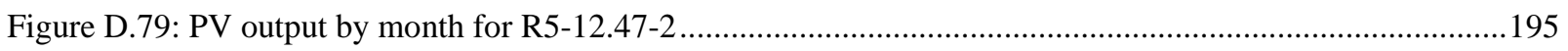

Figure D.80: Comparison of $\mathrm{CO}_{2}$ emissions by month for R5-12.47-2 ….......................................................196

Figure D.81: Comparison of peak load by month for R5-12.47-3 ...............................................................196

Figure D.82: Comparison of energy consumption by month for R5-12.47-3 …................................................197

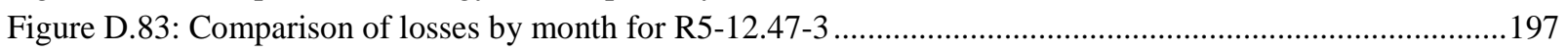

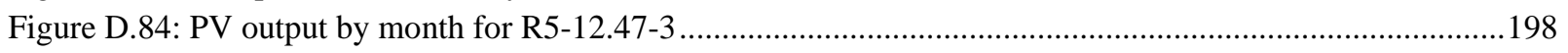

Figure D.85: Comparison of $\mathrm{CO}_{2}$ emissions by month for R5-12.47-3 ........................................................198

Figure D.86: Comparison of peak load by month for R5-12.47-4 ...............................................................199

Figure D.87: Comparison of energy consumption by month for R5-12.47-4 ......................................................199 


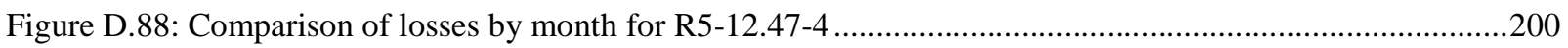

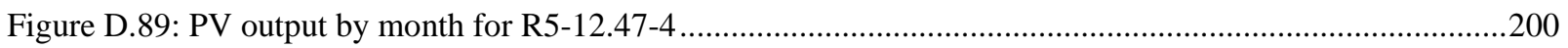

Figure D.90: Comparison of $\mathrm{CO}_{2}$ emissions by month for R5-12.47-4 .........................................................201

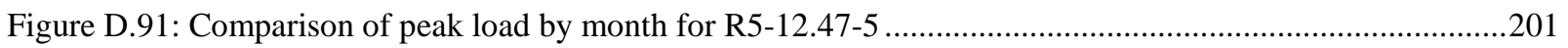

Figure D.92: Comparison of energy consumption by month for R5-12.47-5 ...............................................202

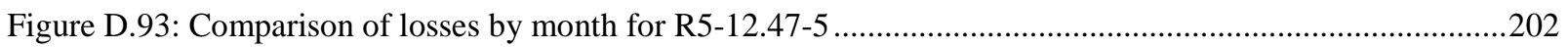

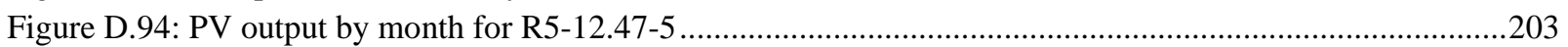

Figure D.95: Comparison of $\mathrm{CO}_{2}$ emissions by month for R5-12.47-5 ............................................................203

Figure D.96: Comparison of peak load by month for R5-25.00-1 ....................................................................204

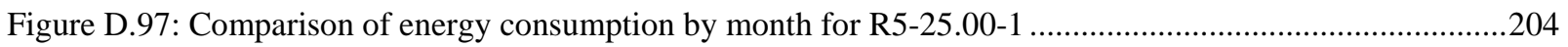

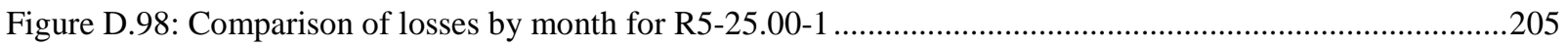

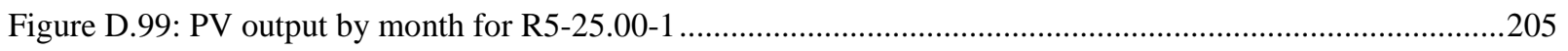

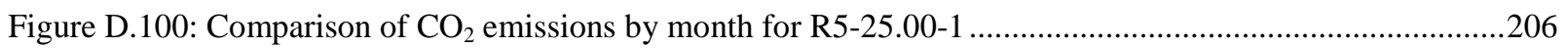

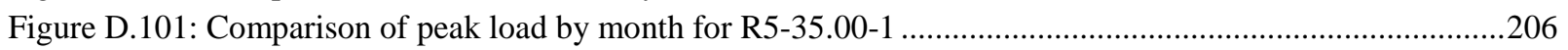

Figure D.102: Comparison of energy consumption by month for R5-35.00-1 ….............................................207

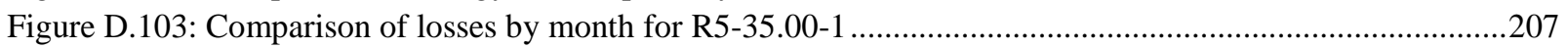

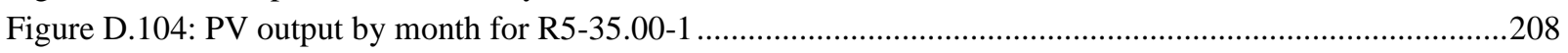

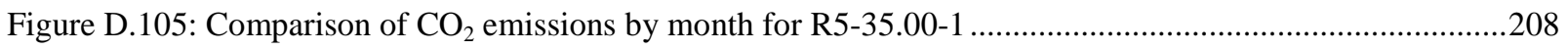

Figure D.106: Comparison of peak load by month for R1-12.47-1 ............................................................209

Figure D.107: Comparison of energy consumption by month for R1-12.47-1 .................................................210

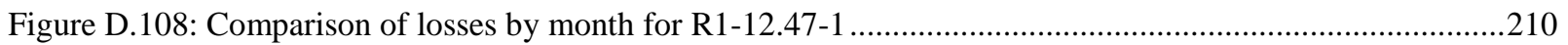

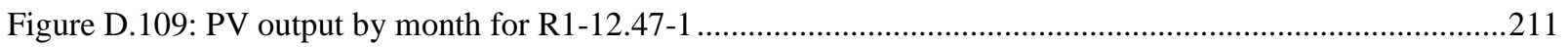

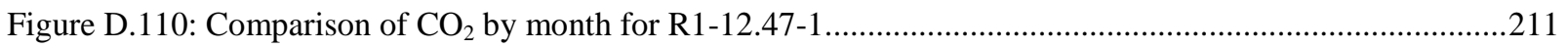

Figure D.111: Comparison of peak load by month for R1-12.47-2 …..............................................................212

Figure D.112: Comparison of energy consumption by month for R1-12.47-2 …...........................................212

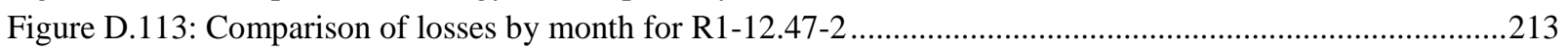

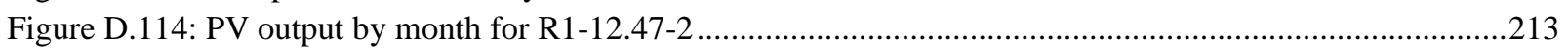

Figure D.115: Comparison of $\mathrm{CO}_{2}$ by month for R1-12.47-2 .....................................................................214

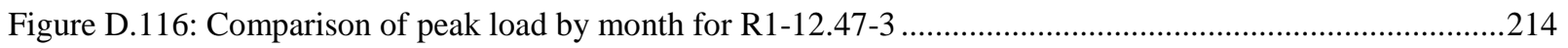

Figure D.117: Comparison of energy consumption by month for R1-12.47-3 …........................................215

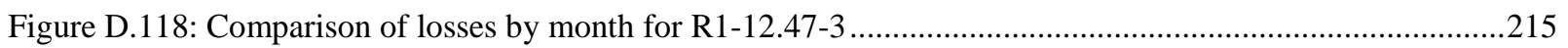

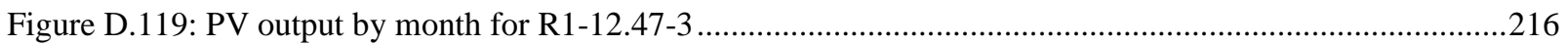

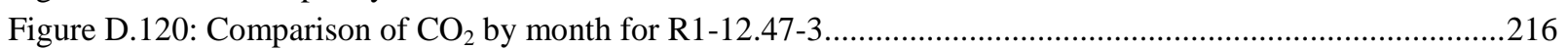

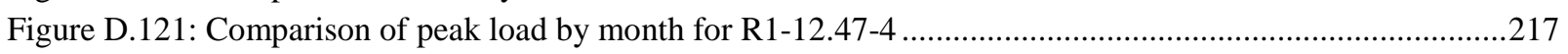

Figure D.122: Comparison of energy consumption by month for R1-12.47-4 …............................................217

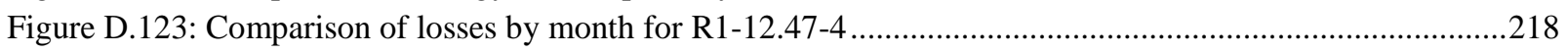

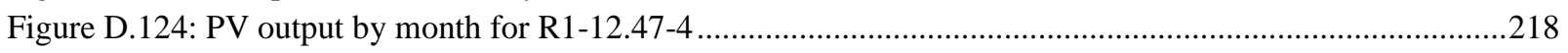

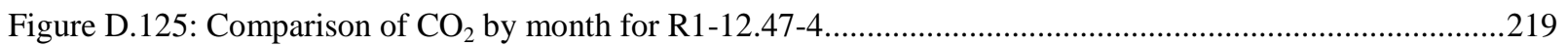

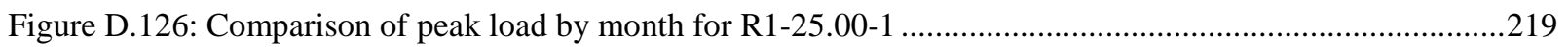

Figure D.127: Comparison of energy consumption by month for R1-25.00-1 ...............................................220

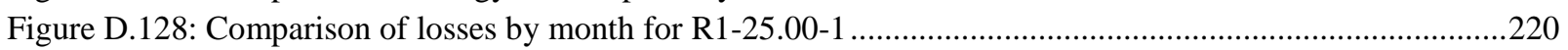

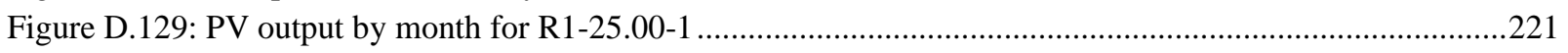

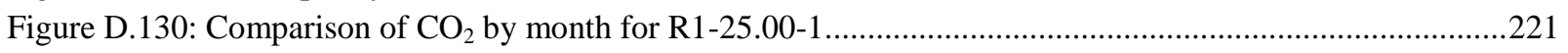

Figure D.131: Comparison of peak load by month for GC-12.47-1_R2 ......................................................222

Figure D.132: Comparison of energy consumption by month for GC-12.47-1_R2 ..........................................222

Figure D.133: Comparison of losses by month for GC-12.47-1_R2 ……......................................................223

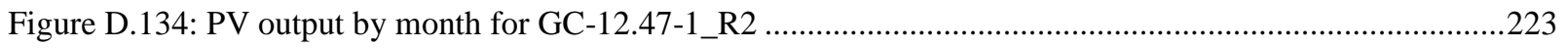

Figure D.135: Comparison of $\mathrm{CO}_{2}$ emissions by month for GC-12.47-1_R2 ……............................................224 
Figure D.136: Comparison of peak load by month for R2-12.47-1 …........................................................224

Figure D.137: Comparison of energy consumption by month for R2-12.47-1 ..............................................225

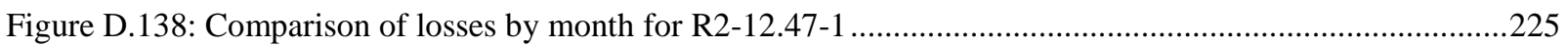

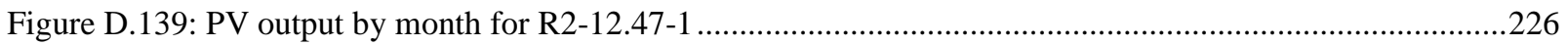

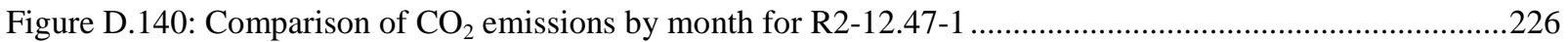

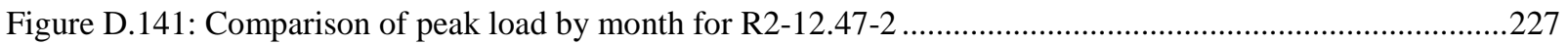

Figure D.142: Comparison of energy consumption by month for R2-12.47-2 …................................................227

Figure D.143: Comparison of losses by month for R2-12.47-2 …..............................................................228

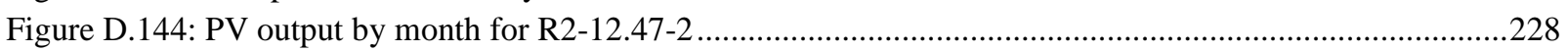

Figure D.145: Comparison of $\mathrm{CO}_{2}$ emissions by month for R2-12.47-2 ….................................................229

Figure D.146: Comparison of peak load by month for R2-25.00-1 ...............................................................229

Figure D.147: Comparison of energy consumption by month for R2-25.00-1 …............................................230

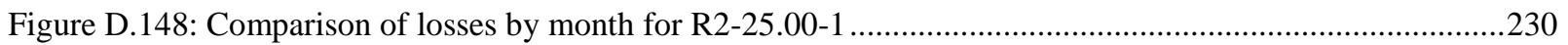

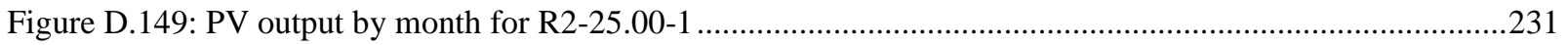

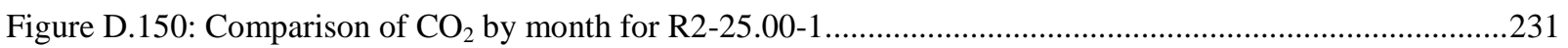

Figure D.151: Comparison of peak load by month for R2-35.00-1 ….......................................................232

Figure D.152: Comparison of energy consumption by month for R2-35.00-1 ................................................232

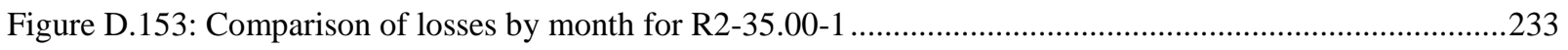

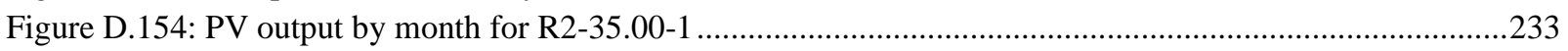

Figure D.155: Comparison of $\mathrm{CO}_{2}$ emissions by month for R2-35.00-1 ….....................................................234

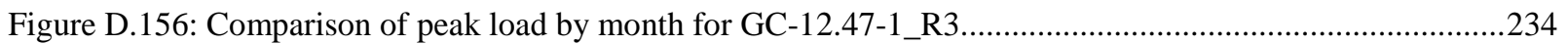

Figure D.157: Comparison of energy consumption by month for GC-12.47-1_R3 ...........................................235

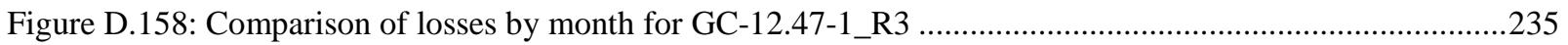

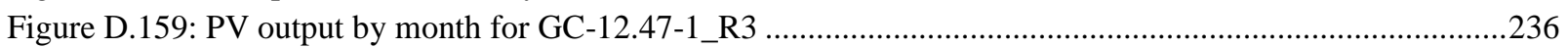

Figure D.160: Comparison of $\mathrm{CO}_{2}$ emissions by month for GC-12.47-1_R3 ....................................................236

Figure D.161: Comparison of peak load by month for R3-12.47-1 ...............................................................2237

Figure D.162: Comparison of energy consumption by month for R3-12.47-1 ....................................................237

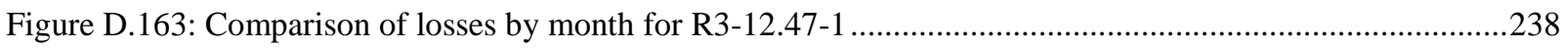

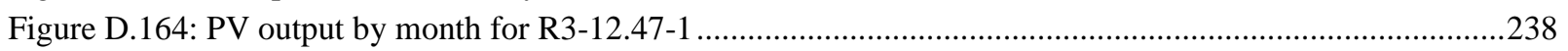

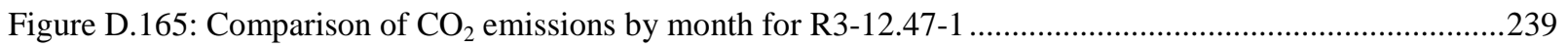

Figure D.166: Comparison of peak load by month for R3-12.47-2 ...........................................................240

Figure D.167: Comparison of energy consumption by month for R3-12.47-2 .............................................240

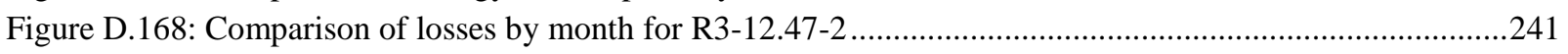

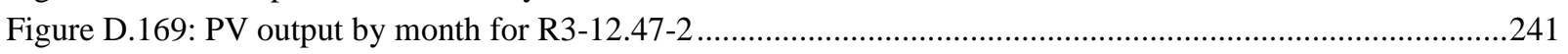

Figure D.170: Comparison of $\mathrm{CO}_{2}$ emissions by month for R3-12.47-2 …..................................................242

Figure D.171: Comparison of peak load by month for R3-12.47-3 ............................................................242

Figure D.172: Comparison of energy consumption by month for R3-12.47-3 ...............................................243

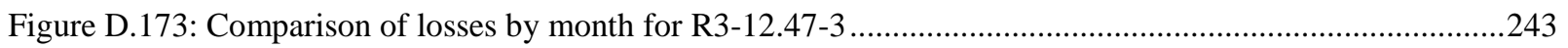

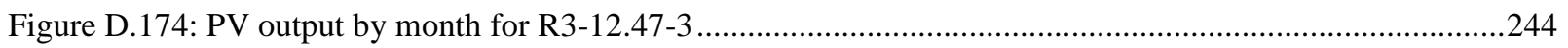

Figure D.175: Comparison of $\mathrm{CO}_{2}$ emissions by month for R3-12.47-3 ....................................................24

Figure D.176: Comparison of peak load by month for GC-12.47-1_R4 ............................................................245

Figure D.177: Comparison of energy consumption by month for GC-12.47-1_R4 ...........................................245

Figure D.178: Comparison of losses by month for GC-12.47-1_R4 ……….................................................246

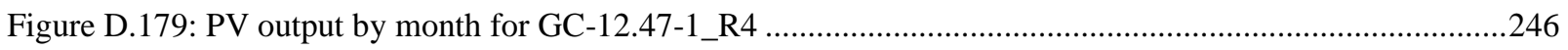

Figure D.180: Comparison of $\mathrm{CO}_{2}$ emissions by month for GC-12.47-1_R4 ...................................................247

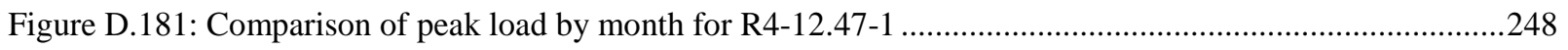

Figure D.182: Comparison of energy consumption by month for R4-12.47-1 ...............................................248

Figure D.183: Comparison of losses by month for R4-12.47-1 ....................................................................249 
Figure D.184: PV output by month for R4-12.47-1

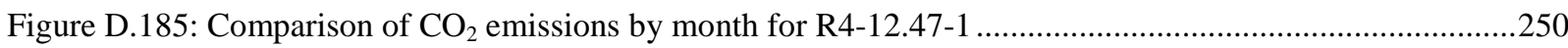

Figure D.186: Comparison of peak load by month for R4-12.47-2 .........................................................250

Figure D.187: Comparison of energy consumption by month for R4-12.47-2 ...........................................251

Figure D.188: Comparison of losses by month for R4-12.47-2 …............................................................251

Figure D.189: PV output by month for R4-12.47-2 ........................................................................252

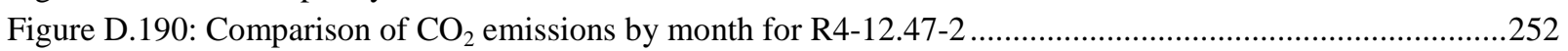

Figure D.191: Comparison of peak load by month for R4-25.00-1 …......................................................253

Figure D.192: Comparison of energy consumption by month for R4-25.00-1 ….........................................253

Figure D.193: Comparison of losses by month for R4-25.00-1 …...........................................................254

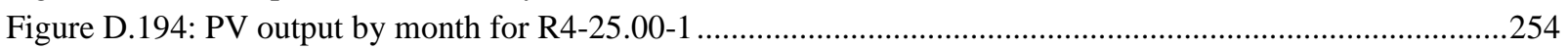

Figure D.195: Comparison of $\mathrm{CO}_{2}$ emissions by month for R4-25.00-1 ...............................................255

Figure D.196: Comparison of peak load by month for GC-12.47-1_R5 .....................................................256

Figure D.197: Comparison of energy consumption by month for GC-12.47-1_R5 .....................................256

Figure D.198: Comparison of losses by month for GC-12.47-1_R5 .........................................................257

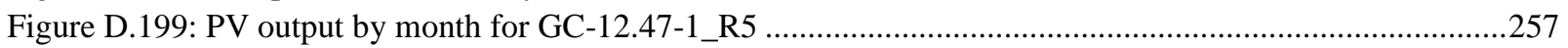

Figure D.200: Comparison of $\mathrm{CO}_{2}$ emissions by month for GC-12.47-1_R5 .............................................258

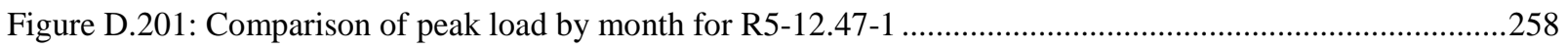

Figure D.202: Comparison of energy consumption by month for R5-12.47-1 .........................................259

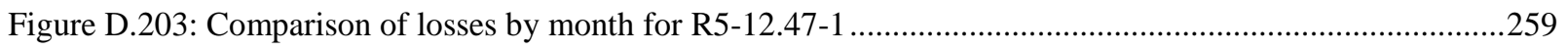

Figure D.204: PV output by month for R5-12.47-1 .............................................................................260

Figure D.205: Comparison of $\mathrm{CO}_{2}$ emissions by month for R5-12.47-1 ...............................................260

Figure D.206: Comparison of peak load by month for R5-12.47-2 .........................................................261

Figure D.207: Comparison of energy consumption by month for R5-12.47-2 …........................................261

Figure D.208: Comparison of losses by month for R5-12.47-2 ….....................................................262

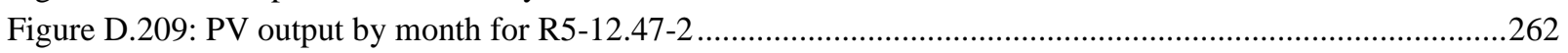

Figure D.210: Comparison of $\mathrm{CO}_{2}$ emissions by month for R5-12.47-2 …...............................................263

Figure D.211: Comparison of peak load by month for R5-12.47-3 ..........................................................263

Figure D.212: Comparison of energy consumption by month for R5-12.47-3 .........................................264

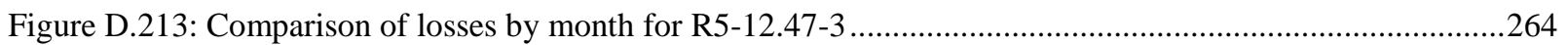

Figure D.214: PV output by month for R5-12.47-3 ...........................................................................265

Figure D.215: Comparison of $\mathrm{CO}_{2}$ emissions by month for R5-12.47-3 ...................................................265

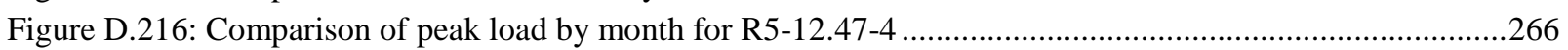

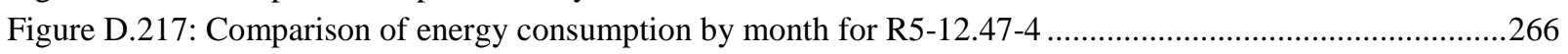

Figure D.218: Comparison of losses by month for R5-12.47-4 …...............................................................267

Figure D.219: PV output by month for R5-12.47-4 .........................................................................267

Figure D.220: Comparison of $\mathrm{CO}_{2}$ emissions by month for R5-12.47-4 ................................................268

Figure D.221: Comparison of peak load by month for R5-12.47-5 .........................................................269

Figure D.222: Comparison of energy consumption by month for R5-12.47-5 ...........................................269

Figure D.223: Comparison of losses by month for R5-12.47-5 …...........................................................270

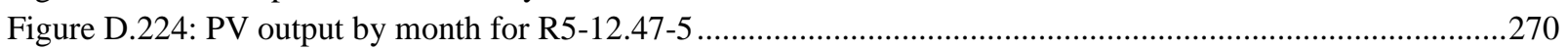

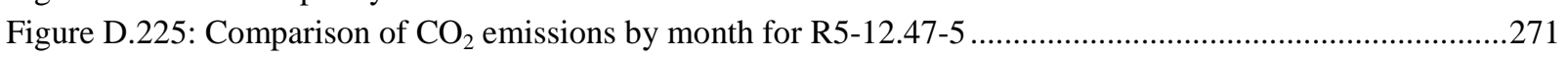

Figure D.226: Comparison of peak load by month for R5-25.00-1 ..............................................................272

Figure D.227: Comparison of energy consumption by month for R5-25.00-1 .........................................272

Figure D.228: Comparison of losses by month for R5-25.00-1 ...............................................................273

Figure D.229: Comparison of $\mathrm{CO}_{2}$ emissions by month for R5-25.00-1 ...............................................273

Figure D.230: Comparison of peak load by month for R5-35.00-1 …........................................................274

Figure D.231: Comparison of energy consumption by month for R5-35.00-1 .........................................274 


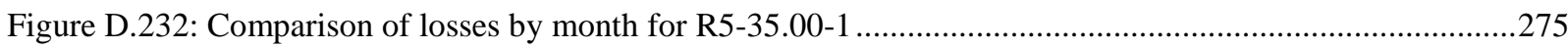

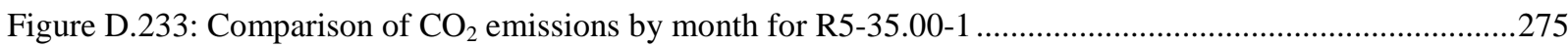

Figure D.234: Comparison of peak load by month for R1-12.47-1 ...............................................................276

Figure D.235: Comparison of energy consumption by month for R1-12.47-1 ..............................................276

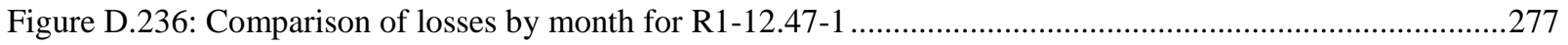

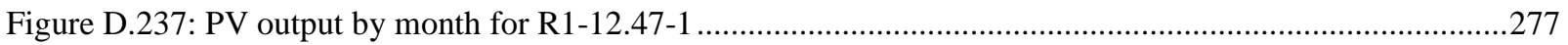

Figure D.238: Comparison of $\mathrm{CO}_{2}$ emissions by month for R1-12.47-1 ….......................................................278

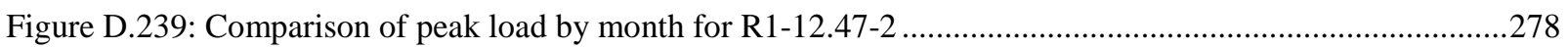

Figure D.240: Comparison of energy consumption by month for R1-12.47-2 ....................................................279

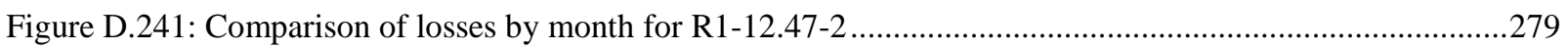

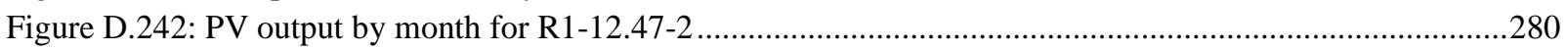

Figure D.243: Comparison of $\mathrm{CO}_{2}$ emissions by month for R1-12.47-2 …................................................28

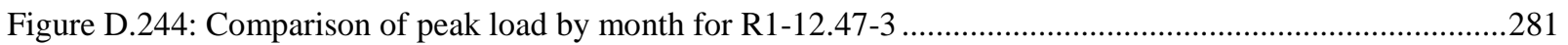

Figure D.245: Comparison of energy consumption by month for R1-12.47-3 ..............................................281

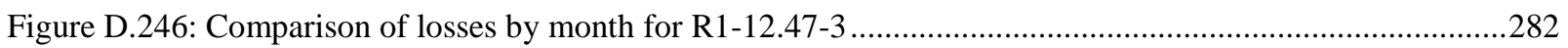

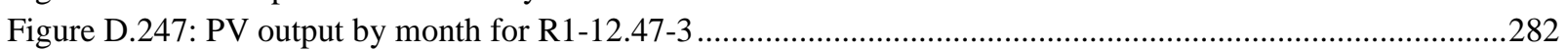

Figure D.248: Comparison of $\mathrm{CO}_{2}$ emissions by month for R1-12.47-3 .....................................................283

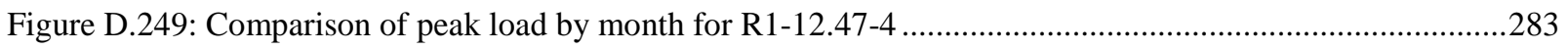

Figure D.250: Comparison of energy consumption by month for R1-12.47-4 ...............................................28

Figure D.251: Comparison of losses by month for R1-12.47-4 …...............................................................28

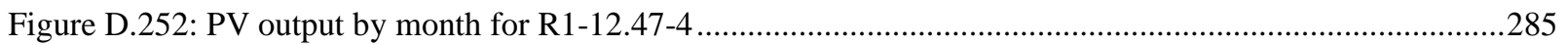

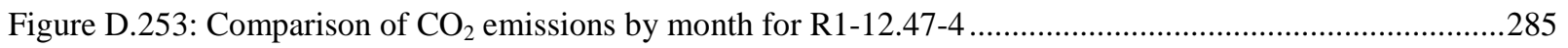

Figure D.254: Comparison of peak load by month for R1-25.00-1 ............................................................286

Figure D.255: Comparison of energy consumption by month for R1-25.00-1 .....................................................286

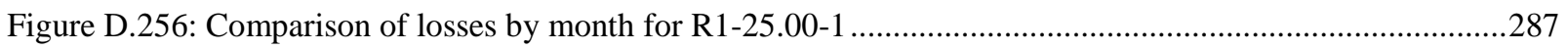

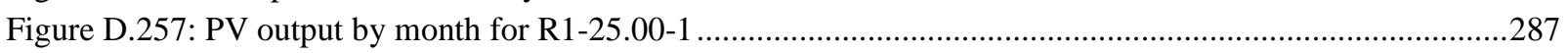

Figure D.258: Comparison of $\mathrm{CO}_{2}$ emissions by month for R1-25.00-1 ............................................................28

Figure D.259: Comparison of peak load by month for R2-12.47-1 ............................................................28

Figure D.260: Comparison of energy consumption by month for R2-12.47-1 ..............................................289

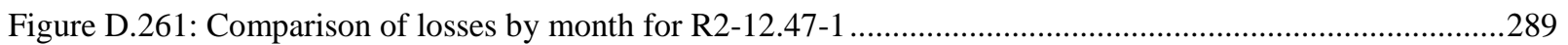

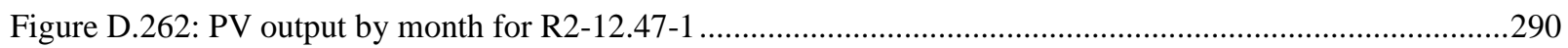

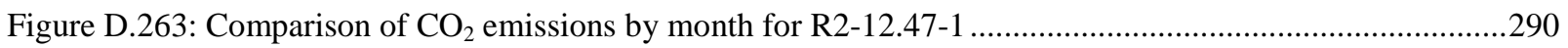

Figure D.264: Comparison of peak load by month for R2-12.47-2 ….......................................................291

Figure D.265: Comparison of energy consumption by month for R2-12.47-2 ….............................................291

Figure D.266: Comparison of losses by month for R2-12.47-2 ….............................................................292

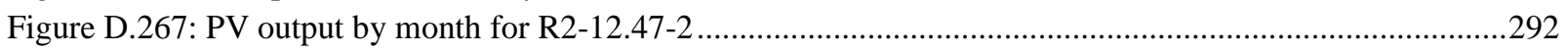

Figure D.268: Comparison of $\mathrm{CO}_{2}$ emissions by month for R2-12.47-2 …..................................................293

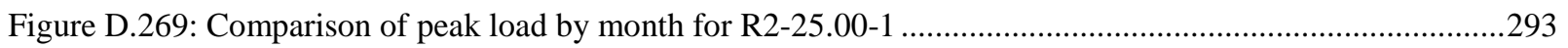

Figure D.270: Comparison of energy consumption by month for R2-25.00-1 …............................................294

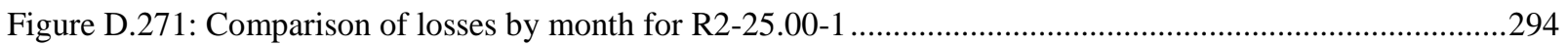

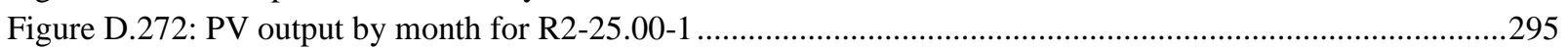

Figure D.273: Comparison of $\mathrm{CO}_{2}$ emissions by month for R2-25.00-1 ….......................................................295

Figure D.274: Comparison of peak load by month for R2-35.00-1 .................................................................296

Figure D.275: Comparison of energy consumption by month for R2-35.00-1 ..................................................296

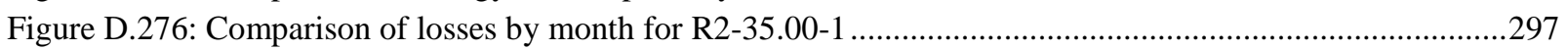

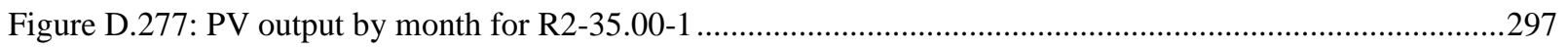

Figure D.278: Comparison of $\mathrm{CO}_{2}$ emissions by month for R2-35.00-1 ….................................................298

Figure D.279: Comparison of peak load by month for R3-12.47-1 ................................................................298 
Figure D.280: Comparison of energy consumption by month for R3-12.47-1 …..........................................299

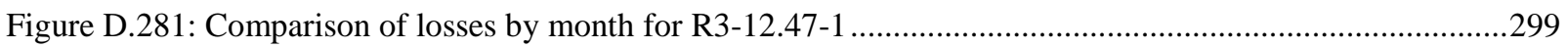

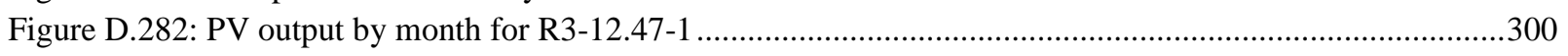

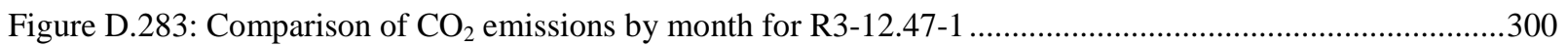

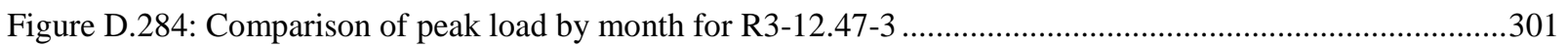

Figure D.285: Comparison of energy consumption by month for R3-12.47-3 …............................................301

Figure D.286: Comparison of losses by month for R3-12.47-3 …...................................................................302

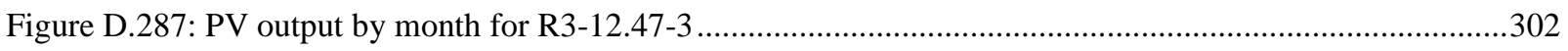

Figure D.288: Comparison of energy consumption by month for R3-12.47-3 .......................................................303

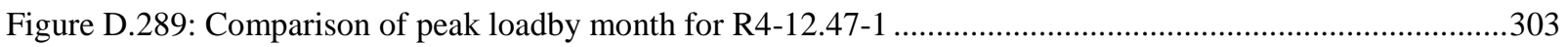

Figure D.290: Comparison of energy consumption by month for R4-12.47-1 …..............................................304

Figure D.291: Comparison of losses by month for R4-12.47-1 …..................................................................304

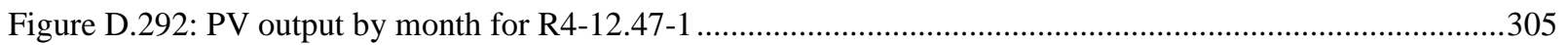

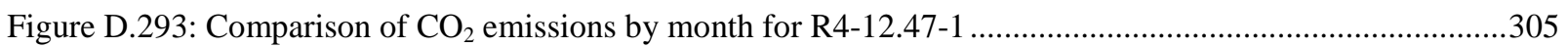

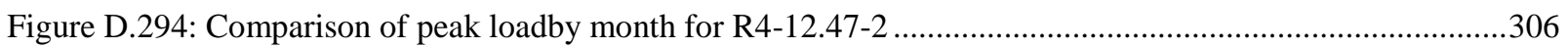

Figure D.295: Comparison of energy consumption by month for R4-12.47-2 ….................................................306

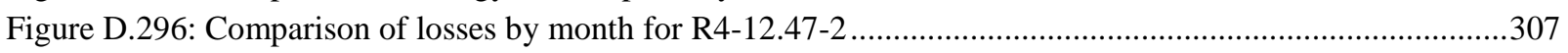

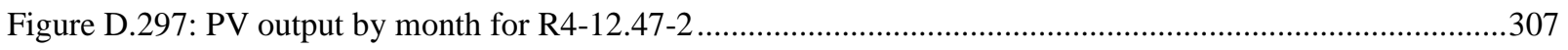

Figure D.298: Comparison of $\mathrm{CO}_{2}$ emissions by month for R4-12.47-2 …....................................................308

Figure D.299: Comparison of peak loadby month for R4-25.00-1 ..................................................................308

Figure D.300: Comparison of energy consumption by month for R4-25.00-1 ….............................................309

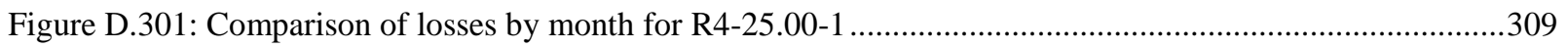

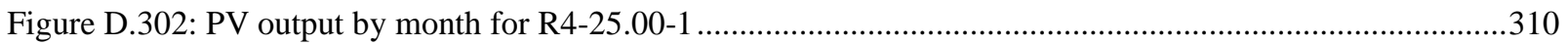

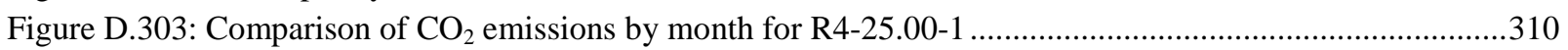

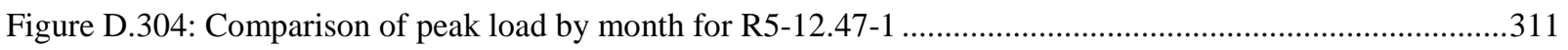

Figure D.305: Comparison of energy consumption by month for R5-12.47-1 …............................................311

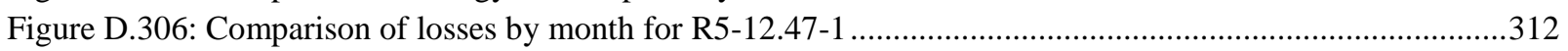

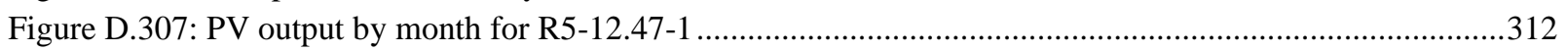

Figure D.308: Comparison of $\mathrm{CO}_{2}$ emissions by month for R5-12.47-1 …................................................

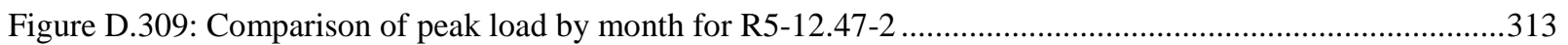

Figure D.310: Comparison of energy consumption by month for R5-12.47-2 …................................................314

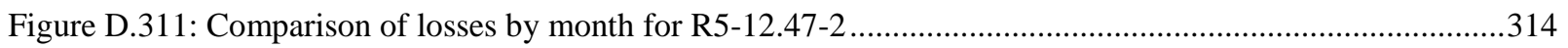

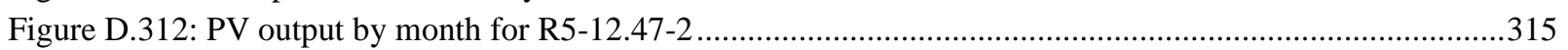

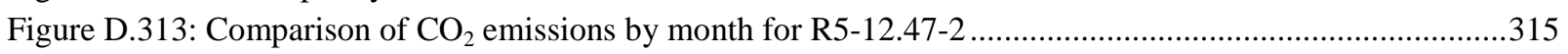

Figure D.314: Comparison of peak load by month for R5-12.47-3 ...............................................................

Figure D.315: Comparison of energy consumption by month for R5-12.47-3 …............................................

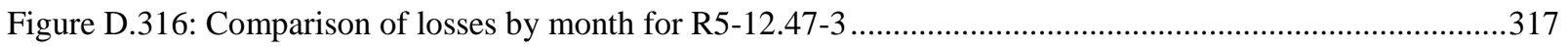

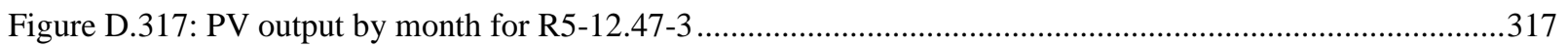

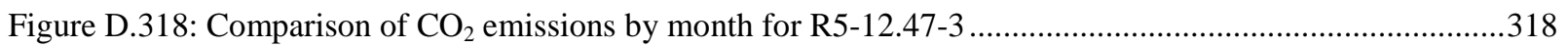

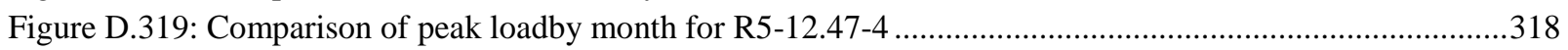

Figure D.320: Comparison of energy consumption by month for R5-12.47-4 ....................................................319

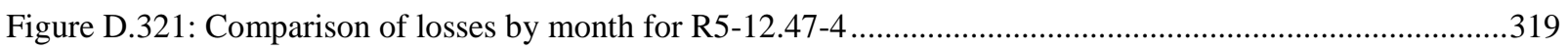

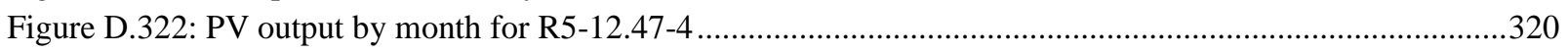

Figure D.323: Comparison of $\mathrm{CO}_{2}$ emissions by month for R5-12.47-4 .......................................................320

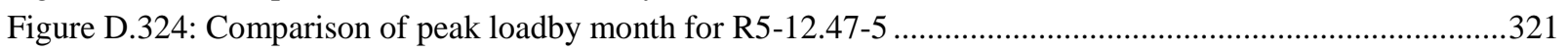

Figure D.325: Comparison of energy consumption by month for R5-12.47-5 …….........................................321

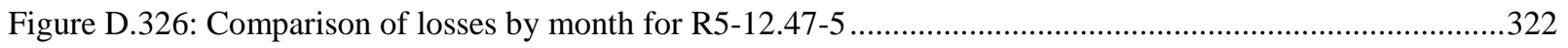

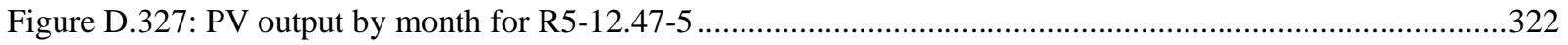


Figure D.328: Comparison of $\mathrm{CO}_{2}$ emissions by month for R5-12.47-5 ...............................................323

Figure D.329: Comparison of peak load by month for R5-25.00-1 ..........................................................323

Figure D.330: Comparison of energy consumption by month for R5-25.00-1 ….......................................324

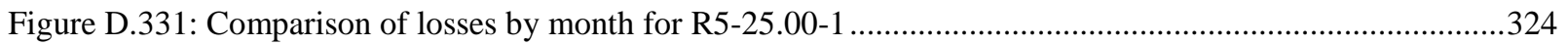

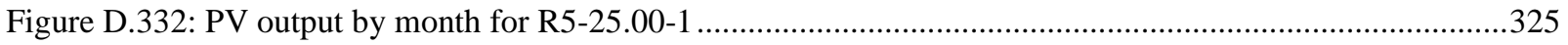

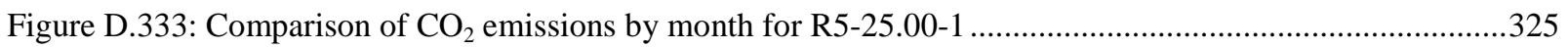

Figure D.334: Comparison of peak load by month for GC-12.47-1_R1 ......................................................326

Figure D.335: Comparison of energy consumption by month for GC-12.47-1_R1 ......................................327

Figure D.336: Comparison of losses by month for GC-12.47-1_R1 …........................................................327

Figure D.337: Comparison of WTG output by month for GC-12.47-1_R1 ................................................328

Figure D.338: Comparison of $\mathrm{CO}_{2}$ output by month for GC-12.47-1_R1 …...........................................328

Figure D.339: Comparison of peak load by month for GC-12.47-1_R2 .................................................329

Figure D.340: Comparison of energy consumption by month for GC-12.47-1_R3 ......................................329

Figure D.341: Comparison of losses by month for GC-12.47-1_R3 ............................................................330

Figure D.342: Comparison of WTG output by month for GC-12.47-1_R3 ..................................................330

Figure D.343: Comparison of $\mathrm{CO}_{2}$ emissions by month for GC-12.47-1_R3 ...............................................331

Figure D.344: Comparison of peak load by month for GC-12.47-1_R4 R....................................................331

Figure D.345: Comparison of energy consumption by month for GC-12.47-1_R4 .....................................332

Figure D.346: Comparison of losses by month for GC-12.47-1_R4 …..................................................332

Figure D.347: Comparison of WTG output by month for GC-12.47-1_R4 ….............................................333

Figure D.348: Comparison of $\mathrm{CO}_{2}$ emissions by month for $\mathrm{GC}-12.47-1$ R4 ...........................................333

Figure D.349: Comparison of peak load by month for GC-12.47-1_R5 ....................................................334

Figure D.350: Comparison of energy consumption by month for GC-12.47-1_R5 .......................................334

Figure D.351: Comparison of losses by month for GC-12.47-1_R5 …......................................................335

Figure D.352: Comparison of WTG output by month for GC-12.47-1_R5 ...............................................335

Figure D.353: Comparison of $\mathrm{CO}_{2}$ emissions by month for $\mathrm{GC}-12.47-1 \_\mathrm{R} 5$............................................336 


\section{Table of Tables}

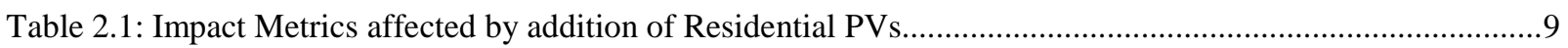

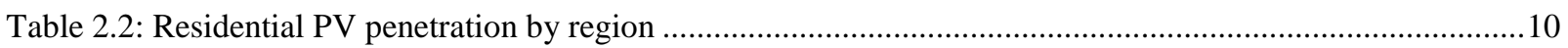

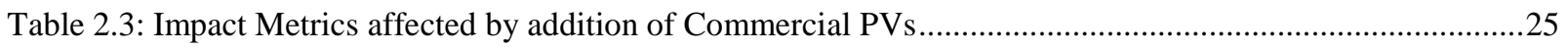

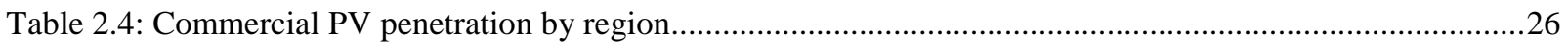

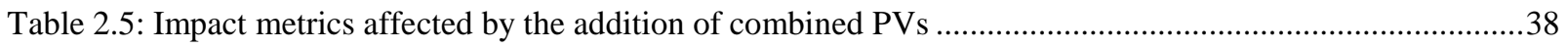

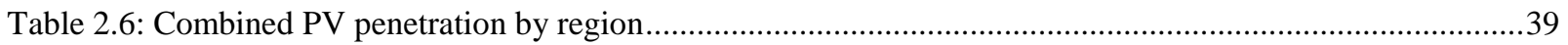

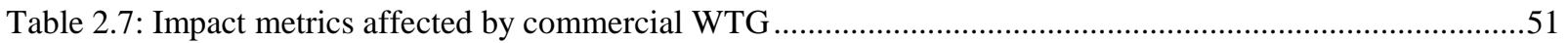

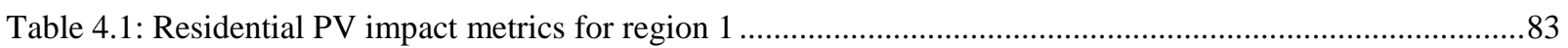

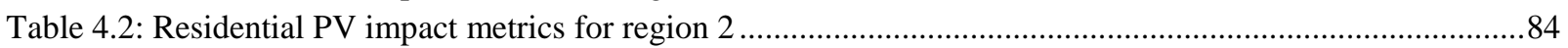

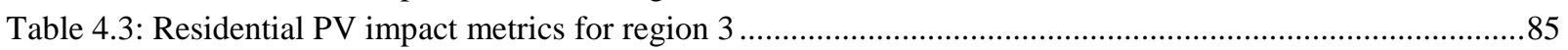

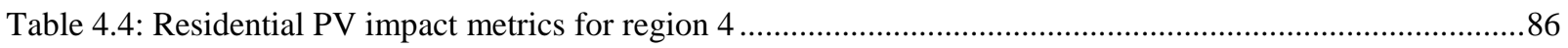

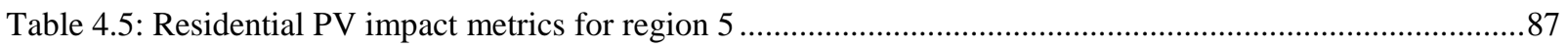

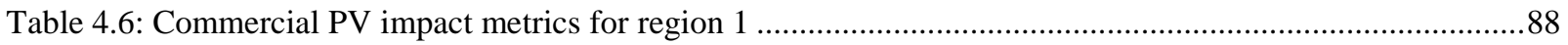

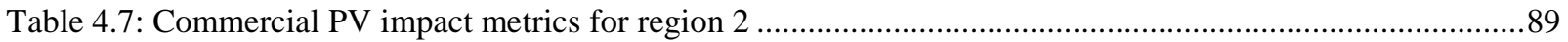

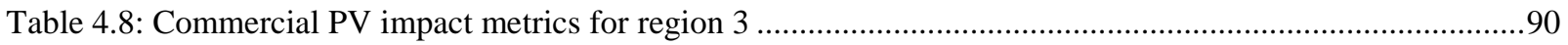

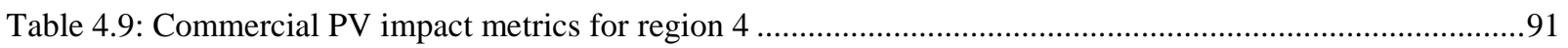

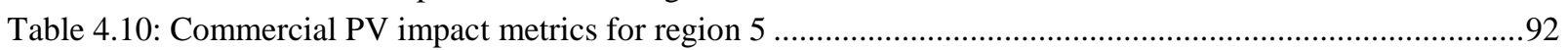

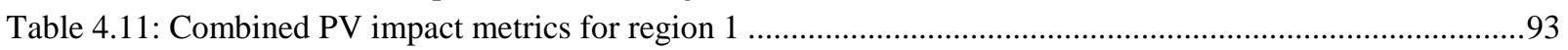

Table 4.12: Combined PV impact metrics for region 2 ..................................................................................94

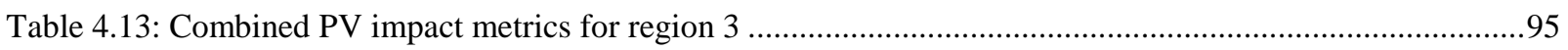

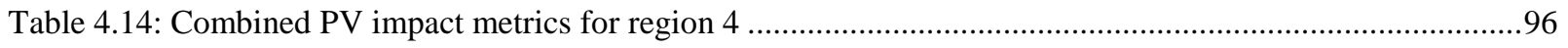

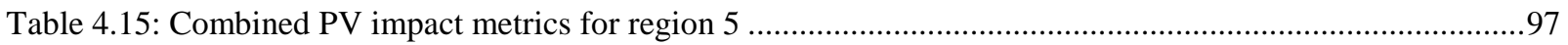

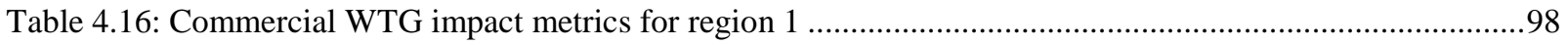

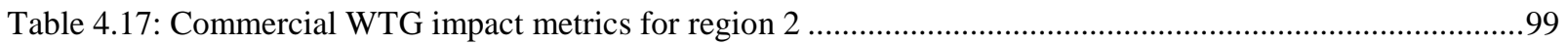

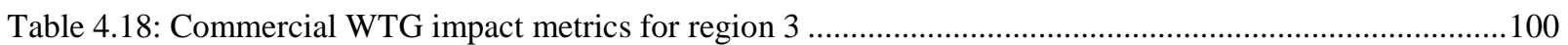

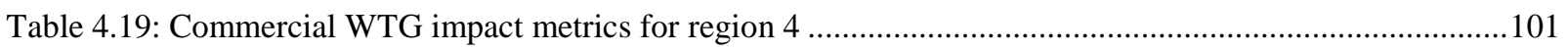

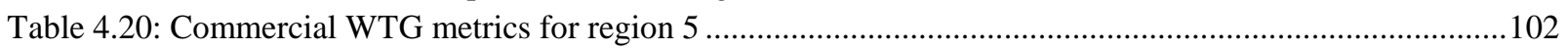

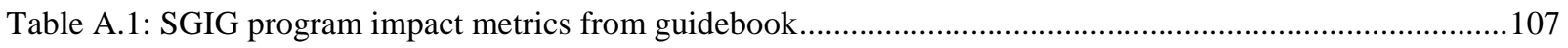

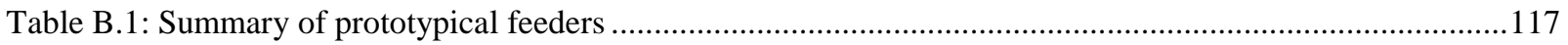

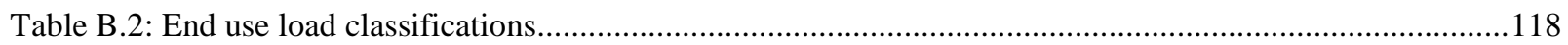

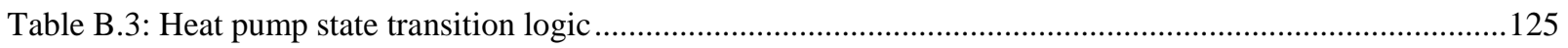

Table B.4: Table of weighting factors for mapping regional parameters.............................................................127

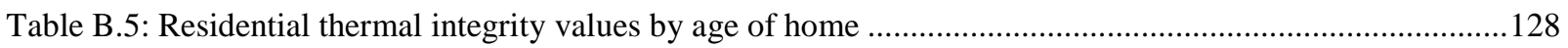

Table B.6: Percentage of single family homes in total population by age and region ..........................................128

Table B.7: Percentage of apartments in total population by age and region ....................................................129

Table B.8: Percentage of mobile homes in total population by age and region ...............................................129

Table B.9: Percentage of key building parameters by region ......................................................................129

Table B.10: Percentage of nighttime heating and cooling set points by housing type ........................................130

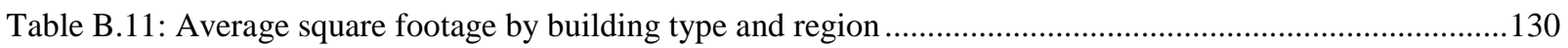

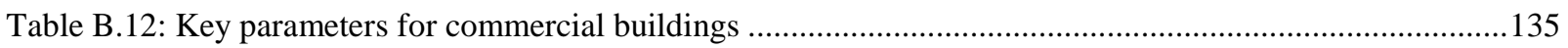

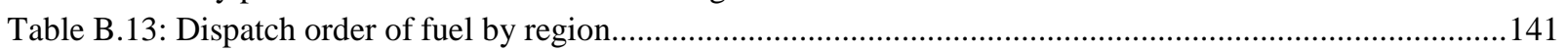

Table B.14: Percent of energy consumed, broken down by fuel type and month in region 1.............................141

Table B.15: Percent of energy consumed, broken down by fuel type and month in region 2..............................142 
Table B.16: Percent of energy consumed, broken down by fuel type and month in region 3

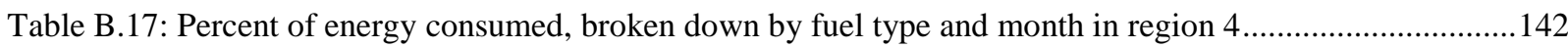

Table B.18: Percent of energy consumed, broken down by fuel type and month in region $5 \ldots \ldots \ldots \ldots \ldots \ldots \ldots \ldots . . . . . . . . . . . . .143$

Table B.19: Average thermal efficiencies by fuel type.

Table B.20: Pollutant production per BTU of fuel (lbs./MBTU)

Table E.1: Base case performance metrics for region 1 336

Table E.2: Base case performance metrics for region 2

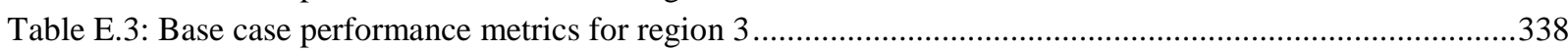

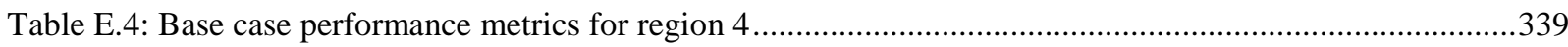

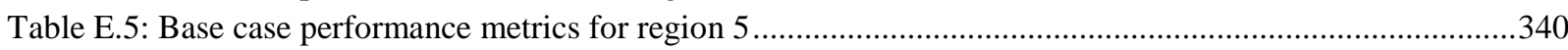

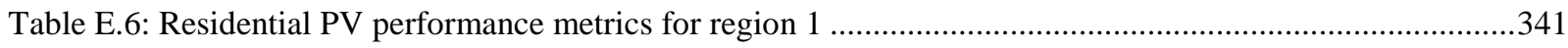

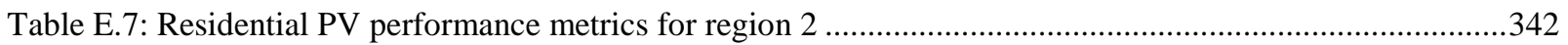

Table E.8: Residential PV performance metrics for region 3 .................................................................343

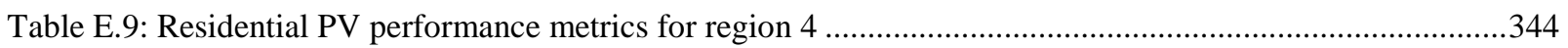

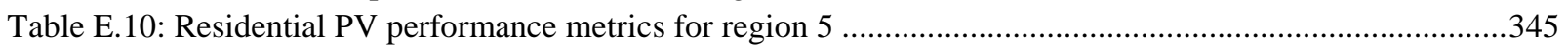

Table E.11: Commercial PV performance metrics for region 1 ......................................................................346

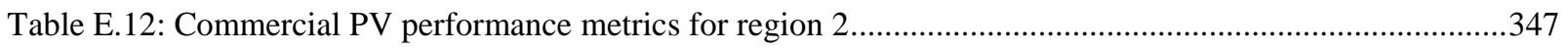

Table E.13: Commercial PV performance metrics for region 3 ................................................................348

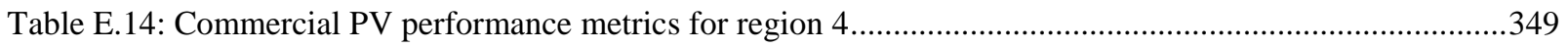

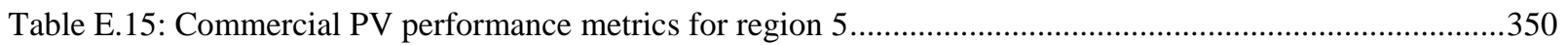

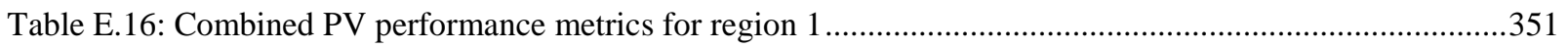

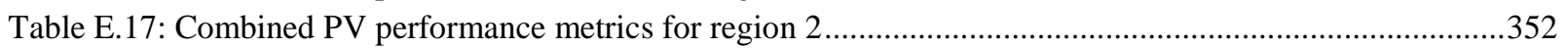

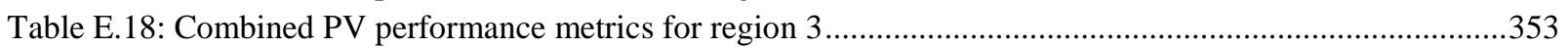

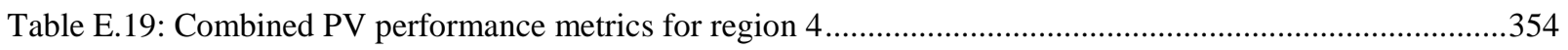

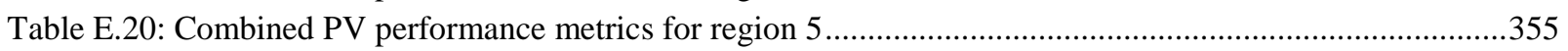

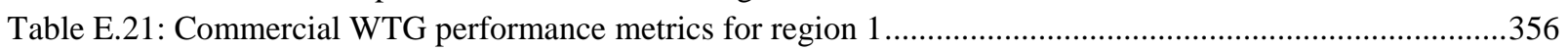

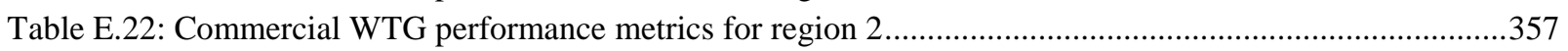

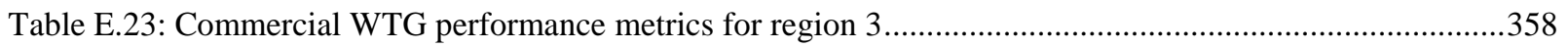

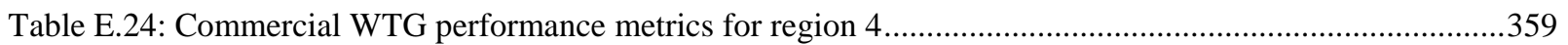

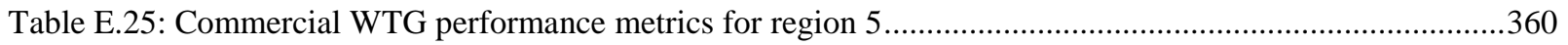




\section{Summary}

This document is one of a series of five reports commissioned by the United States Department of Energy, Office of Electricity Delivery and Energy Reliability. The purpose of these reports is to estimate some of the benefits of deploying technologies similar to those implemented on the Smart Grid Investment Grant (SGIG) projects. Four technical reports cover the various types of technologies deployed in the SGIG projects: distribution automation, demand response, energy storage, and distributed generation. While the results of these reports provide insight into the variation of impacts by technology, feeder composition and region, it should be noted that the actual impacts and benefits of employing specific technologies in individual SGIG projects may vary from these projections. A fifth report in the series examines the benefits of deploying these technologies on a national level. This technical report examines the impacts of distribution automation technologies deployed in the SGIG projects. 


\section{Introduction}

As part of the American Recovery and Reinvestment Act of 2009, the U.S. Department of Energy (DOE) Office of Electricity Delivery and Energy Reliability (OE) provided Smart Grid Investment Grant (SGIG) funding to 99 award recipients totaling \$3.4 Billion [1]. Coupled with matching funds of \$4.6 Billion from industry, the SGIG projects are intended to accelerate the modernization of the nation's electricity infrastructure. To help evaluate the effect of these projects, a set of impact metrics has been developed by the DOE [2]. Once the SGIG projects are complete, it will be possible to analyze collected field measurements and determine the exact benefit from each of the various technologies within each of the projects. OE has several initiatives operating in current and near-term time frames to assess impacts and disseminate information as data becomes available. These initiatives include analysis partnerships with individual SGIG recipients, specific technology assessments, stakeholder briefings, and improvements to existing algorithms and tools.

In order to examine the SGIG project benefits, the Pacific Northwest National Laboratory (PNNL) utilized the GridLAB-D simulation environment to conduct extensive simulations on representative technologies. GridLAB-D was originally developed at PNNL, via DOE OE funding, to provide an open source simulation environment to evaluate the impacts of emerging technologies on the nation's electricity infrastructure. The unique multi-disciplinary agent based structure of GridLAB-D allows for the effective evaluation of complex emerging technologies such as voltage optimization and demand response. These are the same technologies that being deployed as part of the SGIG projects.

The impact of these technologies, at the distribution feeder level across various climate regions of the United States [3], is presented in a series of 4 technical reports, of which this report is the first. Each of the 4 technical reports examines a class of technologies deployed in the SGIG projects. The 4 technical reports examine distribution automation, demand response, energy storage, and renewable integration. A $5^{\text {th }}$ report uses the results of the four technical reports to generate a policy level examination of the various technologies. The final report includes extrapolation to a national level deployment at various penetration levels.

To ensure that the results of this report can be reproduced by other researchers, all of the tools, models, and materials used are openly available at [4]. Through detailed time-series simulations conducted in GridLAB-D, the impact of adding distribution automation capabilities to the grid can be examined on the relevant prototypical feeders. Utilities, regulators, vendors and other stakeholders interested in analyses more specific to their systems, goals, and conditions may make use of these open tools for their own purposes. 


\subsection{Report Scope}

Due to the large number of SGIG projects and the wide range of specific implementations, it is not feasible to simulate each of the specific SGIG projects. In addition to the numerous implementations, it would be necessary to model the electrical infrastructure of each of the projects. To address these issues, the technical reports will model a selection of technologies that are representative of those seen in the SGIG projects, and it will examine their impact on a set of prototypical distribution feeders that are representative of those seen in the various climate regions of North America [3]. By utilizing representative technologies and prototypical distribution feeders, it will be possible for this report to estimate the feeder level impact of each technology. Once the impact of the technologies has been evaluated on the prototypical feeders, the results will be extrapolated to explore the impacts and considerations associated with deploying the technology on a national level.

The technologies deployed as part of the SGIG projects can be placed in one of two categories: direct and enabling. Direct technologies are those that provide direct benefit to the system. Enabling technologies are those that may not provide a direct benefit to the system, but they enable other beneficial technologies. As an example, a communications network does not provide any reduction in energy consumption, but it does enable demand response systems that create reductions in energy consumption.

The technical reports focus on the benefits obtained from the deployment of direct technologies when supported with the necessary enabling technologies.

\subsubsection{Direct Representative Technologies}

These are the 15 technologies that will be specifically analyzed using GridLAB-D simulations. Within each of the 4 technical reports there are one or more specific direct technologies that are examined.

Distribution Automation (DA)

- $\quad$ t1: Volt-VAR Optimization (VVO)

- $\quad$ 2: Capacitor Automation (CA)

- $\quad$ t3: Reclosers and Sectionalizers $(\mathrm{R} \& S)$

- $\quad$ t4: Distribution Management and Outage Management Systems (DMS\&OMS)

- t5: Fault Detection Identification and Reconfiguration (FDIR) 
Demand Response (DR)

- t6: TOU/CPP with enabling technologies

- t7: TOU/CPP without enabling technologies

- t8: TOU with enabling technologies

- $\quad$ 9: TOU without enabling technologies

- t10: Direct Load Control (DLC)

Energy Storage (ES)

- t11: Thermal Energy Storage (TES)

Distributed Generation (DG)

- t12: Solar residential

- t13: Solar commercial

- t14: Solar combined

- t15: Wind commercial

\subsubsection{Enabling Technologies}

In addition to technologies that provide direct benefits to the system, there are those that enable other technologies to benefit the system, but themselves may not provide a direct benefit. The majority of the projects in the SGIG program have committed to deploying a large number of enabling technologies that do not provide any direct measurable benefit. Despite the lack of a direct benefit, these technologies form the foundation needed for the technologies that do provide direct benefits to the system.

\subsubsection{Smart Meters}

Traditional electromechanical metering devices have proven to be accurate and reliable over multiple decades, but have the significant disadvantage of requiring manual data collection; there is no network connectivity. The deployment of new "smart meters" is the largest common element to the SGIG projects, ranging from projects with a few thousand, to projects with multiple millions. These new meters are able to bi-directionally communicate information via a wired or wireless communications network. Communications to the customer can now include time-based electricity rates or event-triggered signals. Communications from the customer allow remote meter reading, as well as usage patterns. 


\subsubsection{Communications Infrastructure}

Communications infrastructure, both wireless and wired, is an excellent example of an enabling technology. A communications infrastructure in an isolated environment does not provide any direct benefit to the system. However, direct technologies and capabilities, such as demand response, would not be possible without a supporting communications infrastructure. For the purposes of the conducted analysis, it is assumed that the required communications infrastructure is available, but it will not be simulated. Zero latency and infinite bandwidth is assumed. While an explicit communications system model is not used in this analysis, there are issues outside the scope of this work where a communications system model would be essential.

\subsubsection{Human Machine Interface}

Human Machine Interfaces (HMI) can exist in many forms. In a single family residence, the HMI can range from a simple thermostat to a fully functional Home Energy Management System (HEMS). An HMI can allow a residential user to see the current price of electricity, interact with their heating and cooling system, or with an energy storage system. By providing an end-user with more information about the current price of electricity and the state of their consumption, the effectiveness of demand response opportunities can be increased.

\subsection{Report Structure}

The structures of the four technical reports follow a similar design. The four reports share a common introduction in Section 1 with Section 2, discussing the representative technologies to be examined in each report. Section 3 contains the detailed feeder level examination of the impact of each technology, while Section 4 examines the change in the impact metrics between the base case and the case with various technologies. It should be noted that the base case is a representative simulation without new technologies; it is not representative of the operation of any actual SGIG project. Section 5 contains the concluding comments. Additionally, there are multiple appendices. Appendices A, B, and C are common to all 4 reports with Appendix A giving a detailed description of the SGIG impact metrics, Appendix B detailing the taxonomy of prototypical distribution feeders, and Appendix C discussing GridLAB-D and the simulation methodology. Appendix D is specific to each report and contains the plots produced for individual feeders from the simulations. Appendix E contains the impact metric values for each technology and is the basis for the differential impact metrics in Section 4.

The fifth report has a structure independent of the four technical reports. 


\section{Distributed Generation Technology Areas}

A study conducted by Electric Power Research Institute (EPRI) indicates that by 2010, 25\% of the new generation in the United States will be distributed [4] and a study by the Natural Gas Foundation concluded that this number could be as high as 30\% [5]. Distributed Generation (DG) can be defined as electric power generation from either renewable and/or non-renewable resources at the distribution level, or on the customer side of the service meter. A review of the SGIG projects indicated that the inclusion of DG was in a relatively small number of projects, but because of its importance it is included as one of the four main technologies types.

In the United States, renewable portfolio standards (RPS) have been developed by the individual states in order to obtain a minimum percentage of their electric power from renewable energy resources within a given time frame. The proliferation of RPSs has enabled a continual shift towards increased penetration level of renewable resources in the power grid [6]. Currently, there are 24 states which have RPS policies in place and these 24 states account for more than half the sales of electricity in the US [6]. There are numerous advantages to integrating renewable resources. For utilities, it might mean less dependence on purchasing high cost power during peak periods from spot markets, increasing their generation mix options, taking advantage of subsidies by increasing their renewable portfolio, or increasing the reliability of the power grid. For customers, having renewable resources supplying their energy needs means the potential for smaller electricity bills and the potential to reduce their carbon footprint. The addition of renewable distributed resources represents a paradigm shift for the power industry, from the traditional central generation scheme to a more distributed generation pattern. Because of this fundamental change in operation, the integration of renewable resources presents significant challenges and opportunities.

In the United States, the most commonly deployed renewable resources are solar photovoltaic (PV) and wind turbine generators (WTG). Many of the SGIG projects identified the need to develop interface capabilities to support the integration of renewable resources in the coming years, with one project specifying a need for a small scale commercial PV deployment. It was also observed that some of the utilities are deploying PV units and WTGs as their own utilitywide initiative. This report examines the effects, at the distribution level, of adding residential scale PVs, commercial scale PVs, combined residential and commercial scale PVs, and commercial level wind turbine generator deployment.

The studies associated with the three PV technology types, residential PV, commercial PV, and combined PV, are similar to each other in many aspects. Each of these technology types has a similar impact on the distribution feeder, with the level of the impact varying for the three cases. The size of the PV units and the number of PV units of these three technology types are very different from each other, which results in varying impacts at both the feeder level and point of interconnect. 
The wind turbine generator studied in this report are commercial scale units, small residential type units are not examined. Effects of this installation were examined at the distribution feeder level, giving insight into the effect of large scale wind integration on the distribution feeder.

For the analysis conducted in the following Sections, the operation of PV and WTG units is in accordance with the IEEE 1547 standard. Both the solar and wind models in this study provide only real power to the grid and are always grid connected; there is no islanded operation and they do not regulate voltage. Section 2.1 will examine the three technologies associated with solar PV and their specific implementations. Section 2.2 will examine the technology associated with WTGs and its specific implementation.

\subsection{Photovoltaic (PV) Model Implementation}

The PV module developed in GridLAB-D is an electrical model which converts values of incident solar radiation into electrical energy. Individual PV systems with name plate values of 600 Volts and 200 Watts is used for all residential, commercial, and industrial applications. For the SGIG analysis, the PVs are assumed to be made of single crystalline silicon material with an efficiency factor of 0.2 [10]. The number of modules in these applications will vary based on the surface area (i.e., the area covered by the PV arrays) as specified by the user. The DC power output of the solar model can be described by equations (2.1) and (2.2), selected from [7]:

$$
\begin{gathered}
P_{D C}=P_{S T C} * \frac{G_{A}}{G_{\text {STC }}} *\left[1+\left(T_{C}-T_{\text {STC }}\right) C_{T}\right] \\
T_{C}=T_{a}+G_{A} \frac{\left(N O C T-20^{\circ} C\right)}{800 \mathrm{~W} / \mathrm{m}^{2}}
\end{gathered}
$$

where:

$P_{D C}:$ DC power output of the solar panel $(\mathrm{kW})$

$P_{S T C}:$ DC power output of the solar panel under standard test conditions $(\mathrm{kW})$

$G_{S T C}:$ Solar irradiance at STC of $1000 \mathrm{~W} / \mathrm{m} 2$

$T_{C}$ : nominal terminal voltage $\left({ }^{\circ} \mathrm{C}\right)$

$T_{S T C}:$ STC temperature of the solar cell, $25^{\circ} \mathrm{C}$

$C_{T}$ : $\quad$ power temperature coefficient (for single crystal silicon $=-0.00437 / \mathrm{K}$ )

$T_{a}$ : ambient temperature in $\left({ }^{\circ} \mathrm{C}\right)$

Manufacturers often assign an allowable output tolerance to the module's rating. For example, if this tolerance is $+/-5 \%$ of the rating, a $100 \mathrm{~W}$ module will actually produce $95 \mathrm{~W}-105 \mathrm{~W}$. The cell temperatures of a solar array will also vary drastically due to the ambient conditions, such as sun intensity, air temperature, etc., and is also accounted for as given in equation (2.1). PV arrays eventually get covered with fine layer of dirt and dust, decreasing the amount of light reaching each cell. The amount of power loss is dependent on the location, type of dust, and the length of 
the time since rainfall. For the PV model used in this analysis, an average derating factor of 0.95 is applied to account for manufacturing tolerance and soiling losses (dirt, etc.) in the PV arrays.

Output power for the solar arrays was determined by the solar irradiance of the particular region. Since all of the thermal models were built off typical meteorological year (TMY) data, these data sets were utilized for the PV generators as well. This kept the electrical output of the PV units correlated with the thermal flux on the buildings. Such a correlation ensured the solar model was producing an output representative to the conditions the rest of the feeder was experiencing.

For the purposes of this study, optimum solar tracking was assumed. The total solar insolation (or irradiation) obtained from the TMY data set was applied to the photovoltaic panel. Efficiencies associated with the process are still applied and equation (2.1) still drives the output power. However, no angle of incidence or panel angle was included in the calculations to determine the solar irradiance received at the panel.

The DC power output from the solar is then converted to AC power with a single phase inverter model. Different inverter models have different efficiency levels, but the average conversion efficiency is around $90 \%$ [9], which is considered for the inverter model used in this analysis. The inverter model operates in a constant power factor mode, where the constant power factor is assumed to be unity for the SGIG analysis, so that only real power from the solar electric system is injected to the distribution grid.

\subsubsection{Residential PVs}

Photovoltaics are expected to be the fastest growing renewable at the distribution level due to the large availability of solar resources in the US [8]. The addition of residential PVs is expected to be the quickest to deploy due to the availability of smaller PV arrays, which are ideal for offsetting some of the major loads of a residential end-user. Both consumers and utilities have been installing small-scale PVs in the residential sector. The average residential PV unit ranges from $3 \mathrm{~kW}-5 \mathrm{~kW}$ and can be easily mounted on roof-tops of residential end-users [10] [11].

While there have been numerous studies of PV integration to the grid, limited work has been done to analyze the effects at the distribution level of residential PV for different climate regions within the United States [12][13]. It is necessary to analyze the impact of residential PV because the large number of installations that can be found on a single distribution feeder. Instead of a single large unit with a single point of interconnection, there are multiple units small units at various locations of the feeder. The large spatial placement of residential PV units presents a challenging analysis problem for planning engineers.

To ensure that the results of this report can be reproduced by other researchers, all of the tools, models, and materials used are openly available at [18]. Through detailed time-series simulations 
conducted in GridLAB-D, the impact of adding residential PVs to the grid can be examined on the relevant prototypical feeders. Utilities, regulators, vendors and other stakeholders interested in analyses more specific to their systems, goals, and conditions may make use of these open tools for their own purposes.

\subsubsection{SGIG Impact Metrics Affected by Residential PVs}

A detailed list of the SGIG impact metrics can be found in Appendix A. These metrics are for all of the SGIG projects. The following SGIG metrics are affected by the addition of residential PVs and will be tracked in this analysis:

Table 2.1: Impact metrics affected by addition of Residential PVs

\begin{tabular}{|c|c|c|}
\hline Index & Metric & Units \\
\hline 1 & Hourly Customer Electricity Usage & $\mathrm{kWh}$ \\
\hline 2 & Monthly Customer Electricity Usage & MWh \\
\hline \multirow{12}{*}{3} & Peak Generation & $\mathrm{kW}$ \\
\hline & Nuclear & $\%$ \\
\hline & Solar & $\%$ \\
\hline & Bio & $\%$ \\
\hline & Wind & $\%$ \\
\hline & Coal & $\%$ \\
\hline & Hydroelectric & $\%$ \\
\hline & Natural Gas & $\%$ \\
\hline & Geothermal & $\%$ \\
\hline & Petroleum & $\%$ \\
\hline & Distributed Solar PV & $\%$ \\
\hline & Distributed Wind & $\%$ \\
\hline 4 & Peak Load & $\mathrm{kW}$ \\
\hline 7 & Annual Electricity Production & MWh \\
\hline 12 & $\mathrm{CO} 2$ Emissions & Tons \\
\hline \multirow{3}{*}{13} & SOx Emissions & Tons \\
\hline & NOx Emissions & Tons \\
\hline & PM-10 Emissions & Tons \\
\hline \multirow{2}{*}{21} & Feeder Real Load & $\mathrm{kW}$ \\
\hline & Feeder Reactive Load & kVAR \\
\hline 29 & Distribution Losses & $\%$ \\
\hline 30 & Distribution Power Factor & $\mathrm{pf}$ \\
\hline 39 & $\mathrm{CO} 2$ Emissions & Tons \\
\hline \multirow{3}{*}{40} & SOx Emissions & Tons \\
\hline & NOx Emissions & Tons \\
\hline & PM-10 Emissions & Tons \\
\hline
\end{tabular}




\subsubsection{Specific Implementation of Residential PVs}

For the SGIG analysis, residential PVs are assumed to be roof mounted units, sized from $3 \mathrm{~kW}$ to $5 \mathrm{~kW}$, and randomly distributed on houses based on the per-feeder penetration level. The level of penetration for the SGIG analysis ranges from $1 \%-6 \%$ of the peak feeder load and is dependent on the region where the PV is being deployed. These deployments are summarized in Table 2.2, using the regions of Figure 2.1, which is also shown in Appendix B.

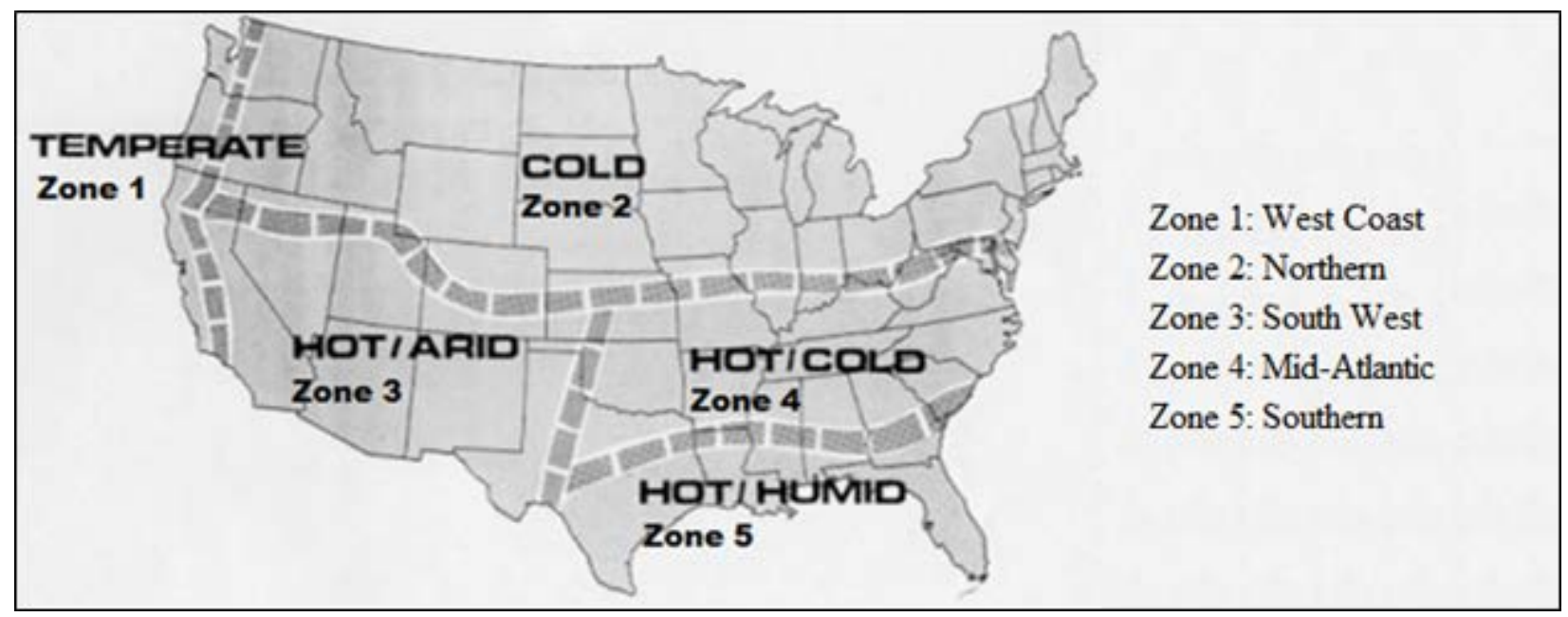

Figure 2.1. Climate Zones Used for Development of Prototypical Feeders

Table 2.2: Residential PV penetration by region

\begin{tabular}{|c|c|}
\hline Region Number & Penetration Level (\% of peak feeder load) \\
\hline 1 & 3 \\
\hline 2 & 1 \\
\hline 3 & 4 \\
\hline 4 & 5 \\
\hline 5 & 6 \\
\hline
\end{tabular}

The penetration levels selected for this analysis conservative, but are still be able to capture the benefits of the technology deployed. The basis for Table 2.2 is obtained from current solar penetration and wind penetration, given in [15] [16], and are divided by states. When different states are grouped together to form a taxonomy region, the solar penetration is often less than $1 \%$. In order to capture the benefits of a large scale renewable deployment, the current penetration levels were extrapolated to present penetration levels that were higher than current, but not so high as to represent an unrealistic scenario. 
The residential PV simulation has been done for only those feeders that have residential houses, so the five GC-12.47-1 feeders and the R3-12.47-2 feeder are excluded from this study. Please see Appendix B for a more detailed discussion of the prototypical feeders used in this report.

\subsubsection{Overall Residential PVs Simulation Results}

In this section, we examine the overall simulation results of the addition of residential PVs to the prototypical distribution feeders. At this level of examination, the data will not be divided into monthly values; only annual values for each feeder will be examined. Simulation results for 22 of the 28 prototypical distribution feeders will be examined for each climate region. As indicated above, 6 of the feeders do not contain any residential end-use loads and are ignored for this section of the analysis. The following sections will examine the impacts of PVs with respect to peak load, annual energy consumption, system losses, power factor, annual output, and $\mathrm{CO}_{2}$ emissions.

\subsubsection{Annual Peak Load}

One of the goals of adding residential photovoltaics to the distribution system is to reduce peak feeder load. However, it is important to note that the addition of PV does not necessarily reduce the peak. The peak load for most residential feeders occurs during the evening while the peak output from solar PV units occurs around noon. As a result, solar PV may reduce the peak load of a feeder, but the reduction will only be a fraction of the aggregate solar PV rating. As a result, the amount of peak load reduction will be vary based on the penetration of residential PV, the time of the feeder peak load, and the climate region. 


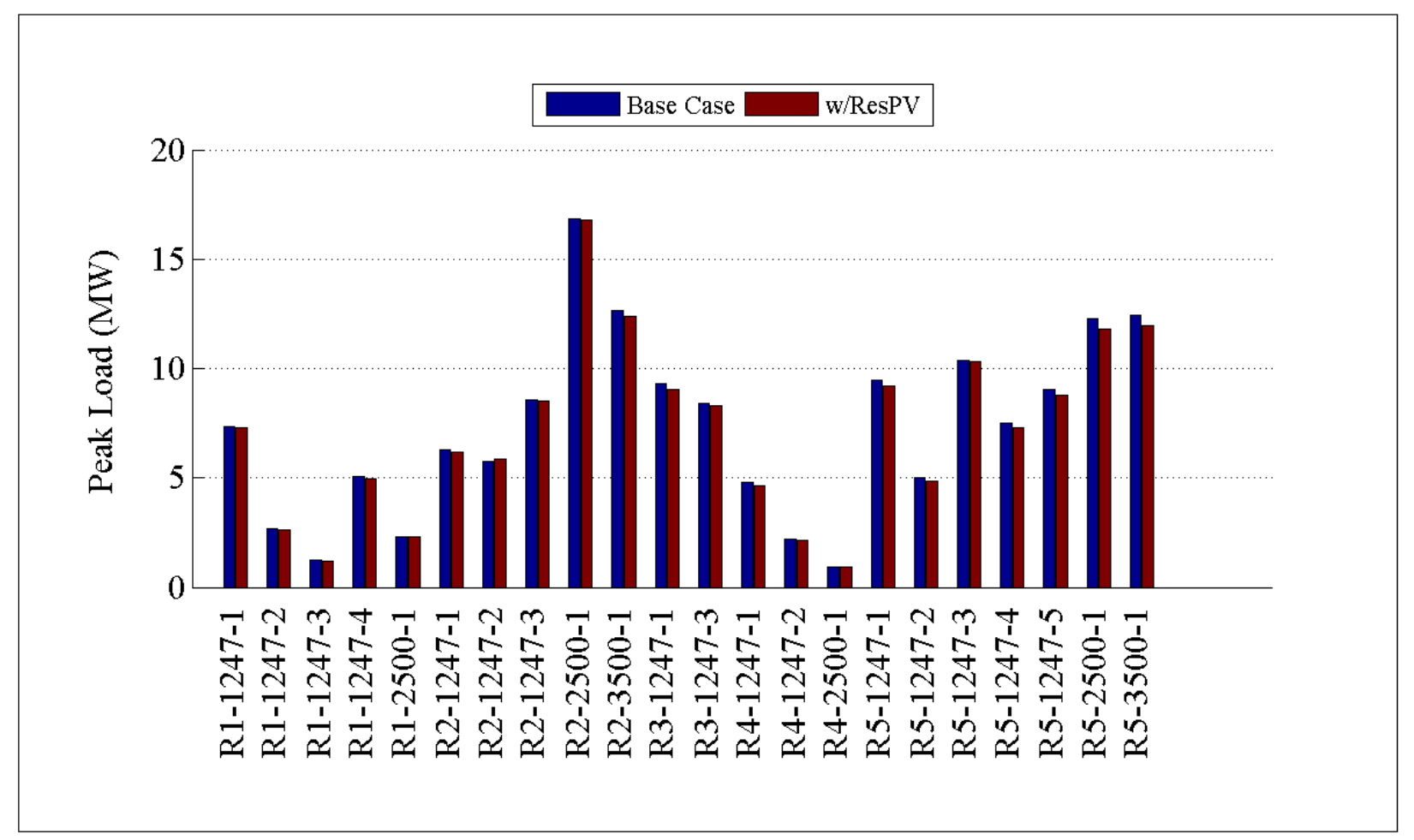

Figure 2.2: Comparison of peak load by feeder

From Figure 2.2, it can be seen that the addition of PV reduces annual peak load in almost all the feeders, except for R2-12.47-3. While there is a nominal reduction in most feeders, certain feeders have larger peak load reduction. This difference is based on the penetration and distribution of PV units, as well as the coincidence between the peak solar and peak load times occur. The change in peak load is shown in Figure 2.3 and the percent change values are shown in Figure 2.4. 


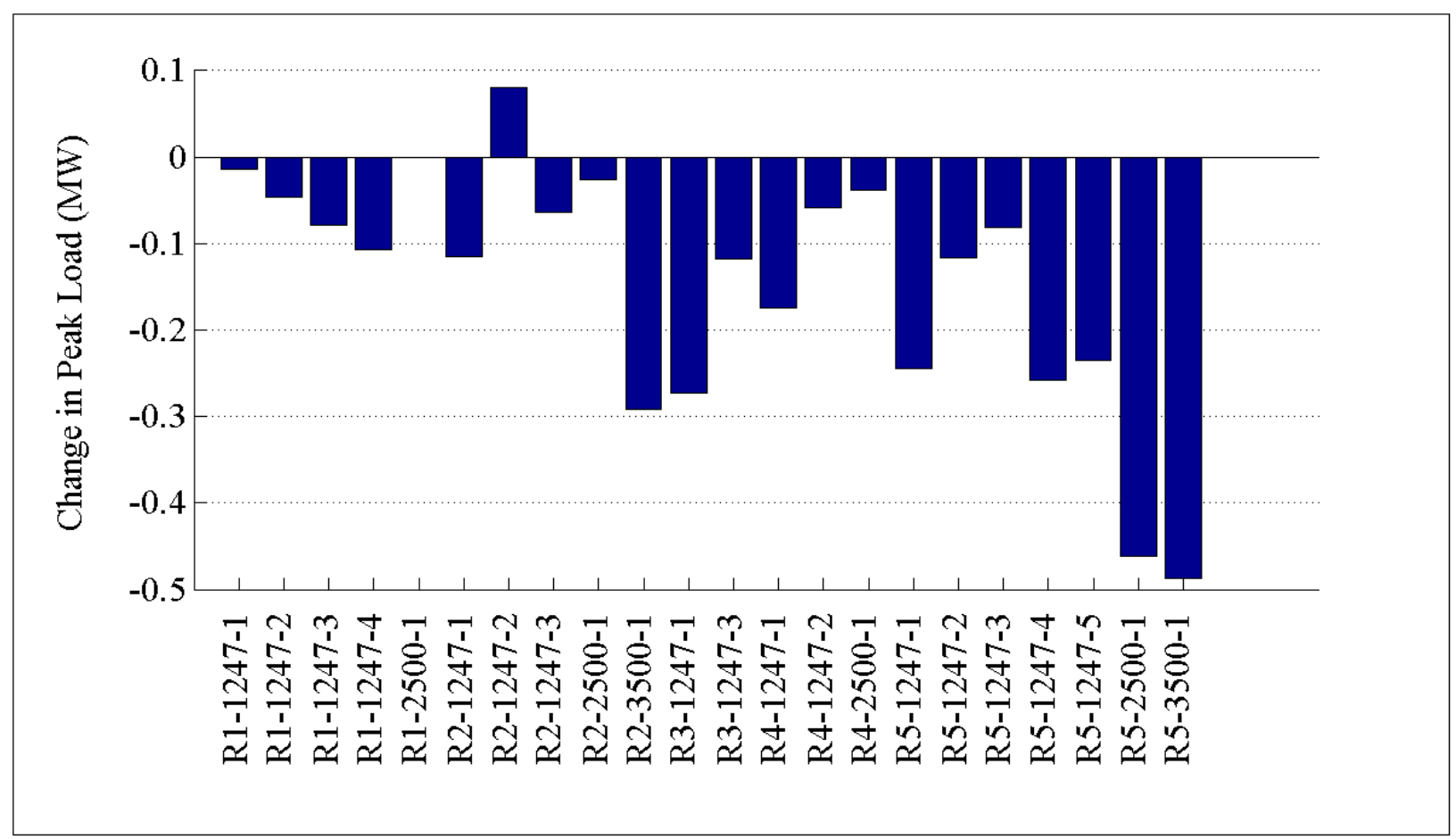

Figure 2.3: Change in peak load on feeders in (MW)

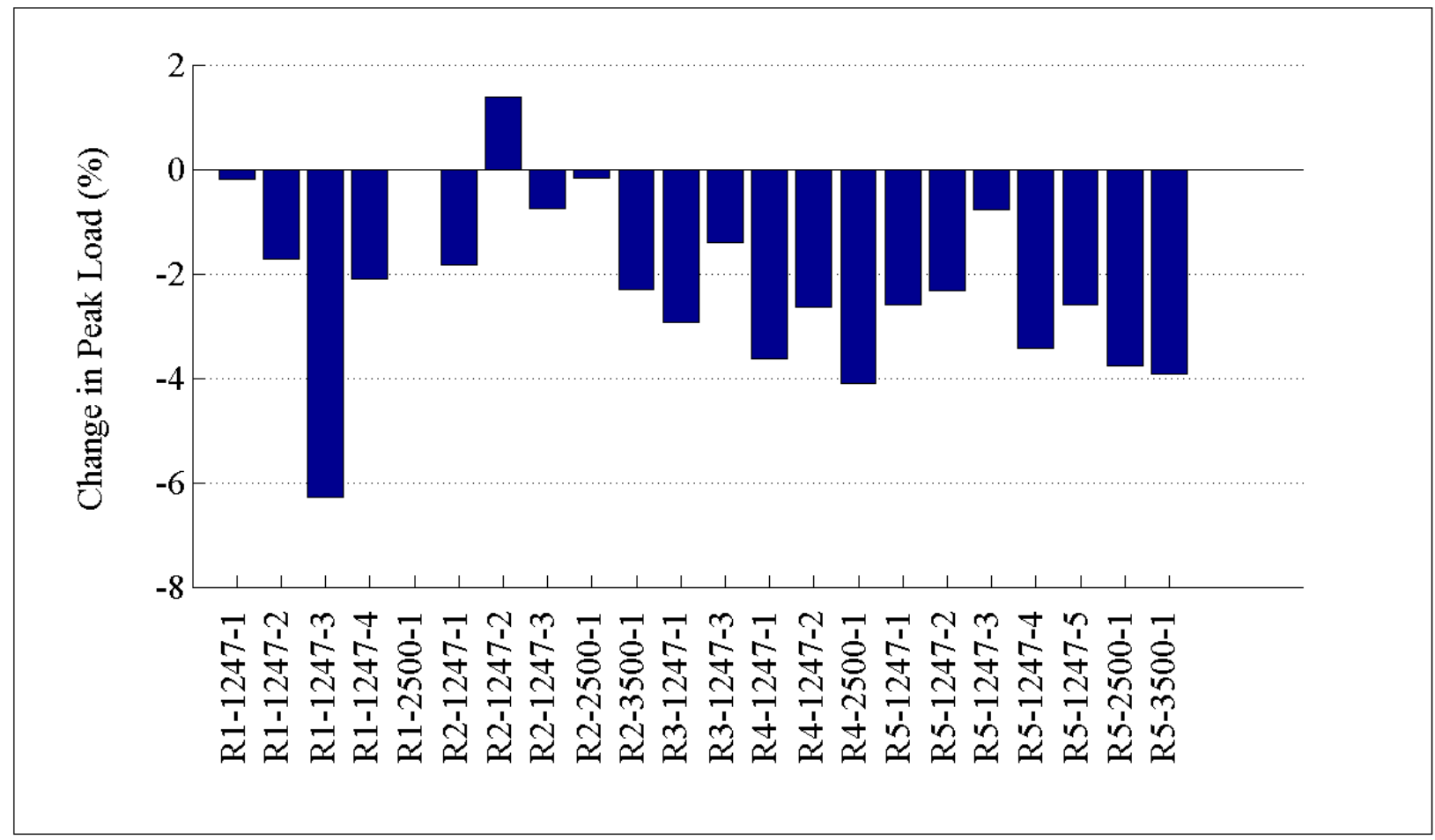

Figure 2.4: Change in peak demand by feeder (\%) 
Figure 2.3 shows the change in the peak load when compared to the base case. The maximum percentage peak reduction was seen for feeder R1-12.47-3. There was a slight increase in peak demand for feeder R2-12.47-2, whereas feeder R1-2500-1 shows no effect on the peak load. The increase in the peak demand associated with R2-12.47-2 is a small fraction of the feeder peak demand ( $1 \%$ of annual peak load, as shown in Figure 2.4). This increase can be explained by voltage dependent loads changing their state behavior when voltage is varied, causing the consumption of more power. For example, variable voltages can cause HVAC (Heating, Ventilation and Air Conditioning) units to shift their behavior and can cause them to consume more power or shift their operations to a time period where there is more coincident load. Also, it is important to note that this behavior is also highly dependent on the feeder type, load composition, and the distribution of PV units.

\subsubsection{Annual Energy Consumption}

Reduction in annual energy supplied to the feeder is the greatest benefit of the addition of residential PVs. In contract to peak load reduction, the reduction in annual energy consumption benefits from energy produced by the PV units at any time. Annual energy consumption for a distribution feeder is the total energy that must be supplied as measured at the head of the feeder. In the case of residential PV deployment, some of the energy that would normally be supplied by the feeder is supplied by the local PV units, thus reducing the annual energy consumption from the perspective of the feeder. The reduction in annual energy consumption is shown in Figure 2.5 for each of the prototypical feeders with residential end-use customers. 


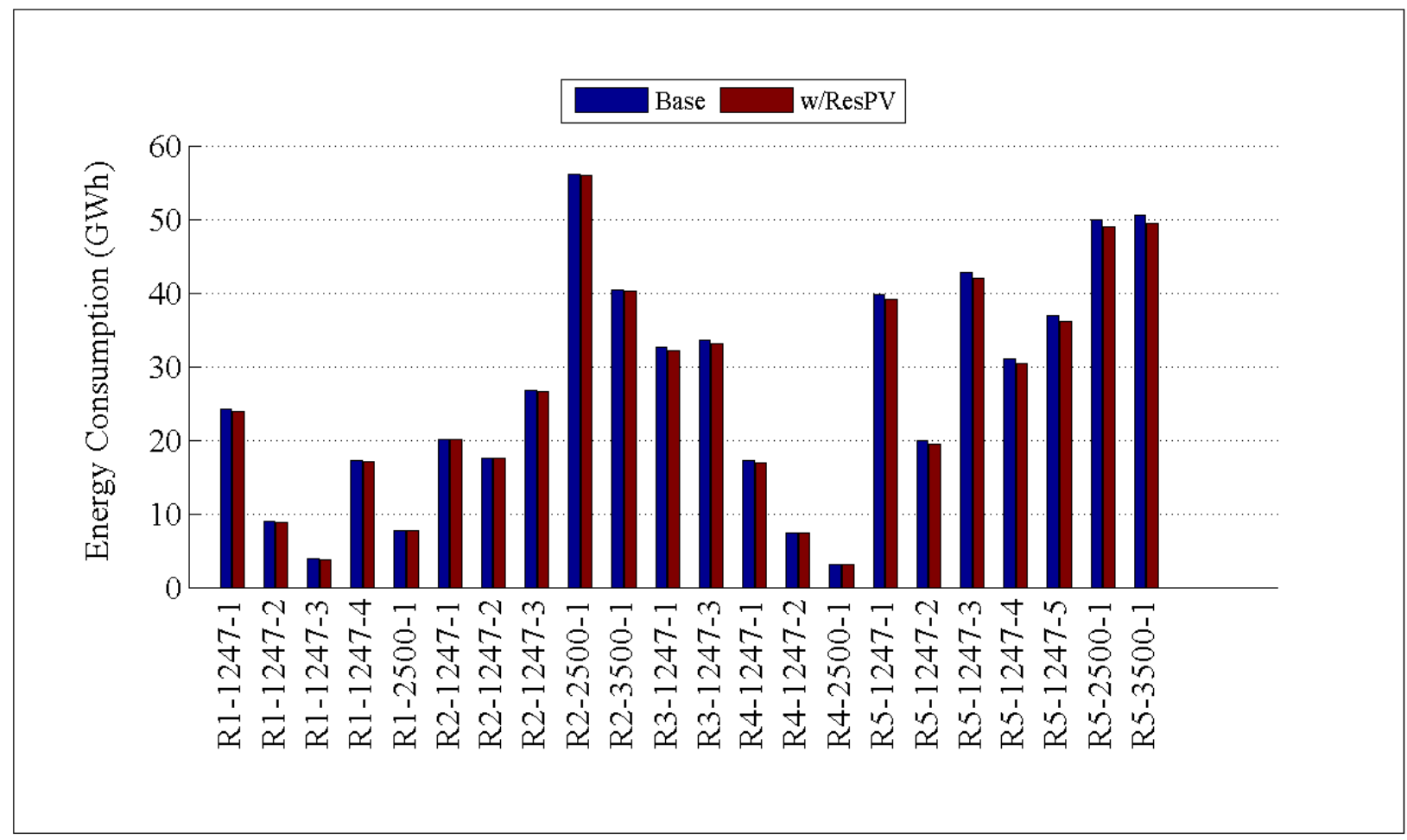

Figure 2.5: Comparison of annual energy consumption by feeder

As can be seen in Figure 2.5, the annual energy consumption provided by the feeder, was reduced for all the feeders with residential PVs added. With the PV units operating in accordance with IEEE 1547, the PV units injected real power at the point of interconnection which supplied some of the local energy demand. This was true even for feeder R2-12.47-2 which had showed an annual peak load increase because of interactions with the end-use loads, as seen in Figure 2.4. Despite the negative impact on peak load, the annual energy consumption was still decreased because the PV units injected real power into the feeder.

The change in annual energy consumption, when compared to the base case, is given by Figure 2.6. Figure 2.7 demonstrates that region 5 shows the largest percentage reduction in the energy consumption. This is primarily because it has the largest penetration of PV units as compared to its feeder load, and because Region 5 has the highest solar resource. 


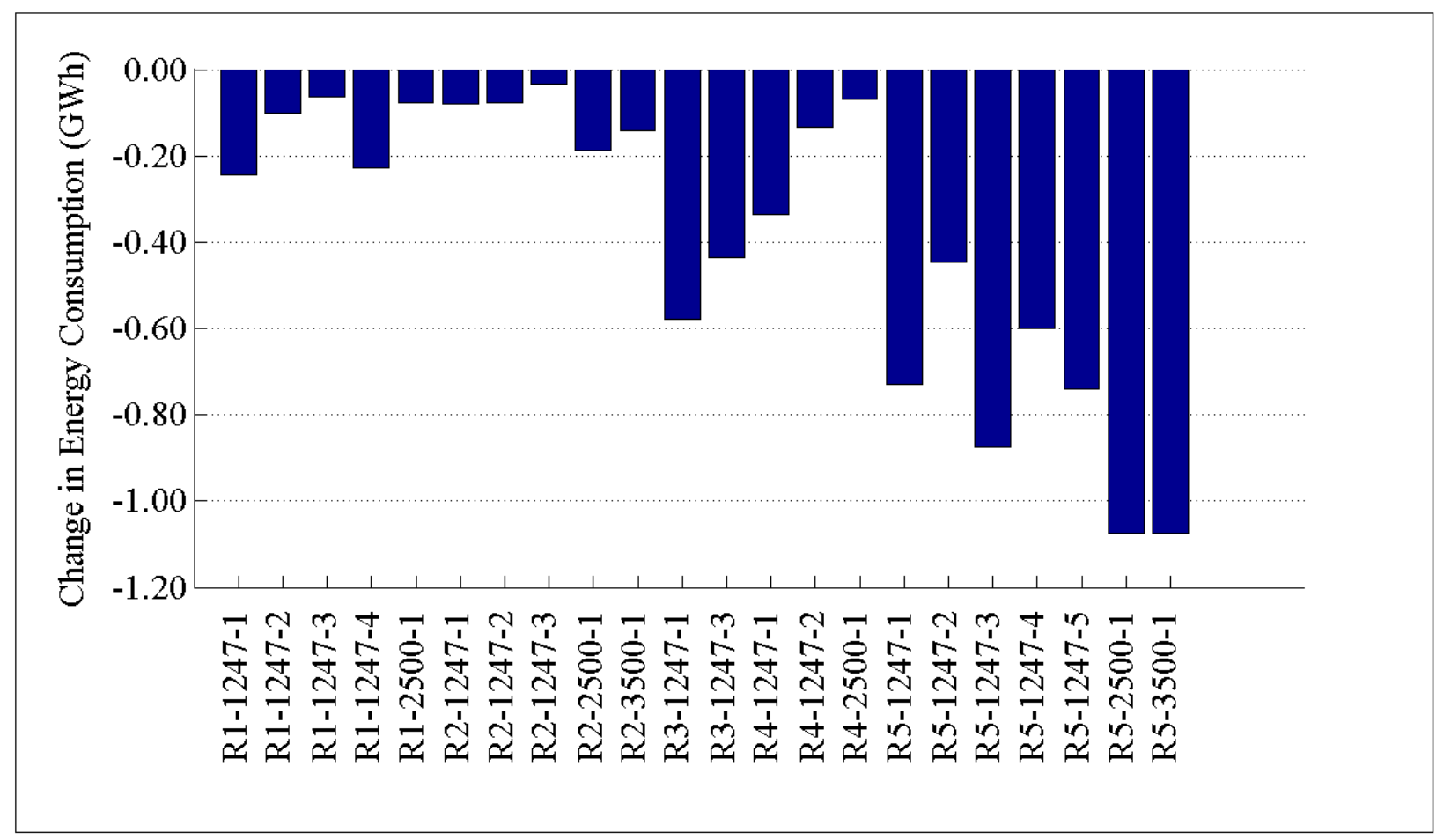

Figure 2.6 : Change in annual energy consumption by feeder (MWh)

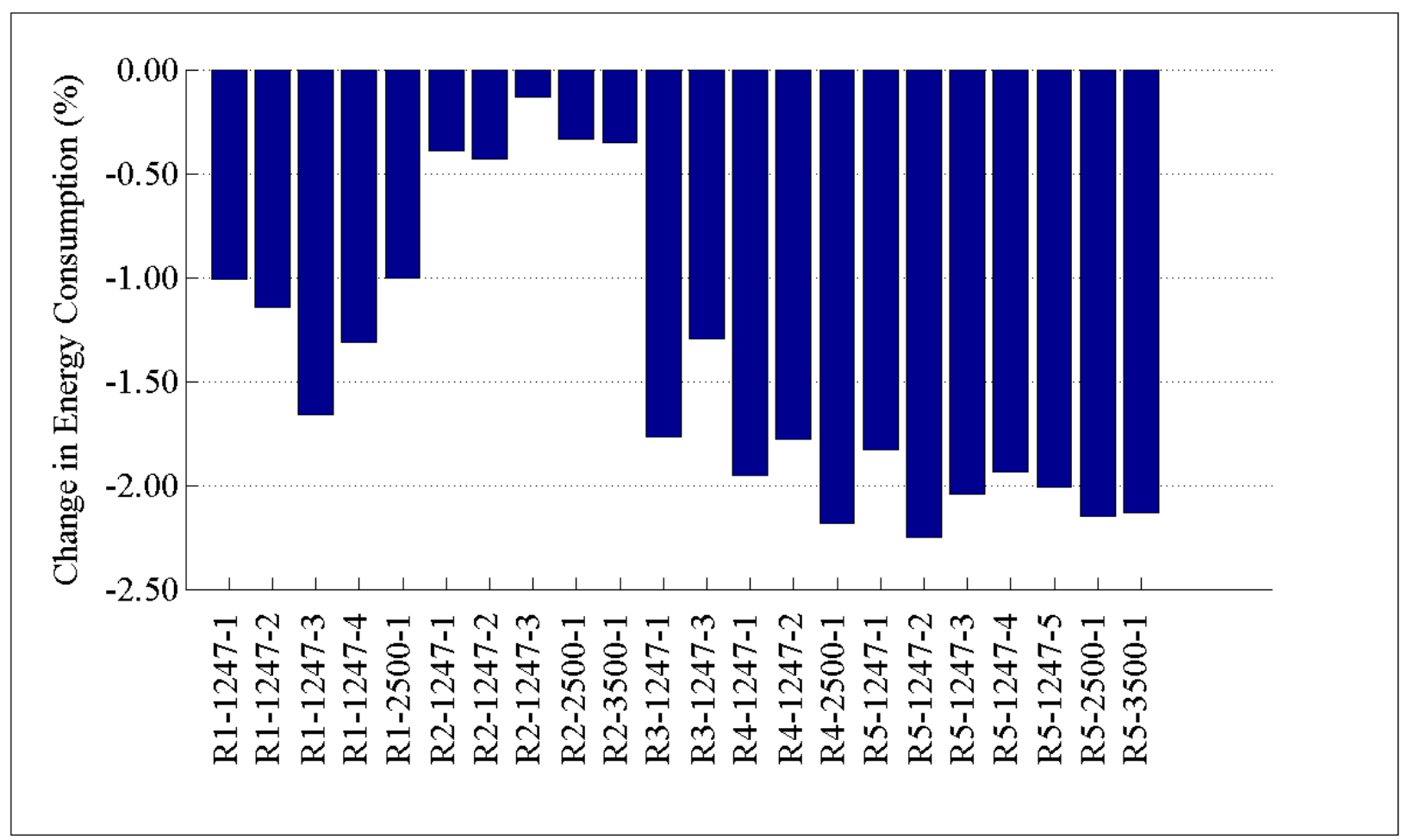

Figure 2.7 : Change in annual energy consumption for feeders (\%) 
The largest reduction in energy consumption is seen for feeder R5-12.47-2 in region 5, where the solar penetration was $6 \%$ of the peak feeder load and solar incidence was highest. From the full year simulations, region 4's solar penetration of $5 \%$ resulted in the second largest reduction in energy consumption.

\subsubsection{Annual System Losses}

One of the benefits of adding PVs at the distribution level is the reduction of system losses. When electrical current flows through a conductor, some of that energy is lost in the form of heat. In the case of alternating current distribution lines, further energy can be lost to inductive losses on the conductor. At peak load, the amount of current flowing through a conductor is at its highest, generating the greatest losses. The total current flow in a conductor is a combination of the current flows associated with real and reactive power components. As a result, reducing either the real or reactive power flow will reduce the losses associated with that current. Solar PV reduces current flows by reducing the amount of real power that a feeder must supply, thereby reducing the current and losses.

Figure 2.8 shows the annual system losses calculated as losses downstream of the distribution feeder head. In this case, the PV injects only real power back to the distribution grid and hence affects only the real part of the current flowing through the conductor.

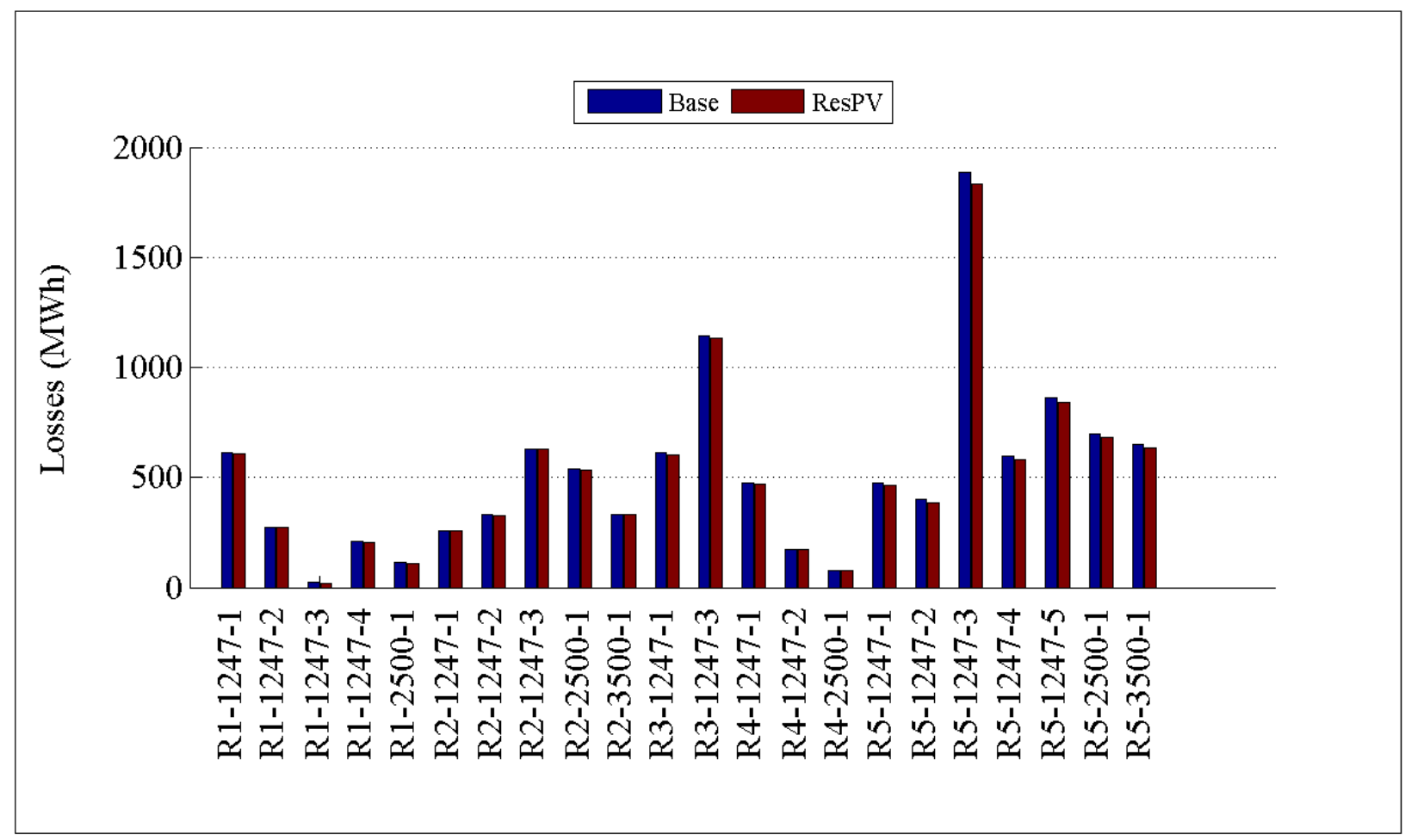

Figure 2.8: Comparison of annual losses by feeder 
The annual losses were reduced for all the feeders when residential PV units were added to the system; however, the level of reduction varied between the different feeders. For example, feeder R5-12.47-3 saw the largest reduction in system losses compared to other feeders, as seen in Figure 2.10.

The reduction in the system losses are not necessarily proportional to the level of PV penetration, but are also dependent on the system type and the placement of the PV units. Since the PV units were randomly placed, it is possible that the largest load, or an entire branch of the feeder, did not have a PV unit associated with it. Therefore, the losses contributed by it will not be offset and the reduction in losses seen at the feeder level will be small. The energy loss reduction is also a function of the feeder loading, because a more heavily-loaded system will tend to have higher losses. Therefore, the addition of DG in the form of PV will reduce line losses whenever there is PV output. However, maximum loss reduction will be achieved when solar generation is during the feeder peak loading time.

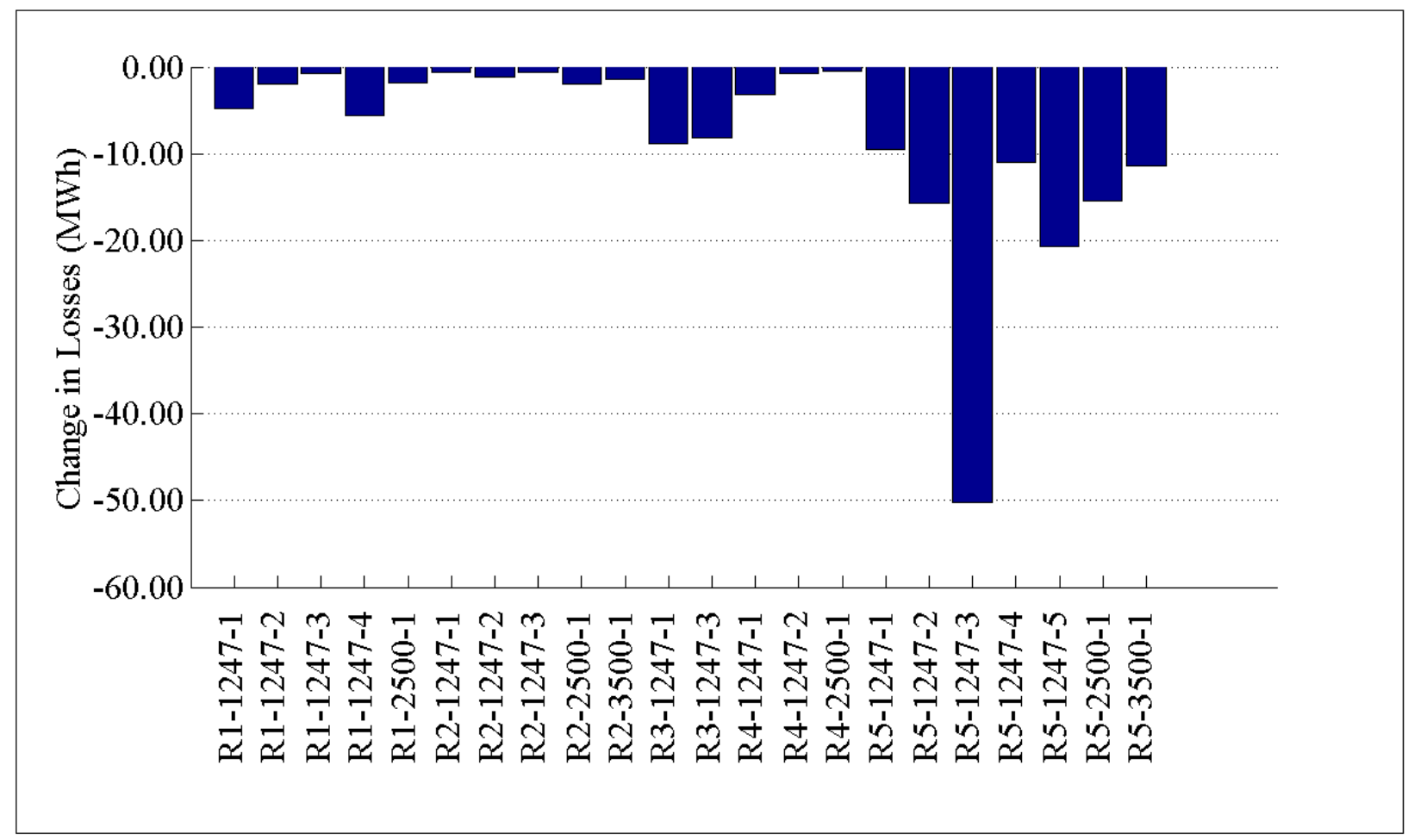

Figure 2.9: Change in annual losses by feeder (MWh) 


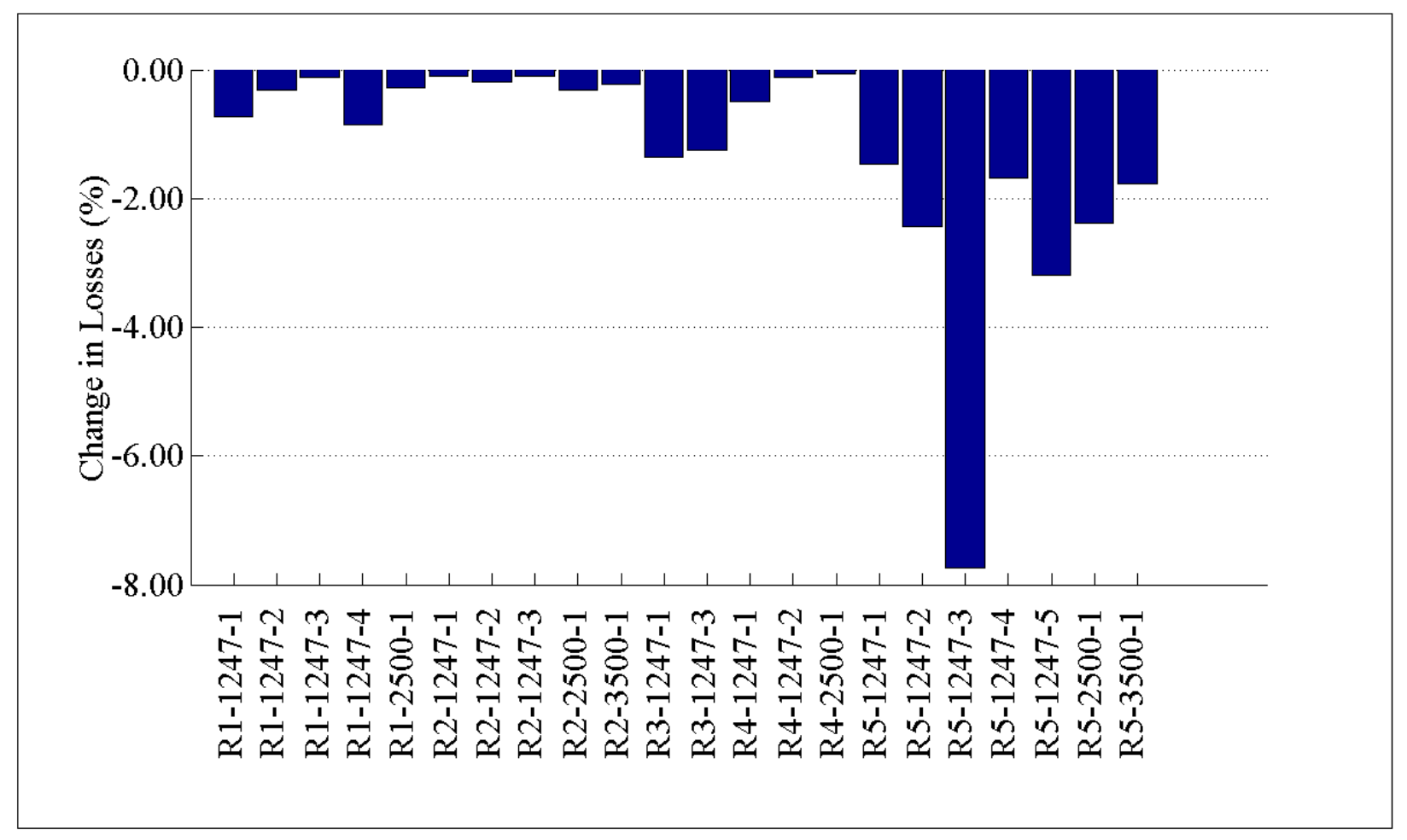

Figure 2.10: Change in annual losses by feeder (\%)

\subsubsection{Power Factor Impact}

The deployment of residential PV units that only produce real power will have an impact on the power factor of the distribution feeders. Since the PV units provide an aggregated amount of real power, this amount of real power will not need to be supplied by the feeder, but the reactive requirements are still similar. As a result, it is possible for the power factor as seen at the substation to degrade and move farther away from unity. Figure 2.11 shows the variation of the average power factor over the course of the year for the prototypical feeders with residential enduse customers. 


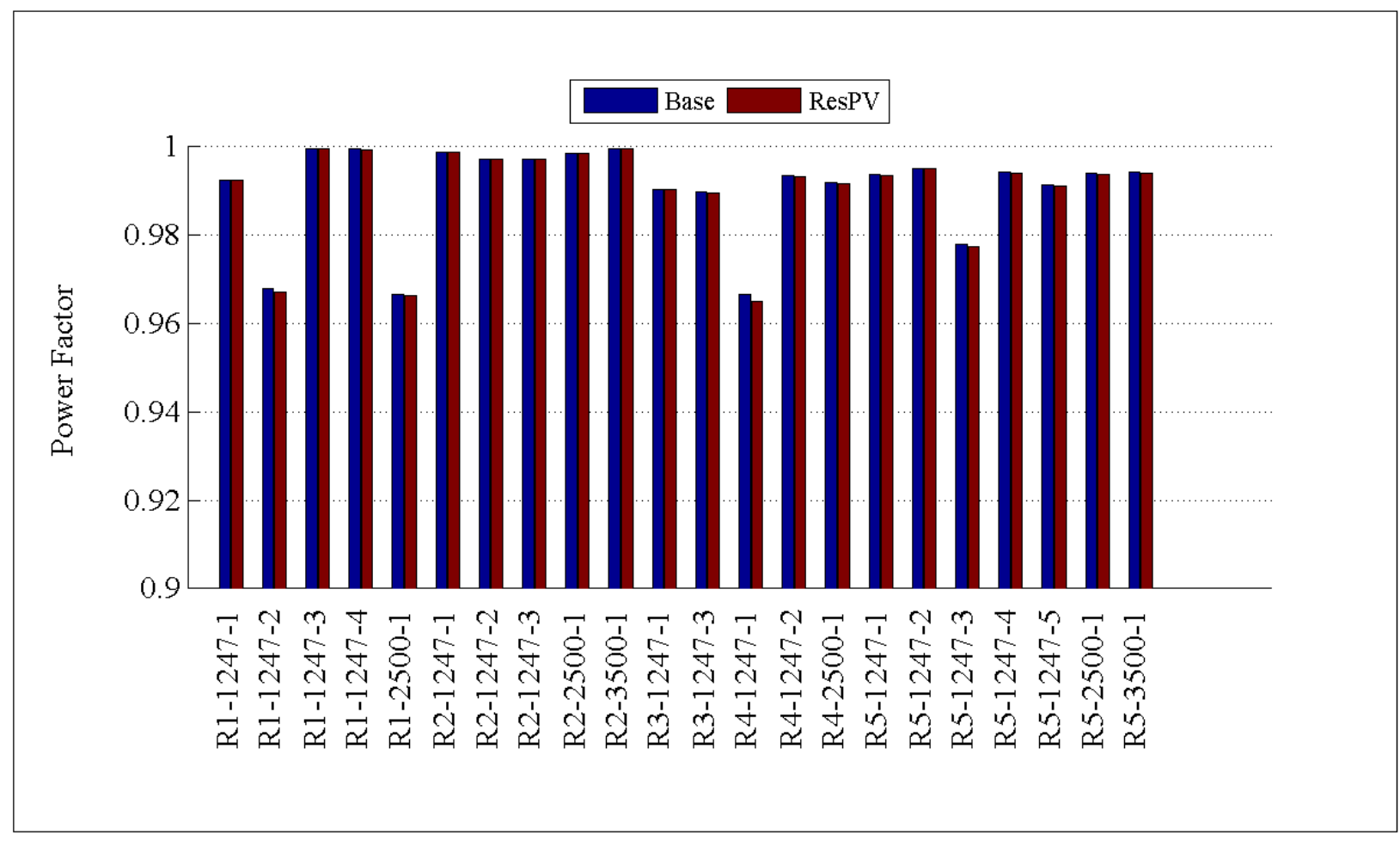

Figure 2.11 : Comparison of average annual power factor by feeder

Figure 2.12 shows the minimum annual power factor for all the feeders. It can be seen that the power factor seems to be more lagging on a few feeders when residential PVs are integrated. This can be explained in the fact that the PVs are only injecting real power to the grid, and there is no control to regulate the reactive power. Without any significant change to the reactive power components of the system, the power factor lags. Overall, this lagging power factor was not improved. This emphasizes the need for reactive power control, either integrated in the in the inverter system, or via addition of automatic capacitor banks on the feeder to perform reactive power control. The next version of IEEE 1547.8 will include guidelines for how to operate distributed resources in other than unity mode. 


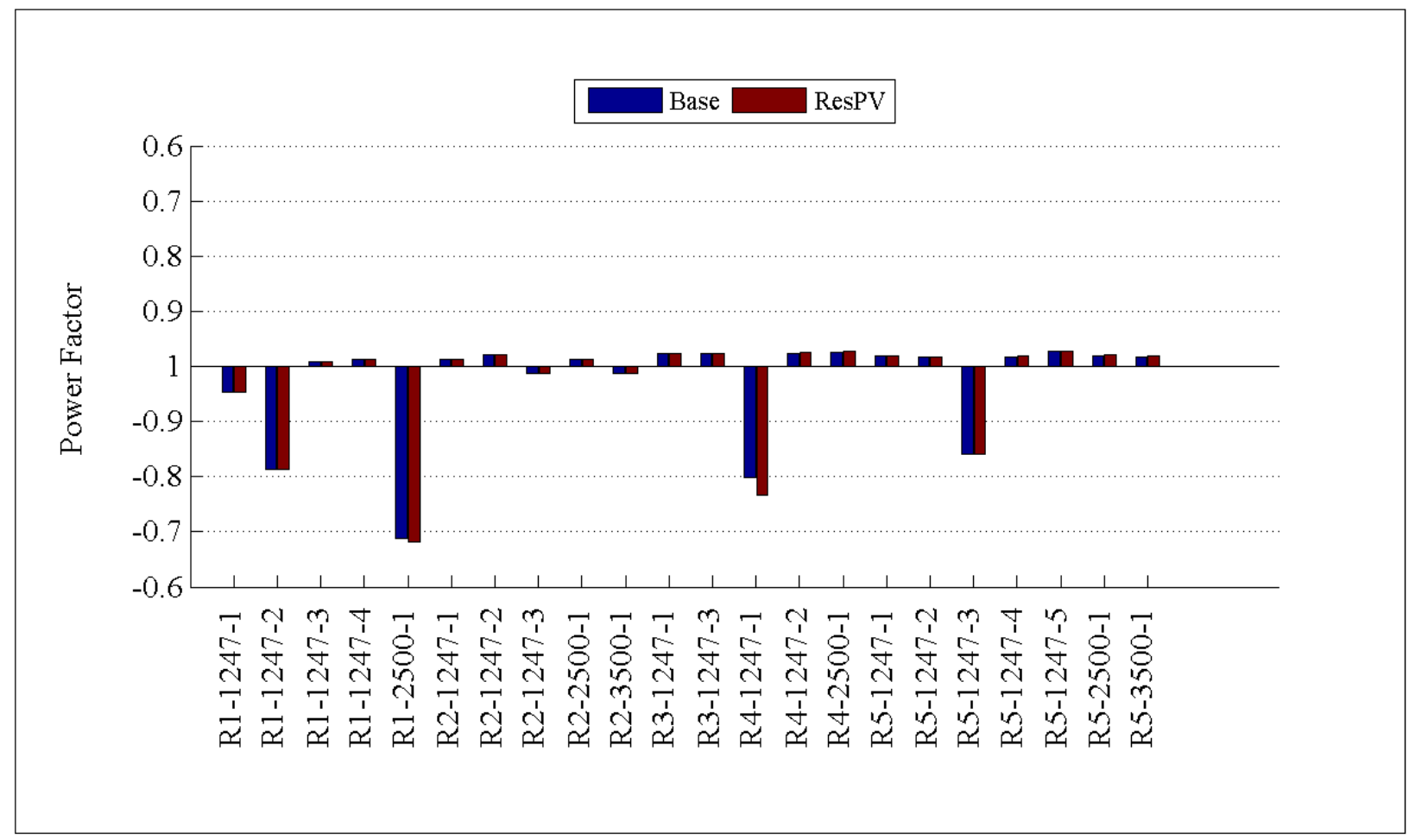

Figure 2.12 : Comparison of minimum annual power factor by feeder

\subsubsection{Annual Residential PV output}

Figure 2.13 shows the annual power output by residential PV arrays added to the distribution feeder. Recall that region 5 had the highest penetration of PV units, as well as the highest PV output as a percent of its peak load. As such, it is not surprising that it has the highest average PV energy output for all five regions. 


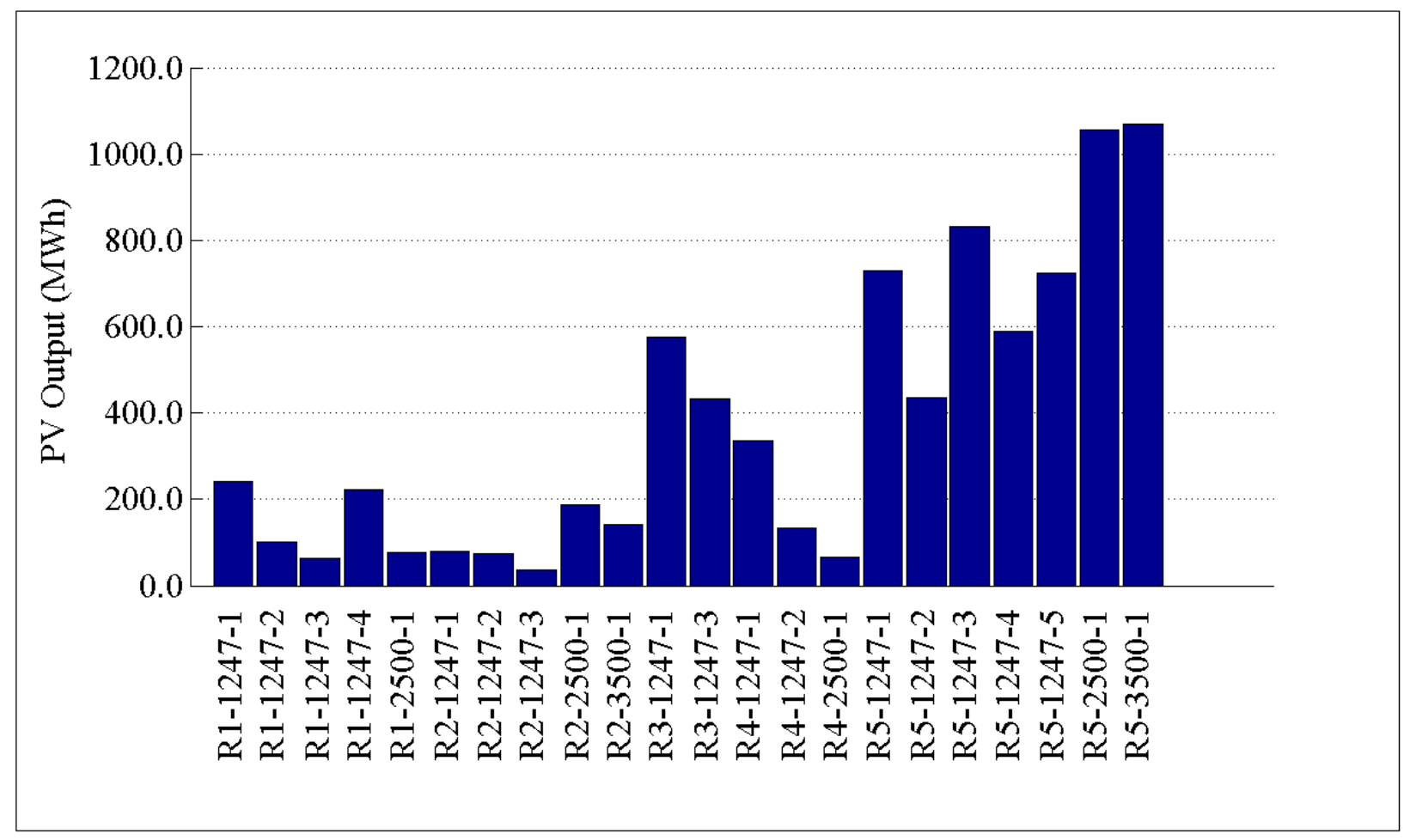

Figure 2.13: Annual residential PV power output by feeder

\subsubsection{Annual $\mathrm{CO}_{2}$ Emissions}

One of the most important benefits of renewable resources for electricity production is reducing the emissions associated with carbon dioxide, particulate matter, and other harmful gases. Environmental emissions for each feeder were estimated using a simple dispatch algorithm. Generation sources were sized by the regional generation types, and ranked to dispatch in an appropriate order. Full commitments were achieved before proceeding to the next generator. For example, consider a region where natural gas turbines dispatch first to support $250 \mathrm{MW}$ of load, followed by $400 \mathrm{MW}$ of petroleum-fired generation. To support $300 \mathrm{MW}$ of load, the natural gas unit is fully dispatched, then the remaining $50 \mathrm{MW}$ is attributed to the petroleum-fired generation. Representative heat rates and emission rates are then applied to these power outputs to determine the overall environmental impacts. The details of these rates, along with the dispatch orders and penetration levels for each region, are explained in Appendix B.

Figure 2.14 shows the annual $\mathrm{CO}_{2}$ emissions for both the base case and the residential PV case. 


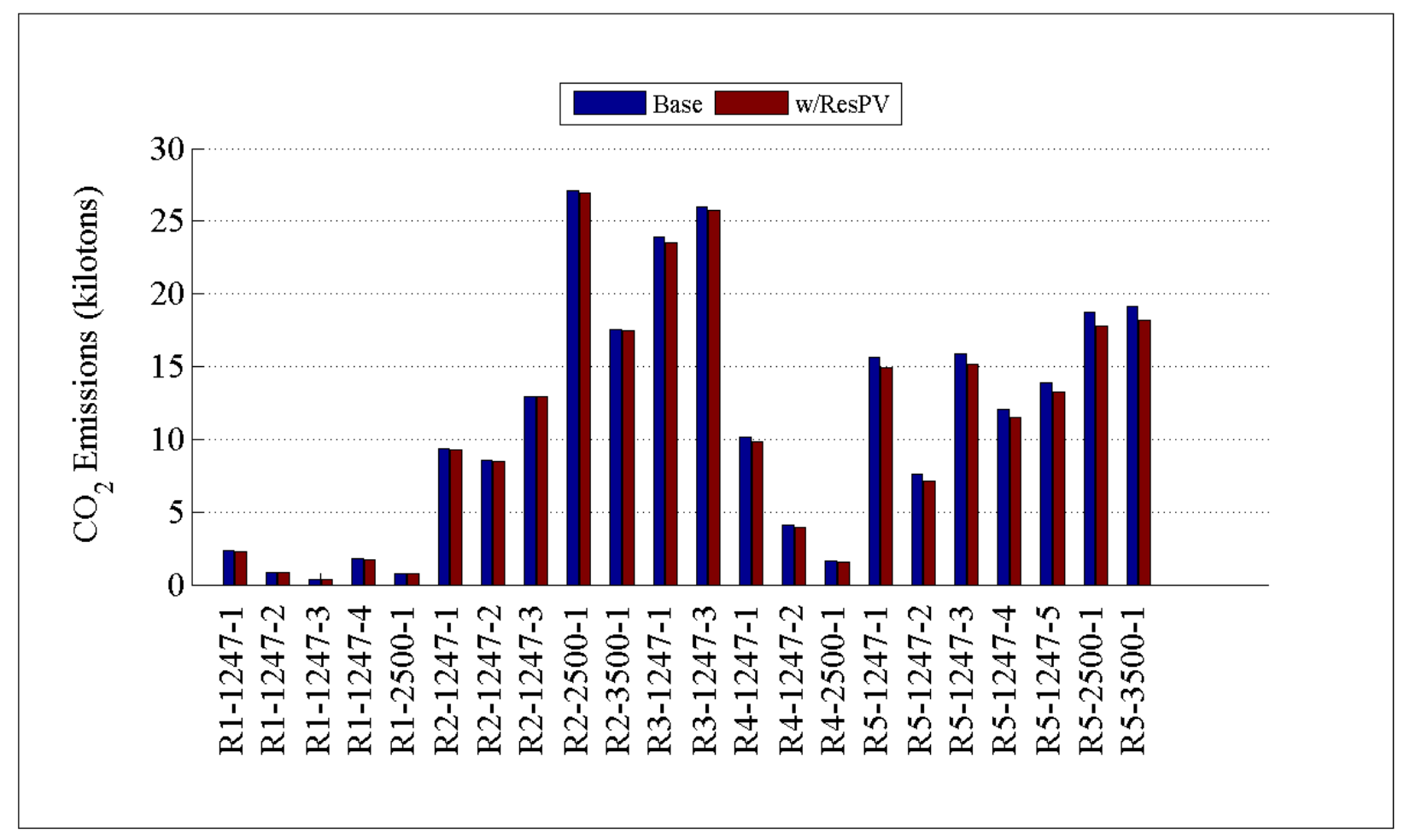

Figure 2.14: Comparison of total annual $\mathrm{CO}_{2}$ emission by feeder

Figure 2.14 shows that the $\mathrm{CO}_{2}$ emissions were reduced on all the feeders when residential PVs were added to the grid. The greater the reduction in energy consumption, the more potential there is for a reduction in emitted $\mathrm{CO}_{2}$. Region 2 received the lowest amount of PV penetration and showed the smallest improvement in energy consumption reduction, as was seen from Figure 2.7. Hence, region 2 also demonstrated the smallest reduction in $\mathrm{CO}_{2}$ emissions. Region 5 received higher penetration of $\mathrm{PV}$ as fraction of the feeder peak load and showed the highest reduction in $\mathrm{CO}_{2}$ emissions. Figure 2.15 and Figure 2.16 show the emission differences in both tons and percentages when compared to the base case. As expected, the addition of residential PV decreased the carbon dioxide emissions on all the feeders. 


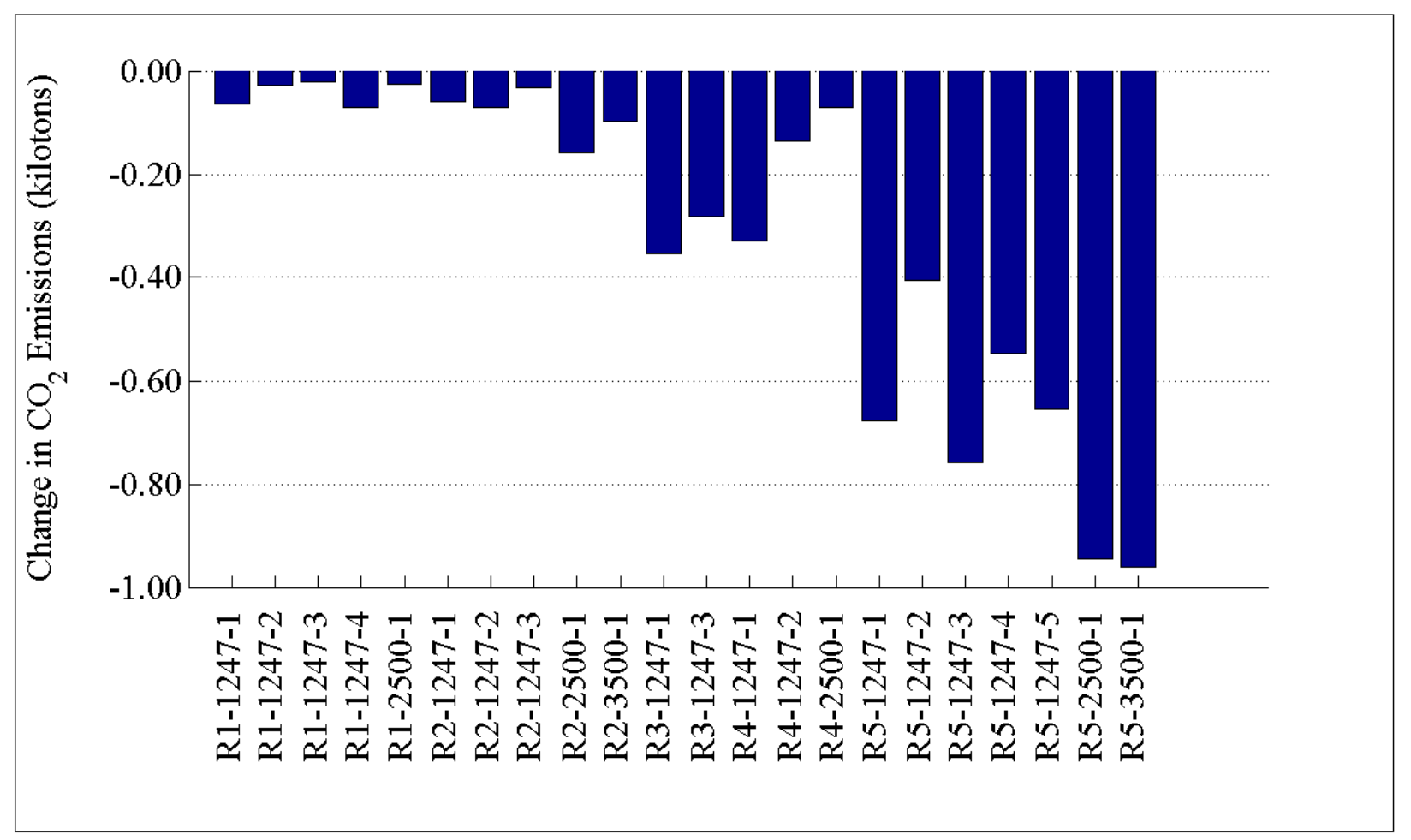

Figure 2.15: Change in total annual $\mathrm{CO}_{2}$ emissions by feeder (tons)

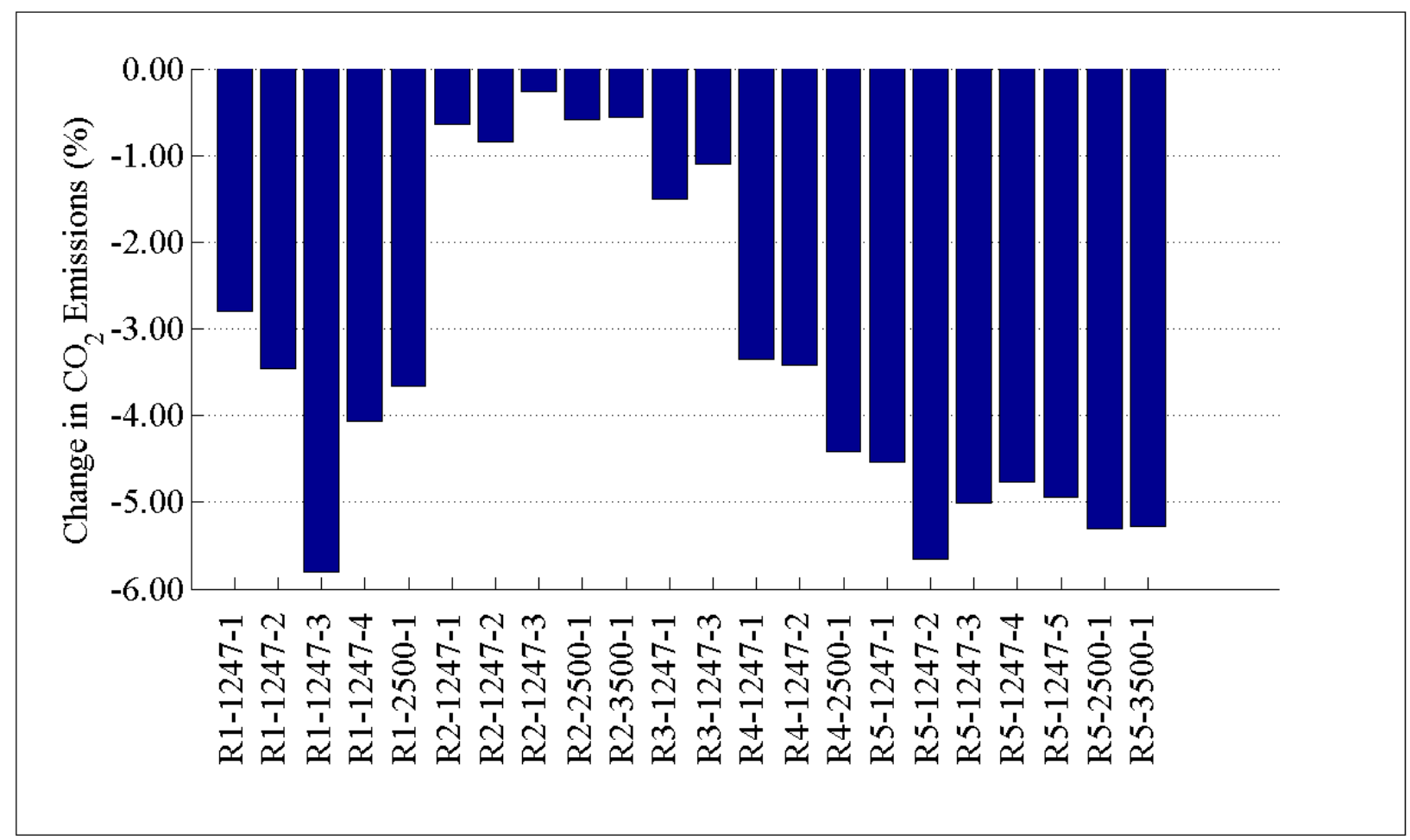

Figure 2.16: Change in total annual $\mathrm{CO}_{2}$ emissions by feeder (\%) 


\subsubsection{Commercial PVs}

The addition of commercial scale PVs is gaining popularity as the penetration of renewable generation sources increases. Both utilities and businesses are taking the initiative in installing commercial scale PV systems. Commercial PV arrays are generally larger in size when compared to residential PV installations and can be either rooftop mounted or ground mounted, either as one large unit or connected to the grid as solar farms.

As with the residential PV, the tools, models, and materials used to model the commercial PV placements are openly available at [18].

\subsubsection{SGIG Metrics Affected by Commercial PVs}

The following SGIG metrics are affected by commercial PVs and will be tracked in this analysis:

Table 2.3: Impact metrics affected by addition of Commercial PVs

\begin{tabular}{|c|c|c|}
\hline Index & Metric & Units \\
\hline 1 & Hourly Customer Electricity Usage & $\mathrm{kWh}$ \\
\hline 2 & Monthly Customer Electricity Usage & MWh \\
\hline \multirow{12}{*}{3} & Peak Generation & $\mathrm{kW}$ \\
\hline & Nuclear & $\%$ \\
\hline & Solar & $\%$ \\
\hline & Bio & $\%$ \\
\hline & Wind & $\%$ \\
\hline & Coal & $\%$ \\
\hline & Hydroelectric & $\%$ \\
\hline & Natural Gas & $\%$ \\
\hline & Geothermal & $\%$ \\
\hline & Petroleum & $\%$ \\
\hline & Distributed Solar PV & $\%$ \\
\hline & Distributed Wind & $\%$ \\
\hline 4 & Peak Load & $\mathrm{kW}$ \\
\hline 7 & Annual Electricity Production & MWh \\
\hline 12 & $\mathrm{CO}_{2}$ Emissions & Tons \\
\hline \multirow{3}{*}{13} & SOx Emissions & Tons \\
\hline & NOx Emissions & Tons \\
\hline & PM-10 Emissions & Tons \\
\hline \multirow{2}{*}{21} & Feeder Real Load & $\mathrm{kW}$ \\
\hline & Feeder Reactive Load & kVAR \\
\hline 29 & Distribution Losses & $\%$ \\
\hline 30 & Distribution Power Factor & $\mathrm{pf}$ \\
\hline 39 & $\mathrm{CO}_{2}$ Emissions & Tons \\
\hline \multirow{3}{*}{40} & SOx Emissions & Tons \\
\hline & NOx Emissions & Tons \\
\hline & PM-10 Emissions & Tons \\
\hline
\end{tabular}




\subsubsection{Specific Implementation of Commercial PV}

The prototypical feeders were populated with PV units as commercial end-use locations. The various types of commercial loads include: office buildings, strip malls, and big box retailers. The commercial loads were populated with $100 \mathrm{~kW}$ solar arrays, randomly distributed across the commercial end-use customers on the feeders. The solar penetration levels were similar to the residential PV penetration levels for all the regions, as shown in Table 2.4. The regional breakdown is the same as was shown in Figure 2.1.

Table 2.4: Commercial PV penetration by region

\begin{tabular}{|c|c|}
\hline Region Number & Penetration Level (\% of peak feeder load) \\
\hline 1 & 3 \\
\hline 2 & 1 \\
\hline 3 & 4 \\
\hline 4 & 5 \\
\hline 5 & 6 \\
\hline
\end{tabular}

\subsubsection{High Level Commercial PV Simulation Results}

In this section, the aggregated annual simulation results will be examined. Simulation results for each of the prototypical distribution feeders will be examined, including five cases of GC12.47-1; one for each climate region. The high level analysis will examine the impacts of PVs with respect to peak load, annual energy consumption, system losses, power factor, annual output, and $\mathrm{CO}_{2}$ emissions.

\subsubsection{Annual Peak Load}

As observed in the previous case with residential installations, peak reduction might not necessarily be a benefit of commercial PV integration, as shown by Figure 2.17. 


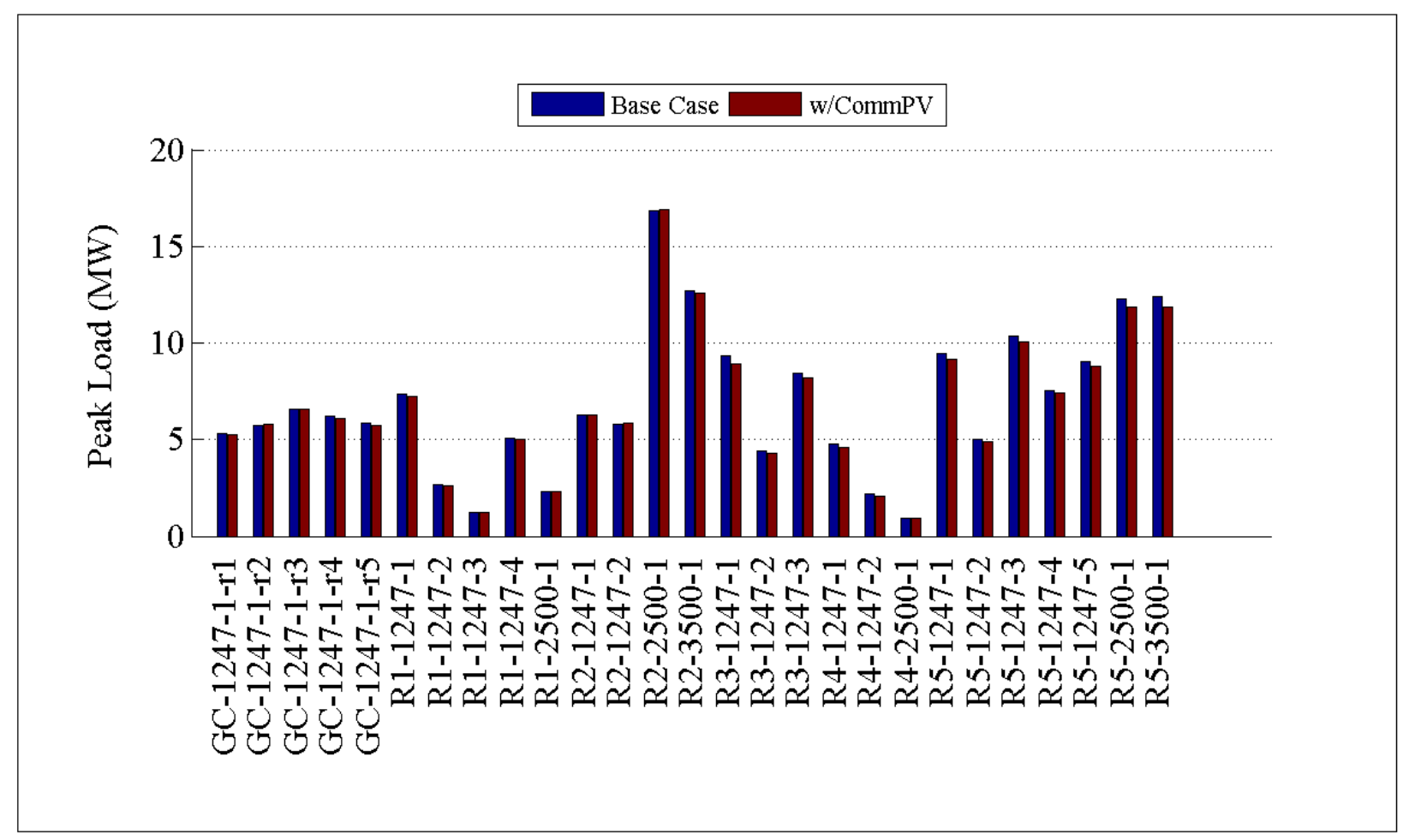

Figure 2.17 : Comparison of peak load by feeders

The maximum peak reduction observed was seen on feeders R4-12.47-2. An increase in peak load was seen on four of the feeders and was equal to no more than $0.8 \%$, as seen in Figure 2.19. As was the case with adding PV units to the residential loads, having end-use loads with voltage dependence can sometimes create increases in peak because of increases in local voltage as well as changes in operating states. Also, as explained with the residential PV units, PV peak output doesn't necessarily occur at the same time as the feeder peak load, so the ability to reduce the peak is a function of locations as well as end-use load composition. 


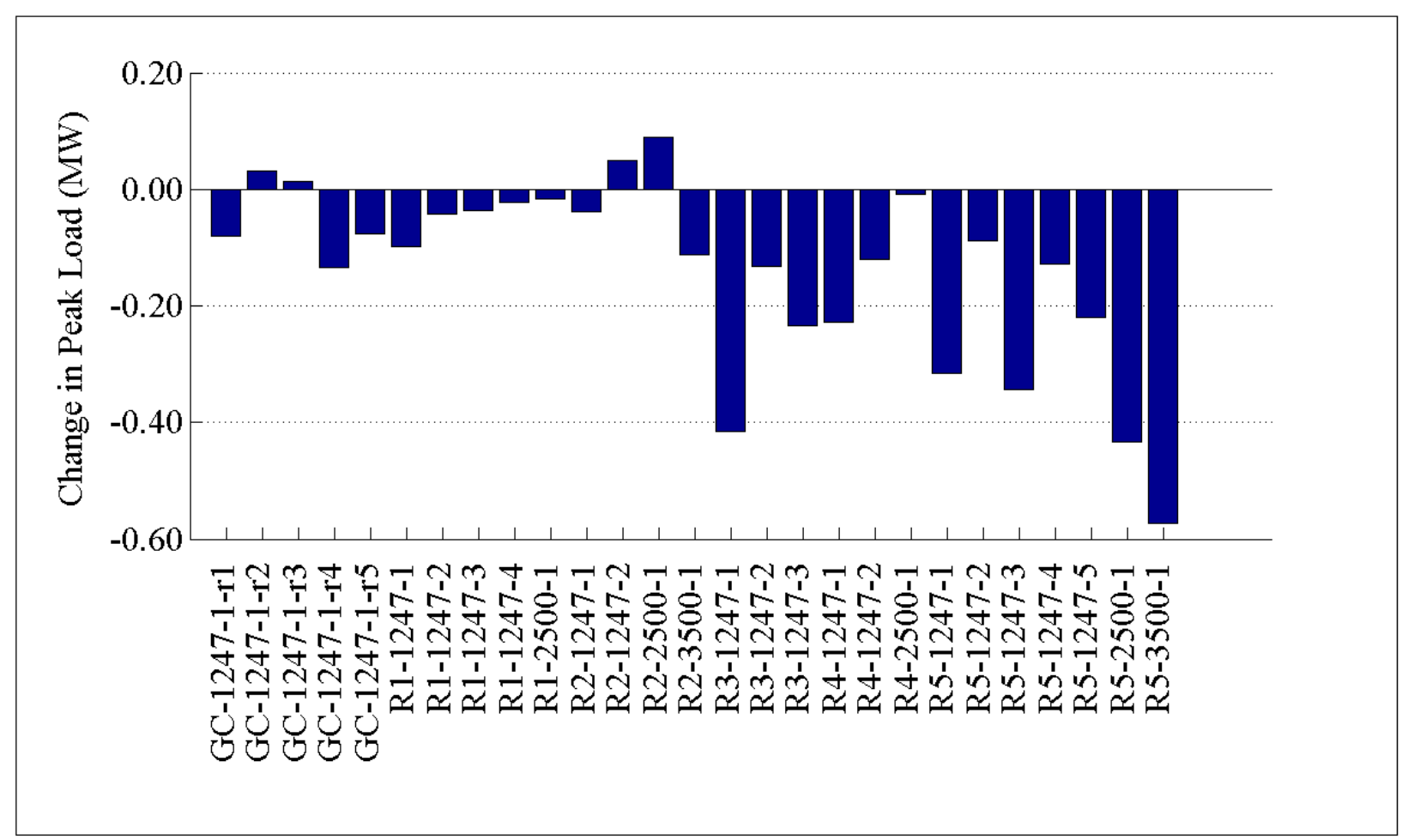

Figure 2.18: Change in peak load by feeder (MW)

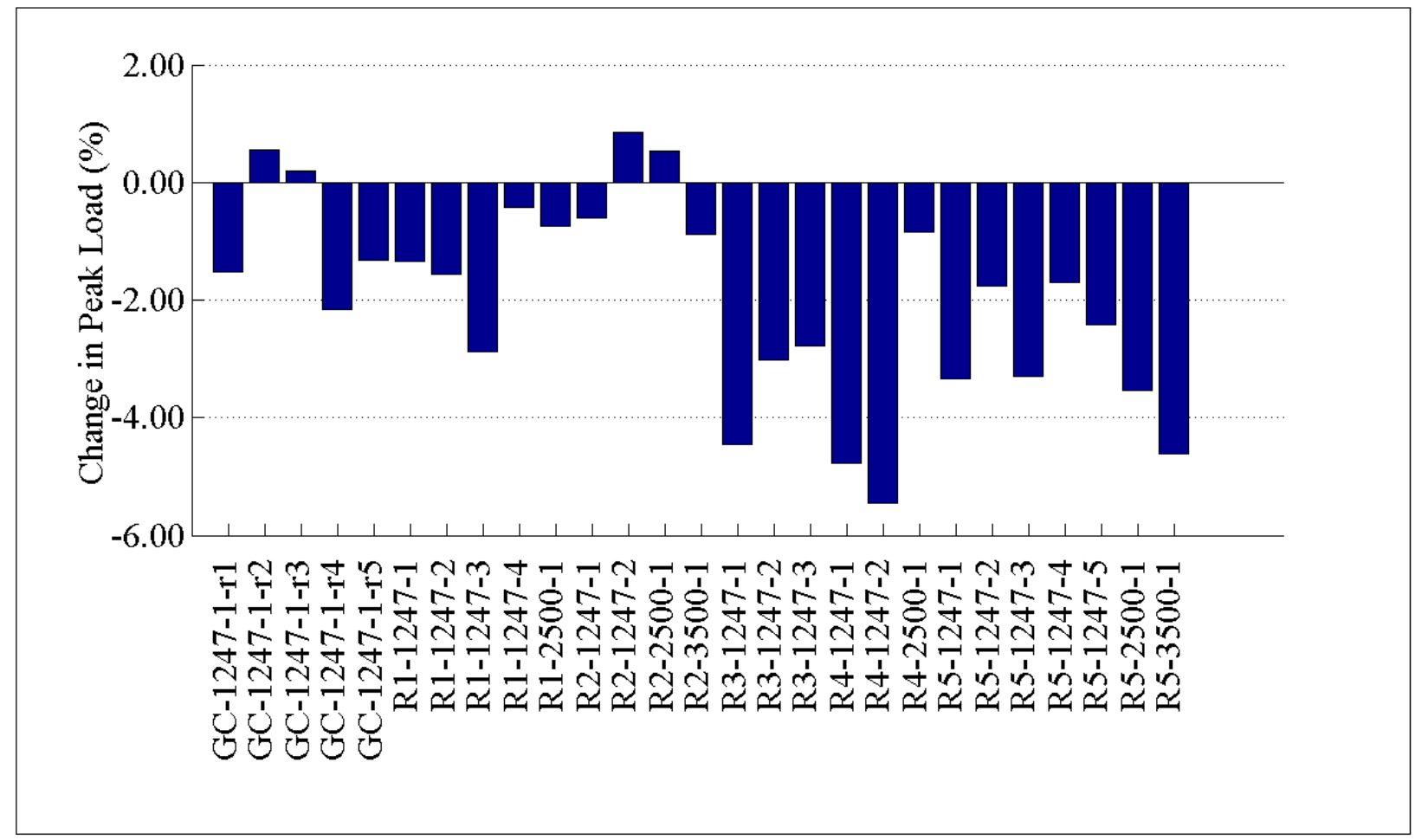

Figure 2.19: Change in peak load by feeder (\%) 


\subsubsection{Annual Energy Consumption}

The addition of commercial scale PV reduces the average annual energy consumption for all the feeders, as shown in Figure 2.20. Similar to the previous residential annual energy consumption is the energy that must be supplied by the feeder via a substation transformer.

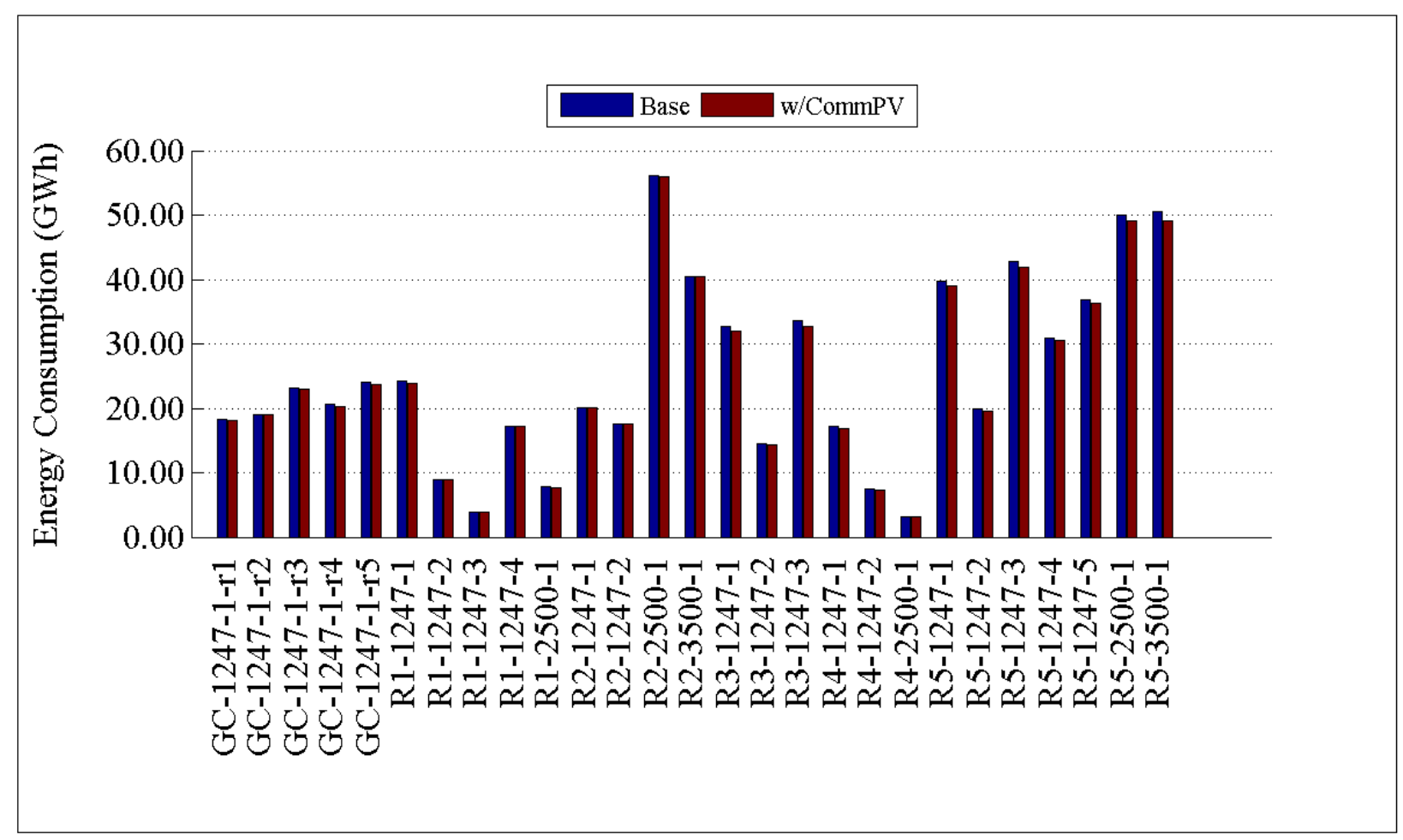

Figure 2.20 : Comparison of annual energy consumption by feeder (MWh)

From Figure 2.21 and Figure 2.22, it can be observed that the maximum reduction in annual energy consumption that can be achieved by a single feeder is about $1.3 \mathrm{GWh}$, or $3 \%$, which occurs on feeder R3-12.47-3. Similar to the performance of the residential PV units, the reduction in annual energy consumption is not only dependent on the penetration level of PV. For example, region 5 had the largest PV penetration, but the feeders in region 3 show a slightly higher reduction in annual energy consumption. Factors such as end-use load composition and climate will also have an impact on the reduction of annual energy consumption. 


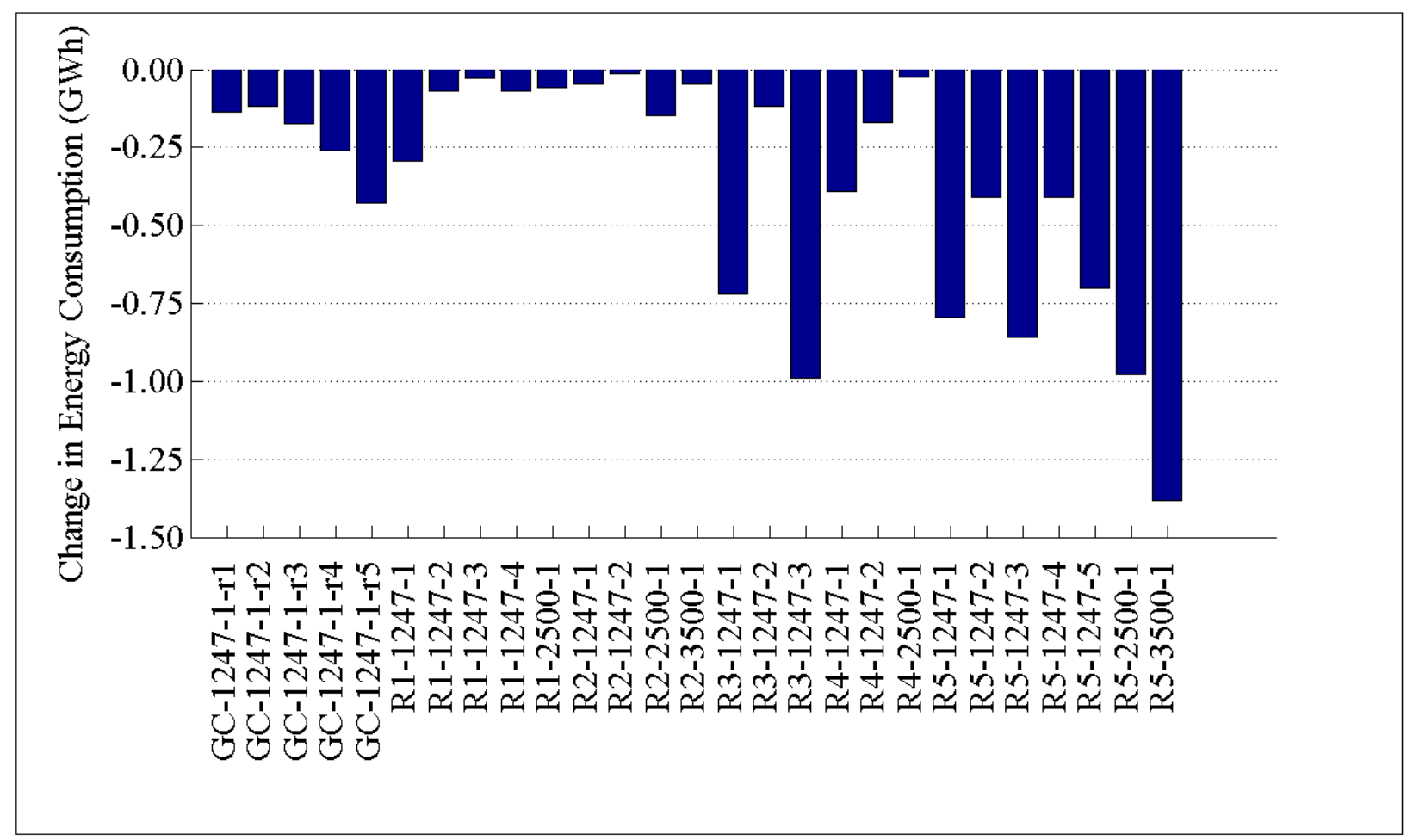

Figure 2.21 : Change in annual energy consumption by feeder (GWh)

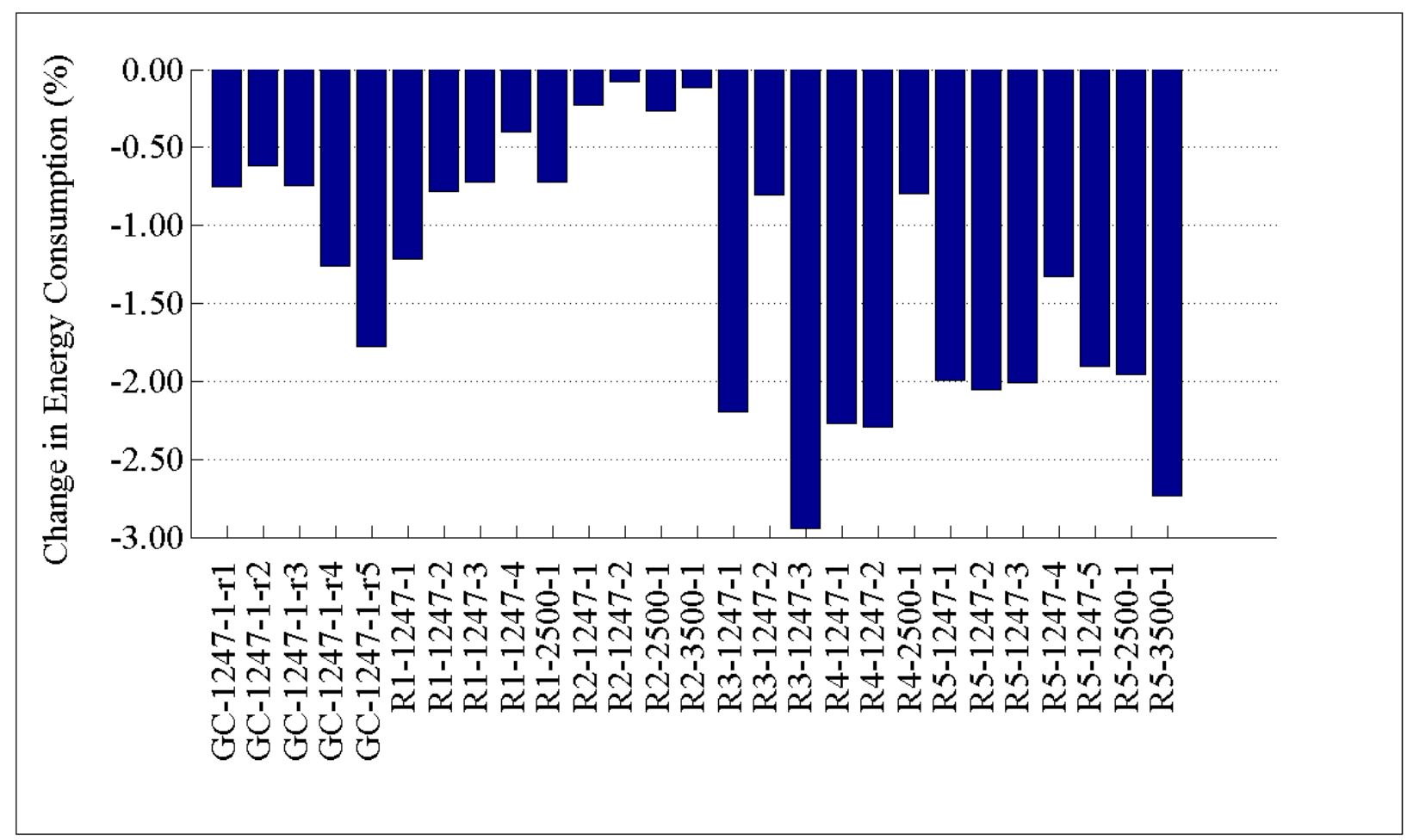

Figure 2.22 : Change in annual energy consumption by feeders (\%) 


\subsubsection{Annual System Losses}

The addition of commercial PV units also results in increased system efficiency by reducing system losses, as shown in Figure 2.23. The annual system losses for each feeder are examined and it is seen that they decreased due to the same reasons described in Section 2.1.1.6 for the residential PV integration.

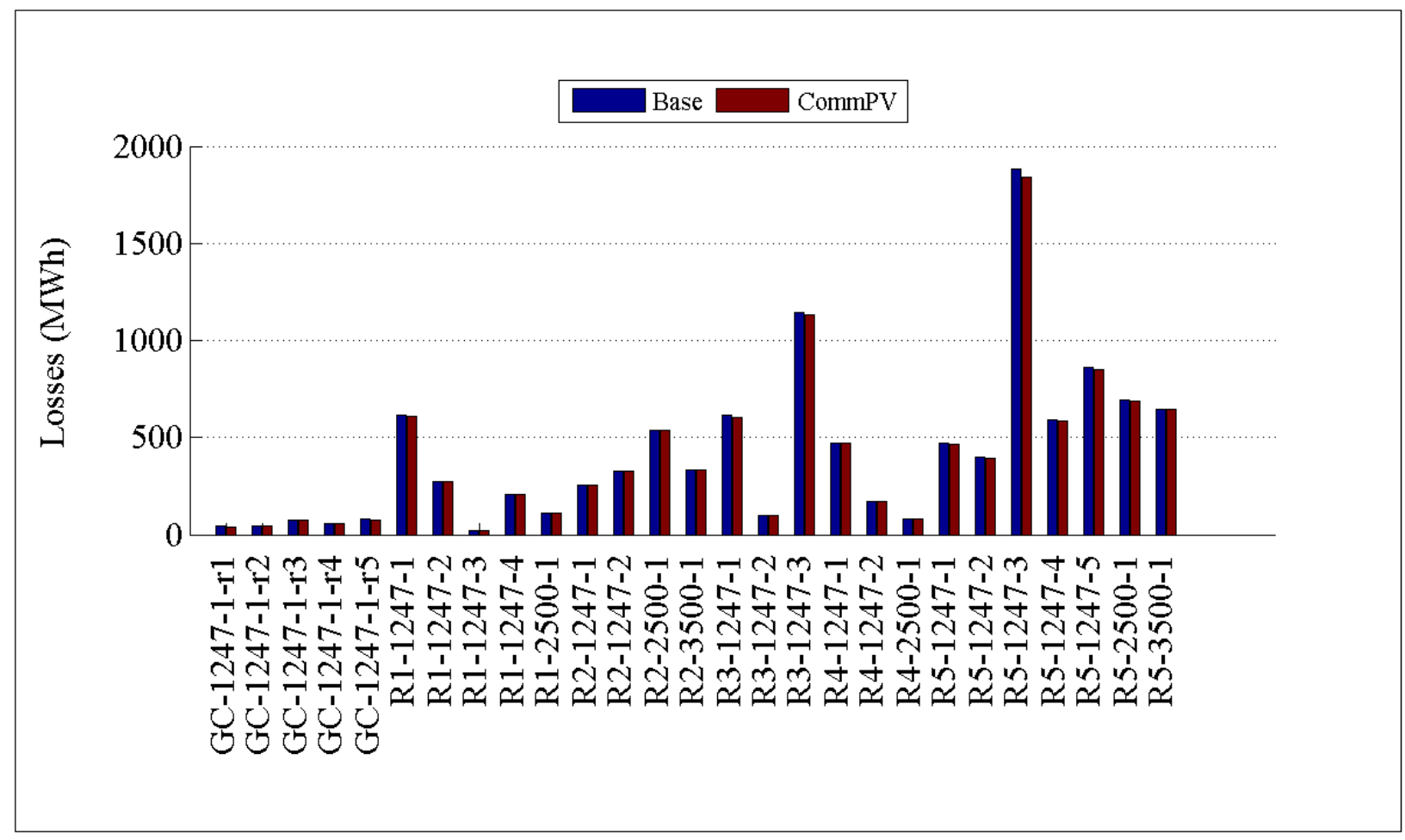

Figure 2.23: Comparison of total annual losses by feeder

As seen from Figure 2.24 and Figure 2.25, losses were reduced for nearly all the feeders. However, feeder R4-2500-1 showed no noticeable change. The largest loss reduction was seen on feeder R5-12.47-3. The reduction in losses varies for the different feeders since losses are affected by a number of factors, such as end-use load composition, equipment sizing, feeder design, and most importantly the distribution of the PV units on the feeder. These various factors cause the imbalance in the observed load reduction previously described in Section 2.1.1.6. 


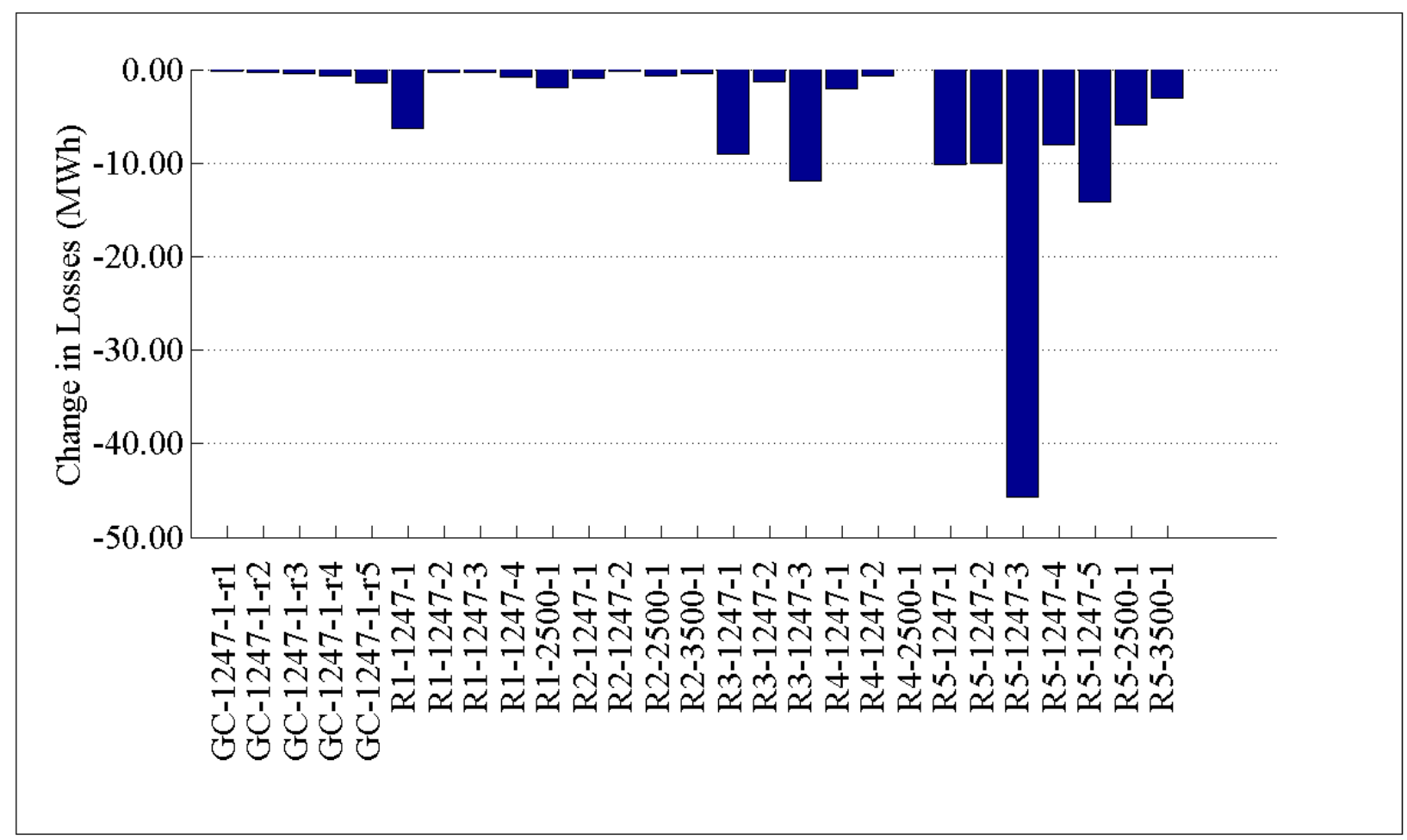

Figure 2.24: Change in annual losses by feeder (MWh)

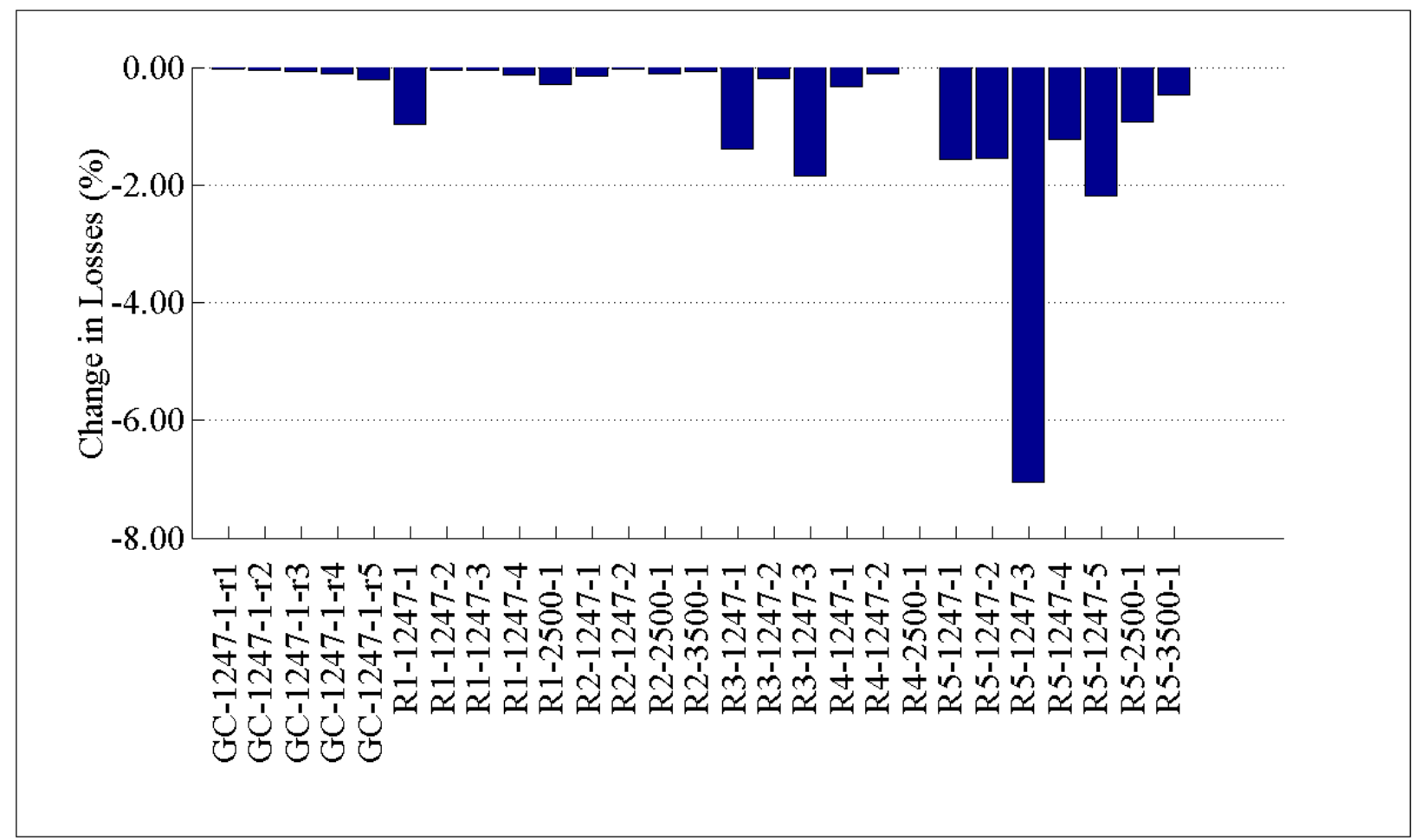

Figure 2.25: Change in annual losses by feeder (\%) 


\subsubsection{Power Factor Impact}

The deployment of commercial PV units that only produce real power will have an impact on the power factor of the distribution feeders, similar to the residential PV units. Since the PV units provide an aggregated amount of real power, this amount of real power will not need to be supplied by the feeder, but the reactive requirements are still similar. As a result, it is possible for the power factor as seen at the substation to degrade and move farther away from unity. Figure 2.26 shows the variation of the average power factor over the course of the year for the

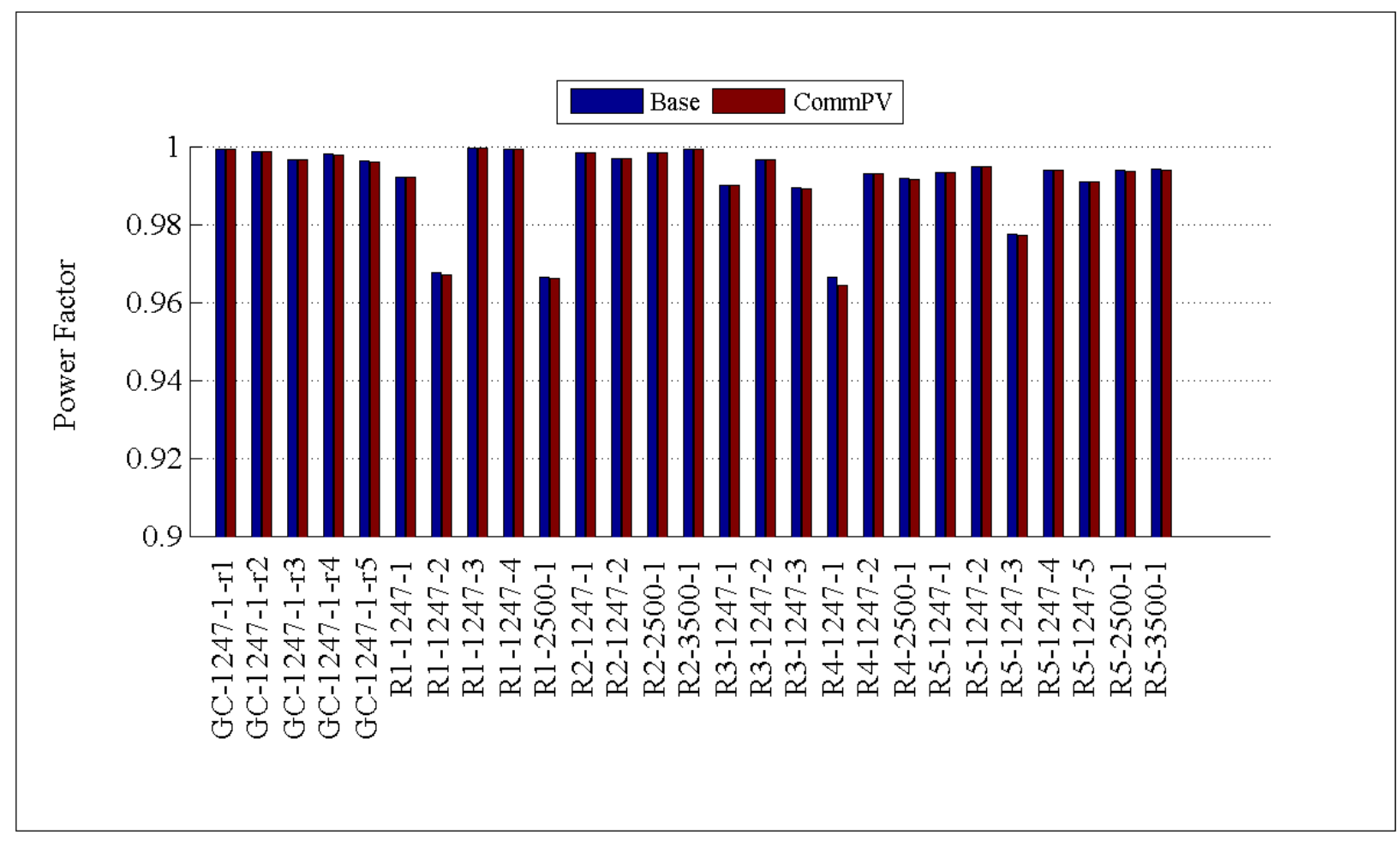

Figure 2.26: Comparison of average annual power factor by feeder 


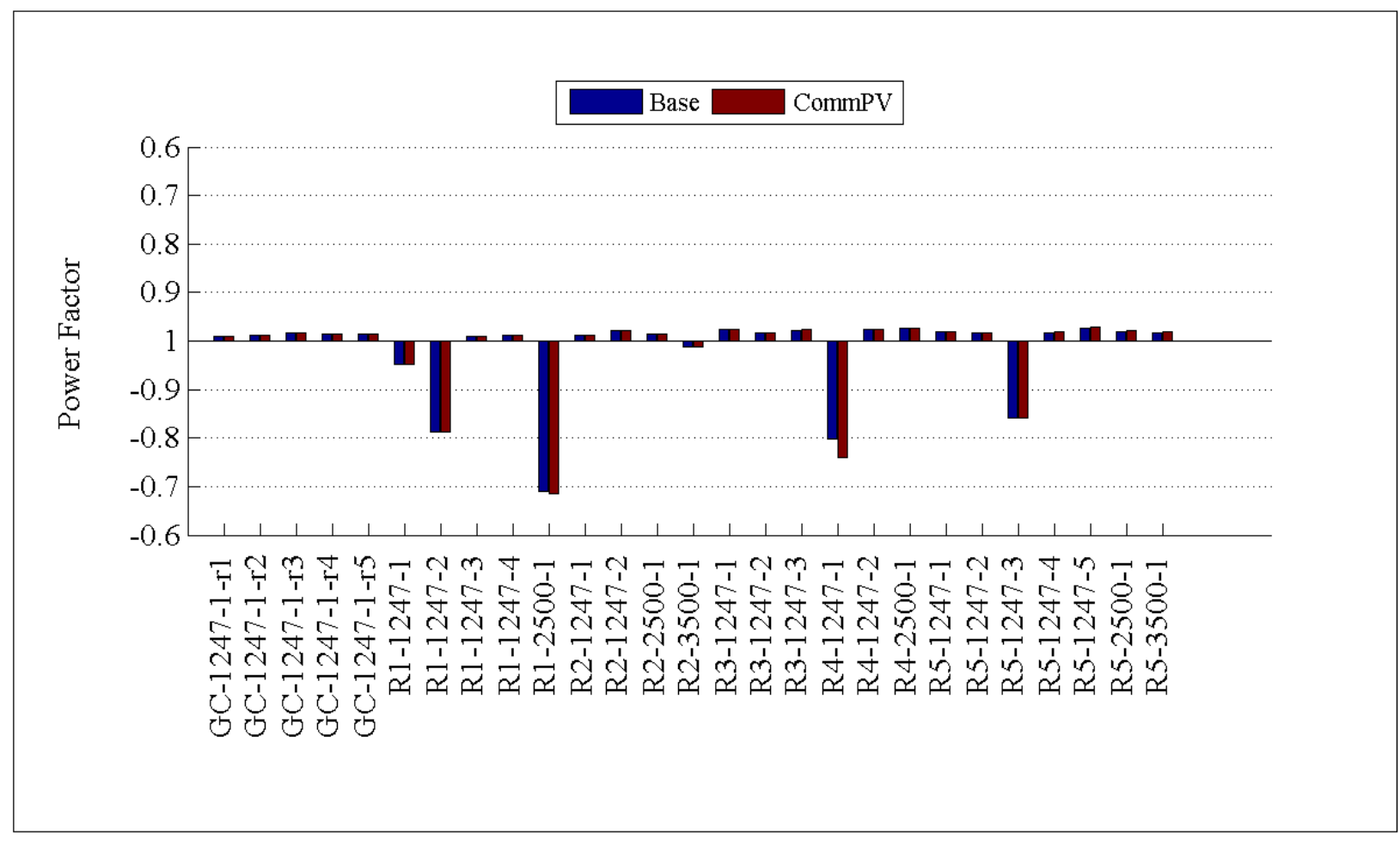

Figure 2.27: Comparison of minimum annual power factor by feeders

As observed in the residential PV installations and in Figure 2.27, the lagging power factor was not improved for the feeders with a larger lagging power factor. This again emphasizes the potential benefit of including reactive power controls, either integrated in the in the inverter system or via addition of automatic capacitor banks on the feeder. Once again, the next release of IEEE 1547.8 will include guidelines for distributed resources producing other than unity power factor power.

\subsubsection{Annual Commercial PV output}

Figure 2.28 shows the annual energy produced by the addition of commercial PV. The commercial PV output shown is the sum of the commercial PV installations on office buildings, strip malls and big box retailers. The largest PV output is observed for feeder R5-35.00-1 in region 5, which contained a commercial PV penetration of $6 \%$ of the feeder peak load. Feeders in region 4 received the second largest commercial PV penetration (5\% of feeder peak load), but do not have the second highest PV output. This indicates that PV output in a region is not only dependent on the penetration level. In this study, fixed PV arrays of $100 \mathrm{~kW}$ were distributed on commercial loads, one array per load, which limited the number of PV units on the feeder based on the number of commercial end-use customers. 


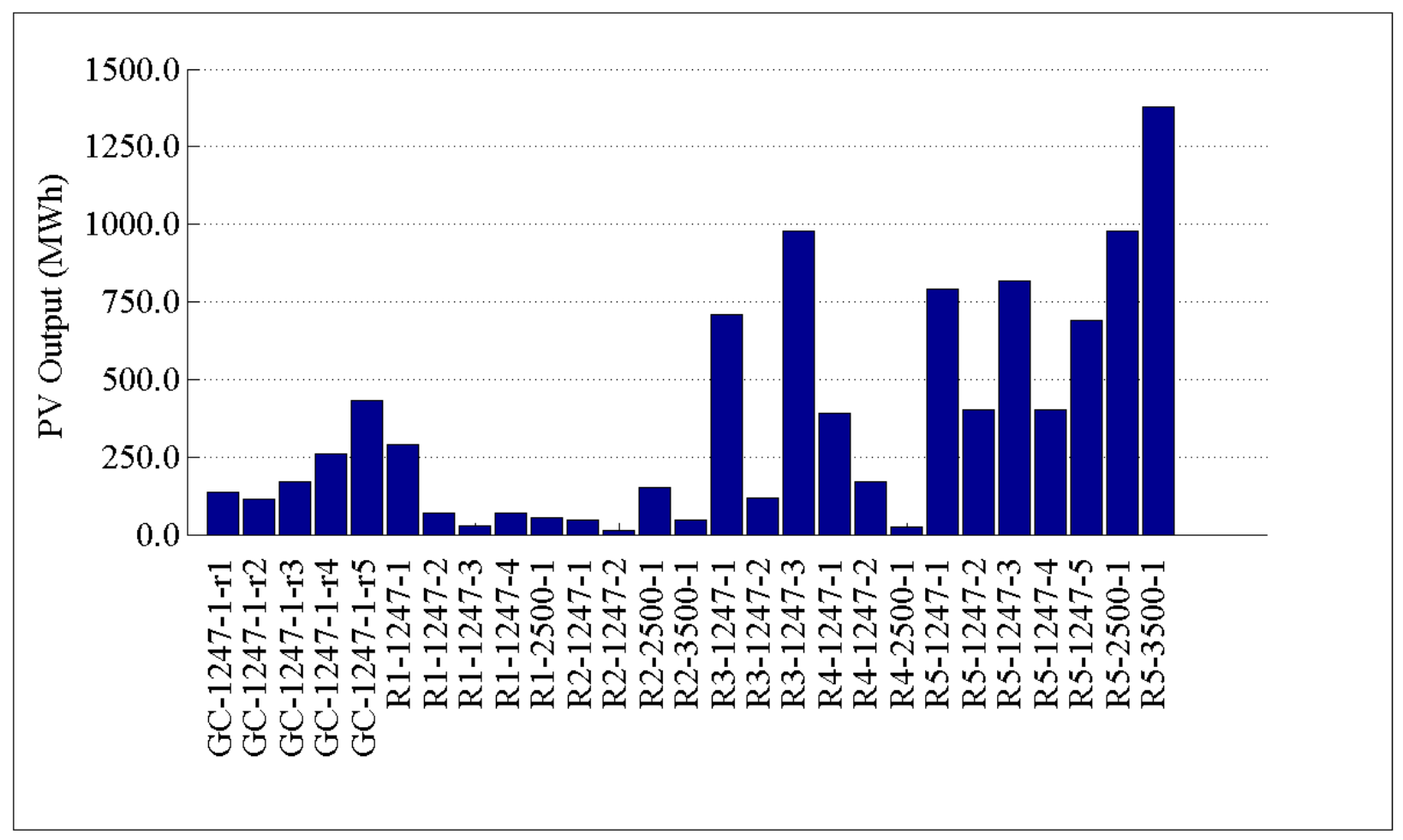

Figure 2.28: Annual commercial PV output by feeder

\subsubsection{Annual $\mathrm{CO}_{2}$ emissions}

Figure 2.29, Figure 2.30, and Figure 2.31 show the annual reduction of carbon dioxide emitted by generating resources as a result of adding PV units to commercial end-use loads. Similar to the residential PV installations, a reduction in energy consumption reduces the need for more carbon-intense sources of power; thus, reducing carbon dioxide emission. The details for the emissions calculations are again outlined in Appendix B. 


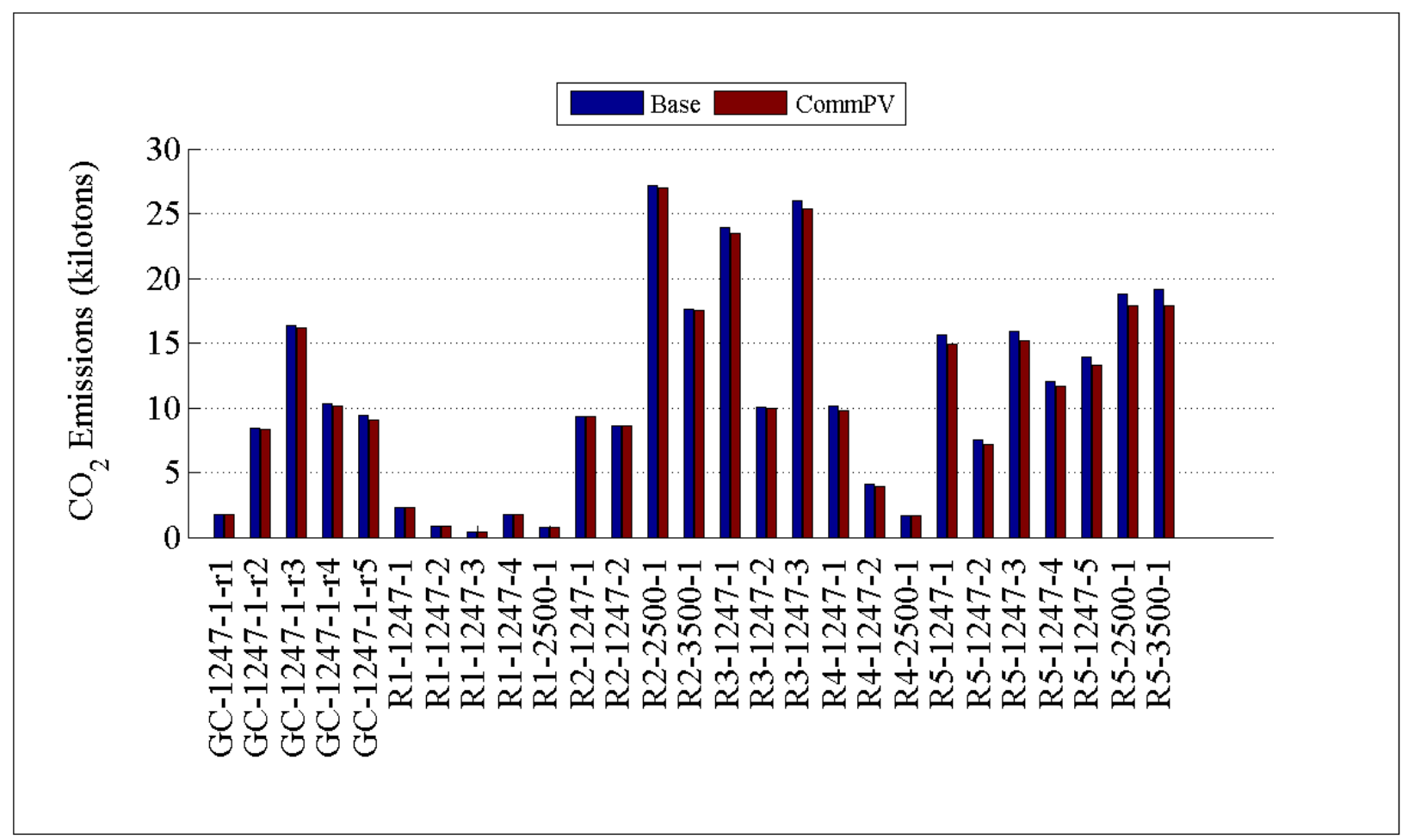

Figure 2.29 : Change in total annual $\mathrm{CO}_{2}$ emissions by feeder (kilotons)

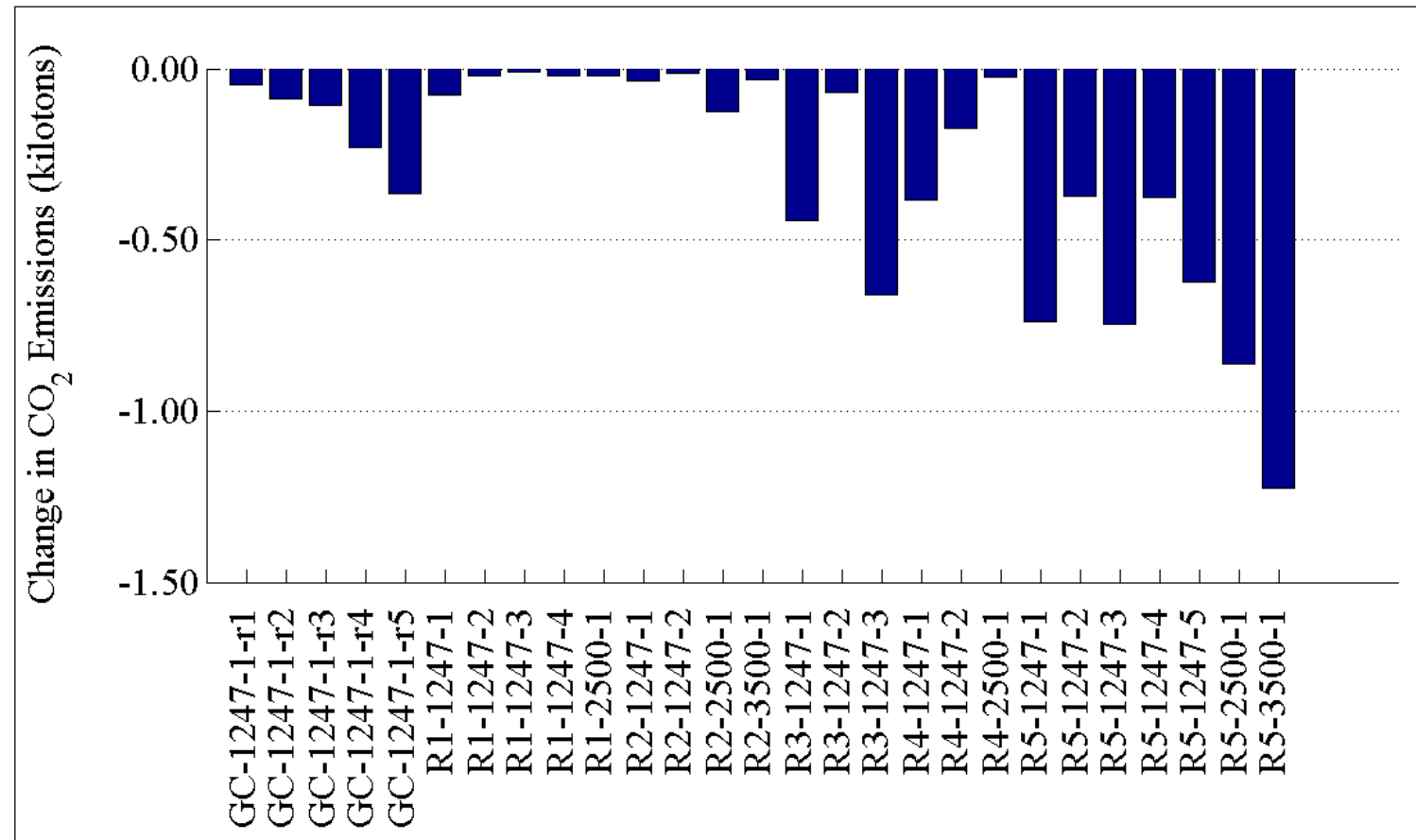

Figure 2.30: Change in total annual $\mathrm{CO}_{2}$ emissions by feeder (tons) 


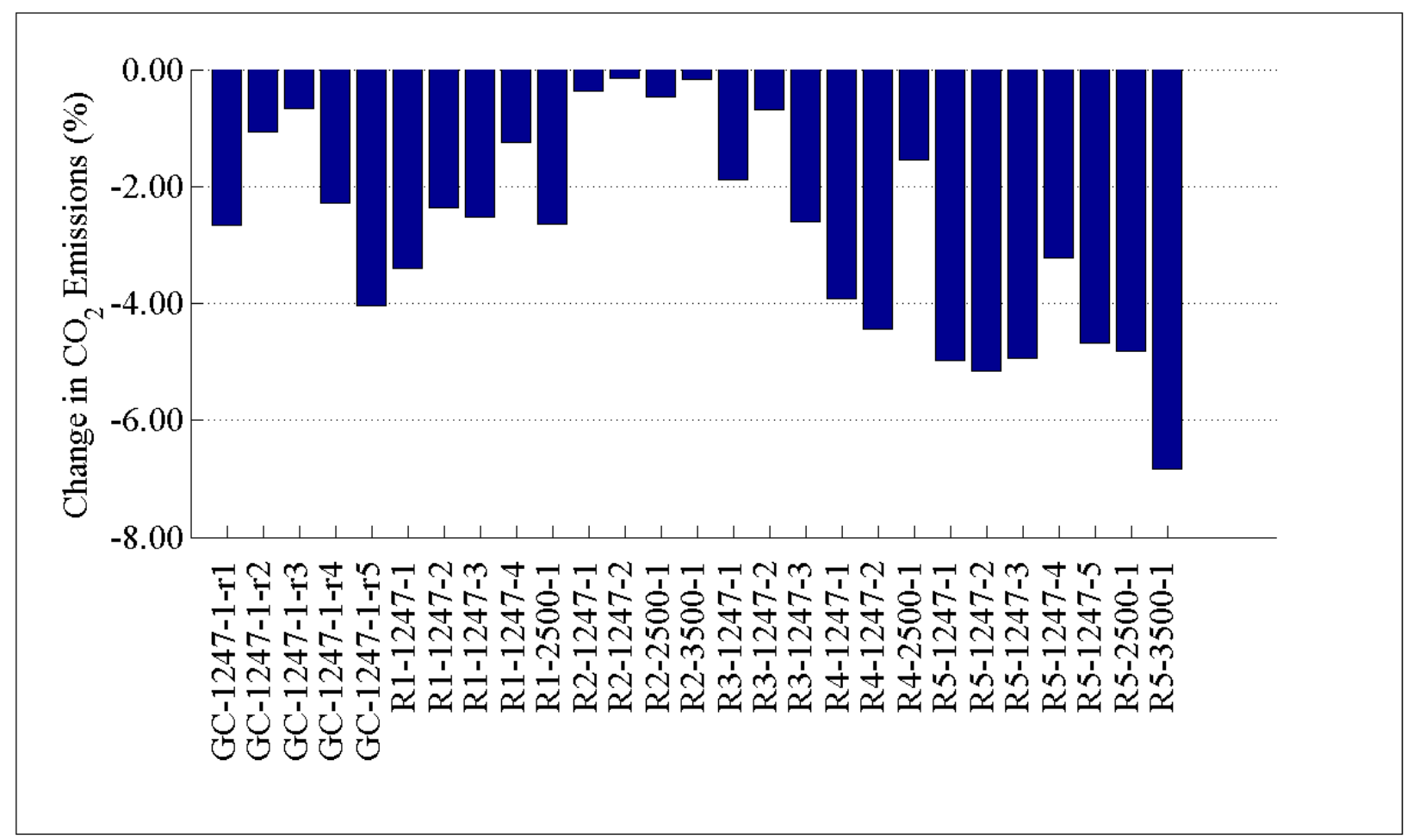

Figure 2.31: Change in total annual $\mathrm{CO}_{2}$ emissions by feeder $(\%)$

\subsubsection{Addition of both commercial and residential (Combined) PVs}

In the previous sections residential and commercial PV installations we examined as separate cases. In reality, these installations could be occurring simultaneously on the same distribution feeder. Individually, these installations (residential and commercial) have different levels of impact on the distribution feeder. When both residential and commercial installations coexist on the same feeder, they will have a cumulative impact. This concurrent deployment needs to be analyzed for distribution planning purposes and proper resource deployment.

\subsubsection{SGIG Metrics Affected by Combined PVs}

The following SGIG metrics are affected by the addition of combined commercial and residential PVs on to the distribution system and will be examined in this report. 
Table 2.5: Impact metrics affected by the addition of combined PVs

\begin{tabular}{|c|c|c|}
\hline Index & Metric & Units \\
\hline 1 & Hourly Customer Electricity Usage & $\mathrm{kWh}$ \\
\hline 2 & Monthly Customer Electricity Usage & MWh \\
\hline \multirow{12}{*}{3} & Peak Generation & $\mathrm{kW}$ \\
\hline & Nuclear & $\%$ \\
\hline & Solar & $\%$ \\
\hline & Bio & $\%$ \\
\hline & Wind & $\%$ \\
\hline & Coal & $\%$ \\
\hline & Hydroelectric & $\%$ \\
\hline & Natural Gas & $\%$ \\
\hline & Geothermal & $\%$ \\
\hline & Petroleum & $\%$ \\
\hline & Distributed Solar PV & $\%$ \\
\hline & Distributed Wind & $\%$ \\
\hline 4 & Peak Load & $\mathrm{kW}$ \\
\hline 7 & Annual Electricity Production & MWh \\
\hline 12 & $\mathrm{CO}_{2}$ Emissions & Tons \\
\hline \multirow{3}{*}{13} & SOx Emissions & Tons \\
\hline & NOx Emissions & Tons \\
\hline & PM-10 Emissions & Tons \\
\hline \multirow{2}{*}{21} & Feeder Real Load & $\mathrm{kW}$ \\
\hline & Feeder Reactive Load & kVAR \\
\hline 29 & Distribution Losses & $\%$ \\
\hline 30 & Distribution Power Factor & $\mathrm{pf}$ \\
\hline 39 & $\mathrm{CO}_{2}$ Emissions & Tons \\
\hline \multirow{3}{*}{40} & SOx Emissions & Tons \\
\hline & NOx Emissions & Tons \\
\hline & PM-10 Emissions & Tons \\
\hline
\end{tabular}

\subsubsection{Specific Implementation of Combined PV}

Combined PV used penetration levels, as shown in Table 2.6, for different regions, but had both commercial scale $(100 \mathrm{~kW}$ array size) and residential scale PV units $(\sim 3 \mathrm{~kW}-5 \mathrm{~kW}$ array size). These PV units were populated randomly over the prototypical feeders at the appropriate end-use customer types. Seven feeders, which were purely residential or purely commercial, were excluded from this simulation. Figure 2.32 again shows the various portions of the continental United States each climate region represents. 


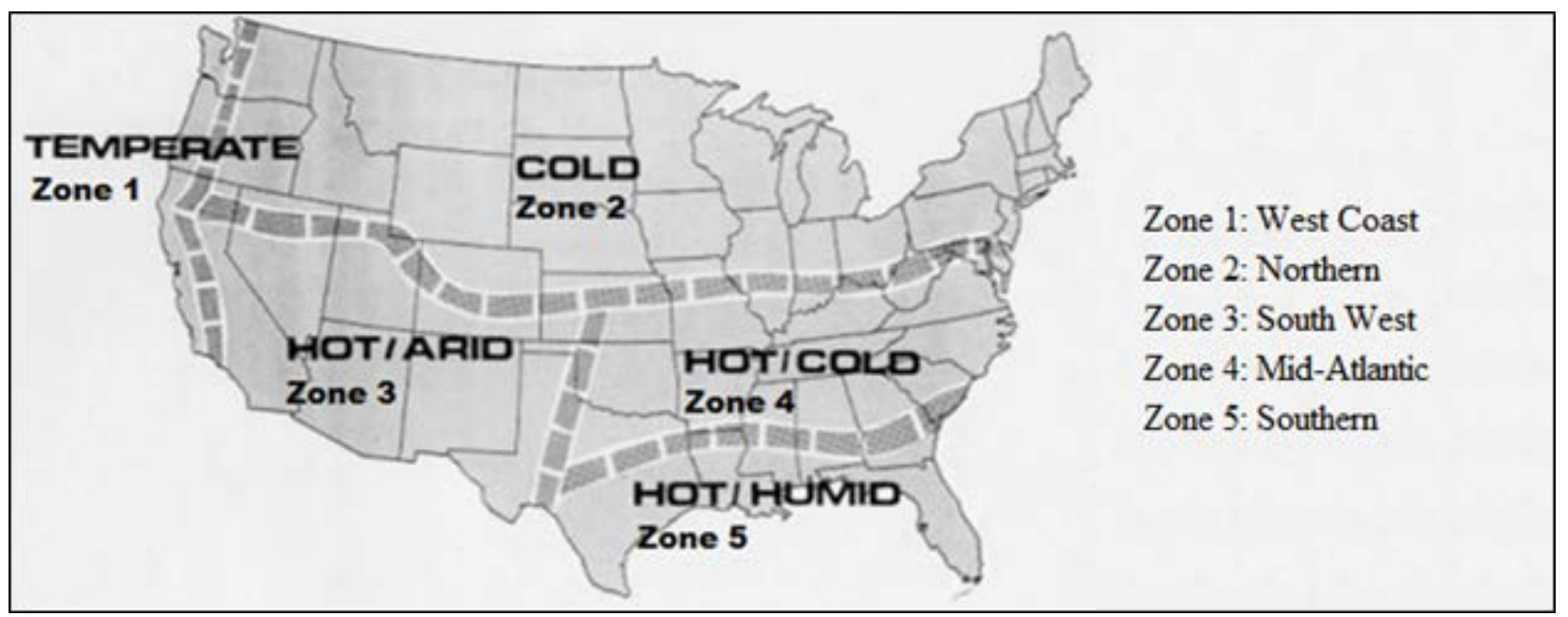

Figure 2.32 Climate Zones Used for Development of Prototypical Feeders

Table 2.6: Combined PV penetration by region

\begin{tabular}{|c|c|}
\hline Region Number & Penetration Level (\% of peak feeder load) \\
\hline 1 & 3 \\
\hline 2 & 1 \\
\hline 3 & 4 \\
\hline 4 & 5 \\
\hline 5 & 6 \\
\hline
\end{tabular}

\subsubsection{High Level Combined PV Simulation Results}

In this section, the high level results of the combined PV simulations are examined. At this level of examination, the data is not divided into monthly values; only annual values are examined. Simulation results of 21 prototypical feeders are examined, which excludes the feeders that are purely residential or purely commercial. The high level analysis will examine the impacts of PVs with respect to peak load, annual energy consumption, system losses, power factor, annual output, and $\mathrm{CO}_{2}$ emissions.

\subsubsection{Annual Peak Load}

As seen in previous sections for residential PV integration and commercial PV integration, peak reduction is not the primary benefit from adding PV units to a distribution feeder. However, it is interesting to note that peak reduction is observed for all but one of the feeders under the combined PV case. Since there was an equal penetration of commercial and residential PV units on the feeders, this helped mitigate the voltage issues caused when a large PV unit, as in the case of commercial PV unit, was added to the grid; thus, reducing the effect that variations in the line voltage had on the energy consumption of the end-use loads. Figure 2.33 shows the comparison 
of annual peak load reduction for all the feeders under study. Figure 2.34 and Figure 2.35 show the change in annual peak load due to the addition of combined PVs.

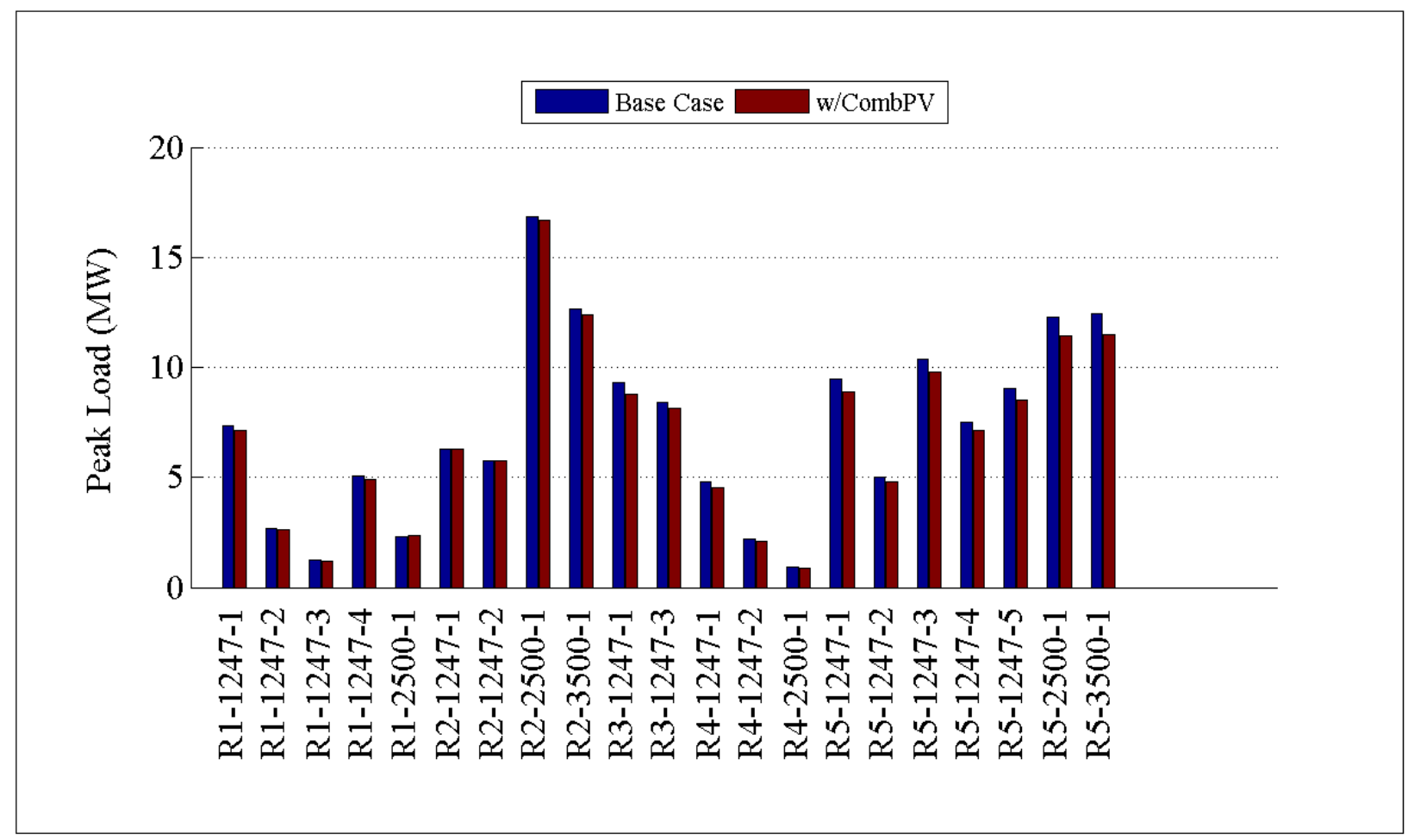

Figure 2.33 : Comparison of peak load by feeder 


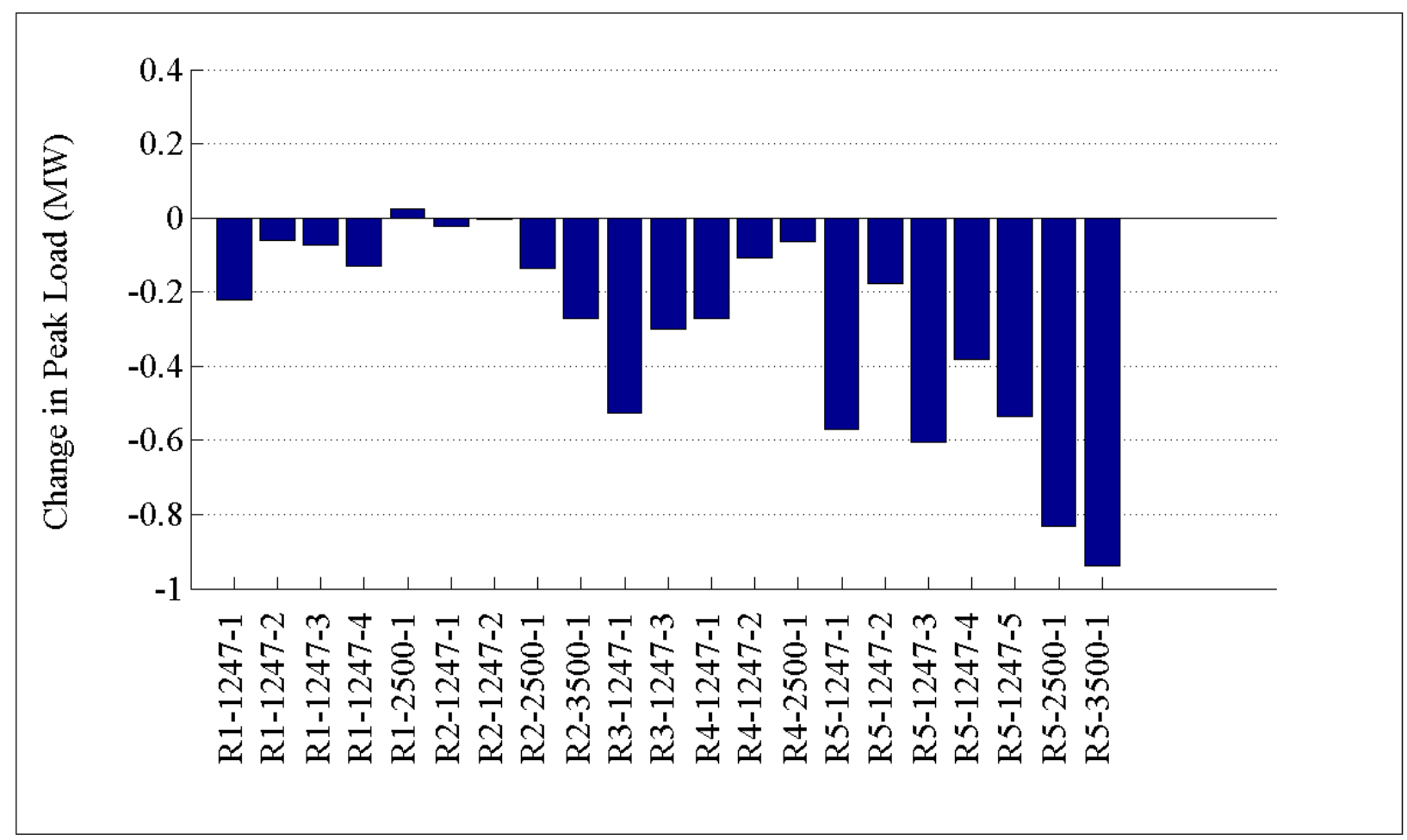

Figure 2.34 : Change in peak load by feeder (MW)

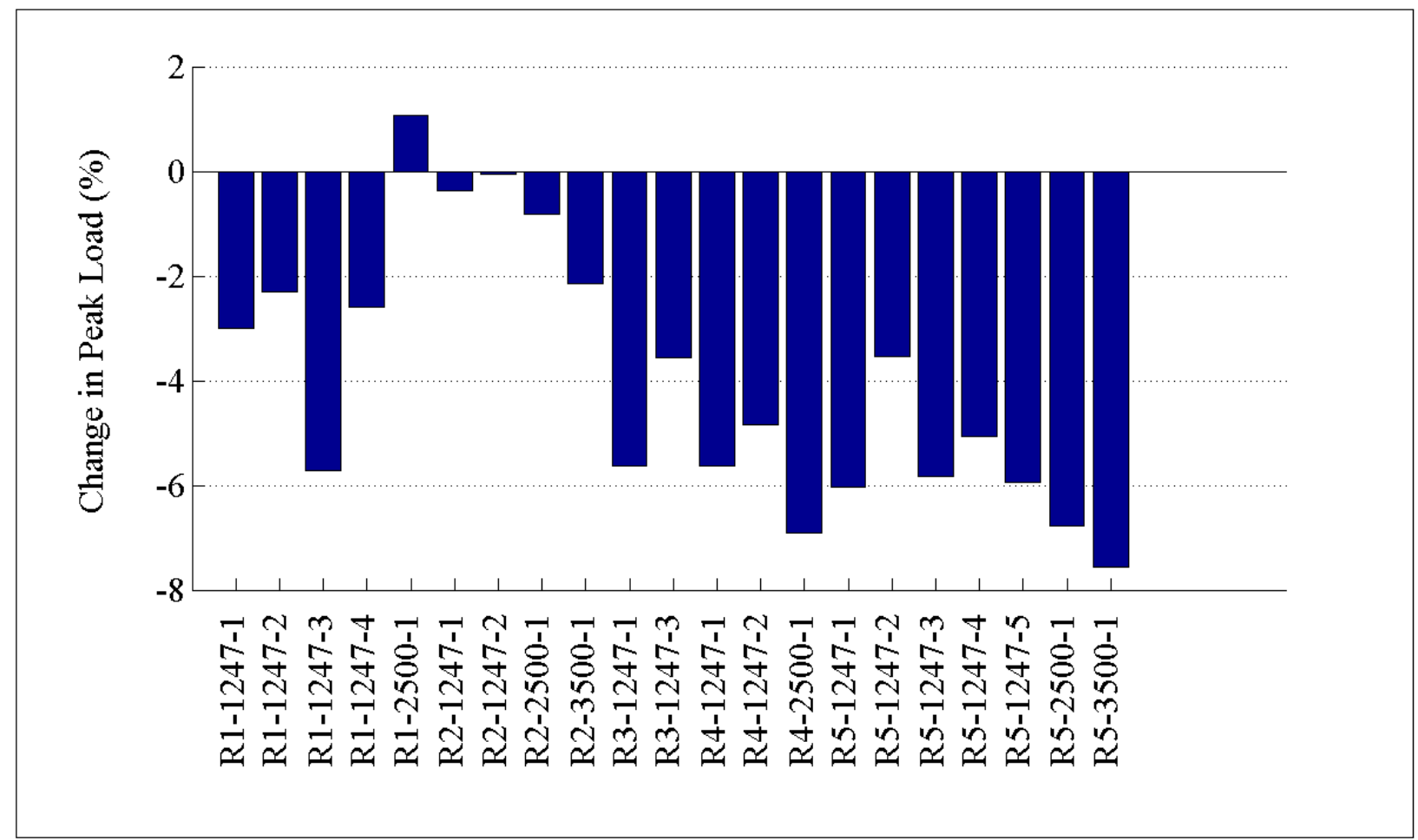

Figure 2.35: Change in peak load by feeder $(\%)$ 


\subsubsection{Annual Energy Consumption}

As seen in the residential and commercial PV installations, the reduction of annual energy consumption is the primary benefit of installing PV units. As shown in Figure 2.36, energy consumption is reduced for all the feeders when a combination of PV units are installed on the distribution feeders. Figure 2.37 and Figure 2.38 show the energy savings in both kW and percent when compared to the base case.

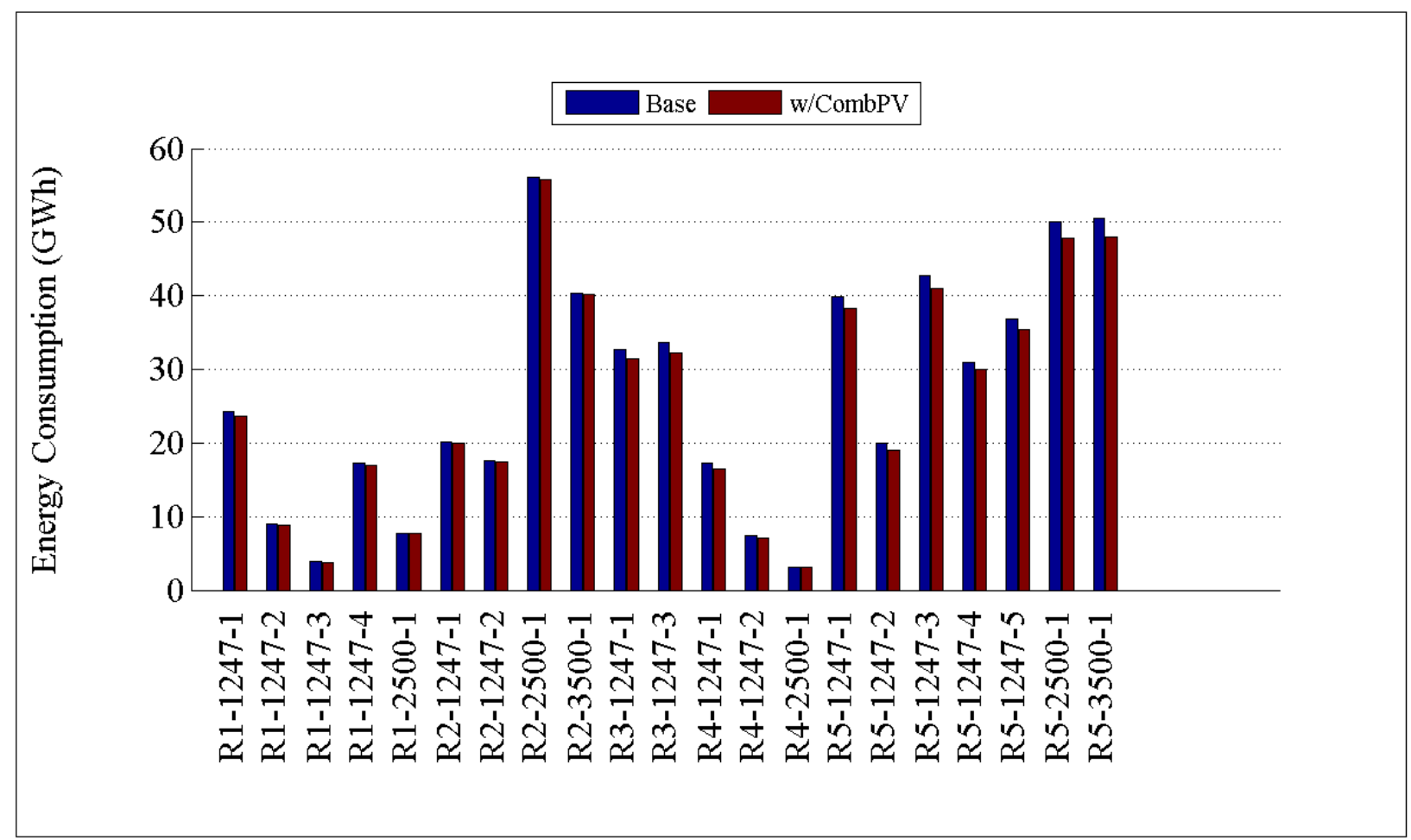

Figure 2.36: Comparison of annual energy consumption by feeder (GWh) 


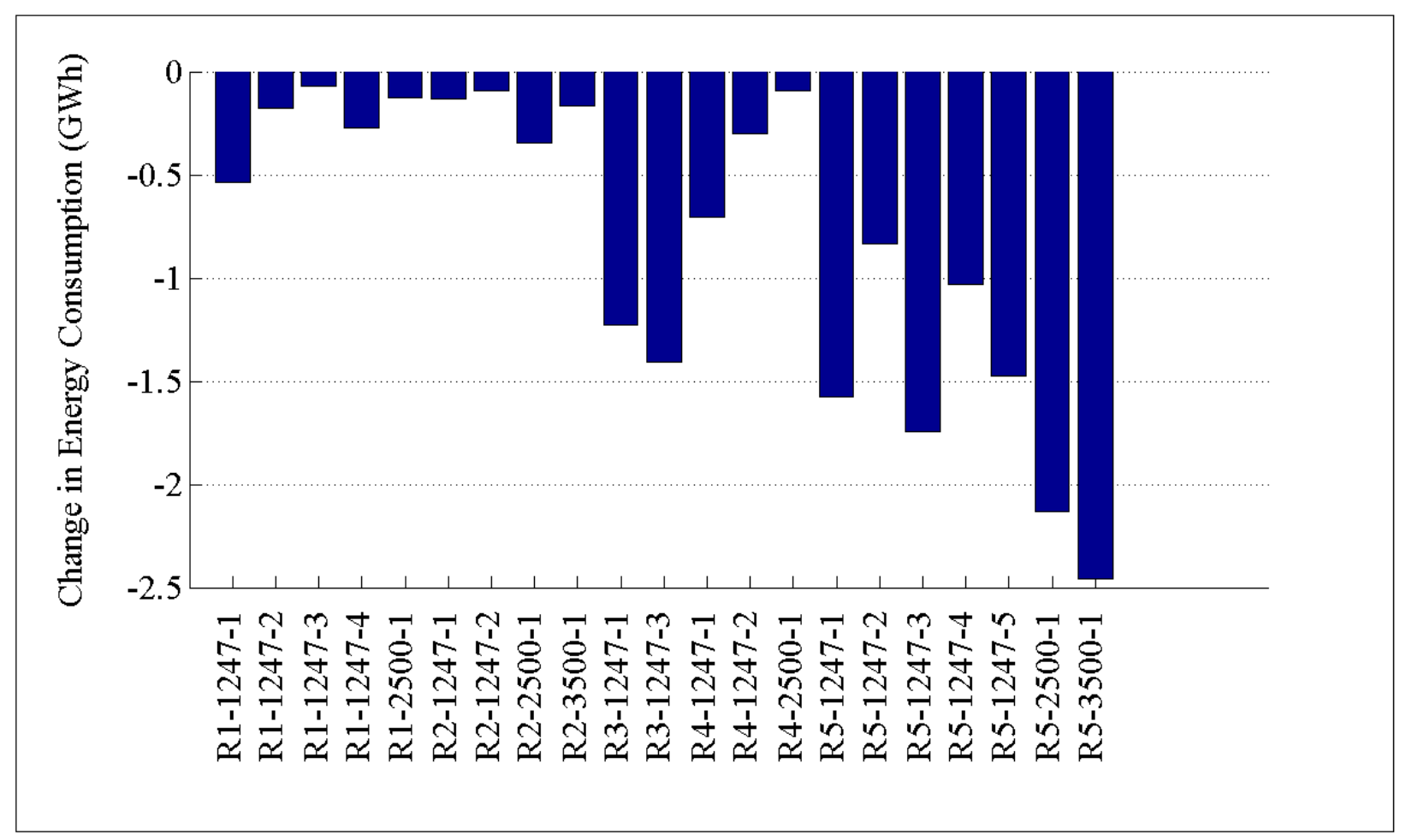

Figure 2.37: Change in annual energy consumption by feeder (GWh)

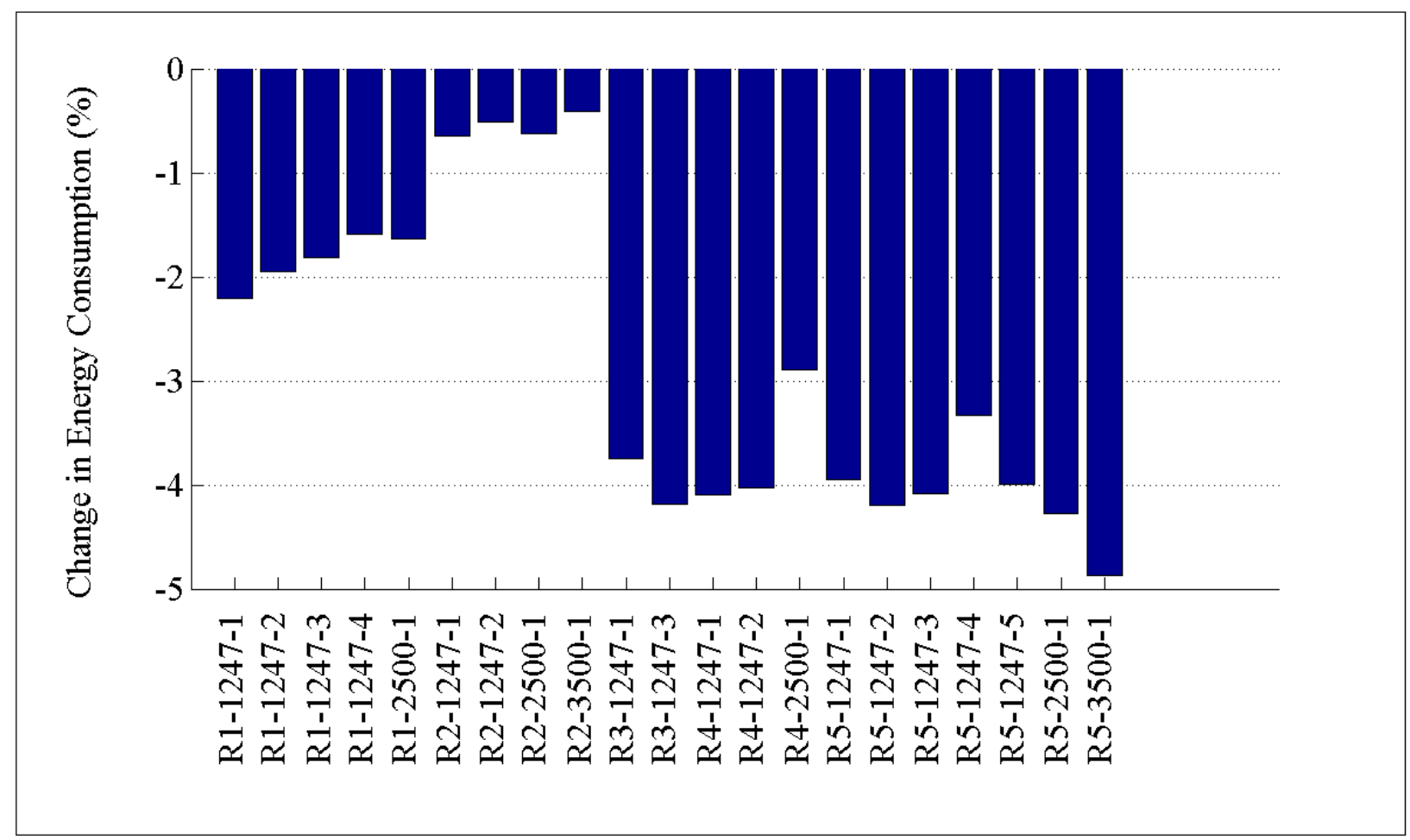

Figure 2.38: Change in annual energy consumption by feeder (\%) 


\subsubsection{Annual System Losses}

As stated in previous sections, the reduction of distribution system losses is also one of the primary benefits of PV installation. It can be observed from Figure 2.39, Figure 2.40, and Figure 2.41 that the integration of combined PV also results in the reduction of system losses. Although the amount of the reduction in losses is different for different components and different feeders, it can be concluded that the addition of PV generally increases system efficiency by reducing real power losses.

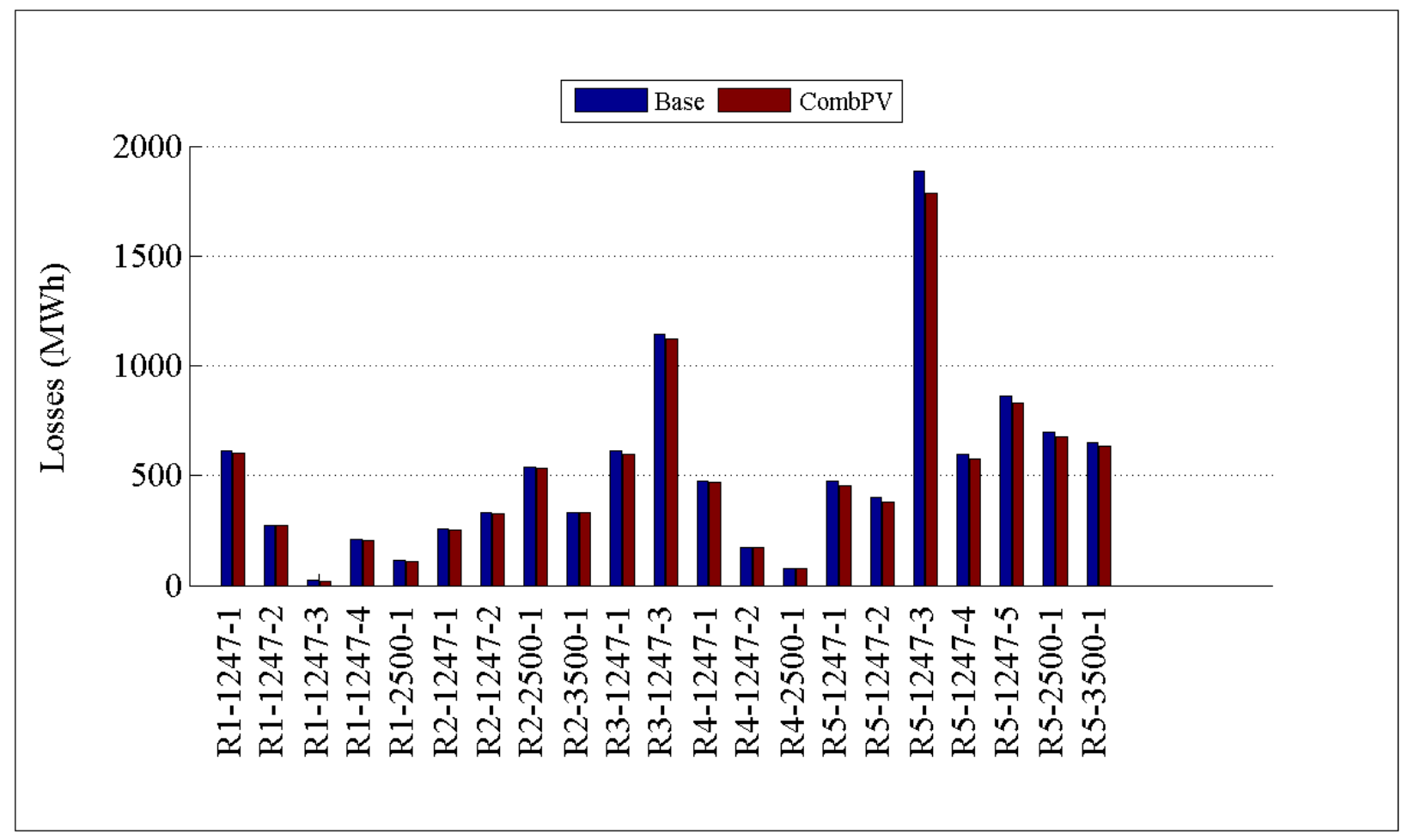

Figure 2.39: Comparison of total annual losses by feeder (MWh) 


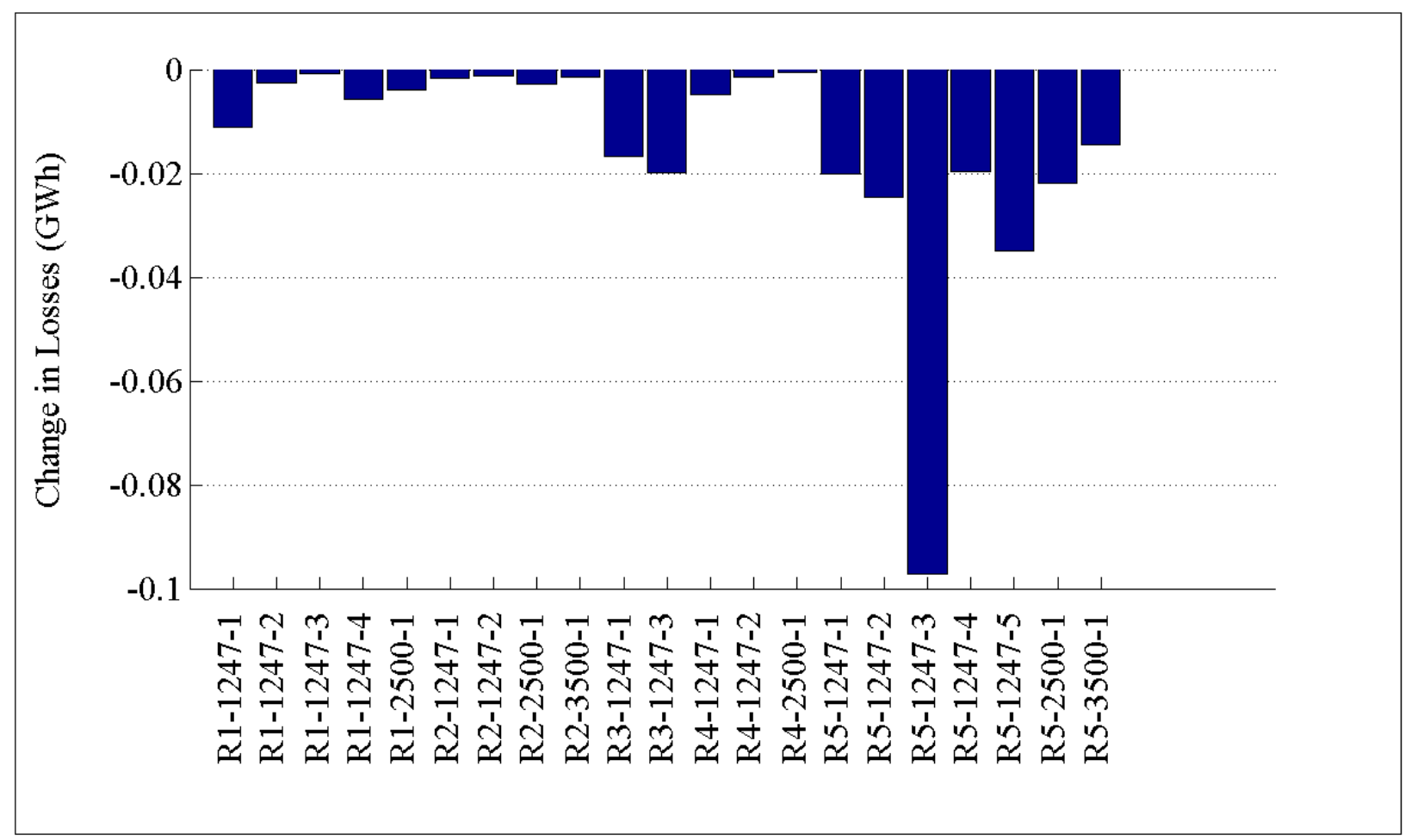

Figure 2.40: Change in annual losses by feeder (GWh)

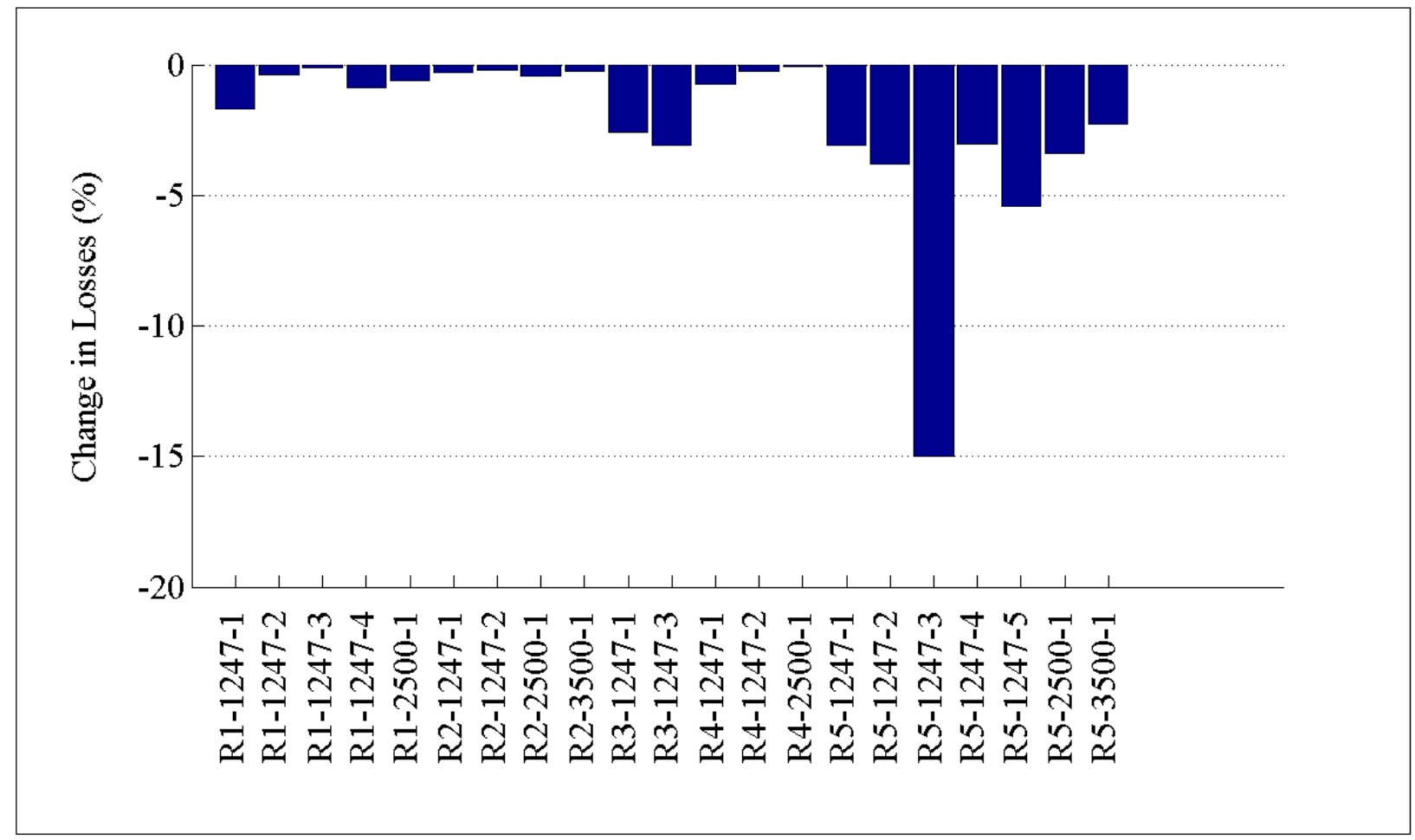

Figure 2.41: Change in annual losses by feeder (\%) 


\subsubsection{Power Factor Impact}

The deployment of a combination of residential and commercial PV units is similar to the results that were seen for purely residential and purely commercial. The deployment of PV units that only produce real power will have an impact on the power factor of the distribution feeders. Since the PV units provide an aggregated amount of real power, this amount of real power will not need to be supplied by the feeder, but the reactive requirements are still similar. As a result, it is possible for the power factor as seen at the substation to degrade and move farther away from unity. Figure 2.42 shows the variation of the average power factor over the course of the year while Figure 2.43 examines the minimum annual power factor.

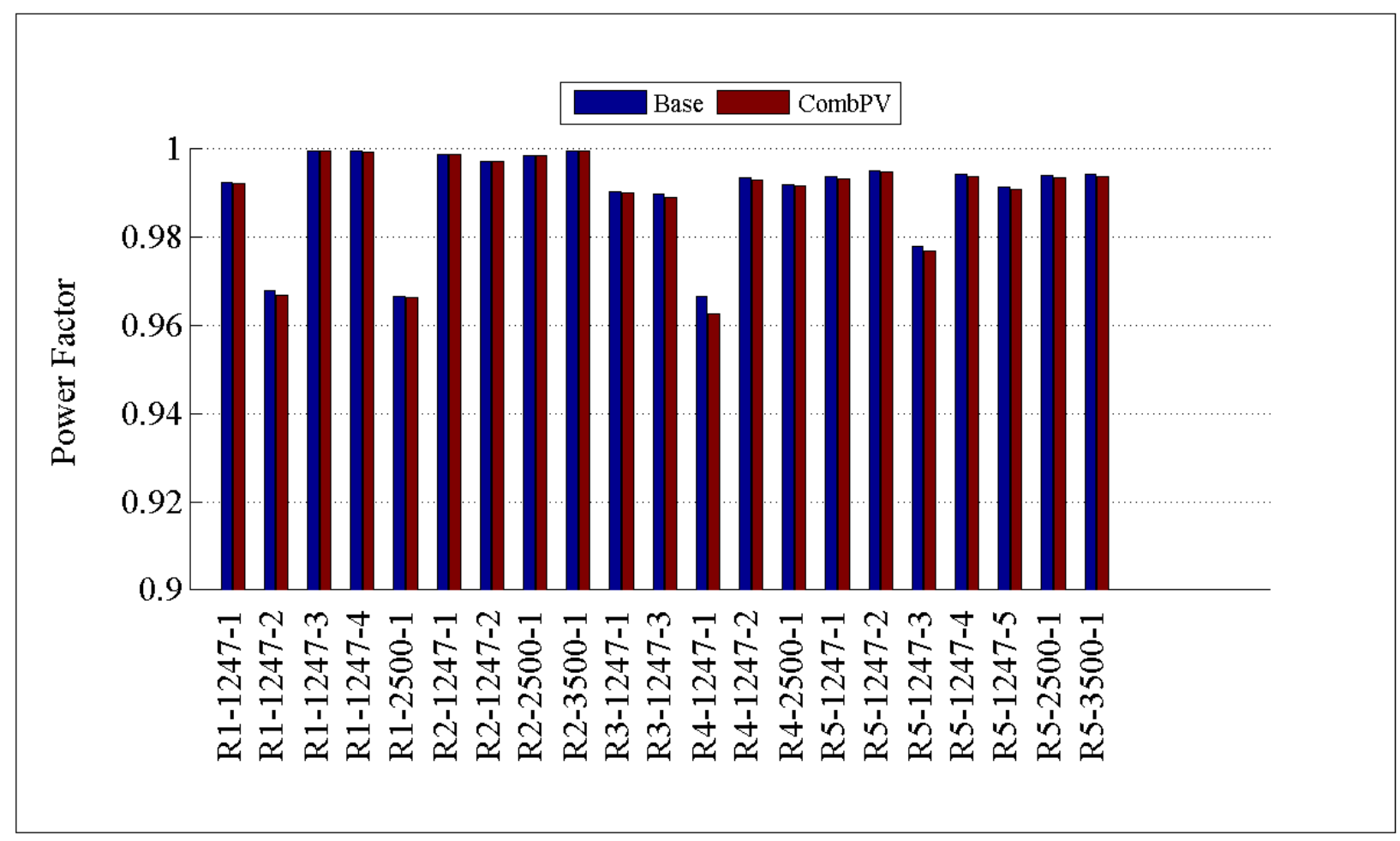

Figure 2.42 : Comparison of annual average power factor by feeder 


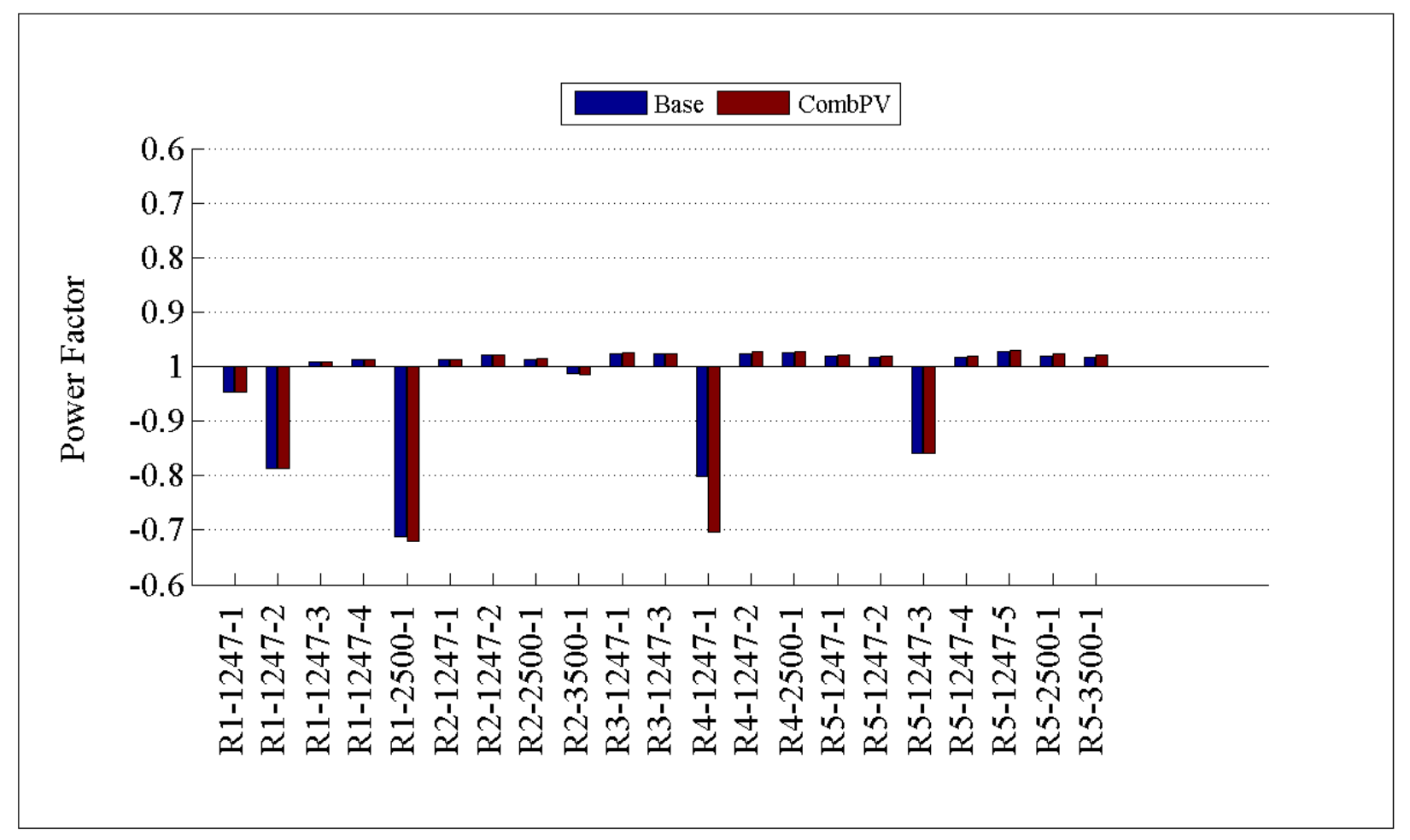

Figure 2.43: Comparison of minimum annual power factor by feeder

\subsubsection{Annual Combined PV Output}

Figure 2.44 shows the combined annual PV output for each of the prototypical feeders. Similar to the results for residential and commercial PV deployments, it can be observed that feeders in region 5 had the largest PV output. Consistent with both the individual residential and commercial studies, the largest amount of PV production was not necessarily only dependent on the amount of PV penetration in that region. Region 5 had the highest PV penetration and the greatest overall output, but region 4 contained the second highest penetration levels. However, it does not have the second highest PV output. 


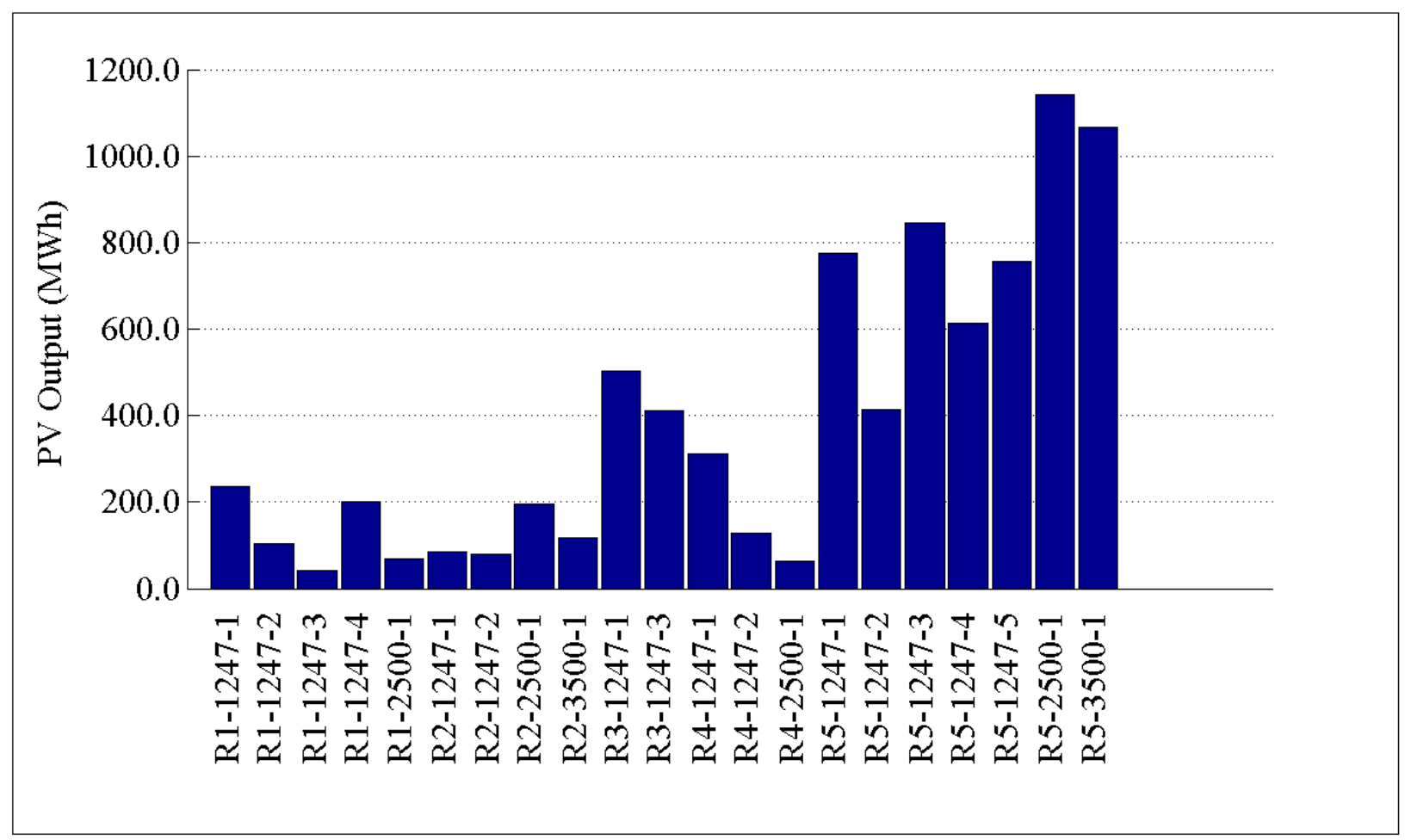

Figure 2.44: Annual combined PV output by feeder

\subsubsection{Annual $\mathrm{CO}_{2}$ emissions}

Similar to the other PV integration technologies discussed in previous sections, carbon dioxide emissions for the feeder were reduced with the addition of PV. Figure 2.45, Figure 2.46 and Figure 2.47 demonstrate that annual carbon dioxide emissions are reduced when the energy consumption is reduced. The amount of $\mathrm{CO}_{2}$ reduced is directly proportional to the amount of energy consumption reduced and will also vary depending on the generation mix for the region. 


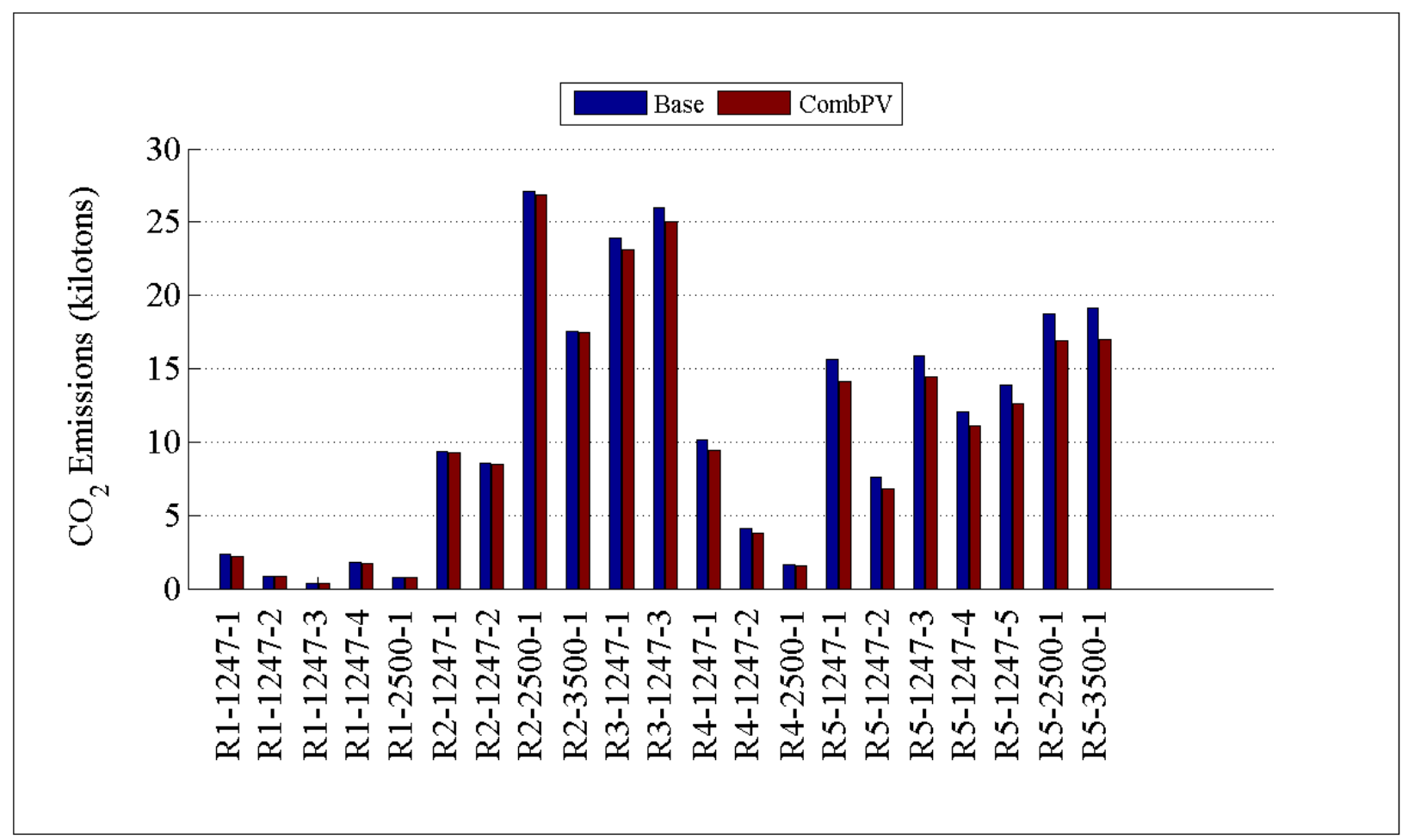

Figure 2.45: Comparison of annual $\mathrm{CO}_{2}$ emission by feeder

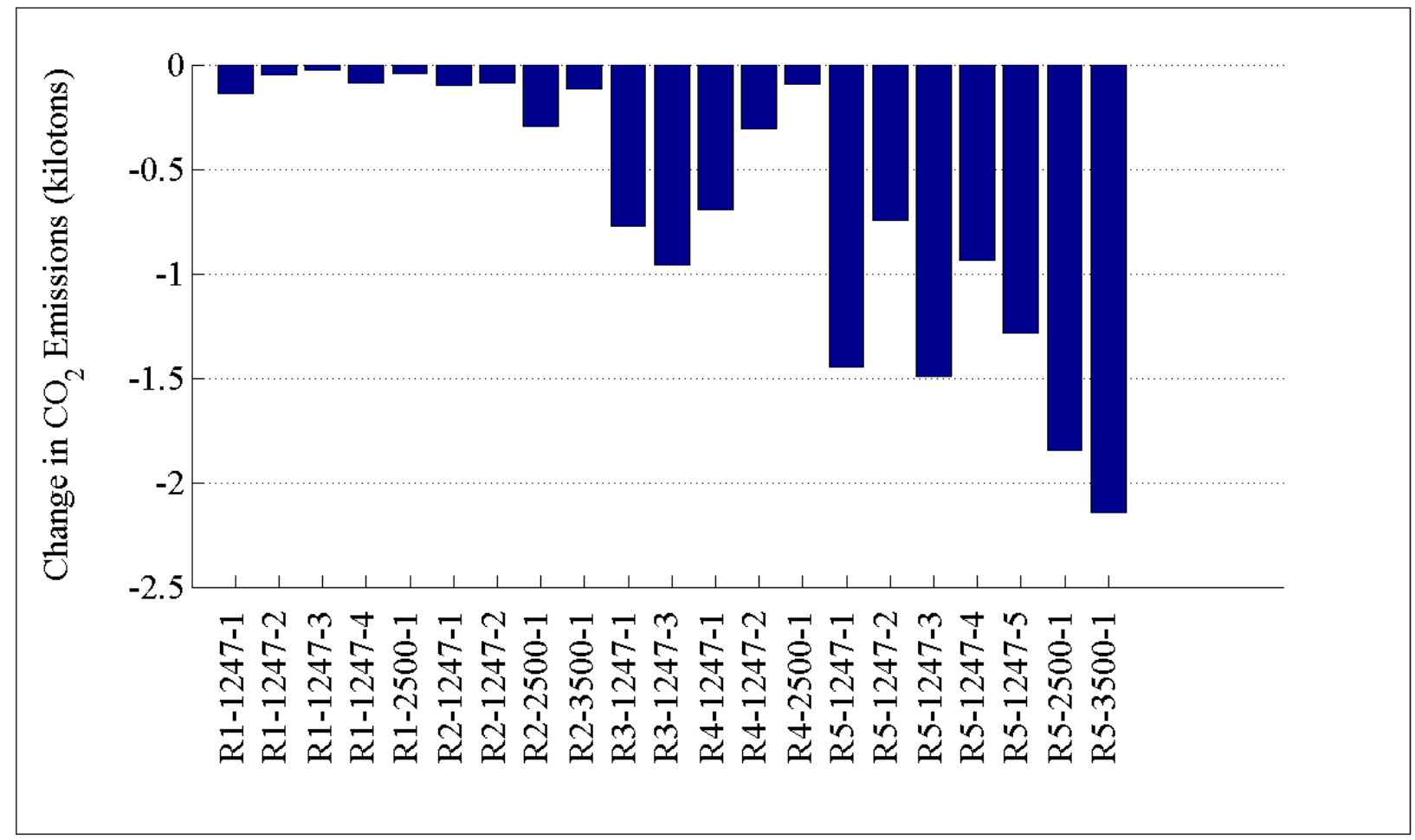

Figure 2.46: Change in annual $\mathrm{CO}_{2}$ emission by feeder (kilotons) 


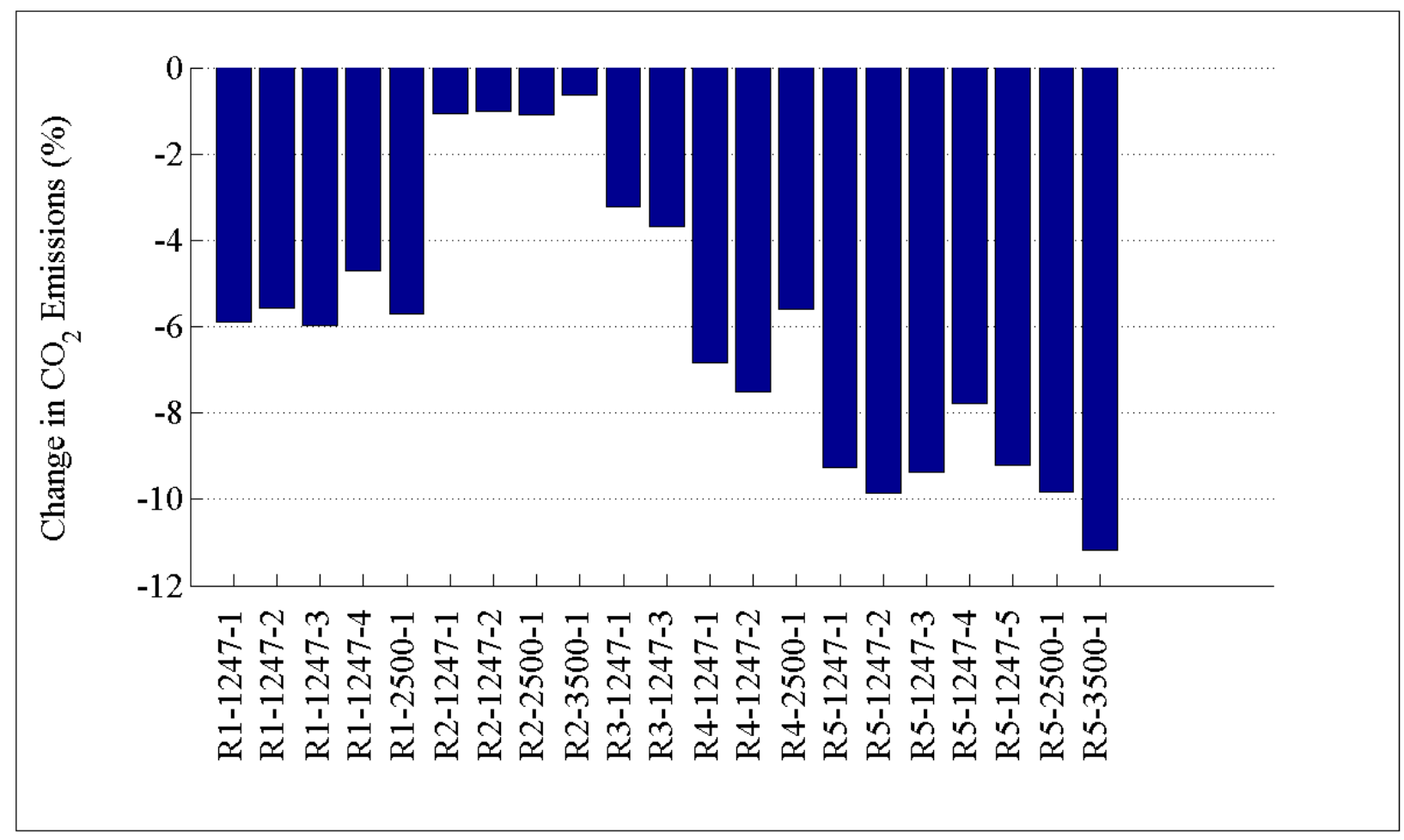

Figure 2.47: Change in annual $\mathrm{CO}_{2}$ emission by feeder (\%)

\subsection{Addition of Commercial WTG}

In this section, the addition of commercial wind turbine generators at the distribution level will be examined. As the delivered cost of wind power from large wind turbines continues to fall, the cost of wind power becomes ever more competitive with utility supplied power. The improving economics of wind generation has prompted schools, businesses, and ranchers to consider the possibility of installing a single large wind turbine to sell power to the utility, or to offset their own electrical needs. The SGIG projects have mentioned the development of interface capabilities for the future addition of community-scale wind turbines. Given these deployments, WTG inclusion in this report is in the interest of completeness, along with the view that increasing penetration in the distribution infrastructure is inevitable. When compared to solar, small-scale wind turbines at the residential level have still not gained popularity. For the purposes of the SGIG analysis, a large-scale wind turbine connected to the distribution feeder was considered to simulate installations currently carried on by utilities in the US.

Much like the photovoltaic simulations, the analysis can be replicated and adapted by interested parties using the GridLAB-D materials available at [18]. All of the tools, models, and materials used by the researchers for this portion of the study are openly available. 


\subsubsection{SGIG Metrics Affected by Commercial WTG}

The following SGIG metrics are affected by the addition of commercial WTG and will be tracked in this analysis:

Table 2.7: Impact metrics affected by commercial WTG

\begin{tabular}{|c|c|c|}
\hline Index & Metric & Units \\
\hline 1 & Hourly Customer Electricity Usage & $\mathrm{kWh}$ \\
\hline 2 & Monthly Customer Electricity Usage & MWh \\
\hline \multirow{12}{*}{3} & Peak Generation & $\mathrm{kW}$ \\
\hline & Nuclear & $\%$ \\
\hline & Solar & $\%$ \\
\hline & Bio & $\%$ \\
\hline & Wind & $\%$ \\
\hline & Coal & $\%$ \\
\hline & Hydroelectric & $\%$ \\
\hline & Natural Gas & $\%$ \\
\hline & Geothermal & $\%$ \\
\hline & Petroleum & $\%$ \\
\hline & Distributed Solar PV & $\%$ \\
\hline & Distributed Wind & $\%$ \\
\hline 4 & Peak Load & $\mathrm{kW}$ \\
\hline 7 & Annual Electricity Production & MWh \\
\hline 12 & $\mathrm{CO}_{2}$ Emissions & Tons \\
\hline \multirow{3}{*}{13} & SOx Emissions & Tons \\
\hline & NOx Emissions & Tons \\
\hline & PM-10 Emissions & Tons \\
\hline \multirow{2}{*}{21} & Feeder Real Load & $\mathrm{kW}$ \\
\hline & Feeder Reactive Load & $\mathrm{kVAR}$ \\
\hline 29 & Distribution Losses & $\%$ \\
\hline 30 & Distribution Power Factor & $\mathrm{pf}$ \\
\hline 39 & $\mathrm{CO}_{2}$ Emissions & Tons \\
\hline \multirow{3}{*}{40} & SOx Emissions & Tons \\
\hline & NOx Emissions & Tons \\
\hline & PM-10 Emissions & Tons \\
\hline
\end{tabular}

\subsubsection{Specific Implementation of Commercial WTG}

This simulation involved the modeling of a single large-scale wind turbine on a purely commercial prototypical feeder. The wind turbine in our simulation is a $1.8 \mathrm{MW}$ unit based on a device produced by Vestas. The effect of the addition of these turbines on a commercially loaded feeder is examined. Several locations, such as the beginning of the feeder, mid-feeder, and at the end of the feeder, were examined to determine a desirable installation location. The best overall energy savings occurred during the mid-feeder placement, so this point was used for all simulations. Furthermore, this simulation represented a more realistic scenario where the commercial wind turbine is not located directly near the substation. 
The theoretical power available in the wind $\left(P_{\text {wind }}\right)$ is given by equation 2.3 , where $\rho$ is the air density, $A$ is the area swept by the rotor, $v$ is the wind velocity, and $R$ is the blade radius.

$$
P_{\text {wind }}=\frac{1}{2} \rho A v^{3}=\frac{1}{2} \rho \pi R^{2} v^{3}
$$

The fraction of the power extracted from the wind by a practical wind turbine is usually represented by $C_{p}$, which is the coefficient of performance, or power coefficient. The actual mechanical power output can be written as equation 2.4 , where $C_{p}$ is a function of tip speed ratio, $\lambda$, and blade pitch angle, $\beta$ (deg). The tip ratio is defined in equation 2.5 , where, $\omega_{R}$ is the mechanical angular speed.

$$
\begin{gathered}
P_{\text {mech }}=\frac{1}{2} \rho \pi R^{2} v^{3} C_{p}(\lambda, \beta) \\
\lambda=\frac{\omega_{R} R}{v}
\end{gathered}
$$

In the model used for the SGIG analysis, $C_{p}$ is calculated using the Vestas manufacturer specification sheet [17]. The wind turbine model consists of two parts: the mechanical model and the electrical model. The mechanical power output is achieved using equations 2.3 and 2.4. Wind data for this mechanical input is once again obtained from typical meteorological year data. To keep power output consistent with weather conditions affecting the rest of the simulation models, the 1-hour reading from the TMY file was utilized for the wind speed. Direction was ignored for these simulations and it is assumed the turbine had the ability to track into the wind. The converted mechanical power is then used by a $90 \%$ efficient synchronous generator to convert the mechanical power to electrical power. While the electrical model for the generator is simplistic, it is adequate to examine the impacts of WTG operation on prototypical feeders. If specific distribution feeders were to be analyzed, significantly more accurate electrical models of the WTGs would be necessary.

\subsubsection{High Level Commercial WTG Results}

In this section, the high level results of the addition of a single large WTG connected to the distribution feeder will be examined. At this level of examination, the data will not be divided into monthly values; only annual values will be examined. Simulation results for the five purely commercial GC-12.47-1 feeders will be examined for each taxonomy region. The high level 
analysis will examine the impacts of WTGs with respect to peak load, annual energy consumption, system losses, power factor, annual output, and $\mathrm{CO}_{2}$ emissions.

\subsubsection{Annual Peak Load}

Figure 2.48 shows a comparison of peak load on feeders when a commercial wind turbine is added to the feeder compared to the base case. The direct changes are shown in Figure 2.49 and Figure 2.50. As the differences show, peak demand is reduced for all the feeders except for GC12.47-1_R4. This is similar to the behavior observed from the solar integration studies. As with the solar cases, peak demand reduction is not necessarily a benefit of commercial WTG and is largely dependent on the feeder characteristics and the end-use load behavior. However, it can be noted that the peak increase is less than $0.5 \%$ when compared to base case peak demand.

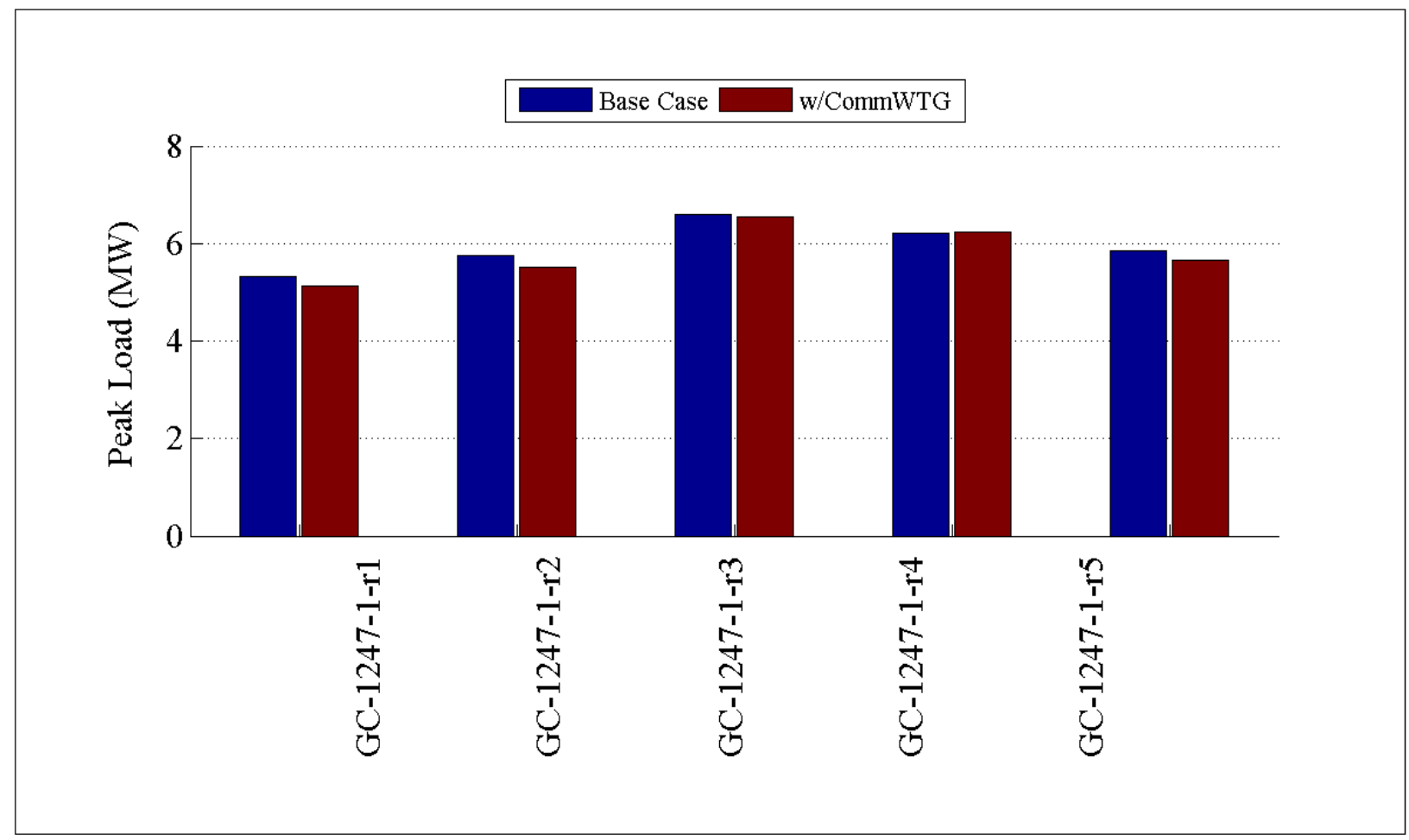

Figure 2.48: Comparison of peak load by feeder 


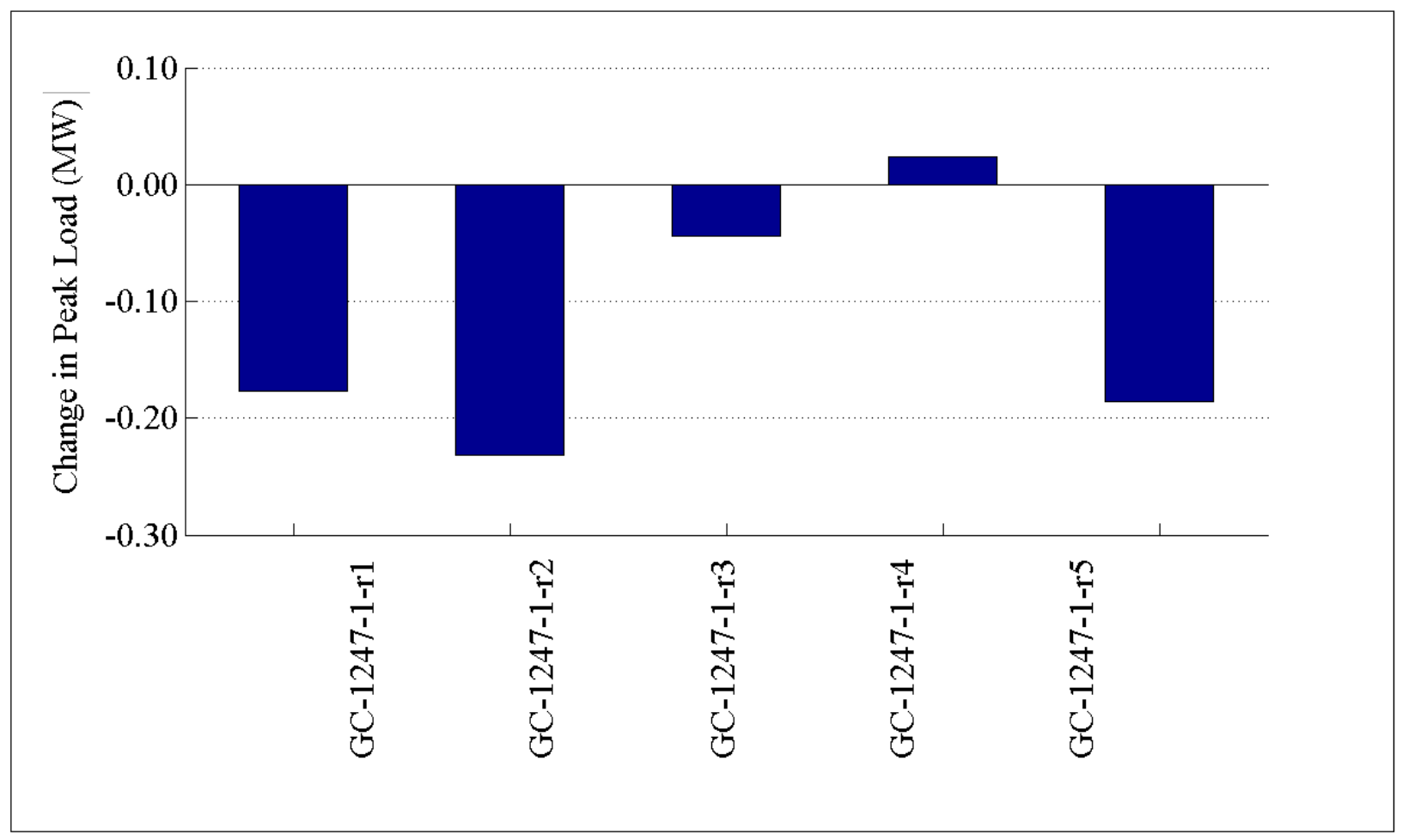

Figure 2.49: Change in peak load by feeder (MW)

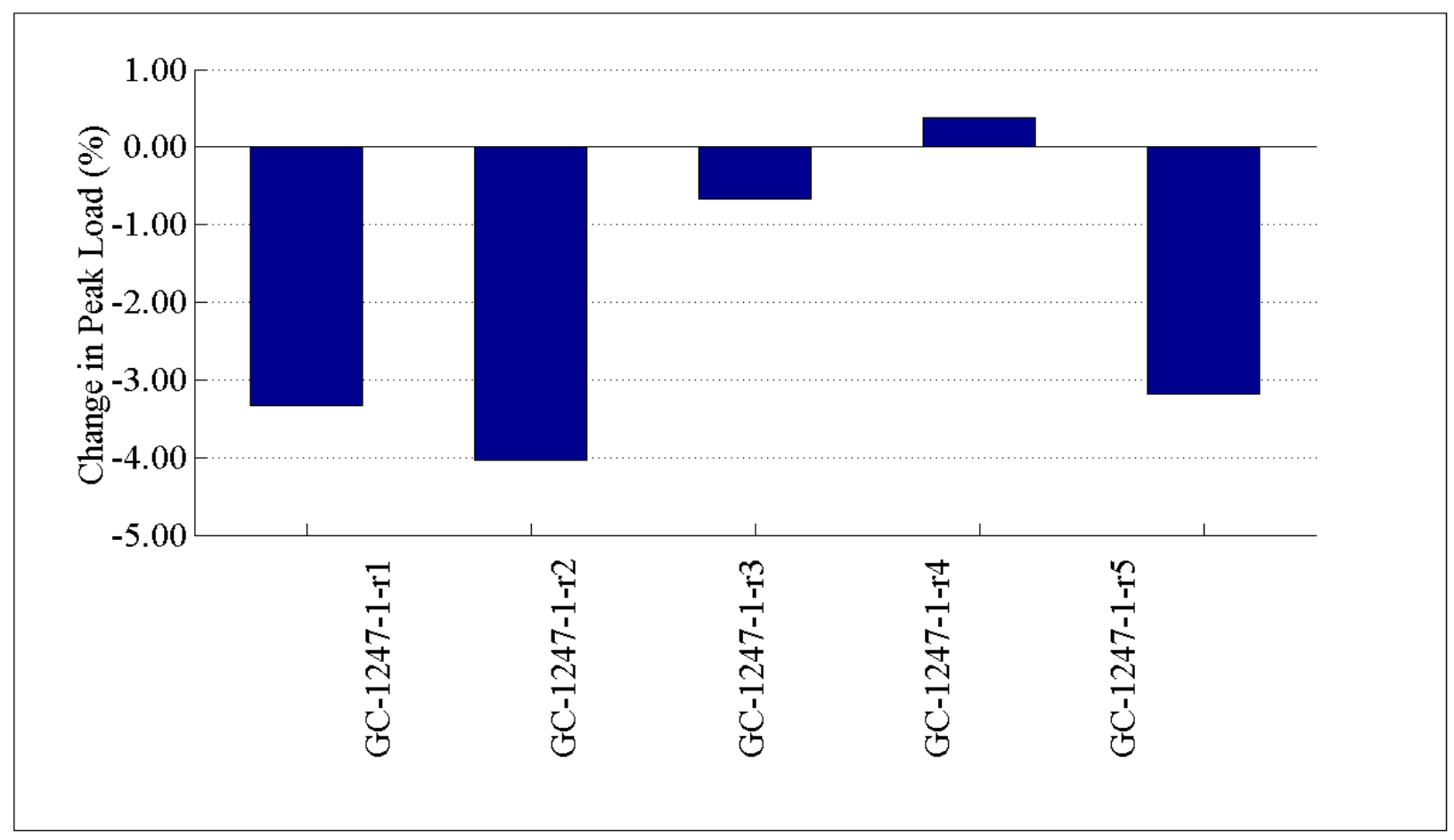

Figure 2.50: Change in peak load by feeder (\%) 


\subsubsection{Annual Energy Consumption}

Figure 2.51 shows the comparison of annual energy consumption for all the feeders. Similar to the PV technologies, the addition of a WTG reduces the annual energy consumption for all the feeders; it is this reduction in annual energy consumption that is the primary benefit of WTGs. Figure 2.52 and Figure 2.53 show that a maximum of $4 \mathrm{GWh}$, or $22 \%$, of energy savings can be achieved by the addition of a single $1.8 \mathrm{MW}$ wind turbine to the GC feeders within the taxonomy. Since the GC feeders have a peak load of around $5 \mathrm{MW}$ a single $1.8 \mathrm{MW}$ WTG represents a very high penetration level for that single feeder.

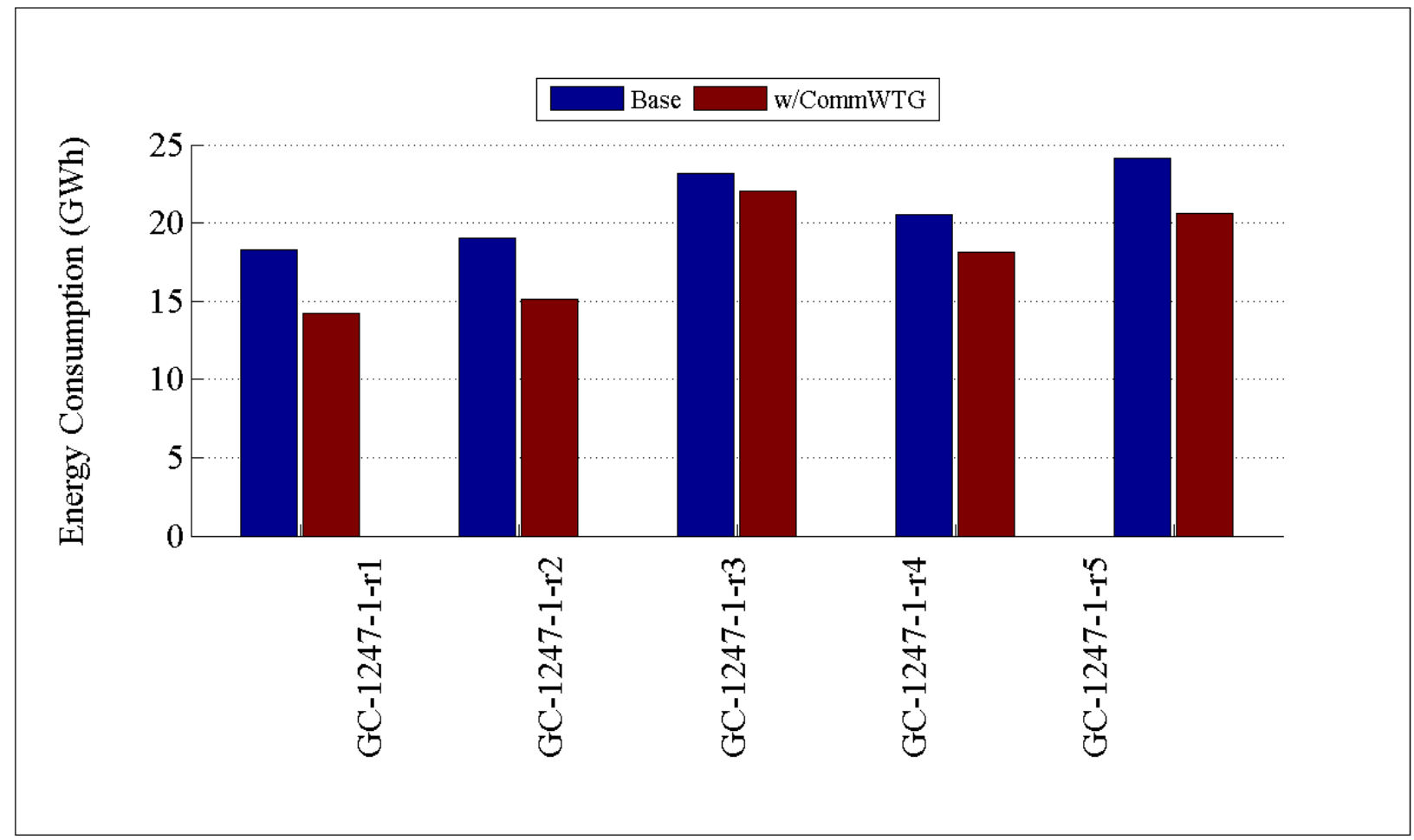

Figure 2.51: Comparison of annual energy consumption by feeder (GWh) 


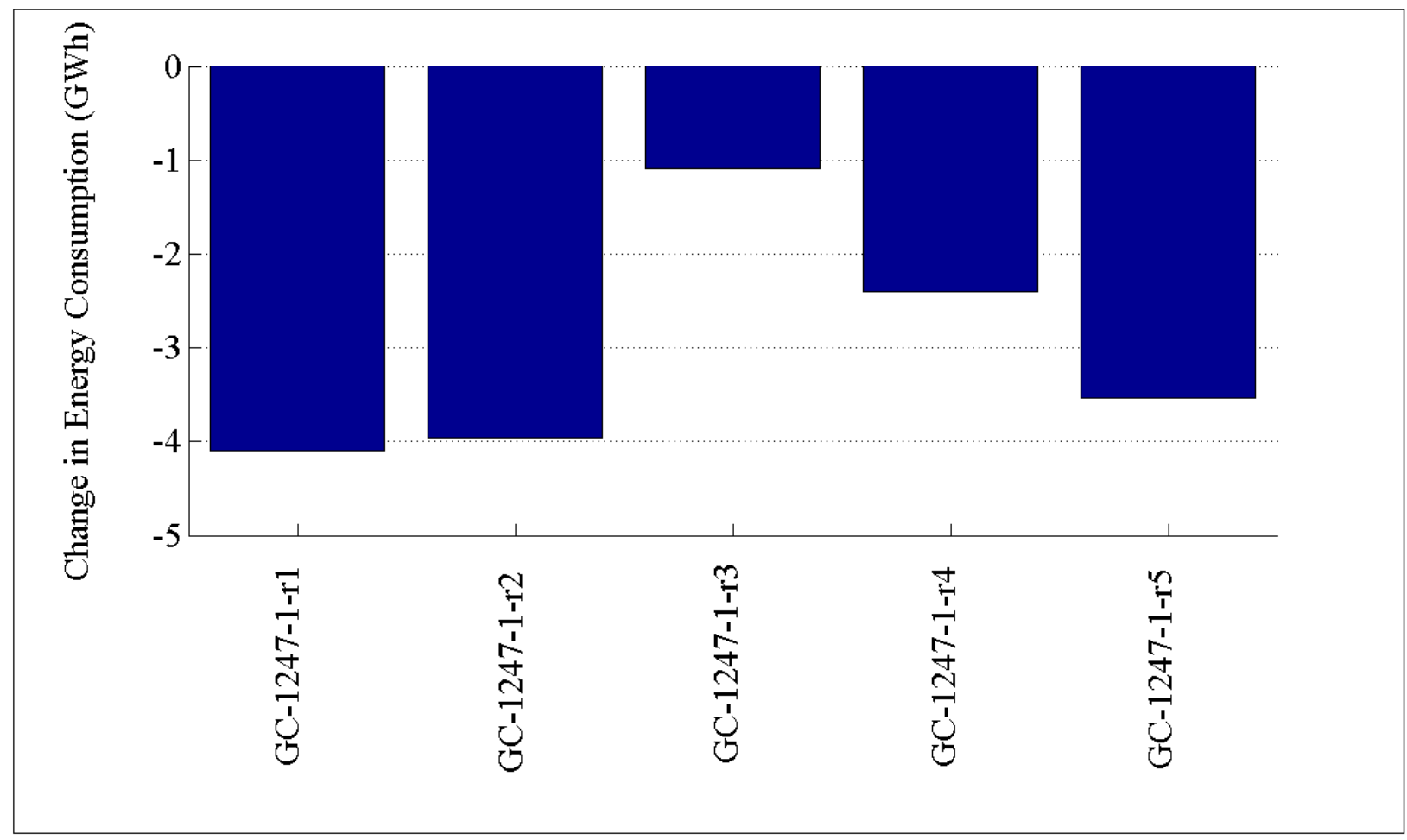

Figure 2.52: Change in annual energy consumption by feeder (GWh)

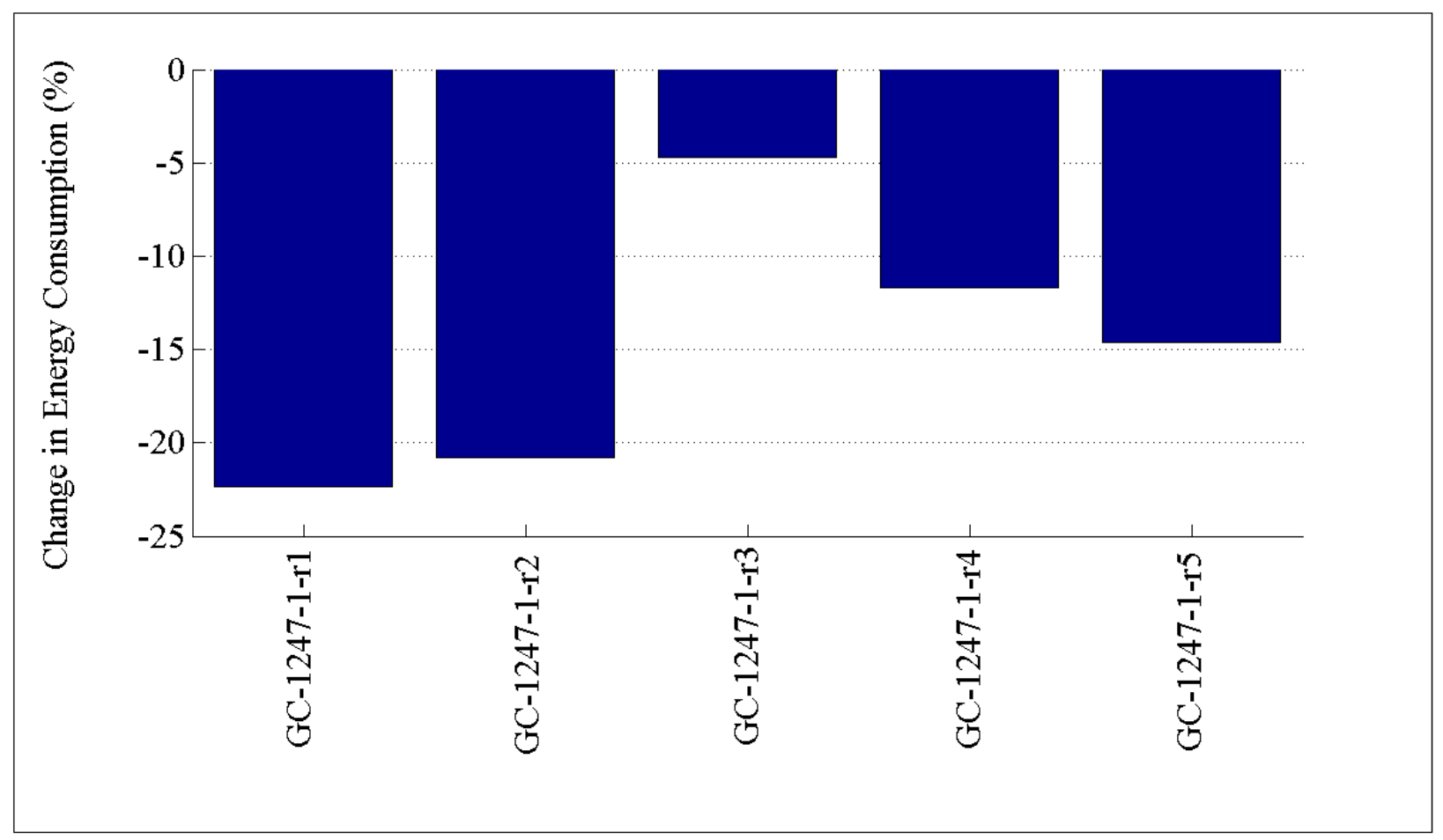

Figure 2.53: Change in annual energy consumption by feeder (\%) 


\subsubsection{Annual System Losses}

The reduction of system losses is another benefit of integrating a commercial WTG. Figure 2.54 shows the comparison of annual system losses by feeder. Figure 2.55 and Figure 2.56 show the reduction in annual system losses for the five GC feeders. The newer WTG models implemented provide for reactive power compensation, and thus improve the performance of the WTG. Reductions in losses were quite large because of the design characteristics of the GC feeders. The GC feeders are relatively small feeders serving a small number of large commercial customers. In this configuration there are few laterals so that reductions in line flows affect sectionals where the majority of the feeder power flows. As a result, the loss reductions for the GC feeders occur primarily in the series elements of the overhead lines.

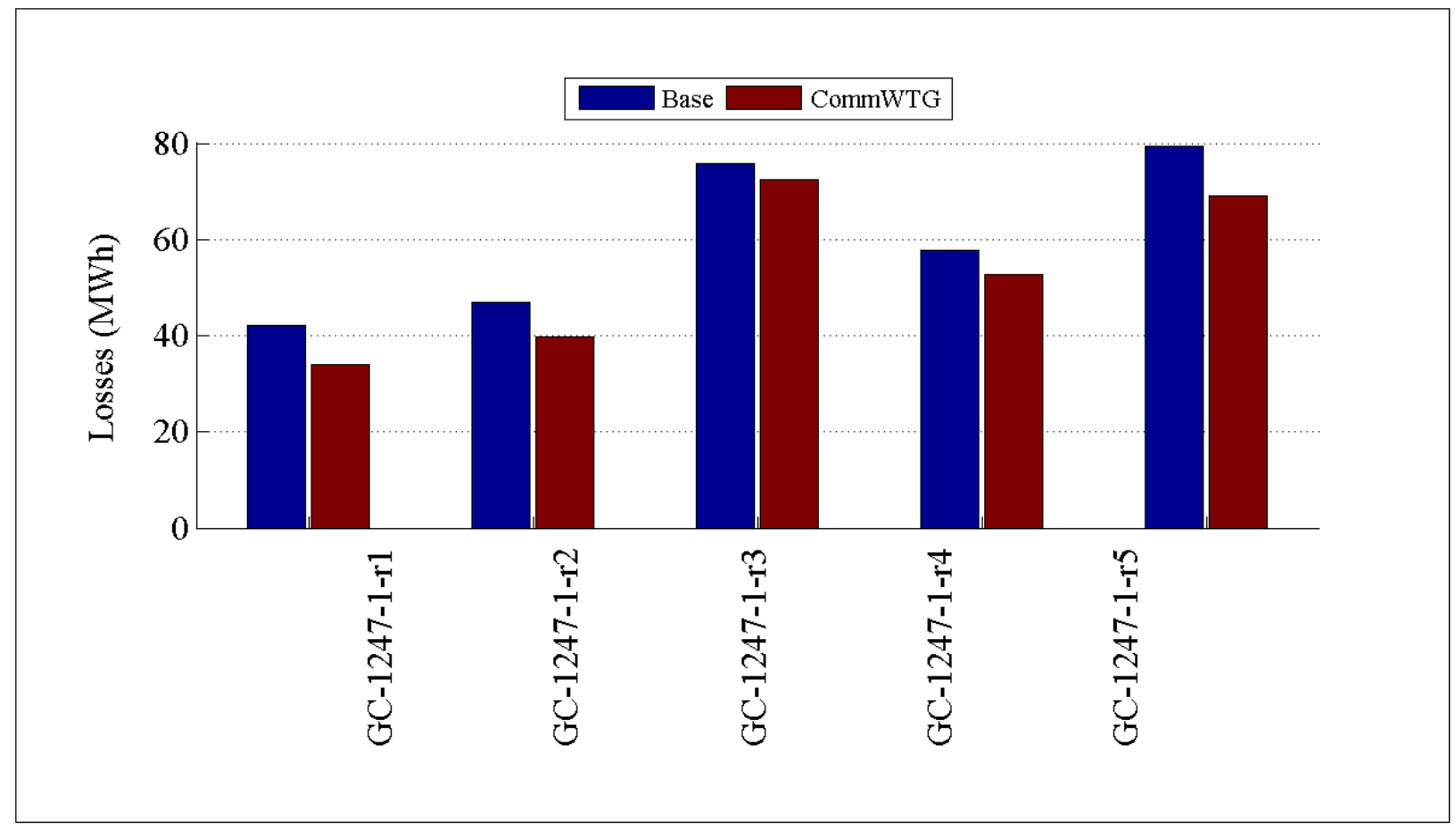

Figure 2.54: Comparison of total annual losses by feeder 


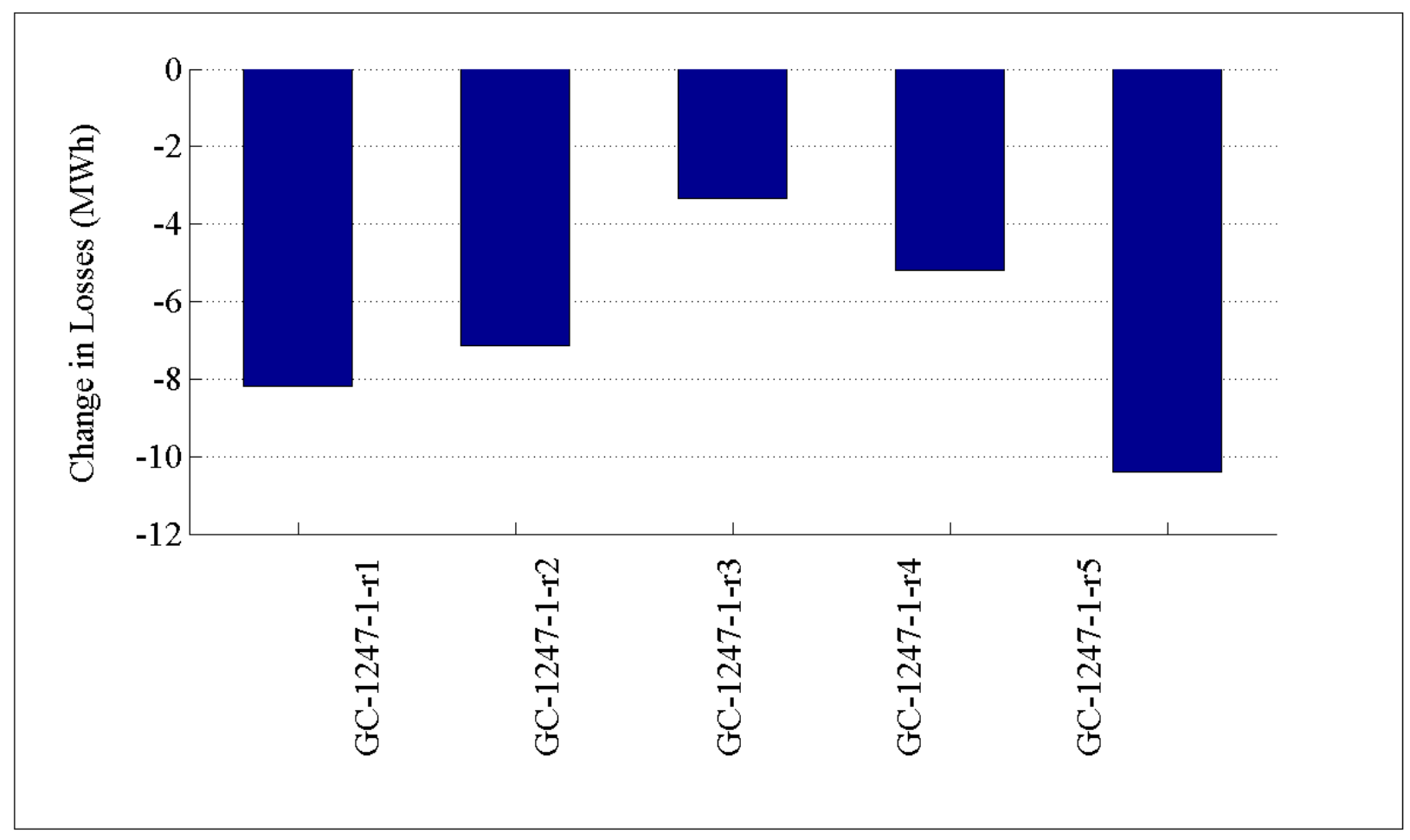

Figure 2.55: Change in annual losses by feeder (MWh)

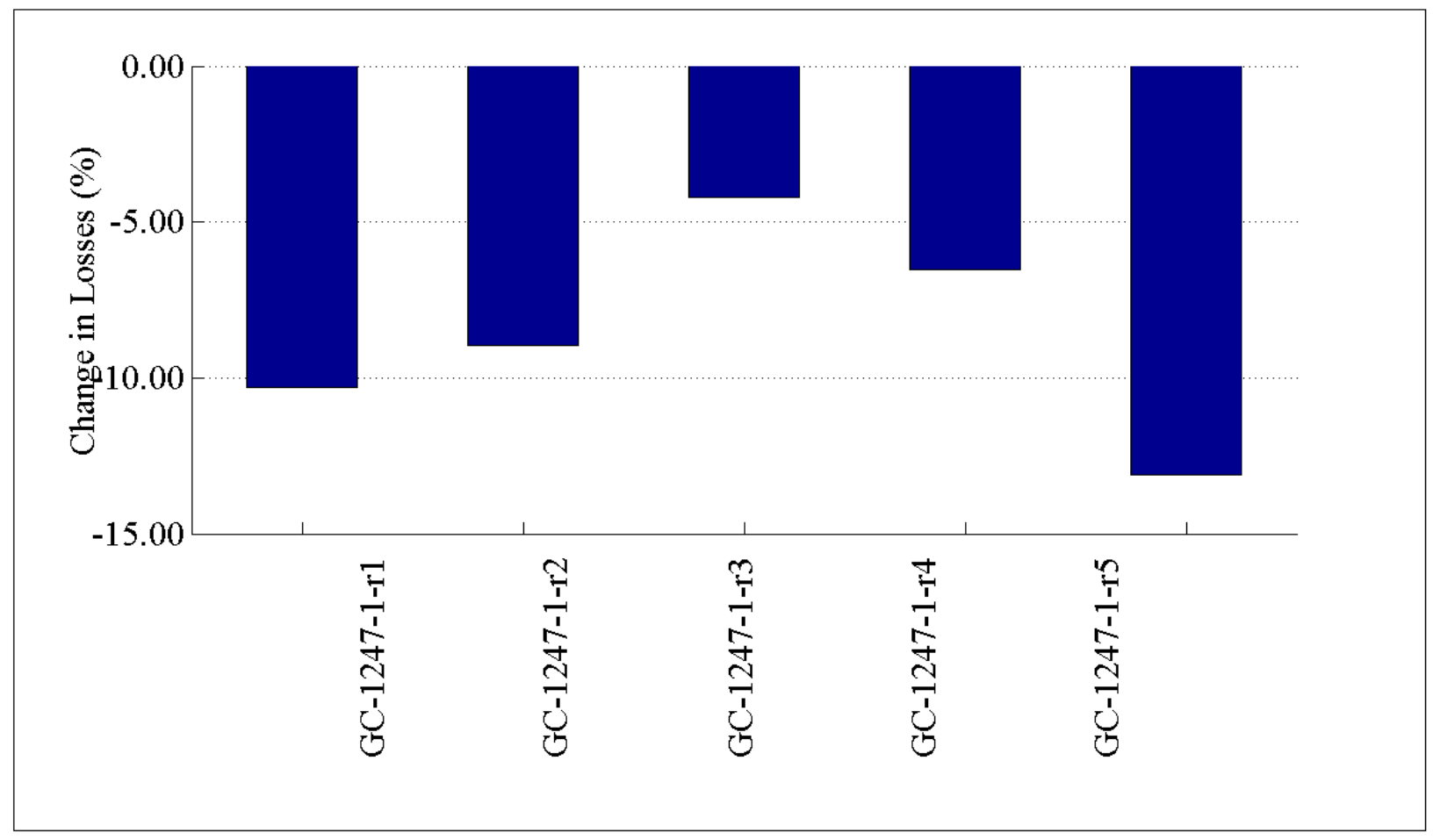

Figure 2.56: Change in annual losses by feeder (\%) 


\subsubsection{Annual Wind Power Output}

Figure 2.57 shows the total annual wind power output for all the commercial GC feeders. The GC feeder in region 1 had the highest amount of wind power generated. This figure is very useful because the decision to deploy commercial WTGs in a region is partially dependent upon on the capacity of wind power that can be extracted in a particular region. From Figure 2.57, it is observed that feeders in region 1, 2, and 5 are most favorable for commercial wind installations. While this generalization to the regional level is useful for some applications, wind resources within a region will vary greatly. As a result, the deployment of a WTG on a specific feeder would need climate information with a higher level of granularity than provided by regionalization of the nation.

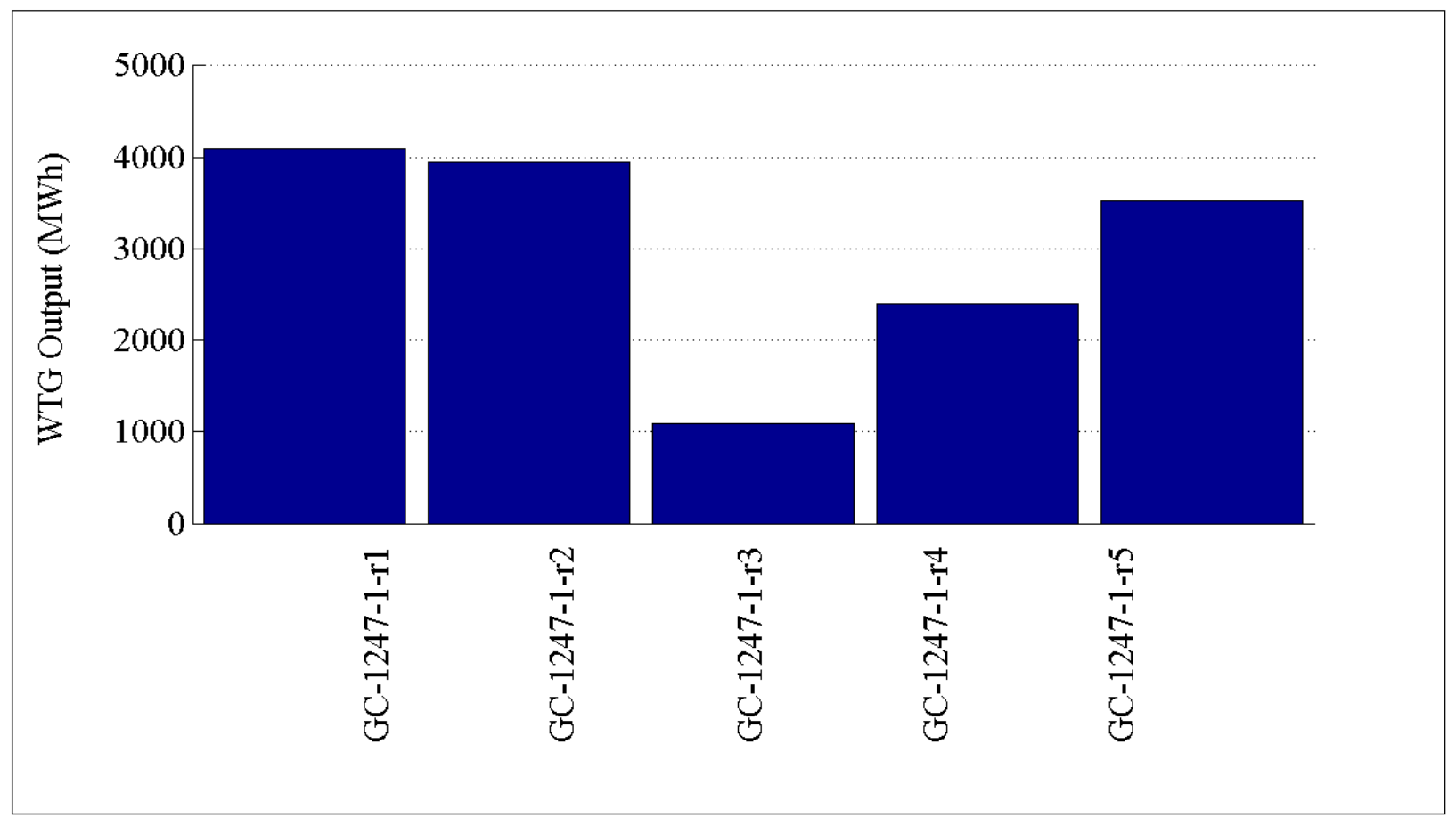

Figure 2.57 : Comparison of annual wind output by feeders

\subsubsection{Annual $\mathrm{CO}_{2}$ Emissions}

Reduction of carbon dioxide emissions is another important benefit from the integration of WTGs at the distribution level. The amount of carbon dioxide emitted is a result of the energy consumed and the mix of generating resources in that region. The greater the energy consumption, in general, the greater the $\mathrm{CO}_{2}$ emission will be. Figure 2.58 compares the annual $\mathrm{CO}_{2}$ emission by feeder. Figure 2.59 and Figure 2.60 show the change in annual carbon dioxide emissions for the GC feeders. As was the case with the added solar distributed generation, adding wind turbines decreased the energy consumed by the feeder. This reduction resulted in a direct reduction of $\mathrm{CO}_{2}$ emissions. 


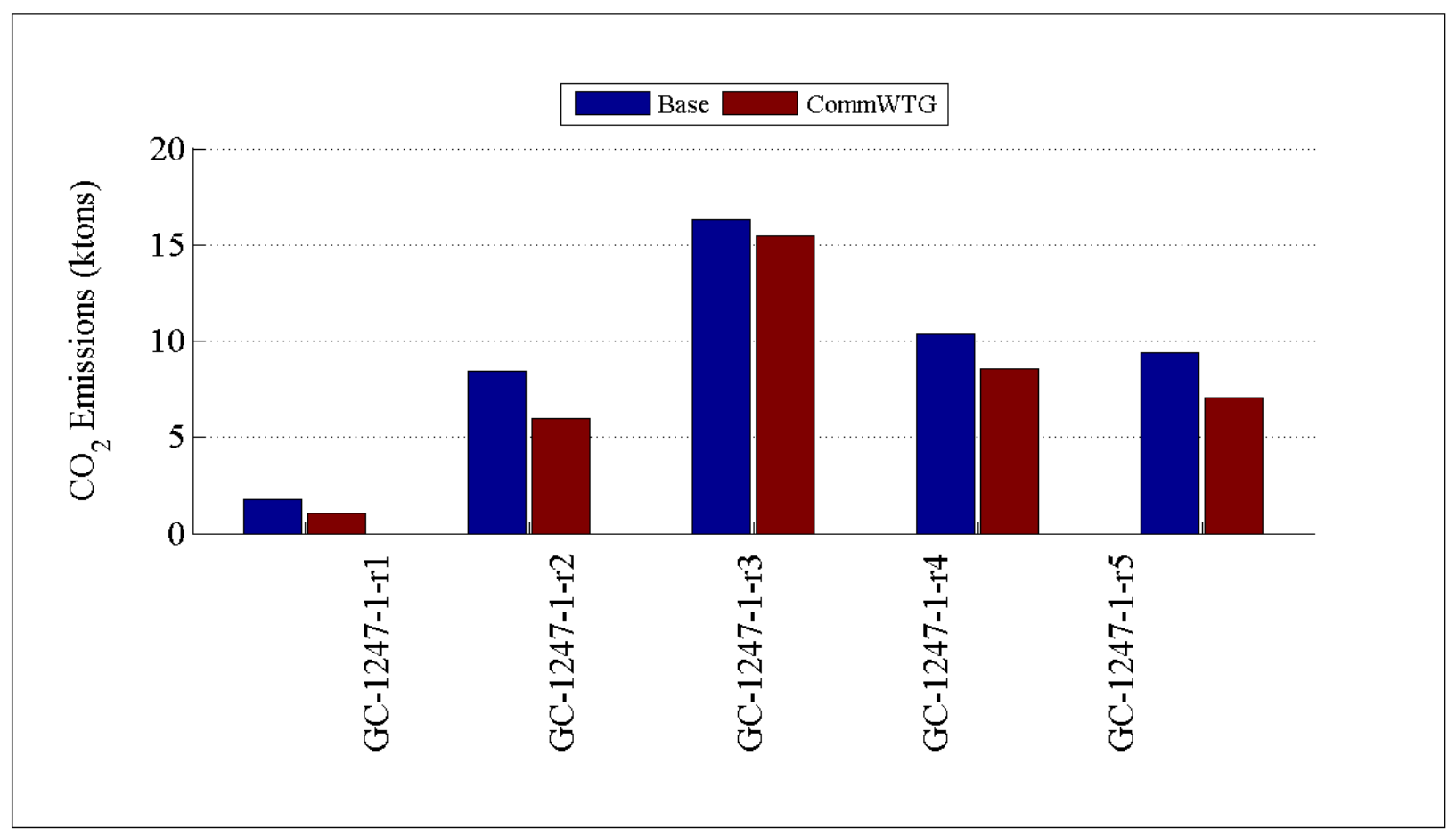

Figure 2.58 : Comparison of annual $\mathrm{CO}_{2}$ emission by feeders

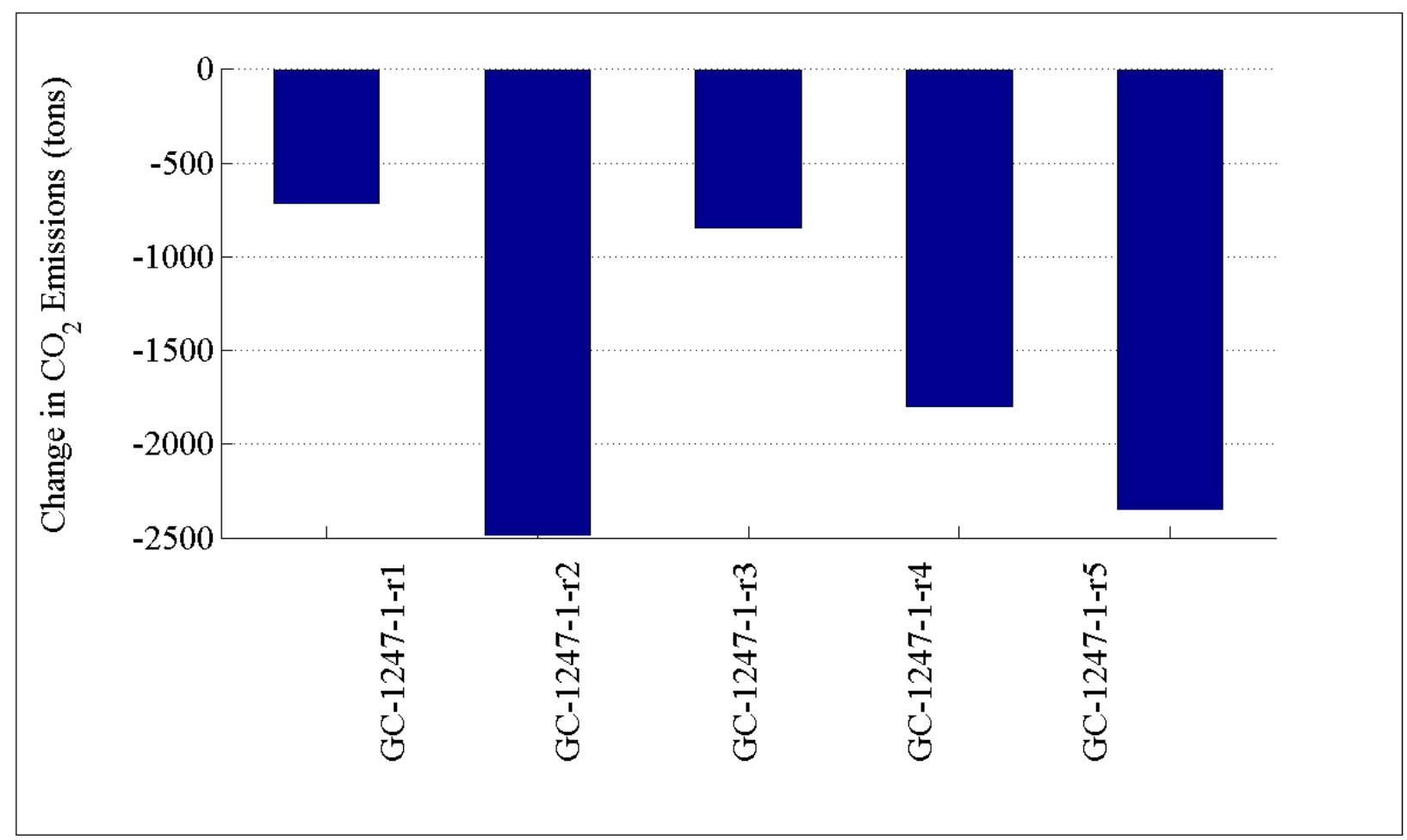

Figure 2.59 : Change in annual $\mathrm{CO}_{2}$ emission by feeders (tons) 


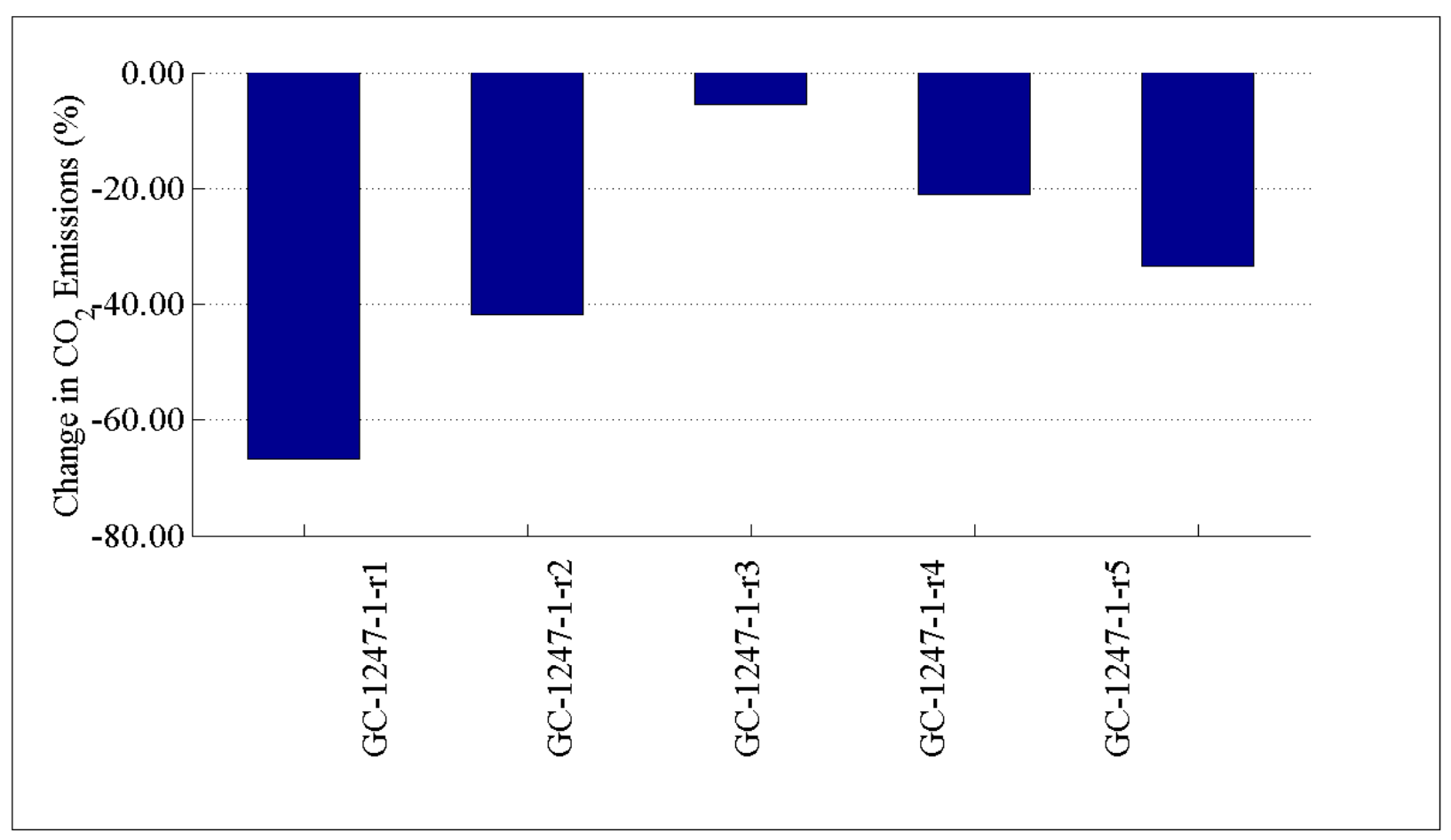

Figure 2.60 : Change in annual $\mathrm{CO}_{2}$ emission by feeders (\%) 


\section{Detailed Individual Prototypical Feeder Results}

Due to the large number of plots generated by the simulations, it is not practical to place all of the results in this section. Section 3 will examine the output results of a single feeder and the output for the remaining feeders will be provided in Appendix D. Analysis presented in this section can be extended to other feeders detailed in Appendix D.

\subsection{Residential PV}

For residential PV, there are 6 plots that will be displayed for each feeder: peak monthly demand, monthly energy consumption, monthly losses, monthly PV output, and monthly $\mathrm{CO}_{2}$ emissions.

\subsubsection{Example Feeder R1-12.47-1}

Figure 3.1 through Figure 3.5 show the monthly plots that are generated for feeder R1-12.471. This particular feeder belongs to climate region 1, which represents the west coast of the United States, and typically has a temperate climate. This region received a penetration of residential PV units equal to 3\% of feeder peak load. This particular feeder, R1-12.47-1, has a moderate suburban and rural population with almost 1,200 single family residences and is ideal for the analysis of residential PV installation.

Figure 3.1 shows a comparison of peak load by month for the simulations on this feeder. It is observed that peak load was reduced for all the feeders when residential PV was installed on the system. 


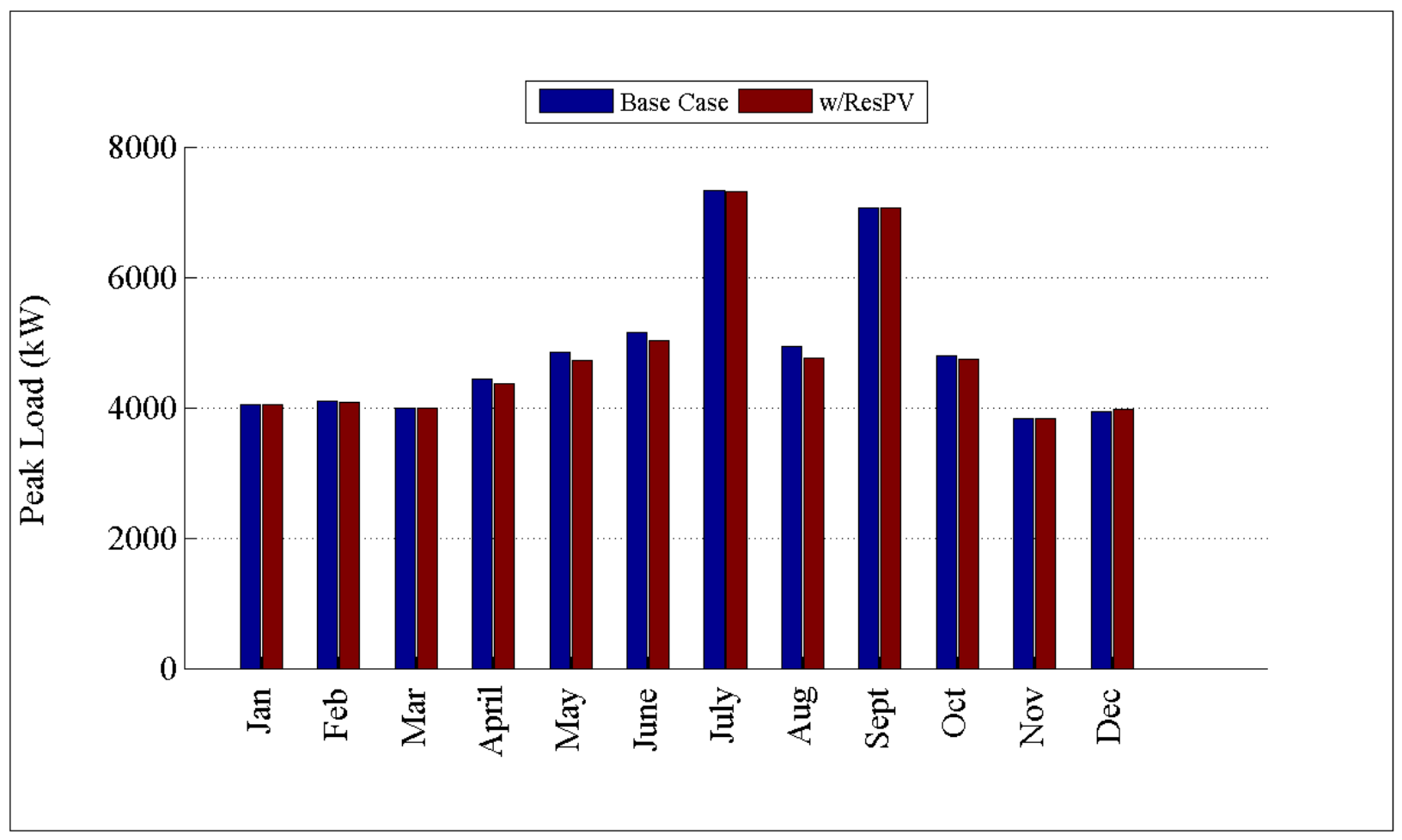

Figure 3.1: Comparison of peak load by month for R1-12.47-1

Figure 3.2 shows a comparison of reductions in energy consumption when residential PV units were added to this distribution feeder. As stated in Section 2, a reduction in the energy consumption is the most important benefits achieved by residential PV installations. The results demonstrate that energy consumption was reduced for every month under simulation.

It is interesting to note that the overall energy consumption decreased during the period of high solar availability (i.e., summer and spring months). Temperature impacts on the thermal models used for residential and commercial buildings are the likely cause of this decrease. However, the introduction of residential PV still served to reduce the overall energy consumption during these months.

As seen in Figure 3.1, the months of December and January showed a very slight increase of peak load; however, the energy consumption is reduced for the same months, as seen in Figure 3.2. Since the peak solar output typically does not coincide with the peak feeder load, a direct reduction did not occur. Furthermore, the change in voltage caused by the solar generation altered the states of the different loads in GridLAB-D's voltage-dependent models. As such, the devices would be operating in a slightly different manner during the feeder peak, and may consume more power at this time. However, the PV was still providing energy into the system at some point, so the overall energy consumption was reduced. 


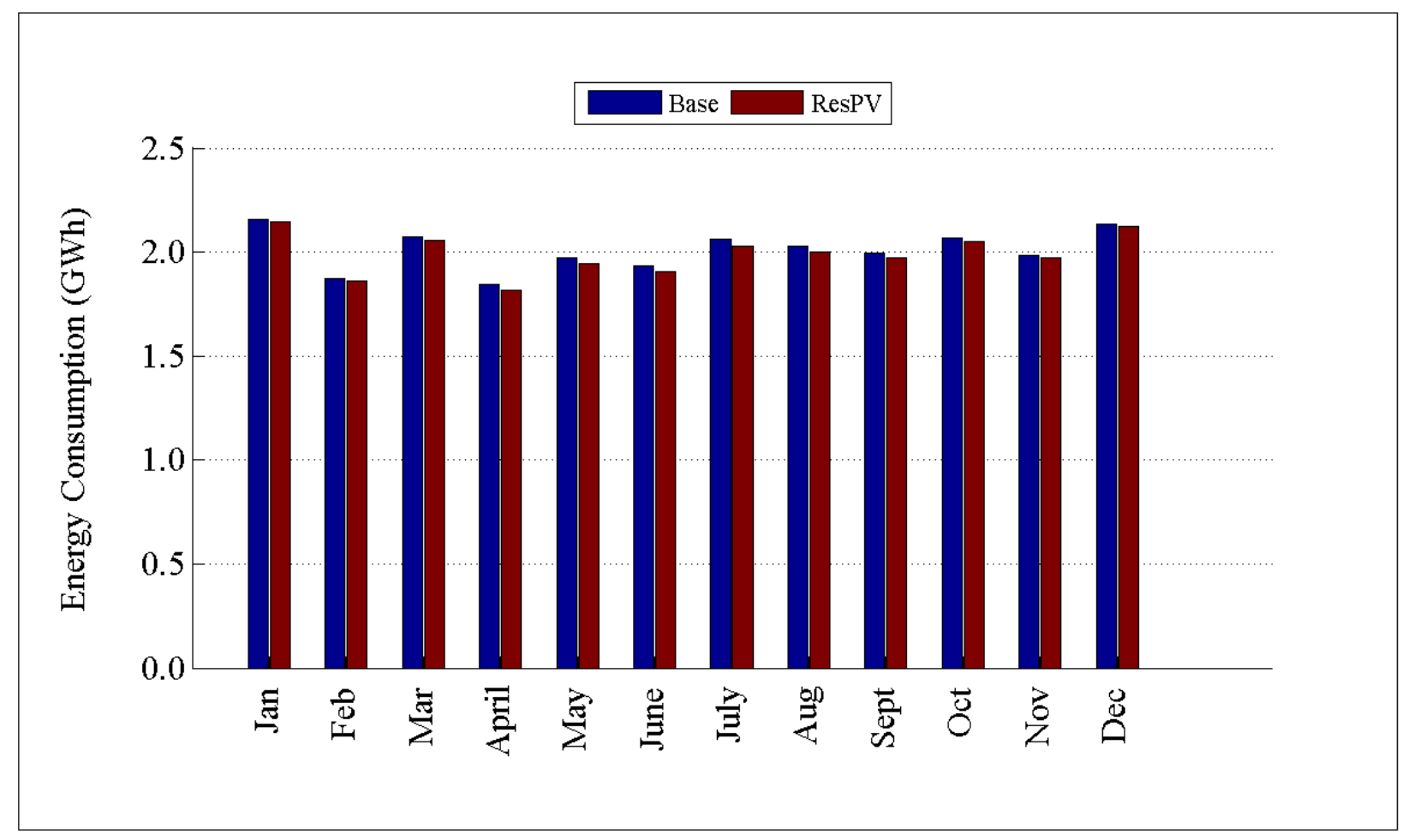

Figure 3.2: Comparison of energy consumption by month for R1-12.47-1

The reduction of losses is also a benefit associated with residential PV installations, as was demonstrated in Section 2. The monthly losses plots for 'Base' and 'ResPV' are shown in Figure 3.3 for 4 different loss types: losses in overhead lines 'OHL', underground lines 'UGL', transformers 'TFR', and triplex(secondary) lines 'TPL'. As can be seen from the figure, losses were decreased for all the components in the distribution system. The largest loss savings were achieved on overhead lines and distribution transformers. Higher savings can be achieved with higher residential PV penetration on this system. 


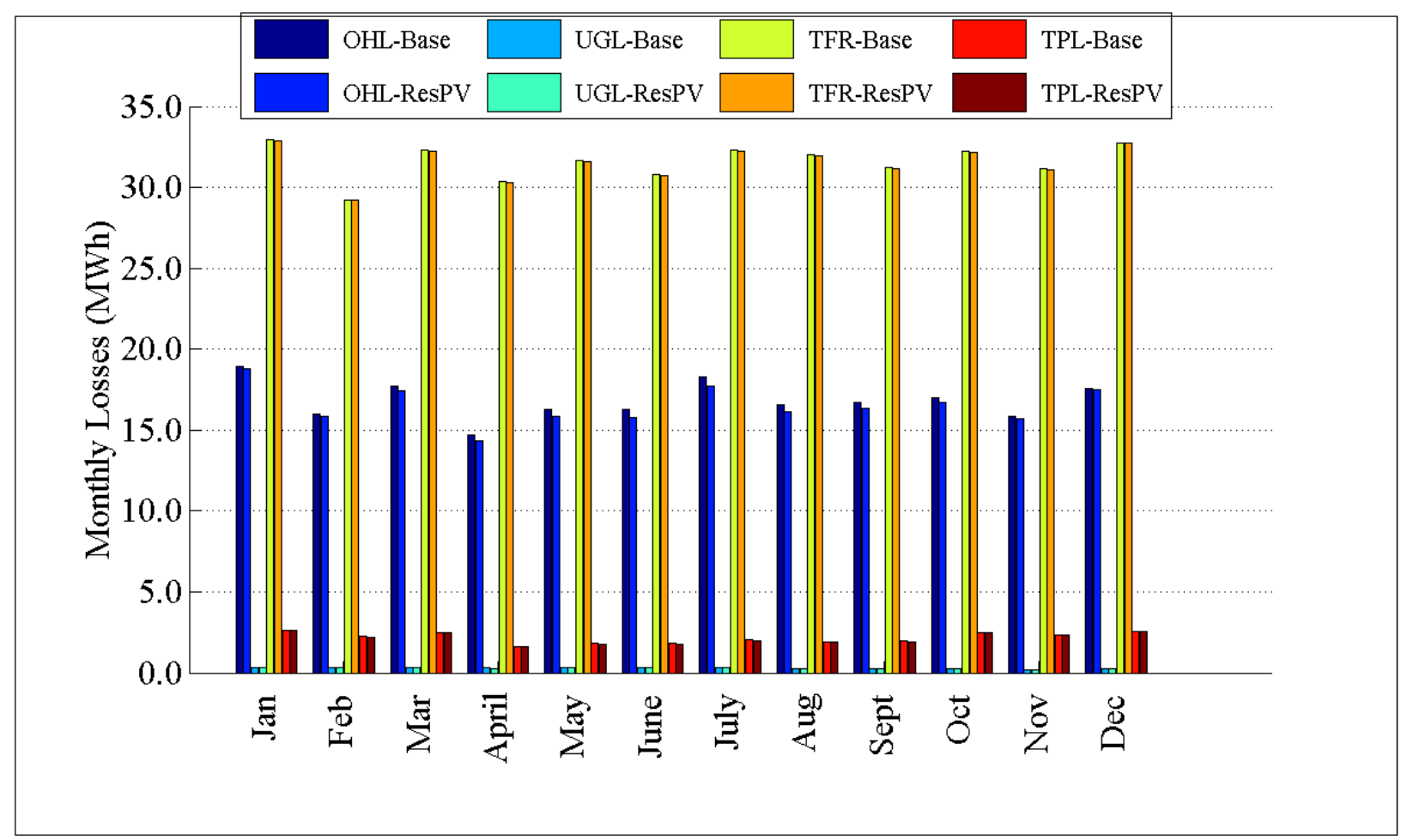

Figure 3.3: Comparison of losses by month for R1-12.47-1

Figure 3.4 shows the monthly PV output profile for feeder R1-12.47-1. As previously mentioned, this feeder received a penetration of residential PV units equal to $3 \%$ of feeder peak load. As expected, peak PV output occurred during the expected peak solar interval: summer. The months of June and July produced the most energy output from the solar distributed generation. 


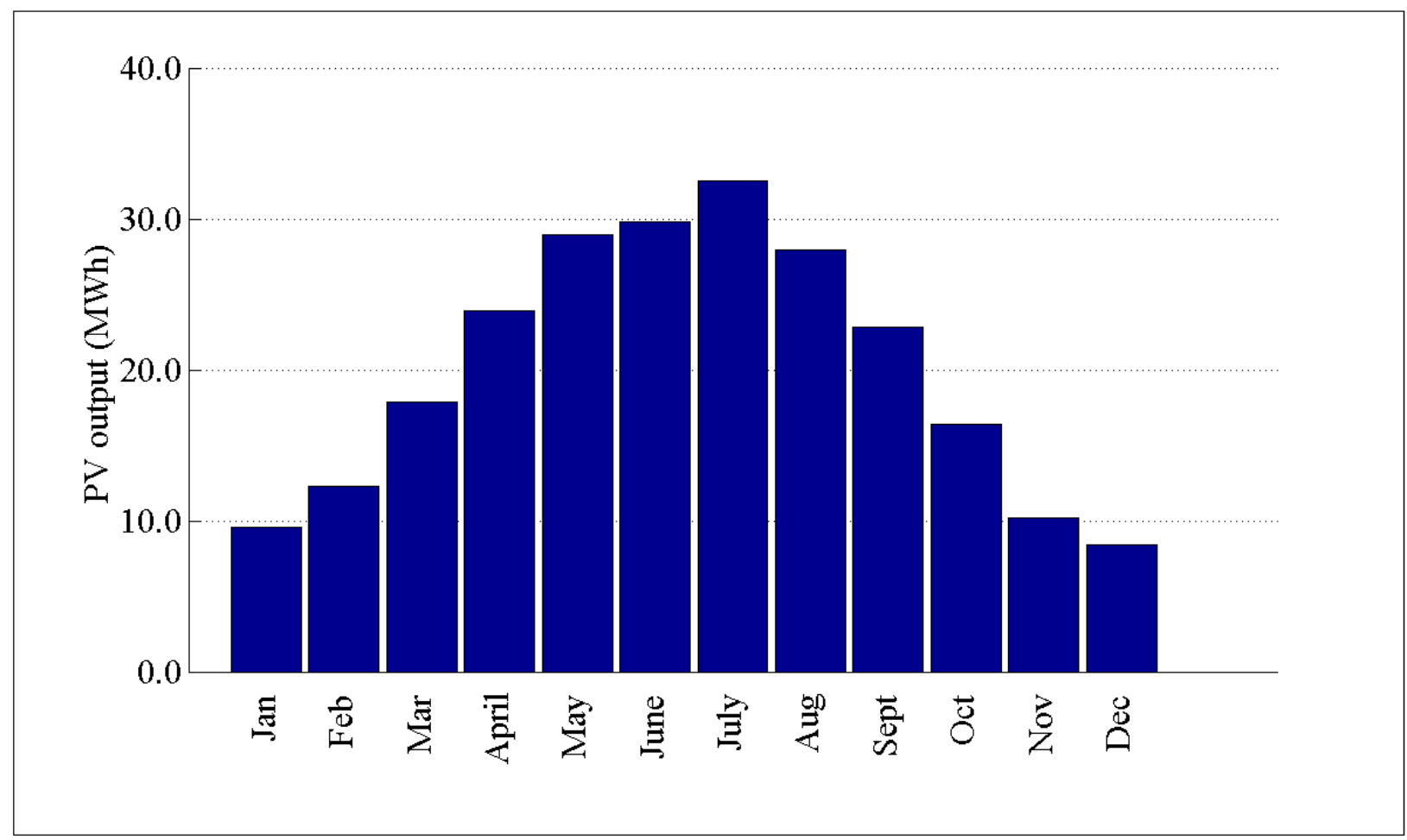

Figure 3.4: Comparison of PV output by month for R1-12.47-1

Figure 3.5 shows the carbon dioxide emission comparison to the base case when residential PV units were deployed on feeder R1-12.47-1. The reduction in energy consumption is directly related to the amount of carbon dioxide emission reduction. For these studies, the addition of residential PV units decreases the $\mathrm{CO}_{2}$ emissions with a strong seasonal influence. 


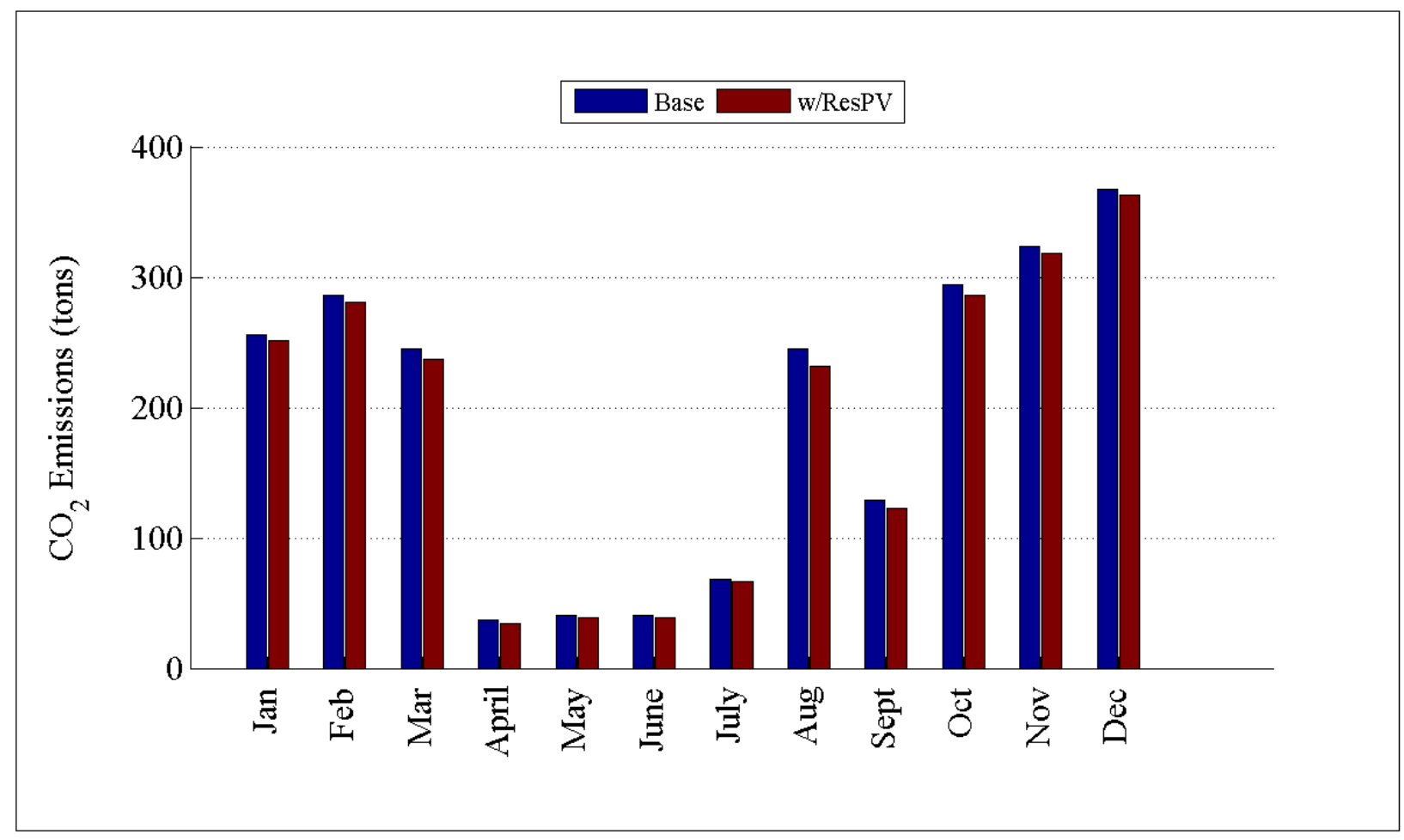

Figure 3.5: Comparison of $\mathrm{CO}_{2}$ emissions by month for R1-12.47-1

\subsection{Commercial PV}

Only the feeders which had commercial loads were simulated in this category, therefore only 27 out of the total 28 prototypical feeders were simulated. Feeder R2-12.47-3 did not have any commercial loads and thus was not selected for this simulation. For commercial PV, there are 5 plots that will be displayed for each feeder: peak monthly demand, monthly energy consumption, monthly losses, monthly PV output, and monthly $\mathrm{CO}_{2}$ emissions.

\subsubsection{Example Feeder GC-12-47-1_R1}

Figure 3.6 through Figure 3.10 show the monthly plots that are generated for feeder GC-12.471_R1. This feeder belongs to region 1, which represents the west coast of the United States and has a temperate climate. This region received a penetration of commercial PV units equal to $3 \%$ of feeder peak load, each with fixed array sizes of $100 \mathrm{~kW}$. This feeder is comprised of large commercial loads, such as a large shopping mall, and is well suited for the analysis of the addition of commercial PV units. 


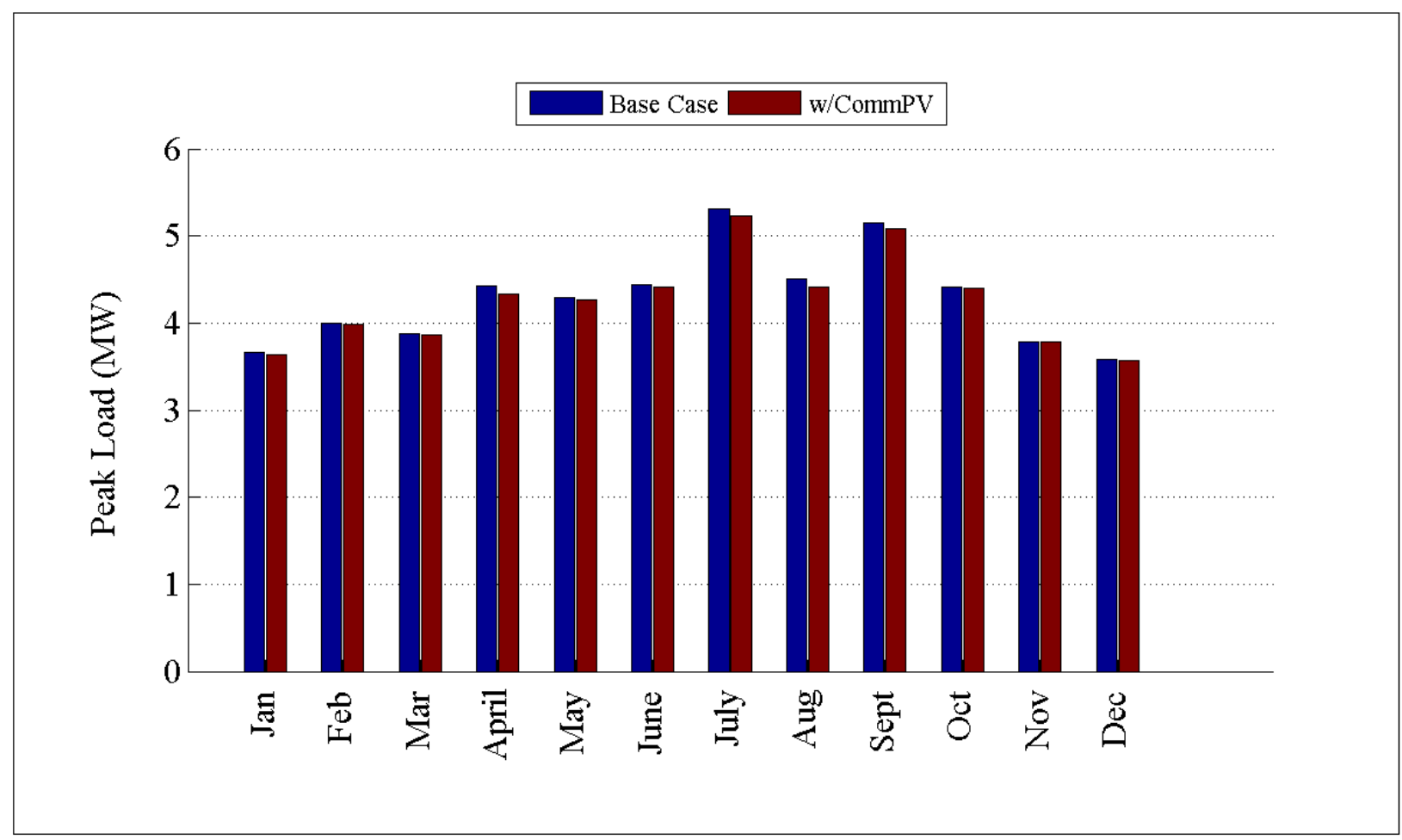

Figure 3.6: Comparison of peak load by month for GC-12.47-1_R1

Reduction of peak load is not a primary benefit of commercial PV installations; however, there is the potential for some reduction in peak load. Figure 3.6 shows a comparison of peak load for months under the simulation. Despite not being a primary benefit of PV, the feeder peak load was reduced for all months except for the month of November. 


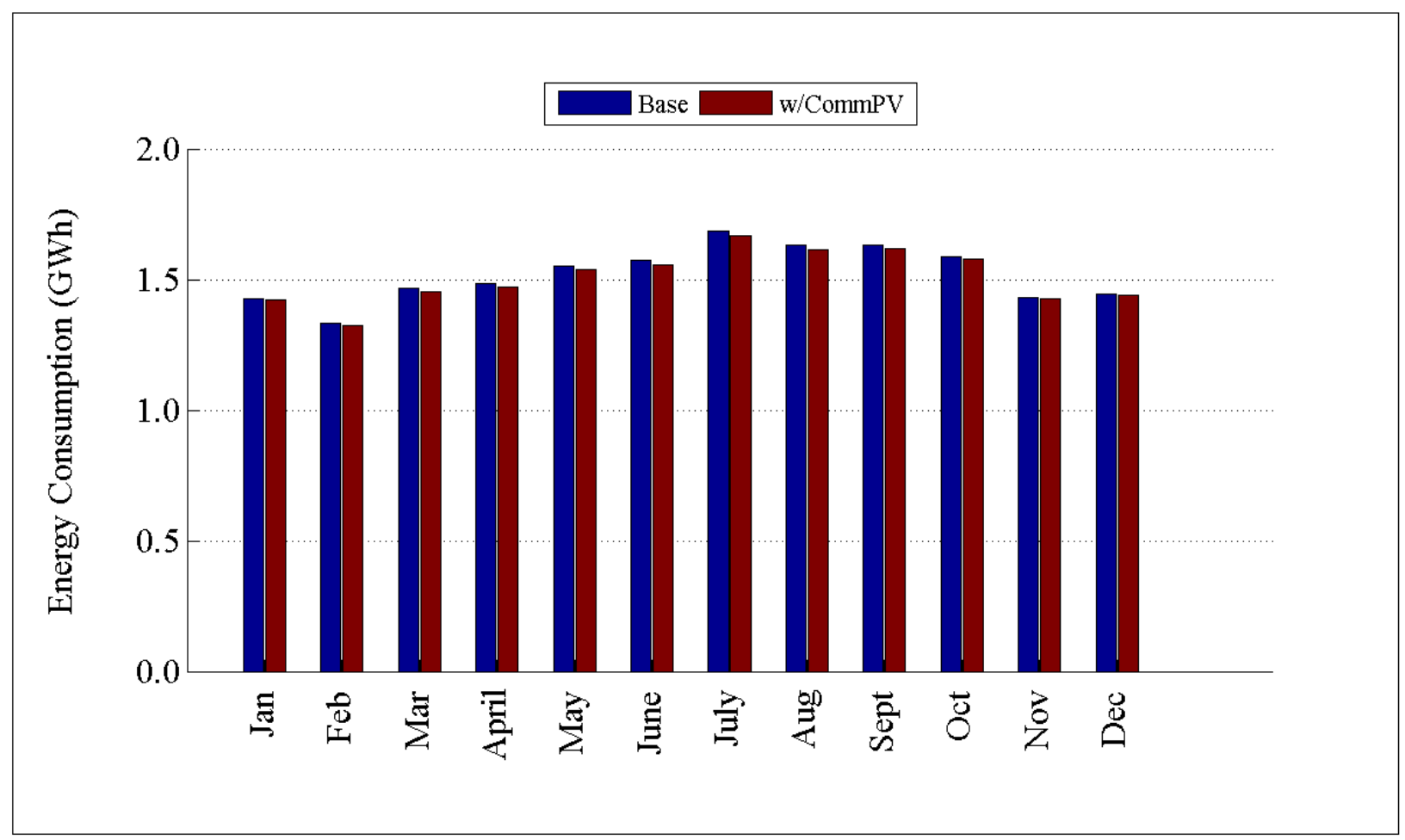

Figure 3.7: Comparison of energy consumption by month for GC-12.47-1_R1

As discussed in previous sections, reduced energy consumption is the primary benefit of commercial PV units. The reduction in energy consumption can be seen in Figure 3.7 for feeder GC-12.47-1_R1. The figure shows that energy consumption was reduced for all the months and that the maximum energy reduction appears to occur in the months when solar availability is high, e.g. July and August. 


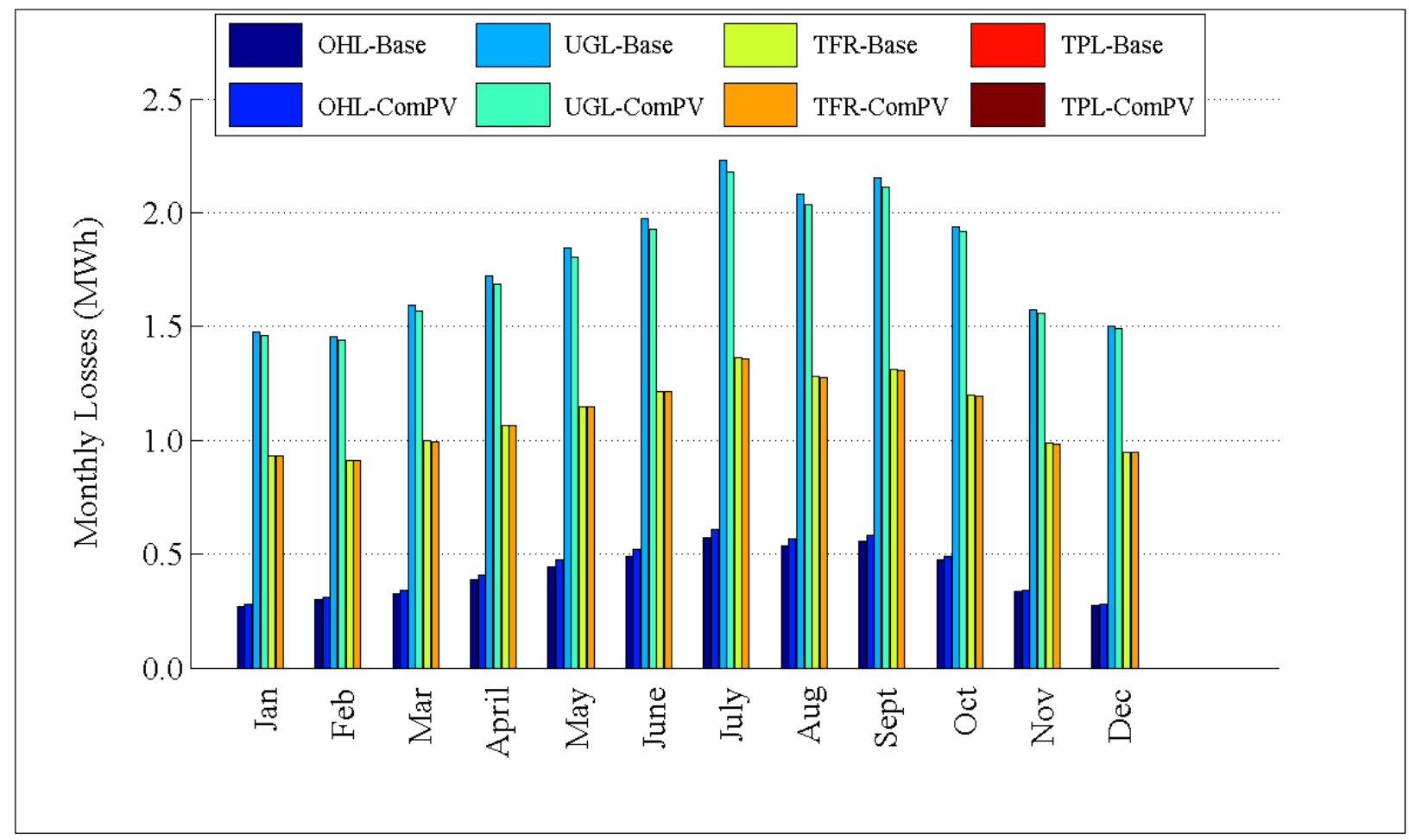

Figure 3.8: Comparison of losses by month for GC-12.47-1_R1

As discussed in the residential PV installation case, the reduction of distribution system losses is a benefits of PV installation. Figure 3.8 shows a comparison of monthly losses plots 'Base' and 'ComPV' for 4 different loss types: losses in overhead lines 'OHL', underground lines 'UGL', transformers 'TFR', and triplex (secondary) lines 'TPL'. It can be seen in the figure that the majority of losses for feeder GC-12.47-1_R1 occur in the underground lines and the major loss reduction occurs for that component when commercial PV units are added to feeder. However, the overhead line losses increase when commercial PV is installed on the feeder. This can be explained by the fact that the commercial PV units were of fixed array size and not sized appropriately based on the demand of the end-use load. This sizing increased the potential for the excessive amounts of reverse current flow in the overhead lines, causing the losses to increase. Therefore, appropriate sizing of PV is important to achieve a reduction in losses for every component of the distribution system.

Figure 3.9 shows the monthly PV output for GC-12.47-1_R1 feeder. As expected, the PV output is higher for summer months when compared to winter months. 


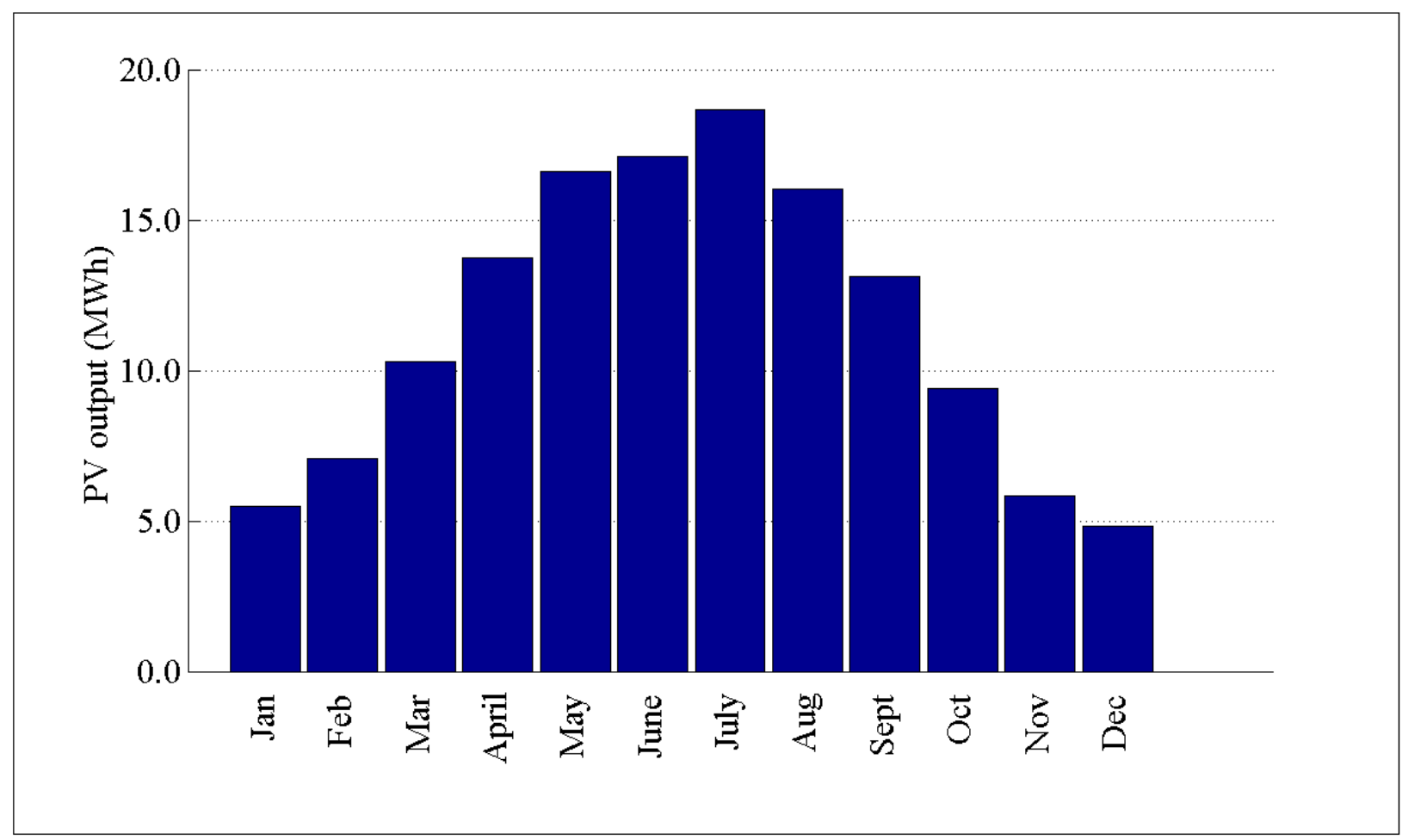

Figure 3.9: PV output by month for GC-12.47-1_R1

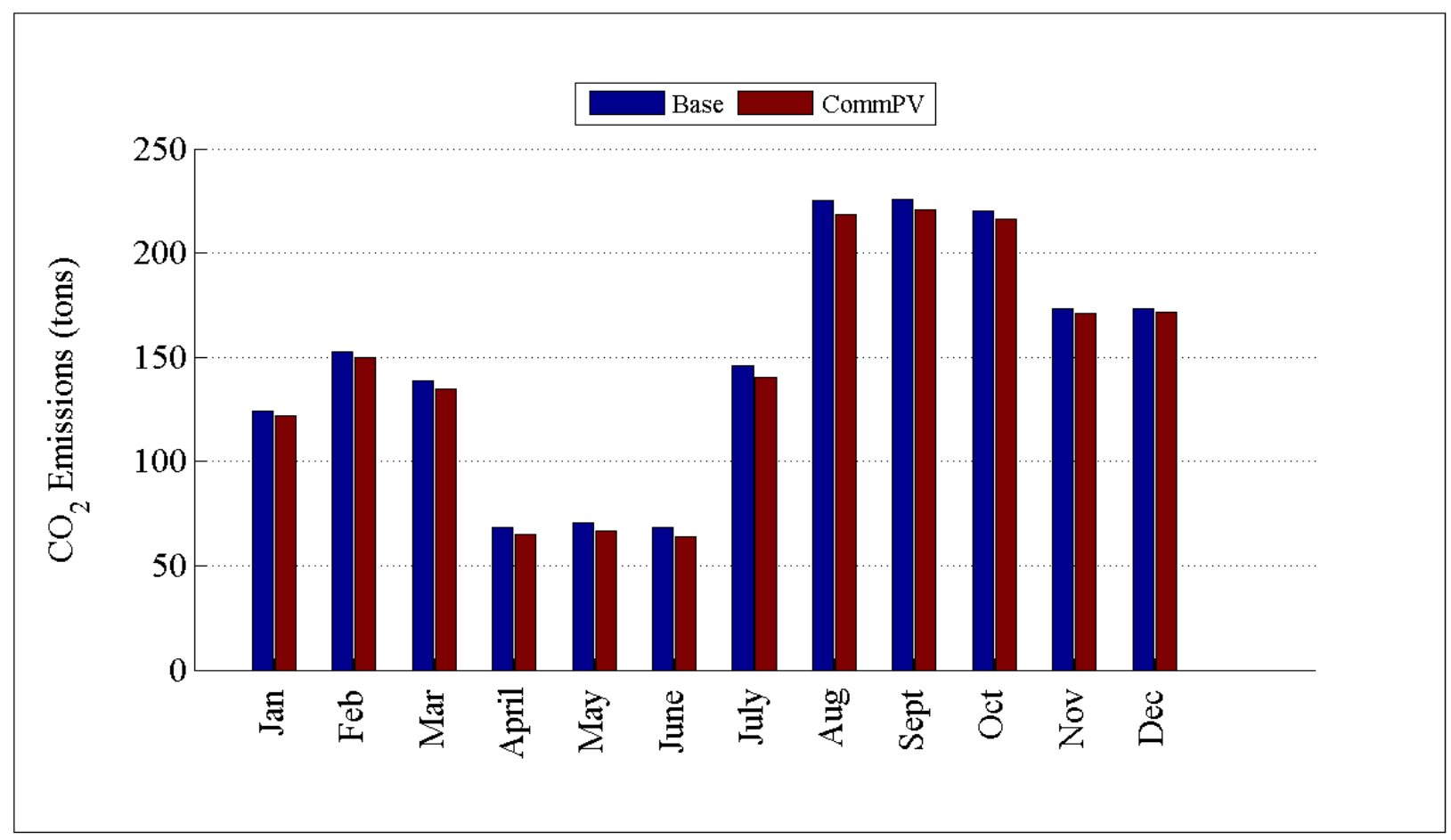

Figure 3.10: Comparison of $\mathrm{CO}_{2}$ emissions by month for GC-12.47-R1 
Reduction in energy consumption leads to a reduction in carbon dioxide emissions, as discussed in previous sections. Figure 3.10 shows that carbon dioxide emissions were reduced for all months for GC-12.47-1_R1.

\subsection{Combined PV}

There were 21 prototypical feeders out of a potential 28 simulated in this category; any feeder with purely residential or purely commercial loads was not simulated. These simulations focused on the analysis when both residential PV units $(\sim 3 \mathrm{~kW}-5 \mathrm{~kW})$ and commercial PV units $(\sim 100 \mathrm{~kW})$ were deployed on the distribution feeders. This analysis is particularly interesting because some of the issues caused by the addition of PV can be solved by adding different sized PV units. For combined PV deployments, there are 5 plots that will be displayed for each feeder: peak monthly demand, monthly energy consumption, monthly losses, monthly PV output and monthly $\mathrm{CO}_{2}$ emissions.

\subsubsection{Example Feeder R5-35.00-1}

Figure 3.11 through Figure 3.15 show the plots that are generated for feeder R5-35.00-1. Region 5 represents the southeast part of the United States, which has a hot and humid climate. Feeder R5-35.00-1 is comprised of mostly family residences with a moderate number of commercial end-use loads.

Figure 3.11 shows the monthly peak load for the R5-35.00-1 feeder. It can be seen from the plot that the peak monthly demand decreases for all the months. It should be noted that the peak load reduction is dependent on the feeder characteristics, climate, PV unit distribution, and load composition. Different feeders with different load compositions, even if they are in the same region, may not experience the same peak reduction for each of the months. 


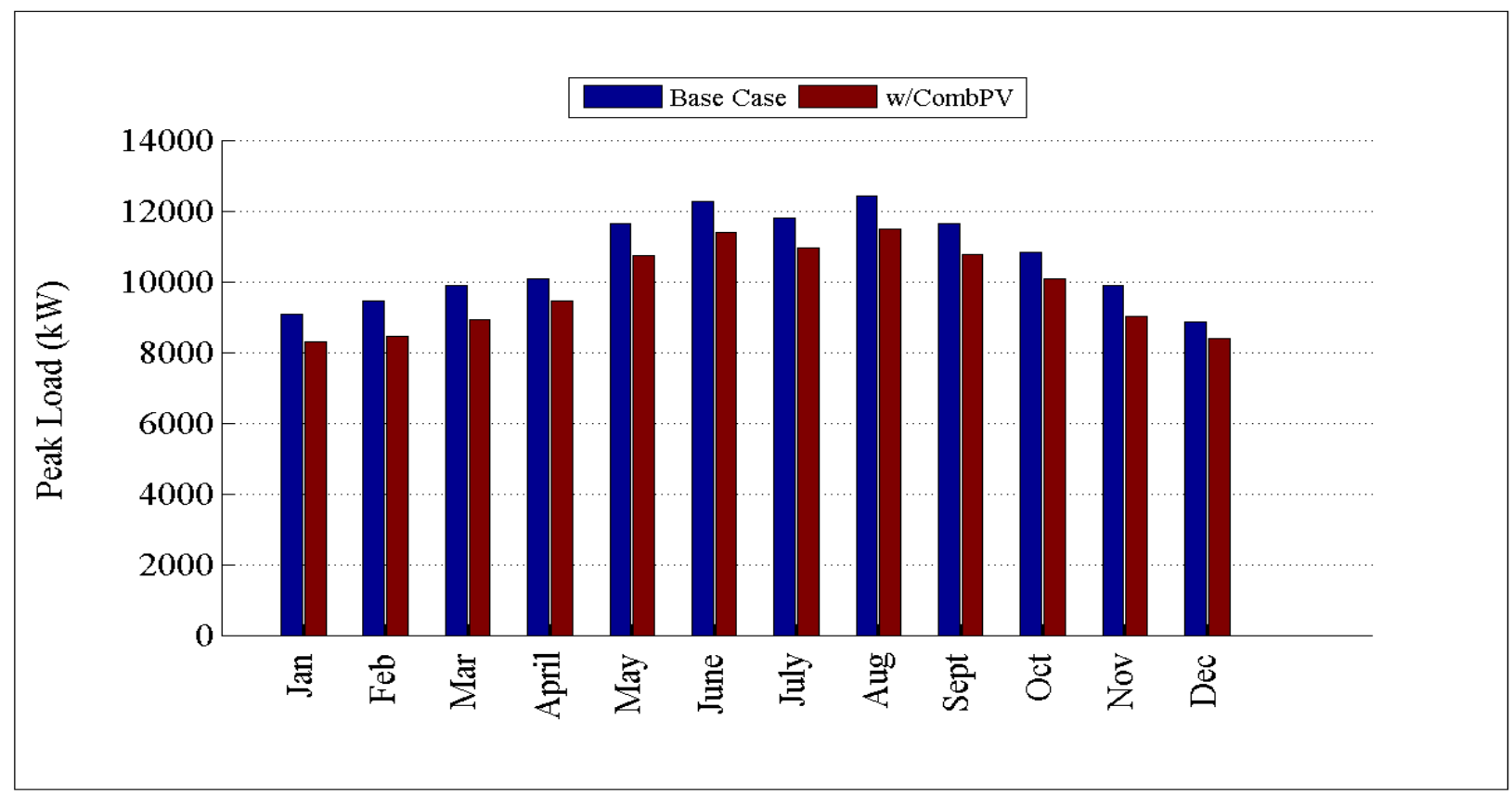

Figure 3.11: Comparison of peak load by month for R5-35.00-1

Figure 3.12 shows the monthly comparison of energy consumption for feeder R5-35.00-1. As noted in previous sections, a reduction in the energy consumption is the primary benefit of combined PV installations. The addition of combined PV generation to the feeder reduces the overall energy consumption for every month of the year. As expected, the greatest reduction is once again during the summer months when the maximum solar energy is available. 


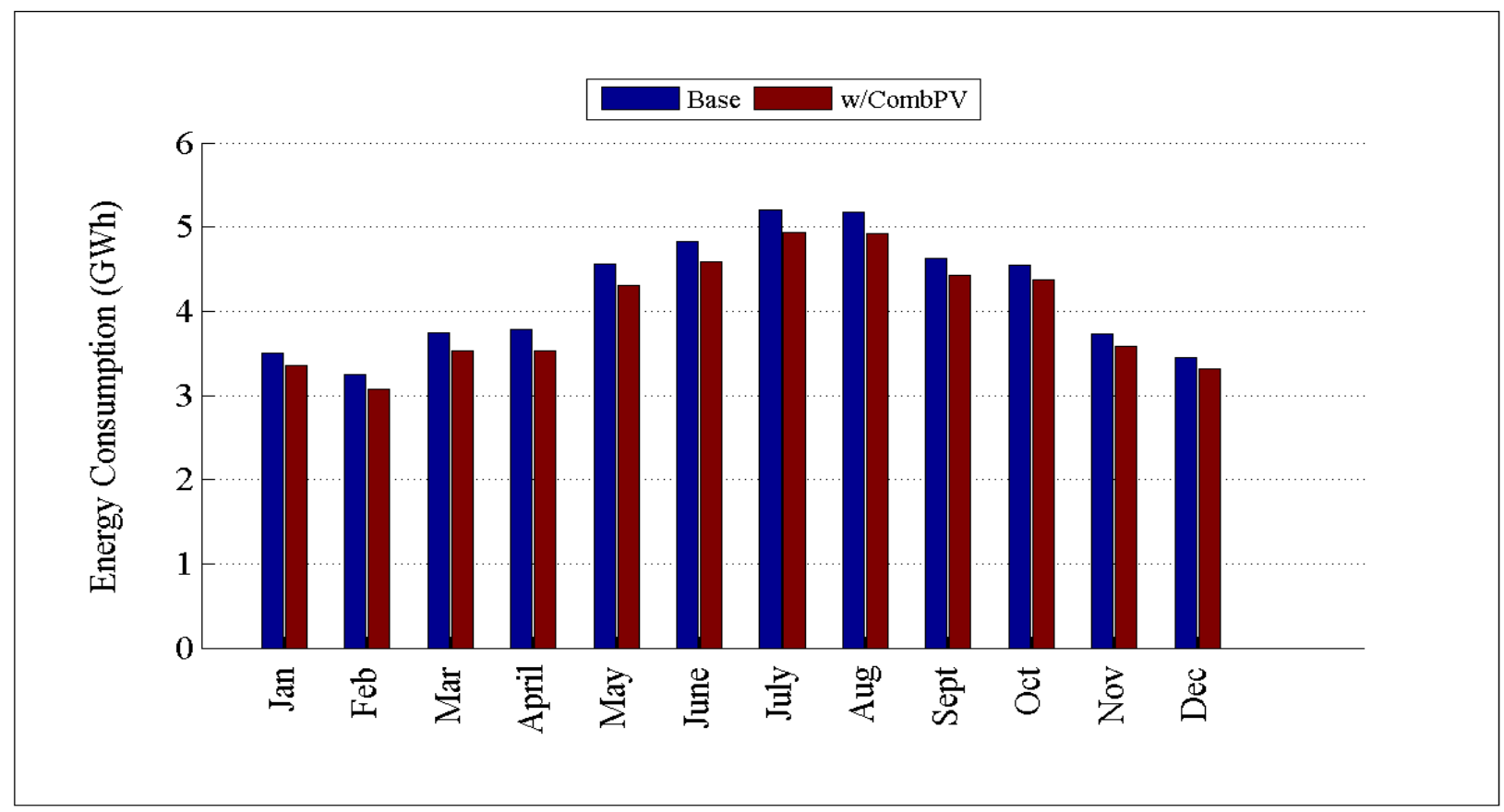

Figure 3.12: Comparison of energy consumption by month for R5-35.00-1

As seen in previous implementations, reduction in losses is another benefit of combined PV deployments. As shown in Figure 3.13, the largest losses for feeder R5-35.00-1 come from the distribution transformers. It can be observed that the real power losses were reduced for almost all components of the distribution feeder, except for a slight increase on the overhead lines. This slight increase can be attributed to the same reasons described in previous sections. Specifically, the commercial PV arrays were of fixed size and not sized for optimal interaction with the local end-use load level. This increased the potential for reverse current flow in the overhead lines, causing the losses to increase. Once again, for a specific deployment of PV it would be necessary to appropriately size the units for optimal operation, the distributions of seizes used here are only appropriate for regional level analysis. 


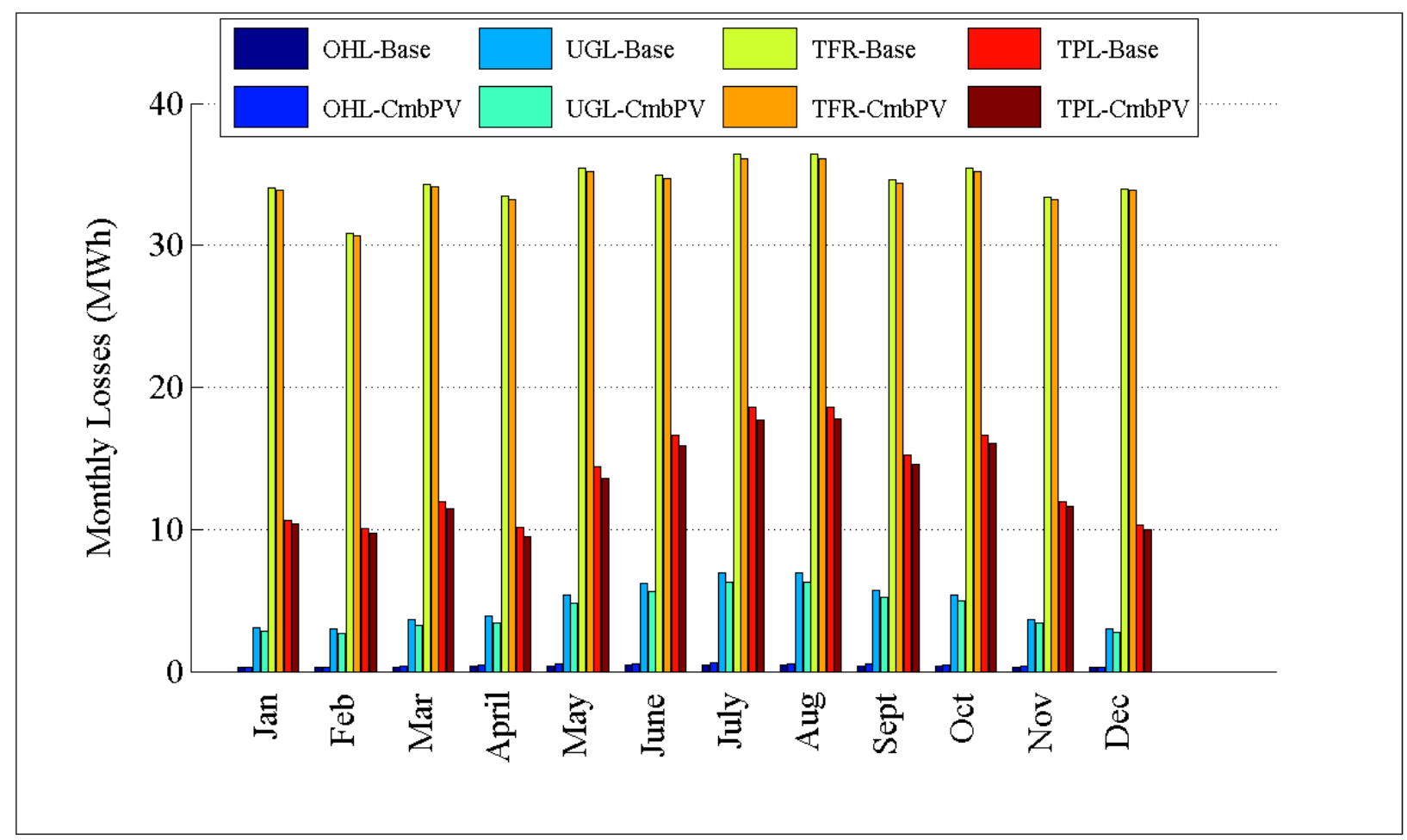

Figure 3.13: Comparison of losses by month for R5-35.00-1 


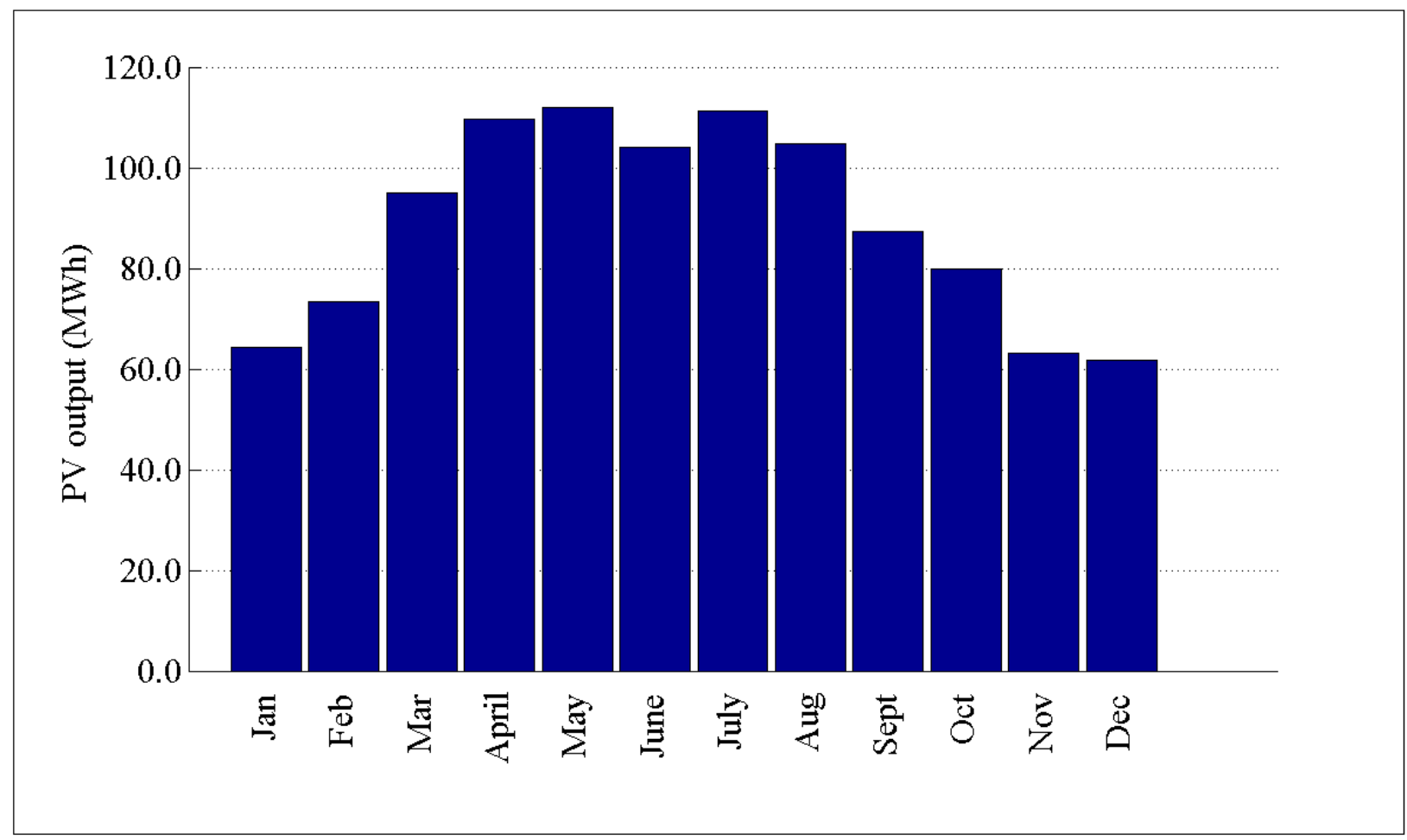

Figure 3.14: Comparison of PV output by month for R5-35.00-1

Figure 3.14 shows the combined monthly PV output, for both residential and commercial units, for feeder R5-35.00-1. From the figure it can once again be seen that the summer months yield the highest solar output, which directly reflects the high solar availability during spring and summer months.

Figure 3.15 shows the reduction on carbon dioxide emissions for feeder R5-35.00-1. Once again, it can be seen that reductions in energy consumption leads to reductions in carbon dioxide emissions for all the months. 


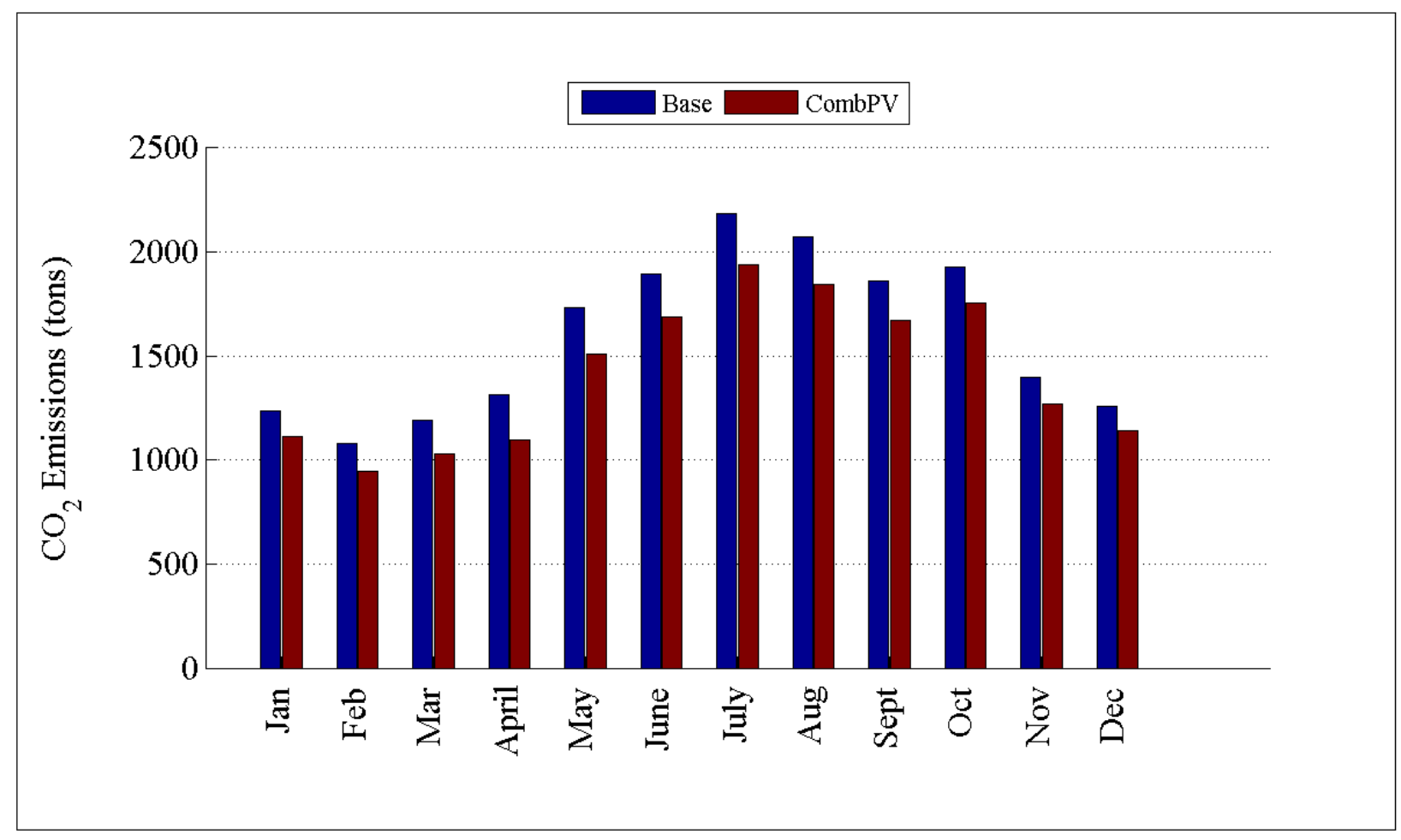

Figure 3.15: Comparison of $\mathrm{CO}_{2}$ emissions by month for R5-35.00-1

\subsection{Commercial WTG}

Commercial wind generators were only simulated for the GC feeders, one for each of the five climate regions. The main intent for the analysis was to study the effect of the addition of a single large wind turbine, $1.8 \mathrm{MW}$, on the distribution feeder. For commercial WTG, there are 5 plots that will be displayed for each feeder: peak monthly demand, monthly energy consumption, monthly losses, monthly PV output, and monthly $\mathrm{CO}_{2}$ emissions.

\subsubsection{Example Feeder GC-12.47-1_R2}

Figure 3.16 through Figure 3.20 show the plots that are generated for feeder GC-12.47-1_R2 when it is operated with a single large WTG. Climate region 2 represents the north central and north eastern part of the United States, which generally has a cold climate, but does have considerable wind availability. A model of a 1.8 MW WTG was added to the feeder and the impact of its operation was compared to the base case.

Figure 3.16 shows the effect of adding a commercial WTG on feeder GC-12.47-1_R2. It can be observed that the peak load is reduced for nearly all the months. As with the solar PV cases, the peak wind generation may not necessarily coincide with the peak feeder load. Such a case occurs for the months of November and December, where no significant peak change was observed. During these months, there was little to no wind during the peak load periods. 


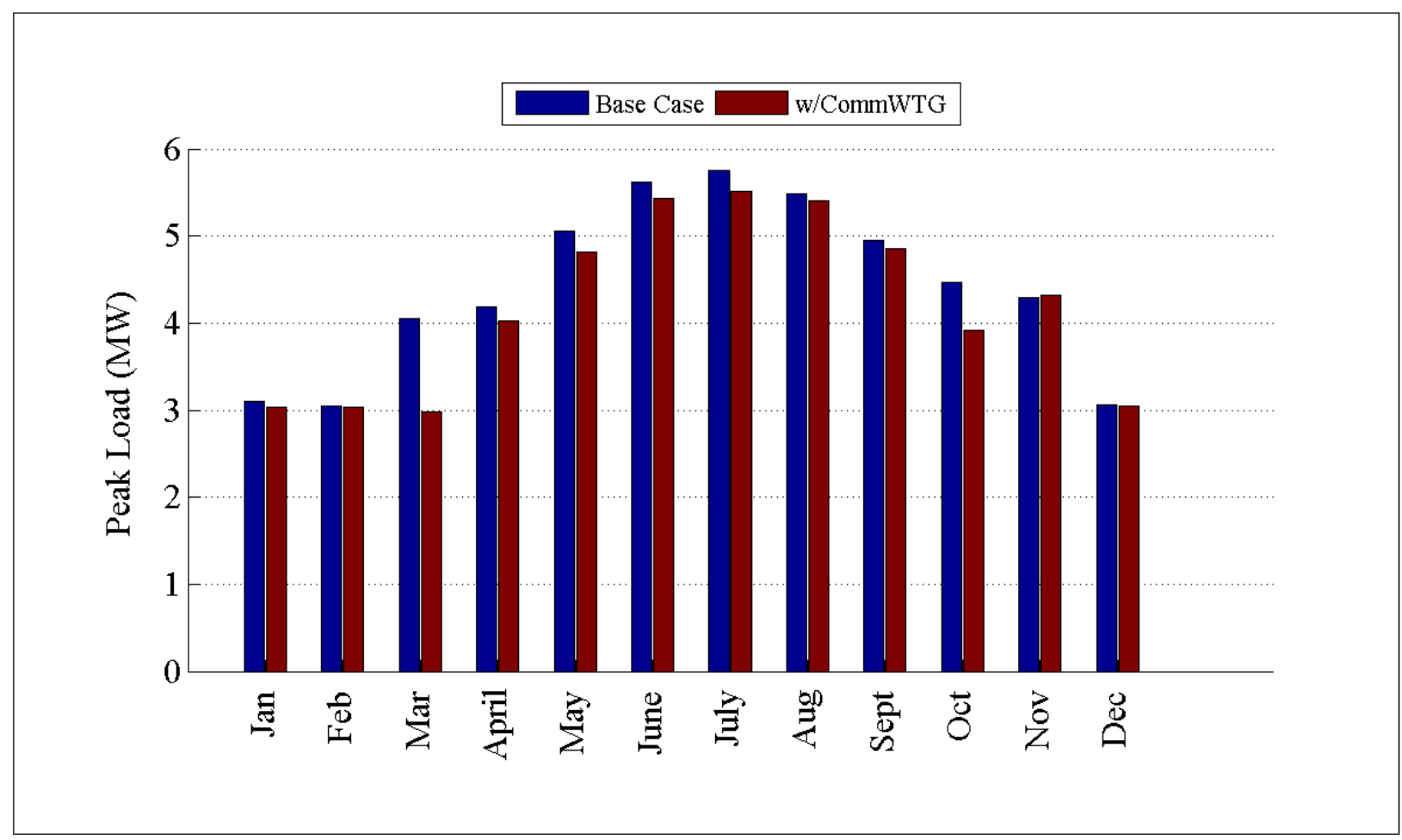

Figure 3.16: Comparison of peak load by month for GC-12.47-1_R2

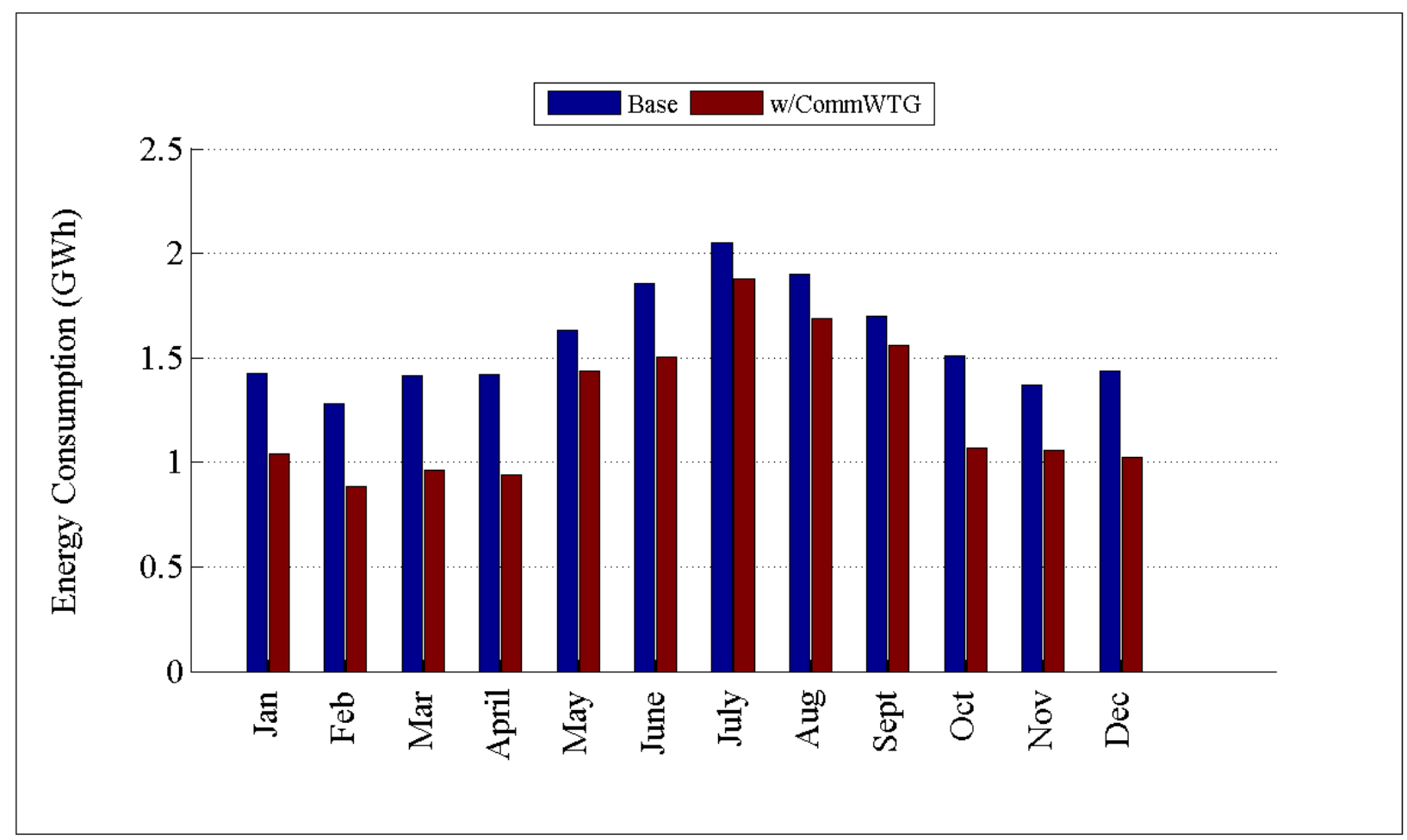

Figure 3.17: Comparison of energy consumption by month for GC-12.47-1_R2 
Figure 3.17 shows the reduction in monthly energy consumption for feeder GC-12.47-1_R2. Similar to the PV technologies described in previous sections, the addition of a large WTG considerably reduces energy consumption. From Figure 3.19, it can be seen that the wind production in the months of March and April is very high, which leads to a large reduction in the energy consumption from the perspective of the feeder.

The reduction of losses is another benefit on integrating a large WTG. Figure 3.18 shows the monthly losses associated with various components on feeder GC-12.47-1_R2. There are 4 different loss types: losses in overhead lines 'OHL', underground lines 'UGL', transformers 'TFR', and triplex lines 'TPL' for base case and commercial WTG 'CWTG". As seen from Figure 3.18, the largest reduction in losses occurred on underground cables. However, nearly all of the components show a sizeable reduction in losses with integration of the wind turbine generator.

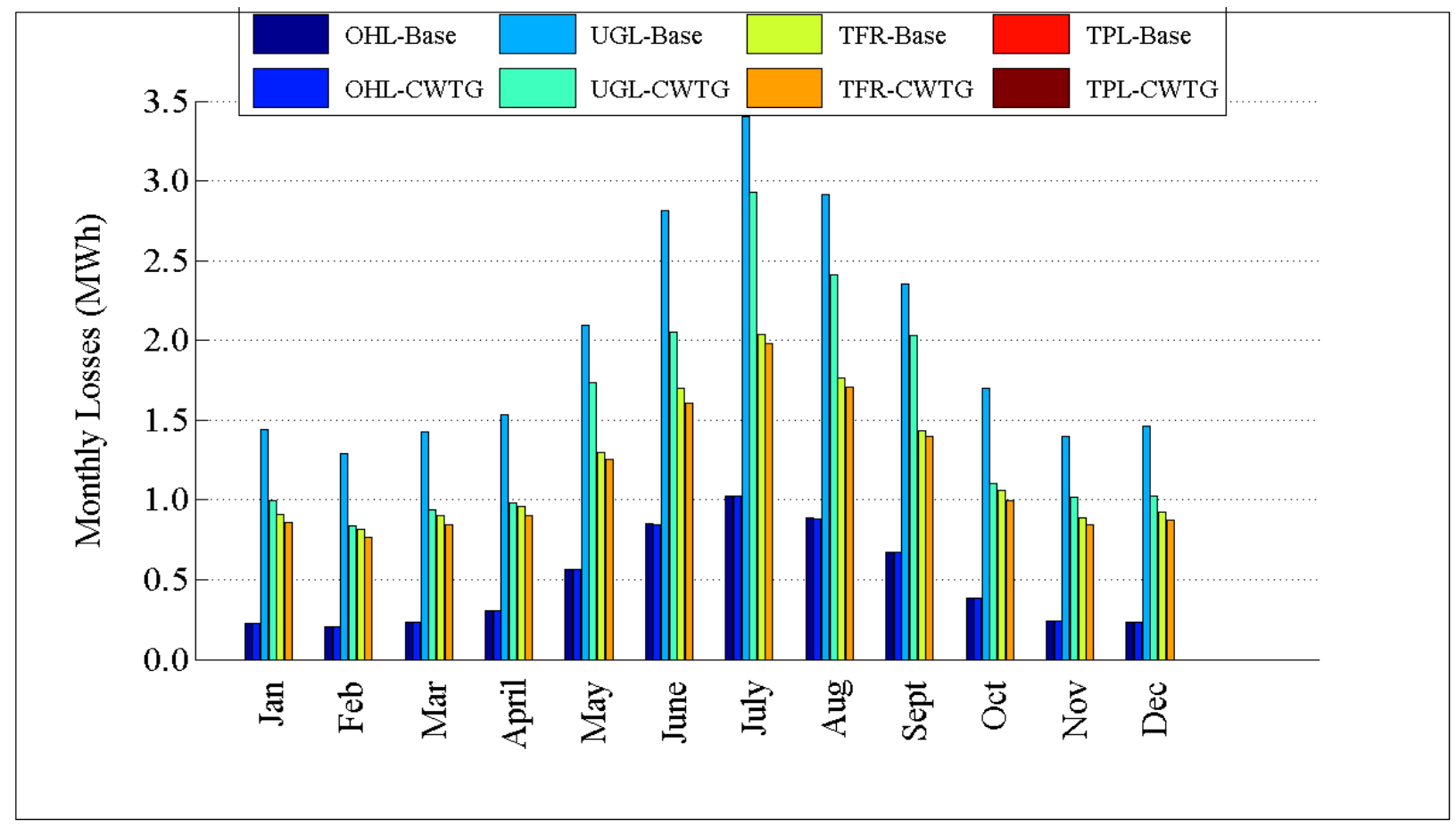

Figure 3.18: Comparison of losses by month for GC-12.47-1_R2 


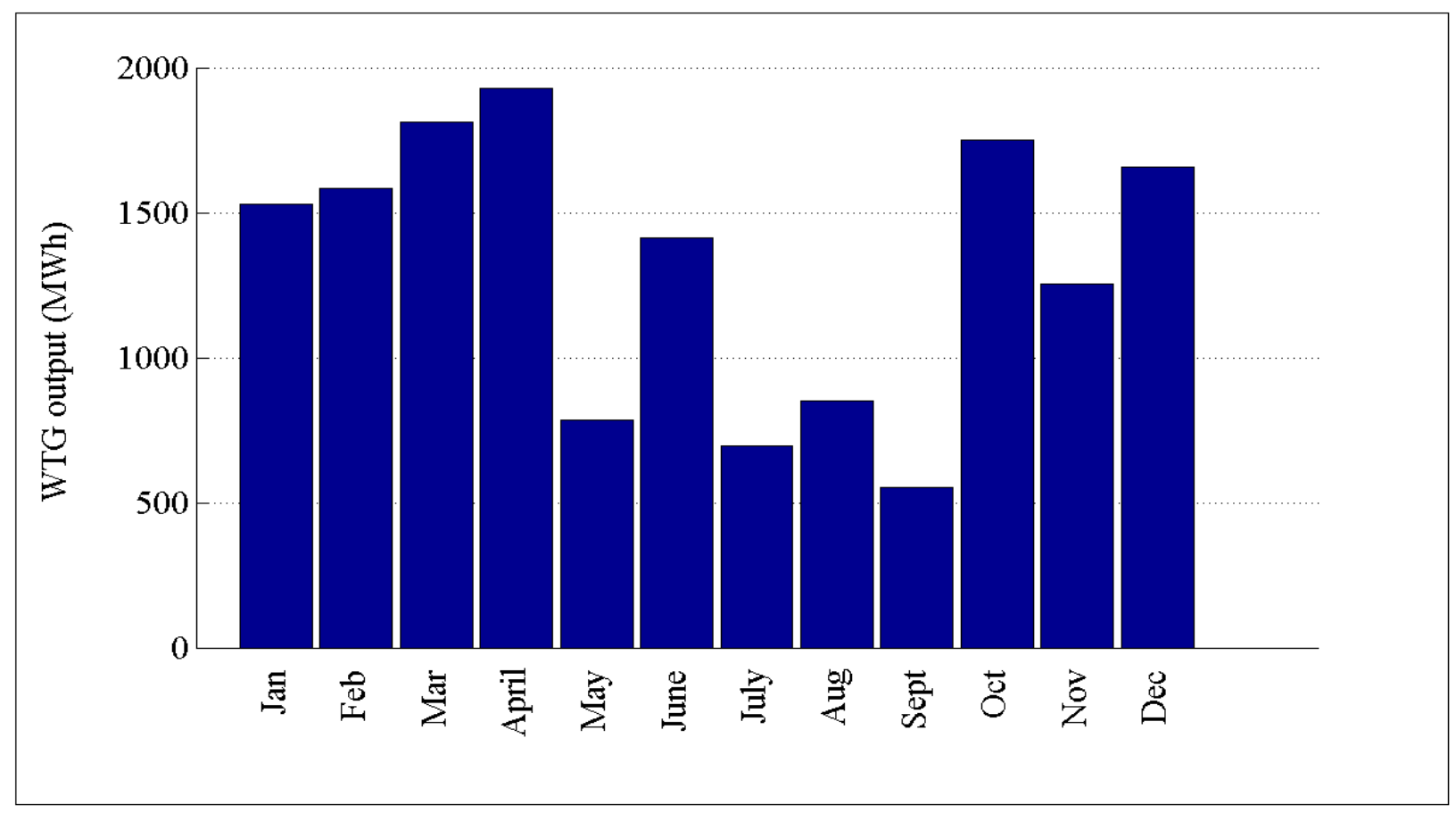

Figure 3.19: Comparison of WTG output by month for GC-12.47-1_R2

The monthly wind output for feeder GC-12.47-1_R2 is given in Figure 3.19. In contrast to the output of solar PV, the WTG tends to have higher energy outputs in the winter and shoulder months. Similar to solar PV, this generalization is only appropriate for regionalized values, a specific WTG installation may have a seasonal output that is much different than the regional average.

Similar to PV technologies, reduction in energy consumption leads to reduction in the carbon dioxide emissions, as shown in Figure 3.20. In general, the larger the reduction in energy consumption, the larger the reduction in $\mathrm{CO}_{2}$ emitted. The reduction in emissions will be heavily dependent on the generation mix within the region. 


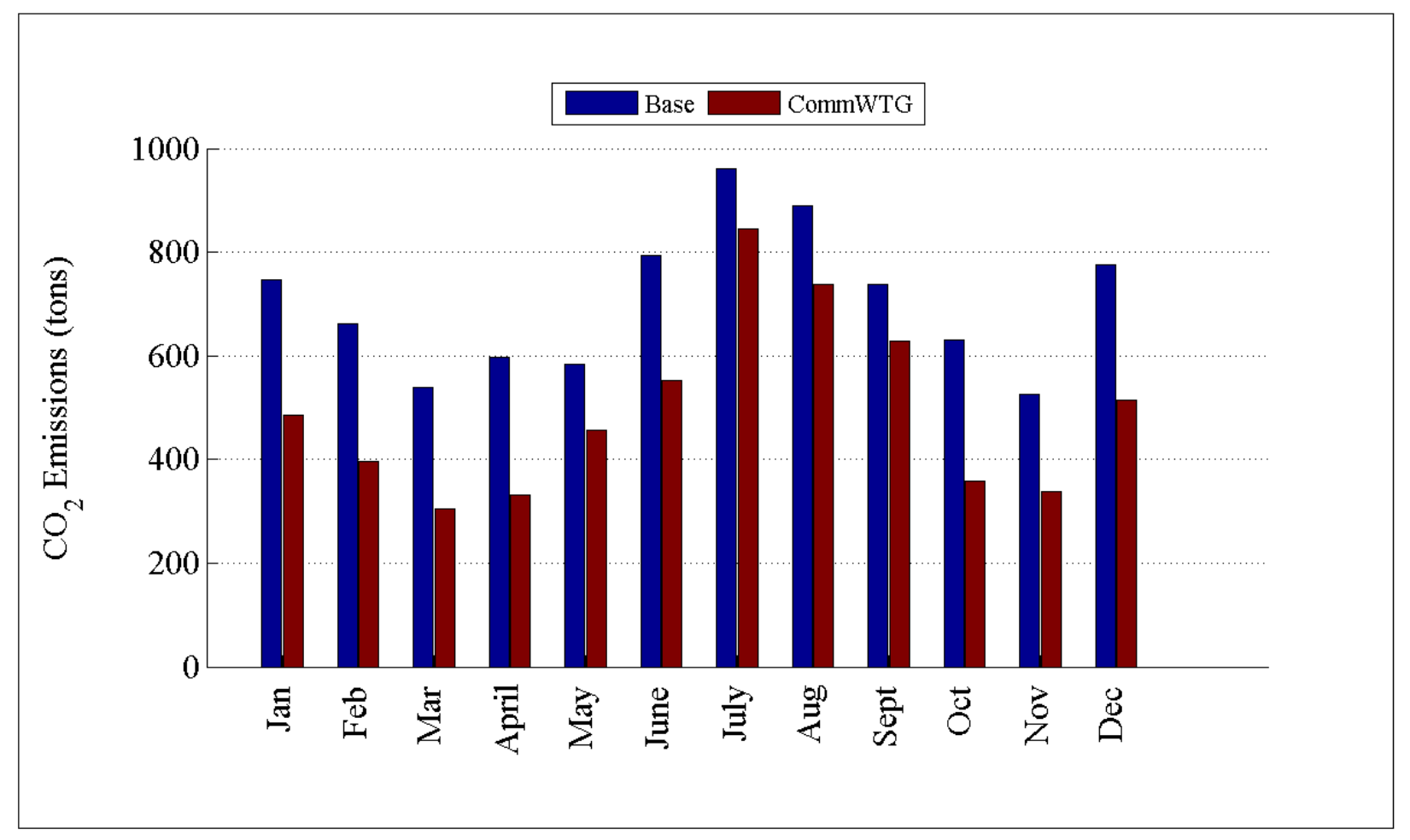

Figure 3.20: Comparison of $\mathrm{CO}_{2}$ by month for GC-12.47-1_R2 


\section{SGIG Impact Metric Values}

Specific metric impact values are filled in, by feeder, for the metrics identified in Sections 2.1.1.1, 2.1.2.1, 2.1.3.1 and 2.2.1. The raw metric values, by technology and region, are in Appendix E. Please note that some of the values reported in the metrics table are zero due to very small difference from the base case. These values were rounded off to the next largest value.

\subsection{Residential PV Impact Metrics}


Table 4.1: Residential PV impact metrics for region 1

\begin{tabular}{|c|c|c|c|c|c|c|c|}
\hline Index & $\Delta$ Metric & Units & 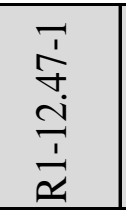 & 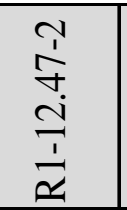 & 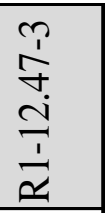 & 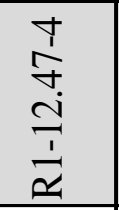 & $\begin{array}{l}7 \\
\delta \\
\delta \\
\\
\stackrel{1}{1} \\
\end{array}$ \\
\hline 1 & $\begin{array}{l}\text { Hourly Customer } \\
\text { Electricity Usage }\end{array}$ & $\mathrm{kWh}$ & -27.25 & -11.46 & -7.16 & -25.27 & -8.68 \\
\hline 2 & $\begin{array}{l}\text { Monthly Customer } \\
\text { Electricity Usage }\end{array}$ & MWh & -19.90 & -8.37 & -5.23 & -18.45 & -6.33 \\
\hline \multirow{12}{*}{3} & Peak Generation & $\mathrm{kW}$ & 69.40 & -12.81 & -84.65 & -134.18 & 42.60 \\
\hline & Nuclear & $\%$ & -0.12 & -0.72 & -0.54 & 0.65 & -0.19 \\
\hline & Solar & $\%$ & 0.00 & -0.04 & -0.04 & 0.04 & 0.00 \\
\hline & Bio & $\%$ & -0.01 & 0.04 & 0.05 & -0.05 & -0.01 \\
\hline & Wind & $\%$ & -0.05 & -0.56 & -0.50 & 0.54 & -0.07 \\
\hline & Coal & $\%$ & -0.03 & 1.45 & 1.52 & -1.48 & -0.05 \\
\hline & Hydroelectric & $\%$ & -0.41 & -10.89 & -10.44 & 10.77 & -0.67 \\
\hline & Natural Gas & $\%$ & -0.46 & 9.22 & 10.10 & -9.63 & -0.75 \\
\hline & Geothermal & $\%$ & -0.03 & 0.23 & -1.64 & -2.01 & -0.05 \\
\hline & Petroleum & $\%$ & -0.18 & 0.34 & -0.35 & -0.38 & -0.01 \\
\hline & Distributed Solar PV & $\%$ & 1.30 & 0.93 & 1.84 & 1.55 & 1.81 \\
\hline & Distributed Wind & $\%$ & 0.00 & 0.00 & 0.00 & 0.00 & 0.00 \\
\hline 4 & Peak Load & MW & -13.31 & -46.06 & -79.09 & -106.55 & -0.10 \\
\hline 7 & \begin{tabular}{|l|} 
Annual Electricity \\
Production
\end{tabular} & MWh & -243.46 & -102.40 & -63.54 & -226.93 & -77.84 \\
\hline 12 & $\mathrm{CO} 2$ Emissions & Tons & -62.10 & -27.43 & -21.48 & -68.92 & -26.49 \\
\hline \multirow{3}{*}{13} & SOx Emis sions & Tons & 0.00 & 0.00 & 0.00 & 0.00 & 0.00 \\
\hline & NOx Emis sions & Tons & 0.00 & 0.00 & 0.00 & -0.01 & 0.00 \\
\hline & PM-10 Emis sions & Tons & -0.01 & 0.00 & 0.00 & -0.01 & 0.00 \\
\hline \multirow{2}{*}{21} & Feeder Real Load & MW & -27.79 & -11.69 & -7.25 & -25.91 & -8.89 \\
\hline & Feeder Reactive Load & MVAR & -0.94 & -0.22 & -0.04 & -0.34 & -0.24 \\
\hline 29 & Distribution Losses & $\%$ & 0.01 & 0.01 & -0.01 & -0.02 & -0.01 \\
\hline 30 & Distribution Power Factor & $\mathrm{pf}$ & 0.00 & 0.00 & 0.00 & 0.00 & 0.00 \\
\hline 39 & $\mathrm{CO} 2$ Emissions & Tons & -63.57 & -28.18 & -21.64 & -70.05 & -26.94 \\
\hline \multirow{3}{*}{40} & SOx & Tons & 0.00 & 0.00 & 0.00 & 0.00 & 0.00 \\
\hline & NOx & Tons & 0.00 & 0.00 & 0.00 & -0.01 & 0.00 \\
\hline & PM-10 & Tons & -0.01 & 0.00 & 0.00 & -0.01 & 0.00 \\
\hline
\end{tabular}


Table 4.2: Residential PV impact metrics for region 2

\begin{tabular}{|c|c|c|c|c|c|c|c|}
\hline Index & $\Delta$ Metric & Units & 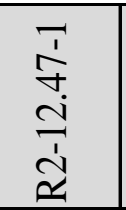 & 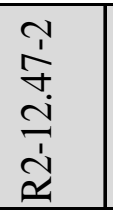 & 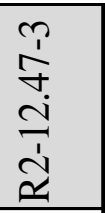 & 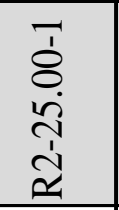 & 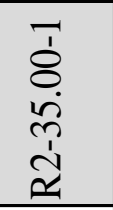 \\
\hline 1 & $\begin{array}{l}\text { Hourly Customer } \\
\text { Electricity Usage }\end{array}$ & $\mathrm{kWh}$ & -8.97 & -8.49 & -3.90 & -21.06 & -16.02 \\
\hline 2 & $\begin{array}{l}\text { Monthly Customer } \\
\text { Electricity Usage }\end{array}$ & MWh & -6.54 & -6.20 & -2.85 & -15.38 & -11.69 \\
\hline \multirow{12}{*}{3} & Peak Generation & $\mathrm{kW}$ & -192.59 & 191.26 & -90.30 & 30.84 & -293.43 \\
\hline & Nuclear & $\%$ & 0.34 & -0.49 & -1.54 & -0.09 & 1.62 \\
\hline & Solar & $\%$ & 0.00 & 0.00 & 0.00 & 0.00 & 0.00 \\
\hline & Bio & $\%$ & 0.01 & -0.02 & -0.02 & 0.00 & 0.02 \\
\hline & Wind & $\%$ & 0.02 & -0.03 & -0.29 & 0.00 & 0.29 \\
\hline & Coal & $\%$ & 0.60 & -0.88 & 1.79 & -0.16 & -1.64 \\
\hline & Hydroelectric & $\%$ & -1.24 & -0.14 & -1.61 & -0.03 & 1.52 \\
\hline & Natural Gas & $\%$ & 0.21 & -0.30 & 1.91 & -0.06 & -1.86 \\
\hline & Geothermal & $\%$ & -0.07 & 0.00 & -0.07 & 0.00 & -0.07 \\
\hline & Petroleum & $\%$ & -0.43 & 1.36 & -0.37 & -0.16 & -0.43 \\
\hline & Distributed Solar PV & $\%$ & 0.56 & 0.50 & 0.18 & 0.50 & 0.54 \\
\hline & Distributed Wind & $\%$ & 0.00 & 0.00 & 0.00 & 0.00 & 0.00 \\
\hline \multirow[b]{2}{*}{4} & Peak Load & MW & -114.54 & 80.27 & -63.80 & -26.60 & -292.30 \\
\hline & \begin{tabular}{|l|} 
Annual Electricity \\
Production
\end{tabular} & MWh & -79.13 & -75.59 & -34.80 & -186.55 & -141.80 \\
\hline 12 & $\mathrm{CO} 2$ Emissions & Tons & -58.98 & -70.27 & -32.39 & -156.74 & -96.78 \\
\hline \multirow{3}{*}{13} & SOx Emis sions & Tons & -0.02 & -0.03 & -0.01 & -0.07 & -0.04 \\
\hline & NOx Emissions & Tons & -0.02 & -0.02 & -0.01 & -0.04 & -0.02 \\
\hline & PM-10 Emis sions & Tons & -0.01 & -0.01 & 0.00 & -0.02 & -0.01 \\
\hline \multirow{2}{*}{21} & Feeder Real Load & MW & -9.03 & -8.63 & -3.97 & -21.30 & -16.19 \\
\hline & Feeder Reactive Load & MVAR & -0.10 & -0.27 & -0.07 & -0.21 & -0.33 \\
\hline 29 & Distribution Losses & $\%$ & 0.00 & 0.00 & 0.00 & 0.00 & 0.00 \\
\hline 30 & Distribution Power Factor & $\mathrm{pf}$ & 0.00 & 0.00 & 0.00 & 0.00 & 0.00 \\
\hline 39 & $\mathrm{CO} 2$ Emissions & Tons & -59.55 & -71.50 & -33.06 & -158.37 & -97.72 \\
\hline \multirow{3}{*}{40} & SOx & Tons & -0.02 & -0.03 & -0.01 & -0.07 & -0.04 \\
\hline & NOx & Tons & -0.02 & -0.02 & -0.01 & -0.04 & -0.02 \\
\hline & PM-10 & Tons & -0.01 & -0.01 & 0.00 & -0.02 & -0.01 \\
\hline
\end{tabular}


Table 4.3: Residential PV impact metrics for region 3

\begin{tabular}{|c|c|c|c|c|}
\hline Index & $\Delta$ Metric & Units & 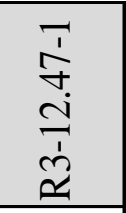 & 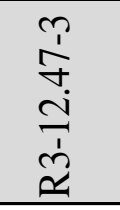 \\
\hline 1 & $\begin{array}{l}\text { Hourly Customer } \\
\text { Electricity Usage }\end{array}$ & $\mathrm{kWh}$ & -64.88 & -48.69 \\
\hline 2 & \begin{tabular}{|l} 
Monthly Customer \\
Electricity Usage
\end{tabular} & MWh & -47.36 & -35.55 \\
\hline \multirow{12}{*}{3} & Peak Generation & $\mathrm{kW}$ & -330.54 & -78.90 \\
\hline & Nuclear & $\%$ & 0.06 & -0.05 \\
\hline & Solar & $\%$ & 0.00 & 0.00 \\
\hline & Bio & $\%$ & 0.00 & 0.00 \\
\hline & Wind & $\%$ & 0.02 & -0.01 \\
\hline & Coal & $\%$ & 0.26 & -0.20 \\
\hline & Hydroelectric & $\%$ & -1.25 & -0.03 \\
\hline & Natural Gas & $\%$ & 0.24 & -0.18 \\
\hline & Geothermal & $\%$ & -1.40 & -1.16 \\
\hline & \begin{tabular}{|l|} 
Petroleum \\
\end{tabular} & $\%$ & -0.25 & -0.25 \\
\hline & Dis tributed Solar PV & $\%$ & 2.32 & 1.87 \\
\hline & Distributed Wind & $\%$ & 0.00 & 0.00 \\
\hline \multirow[b]{2}{*}{4} & Peak Load & MW & -273.28 & -118.28 \\
\hline & $\begin{array}{l}\text { Annual Electricity } \\
\text { Production }\end{array}$ & MWh & -577.14 & -434.71 \\
\hline 12 & $\mathrm{CO} 2$ Emis sions & Tons & -349.23 & -276.83 \\
\hline \multirow{3}{*}{13} & SOx Emis sions & Tons & -0.08 & -0.07 \\
\hline & NOx Emis sions & Tons & -0.06 & -0.05 \\
\hline & PM-10 Emis sions & Tons & -0.05 & -0.04 \\
\hline \multirow{2}{*}{21} & Feeder Real Load & MW & -65.88 & -49.62 \\
\hline & Feeder Reactive Load & MVAR & -1.49 & -0.91 \\
\hline 29 & Distribution Losses & $\%$ & 0.01 & 0.02 \\
\hline 30 & Distribution Power Factor & $\mathrm{pf}$ & 0.00 & 0.00 \\
\hline 39 & $\mathrm{CO} 2$ Emis sions & Tons & -354.37 & -281.26 \\
\hline \multirow{3}{*}{40} & SOx & Tons & -0.08 & -0.07 \\
\hline & NOx & Tons & -0.06 & -0.05 \\
\hline & PM-10 & Tons & -0.05 & -0.04 \\
\hline
\end{tabular}


Table 4.4: Residential PV impact metrics for region 4

\begin{tabular}{|c|c|c|c|c|c|}
\hline Index & $\Delta$ Metric & Units & 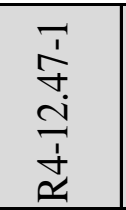 & 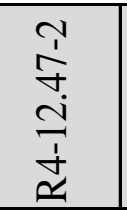 & 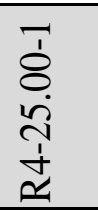 \\
\hline 1 & $\begin{array}{l}\text { Hourly Customer } \\
\text { Electricity Usage }\end{array}$ & $\mathrm{kWh}$ & -37.94 & -15.05 & -7.72 \\
\hline 2 & \begin{tabular}{|l|} 
Monthly Customer \\
Electricity Usage \\
\end{tabular} & MWh & -27.70 & -10.99 & -5.64 \\
\hline \multirow{12}{*}{3} & Peak Generation & $\mathrm{kW}$ & -190.61 & -29.47 & -53.15 \\
\hline & Nuclear & $\%$ & 0.08 & -1.96 & 0.38 \\
\hline & Solar & $\%$ & 0.00 & 0.00 & 0.00 \\
\hline & Bio & $\%$ & 0.00 & -0.03 & 0.00 \\
\hline & Wind & $\%$ & 0.00 & 0.00 & 0.01 \\
\hline & Coal & $\%$ & 0.20 & 0.32 & 0.90 \\
\hline & Hydroelectric & $\%$ & -2.20 & -2.16 & -3.09 \\
\hline & Natural Gas & $\%$ & -0.90 & 1.12 & -0.43 \\
\hline & Geothermal & $\%$ & 0.00 & 0.00 & 0.00 \\
\hline & Petroleum & $\%$ & -0.48 & -0.33 & -0.33 \\
\hline & Distributed Solar PV & $\%$ & 3.30 & 3.03 & 2.56 \\
\hline & Distributed Wind & $\%$ & 0.00 & 0.00 & 0.00 \\
\hline \multirow[b]{2}{*}{4} & Peak Load & MW & -174.48 & -58.26 & -38.77 \\
\hline & \begin{tabular}{|l|} 
Annual Electricity \\
Production
\end{tabular} & MWh & -335.59 & -132.65 & -68.08 \\
\hline 12 & $\mathrm{CO} 2$ Emissions & Tons & -323.05 & -133.23 & -68.59 \\
\hline \multirow{3}{*}{13} & SOx Emis sions & Tons & -0.15 & -0.06 & -0.03 \\
\hline & NOx Emis sions & Tons & -0.09 & -0.04 & -0.02 \\
\hline & PM-10 Emissions & Tons & -0.05 & -0.02 & -0.01 \\
\hline \multirow{2}{*}{21} & Feeder Real Load & MW & -38.31 & -15.14 & -7.77 \\
\hline & Feeder Reactive Load & MVAR & -0.83 & -0.06 & -0.07 \\
\hline 29 & Distribution Losses & $\%$ & 0.04 & 0.03 & 0.04 \\
\hline 30 & Distribution Power Factor & $\mathrm{pf}$ & 0.00 & 0.00 & 0.00 \\
\hline 39 & CO2 Emissions & Tons & -328.60 & -135.14 & -69.68 \\
\hline \multirow{3}{*}{40} & SOx & Tons & -0.15 & -0.06 & -0.03 \\
\hline & NOx & Tons & -0.09 & -0.04 & -0.02 \\
\hline & PM-10 & Tons & -0.05 & -0.02 & -0.01 \\
\hline
\end{tabular}


Table 4.5: Residential PV impact metrics for region 5

\begin{tabular}{|c|c|c|c|c|c|c|c|c|c|}
\hline Index & $\Delta$ Metric & Units & 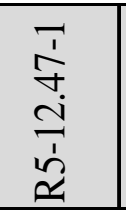 & 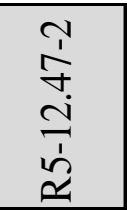 & 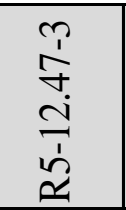 & 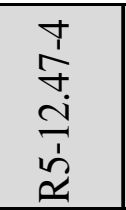 & 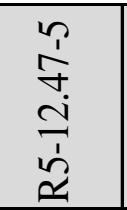 & 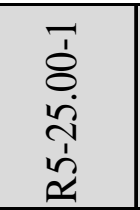 & 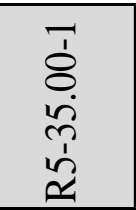 \\
\hline 1 & $\begin{array}{l}\text { Hourly Customer } \\
\text { Electricity Usage }\end{array}$ & $\mathrm{kWh}$ & -82.07 & -49.25 & -94.05 & -67.10 & -82.29 & -120.83 & -121.47 \\
\hline 2 & \begin{tabular}{|l|} 
Monthly Customer \\
Electricity Usage \\
\end{tabular} & MWh & -59.91 & -35.95 & -68.65 & -48.98 & -60.07 & -88.21 & -88.67 \\
\hline \multirow{12}{*}{3} & Peak Generation & $\mathrm{kW}$ & -226.85 & -13.05 & 117.64 & -298.25 & -153.53 & -490.04 & -579.69 \\
\hline & Nuclear & $\%$ & -0.03 & -0.29 & -0.26 & 0.08 & 0.19 & 0.03 & 0.11 \\
\hline & Solar & $\%$ & 0.00 & 0.00 & 0.00 & 0.00 & 0.00 & 0.00 & 0.00 \\
\hline & Bio & $\%$ & 0.00 & -0.01 & -0.01 & 0.00 & 0.02 & 0.00 & 0.00 \\
\hline & Wind & $\%$ & 0.00 & -0.03 & -0.03 & 0.01 & -0.27 & 0.00 & 0.01 \\
\hline & Coal & $\%$ & -0.16 & -0.62 & -0.58 & -0.77 & -0.48 & -1.20 & -1.21 \\
\hline & Hydroelectric & $\%$ & -0.63 & -0.46 & -0.01 & -0.63 & -0.59 & -0.63 & -0.63 \\
\hline & Natural Gas & $\%$ & -0.10 & -1.07 & -0.97 & 0.29 & -0.08 & 0.12 & 0.40 \\
\hline & Geothermal & $\%$ & 0.00 & 0.00 & 0.00 & 0.00 & 0.00 & 0.00 & 0.00 \\
\hline & Petroleum & $\%$ & -1.86 & -1.86 & -0.81 & -1.86 & -1.98 & -1.86 & -1.86 \\
\hline & Dis tributed Solar PV & $\%$ & 2.78 & 4.34 & 2.67 & 2.88 & 3.20 & 3.53 & 3.17 \\
\hline & Distributed Wind & $\%$ & 0.00 & 0.00 & 0.00 & 0.00 & 0.00 & 0.00 & 0.00 \\
\hline \multirow[b]{2}{*}{4} & Peak Load & MW & -244.59 & -115.87 & -81.50 & -257.53 & -234.78 & -461.70 & -487.40 \\
\hline & \begin{tabular}{|l|} 
Annual Electricity \\
Production
\end{tabular} & MWh & -728.46 & -447.21 & -874.03 & -598.71 & -741.49 & -1073.93 & -1075.49 \\
\hline 12 & $\mathrm{CO} 2$ Emis sions & Tons & -669.78 & -394.62 & -720.25 & -537.56 & -638.27 & -931.17 & -949.63 \\
\hline \multirow{3}{*}{13} & SOx Emis sions & Tons & -0.29 & -0.17 & -0.29 & -0.23 & -0.26 & -0.38 & -0.39 \\
\hline & NOx Emis sions & Tons & -0.18 & -0.10 & -0.18 & -0.14 & -0.16 & -0.24 & -0.24 \\
\hline & PM-10 Emis sions & Tons & -0.10 & -0.06 & -0.11 & -0.08 & -0.09 & -0.14 & -0.14 \\
\hline \multirow{2}{*}{21} & Feeder Real Load & MW & -83.16 & -51.05 & -99.78 & -68.35 & -84.65 & -122.59 & -122.77 \\
\hline & Feeder Reactive Load & MVAR & -1.85 & -1.52 & -15.69 & -1.15 & -5.46 & -1.53 & -0.52 \\
\hline 29 & Distribution Losses & $\%$ & 0.00 & -0.03 & -0.03 & 0.00 & -0.01 & 0.00 & 0.00 \\
\hline 30 & Distribution Power Factor & $\mathrm{pf}$ & 0.00 & 0.00 & 0.00 & 0.00 & 0.00 & 0.00 & 0.00 \\
\hline 39 & $\mathrm{CO} 2$ Emissions & Tons & -678.17 & -405.27 & -757.86 & -547.87 & -654.80 & -944.50 & -961.10 \\
\hline \multirow{3}{*}{40} & SOx & Tons & -0.29 & -0.17 & -0.30 & -0.23 & -0.27 & -0.38 & -0.40 \\
\hline & NOx & Tons & -0.18 & -0.10 & -0.19 & -0.14 & -0.17 & -0.24 & -0.25 \\
\hline & PM-10 & Tons & -0.10 & -0.06 & -0.11 & -0.08 & -0.10 & -0.14 & -0.14 \\
\hline
\end{tabular}




\subsection{Commercial PV Impact Metrics}

Table 4.6: Commercial PV impact metrics for region 1

\begin{tabular}{|c|c|c|c|c|c|c|c|c|}
\hline Index & $\Delta$ Metric & Units & 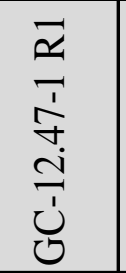 & $\begin{array}{l}\underset{1}{+} \\
\stackrel{+}{\sim} \\
\frac{1}{\Delta}\end{array}$ & 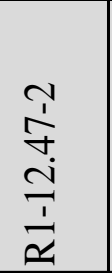 & 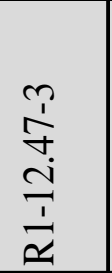 & 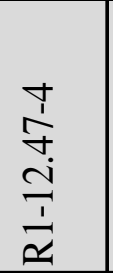 & 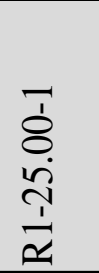 \\
\hline 1 & \begin{tabular}{|l} 
Hourly Customer \\
Electricity Usage
\end{tabular} & $\mathrm{kWh}$ & -15.69 & -32.78 & -7.97 & -3.13 & -7.87 & -6.21 \\
\hline 2 & $\begin{array}{l}\text { Monthly Customer } \\
\text { Electricity Usage }\end{array}$ & MWh & -11.45 & -23.93 & -5.82 & -2.28 & -5.75 & -4.53 \\
\hline \multirow{12}{*}{3} & Peak Generation & $\mathrm{kW}$ & -97.30 & -71.87 & -54.49 & -56.22 & -23.29 & -3.93 \\
\hline & Nuclear & $\%$ & 0.03 & -0.04 & 0.05 & 0.18 & 0.00 & -0.06 \\
\hline & Solar & $\%$ & 0.00 & 0.00 & 0.00 & 0.00 & 0.00 & 0.00 \\
\hline & Bio & $\%$ & 0.00 & 0.00 & 0.00 & 0.01 & 0.00 & 0.00 \\
\hline & Wind & $\%$ & 0.01 & -0.01 & 0.02 & 0.07 & 0.00 & -0.02 \\
\hline & Coal & $\%$ & 0.01 & -0.01 & 0.01 & 0.05 & 0.00 & -0.02 \\
\hline & Hydroelectric & $\%$ & 0.12 & -0.14 & 0.18 & 0.61 & 0.01 & -0.22 \\
\hline & Natural Gas & $\%$ & 0.13 & -0.15 & 0.20 & 0.69 & 0.01 & -0.24 \\
\hline & Geothermal & $\%$ & -1.16 & -1.00 & -1.20 & -2.52 & -0.05 & -0.42 \\
\hline & Petroleum & $\%$ & -0.35 & -0.35 & -0.35 & -0.35 & -0.38 & -0.35 \\
\hline & Distributed Solar PV & $\%$ & 1.20 & 1.71 & 1.07 & 1.26 & 0.41 & 1.33 \\
\hline & Distributed Wind & $\%$ & 0.00 & 0.00 & 0.00 & 0.00 & 0.00 & 0.00 \\
\hline 4 & Peak Load & MW & -80.46 & -98.60 & -41.57 & -36.23 & -21.89 & -17.43 \\
\hline 7 & $\begin{array}{l}\text { Annual Electricity } \\
\text { Production }\end{array}$ & MWh & -137.66 & -293.45 & -70.10 & -27.68 & -69.75 & -56.30 \\
\hline 12 & $\mathrm{CO} 2$ Emis sions & Tons & -46.19 & -74.89 & -19.09 & -9.66 & -21.92 & -19.28 \\
\hline \multirow{3}{*}{13} & SOx Emis sions & Tons & 0.00 & 0.00 & 0.00 & 0.00 & 0.00 & 0.00 \\
\hline & NOx Emis sions & Tons & 0.00 & -0.01 & 0.00 & 0.00 & 0.00 & 0.00 \\
\hline & PM-10 Emis sions & Tons & -0.01 & -0.01 & 0.00 & 0.00 & 0.00 & 0.00 \\
\hline \multirow{2}{*}{21} & Feeder Real Load & MW & -15.71 & -33.50 & -8.00 & -3.16 & -7.96 & -6.43 \\
\hline & Feeder Reactive Load & MVAR & 0.01 & -1.78 & -0.16 & -0.08 & -0.25 & -0.33 \\
\hline 29 & Dis tribution Losses & $\%$ & 0.00 & 0.00 & 0.02 & 0.00 & 0.00 & -0.01 \\
\hline 30 & Distribution Power Factor & $\mathrm{pf}$ & 0.00 & 0.00 & 0.00 & 0.00 & 0.00 & 0.00 \\
\hline 39 & $\mathrm{CO} 2$ Emis sions & Tons & -46.28 & -76.73 & -19.51 & -9.72 & -22.18 & -19.67 \\
\hline \multirow{3}{*}{40} & SOx & Tons & 0.00 & 0.00 & 0.00 & 0.00 & 0.00 & 0.00 \\
\hline & NOx & Tons & 0.00 & -0.01 & 0.00 & 0.00 & 0.00 & 0.00 \\
\hline & PM-10 & Tons & -0.01 & -0.01 & 0.00 & 0.00 & 0.00 & 0.00 \\
\hline
\end{tabular}


Table 4.7: Commercial PV impact metrics for region 2

\begin{tabular}{|c|c|c|c|c|c|c|c|c|}
\hline Index & $\Delta$ Metric & Units & 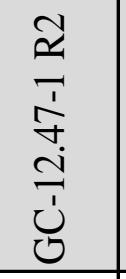 & 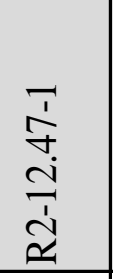 & 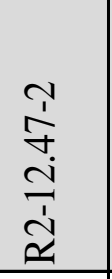 & 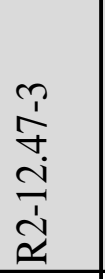 & 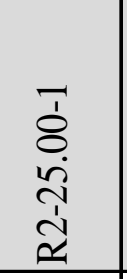 & $\begin{array}{l}7 \\
\delta \\
\dot{8} \\
\tilde{n} \\
\dot{1} \\
\tilde{1}\end{array}$ \\
\hline 1 & $\begin{array}{l}\text { Hourly Customer } \\
\text { Electricity Usage }\end{array}$ & $\mathrm{kWh}$ & -13.36 & -5.18 & -1.52 & 0.00 & -16.78 & -5.16 \\
\hline 2 & \begin{tabular}{|l|} 
Monthly Customer \\
Electricity Usage
\end{tabular} & MWh & -9.75 & -3.78 & -1.11 & 0.00 & -12.25 & -3.77 \\
\hline \multirow{12}{*}{3} & Peak Generation & $\mathrm{kW}$ & 131.17 & -55.06 & 103.03 & 0.00 & 351.80 & 23.01 \\
\hline & Nuclear & $\%$ & -0.45 & 0.07 & -0.24 & 0.00 & 1.19 & 1.32 \\
\hline & Solar & $\%$ & 0.00 & 0.00 & 0.00 & 0.00 & 0.00 & 0.00 \\
\hline & Bio & $\%$ & -0.01 & 0.00 & -0.01 & 0.00 & 0.01 & 0.01 \\
\hline & Wind & $\%$ & -0.02 & 0.00 & -0.01 & 0.00 & 0.26 & 0.27 \\
\hline & Coal & $\%$ & -0.80 & 0.13 & -0.44 & 0.00 & -2.34 & -2.12 \\
\hline & Hydroelectric & $\%$ & -0.13 & -0.07 & -0.07 & 0.00 & 1.49 & 1.53 \\
\hline & Natural Gas & $\%$ & -0.28 & 0.05 & -0.15 & 0.00 & -2.08 & -2.01 \\
\hline & Geothermal & $\%$ & 0.00 & -0.07 & 0.00 & 0.00 & 0.00 & 0.00 \\
\hline & Petroleum & $\%$ & 0.53 & -0.43 & 0.83 & 0.00 & 1.09 & 0.83 \\
\hline & Distributed Solar PV & $\%$ & 1.16 & 0.31 & 0.09 & 0.00 & 0.37 & 0.17 \\
\hline & Distributed Wind & $\%$ & 0.00 & 0.00 & 0.00 & 0.00 & 0.00 & 0.00 \\
\hline \multirow[b]{2}{*}{4} & Peak Load & MW & 31.50 & -37.44 & 48.79 & 0.00 & 88.80 & -111.80 \\
\hline & $\begin{array}{l}\text { Annual Electricity } \\
\text { Production }\end{array}$ & MWh & -117.27 & -46.33 & -13.44 & 0.00 & -147.67 & -45.65 \\
\hline 12 & $\mathrm{CO} 2$ Emis sions & Tons & -89.02 & -33.76 & -12.61 & 0.00 & -125.72 & -30.81 \\
\hline \multirow{3}{*}{13} & SOx Emis sions & Tons & -0.04 & -0.01 & -0.01 & 0.00 & -0.05 & -0.01 \\
\hline & NOx Emis sions & Tons & -0.02 & -0.01 & 0.00 & 0.00 & -0.03 & -0.01 \\
\hline & PM-10 Emis sions & Tons & -0.01 & -0.01 & 0.00 & 0.00 & -0.02 & 0.00 \\
\hline \multirow{2}{*}{21} & Feeder Real Load & MW & -13.39 & -5.29 & -1.53 & 0.00 & -16.86 & -5.21 \\
\hline & Feeder Reactive Load & MVAR & -0.11 & -0.15 & -0.05 & 0.00 & -0.14 & -0.14 \\
\hline 29 & Dis tribution Losses & $\%$ & 0.00 & 0.00 & 0.00 & 0.00 & 0.00 & 0.00 \\
\hline 30 & Distribution Power Factor & $\mathrm{pf}$ & 0.00 & 0.00 & 0.00 & 0.00 & 0.00 & 0.00 \\
\hline 39 & CO2 Emis sions & Tons & -89.22 & -34.39 & -12.81 & 0.00 & -126.57 & -31.08 \\
\hline \multirow{3}{*}{40} & SOx & Tons & -0.04 & -0.01 & -0.01 & 0.00 & -0.05 & -0.01 \\
\hline & NOx & Tons & -0.02 & -0.01 & 0.00 & 0.00 & -0.03 & -0.01 \\
\hline & PM-10 & Tons & -0.01 & -0.01 & 0.00 & 0.00 & -0.02 & 0.00 \\
\hline
\end{tabular}


Table 4.8: Commercial PV impact metrics for region 3

\begin{tabular}{|c|c|c|c|c|c|c|}
\hline Index & $\Delta$ Metric & Units & 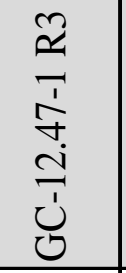 & 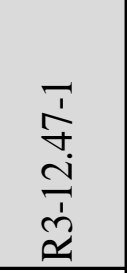 & 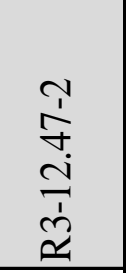 & 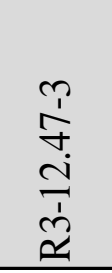 \\
\hline 1 & $\begin{array}{l}\text { Hourly Customer } \\
\text { Electricity Usage }\end{array}$ & $\mathrm{kWh}$ & -19.70 & -81.04 & -13.19 & -111.50 \\
\hline 2 & \begin{tabular}{|l|} 
Monthly Customer \\
Electricity Usage \\
\end{tabular} & MWh & -14.38 & -59.16 & -9.63 & -81.40 \\
\hline \multirow{12}{*}{3} & Peak Generation & $\mathrm{kW}$ & 106.42 & -530.48 & -221.83 & 3.71 \\
\hline & Nuclear & $\%$ & 0.93 & 0.13 & 0.21 & -1.46 \\
\hline & Solar & $\%$ & 0.00 & 0.00 & 0.00 & 0.01 \\
\hline & Bio & $\%$ & 0.02 & 0.00 & 0.01 & -0.05 \\
\hline & Wind & $\%$ & 0.37 & 0.03 & 0.05 & -0.31 \\
\hline & Coal & $\%$ & 0.70 & 0.55 & 0.88 & -1.26 \\
\hline & Hydroelectric & $\%$ & 0.73 & -2.76 & -1.25 & -1.94 \\
\hline & Natural Gas & $\%$ & -4.32 & 0.50 & 0.80 & 2.43 \\
\hline & Geothermal & $\%$ & 0.13 & -1.40 & -1.40 & -0.59 \\
\hline & Petroleum & $\%$ & 0.32 & -0.25 & -0.25 & -0.25 \\
\hline & Distributed Solar PV & $\%$ & 1.12 & 3.20 & 0.96 & 3.42 \\
\hline & Distributed Wind & $\%$ & 0.00 & 0.00 & 0.00 & 0.00 \\
\hline \multirow[b]{2}{*}{4} & Peak Load & MW & 12.73 & -415.09 & -133.12 & -233.04 \\
\hline & $\begin{array}{l}\text { Annual Electricity } \\
\text { Production }\end{array}$ & MWh & -173.06 & -718.89 & -116.82 & -988.69 \\
\hline 12 & $\mathrm{CO} 2$ Emis sions & Tons & -107.63 & -437.70 & -67.95 & -653.55 \\
\hline \multirow{3}{*}{13} & SOx Emis sions & Tons & -0.02 & -0.10 & -0.01 & -0.18 \\
\hline & NOx Emis sions & Tons & -0.02 & -0.07 & -0.01 & -0.12 \\
\hline & PM-10 Emis sions & Tons & -0.02 & -0.06 & -0.01 & -0.10 \\
\hline \multirow[t]{2}{*}{21} & Feeder Real Load & MW & -19.76 & -82.07 & -13.34 & -112.86 \\
\hline & Feeder Reactive Load & MVAR & -0.21 & -2.11 & -0.25 & -2.18 \\
\hline 29 & Distribution Losses & $\%$ & 0.00 & 0.01 & 0.00 & 0.07 \\
\hline 30 & Distribution Power Factor & $\mathrm{pf}$ & 0.00 & 0.00 & 0.00 & 0.00 \\
\hline 39 & $\mathrm{CO} 2$ Emis sions & Tons & -107.93 & -442.73 & -68.75 & -659.13 \\
\hline \multirow{3}{*}{40} & SOx & Tons & -0.03 & -0.10 & -0.01 & -0.17 \\
\hline & NOx & Tons & -0.02 & -0.07 & -0.01 & -0.12 \\
\hline & PM-10 & Tons & -0.02 & -0.07 & -0.01 & -0.10 \\
\hline
\end{tabular}


Table 4.9: Commercial PV impact metrics for region 4

\begin{tabular}{|c|c|c|c|c|c|c|}
\hline Index & $\Delta$ Metric & Units & 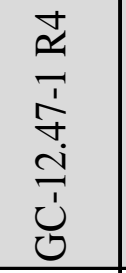 & 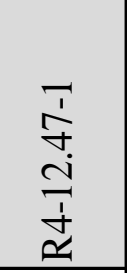 & 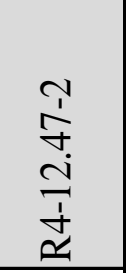 & $\begin{array}{l}\bar{\delta} \\
\dot{8} \\
\sim \\
\dot{\sim} \\
\simeq\end{array}$ \\
\hline 1 & $\begin{array}{l}\text { Hourly Customer } \\
\text { Electricity Usage }\end{array}$ & $\mathrm{kWh}$ & -29.44 & -44.35 & -19.45 & -2.83 \\
\hline 2 & \begin{tabular}{|l|} 
Monthly Customer \\
Electricity Usage \\
\end{tabular} & MWh & -21.49 & -32.38 & -14.20 & -2.07 \\
\hline \multirow{12}{*}{3} & Peak Generation & $\mathrm{kW}$ & -153.90 & -267.77 & -141.70 & -2.10 \\
\hline & Nuclear & $\%$ & 0.07 & 0.19 & 0.25 & -0.14 \\
\hline & Solar & $\%$ & 0.00 & 0.00 & 0.00 & 0.00 \\
\hline & Bio & $\%$ & 0.00 & 0.00 & 0.00 & 0.00 \\
\hline & Wind & $\%$ & 0.00 & 0.01 & 0.01 & 0.00 \\
\hline & Coal & $\%$ & 0.18 & 0.49 & 0.59 & -0.34 \\
\hline & Hydroelectric & $\%$ & -1.68 & -2.20 & -3.09 & -0.52 \\
\hline & Natural Gas & $\%$ & 0.06 & -1.95 & -1.88 & -0.10 \\
\hline & Geothermal & $\%$ & 0.00 & 0.00 & 0.00 & 0.00 \\
\hline & Petroleum & $\%$ & -0.48 & -0.48 & -0.33 & -0.33 \\
\hline & Dis tributed Solar PV & $\%$ & 1.85 & 3.95 & 4.46 & 1.44 \\
\hline & Distributed Wind & $\%$ & 0.00 & 0.00 & 0.00 & 0.00 \\
\hline \multirow[b]{2}{*}{4} & Peak Load & MW & -134.40 & -228.74 & -120.12 & -7.88 \\
\hline & $\begin{array}{l}\text { Annual Electricity } \\
\text { Production }\end{array}$ & MWh & -258.55 & -390.60 & -171.04 & -24.82 \\
\hline 12 & $\mathrm{CO} 2$ Emis sions & Tons & -231.25 & -377.28 & -171.87 & -24.91 \\
\hline \multirow{3}{*}{13} & SOx Emis sions & Tons & -0.10 & -0.17 & -0.08 & -0.01 \\
\hline & NOx Emis sions & Tons & -0.06 & -0.11 & -0.05 & -0.01 \\
\hline & PM-10 Emissions & Tons & -0.03 & -0.06 & -0.03 & 0.00 \\
\hline \multirow{2}{*}{21} & Feeder Real Load & MW & -29.52 & -44.59 & -19.52 & -2.83 \\
\hline & Feeder Reactive Load & MVAR & -0.16 & -0.62 & -0.23 & -0.01 \\
\hline 29 & Distribution Losses & $\%$ & 0.00 & 0.05 & 0.04 & 0.02 \\
\hline 30 & Distribution Power Factor & $\mathrm{pf}$ & 0.00 & 0.00 & 0.00 & 0.00 \\
\hline 39 & $\mathrm{CO} 2$ Emis sions & Tons & -231.88 & -382.80 & -174.15 & -25.23 \\
\hline \multirow{3}{*}{40} & SOx & Tons & -0.10 & -0.18 & -0.08 & -0.01 \\
\hline & NOx & Tons & -0.06 & -0.11 & -0.05 & -0.01 \\
\hline & PM-10 & Tons & -0.03 & -0.06 & -0.03 & 0.00 \\
\hline
\end{tabular}


Table 4.10: Commercial PV impact metrics for region 5

\begin{tabular}{|c|c|c|c|c|c|c|c|c|c|c|}
\hline Index & $\Delta$ Metric & Units & 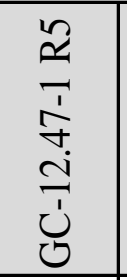 & 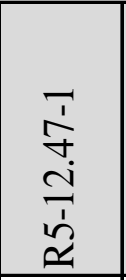 & 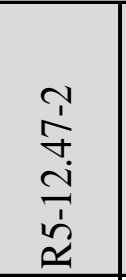 & 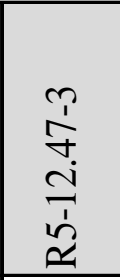 & 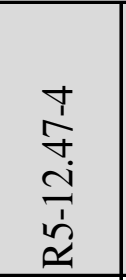 & 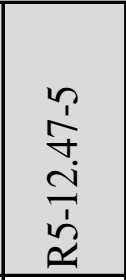 & 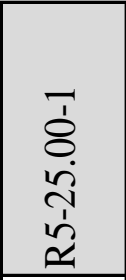 & $\begin{array}{l}\bar{\delta} \\
\dot{8} \\
\ddot{b} \\
\dot{b} \\
\tilde{c}\end{array}$ \\
\hline 1 & $\begin{array}{l}\text { Hourly Customer } \\
\text { Electricity Usage }\end{array}$ & $\mathrm{kWh}$ & -48.80 & -89.58 & -45.53 & -92.84 & -45.96 & -78.57 & -111.13 & -157.4 \\
\hline 2 & $\begin{array}{l}\text { Monthly Customer } \\
\text { Electricity Usage }\end{array}$ & MWh & -35.62 & -65.39 & -33.24 & -67.77 & -33.55 & -57.35 & -81.13 & -114.94 \\
\hline \multirow{12}{*}{3} & Peak Generation & $\mathrm{kW}$ & 134.15 & -340.84 & -41.08 & -403.25 & -73.90 & \begin{tabular}{|l|}
-191.53 \\
\end{tabular} & \begin{tabular}{|l|}
-303.04 \\
\end{tabular} & -518.88 \\
\hline & Nuclear & $\%$ & -0.80 & 0.04 & -0.13 & 0.08 & -0.10 & 0.28 & -0.47 & -0.38 \\
\hline & Solar & $\%$ & 0.00 & 0.00 & 0.00 & 0.00 & 0.00 & 0.00 & 0.00 & 0.00 \\
\hline & Bio & $\%$ & -0.03 & 0.00 & 0.00 & 0.00 & 0.00 & 0.02 & -0.02 & -0.02 \\
\hline & Wind & $\%$ & 0.20 & 0.00 & -0.01 & 0.01 & -0.01 & -0.26 & 0.24 & 0.25 \\
\hline & Coal & $\%$ & -0.87 & -0.77 & -0.29 & -0.37 & -0.22 & -0.30 & -0.13 & -0.60 \\
\hline & Hydroelectric & $\%$ & 0.12 & -0.63 & -0.01 & -0.78 & 0.00 & -0.42 & 0.14 & -0.63 \\
\hline & \begin{tabular}{|l} 
Natural Gas \\
\end{tabular} & $\%$ & -2.20 & 0.14 & -0.49 & 0.31 & -0.38 & 0.23 & -0.95 & -0.62 \\
\hline & Geothermal & $\%$ & 0.00 & 0.00 & 0.00 & 0.00 & 0.00 & 0.00 & 0.00 & 0.00 \\
\hline & Petroleum & $\%$ & 1.11 & -1.86 & -1.77 & -1.98 & -1.70 & -1.98 & -1.55 & -1.86 \\
\hline & Distributed Solar PV & $\%$ & 2.48 & 3.07 & 2.71 & 2.73 & 2.41 & 2.44 & 2.74 & 3.86 \\
\hline & Distributed Wind & $\%$ & 0.00 & 0.00 & 0.00 & 0.00 & 0.00 & 0.00 & 0.00 & 0.00 \\
\hline \multirow[b]{2}{*}{4} & Peak Load & MW & -76.94 & -315.69 & -88.32 & -343.30 & -128.04 & -219.44 & -433.20 & -572.60 \\
\hline & \begin{tabular}{|l|} 
Annual Electricity \\
Production
\end{tabular} & MWh & -428.87 & -794.90 & -408.92 & -858.97 & -410.59 & -702.38 & -979.49 & -1382.29 \\
\hline 12 & $\mathrm{CO} 2$ Emis sions & Tons & -363.79 & -730.36 & -362.97 & -710.83 & -369.33 & -607.43 & \begin{tabular}{|l|}
-852.46 \\
\end{tabular} & -1215.18 \\
\hline \multirow{3}{*}{13} & SOx Emis sions & Tons & -0.14 & -0.31 & -0.15 & -0.28 & -0.16 & -0.25 & -0.34 & -0.49 \\
\hline & NOx Emis sions & Tons & -0.09 & -0.19 & -0.09 & -0.18 & -0.10 & -0.15 & -0.21 & -0.31 \\
\hline & PM-10 Emissions & Tons & -0.05 & -0.11 & -0.05 & -0.11 & -0.05 & -0.09 & -0.13 & -0.18 \\
\hline \multirow{2}{*}{21} & Feeder Real Load & MW & -48.96 & -90.74 & -46.68 & -98.06 & -46.87 & -80.18 & -111.81 & -157.80 \\
\hline & Feeder Reactive Load & MVAR & -0.42 & -4.23 & -0.95 & -17.25 & -1.31 & -5.36 & -1.02 & -0.91 \\
\hline 29 & Distribution Losses & $\%$ & 0.00 & 0.00 & -0.01 & -0.02 & 0.00 & 0.01 & 0.02 & 0.03 \\
\hline 30 & Distribution Power Factor & $\mathrm{pf}$ & 0.00 & 0.00 & 0.00 & 0.00 & 0.00 & 0.00 & 0.00 & 0.00 \\
\hline 39 & $\mathrm{CO} 2$ Emis sions & Tons & -364.99 & -739.43 & -371.12 & -746.56 & -376.60 & -621.10 & -861.66 & -1225.53 \\
\hline \multirow{3}{*}{40} & SOx & Tons & -0.14 & -0.32 & -0.16 & -0.30 & -0.16 & -0.25 & -0.35 & -0.50 \\
\hline & NOx & Tons & -0.09 & -0.20 & -0.10 & -0.19 & -0.10 & -0.16 & -0.22 & -0.31 \\
\hline & PM-10 & Tons & -0.05 & -0.11 & -0.06 & -0.11 & -0.06 & -0.09 & -0.13 & -0.18 \\
\hline
\end{tabular}




\subsection{Combined PV Impact Metrics}

Table 4.11: Combined PV impact metrics for region 1

\begin{tabular}{|c|c|c|c|c|c|c|c|}
\hline Index & $\Delta$ Metric & Units & $\begin{array}{l}\frac{1}{\Delta} \\
\stackrel{+}{J} \\
\frac{1}{\vec{a}}\end{array}$ & 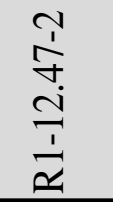 & $\begin{array}{l}\hat{1} \\
\stackrel{+}{+} \\
\stackrel{1}{c} \\
\frac{1}{a}\end{array}$ & 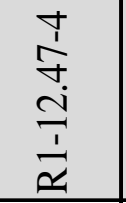 & 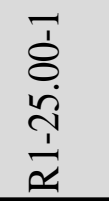 \\
\hline 1 & $\begin{array}{l}\text { Hourly Customer } \\
\text { Electricity Usage }\end{array}$ & $\mathrm{kWh}$ & -59.78 & -19.61 & -7.85 & -30.72 & -14.11 \\
\hline 2 & \begin{tabular}{|l} 
Monthly Customer \\
Electricity Usage \\
\end{tabular} & $\mathrm{MWh}$ & -43.64 & -14.31 & -5.73 & -22.42 & -10.30 \\
\hline \multirow{12}{*}{3} & Peak Generation & $\mathrm{kW}$ & -221.32 & -22.70 & -79.12 & -160.97 & 105.04 \\
\hline & Nuclear & $\%$ & 0.00 & -0.74 & -0.53 & 0.66 & -0.35 \\
\hline & Solar & $\%$ & 0.00 & -0.04 & -0.04 & 0.04 & -0.01 \\
\hline & Bio & $\%$ & 0.00 & 0.04 & 0.05 & -0.05 & -0.02 \\
\hline & Wind & $\%$ & 0.00 & -0.57 & -0.50 & 0.55 & -0.14 \\
\hline & Coal & $\%$ & 0.00 & 1.44 & 1.53 & -1.48 & -0.10 \\
\hline & Hydroelectric & $\%$ & 0.01 & -10.95 & -10.40 & 10.79 & -1.22 \\
\hline & Natural Gas & $\%$ & 0.01 & 9.10 & 10.17 & -9.60 & -1.37 \\
\hline & Geothermal & $\%$ & -2.65 & 0.22 & -1.05 & -2.49 & -0.09 \\
\hline & Petroleum & $\%$ & -0.35 & -0.25 & -0.35 & -0.38 & 1.01 \\
\hline & Distributed Solar PV & $\%$ & 2.98 & 1.75 & 1.12 & 1.97 & 2.30 \\
\hline & Dis tributed Wind & $\%$ & 0.00 & 0.00 & 0.00 & 0.00 & 0.00 \\
\hline 4 & Peak Load & MW & -219.96 & -61.80 & -71.98 & -130.71 & 24.59 \\
\hline 7 & $\begin{array}{l}\text { Annual Electricity } \\
\text { Production }\end{array}$ & MWh & -534.74 & -174.29 & -69.57 & -274.80 & -127.53 \\
\hline 12 & $\mathrm{CO} 2$ Emissions & Tons & -134.04 & -45.82 & -23.33 & -83.05 & -42.73 \\
\hline \multirow{3}{*}{13} & SOx Emis sions & Tons & 0.00 & 0.00 & 0.00 & 0.00 & 0.00 \\
\hline & NOx Emis sions & Tons & -0.01 & 0.00 & 0.00 & -0.01 & 0.00 \\
\hline & PM-10 Emis sions & Tons & -0.02 & -0.01 & 0.00 & -0.01 & -0.01 \\
\hline \multirow{2}{*}{21} & Feeder Real Load & MW & -61.04 & -19.90 & -7.94 & -31.37 & -14.56 \\
\hline & Feeder Reactive Load & MVAR & -2.81 & -0.37 & -0.13 & -0.56 & -0.64 \\
\hline 29 & Distribution Losses & $\%$ & 0.01 & 0.03 & -0.01 & -0.01 & -0.03 \\
\hline 30 & Distribution Power Factor & $\mathrm{pf}$ & 0.00 & 0.00 & 0.00 & 0.00 & 0.00 \\
\hline 39 & $\mathrm{CO} 2$ Emis sions & Tons & -137.29 & -47.01 & -23.50 & -84.31 & -43.55 \\
\hline \multirow{3}{*}{40} & SOx & Tons & 0.00 & 0.00 & 0.00 & 0.00 & 0.00 \\
\hline & NOx & Tons & -0.01 & 0.00 & 0.00 & -0.01 & 0.00 \\
\hline & PM-10 & Tons & -0.02 & -0.01 & 0.00 & -0.01 & -0.01 \\
\hline
\end{tabular}


Table 4.12: Combined PV impact metrics for region 2

\begin{tabular}{|c|c|c|c|c|c|c|}
\hline Index & $\Delta$ Metric & Units & 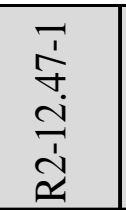 & 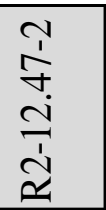 & 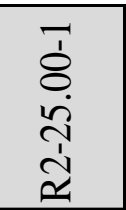 & $\begin{array}{l}7 \\
\delta \\
\delta \\
\tilde{n} \\
\dot{1} \\
\tilde{1}\end{array}$ \\
\hline 1 & $\begin{array}{l}\text { Hourly Customer } \\
\text { Electricity Usage }\end{array}$ & $\mathrm{kWh}$ & -14.77 & -10.21 & -39.38 & -18.59 \\
\hline 2 & \begin{tabular}{|l} 
Monthly Customer \\
Electricity Usage
\end{tabular} & MWh & -10.78 & -7.45 & -28.74 & -13.57 \\
\hline \multirow{12}{*}{3} & Peak Generation & $\mathrm{kW}$ & 2.79 & 24.42 & -73.88 & -461.00 \\
\hline & Nuclear & $\%$ & -0.11 & -0.13 & -0.10 & 0.41 \\
\hline & Solar & $\%$ & 0.00 & 0.00 & 0.00 & 0.00 \\
\hline & Bio & $\%$ & 0.00 & 0.00 & 0.00 & 0.01 \\
\hline & Wind & $\%$ & -0.01 & -0.01 & -0.01 & 0.02 \\
\hline & Coal & $\%$ & -0.20 & -0.22 & -0.18 & 0.73 \\
\hline & Hydroelectric & $\%$ & -0.03 & -0.04 & -0.34 & -1.55 \\
\hline & \begin{tabular}{|l} 
Natural Gas \\
\end{tabular} & $\%$ & -0.07 & -0.08 & -0.06 & 0.25 \\
\hline & Geothermal & $\%$ & 0.00 & 0.00 & -0.07 & -0.07 \\
\hline & Petroleum & $\%$ & -0.37 & -0.06 & -0.43 & -0.43 \\
\hline & \begin{tabular}{|l|} 
Distributed Solar PV \\
\end{tabular} & $\%$ & 0.79 & 0.53 & 1.19 & 0.62 \\
\hline & Distributed Wind & $\%$ & 0.00 & 0.00 & 0.00 & 0.00 \\
\hline \multirow[b]{2}{*}{4} & Peak Load & MW & -23.45 & -3.17 & -137.50 & -271.20 \\
\hline & \begin{tabular}{|l|} 
Annual Electricity \\
Production
\end{tabular} & MWh & -131.17 & -90.59 & -347.78 & -164.36 \\
\hline 12 & $\mathrm{CO} 2$ Emis sions & Tons & -97.23 & -84.84 & -293.58 & -112.75 \\
\hline \multirow{3}{*}{13} & SOx Emis sions & Tons & -0.04 & -0.04 & -0.12 & -0.04 \\
\hline & NOx Emis sions & Tons & -0.02 & -0.02 & -0.08 & -0.03 \\
\hline & PM-10 Emis sions & Tons & -0.01 & -0.01 & -0.04 & -0.02 \\
\hline \multirow{2}{*}{21} & Feeder Real Load & MW & -14.97 & -10.34 & -39.70 & -18.76 \\
\hline & Feeder Reactive Load & MVAR & -0.29 & -0.32 & -0.48 & -0.41 \\
\hline 29 & Distribution Losses & $\%$ & 0.00 & 0.00 & 0.00 & 0.00 \\
\hline 30 & Distribution Power Factor & $\mathrm{pf}$ & 0.00 & 0.00 & 0.00 & 0.00 \\
\hline 39 & $\mathrm{CO} 2$ Emis sions & Tons & -98.53 & -86.21 & -296.18 & -113.76 \\
\hline \multirow{3}{*}{40} & SOx & Tons & -0.04 & -0.04 & -0.12 & -0.05 \\
\hline & NOx & Tons & -0.03 & -0.02 & -0.08 & -0.03 \\
\hline & PM-10 & Tons & -0.01 & -0.01 & -0.04 & -0.02 \\
\hline
\end{tabular}


Table 4.13: Combined PV impact metrics for region 3

\begin{tabular}{|c|c|c|c|c|}
\hline Index & $\Delta$ Metric & Units & 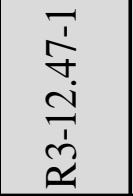 & 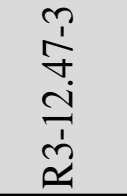 \\
\hline 1 & $\begin{array}{l}\text { Hourly Customer } \\
\text { Electricity Usage }\end{array}$ & $\mathrm{kWh}$ & -138.01 & -158.08 \\
\hline 2 & $\begin{array}{l}\text { Monthly Customer } \\
\text { Electricity Usage }\end{array}$ & $\mathrm{MWh}$ & -100.75 & -115.40 \\
\hline \multirow{12}{*}{3} & Peak Generation & $\mathrm{kW}$ & -539.80 & -336.83 \\
\hline & Nuclear & $\%$ & 0.02 & 0.04 \\
\hline & Solar & $\%$ & 0.00 & 0.00 \\
\hline & Bio & $\%$ & 0.00 & 0.00 \\
\hline & Wind & $\%$ & 0.00 & 0.01 \\
\hline & Coal & $\%$ & 0.07 & 0.19 \\
\hline & Hydroelectric & $\%$ & -3.98 & -1.89 \\
\hline & Natural Gas & $\%$ & 0.06 & 0.17 \\
\hline & Geothermal & $\%$ & -1.40 & -1.40 \\
\hline & Petroleum & $\%$ & -0.25 & -0.25 \\
\hline & Distributed Solar PV & $\%$ & 5.48 & 3.12 \\
\hline & Dis tributed Wind & $\%$ & 0.00 & 0.00 \\
\hline \multirow[b]{2}{*}{4} & Peak Load & MW & -525.10 & -299.75 \\
\hline & $\begin{array}{l}\text { Annual Electricity } \\
\text { Production }\end{array}$ & MWh & \#\#\#\#\#\# & -1404.73 \\
\hline 12 & $\mathrm{CO} 2$ Emissions & Tons & -762.02 & -944.94 \\
\hline \multirow{3}{*}{13} & SOx Emis sions & Tons & -0.18 & -0.26 \\
\hline & NOx Emissions & Tons & -0.13 & -0.18 \\
\hline & PM-10 Emissions & Tons & -0.11 & -0.14 \\
\hline \multirow{2}{*}{21} & Feeder Real Load & MW & -139.92 & -160.36 \\
\hline & Feeder Reactive Load & MVAR & -3.47 & -3.20 \\
\hline 29 & Distribution Losses & $\%$ & 0.02 & 0.09 \\
\hline 30 & Distribution Power Factor & $\mathrm{pf}$ & 0.00 & 0.00 \\
\hline 39 & $\mathrm{CO} 2$ Emis sions & Tons & -771.92 & -955.78 \\
\hline \multirow{3}{*}{40} & SOx & Tons & -0.18 & -0.26 \\
\hline & NOx & Tons & -0.13 & -0.18 \\
\hline & PM-10 & Tons & -0.11 & -0.14 \\
\hline
\end{tabular}


Table 4.14: Combined PV impact metrics for region 4

\begin{tabular}{|c|c|c|c|c|c|}
\hline Index & $\Delta$ Metric & Units & 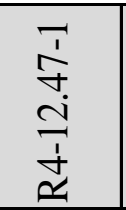 & 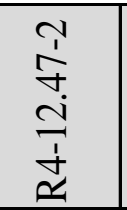 & 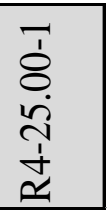 \\
\hline 1 & $\begin{array}{l}\text { Hourly Customer } \\
\text { Electricity Usage }\end{array}$ & $\mathrm{kWh}$ & -79.80 & -34.14 & -10.24 \\
\hline 2 & \begin{tabular}{|l|} 
Monthly Customer \\
Electricity Usage \\
\end{tabular} & MWh & -58.26 & -24.92 & -7.48 \\
\hline \multirow{12}{*}{3} & Peak Generation & $\mathrm{kW}$ & -310.17 & -55.58 & -84.82 \\
\hline & Nuclear & $\%$ & 0.19 & -2.19 & 0.54 \\
\hline & Solar & $\%$ & 0.00 & 0.00 & 0.00 \\
\hline & Bio & $\%$ & 0.00 & -0.03 & 0.00 \\
\hline & Wind & $\%$ & 0.01 & 0.00 & 0.01 \\
\hline & Coal & $\%$ & 0.51 & -0.28 & 1.27 \\
\hline & Hydroelectric & $\%$ & -2.20 & -3.09 & -3.09 \\
\hline & Natural Gas & $\%$ & -2.82 & -0.32 & -3.20 \\
\hline & Geothermal & $\%$ & 0.00 & 0.00 & 0.00 \\
\hline & Petroleum & $\%$ & -0.48 & -0.33 & -0.33 \\
\hline & Distributed Solar PV & $\%$ & 4.80 & 6.25 & 4.79 \\
\hline & Distributed Wind & $\%$ & 0.00 & 0.00 & 0.00 \\
\hline \multirow[b]{2}{*}{4} & Peak Load & MW & -270.30 & -106.90 & -65.26 \\
\hline & \begin{tabular}{|l|} 
Annual Electricity \\
Production
\end{tabular} & MWh & -703.85 & -300.53 & -90.21 \\
\hline 12 & $\mathrm{CO} 2$ Emis sions & Tons & -682.01 & -302.74 & -90.79 \\
\hline \multirow{3}{*}{13} & SOx Emis sions & Tons & -0.32 & -0.14 & -0.04 \\
\hline & NOx Emis sions & Tons & -0.19 & -0.09 & -0.03 \\
\hline & PM-10 Emis sions & Tons & -0.10 & -0.05 & -0.01 \\
\hline \multirow{2}{*}{21} & Feeder Real Load & MW & -80.35 & -34.31 & -10.30 \\
\hline & Feeder Reactive Load & MVAR & -1.26 & -0.31 & -0.04 \\
\hline 29 & Distribution Losses & $\%$ & 0.09 & 0.08 & 0.06 \\
\hline 30 & Distribution Power Factor & $\mathrm{pf}$ & 0.00 & 0.00 & 0.00 \\
\hline 39 & $\mathrm{CO} 2$ Emissions & Tons & -692.74 & -306.95 & -92.21 \\
\hline \multirow{3}{*}{40} & SOx & Tons & -0.32 & -0.14 & -0.04 \\
\hline & NOx & Tons & -0.19 & -0.09 & -0.03 \\
\hline & PM-10 & Tons & -0.10 & -0.05 & -0.01 \\
\hline
\end{tabular}


Table 4.15: Combined PV impact metrics for region 5

\begin{tabular}{|c|c|c|c|c|c|c|c|c|c|}
\hline Index & $\Delta$ Metric & Units & 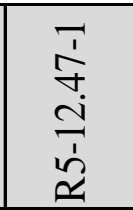 & 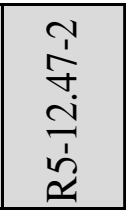 & 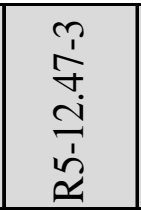 & 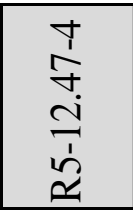 & 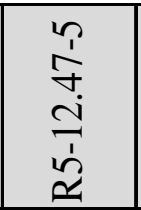 & 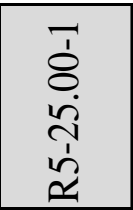 & $\begin{array}{l}7 \\
\delta \\
\dot{8} \\
\tilde{n} \\
\hat{1} \\
\alpha\end{array}$ \\
\hline 1 & $\begin{array}{l}\text { Hourly Customer } \\
\text { Electricity Usage }\end{array}$ & $\mathrm{kWh}$ & -177.30 & -92.45 & -188.26 & -115.63 & -164.39 & -241.18 & -279.22 \\
\hline 2 & \begin{tabular}{|l|} 
Monthly Customer \\
Electricity Usage
\end{tabular} & MWh & -129.43 & -67.49 & -137.43 & -84.41 & -120.01 & -176.06 & -203.83 \\
\hline \multirow{12}{*}{3} & Peak Generation & $\mathrm{kW}$ & -553.68 & 21.89 & -597.72 & -267.35 & -554.36 & -727.07 & -947.98 \\
\hline & Nuclear & $\%$ & -0.03 & -0.85 & -0.01 & -0.22 & 0.03 & -0.44 & 0.01 \\
\hline & Solar & $\%$ & 0.00 & 0.00 & 0.00 & 0.00 & 0.00 & 0.00 & 0.00 \\
\hline & Bio & $\%$ & 0.00 & -0.03 & 0.00 & -0.01 & 0.00 & -0.02 & 0.00 \\
\hline & Wind & $\%$ & 0.00 & 0.19 & 0.00 & -0.02 & 0.00 & 0.24 & 0.00 \\
\hline & Coal & $\%$ & -3.59 & -1.00 & -3.08 & -3.00 & -3.13 & -2.28 & -5.05 \\
\hline & Hydroelectric & $\%$ & -0.63 & 0.12 & -0.78 & -0.63 & -0.78 & -0.63 & -0.63 \\
\hline & Natu & $\%$ & -0.09 & -2.42 & -0.04 & -0.81 & 0.10 & -0.86 & 0.0 \\
\hline & Geothermal & $\%$ & 0.00 & 0.00 & 0.00 & 0.00 & 0.00 & 0.00 & 0.00 \\
\hline & Petroleum & $\%$ & -1.86 & 0.83 & -1.98 & -1.86 & -1.98 & -1.86 & -1.86 \\
\hline & Distributed Solar PV & $\%$ & 6.20 & 3.16 & 5.89 & 6.54 & 5.76 & 5.85 & 7.49 \\
\hline & Distributed Wind & $\%$ & 0.00 & 0.00 & 0.00 & 0.00 & 0.00 & 0.00 & 0.00 \\
\hline \multirow[b]{2}{*}{4} & Peak Load & MW & -570.03 & -176.12 & -604.45 & -380.91 & -537.35 & -832.50 & -939.50 \\
\hline & \begin{tabular}{|l} 
Annual Electricity \\
Production
\end{tabular} & MWh & -1573.19 & -834.38 & -1746.37 & -1032.64 & -1475.06 & -2134.64 & -2460.5 \\
\hline 12 & $\mathrm{CO} 2$ Emis sions & Tons & -1427.24 & \begin{tabular}{|l|}
-727.87 \\
\end{tabular} & -1417.15 & -918.02 & -1252.90 & -1821.20 & -2121.42 \\
\hline \multirow{3}{*}{13} & SOx Emis sions & Tons & -0.60 & -0.30 & -0.55 & -0.38 & -0.50 & -0.72 & -0.8 \\
\hline & NOx Emis sions & Tons & -0.37 & -0.19 & -0.35 & -0.24 & -0.31 & -0.45 & -0.53 \\
\hline & PM-10 Emissions & Tons & -0.21 & -0.11 & -0.21 & -0.14 & -0.19 & -0.27 & -0.32 \\
\hline \multirow{2}{*}{21} & Feeder Real Load & MW & -179.59 & -95.25 & -199.36 & -117.88 & -168.39 & -243.68 & -280.89 \\
\hline & Feeder Reactive Load & MVAR & -6.46 & -2.44 & -33.44 & -2.49 & -10.93 & -2.40 & -1.5 \\
\hline 29 & Distribution Losses & $\%$ & 0.00 & -0.04 & -0.05 & 0.00 & 0.00 & 0.02 & 0.0 \\
\hline 30 & Distribution Power Factor & $\mathrm{pf}$ & 0.00 & 0.00 & 0.00 & 0.00 & 0.00 & 0.00 & 0.00 \\
\hline 39 & $\mathrm{CO} 2$ Emis sions & Tons & -1444.90 & \begin{tabular}{|l|l|}
-745.66 \\
\end{tabular} & -1489.91 & -935.96 & -1283.07 & -1844.13 & -2142.90 \\
\hline \multirow{3}{*}{40} & SOx & Tons & -0.61 & -0.31 & -0.58 & -0.39 & -0.51 & -0.73 & -0.86 \\
\hline & NOx & Tons & -0.38 & -0.19 & -0.37 & -0.24 & -0.32 & -0.46 & -0.5 \\
\hline & PM-10 & Tons & -0.22 & -0.11 & -0.22 & -0.14 & -0.19 & -0.27 & -0.32 \\
\hline
\end{tabular}




\subsection{Commercial WTG Impact Metrics}

Table 4.16: Commercial WTG impact metrics for region 1

\begin{tabular}{|c|c|c|c|}
\hline Index & $\Delta$ Metric & Units & 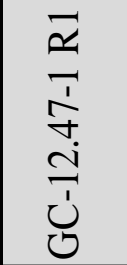 \\
\hline 1 & $\begin{array}{l}\text { Hourly Customer } \\
\text { Electricity Usage }\end{array}$ & $\mathrm{kWh}$ & -466.03 \\
\hline 2 & $\begin{array}{l}\text { Monthly Customer } \\
\text { Electricity Usage }\end{array}$ & MWh & -340.20 \\
\hline \multirow{12}{*}{3} & Peak Generation & $\mathrm{kW}$ & -54.69 \\
\hline & Nuclear & $\%$ & -0.25 \\
\hline & Solar & $\%$ & -0.01 \\
\hline & Bio & $\%$ & -0.02 \\
\hline & Wind & $\%$ & -0.09 \\
\hline & Coal & $\%$ & -0.20 \\
\hline & Hydroelectric & $\%$ & -0.86 \\
\hline & Natural Gas & $\%$ & -0.96 \\
\hline & Geothermal & $\%$ & -2.84 \\
\hline & Petroleum & $\%$ & -0.35 \\
\hline & Dis tributed Solar PV & $\%$ & 0.00 \\
\hline & Dis tributed Wind & $\%$ & 5.57 \\
\hline 4 & Peak Load & MW & -176.70 \\
\hline 7 & $\begin{array}{l}\text { Annual Electricity } \\
\text { Production }\end{array}$ & MWh & \#\#\#\#\# \\
\hline 12 & $\mathrm{CO} 2$ Emissions & Tons & -713.43 \\
\hline \multirow{3}{*}{13} & SOx Emissions & Tons & -0.02 \\
\hline & NOx Emis sions & Tons & -0.06 \\
\hline & PM-10 Emissions & Tons & -0.10 \\
\hline \multirow{2}{*}{21} & Feeder Real Load & MW & -466.97 \\
\hline & Feeder Reactive Load & MVAR & -194.67 \\
\hline 29 & Distribution Losses & $\%$ & 0.01 \\
\hline 30 & Distribution Power Factor & $\mathrm{pf}$ & -0.05 \\
\hline 39 & $\mathrm{CO} 2$ Emis sions & Tons & -714.98 \\
\hline \multirow{3}{*}{40} & SOx & Tons & -0.02 \\
\hline & NOx & Tons & -0.06 \\
\hline & PM-10 & Tons & -0.10 \\
\hline
\end{tabular}


Table 4.17: Commercial WTG impact metrics for region 2

\begin{tabular}{|c|c|c|c|}
\hline Index & $\Delta$ Metric & Units & 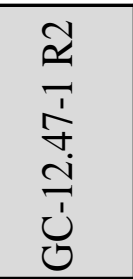 \\
\hline 1 & $\begin{array}{l}\text { Hourly Customer } \\
\text { Electricity Usage }\end{array}$ & $\mathrm{kWh}$ & -450.89 \\
\hline 2 & $\begin{array}{l}\text { Monthly Customer } \\
\text { Electricity Usage }\end{array}$ & MWh & -329.15 \\
\hline \multirow{12}{*}{3} & Peak Generation & $\mathrm{kW}$ & -288.86 \\
\hline & Nuclear & $\%$ & 0.28 \\
\hline & Solar & $\%$ & 0.00 \\
\hline & Bio & $\%$ & 0.01 \\
\hline & Wind & $\%$ & 0.01 \\
\hline & Coal & $\%$ & 0.49 \\
\hline & Hydroelectric & $\%$ & -3.49 \\
\hline & Natural Gas & $\%$ & 0.17 \\
\hline & Geothermal & $\%$ & -0.07 \\
\hline & Petroleum & $\%$ & -0.43 \\
\hline & Dis tributed Solar PV & $\%$ & 0.00 \\
\hline & Distributed Wind & $\%$ & 3.03 \\
\hline \multirow[b]{2}{*}{4} & Peak Load & MW & -231.76 \\
\hline & \begin{tabular}{|l|} 
Annual Electricity \\
Production
\end{tabular} & MWh & -3956.88 \\
\hline 12 & $\mathrm{CO} 2$ Emissions & Tons & -2480.11 \\
\hline \multirow{3}{*}{13} & SOx Emis sions & Tons & -1.09 \\
\hline & NOx Emis sions & Tons & -0.69 \\
\hline & PM-10 Emis sions & Tons & -0.37 \\
\hline \multirow{2}{*}{21} & Feeder Real Load & MW & -451.70 \\
\hline & Feeder Reactive Load & MVAR & -188.16 \\
\hline 29 & Distribution Losses & $\%$ & 0.02 \\
\hline 30 & Distribution Power Factor & $\mathrm{pf}$ & -0.07 \\
\hline 39 & $\mathrm{CO} 2$ Emissions & Tons & -2485.20 \\
\hline \multirow{3}{*}{40} & SOx & Tons & -1.09 \\
\hline & NOx & Tons & -0.70 \\
\hline & PM-10 & Tons & -0.37 \\
\hline
\end{tabular}


Table 4.18: Commercial WTG impact metrics for region 3

\begin{tabular}{|c|c|c|c|}
\hline Index & $\Delta$ Metric & Units & 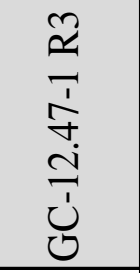 \\
\hline 1 & $\begin{array}{l}\text { Hourly Customer } \\
\text { Electricity Usage }\end{array}$ & $\mathrm{kWh}$ & -124.55 \\
\hline 2 & \begin{tabular}{|l|} 
Monthly Customer \\
Electricity Usage \\
\end{tabular} & $\mathrm{MWh}$ & -90.92 \\
\hline \multirow{12}{*}{3} & Peak Generation & $\mathrm{kW}$ & -74.11 \\
\hline & Nuclear & $\%$ & 1.11 \\
\hline & Solar & $\%$ & 0.00 \\
\hline & Bio & $\%$ & 0.02 \\
\hline & Wind & $\%$ & 0.41 \\
\hline & Coal & $\%$ & 1.47 \\
\hline & Hydroelectric & $\%$ & 0.85 \\
\hline & Natural Gas & $\%$ & -3.62 \\
\hline & Geothermal & $\%$ & -0.18 \\
\hline & Petroleum & $\%$ & -0.20 \\
\hline & Dis tributed Solar PV & $\%$ & 0.00 \\
\hline & Distributed Wind & $\%$ & 0.12 \\
\hline \multirow[b]{2}{*}{4} & Peak Load & MW & -44.05 \\
\hline & $\begin{array}{l}\text { Annual Electricity } \\
\text { Production }\end{array}$ & $\mathrm{MWh}$ & -1094.41 \\
\hline 12 & CO2 Emissions & Tons & -844.50 \\
\hline \multirow{3}{*}{13} & SOx Emis sions & Tons & -0.30 \\
\hline & NOx Emis sions & Tons & -0.19 \\
\hline & PM-10 Emissions & Tons & -0.13 \\
\hline \multirow{2}{*}{21} & Feeder Real Load & MW & -124.93 \\
\hline & Feeder Reactive Load & MVAR & -52.15 \\
\hline 29 & Distribution Losses & $\%$ & 0.00 \\
\hline 30 & Distribution Power Factor & $\mathrm{pf}$ & 0.00 \\
\hline 39 & $\mathrm{CO} 2$ Emis sions & Tons & -847.11 \\
\hline \multirow{3}{*}{40} & SOx & Tons & -0.30 \\
\hline & NOx & Tons & -0.20 \\
\hline & PM-10 & Tons & -0.13 \\
\hline
\end{tabular}


Table 4.19: Commercial WTG impact metrics for region 4

\begin{tabular}{|c|c|c|c|}
\hline Index & $\Delta$ Metric & Units & 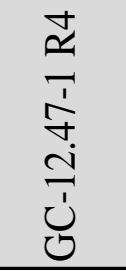 \\
\hline 1 & $\begin{array}{l}\text { Hourly Customer } \\
\text { Electricity Usage }\end{array}$ & $\mathrm{kWh}$ & -273.75 \\
\hline 2 & $\begin{array}{l}\text { Monthly Customer } \\
\text { Electricity Usage }\end{array}$ & MWh & -199.84 \\
\hline \multirow{12}{*}{3} & Peak Generation & $\mathrm{kW}$ & 343.53 \\
\hline & Nuclear & $\%$ & 0.52 \\
\hline & Solar & $\%$ & 0.00 \\
\hline & Bio & $\%$ & 0.02 \\
\hline & Wind & $\%$ & -0.04 \\
\hline & Coal & $\%$ & -3.81 \\
\hline & Hydroelectric & $\%$ & 0.74 \\
\hline & Natural Gas & $\%$ & -2.14 \\
\hline & Geothermal & $\%$ & 0.00 \\
\hline & Petroleum & $\%$ & 1.40 \\
\hline & Distributed Solar PV & $\%$ & 0.00 \\
\hline & Distributed Wind & $\%$ & 3.31 \\
\hline \multirow[b]{2}{*}{4} & Peak Load & MW & 23.48 \\
\hline & $\begin{array}{l}\text { Annual Electricity } \\
\text { Production }\end{array}$ & MWh & -2403.22 \\
\hline 12 & $\mathrm{CO} 2$ Emis sions & Tons & -1793.06 \\
\hline \multirow{3}{*}{13} & SOx Emis sions & Tons & -0.83 \\
\hline & NOx Emis sions & Tons & -0.51 \\
\hline & PM-10 Emis sions & Tons & -0.27 \\
\hline \multirow{2}{*}{21} & Feeder Real Load & MW & -274.34 \\
\hline & Feeder Reactive Load & MVAR & -114.40 \\
\hline 29 & Distribution Losses & $\%$ & 0.01 \\
\hline 30 & Distribution Power Factor & $\mathrm{pf}$ & -0.03 \\
\hline 39 & $\mathrm{CO} 2$ Emis sions & Tons & -1797.38 \\
\hline \multirow{3}{*}{40} & SOx & Tons & -0.84 \\
\hline & $\mathrm{NOx}$ & Tons & -0.51 \\
\hline & PM-10 & Tons & -0.27 \\
\hline
\end{tabular}


Table 4.20: Commercial WTG metrics for region 5

\begin{tabular}{|c|c|c|c|}
\hline Index & $\Delta$ Metric & Units & 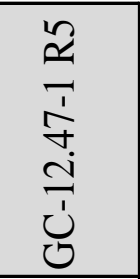 \\
\hline 1 & \begin{tabular}{|l}
$\begin{array}{l}\text { Hourly Customer } \\
\text { Electricity Usage }\end{array}$ \\
\end{tabular} & $\mathrm{kWh}$ & -402.21 \\
\hline 2 & $\begin{array}{l}\text { Monthly Customer } \\
\text { Electricity Usage }\end{array}$ & MWh & -293.62 \\
\hline \multirow{12}{*}{3} & Peak Generation & $\mathrm{kW}$ & -57.26 \\
\hline & Nuclear & $\%$ & -0.31 \\
\hline & Solar & $\%$ & 0.00 \\
\hline & Bio & $\%$ & -0.01 \\
\hline & Wind & $\%$ & -0.03 \\
\hline & Coal & $\%$ & -1.34 \\
\hline & Hydroelectric & $\%$ & -0.63 \\
\hline & Natural Gas & $\%$ & -1.15 \\
\hline & Geothermal & $\%$ & 0.00 \\
\hline & Petroleum & $\%$ & -1.86 \\
\hline & Distributed Solar PV & $\%$ & 0.00 \\
\hline & Distributed Wind & $\%$ & 5.33 \\
\hline \multirow[b]{2}{*}{4} & Peak Load & MW & -185.58 \\
\hline & \begin{tabular}{|l|} 
Annual Electricity \\
Production
\end{tabular} & MWh & -3533.80 \\
\hline 12 & $\mathrm{CO} 2$ Emis sions & Tons & -2342.49 \\
\hline \multirow{3}{*}{13} & SOx Emissions & Tons & -0.74 \\
\hline & NOx Emis sions & Tons & -0.50 \\
\hline & PM-10 Emis sions & Tons & -0.35 \\
\hline \multirow{2}{*}{21} & Feeder Real Load & MW & -403.40 \\
\hline & Feeder Reactive Load & MVAR & -168.44 \\
\hline 29 & Distribution Losses & $\%$ & 0.01 \\
\hline 30 & Distribution Power Factor & $\mathrm{pf}$ & -0.02 \\
\hline 39 & $\mathrm{CO} 2$ Emis sions & Tons & -2349.80 \\
\hline \multirow{3}{*}{40} & SOx & Tons & -0.74 \\
\hline & NOx & Tons & -0.50 \\
\hline & PM-10 & Tons & -0.35 \\
\hline
\end{tabular}




\section{Conclusion and Observations}

The SGIG proposals demonstrated considerable interest in the area of distributed generation, specifically in the areas of solar photovoltaic and wind turbine generators. Additionally, there was considerable interest in developing interface capabilities for the future addition of renewable distributed resources. Only one of the SGIG proposals specifically mentioned implementing 100kW PV's in their system. However, there were not enough details for residential PV system size or the WTG installations to extrapolate a unit size. In order to assess the impact of DG on all the prototypical feeders, assumptions were made for residential PV $(3 \mathrm{~kW}-5 \mathrm{~kW})$ and WTG $(1.8$ $\mathrm{MW}$ ) ratings.

\subsection{Distributed Generation Observations and Conclusions}

During the simulation of distributed generation across the different climate regions, many different metrics were recorded and examined. Some of the metrics are the primary drivers for the installation of renewable distributed generation, and some of the metrics were secondary benefits. This section will provide some overall observations and conclusions, including some assumptions, from this analysis. A brief summary of this section will be presented in Section 5.2 .

There are several reasons why utilities may choose to deploy or integrate customer owned distributed generation at the distribution level. A customer may choose to install PV on his or her rooftop to reduce energy consumption and to obtain benefits from net metering. The utilities can deploy DGs to offset peak load so that they don't have to buy power from the market, which can be volatile. Additionally, they may able to accommodate additional load growth with no transmission investment. For the purposes of these simulations, a low, $1 \%$ to $6 \%$ of feeder peak load was used as the PV population criterion. A single 1.8 MW WTG was used for commercial feeders. The PV and WTG units integrated to the distribution feeders were operated in accordance with the IEEE 1547 standards of distributed generation interconnection. The PV and WTG units were grid connected and operated at unity power factor (i.e., they only supplied real power to the grid) with no active voltage control.

From the simulations, it was clear that reductions in annual energy consumption were always achieved on the prototypical feeders for both PV and WTG integration; the reduction in annual energy consumption being the primary benefit of these technologies. One of the other important observations made was the effect of PV integration on the peak demand of the feeder. In most of the feeders, it was observed that peak feeder load was reduced when PVs were integrated onto the distribution feeder. However, in some feeders, there was an increase in the peak load. The amount of the peak load increase was less than $0.5 \%$ when compared to the base case. This is primarily attributed to the random distribution of the PV units in this analysis, which potentially generates clusters of PV units. These clustered units have the effect of raising the local voltages 
because of their injection of real power without a corresponding voltage regulation capability; the lack of voltage regulation is in accordance with IEEE 1547. The local rise in voltage interacts with the voltage dependent end-use loads and can impact the peak load.

There were other secondary metrics which showed benefits as a result of DG deployment. System losses were mostly seen to decrease, with the effect varying due to different feeder compositions and various end-use load types. Increasing the penetration of PVs on the feeder was not the only factor affecting these metrics. For example, losses can be considerably lower for feeders with balanced loads, new conductors, properly sized distribution transformers, and correct placement of PVs. Throughout the nation, there are older feeders, which have not been upgraded, and can have improper equipment sizing and old conductors. Such feeder configurations can worsen the system losses due to improper placement as the penetration of PV units is increased.

It can also be concluded that distributed generation, when renewable, always decreases the pollutant emissions. The extent to which the emissions are reduced will be heavily dependent on the generation mix within the region, with each generation type within the mix producing varying amounts of $\mathrm{CO}_{2}, \mathrm{NOx}, \mathrm{SOx}$, and $\mathrm{PM}-10$. If a particular region generates a majority of its electricity from carbon intensive sources, then the emission profile will see significant improvements with the deployment of renewable distribution generation. In contrast, regions such as the Pacific Northwest where hydropower composes a majority of the generation mix will only see a moderate improvement in the emission profile when renewable distribution generation resources are deployed.

\subsection{Distributed Generation Observations and Conclusions Summary}

The analysis presented in this report has shown that many, but not all, of the benefits of the DG technologies deployed in the SGIG projects can be quantified and tracked using the SGIG metrics guidebook [2]. From the analysis conducted, and the metrics tracked, the following conclusions and observations can be made about DG technologies

1) DG technologies can be deployed by a utility, or commercial, industrial, or residential customers.

2) DG technologies provide the primary benefit of reducing the amount of energy that must be supplied by the feeder for consumption by the end-use customers.

3) DG technologies, when renewable, reduce net system emissions.

4) DG technologies increase system efficiency if properly coordinated, and have the potential to increase system efficiency at higher penetration levels. 
5) In this report, DG technologies were deployed at the customer level, but have impacts at the feeder, as well as the transmission system.

6) DGs, particularly renewables, provide numerous benefits which have been tracked using the metrics specified in the SGIG guidebook [2]. However, there are metrics that are either not directly tracked though the SGIG smart grid metrics, or were outside the scope of this analysis. If these metrics are included then DG provides numerous benefits that make it an even more attractive technology. Potential metrics are:

a) Deferred transmission capacity investment: This is an SGIG smart grid metric, but a full analysis would require financial analysis of a specific utility and their long term planning strategy.

b) Deferred distribution capacity investment: This is an SGIG smart grid metric, but a full analysis would require financial analysis of a specific utility and their long term planning strategy. Improvement in load factor and feeder voltage profile measurements would provide utilities a good view for planning their distribution infrastructure to accommodate future load growth.

c) Power quality: By providing sources near the end use load, voltage flicker and voltage sags could be reduced. This is especially true on long rural feeders.

\subsubsection{Observations and Conclusions Summary for PV Integration}

There were three different implementation scenarios (residential PV, commercial PV and combined PV) studied under PV integration. The following conclusions and observations can be made from the various analyses:

1) The primary benefit of solar PV is reduced annual energy consumption from the perspective of the distribution feeder. The penetration levels in the simulations (2\%$6 \%$ of peak load) provided a reduction of between $0.5 \%$ and $5 \%$ of annual energy consumption on most feeders.

2) Peak load is generally reduced on all the feeders and is greatest in areas where PV output is coincident with peak load.

3) In general losses are reduced, but there are exceptions. Large unbalances of PV generation, high penetration level without other compensating technologies, or improperly sized PV generation can increase losses.

4) Annual $\mathrm{CO}_{2}$ emissions are reduced $1 \%-5 \%$, varying with generation mix. 


\subsubsection{Observations and conclusions Summary for WTG Integration}

From the simulation results and impact metrics study, the following conclusions and observations can be made for commercial wind:

1) The primary benefit of WTGs is a reduction in the annual energy consumption from the perspective of the distribution feeder. For the examined feeders, a single $1.8 \mathrm{MW}$ wind turbine was installed. This provided between $5 \%$ and $20 \%$ reduction in annual energy consumption on the commercial feeders.

2) Peak load reductions of between $1 \%$ and $5 \%$ were achieved on most of the feeders and were greatest in areas where wind is coincident with peak load.

3) $\mathrm{CO}_{2}$ emissions were reduced by $10 \%$ to $50 \%$. Emission reductions were high because of the size of the WTG's, $1.8 \mathrm{MW}$, was large in comparison to the feeder peak load, approximately $5 \mathrm{MW}$ on the commercial feeders. Additionally, WTGs tend to produce more power at night when the generation sources tend to be carbon intensive. 


\section{Appendix A: SGIG Program Impact Metrics}

An important component of the SGIG projects is the transfer of information from the individual projects to the broader industry audience. The aim of this transfer is to allow individuals, research organizations and utilities to better understand the performance of the various technologies deployed on the various projects. Due to the large amount of potential data, it is not feasible for each grant recipient to provide all of the available raw data. To address the issue of data collection, the "Guidebook for ARRA Smart Grid Program Metrics and Benefits" [2] was developed as a starting point for the discussion of data collection and impact categories. Specifically, the document contained a table of impact metrics against which each project could be evaluated; it is these metrics that are used in the 4 technical reports in this series to evaluate the impact of the various technologies. Table A.1 is a complete list of all 74 metrics listed in the Guidebook and is included in this appendix as a reference. Not every metric is used for each technology, only those that are relevant to the specific technology are examined in Section 2.

Table A.1: SGIG program impact metrics from guidebook

\begin{tabular}{|c|c|c|c|c|}
\hline$\#$ & Metric & $\begin{array}{l}\text { Project } \\
\text { Value }\end{array}$ & $\begin{array}{l}\text { System } \\
\text { Value }\end{array}$ & Remarks \\
\hline \multicolumn{5}{|c|}{ A 2.1 IMPACT METRICS: AMI and Customer Systems } \\
\hline \multicolumn{5}{|c|}{ Metrics Related Primarily to Economic Benefits } \\
\hline 1 & $\begin{array}{l}\text { Hourly Customer } \\
\text { Electricity Usage }\end{array}$ & $\begin{array}{l}\mathrm{kWh} \\
\$ / \mathrm{kWh}\end{array}$ & $\begin{array}{c}\text { Not } \\
\text { Applicable }\end{array}$ & $\begin{array}{l}\text { Hourly electricity consumption information }(\mathrm{kWh}) \\
\text { and applicable retail tariff rate. Nature of this data } \\
\text { will be negotiated with DOE }\end{array}$ \\
\hline 2 & $\begin{array}{l}\text { Monthly Customer } \\
\text { Electricity Usage }\end{array}$ & $\begin{array}{l}\mathrm{MWh} \\
\$ / \mathrm{kWh}\end{array}$ & $\begin{array}{c}\text { Not } \\
\text { Applicable }\end{array}$ & $\begin{array}{l}\text { Monthly electricity consumption information } \\
(\mathrm{kWh}) \text { and applicable retail tariff rate. The nature } \\
\text { of this data will be negotiated with DOE }\end{array}$ \\
\hline 3 & Peak Generation and Mix & $\begin{array}{l}\text { MW } \\
\text { Mix }\end{array}$ & $\begin{array}{l}\text { MW } \\
\text { Mix }\end{array}$ & Specify intermittent generation by type and amount \\
\hline 4 & Peak Load and Mix & $\begin{array}{l}\text { MW } \\
\text { Mix }\end{array}$ & $\begin{array}{l}\text { MW } \\
\text { Mix }\end{array}$ & Specify controllable load by type \\
\hline 5 & Annual Generation Cost & $\$$ & $\$$ & Total cost of generation to serve load \\
\hline 6 & Hourly Generation Cost & $\$ / \mathrm{MWh}$ & $\$ / \mathrm{MWh}$ & Aggregate or market price of energy in each hour \\
\hline 7 & $\begin{array}{l}\text { Annual Electricity } \\
\text { Production }\end{array}$ & $\mathrm{MWh}$ & MWh & Total electricity produced by central generation \\
\hline 8 & Ancillary Services Cost & $\$$ & $\$$ & Total cost of Ancillary services \\
\hline 9 & Meter Operations Cost & $\$$ & $\begin{array}{c}\text { Not } \\
\text { Applicable }\end{array}$ & $\begin{array}{l}\text { Includes operations, maintenance, reading and data } \\
\text { management }\end{array}$ \\
\hline 10 & Truck Rolls Avoided & $\#$ & $\begin{array}{c}\text { Not } \\
\text { Applicable }\end{array}$ & $\begin{array}{l}\text { Could include trips for meter reading, } \\
\text { connection/disconnection, inspection and } \\
\text { maintenance }\end{array}$ \\
\hline
\end{tabular}




\begin{tabular}{|c|c|c|c|c|}
\hline \# & Metric & $\begin{array}{l}\text { Project } \\
\text { Value }\end{array}$ & $\begin{array}{l}\text { System } \\
\text { Value }\end{array}$ & Remarks \\
\hline \multicolumn{5}{|c|}{ Metrics Related Primarily to Environmental Benefits } \\
\hline 11 & $\begin{array}{l}\text { Meter Operations Vehicle } \\
\text { Miles }\end{array}$ & Miles & $\begin{array}{c}\text { Not } \\
\text { Applicable }\end{array}$ & $\begin{array}{l}\text { Total miles accumulated related to meter } \\
\text { operations }\end{array}$ \\
\hline 12 & $\mathrm{CO} 2$ Emissions & Tons & Tons & Could be modeled or estimated \\
\hline 13 & $\begin{array}{l}\text { Pollutant Emissions (SOx, } \\
\text { NOx, PM-10) }\end{array}$ & Tons & Tons & Could be modeled or estimated \\
\hline \multicolumn{5}{|c|}{ Metrics Related Primarily to AMI System Performance } \\
\hline 14 & Meter Data Completeness & $\%$ & $\begin{array}{c}\text { Not } \\
\text { Applicable }\end{array}$ & $\begin{array}{l}\text { Portion of meters that are online and successfully } \\
\text { reporting in }\end{array}$ \\
\hline 15 & $\begin{array}{l}\text { Meters Reported Daily by } \\
\text { 2AM }\end{array}$ & $\%$ & $\begin{array}{c}\text { Not } \\
\text { Applicable }\end{array}$ & $\begin{array}{l}\text { Portion of meter reads received by } 2 \mathrm{AM} \text { the } \\
\text { following day }\end{array}$ \\
\hline \multicolumn{5}{|c|}{ A 2.2 Impact Metrics: Electric Distribution Systems } \\
\hline \multicolumn{5}{|c|}{ Metrics Related to Economic Benefits } \\
\hline 16 & $\begin{array}{l}\text { Hourly Customer } \\
\text { Electricity Usage* }\end{array}$ & $\begin{array}{l}\mathrm{kWh} \\
\$ / \mathrm{kWh}\end{array}$ & $\begin{array}{c}\text { Not } \\
\text { Applicable }\end{array}$ & $\begin{array}{l}\text { Hourly electricity consumption information }(\mathrm{kWh}) \\
\text { and applicable retail tariff rate. }\end{array}$ \\
\hline 17 & Annual Storage Dispatch* & KWh & $\begin{array}{c}\text { Not } \\
\text { Applicable }\end{array}$ & $\begin{array}{l}\text { Total number of hours that storage is dispatched } \\
\text { for retail load shifting }\end{array}$ \\
\hline 18 & $\begin{array}{l}\text { Average Energy Storage } \\
\text { Efficiency* }\end{array}$ & $\%$ & $\begin{array}{c}\text { Not } \\
\text { Applicable }\end{array}$ & Efficiency of energy storage devices installed \\
\hline 19 & Monthly Demand Charges* & $\begin{array}{l}\$ / \mathrm{kW}- \\
\text { month }\end{array}$ & $\begin{array}{c}\text { Not } \\
\text { Applicable }\end{array}$ & Average commercial or industrial demand charges \\
\hline 20 & $\begin{array}{l}\text { Distribution Feeder or } \\
\text { Equipment Overload } \\
\text { Incidents }\end{array}$ & \# & $\begin{array}{c}\text { Not } \\
\text { Applicable }\end{array}$ & $\begin{array}{l}\text { The total time during the reporting period that } \\
\text { feeder or equipment loads exceeded design ratings }\end{array}$ \\
\hline 21 & Distribution Feeder Load & $\begin{array}{l}\text { MW } \\
\text { MVAR }\end{array}$ & $\begin{array}{c}\text { Not } \\
\text { Applicable }\end{array}$ & $\begin{array}{l}\text { Real and reactive power readings for those feeders } \\
\text { involved in the project. Information should be } \\
\text { based on hourly loads }\end{array}$ \\
\hline 22 & $\begin{array}{l}\text { Deferred Distribution } \\
\text { Capacity Investments }\end{array}$ & $\$$ & $\begin{array}{c}\text { Not } \\
\text { Applicable }\end{array}$ & $\begin{array}{l}\text { The value of the capital project(s) deferred, and the } \\
\text { time of the deferral }\end{array}$ \\
\hline 23 & $\begin{array}{l}\text { Equipment Failure } \\
\text { Incidents }\end{array}$ & $\#$ & $\begin{array}{c}\text { Not } \\
\text { Applicable }\end{array}$ & $\begin{array}{l}\text { Incidents of equipment failure within the project } \\
\text { scope, including reason for failure }\end{array}$ \\
\hline 24 & $\begin{array}{l}\text { Distribution Equipment } \\
\text { Maintenance Cost }\end{array}$ & $\$$ & $\begin{array}{c}\text { Not } \\
\text { Applicable }\end{array}$ & $\begin{array}{l}\text { Activity based cost for distribution equipment } \\
\text { maintenance during the reporting period }\end{array}$ \\
\hline 25 & $\begin{array}{l}\text { Distribution Operations } \\
\text { Cost }\end{array}$ & $\$$ & $\begin{array}{c}\text { Not } \\
\text { Applicable }\end{array}$ & $\begin{array}{l}\text { Activity based cost for distribution operations } \\
\text { during the reporting period }\end{array}$ \\
\hline 26 & $\begin{array}{l}\text { Distribution Feeder } \\
\text { Switching Operations }\end{array}$ & $\#$ & $\begin{array}{c}\text { Not } \\
\text { Applicable }\end{array}$ & $\begin{array}{l}\text { Activity based cost for feeders switching } \\
\text { operations during the reporting period }\end{array}$ \\
\hline 27 & $\begin{array}{l}\text { Distribution Capacitor } \\
\text { Switching Cost }\end{array}$ & $\$$ & $\begin{array}{c}\text { Not } \\
\text { Applicable }\end{array}$ & $\begin{array}{l}\text { Activity based cost for capacitor switching } \\
\text { operations during the reporting period }\end{array}$ \\
\hline 28 & $\begin{array}{l}\text { Distribution Restoration } \\
\text { Cost }\end{array}$ & $\$$ & $\begin{array}{c}\text { Not } \\
\text { Applicable }\end{array}$ & $\begin{array}{l}\text { Total cost for distribution restoration during the } \\
\text { reporting period }\end{array}$ \\
\hline 29 & Distribution Losses & $\%$ & $\begin{array}{c}\text { Not } \\
\text { Applicable }\end{array}$ & $\begin{array}{l}\text { Losses for the portion of the distribution system } \\
\text { involved in the project. Modeled or calculated. }\end{array}$ \\
\hline
\end{tabular}




\begin{tabular}{|c|c|c|c|c|}
\hline$\#$ & Metric & $\begin{array}{l}\text { Project } \\
\text { Value }\end{array}$ & $\begin{array}{l}\text { System } \\
\text { Value }\end{array}$ & Remarks \\
\hline 30 & Distribution Power Factor & $\mathrm{pf}$ & $\begin{array}{c}\text { Not } \\
\text { Applicable }\end{array}$ & $\begin{array}{l}\text { Power factor for the portion of the distribution } \\
\text { system involved in the project. Modeled or } \\
\text { calculated. }\end{array}$ \\
\hline 31 & Truck Rolls Avoided & \# & $\begin{array}{c}\text { Not } \\
\text { Applicable }\end{array}$ & $\begin{array}{l}\text { Estimate of the number of times a crew would have } \\
\text { been dispatched to perform a distribution } \\
\text { operations or maintenance function }\end{array}$ \\
\hline \multicolumn{5}{|c|}{ Metrics Related Primarily to Reliability Benefits } \\
\hline 32 & SAIF & Index & $\begin{array}{c}\text { Not } \\
\text { Applicable }\end{array}$ & \multirow{3}{*}{$\begin{array}{l}\text { As defined in IEEE Std 1366-2003, and do not } \\
\text { include major events days. Only events involving } \\
\text { infrastructure that is part of the project should be } \\
\text { included. }\end{array}$} \\
\hline 33 & SAIDI/CAIDI & Index & $\begin{array}{c}\text { Not } \\
\text { Applicable }\end{array}$ & \\
\hline 34 & MAIFI & Index & $\begin{array}{c}\text { Not } \\
\text { Applicable }\end{array}$ & \\
\hline 35 & Outrage Response Time & Minutes & $\begin{array}{c}\text { Not } \\
\text { Applicable }\end{array}$ & $\begin{array}{l}\text { Time between outage occurrence and action } \\
\text { initiated }\end{array}$ \\
\hline 36 & Major Event Information & $\begin{array}{l}\text { Event } \\
\text { Statistics }\end{array}$ & $\begin{array}{c}\text { Not } \\
\text { Applicable }\end{array}$ & $\begin{array}{l}\text { Information should including, but not limited to } \\
\text { project infrastructure involved (transmission lines, } \\
\text { substations and feeders), cause of the event, } \\
\text { number of customers affected, total time for } \\
\text { restoration, and restoration costs. }\end{array}$ \\
\hline 37 & $\begin{array}{l}\text { Number of High } \\
\text { Impedance Faults Cleared }\end{array}$ & \# & $\begin{array}{c}\text { Not } \\
\text { Applicable }\end{array}$ & $\begin{array}{l}\text { Faults cleared that could be designed as high } \\
\text { impedance or slow clearing }\end{array}$ \\
\hline \multicolumn{5}{|c|}{ Metrics Related Primarily to Environmental Benefits } \\
\hline 38 & $\begin{array}{l}\text { Distribution Operations } \\
\text { Vehicle Miles }\end{array}$ & Miles & $\begin{array}{c}\text { Not } \\
\text { Applicable }\end{array}$ & $\begin{array}{l}\text { Total miles for distribution operations and } \\
\text { maintenance during the reporting period }\end{array}$ \\
\hline 39 & CO2 Emissions & Tons & Tons & Could be modeled or estimated \\
\hline 40 & $\begin{array}{l}\text { Pollutant Emissions (SOx, } \\
\text { NOx, PM-10) }\end{array}$ & Tons & Tons & Could be modeled or estimated \\
\hline \multicolumn{5}{|c|}{ A 2.3 Impact Metrics: Electric Transmission Systems } \\
\hline \multicolumn{5}{|c|}{ Metrics Related Primarily to Economic Benefits } \\
\hline 41 & Annual Storage Dispatch* & MWh & MWh & $\begin{array}{l}\text { Total number of hours that storage is dispatched } \\
\text { for wholesale energy markets or Ancillary services }\end{array}$ \\
\hline 42 & Capacity Market Value* & \$/MW & \$/MW & Capacity value \\
\hline 43 & Ancillary Services Prices* & $\$ / \mathrm{MWh}$ & $\$ / \mathrm{MWh}$ & $\begin{array}{l}\text { Ancillary service price during hours when Storage } \\
\text { was dispatched }\end{array}$ \\
\hline 44 & Annual Generation Cost & $\begin{array}{c}\text { Not } \\
\text { Applicable }\end{array}$ & $\$$ & Total cost generation to serve load \\
\hline
\end{tabular}




\begin{tabular}{|c|c|c|c|c|}
\hline$\#$ & Metric & $\begin{array}{l}\text { Project } \\
\text { Value }\end{array}$ & $\begin{array}{l}\text { System } \\
\text { Value }\end{array}$ & Remarks \\
\hline 45 & Hourly Generation Cost & $\begin{array}{c}\text { Not } \\
\text { Applicable }\end{array}$ & $\$ / \mathrm{MWh}$ & Aggregate or market price of energy in each hour \\
\hline 46 & Peak Generation and Mix & $\begin{array}{c}\text { Not } \\
\text { Applicable }\end{array}$ & $\begin{array}{l}\text { MW } \\
\text { Mix }\end{array}$ & Specify intermittent generation by type and amount \\
\hline 47 & Peak Load and Mix & $\begin{array}{c}\text { Not } \\
\text { Applicable }\end{array}$ & $\begin{array}{l}\text { MW } \\
\text { Mix }\end{array}$ & Specify controllable load by type \\
\hline 48 & $\begin{array}{l}\text { Annual Generation } \\
\text { Dispatch }\end{array}$ & $\begin{array}{c}\text { Not } \\
\text { Applicable }\end{array}$ & $\begin{array}{l}\text { MW } \\
\text { Mix }\end{array}$ & Total electricity produced by central generation \\
\hline 49 & Ancillary Services Cost & $\begin{array}{c}\text { Not } \\
\text { Applicable }\end{array}$ & $\$$ & Total cost of Ancillary services \\
\hline 50 & Congestion Cost & MW & $\begin{array}{c}\text { Not } \\
\text { Applicable }\end{array}$ & $\begin{array}{l}\text { Total transmission congestion cost during the } \\
\text { reporting period }\end{array}$ \\
\hline 51 & $\begin{array}{l}\text { Transmission Line or } \\
\text { Equipment Overload } \\
\text { Incidents }\end{array}$ & \# & $\begin{array}{c}\text { Not } \\
\text { Applicable }\end{array}$ & $\begin{array}{l}\text { The total time during the reporting period that line } \\
\text { loads exceeded design ratings }\end{array}$ \\
\hline 52 & Transmission Line Load & $\begin{array}{l}\text { MW } \\
\text { MVAR }\end{array}$ & $\begin{array}{c}\text { Not } \\
\text { Applicable }\end{array}$ & $\begin{array}{l}\text { Real and reactive power readings for those lines } \\
\text { involved in the project. Information should be } \\
\text { based on hourly loads }\end{array}$ \\
\hline 53 & $\begin{array}{l}\text { Deferred Transmission } \\
\text { Capacity Investments }\end{array}$ & $\$$ & $\begin{array}{c}\text { Not } \\
\text { Applicable }\end{array}$ & $\begin{array}{l}\text { The value of the capital project(s) deferred, and the } \\
\text { time of the deferral }\end{array}$ \\
\hline 54 & $\begin{array}{l}\text { Equipment Failure } \\
\text { Incidents }\end{array}$ & \# & $\begin{array}{c}\text { Not } \\
\text { Applicable }\end{array}$ & $\begin{array}{l}\text { Incidents of equipment failure within the project } \\
\text { scope, including reason for failure }\end{array}$ \\
\hline 55 & $\begin{array}{l}\text { Transmission Equipment } \\
\text { Maintenance Cost }\end{array}$ & $\$$ & $\begin{array}{c}\text { Not } \\
\text { Applicable }\end{array}$ & $\begin{array}{l}\text { Activity based cost for transmission equipment } \\
\text { maintenance during the reporting period }\end{array}$ \\
\hline 56 & $\begin{array}{l}\text { Transmission Operations } \\
\text { Cost }\end{array}$ & $\$$ & $\begin{array}{c}\text { Not } \\
\text { Applicable }\end{array}$ & $\begin{array}{l}\text { Activity based cost for transmission operations } \\
\text { during the reporting period }\end{array}$ \\
\hline 57 & $\begin{array}{l}\text { Transmission Restoration } \\
\text { Cost }\end{array}$ & $\$$ & $\begin{array}{c}\text { Not } \\
\text { Applicable }\end{array}$ & $\begin{array}{l}\text { Total cost for transmission restoration during the } \\
\text { reporting period }\end{array}$ \\
\hline 58 & Transmission Losses & $\%$ & $\begin{array}{c}\text { Not } \\
\text { Applicable }\end{array}$ & $\begin{array}{l}\text { Losses for the portion of the transmission system } \\
\text { involved in the project. Could be modeled or } \\
\text { calculated. }\end{array}$ \\
\hline 59 & Transmission Power Factor & $\mathrm{pf}$ & $\begin{array}{c}\text { Not } \\
\text { Applicable }\end{array}$ & $\begin{array}{l}\text { Power factor for the portion of the transmission } \\
\text { system involved in the project. Could be modeled } \\
\text { or calculated. }\end{array}$ \\
\hline \multicolumn{5}{|c|}{ Metrics Related Primarily to Transmission Reliability } \\
\hline 60 & $\begin{array}{l}\text { BPS Transmission Related } \\
\text { Events Resulting in Loss of } \\
\text { Load (NERC ALR 1-4) }\end{array}$ & \# & $\begin{array}{c}\text { Not } \\
\text { Applicable }\end{array}$ & $\begin{array}{l}\text { BPS Transmission Related Events Resulting in } \\
\text { Loss of Load (NERC ALR 1-4) }\end{array}$ \\
\hline 61 & $\begin{array}{l}\text { Energy Emergency Alert } 3 \\
\text { (NERC ALR 6-2) }\end{array}$ & \# & $\begin{array}{c}\text { Not } \\
\text { Applicable }\end{array}$ & Energy Emergency Alert 3 (NERC ALR-6-2) \\
\hline \multicolumn{5}{|c|}{ Metrics Related Primarily to Environmental Benefits } \\
\hline
\end{tabular}




\begin{tabular}{|c|c|c|c|c|}
\hline$\#$ & Metric & $\begin{array}{l}\text { Project } \\
\text { Value }\end{array}$ & $\begin{array}{l}\text { System } \\
\text { Value }\end{array}$ & Remarks \\
\hline 62 & $\begin{array}{l}\text { Transmission Operations } \\
\text { Vehicle Miles }\end{array}$ & Miles & $\begin{array}{c}\text { Not } \\
\text { Applicable }\end{array}$ & $\begin{array}{l}\text { Total mileage for transmission operations and } \\
\text { maintenance during the reporting period }\end{array}$ \\
\hline 63 & $\mathrm{CO} 2$ Emissions & tons & tons & Could be modeled or estimated \\
\hline 64 & $\begin{array}{l}\text { Pollutant Emissions (SOx, } \\
\text { NOx, PM-10) }\end{array}$ & tons & tons & Could be modeled or estimated \\
\hline \multicolumn{5}{|c|}{ Metrics Related Primarily to Energy Security Benefits } \\
\hline 65 & Number, Type, and Size & $\begin{array}{l}\text { Events } \\
\text { Cause } \\
\text { Load Lost }\end{array}$ & $\begin{array}{c}\text { Not } \\
\text { Applicable }\end{array}$ & $\begin{array}{l}\text { Causes could include line trips, generator trips, or } \\
\text { other large disturbances }\end{array}$ \\
\hline 66 & Duration & $\begin{array}{l}\text { Minutes/ } \\
\text { Hours }\end{array}$ & $\begin{array}{c}\text { Not } \\
\text { Applicable }\end{array}$ & \\
\hline 67 & PMU Dynamic Data & PMU Data & $\begin{array}{c}\text { Not } \\
\text { Applicable }\end{array}$ & From related PMU's \\
\hline 68 & Detection & Application & $\begin{array}{c}\text { Not } \\
\text { Applicable }\end{array}$ & Application that detected the event \\
\hline 69 & Events Prevented & \# & $\begin{array}{c}\text { Not } \\
\text { Applicable }\end{array}$ & Include reason for prevention \\
\hline \multicolumn{5}{|c|}{ Metrics related primarily to PMU/PDC System Performance } \\
\hline 70 & PMU Data Completeness & $\%$ & $\begin{array}{c}\text { Not } \\
\text { Applicable }\end{array}$ & $\begin{array}{l}\text { Portion of PMU that are operational and } \\
\text { successfully provided data }\end{array}$ \\
\hline 71 & Network Completeness & $\%$ & $\begin{array}{c}\text { Not } \\
\text { Applicable }\end{array}$ & Portion of PMUs networked into regional PDCs \\
\hline 72 & PMU/PDC Performance & $\begin{array}{l}\text { Reliability } \\
\text { Quality }\end{array}$ & $\begin{array}{c}\text { Not } \\
\text { Applicable }\end{array}$ & \\
\hline 73 & $\begin{array}{l}\text { Communications } \\
\text { Performance }\end{array}$ & Availability & $\begin{array}{c}\text { Not } \\
\text { Applicable }\end{array}$ & \\
\hline 74 & Application Performance & Description & $\begin{array}{c}\text { Not } \\
\text { Applicable }\end{array}$ & $\begin{array}{l}\text { Usefulness of applications, including reliability } \\
\text { improvements, markets and congestion } \\
\text { management, operational efficiency }\end{array}$ \\
\hline
\end{tabular}

The metrics shown in Table A.1 were developed for field demonstrations and were not originally intended for simulations. To address this issue, definitions of the metrics in Table A.1 as implemented in the analysis will be given. Because the simulations in this report only examine impacts at the distribution level, transmission level impact metrics will not be examined. Of the distribution metrics, many will not be used because they are associated with a monetary cost that would require information from a specific utility. For example, meter operation costs.

The metrics will be presented in two separate places in this report. Appendix E will contain the metric values for each technology on each feeder. These values are individual to a single 
technology. Section 4.1, 4.2, and 4.3 will show the difference in metric values between the base case and the specific technology, for each feeder.

1) Hourly customer electricity usage: Instead of reporting a time series of values for an entire year this metric will report the average hourly end use consumption.

2) Monthly customer electricity usage: Instead of reporting a time series of values for an entire year this metric will report the average monthly end use consumption.

3) Peak generation and mix: This metric will report the peak generation as well as the percentages for generation composition. This is the generation that is required to supply the demand as measured at the substation. The generation composition will include the breakdown of central generation as well as distributed resources on the distribution system.

4) Peak load and mix: This is the maximum annual end use demand as consumed by the end use customers. This is the load that the utilities meter and charge for. The percent of load that is controllable will also be included.

5) Annual generation cost: Because this is dependent on the business structure of specific utilities, this metric will not be used in evaluating the simulation results.

6) Hourly generation cost: Because this is dependent on the business structure of specific utilities, this metric will not be used in evaluating the simulation results.

7) Annual electricity production: This metric reports the total energy that is required to supply the demand as measured at the substation

8) Ancillary services cost: Because this is dependent on the business structure of specific utilities, this metric will not be used in evaluating the simulation results.

9) Meter operations cost: Because this is dependent on the business structure of specific utilities, this metric will not be used in evaluating the simulation results.

10) Truck rolls avoided: Because this is dependent on the operational procedures of specific utilities, this metric will not be used in evaluating the simulation results.

11) Meter operations vehicle miles: Because this is dependent on the operational procedures of specific utilities, this metric will not be used in evaluating the simulation results.

12) CO2 emissions: This metric measures the $\mathrm{CO} 2$ emissions required to supply the electricity to the end use load.

13) Pollutant emissions: This metric measures SOx, NOx, and PM-10 emissions required to supply the electricity to the end use load. 
14) Meter data completeness: Because this is dependent on the operational procedures of specific utilities, this metric will not be used in evaluating the simulation results.

15) Meter reported daily by 2 a.m.: Because this is dependent on the operational procedures of specific utilities, this metric will not be used in evaluating the simulation results.

16) Hourly customer electricity usage: For the purposes of this work, this metric is identical to metric 1 , and will not be used.

17) Annual storage dispatch: This metric examines the total number of hours that energy storage is dispatched.

18) Average energy storage efficiency: This is the average round trip efficiency for all energy storage units on a feeder.

19) Monthly demand charge: Because this is dependent on the business structure of specific utilities, this metric will not be used in evaluating the simulation results.

20) Distribution feeder or equipment overloads incidents: Because the taxonomy of prototypical feeders is used for analysis there are not overloads included. This is because the average distribution feeder does not normally have overload conditions. As a result, this metric will not be used.

21) Distribution feeder load: This metric gives the annual average hourly load as measured at the substation. Both real and reactive powers are examined.

22) Deferred distribution capacity investment: Because this is dependent on the business structure of specific utilities, this metric will not be used in evaluating the simulation results.

23) Equipment failure incidents: Because the conducted analysis uses representative technologies there is no information associated with equipment failure. The only failures are faults included for the analysis of FDIR. As a result this metric will not be used.

24) Distribution equipment maintenance cost: Because this is dependent on the business structure of specific utilities, this metric will not be used in evaluating the simulation results.

25) Distribution operations cost: Because this is dependent on the business structure of specific utilities, this metric will not be used in evaluating the simulation results.

26) Distribution feeder switching operations: Because this is dependent on the operational procedures and business structure of specific utilities, this metric will not be used in evaluating the simulation results. 
27) Distribution capacitor switching costs: Because this is dependent on the operational procedures and business structure of specific utilities, this metric will not be used in evaluating the simulation results.

28) Distribution restoration cost: Because this is dependent on the business structure of specific utilities, this metric will not be used in evaluating the simulation results.

29) Distribution losses: This metric measures the distribution losses; both series and shunt losses are included. Series losses due to overhead lines, underground lines, transformers, and triplex lines are included. Shunt losses due to underground lines and transformers are included. For the purposes of this metric all losses are combined into a single value but some plots will be provided that break the losses into the various components.

30) Distribution power factor: The distribution power factor is the power factor as calculated at the substation.

31) Truck tolls avoided: Because this is dependent on the operational procedures of specific utilities, this metric will not be used in evaluating the simulation results.

32) SAIFI: As defined in IEEE standard 1366 SAIFI is the system average interruption frequency index. SAIFI indicated how often the average customer experiences a sustained interruption and is calculated by dividing the sum of the total number of customers interrupted by the total number of customers served.

33) SAIDI/CAIDI: As defined in IEEE standard 1366 SAIDI is the system average interruption duration index. SAIDI indicates the total duration of interruption for the average customers and is calculated by dividing the sum of the customer interruption durations by the total number of customers served. As defined in IEEE standard 1366 CAIDI is the customer average interruption duration index. CAIDI represents the average time required to restore service and is calculated by dividing the sum of the customer interruption durations by the total number of customers interrupted.

34) MAIFI: As defined in IEEE standard 1366 MAIFI is the momentary average interruption frequency index. MAIFI is the average frequency of momentary interruptions and is calculated by dividing the sum of the total number of customer momentary interruptions by the total number of customers served.

35) Outage response time: When a fault occurs on the system there are several important times. How long to identify the existence of a fault, how long to locate the fault, and how long to repair the fault. The outage response time is the time between the occurrence of the fault and the time to identify the existence of the fault. 
36) Major event information: Major events generally impact a large geographic area which includes multiple distribution substations and the interconnecting transmission or subtransmission system. Since this report is looking primarily at individual feeders this metric will not be used.

37) Number of high impedance faults cleared: This metric is based on the occurrence of high impedance faults in a specific system. The occurrence of faults is only handled in the fault detection identification and restoration technology; high impedance faults are not specifically examined.

38) Distribution operations vehicle miles: Because this is dependent on the operational procedures of specific utilities, this metric will not be used in evaluating the simulation results.

39) CO2 emissions: This metric measures the $\mathrm{CO} 2$ emissions required to supply the demand as measured at the substations.

40) Pollutant emissions: This metric measures the SOx, NOx, and PM-10 emissions required to supply the demand as measured at the substations. 


\section{Appendix B: Taxonomy of Prototypical Distribution Feeders}

As part of the DOE-OE Modern Grid Initiative (MGI) efforts of 2008, a Taxonomy of Prototypical Distribution Feeders was developed [2]. The feeders within this taxonomy were designed to provide researchers with an openly available set of distribution feeder models which are representative of those seen in the continental United States. To construct these representative feeder models, actual feeder models were obtained from utilities across the country and their fundamental characteristics were examined. A detailed statistical analysis was conducted to determine the optimal subset of feeders that could effectively represent the entire data set. The development of the complete Taxonomy of feeder was an extensive process and is fully documented in the report titled "Modern Grid Initiative Distribution Taxonomy Final Report" [2]. Because climate and energy consumption are closely coupled, the prototypical feeders were divided into five climate regions, Figure B.1, based on the U.S DOE handbook (1980) providing design guidance for energy-efficient small office buildings [21].

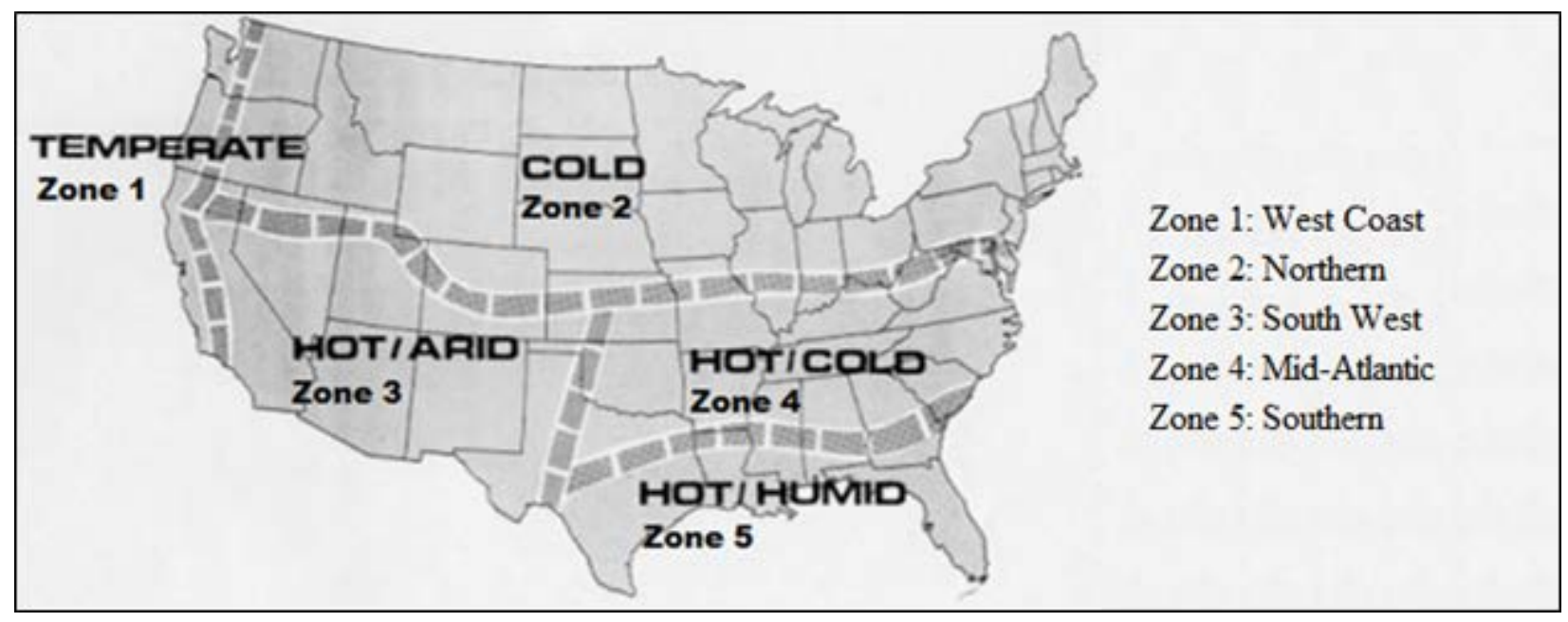

Figure B.1: Climate Zones Used for Development of Prototypical Feeders

Within each of the climate zones, there are a set of feeders that are approximations of the types of feeders that are seen within that zone. Table B.1 gives a summary of the 24 prototypical feeders, including feeder name, base voltage, peak load, and a qualitative description. The peak loading used for the SGIG project analysis is slightly different than the original values from the 2008 report. The difference in peak load is due to improved modeling methods used to represent the end-use load. These methods will be discussed in Sections B.2.1. and B.2.2. 
Table B.1: Summary of prototypical feeders

\begin{tabular}{|l|r|r|l|}
\hline \multicolumn{1}{|c|}{ Feeder } & $\begin{array}{c}\text { Base } \\
\mathrm{kV}\end{array}$ & Peak kVA & \\
\hline R1-12.47-1 & 12.5 & 4,300 & Moderate suburban and rural \\
\hline R1-12.47-2 & 12.47 & 2,400 & Moderate suburban and light rural \\
\hline R1-12.47-3 & 12.47 & 1,800 & Small urban center \\
\hline R1-12.47-4 & 12.47 & 4,900 & Heavy suburban \\
\hline R1-25.00-1 & 24.9 & 2,300 & Light rural \\
\hline R2-12.47-1 & 12.47 & 6,700 & Light urban \\
\hline R2-12.47-2 & 12.47 & 6,700 & Moderate suburban \\
\hline R2-12.47-3 & 12.47 & 4,800 & Light suburban \\
\hline R2-25.00-1 & 24.9 & 21,300 & Moderate urban \\
\hline R2-35.00-1 & 34.5 & 6,900 & Light rural \\
\hline R3-12.47-1 & 12.47 & 11,600 & Heavy urban \\
\hline R3-12.47-2 & 12.47 & 4,000 & Moderate urban \\
\hline R3-12.47-3 & 12.47 & 9,400 & Heavy suburban \\
\hline R4-12.47-1 & 13.8 & 6,700 & Heavy urban with rural spur \\
\hline R4-12.47-2 & 12.5 & 2,100 & Light suburban and moderate urban \\
\hline R4-25.00-1 & 24.9 & 1,000 & Light rural \\
\hline R5-12.47-1 & 13.8 & 10,800 & Heavy suburban and moderate urban \\
\hline R5-12.47-2 & 12.47 & 4,200 & Moderate suburban and heavy urban \\
\hline R5-12.47-3 & 13.8 & 4,800 & Moderate rural \\
\hline R5-12.47-4 & 12.47 & 6,200 & Moderate suburban and urban \\
\hline R5-12.47-5 & 12.47 & 8,500 & Moderate suburban and light urban \\
\hline R5-25.00-1 & 22.9 & 9,300 & Heavy suburban and moderate urban \\
\hline R5-35.00-1 & 34.5 & 12,100 & Moderate suburban and light urban \\
\hline GC-12.47-1 & 12.47 & 5,400 & Single large commercial or industrial \\
\hline & & & \\
\hline
\end{tabular}

The original prototypical feeders were modeled in detail from the substation to the end-use point of interconnection, but did not include detailed load models. To use these feeders for an accurate analytic assessment of the SGIG projects, it was necessary to model the end-use load models in the appropriate level of detail as was done for the 2010 report on Conservation Voltage Reduction [22].

\section{B.1 End-use Load Models}

The taxonomy of prototypical feeders accurately represents the electrical infrastructure of the distribution feeders, but not the end-use loads. Since it is the end-use loads that consume the majority of the energy on a distribution feeder, it is critical to accurately represent their operation. 
For the taxonomy of feeders to be of use the end-use loads are classified into various categories. In 2010, an analysis of conservation voltage reduction was conducted in GridLAB-D that classified loads, as shown in Table B.2 [22]. Because the analysis of the SGIG projects includes technologies other than conservation voltage reduction, a more complete handling of end-use load classifications is necessary and will be discussed in detail in section B.2. This is especially true of technologies such as demand response where the physical characteristics of the buildings are fundamental.

Table B.2: End-use load classifications

\begin{tabular}{|l|l|}
\hline \multicolumn{1}{|c|}{ Load Class } & \multicolumn{1}{c|}{ Description } \\
\hline Residential 1 & Pre-1980 <2000 sqft. \\
\hline Residential 2 & Post-1980<2000 sqft. \\
\hline Residential 3 & Pre-1980 >2000 sqft. \\
\hline Residential 4 & Post-1980 >2000 sqft. \\
\hline Residential 5 & Mobile Homes \\
\hline Residential 6 & Apartment Complex \\
\hline Commercial 1 & $>35$ kVA \\
\hline Commercial 2 & $<35$ kVA \\
\hline Industrial & All Industrial \\
\hline
\end{tabular}

Regardless of how end-use loads are classified, the component end-use loads are modeled as a combination of ZIP models and multi-state physical models. The ZIP load model and the multistate model are described in the following Sections.

\section{B.1.1 ZIP Loads}

ZIP models are two state models, energized and de-energized. When energized there is only a single operational state and the energy consumption can be determined using (B1) for real power, (B2) for reactive power, and (B3) as a constraint [24].

$$
\begin{aligned}
& P_{i}=\left[\frac{\left|V_{a}^{2}\right|}{\left|V_{n}^{2}\right|} \cdot\left|S_{n}\right| \cdot Z_{\%} \cdot \cos \left(Z_{\theta}\right)+\frac{\left|V_{a}\right|}{\left|V_{n}\right|} \cdot\left|S_{n}\right| \cdot I_{\%} \cdot \cos \left(I_{\theta}\right)+\left|S_{n}\right| \cdot P_{\%} \cdot \cos \left(P_{\theta}\right)\right] \\
& Q_{i}=\left[\frac{\left|V_{a}^{2}\right|}{\left|V_{n}^{2}\right|} \cdot\left|S_{n}\right| \cdot Z_{\%} \cdot \sin \left(Z_{\theta}\right)+\frac{\left|V_{a}\right|}{\left|V_{n}\right|} \cdot\left|S_{n}\right| \cdot I_{\%} \cdot \sin \left(I_{\theta}\right)+\left|S_{n}\right| \cdot P_{\%} \cdot \sin \left(P_{\theta}\right)\right] \\
& 100=Z_{\%}+I_{\%}+P_{\%}
\end{aligned}
$$


where:

$P_{i}: \quad$ real power consumption of the $\mathrm{i}^{\text {th }}$ load

$Q_{i}$ : $\quad$ reactive power consumption of the $\mathrm{i}^{\text {th }}$ load

$V_{a}$ : actual terminal voltage

$V n$ : nominal terminal voltage

$S_{n}: \quad$ apparent Power consumption at nominal voltage

$Z_{\%}$ : percent of load that is constant impedance

$I_{\%}$ : percent of load that is constant current

$P_{\%}$ : percent of load that is constant power

$Z_{\theta}$ : phase angle of constant impedance component

$I_{\theta}$ : phase angle of constant current component

$P_{\theta}$ : phase angle of constant power component

In a time-variant load representation, the coefficients of the ZIP model, $V_{\mathrm{n}}, S_{\mathrm{n}}, Z_{\%}, I_{\%}, P_{\%}, Z_{\theta}$, $I_{\theta}$, and $P_{\theta}$, remain constant, but the power consumption, $P_{i}$ and $Q_{i}$, of the $i^{\text {th }}$ load varies with the actual terminal voltage, $V_{a}$. The ZIP model is similar to the polynomial representation used in many commercial software packages. In the polynomial representation of the ZIP load, the constant coefficient is equivalent to $P \%$, the linear coefficient is equivalent to $I \%$, and the quadratic coefficient is equivalent to $Z_{\%}$. The ZIP model only varies the power consumption as a function of actual terminal voltage, $V_{a}$.

In (B1) and (B2), there are six constants that define the voltage dependent behavior of the ZIP load: $Z_{\%}, I_{\%}, P_{\%}, Z_{\theta}, I_{\theta}$, and $P_{\theta}$. Because the actual value of the distribution feeder voltage continually changes, it is critical to understand how the energy consumption of end-use loads will vary. Specifically, what are the six constants that accurately reflect various end-use loads? For loads such as a heating element, it is clear that the load is $100 \% \mathrm{Z}$, but for more complicated loads such as a Liquid Crystal Display (LCD) or Compact Florescent Light (CFL), the proper ratios are not as apparent.

As part of the 2010 report on conservation voltage reduction a number of laboratory tests were conducted to determine the six constants for various end-use loads; these values have been incorporated into the end-use load models for this study. Figure B.2 is an example of the laboratory testing that was conducted on a $13 \mathrm{~W}$ compact florescent light bulb. 

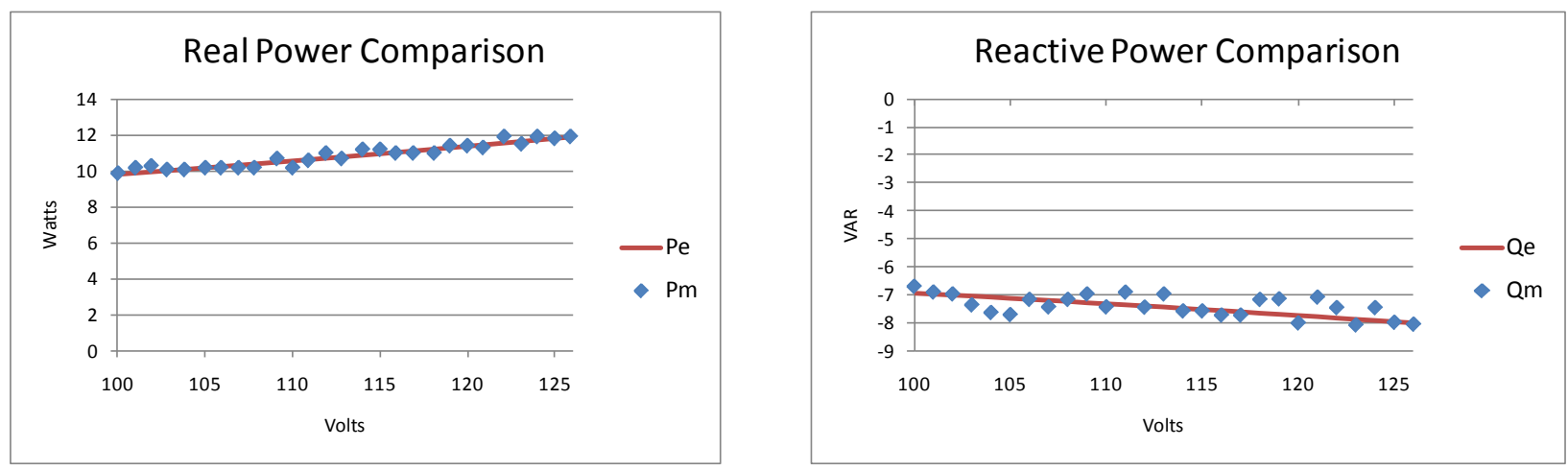

Figure B.2: Voltage dependent energy consumption of 13W CFL

\begin{tabular}{|l|c|c|c|c|c|c|}
\cline { 2 - 7 } \multicolumn{1}{c|}{} & \multicolumn{6}{c|}{ ZIP Values } \\
\cline { 2 - 7 } \multicolumn{1}{c|}{ Z-\% } & I-\% & P-\% & Z-pf & I- pf & P-pf \\
\hline CFL-13W & $40.85 \%$ & $0.67 \%$ & $58.49 \%$ & -0.88 & 0.42 & -0.78 \\
\hline
\end{tabular}

In traditional distribution analysis ZIP models are generally not developed for every individual load, instead models are developed for load classes such as residential, commercial, and industrial. Every load within a given load class then uses the same ZIP values with the exception of the apparent power consumption at nominal voltage, $S_{n}$. The value of $S_{n}$ for each load may change at 1-hour intervals to generate a daily load profile at the feeder level. The use of similar ZIP values for each load class, which only change at 1-hour intervals, is not able to represent coincidental load peaks that occur at the distribution level.

\section{B.1.2 Single-State Detailed Physical Models}

When the energy consumption of an end-use load is a function of variables other than terminal voltage, the use of a ZIP model is not adequate. This is true of any load with an external control system or an internal control loop. To illustrate this issue, the air conditioning system of a single family residence will be examined while in the cooling mode. As with the ZIP model, an air conditioning system is a two state model (ON or OFF), but only has a single operational state.

Because a cooling system operates to maintain internal air temperature within a band, parameters such as near term history of operation, time of year, outside air temperature, building construction, and terminal voltage will impact the instantaneous power consumption, as well as the energy consumption. To examine these issues, a physical model of the cooling system and the structure of the building, is constructed using an equivalent thermal parameter (ETP) model [24]. Because the ETP model has been shown to be an accurate representation of residential and small commercial building instantaneous power draw, as well as energy consumption, it will be used for the formulation of the physical model. 
Figure B.3 is a diagram showing the heat flow for the ETP model of a single family residence, i.e., a house. While the heating/cooling system can be one of any numerous types, for the purposes of this paper, it is assumed that the system is a heat pump in the cooling mode. In addition to the heat removal of the heat pump while cooling and the heat gain through the building exterior, there are two additional significant flows of heat within a house: incident solar radiation and internal gains from waste heat generated by end-use loads. These sources and sinks of heat constitute the total heat energy exchange in the house. This flow of heat is then divided between the air in the house and the mass of the house, i.e., walls and furniture. A portion of the incident solar energy shining through a window will heat the interior air of the house, while the remaining incident energy will be absorbed by the walls, floors, and furniture. The same division occurs with the waste heat from end-use loads. The internal air temperature of the house is thermally coupled to the internal mass temperature, and the internal air temperature is then thermally coupled to the outside air temperature through the thermal envelope of the house.

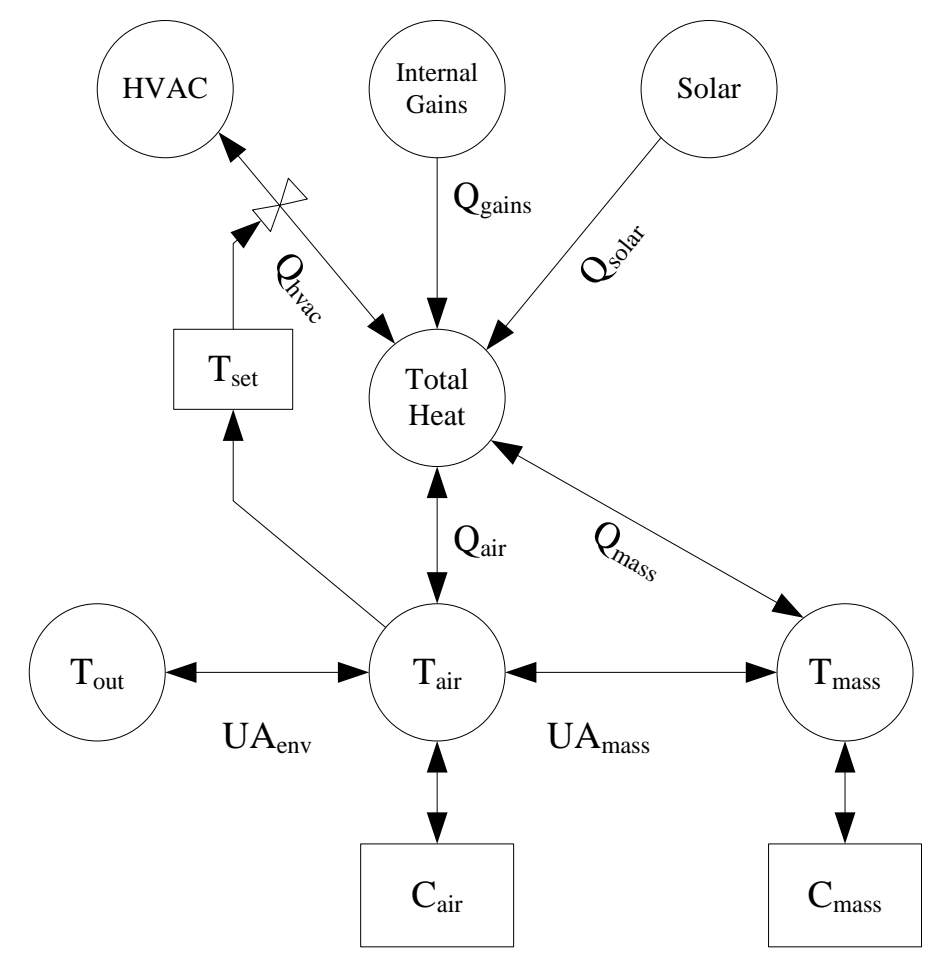

Figure B.3: The ETP mode of a residential heating/cooling system

where,

$\begin{array}{ll}C_{\text {air }}: & \text { air heat capacity }\left(\mathrm{Btu} /{ }^{\circ} \mathrm{F}\right) \\ C_{\text {mass }}: & \text { mass heat capacity }\left(\mathrm{Btu} /{ }^{\circ} \mathrm{F}\right) \\ U A_{\text {env }}: \text { external gain } / \text { heat loss coefficient }\left(\mathrm{Btu} /{ }^{\circ} \mathrm{F}-\mathrm{h}\right) \\ U A_{\text {mass }}: & \text { internal gain } / \text { heat loss coefficient }\left(\mathrm{Btu} /{ }^{\circ} \mathrm{F}-\mathrm{h}\right) \\ T_{\text {out }}: & \text { air temperature outside the house }\left({ }^{\circ} \mathrm{F}\right)\end{array}$




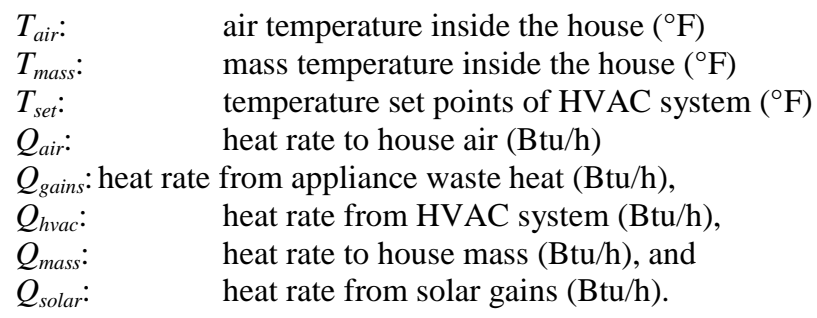

Equation (B4) is the second order differential equation that describes the heat flows shown in Figure B.3 [24]. Its solution determines the time-varying temperature of the house, both air and mass, given the thermal inputs. With the inside air temperature, $T_{a i r}$, known, the thermal behavior of the heat pump system in response to the defined thermostatic set point, $T_{\text {set }}$, can be determined.

$$
a \frac{d^{2} T_{a i r}}{d t^{2}}+b \frac{d T_{a i r}}{d t}+c T_{\text {air }}=d
$$

Where,

$$
\begin{aligned}
& a=\frac{C_{\text {mass }} \cdot C_{\text {air }}}{U A_{\text {mass }}} \\
& b=\frac{C_{\text {mass }} \cdot\left(U A_{\text {env }}+U A_{\text {mass }}\right)}{U A_{\text {mass }}}+C_{\text {air }} \\
& c=U A_{\text {env }} \\
& d=Q_{\text {mass }}+Q_{\text {air }}+\left(U A_{\text {env }} \cdot T_{\text {out }}\right)
\end{aligned}
$$

With the temperature of the house known from (B4) and the occupant-controlled set point fixed, the operation of the cooling system can be determined. Based on these values, the cooling system will operate long enough to remove the heat necessary to maintain the inside air temperature, $T_{\text {air }}$, within the desired range. The electrical input energy to the motor, $S_{\text {comp-motor, }}$ necessary to provide the thermal heat energy, is a function of two elements: the heat flow through the cooling unit, $Q_{h v a c}$, and the electrical losses of the compressor motor, $S_{\text {losses}}$; as shown in (B5) [23] - [24]. 


$$
S_{\text {comp-motor }}=\left[Q_{\text {hvac }}\left(T_{\text {out }}, V_{T}, C O P\right)+S_{\text {losses }}\left(V_{T}\right)\right]
$$

The coefficient of performance (COP) is a scalar value that relates the cooling rate of the heat pump unit to the mechanical power delivered by the compressor as a function of temperature and operation time. A higher value of COP indicates less electrical power is necessary to remove a given amount of heat from the air. $V_{T}$ is the terminal voltage of the system compressor motor. Additionally, it should be noted that $Q_{\text {hvac }}$ is expressed in terms of British thermal units (Btu) consistent with the conventions of the heating/cooling industry in the United States and the derivation of the ETP model of [24], while $S_{\text {losses }}$ is expressed in SI units. As a result, the two terms of (B5) must be converted using the conversion of $1.0 \mathrm{Btu} / \mathrm{h}=0.2931 \mathrm{~W}$.

Because both of the elements of (B5) are voltage dependent, changes in line voltage will cause a change in power consumption. The cooling system's heat removal rate, $Q_{h v a c}$, can be solved using heat transfer equations based on the available mechanical torque of the compressor [24]. The motor losses, $S_{\text {losses, }}$, can be determined using the traditional split phase motor model of [23] and [24]. When (B5) is implemented in a time-series simulation, the result is a model that determines the energy consumption, both real and reactive, of the cooling system as a function of the outside air temperature, the inside air temperature, equipment parameters, terminal voltage, and occupant-controlled set point.

Unlike ZIP models that apply the same values to each load in a given load class, physical models are specific to each individual load. The values of physical models vary on a 1 second or 1 minute basis to capture the true time-variant nature of the end-use load.

The previous example of a physical model has examined a heat pump in the cooling mode, which is one of multiple operational states. Because of the design of heat pumps, their energy consumption varies according to their current operational state. To properly capture the energy consumption it is necessary to construct a multi-state load model.

\section{B.1.3 Multi-State Detailed Physical Models}

A multi-state time-variant load model uses more than one state to describe the energy consumption of an end-use load. Each state is governed either by a ZIP model and/or a physical model, with transitions between states determined by either internal state transition rules or external signals. For example, a typical heat pump has four normal operating states: State 1 (off), State 2 (cooling), State 3 (heating-normal), and State 4 (heating-emergency). State 2 operates as described in the previous section, and State 3 follows a similar description but with different values that represent the change in the heating cycle, i.e., heat is added instead of removed. State 4 operates as State 3, except that the COP is 1.0 and the load is a ZIP model. There are other abnormal states such as "stalled compressor motor" or "low refrigerant charge", but they will not 
be examined in this paper. Additionally, there are numerous heat pump types and many differing thermostatic controllers that are commercially available, but this paper will discuss a "typical" design. Because a heat pump has two heat-flow configurations, the value of $T_{\text {set }}$ must be split into a heating set point, $T_{\text {low }}$, and a cooling set point, $T_{\text {high }}$. These set points determine the mode of operation of the heat pump system at any given time: off, cooling, heating-normal, or heatingemergency, as shown in Figure B.4.

For a simple single state simulation, the heat pump system would be operating to either heat or cool the house, as discussed in the previous section. For a time-series simulation, the multi-state model captures the transitions between states. While a heat pump system may not transition through all operational states in a single day, it is likely that it will transition through more than one state in any given day. For example, on a mild autumn night, the heat pump may operate to heat the house, then as the sun heats the house during the day, it may be necessary to switch to cooling.

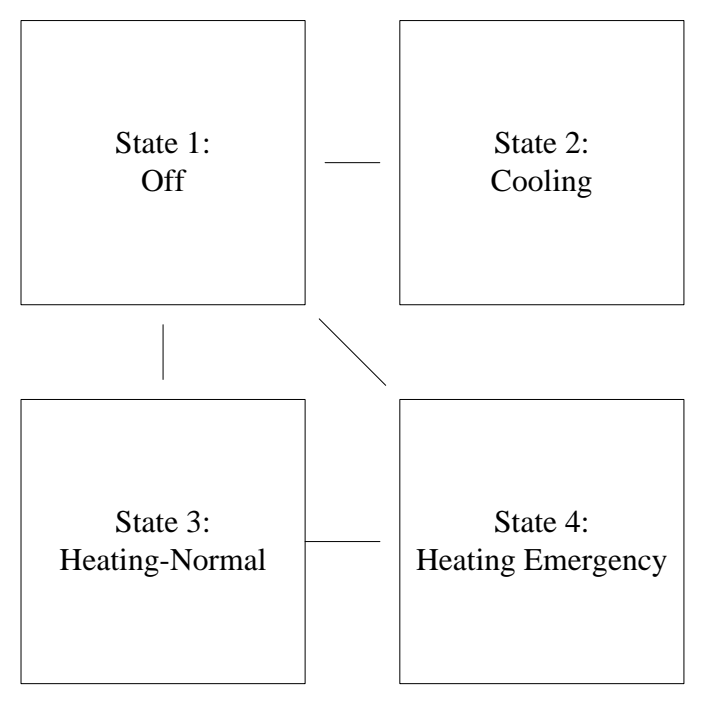

Figure B.4: Multi-state load model

To be in States 2, 3, or 4, the heat pump unit must be turned "on" with defined set points, both occupant-controlled and internal. The occupant-controlled set points are $T_{\text {high }}$ and $T_{\text {low. }}$ If the internal air temperature $T_{\text {air }}$ rises above $T_{\text {high }}$ plus a dead band, $D B_{\text {high }}$, then the heat pump will start cooling. If $T_{\text {air }}$ decreases below $T_{\text {low }}$ minus a dead band, $D B_{\text {low }}$ then the heat pump will start heating normally. If $T_{\text {out }}$ decreases to a temperature, $T_{\text {aux }}$, where the heat pump efficiency becomes too low to effectively heat the home, the system will start heating in the emergency state using resistive heating elements. In addition to the internal control parameters of $T_{a u x}$, the $D B_{\text {low }}$ and $D B_{\text {high }}$ are internal parameters that are not occupant-controlled, but are included to prevent the heat pump from cycling excessively. Table B.3 gives the logic for the allowable state transitions shown in Figure B.4. 
Table B.3: Heat pump state transition logic

\begin{tabular}{|c|c|c|}
\hline From State & To State & Transition Rule \\
\hline 1 & 2 & $T_{\text {air }}>\left(T_{\text {high }}+D B_{\text {high }}\right)$ \\
\hline 1 & 3 & $T_{\text {air }}<\left(T_{\text {low }}-D B_{\text {low }}\right)$ \\
\hline 1 & 4 & $\begin{array}{c}T_{\text {air }}<\left(T_{\text {low }}-D B_{\text {low }}\right) \& T_{\text {out }} \\
<T_{\text {aux }}\end{array}$ \\
\hline 2 & 1 & $T_{\text {air }}<\left(T_{\text {high }}-D B_{\text {high }}\right)$ \\
\hline 3 & 1 & $T_{\text {air }}>\left(T_{\text {low }}+D B_{\text {low }}\right)$ \\
\hline 3 & 4 & $T_{\text {out }}<T_{\text {aux }}$ \\
\hline 4 & 1 & $T_{\text {air }}>\left(T_{\text {low }}+D B_{\text {low }}\right)$ \\
\hline
\end{tabular}

Each of the four discrete states of operation has a different set of characteristics that determine the instantaneous power consumption. In State 1, there is no power draw because the system is off. In State 2 and State 3, there is an electric fan motor plus a compressor motor. Similar to State 3, State 4 provides heating with an associated electric fan for ventilation, but with the difference that heating is provided by resistive heating elements and not a heat pump. The instantaneous power draw of the four states shown in Figure B.4 is given by (B6)-(B9).

State 1: Off

$$
S_{H V A C}=0
$$

State 2: Cooling

$$
S_{\text {HVAC }}=S_{\text {fan-motor }}+S_{\text {comp-motor }}
$$

State 3: Heating-Normal

$$
S_{\text {HVAC }}=S_{\text {fan-motor }}+S_{\text {comp-motor }}
$$

State 4: Heating-Emergency 


$$
S_{\text {HVAC }}=S_{\text {fan-motor }}+\frac{V_{T}^{2}}{R_{\text {elements }}}
$$

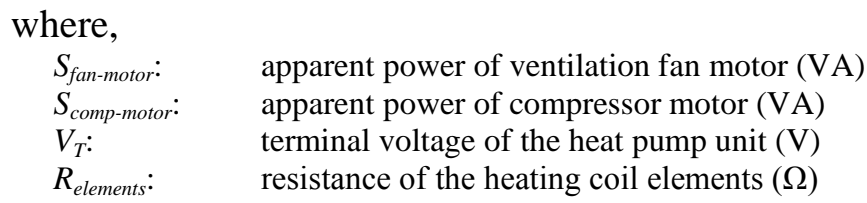

While the power consumption for State 2 and State 3, given by (B7) and (B8) respectively appear to be the same, there are different internal models for $Q_{h v a c}$, particularly with respect to the COPs. With the instantaneous power draw determined by (B6)-(B9), the time necessary to heat or cool the house to within the occupant-controlled set points is determined by the solution to (B4). The result is that variations in temperature, voltage, and efficiency are translated into a variable duty cycle of the heat pump. This information can then be used to determine the instantaneous power demand and the energy consumption of the heat pump over time.

\section{B.2 Model Extraction and Population}

Section B.1 discussed the physical infrastructure of the distribution feeders and gave an overview of the level of detail that is modeled at the end-use. This section describes how the detailed end-use models are populated onto the prototypical distribution feeders.

The taxonomy of prototypical feeders was originally populated with a series of spot loads representing a standard peak load study. Each spot load was classified as residential, commercial, agricultural, or industrial. In this analysis, due to the broad nature of industrial and agricultural loads and the difficulty in accurately representing these loads, each of these loads was re-classified as commercial, leaving only residential and commercial loads. Each load was replaced with building models appropriate to the region of the United States where the prototypical feeder was located. The representative commercial and residential models will be described here.

\section{B.2.1 Residential Loads}

At each triplex node, the residential spot load was replaced with a number of residential house models, which under peak conditions approximately matched the original spot load. The number of house models replacing the original peak load depended upon a scaling factor unique to each taxonomy feeder model and was used to calibrate the populated feeder model to the peak load study. For example, if the original spot load was $10 \mathrm{kVA}$ and the feeder scaling factor was determined to be $5 \mathrm{kVA}$ / house, the spot load would be replaced with two house models. In all cases, the number of homes was rounded to the nearest integer, while the residual from the 
rounding was used as a weighting factor. For example, if the same $10 \mathrm{kVA}$ load was used with a scaling factor of $5.5 \mathrm{kVA} /$ home, the number of homes would be 1.82 . The number was rounded to two homes and the difference of 0.18 was used as a weighting factor on the square footage of the homes populated at that location, creating two house models with a slightly lower than the average square footage. The scaling factor was used to calibrate the new feeder model to the peak load study. Multiple annual simulations were run on each feeder until the peak load for the annual simulation approximately equaled that of the peak load study.

The parameters of each home were determined by the climate region the feeder was located in. Data from the Energy Information Administration's (EIA) 2005 Residential Energy Consumption Survey [25] was used to create a population of homes for each feeder which contained the average characteristics from that region. The EIA divides the country into ten regions, while the U.S. DOE Handbook providing design guidance for energy-efficient small office buildings [13], which was used to create the taxonomy feeders, only uses five. Table B.4 shows the weighting factors used to map the characteristics between the two sets of regional data.

Table B.4: Table of weighting factors for mapping regional parameters

\begin{tabular}{|c|c|c|c|}
\hline \multicolumn{2}{|c|}{ Taxonomy Feeder Climate Regions } & \multicolumn{2}{|c|}{ Building Survey Climate Region Weighting } \\
\hline 1 & West Coast & 1 & Pacific \\
\hline \multirow{5}{*}{2} & \multirow{5}{*}{ Northern } & 0.5 & Mountain \\
\hline & & 1 & W N Central \\
\hline & & 1 & E N Central \\
\hline & & 1 & Mid Atlantic \\
\hline & & 1 & New England \\
\hline \multirow{2}{*}{3} & \multirow{2}{*}{ Southwest } & 0.5 & Mountain \\
\hline & & 0.33 & W S Central \\
\hline \multirow{3}{*}{4} & \multirow{3}{*}{ Mid-Atlantic } & 0.33 & W S Central \\
\hline & & 0.5 & E S Central \\
\hline & & 0.5 & S Atlantic \\
\hline \multirow{3}{*}{5} & \multirow{3}{*}{ Southern } & 0.33 & W S Central \\
\hline & & 0.5 & E S Central \\
\hline & & 0.5 & S Atlantic \\
\hline
\end{tabular}

From the EIA data and the weighting factors, a set of key, average building parameters were created as a basis for the population of each feeder. The residential building models were broken into three types: single family homes, apartments, and mobile homes. The age of the home was used to create a set of thermal integrity levels for each housing age and type, from poorly insulated to well insulated, and key parameters were assigned by region and age of home. Table B.5 shows the average thermal integrity properties by age of the single family homes, 
apartments, and mobile homes. Each of these parameters was then randomized, where appropriate, around the average value with either a normal or uniform distribution to create a diversified population which approximately represents the average household characteristics in that region. More details on the randomizations used can be found in the feeder generator script found on the open source repository [4].

Table B.6, Table B.7, and Table B.8 provide a breakdown of the percentage of single family homes, apartments, and mobile homes, and their corresponding ages, used in creating the randomized population of buildings per region. In addition, other average parameter values were extracted from the EIA documentation, including square footage, cooling and heating set points, heating type, air conditioning penetration, electric water heater penetration, and pool pump penetration. These are listed in Table B.9 through Table B.11.

Table B.5: Residential thermal integrity values by age of home

\begin{tabular}{|c|c|c|c|c|c|c|c|c|c|c|c|}
\hline & $\begin{array}{c}\mathrm{R} \\
\text { Roof }\end{array}$ & $\begin{array}{c}\mathrm{R} \\
\text { Wall }\end{array}$ & $\begin{array}{c}\mathrm{R} \\
\text { Floor }\end{array}$ & $\begin{array}{c}\text { Glass } \\
\text { Layers }\end{array}$ & $\begin{array}{c}\text { Glass } \\
\text { Type }\end{array}$ & $\begin{array}{c}\text { Glazing } \\
\text { Treatment }\end{array}$ & $\begin{array}{c}\text { Window } \\
\text { Frame }\end{array}$ & $\begin{array}{c}\mathrm{R} \\
\text { Door }\end{array}$ & $\begin{array}{c}\text { Air } \\
\text { Infiltration }\end{array}$ & $\begin{array}{c}\text { COP } \\
\text { High }\end{array}$ & $\begin{array}{c}\text { COP } \\
\text { Low }\end{array}$ \\
\hline Single Family & & & & & & & & & & & \\
\hline Pre-1940 & 16 & 10 & 10 & 1 & Glass & Clear & Alum. & 3 & 0.75 & 2.8 & 2.4 \\
\hline $1940-1949$ & 19 & 11 & 12 & 2 & Glass & Clear & Alum. & 3 & 0.75 & 3.0 & 2.5 \\
\hline $1950-1959$ & 19 & 14 & 16 & 2 & Glass & Clear & Alum. & 3 & 0.50 & 3.2 & 2.6 \\
\hline $1960-1969$ & 30 & 17 & 19 & 2 & Glass & Clear & TB & 3 & 0.50 & 3.4 & 2.8 \\
\hline $1970-1979$ & 34 & 19 & 20 & 2 & Glass & Clear & TB & 3 & 0.50 & 3.6 & 3.0 \\
\hline $1980-1989$ & 36 & 22 & 22 & 2 & Low-e & Clear & TB & 5 & 0.25 & 3.8 & 3.0 \\
\hline $1990-2005$ & 48 & 28 & 30 & 3 & Low-e & Abs. & Ins. & 11 & 0.25 & 4.0 & 3.0 \\
\hline Apartment & & & & & & & & & & & \\
\hline Pre-1960 & 13 & 12 & 9 & 1 & Glass & Clear & Alum. & 2 & 0.75 & 2.8 & 1.9 \\
\hline $1960-1989$ & 20 & 12 & 13 & 2 & Glass & Abs. & TB & 3 & 0.25 & 3.0 & 2.0 \\
\hline $1990-2005$ & 29 & 14 & 13 & 2 & Low-e & Refl. & Ins. & 6 & 0.13 & 3.2 & 2.1 \\
\hline Mobile Home & & & & & & & & & & \\
\hline $1960-1989$ & 13 & 9 & 12 & 1 & Glass & Clear & Alum. & 2 & 0.75 & 2.8 & 1.9 \\
\hline $1990-2005$ & 24 & 12 & 18 & 2 & Low-e & Clear & TB & 3 & 0.75 & 3.5 & 2.2 \\
\hline
\end{tabular}

Note 1: R is in units of ${ }^{\circ} \mathrm{F} . s f . h / \mathrm{BTU}$, air infiltration is in units of air changes / hour, COP is in units of BTU/kWh

Note 2: Low-e refers to low emissivity glass, Abs. refers to absorptive glass, Refl. refers to reflective glass, Alum. refers to an aluminum frame, TB refers to thermal break insulation, Ins. refers to insulated

Table B.6: Percentage of single family homes in total population by age and region

\begin{tabular}{|l|c|c|c|c|c|c|c|}
\hline & Pre-1940 & $\begin{array}{c}1940- \\
1949\end{array}$ & $\begin{array}{c}1950- \\
1959\end{array}$ & $\begin{array}{c}1960- \\
1969\end{array}$ & $\begin{array}{c}1970- \\
1979\end{array}$ & $\begin{array}{c}1980- \\
1989\end{array}$ & $\begin{array}{c}1990- \\
2005\end{array}$ \\
\hline Region 1 & 8.05 & 7.24 & 10.90 & 8.67 & 13.84 & 12.64 & 12.97 \\
\hline Region 2 & 15.74 & 7.02 & 12.90 & 9.71 & 9.41 & 7.44 & 15.32 \\
\hline Region 3 & 4.48 & 2.52 & 8.83 & 8.43 & 11.85 & 13.15 & 24.11 \\
\hline Region 4 & 5.26 & 3.37 & 8.06 & 8.27 & 10.81 & 12.49 & 25.39 \\
\hline Region 5 & 5.26 & 3.37 & 8.06 & 8.27 & 10.81 & 12.49 & 25.39 \\
\hline
\end{tabular}


Table B.7: Percentage of apartments in total population by age and region

\begin{tabular}{|c|c|c|c|}
\hline & Pre-1960 & $\begin{array}{c}1960- \\
1989\end{array}$ & $\begin{array}{c}1990- \\
2005\end{array}$ \\
\hline Region 1 & 3.56 & 12.23 & 2.56 \\
\hline Region 2 & 4.81 & 8.87 & 3.03 \\
\hline Region 3 & 1.98 & 11.59 & 4.78 \\
\hline Region 4 & 2.17 & 10.91 & 5.02 \\
\hline Region 5 & 2.17 & 10.91 & 5.02 \\
\hline
\end{tabular}

Table B.8: Percentage of mobile homes in total population by age and region

\begin{tabular}{|c|c|c|}
\hline & $\begin{array}{c}1960- \\
1989\end{array}$ & $\begin{array}{c}1990- \\
2005\end{array}$ \\
\hline Region 1 & 5.54 & 1.81 \\
\hline Region 2 & 8.87 & 3.03 \\
\hline Region 3 & 5.24 & 3.02 \\
\hline Region 4 & 4.91 & 3.33 \\
\hline Region 5 & 4.91 & 3.33 \\
\hline
\end{tabular}

Table B.9: Percentage of key building parameters by region

\begin{tabular}{|c|c|c|c|c|c|c|c|}
\hline & \multicolumn{3}{|c|}{ Heating Fuel Type } & \multirow{2}{*}{$\begin{array}{c}\text { With Air } \\
\text { Conditioner }\end{array}$} & \multirow{2}{*}{$\begin{array}{l}\text { With Electric } \\
\text { Water Heater }\end{array}$} & \multirow{2}{*}{$\begin{array}{c}\text { With Pool } \\
\text { Pump* }\end{array}$} & \multirow{2}{*}{$\begin{array}{c}\text { One-Story } \\
\text { Home* }\end{array}$} \\
\hline & Non-Electric & Heat Pump & Resistance & & & & \\
\hline Region 1 & 70.51 & 3.21 & 26.28 & 43.48 & 25.45 & 9.04 & 68.87 \\
\hline Region 2 & 89.27 & 1.77 & 8.96 & 75.28 & 25.15 & 5.91 & 52.10 \\
\hline Region 3 & 67.23 & 5.59 & 27.18 & 52.59 & 34.80 & 8.18 & 77.45 \\
\hline Region 4 & 44.25 & 19.83 & 35.92 & 96.73 & 64.28 & 6.57 & 70.43 \\
\hline Region 5 & 44.25 & 19.83 & 35.92 & 96.73 & 64.28 & 6.57 & 70.43 \\
\hline
\end{tabular}

*Note: Percentage with pool pumps and one-story homes was only applied to single family homes. 
Table B.10: Percentage of nighttime heating and cooling set points by housing type

\begin{tabular}{|c|c|c|c|}
\hline & $\begin{array}{c}\text { Single } \\
\text { Family }\end{array}$ & Apartment & $\begin{array}{c}\text { Mobile } \\
\text { Home }\end{array}$ \\
\hline Set point $\left({ }^{\circ} \mathrm{F}\right)$ & \multicolumn{3}{|c|}{ Cooling } \\
\hline $65-69$ & 9.8 & 15.5 & 13.8 \\
\hline $70-70$ & 14.0 & 20.7 & 17.2 \\
\hline $71-73$ & 16.6 & 10.3 & 17.2 \\
\hline $74-76$ & 30.6 & 31.0 & 27.6 \\
\hline $77-79$ & 20.6 & 15.5 & 13.8 \\
\hline $80-85$ & 8.4 & 6.9 & 10.3 \\
\hline & \multicolumn{3}{|c|}{ Heating } \\
\hline $59-63$ & 14.1 & 8.5 & 12.9 \\
\hline $64-66$ & 20.4 & 13.2 & 17.7 \\
\hline $67-69$ & 23.1 & 14.7 & 16.1 \\
\hline $70-70$ & 16.3 & 27.9 & 27.4 \\
\hline $71-73$ & 12.0 & 10.9 & 8.1 \\
\hline $74-79$ & 14.1 & 24.8 & 17.7 \\
\hline
\end{tabular}

Table B.11: Average square footage by building type and region

\begin{tabular}{|c|c|c|c|}
\hline & $\begin{array}{c}\text { Single } \\
\text { Family }\end{array}$ & Apartment & $\begin{array}{c}\text { Mobile } \\
\text { Home }\end{array}$ \\
\hline Region 1 & 2209 & 820 & 1054 \\
\hline Region 2 & 2951 & 798 & 1035 \\
\hline Region 3 & 2370 & 764 & 1093 \\
\hline Region 4 & 2655 & 901 & 1069 \\
\hline Region 5 & 2655 & 901 & 1069 \\
\hline
\end{tabular}

Of note is the cooling and heating set points found in Table B.10. Heating and cooling set points bins were chosen randomly and independently, except to require that the heating set point be below the cooling set point. Within each bin a uniform distribution was used to determine the actual nighttime set point for each home. Additionally, data from the surveys showed average daytime versus nighttime offsets. Offsets were uniformly distributed between zero and twice the average offset, and the time at which the offsets occurred was randomized across the population. Figure B.5 provides a few examples of the diversity of cooling set points established through this methodology, while Figure B.6 shows the average cooling set point on a summer day of all the residential homes within the R1-12.47-2 feeder. 


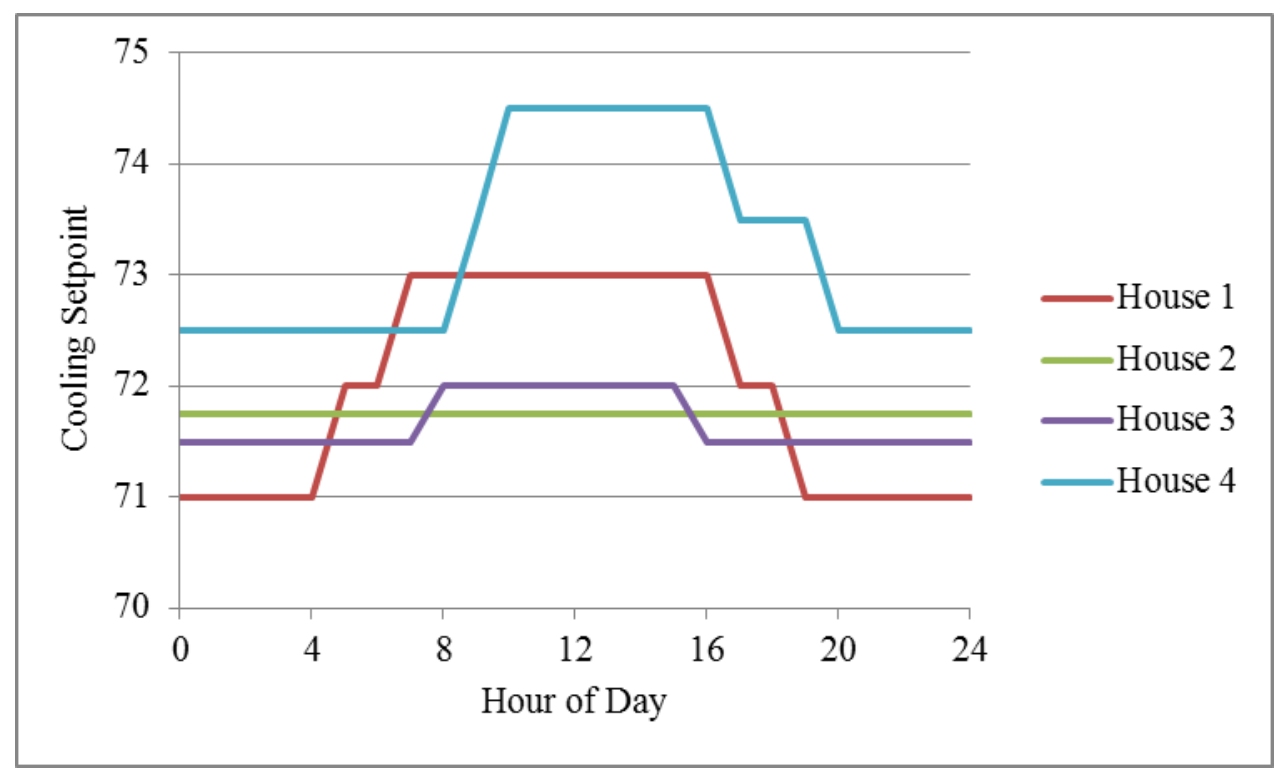

Figure B.5: Exemplary cooling set points diversified with time and daytime and nighttime offsets

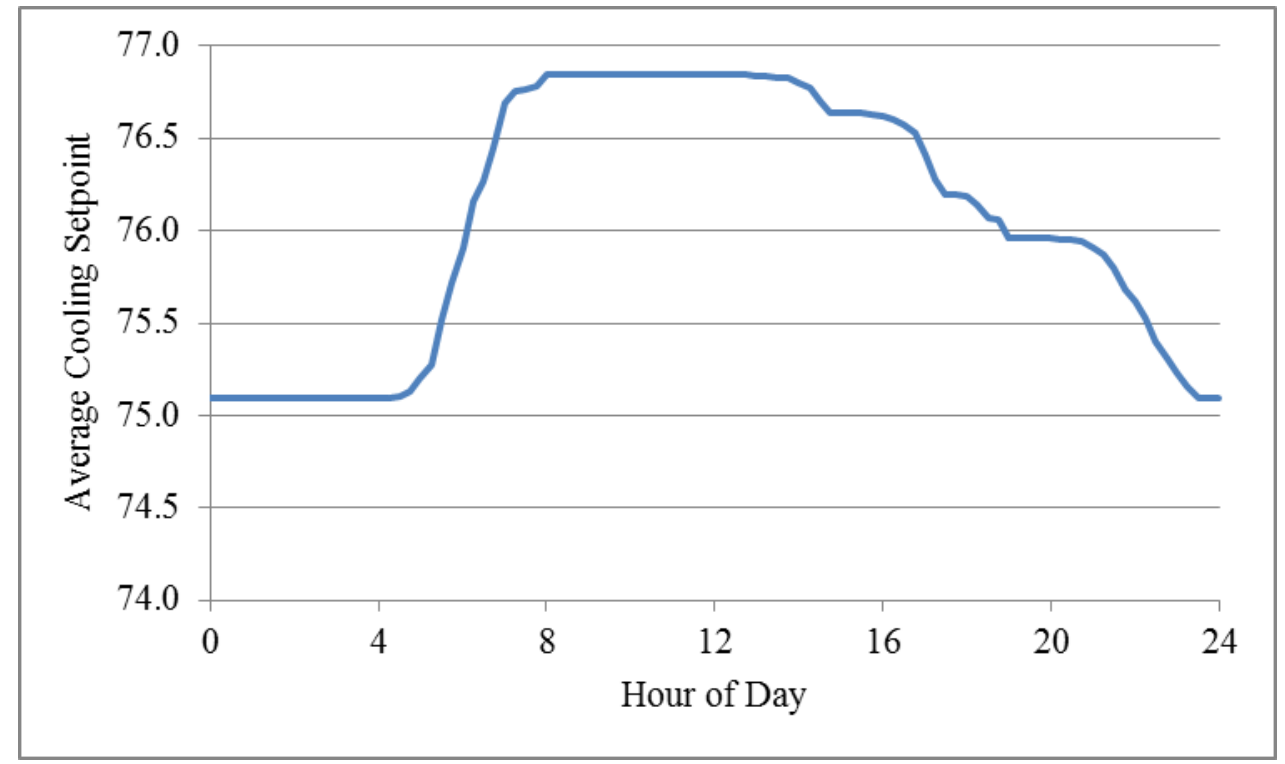

Figure B.6: Average cooling set points of entire population of R1-12.47-2

It is important to note that the populated building models were not designed to represent any particular feeder circuit or city in the United States, but rather as a blended average of large climate regions within the United States. While this will not perfectly capture the behavior of any particular city or utility, it is designed as a representative analysis. Additional methods exist where a utility can provide very specific load data which is much more representative of the local population, and design an analysis which is much more suited to that particular application. 
The parameter values, in conjunction with estimated demand, were used to describe the state models of the hot water heater, HVAC system, and pool pump. However, additional loads were represented as scheduled ZIP loads. "Appliances" such as refrigerators and lights were divided into two categories: responsive and unresponsive loads. Responsive loads indicate that the customer is able to modify the behavior of the appliance due to a price signal, while unresponsive loads indicate that the customer is typically not willing or able to modify the behavior without investment in additional technologies (e.g. demand response enabled appliances). Responsive loads included lights, plug loads, clothes washers, clothes dryers, dishwashers, cooking ranges, and microwaves, while unresponsive loads included refrigerator and freezer loads. These were divided in anticipation of demand response studies and the shift of customer behavior that is associated with Time-of-Use or Critical Peak pricing. ELCAP load data [18] was used to create a base hourly load profile for responsive and unresponsive loads, with adjustments made for 20 years of increased efficiency and increased or decreased demand, and included seasonal and weekday versus weekend effects, as shown in Figure B.7 and Figure B.8. Additionally, loads were scaled as a function of square footage using a regression, again using ELCAP data. The proper scalar from the regression is shown in (B10):

$$
k=324.9 * \text { floor }_{\text {area }}{ }^{.42} * 1000 / 8760
$$

The scalar was then randomized +/- $20 \%$ over a uniform distribution. While this provided no single home with a load shape representative of a time-series of an actual home, the aggregate load shape was representative of an entire population of homes, and internal loading of each home provided internal heat gains appropriate to that size of home. 


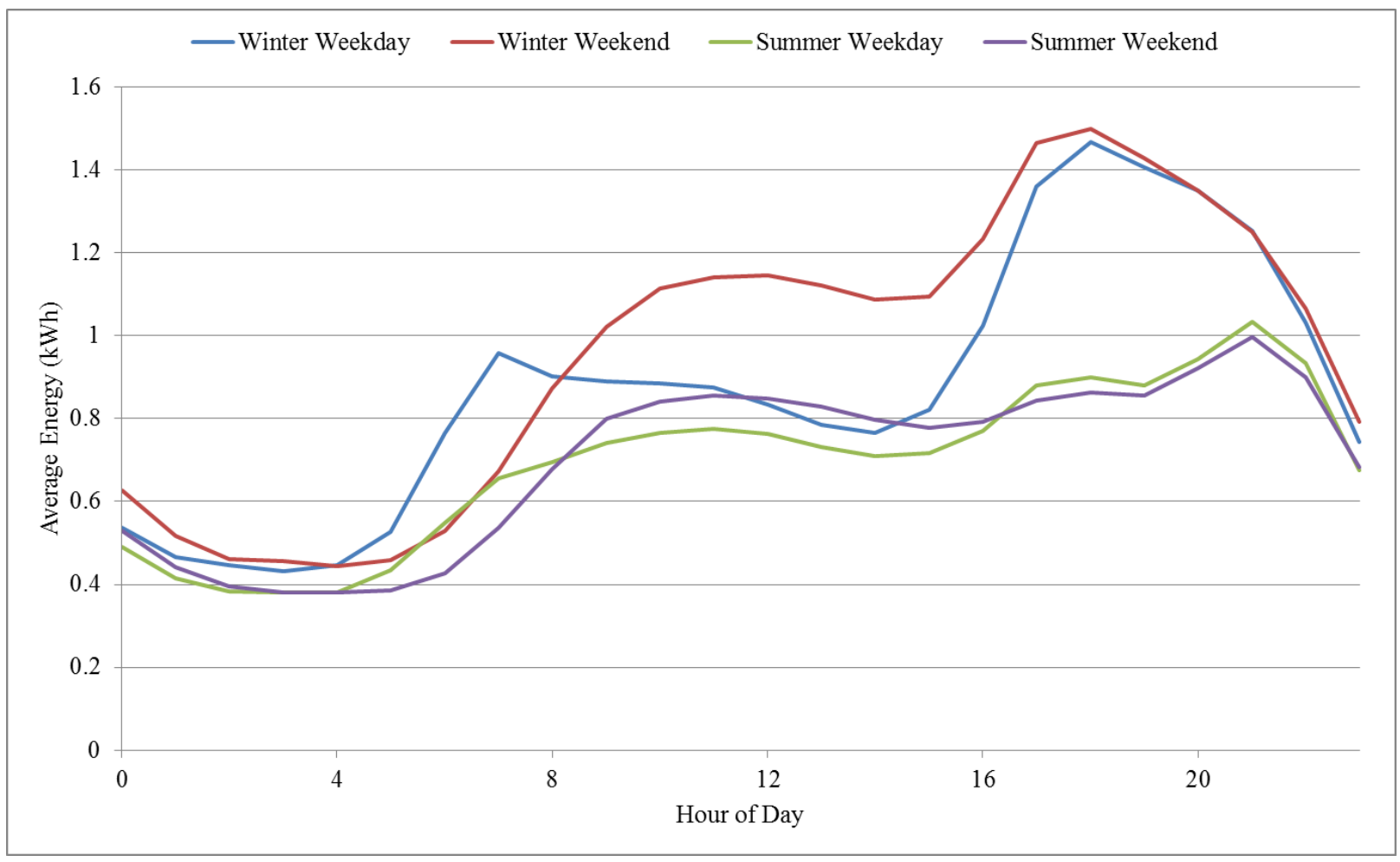

Figure B.7: Average energy consumption of responsive loads

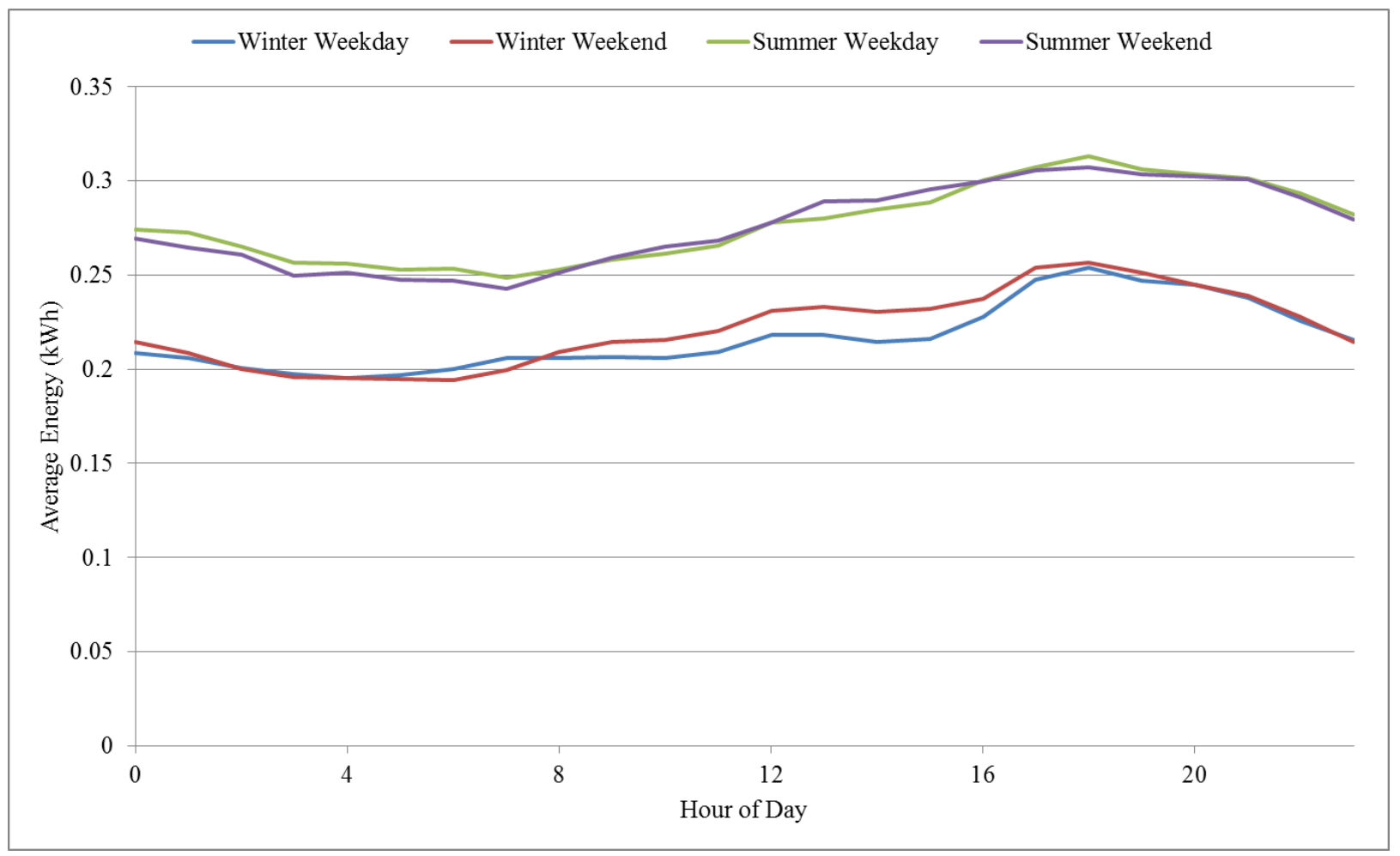

Figure B.8: Average energy consumption of unresponsive loads 


\section{B.2.2 Commercial Loads}

At this time, a fully implemented, multi-zone commercial building model is not available within GridLAB-D. However, to represent the "zones" of a commercial building, multiple house models were created to represent the commercial load. These loads were created using very generic commercial building characteristics and load patterns. The commercial loads (and the re-classified industrial and agricultural loads) were divided into three types: office buildings, large retail "box" buildings, and small retail strip malls. The key characteristics of these models were developed through federally-supported building codes and end-use metering studies, and are not based on regional differences as the residential models were [19-20]. Population of the prototypical feeders and the three types of buildings was performed by size of the original load and the number of phases the load was attached to. Similar to the residential loading, a scalar was used to calibrate the loading on each feeder model, modifying the number of loads and size of each load.

Office buildings were represented by a three-story, fifteen-zone model as shown in Figure B.9. These replaced loads within the taxonomy feeder that were three-phase and "larger", as defined by the scaling factor. The average square footage was $40,000 \mathrm{sf}$, with a uniform deviation of $50 \%$, while maintaining the geometrical relationship of each zone. Each of the zones has identical parameter values, except square footage, aspect ratio, external wall area, external floor area, and external ceiling area. Assumptions are made in this model to better represent the zonal attributes of a commercial building. It is assumed that the adjacent zone has approximately the same air and mass temperature as the current zone, so that there is no heat transfer across the boundaries. This means that the internal wall, ceiling, or floor areas do not lose or gain heat from adjacent zones, and can therefore be ignored when defining the thermal envelope of the building. For example, Zone 5 on the second floor in Figure B.9 will have an external wall area of $0 \mathrm{sf}$., an external floor area of $0 \mathrm{sf}$., and an external ceiling area of $0 \mathrm{sf}$. This zone would only have heat added (or removed) through end-use loads and the HVAC system. Zone 2 on the third floor will have an external wall area equal to one-half its total wall area, and external floor area also equal to $0 \mathrm{sf}$., and an external ceiling area equal to its floor area, allowing additional heat flows across the external boundaries. By defining each zone within the constraints of the geometrical model, then defining where heat transfer across boundaries is allowed and not allowed, a zonal model can be roughly represented. Notice that Figure B.9 contains a variable ' $x$ '. This variable would be adjusted by the randomly chosen square footage so that $3 * 1.5^{*} x^{2}$ equaled the total square footage, while all other parameters except for the widths of Zones 1-4 adjusted within the geometrical constraints. The other building type zones were defined in a similar manner. Table B.12 shows the key parameters used to define the office building zones. Additionally, since the office building is considered a larger, single owner, customer billing was performed as an aggregate of all the "zones". 


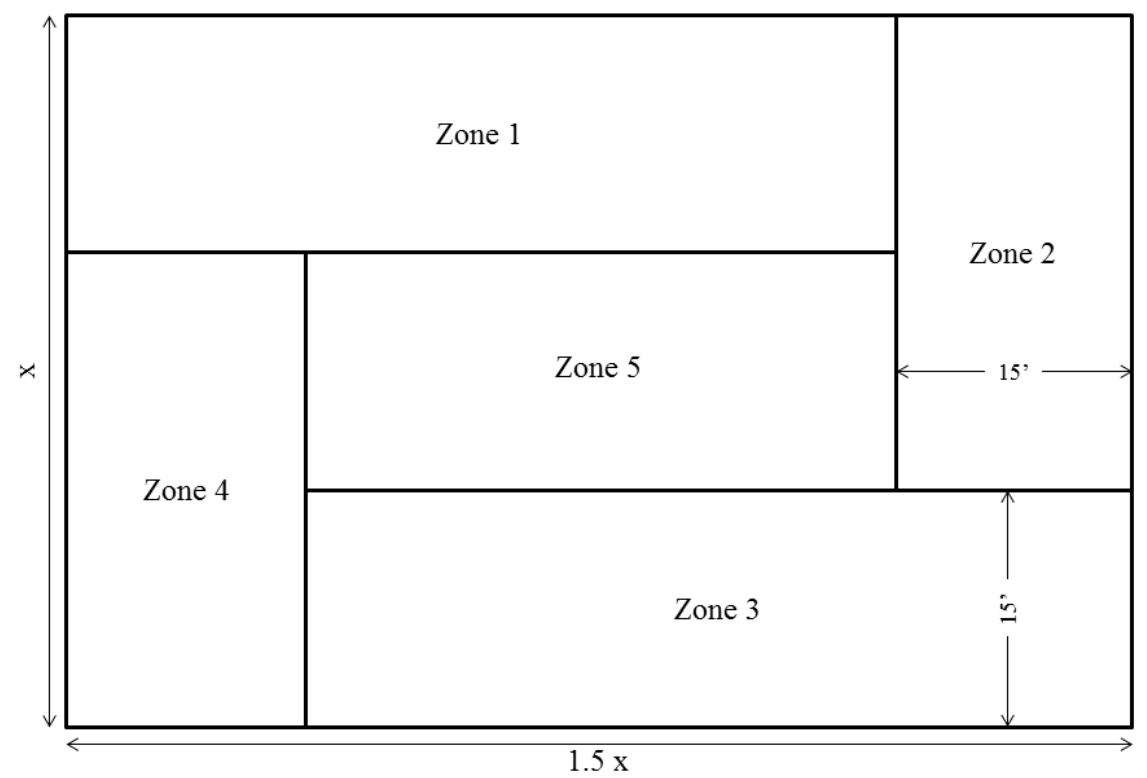

Figure B.9: Office zonal floor plan representing 1 of 3 identical floors

Table B.12: Key parameters for commercial buildings

\begin{tabular}{|c|c|c|c|}
\hline & Office & Big Box & Strip Mall \\
\hline Square Footage & $40,000+/-50 \%$ & $20,000+/-50 \%$ & $2400+/ 30 \%$ \\
\hline Ceiling Height & 13 & 14 & 12 \\
\hline Air Infiltration & 0.69 & 1.5 & 1.76 \\
\hline R Roof & 19 & 19 & 19 \\
\hline R Wall & 18.3 & 18.3 & 18.3 \\
\hline R Floor & 46 & 46 & 40 \\
\hline R Door & 3 & 3 & 2 \\
\hline Glazing Layers & 2 & 2 & Glass \\
\hline Glass Type & Glass & Glass & Low S \\
\hline Glazing Treatment* & Low S & Low S & 1 \\
\hline Window Frame & None & None & $0.03 / 0.05$ \\
\hline No. of Doors* & 0 & $0 / 1 / 24$ & 3.6 \\
\hline Window to Wall Ratio & $0 / 0.33$ & $0 / 0.76$ & $3+/-20 \%$ \\
\hline Internal Gains (W/sf) & 3.24 & 3.6 & \\
\hline Cooling COP & $3+/-20 \%$ & $3+/-20 \%$ & \\
\hline
\end{tabular}

*Note: Low $\mathrm{S}$ refers to low solar glazing.

*Note: Number of doors refers to the number of doors externally exposed, and is translated into a wall area used by the doors - 24 doors refers to the surface area used by 24 doors. Office accounts for door area in the window area. 
Big box retail buildings were represented as a one-story, six-zone model as shown in Figure B.10, and were used to replace "larger" two-phase loads and "smaller" three-phase loads, as defined by the scaling factor. The overall square footage was defined as 20,000 sf., with a uniform deviation of 50\%. Table B.12 shows the key parameters used to define the retail big box building zones. Again, this building was considered a single occupant and customer billing was performed on the aggregate of all the "zones".

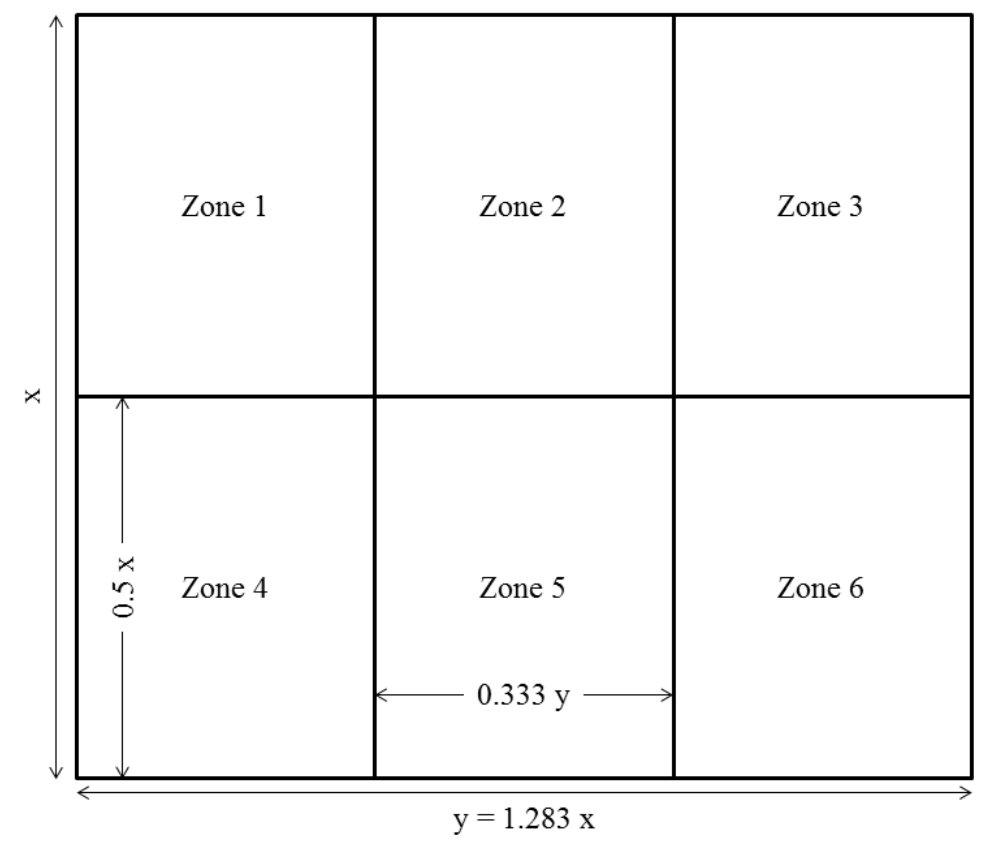

Figure B.10: Retail "big box" zonal floor plan

A retail strip mall model was used to represent all other loads, including all one-phase loads and "smaller" two- or three-phase loads. These were represented by one-story, single-zone models connected in series as shown in Figure B.11. Individual zones were defined as 1200 or 2400 sf., with a uniform deviation of $30 \%$. Table B.12 shows the key parameters used to define the retail strip mall building zones. In this case, ownership was considered on a per-zone basis, so customer billing was also performed on a per-zone basis. 


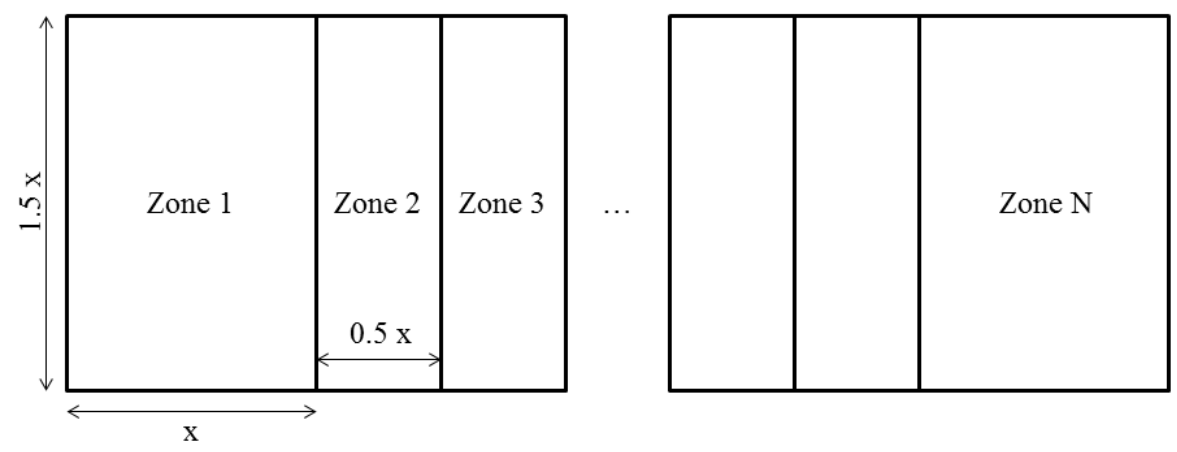

Figure B.11: Retail strip mall zonal floor plan with $\mathrm{N}$ zones depending upon scaling factor

Additionally, it was assumed that all commercial buildings had both heating and cooling systems and heating was always represented by a gas heating unit rather than a heat pump or resistive heat unit. Again, internal loads are very important drivers for both heating and cooling of the space, displacing heating load while adding cooling load. Commercial building load is highly occupant driven, and is typically very recurring. Data from end-use metering projects was used to create average end-use load shapes for weekdays and weekends [21]. Again, certain loads were slightly scaled up or down to reflect changes in efficiencies or standard usage. Weekdays are assumed to be Mon-Fri for office buildings, Mon.-Sun. for big box buildings, and Mon.-Sat. for strip malls. Average load shapes are shown in Figure B.12 through Figure B.15. Notice that the $\mathrm{y}$-axis is in units of W/sf. The load shape applied to each zone is scaled as a function of square footage then randomized on a zonal basis by +/- $20 \%$ over a uniform distribution. In addition to the magnitude randomization, the load shape was also randomly "skewed" in time. Each of the zones within the building were considered to be on the same schedule, however, across the population of buildings, not all started and ended at the same time. The load shapes were temporally shifted from those shown in Figure B.12 through Figure B.15 in 30-minute blocks using a normal distribution of average of 0 minutes and standard deviation of 30 minutes. This produced a more diversified load across the entire population. 


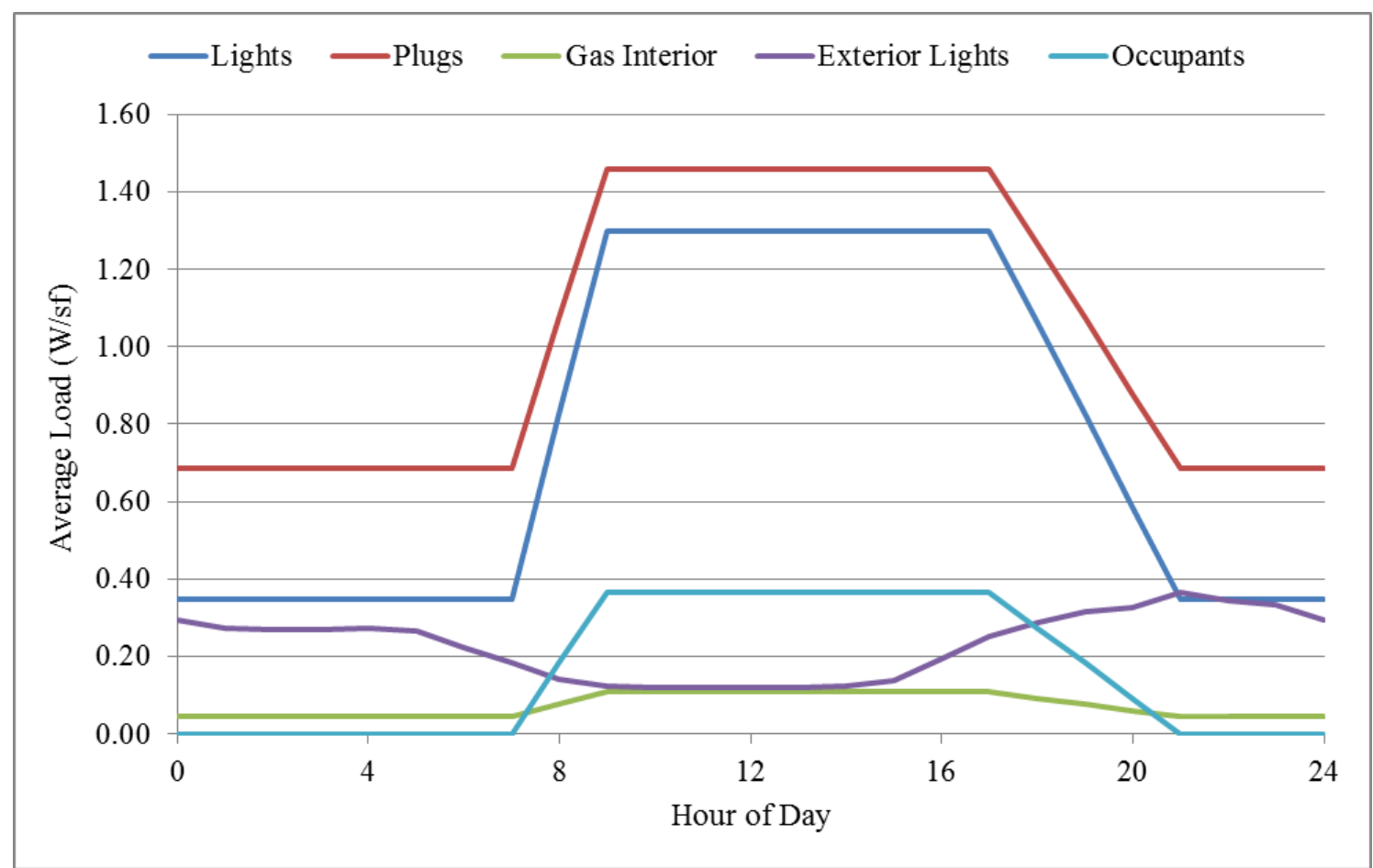

Figure B.12: Average office end-use load shape (weekday)

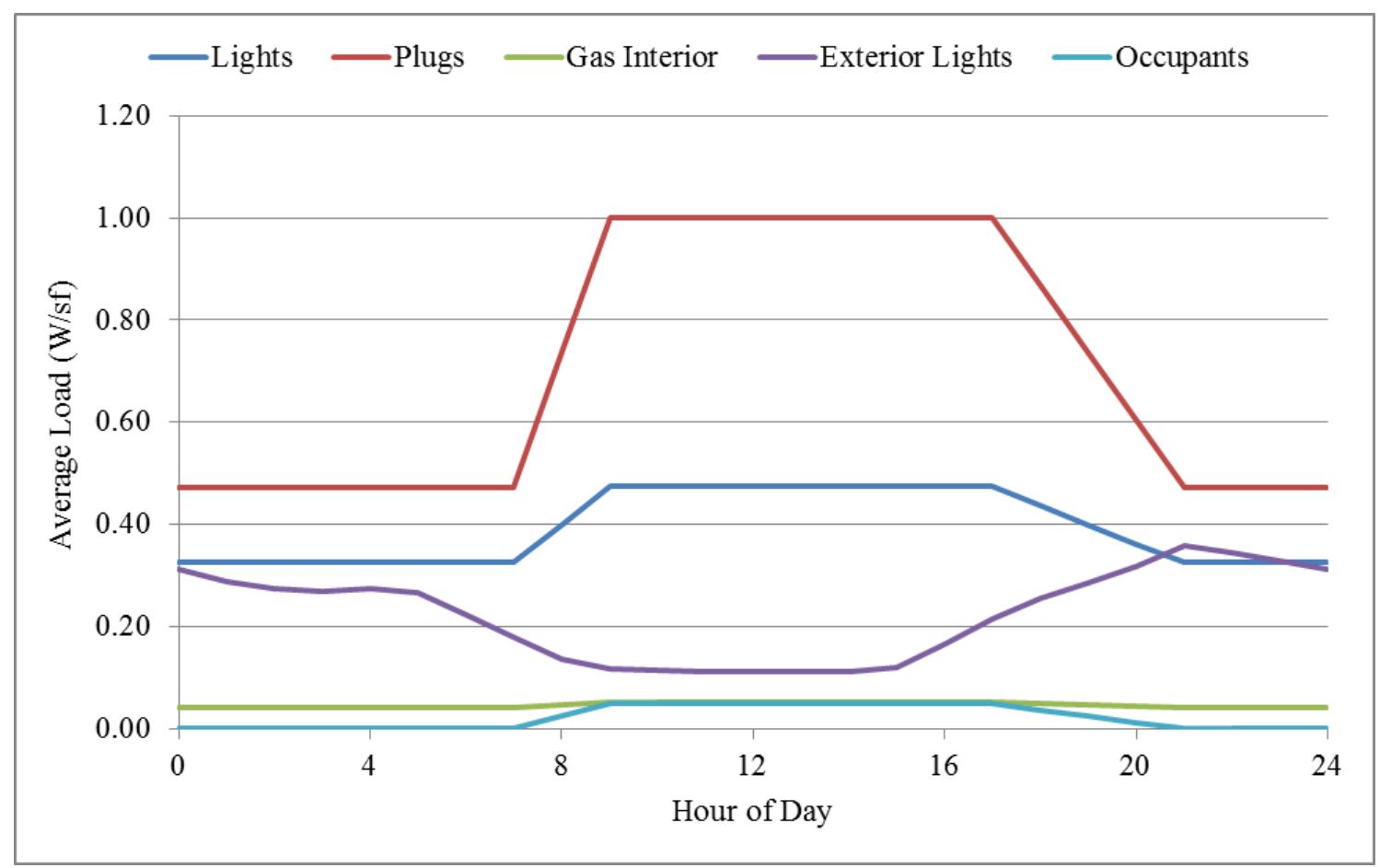

Figure B.13: Average office end-use load shape (weekend) 


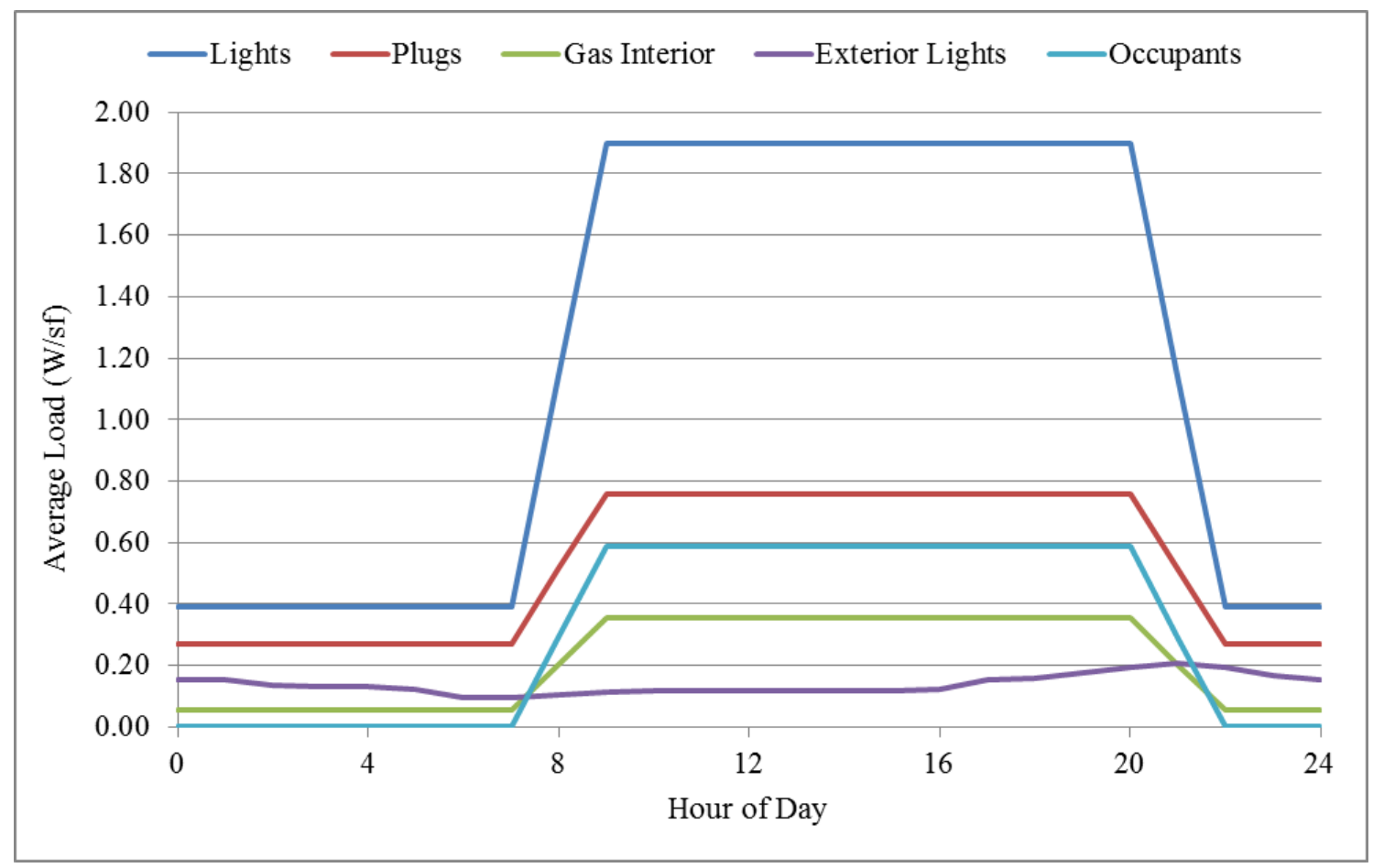

Figure B.14: Average big box and strip mall end-use load shape (weekday)

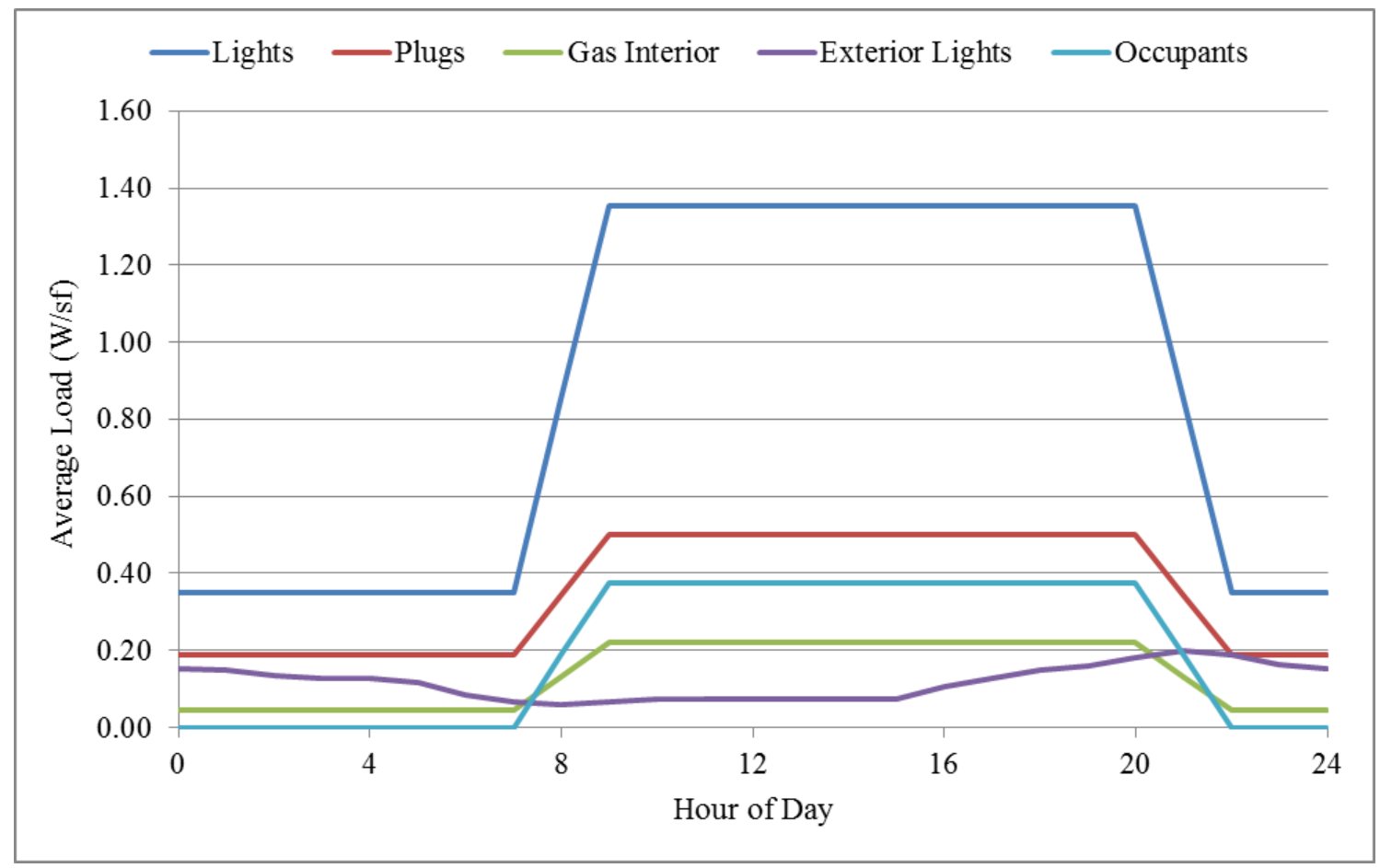

Figure B.15: Average big box and strip mall end-use load shape (weekend) 
Finally, there were a number of loads on the prototypical feeders that were far smaller than could be described by a building model at peak load, often less than $1 \mathrm{kVA}$. While there are a number of options for representation of these loads, such as traffic lights or a small espresso stand, it was determined that without data to indicate what these loads represented they would be best represented by street lighting loads. These small loads were converted to a scheduled one-, two-, or three-phase load, depending on the original load and the full rated load was applied during dark hours and zero load was applied during daylight hours. While it is understood that this is not an accurate representation of true street light loading and operation, the loads were small enough and infrequent enough that a simple scheduled load had little to no effect on the overall operation of the feeder circuits.

\section{B.3 Taxonomy Feeder Emission Profiles}

Increasing operational efficiency of the electrical power system can lead to a reduction in pollutant emissions. Peak load reduction or peak shifting has been shown to reduce emissions, mainly due to reducing the need to use "peaker" units. These are typically older, less efficient generators, designed for quick start-up and shutdown, and are often single cycle natural gas turbine generators or petroleum fired plants. Reduction in overall energy consumption or shifting of production to more efficient energy sources can also reduce emissions by reducing the amount of fuel burned for electricity production. Solutions for the amount of emissions created are traditionally performed at the transmission level, using optimal power flow and economic dispatch, and are typically not well-suited for distribution level simulation. The following section is a brief description of how GridLAB-D estimates emissions impacts at the distribution level.

To capture the emissions level benefits to the system, generation mixes were assumed in each region and the nine most heavily consumed fuels for electrical generation in the U.S. were used. In each region, the fuels are dispatched in order from first to last by capacity factor, as shown in Table B.13. Exceptions are made for a number of the renewable resources, such as wind, solar, and biomass, as they are assumed to be dispatched when available. The level of penetration by each fuel type was determined for each region by month as shown in Table B.14-Table B.18. These values were determined from the EIA's Annual Electric Generator Report [25], utilizing state-by-state breakdowns of annual energy production. 
Table B.13: Dispatch order of fuel by region

\begin{tabular}{|c|c|c|c|c|c|}
\hline Region & 1 & 2 & 3 & 4 & 5 \\
\hline \multirow{4}{*}{$\begin{array}{l}\text { Order of } \\
\text { dispatch }\end{array}$} & Nuclear & Nuclear & Nuclear & Nuclear & Nuclear \\
\cline { 2 - 6 } & Solar & Solar & Solar & Solar & Solar \\
\cline { 2 - 6 } & Biomass & Biomass & Biomass & Biomass & Biomass \\
\cline { 2 - 6 } & Wind & Wind & Wind & Wind & Wind \\
\cline { 2 - 7 } & Natural Gas & Natural Gas & Natural Gas & Natural Gas & Coal \\
\cline { 2 - 6 } & Coal & Hydroelectric & Hydroelectric & Hydroelectric & Hydroelectric \\
\cline { 2 - 6 } & Geothermal & Geothermal & Geothermal & Geothermal & Geothermal \\
\cline { 2 - 6 } & Petroleum & Petroleum & Petroleum & Petroleum & Petroleum \\
\hline
\end{tabular}

Table B.14: Percent of energy consumed, broken down by fuel type and month in region 1

\begin{tabular}{|l|r|r|r|r|r|r|r|r|r|r|r|r|}
\hline Region 1 & Jan & Feb & Mar & April & May & June & July & Aug & Sept & Oct & Nov & Dec \\
\hline Nuclear & 9.86 & 8.68 & 11.47 & 13.08 & 10.63 & 9.73 & 10.68 & 8.93 & 10.09 & 8.5 & 9.83 & 10.41 \\
\hline Solar & 0.01 & 0.08 & 0.18 & 0.23 & 0.25 & 0.24 & 0.25 & 0.24 & 0.21 & 0.15 & 0.09 & 0.04 \\
\hline Biomass & 0.58 & 0.78 & 0.77 & 0.72 & 0.73 & 0.73 & 0.67 & 0.65 & 0.72 & 0.82 & 0.81 & 0.73 \\
\hline Wind & 2.37 & 1.86 & 4.39 & 4.57 & 4.63 & 5.44 & 4.07 & 4.66 & 3.55 & 3.64 & 3.17 & 1.44 \\
\hline Hydroelectric & 43.43 & 37.29 & 38.84 & 49.88 & 56.78 & 58.39 & 36.88 & 29.63 & 26.32 & 31.09 & 36.02 & 36.29 \\
\hline Natural Gas & 34.61 & 41.6 & 34.96 & 25.6 & 22.89 & 21.1 & 41.38 & 48.31 & 51.24 & 45.88 & 42.02 & 42.13 \\
\hline Coal & 5.44 & 5.77 & 5.42 & 2.14 & 0.45 & 0.86 & 2.88 & 4.09 & 4.38 & 5.97 & 4 & 5.14 \\
\hline Geothermal & 3.29 & 3.49 & 3.51 & 3.35 & 3.29 & 3.1 & 2.84 & 3.09 & 3.11 & 3.54 & 3.63 & 3.35 \\
\hline Petroleum & 0.43 & 0.45 & 0.45 & 0.43 & 0.35 & 0.41 & 0.36 & 0.38 & 0.39 & 0.4 & 0.44 & 0.47 \\
\hline
\end{tabular}


Table B.15: Percent of energy consumed, broken down by fuel type and month in region 2

\begin{tabular}{|l|r|r|r|r|r|r|r|r|r|r|r|r|}
\hline Region 2 & Jan & Feb & Mar & April & May & June & July & Aug & Sept & Oct & Nov & Dec \\
\hline Nuclear & 26.47 & 26.9 & 27.74 & 25.27 & 28.52 & 27.95 & 26.33 & 24.75 & 27.04 & 25.09 & 25.63 & 25.42 \\
\hline Solar & 0 & 0 & 0.01 & 0.01 & 0.01 & 0.01 & 0.01 & 0.01 & 0.01 & 0.01 & 0 & 0 \\
\hline Biomass & 0.64 & 0.72 & 0.82 & 0.9 & 0.92 & 0.84 & 0.82 & 0.76 & 0.83 & 0.85 & 0.89 & 0.75 \\
\hline Wind & 2.23 & 2.71 & 2.9 & 3.34 & 2.79 & 1.7 & 1.41 & 1.6 & 1.73 & 2.82 & 3.22 & 2.99 \\
\hline Coal & 49.62 & 49.36 & 46.7 & 46.31 & 44.39 & 45.54 & 47.18 & 46.33 & 46.05 & 49.04 & 49.05 & 50.69 \\
\hline Natural Gas & 12.31 & 13.49 & 14.19 & 14.67 & 13.43 & 14.47 & 16.33 & 19.87 & 17.97 & 15.73 & 14.51 & 13.22 \\
\hline Hydroelectric & 6.11 & 5.99 & 6.92 & 9.11 & 9.51 & 9.05 & 7.42 & 6.08 & 5.98 & 6.13 & 6.34 & 6.43 \\
\hline Geothermal & 0.07 & 0.07 & 0.08 & 0.08 & 0.08 & 0.07 & 0.07 & 0.07 & 0.08 & 0.07 & 0.08 & 0.08 \\
\hline Petroleum & 2.55 & 0.74 & 0.64 & 0.32 & 0.34 & 0.37 & 0.43 & 0.6 & 0.33 & 0.27 & 0.28 & 0.43 \\
\hline
\end{tabular}

Table B.16: Percent of energy consumed, broken down by fuel type and month in region 3

\begin{tabular}{|l|r|r|r|r|r|r|r|r|r|r|r|r|}
\hline Region 3 & Jan & Feb & \multicolumn{1}{|c|}{ Mar } & April & May & June & July & Aug & Sept & Oct & Nov & Dec \\
\hline Nuclear & 9.82 & 8.88 & 10.24 & 11.6 & 10.83 & 9.72 & 8.65 & 8.5 & 7.13 & 8.62 & 9.63 & 9.38 \\
\hline Solar & 0.01 & 0.05 & 0.13 & 0.16 & 0.17 & 0.13 & 0.13 & 0.14 & 0.13 & 0.1 & 0.06 & 0.03 \\
\hline Biomass & 0.22 & 0.28 & 0.29 & 0.29 & 0.25 & 0.25 & 0.23 & 0.21 & 0.25 & 0.27 & 0.29 & 0.26 \\
\hline Wind & 2.13 & 3.08 & 3.26 & 3.77 & 2.8 & 2.45 & 2.05 & 2.2 & 2.34 & 3.55 & 3.02 & 2.77 \\
\hline Coal & 50.18 & 43.95 & 41.77 & 42.34 & 43.59 & 41.52 & 40.24 & 41.42 & 43.7 & 47.9 & 49.94 & 46.58 \\
\hline Natural Gas & 32.79 & 37.12 & 37.34 & 33.17 & 33.92 & 37.88 & 41.67 & 41.48 & 40.32 & 33.07 & 31.29 & 34.43 \\
\hline Hydroelectric & 2.89 & 4.75 & 4.95 & 6.72 & 6.68 & 6.4 & 5.58 & 4.59 & 4.47 & 4.74 & 3.76 & 4.6 \\
\hline Geothermal & 1.63 & 1.62 & 1.7 & 1.67 & 1.53 & 1.4 & 1.25 & 1.26 & 1.42 & 1.52 & 1.79 & 1.7 \\
\hline Petroleum & 0.32 & 0.26 & 0.32 & 0.28 & 0.24 & 0.25 & 0.2 & 0.2 & 0.22 & 0.24 & 0.22 & 0.24 \\
\hline
\end{tabular}

Table B.17: Percent of energy consumed, broken down by fuel type and month in region 4

\begin{tabular}{|l|r|r|r|r|r|r|r|r|r|r|r|r|}
\hline Region 4 & Jan & Feb & Mar & April & May & June & July & Aug & Sept & Oct & Nov & Dec \\
\hline Nuclear & 23.16 & 23.97 & 23.95 & 24.4 & 24.92 & 22.45 & 23.15 & 21.91 & 23.58 & 24.33 & 23.99 & 22.77 \\
\hline Solar & 0 & 0 & 0 & 0 & 0 & 0 & 0 & 0 & 0 & 0 & 0 & 0 \\
\hline Biomass & 0.21 & 0.19 & 0.21 & 0.25 & 0.21 & 0.18 & 0.18 & 0.18 & 0.21 & 0.22 & 0.22 & 0.18 \\
\hline Wind & 0.69 & 0.88 & 1.03 & 1.16 & 0.78 & 0.64 & 0.53 & 0.6 & 0.59 & 1.13 & 1.18 & 1.04 \\
\hline Coal & 61.55 & 60.14 & 57.45 & 58.24 & 57.41 & 56.92 & 56.89 & 57.14 & 56.06 & 58.36 & 58.48 & 59.96 \\
\hline Natural Gas & 9.98 & 11.44 & 12.86 & 11.25 & 11.38 & 16.04 & 16.75 & 17.49 & 16.14 & 10.51 & 9.83 & 10.19 \\
\hline Hydroelectric & 3.37 & 2.67 & 3.71 & 4.21 & 4.73 & 3.32 & 2.05 & 2.2 & 3.09 & 5.09 & 5.96 & 5.51 \\
\hline Geothermal & 0 & 0 & 0 & 0 & 0 & 0 & 0 & 0 & 0 & 0 & 0 & 0 \\
\hline Petroleum & 1.04 & 0.71 & 0.8 & 0.49 & 0.56 & 0.45 & 0.45 & 0.48 & 0.36 & 0.36 & 0.34 & 0.36 \\
\hline
\end{tabular}


Table B.18: Percent of energy consumed, broken down by fuel type and month in region 5

\begin{tabular}{|l|l|l|l|r|r|r|r|r|r|r|r|r|}
\hline Region 5 & Jan & Feb & Mar & April & May & June & July & Aug & Sept & Oct & Nov & Dec \\
\hline Nuclear & 18.26 & 18.55 & 18.53 & 17.36 & 14.67 & 13.53 & 13.74 & 13.85 & 13.65 & 12.7 & 14.94 & 16.41 \\
\hline Solar & 0 & 0 & 0 & 0 & 0 & 0 & 0 & 0 & 0 & 0 & 0 & 0 \\
\hline Biomass & 0.46 & 0.45 & 0.48 & 0.46 & 0.3 & 0.31 & 0.31 & 0.33 & 0.34 & 0.39 & 0.46 & 0.46 \\
\hline Wind & 2.14 & 2.6 & 2.7 & 2.95 & 1.91 & 1.74 & 1.44 & 1.48 & 1.43 & 2.52 & 2.63 & 2.26 \\
\hline Natural Gas & 38.8 & 41.01 & 45.26 & 44.78 & 47.26 & 51.29 & 51.75 & 51.68 & 51.03 & 47.55 & 43.83 & 41.73 \\
\hline Coal & 37.3 & 34.53 & 29.66 & 30.82 & 32.04 & 30.37 & 30.38 & 30.17 & 30.72 & 33.46 & 35.06 & 35.97 \\
\hline Hydroelectric & 1.42 & 0.86 & 1.57 & 1.51 & 1.61 & 0.78 & 0.58 & 0.63 & 0.99 & 1.75 & 2.12 & 2.35 \\
\hline Geothermal & 0 & 0 & 0 & 0 & 0 & 0 & 0 & 0 & 0 & 0 & 0 & 0 \\
\hline Petroleum & 1.62 & 2 & 1.79 & 2.12 & 2.2 & 1.96 & 1.8 & 1.86 & 1.84 & 1.62 & 0.95 & 0.82 \\
\hline
\end{tabular}

At each 15-minute measurement interval, the energy consumed over the previous interval is used to determine the amount of energy delivered by each fuel source. The peak load of the base case for each month is used to scale the percentages. Figure B.16 shows an example of how this is performed in GridLAB-D using June in Region 3. It can be seen that the peak load for that month would utilize all the generation fuels at the levels shown in Table B.16. At the shown 15minute period, the base case load is approximately $95 \%$ of the peak for June for this particular feeder. During the same 15-minute period, the representative technology case is only $87 \%$ of the base case peak feeder loading. This results in a reduction of generation by approximately $3 \%$ for hydroelectric and 5\% for natural gas. This calculation is performed at every 15 -minute interval to determine the energy consumed by each fuel type over the course of the entire annual simulation of 1-minute intervals. 


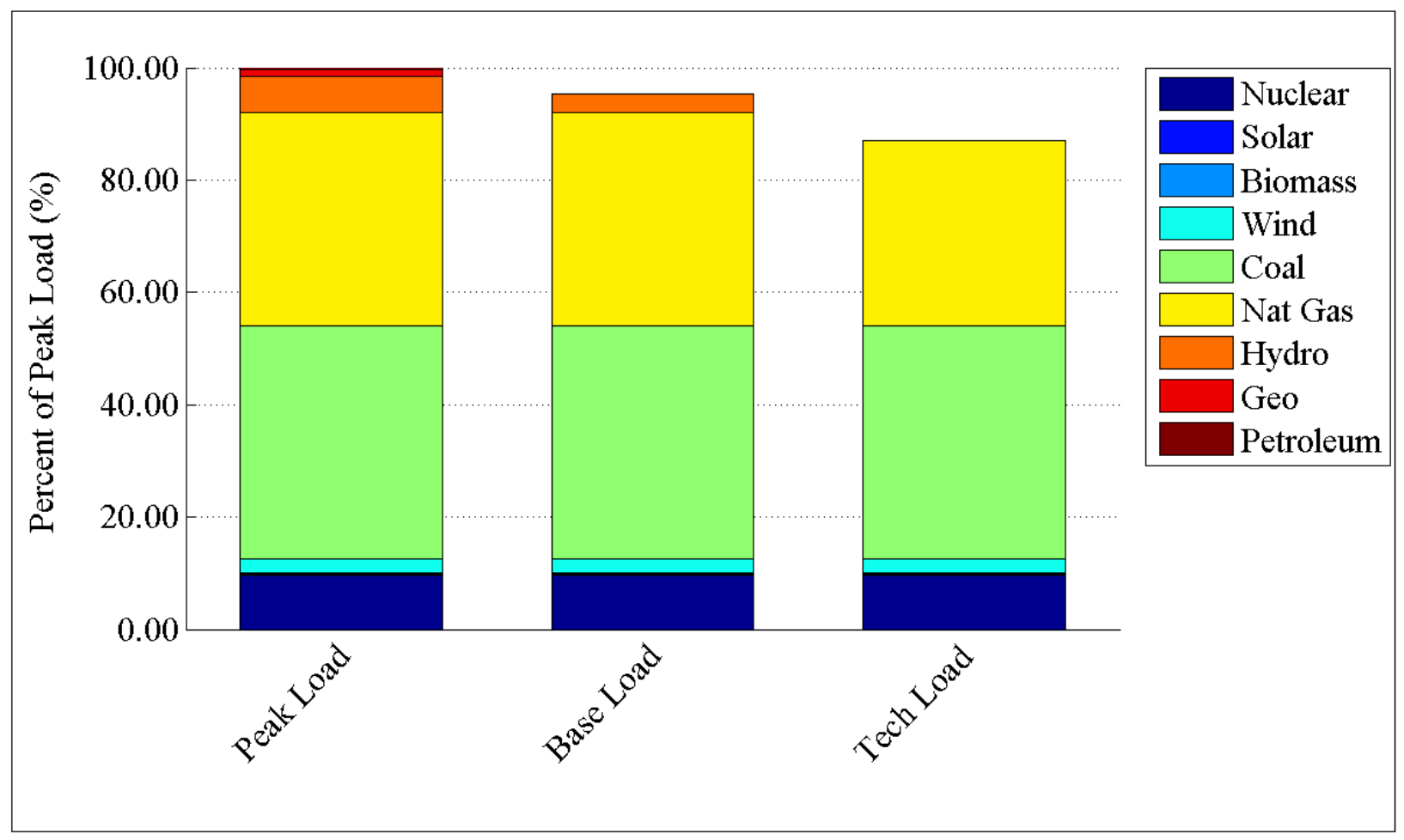

Figure B.16: 15-minute interval comparing fuel dispatch for the peak load versus the base case load versus a technology modified load.

Assumed average thermal efficiencies are then used to convert the energy delivered to the amount of fuel used, where applicable. The values used are shown in Table B.19. Finally, assumed average values for conversion efficiencies are used to convert from fuel used to emissions levels for carbon dioxide, sulfur dioxide, and nitrous oxides. The conversion values assumed are shown in Table B.20. These values are not indicative of any single plant, but rather broad averages across the U.S. While this is a very simplified means of dispatching and assigning generation, ignoring complex issues such as inefficiencies due to warm-up cycles, maintenance periods, and economic or optimal dispatching, it should provide a general indication of how changes in operation of a distribution circuit can reduce pollutant emissions. 
Table B.19: Average thermal efficiencies by fuel type.

\begin{tabular}{|l|r|}
\hline & MBTUs / MWh \\
\hline Nuclear & 10.46 \\
\hline Solar & N/A \\
\hline Biomass & 12.93 \\
\hline Wind & N/A \\
\hline Natural Gas & 8.16 \\
\hline Coal & 10.41 \\
\hline Hydroelectric & N/A \\
\hline Geothermal & 21.02 \\
\hline Petroleum & 11 \\
\hline
\end{tabular}

Table B.20: Pollutant production per BTU of fuel (lbs./MBTU)

\begin{tabular}{|c|c|c|c|c|}
\hline & $\mathrm{CO}_{2}$ & $\mathrm{SO}_{2}$ & $\mathrm{NO}_{\mathrm{x}}$ & PM-10 \\
\hline Nuclear & 0 & 0 & 0 & 0.017157 \\
\hline Solar & 0 & 0 & 0 & 0.03 \\
\hline Biomass & 195 & 0 & 0.08 & 0.0232 \\
\hline Wind & 0 & 0 & 0 & 0 \\
\hline Natural Gas & 117.08 & 0.001 & 0.0075 & 0 \\
\hline Coal & 205.57 & 0.1 & 0.06 & 0 \\
\hline Hydroelectric & 0 & 0 & 0 & 0 \\
\hline Geothermal & 120 & 0.2 & 0 & 0 \\
\hline Petroleum & 225.13 & 0.1 & 0.04 & 0 \\
\hline
\end{tabular}

\section{B.4 Taxonomy Feeder Descriptions}

The previous sections have described the details of how each of the prototypical feeders is populated with end-use loads. This section is a reproduction of the individual prototypical feeder descriptions from [3] which describes the characteristics of the primary distribution system.

\section{B.4.1 Feeder 1: GC-12.47-1}

This feeder is representative of a single large commercial or industrial load, such as a very large shopping mall or a small lumber mill. These feeders may supply the load through a single large transformer or a group of smaller units. While there may be a couple of smaller loads the behavior of the feeder is primarily determined by the single large customer. This is a $12.47 \mathrm{kV}$ feeder with a peak load of approximately 5,400 kVA. 


\section{B.4.2 Feeder 2: R1-12.47-1}

This feeder is a representation of a moderately populated suburban and rural area. This is composed mainly of single family residences with small amounts of light commercial. Approximately $60 \%$ of the circuit-feet are overhead and $40 \%$ are underground. It would be expected that this feeder is connected to adjacent feeders through normally open switches. For this reason it would be common to limit the feeder loading to $60 \%$ to ensure the ability to transfer load from other feeders, and vice versa. The majority of the load is located relatively near the substation. This is a $12.5 \mathrm{kV}$ feeder with a peak load of approximately $4,300 \mathrm{kVA}$.

\section{B.4.3 Feeder 3: R1-12.47-2}

This feeder is a representation of a moderately populated suburban and lightly populated rural area. This is composed mainly of single family residences with small amounts of light commercial. Approximately $70 \%$ of the circuit-feet are overhead and $30 \%$ underground. It would not be expected that this feeder is connected to adjacent feeders through normally open switches. Even though there are not adjacent feeders for transferring the load, the total feeder loading is low because of the sparse rural loading. In this model an urban substation is feeding a rural load through a long primary circuit. The majority of the load is located relatively distant with respect to the substation. This is a $12.47 \mathrm{kV}$ feeder with a peak load of approximately 2,400 $\mathrm{kVA}$.

\section{B.4.4 Feeder 4: R1-12.47-3}

This feeder is a representation of a moderately populated urban area. This is composed mainly of mid-sized commercial loads with some residences, mostly multi-family. Approximately $85 \%$ of the circuit-feet are overhead and 15\% underground. It would be expected that this feeder is connected to adjacent feeders through normally open switches. For this reason it would be common to limit the feeder loading to $60 \%$ to ensure the ability to transfer load from other feeders, and vice versa. Since this is a small urban core the loading of the feeder is well below $60 \%$. The majority of the load is located relatively near the substation. This is a $12.47 \mathrm{kV}$ feeder with a peak load of approximately $1,800 \mathrm{kVA}$.

\section{B.4.5 Feeder 5: R1-12.47-4}

This feeder is a representation of a heavily populated suburban area. This is composed mainly of single family homes and heavy commercial loads. None of the circuit-feet are overhead and $100 \%$ are underground. It would be expected that this feeder is connected to adjacent feeders through normally open switches. The majority of the load is located relatively near the substation. This is a $12.47 \mathrm{kV}$ feeder with a peak load of approximately $4,900 \mathrm{kVA}$. 


\section{B.4.6 Feeder 6: R1-25.00-1}

This feeder is a representation of a lightly populated rural area. This is composed of a mixture of residential, light commercial, industrial, and agricultural loads. Approximately $60 \%$ of the circuit-feet are overhead and $40 \%$ underground. It would be expected that this feeder is not connected to adjacent feeders through normally open switches. Due to rural location and low population density the feeder is not heavily loaded. The low population density and wide are covered are why this feeder is operated at $24.9 \mathrm{kV}$. The majority of the load is located relatively distant with respect to the substation. This is a $24.9 \mathrm{kV}$ feeder with a peak load of approximately $2,300 \mathrm{kVA}$.

\section{B.4.7 Feeder 7: R2-12.47-1}

This feeder is a representation of a lightly populated urban area. This is composed of single family homes, moderate commercial loads, light industrial loads, and some agricultural loads. This feeder supplies a college and an airport. Approximately $25 \%$ of the circuit-feet are overhead and $75 \%$ underground. It would be expected that this feeder is connected to adjacent feeders through normally open switches. For this reason it would be common to limit the feeder loading to $60 \%$ to ensure the ability to transfer load from other feeders, and vice versa. The majority of the load is located relatively near the substation. This is a $12.47 \mathrm{kV}$ feeder with a peak load of approximately 6,700 kVA.

\section{B.4.8 Feeder 8: R2-12.47-2}

This feeder is a representation of a moderately populated suburban area. This is composed mainly of single family homes with some light commercial loads. Approximately $80 \%$ of the circuit-feet are overhead and $20 \%$ underground. It would be expected that this feeder is connected to adjacent feeders through normally open switches. For this reason it would be common to limit the feeder loading to $60 \%$ to ensure the ability to transfer load from other feeders, and vice versa. The majority of the load is located relatively near the substation. This is a $12.47 \mathrm{kV}$ feeder with a peak load of approximately $6,700 \mathrm{kVA}$.

\section{B.4.9 Feeder 9: R2-12.47-3}

This feeder is a representation of a lightly populated suburban area. This is composed of single family homes, light commercial loads, light industrial loads, and some agricultural loads. Approximately $20 \%$ of the circuit-feet are overhead and $80 \%$ underground. It would be expected that this feeder is connected to adjacent feeders through normally open switches. For this reason it would be common to limit the feeder loading to $60 \%$ to ensure the ability to transfer load from other feeders, and vice versa. The majority of the load is located relatively near the substation. This is a $12.47 \mathrm{kV}$ feeder with a peak load of approximately $4,800 \mathrm{kVA}$. 


\section{B.4.10 Feeder 10: R2-25.00-1}

This feeder is a representation of a moderately populated suburban area. This is composed mainly of single family homes with some light and moderate commercial loads. Approximately $60 \%$ of the circuit-feet are overhead and $40 \%$ underground. It would be expected that this feeder is connected to adjacent feeders through normally open switches. For this reason it would be common to limit the feeder loading to $60 \%$ to ensure the ability to transfer load from other feeders, and vice versa. This is a heavily loaded feeder, well over $60 \%$, with the majority of the load is located relatively near the substation. This is a $24.9 \mathrm{kV}$ feeder with a peak load of approximately $21,300 \mathrm{kVA}$.

\section{B.4.11 Feeder 11: R2-35.00-1}

This feeder is a representation of a lightly populated rural area. This is composed mainly of single family homes with some light and moderate commercial loads. Approximately $90 \%$ of the circuit-feet are overhead and 10\% underground. It would be expected that this feeder is connected to adjacent feeders through normally open switches. But due to the long distances significant portions of the load cannot be shifted to adjacent feeders. In this model a single substation is serving a large geographic area, this is the reason for the higher voltage level; voltage regulators are used on this system. The majority of the load is located relatively distant with respect to the substation. This is a $34.5 \mathrm{kV}$ feeder with a peak load of approximately 6,900 kVA.

\section{B.4.12 Feeder 12: R3-12.47-1}

This feeder is a representation of a heavily populated urban area. This is composed of single family homes, heavy commercial loads, and a small amount of light industrial loads. Approximately $25 \%$ of the circuit-feet are overhead and $75 \%$ underground. It would be expected that this feeder is connected to adjacent feeders through normally open switches. Due to the heavy commercial loads it would be expected that this feeder would be loaded to a high percentage of its rating. The majority of the load is located relatively near the substation. This is a $12.47 \mathrm{kV}$ feeder with a peak load of approximately $11,600 \mathrm{kVA}$.

\section{B.4.13 Feeder 13: R3-12.47-2}

This feeder is a representation of a moderately populated urban area. This is composed of single family homes, light commercial loads, and a small amount of light industrial loads. Approximately $33 \%$ of the circuit-feet are overhead and $67 \%$ underground. It would be expected that this feeder is connected to adjacent feeders through normally open switches. For this reason it would be common to limit the feeder loading to $60 \%$ to ensure the ability to transfer load from other feeders, and vice versa. The majority of the load is located relatively near the substation. This is a $12.47 \mathrm{kV}$ feeder with a peak load of approximately $4,000 \mathrm{kVA}$. 


\section{B.4.14 Feeder 14: R3-12.47-3}

This feeder is a representation of a heavily populated suburban area. This is composed mainly of single family homes with some light agricultural loads. Approximately $75 \%$ of the circuit-feet are overhead and $25 \%$ underground. It would be expected that this feeder has limited connections to adjacent feeders through normally open switches. For this reason it would be common to limit the feeder loading to $75 \%$ to ensure the ability to transfer some loads from other feeders, and vice versa. Due to the low density of suburban loads the majority of the load is located relatively distant with respect to the substation. This is a $12.45 \mathrm{kV}$ feeder with a peak load of approximately $9,400 \mathrm{kVA}$.

\section{B.4.15 Feeder 15: R4-12.47-1}

This feeder is a representation of a heavily populated urban area with the primary feeder extending into a lightly populated rural area. In the urban areas the load is composed of moderate commercial loads with single and multi-family residences. On the rural spur the load is primarily single family residences. Approximately $92 \%$ of the circuit-feet are overhead and $8 \%$ underground. This feeder has connections to adjacent feeders in the urban area, but limited connections in the rural areas. For this reason it would be common to limit the feeder loading to $50 \%$ to ensure the ability to transfer most of the loads from other feeders, and vice versa. Most of the urban load is located near the substation while the rural load is located at a substantial distance. This is a $13.8 \mathrm{kV}$ feeder with a peak load of approximately $6,700 \mathrm{kVA}$.

\section{B.4.16 Feeder 16: R4-12.47-2}

This feeder is a representation of a lightly populated suburban area with a moderately populated urban area. The lightly populated suburban area is composed mostly of single family residences. The commercial complex is a single facility. Approximately $92 \%$ of the circuit-feet are overhead and $8 \%$ underground. This feeder has connections to adjacent feeders in the commercial complex, but limited connections in the rural areas. For this reason it would be common to limit the feeder loading to $50 \%$ to ensure the ability to transfer most of the loads from other feeders, and vice versa. Most of the suburban load is located near the substation while the commercial load is located at a substantial distance. This is a $12.5 \mathrm{kV}$ feeder with a peak load of approximately $2,100 \mathrm{kVA}$.

\section{B.4.17 Feeder 17: R4-25.00-1}

This feeder is a representation of a lightly populated rural area. The load is composed of single family residences with some light commercial. Approximately $88 \%$ of the circuit-feet are overhead and $12 \%$ underground. This feeder has connections to adjacent feeders. This combined with the low load density ensures the ability to transfer most of the loads from other feeders, and vice versa. Most of the load is located at a substantial distance from the substation, 
as is common for higher voltages in rural areas. This is a $24.9 \mathrm{kV}$ feeder with a peak load of approximately $1,000 \mathrm{kVA}$.

\section{B.4.18 Feeder 18: R5-12.47-1}

This feeder is a representation of a heavily populated suburban area and a moderate urban center. This is composed mainly of single family homes and moderate commercial loads. Approximately $95 \%$ of the circuit-feet are overhead and 5\% underground. It would be expected that this feeder has connections to adjacent feeders through normally open switches. For this reason it would be common to limit the feeder loading to $50 \%$ to ensure the ability to transfer most loads from other feeders, and vice versa. The suburban load is near the substation while the commercial load is at the end of the feeder. This is a $13.8 \mathrm{kV}$ feeder with a peak load of approximately $10,800 \mathrm{kVA}$.

\section{B.4.19 Feeder 19: R5-12.47-2}

This feeder is a representation of a moderate suburban area with a heavy urban area. This is composed mainly of heavy commercial and single family residences. Approximately $38 \%$ of the circuit-feet are overhead and $62 \%$ underground. It would be expected that this feeder has connections to adjacent feeders through normally open switches. For this reason it would be common to limit the feeder loading to $50 \%$ to ensure the ability to transfer most loads from other feeders, and vice versa. The heavy commercial load is near the substation while the single family residences are at the end of the feeder. This is a $12.47 \mathrm{kV}$ feeder with a peak load of approximately 4,200 kVA.

\section{B.4.20 Feeder 20: R5-12.47-3}

This feeder is a representation of a moderately populated rural area. This is composed mainly of single family residences with some light commercial. Approximately $92 \%$ of the circuit-feet are overhead and $8 \%$ underground. It would be expected that this feeder has limited connections to adjacent feeders through normally open switches. Due to the low load density of the large rural area the feeder is less than $50 \%$ loaded. The majority of the load is located relatively distant with respect to the substation. Voltage regulators are used on this feeder. This is a 13.8 $\mathrm{kV}$ feeder with a peak load of approximately 4,800 kVA.

\section{B.4.21 Feeder 21: R5-12.47-4}

This feeder is a representation of a moderately populated suburban and urban area. This is composed mainly of single family residences with some moderate commercial loads. Approximately $37 \%$ of the circuit-feet are overhead and $63 \%$ underground. It would be expected that this feeder has connections to adjacent feeders through normally open switches. For this reason it would be common to limit the feeder loading to $50 \%$ to ensure the ability to transfer most of the loads from other feeders, and vice versa. Most of the commercial load is near the 
substation and the residential load is spread out along the length of the entire feeder. This is a $12.47 \mathrm{kV}$ feeder with a peak load of approximately $6,200 \mathrm{kVA}$.

\section{B.4.22 Feeder 22: R5-12.47-5}

This feeder is a representation of a moderately populated suburban area with a lightly populated urban area. This is composed mainly of single family residences with some light commercial loads. Approximately $48 \%$ of the circuit-feet are overhead and $52 \%$ underground. It would be expected that this feeder has connections to adjacent feeders through normally open switches. For this reason it would be common to limit the feeder loading to $50 \%$ to ensure the ability to transfer most of the loads from other feeders, and vice versa. The residential load is spread out across the entire length of the feeder. The primary feeder extends a significant distance before there is any significant load, an express configuration. This is a configuration that can be seen in a well-established area when a new feeder must be routed through an existing area in order to reach areas of new load growth. This is a $12.47 \mathrm{kV}$ feeder with a peak load of approximately $8,500 \mathrm{kVA}$.

\section{B.4.23 Feeder 23: R5-25.00-1}

This feeder is a representation of a heavily populated suburban area with a moderately populated urban area. This is composed mainly of single family residences with some moderate commercial loads. Approximately $35 \%$ of the circuit-feet are overhead and $65 \%$ underground. It would be expected that this feeder has connections to adjacent feeders through normally open switches. For this reason it would be common to limit the feeder loading to $66 \%$ to ensure the ability to transfer most of the loads from other feeders, and vice versa. The residential load is spread out across the entire length of the feeder with the moderate commercial center near the substation. This is a $22.9 \mathrm{kV}$ feeder with a peak load of approximately $9,300 \mathrm{kVA}$.

\section{B.4.24 Feeder 24: R5-35.00-1}

This feeder is a representation of a moderately populated suburban area with a lightly populated urban area. This is composed mainly of single family residences with some moderate commercial loads. Approximately $10 \%$ of the circuit-feet are overhead and $90 \%$ underground. It would be expected that this feeder has connections to adjacent feeders through normally open switches. For this reason it would be common to limit the feeder loading to $50 \%$ to ensure the ability to transfer most of the loads from other feeders, and vice versa. The residential load is spread out across the entire length of the feeder with the moderate commercial center near the substation. This feeder is representative of a substation that is built in a "green field" where significant load growth is expected. The first feeders must go a significant distance before they reach the load, over time the load moves towards the substation and past it. This is a $34.5 \mathrm{kV}$ feeder with a peak load of approximately $12,100 \mathrm{kVA}$. 


\section{Appendix C: Simulation Technology and Methodology}

Simulations of the different project technologies and programs were accomplished using the GridLAB-D software. GridLAB-D provides an agent-based multi-disciplinary environment for the examination and evaluation of emerging technologies. By providing a multi-disciplinary simulation environment, it is possible to bring together diverse teams of experts from multiple fields of study to holistically examine complex systems.

GridLAB-D has been developed through funding from the Department of Energy, Office of Electricity. Through $\$ 5.5$ million of direct funding and supporting projects from DOE-OE, GridLAB-D has developed significant capabilities for analyzing smart grid deployments. The capabilities center on the functionality needed to simulate a distribution feeder power flow and attached loads. The development has included: unbalanced three-phase power flow solvers; detailed end-use models, particularly of a residential home's thermal integrity, HVAC cycles and water heater cycles; and a transactive market that supports double auction bidding. Different combinations of these capabilities enabled simulations of the various technologies and programs evaluated in th0is report.

GridLAB-D conducts time-series simulations with variable time steps. The solution at each time step is a quasi-steady state solution for each of the modules. Convergence is achieved within each module and convergence across modules is coordinated via the GridLAB core as illustrated in Figure C.1.

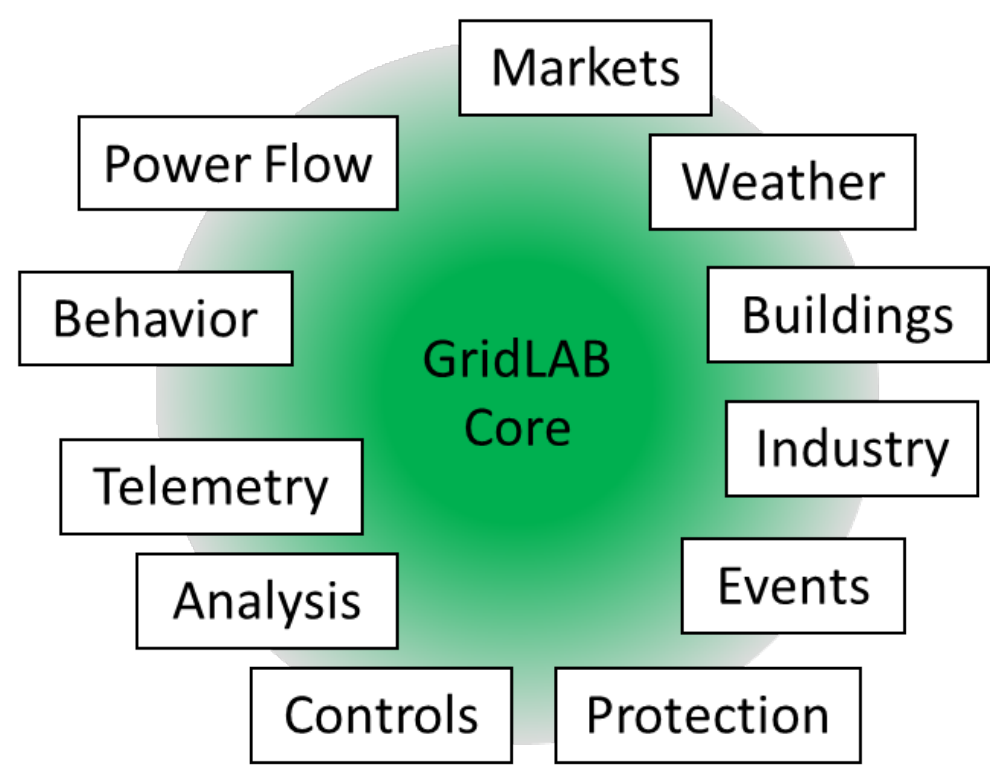

Figure C.1: GridLAB-D architecture 
Time steps are also coordinated by the GridLAB-D core. This is necessary because the various modules in the simulation will generally have different time step requirements. At the end of a time step, every object in the model returns a 'sync' time that indicates how long the object will remain constant without outside influence. The GridLAB core then examines every object and determines what the smallest sync time is; this then becomes length of the next step. This process is performed at every time step so that the system has a variable step size. For a given state variable an example of the variable step sizes are shown in Figure C.2.

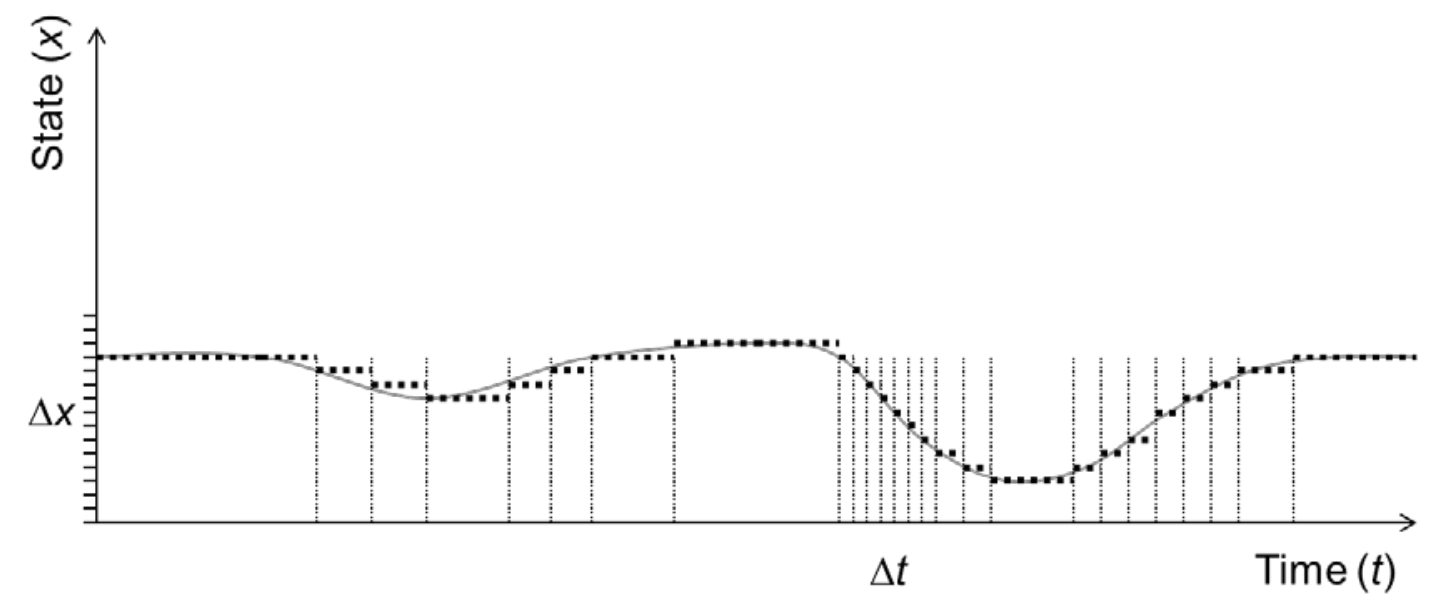

Figure C.2: Variable step sizes in GridLAB-D simulation

When analyzing operations at the distribution level, the major dynamics of interest are mid-term and occur on the order of minutes to hours. For the purposes of this analysis, a minimum time step of one minute was enforced. For operations that occur at intervals of less than one minute, such as a 45 -second delay on a voltage regulator, the operation is aggregated up to the one minute time step; multiple operations cannot occur during the enforced minimum of one minute. Because of the large number of objects and the forced minimum, the simulation proceeded at one-minute time steps for the majority of the simulations. As a result, there are approximately 500,000 time steps in an annual simulation of a single prototypical feeder.

Since the simulations for the SGIG analysis are being conducted over a one year period the minimum step size has been set to one minute. Even with a minimum one minute step size there is the possibility of 525,600 time steps in a single simulation. If a one second minimum step size were used there would be no significant increase in accuracy because most of the dynamic behavior has a time constant greater than one minute. Additionally, the number of time steps would increase by a factor of sixty resulting in significantly more computing time. 


\section{Appendix D: Plots for Individual Feeder Results}

This appendix contains the individual plots for each of the prototypical feeds for each technology, where necessary. Depending on the technology, different values will be plotted, consistent with those shown in Section 3.

\section{D.1 Addition of Residential PVs plots}

Consistent with the plots shown in Section 3.1.1, peak monthly demand, monthly energy consumption, monthly PV output and monthly $\mathrm{CO}_{2}$ emissions plot 'Base Case' and 'ResPV'. Monthly losses plots 'Base' and 'ResPV' for 4 different loss types; losses in overhead lines 'OHL', underground lines 'UGL', transformers 'TFR', and triplex lines 'TPL' are shown in this section.

\section{D.1.1 Detailed Residential PV Plots for R1-12.47-1}

The plots for this feeder were already presented in Section 3.1.1.

\section{D.1.2 Detailed Residential PV Plots for R1-12.47-2}

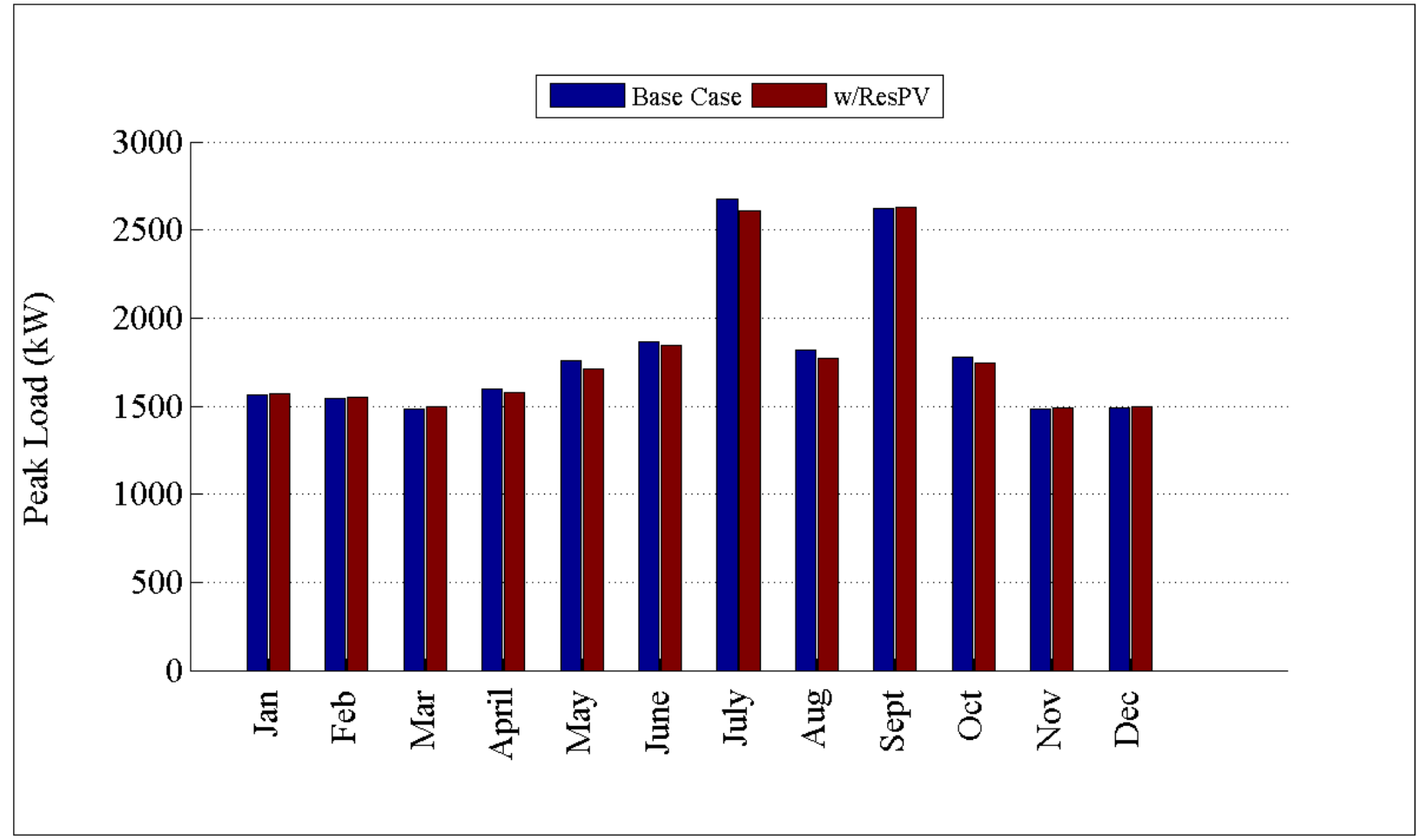

Figure D.1: Comparison of peak load by month for R1-12.47-2 


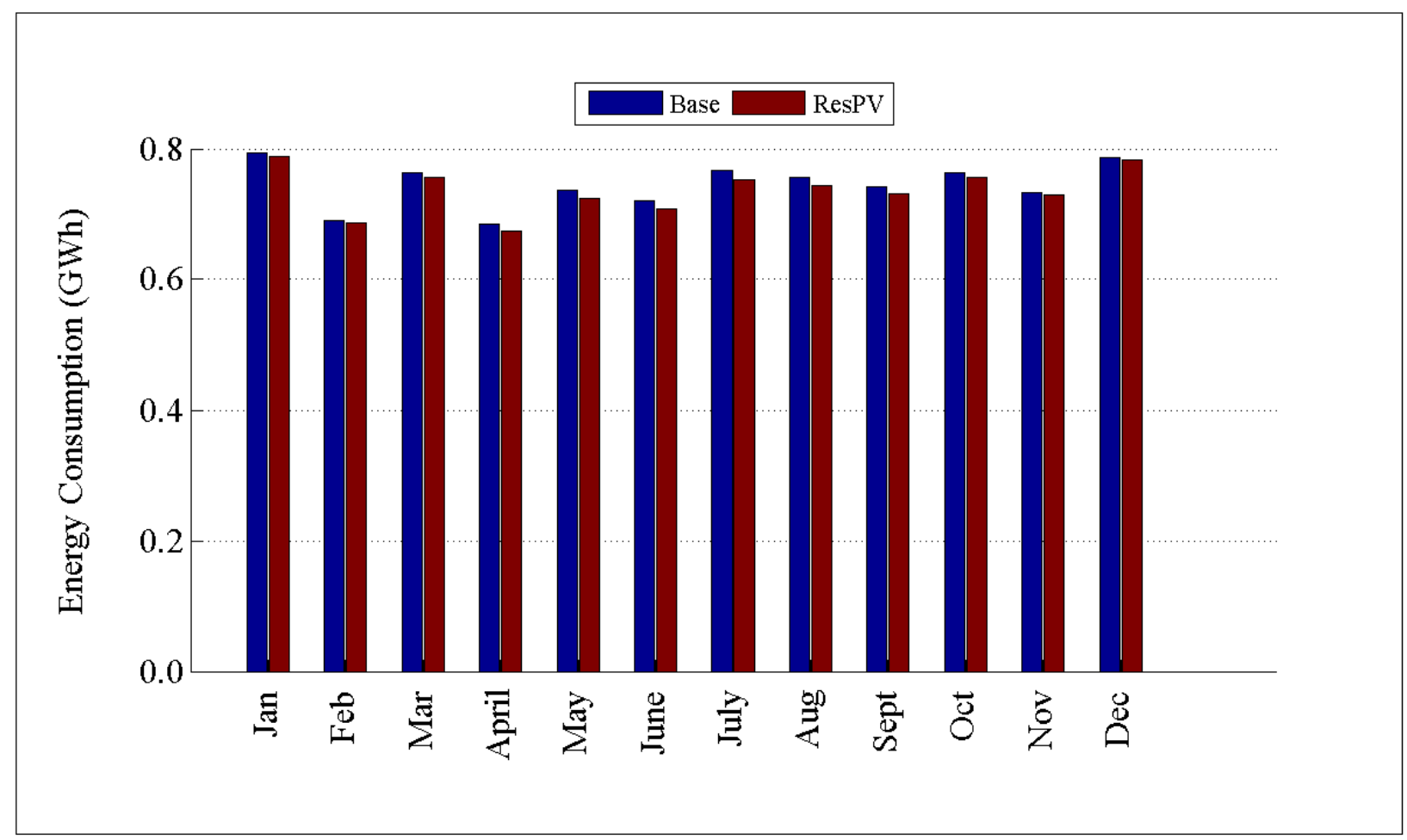

Figure D.2: Comparison of energy consumption by month for R1-12.47-2

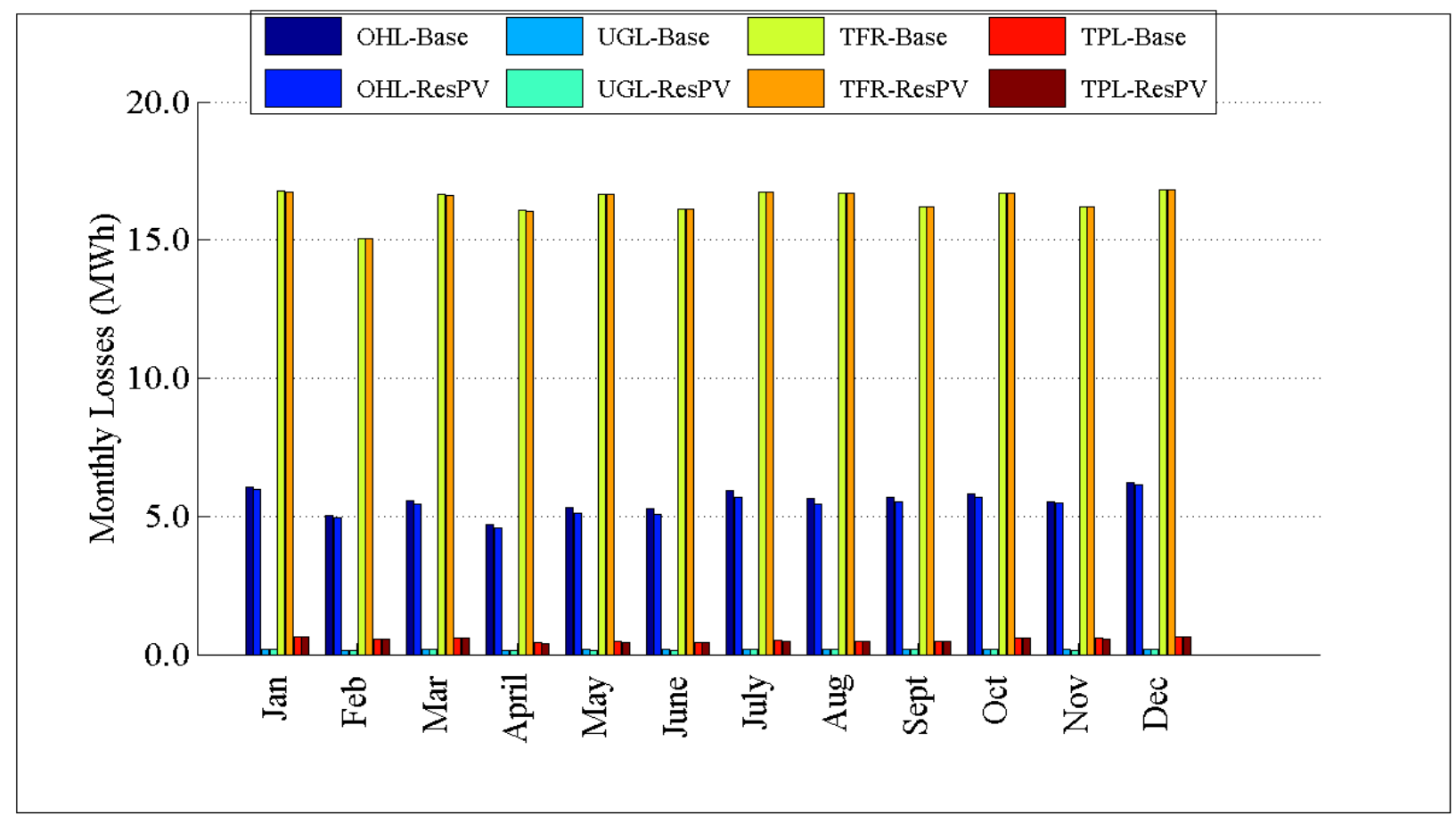

Figure D.3: Comparison of losses by month for R1-12.47-2 


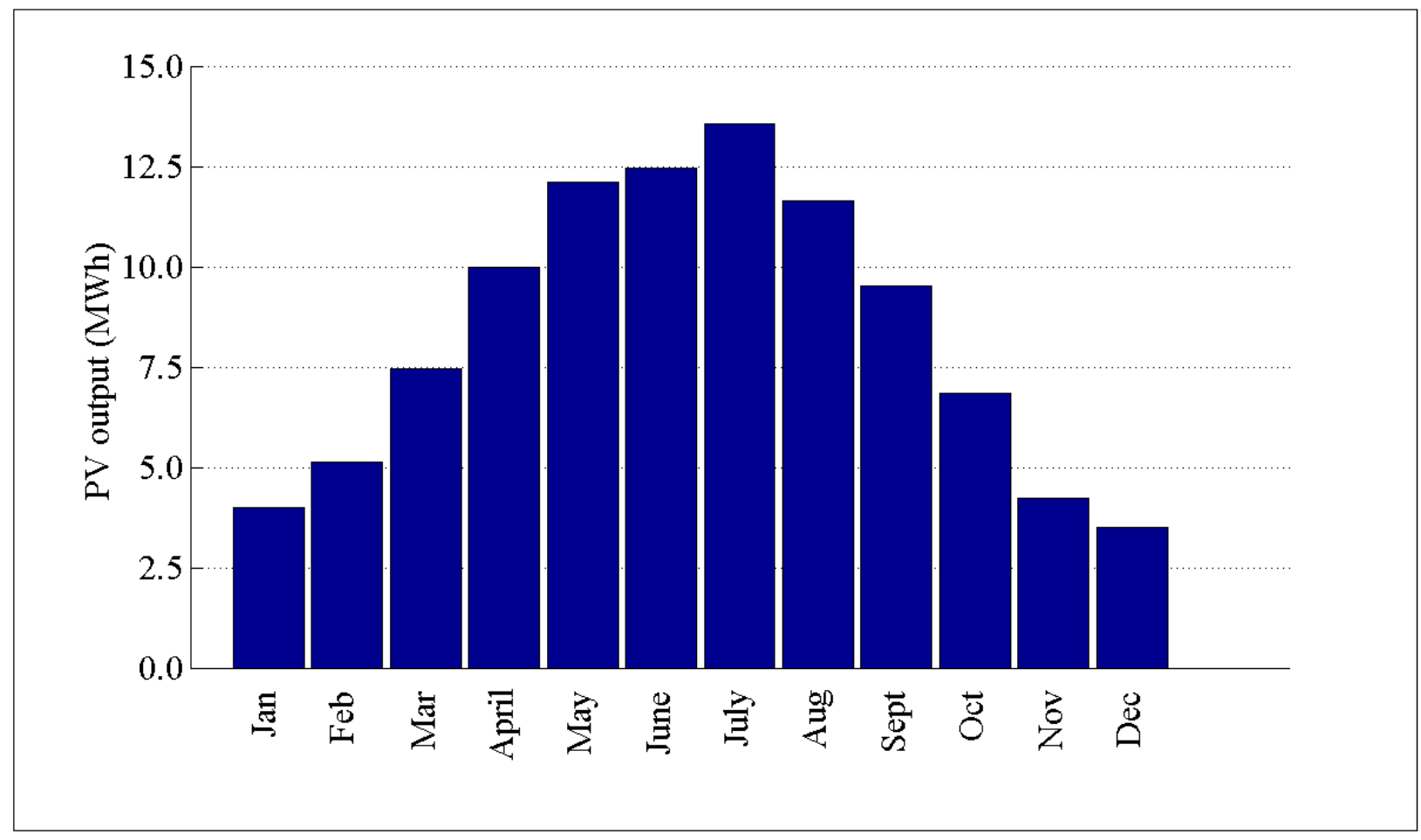

Figure D.4: Comparison of PV output by month for R1-12.47-2

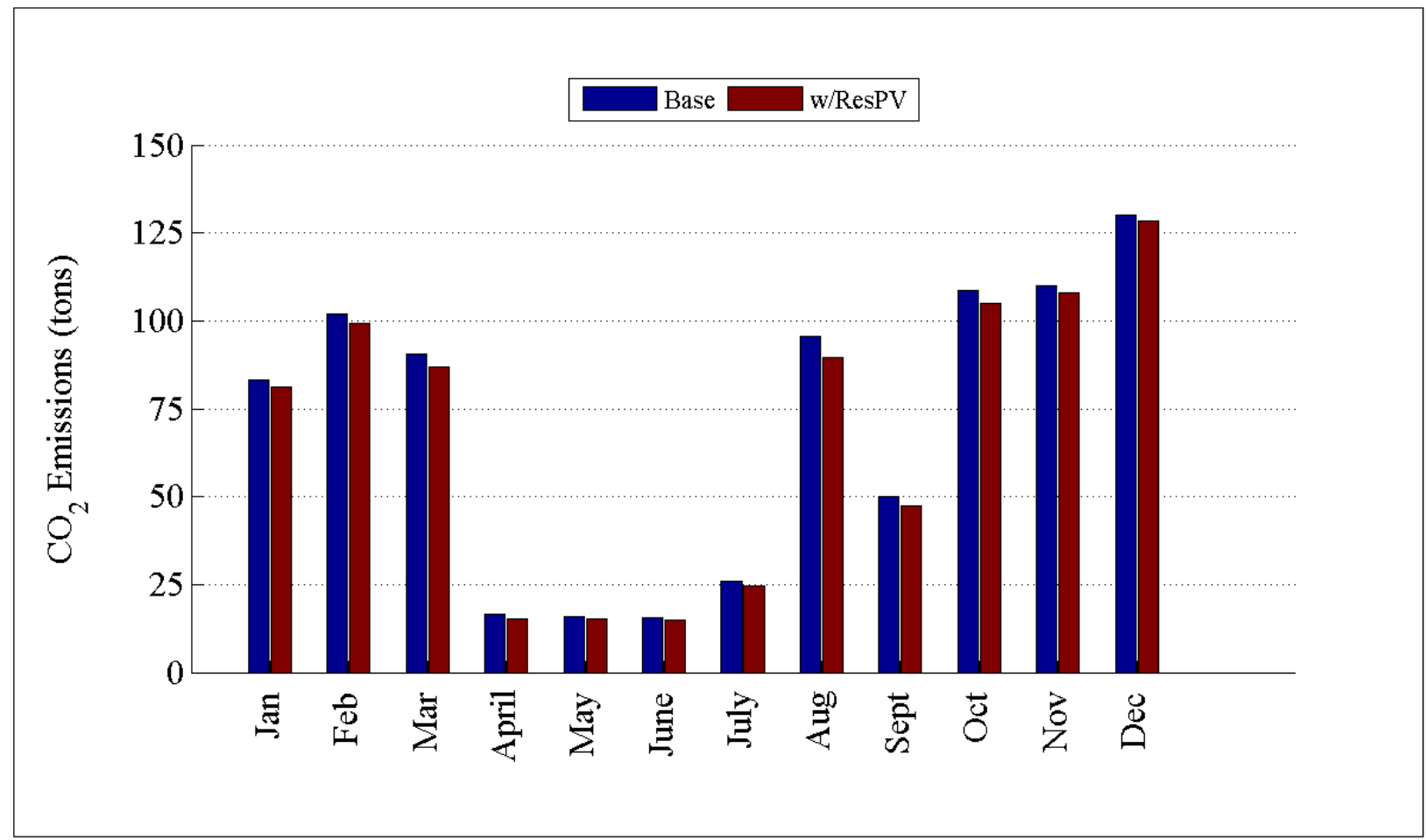

Figure D.5: Comparison of $\mathrm{CO}_{2}$ emissions by month for R1-12.47-2 
D.1.3 Detailed Residential PV Plots for R1-12.47-3

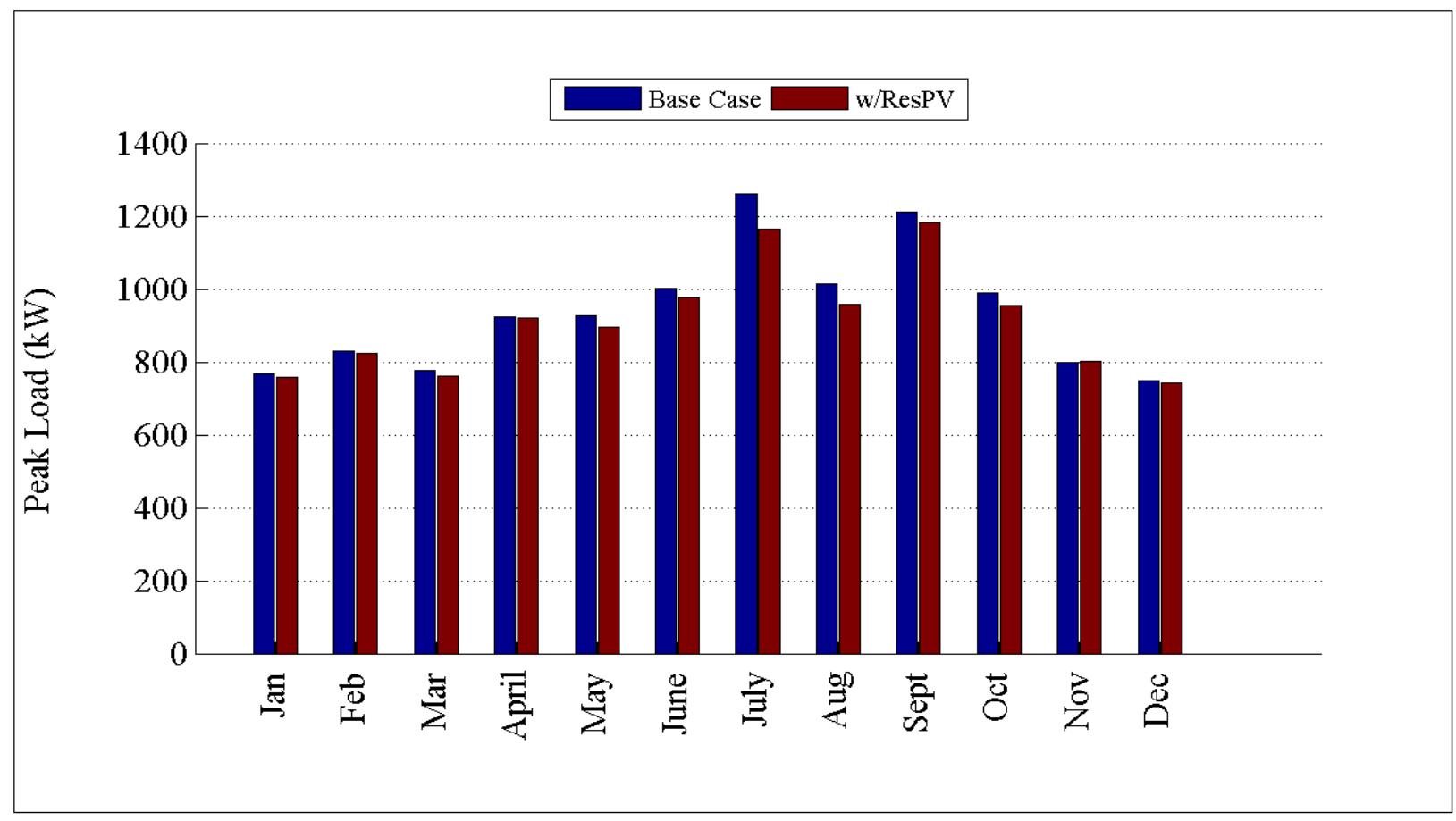

Figure D.6: Comparison of peak load by month for R1-12.47-3

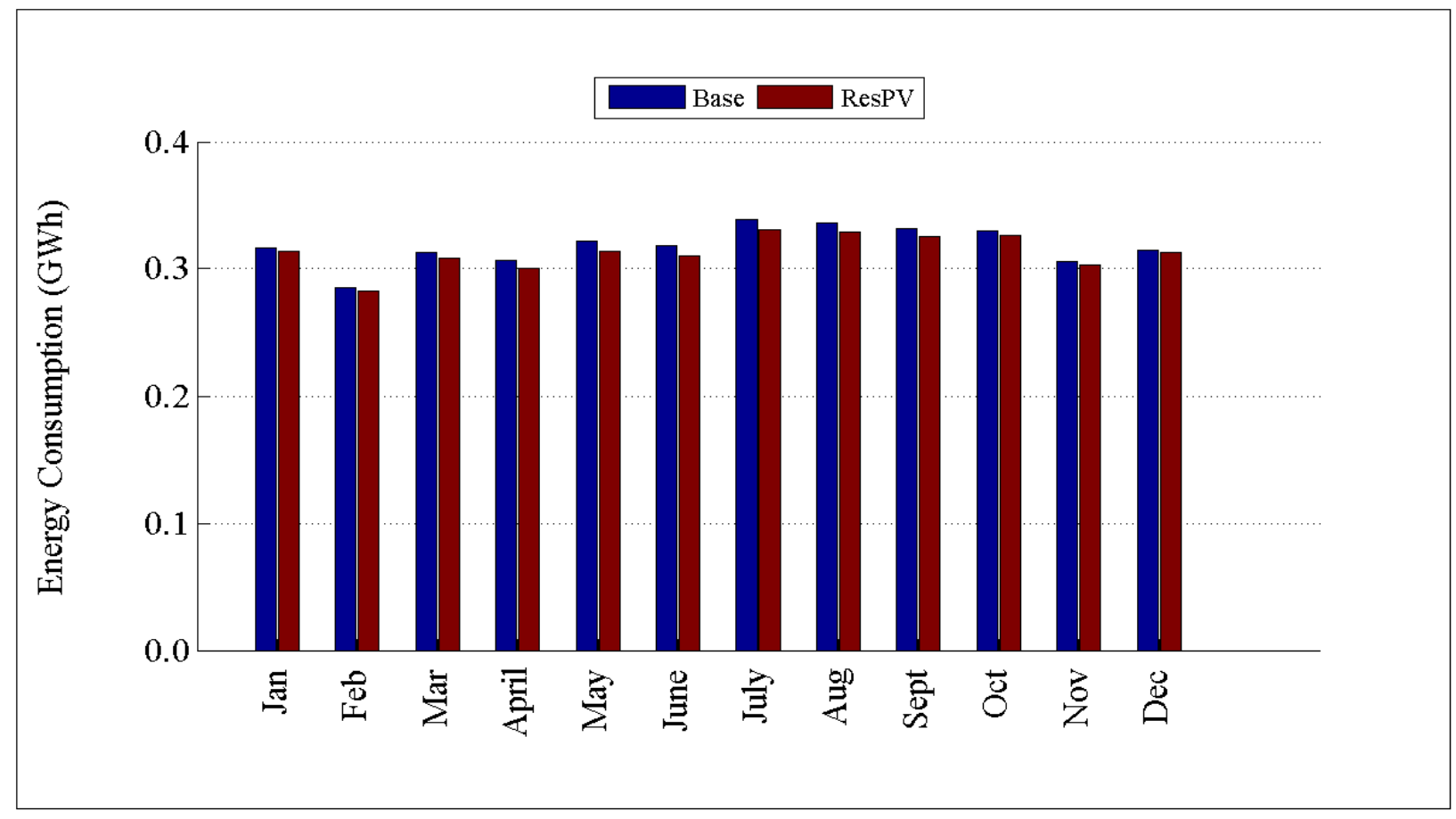

Figure D.7: Comparison of energy consumption by month for R1-12.47-3 


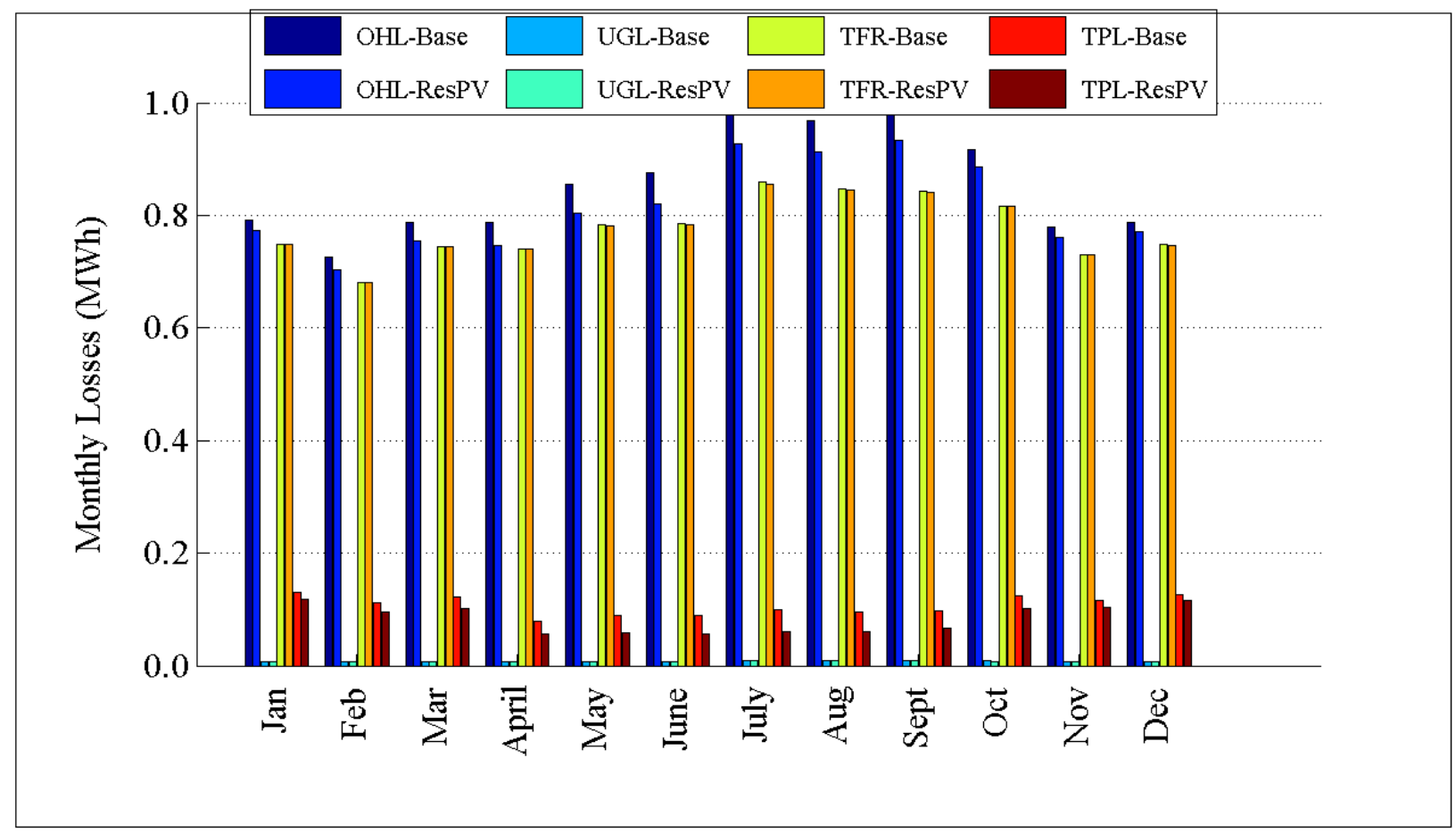

Figure D.8: Comparison of losses by month for R1-12.47-3

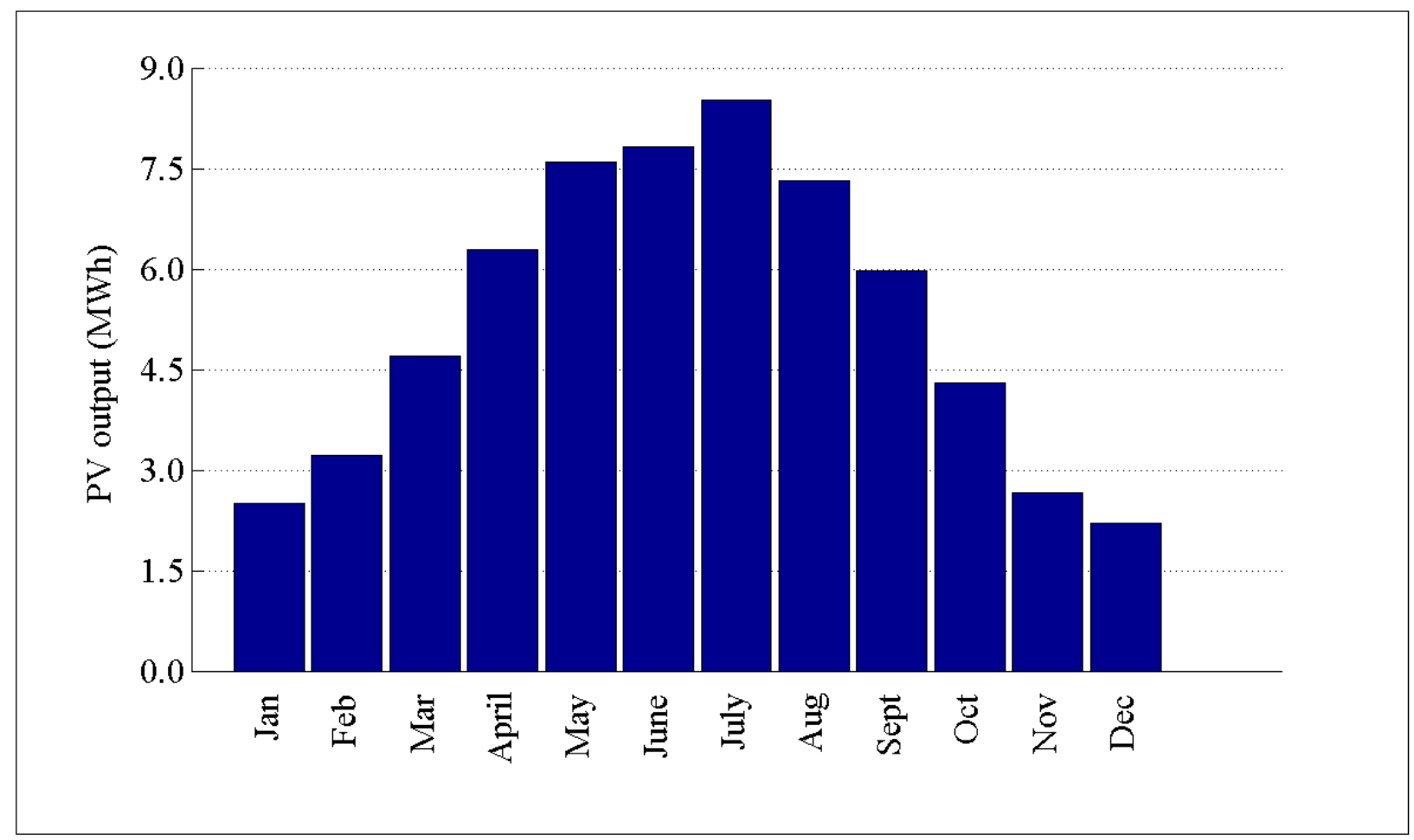

Figure D.9: Comparison of PV output by month for R1-12.47-3 


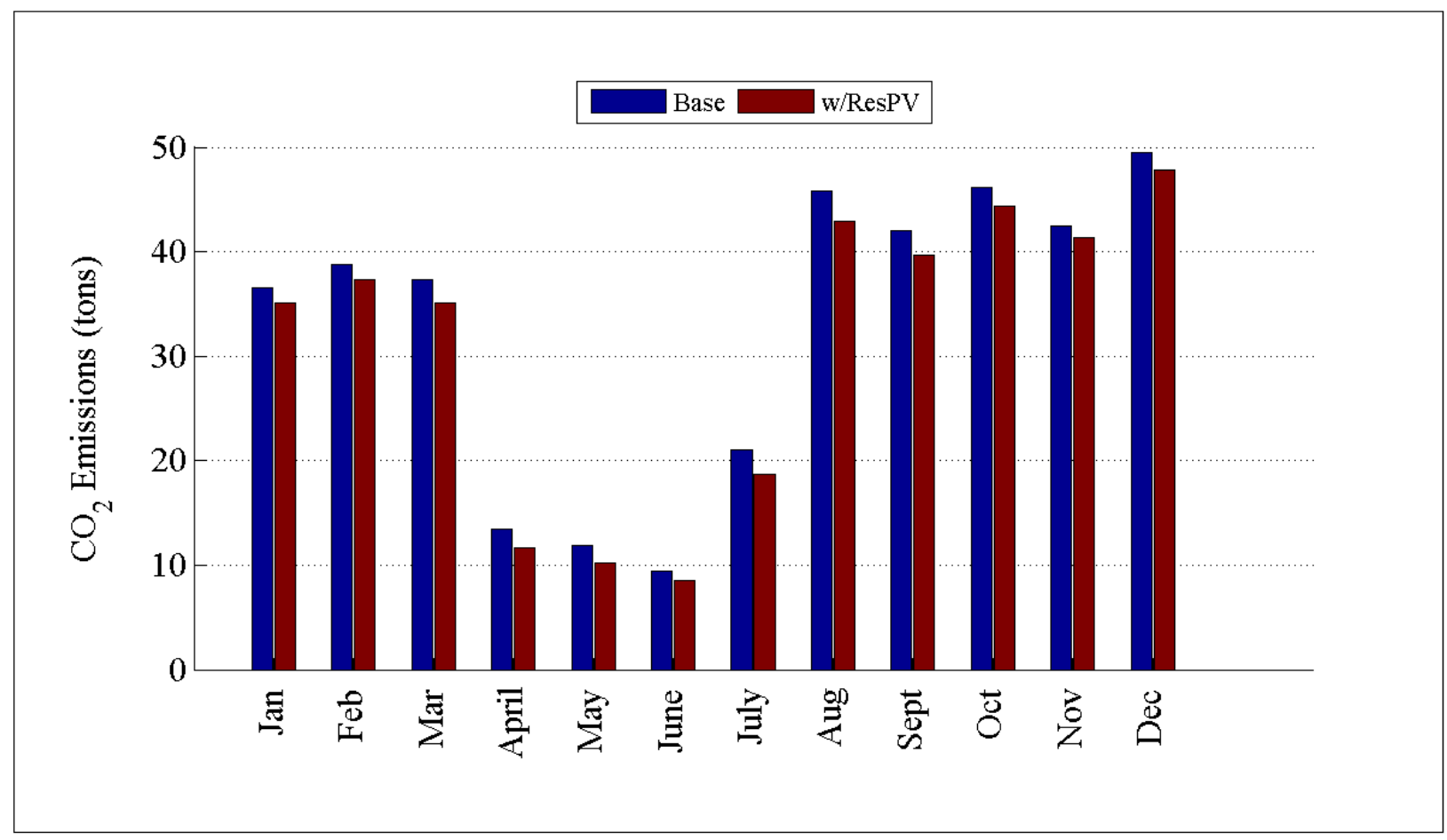

Figure D.10: Comparison of $\mathrm{CO}_{2}$ emissions by month for R1-12.47-3

\section{D.1.4 Detailed Residential PV Plots for R1-12.47-4}

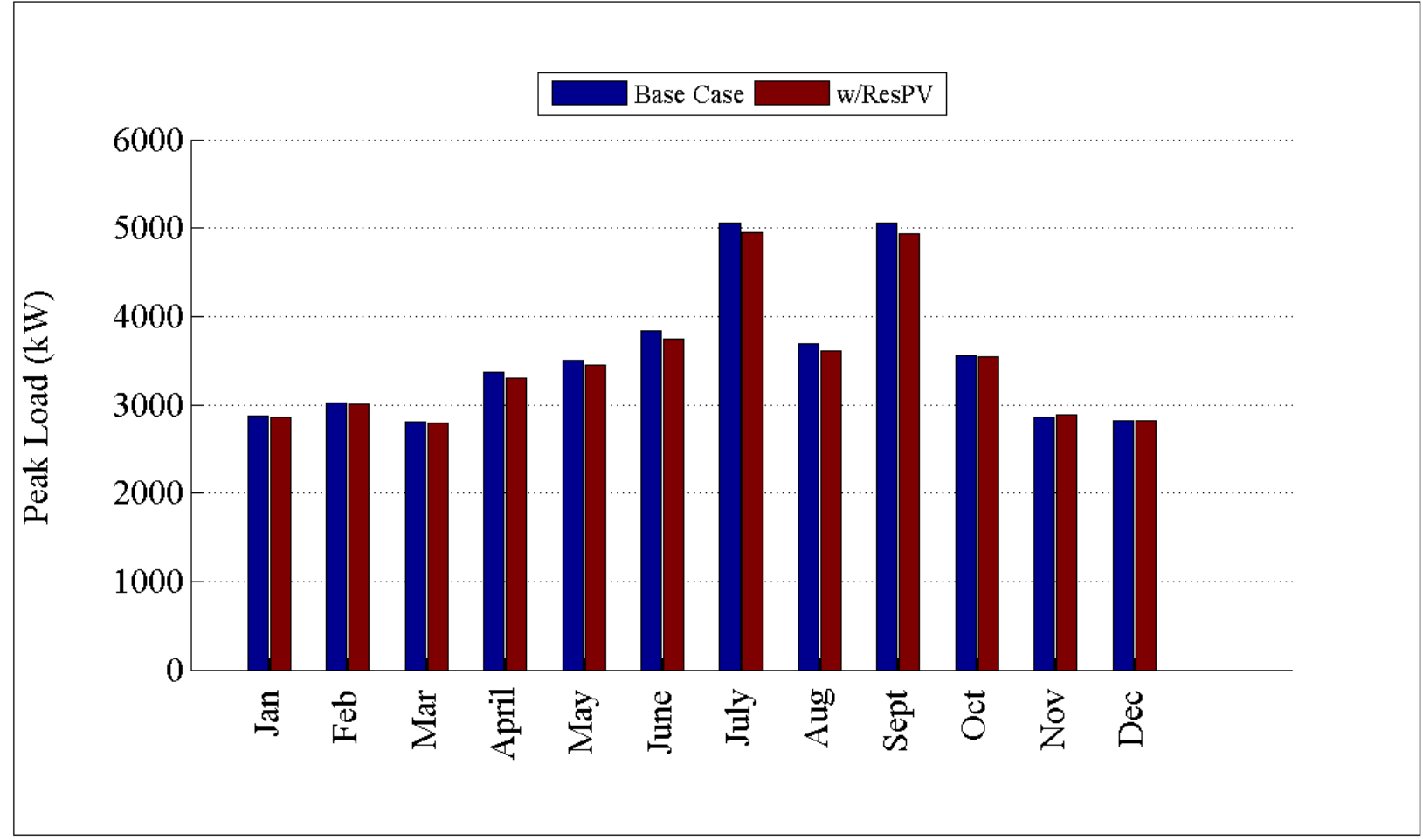

Figure D.11: Comparison of peak load by month for R1-12.47 


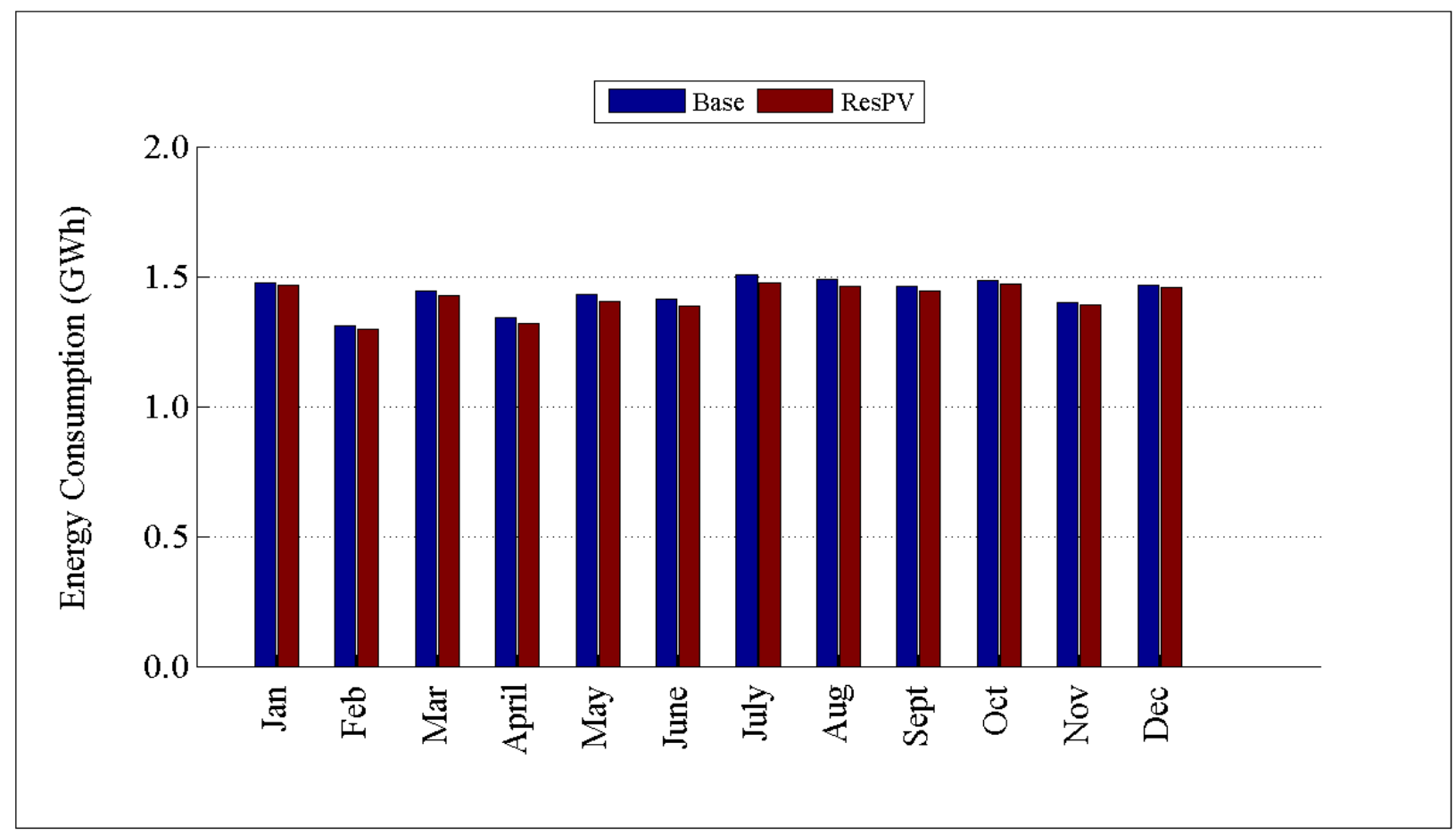

Figure D.12: Comparison of energy consumption by month for R1-12.47-4

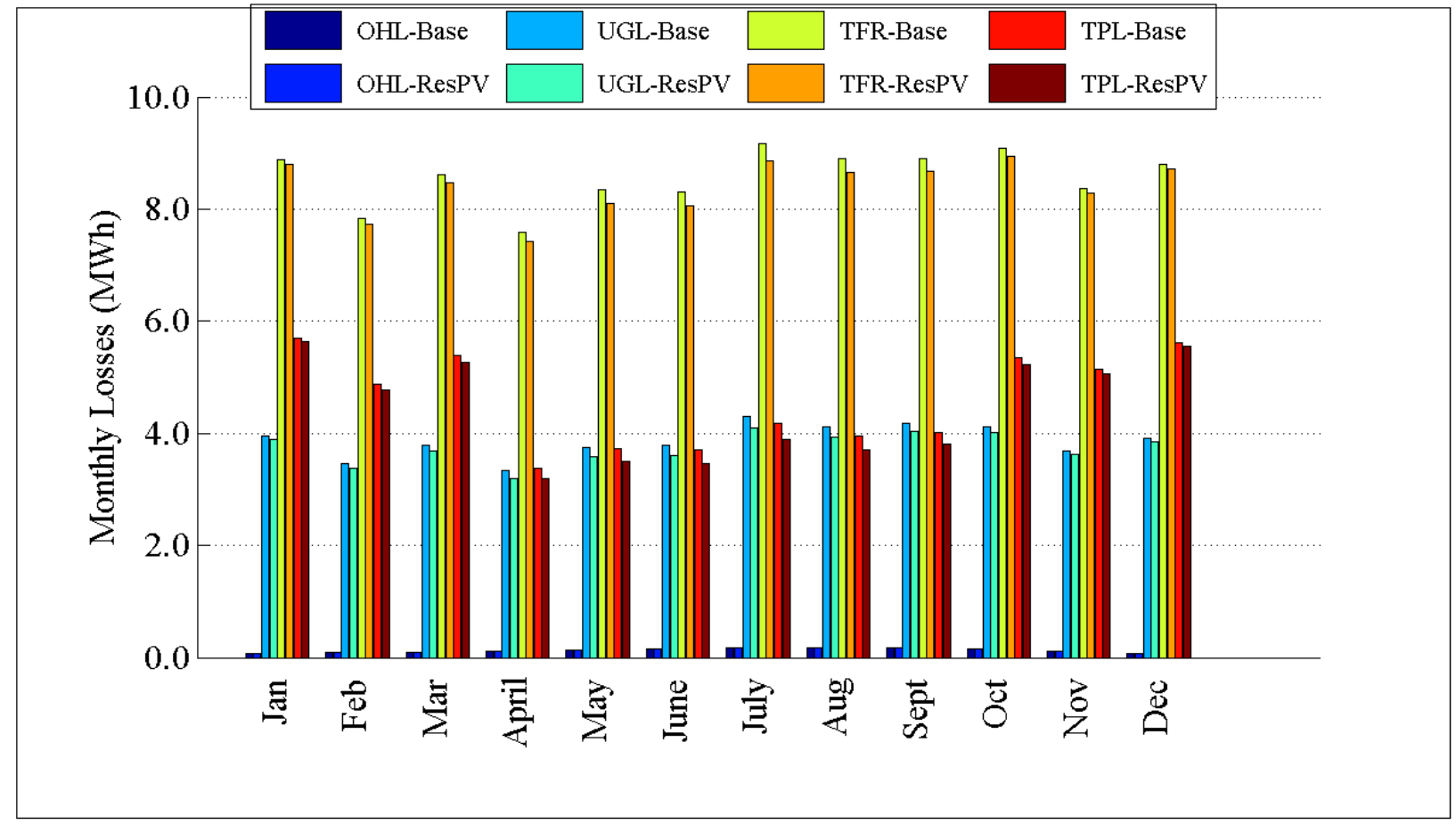

Figure D.13: Comparison of losses by month for R1-12.47-4 


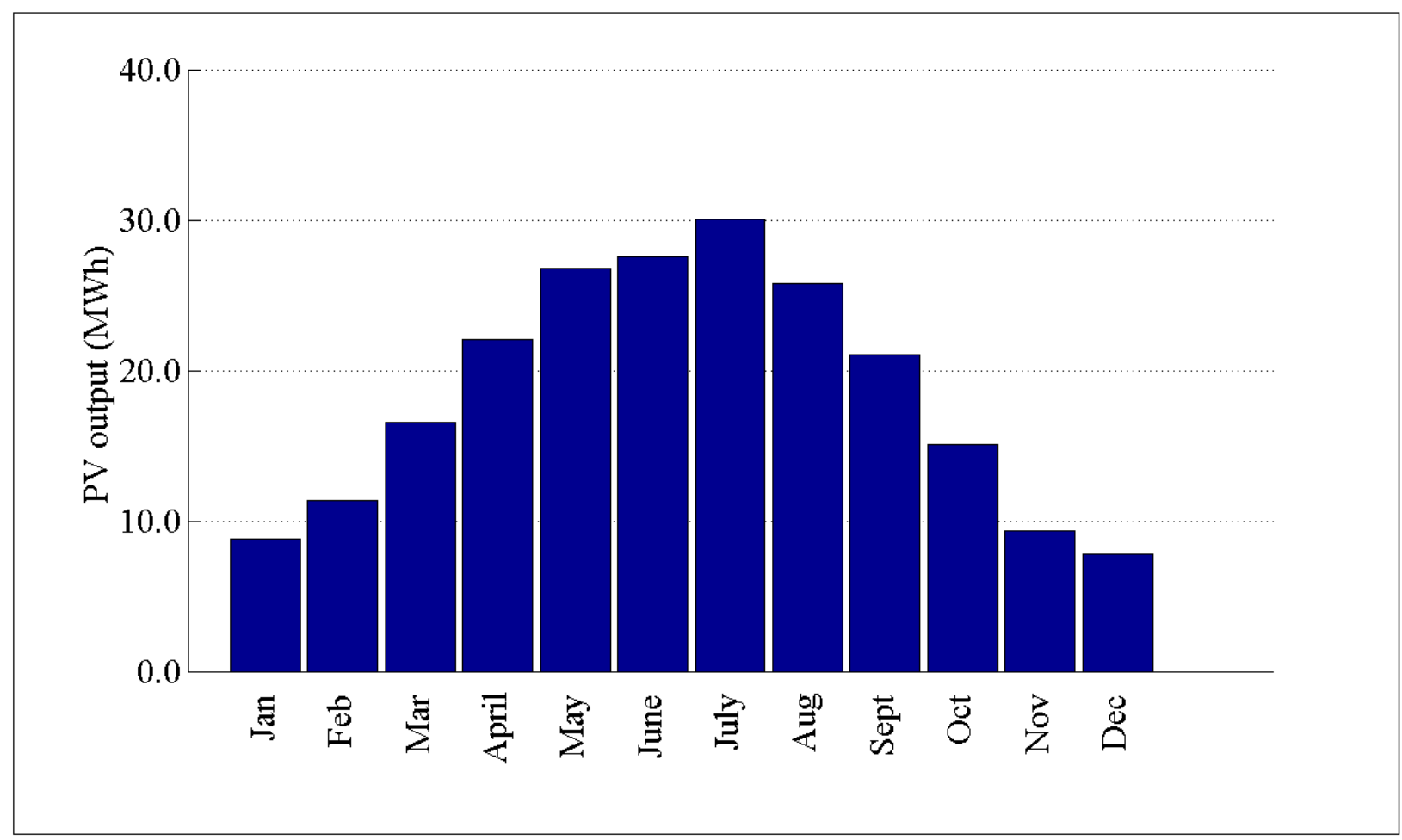

Figure D.14: PV output by month for R1-12.47-4

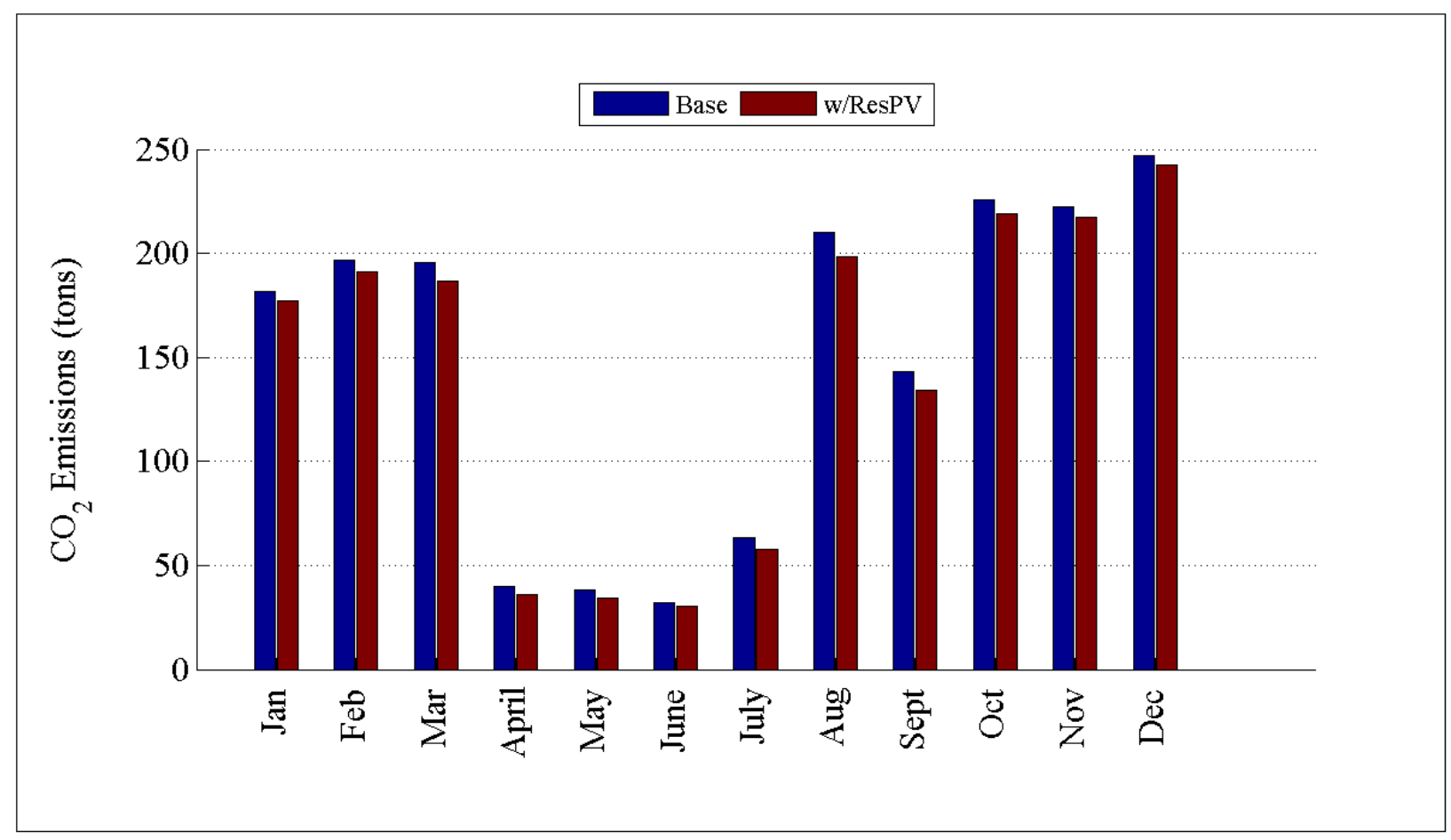

Figure D.15: Comparison of $\mathrm{CO}_{2}$ emissions by month for R1-12.47-4 
D.1.5 Detailed Residential PV Plots for R1-25.00-1

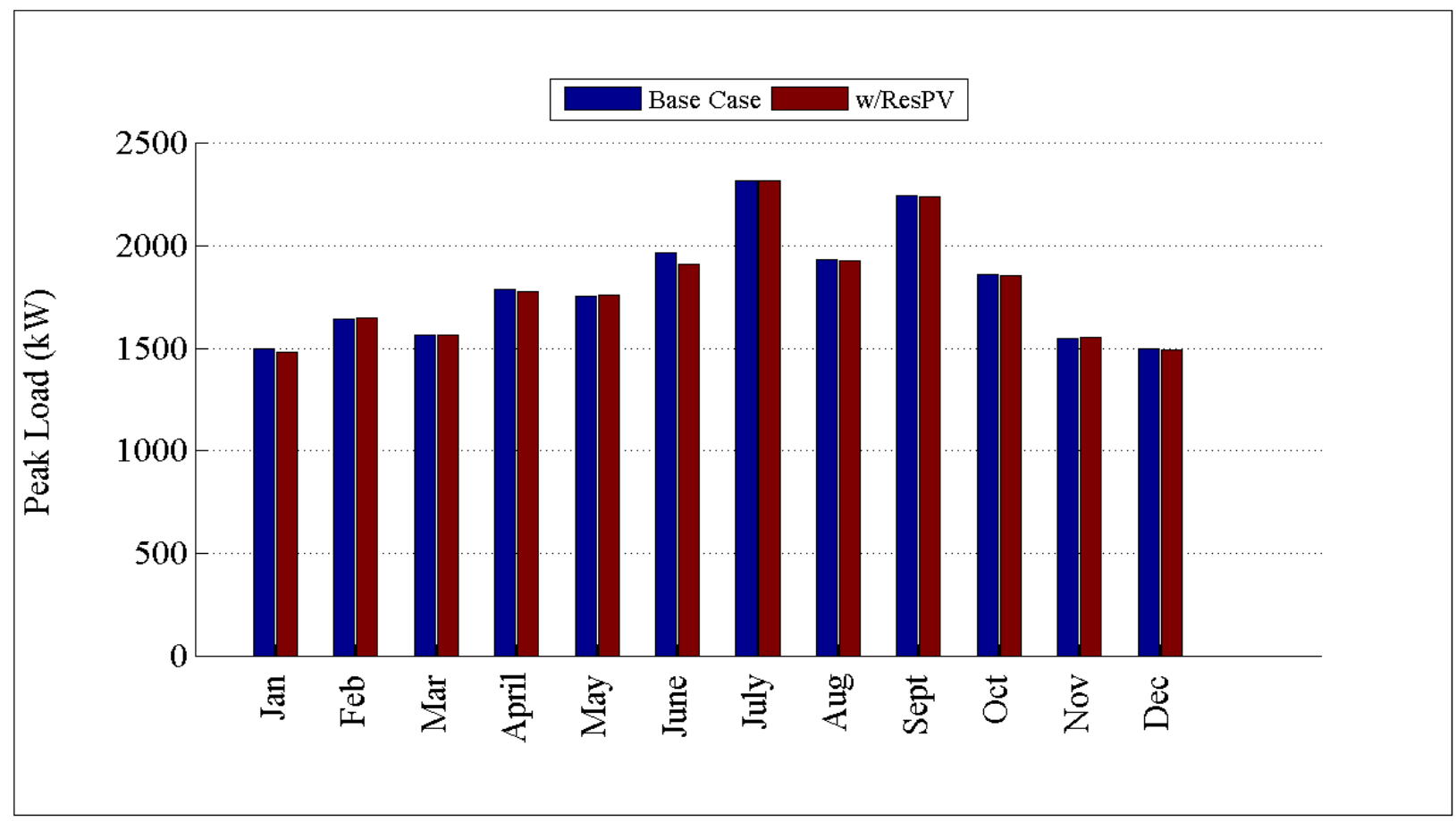

Figure D.16: Comparison of peak load by month for R1-25.00-1

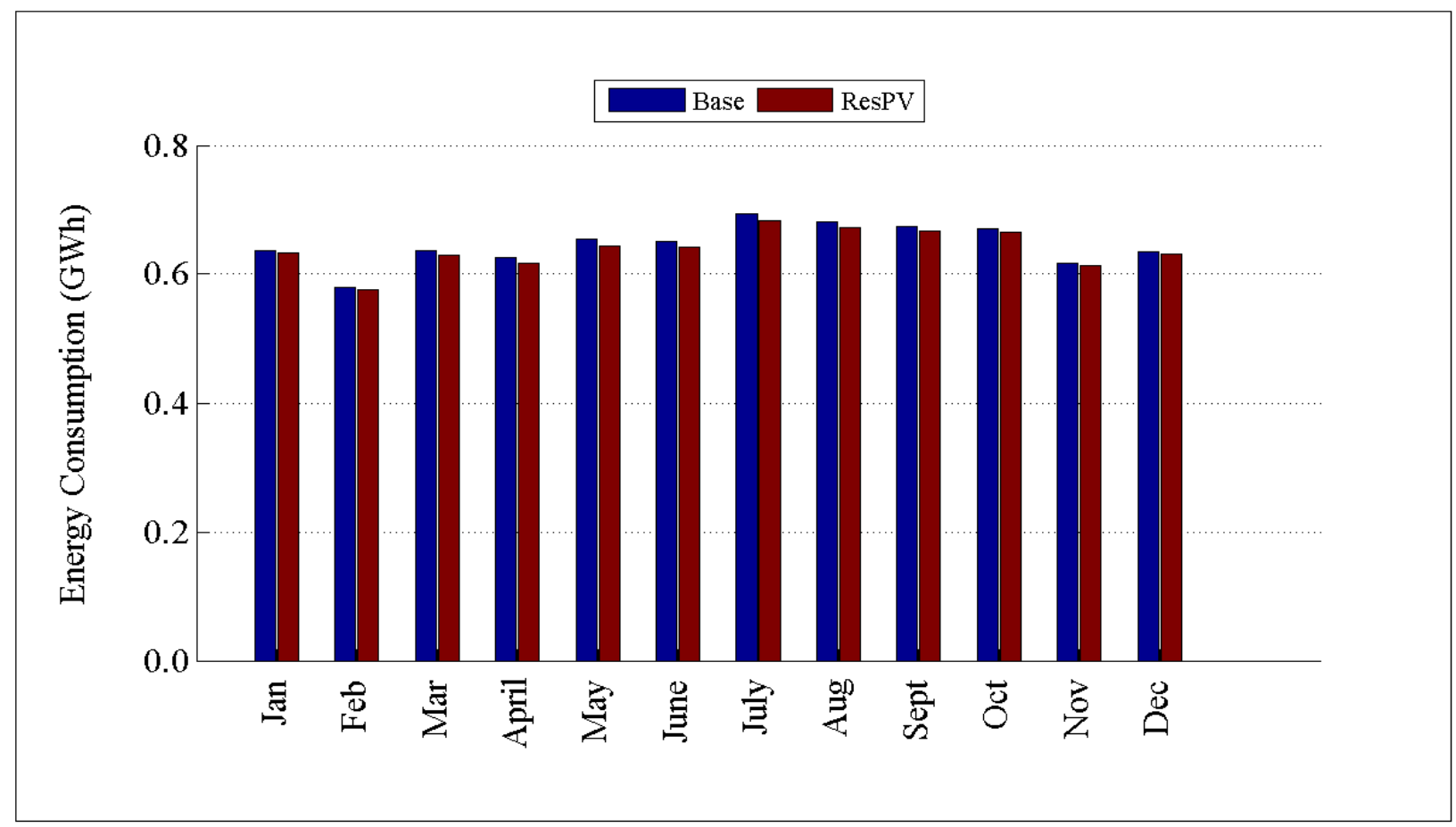

Figure D.17: Comparison of energy consumption by month for R1-25.00-1 


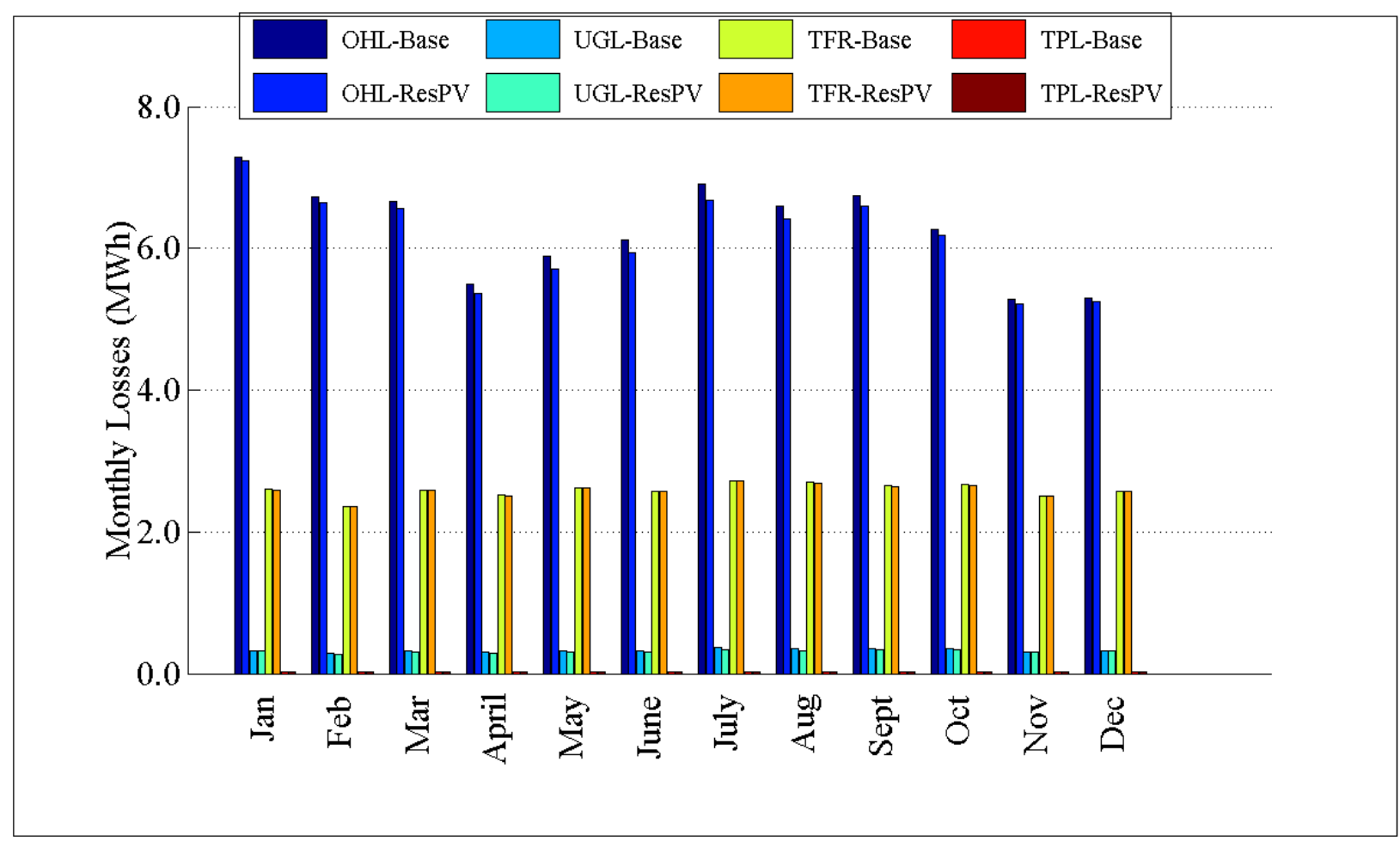

Figure D.18: Comparison of losses by month for R1-25.00-1

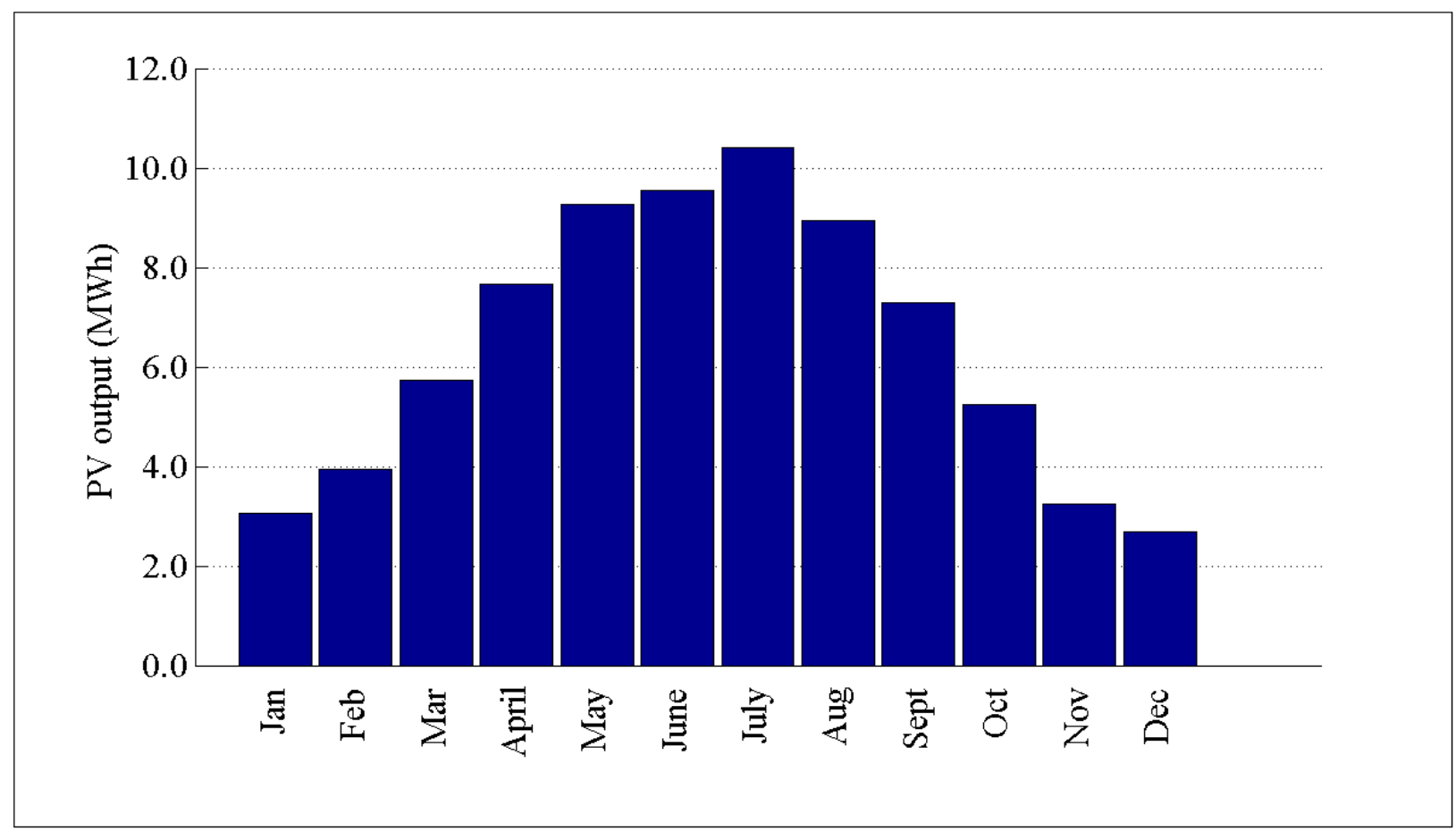

Figure D.19: PV output by month for R1-25.00-1 


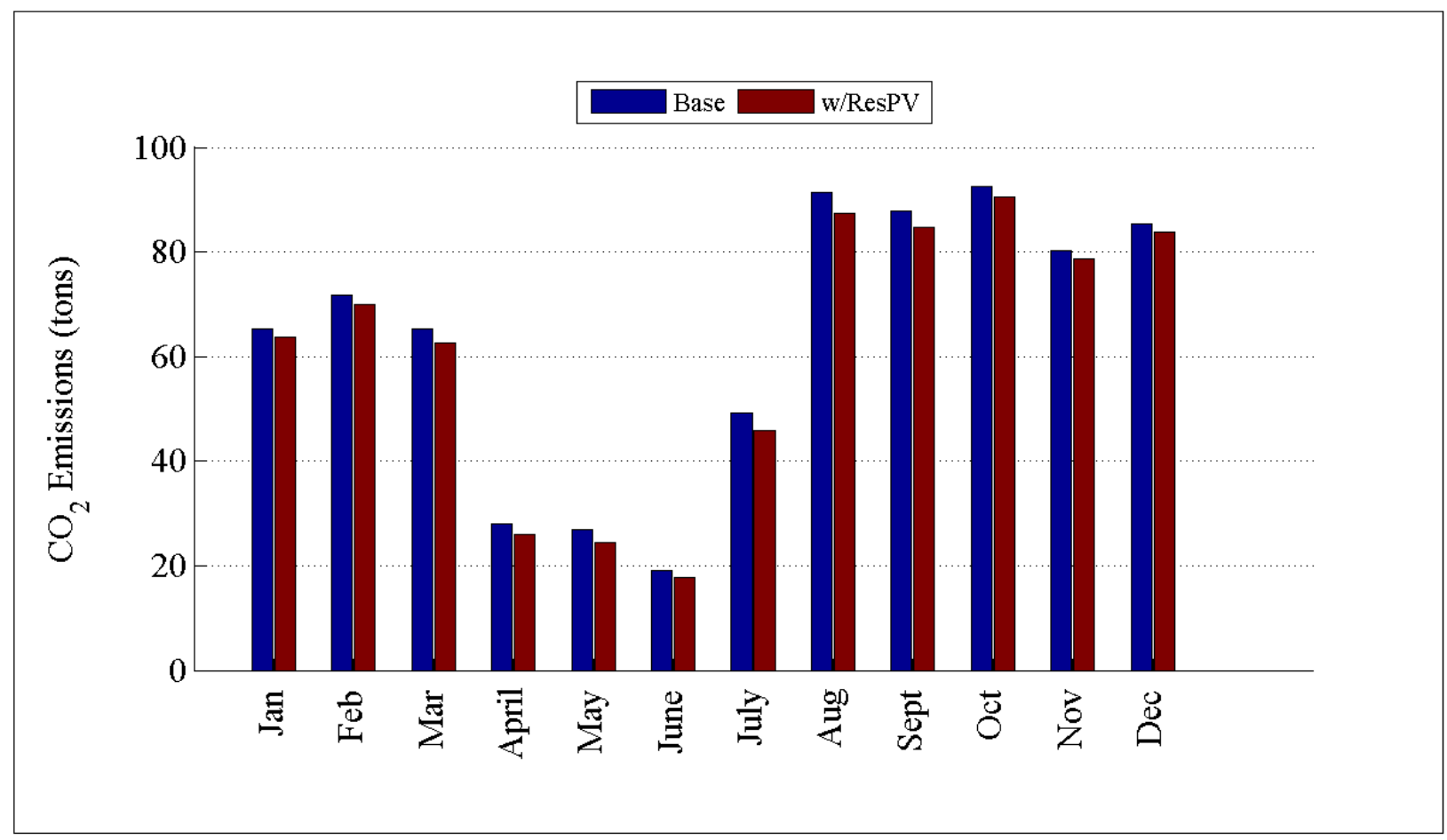

Figure D.20: Comparison of $\mathrm{CO}_{2}$ emissions by month for R1-25.00-1

\section{D.1.6 Detailed Residential PV Plots for R2-12.47-1}

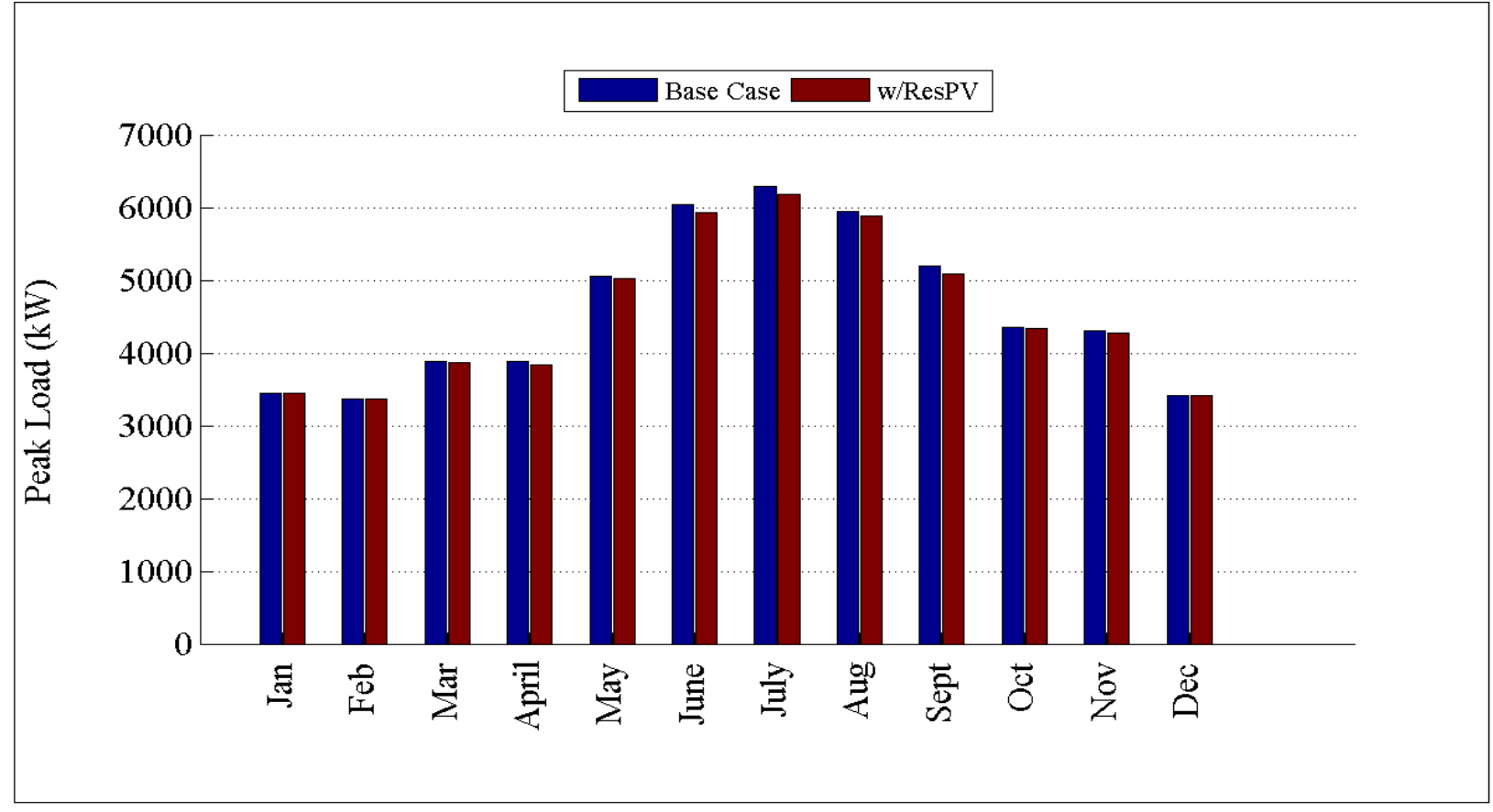

Figure D.21: Comparison of peak load by month for R2-12.47-1 


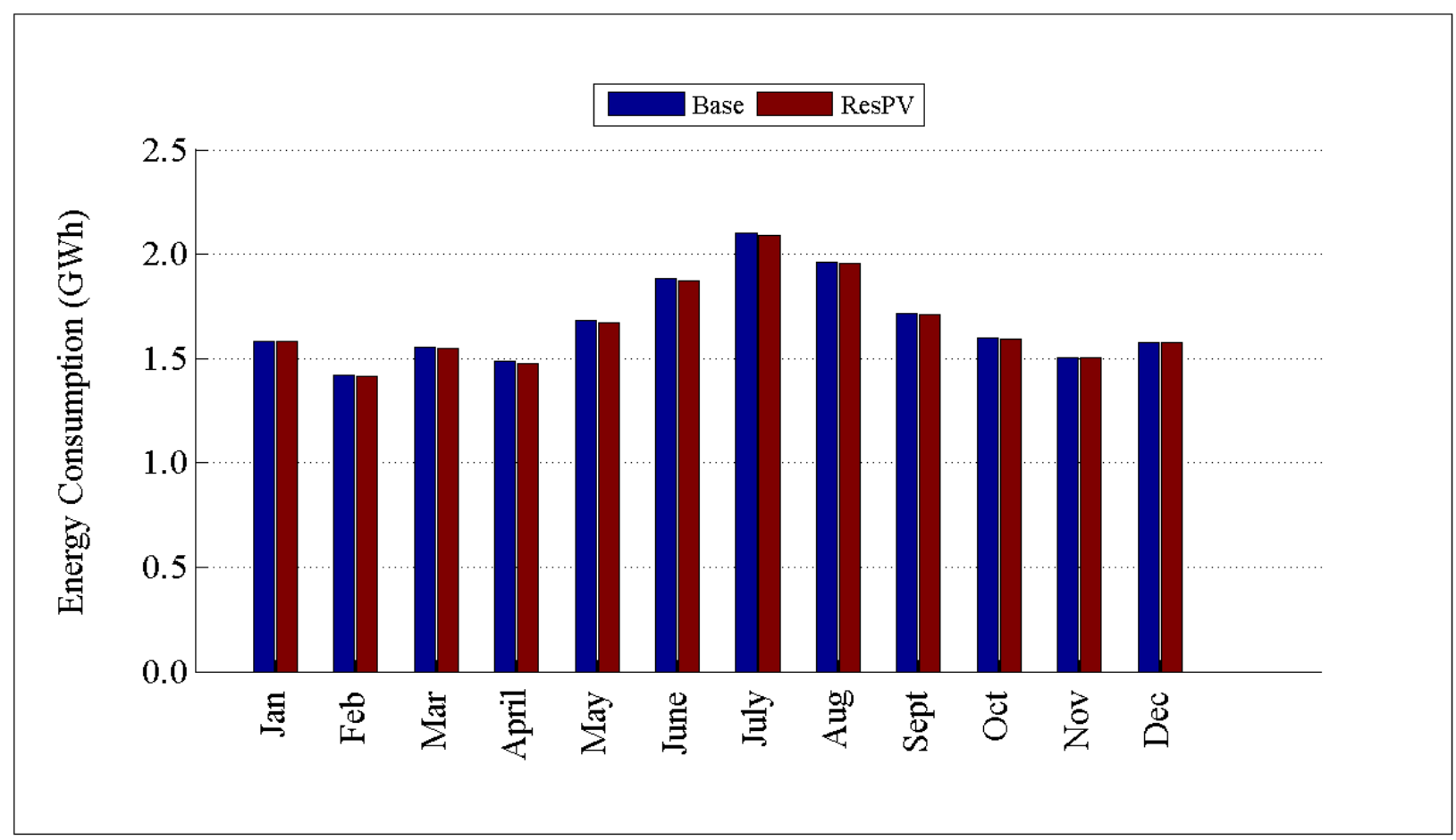

Figure D.22: Comparison of energy consumption by month for R2-12.47-1

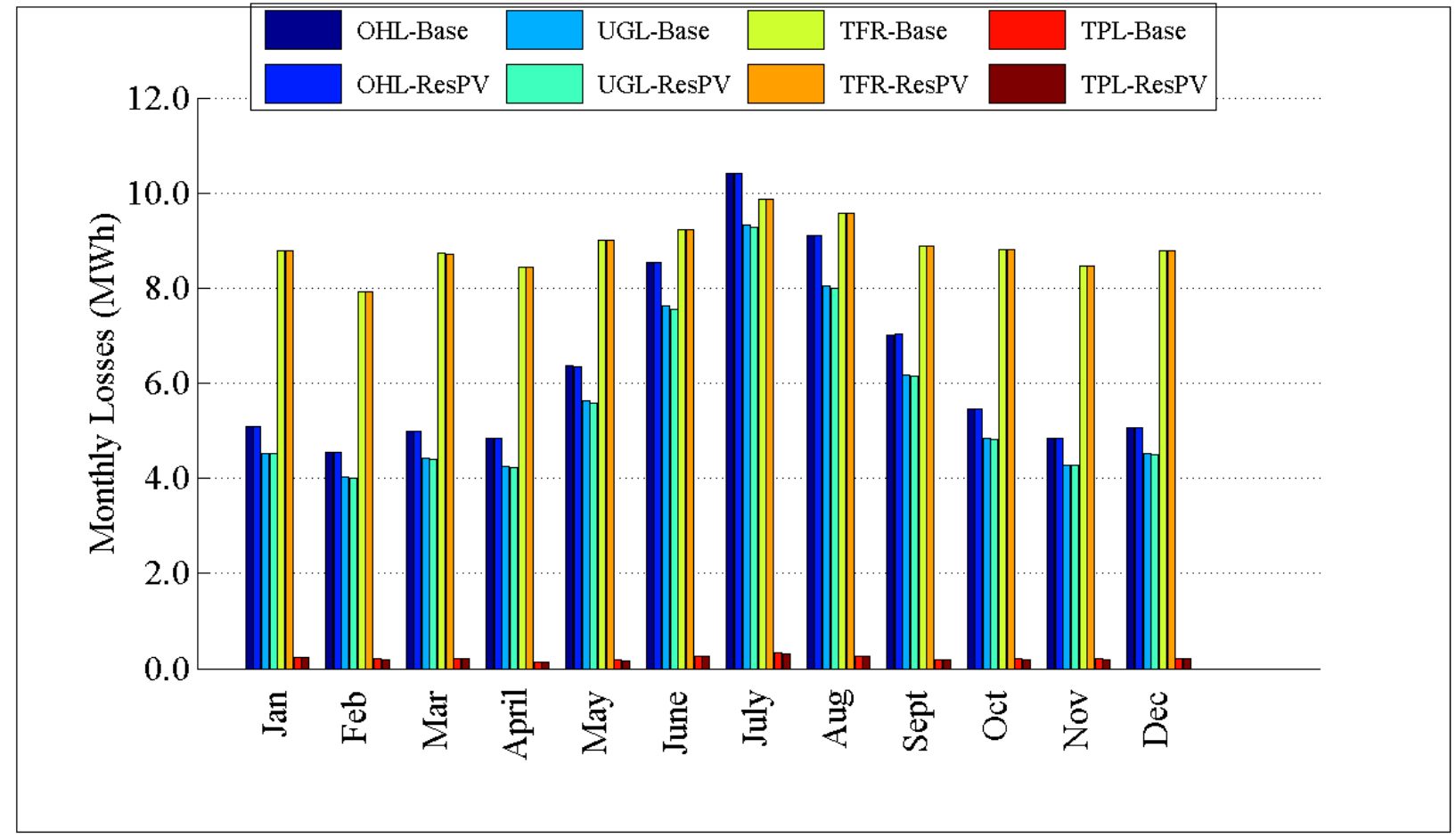

Figure D.23: Comparison of losses by month for R2-12.47-1 


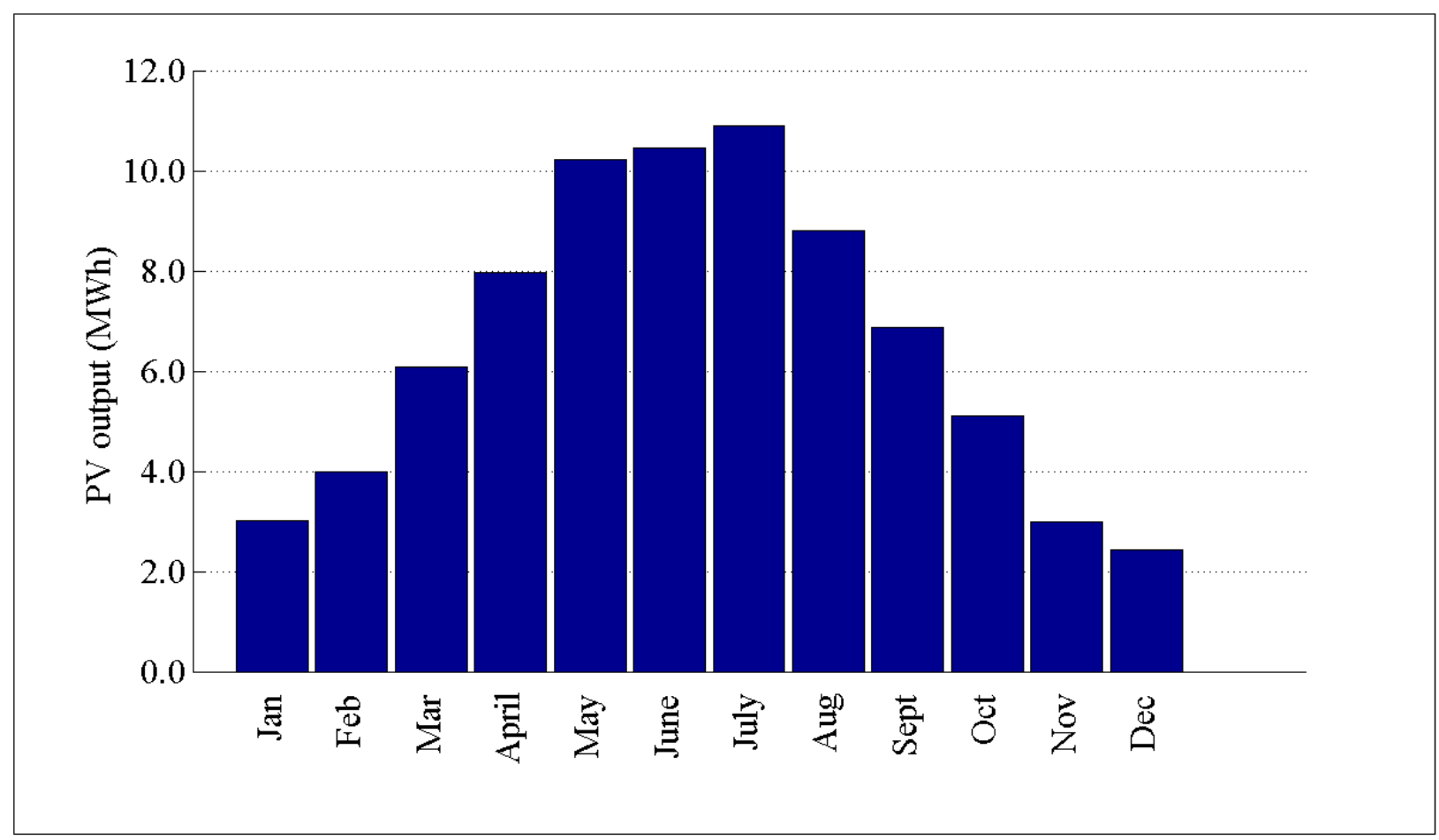

Figure D.24: PV output by month for R2-12.47-1

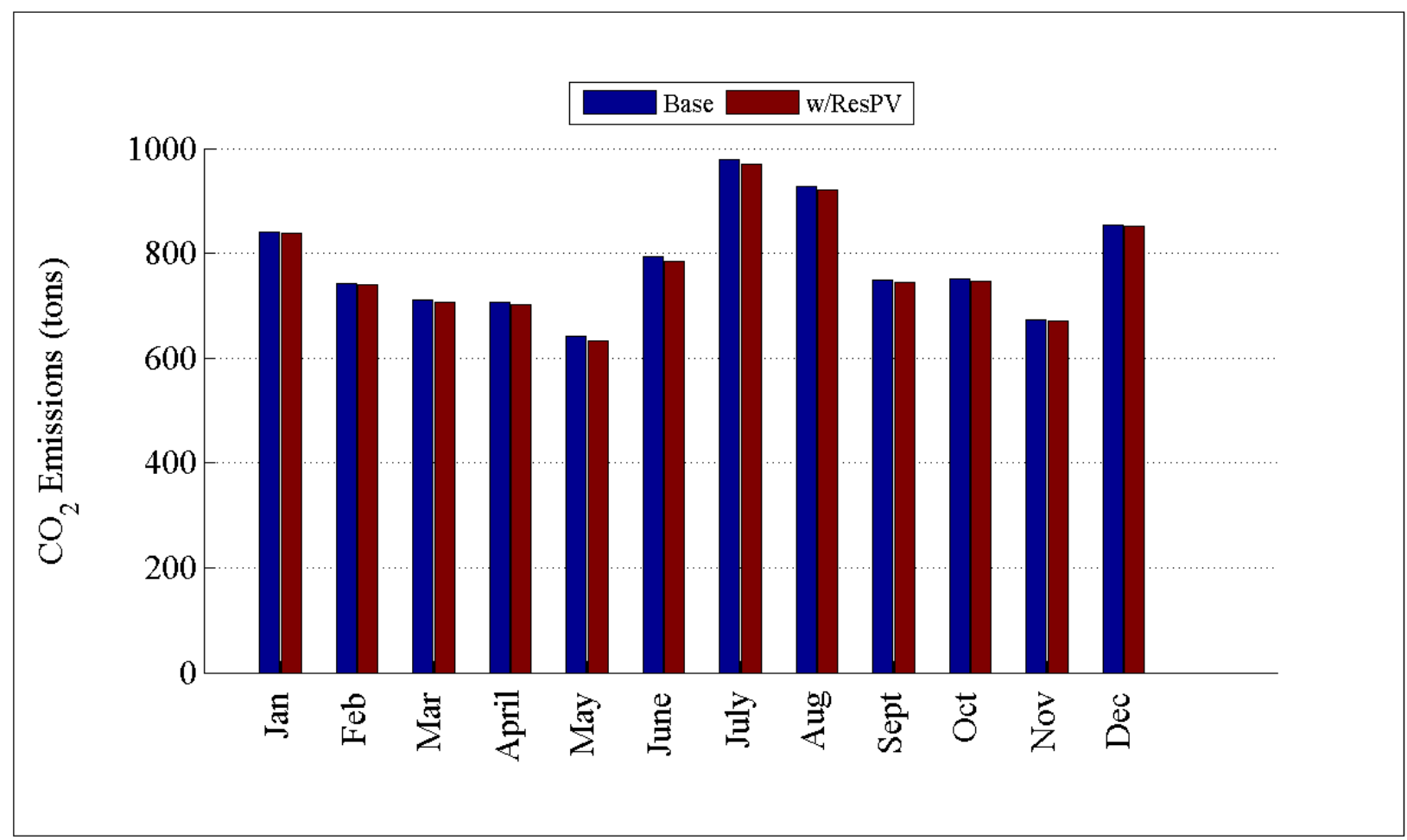

Figure D.25: Comparison of $\mathrm{CO}_{2}$ emissions by month for R2-12.47-1 
D.1.7 Detailed Residential PV Plots for R2-12.47-2

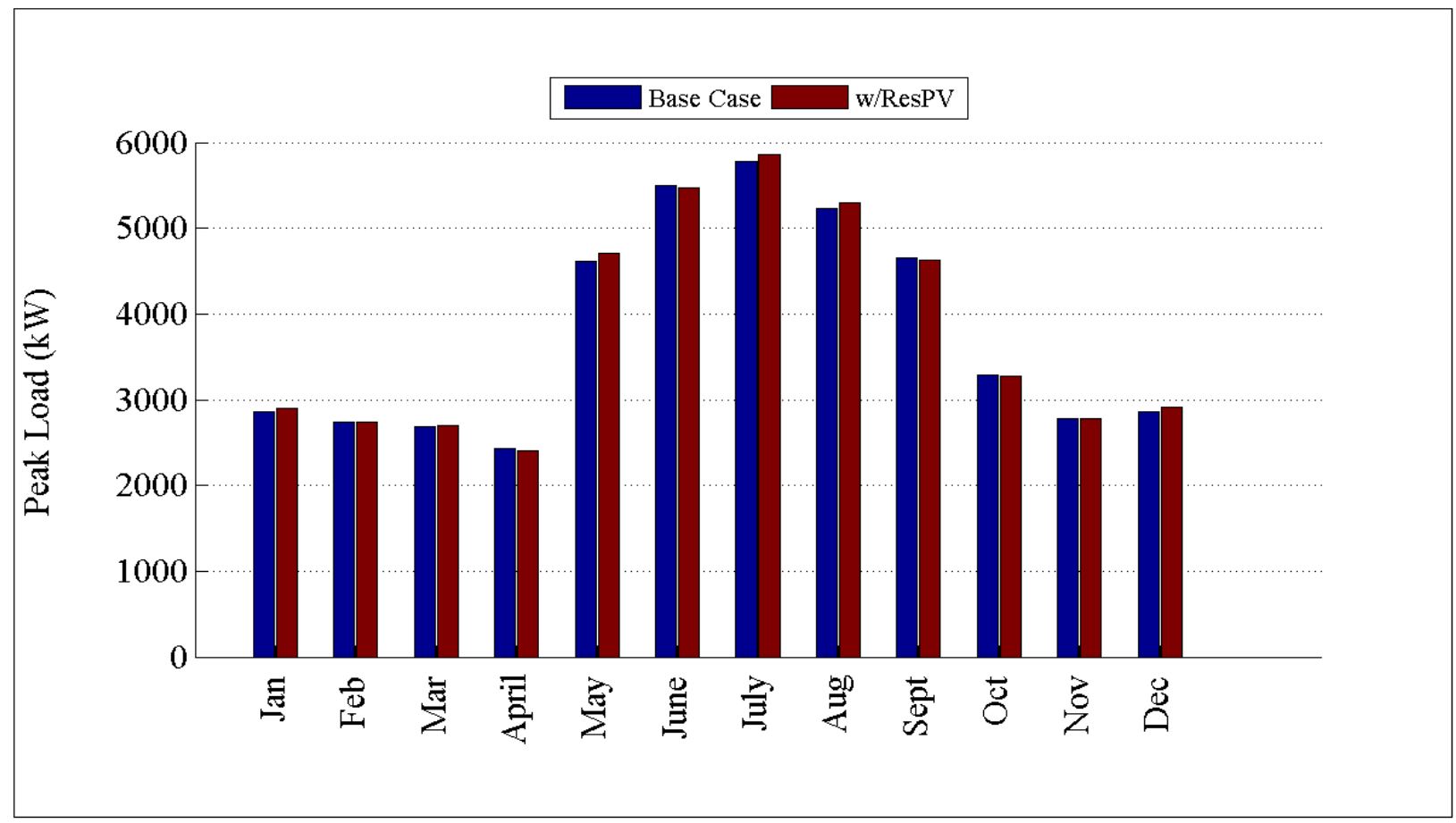

Figure D.26: Comparison of peak load by month for R2-12.47-2

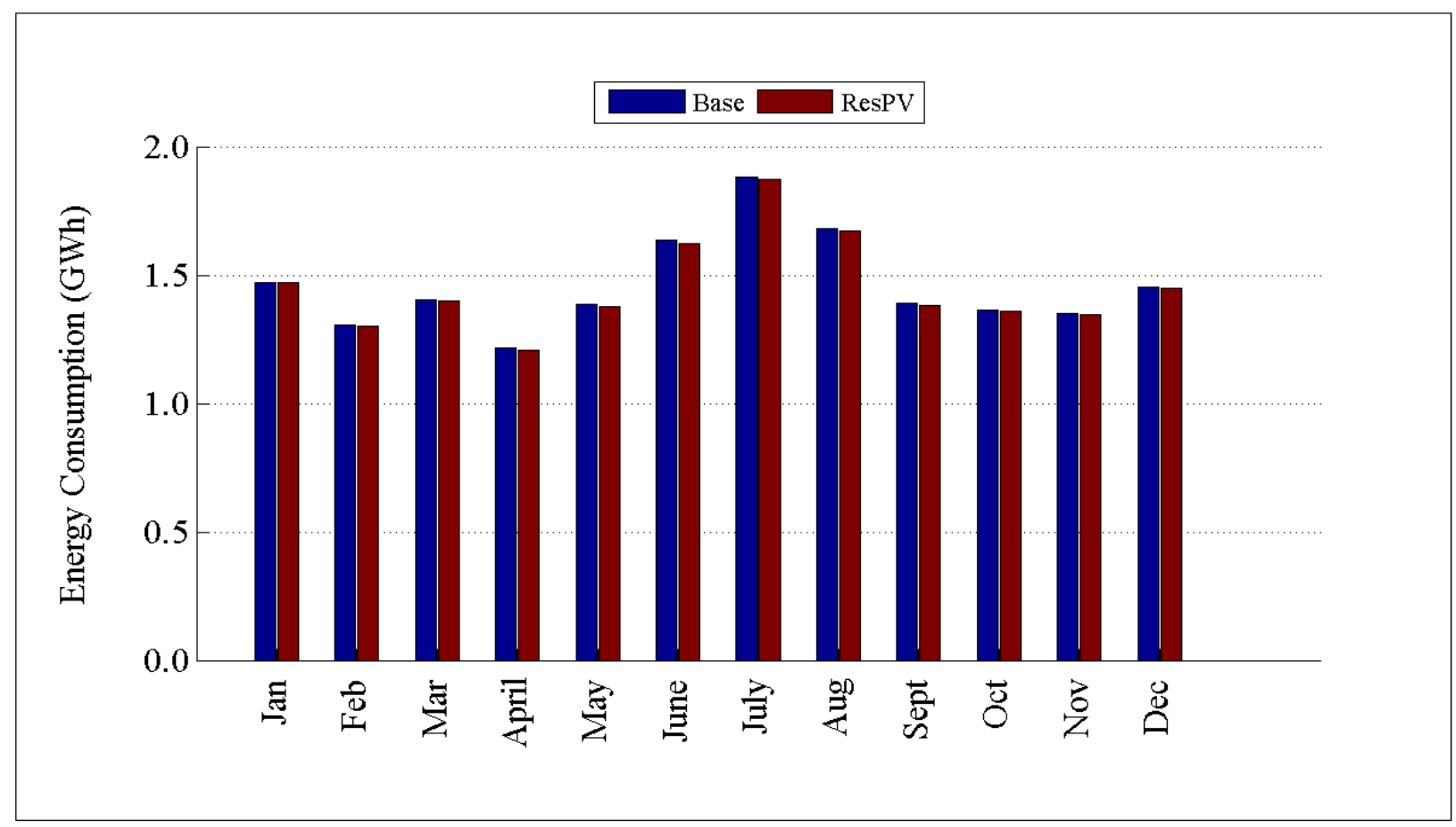

Figure D.27: Comparison of energy consumption by month for R2-12.47-2 


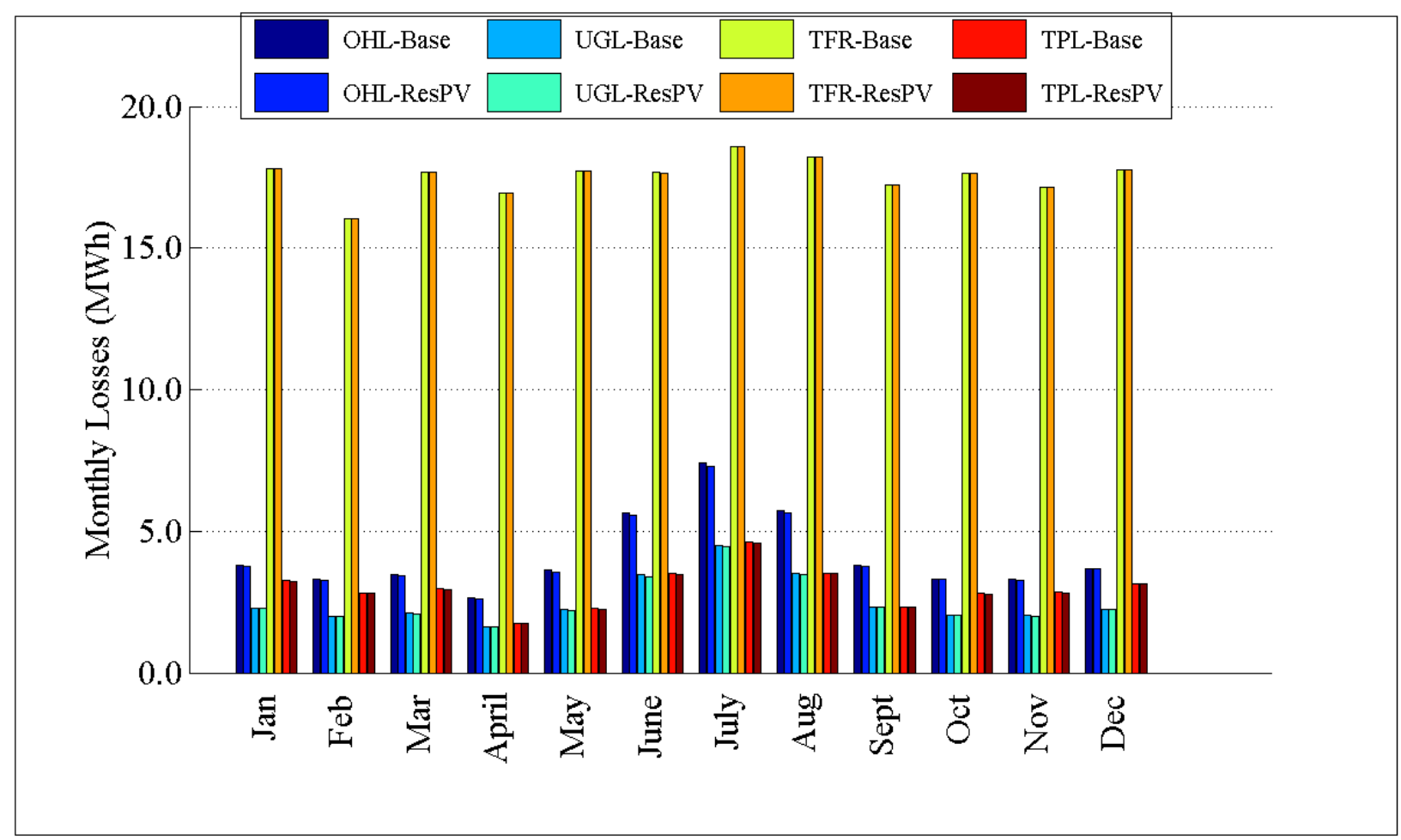

Figure D.28: Comparison of losses by month for R2-12.47-2

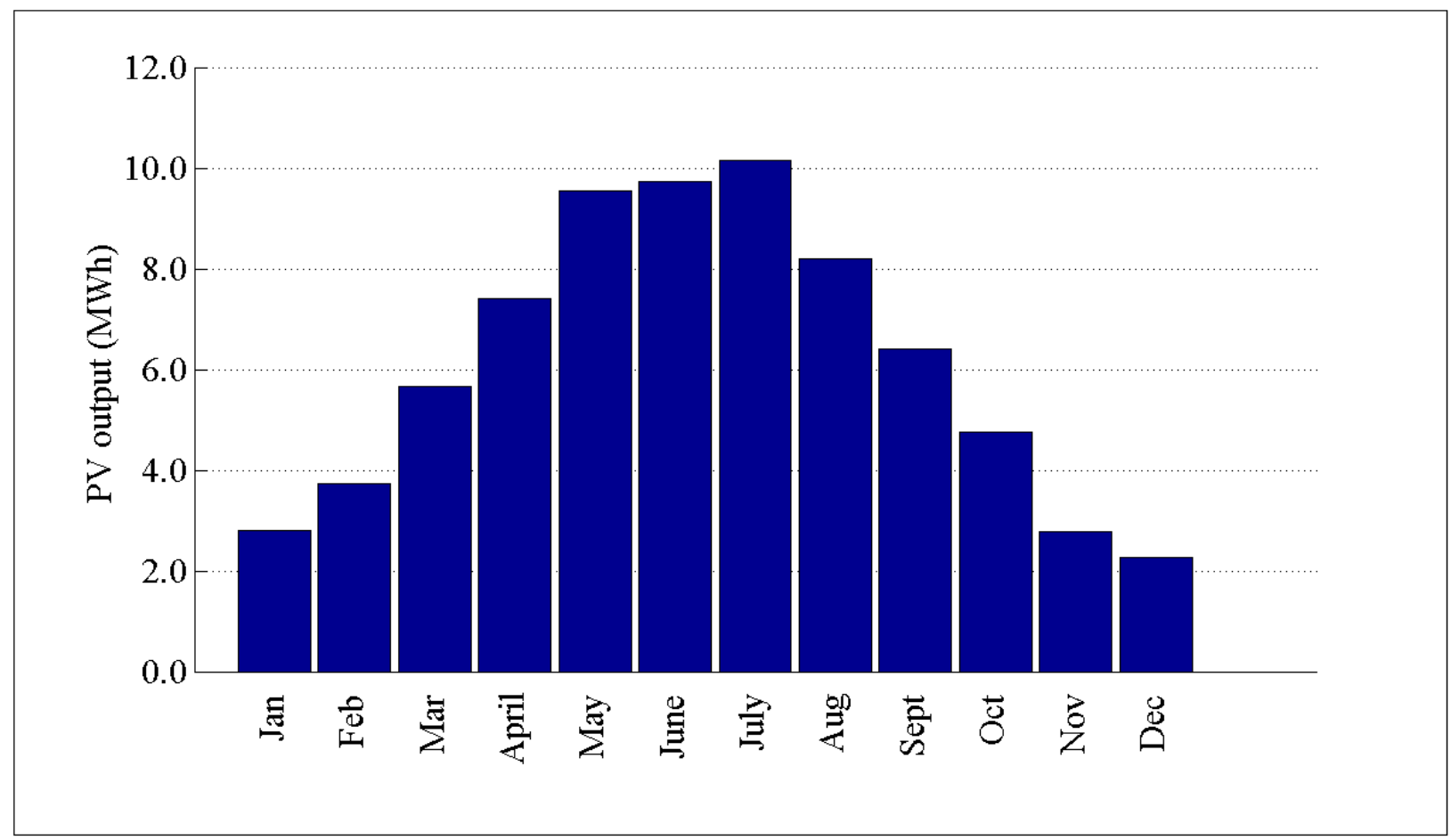

Figure D.29: PV output by month for R2-12.47-2 


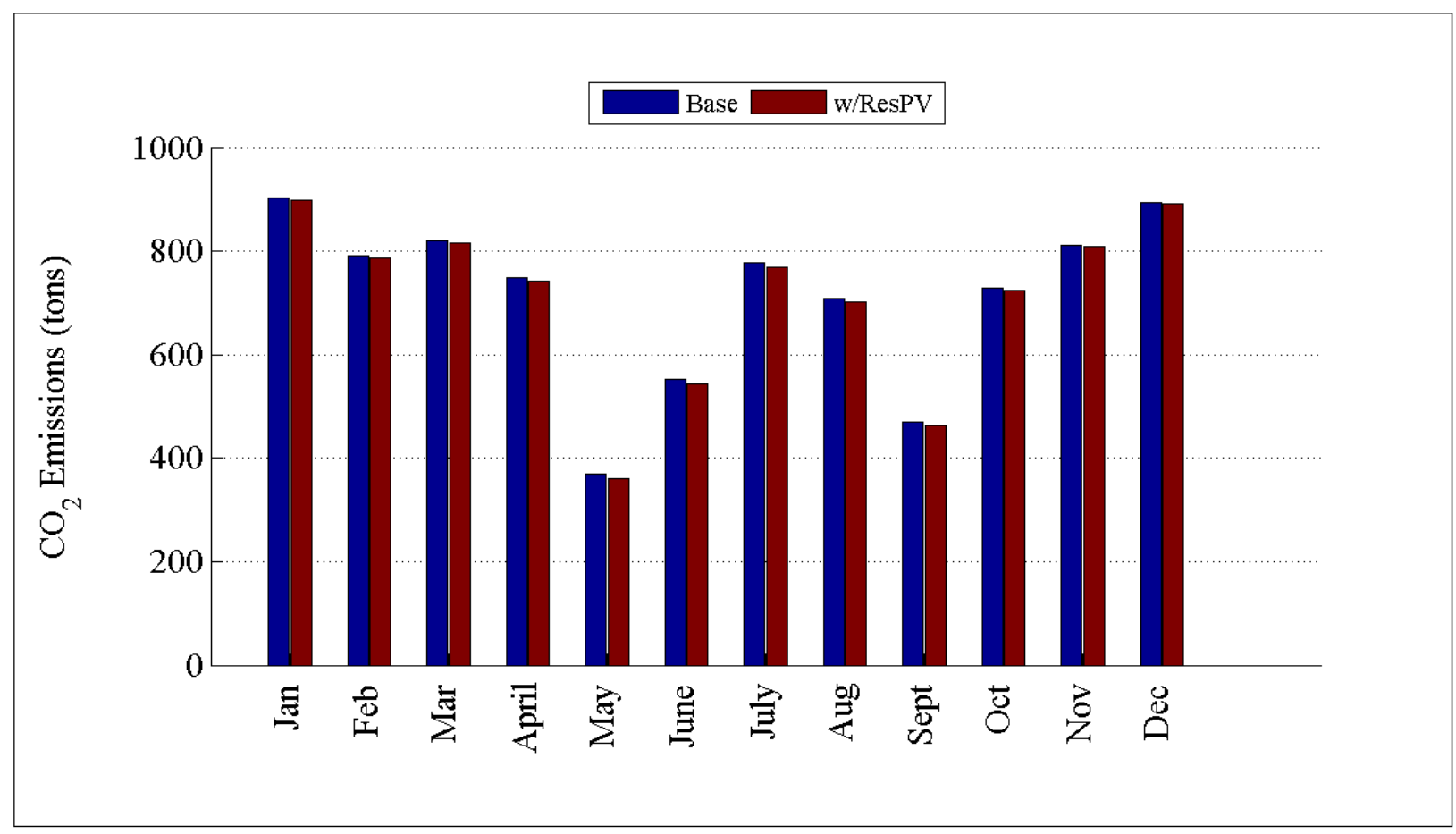

Figure D.30: Comparison of $\mathrm{CO}_{2}$ emissions by month for R2-12.47-2

D.1.8 Detailed Residential PV Plots for R2-12.47-3

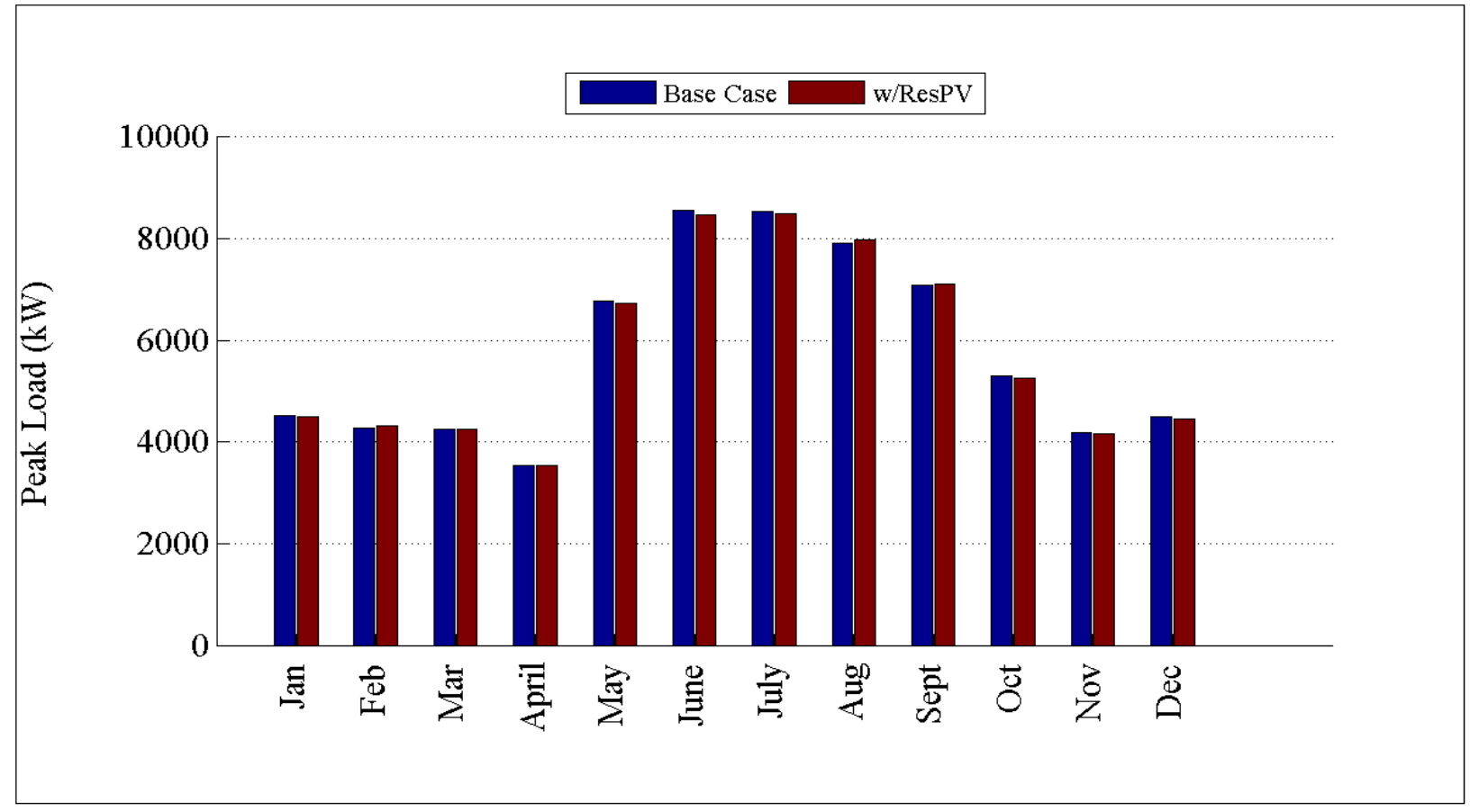

Figure D.31: Comparison of peak load by month for R2-12.47-3 


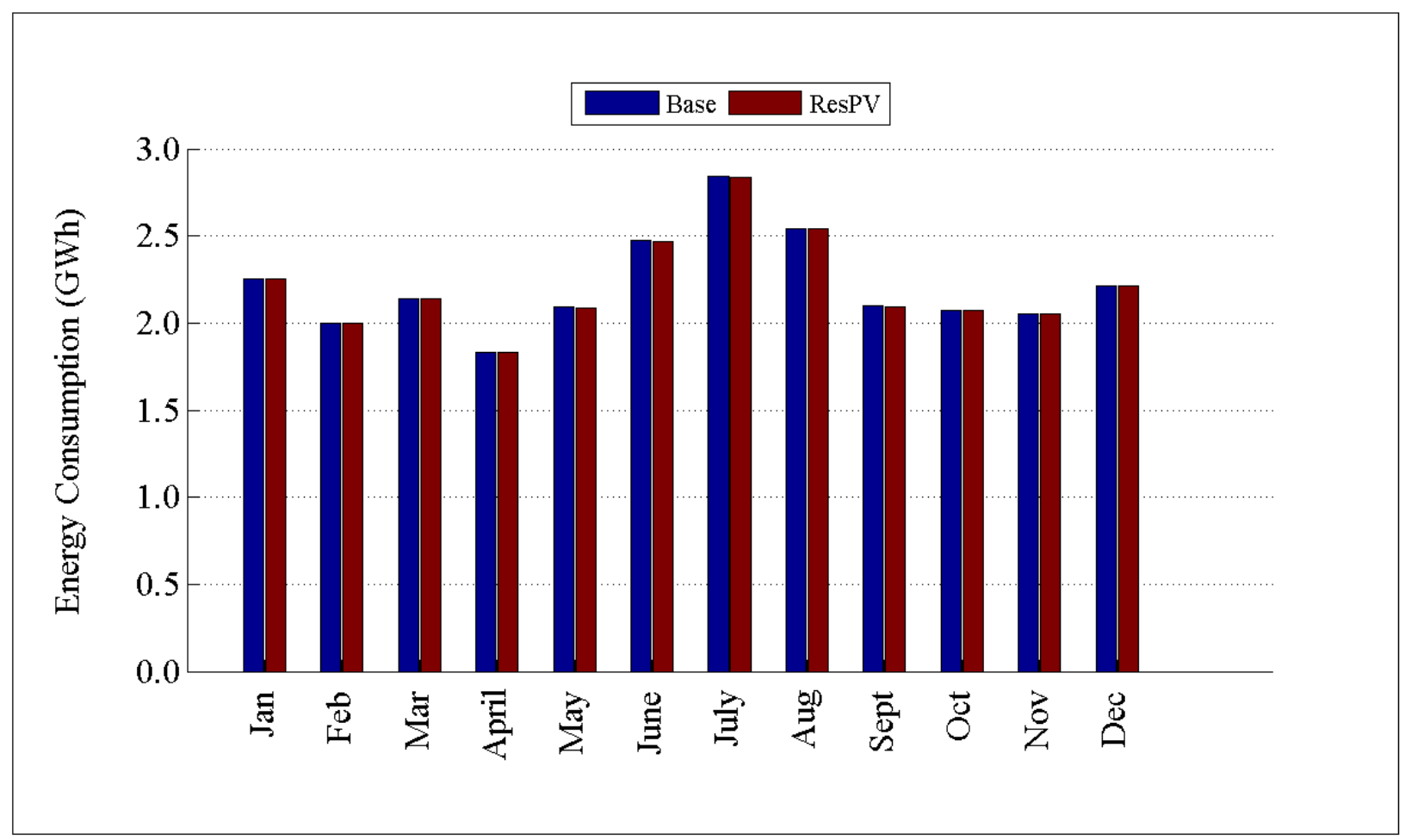

Figure D.32: Comparison of energy consumption by month for R2-12.47-3

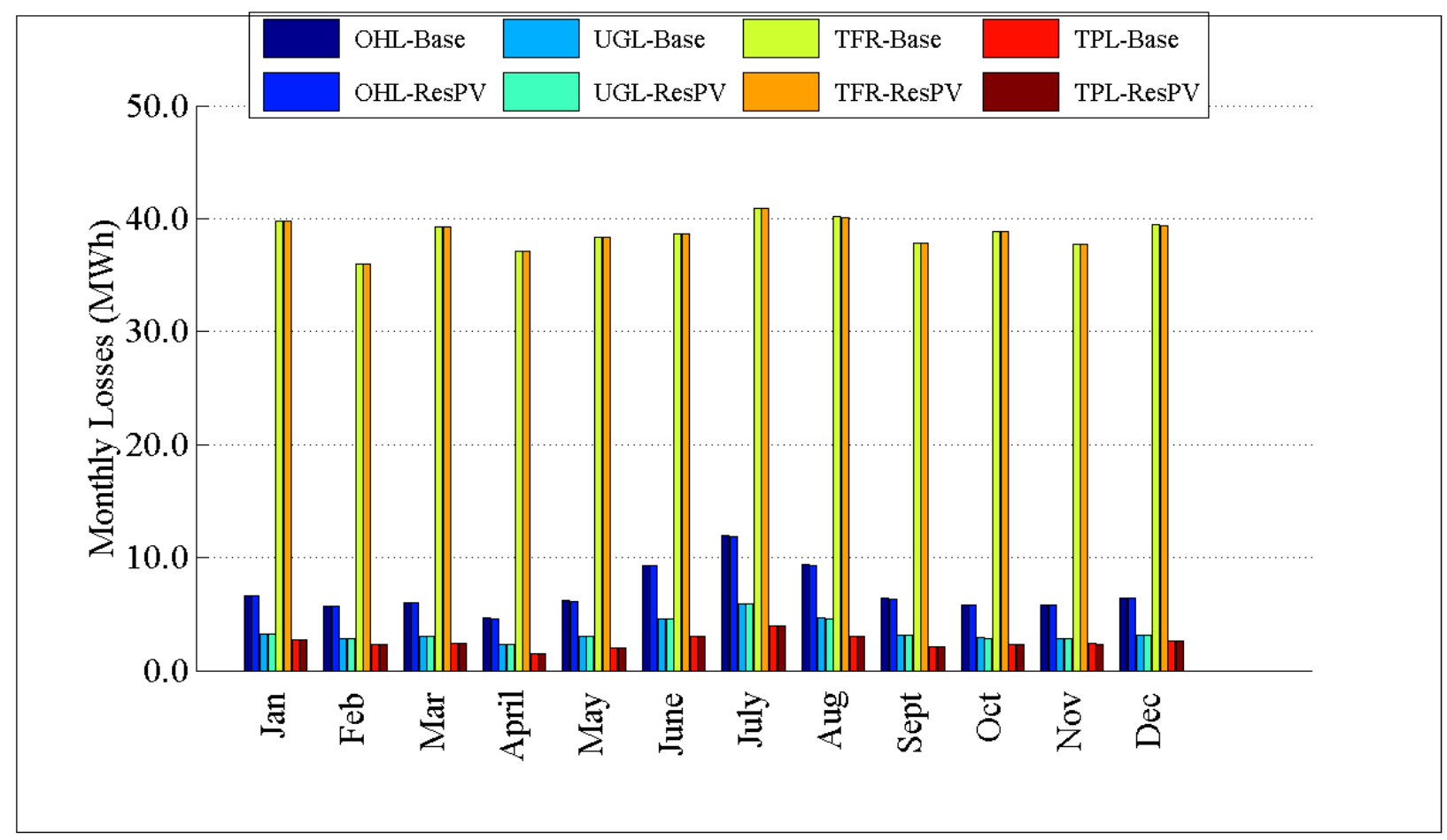

Figure D.33: Comparison of losses by month for R2-12.47-3 


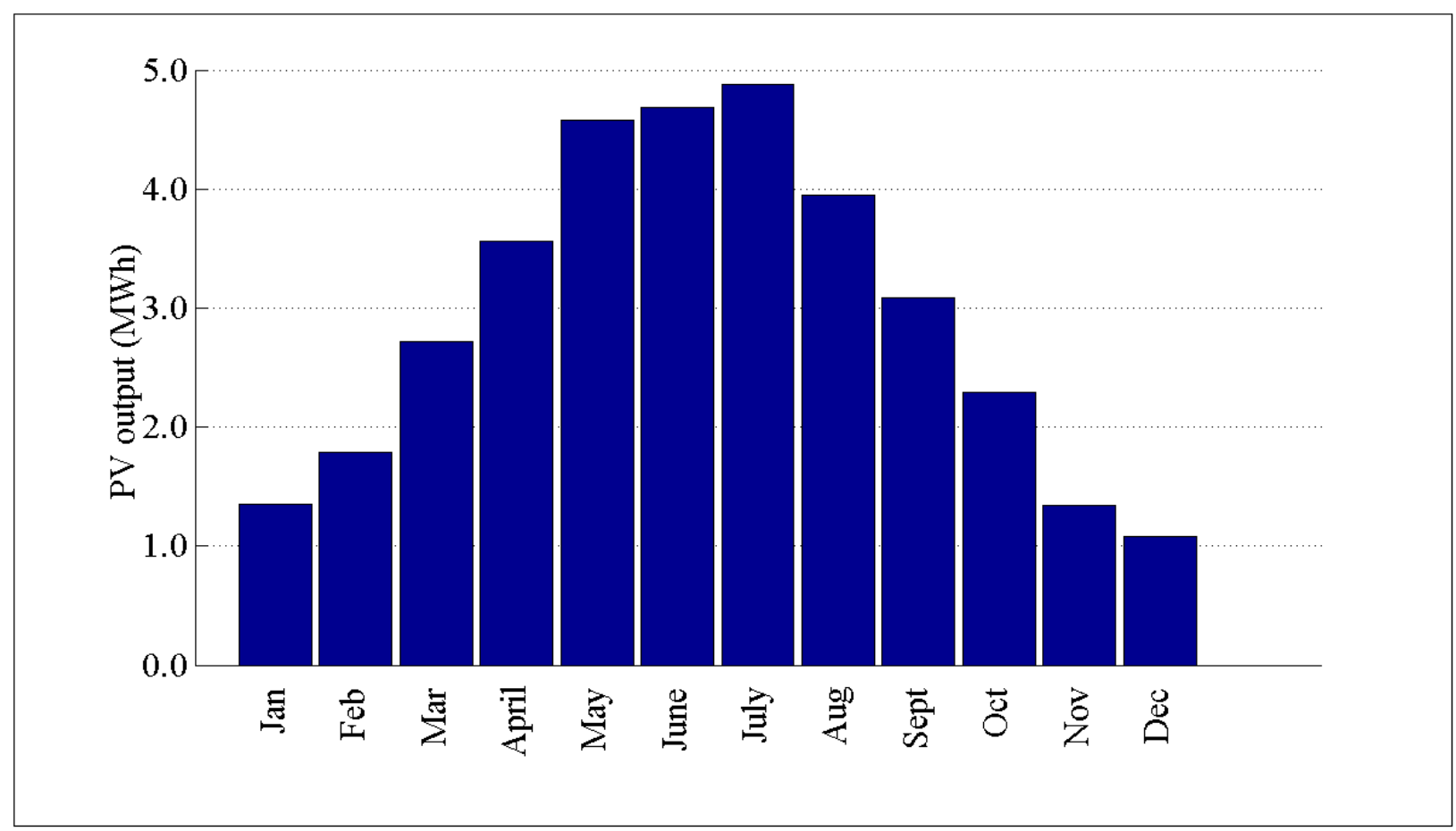

Figure D.34: PV output by month for R2-12.47-1

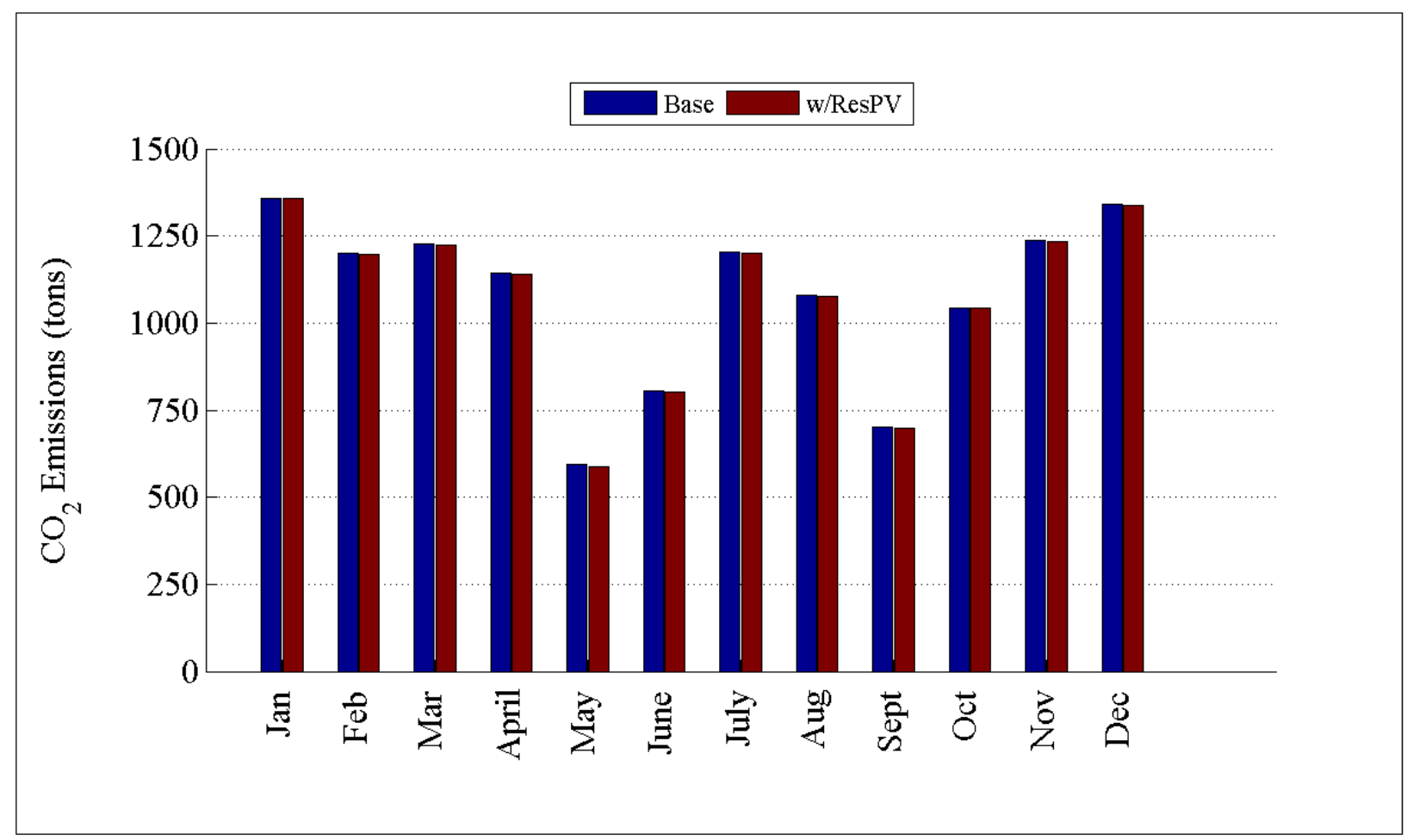

Figure D.35: Comparison of $\mathrm{CO}_{2}$ emissions by month for R2-12.47-3 


\section{D.1.9 Detailed Residential PV Plots for R2-25.00-1}

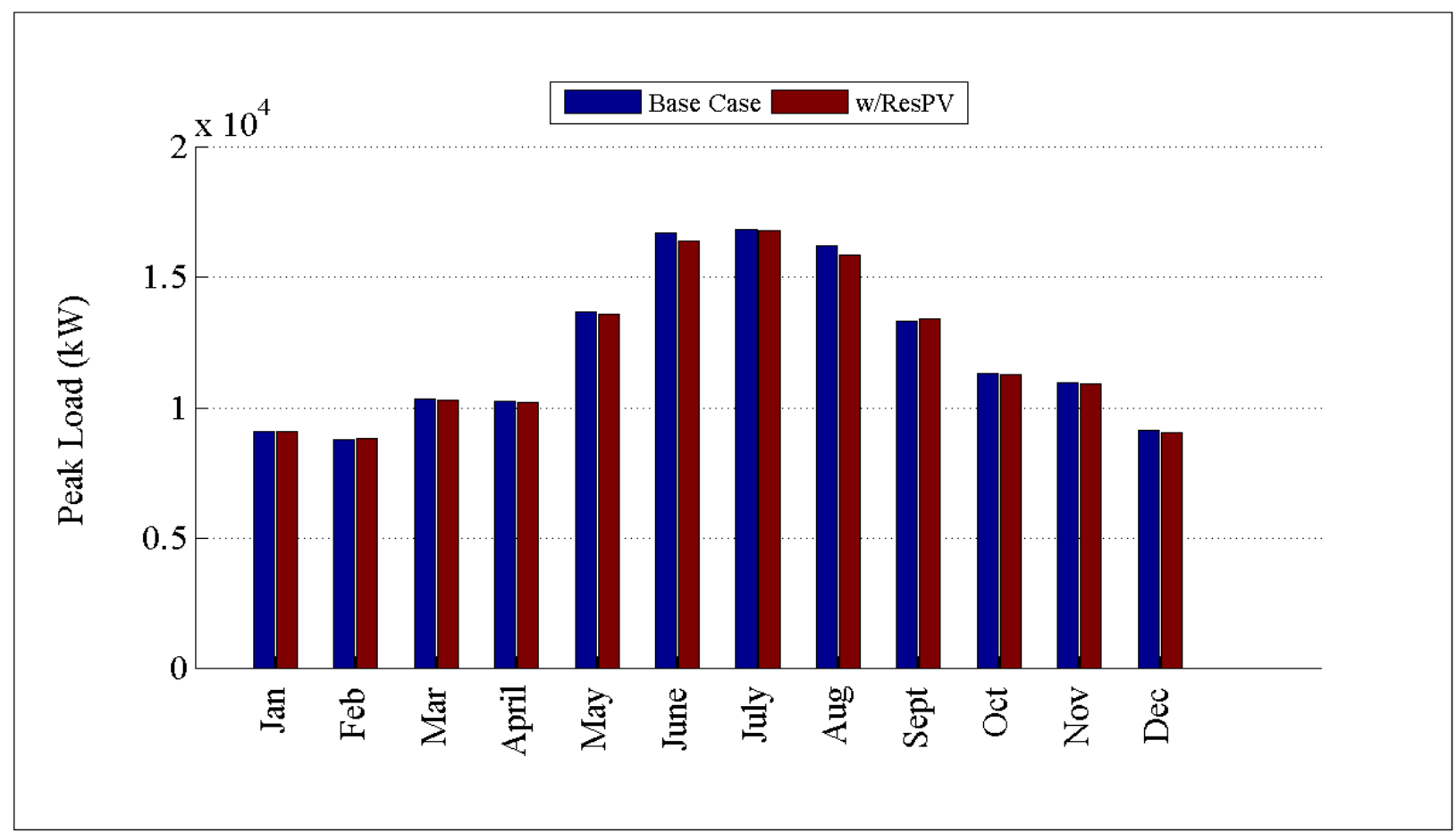

Figure D.36: Comparison of peak load by month for R2-25.00-1

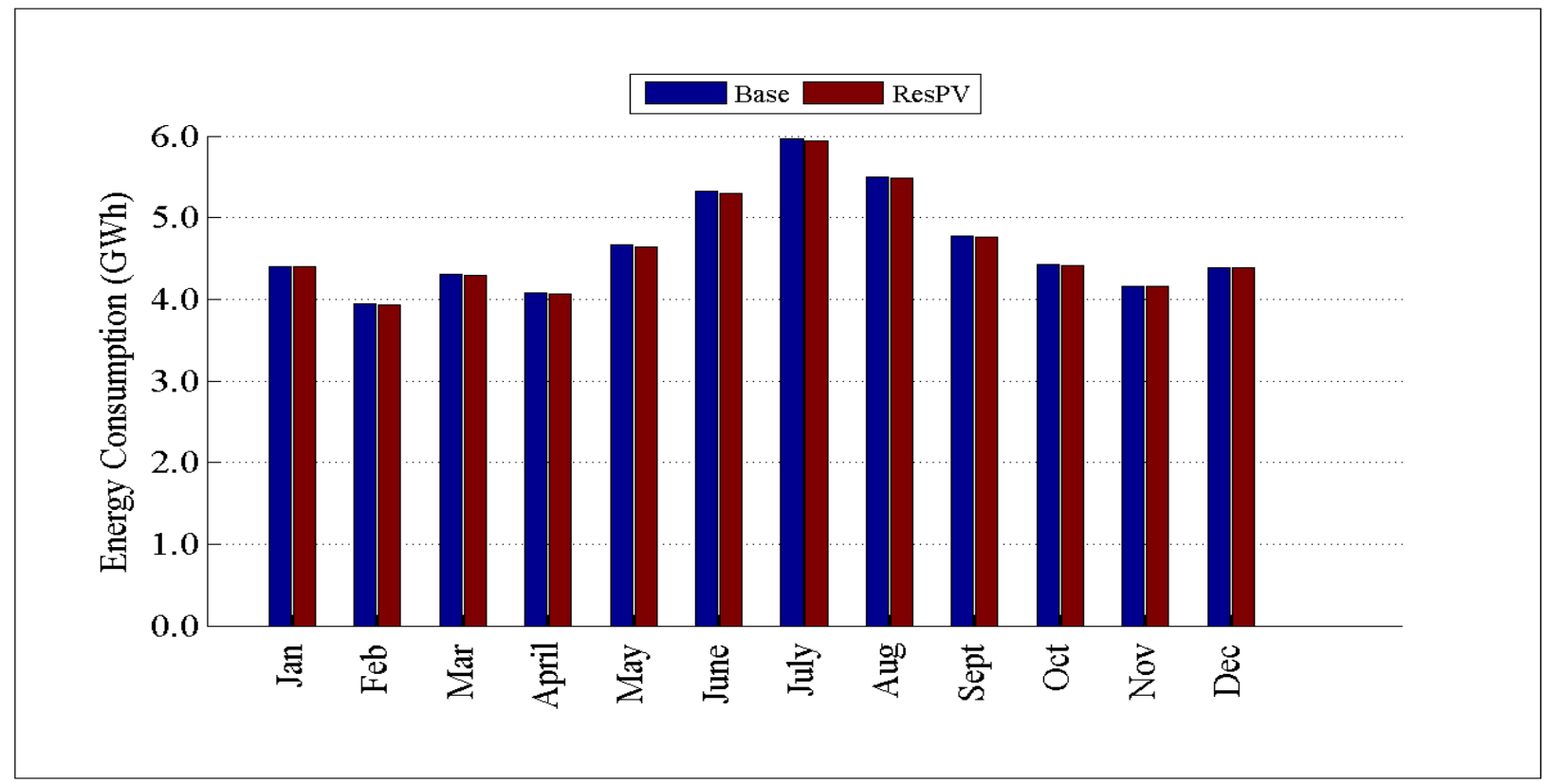

Figure D.37: Comparison of energy consumption by month for R2-25.00-1 


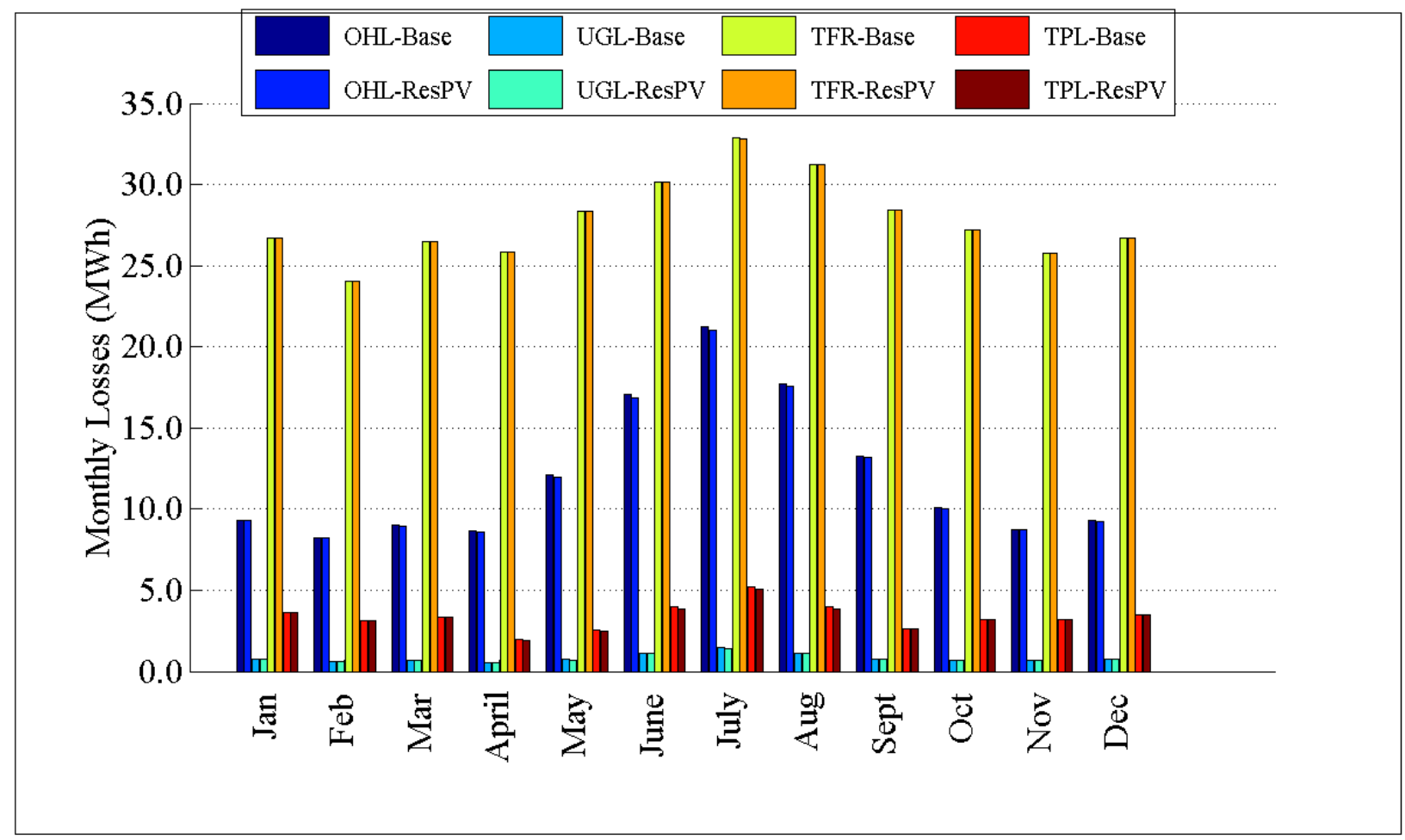

Figure D.38: Comparison of losses by month for R2-25.00-1

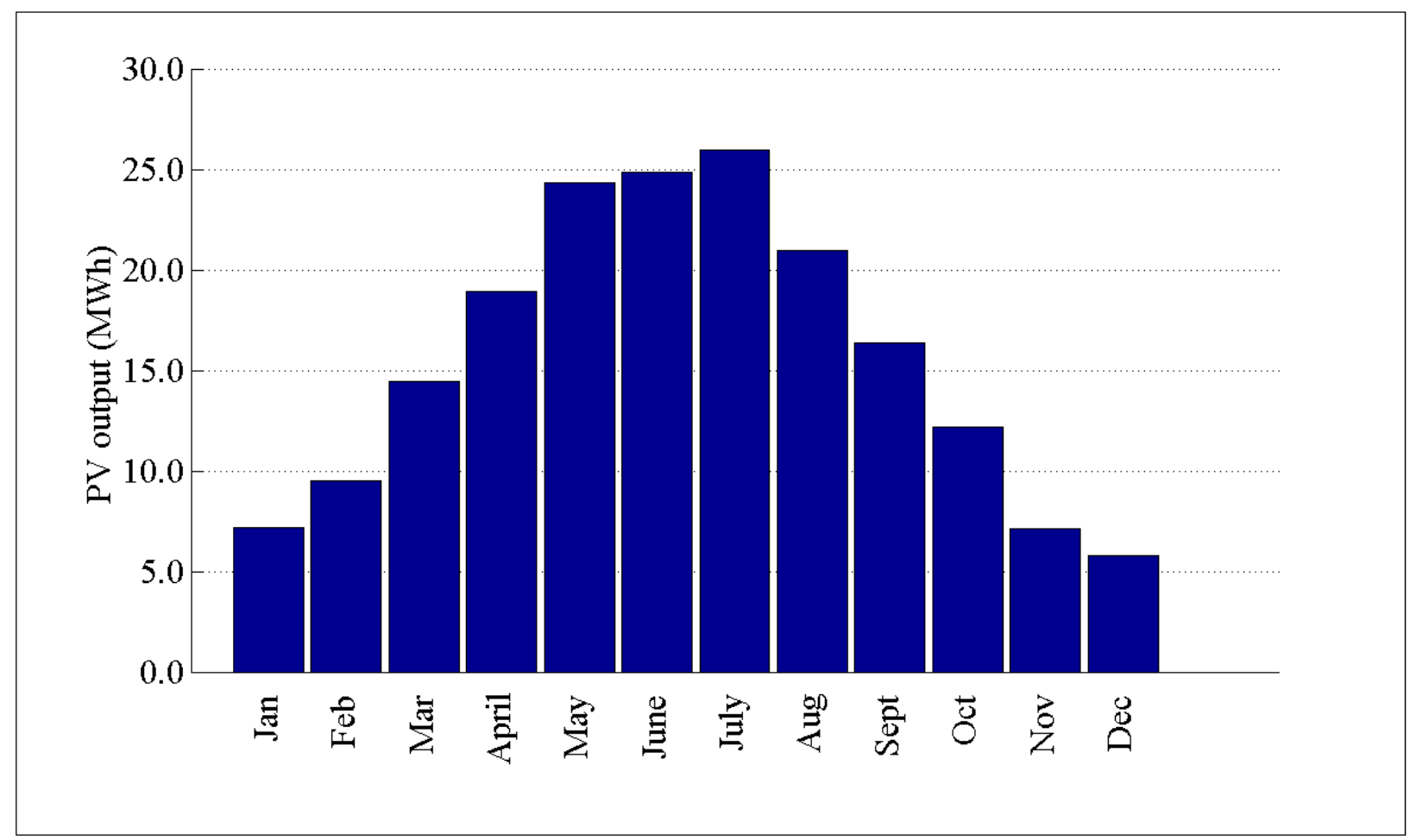

Figure D.39: PV output by month for R2-25.00-1 


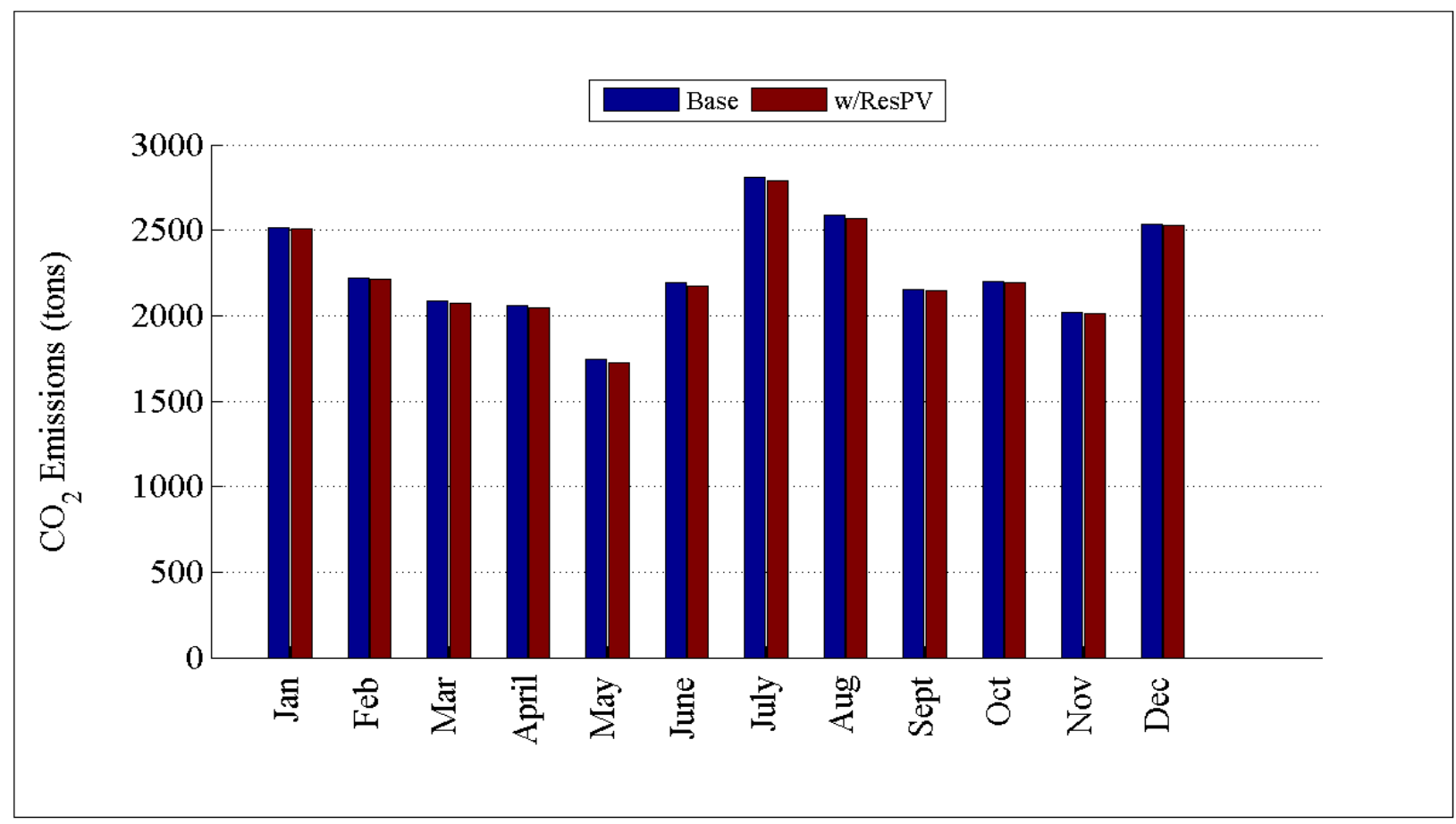

Figure D.40: Comparison of $\mathrm{CO}_{2}$ emissions by month for R2-25.00-1

D.1.10 Detailed Residential PV Plots for R2-35.00-1

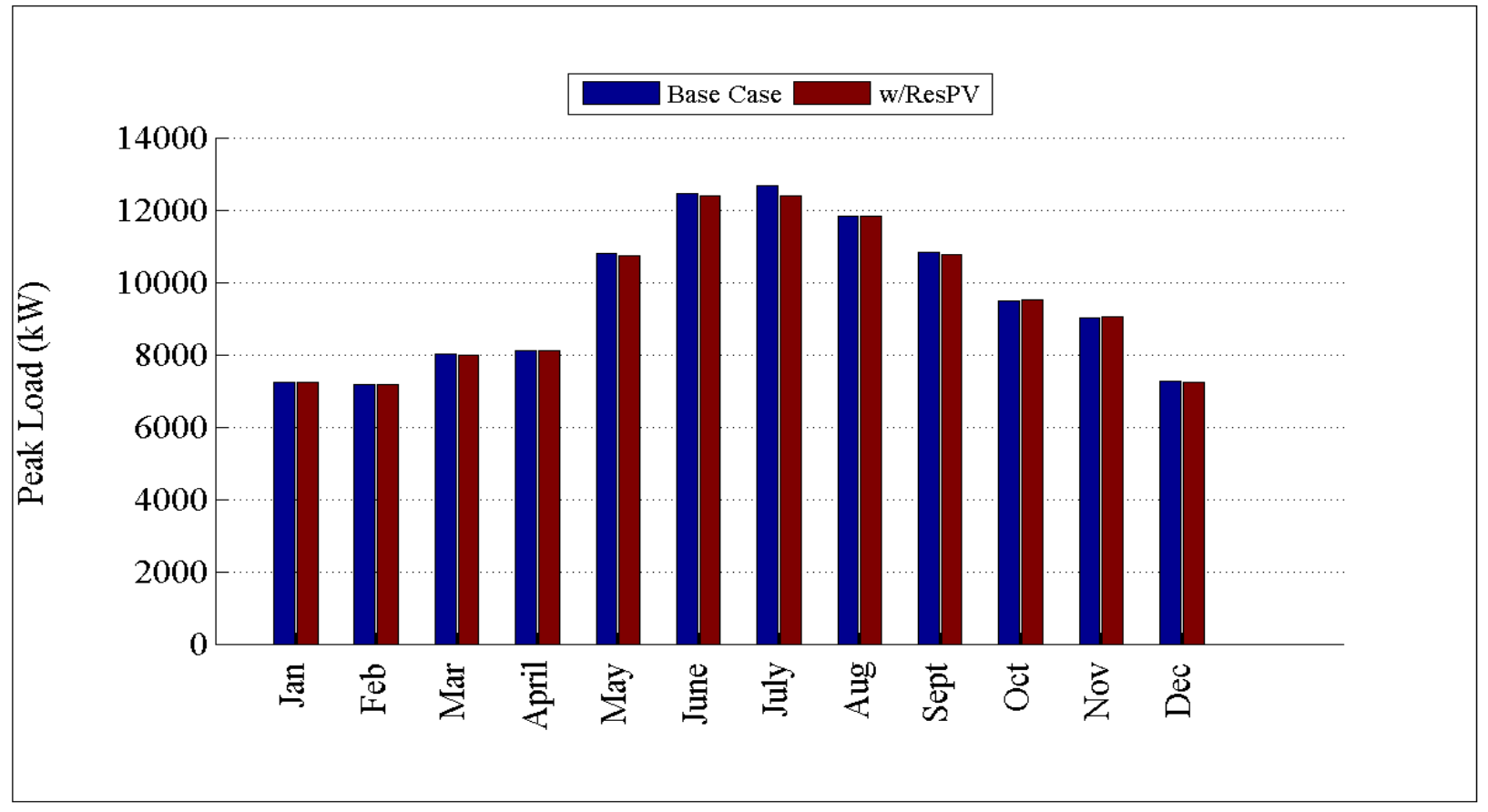

Figure D.41: Comparison of peak load by month for R2-35.00-1 


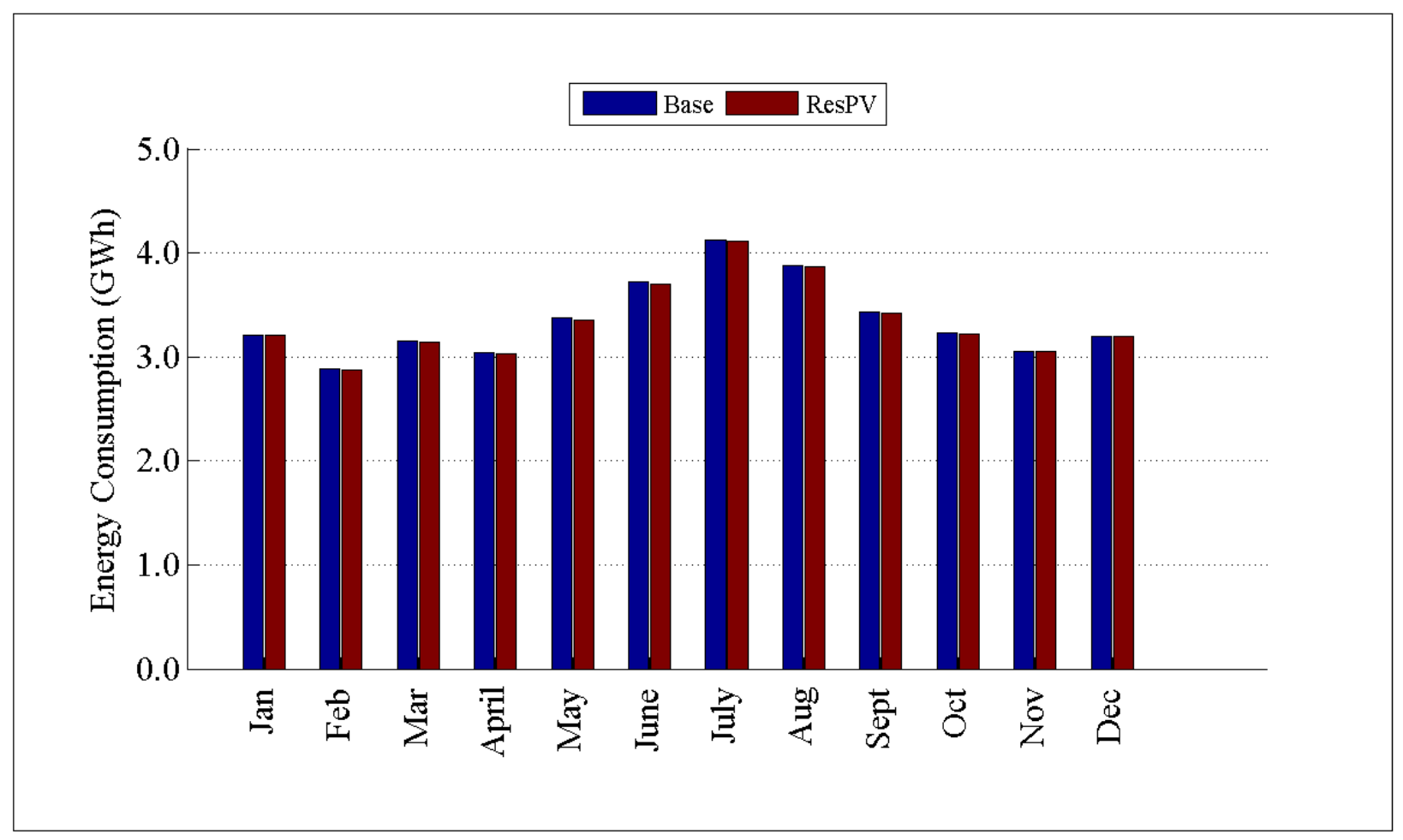

Figure D.42: Comparison of energy consumption by month for R2-35.00-1

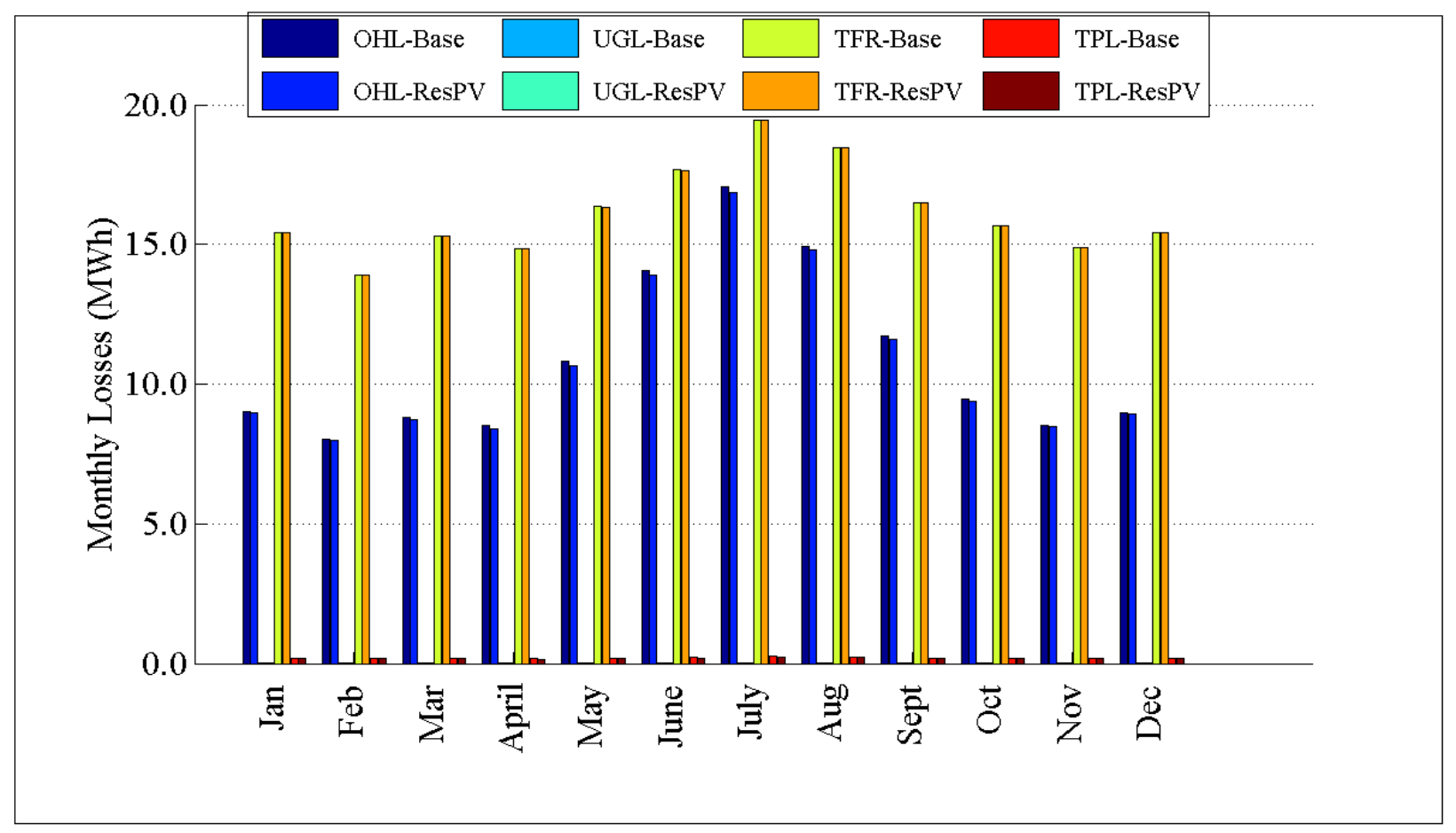

Figure D.43: Comparison of losses by month for R2-35.00-1 


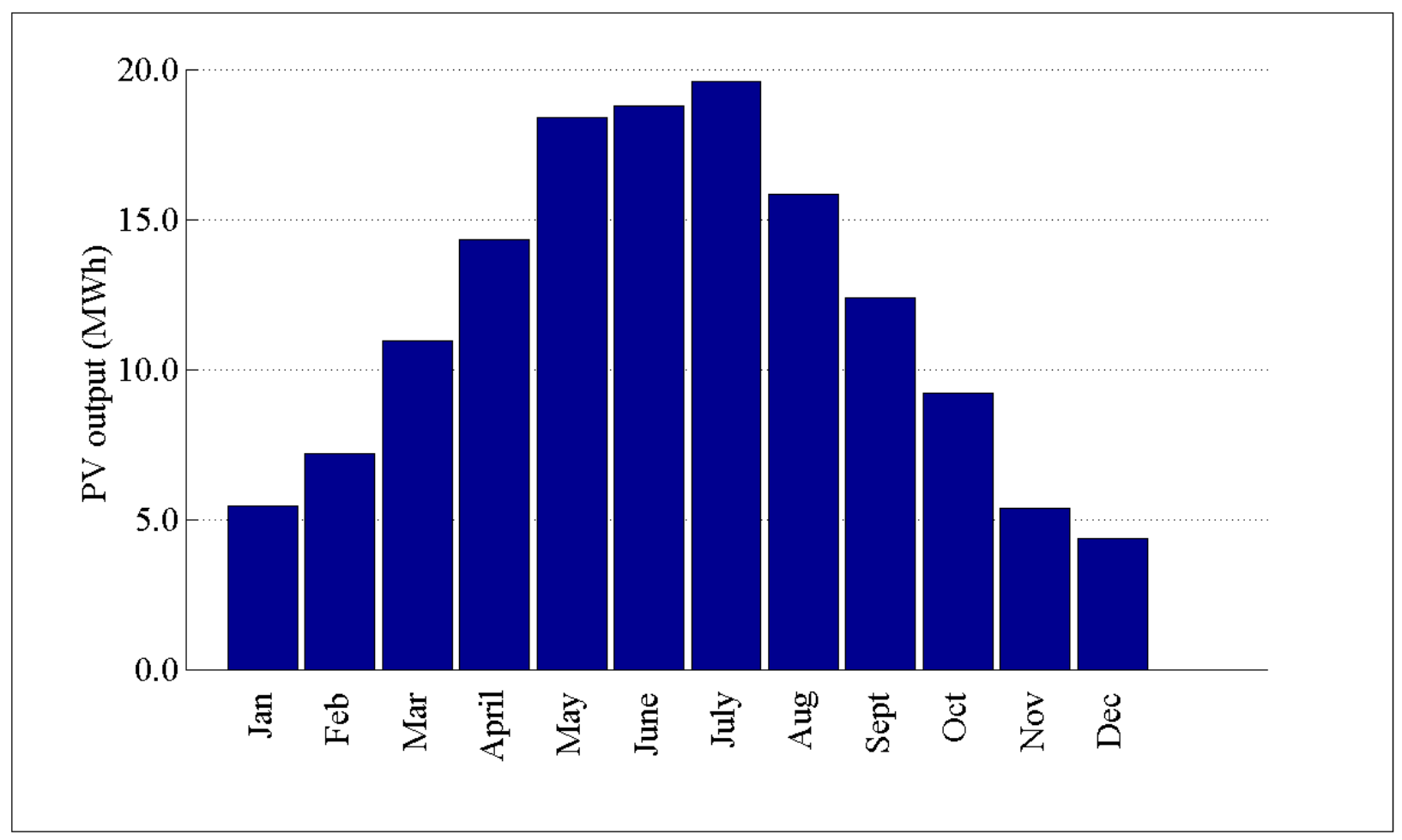

Figure D.44: PV output by month for R2-35.00-1

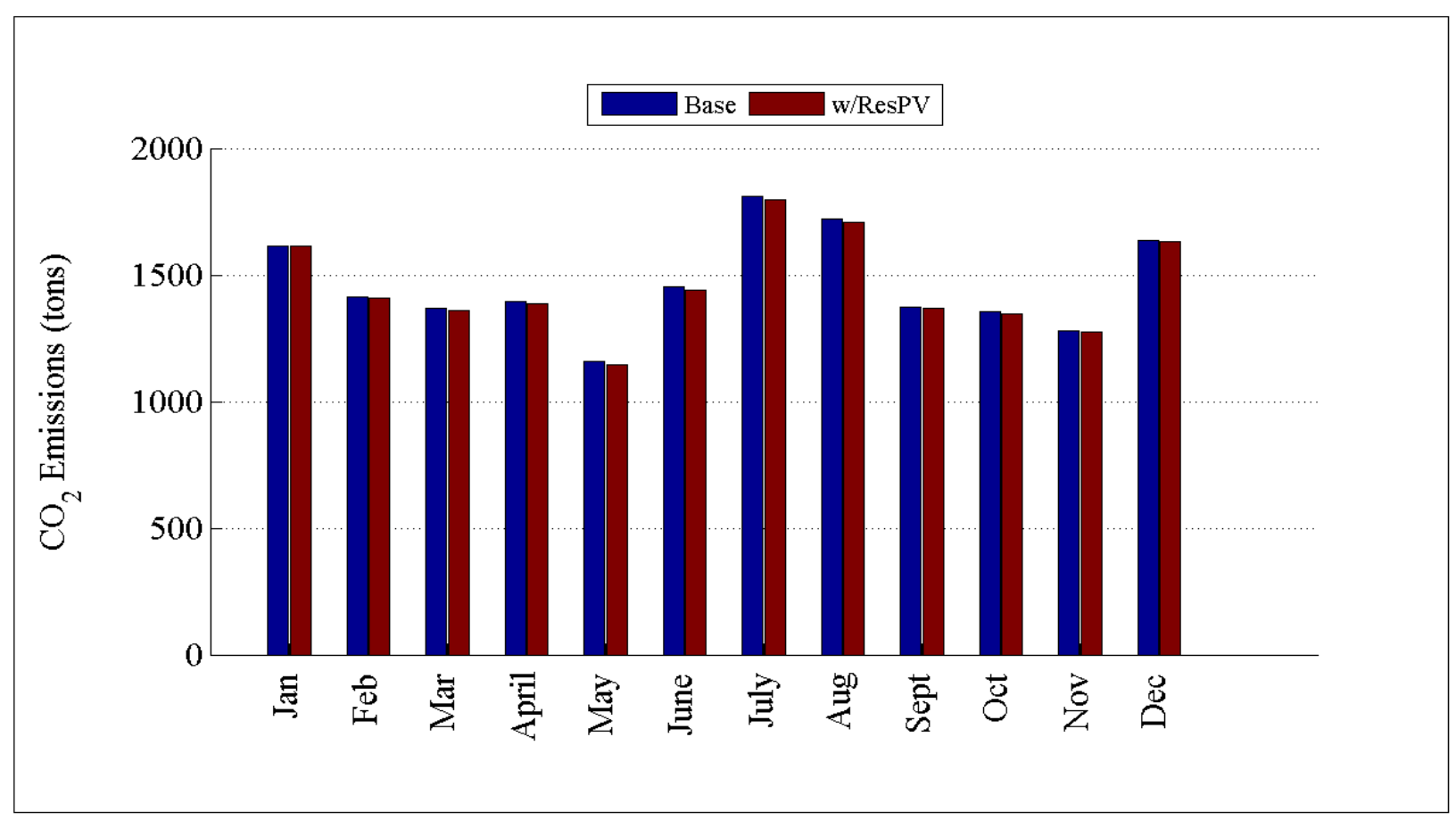

Figure D.45: Comparison of $\mathrm{CO}_{2}$ emissions by month for R2-35.00-1 
D.1.11 Detailed Residential PV Plots for R3-12.47-1

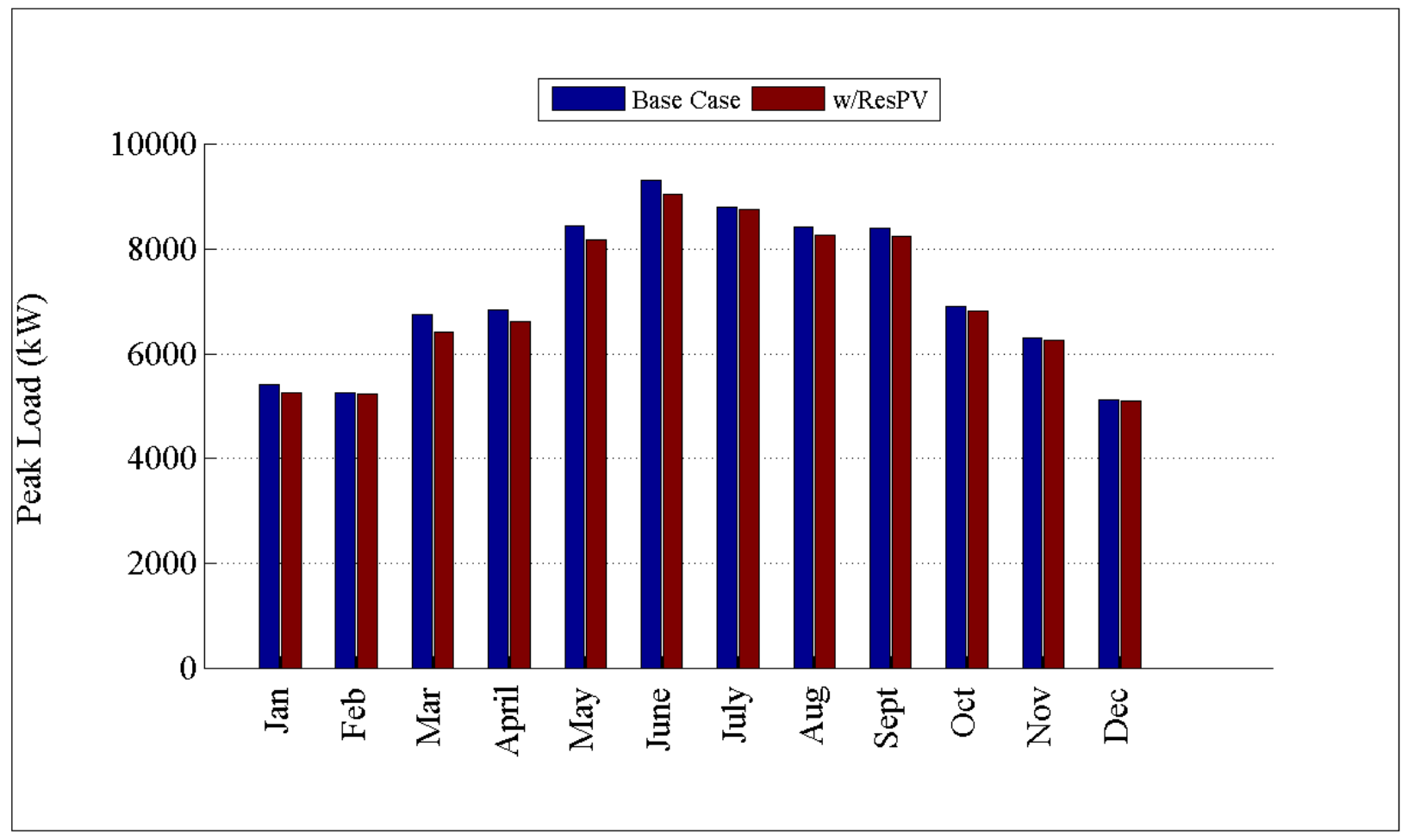

Figure D.46: Comparison of peak load by month for R3-12.47-1 


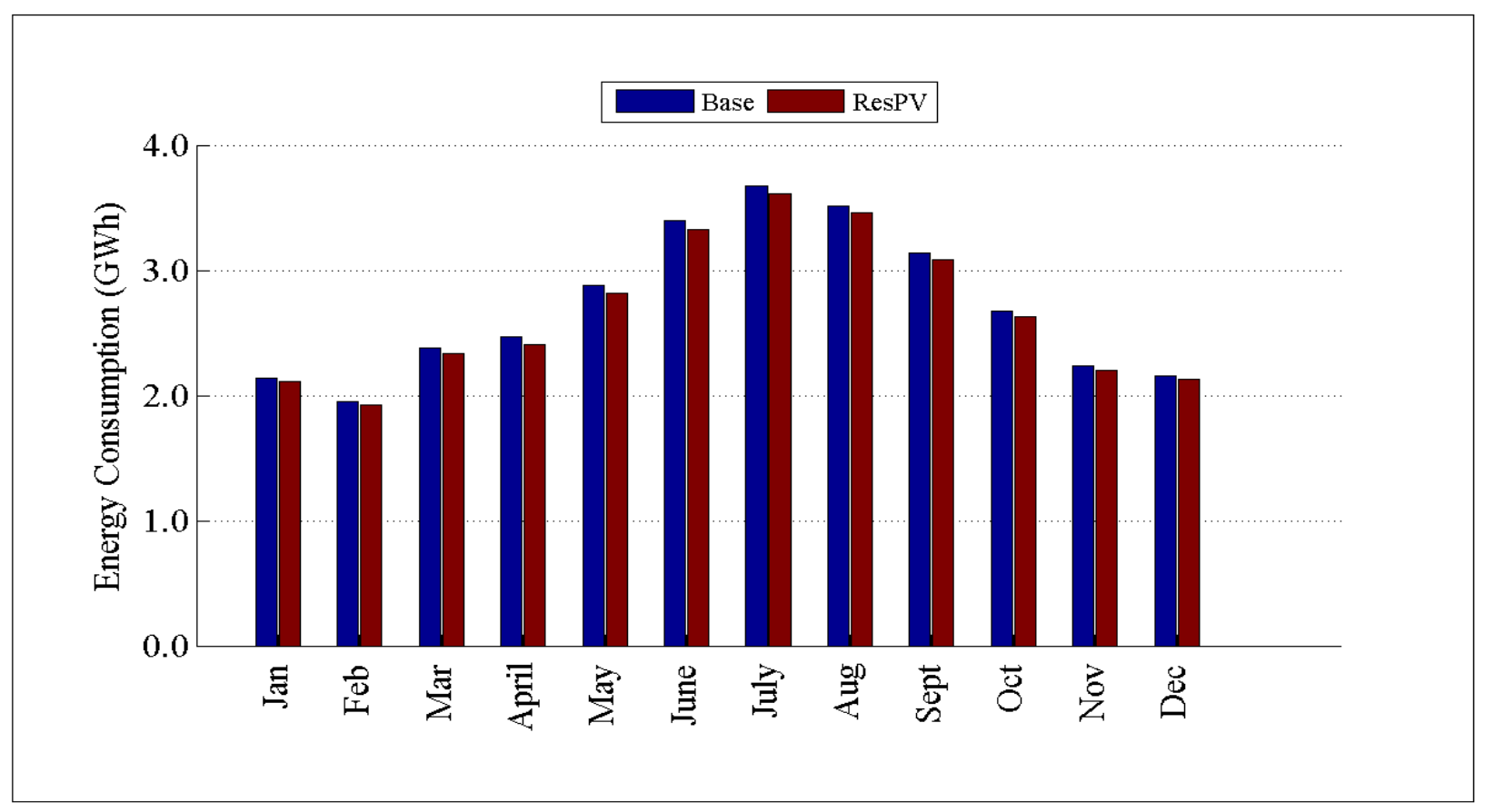

Figure D.47: Comparison of energy consumption by month for R3-12.47-1

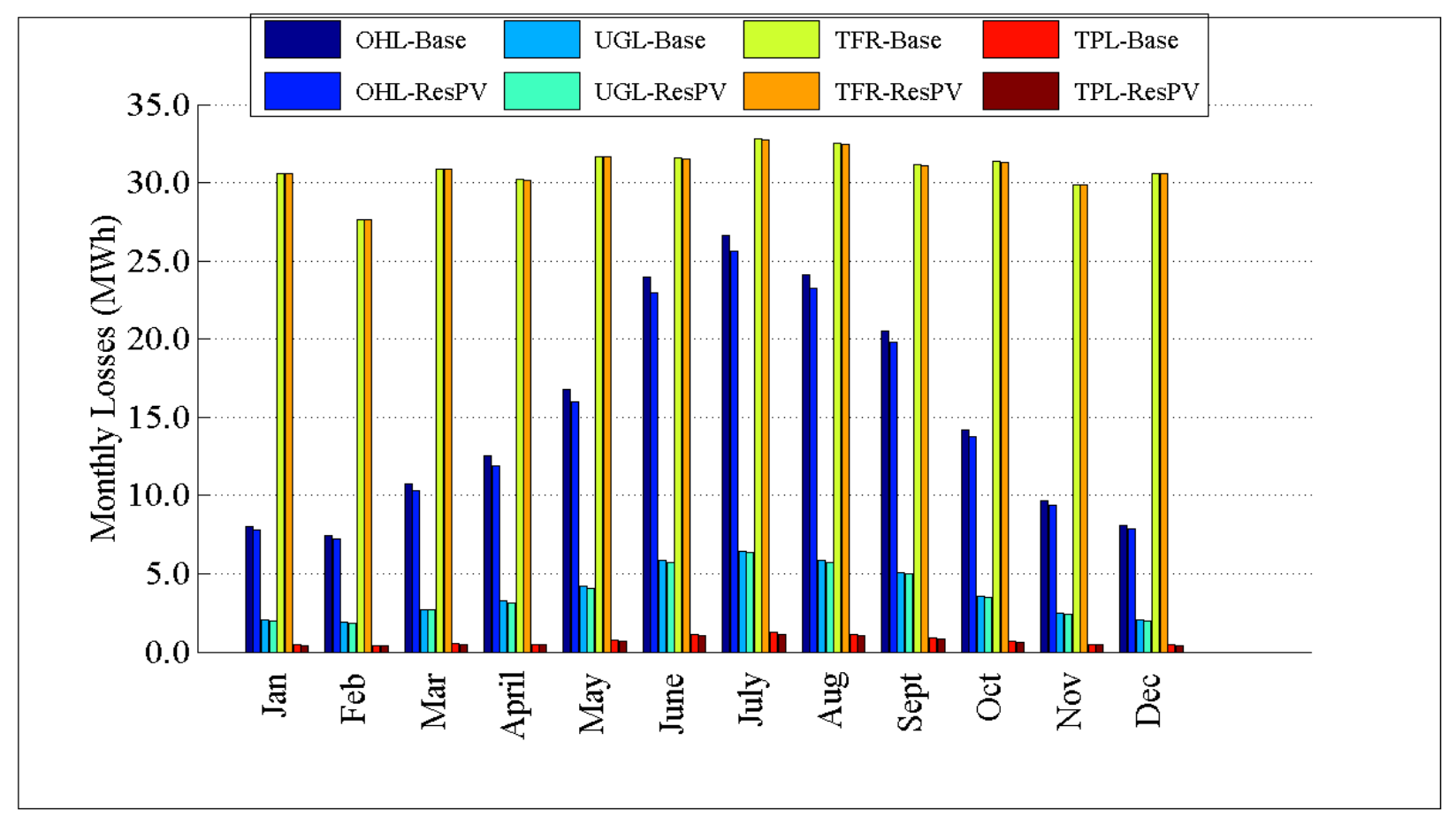

Figure D.48: Comparison of losses by month for R3-12.47-1 


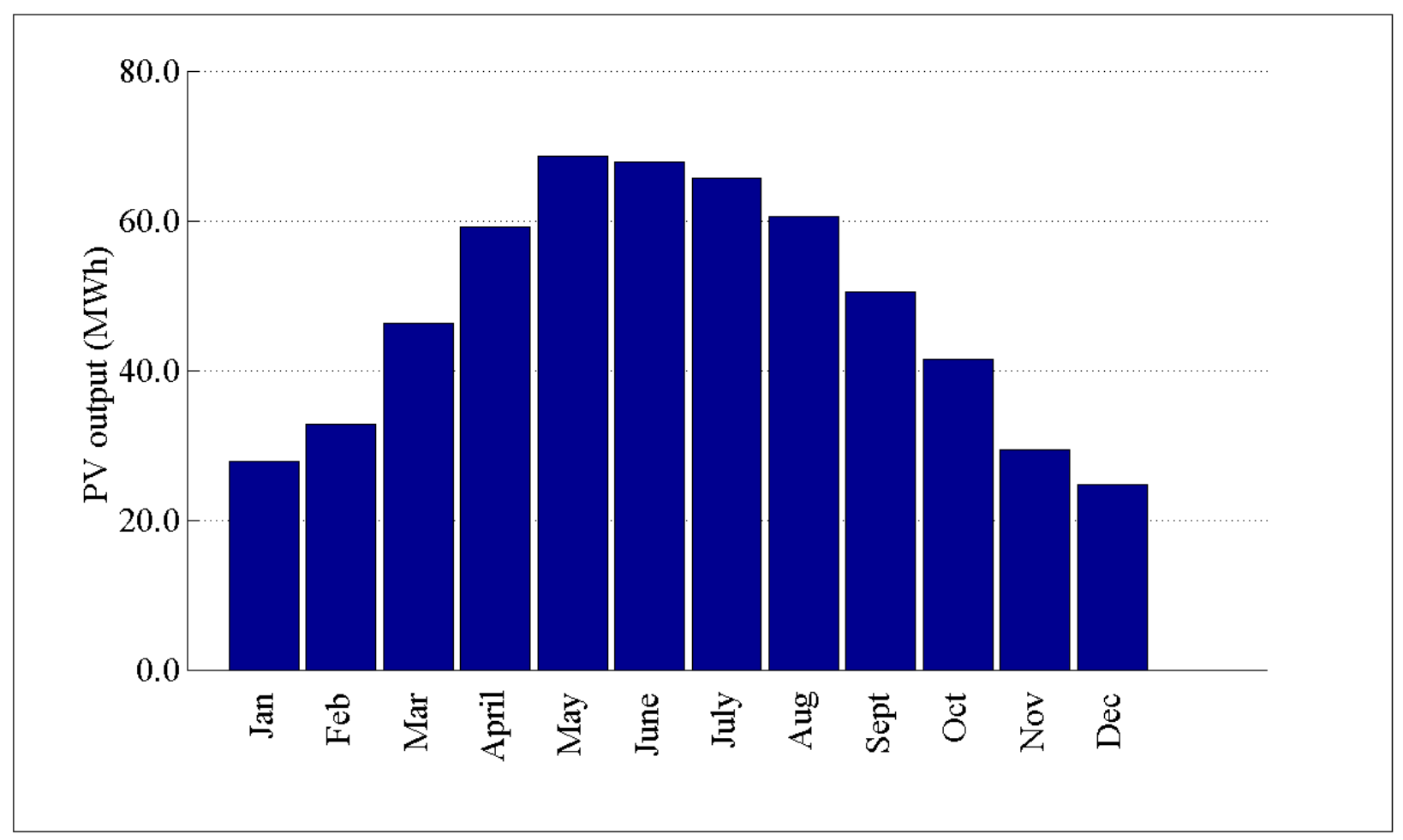

Figure D.49: PV output by month for R3-12.47-1

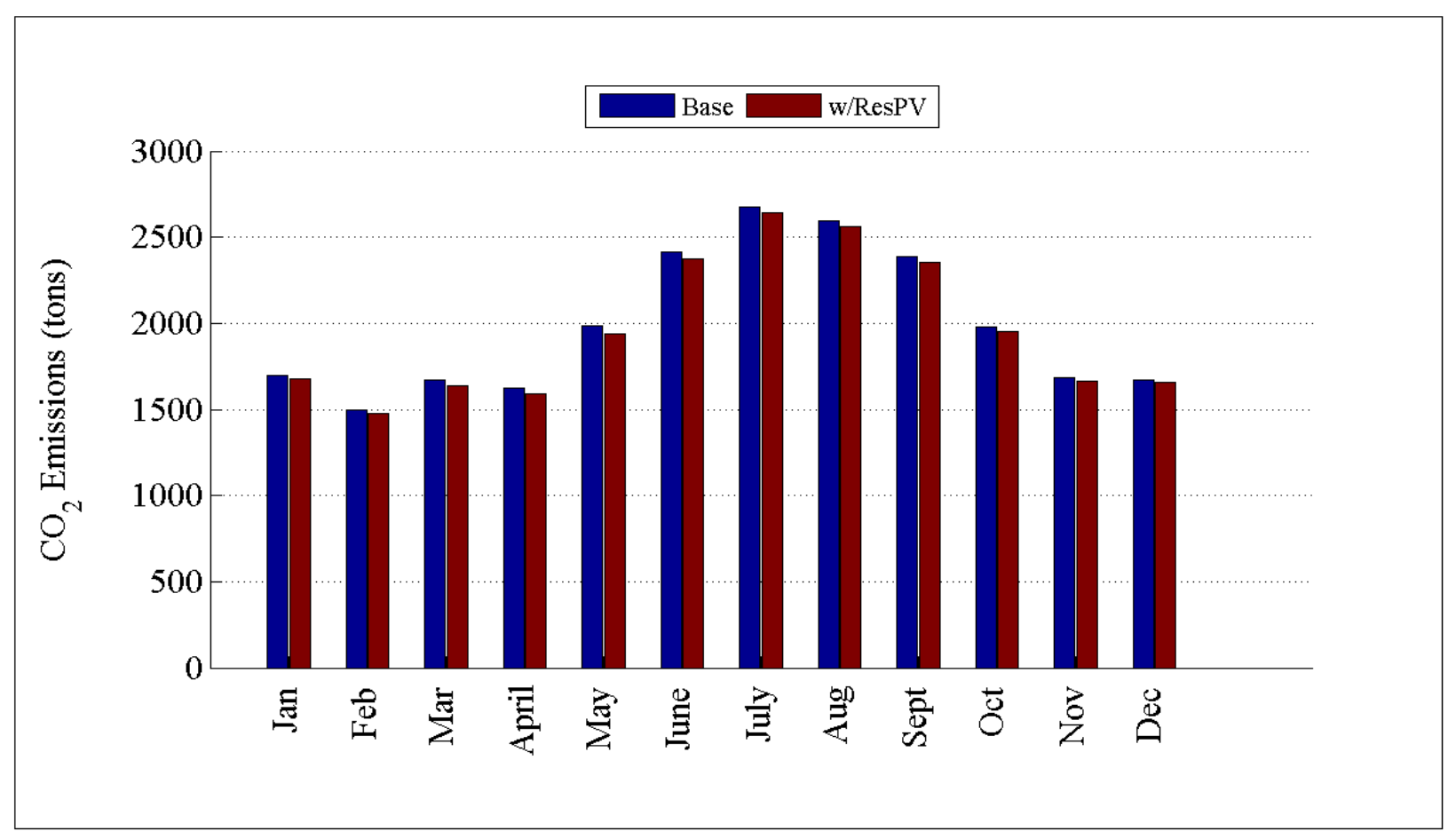

Figure D.50: Comparison of $\mathrm{CO}_{2}$ emissions by month for R3-12.47-1 
D.1.12 Detailed Residential PV Plots for R3-12.47-3

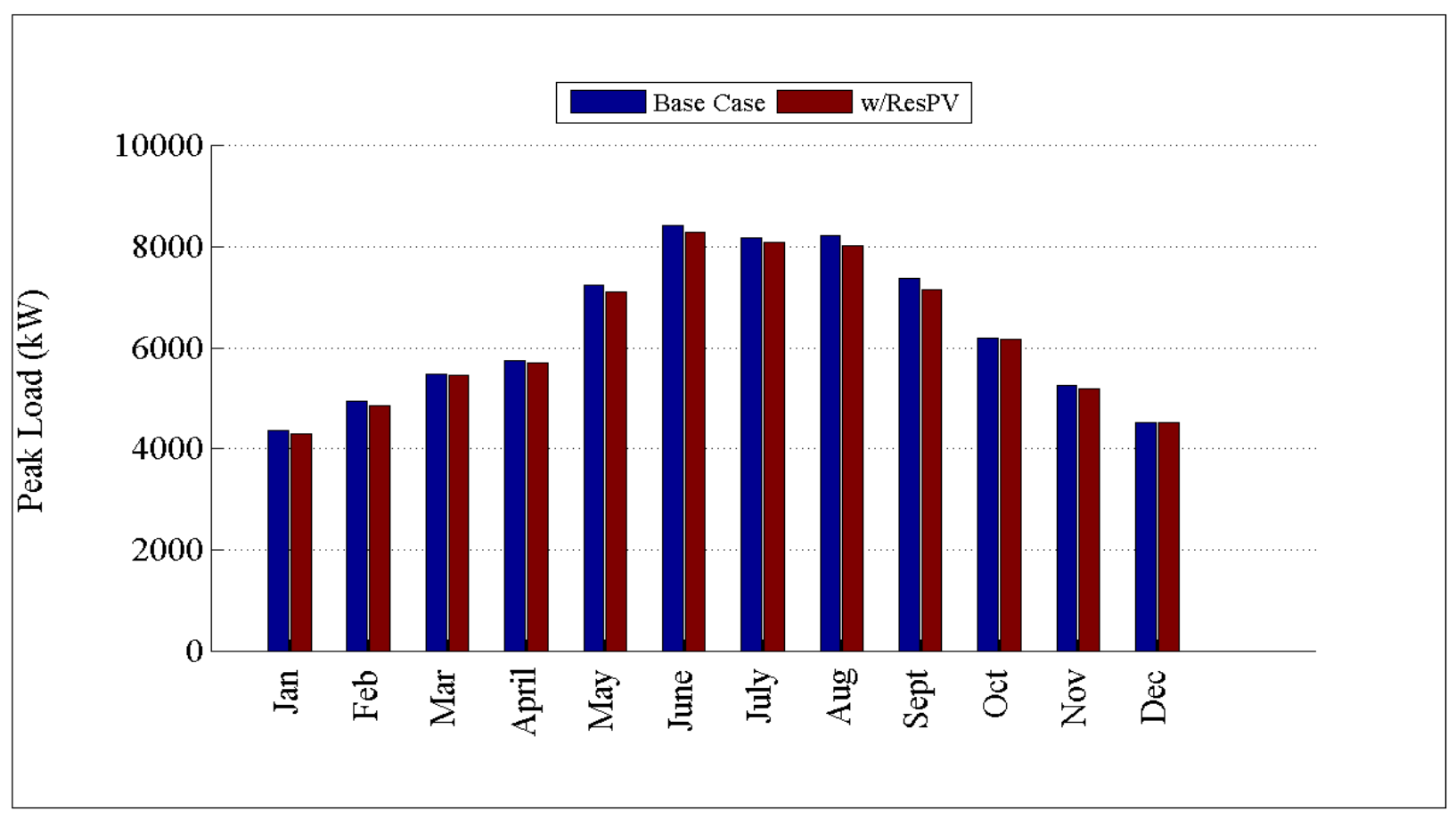

Figure D.51: Comparison of peak load by month for R3-12.47-3

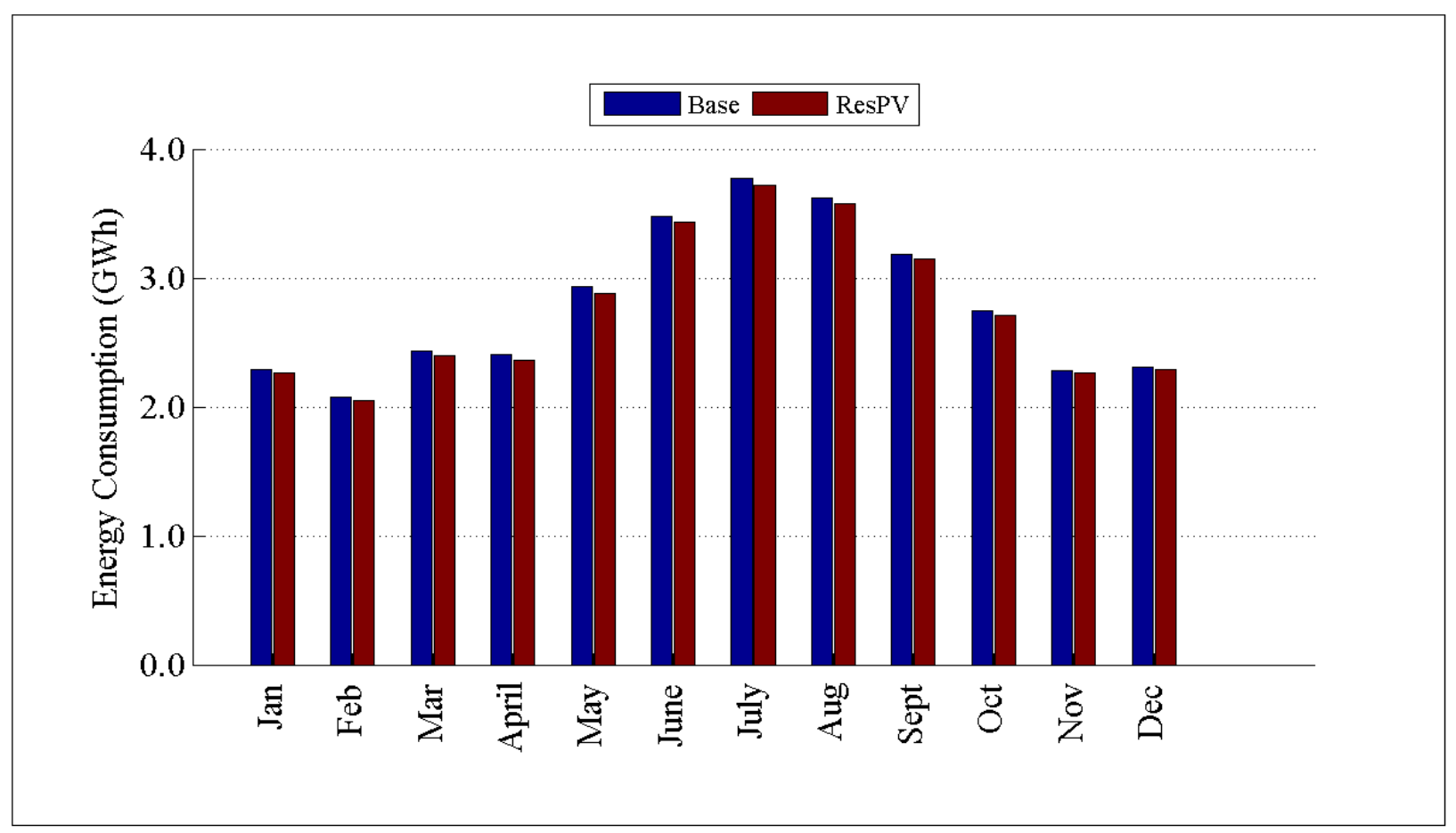

Figure D.52: Comparison of energy consumption by month for R3-12.47-3 


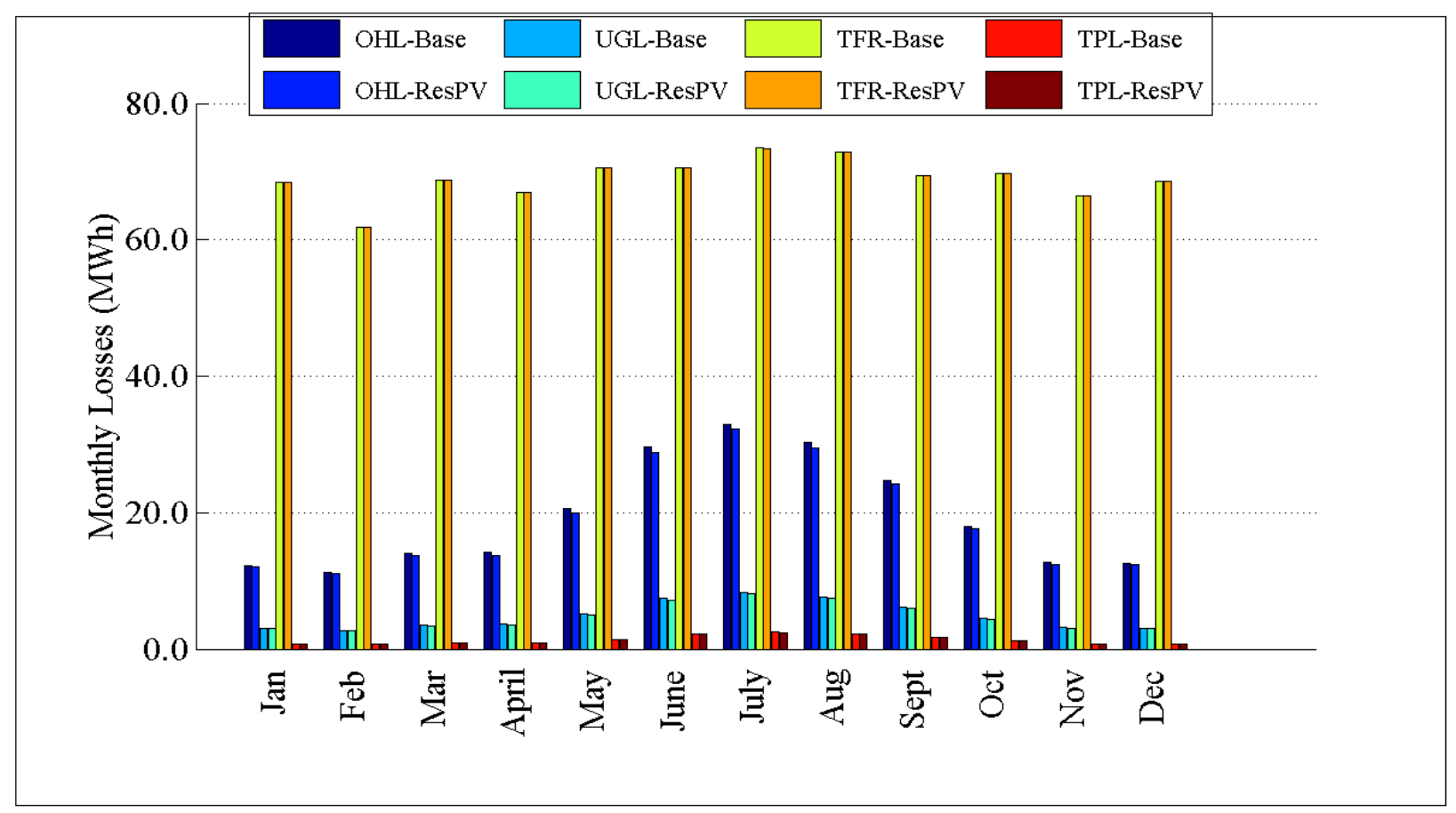

Figure D.53: Comparison of losses by month for R3-12.47-3

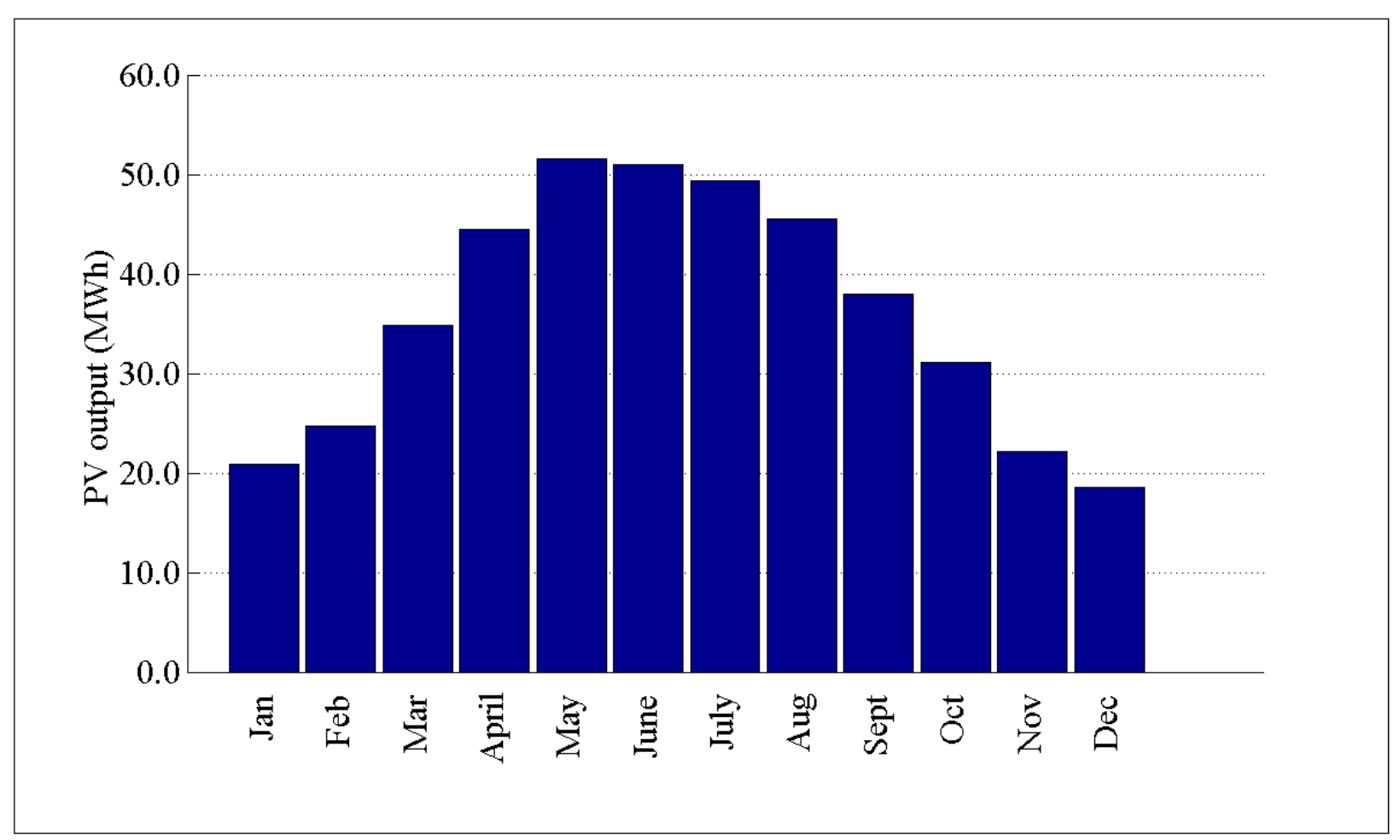

Figure D.54: PV output by month for R3-12.47-3 


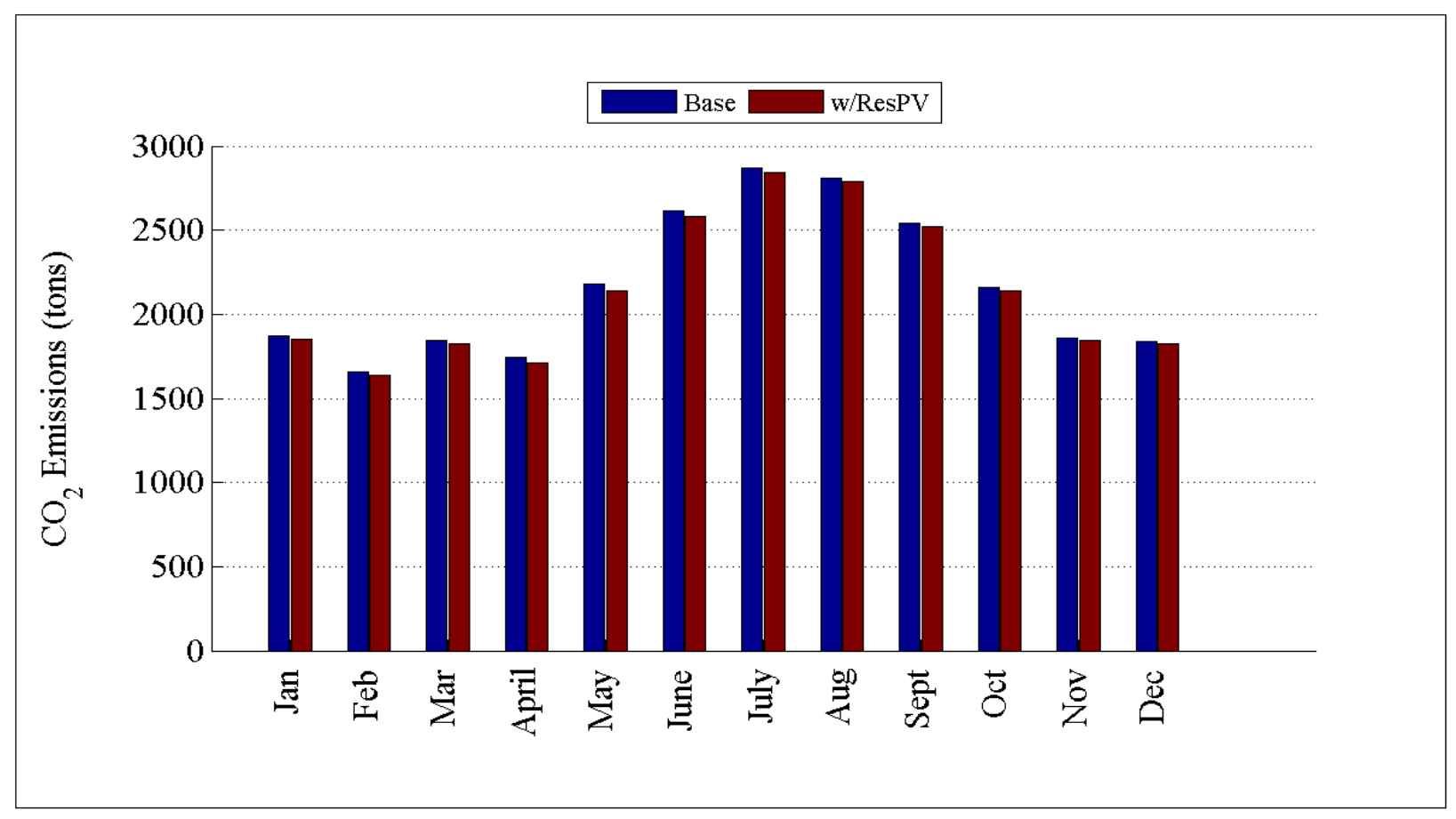

Figure D.55: Comparison of $\mathrm{CO}_{2}$ emissions by month for R3-12.47-3

D.1.13 Detailed Residential PV Plots for R4-12.47-1

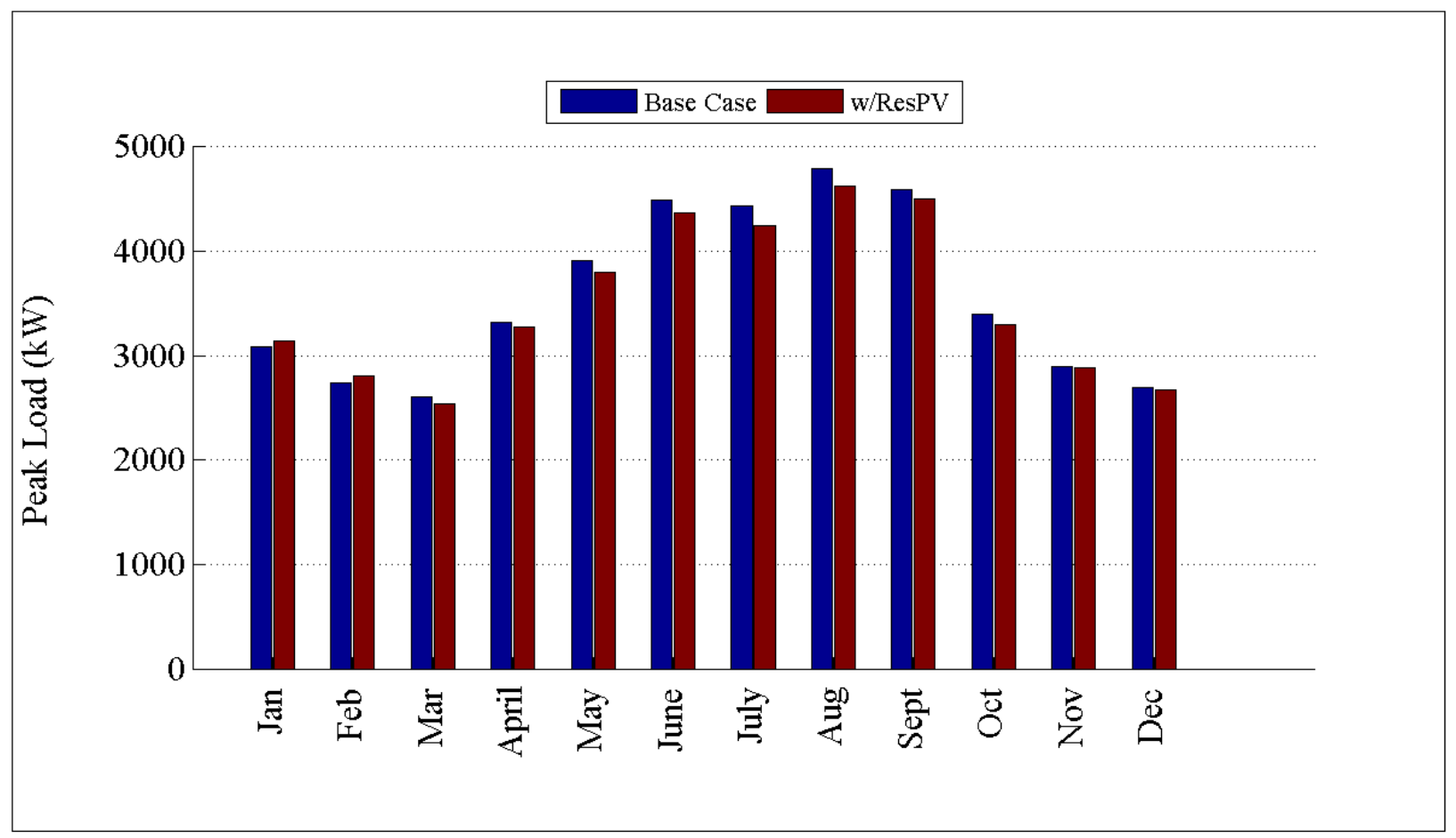

Figure D.56: Comparison of peak load by month for R4-12.47-1 


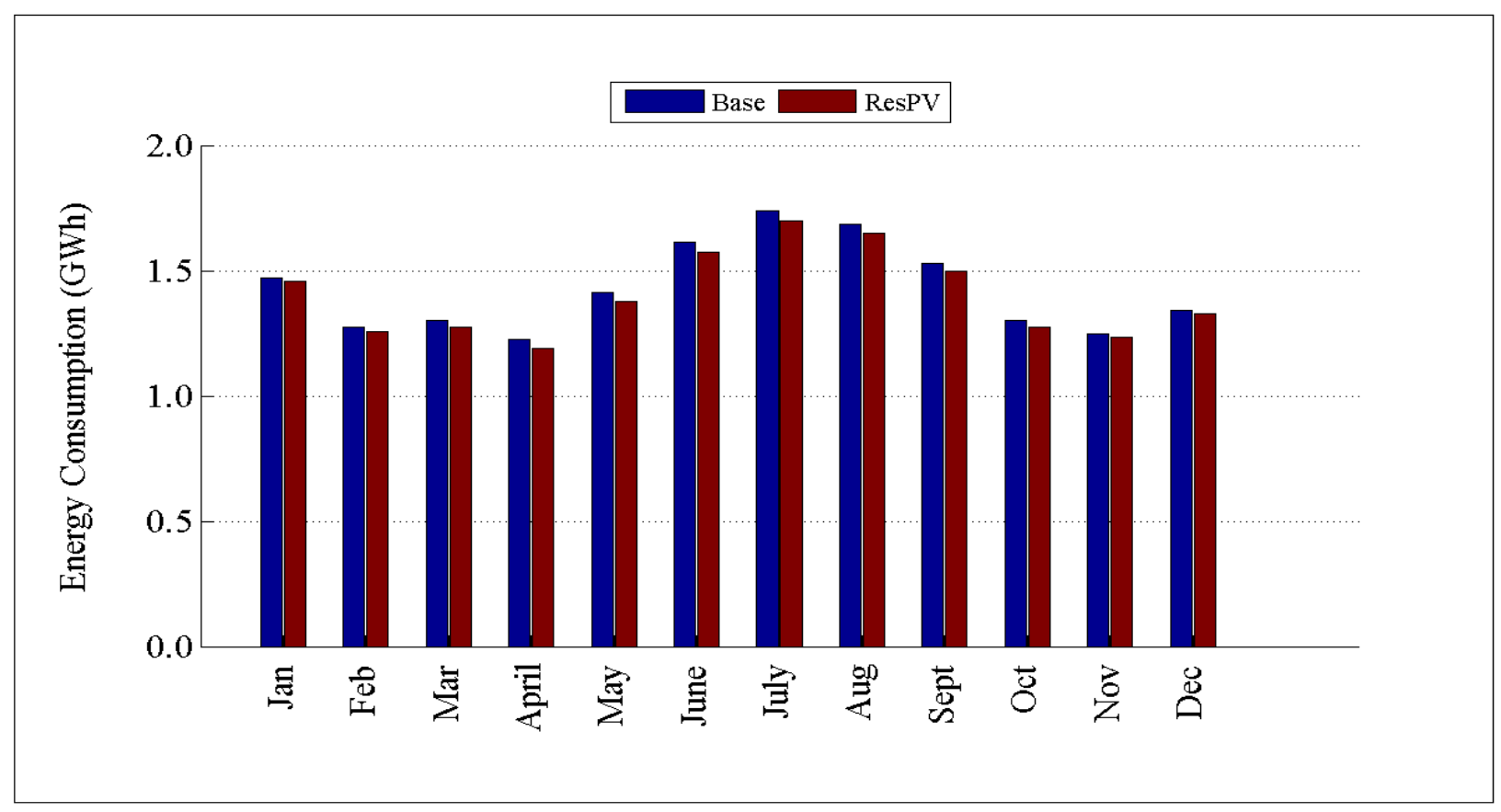

Figure D.57: Comparison of energy consumption by month for R4-12.47-1

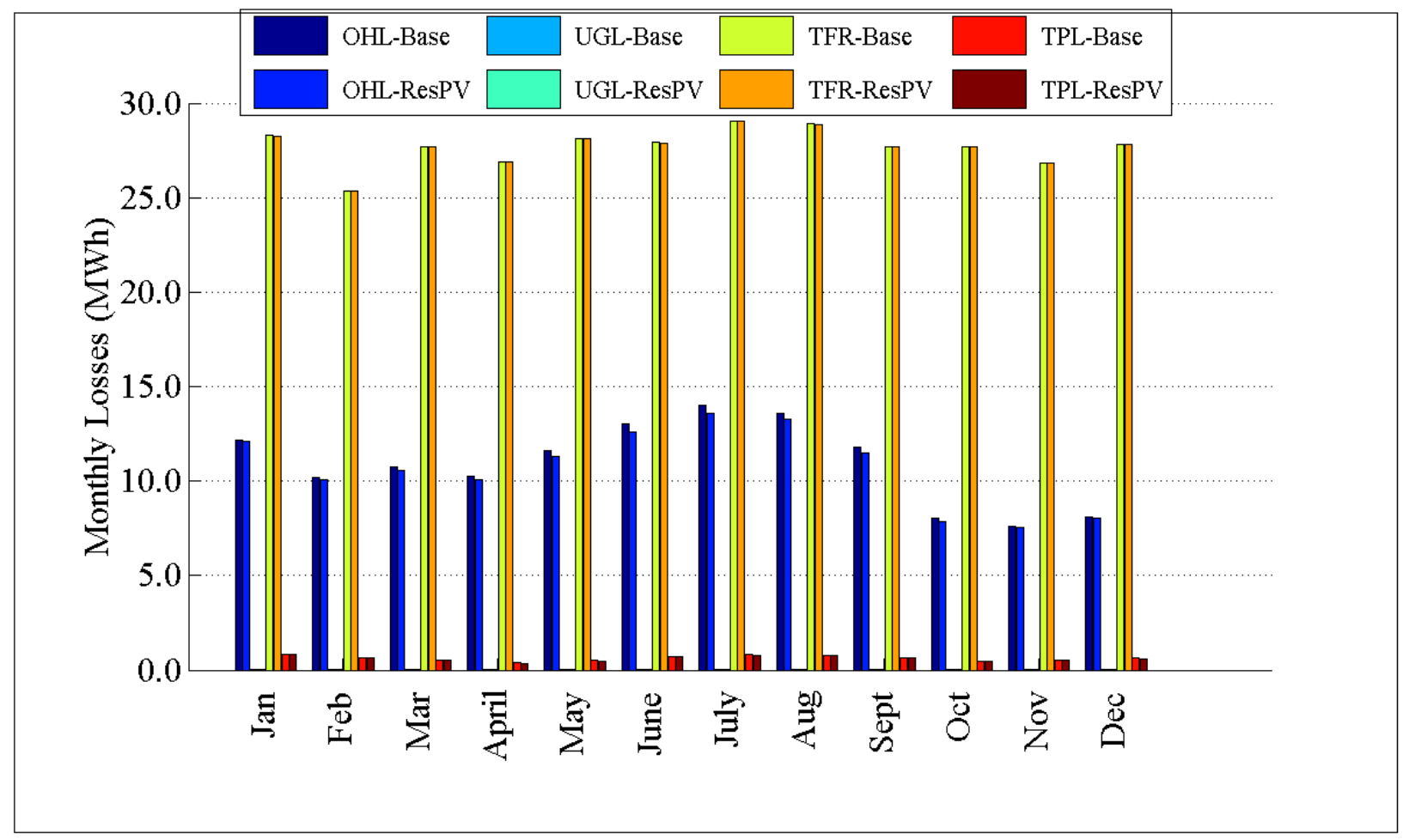

Figure D.58: Comparison of losses by month for R4-12.47-1 


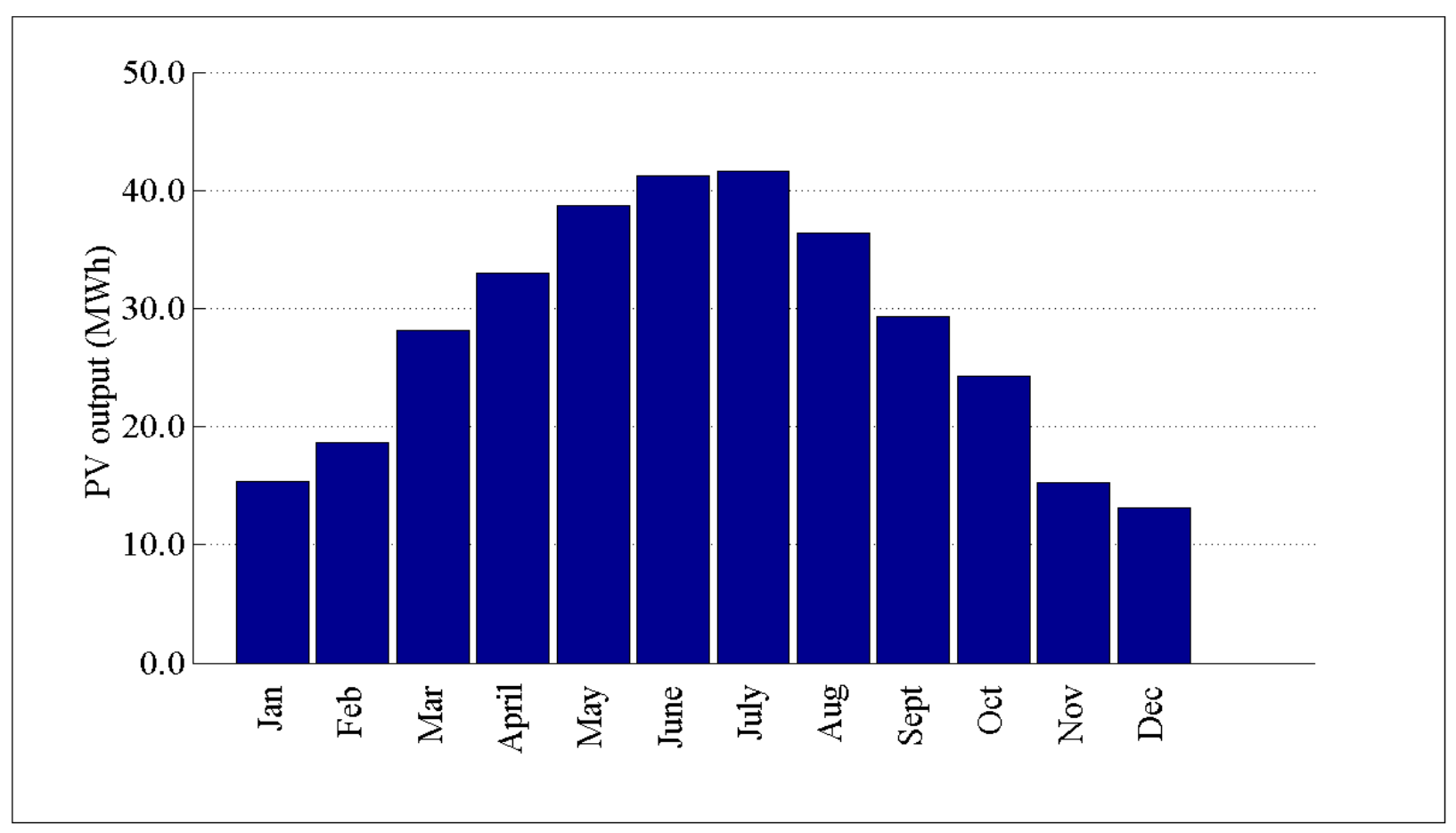

Figure D.59: PV output by month for R4-12.47-1

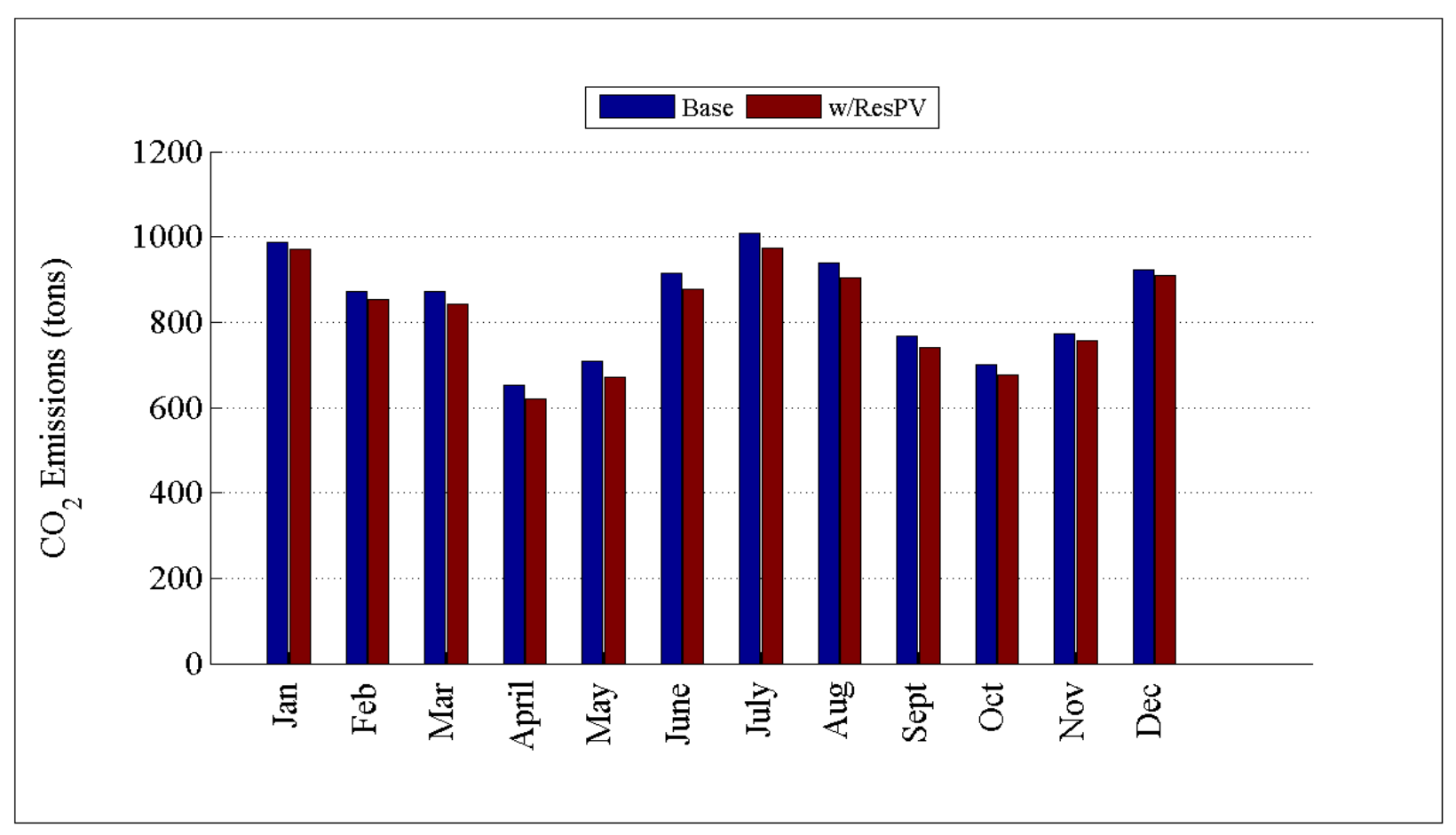

Figure D.60: Comparison of $\mathrm{CO}_{2}$ emissions by month for R4-12.47-1 
D.1.14 Detailed Residential PV Plots for R4-12.47-2

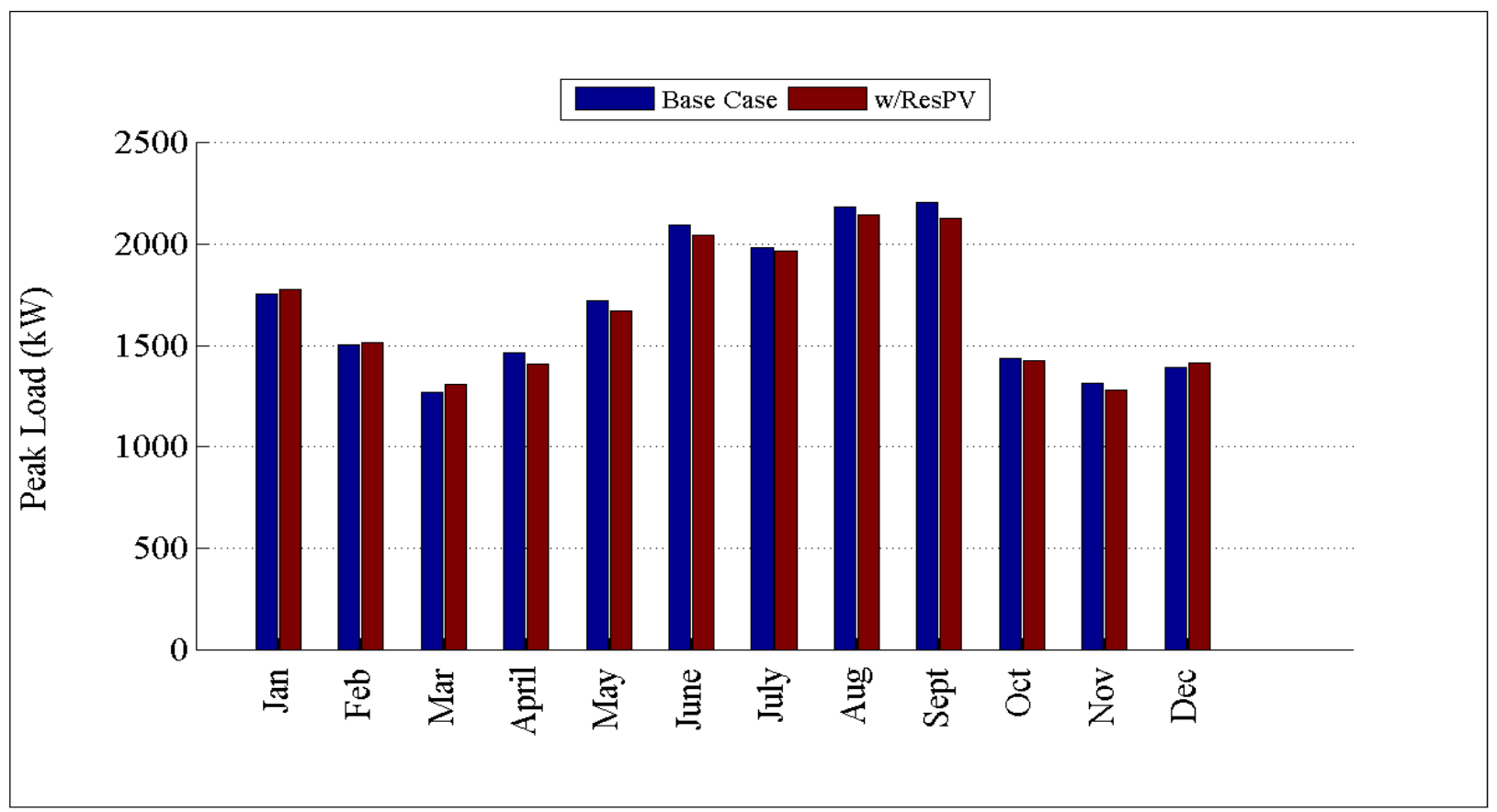

Figure D.61: Comparison of peak load by month for R4-12.47-2

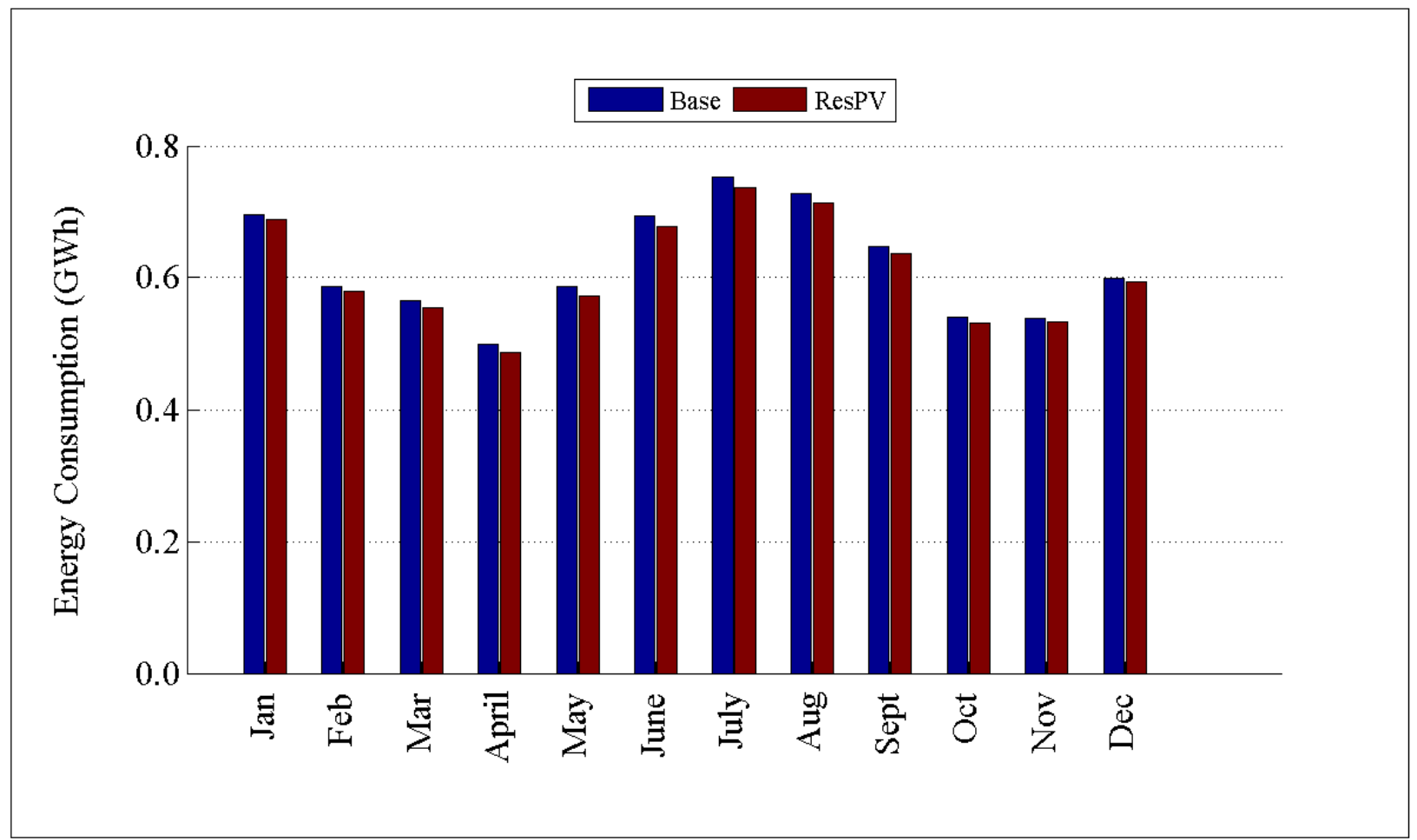

Figure D.62: Comparison of energy consumption by month for R4-12.47-2 


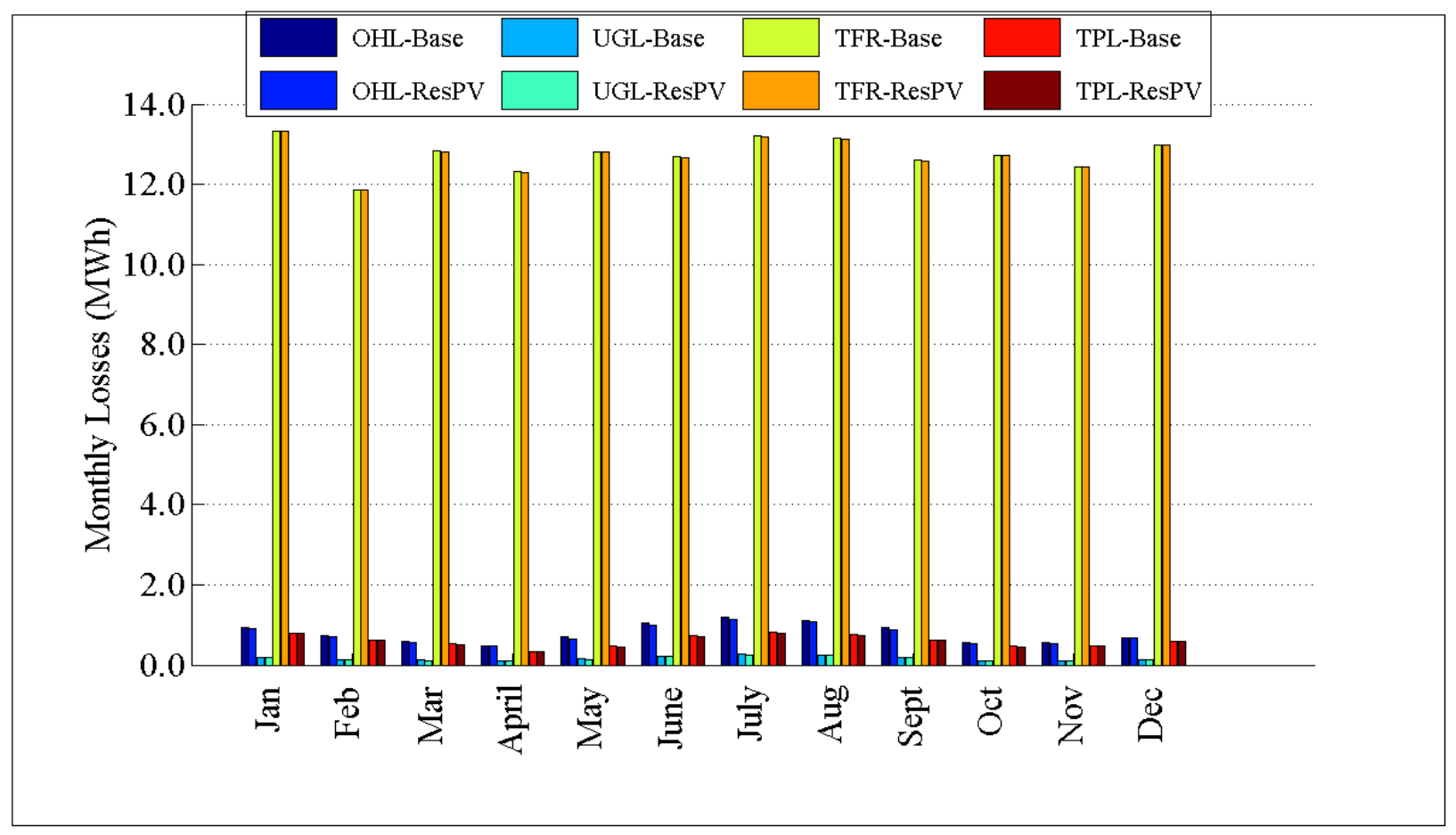

Figure D.63: Comparison of losses by month for R4-12.47-2

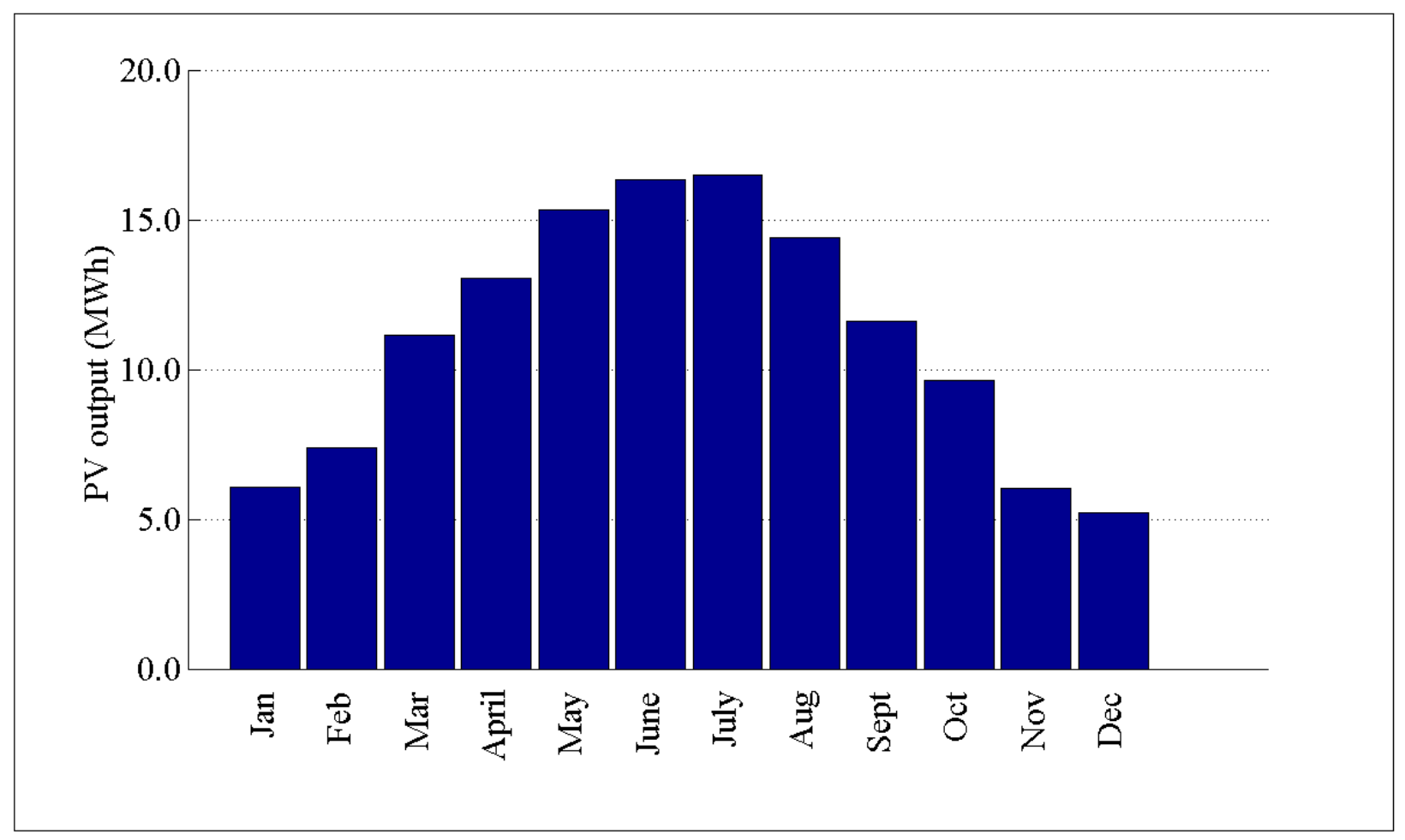

Figure D.64: PV output by month for R4-12.47-2 


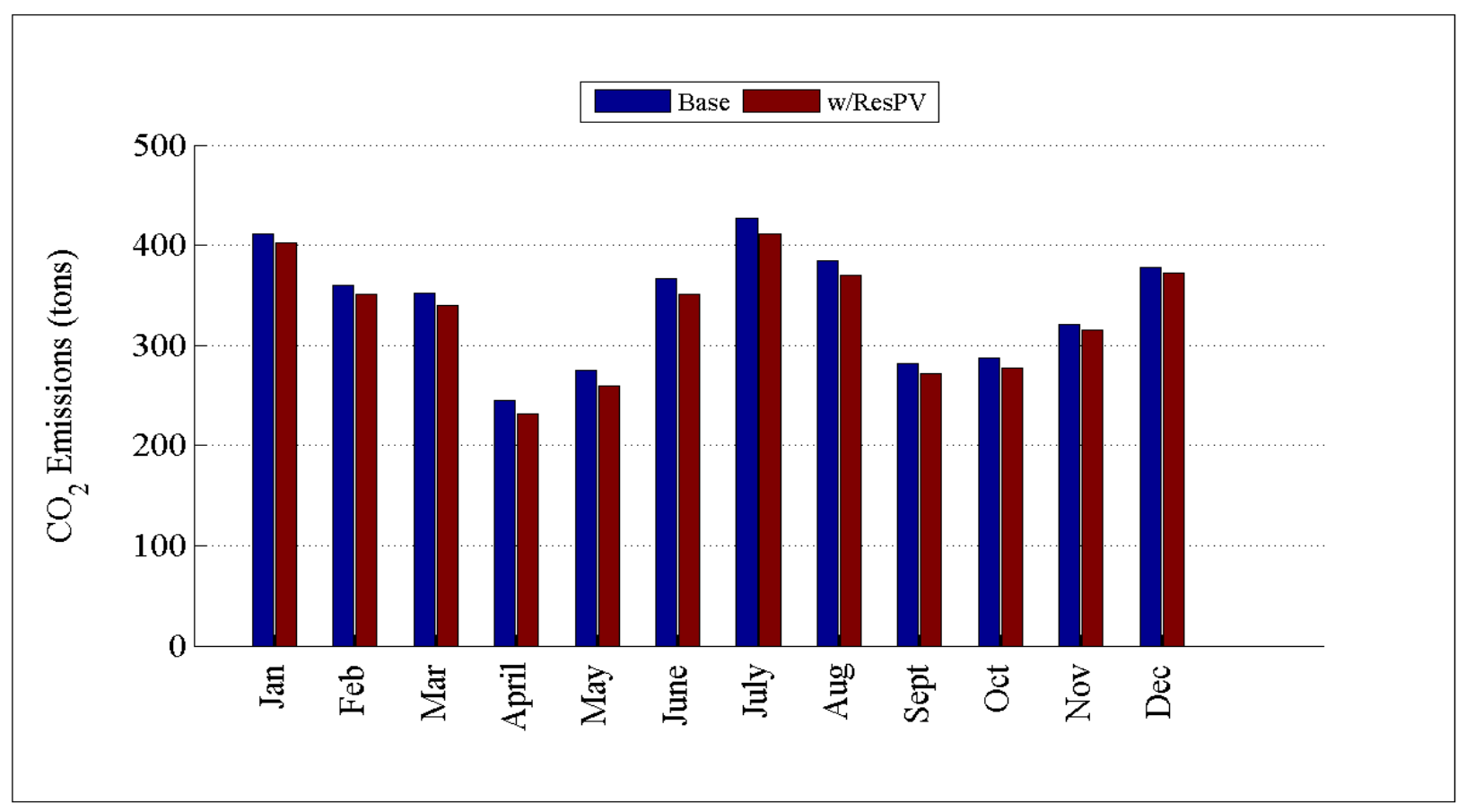

Figure D.65: Comparison of $\mathrm{CO}_{2}$ emissions by month for R3-12.47-1

\section{D.1.15 Detailed Residential PV Plots for R4-25.00-1}

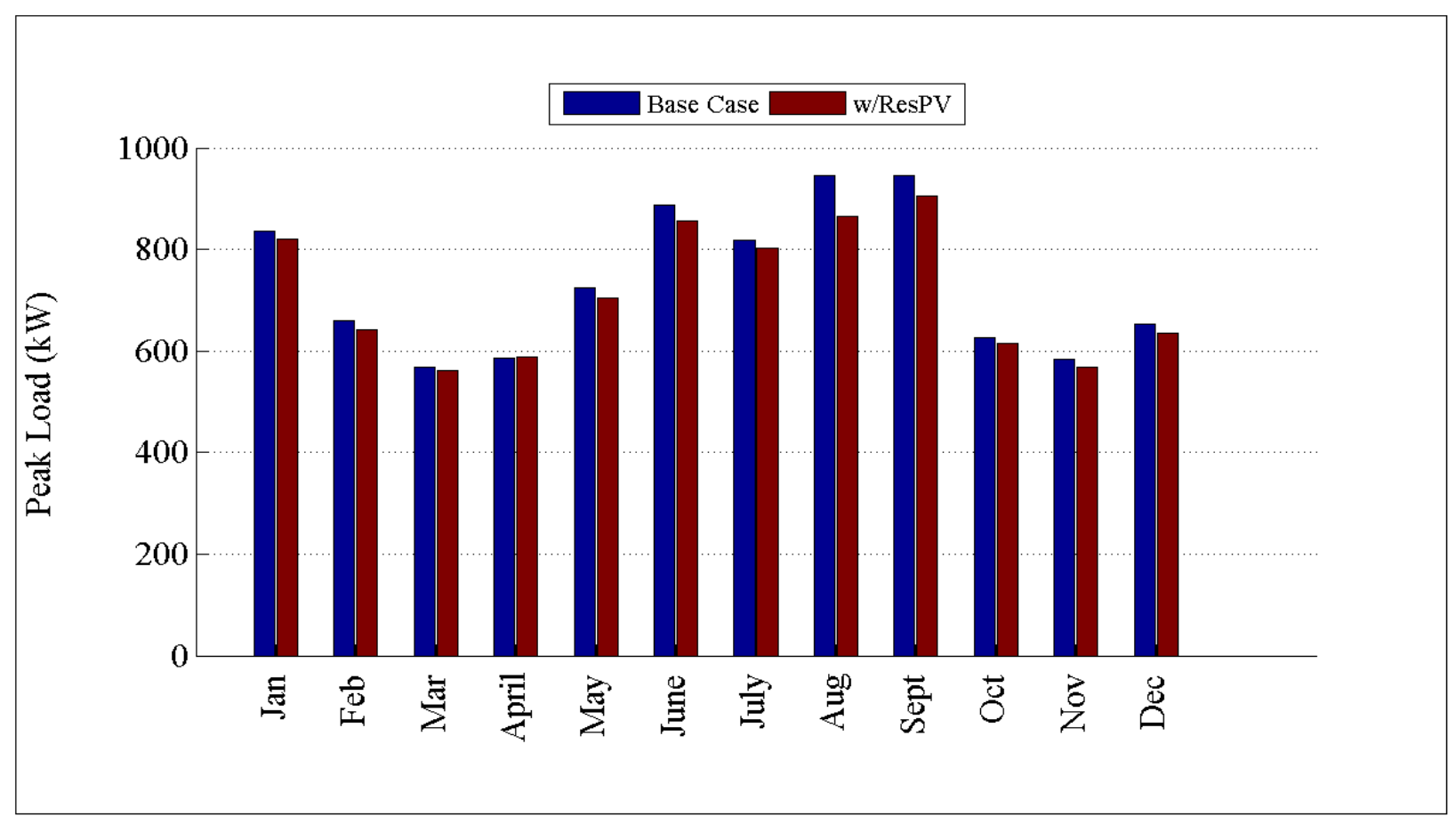

Figure D.66: Comparison of peak load by month for R4-25.00-1 


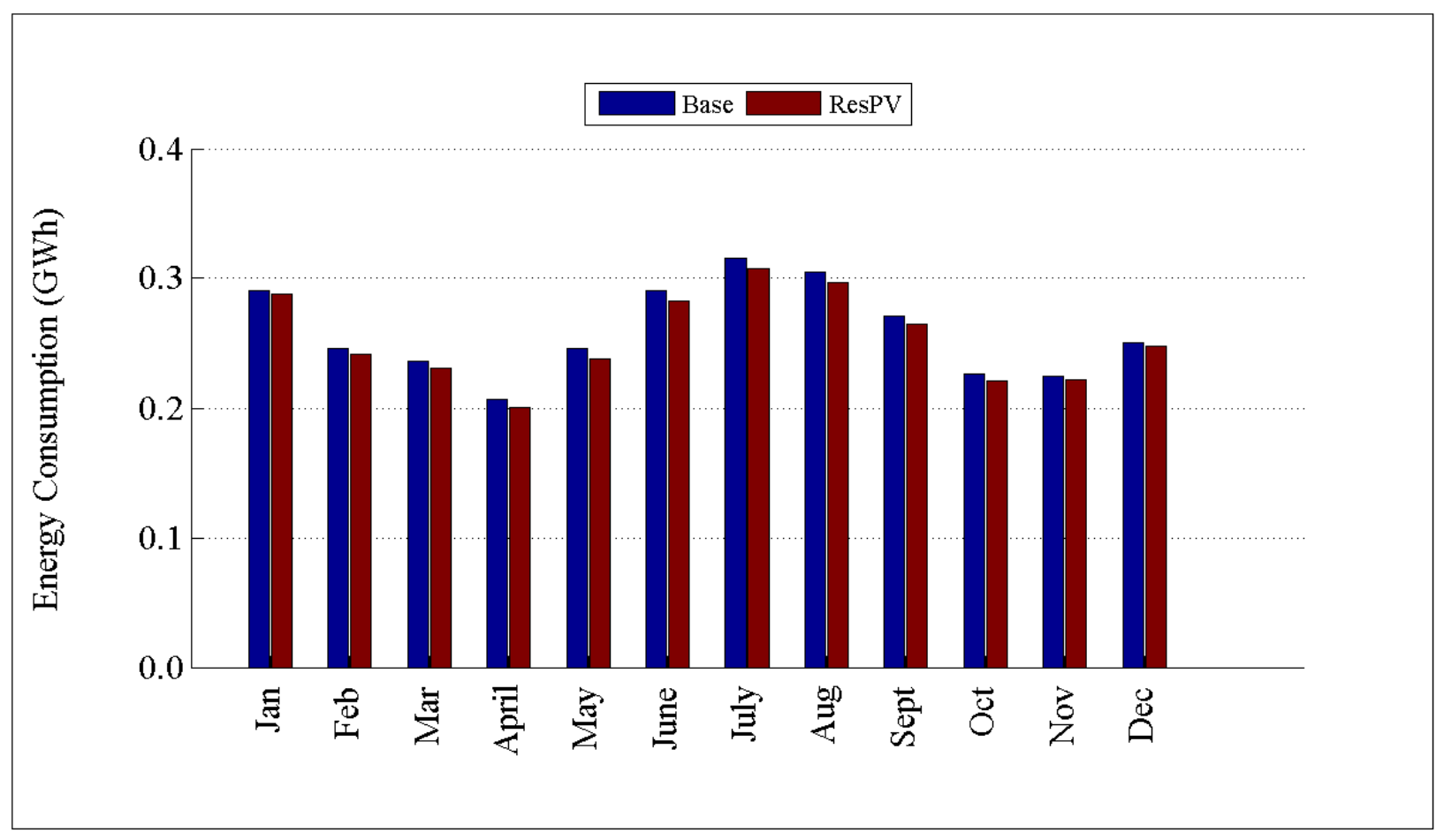

Figure D.67: Comparison of energy consumption by month for R4-25.00-1

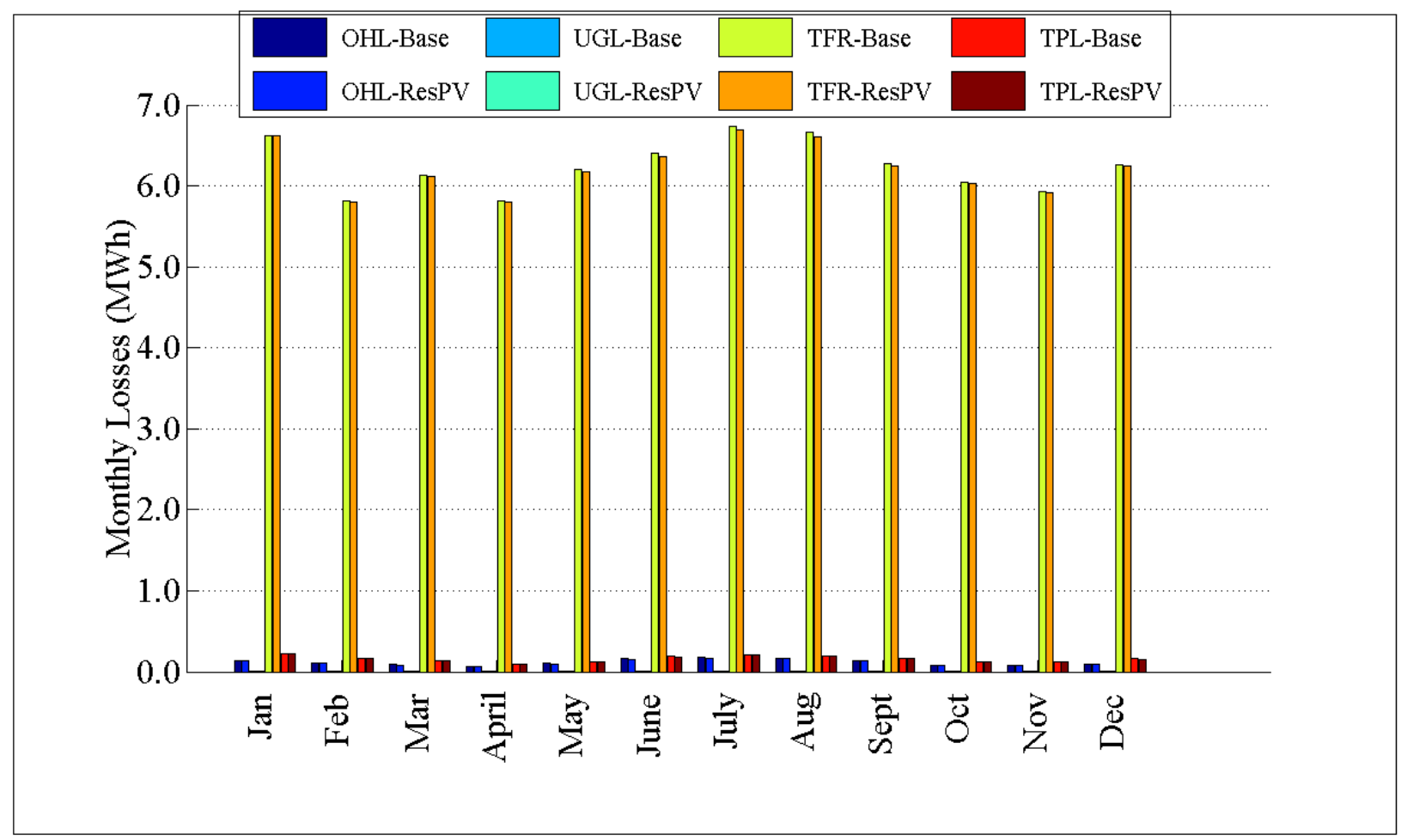

Figure D.68: Comparison of losses by month for R4-25.00-1 


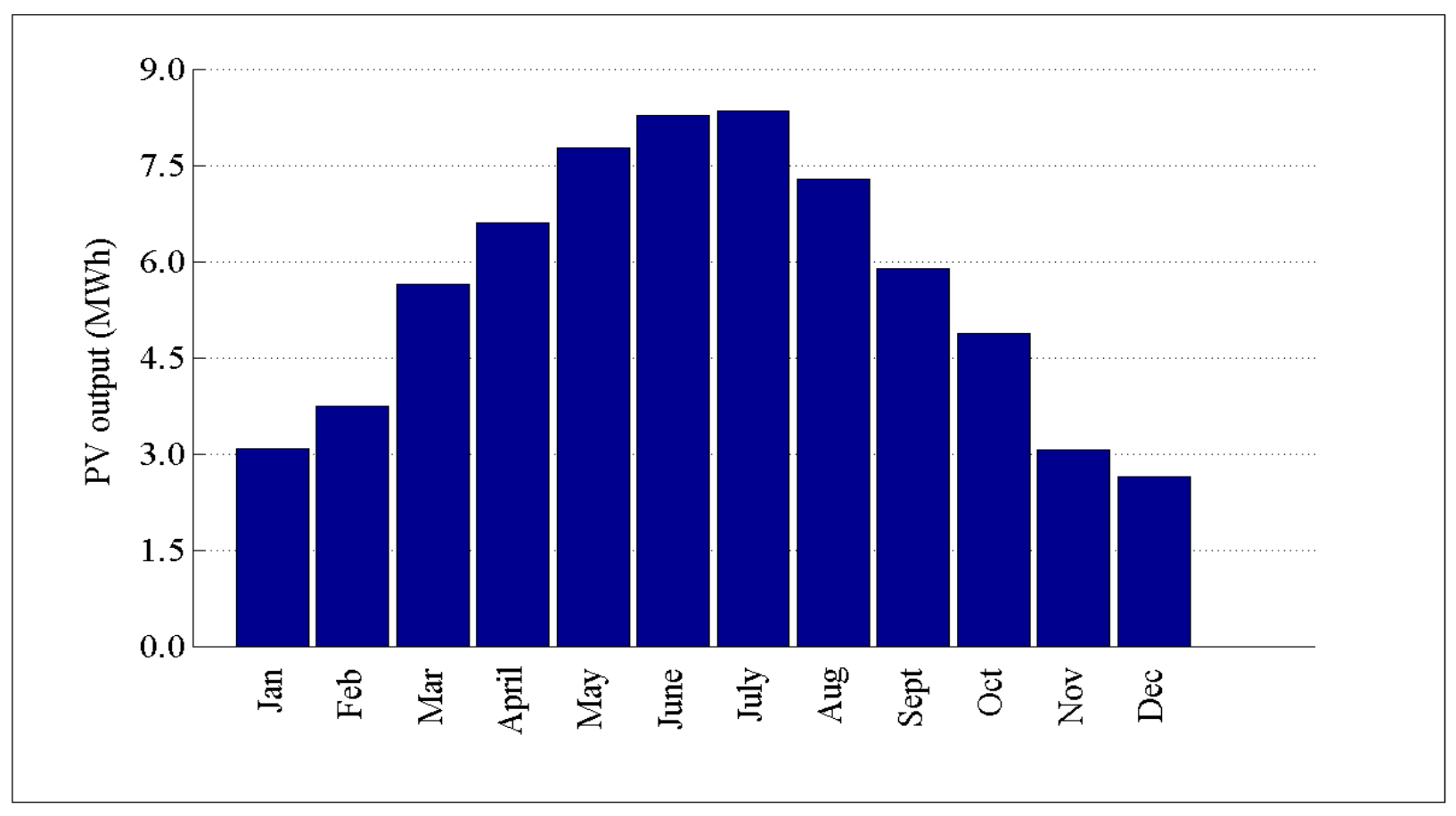

Figure D.69: PV output by month for R4-25.00-1

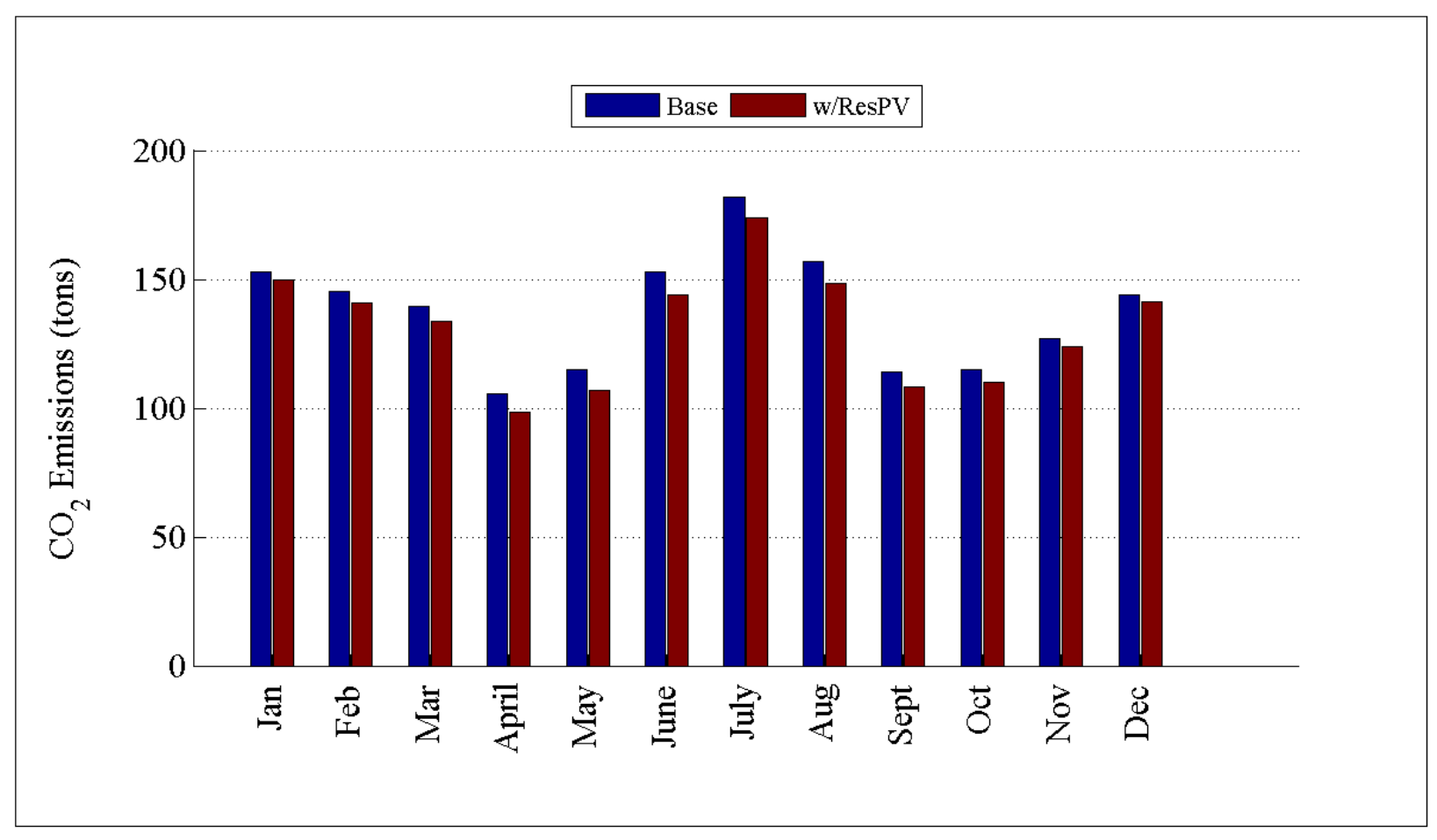

Figure D.70: Comparison of $\mathrm{CO}_{2}$ emissions by month for R4-25.00-1 
D.1.16 Detailed Residential PV Plots for R5-12.47-1

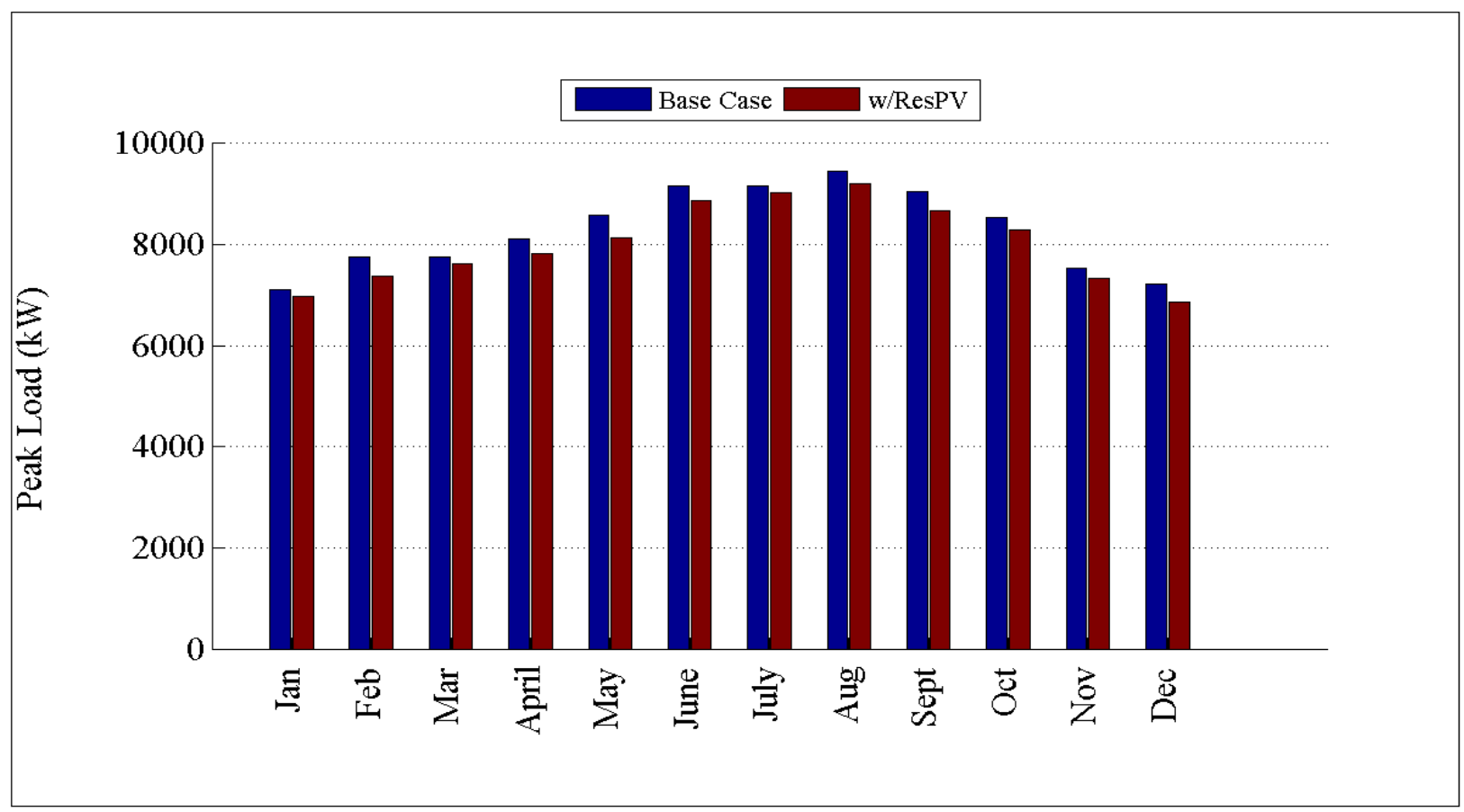

Figure D.71: Comparison of peak load by month for R5-12.47-1 


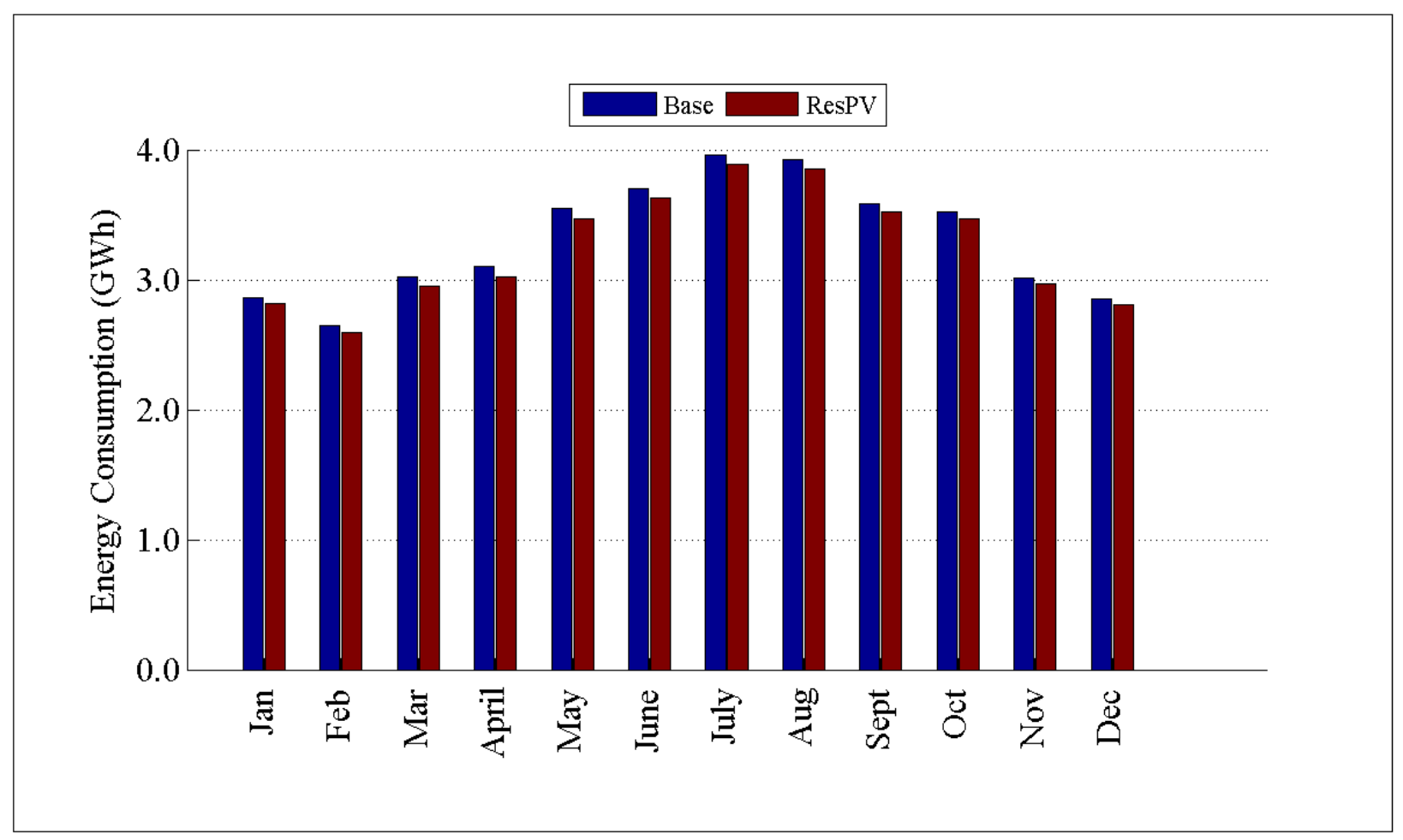

Figure D.72: Comparison of energy consumption by month for R5-12.47-1

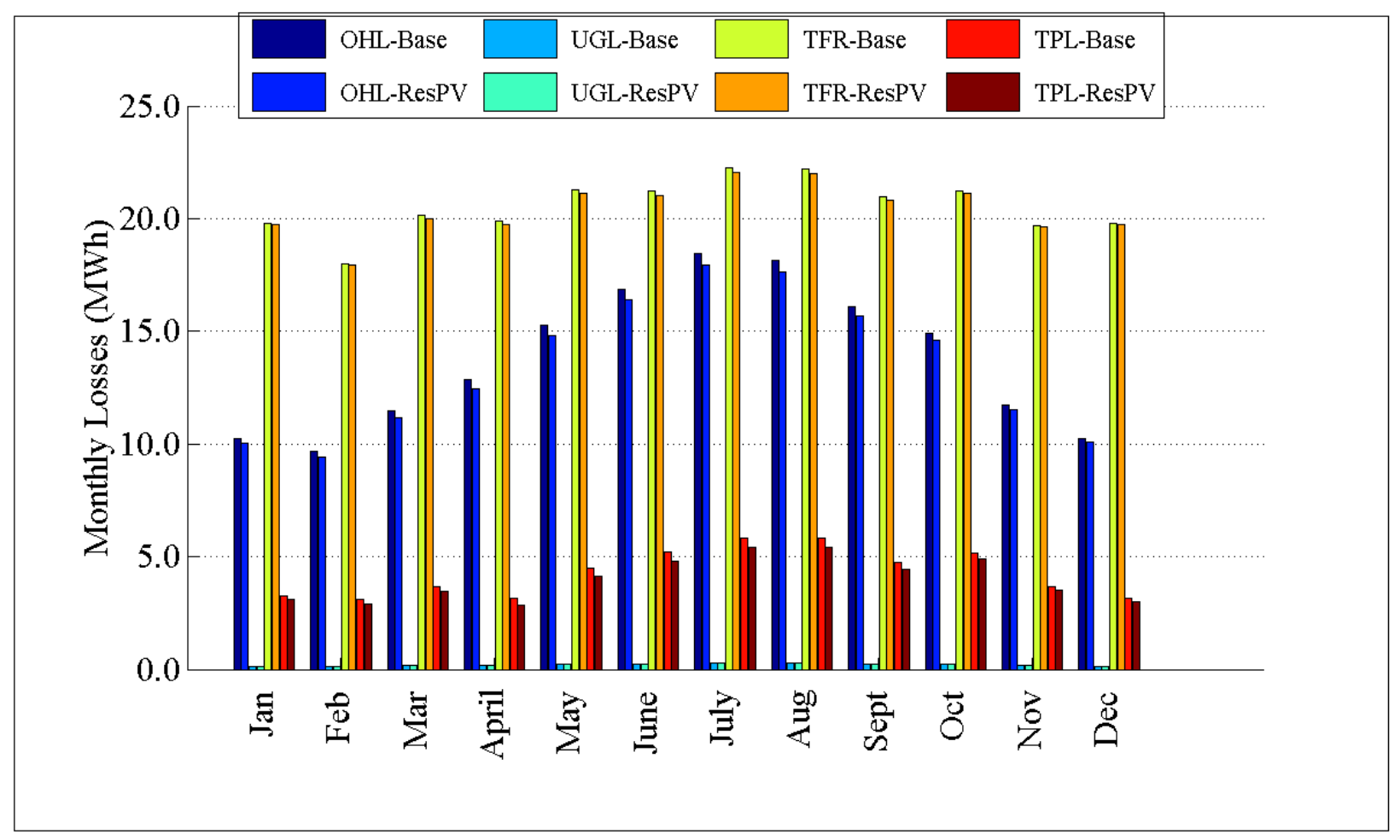

Figure D.73: Comparison of losses by month for R5-12.47-1 


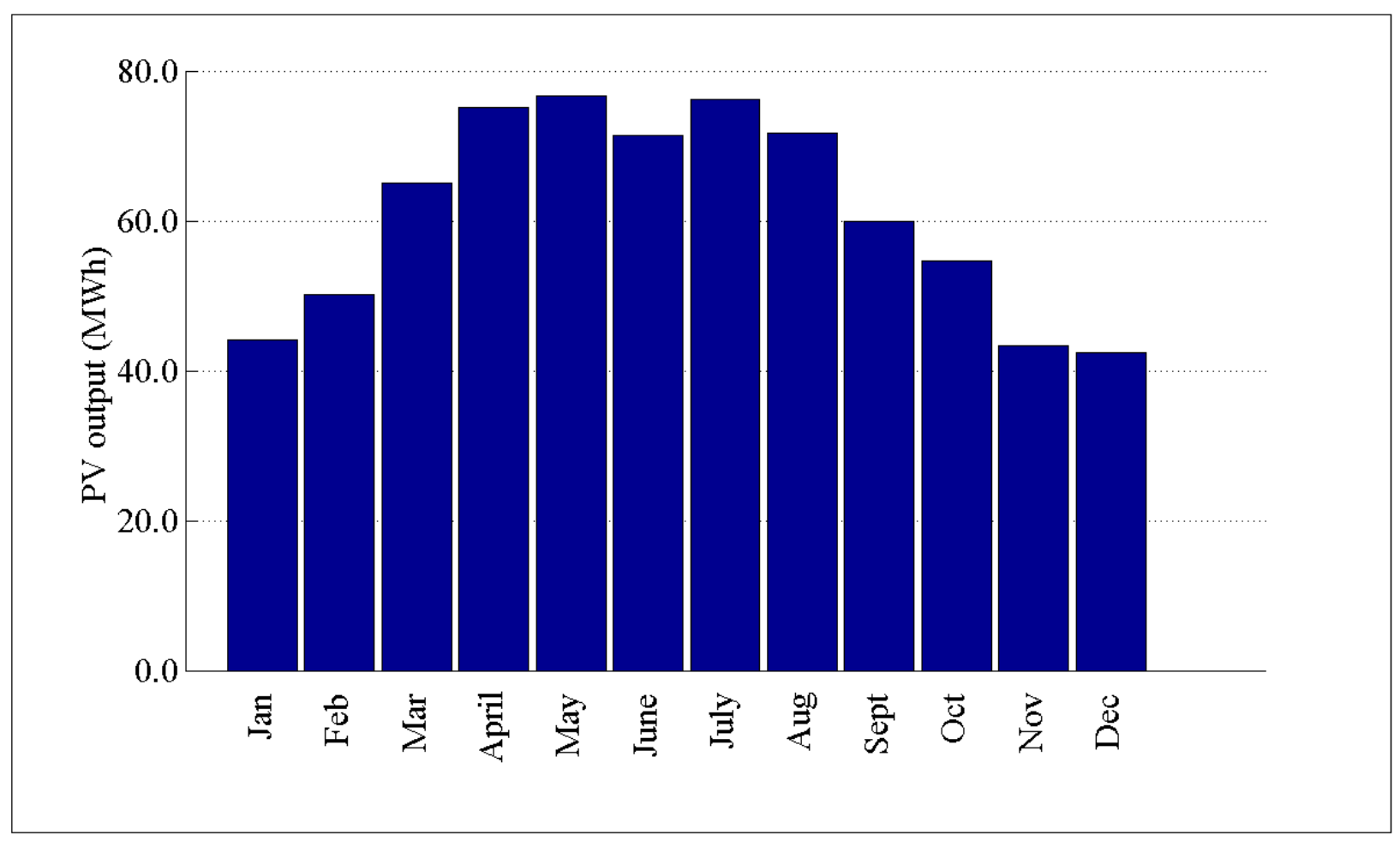

Figure D.74: PV output by month for R5-12.47-1

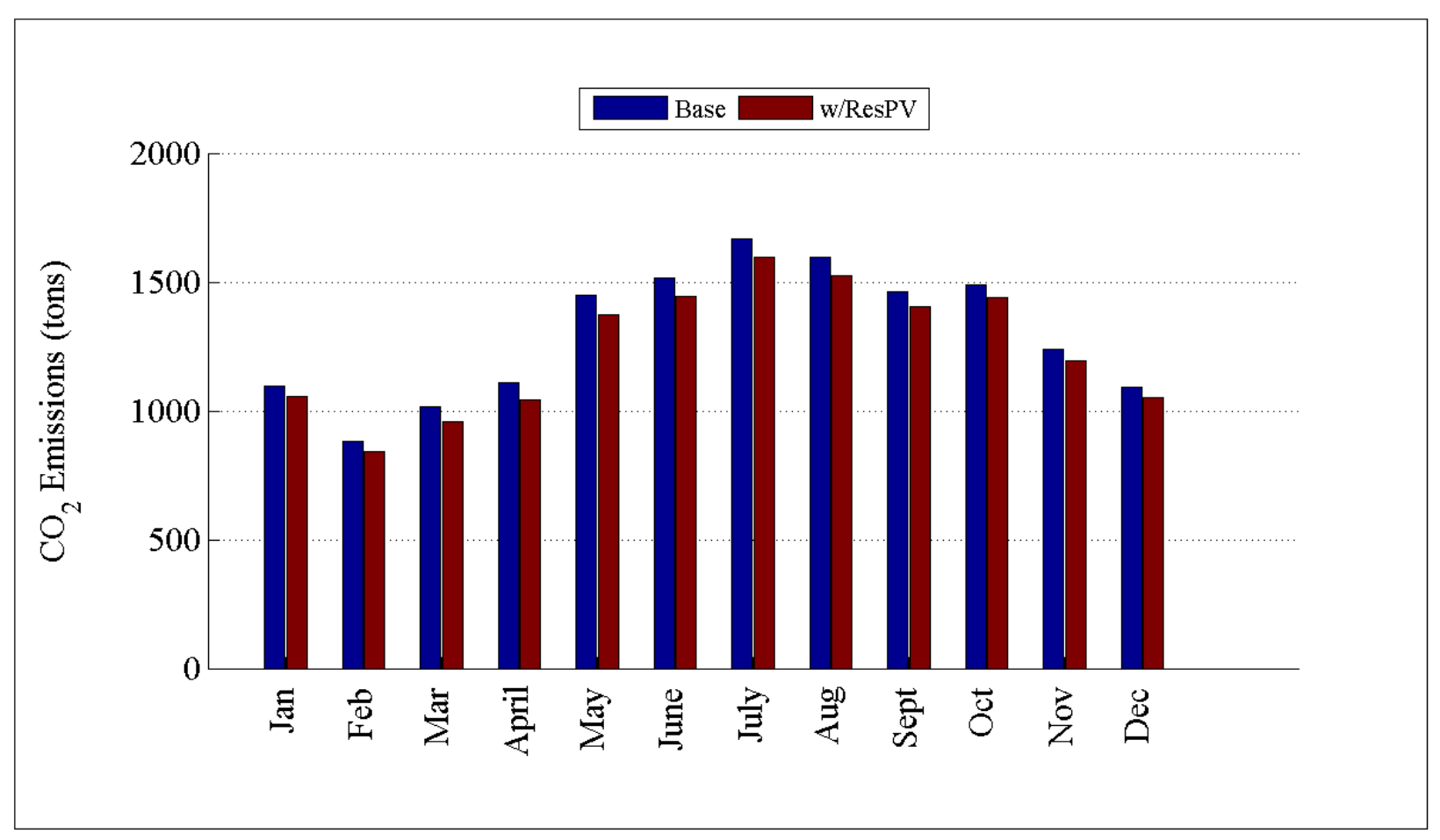

Figure D.75: Comparison of $\mathrm{CO}_{2}$ emissions by month for R5-12.47-1 
D.1.17 Detailed Residential PV Plots for R5-12.47-2

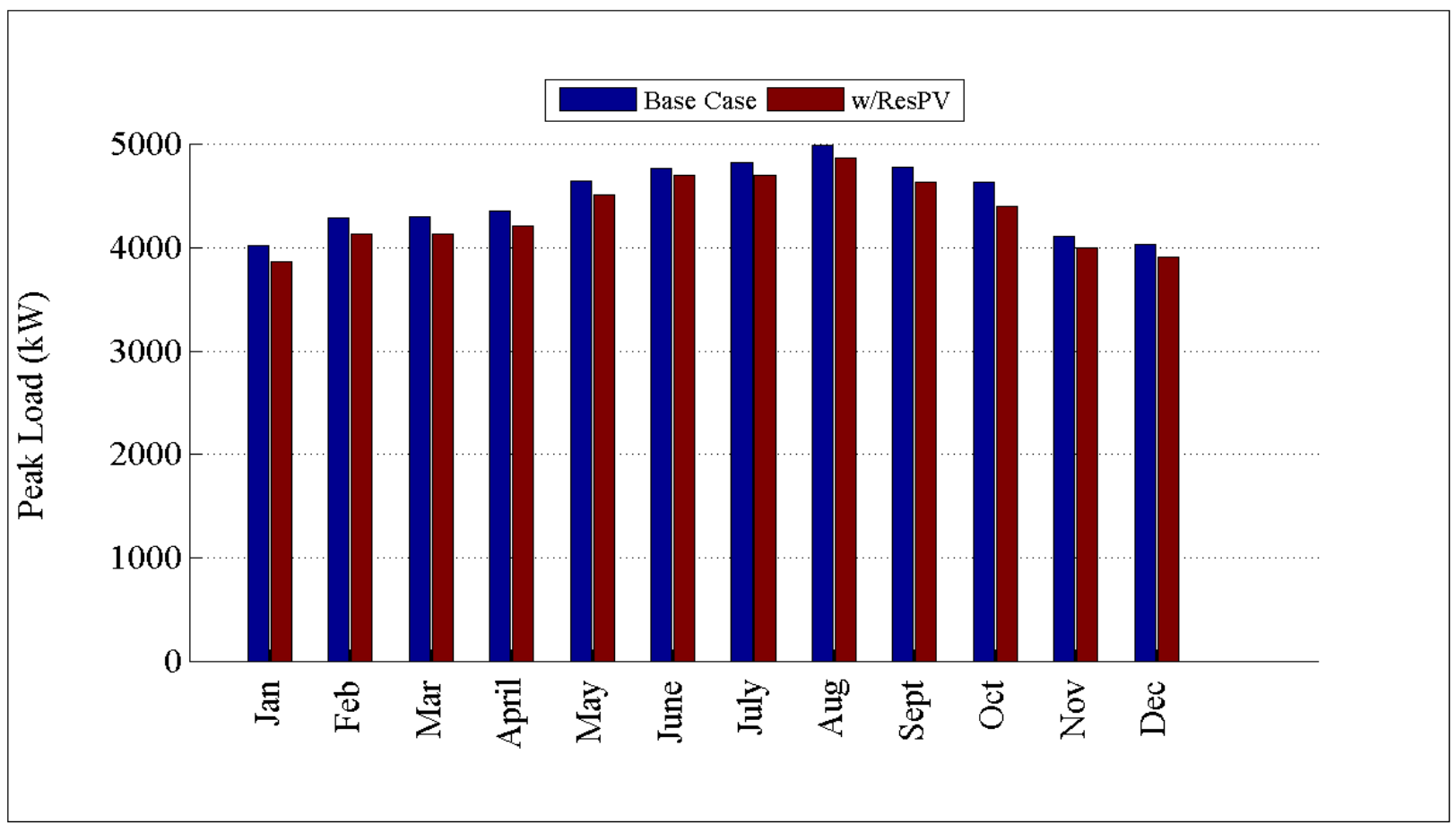

Figure D.76: Comparison of peak load by month for R5-12.47-2

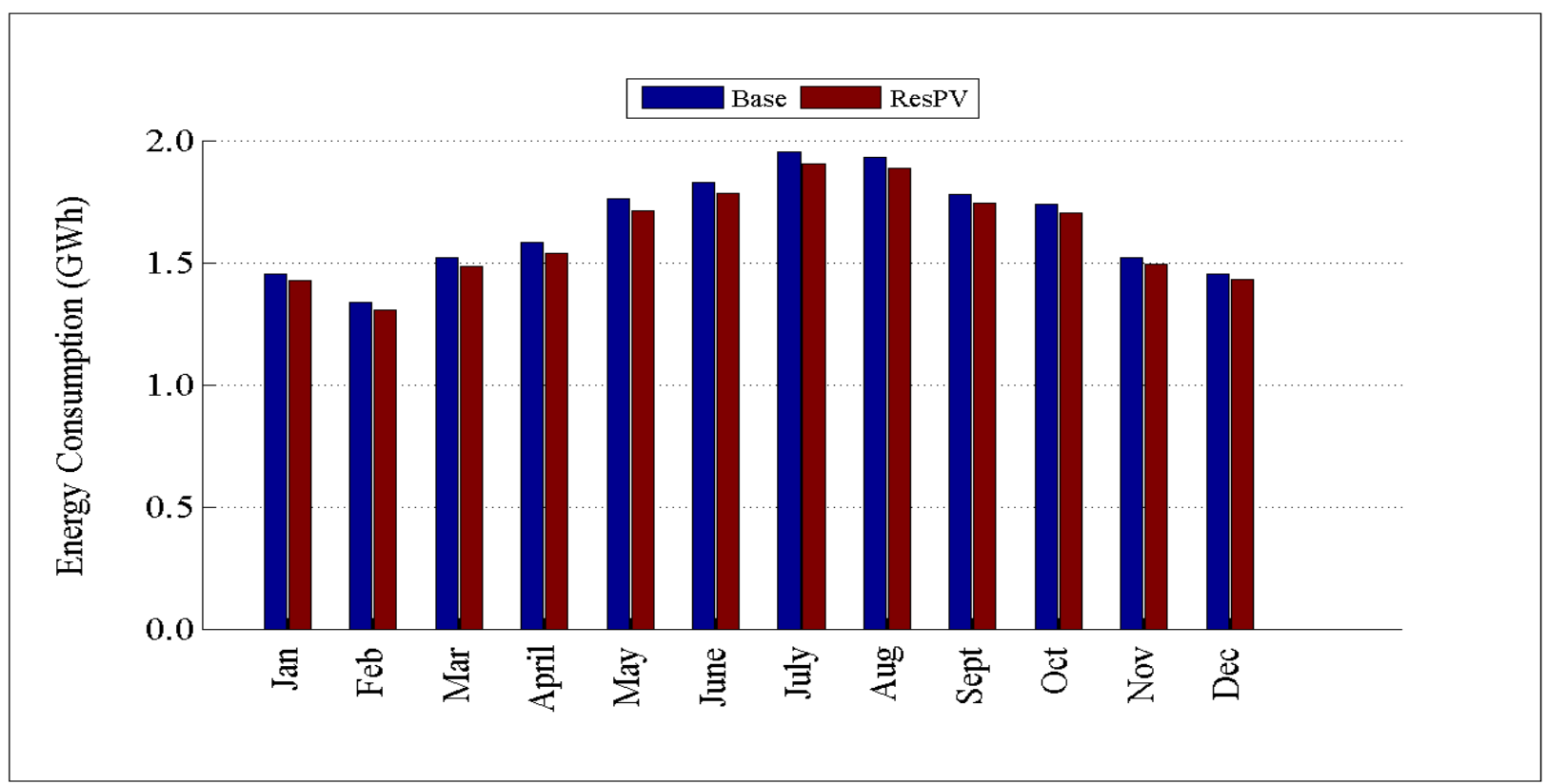

Figure D.77: Comparison of energy consumption by month for R5-12.47-2 


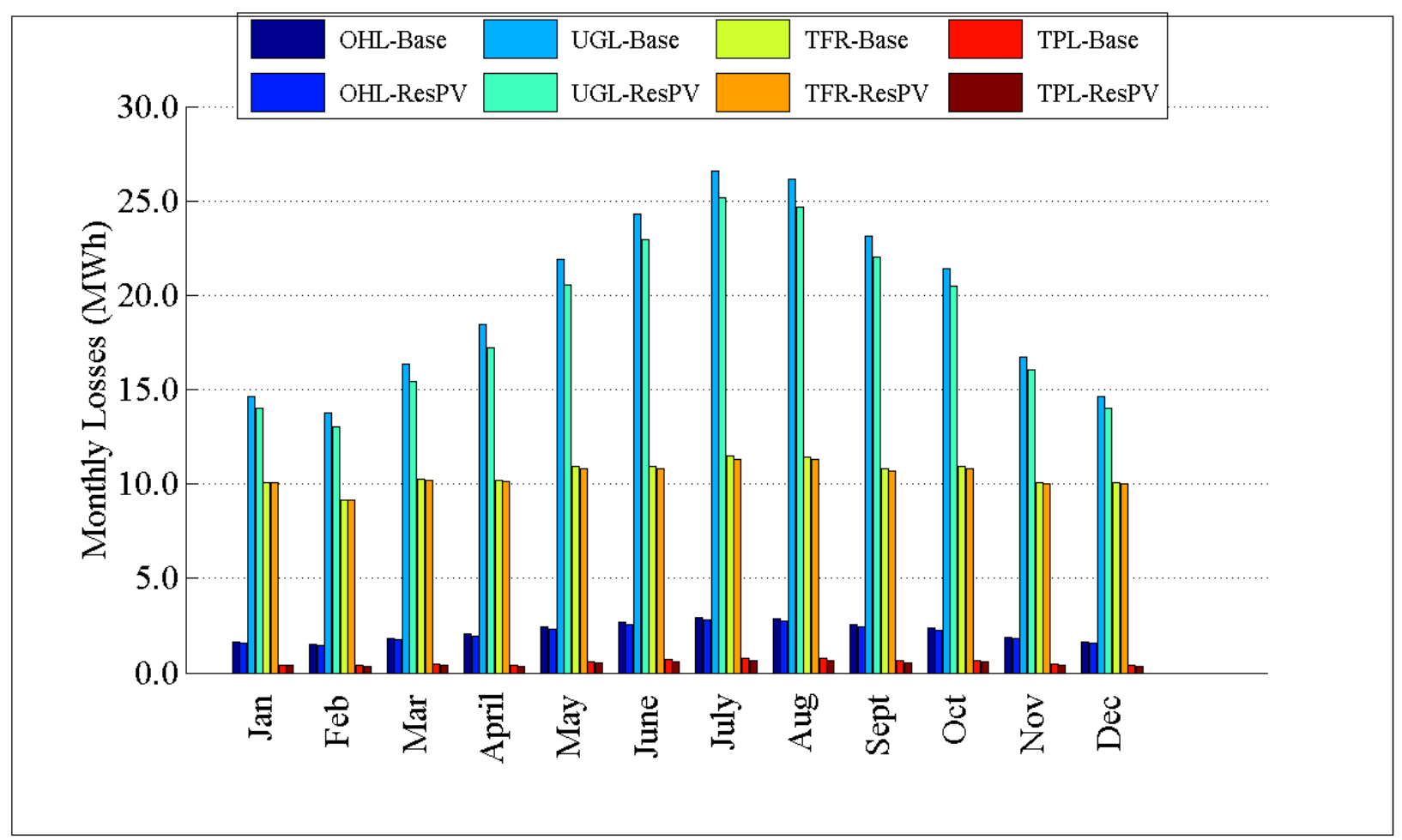

Figure D.78: Comparison of losses by month for R5-12.47-2

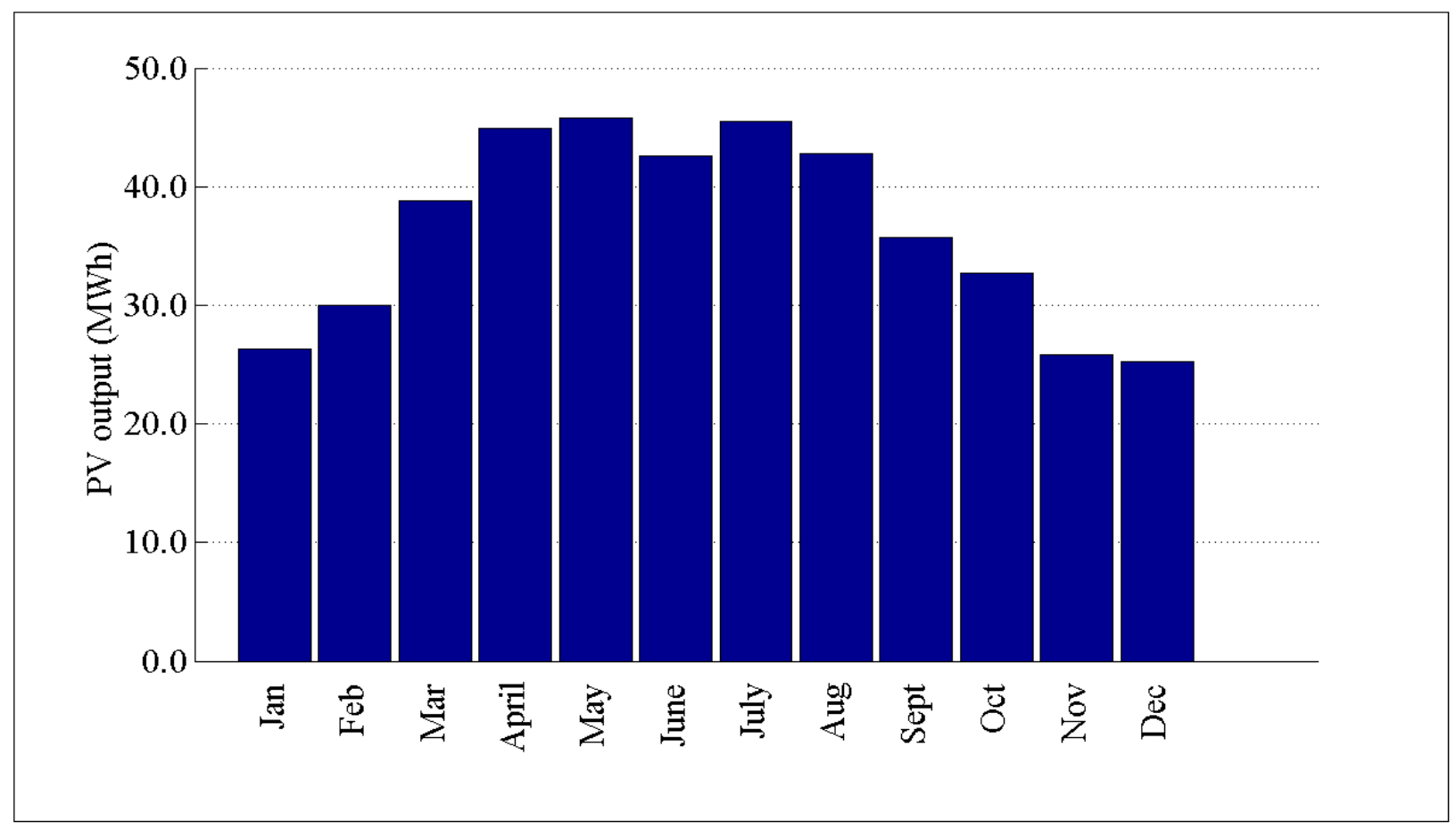

Figure D.79: PV output by month for R5-12.47-2 


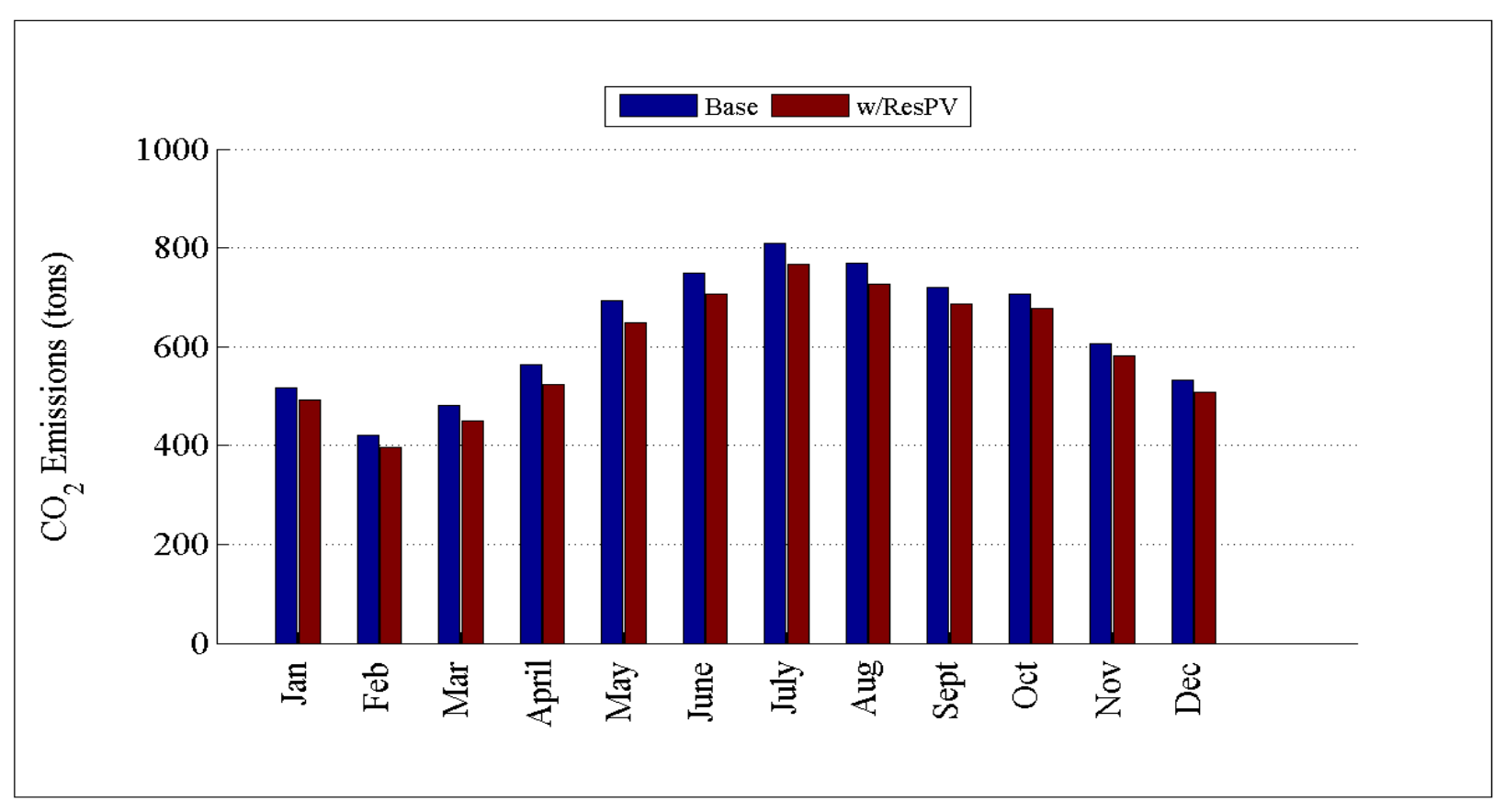

Figure D.80: Comparison of $\mathrm{CO}_{2}$ emissions by month for R5-12.47-2

\section{D.1.18 Detailed Residential PV Plots for R5-12.47-3}

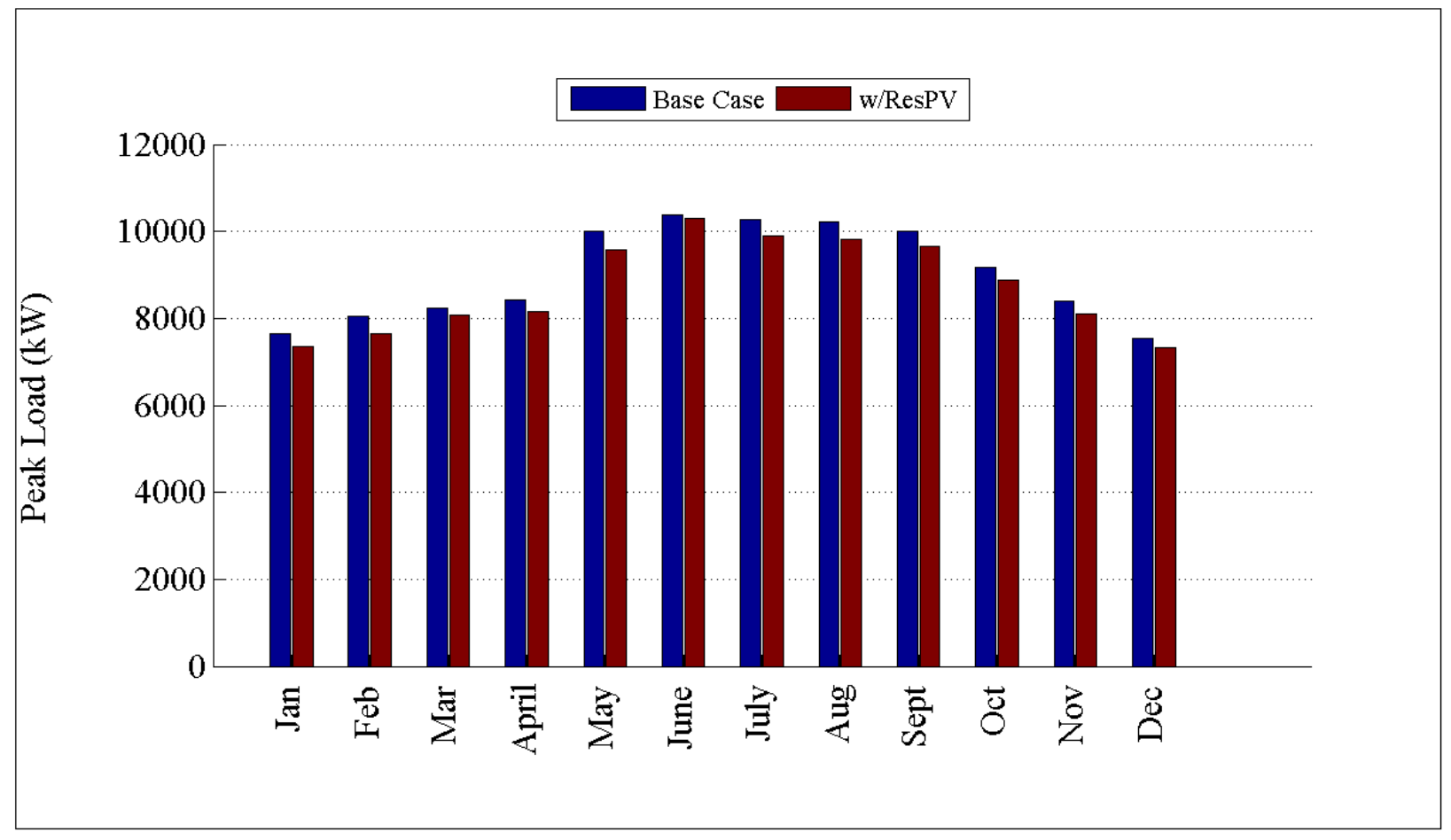

Figure D.81: Comparison of peak load by month for R5-12.47-3 


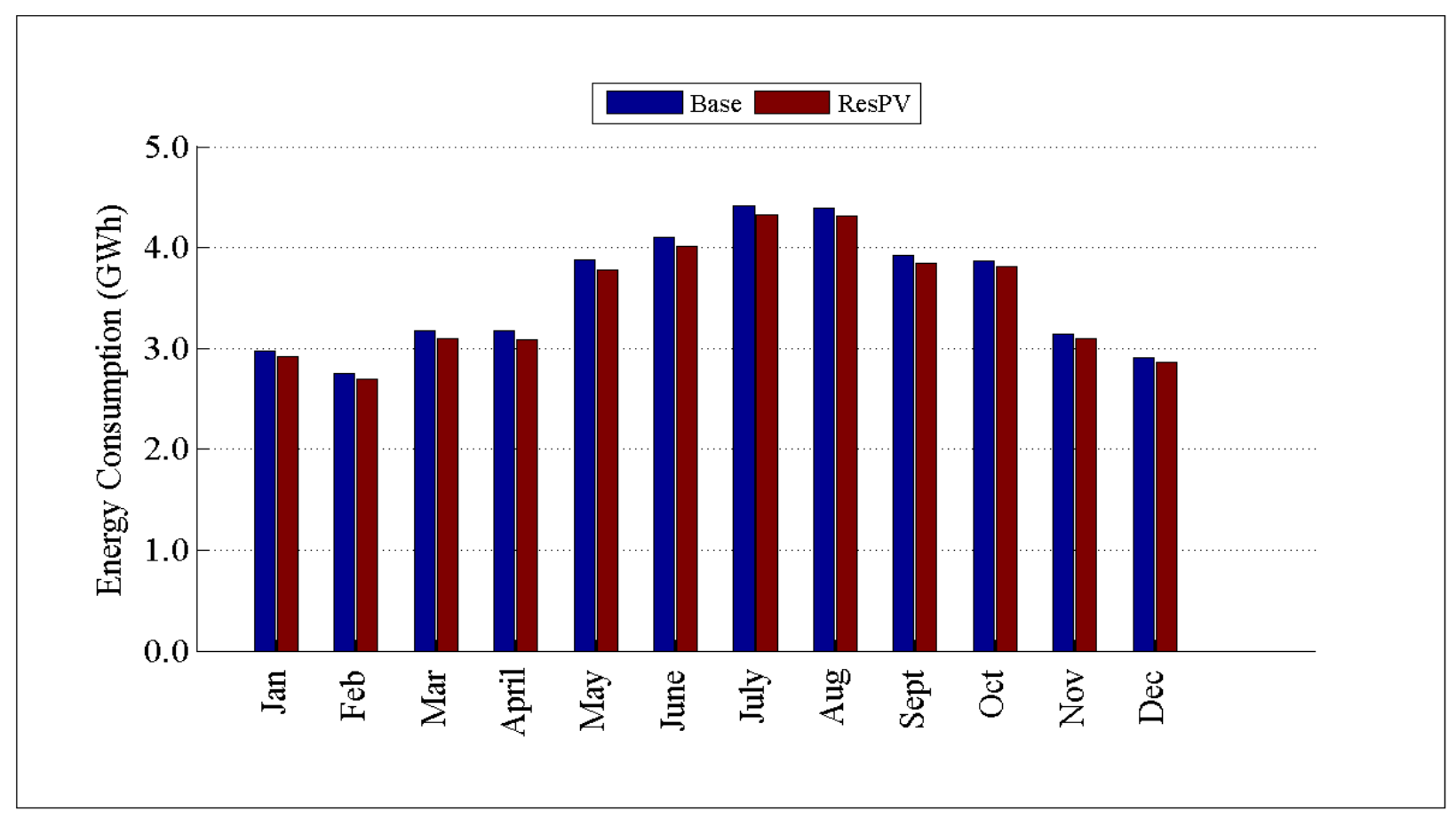

Figure D.82: Comparison of energy consumption by month for R5-12.47-3

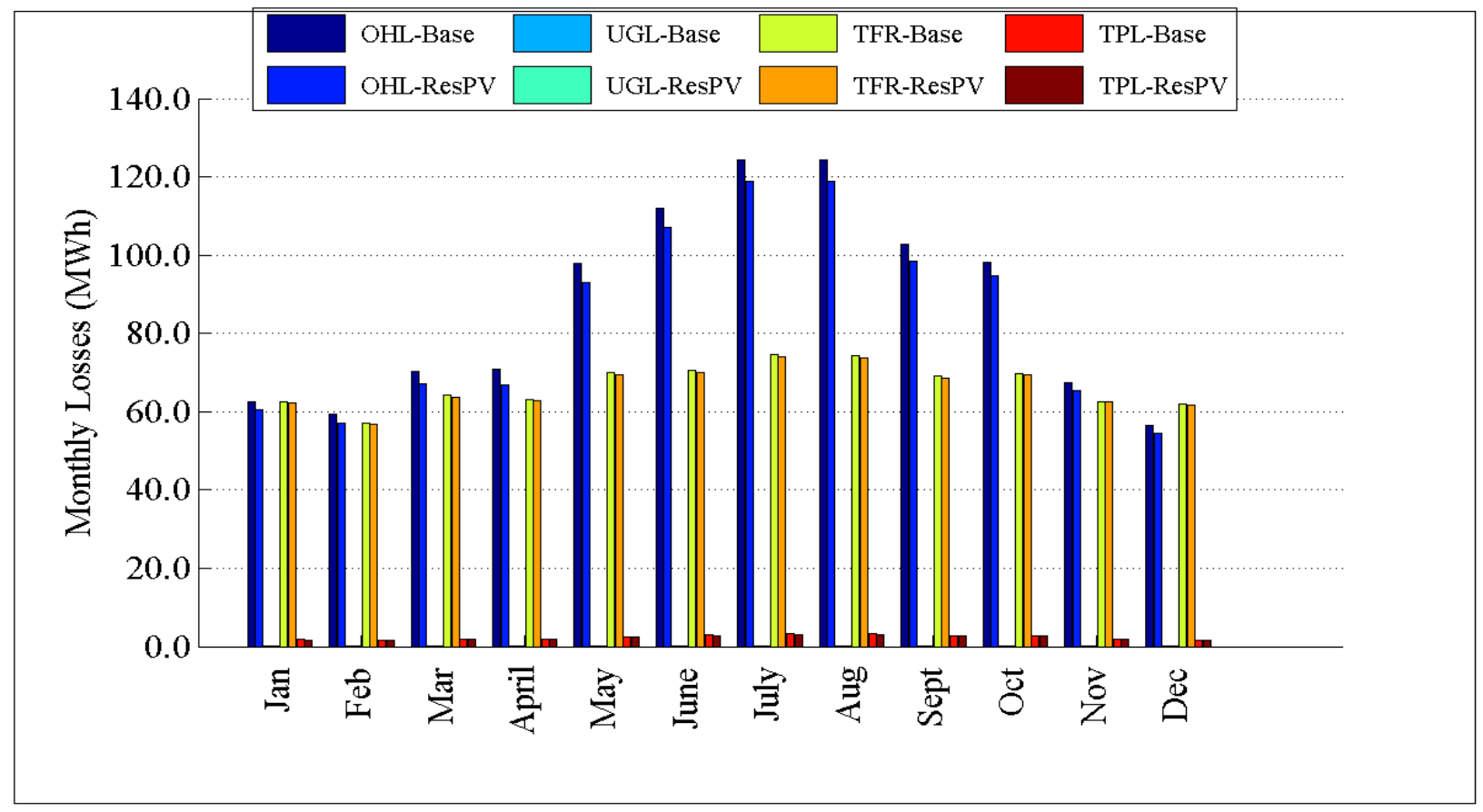

Figure D.83: Comparison of losses by month for R5-12.47-3 


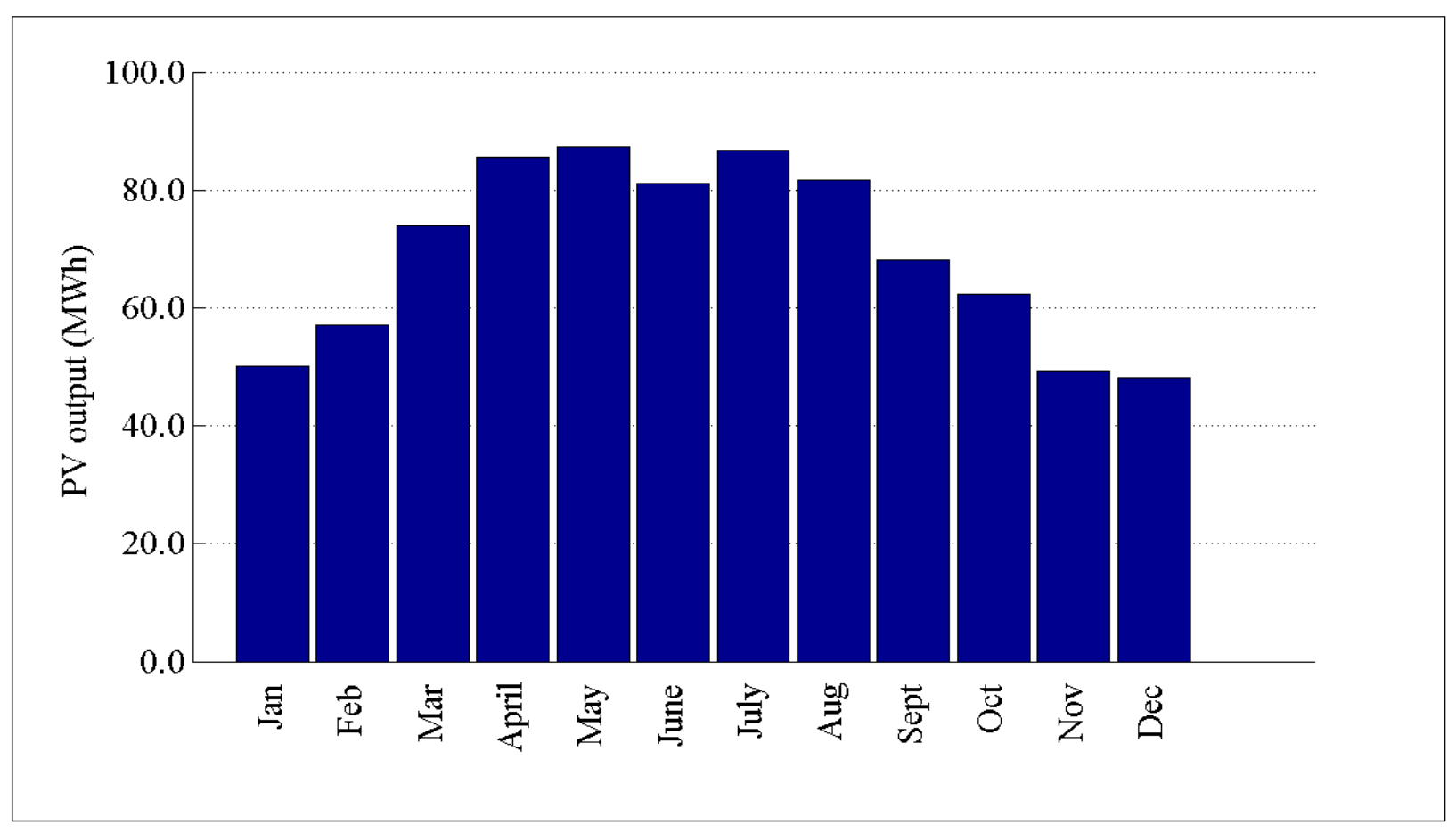

Figure D.84: PV output by month for R5-12.47-3

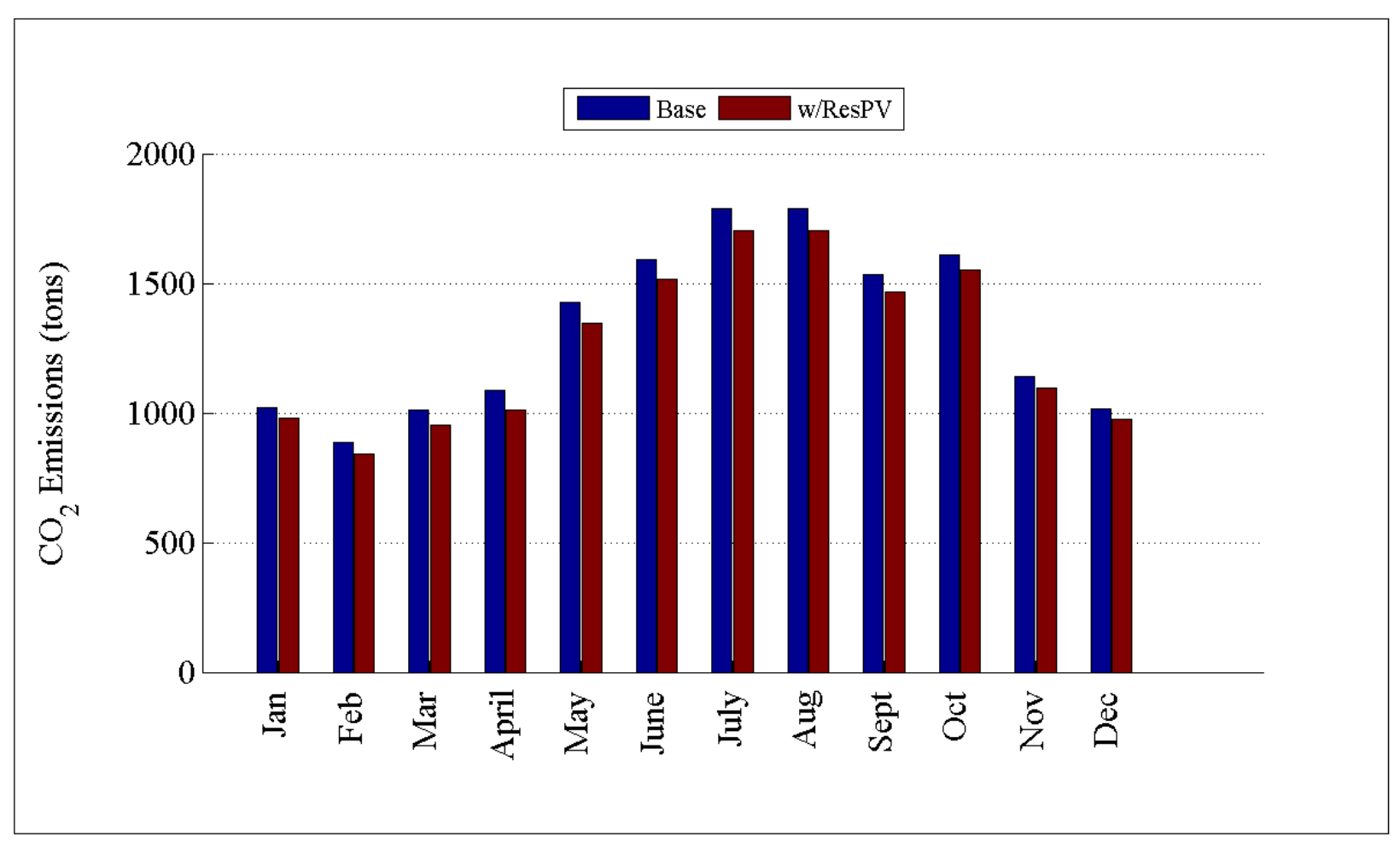

Figure D.85: Comparison of $\mathrm{CO}_{2}$ emissions by month for R5-12.47-3 
D.1.19 Detailed Residential PV Plots for R5-12.47-4

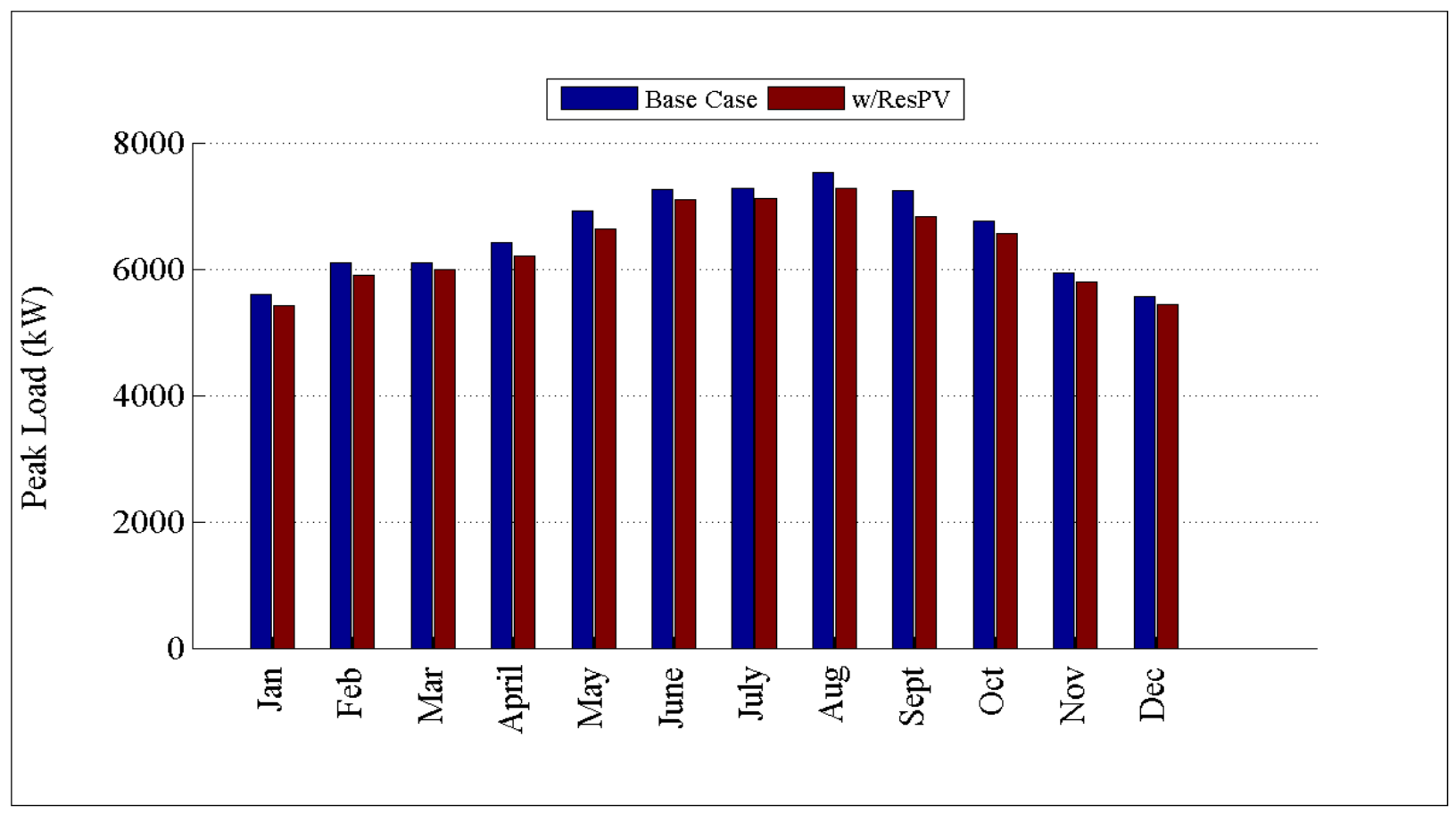

Figure D.86: Comparison of peak load by month for R5-12.47-4

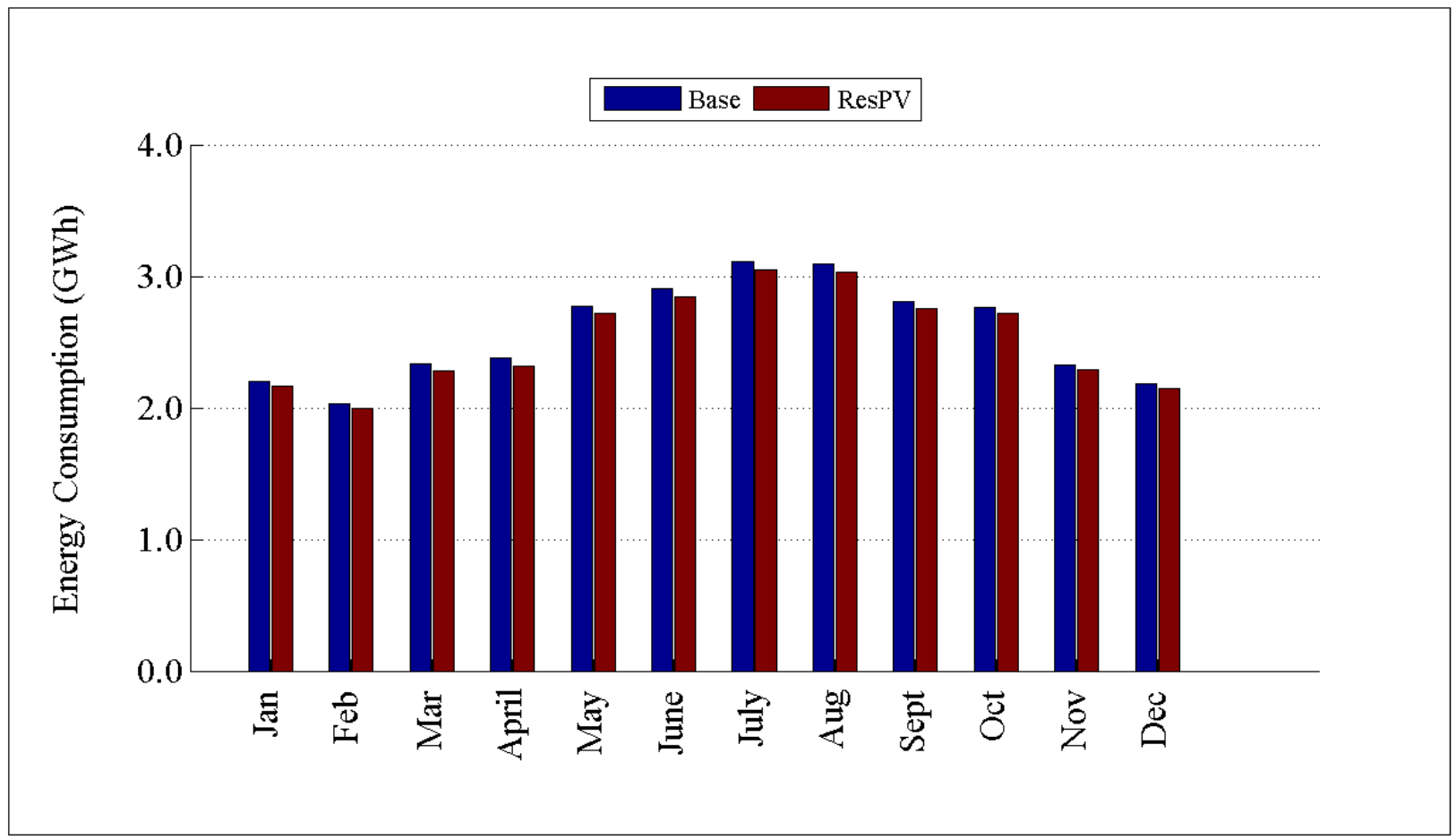

Figure D.87: Comparison of energy consumption by month for R5-12.47-4 


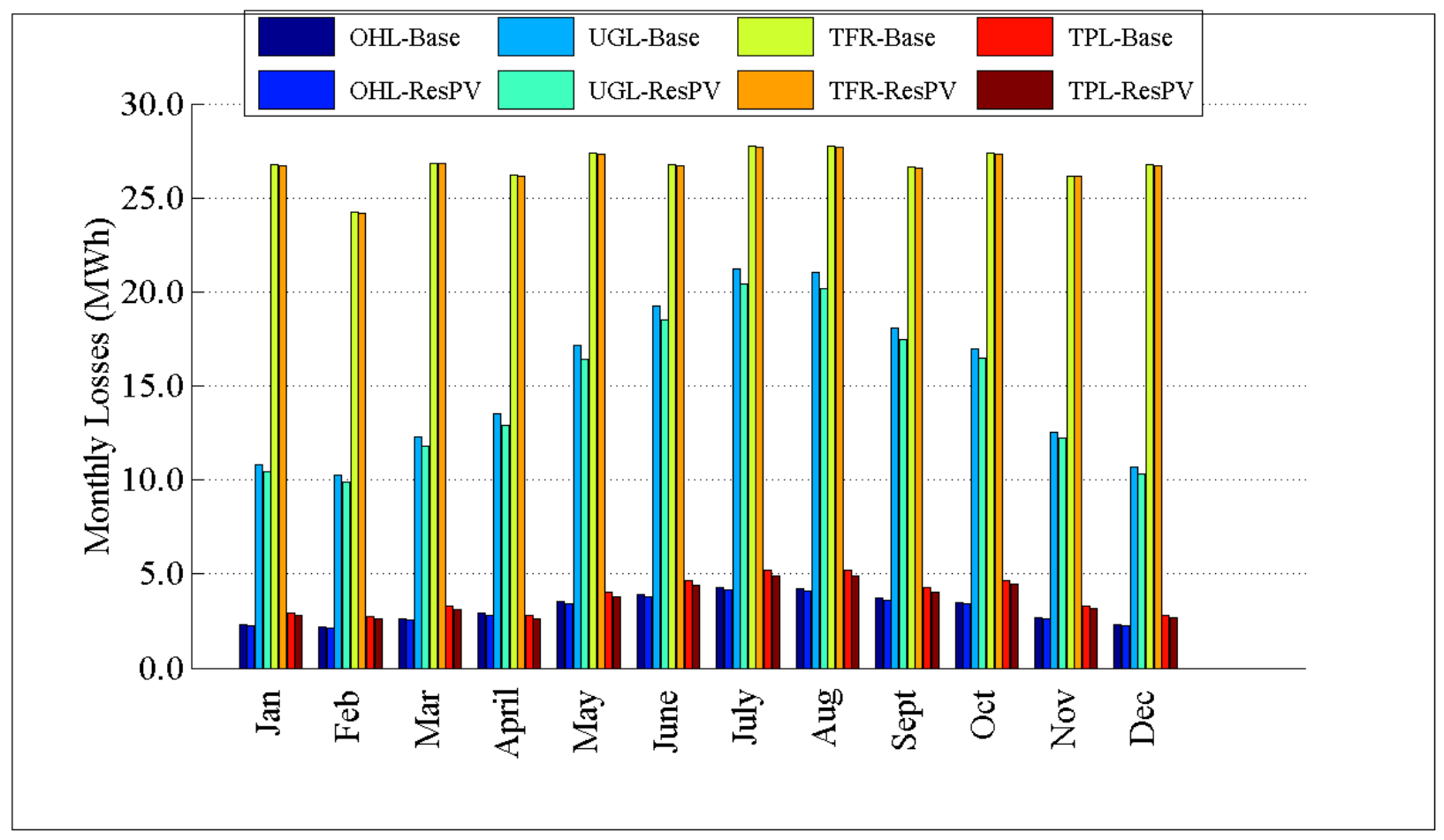

Figure D.88: Comparison of losses by month for R5-12.47-4

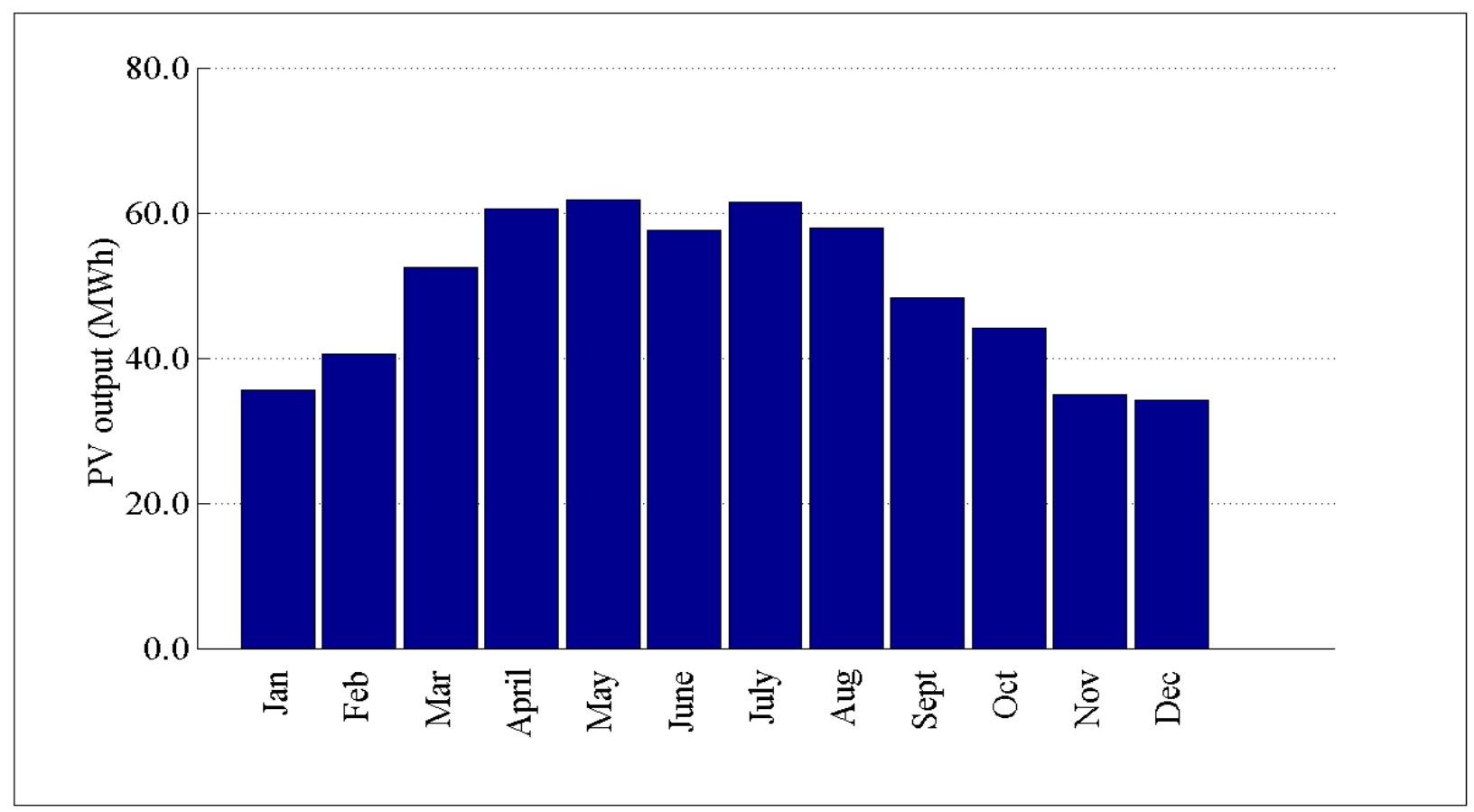

Figure D.89: PV output by month for R5-12.47-4 


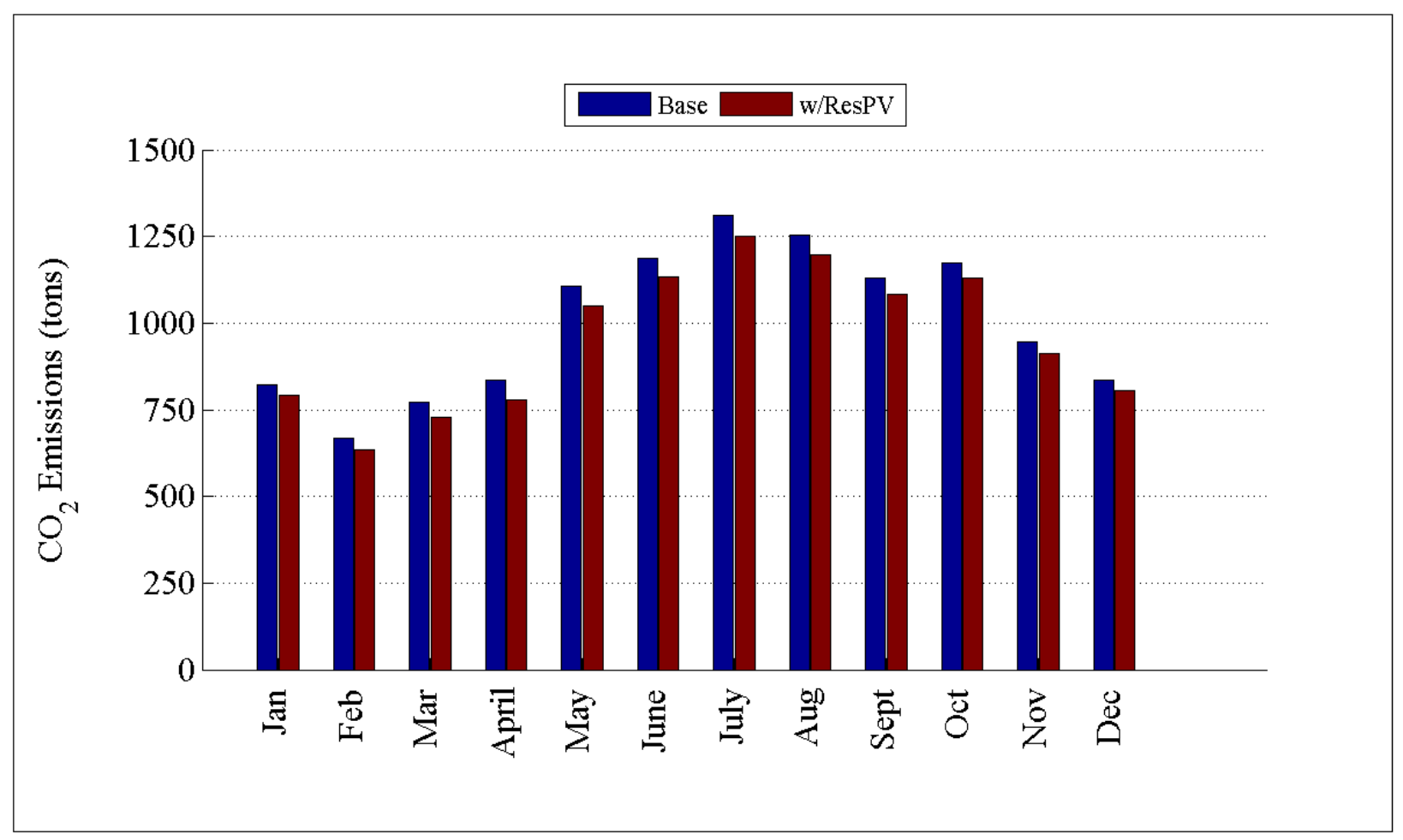

Figure D.90: Comparison of $\mathrm{CO}_{2}$ emissions by month for R5-12.47-4

D.1.20 Detailed Residential PV Plots for R5-12.47-5

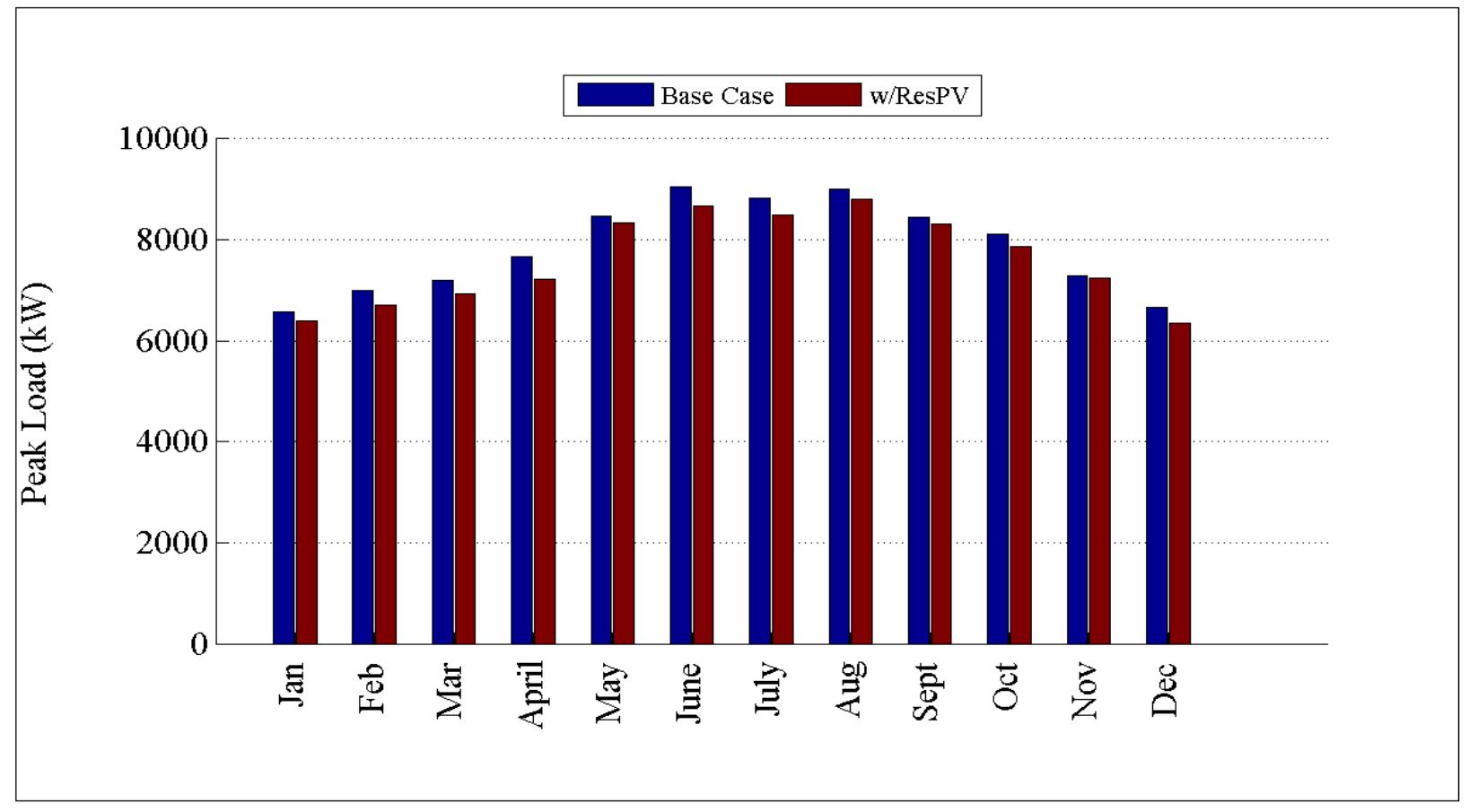

Figure D.91: Comparison of peak load by month for R5-12.47-5 


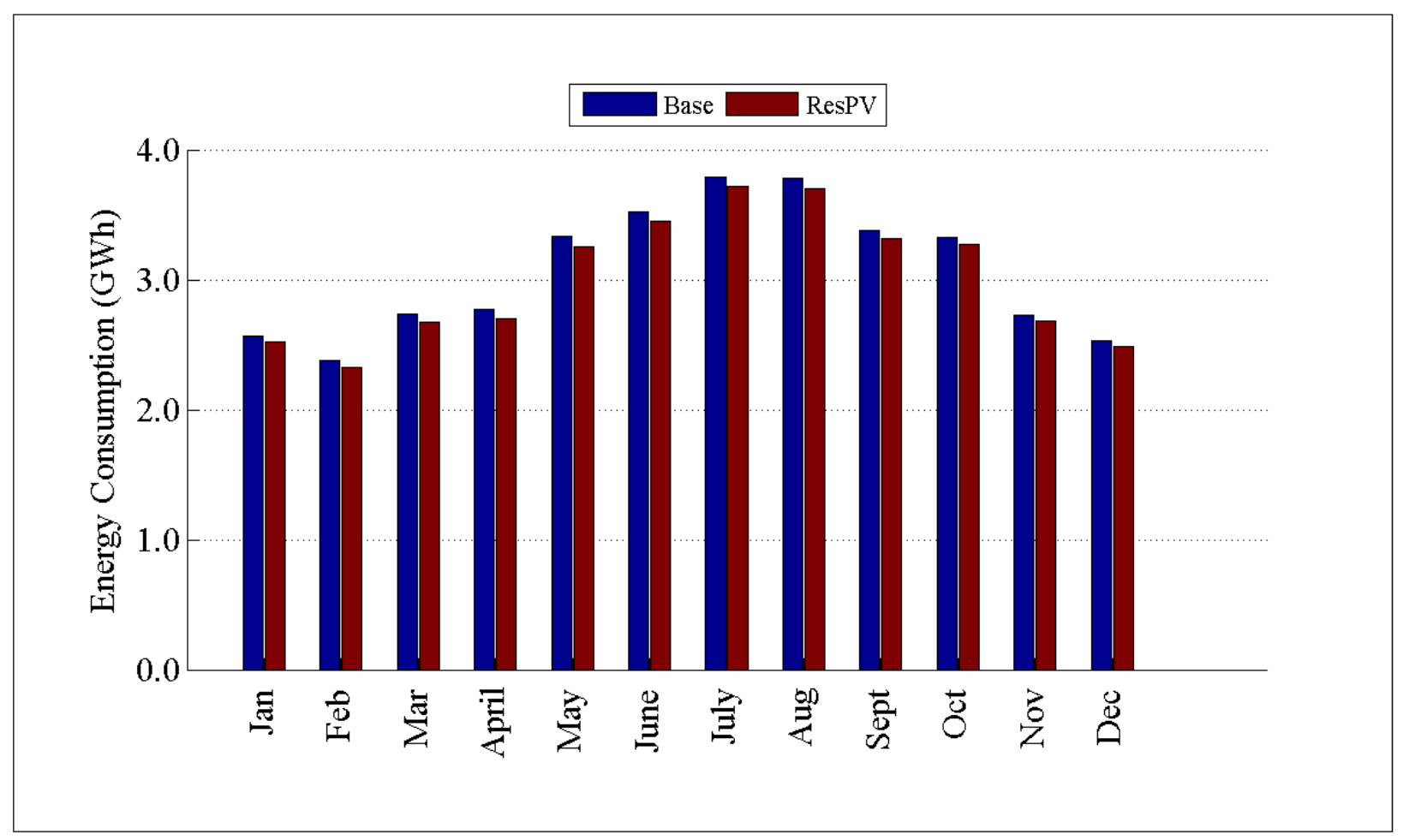

Figure D.92: Comparison of energy consumption by month for R5-12.47-5

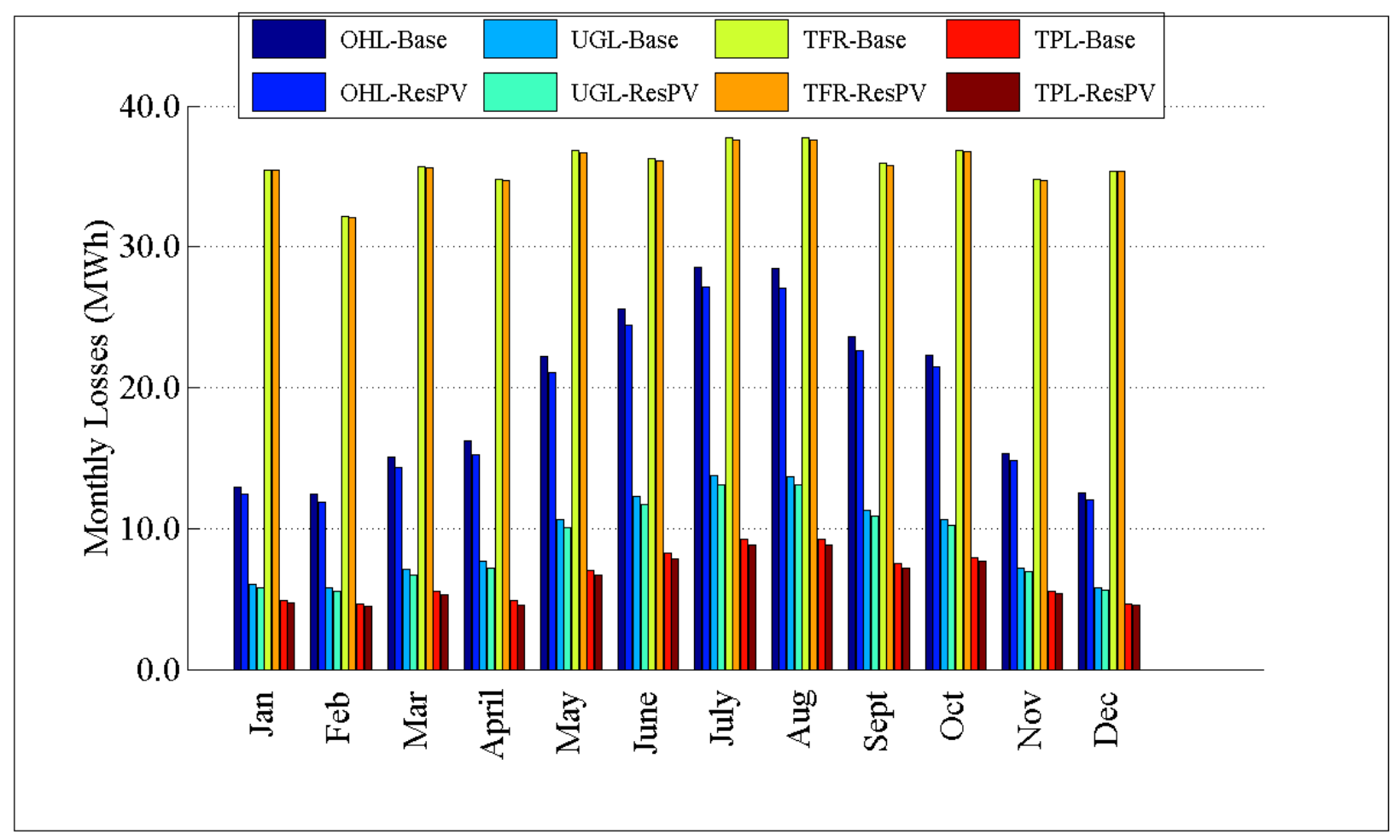

Figure D.93: Comparison of losses by month for R5-12.47-5 


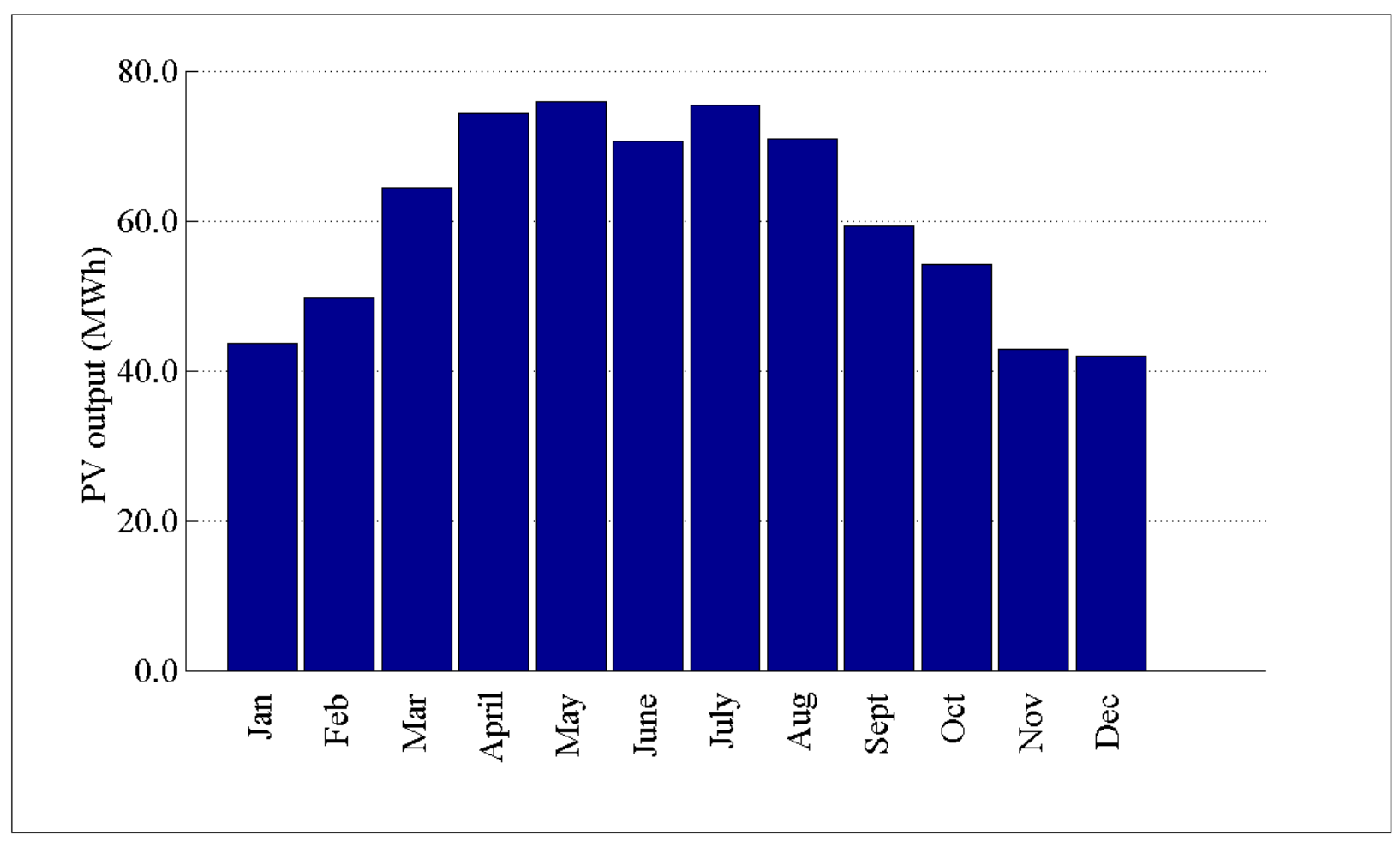

Figure D.94: PV output by month for R5-12.47-5

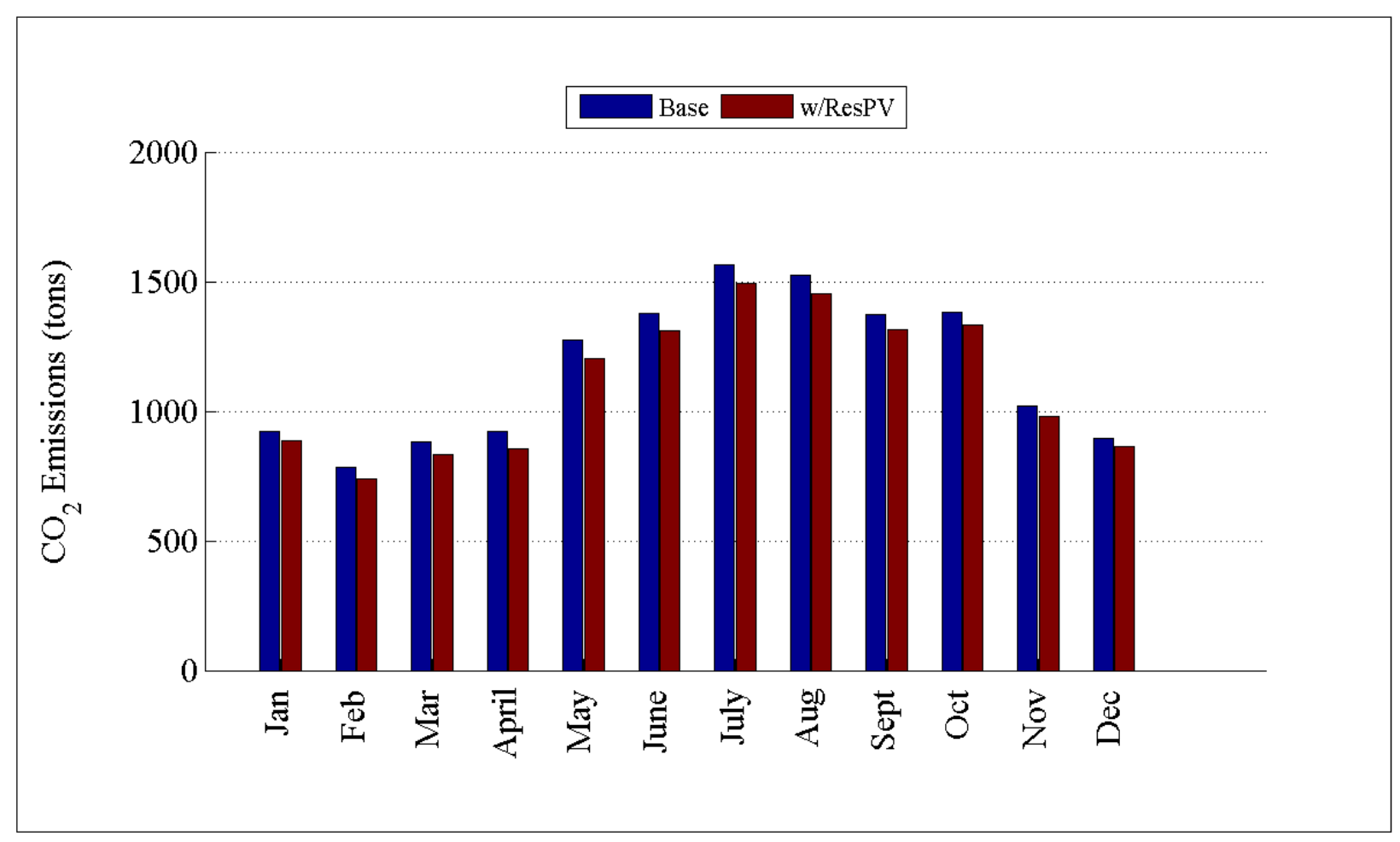

Figure D.95: Comparison of $\mathrm{CO}_{2}$ emissions by month for R5-12.47-5 
D.1.21 Detailed Residential PV Plots for R5-25.00-1

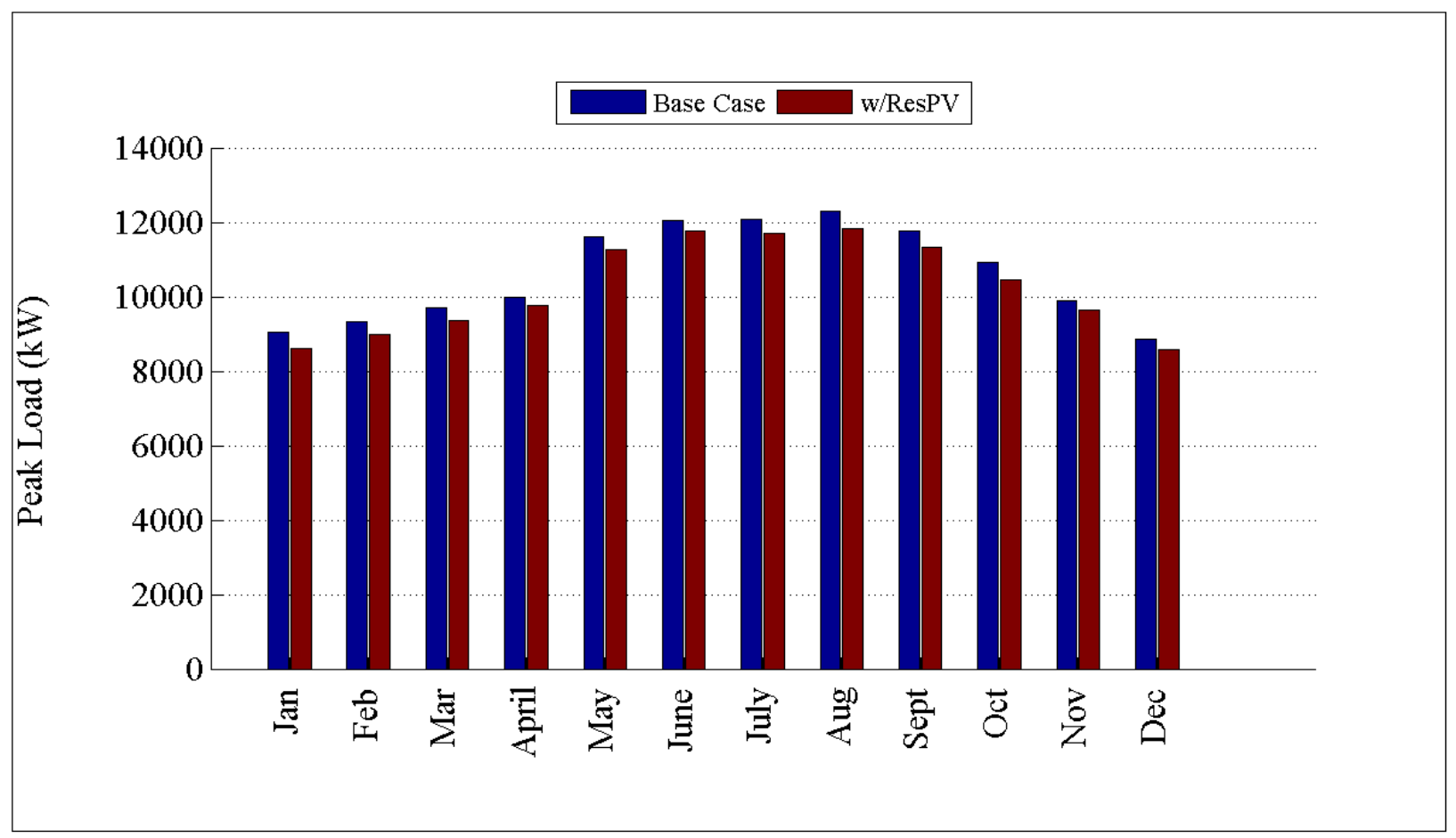

Figure D.96: Comparison of peak load by month for R5-25.00-1

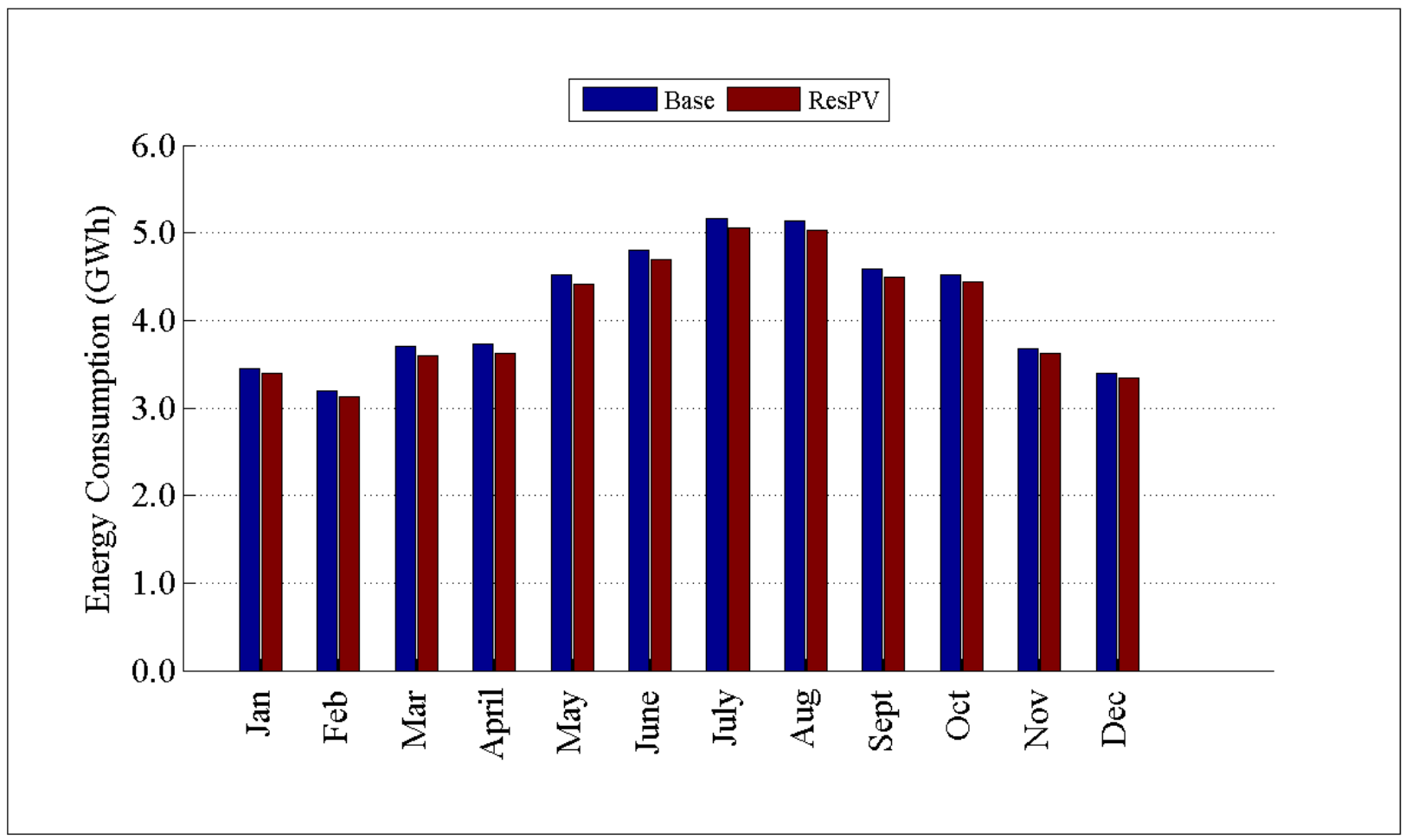

Figure D.97: Comparison of energy consumption by month for R5-25.00-1 


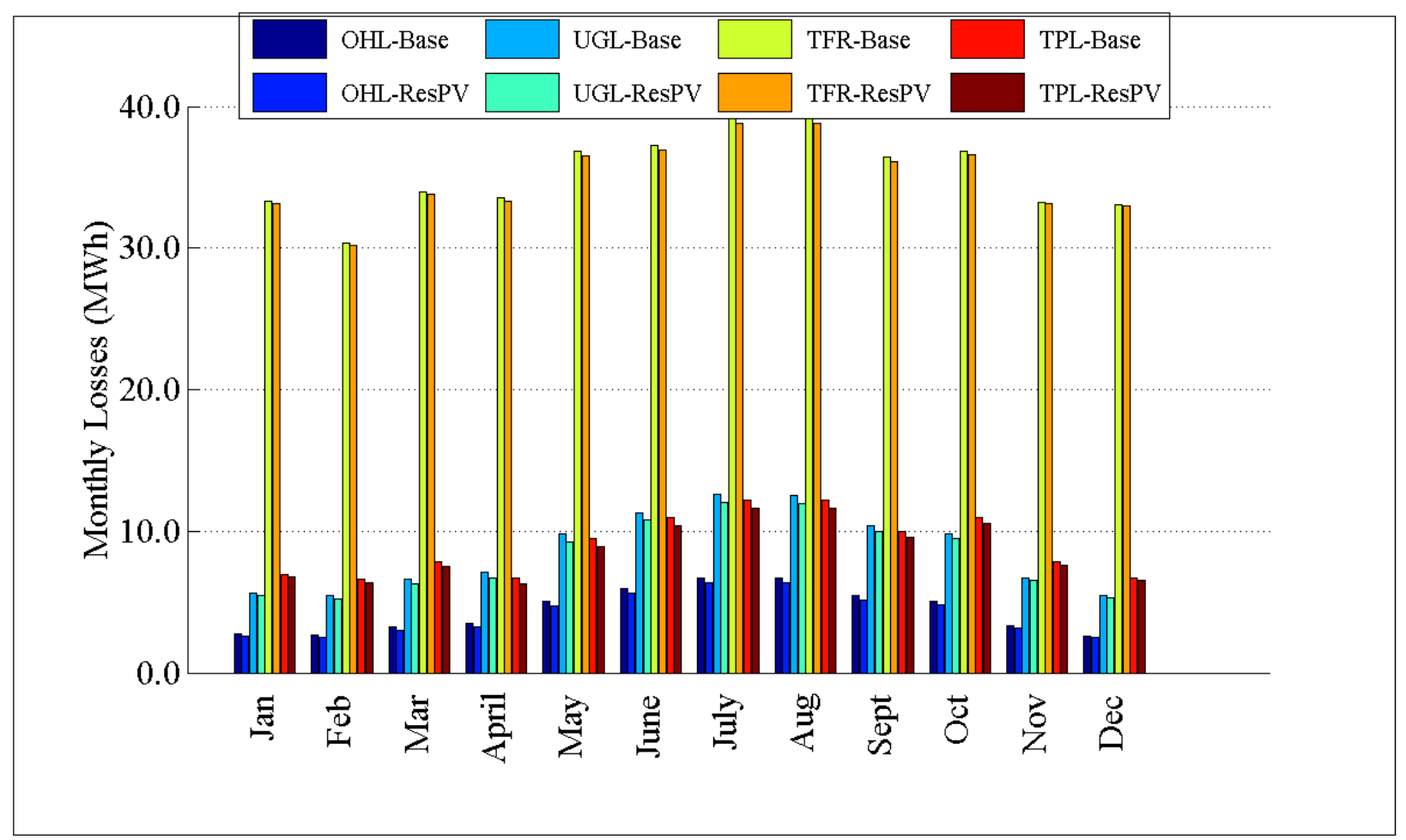

Figure D.98: Comparison of losses by month for R5-25.00-1

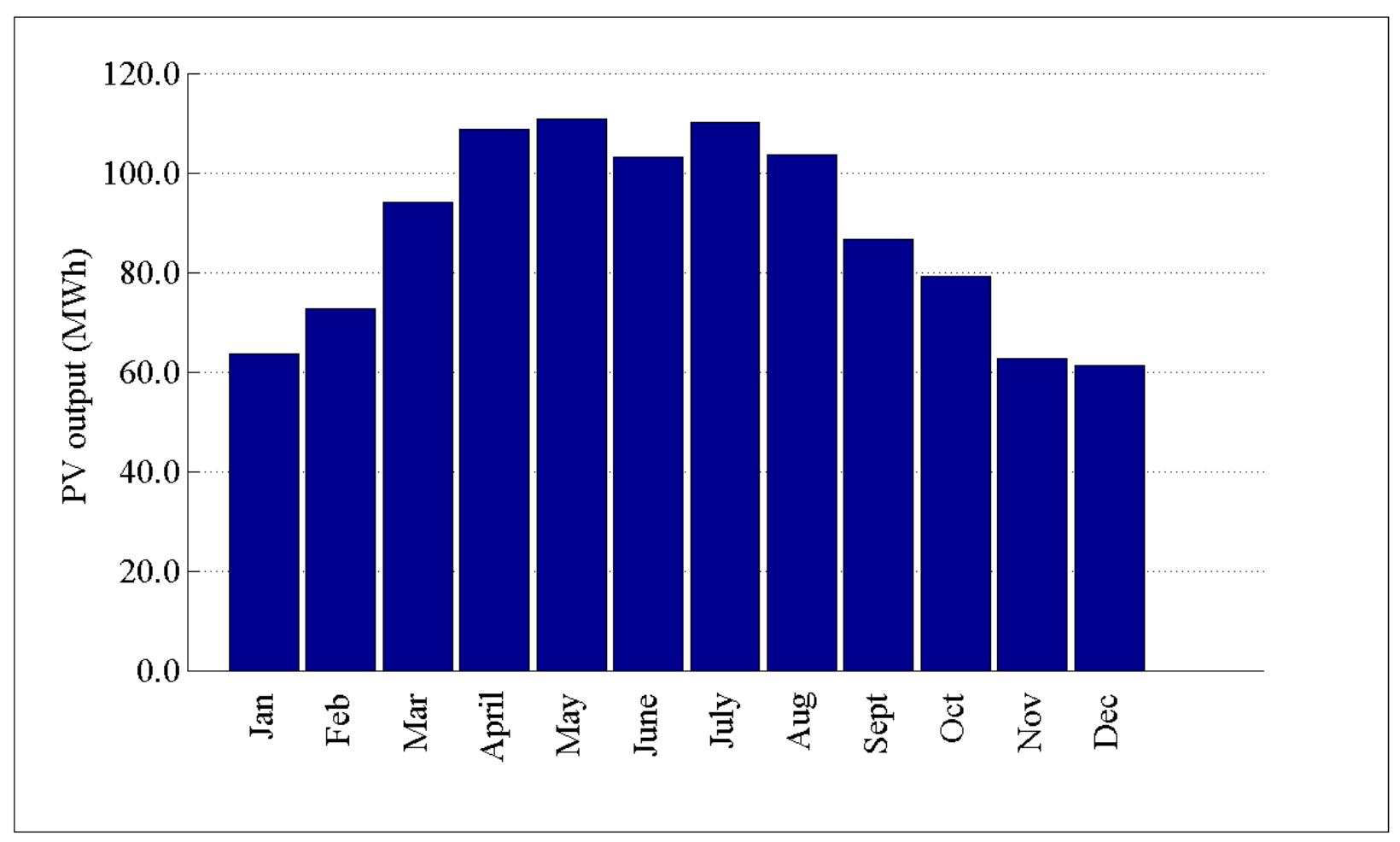

Figure D.99: PV output by month for R5-25.00-1 


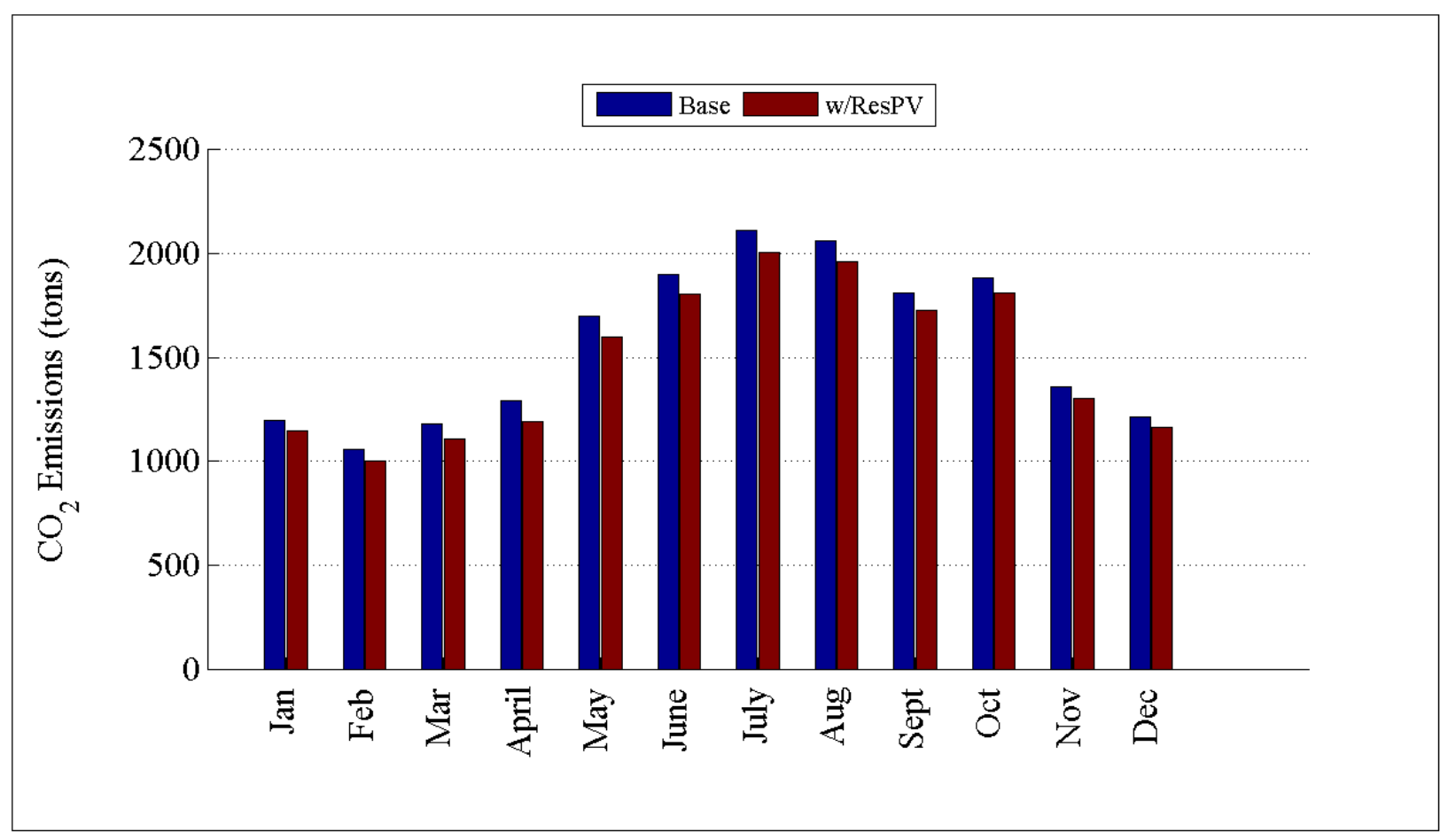

Figure D.100: Comparison of $\mathrm{CO}_{2}$ emissions by month for R5-25.00-1

\section{D.1.22 Detailed Residential PV Plots for R5-35.00-1}

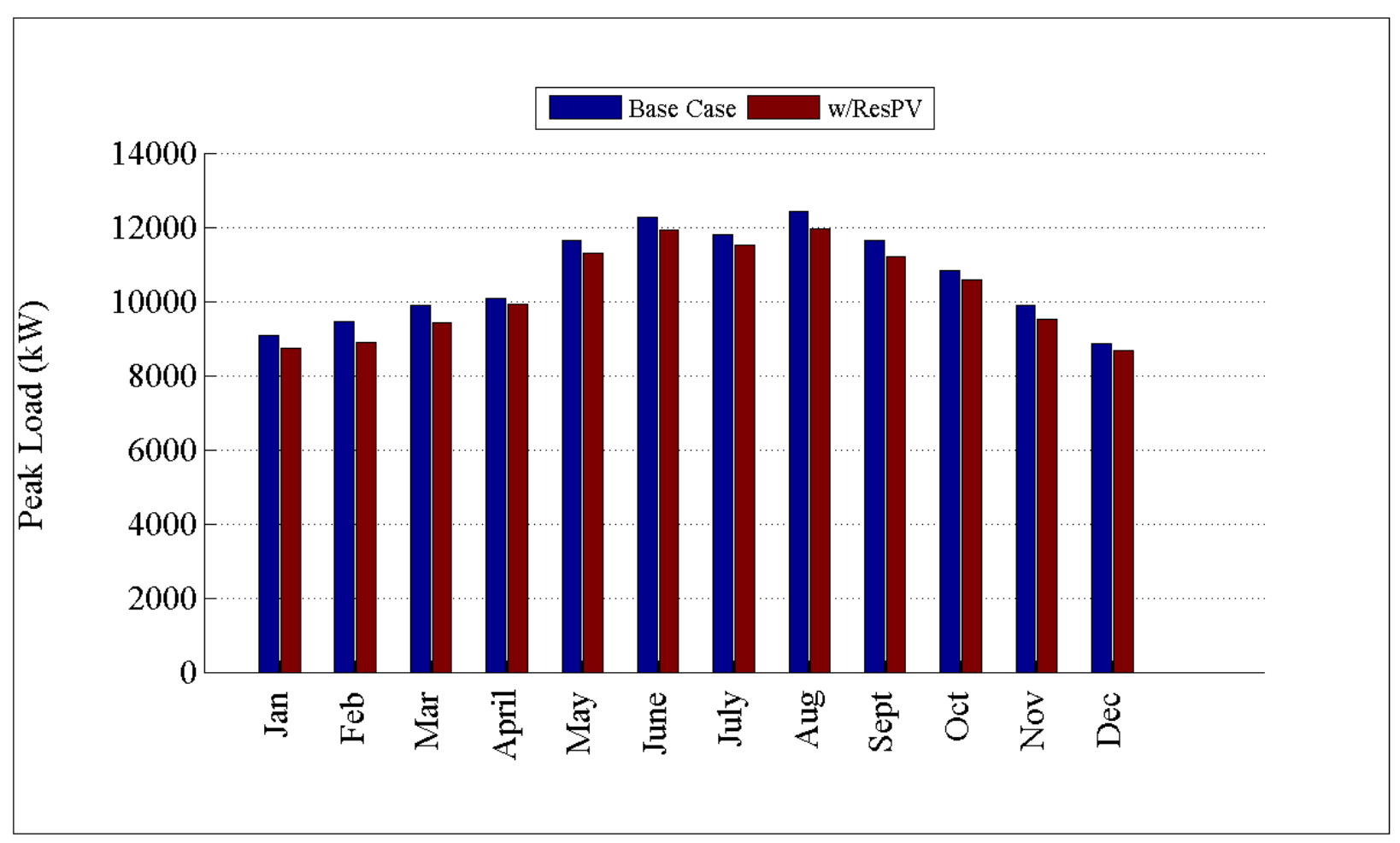

Figure D.101: Comparison of peak load by month for R5-35.00-1 


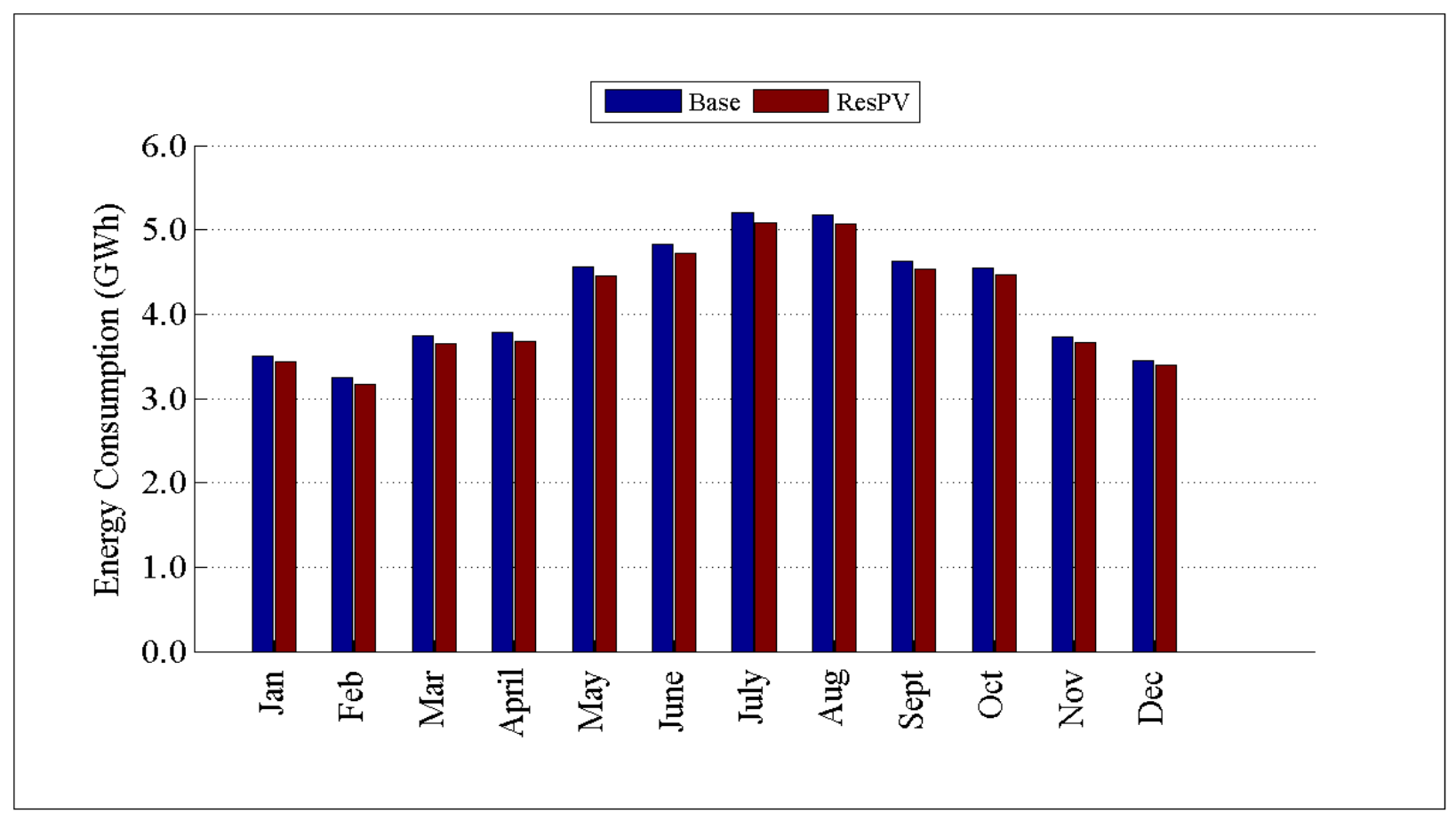

Figure D.102: Comparison of energy consumption by month for R5-35.00-1

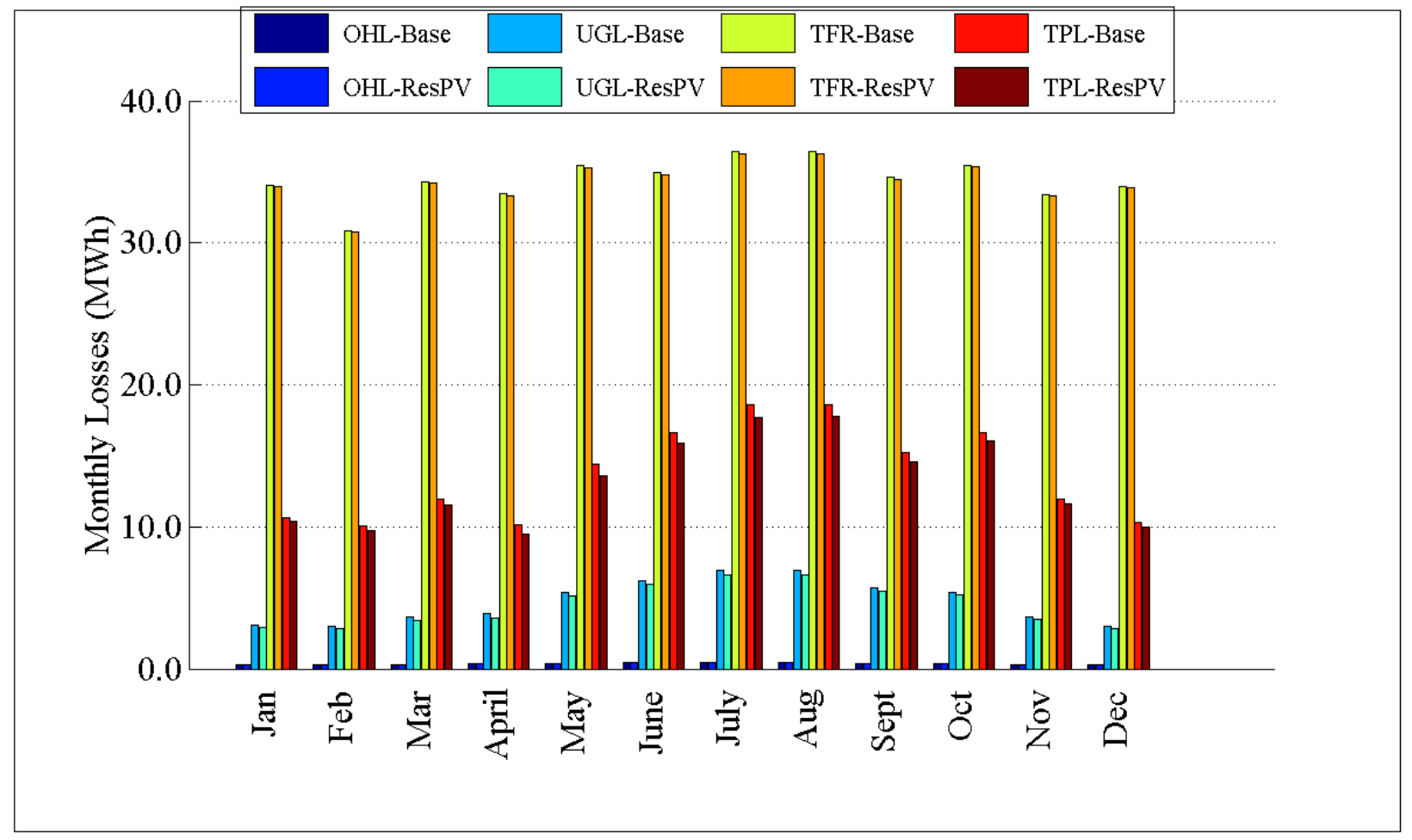

Figure D.103: Comparison of losses by month for R5-35.00-1 


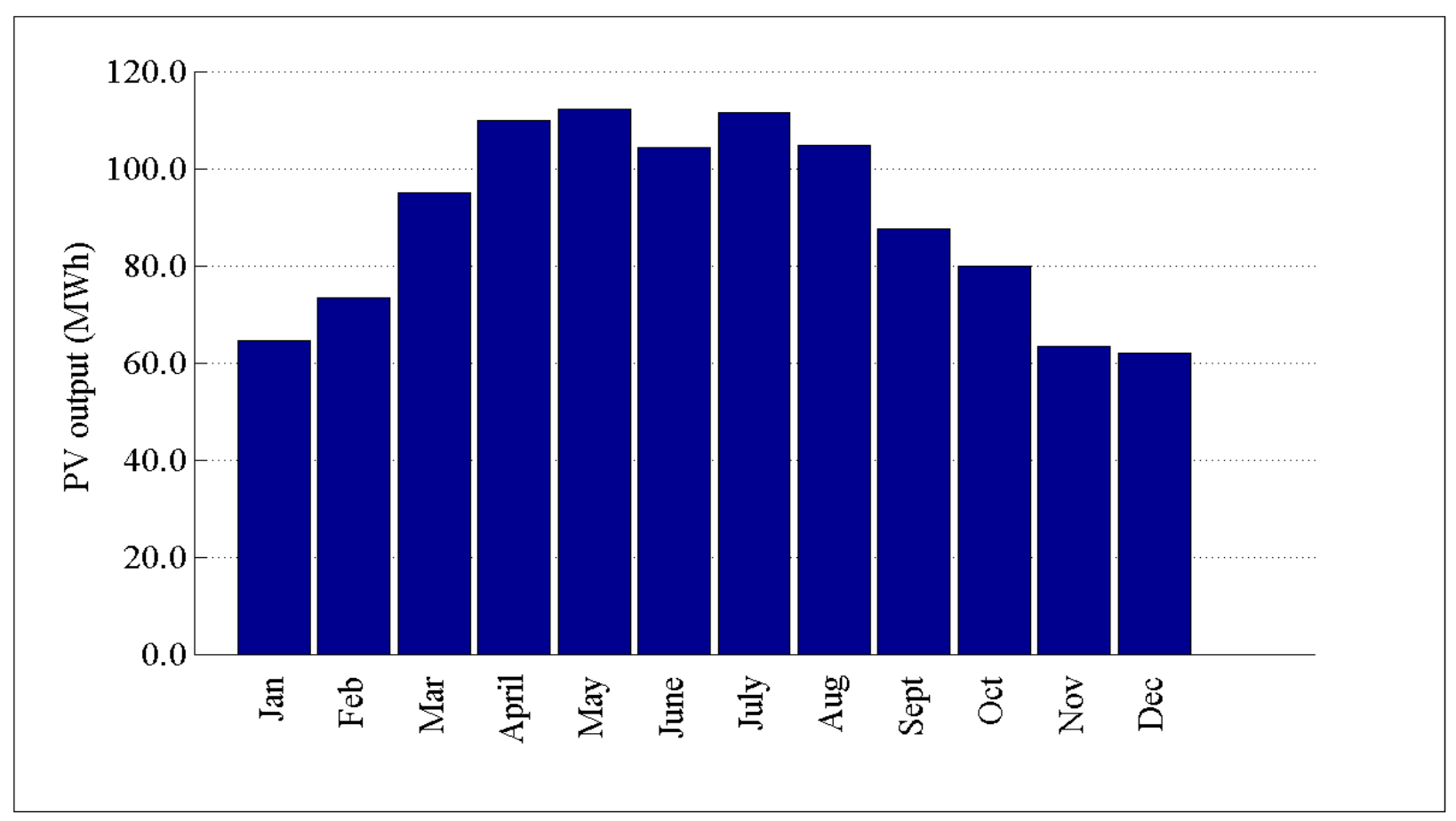

Figure D.104: PV output by month for R5-35.00-1

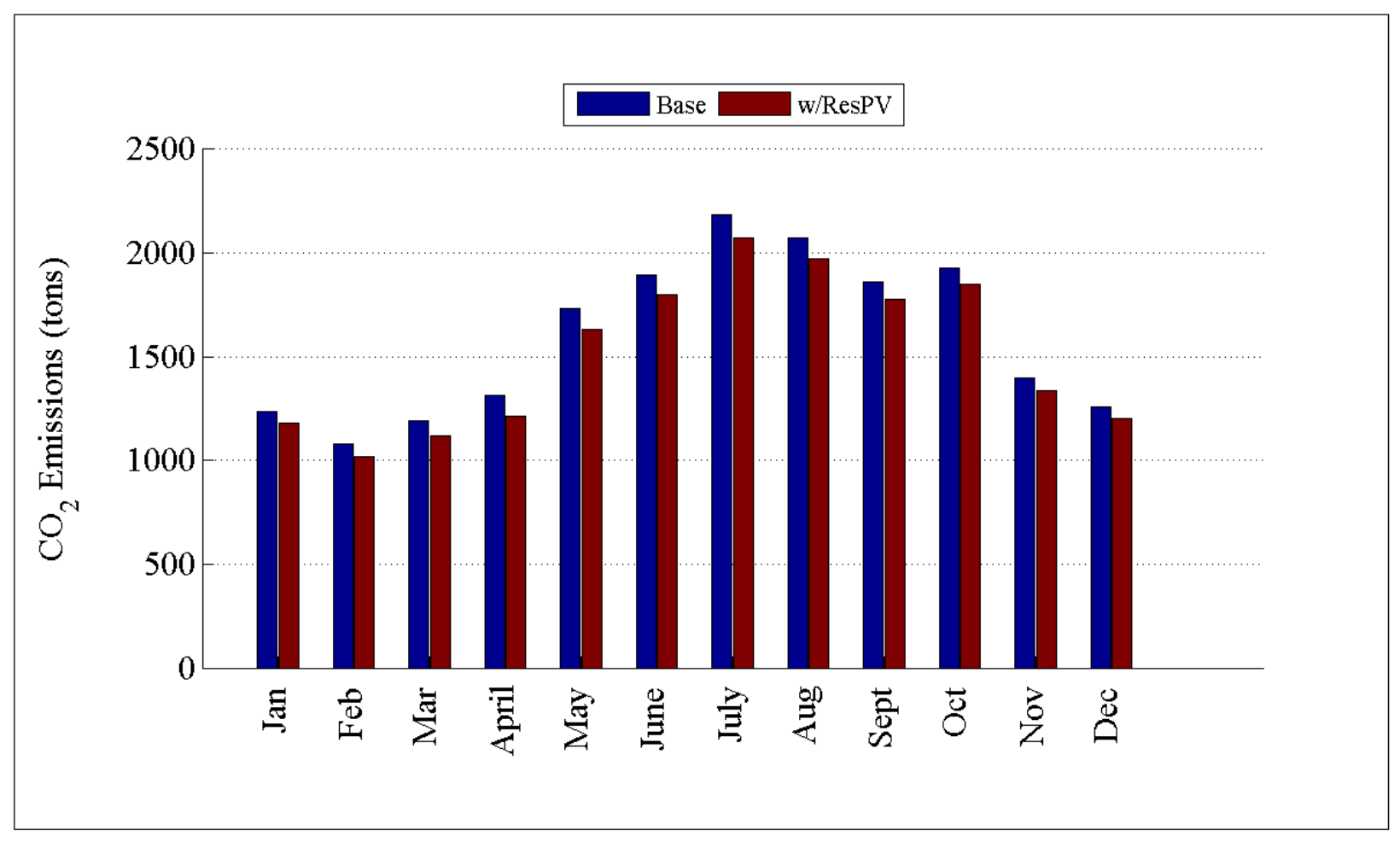

Figure D.105: Comparison of $\mathrm{CO}_{2}$ emissions by month for R5-35.00-1 


\section{D.2 Addition of Commercial PV Plots}

D.2.1 Detailed Commercial PV Plots for GC-12.47-1_R1

The plots for this feeder were already presented in Section 3.2.1.

D.2.2 Detailed Commercial PV Plots for R1-12.47-1

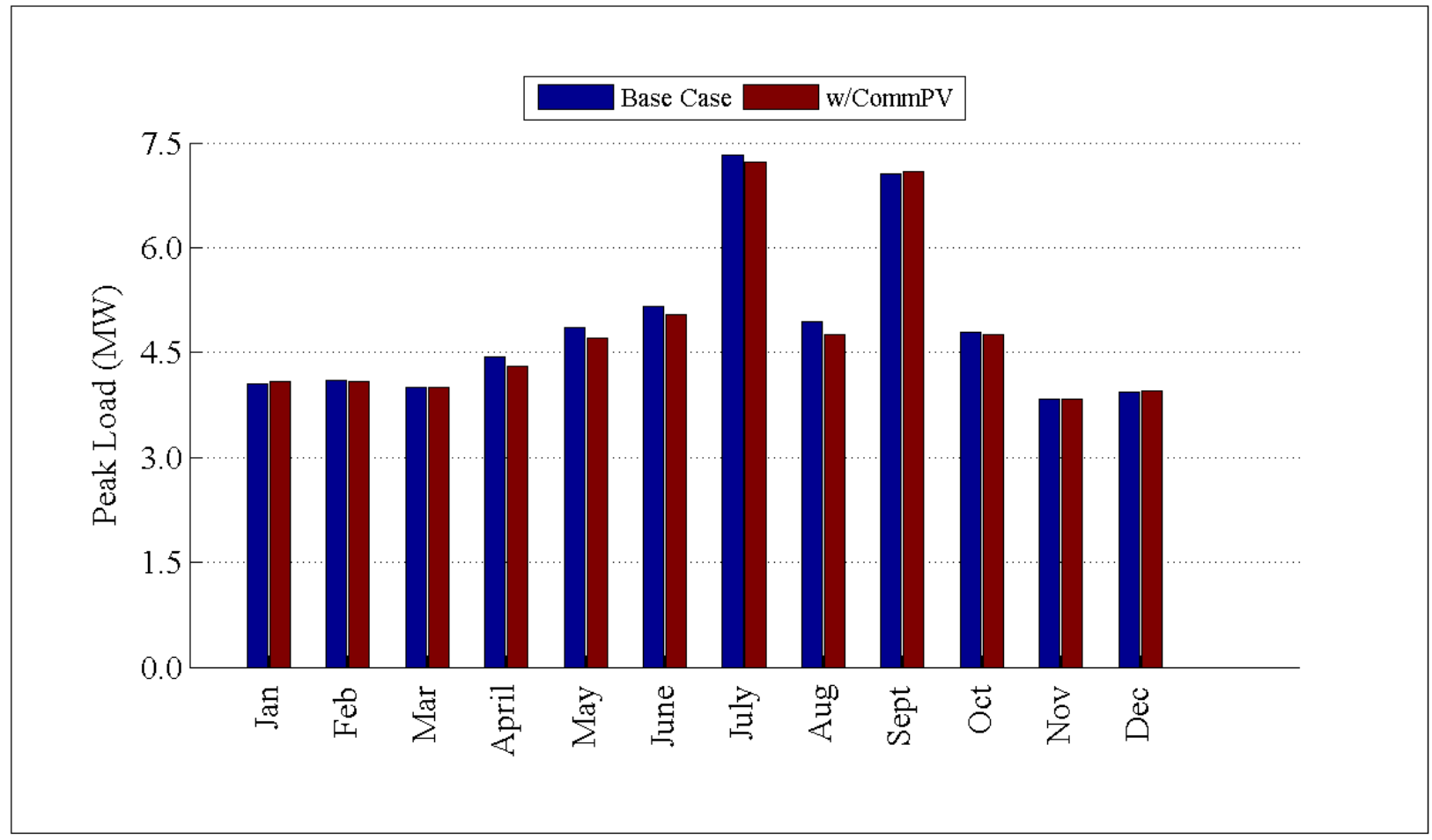

Figure D.106: Comparison of peak load by month for R1-12.47-1 


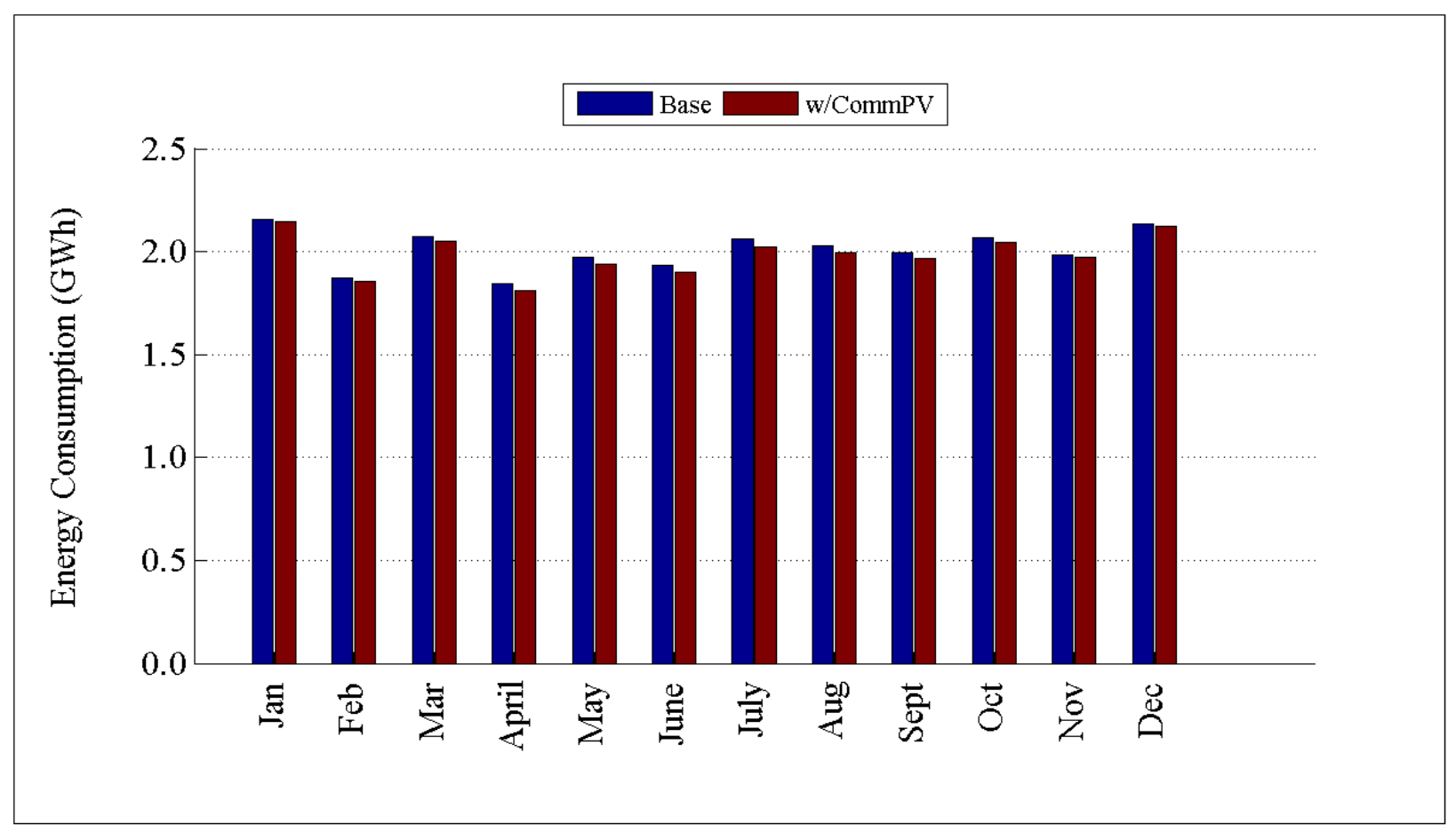

Figure D.107: Comparison of energy consumption by month for R1-12.47-1

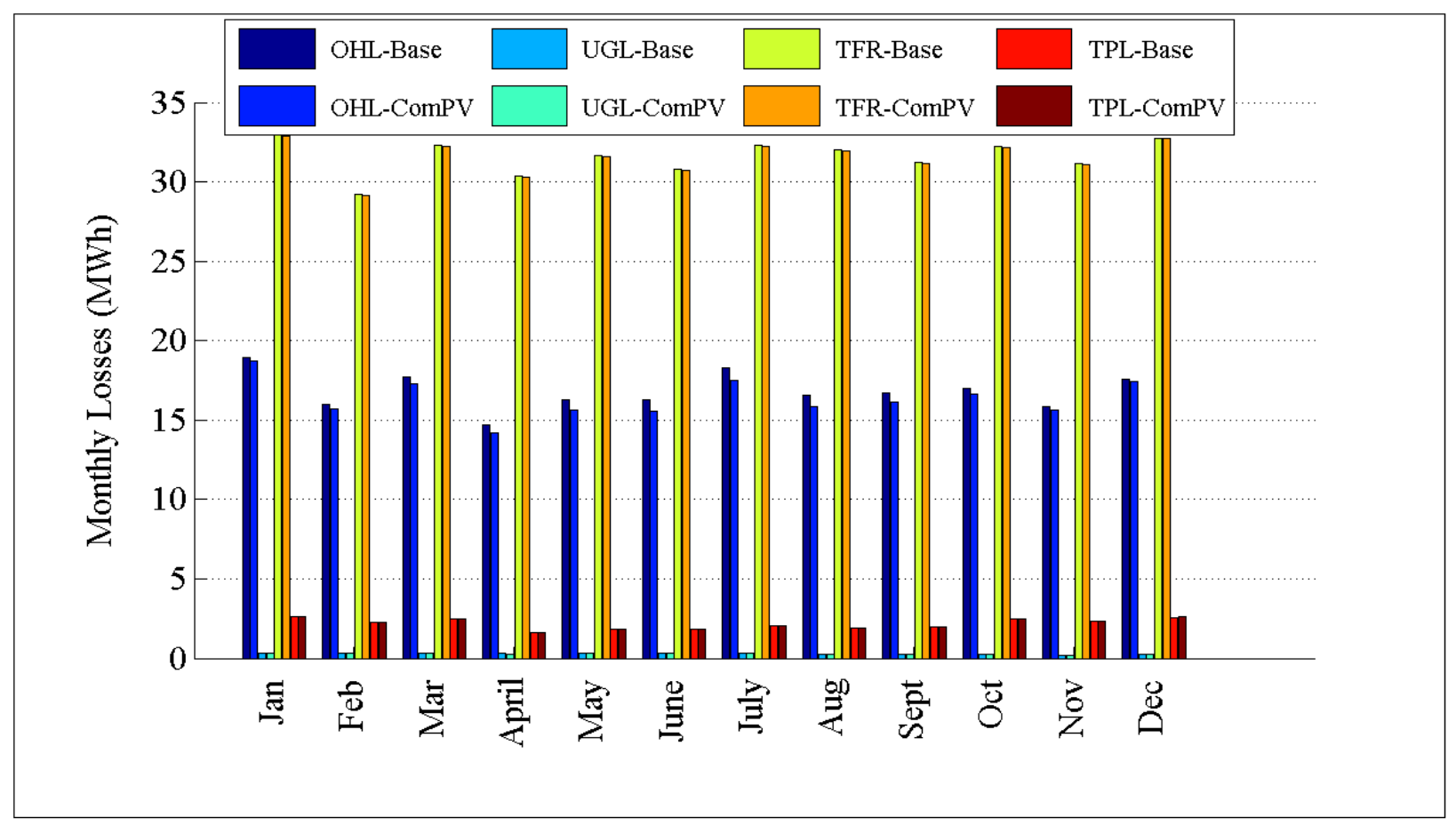

Figure D.108: Comparison of losses by month for R1-12.47-1 


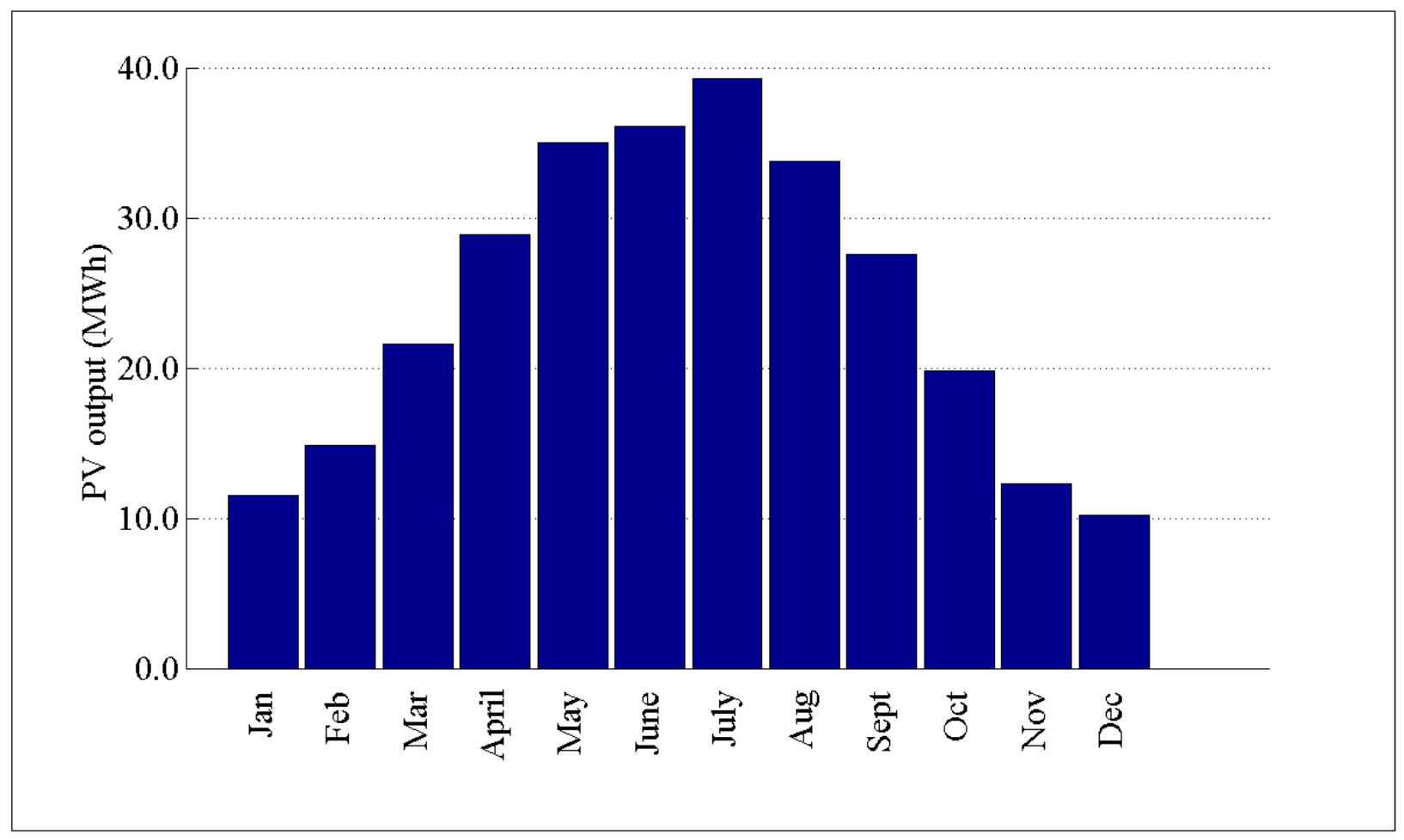

Figure D.109: PV output by month for R1-12.47-1

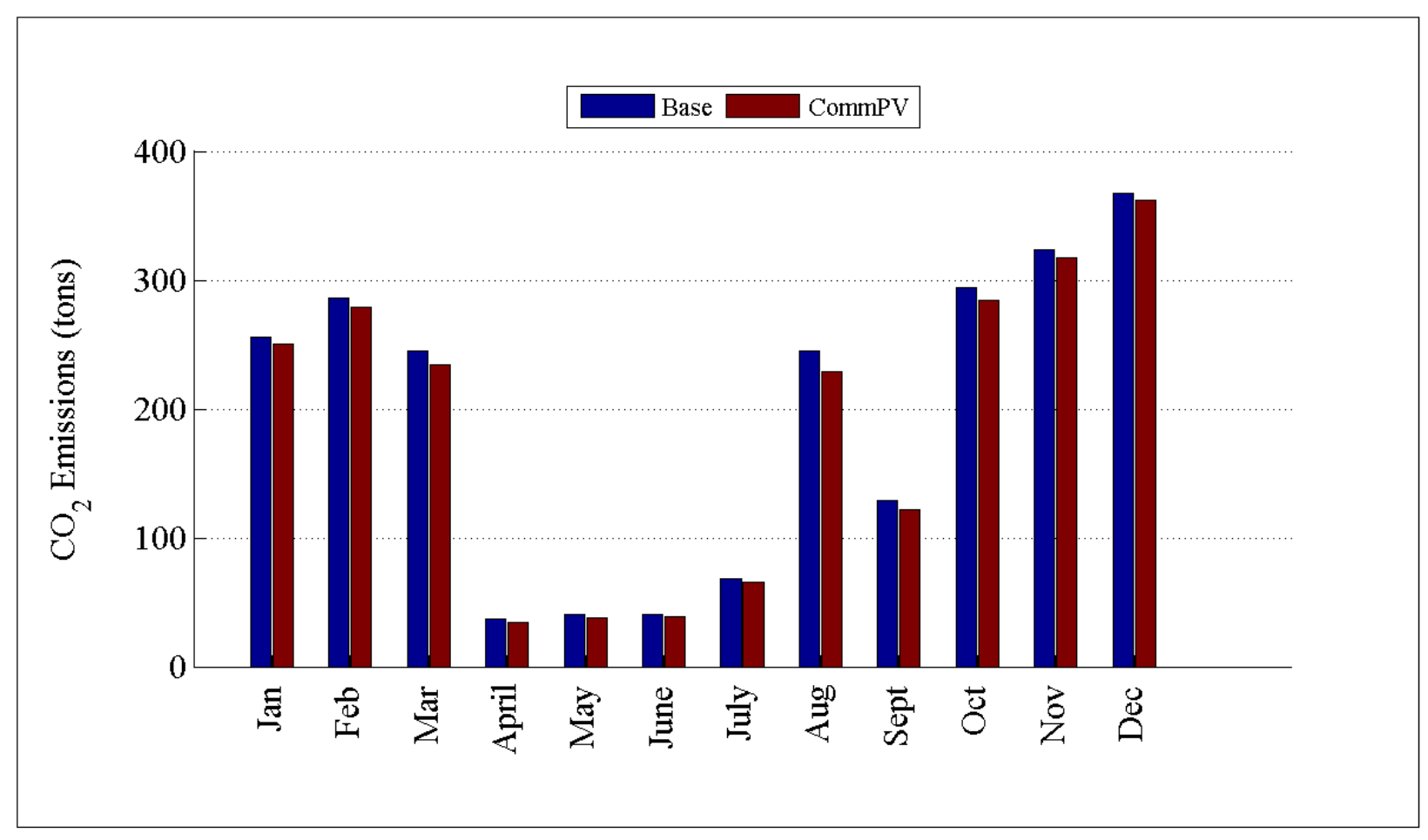

Figure D.110: Comparison of $\mathrm{CO}_{2}$ by month for R1-12.47-1 


\section{D.2.3 Detailed Commercial PV Plots for R1-12.47-2}

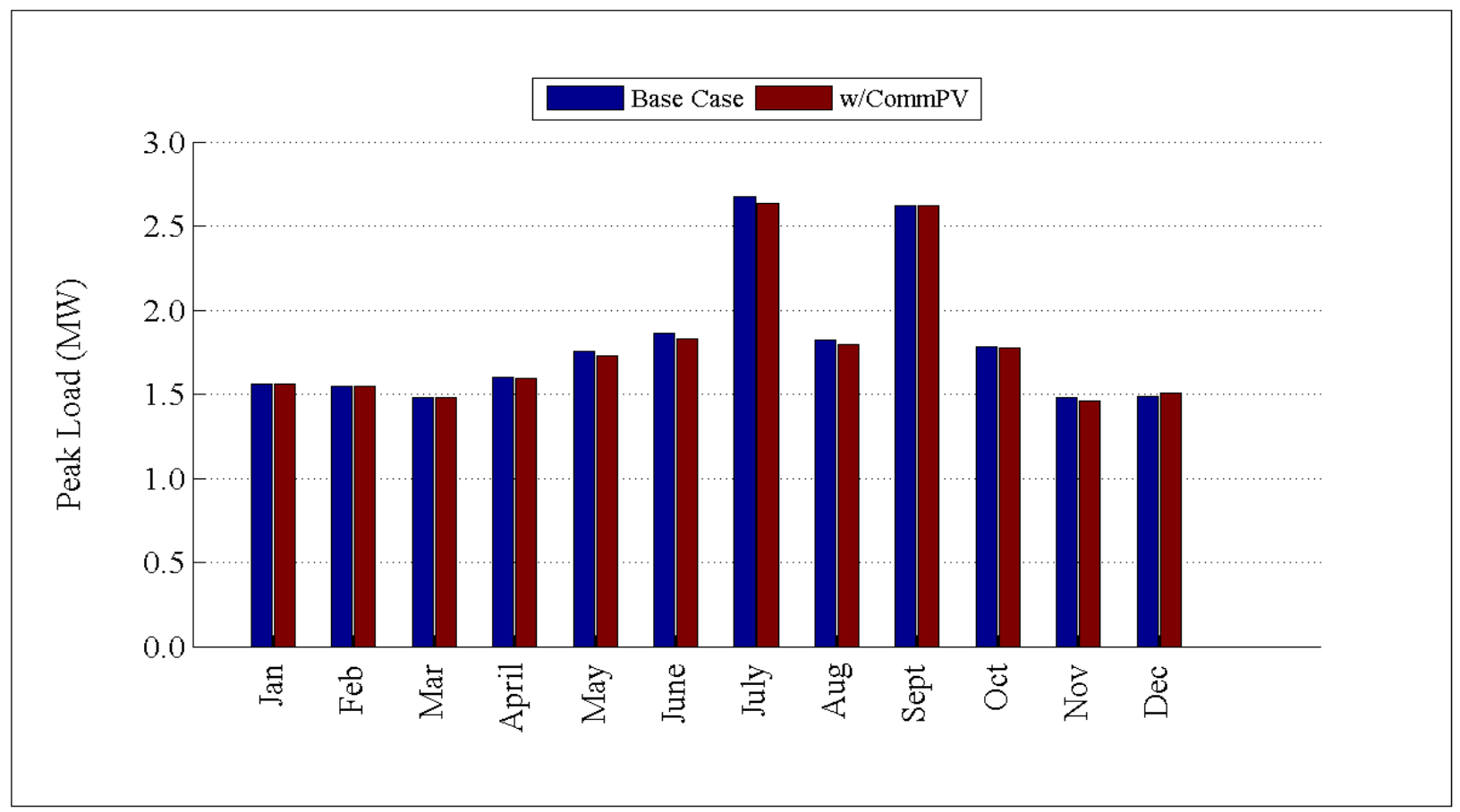

Figure D.111: Comparison of peak load by month for R1-12.47-2

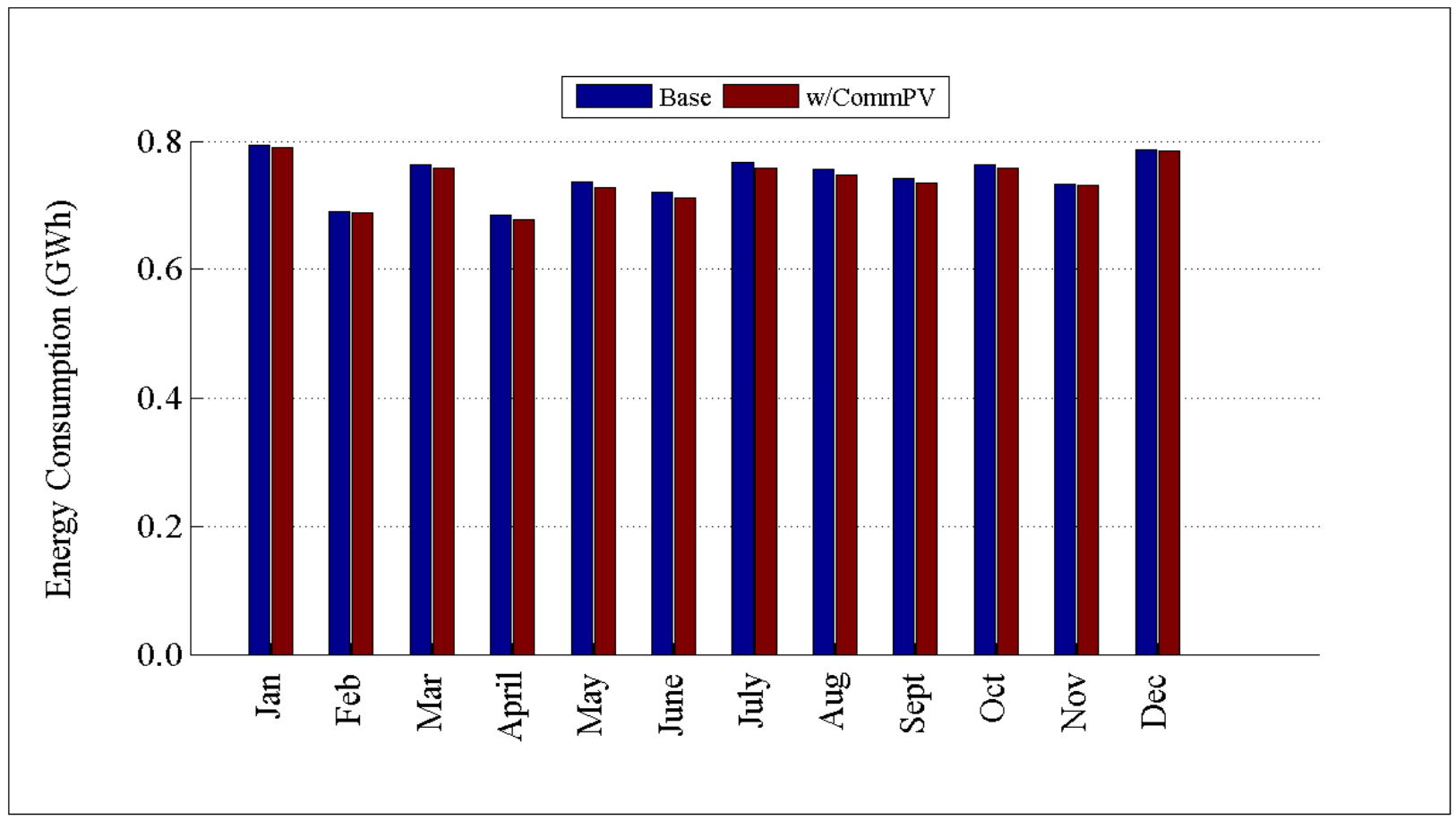

Figure D.112: Comparison of energy consumption by month for R1-12.47-2 


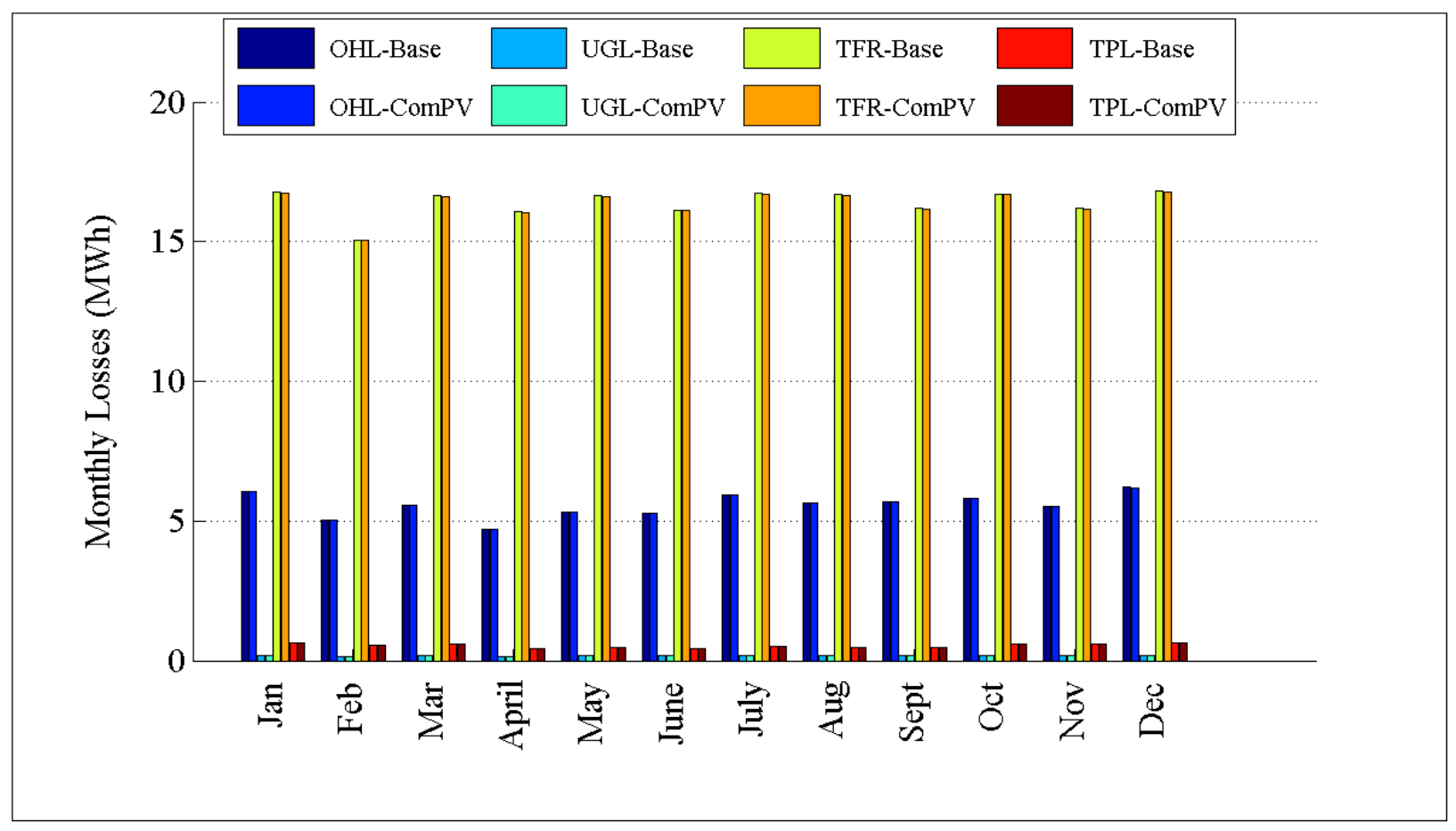

Figure D.113: Comparison of losses by month for R1-12.47-2

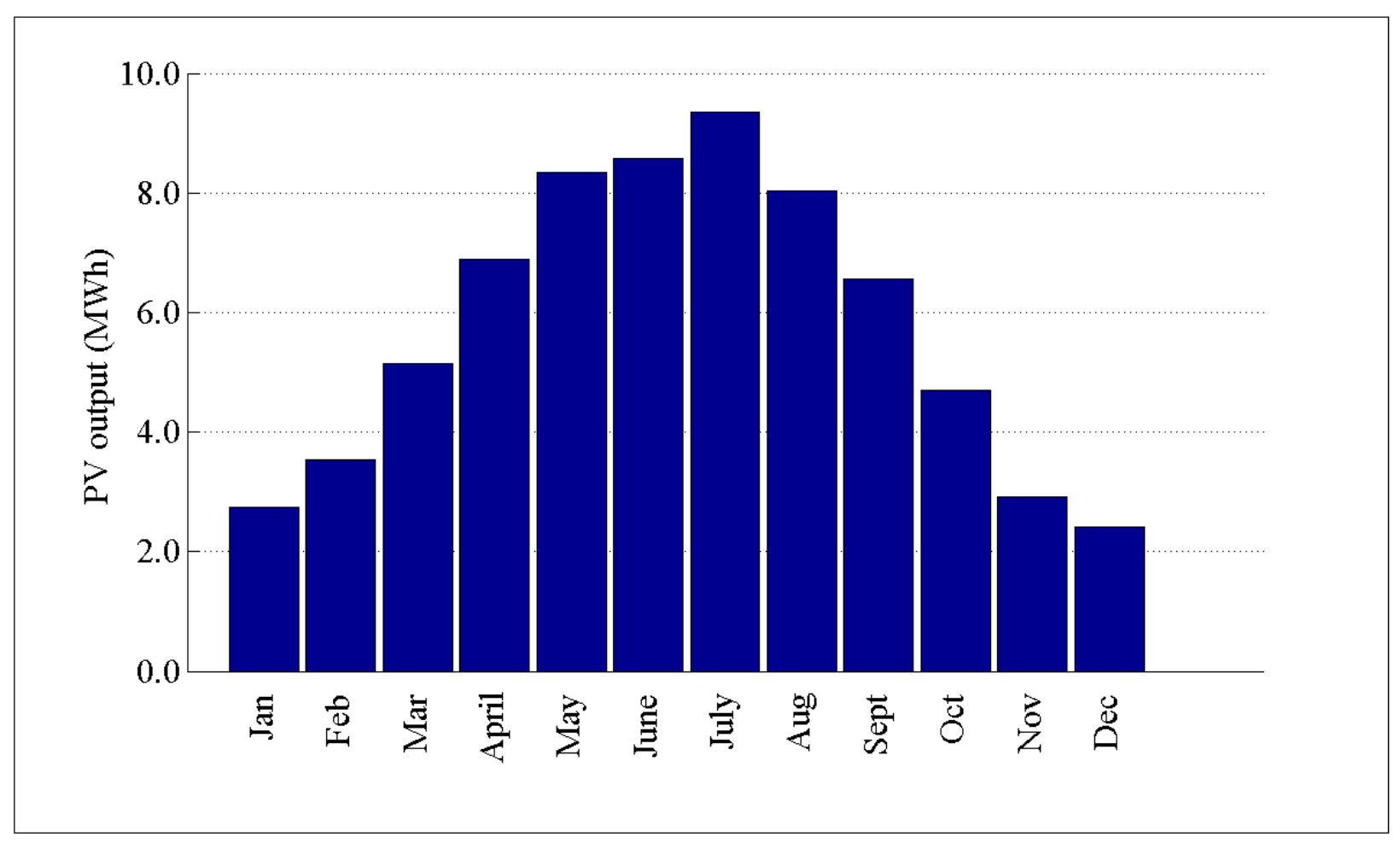

Figure D.114: PV output by month for R1-12.47-2 


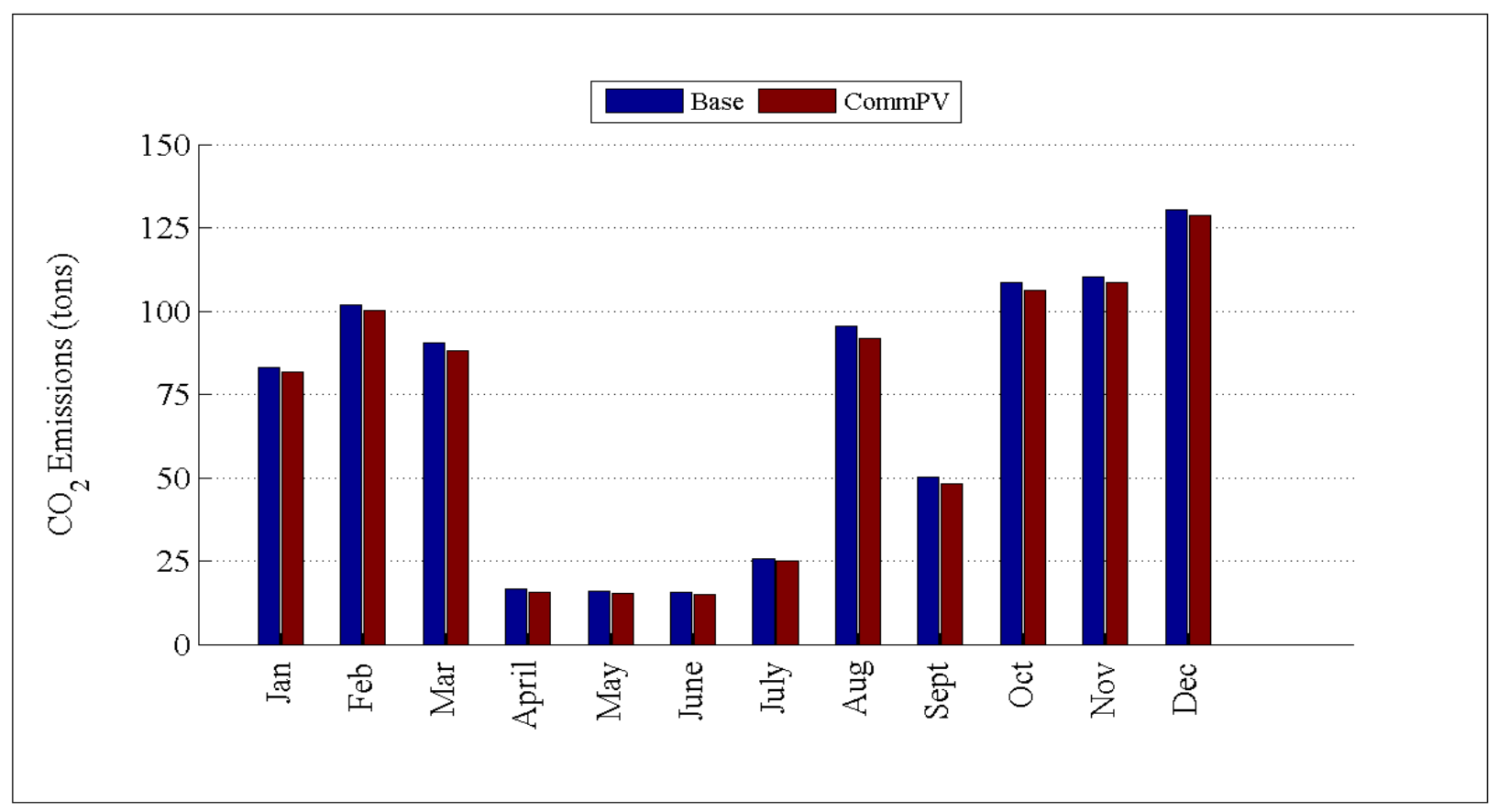

Figure D.115: Comparison of $\mathrm{CO}_{2}$ by month for R1-12.47-2

\section{D.2.4 Detailed Commercial PV Plots for R1-12.47-3}

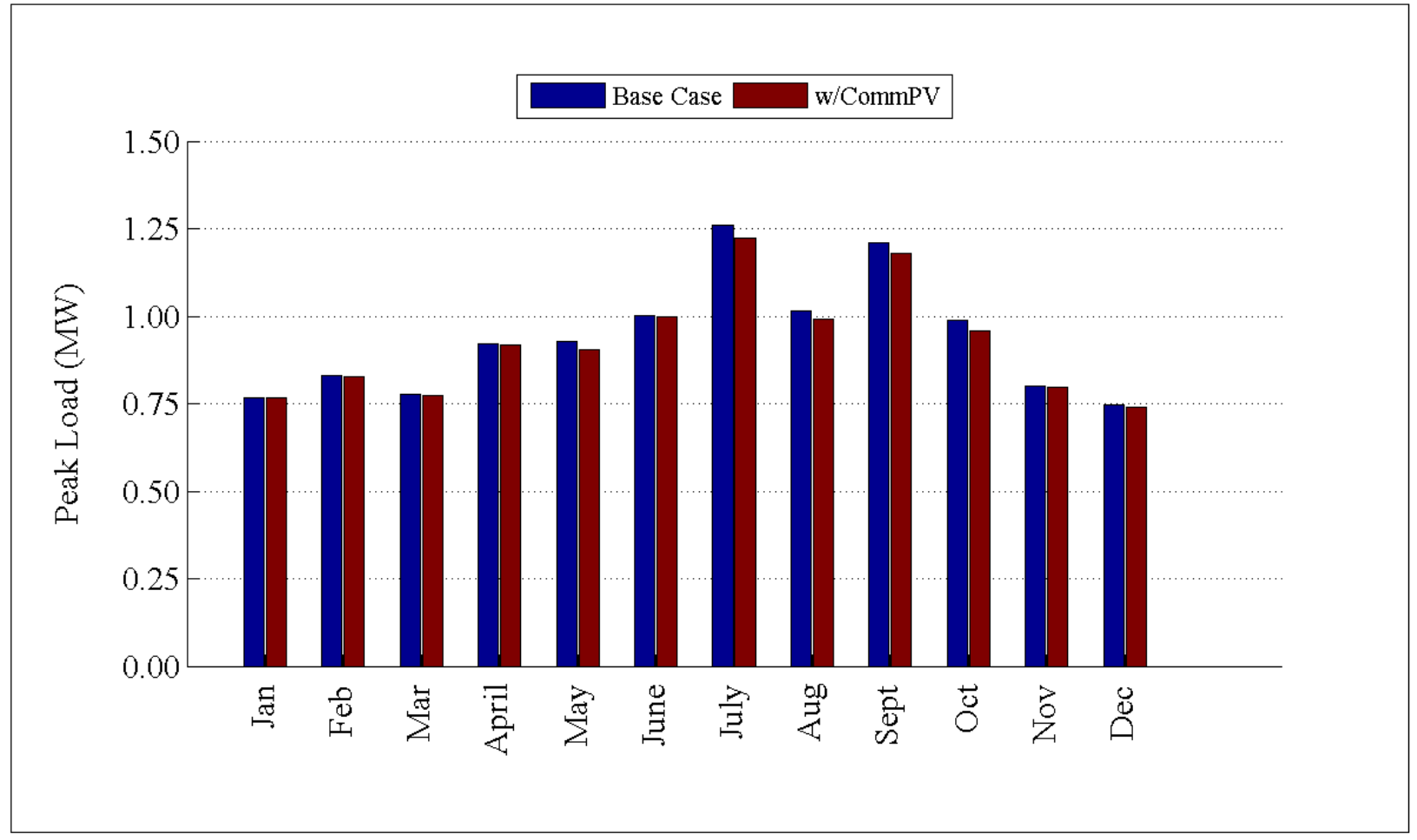

Figure D.116: Comparison of peak load by month for R1-12.47-3 


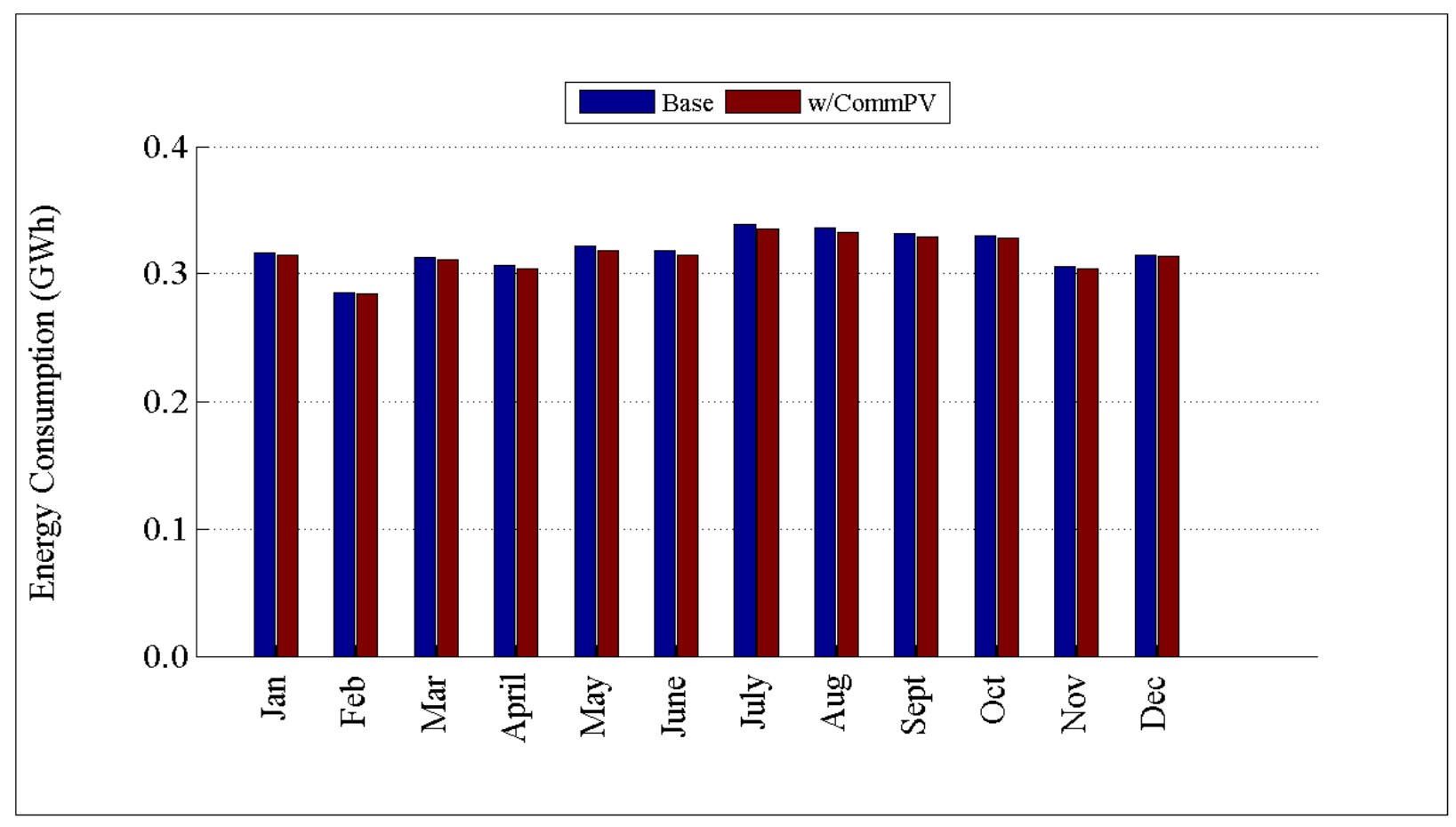

Figure D.117: Comparison of energy consumption by month for R1-12.47-3

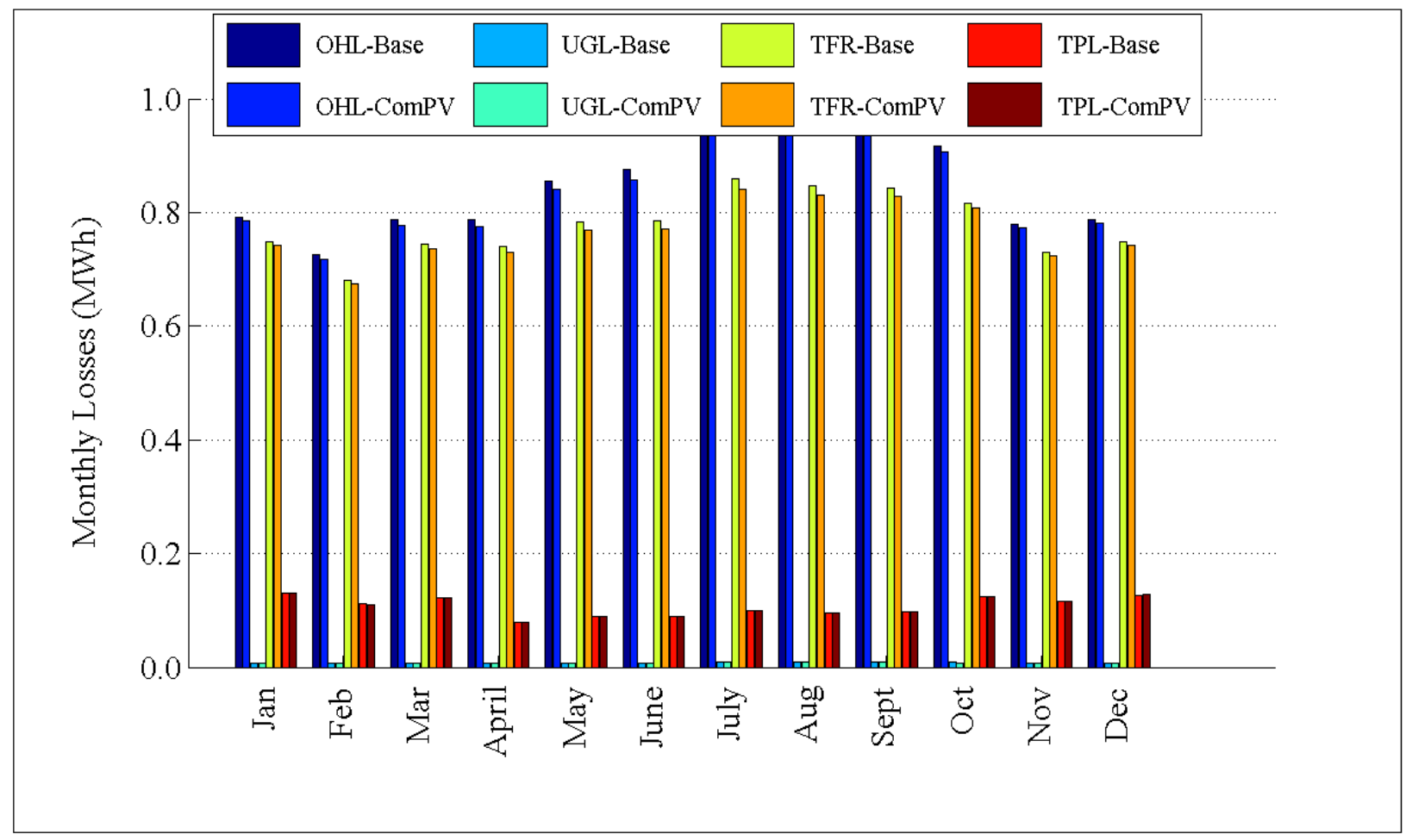

Figure D.118: Comparison of losses by month for R1-12.47-3 


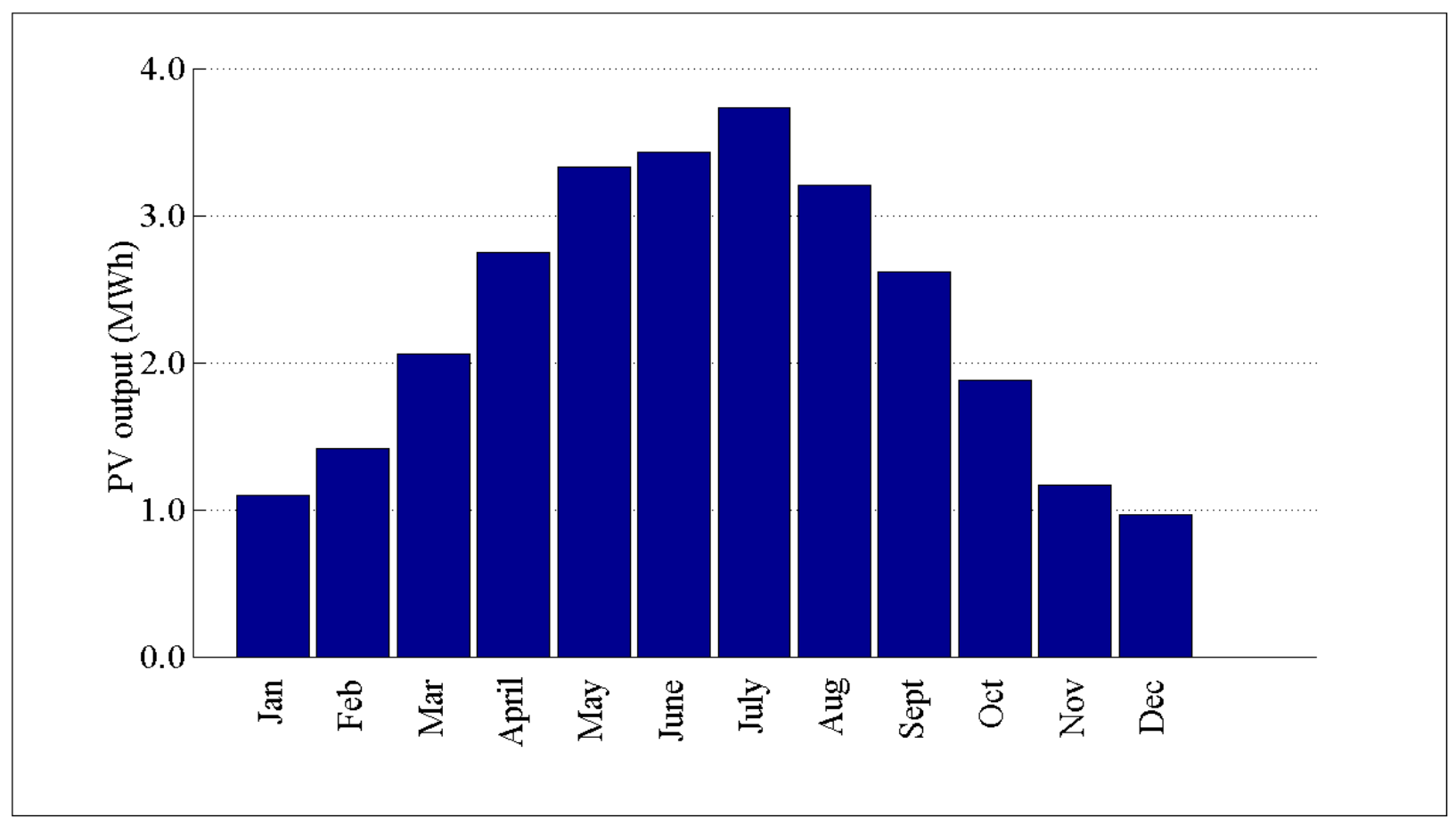

Figure D.119: PV output by month for R1-12.47-3

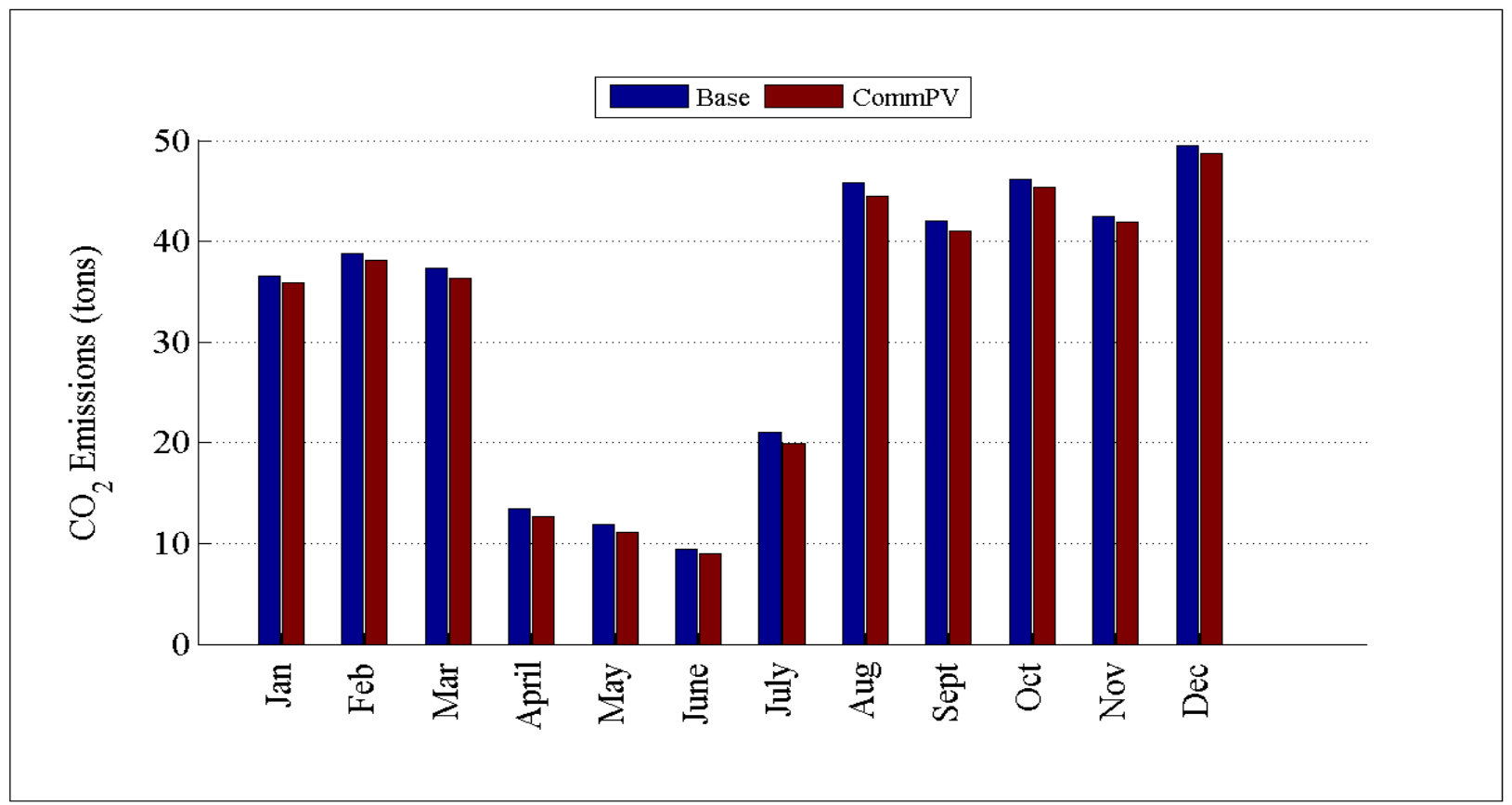

Figure D.120: Comparison of $\mathrm{CO}_{2}$ by month for R1-12.47-3 
D.2.5 Detailed Commercial PV Plots for R1-12.47-4

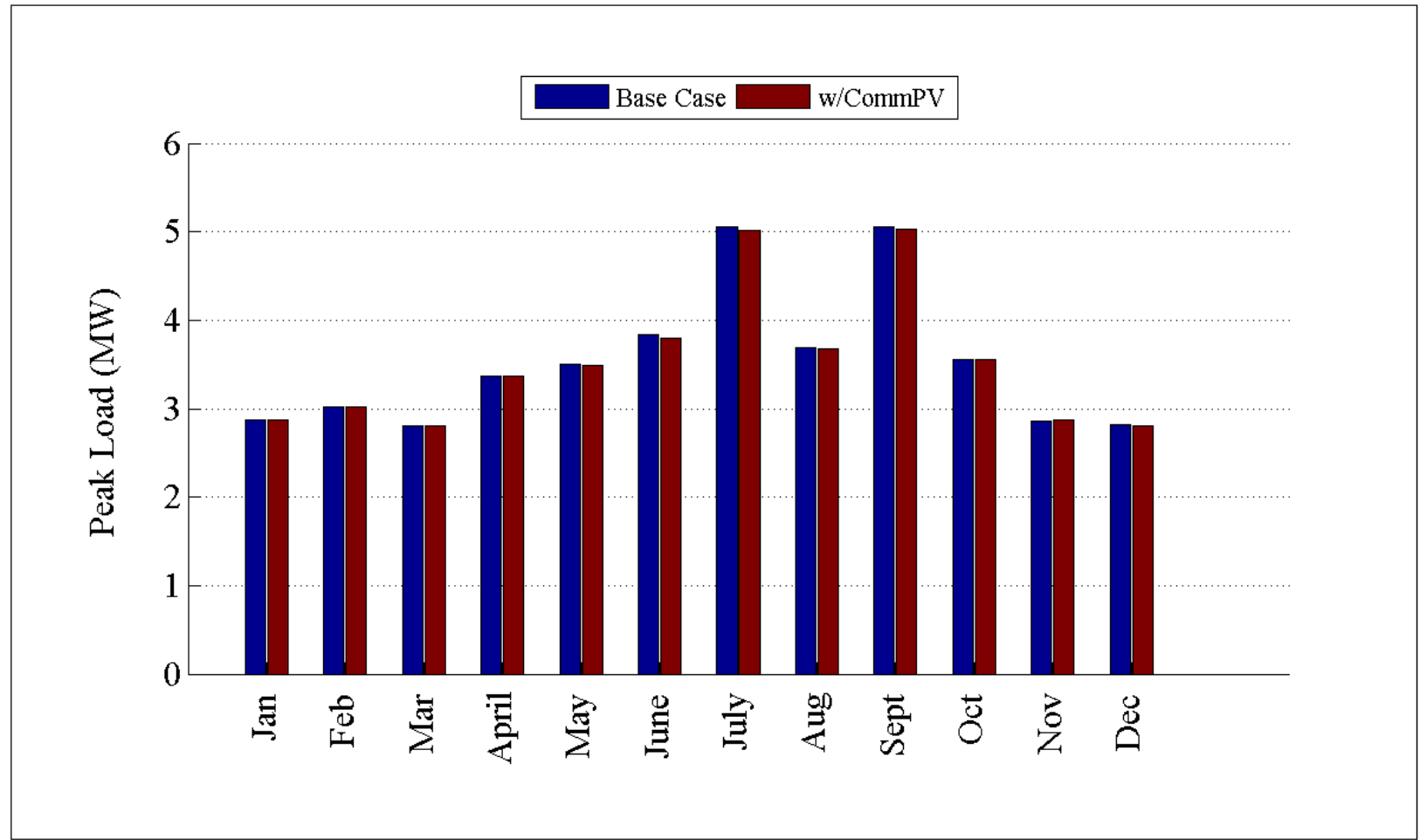

Figure D.121: Comparison of peak load by month for R1-12.47-4

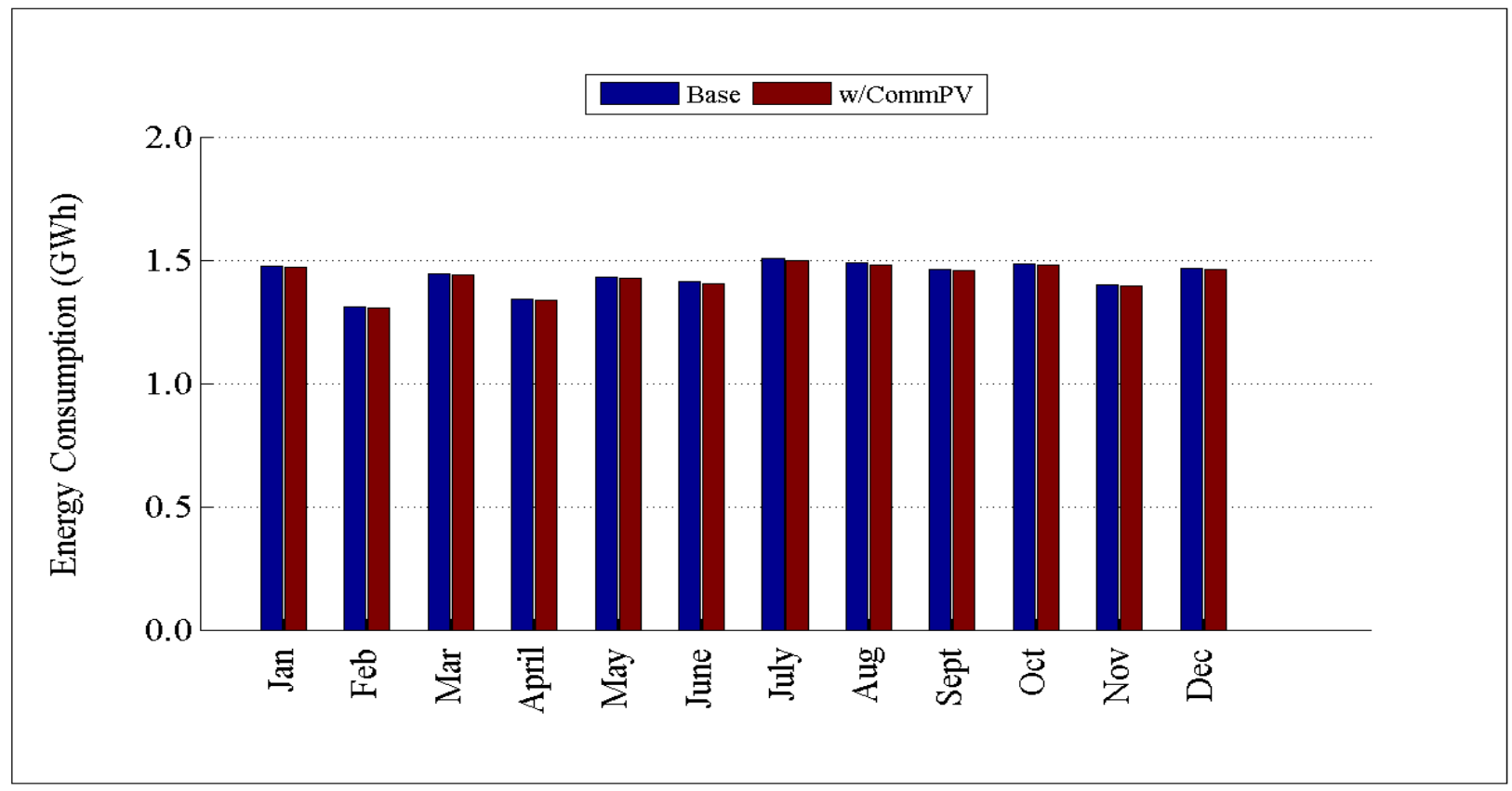

Figure D.122: Comparison of energy consumption by month for R1-12.47-4 


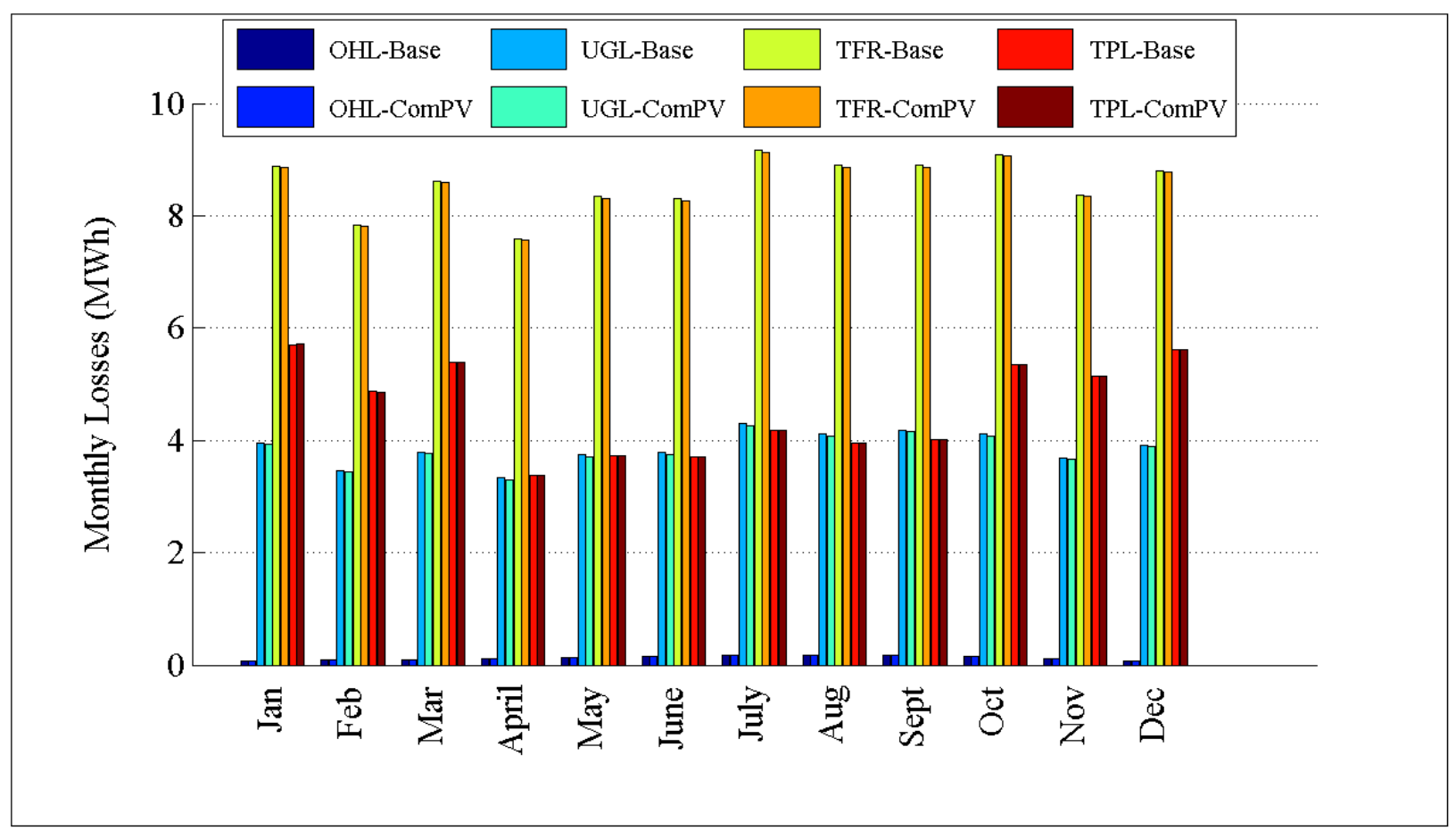

Figure D.123: Comparison of losses by month for R1-12.47-4

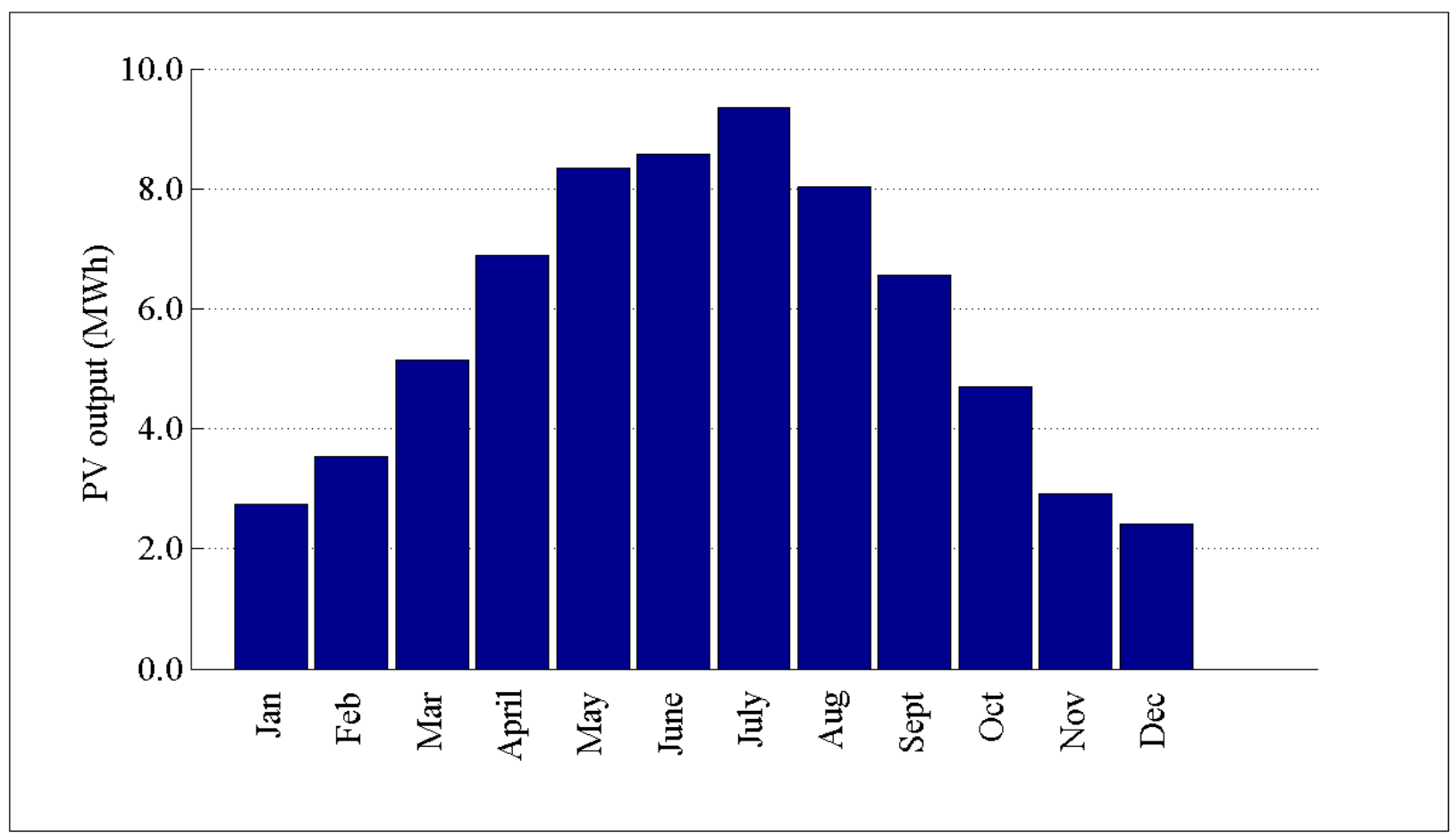

Figure D.124: PV output by month for R1-12.47-4 


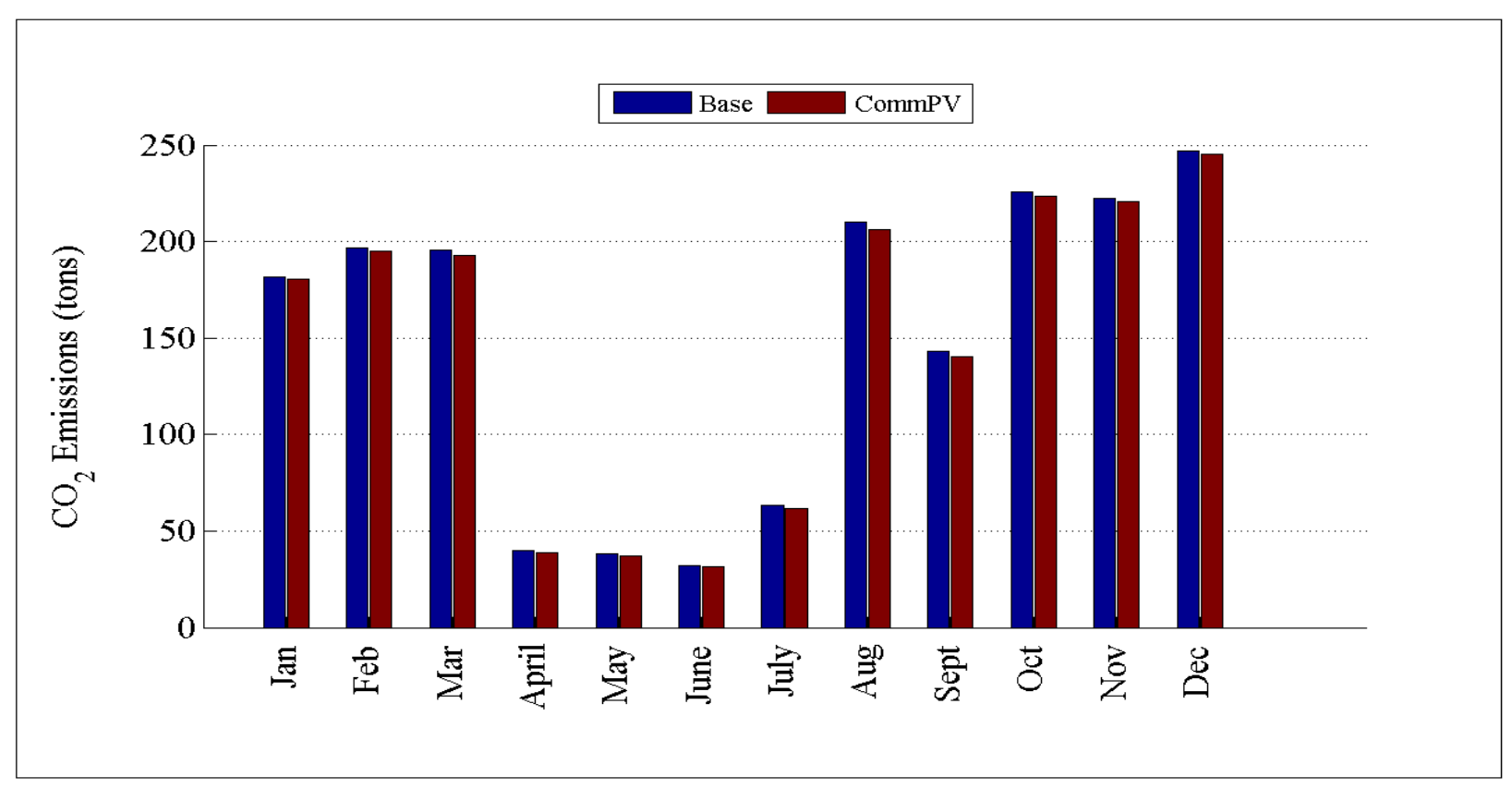

Figure D.125: Comparison of $\mathrm{CO}_{2}$ by month for R1-12.47-4

\section{D.2.6 Detailed Commercial PV Plots for R1-25.00-1}

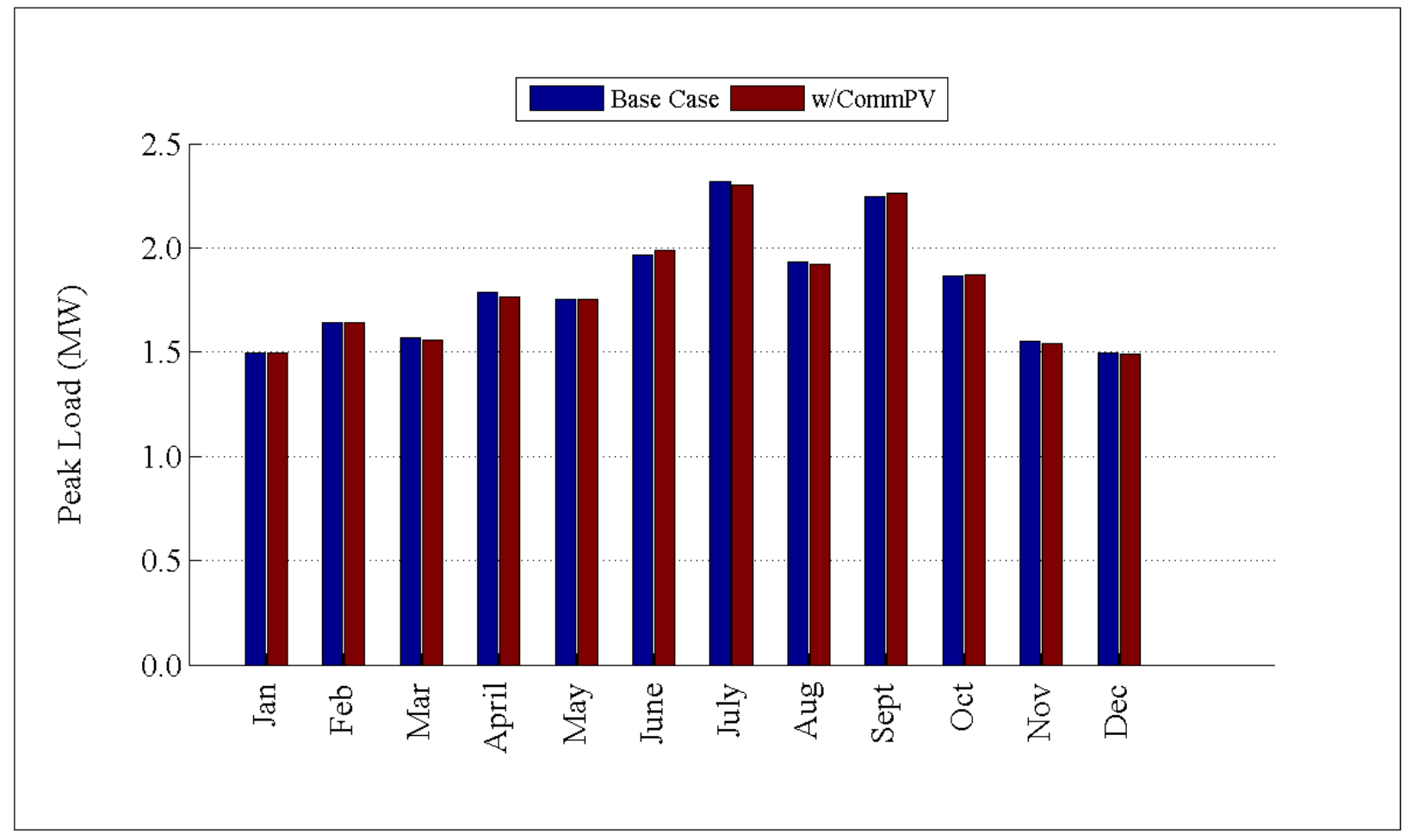

Figure D.126: Comparison of peak load by month for R1-25.00-1 


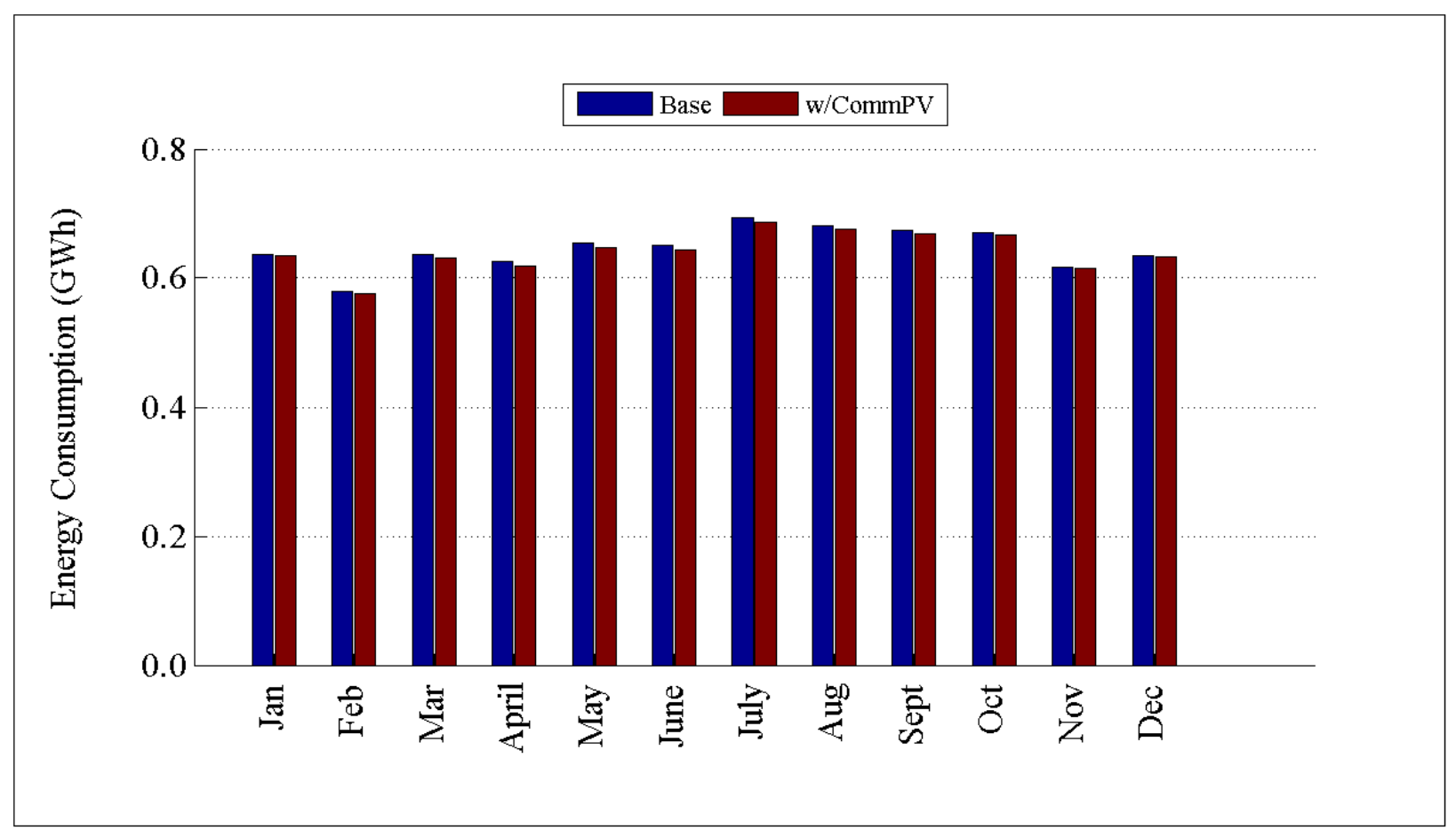

Figure D.127: Comparison of energy consumption by month for R1-25.00-1

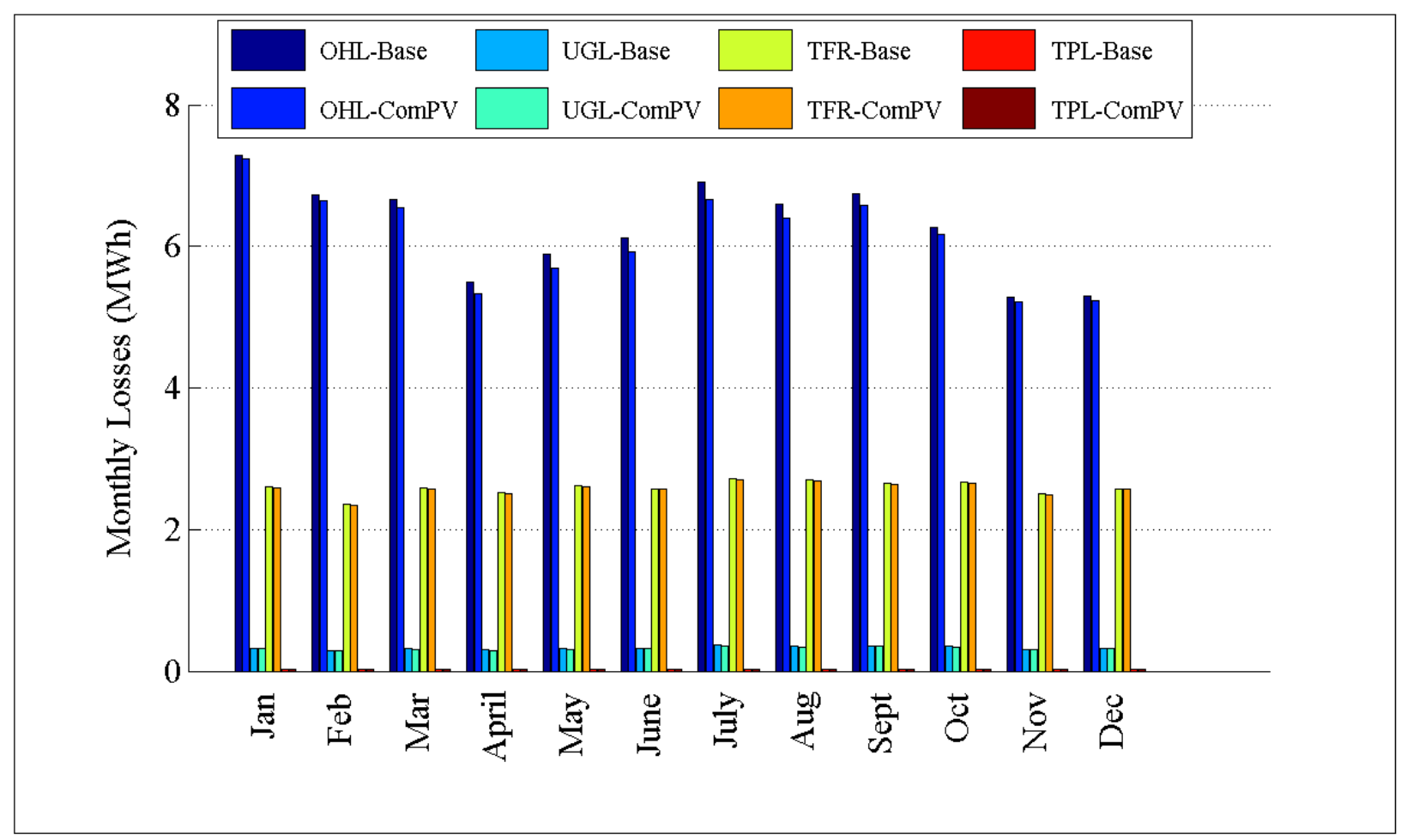

Figure D.128: Comparison of losses by month for R1-25.00-1 


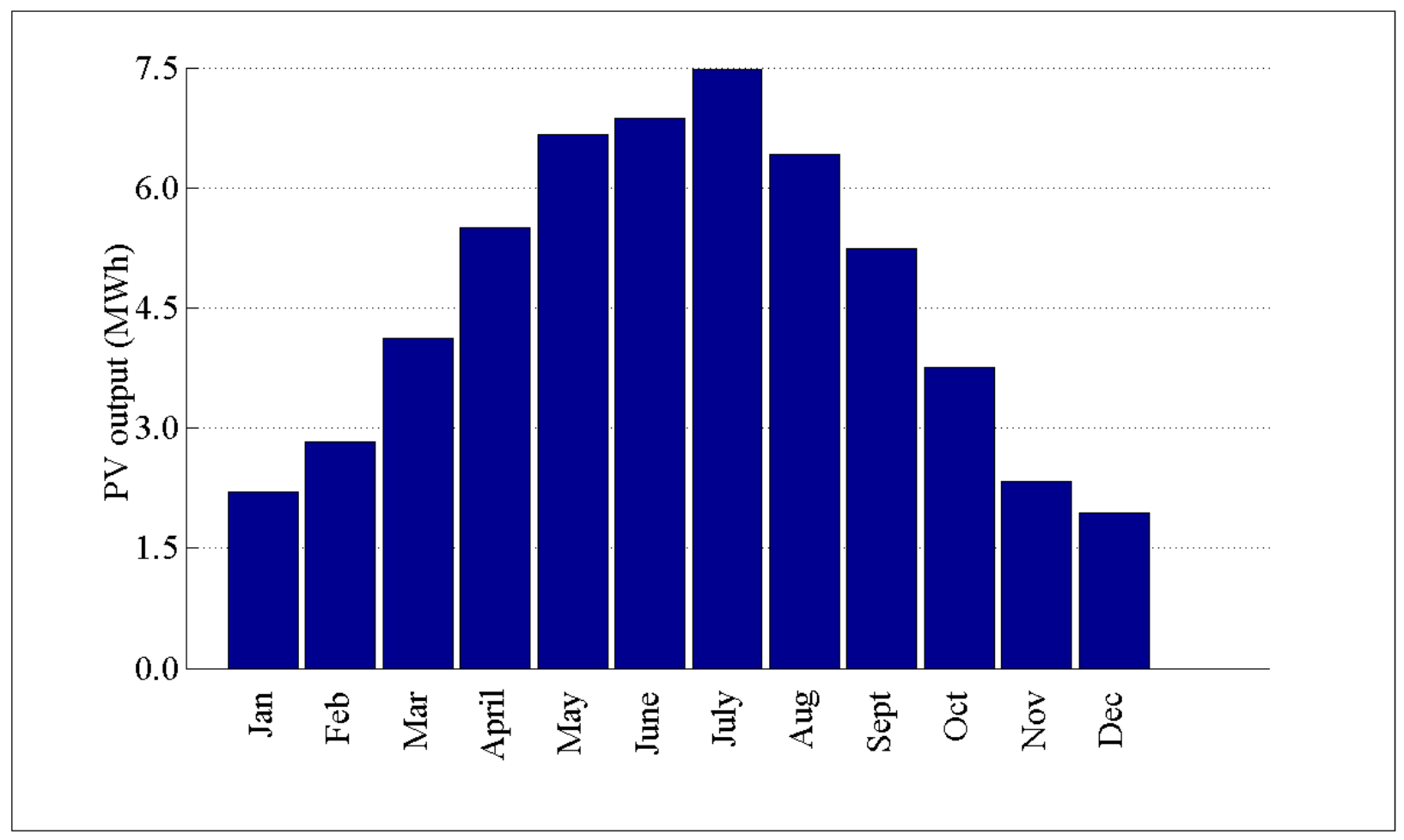

Figure D.129: PV output by month for R1-25.00-1

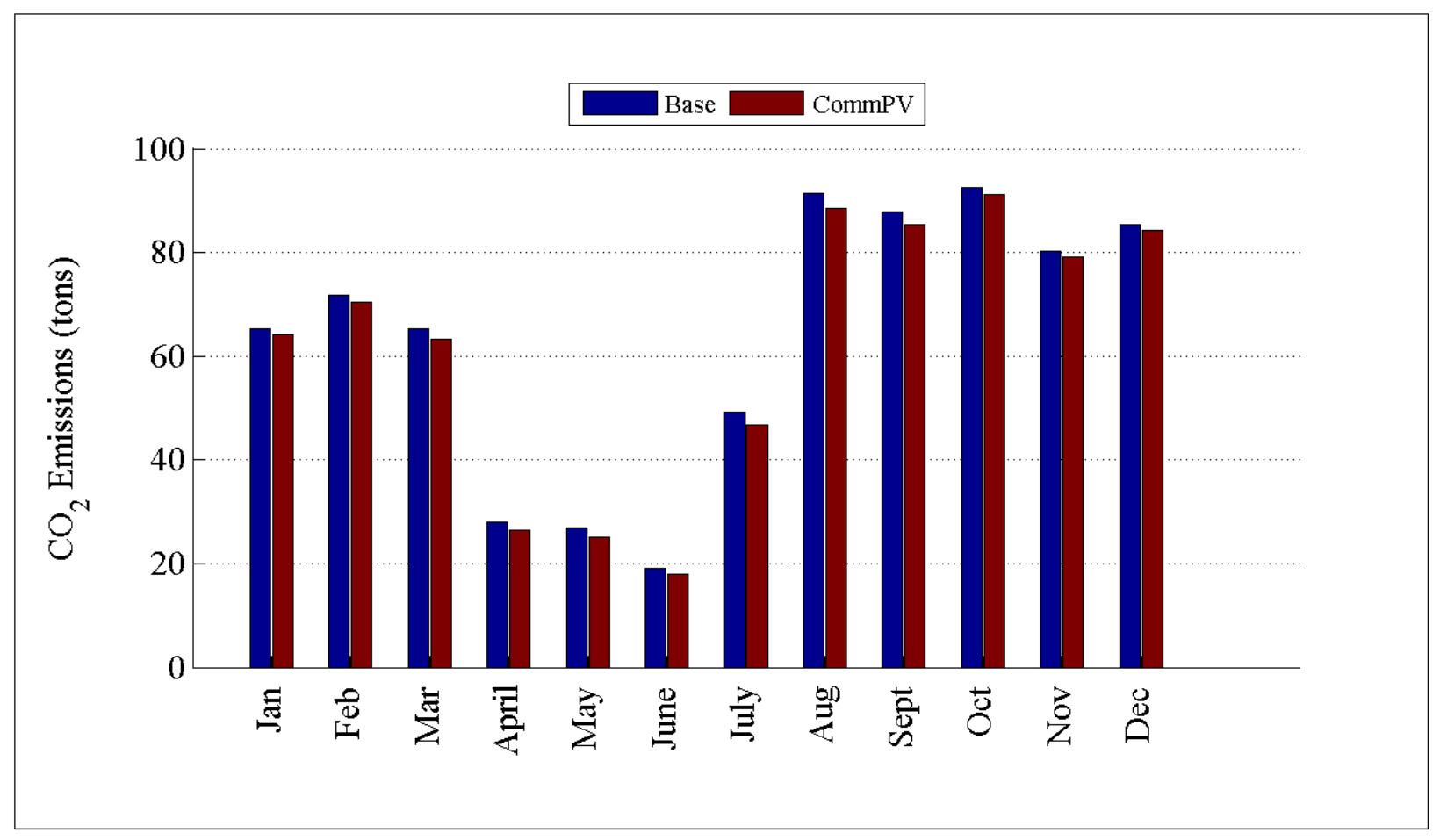

Figure D.130: Comparison of $\mathrm{CO}_{2}$ by month for R1-25.00-1 
D.2.7 Detailed Commercial PV Plots for GC-12.47-1_R2

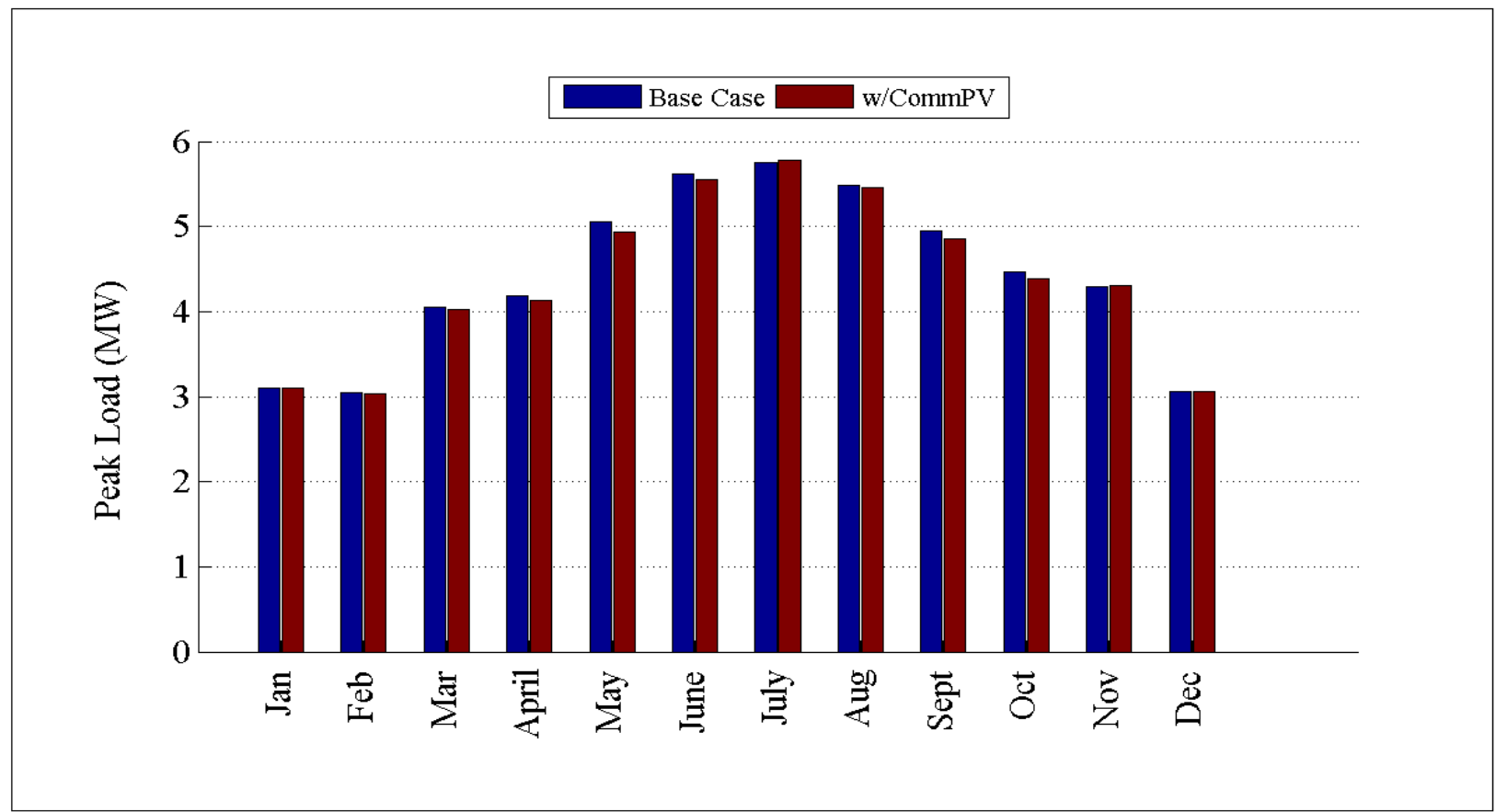

Figure D.131: Comparison of peak load by month for GC-12.47-1_R2

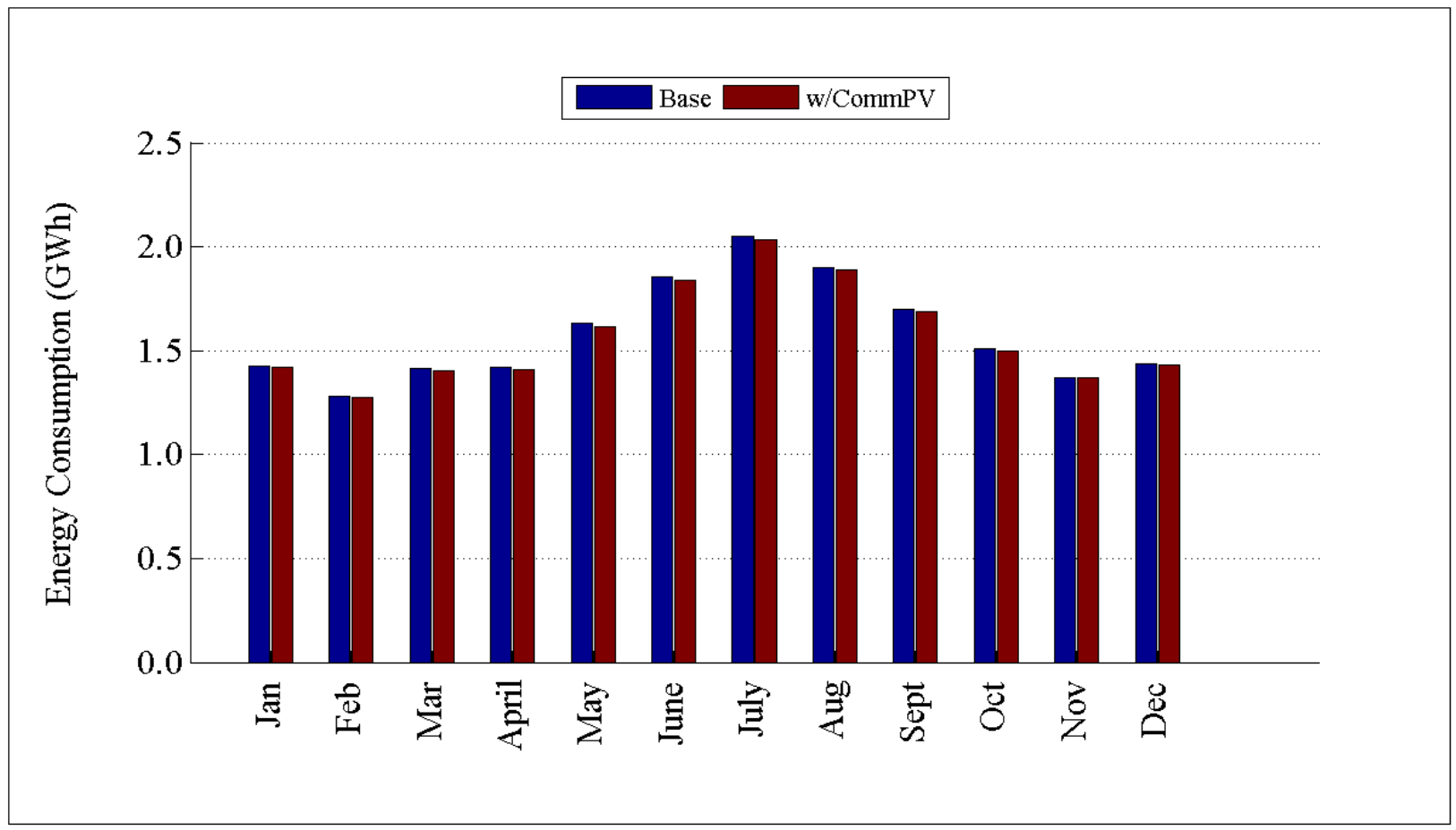

Figure D.132: Comparison of energy consumption by month for GC-12.47-1_R2 


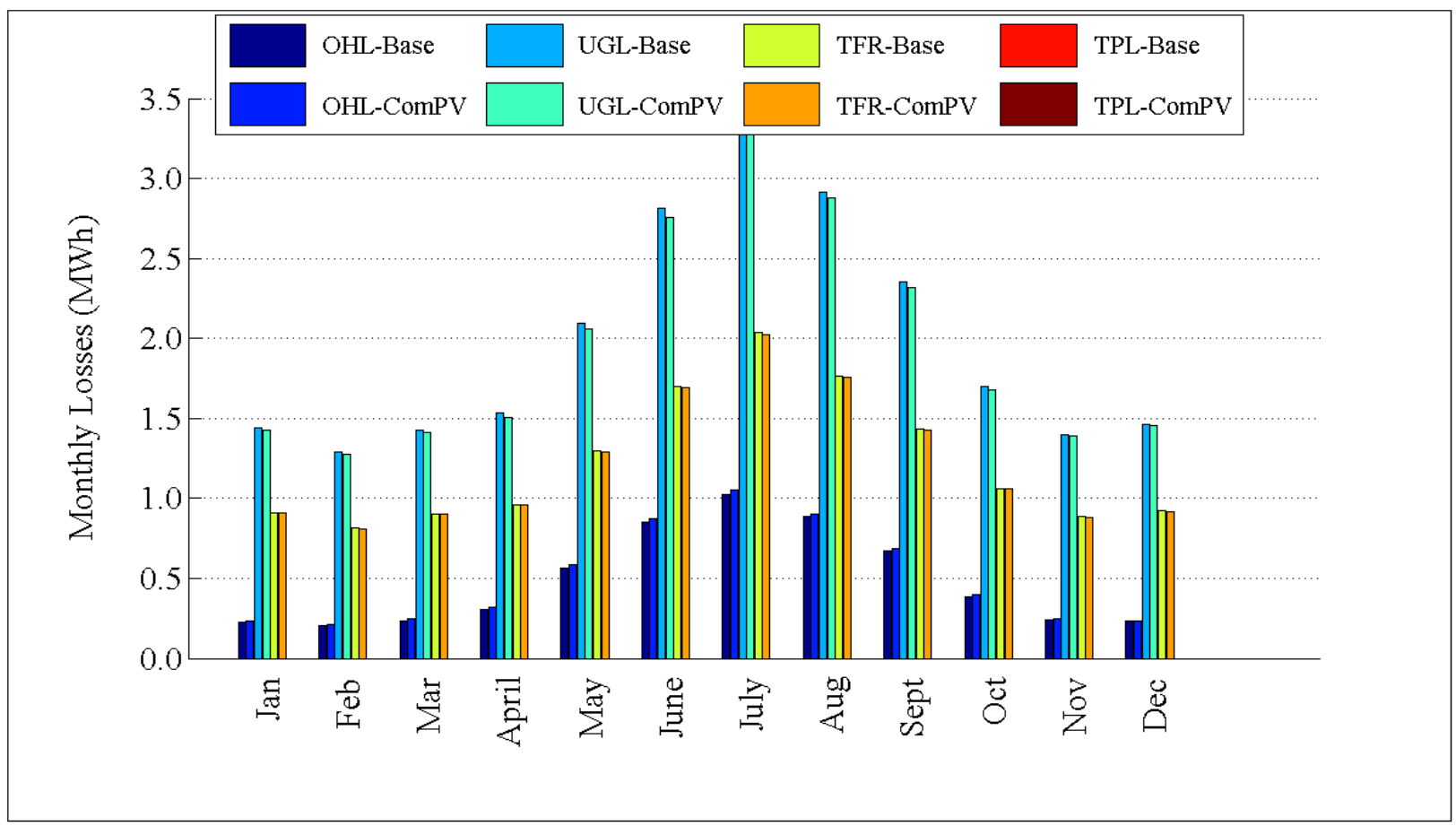

Figure D.133: Comparison of losses by month for GC-12.47-1_R2

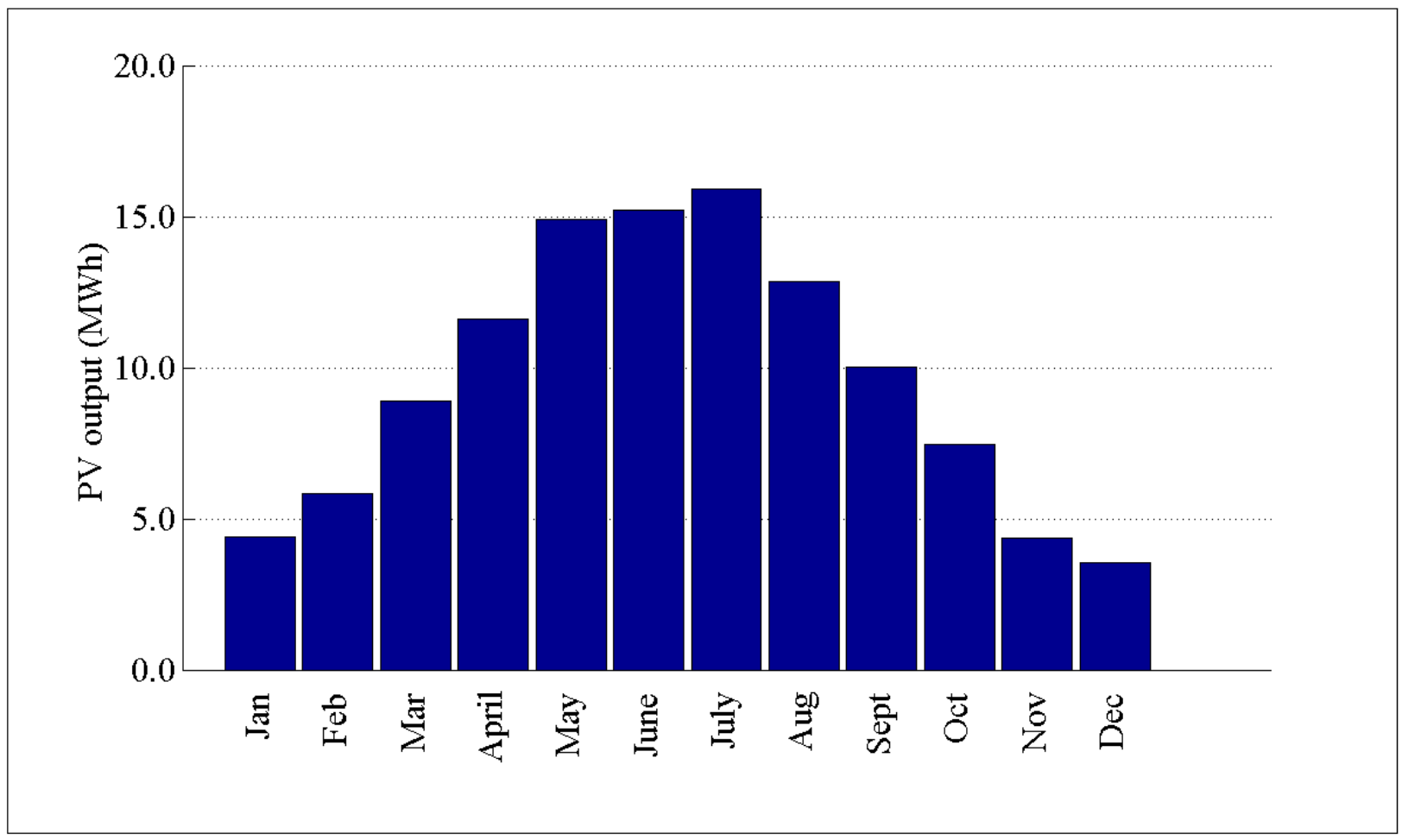

Figure D.134: PV output by month for GC-12.47-1_R2 


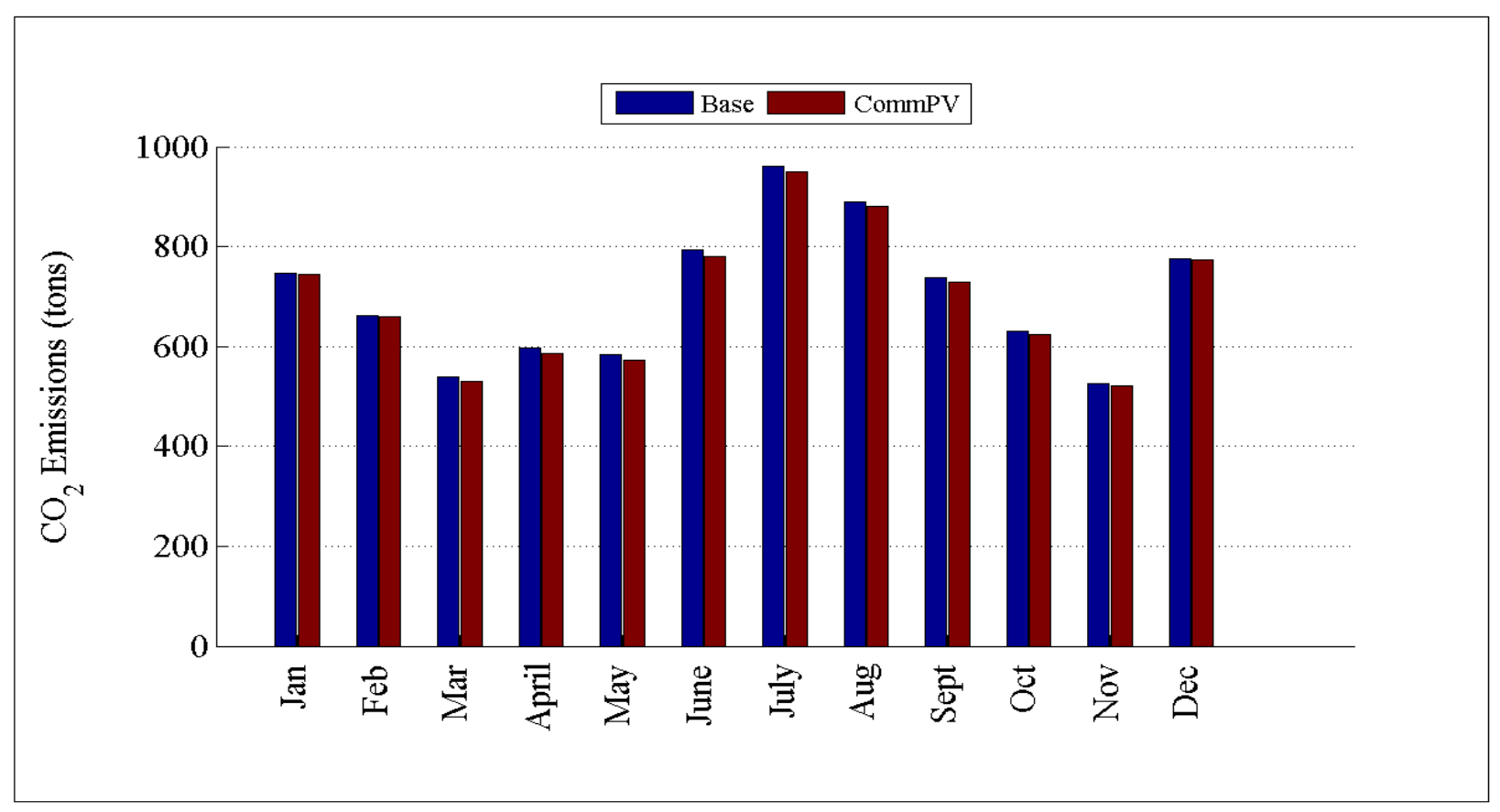

Figure D.135: Comparison of $\mathrm{CO}_{2}$ emissions by month for GC-12.47-1_R2

\section{D.2.8 Detailed Commercial PV for R2-12.47-1}

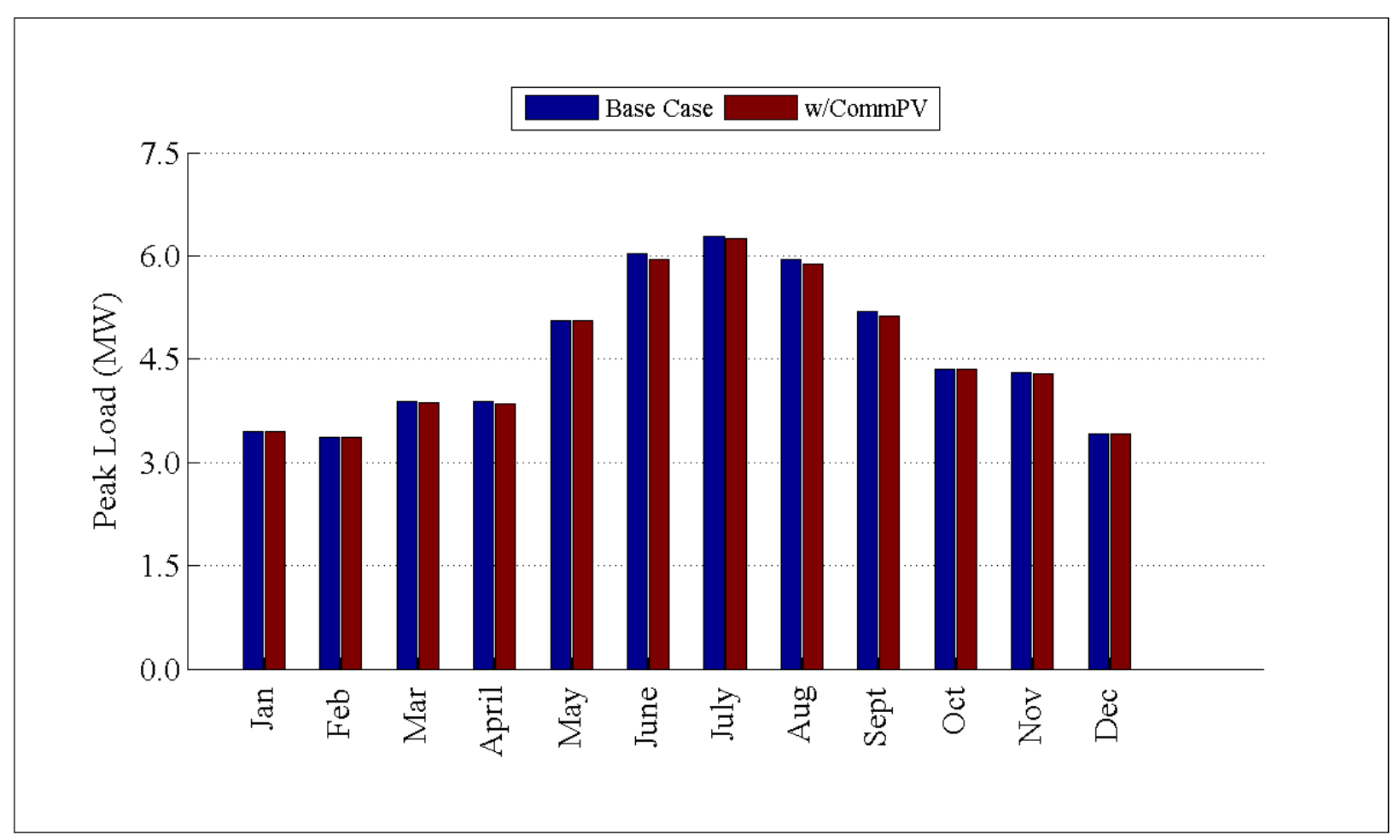

Figure D.136: Comparison of peak load by month for R2-12.47-1 


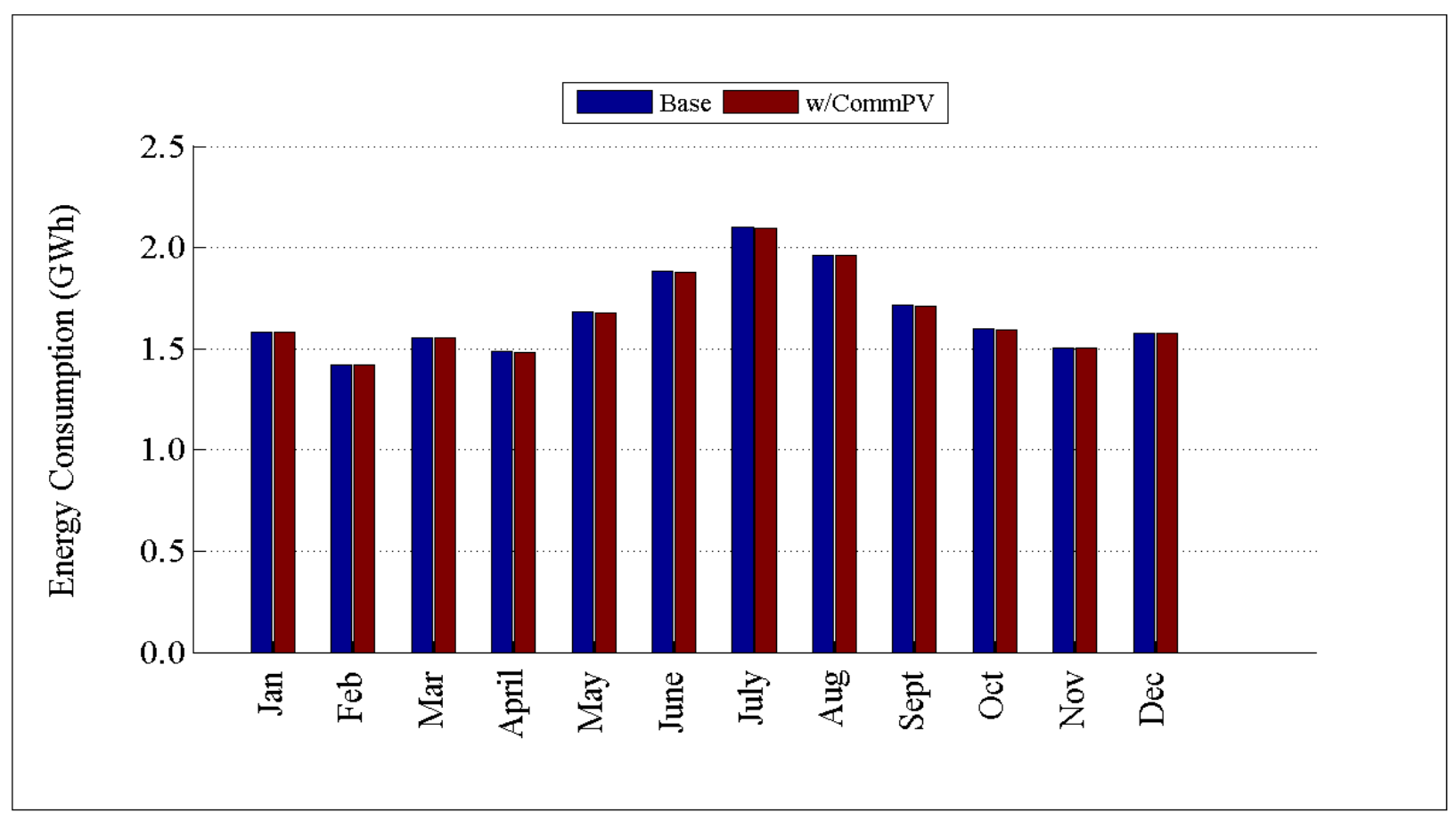

Figure D.137: Comparison of energy consumption by month for R2-12.47-1

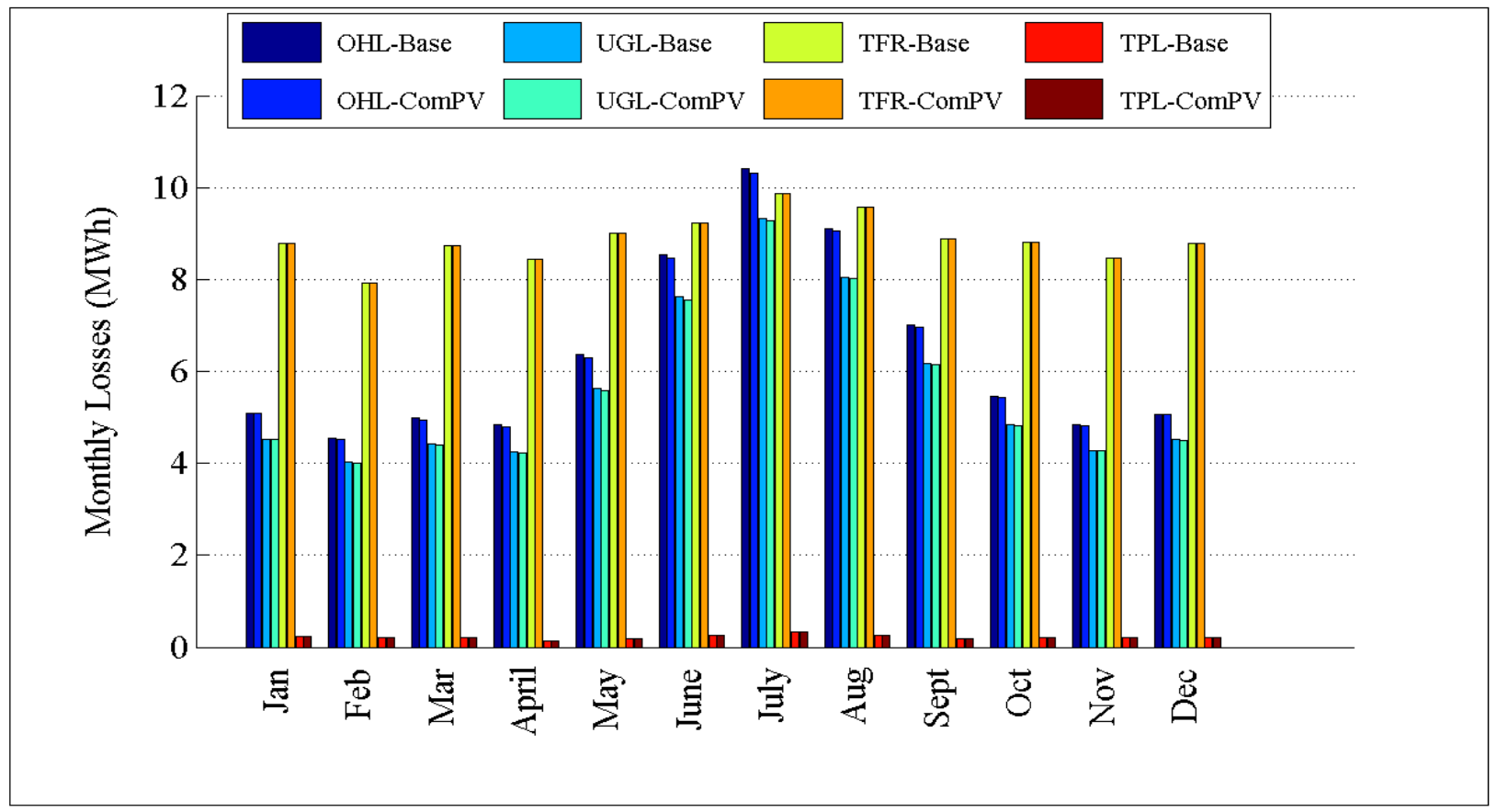

Figure D.138: Comparison of losses by month for R2-12.47-1 


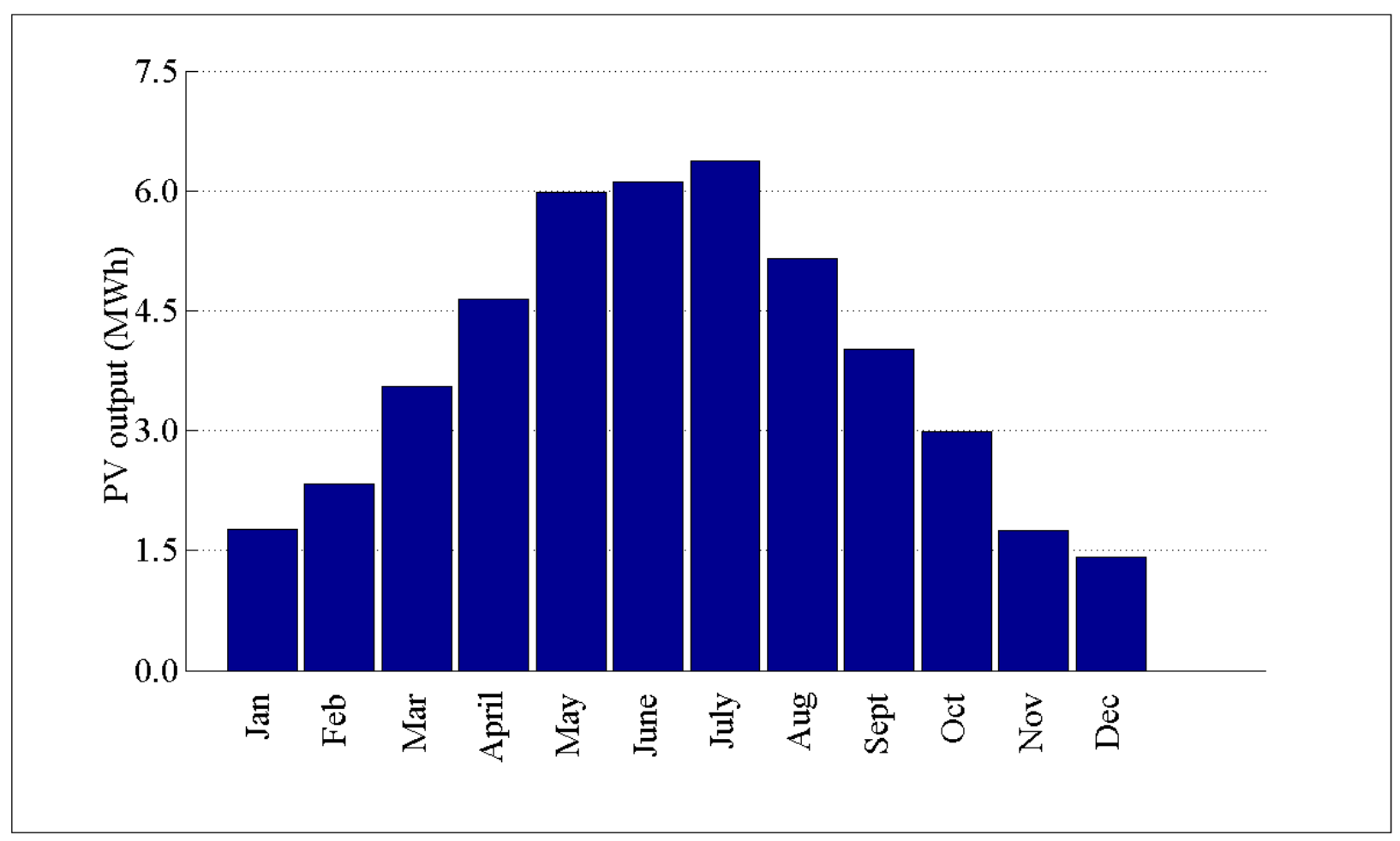

Figure D.139: PV output by month for R2-12.47-1

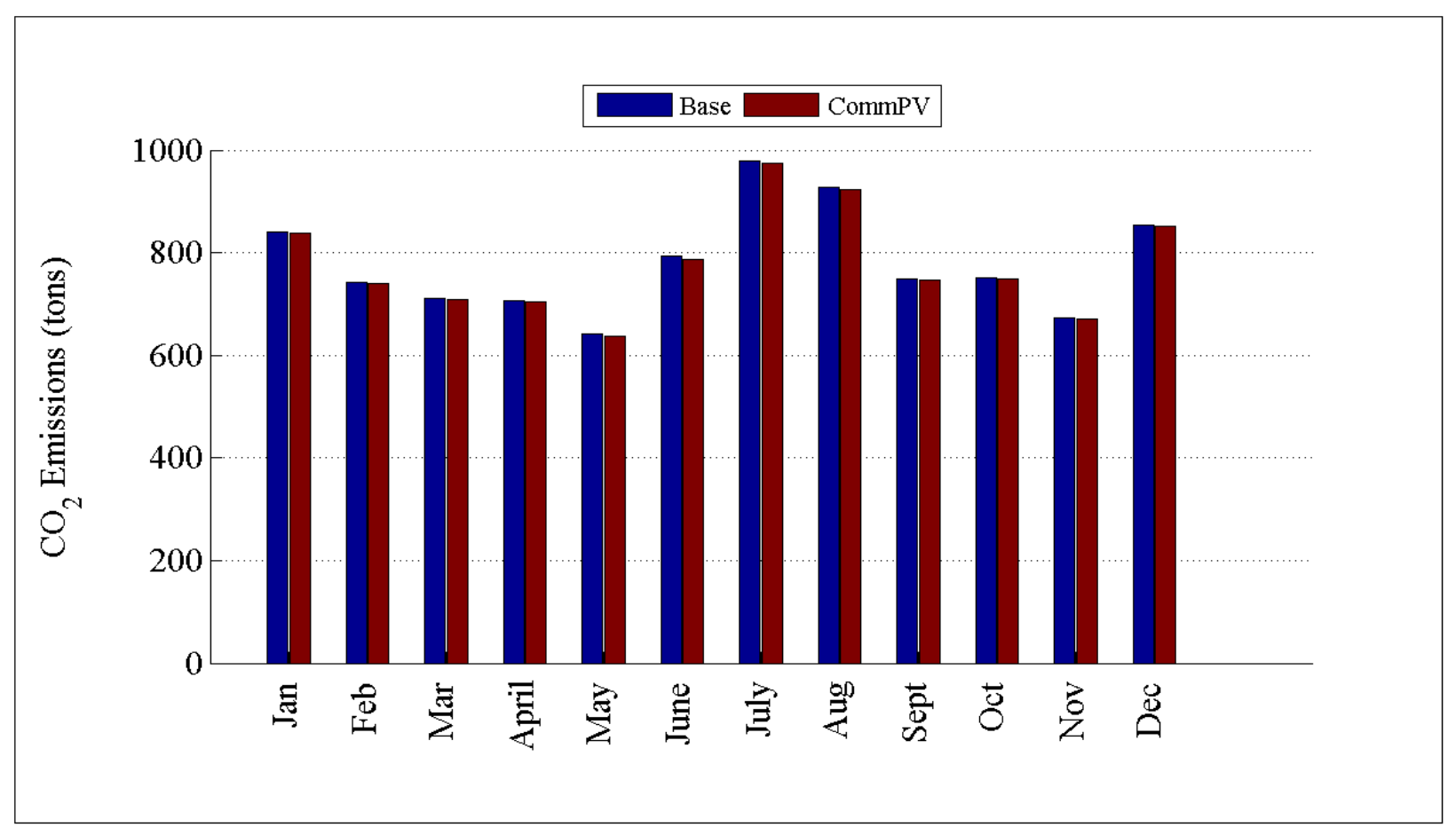

Figure D.140: Comparison of $\mathrm{CO}_{2}$ emissions by month for R2-12.47-1 


\section{D.2.9 Detailed Commercial PV for R2-12.47-2}

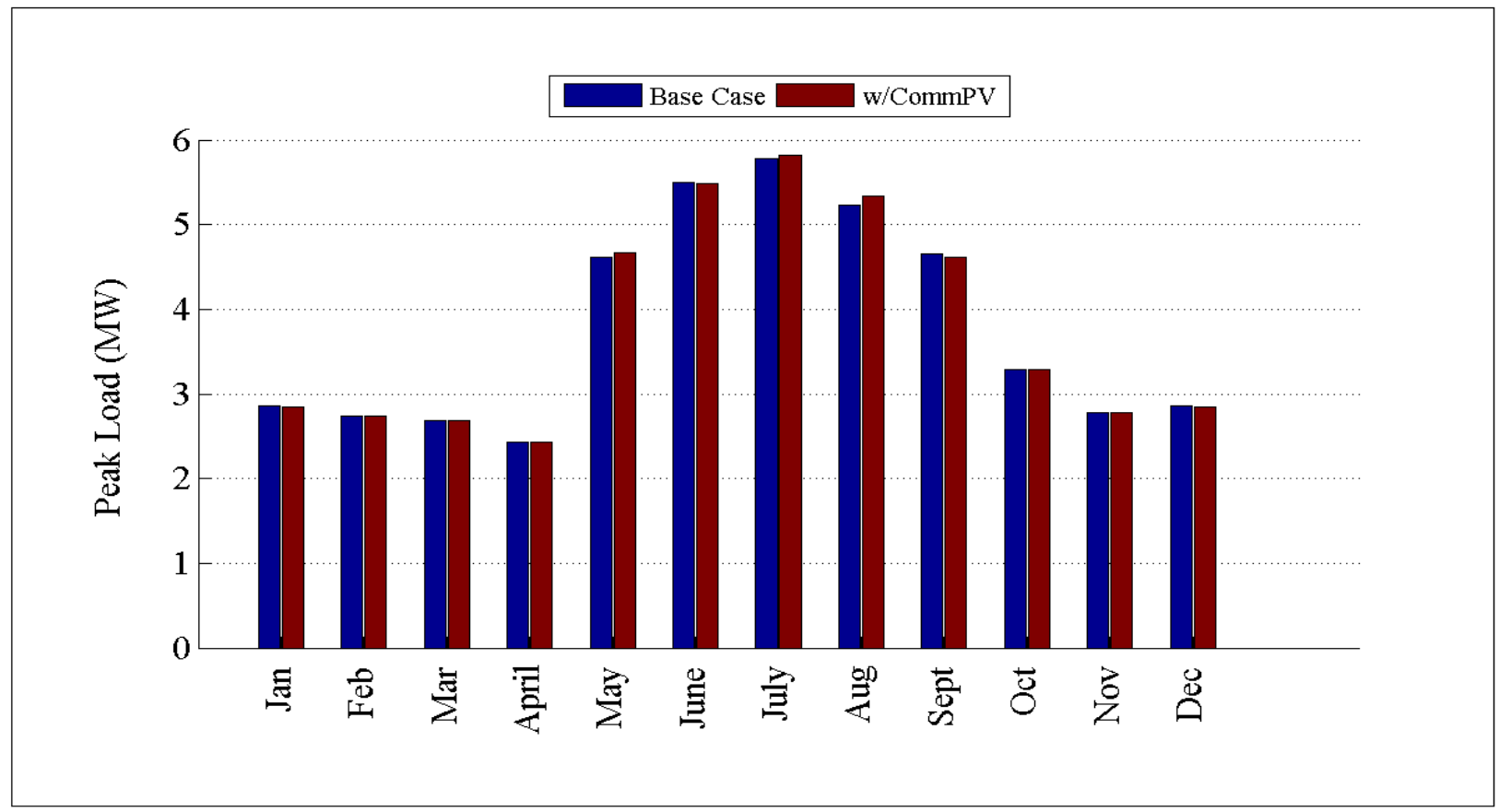

Figure D.141: Comparison of peak load by month for R2-12.47-2

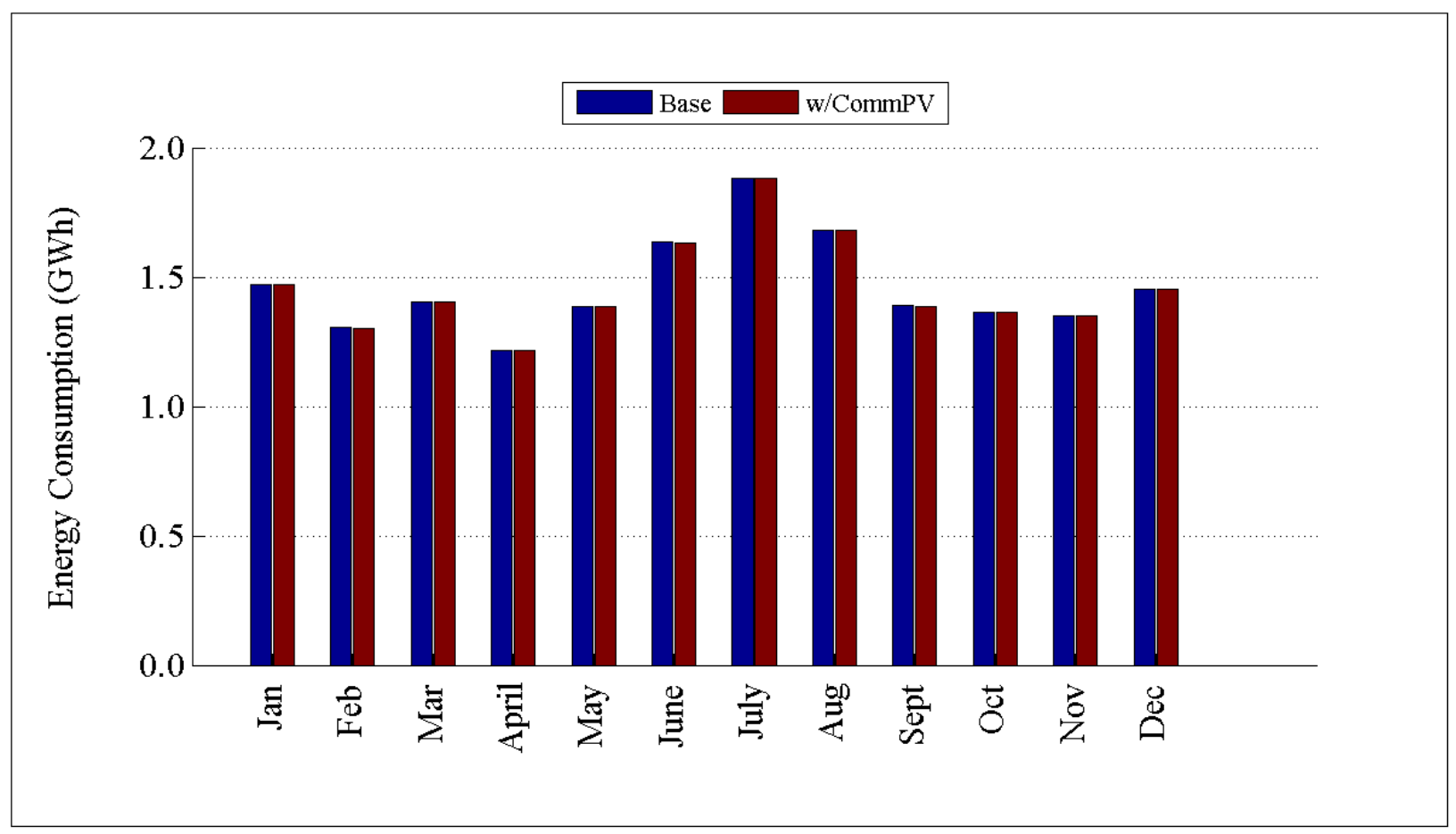

Figure D.142: Comparison of energy consumption by month for R2-12.47-2 


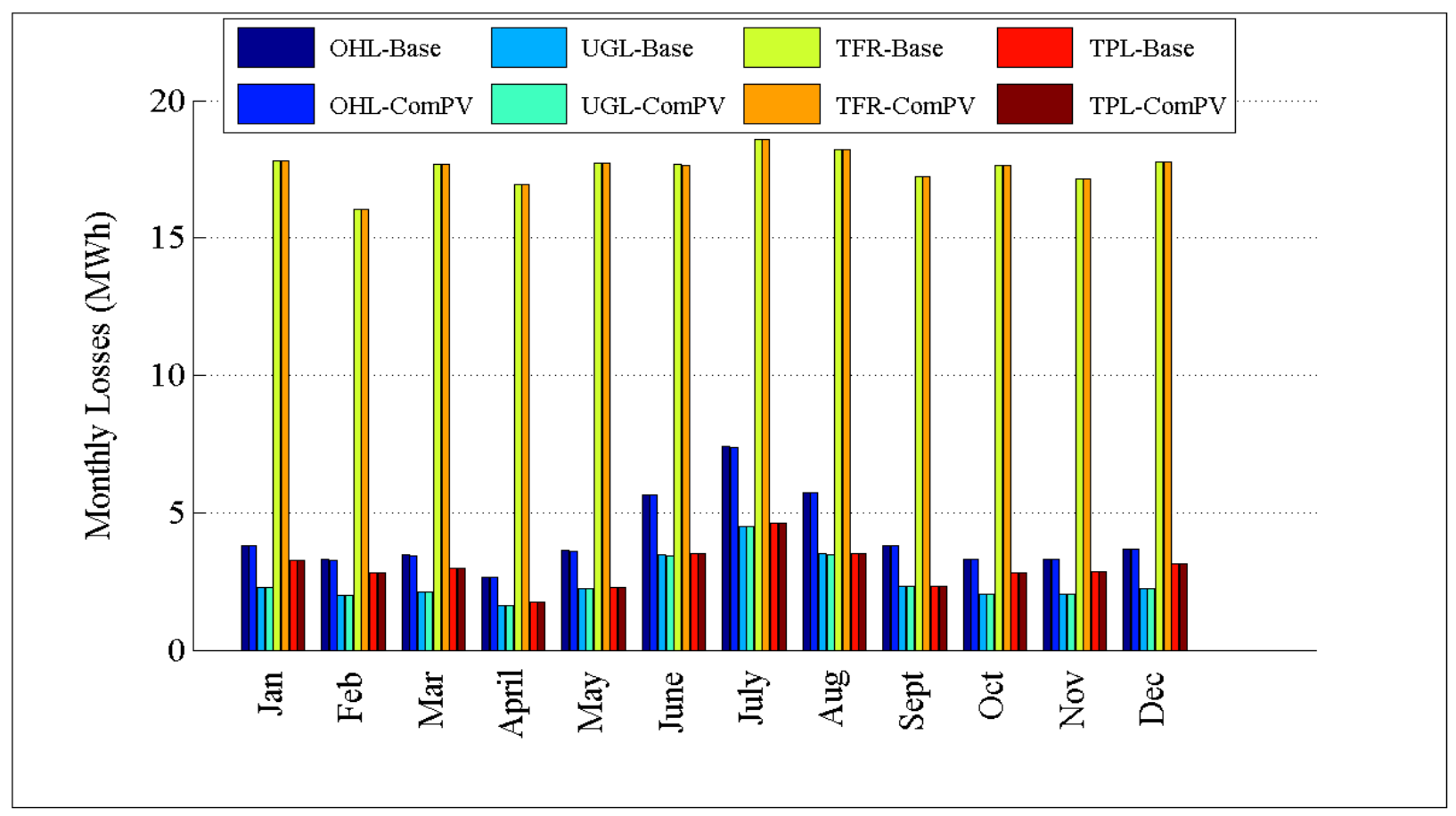

Figure D.143: Comparison of losses by month for R2-12.47-2

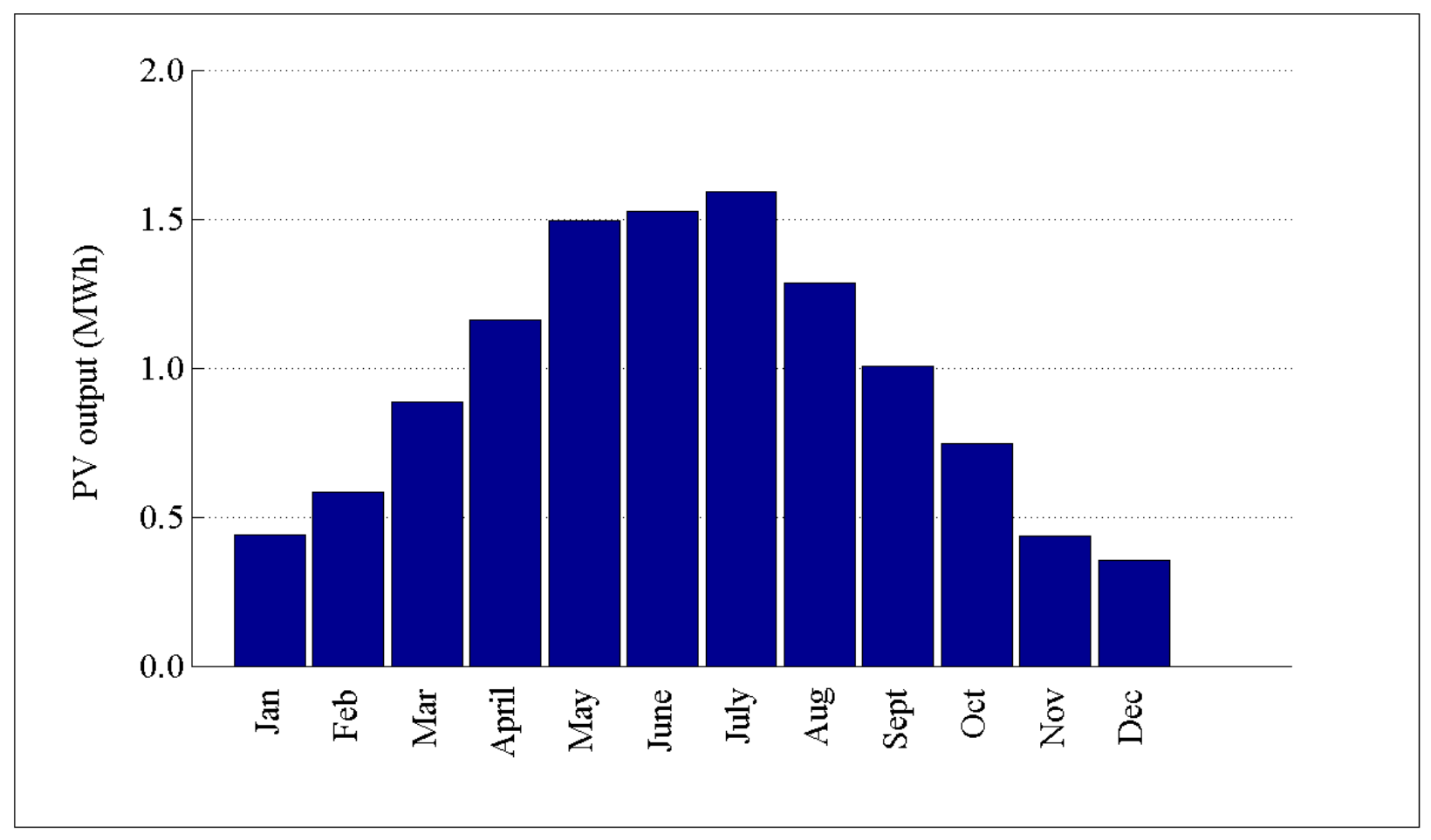

Figure D.144: PV output by month for R2-12.47-2 


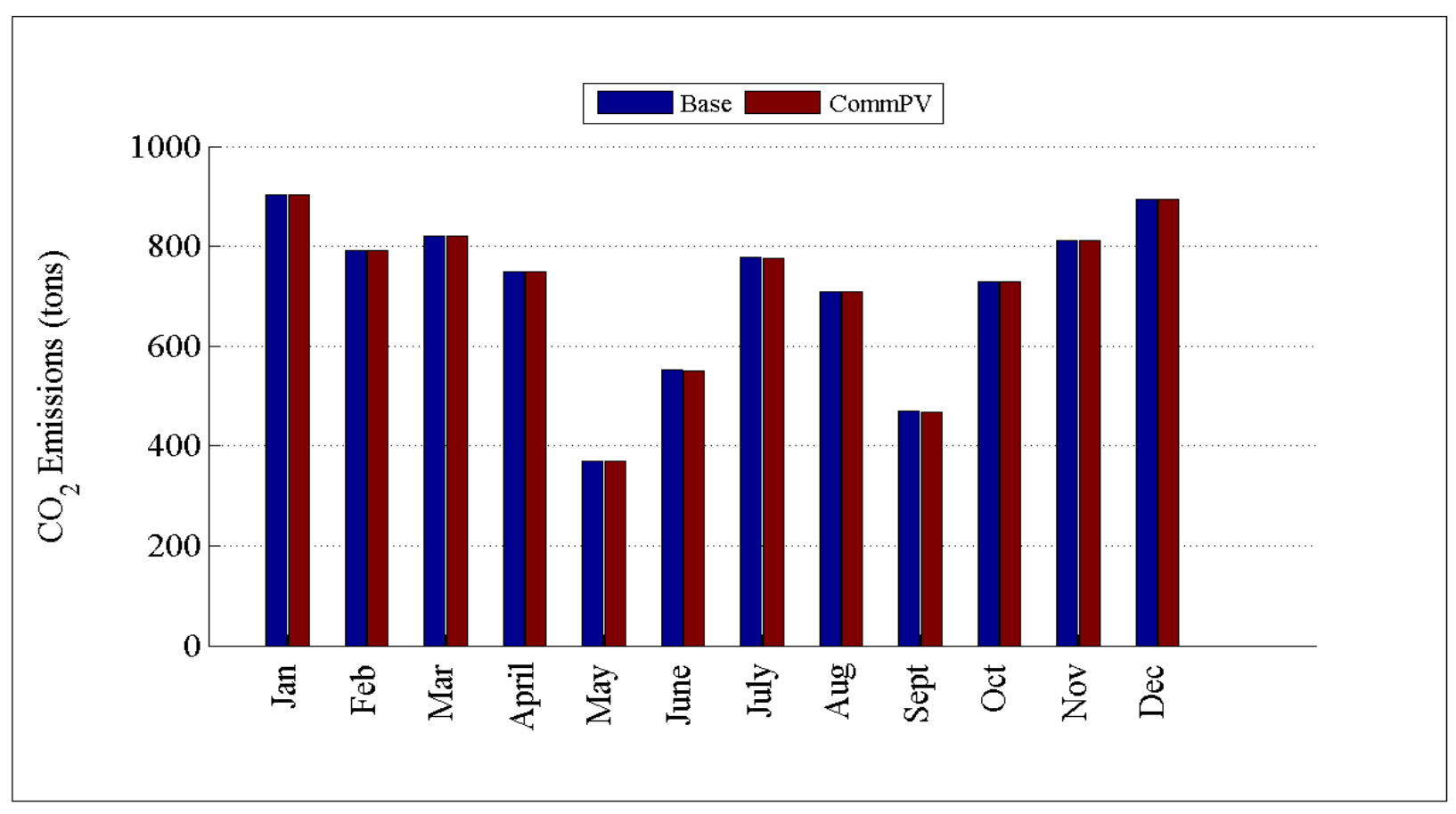

Figure D.145: Comparison of $\mathrm{CO}_{2}$ emissions by month for R2-12.47-2

\section{D.2.10 Detailed Commercial PV for R2-25.00-1}

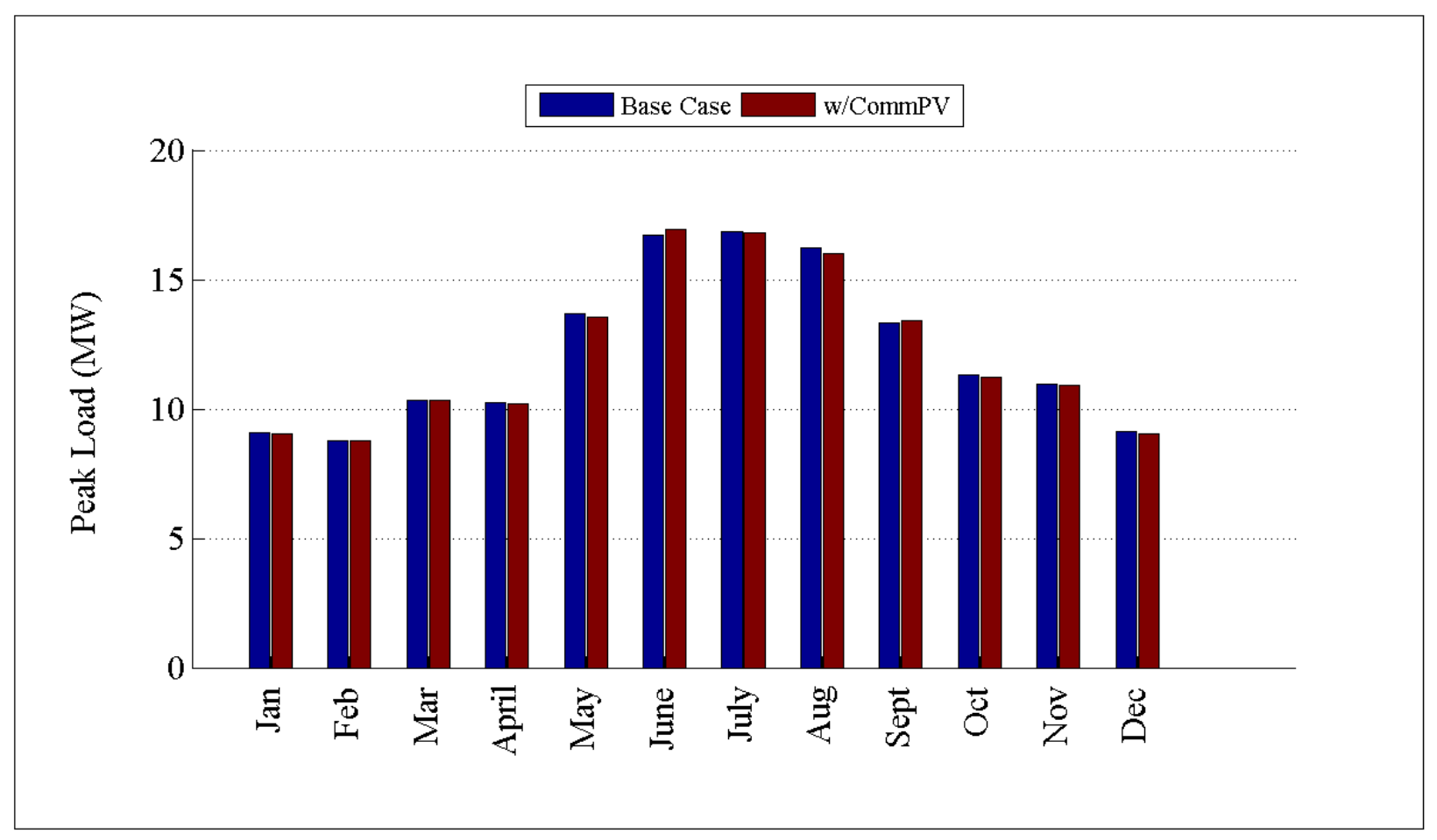

Figure D.146: Comparison of peak load by month for R2-25.00-1 


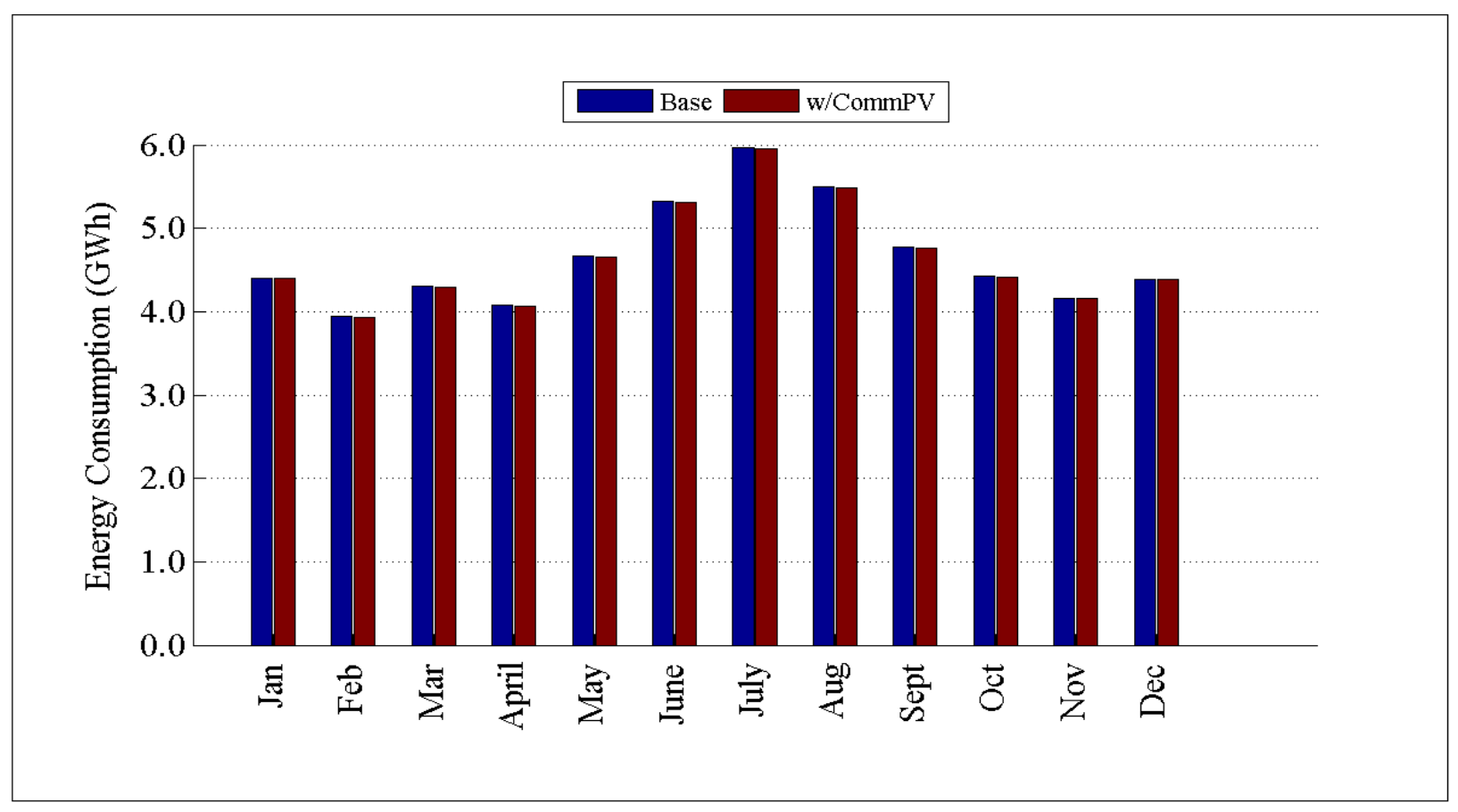

Figure D.147: Comparison of energy consumption by month for R2-25.00-1

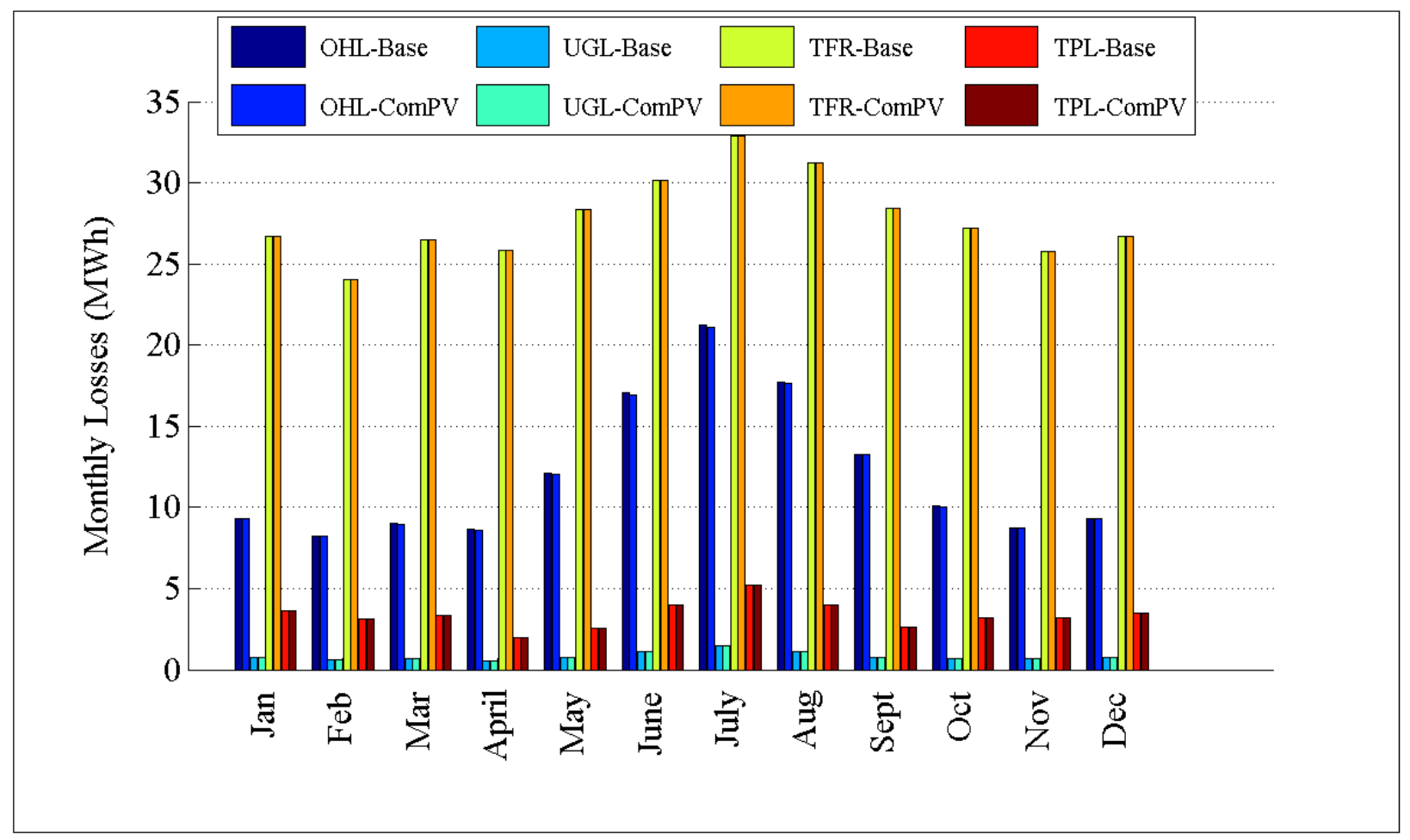

Figure D.148: Comparison of losses by month for R2-25.00-1 


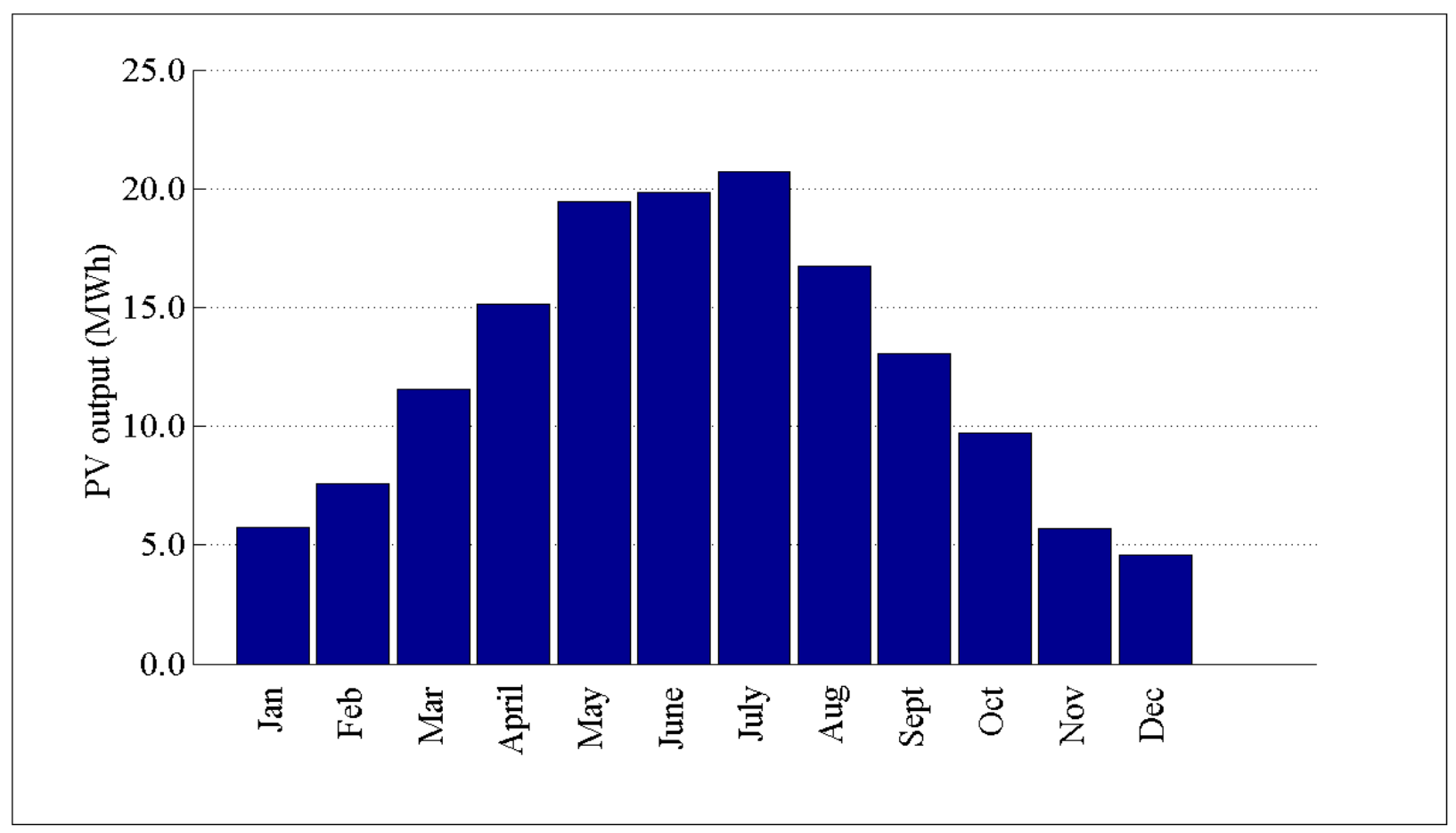

Figure D.149: PV output by month for R2-25.00-1

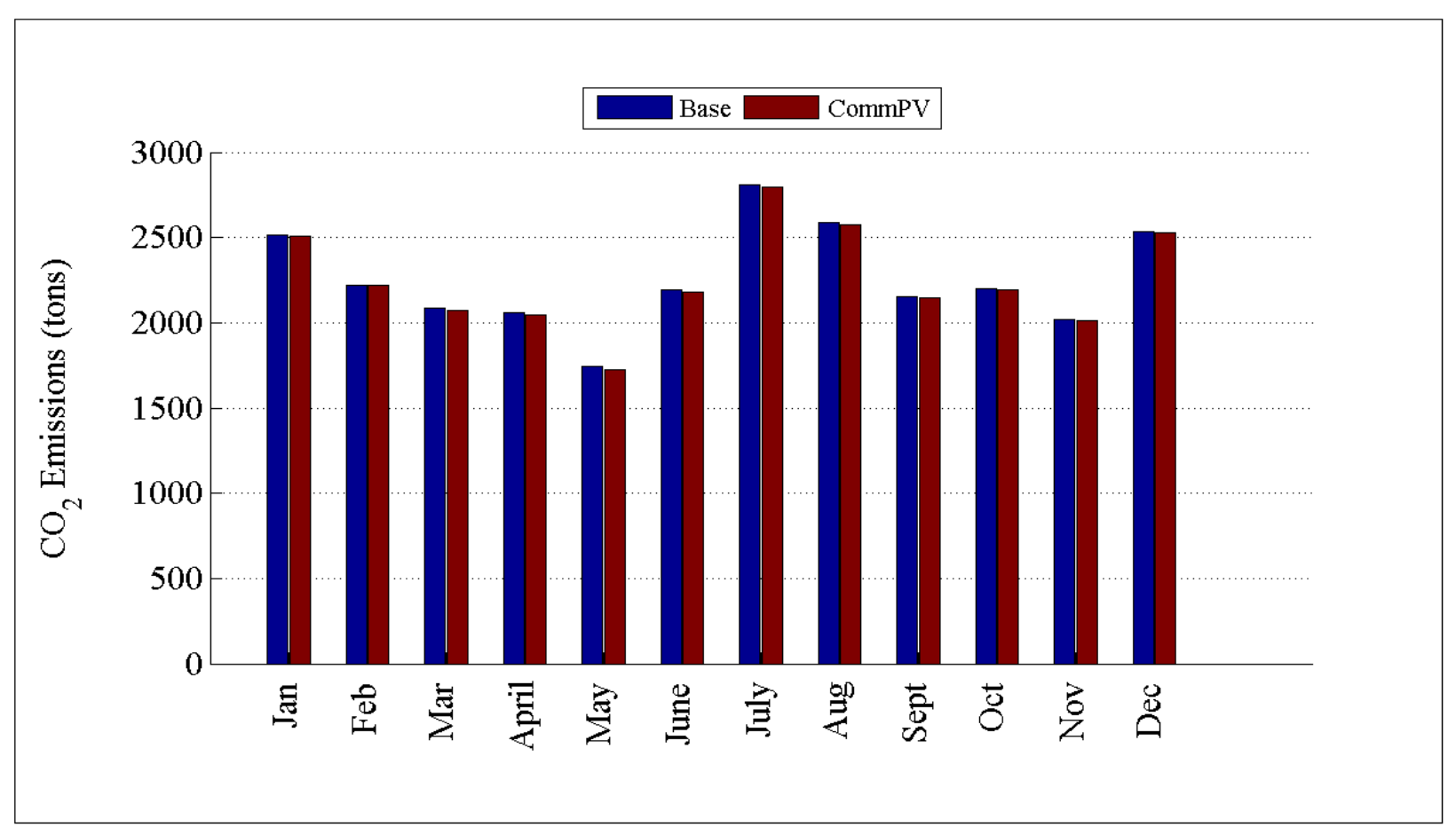

Figure D.150: Comparison of $\mathrm{CO}_{2}$ by month for R2-25.00-1 


\section{D.2.11 Detailed Commercial PV for R2-35.00-1}

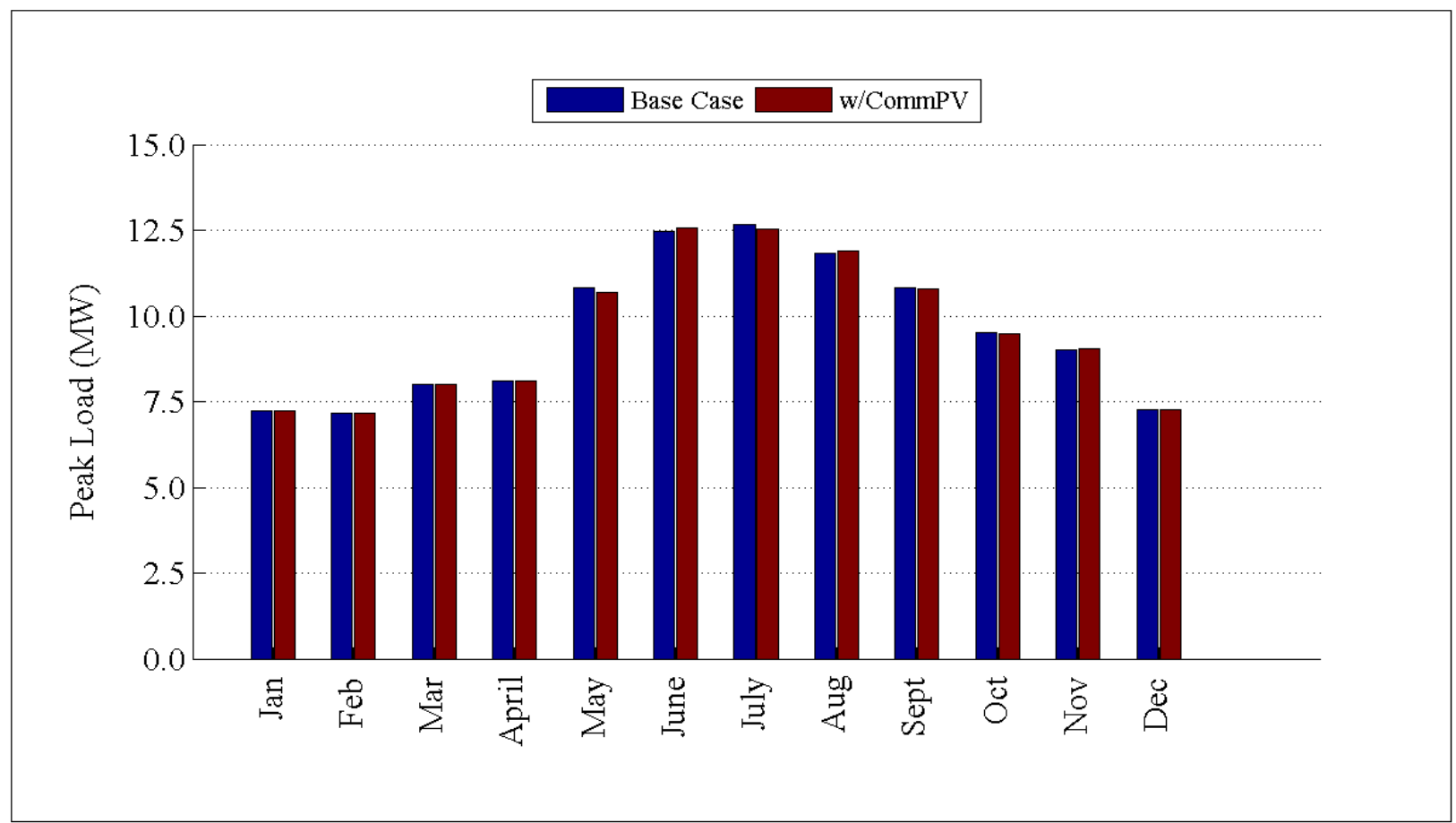

Figure D.151: Comparison of peak load by month for R2-35.00-1

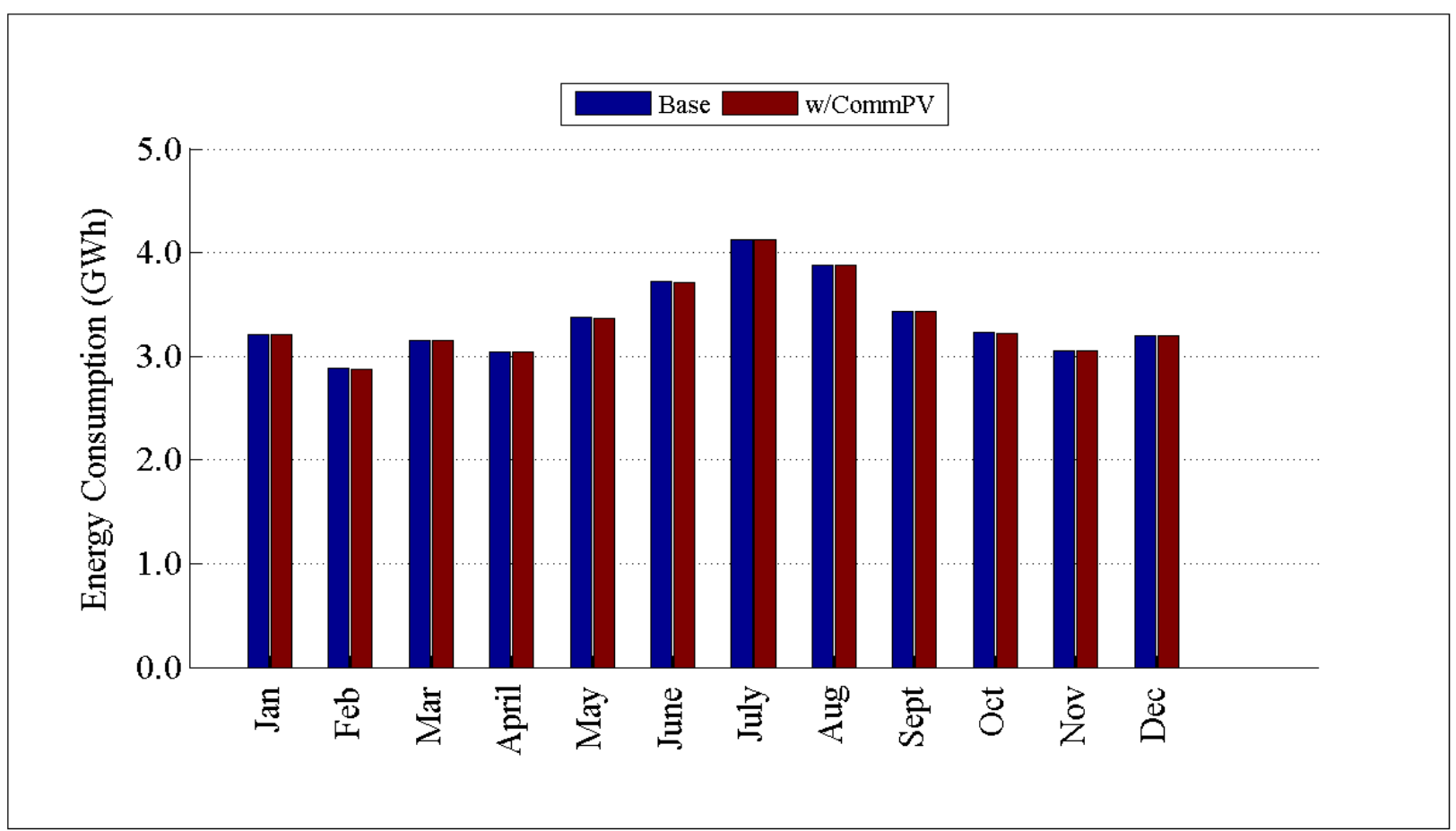

Figure D.152: Comparison of energy consumption by month for R2-35.00-1 


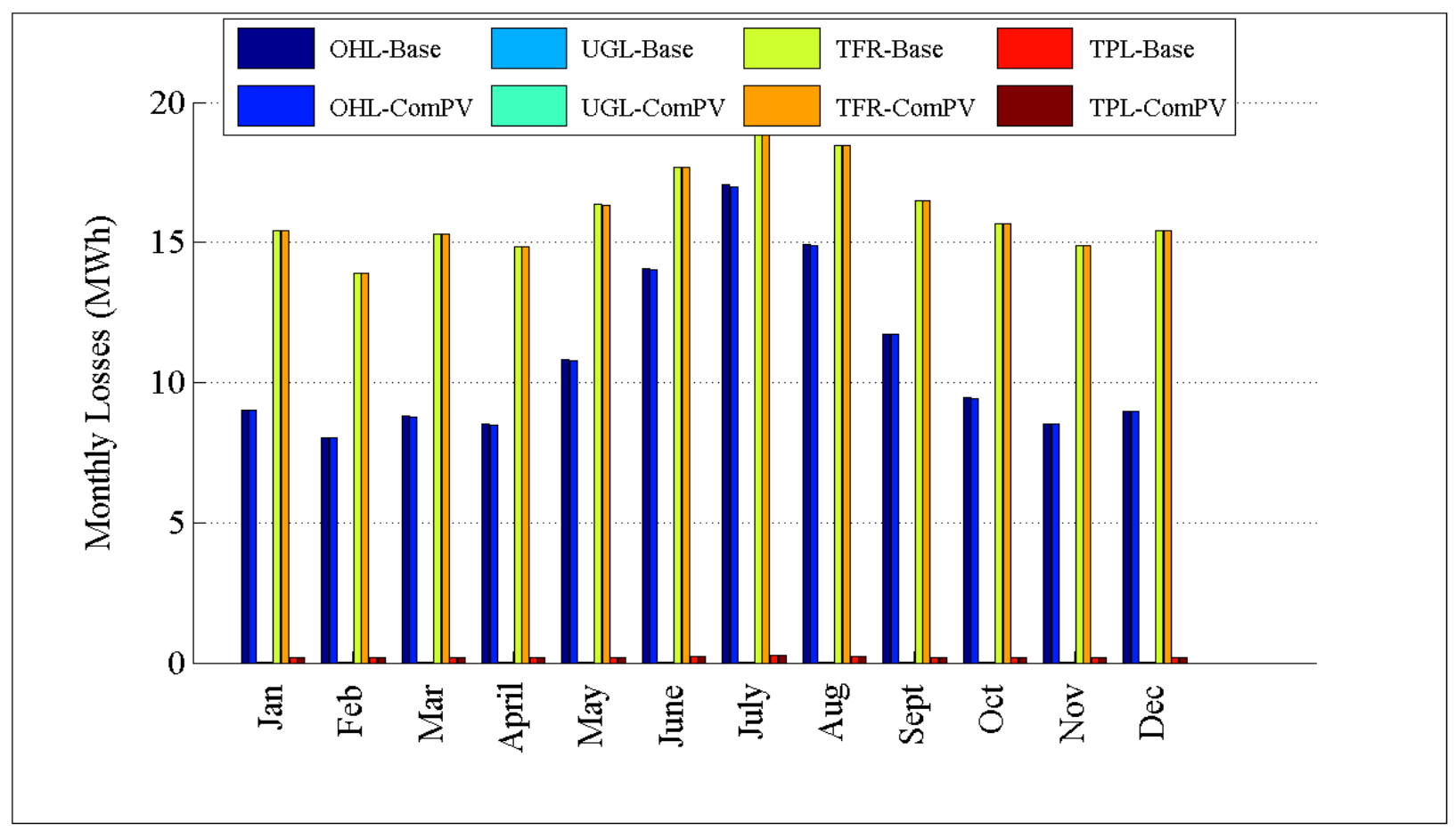

Figure D.153: Comparison of losses by month for R2-35.00-1

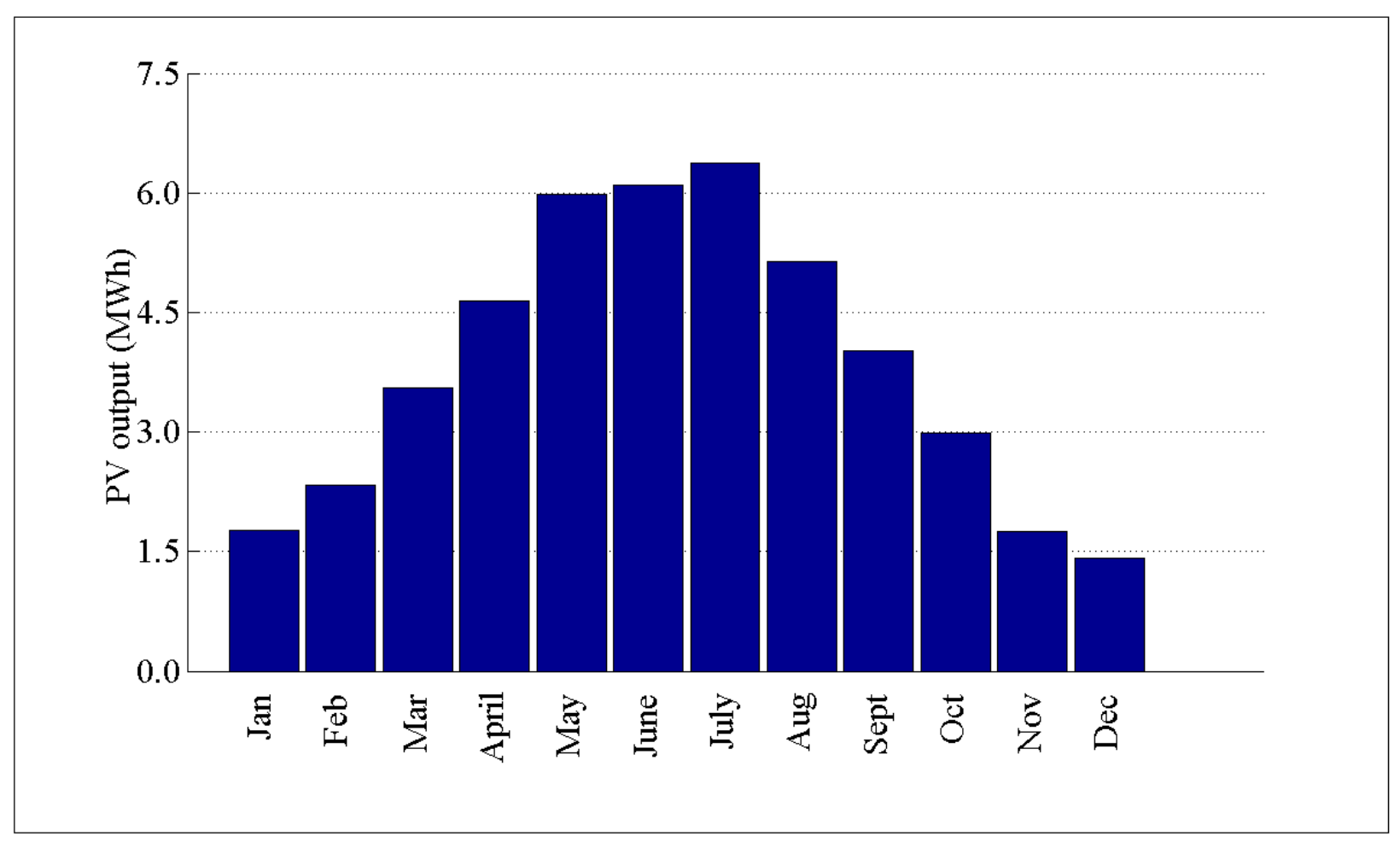

Figure D.154: PV output by month for R2-35.00-1 


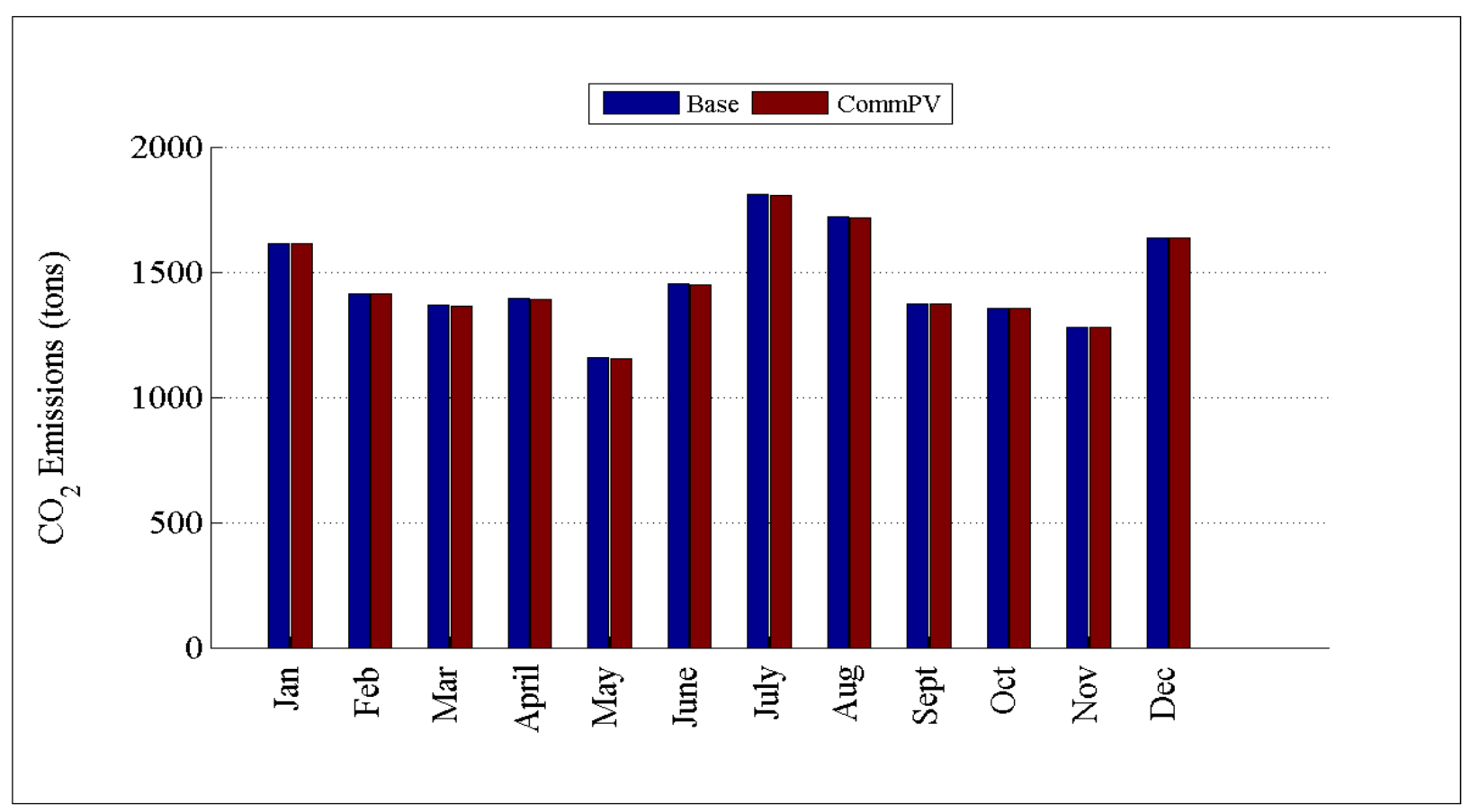

Figure D.155: Comparison of $\mathrm{CO}_{2}$ emissions by month for R2-35.00-1

\section{D.2.12 Detailed Commercial PV for GC-12.47-1_R3}

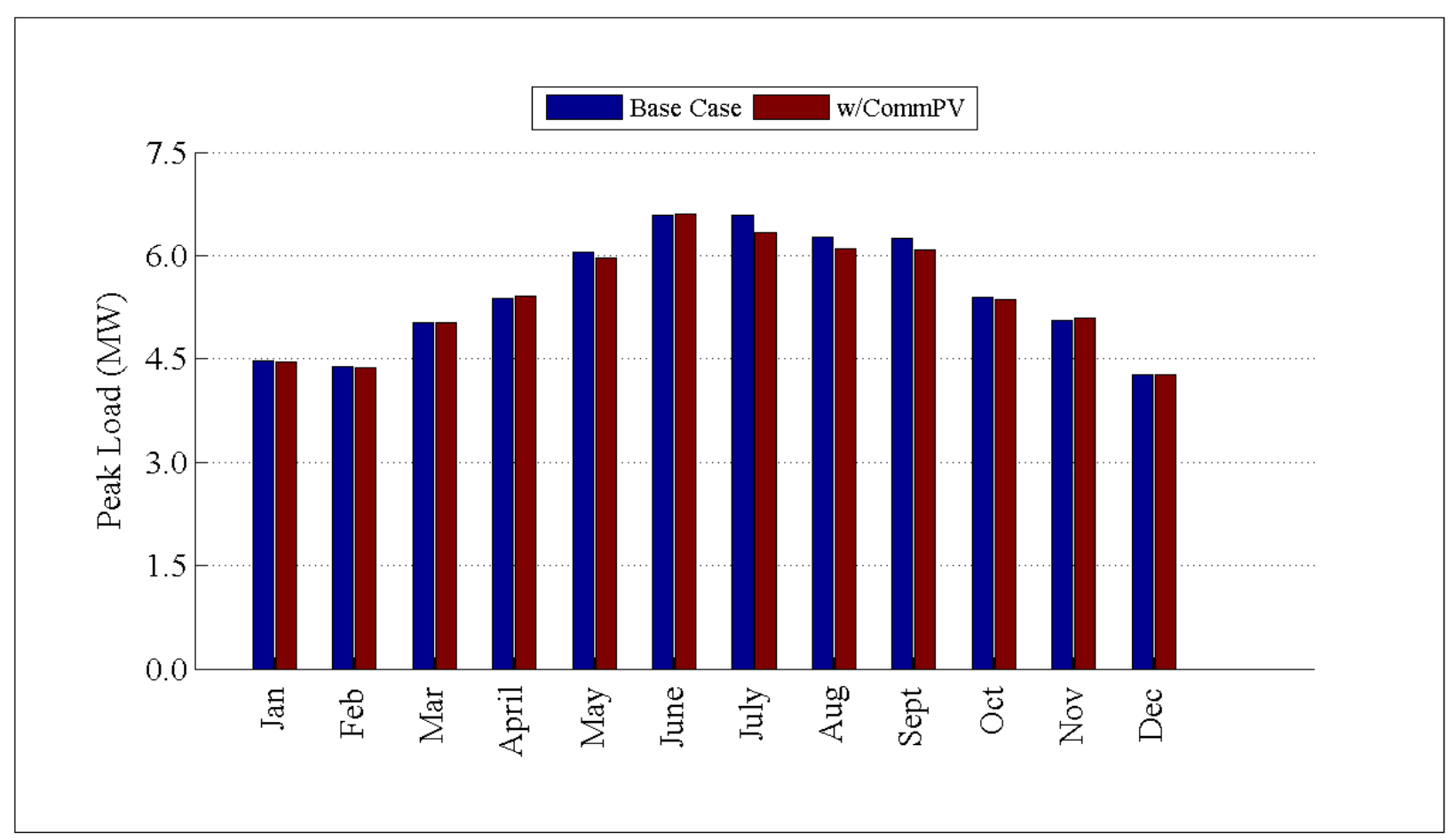

Figure D.156: Comparison of peak load by month for GC-12.47-1_R3 


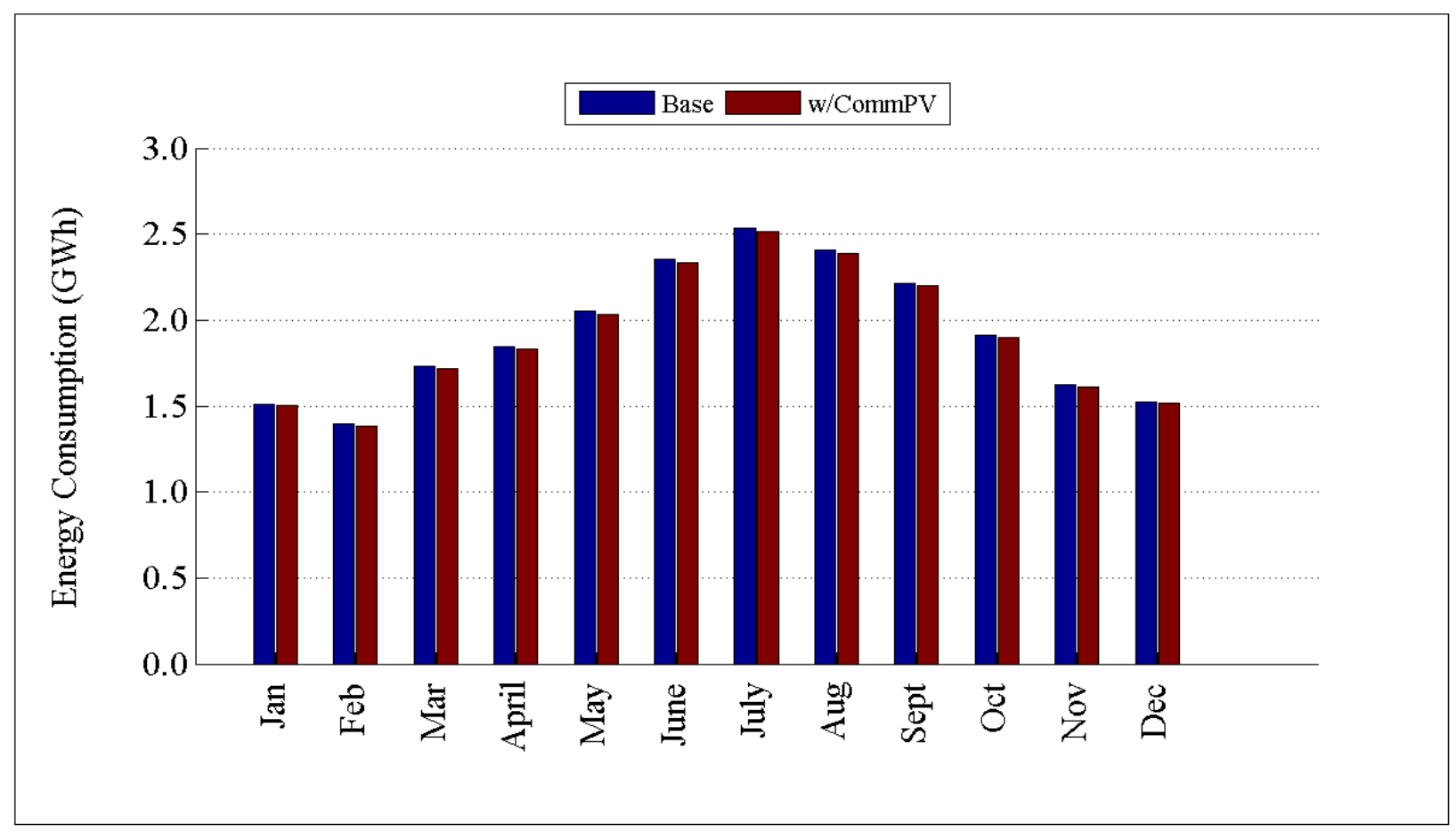

Figure D.157: Comparison of energy consumption by month for GC-12.47-1_R3

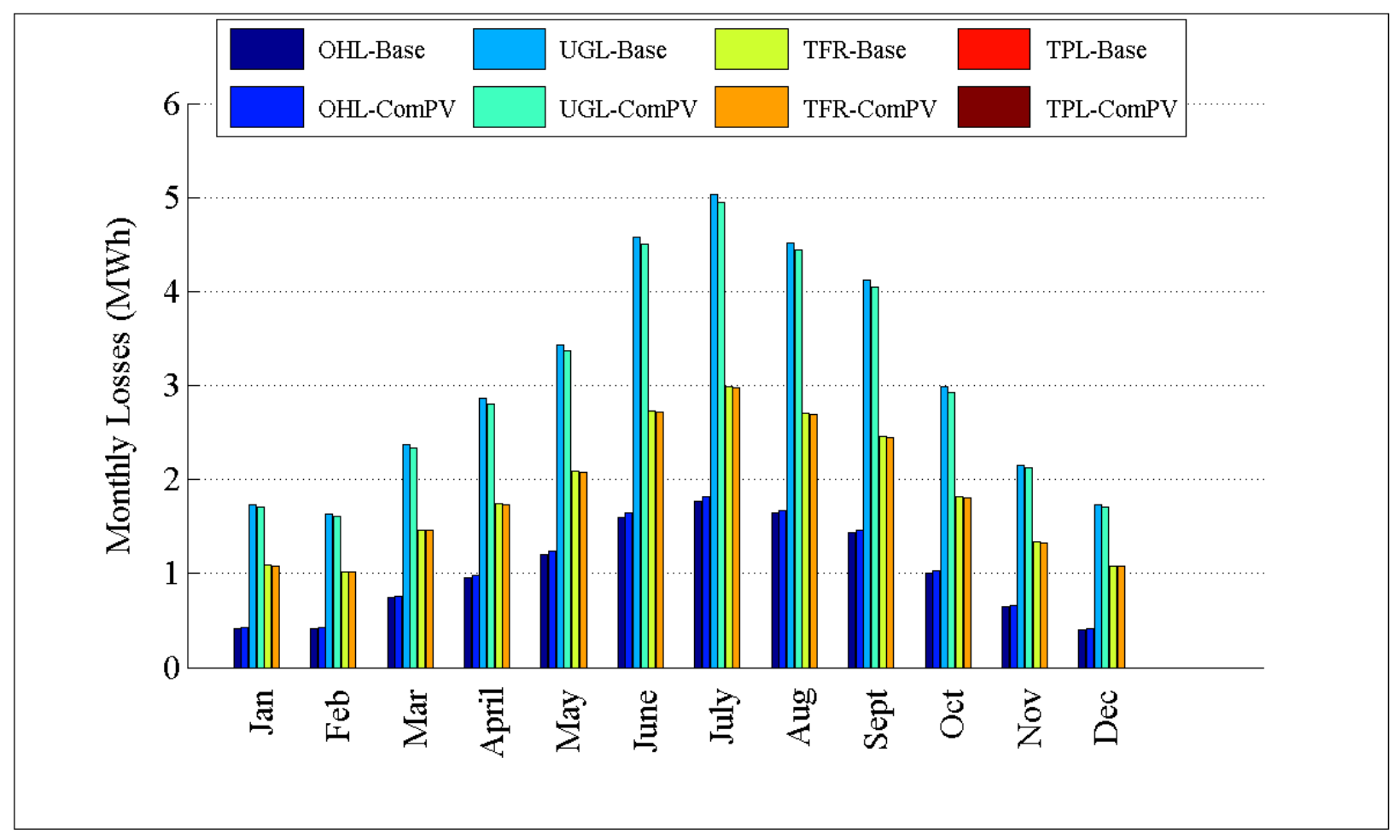

Figure D.158: Comparison of losses by month for GC-12.47-1_R3 


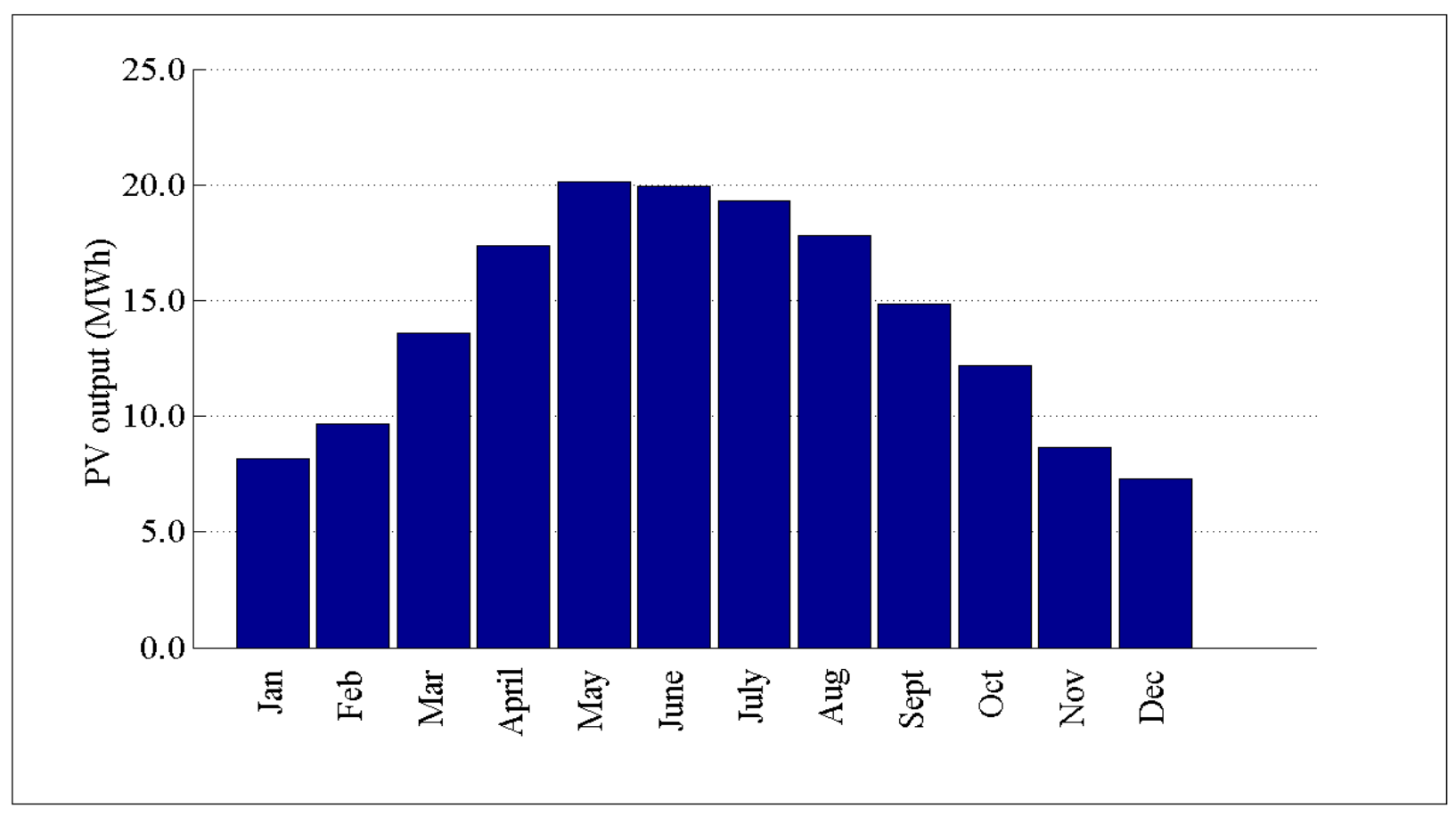

Figure D.159: PV output by month for GC-12.47-1_R3

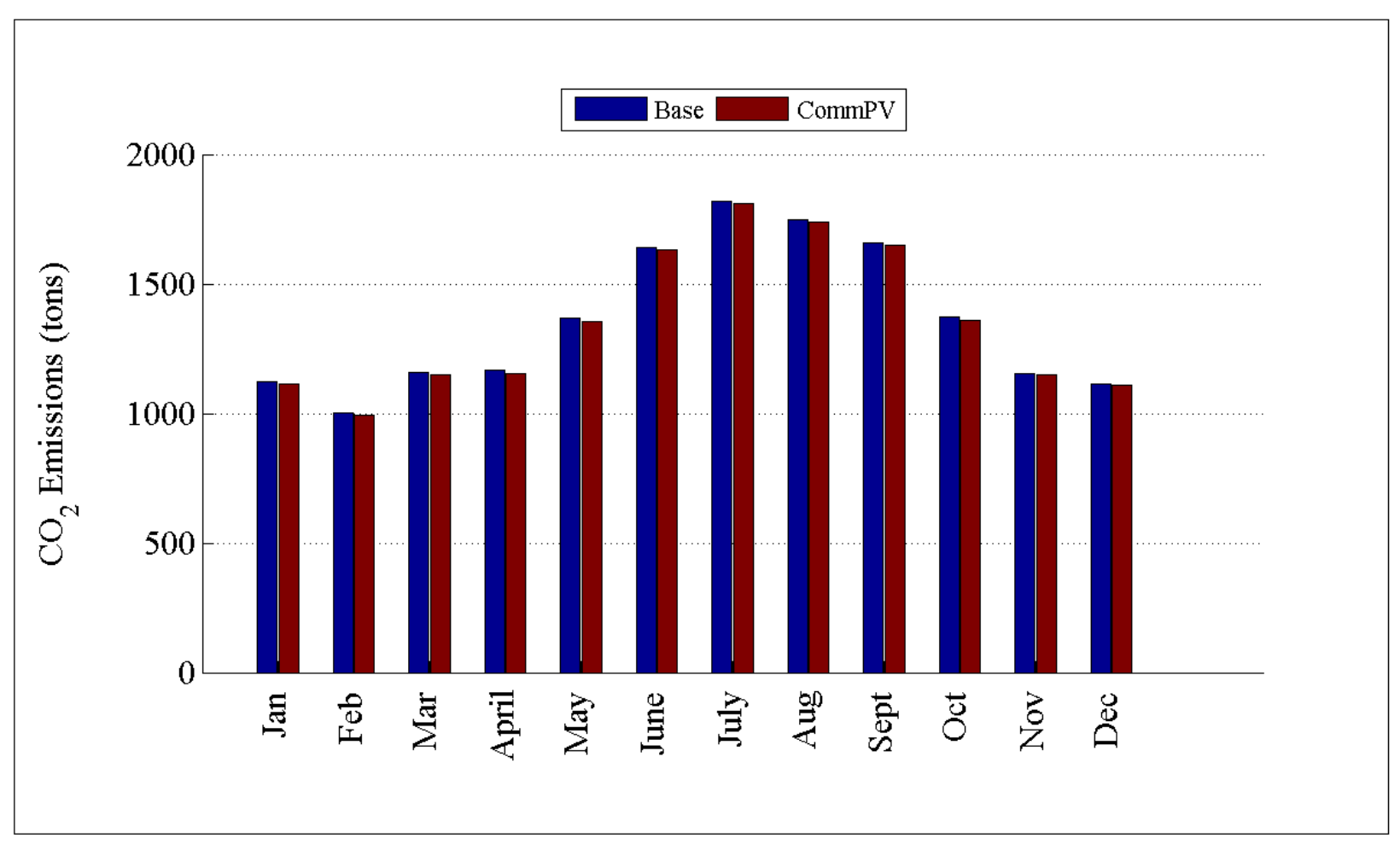

Figure D.160: Comparison of $\mathrm{CO}_{2}$ emissions by month for GC-12.47-1_R3 


\section{D.2.13 Detailed Commercial PV Plots for R3-12.47-1}

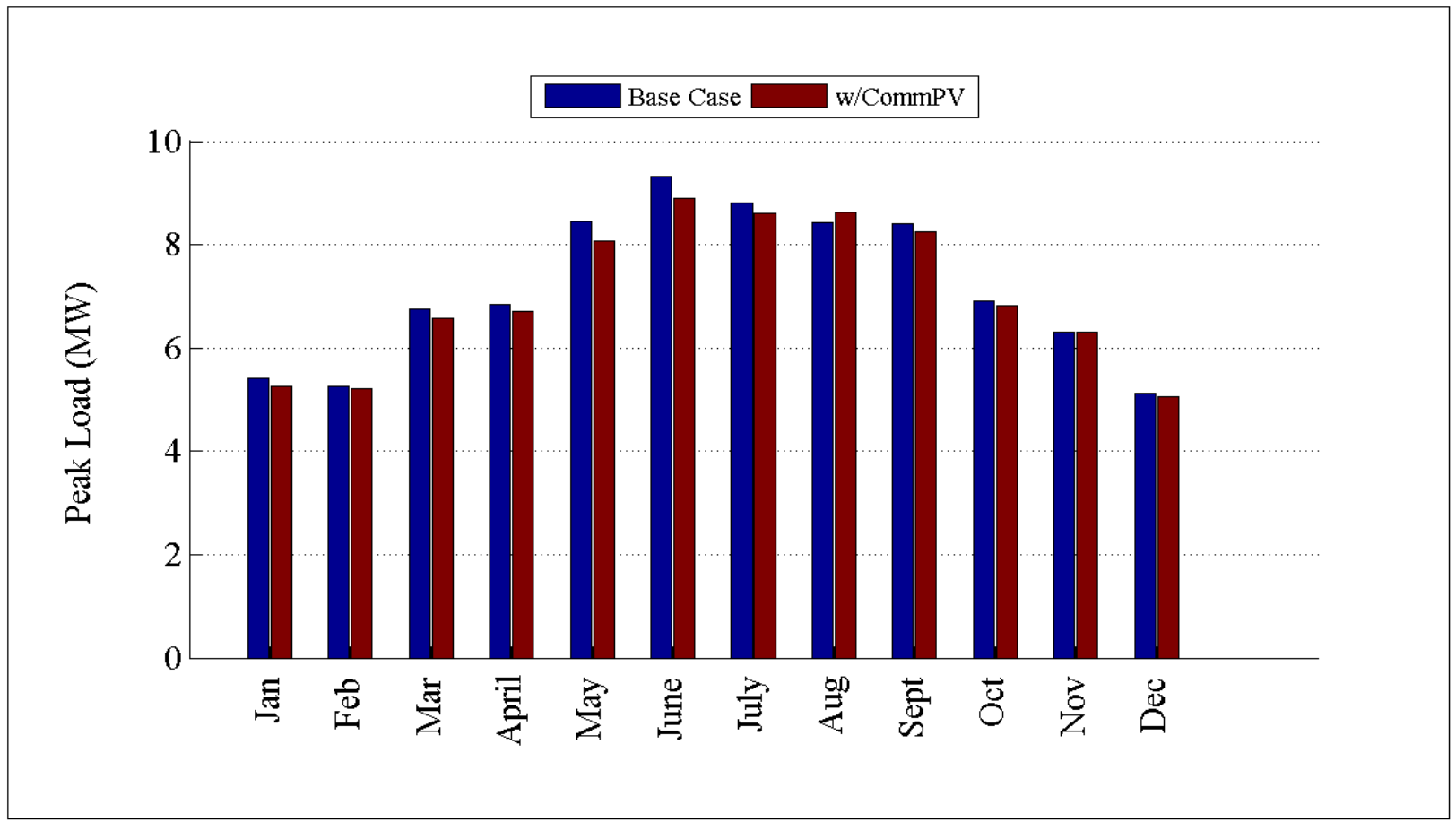

Figure D.161: Comparison of peak load by month for R3-12.47-1

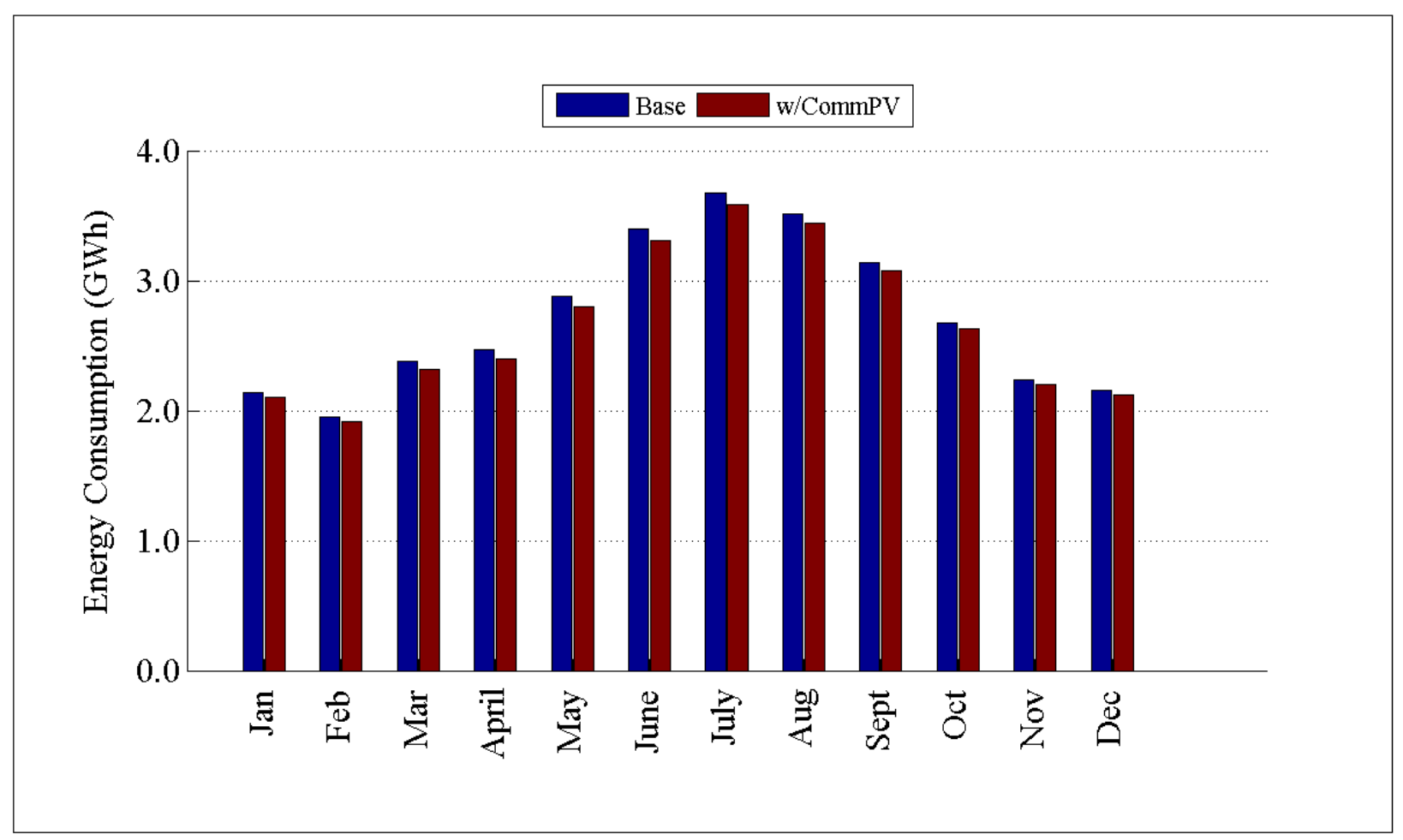

Figure D.162: Comparison of energy consumption by month for R3-12.47-1 


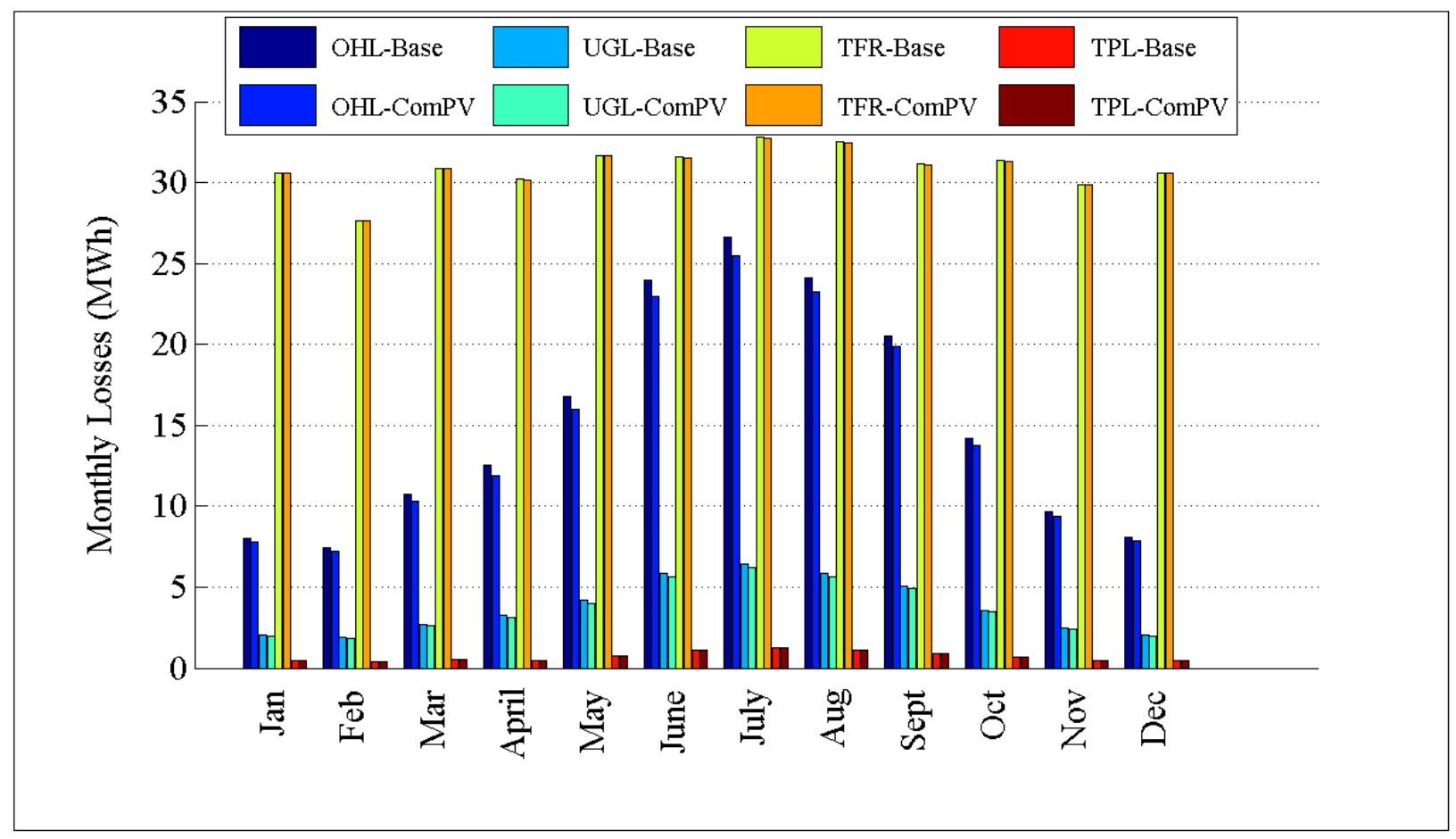

Figure D.163: Comparison of losses by month for R3-12.47-1

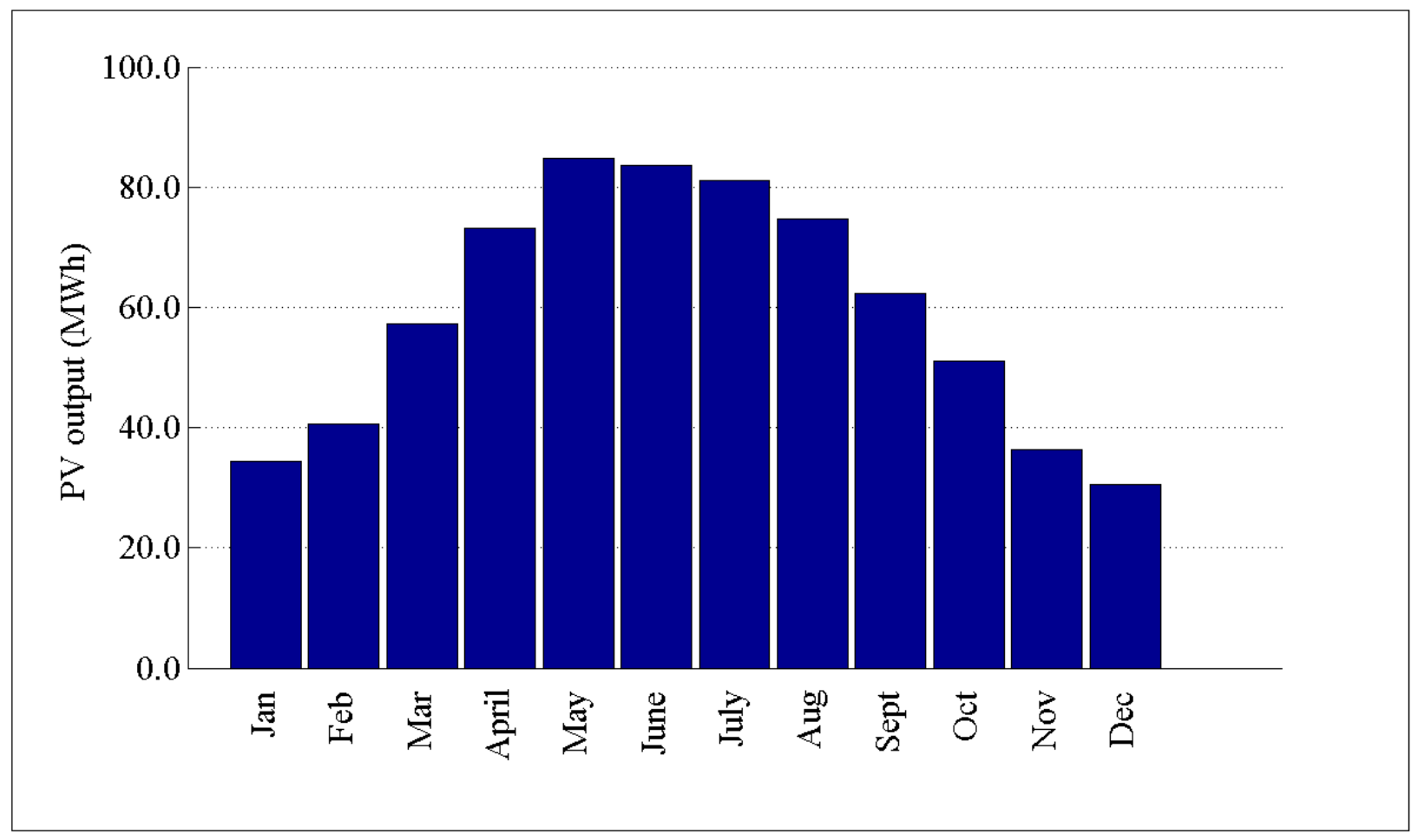

Figure D.164: PV output by month for R3-12.47-1 


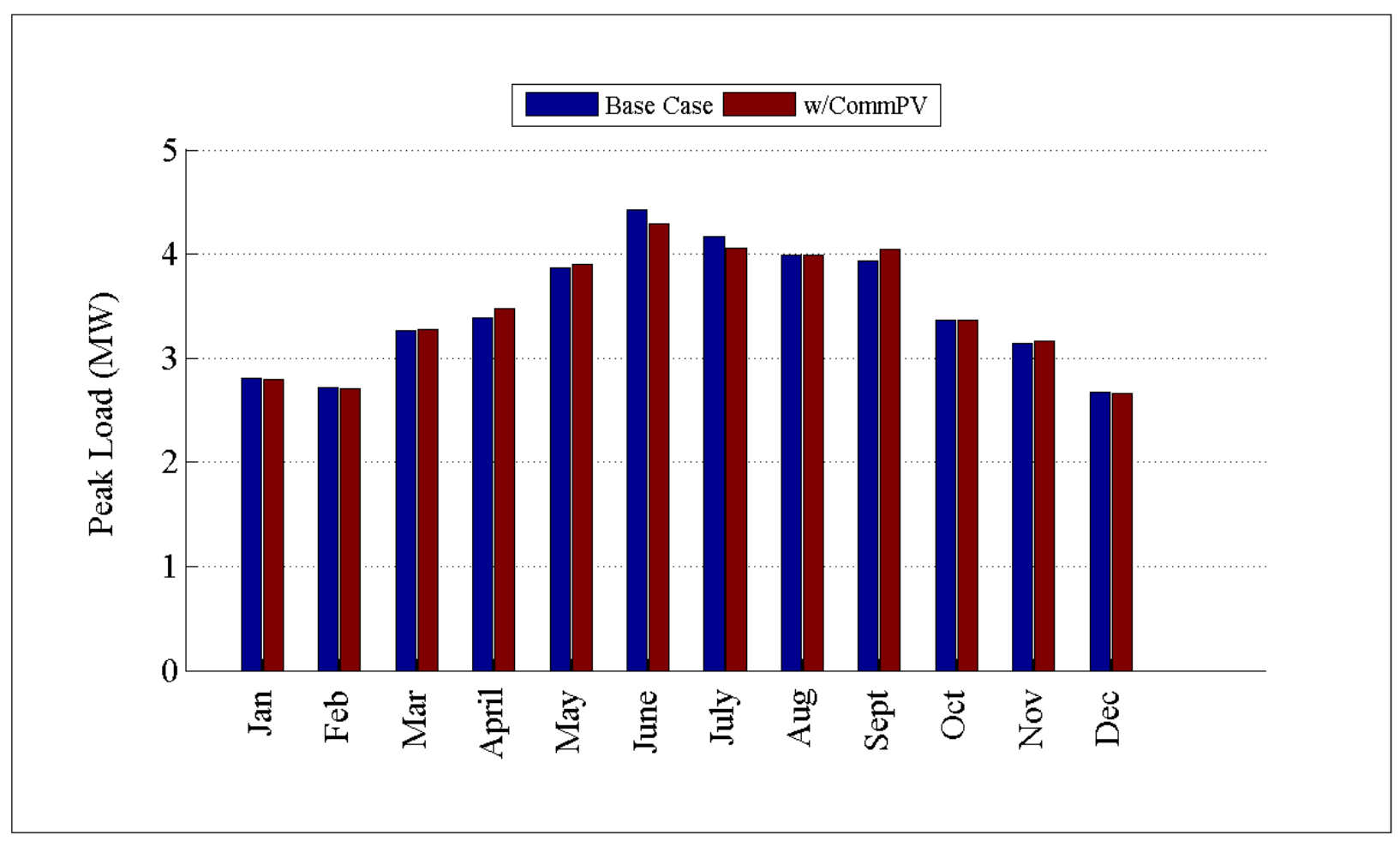

Figure D.165: Comparison of $\mathrm{CO}_{2}$ emissions by month for R3-12.47-1

D.2.14 Detailed Commercial PV Plots for R3-12.47-2 


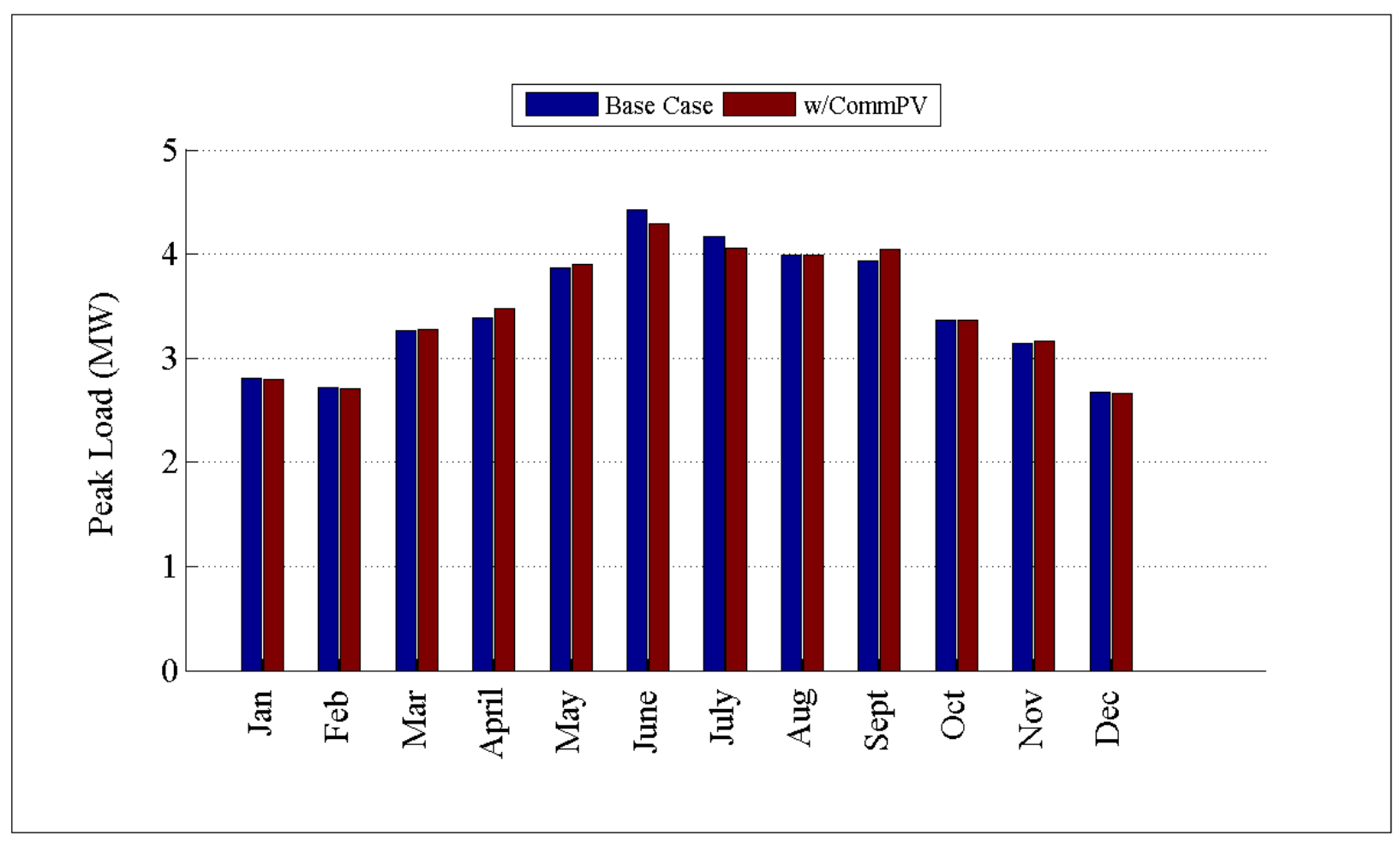

Figure D.166: Comparison of peak load by month for R3-12.47-2

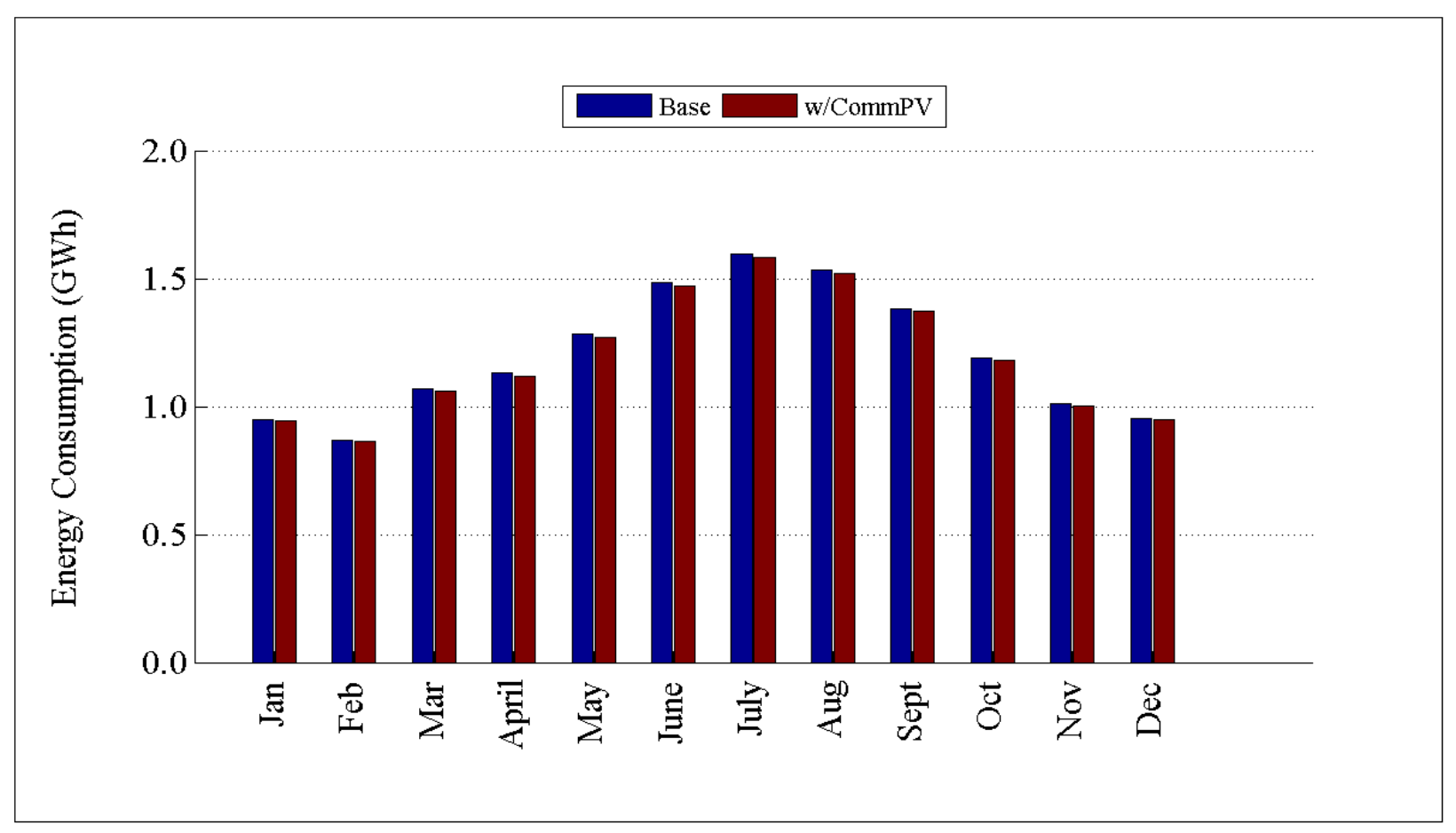

Figure D.167: Comparison of energy consumption by month for R3-12.47-2 


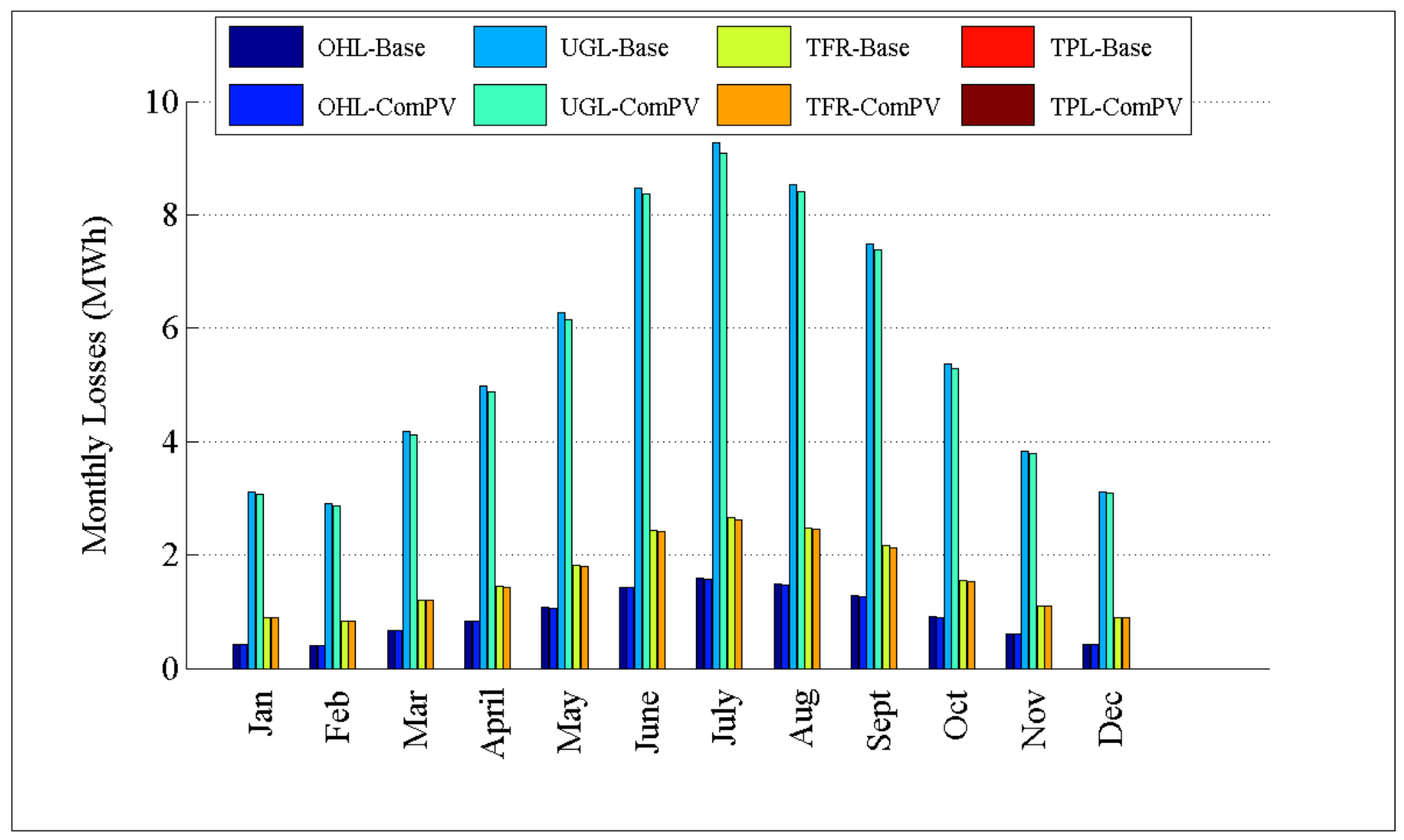

Figure D.168: Comparison of losses by month for R3-12.47-2

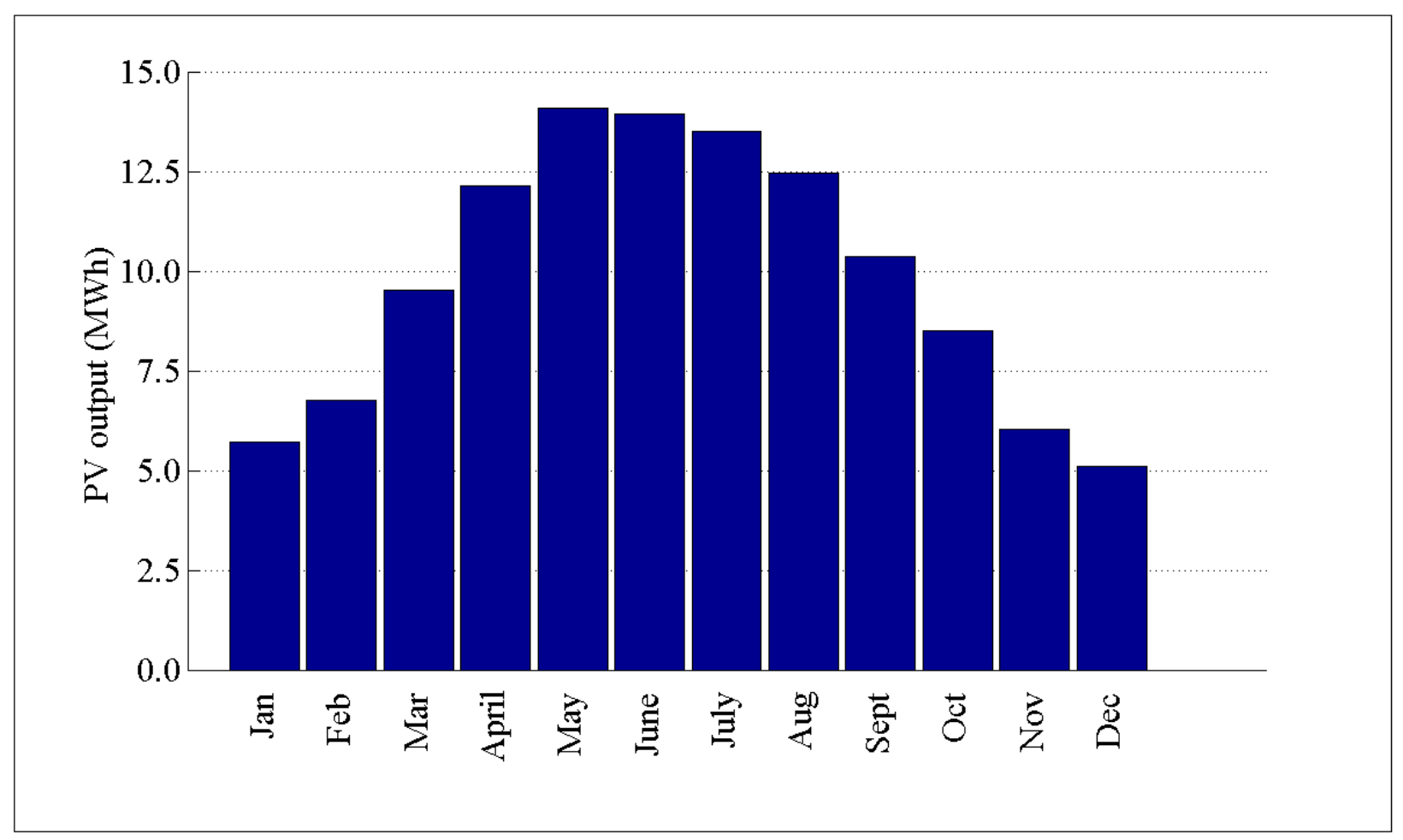

Figure D.169: PV output by month for R3-12.47-2 


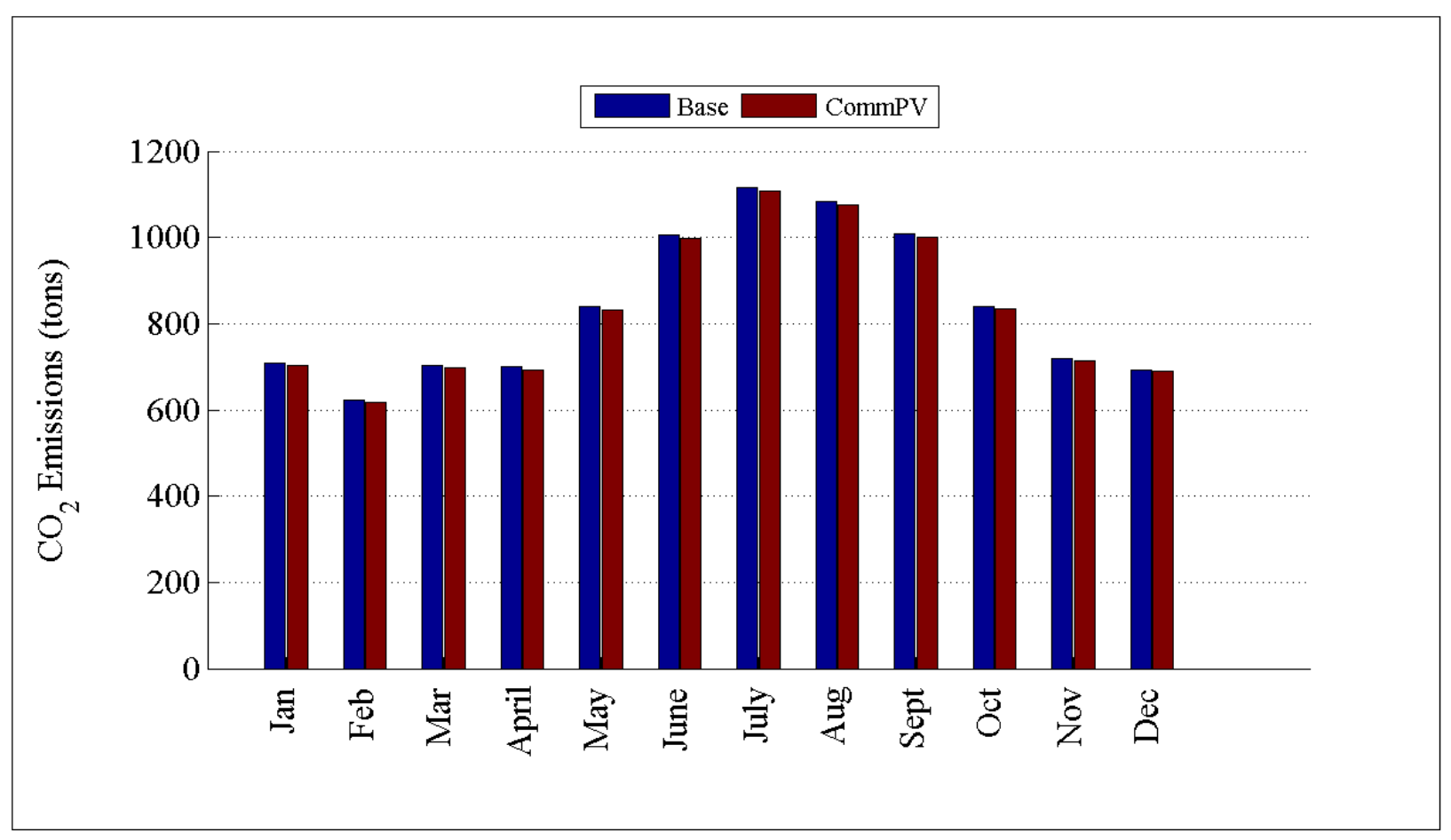

Figure D.170: Comparison of $\mathrm{CO}_{2}$ emissions by month for R3-12.47-2

\section{D.2.15 Detailed Commercial PV Plots for R3-12.47-3}

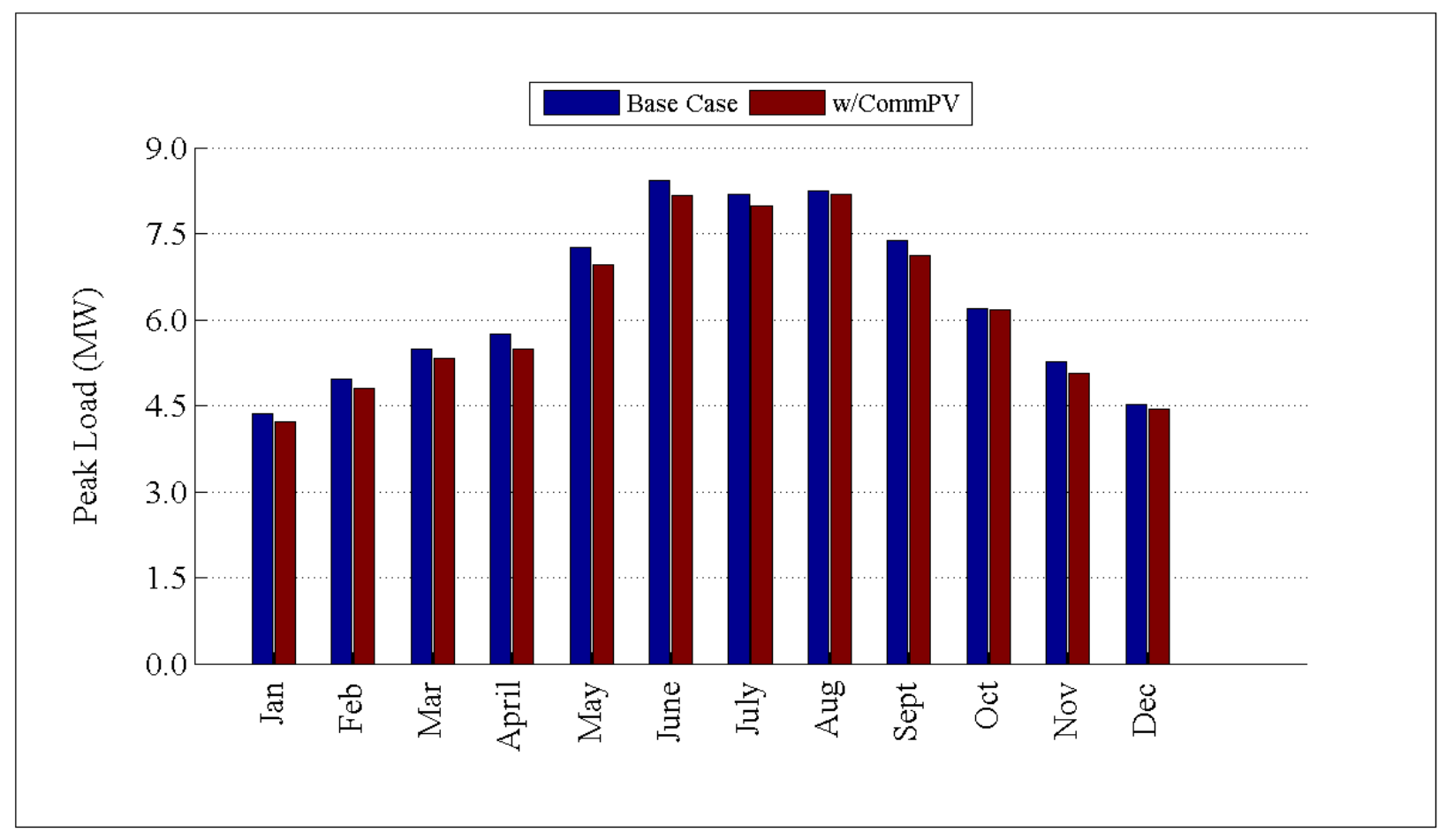

Figure D.171: Comparison of peak load by month for R3-12.47-3 


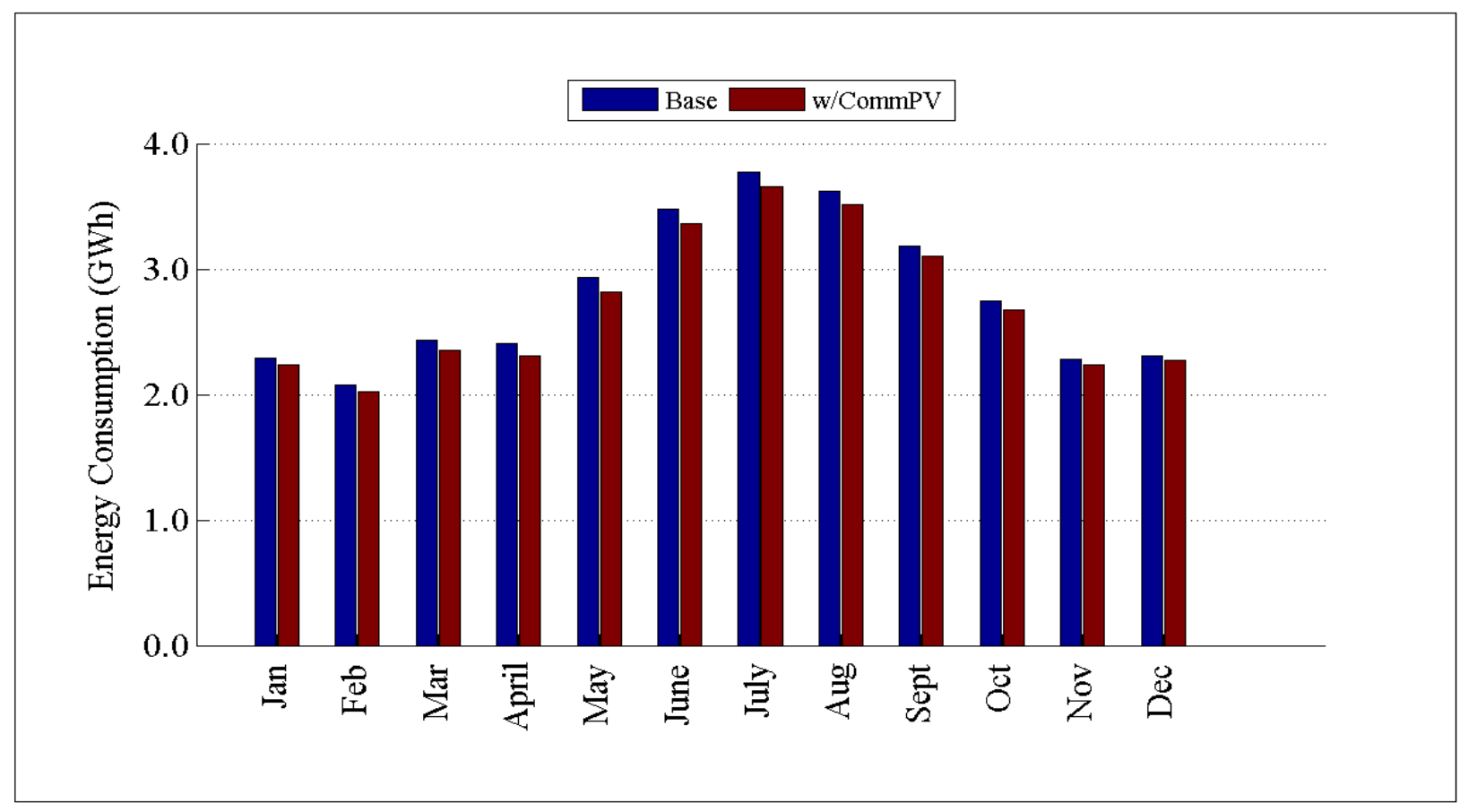

Figure D.172: Comparison of energy consumption by month for R3-12.47-3

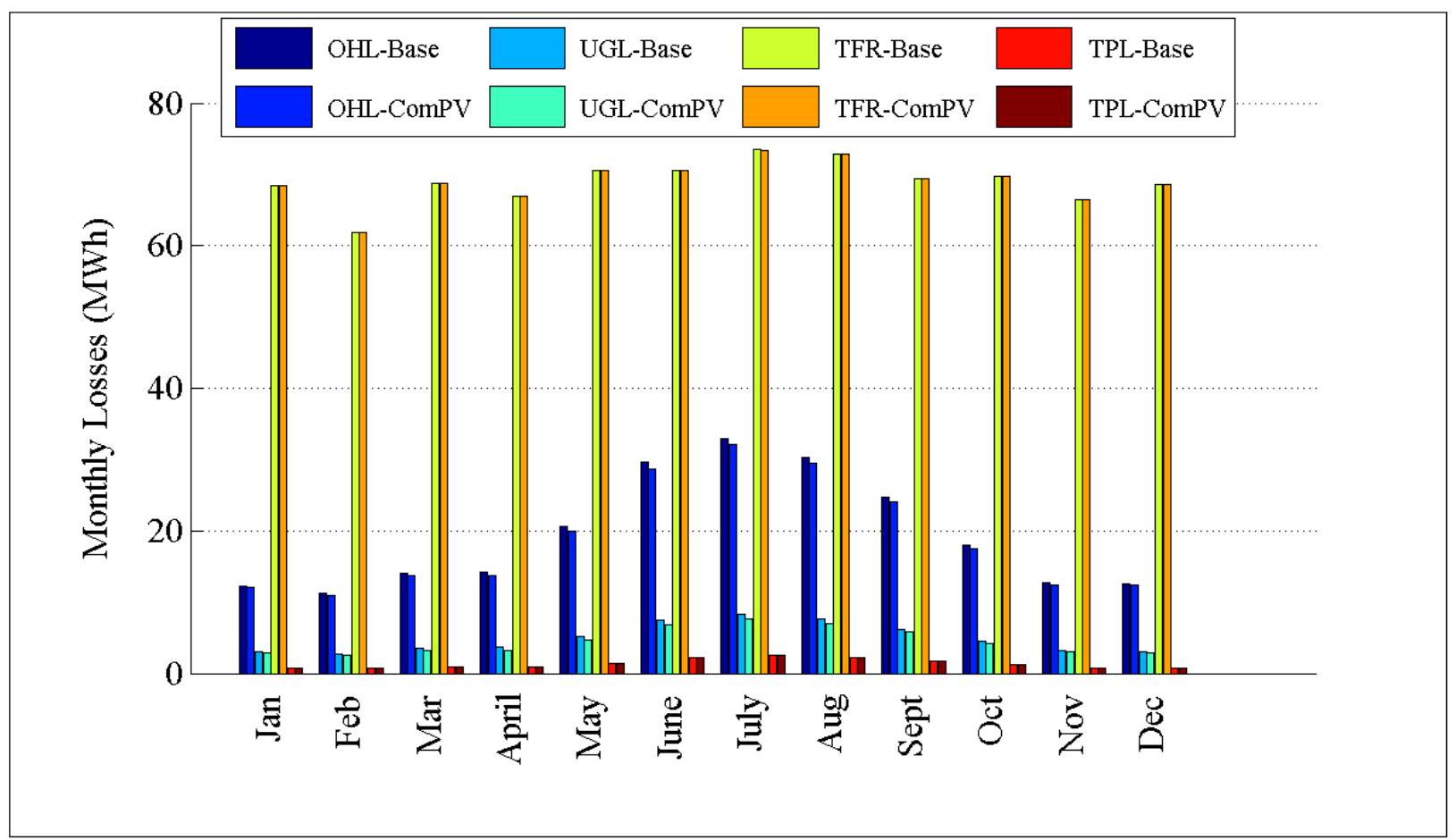

Figure D.173: Comparison of losses by month for R3-12.47-3 


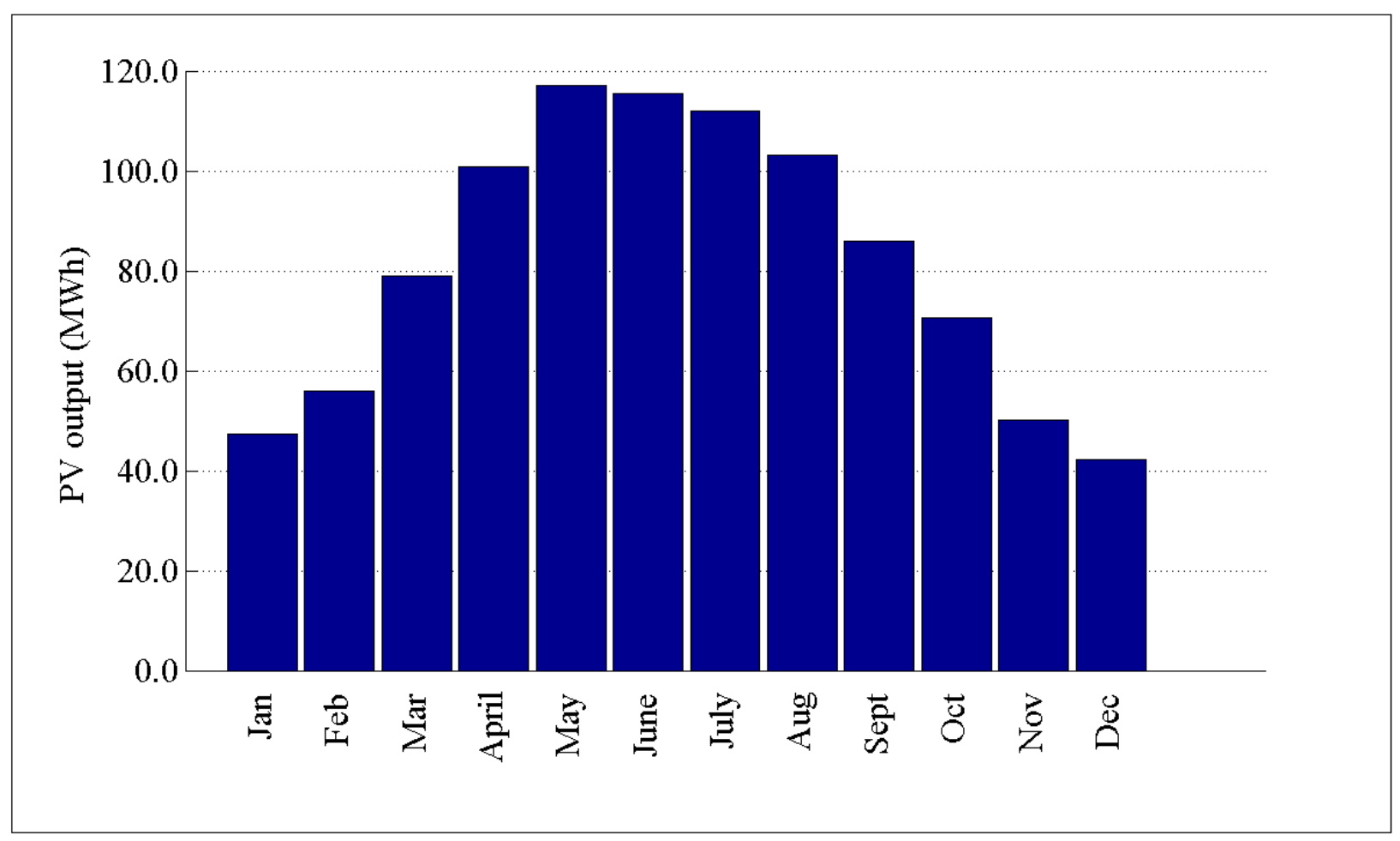

Figure D.174: PV output by month for R3-12.47-3

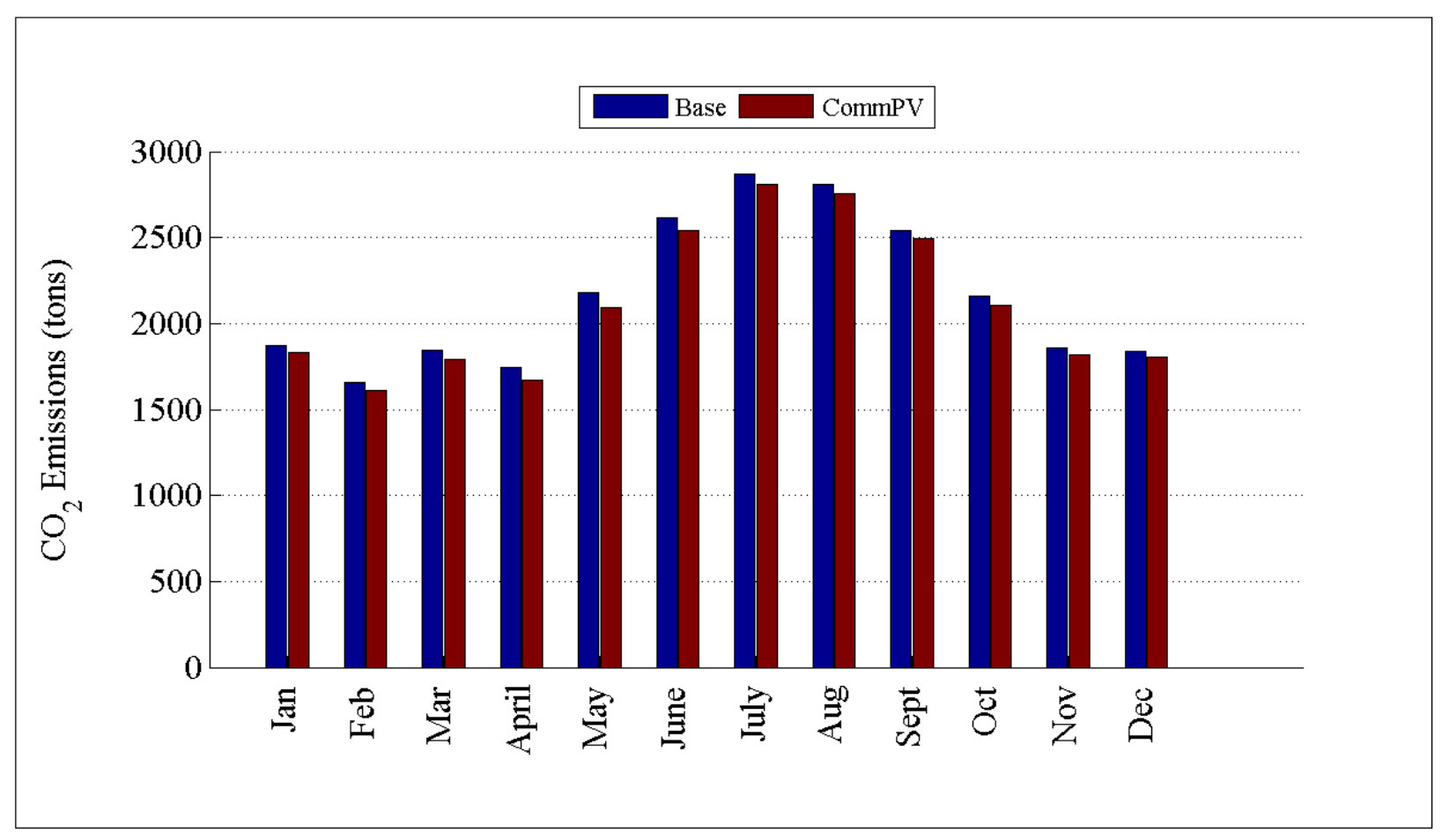

Figure D.175: Comparison of $\mathrm{CO}_{2}$ emissions by month for R3-12.47-3 
D.2.16 Detailed Commercial PV Plots for GC-12.47-1_R4

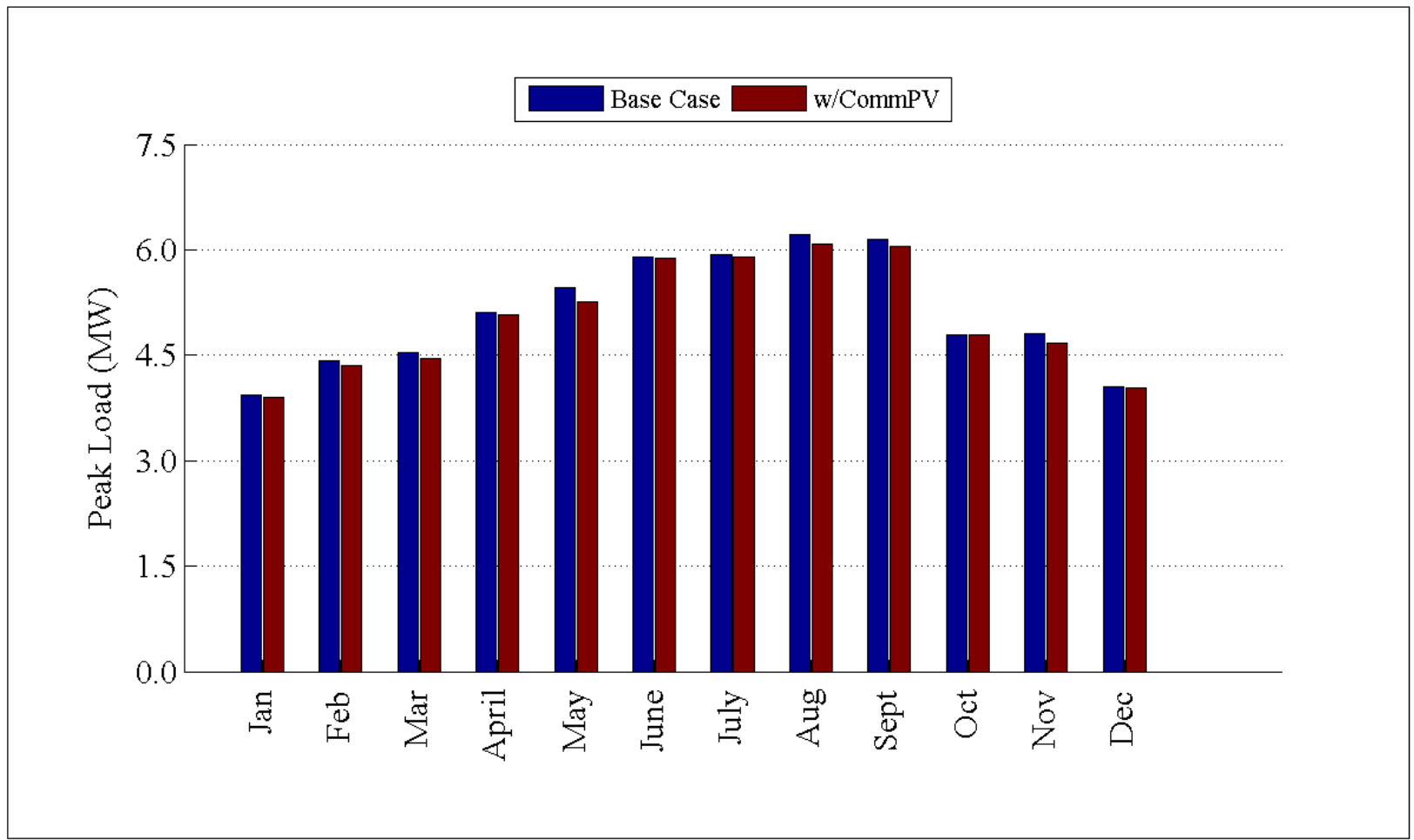

Figure D.176: Comparison of peak load by month for GC-12.47-1_R4

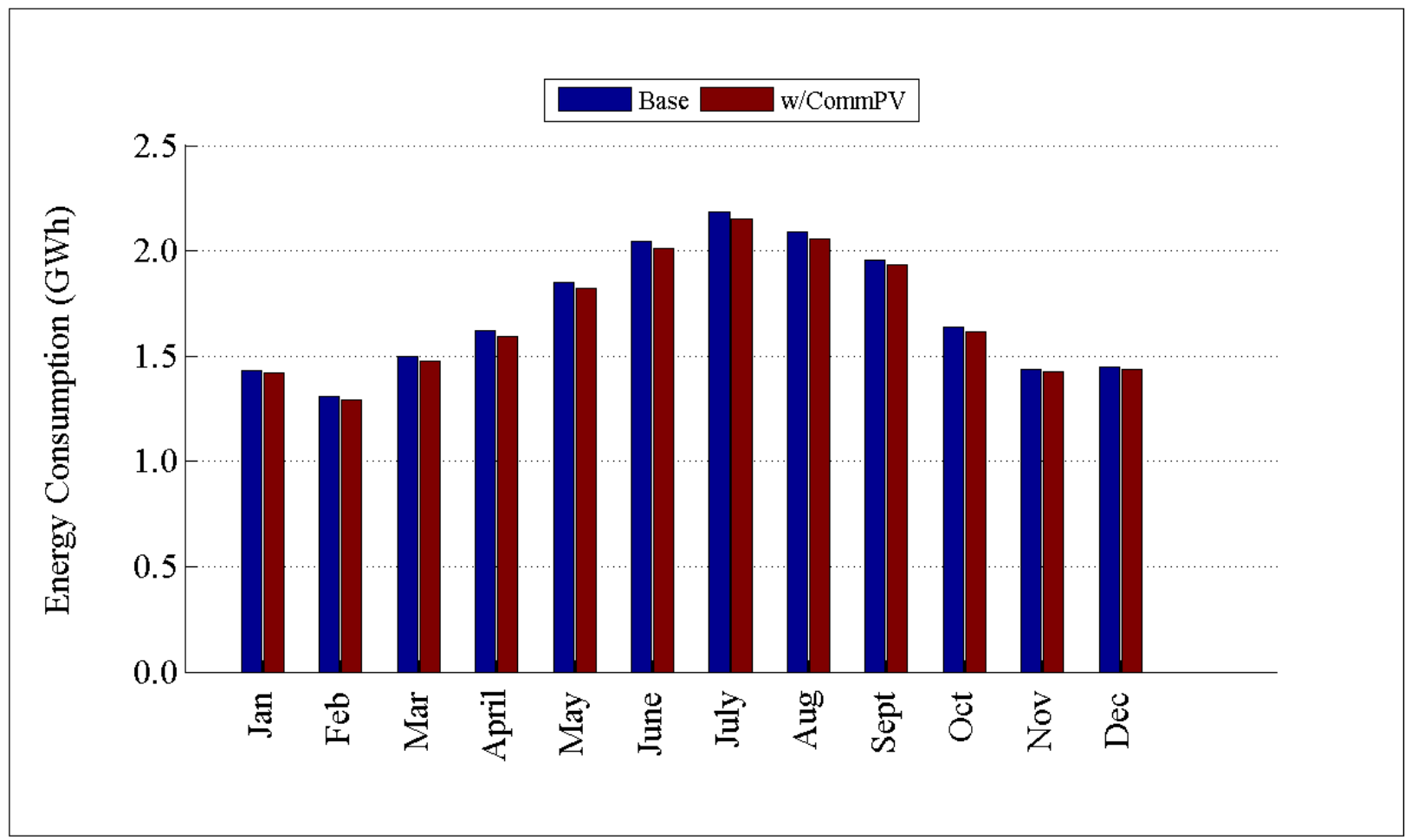

Figure D.177: Comparison of energy consumption by month for GC-12.47-1_R4 


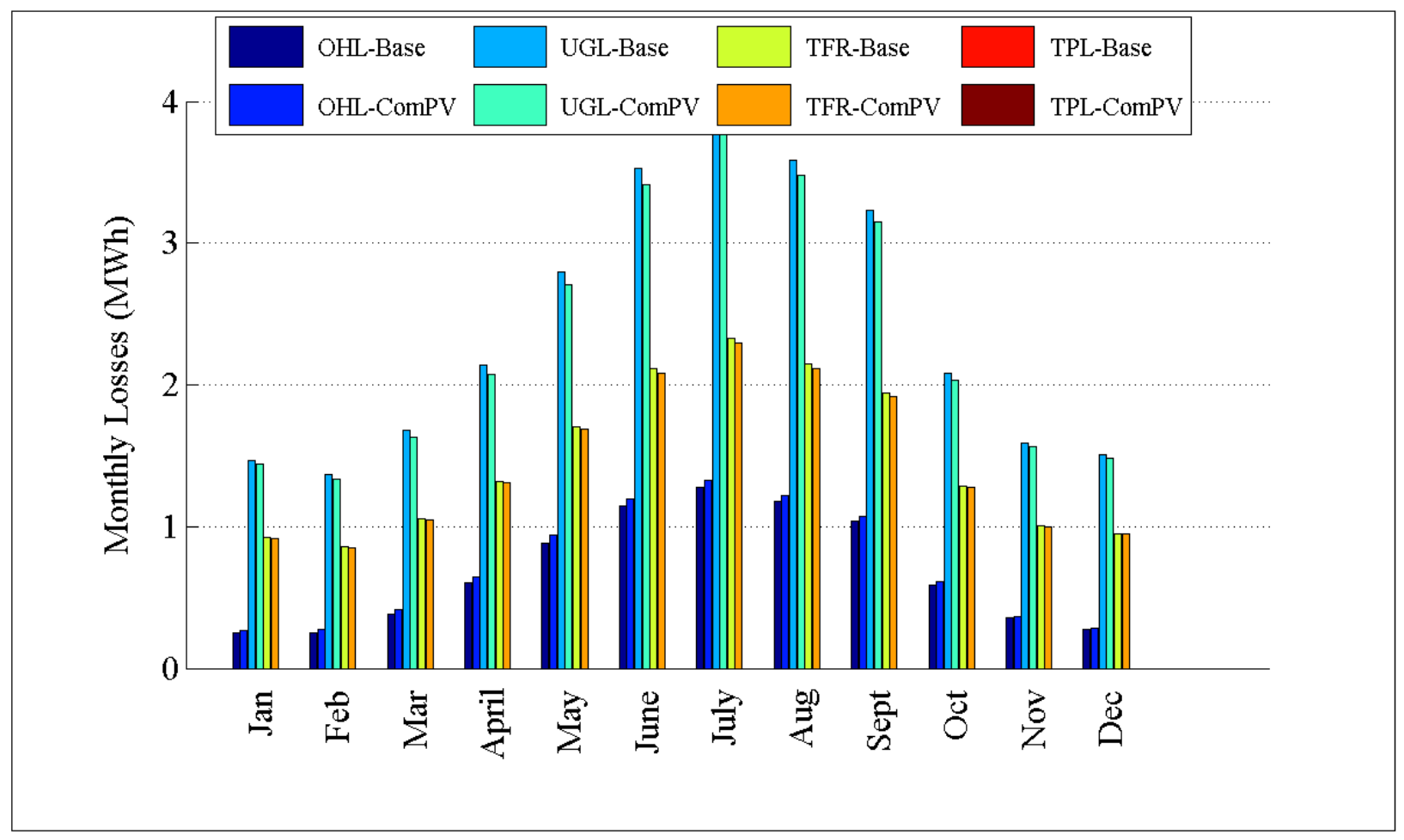

Figure D.178: Comparison of losses by month for GC-12.47-1_R4

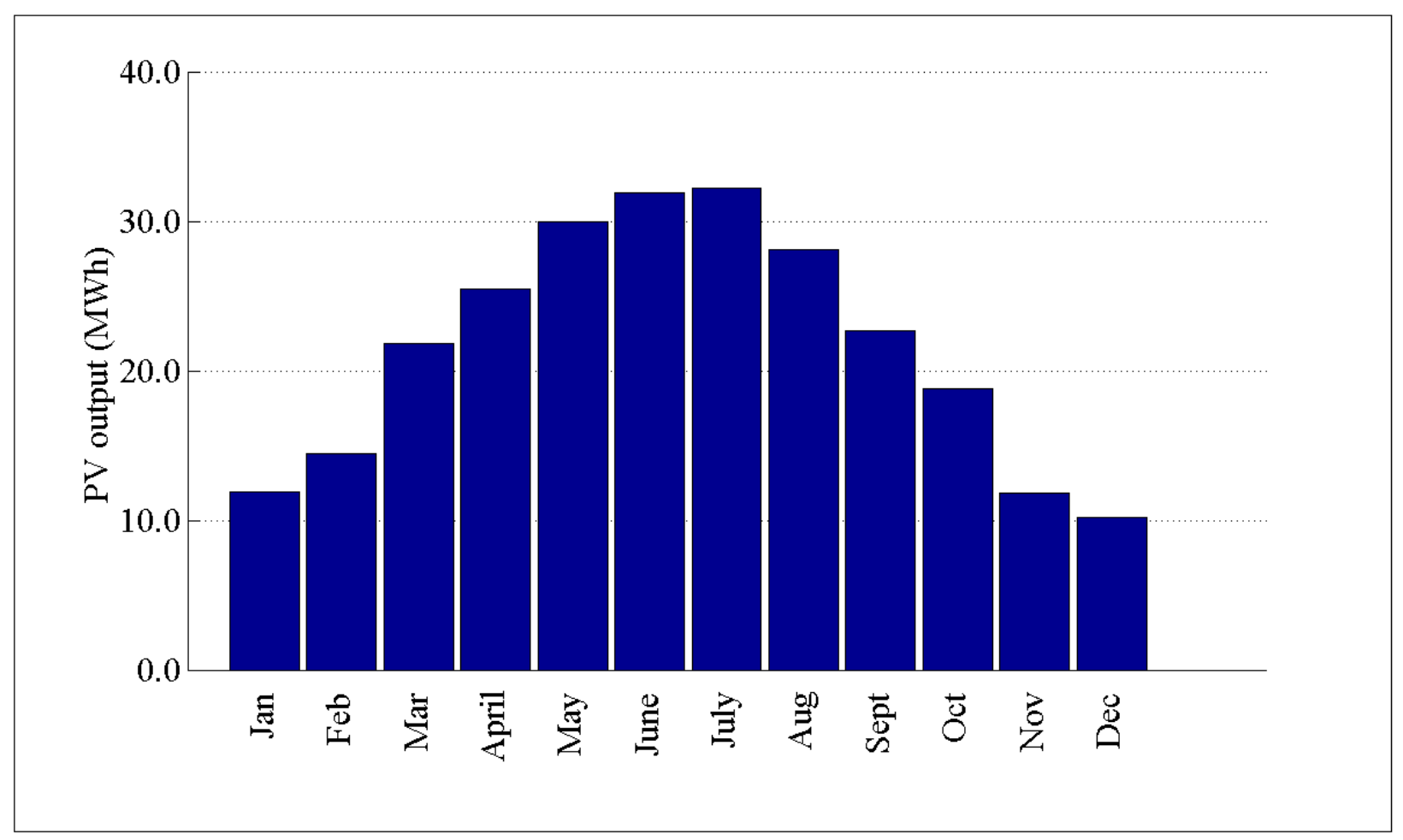

Figure D.179: PV output by month for GC-12.47-1_R4 


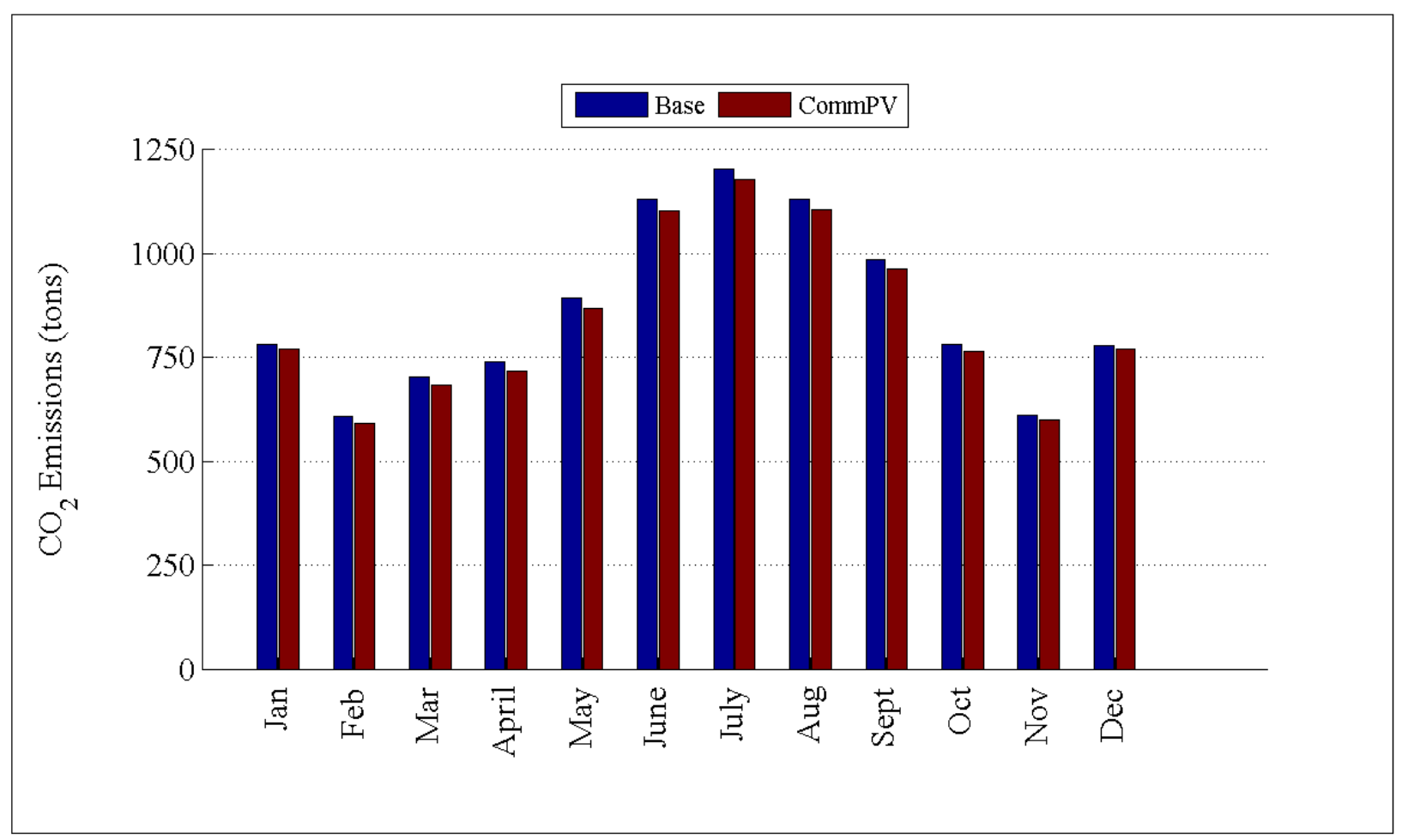

Figure D.180: Comparison of $\mathrm{CO}_{2}$ emissions by month for GC-12.47-1_R4

D.2.17 Detailed Commercial PV Plots for R4-12.47-1 


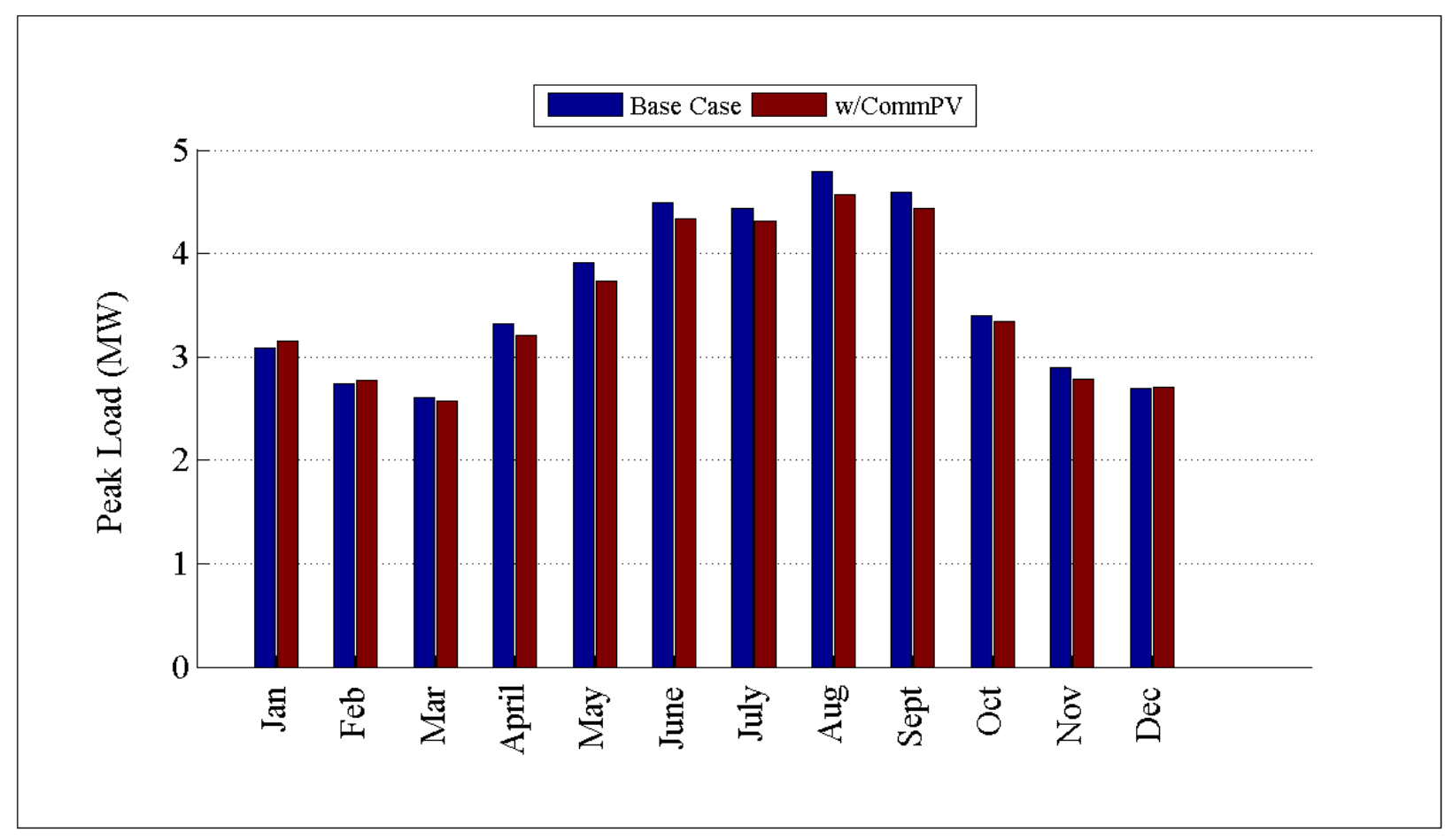

Figure D.181: Comparison of peak load by month for R4-12.47-1

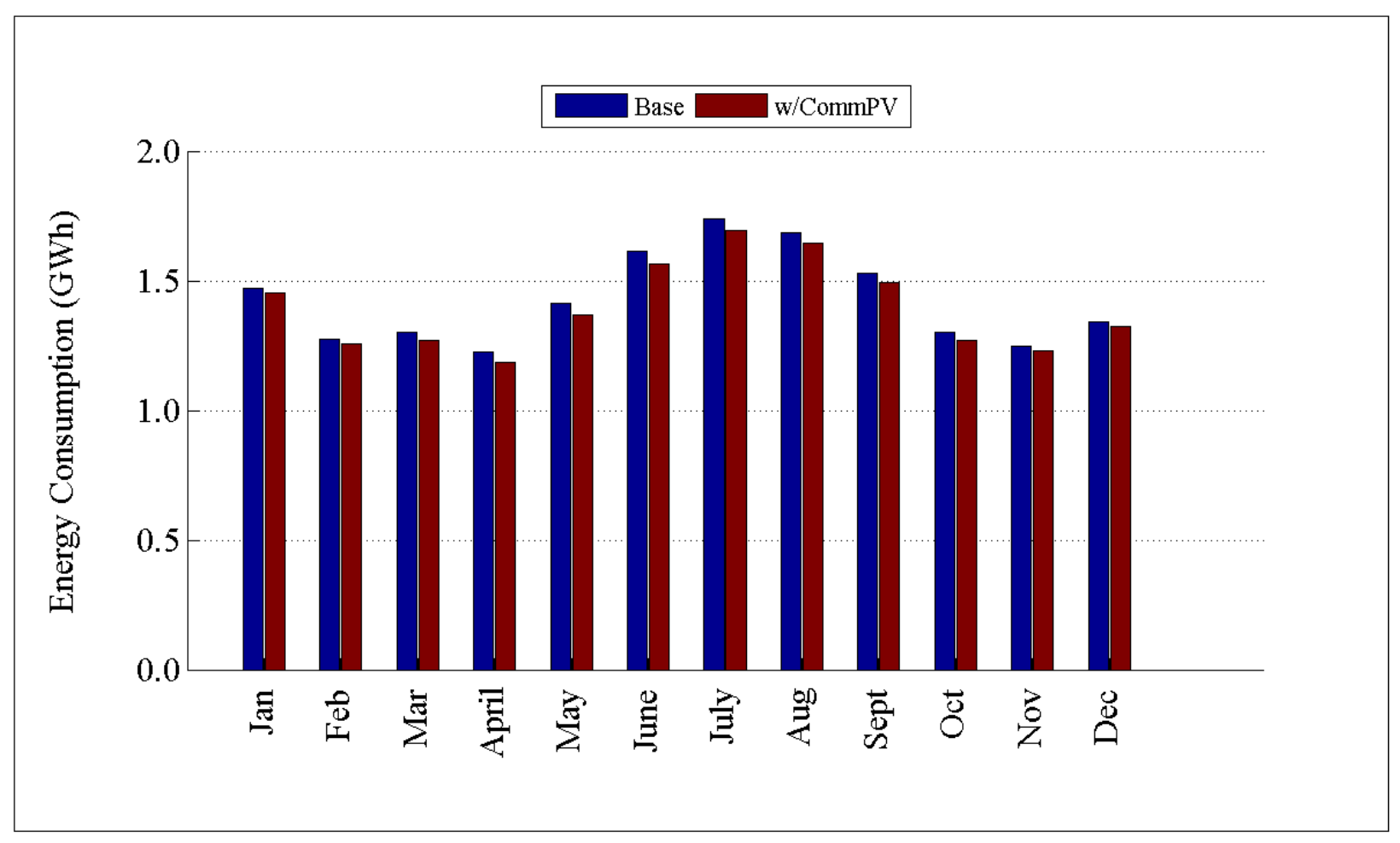

Figure D.182: Comparison of energy consumption by month for R4-12.47-1 


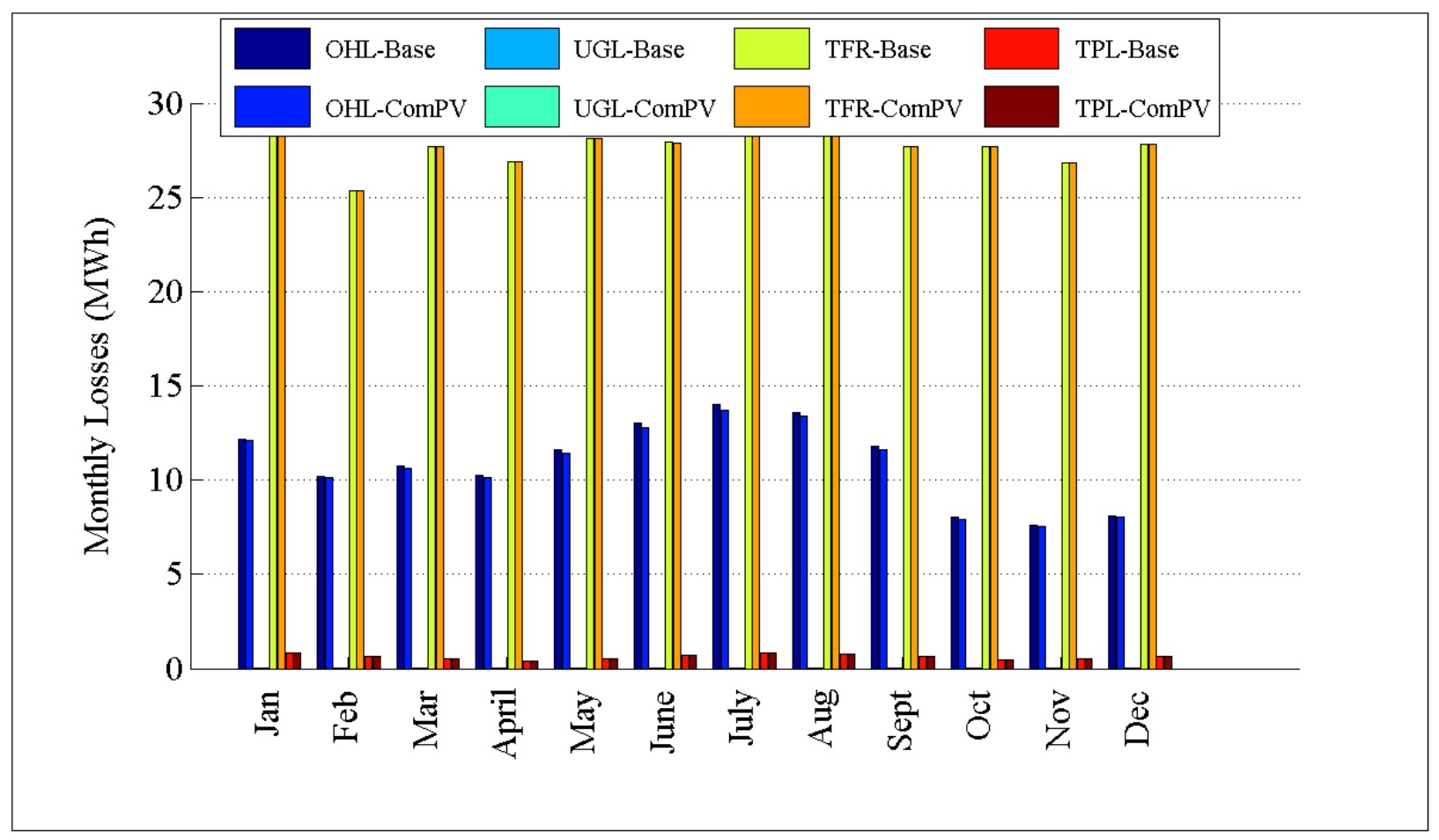

Figure D.183: Comparison of losses by month for R4-12.47-1

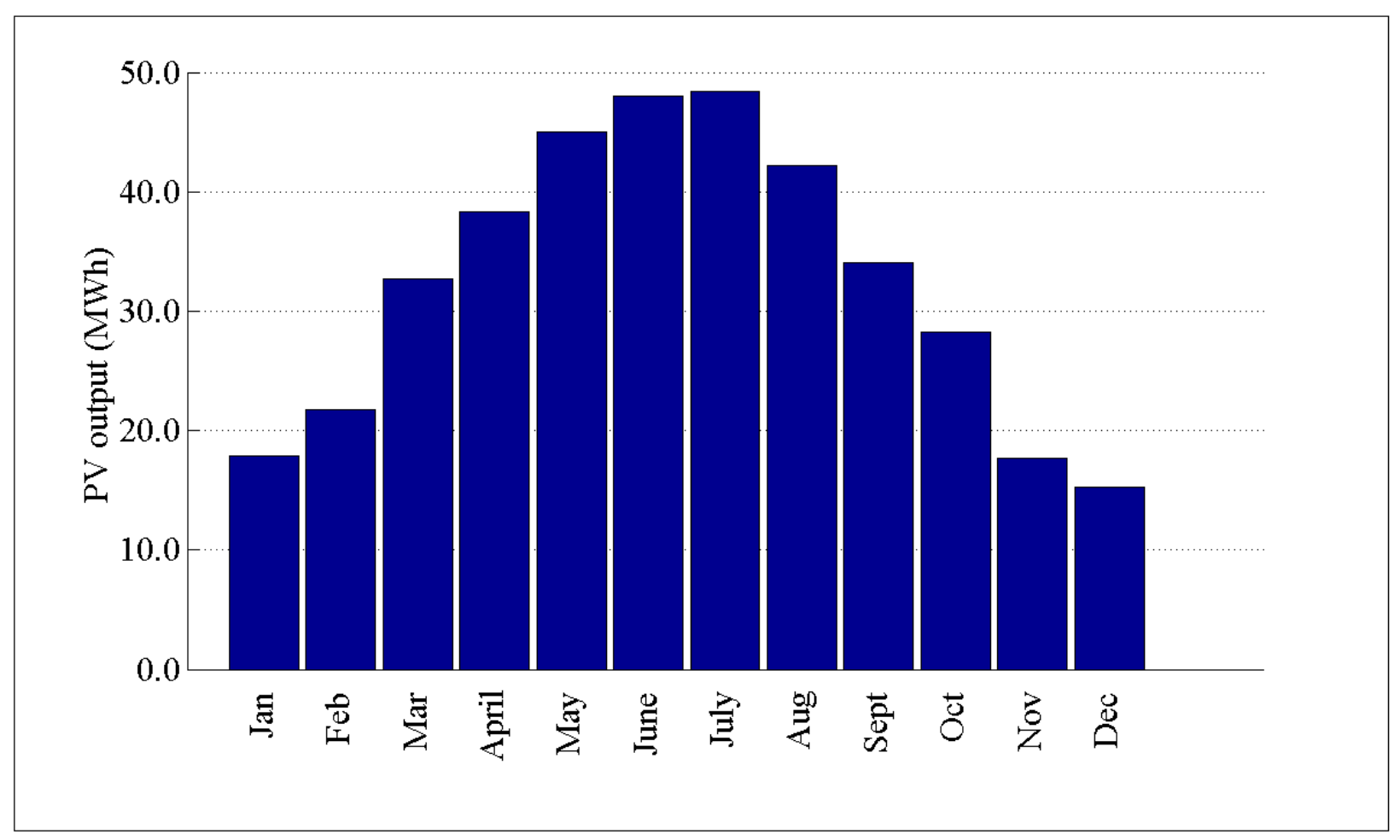

Figure D.184: PV output by month for R4-12.47-1 


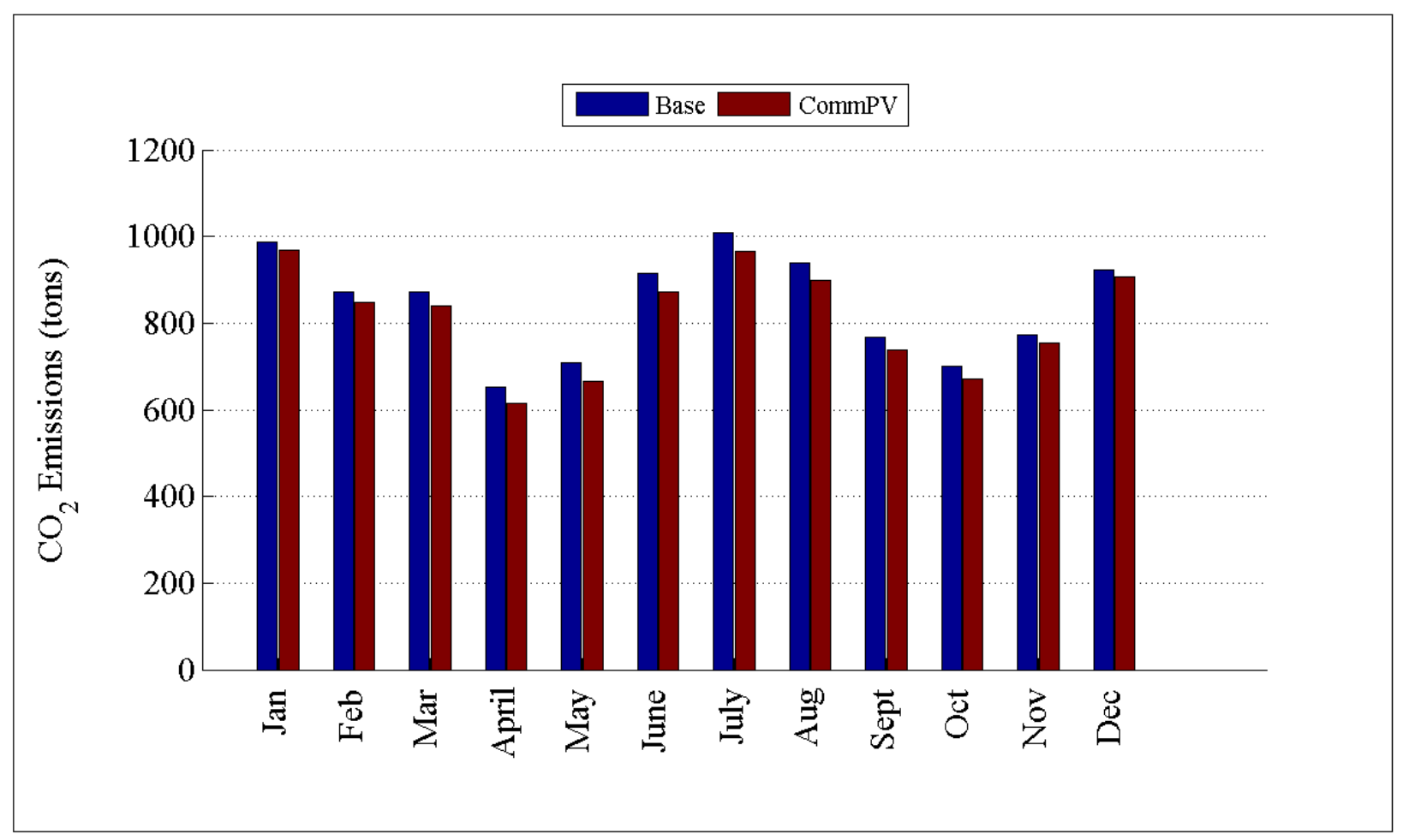

Figure D.185: Comparison of $\mathrm{CO}_{2}$ emissions by month for R4-12.47-1

\section{D.2.18 Detailed Commercial PV Plots for R4-12.47-2}

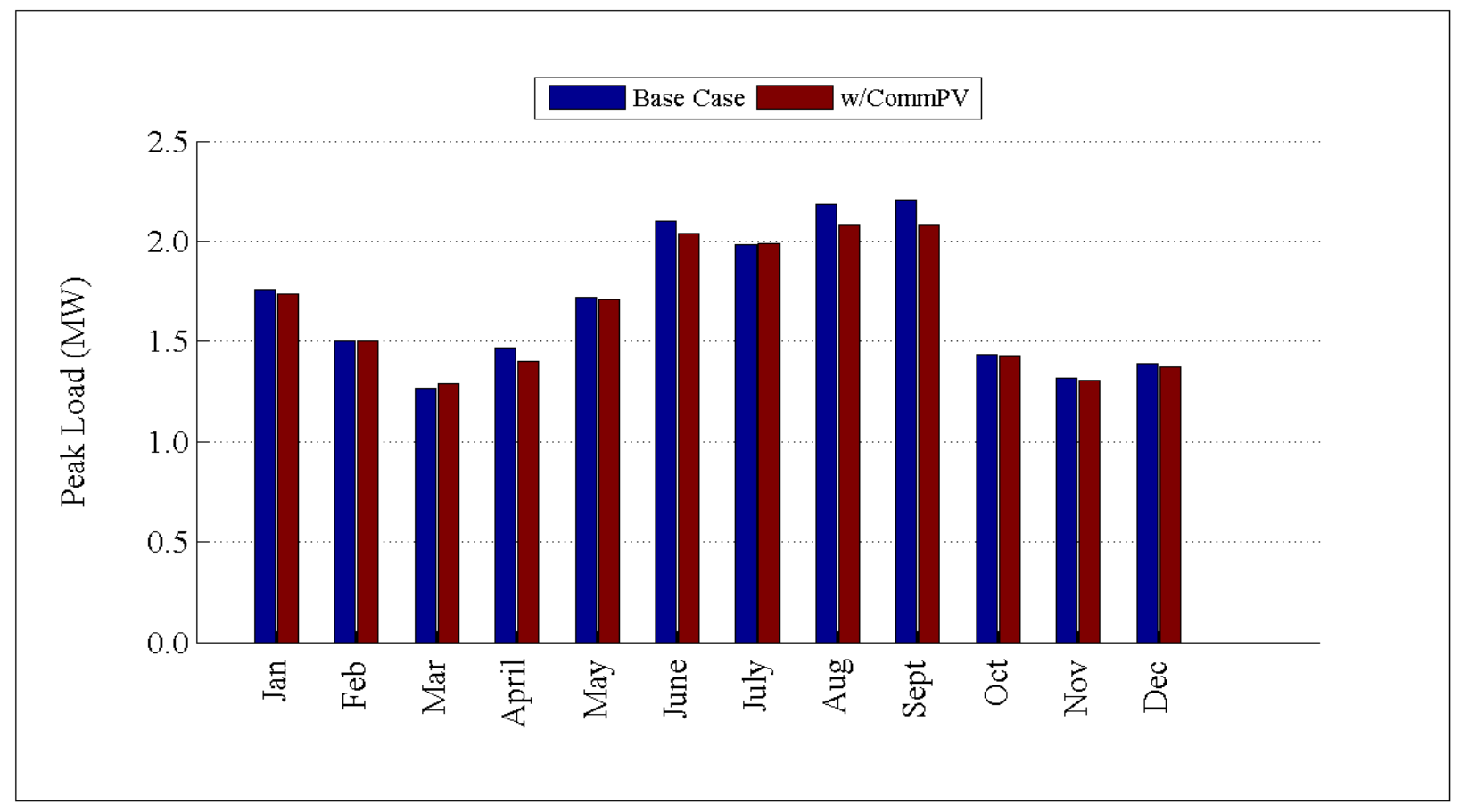

Figure D.186: Comparison of peak load by month for R4-12.47-2 


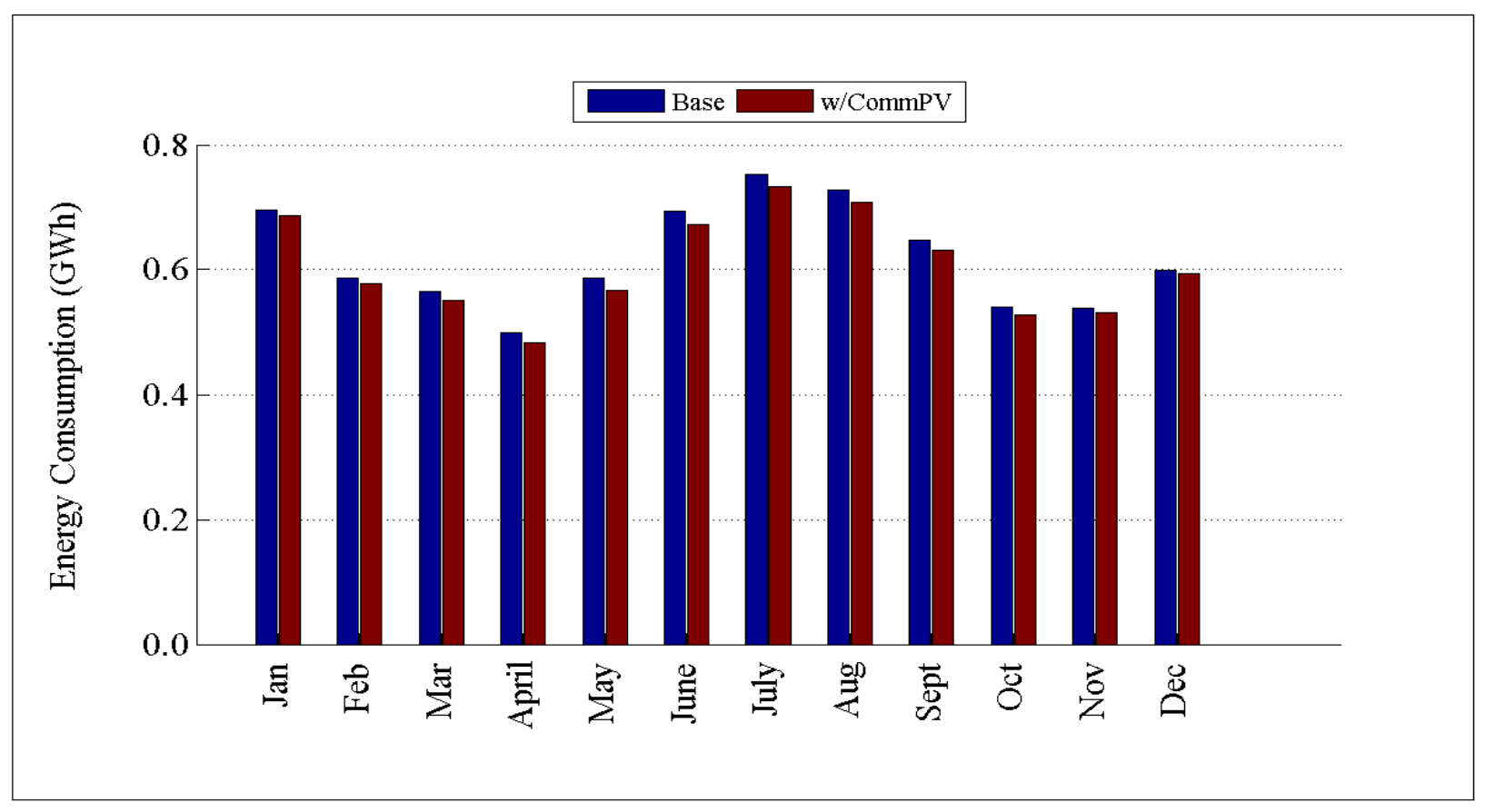

Figure D.187: Comparison of energy consumption by month for R4-12.47-2

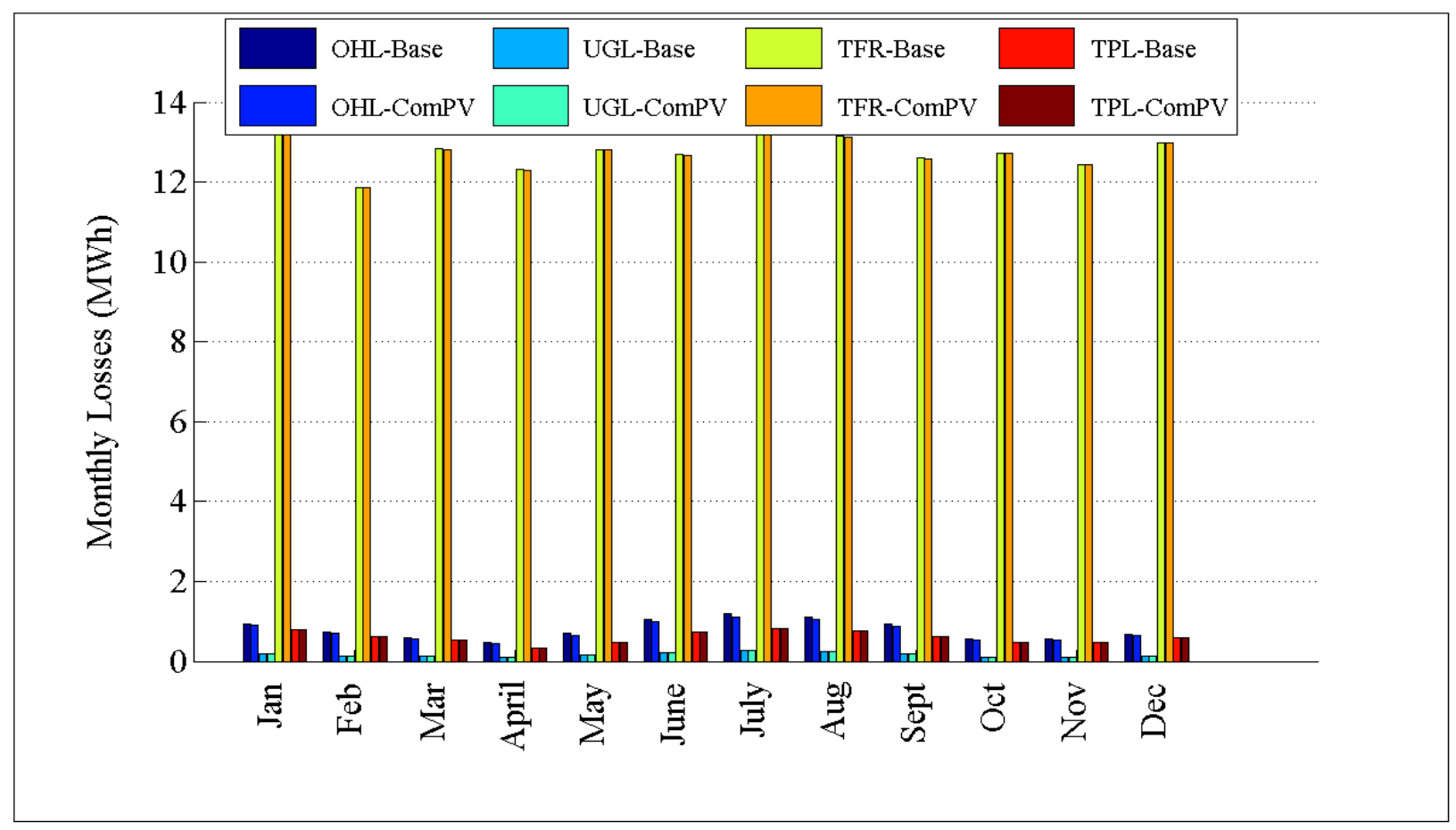

Figure D.188: Comparison of losses by month for R4-12.47-2 


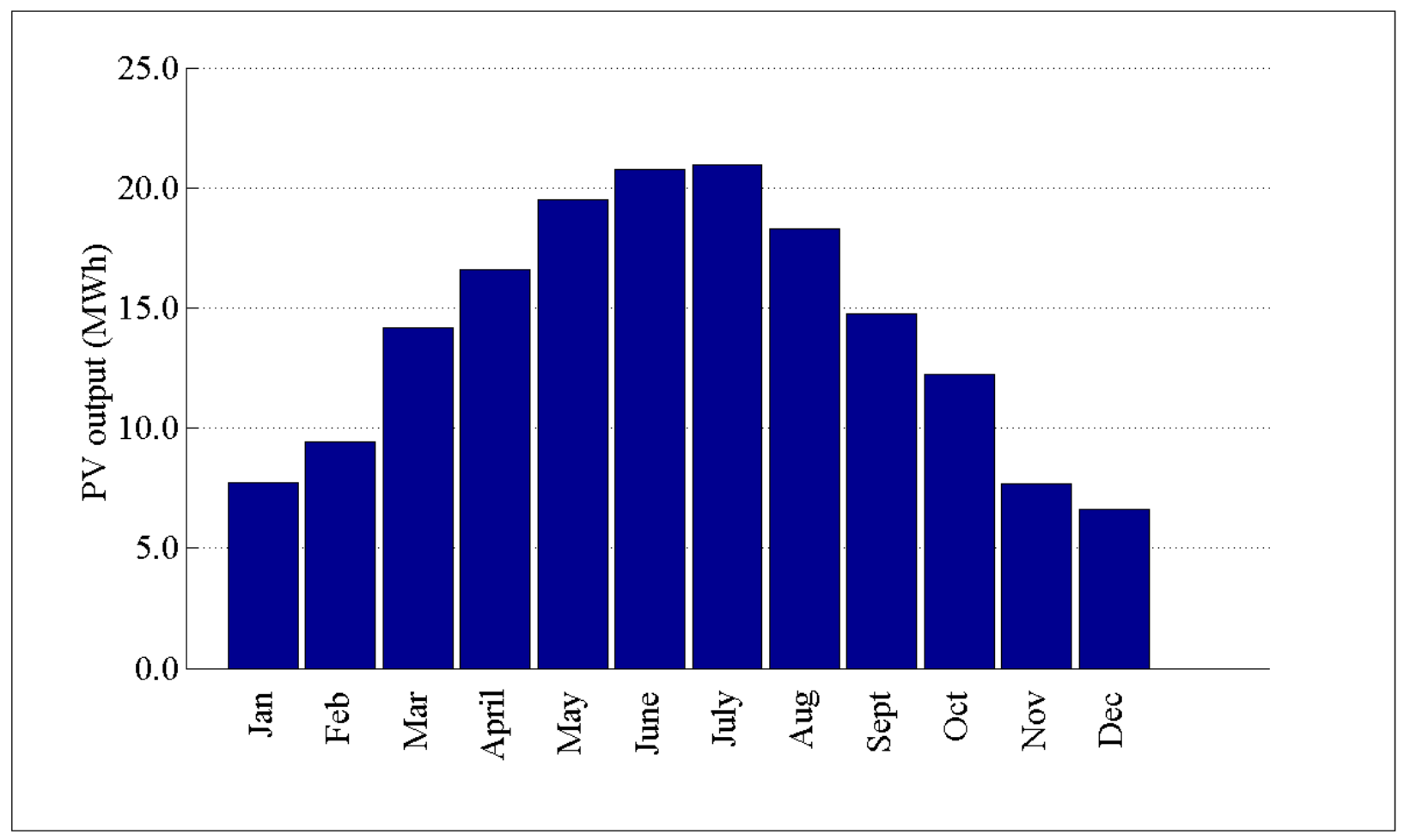

Figure D.189: PV output by month for R4-12.47-2

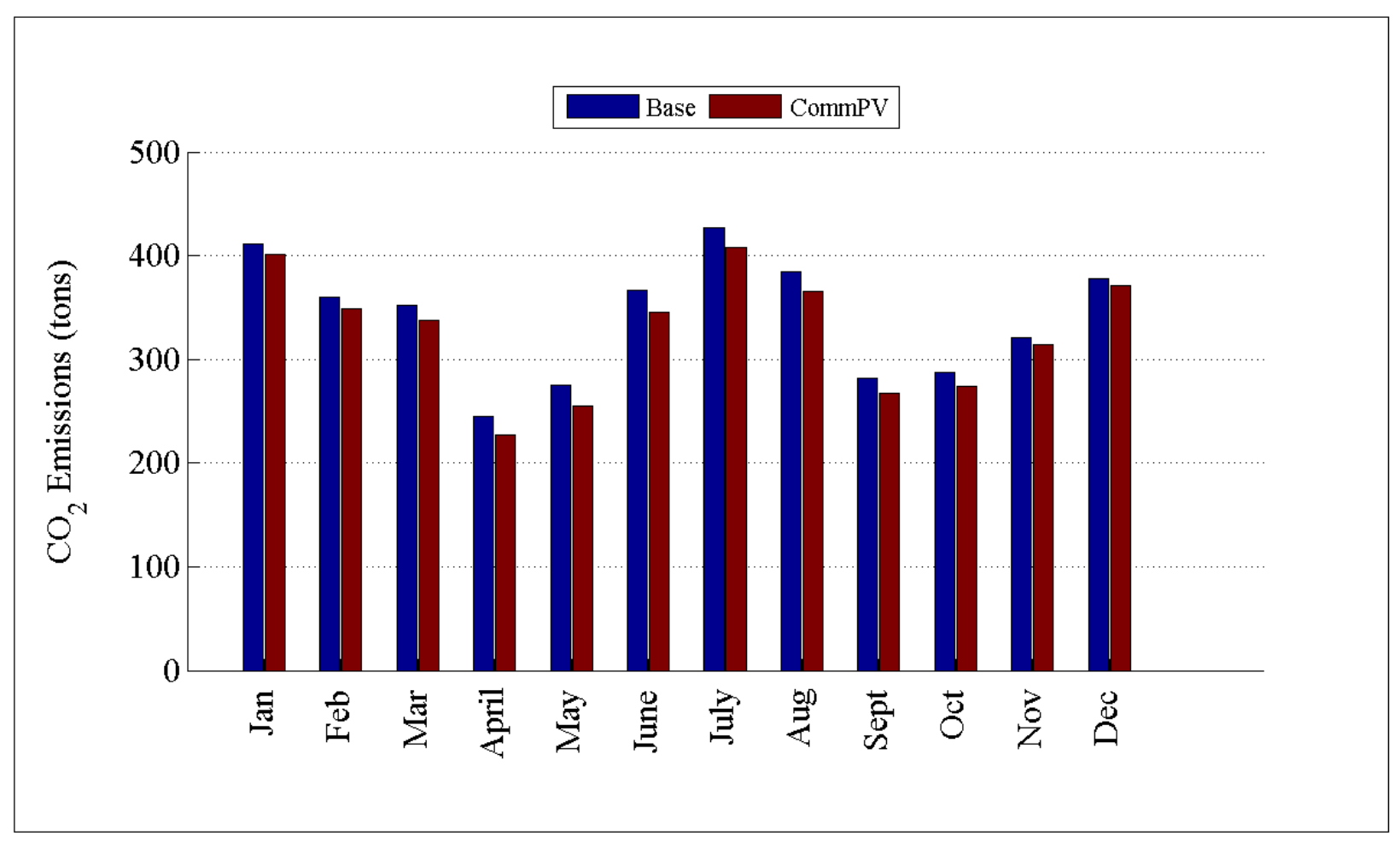

Figure D.190: Comparison of $\mathrm{CO}_{2}$ emissions by month for R4-12.47-2 


\section{D.2.19 Detailed Commercial PV Plots for R4-25.00-1}

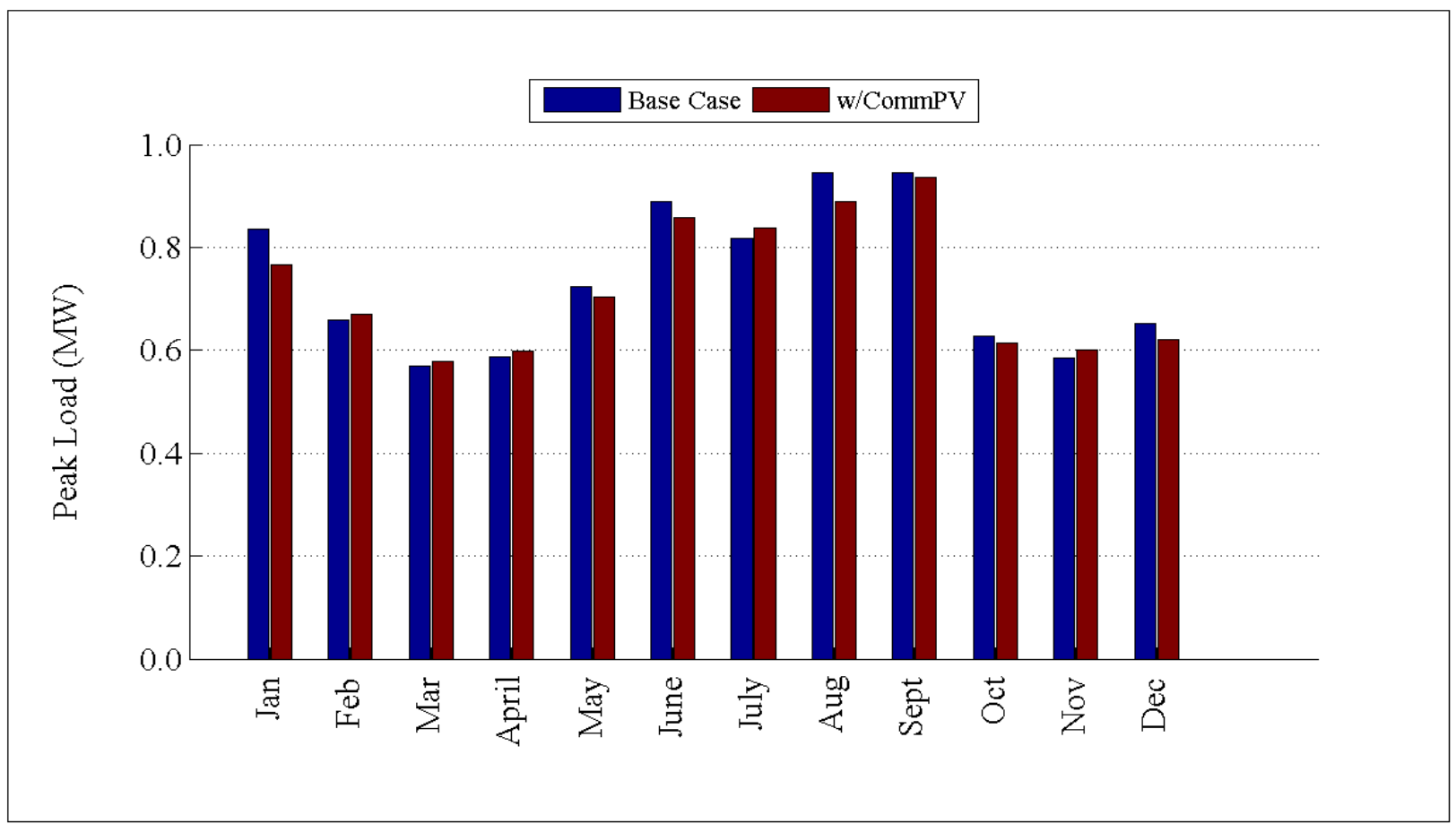

Figure D.191: Comparison of peak load by month for R4-25.00-1

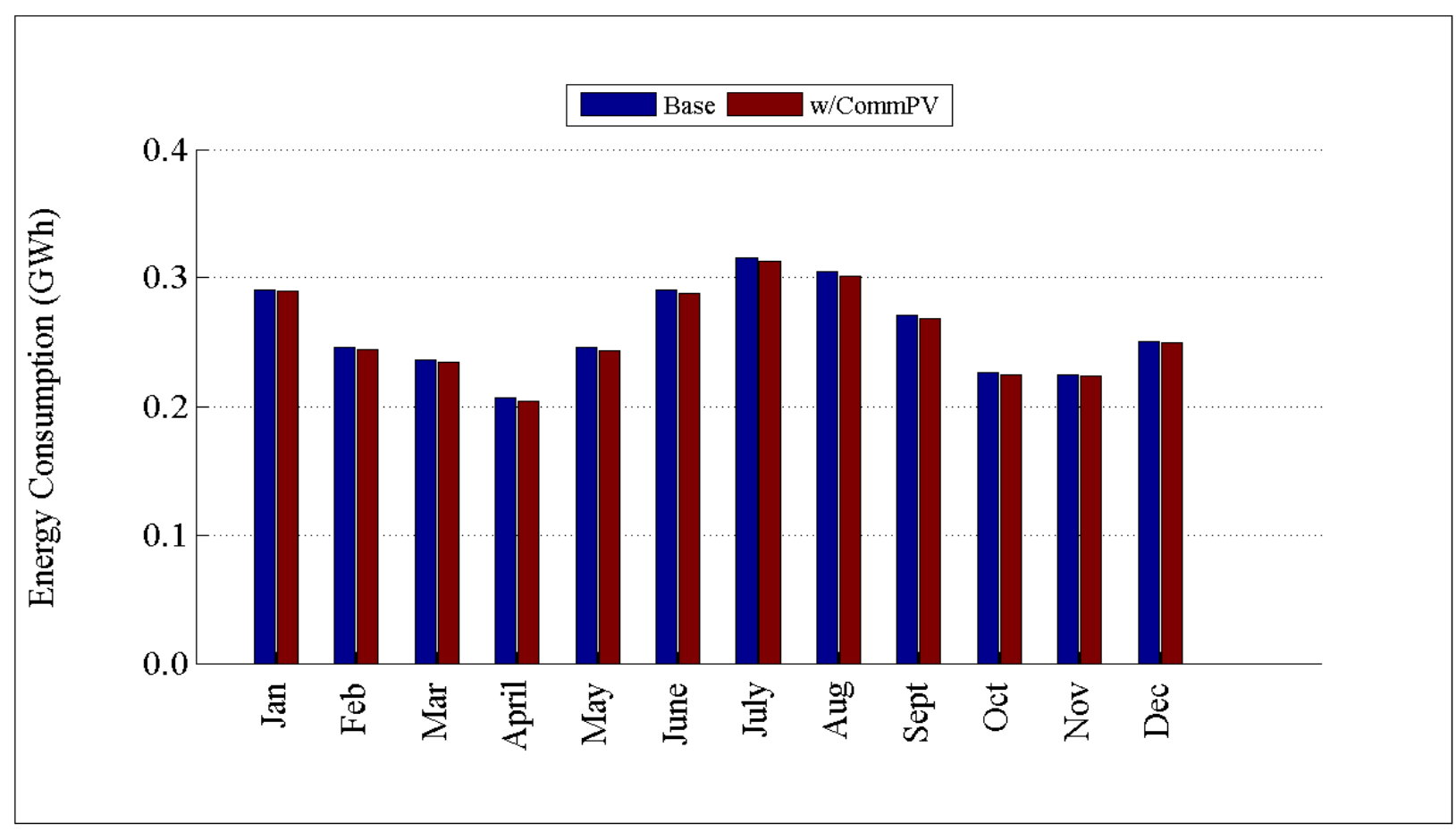

Figure D.192: Comparison of energy consumption by month for R4-25.00-1 


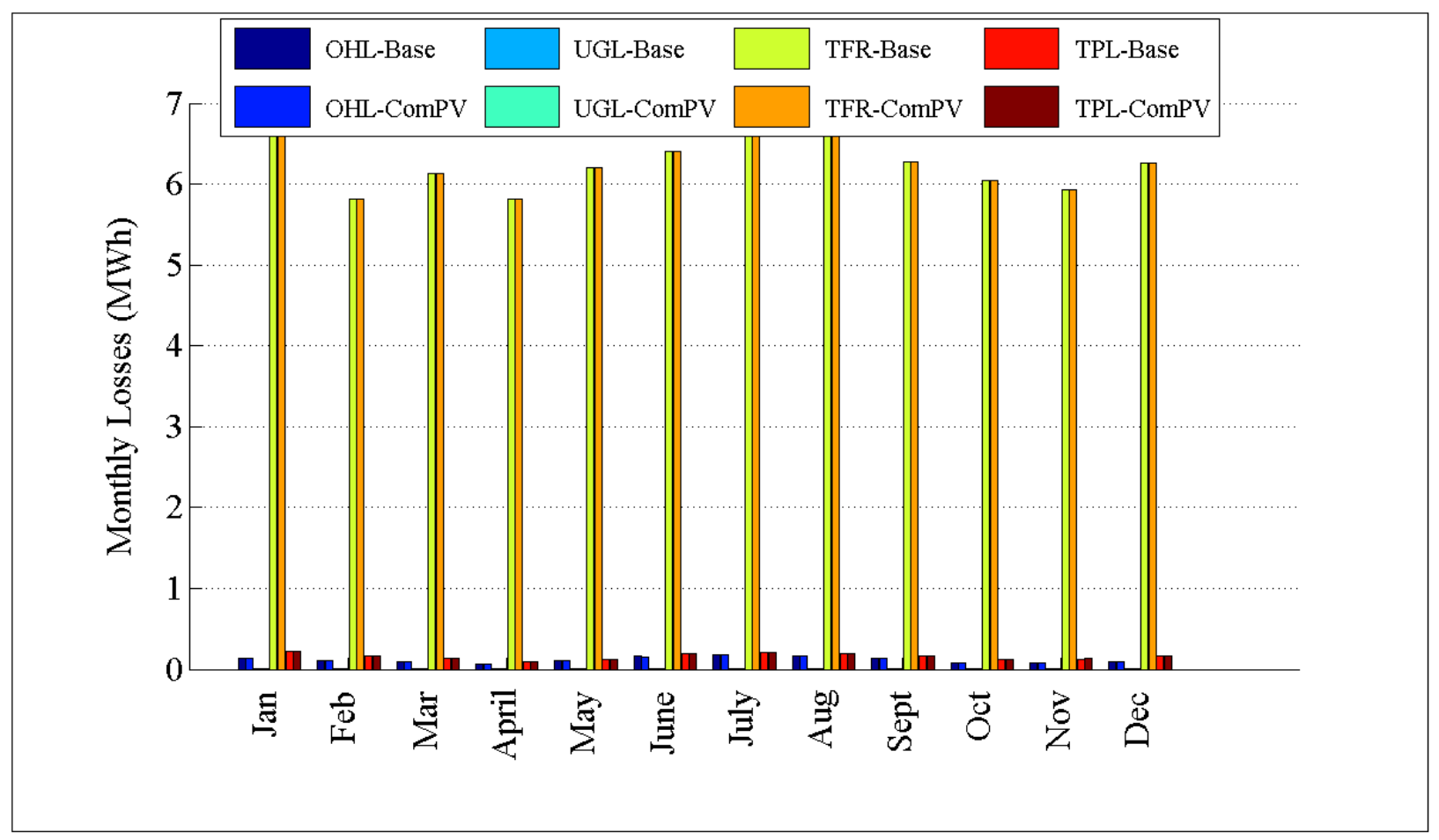

Figure D.193: Comparison of losses by month for R4-25.00-1

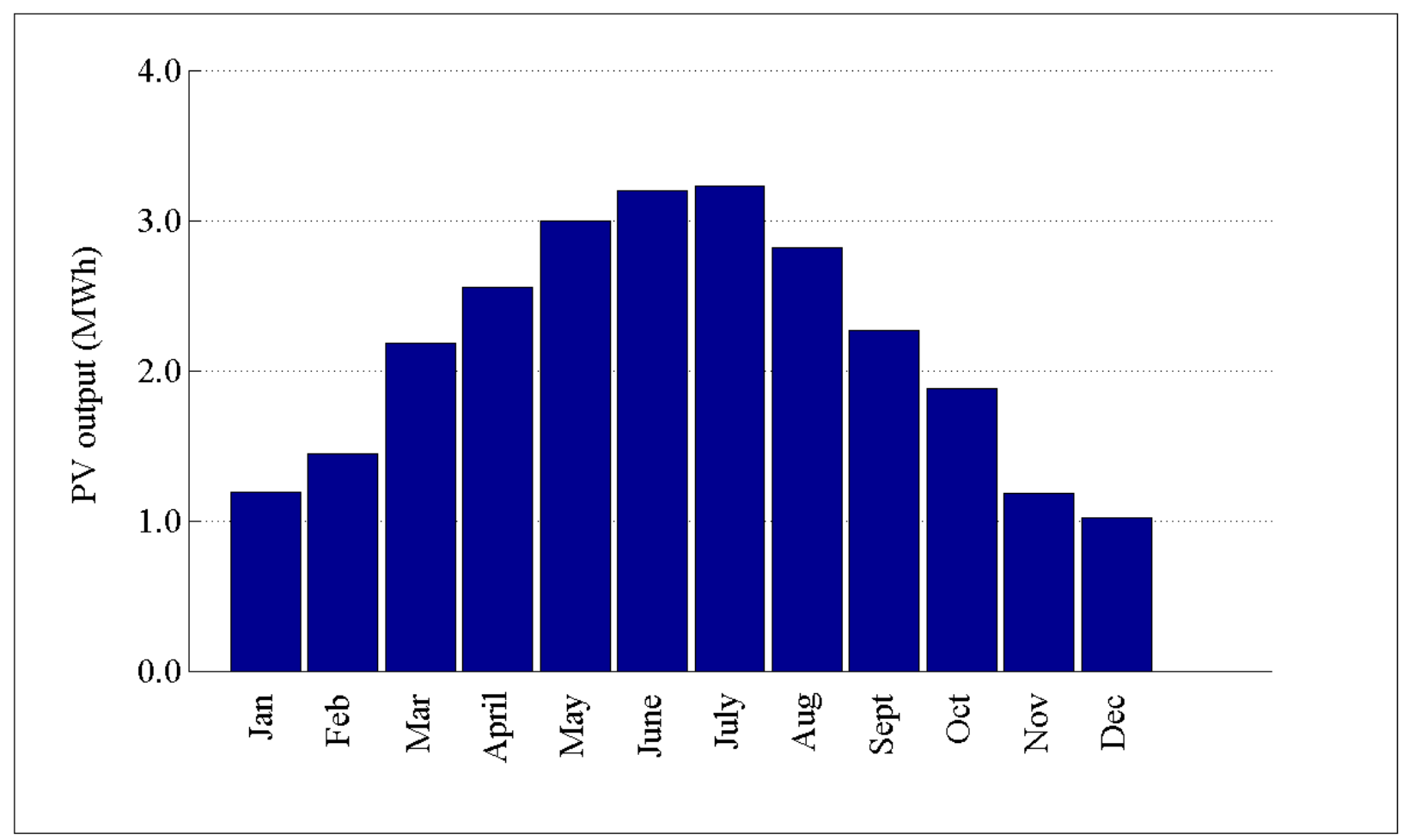

Figure D.194: PV output by month for R4-25.00-1 


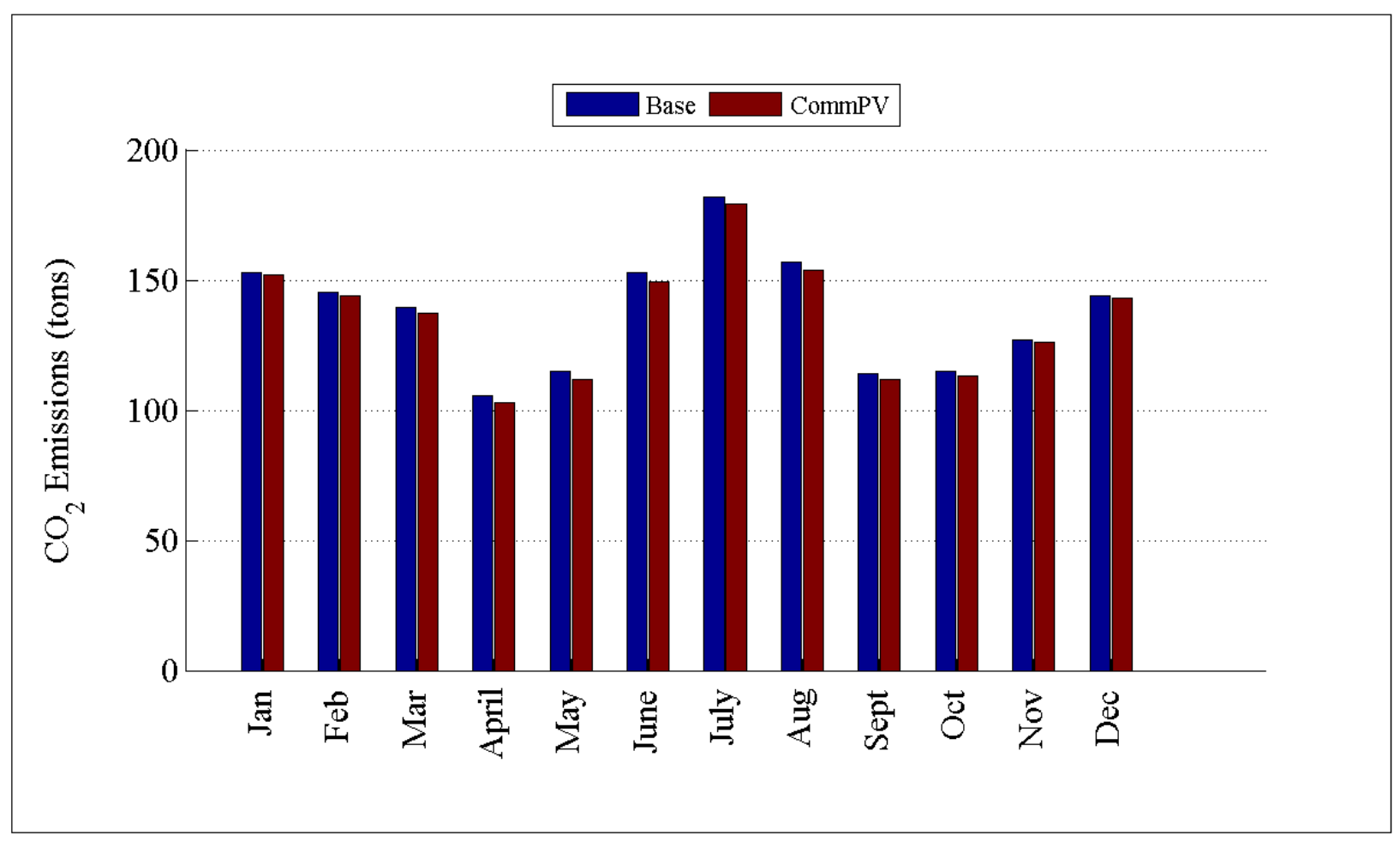

Figure D.195: Comparison of $\mathrm{CO}_{2}$ emissions by month for R4-25.00-1 


\section{D.2.20 Detailed Commercial PV Plots for GC-12.47-1_R5}

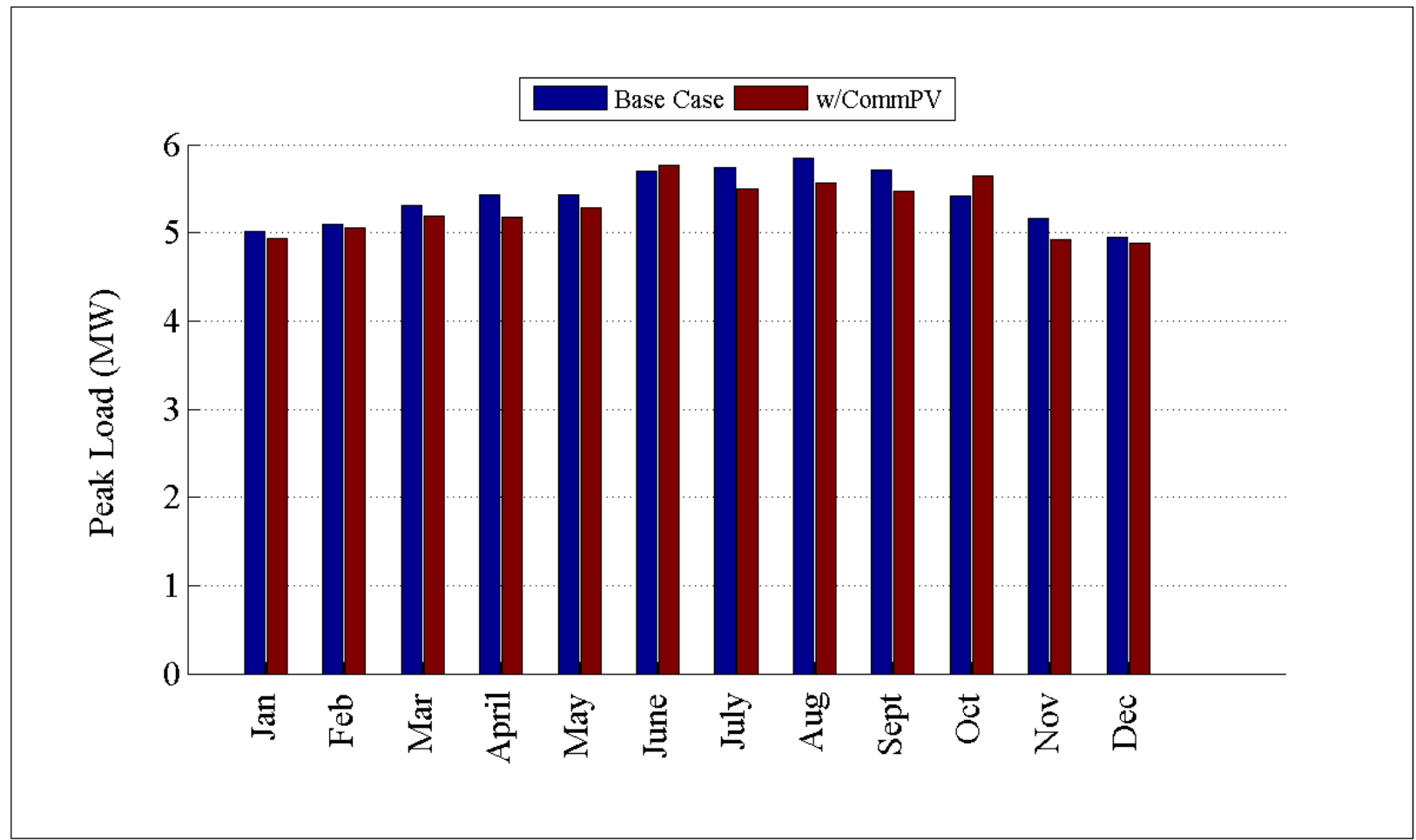

Figure D.196: Comparison of peak load by month for GC-12.47-1_R5

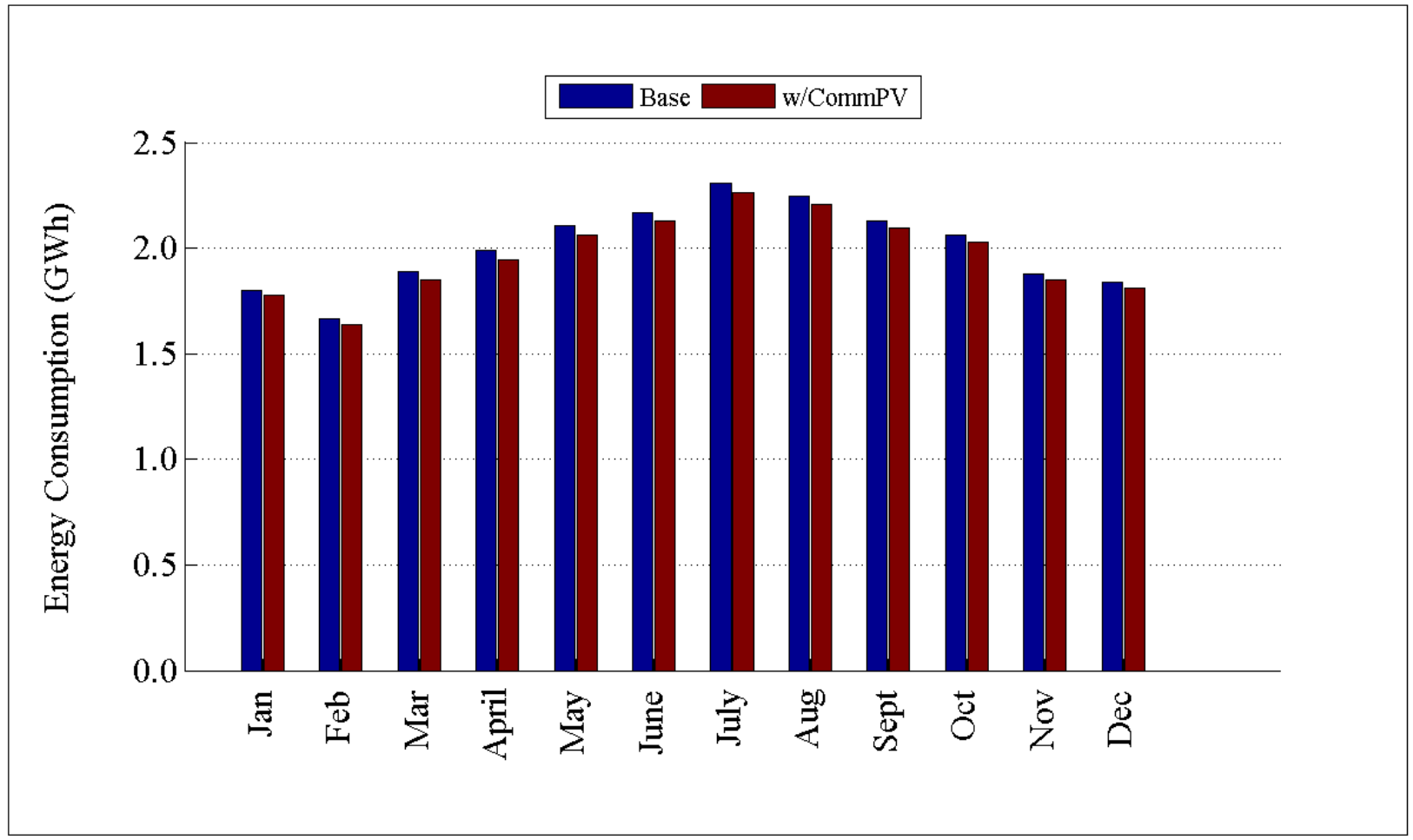

Figure D.197: Comparison of energy consumption by month for GC-12.47-1_R5 256 


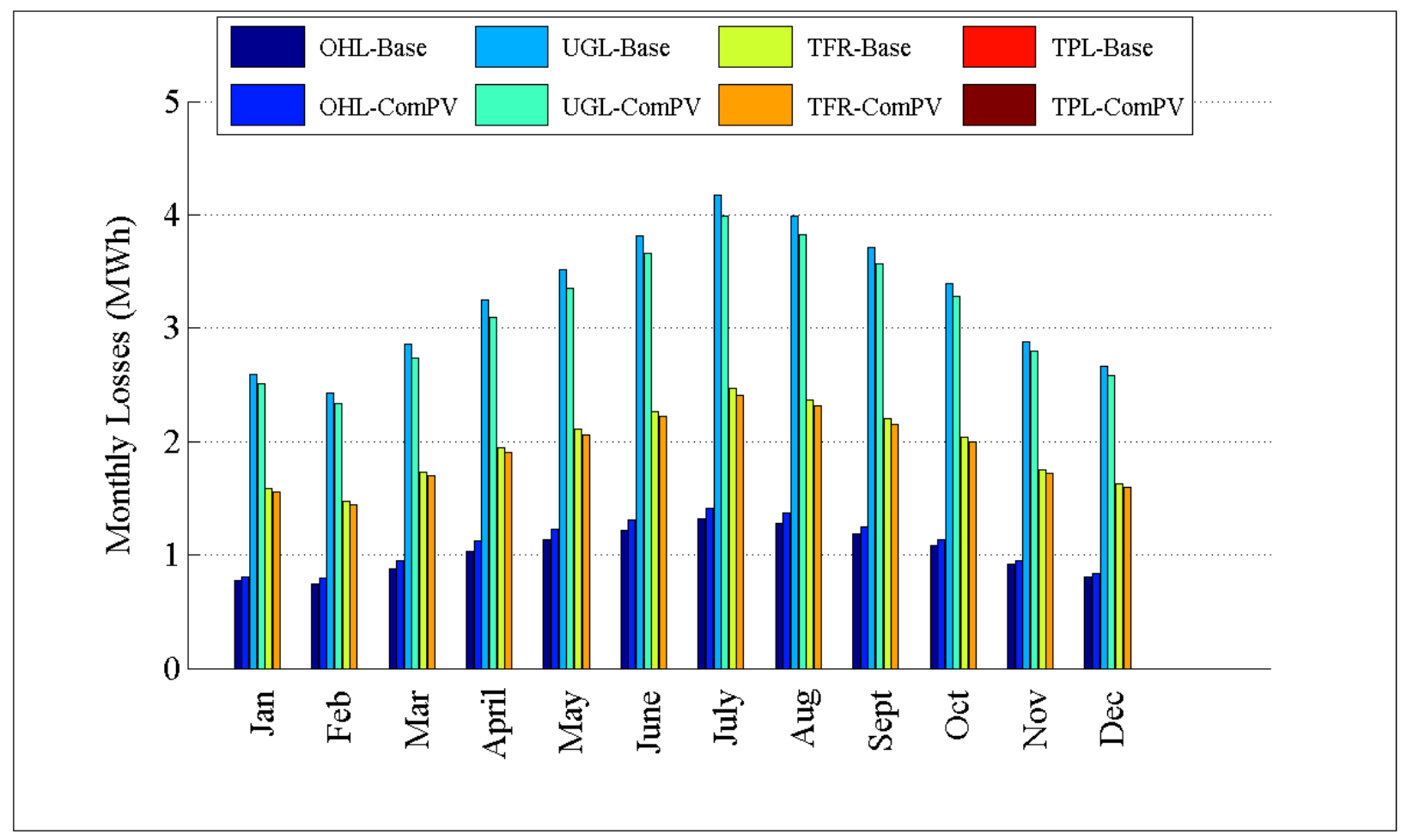

Figure D.198: Comparison of losses by month for GC-12.47-1_R5

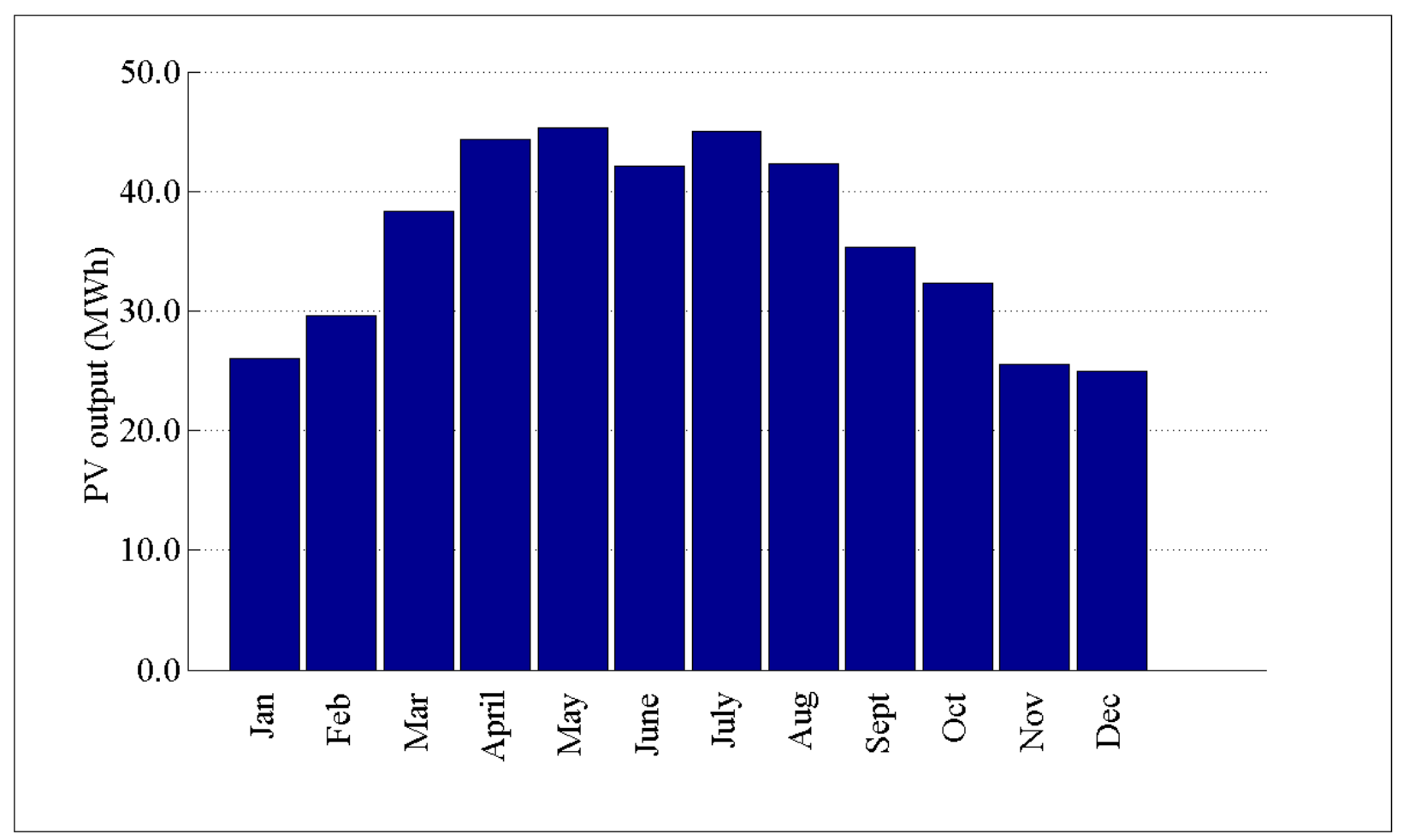

Figure D.199: PV output by month for GC-12.47-1_R5 


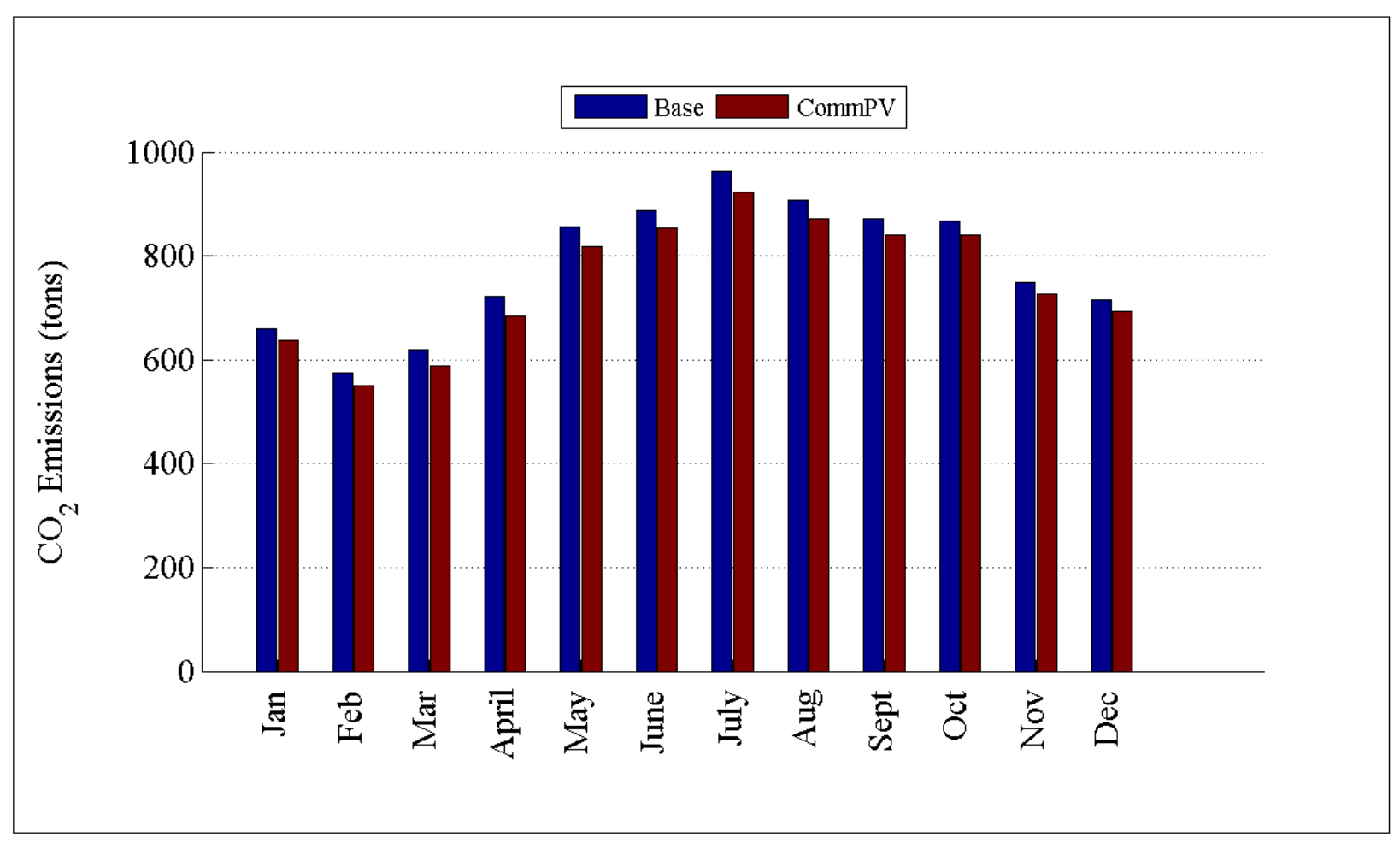

Figure D.200: Comparison of $\mathrm{CO}_{2}$ emissions by month for GC-12.47-1_R5

\section{D.2.21 Detailed Commercial PV Plots for R5-12.47-1}

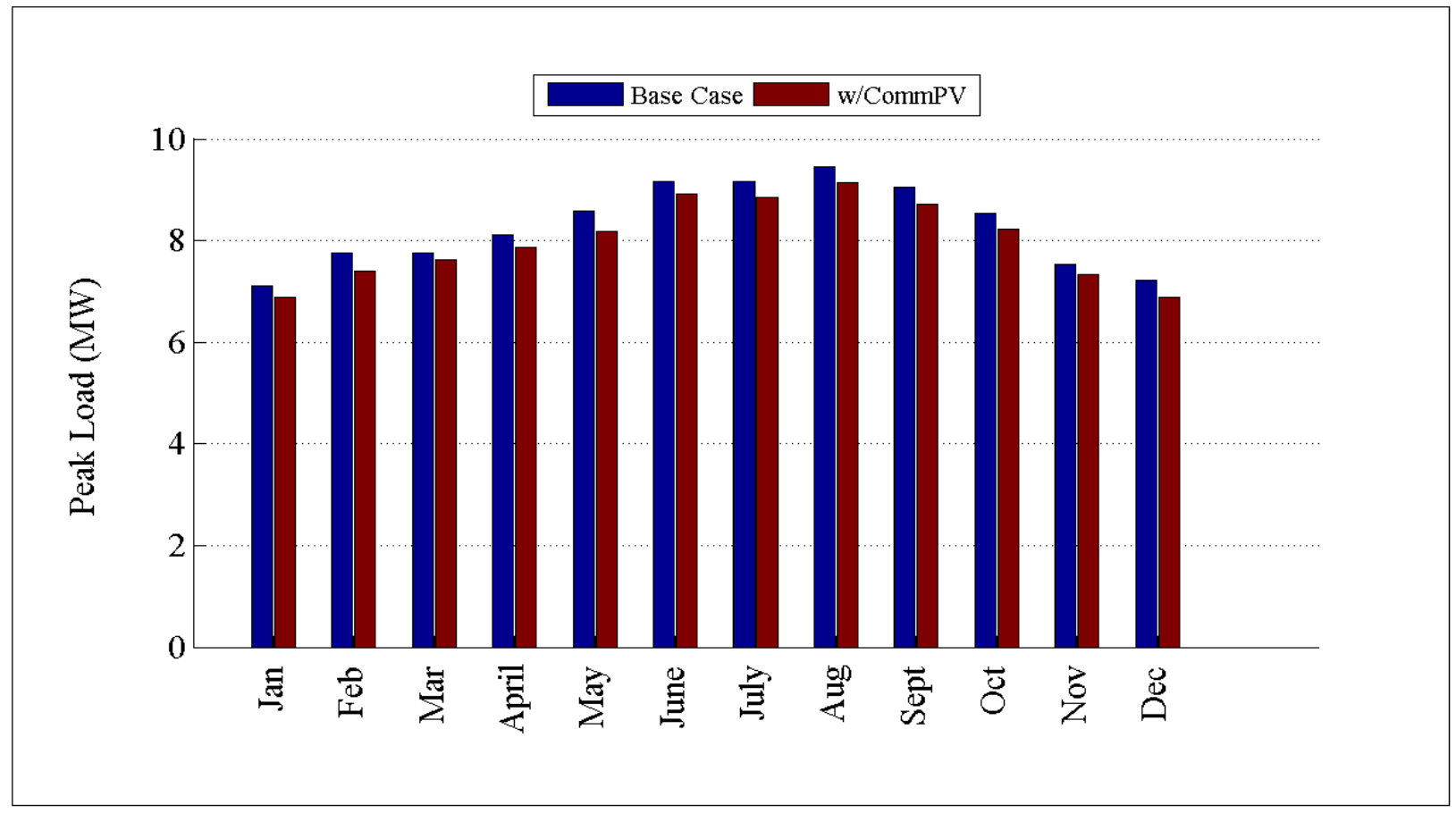

Figure D.201: Comparison of peak load by month for R5-12.47-1 


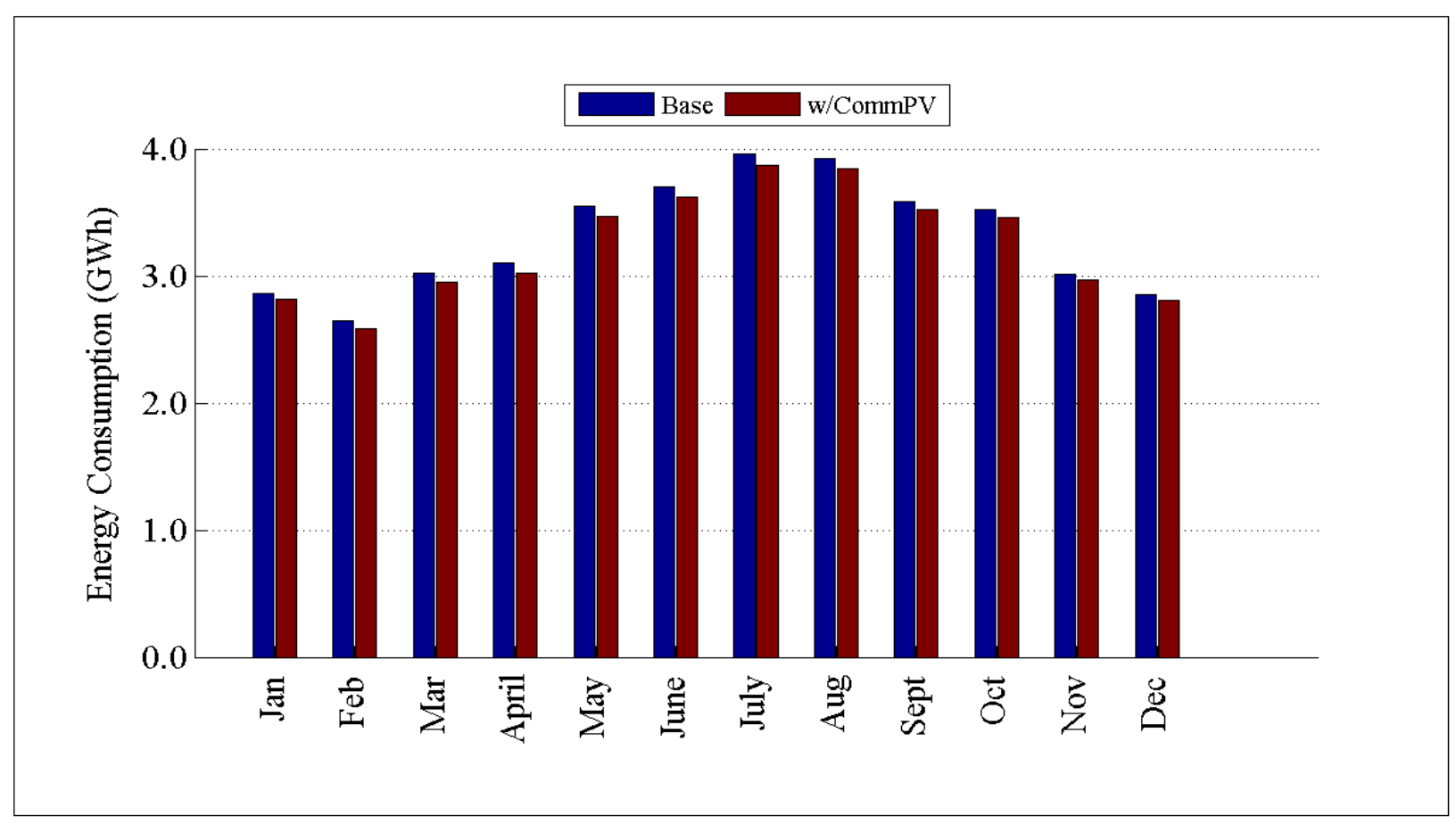

Figure D.202: Comparison of energy consumption by month for R5-12.47-1

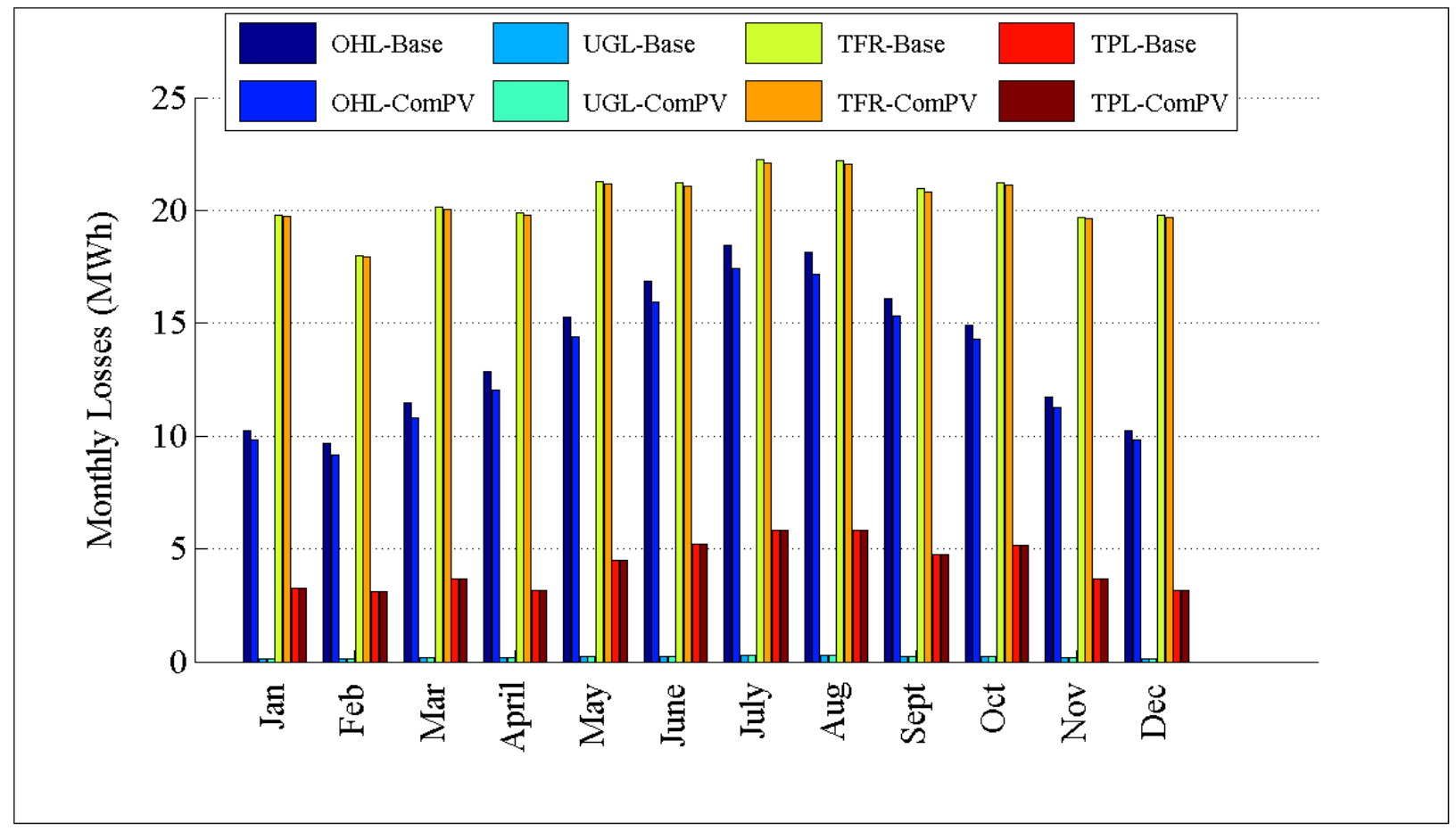

Figure D.203: Comparison of losses by month for R5-12.47-1 


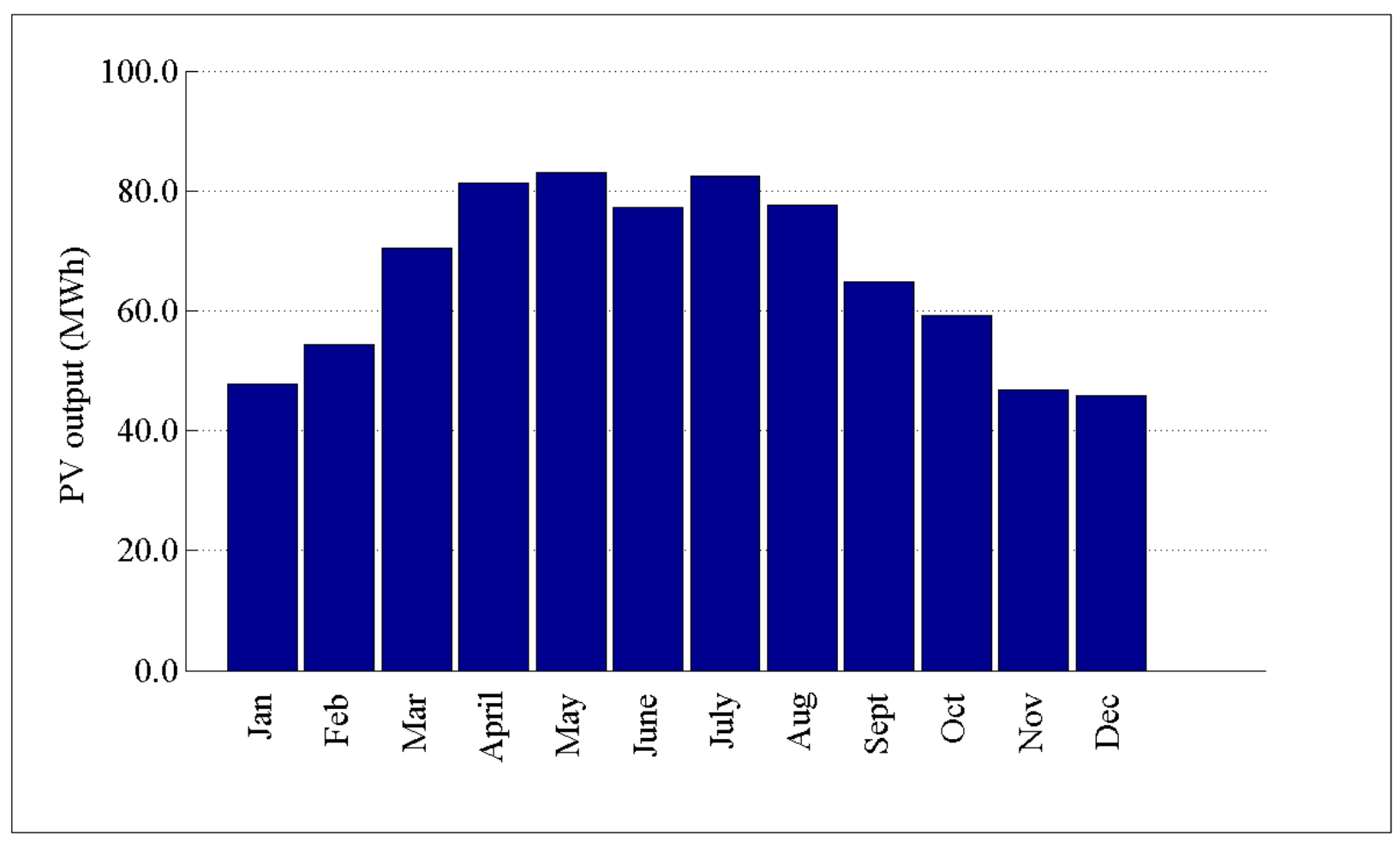

Figure D.204: PV output by month for R5-12.47-1

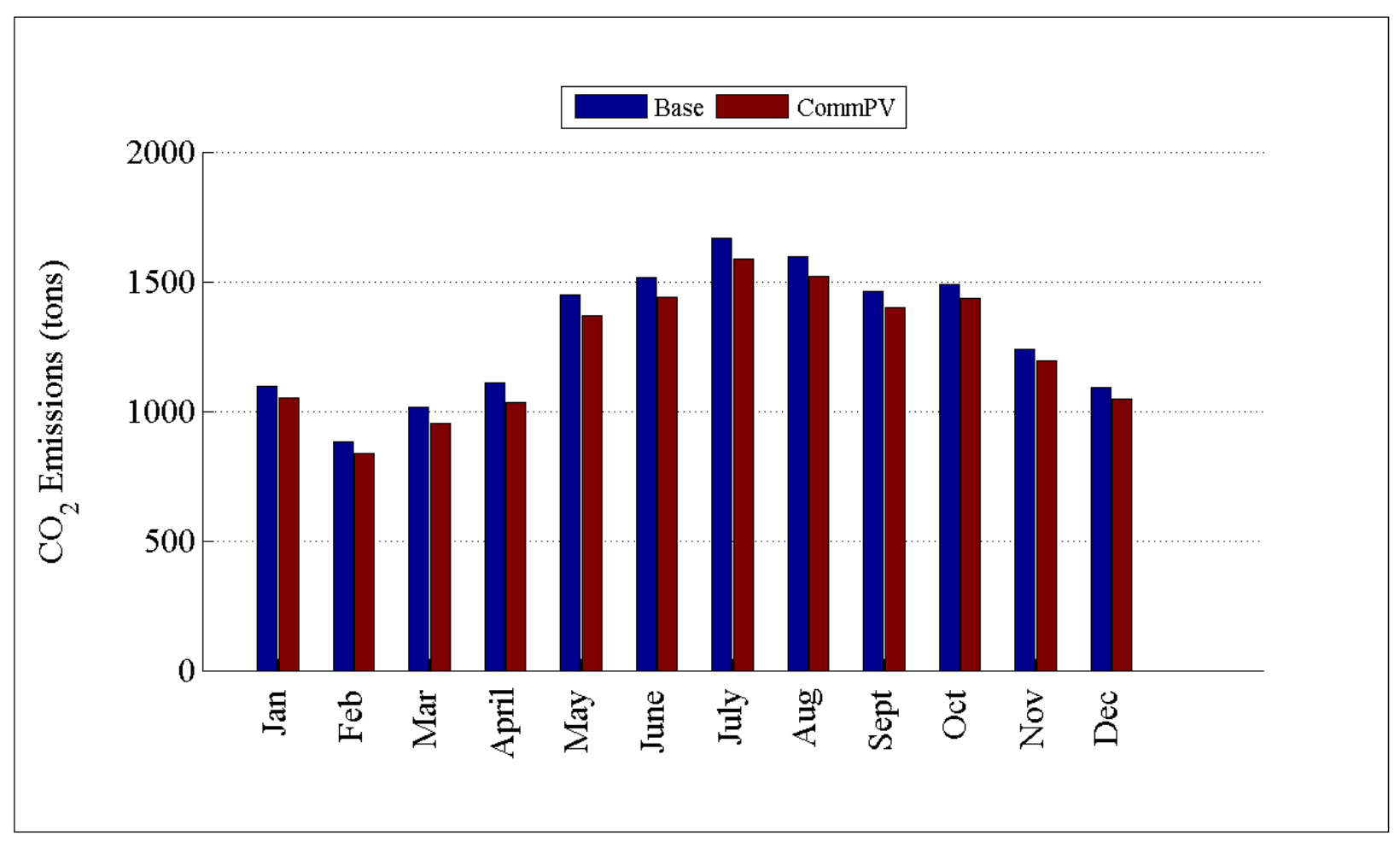

Figure D.205: Comparison of $\mathrm{CO}_{2}$ emissions by month for R5-12.47-1 
D.2.22 Detailed Commercial PV Plots for R5-12.47-2

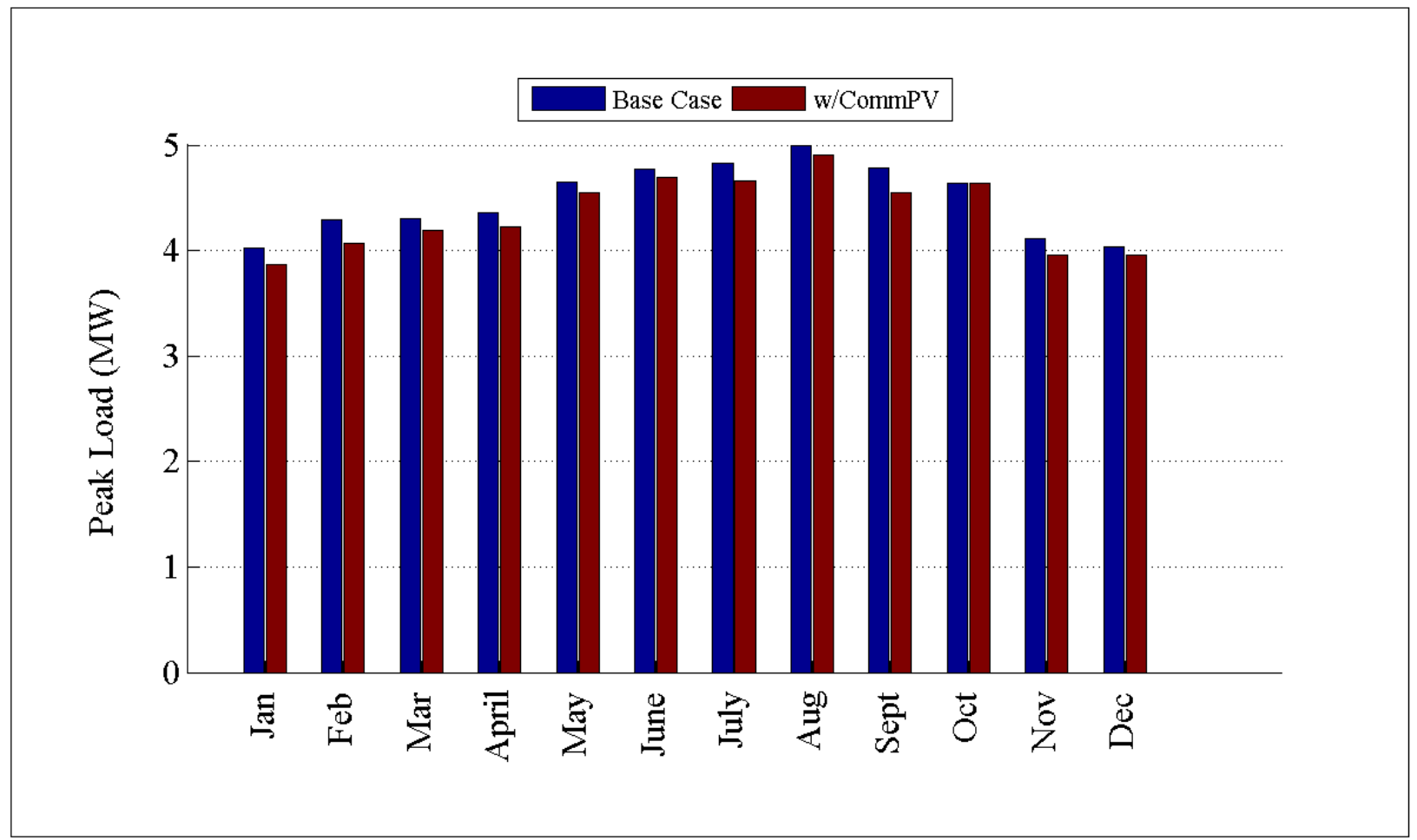

Figure D.206: Comparison of peak load by month for R5-12.47-2

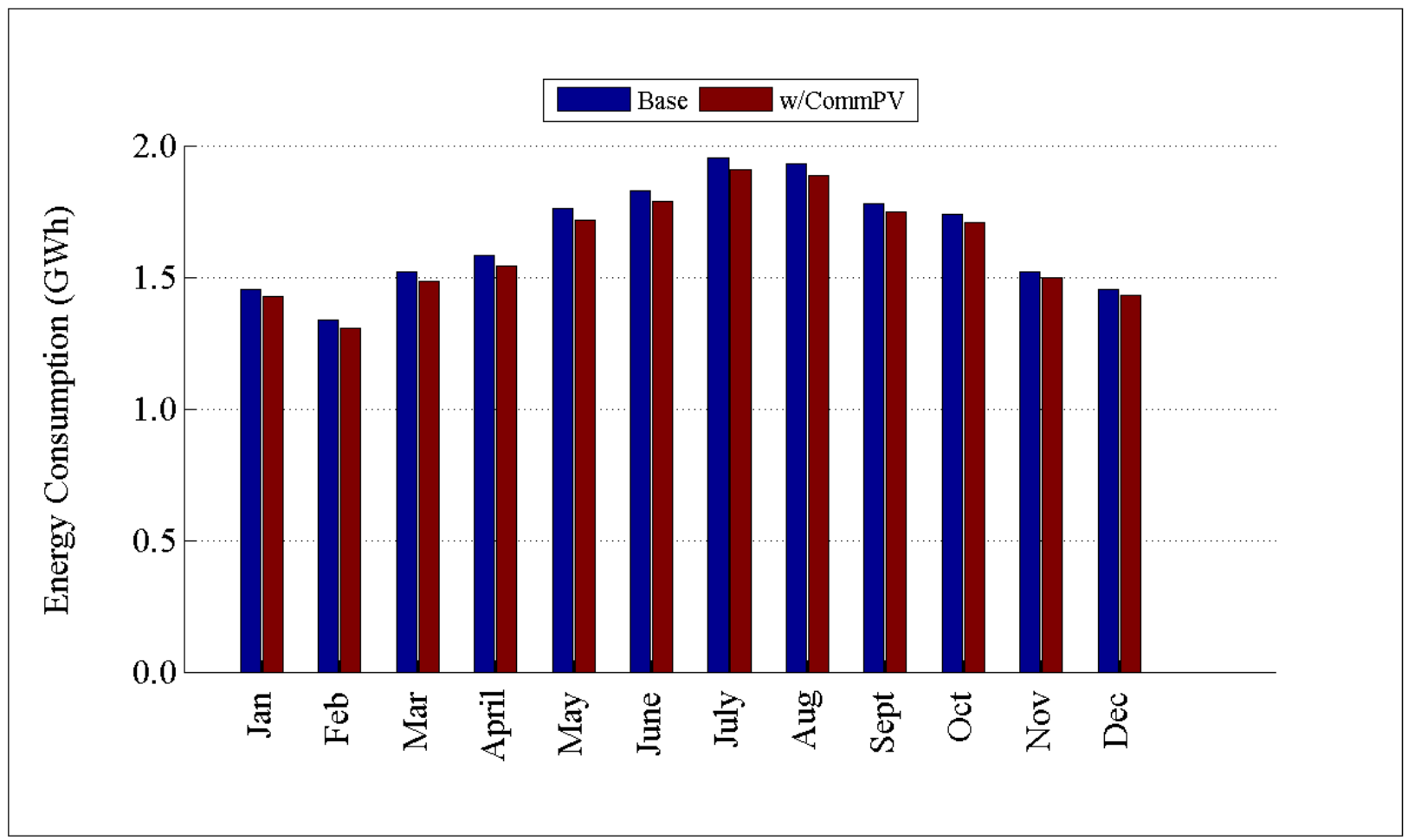

Figure D.207: Comparison of energy consumption by month for R5-12.47-2 


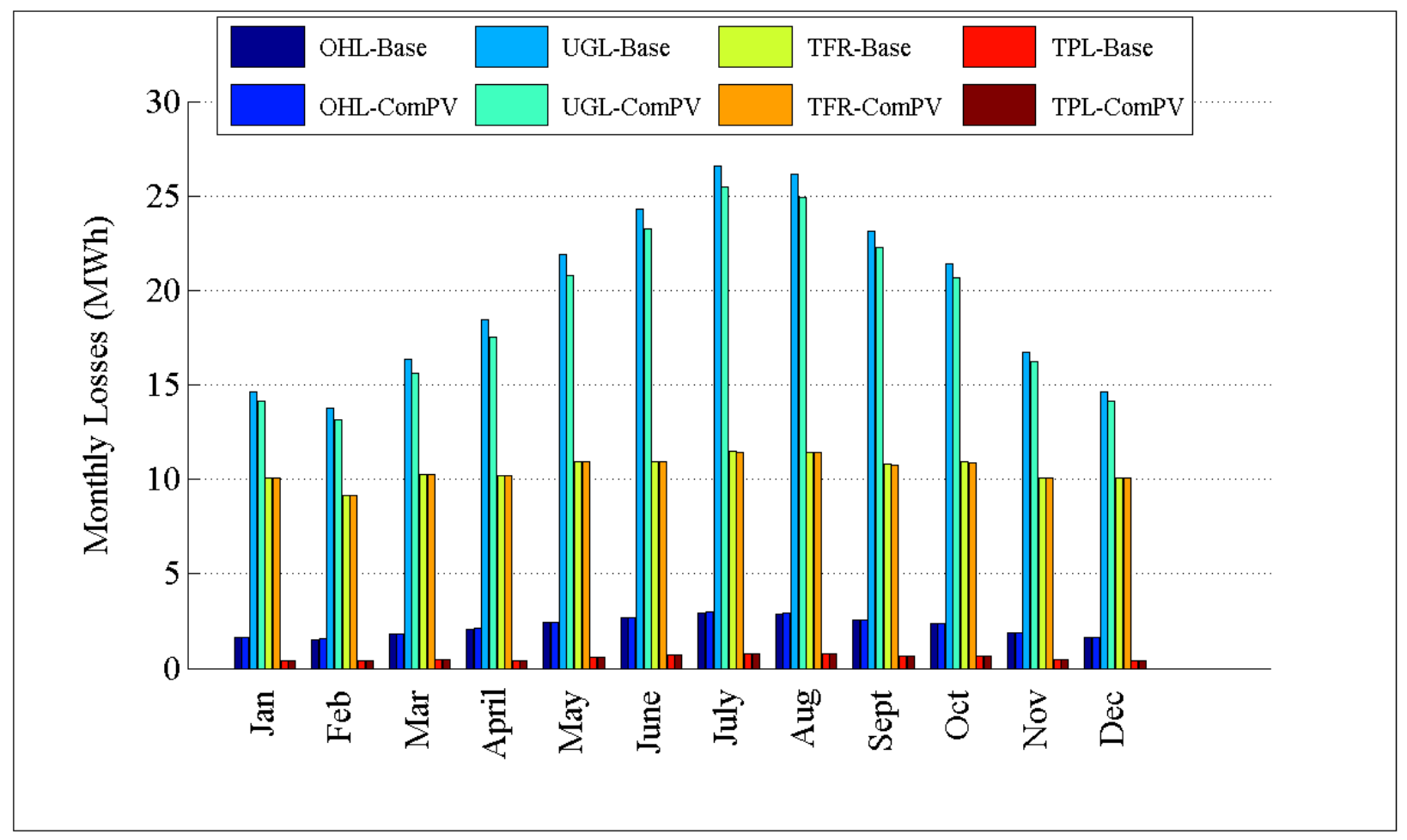

Figure D.208: Comparison of losses by month for R5-12.47-2

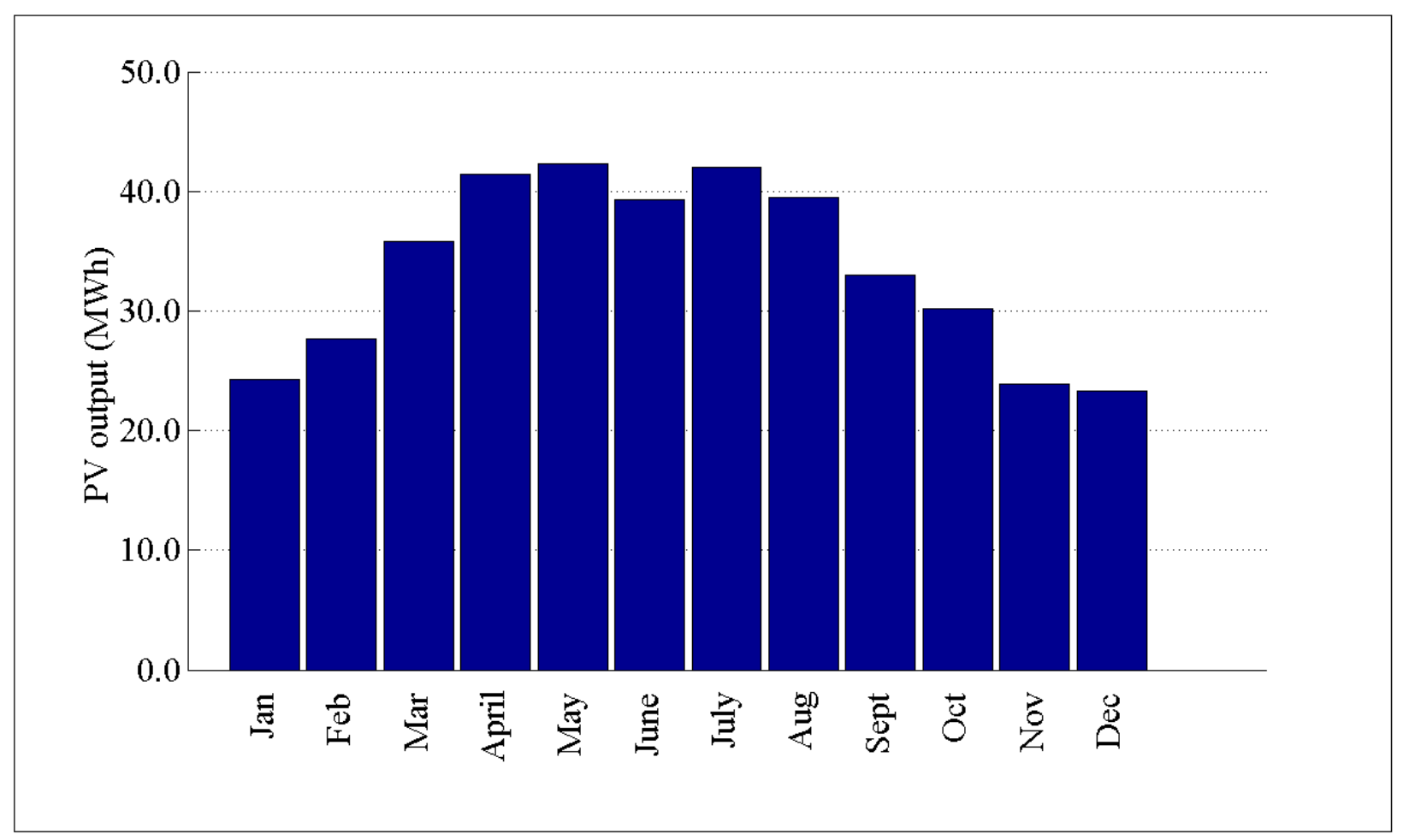

Figure D.209: PV output by month for R5-12.47-2 


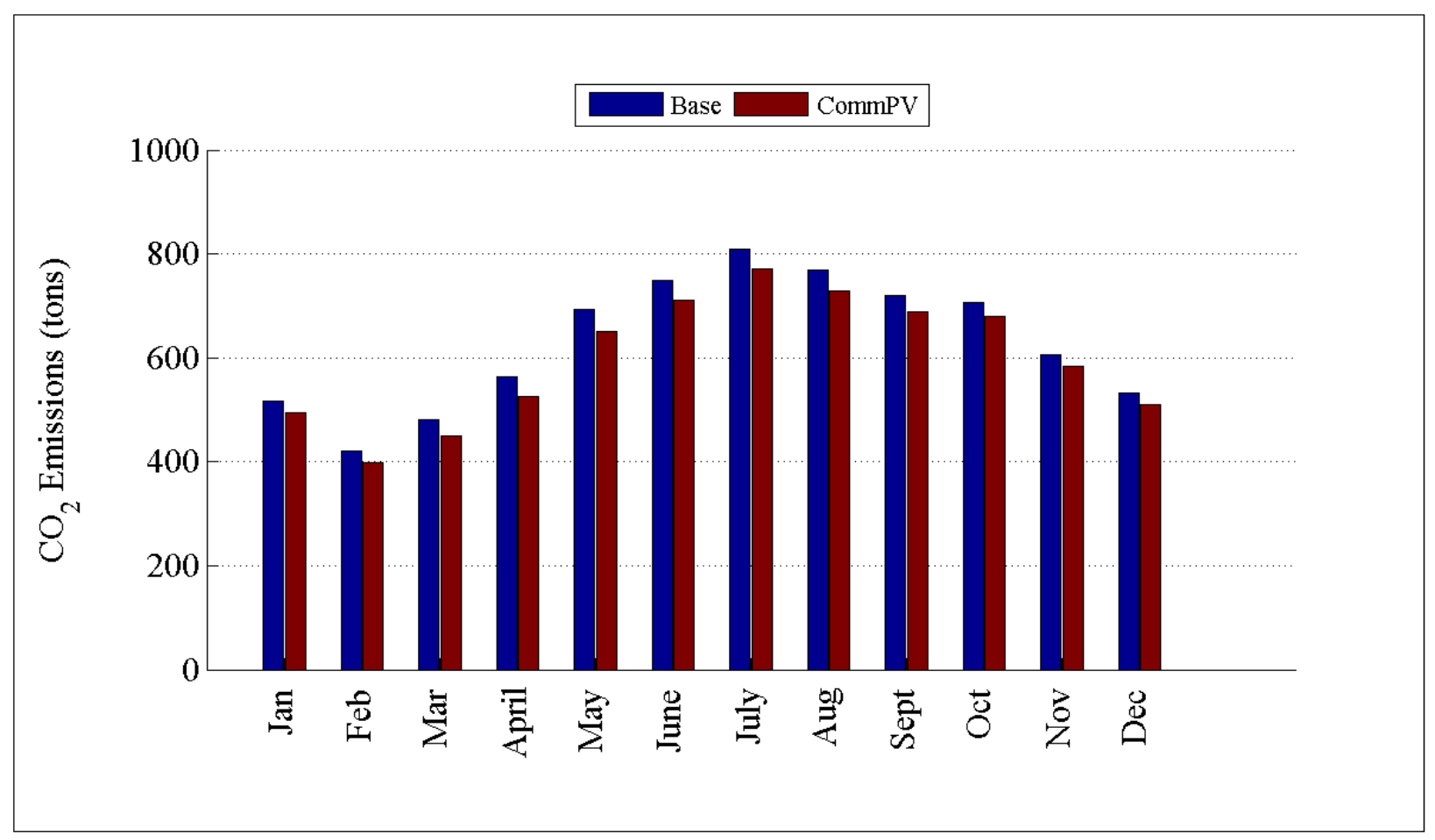

Figure D.210: Comparison of $\mathrm{CO}_{2}$ emissions by month for R5-12.47-2

D.2.23 Detailed Commercial PV Plots for R5-12.47-3

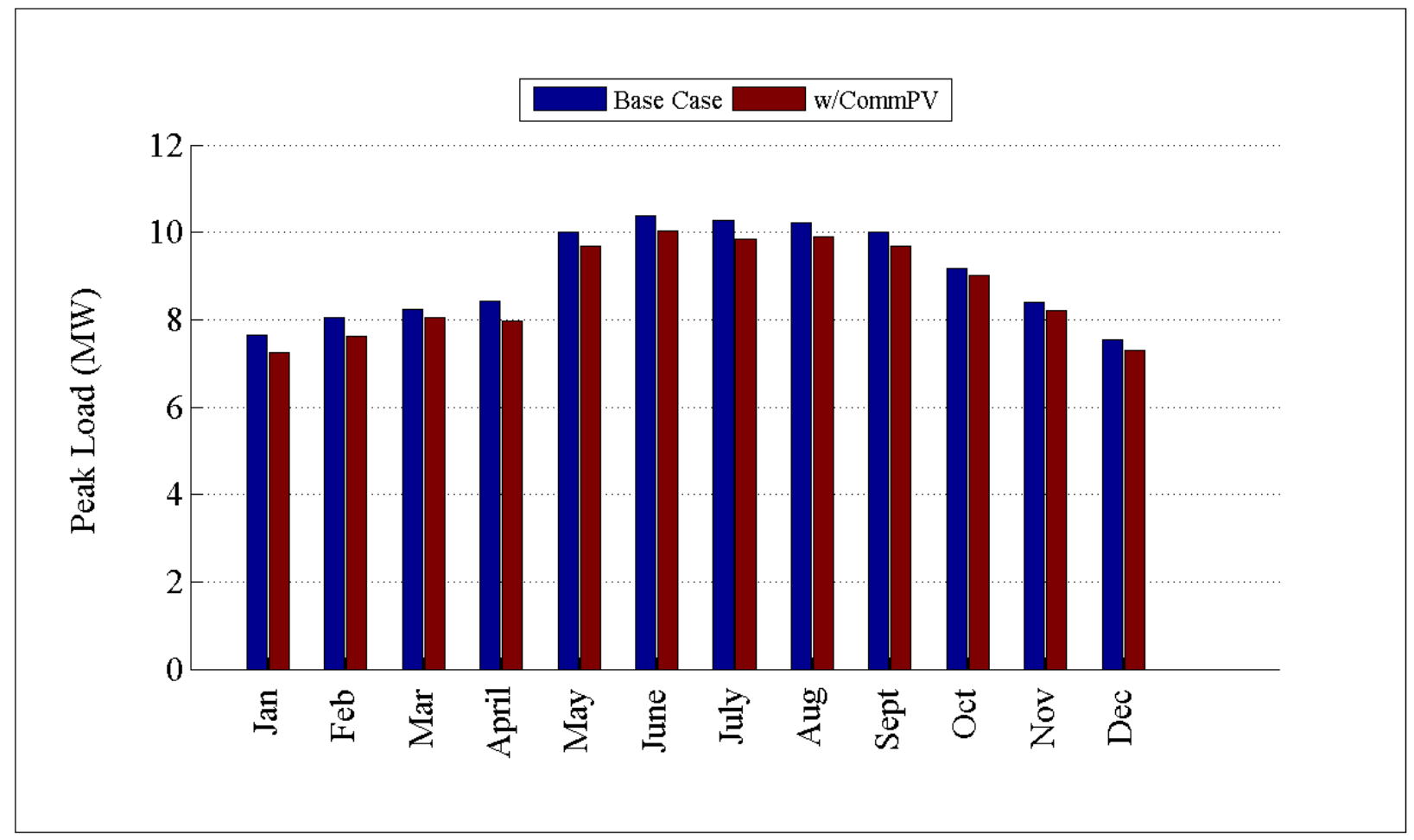

Figure D.211: Comparison of peak load by month for R5-12.47-3 


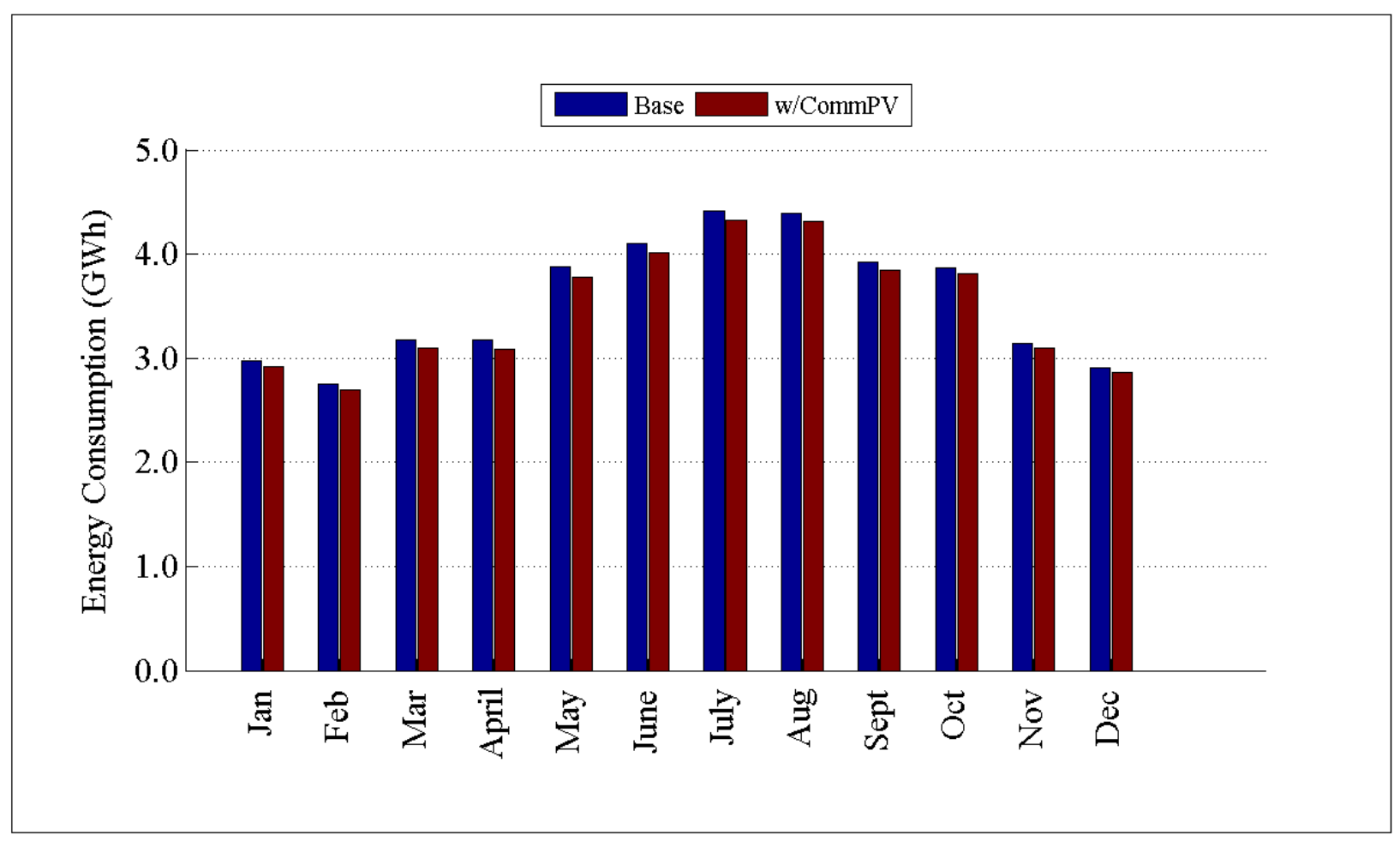

Figure D.212: Comparison of energy consumption by month for R5-12.47-3

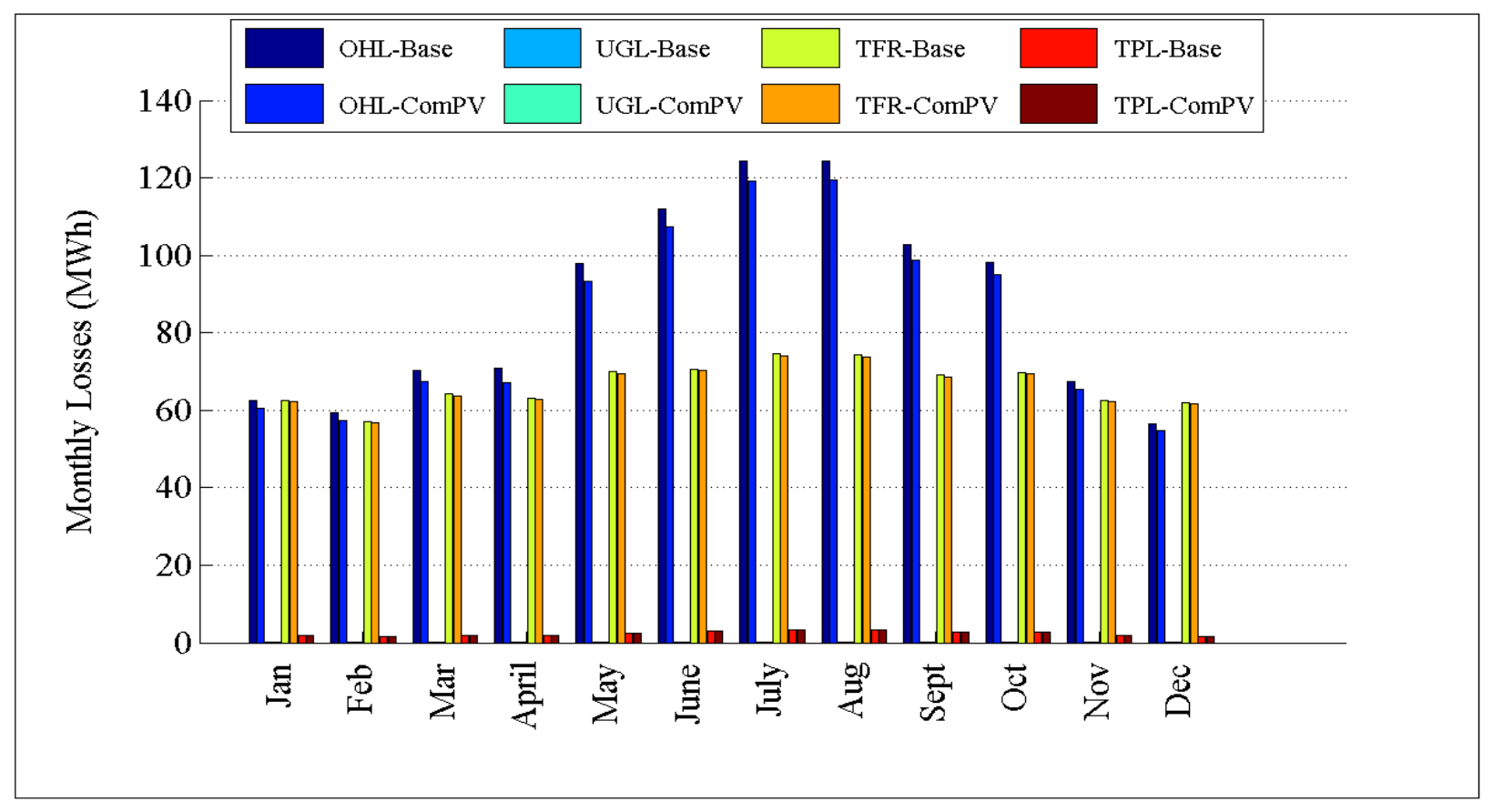

Figure D.213: Comparison of losses by month for R5-12.47-3 


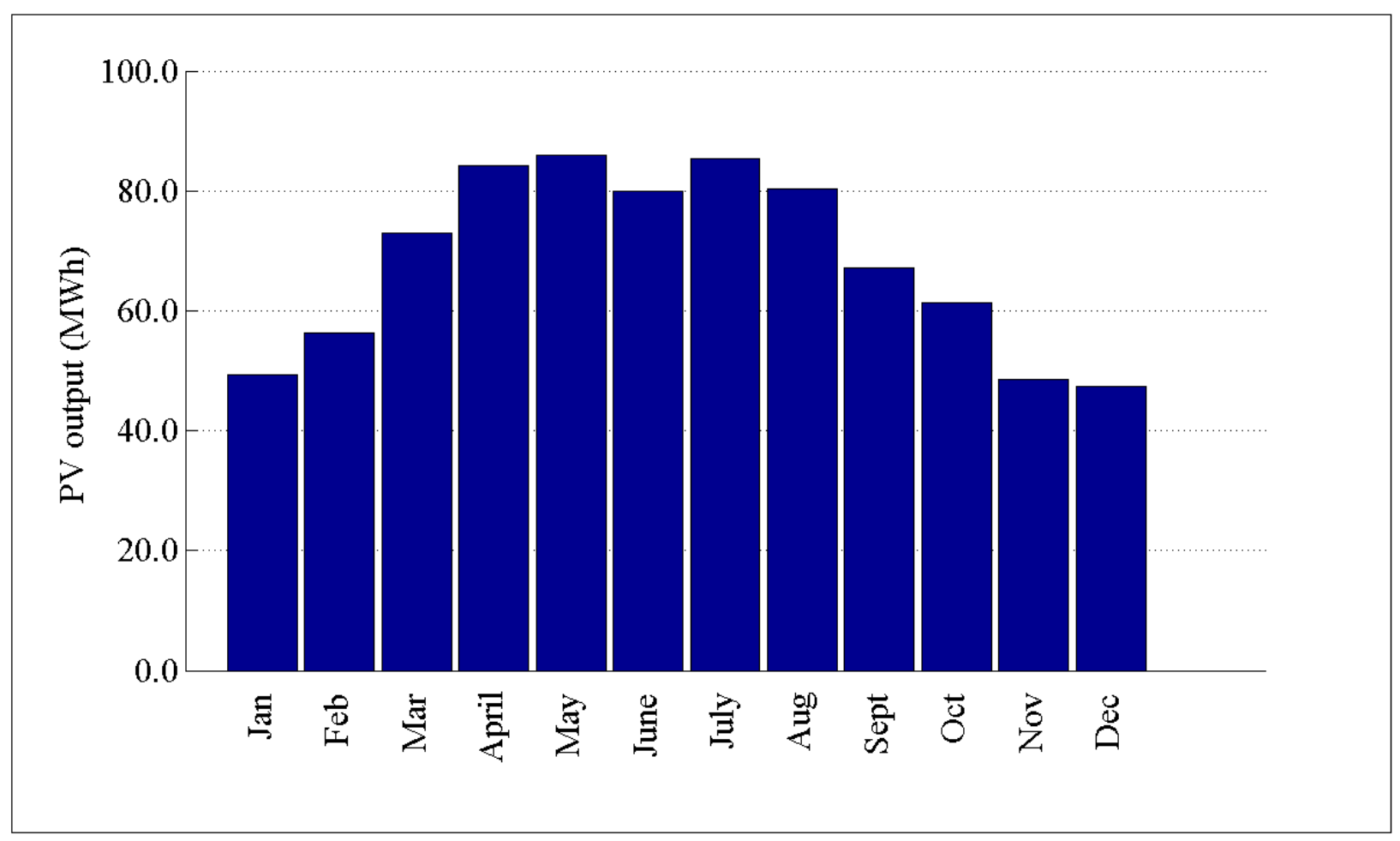

Figure D.214: PV output by month for R5-12.47-3

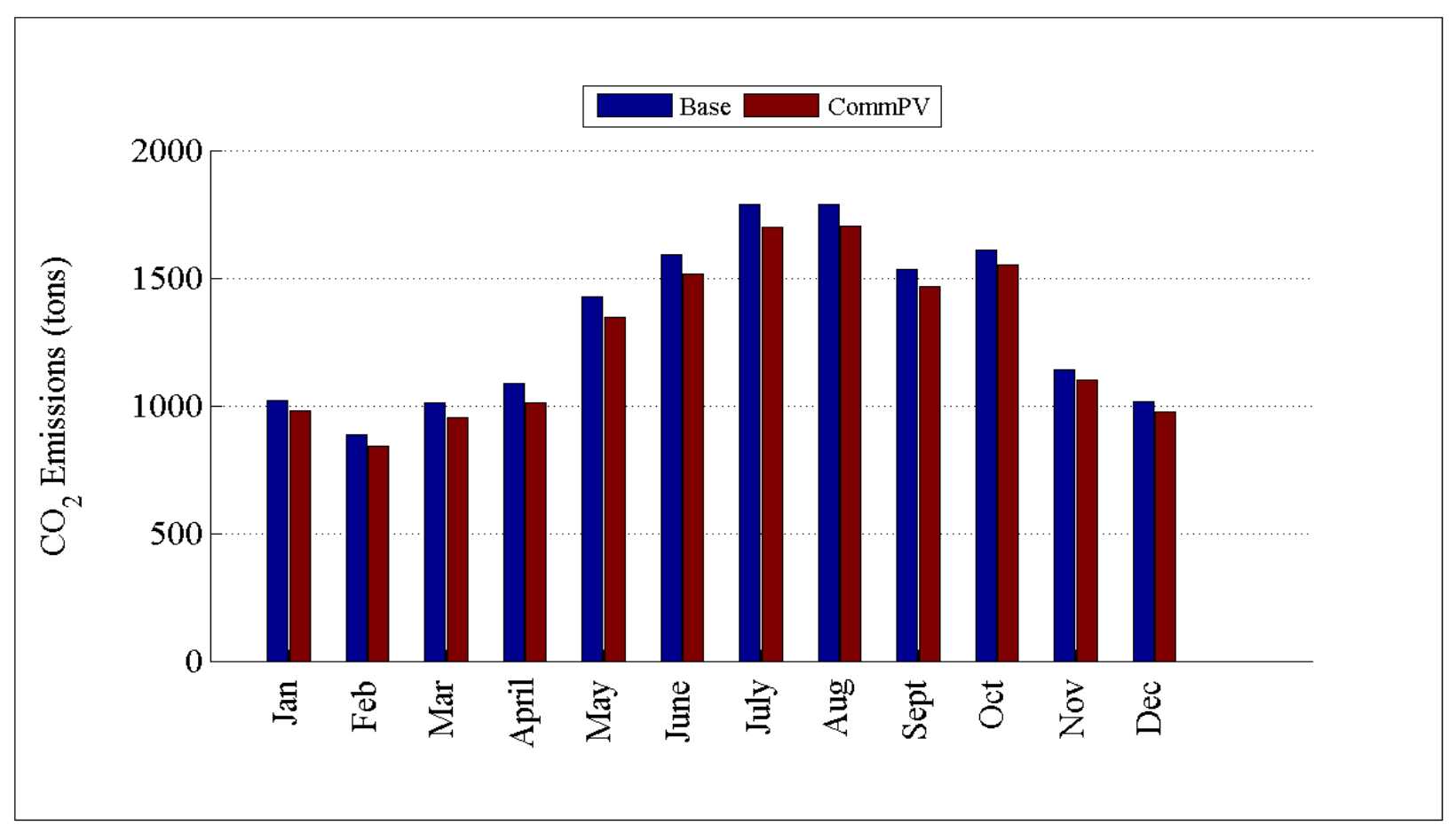

Figure D.215: Comparison of $\mathrm{CO}_{2}$ emissions by month for R5-12.47-3 
D.2.24 Detailed Commercial PV Plots for R5-12.47-4

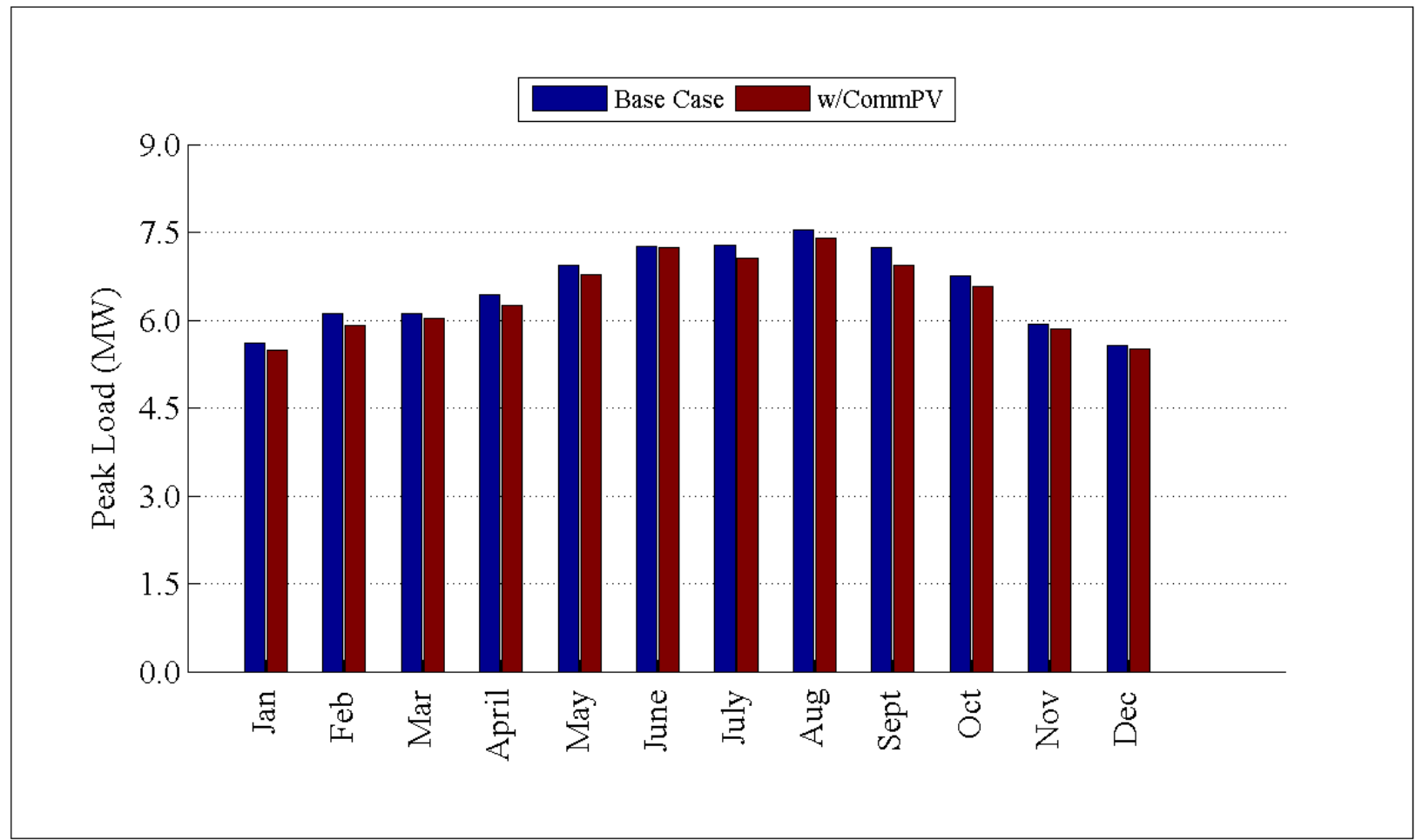

Figure D.216: Comparison of peak load by month for R5-12.47-4

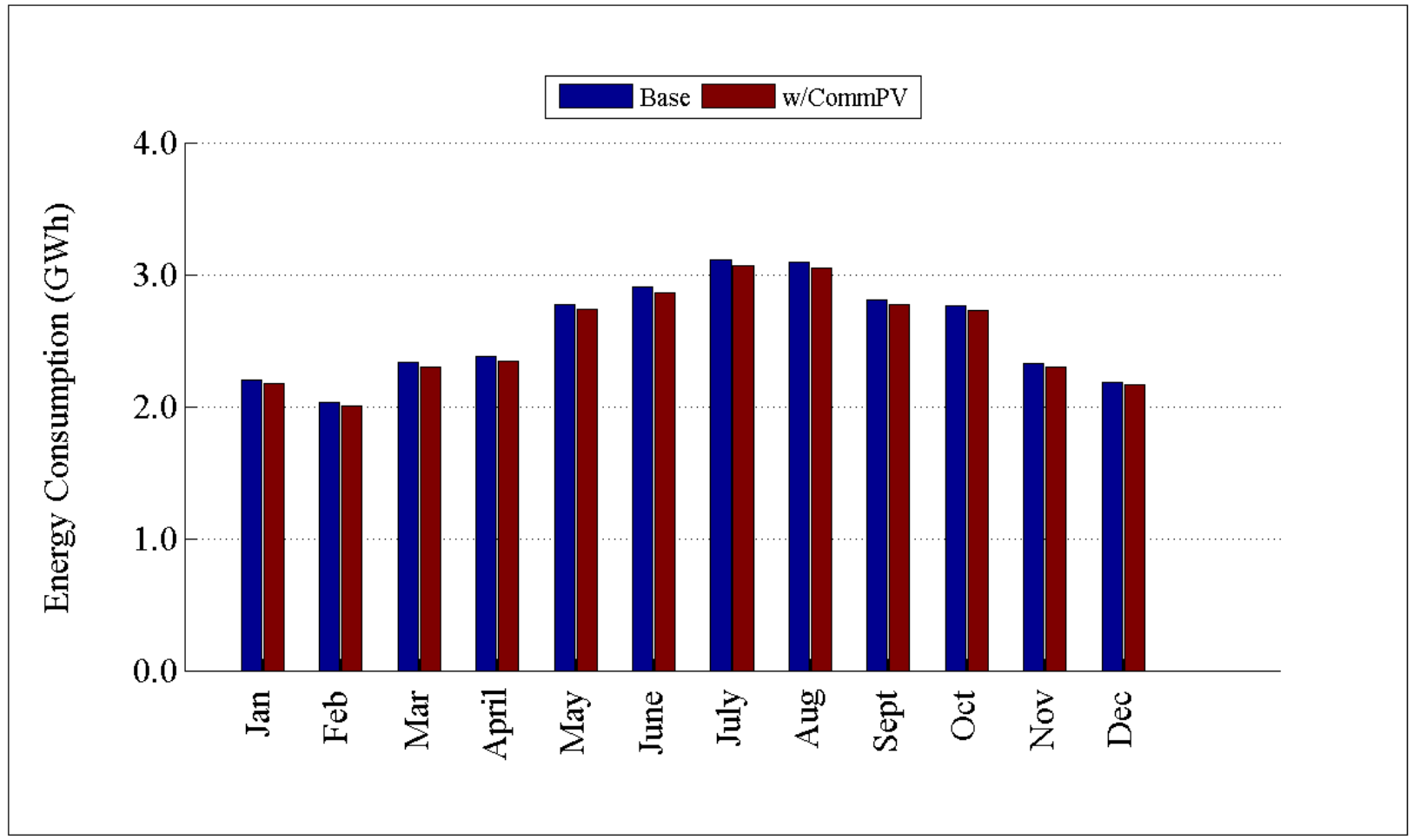

Figure D.217: Comparison of energy consumption by month for R5-12.47-4 266 


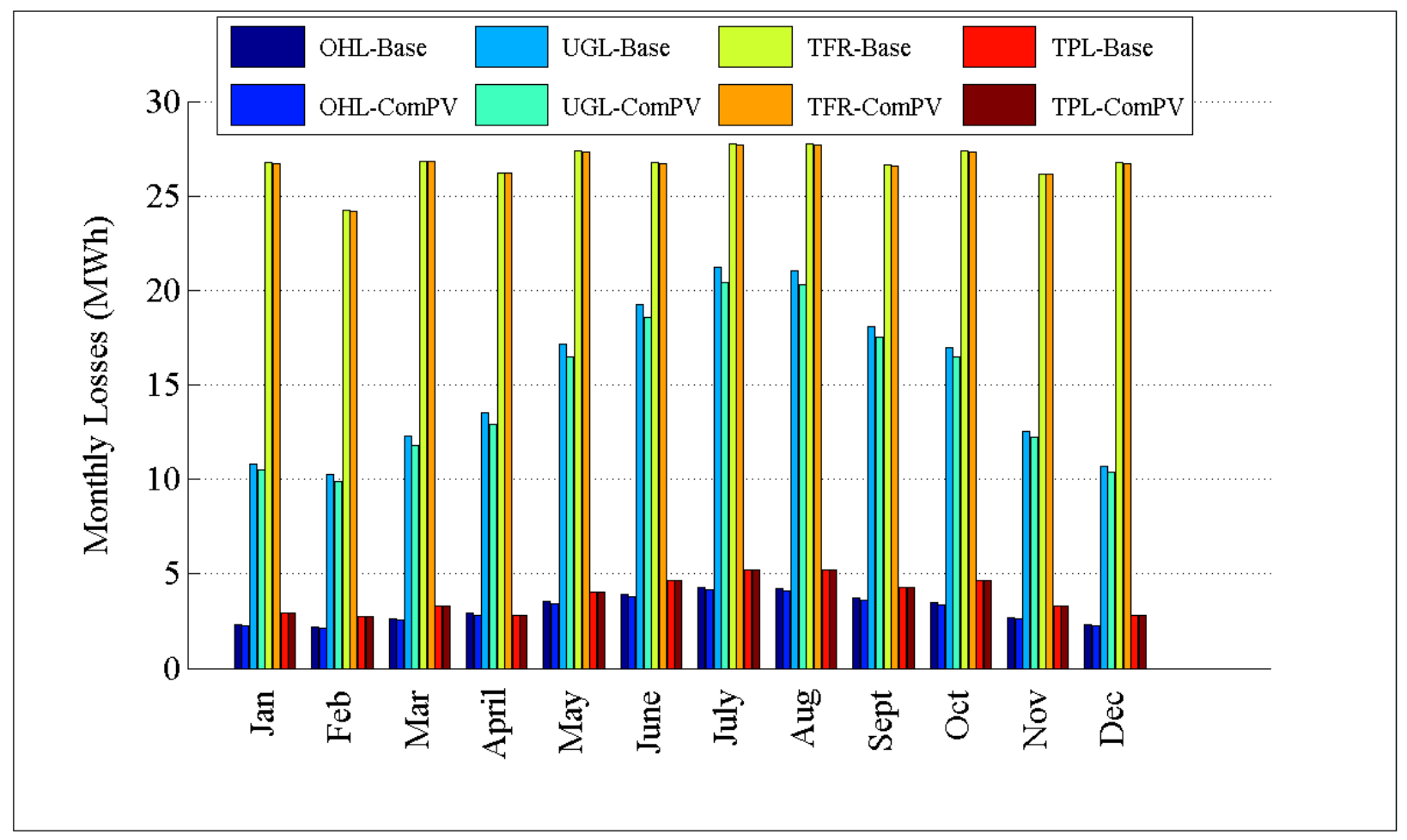

Figure D.218: Comparison of losses by month for R5-12.47-4

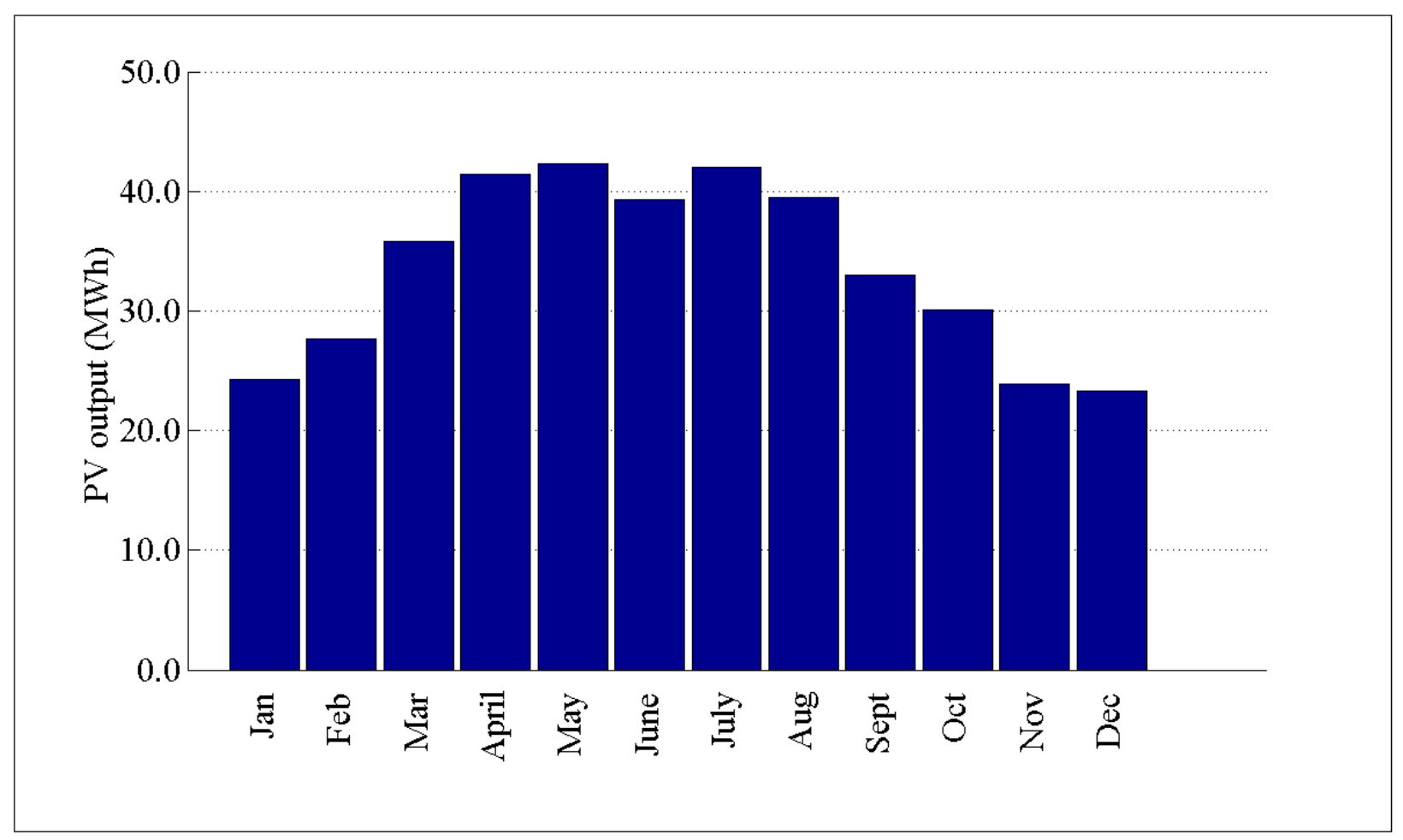

Figure D.219: PV output by month for R5-12.47-4 


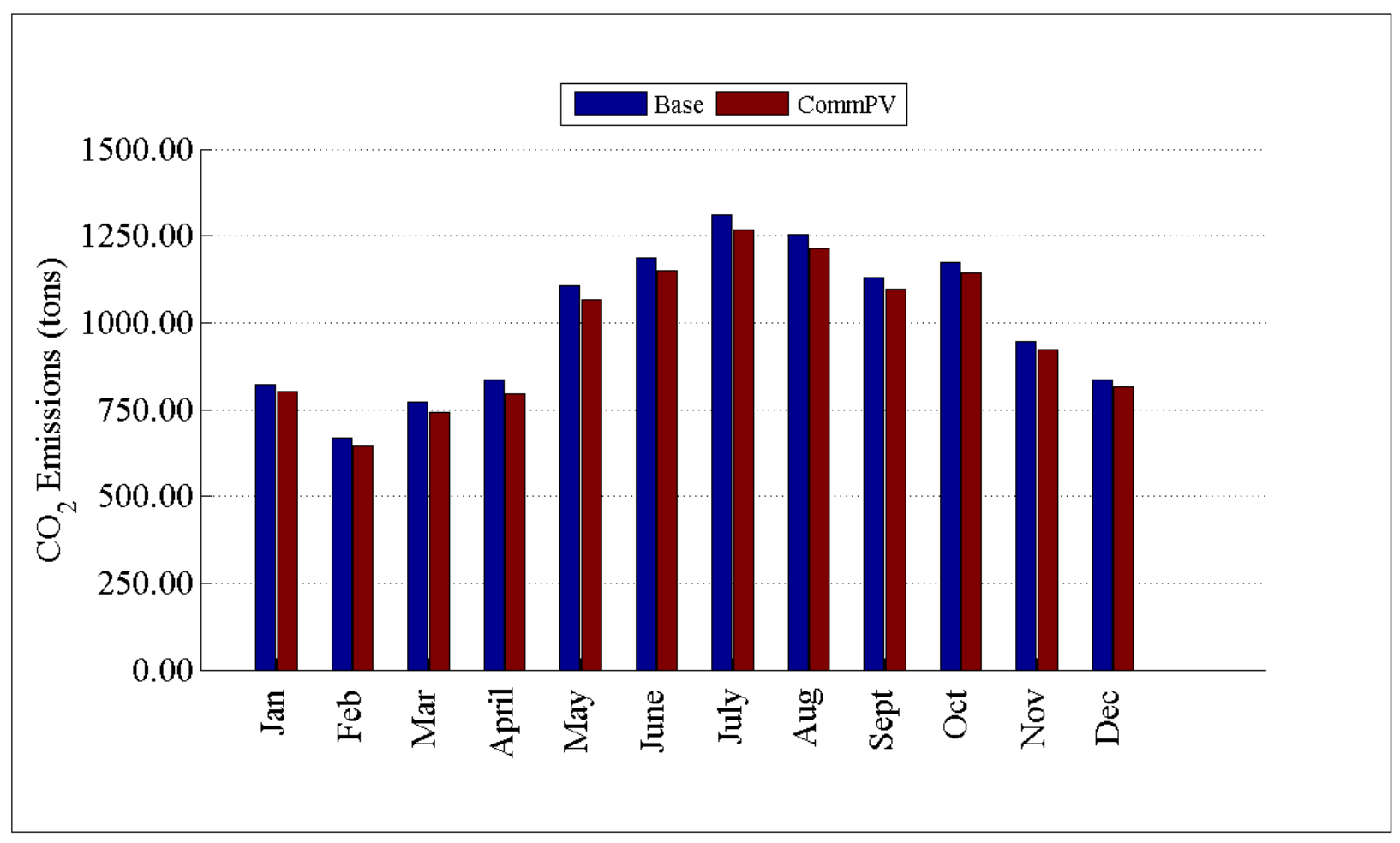

Figure D.220: Comparison of $\mathrm{CO}_{2}$ emissions by month for R5-12.47-4

D.2.25 Detailed Commercial PV Plots for R5-12.47-5 


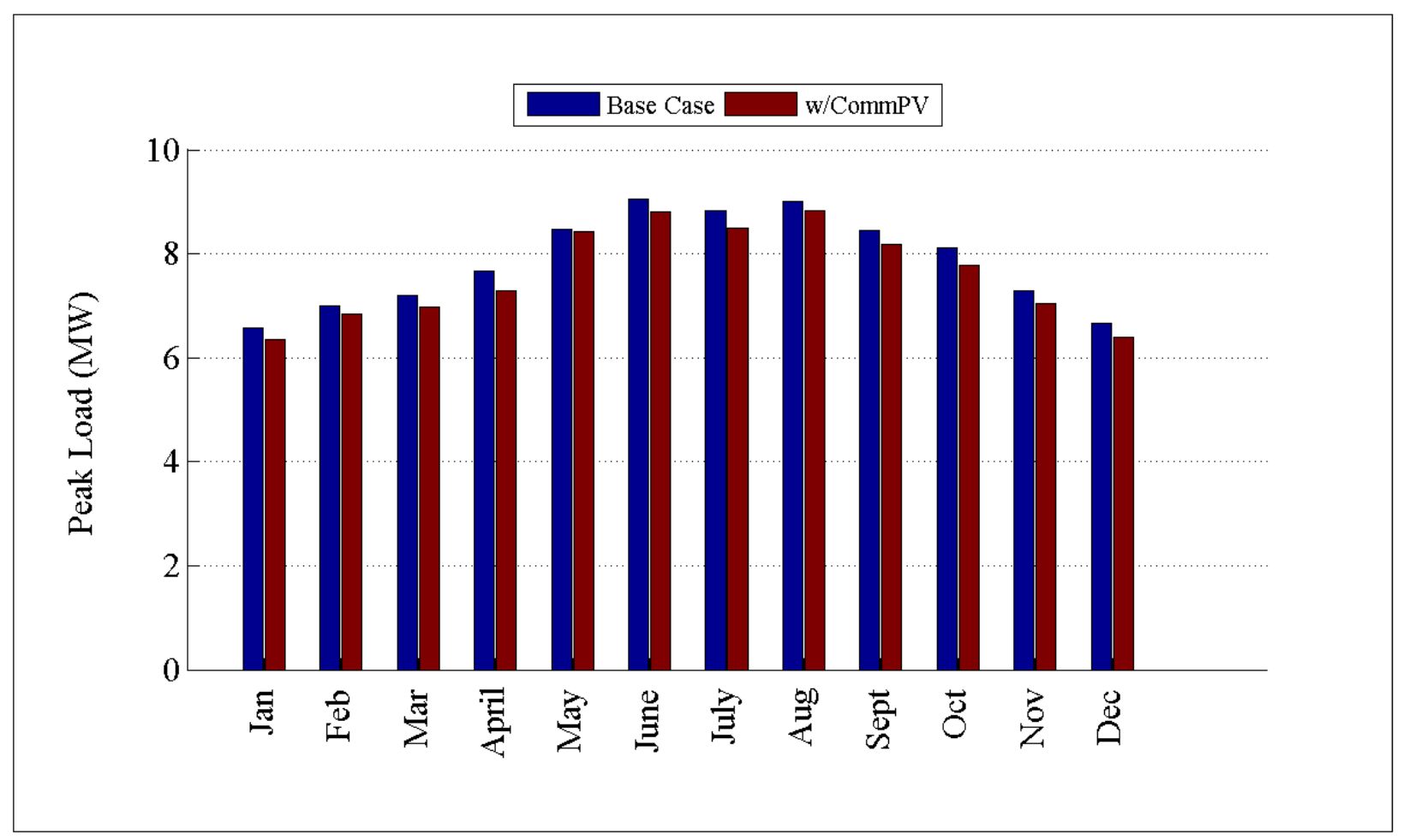

Figure D.221: Comparison of peak load by month for R5-12.47-5

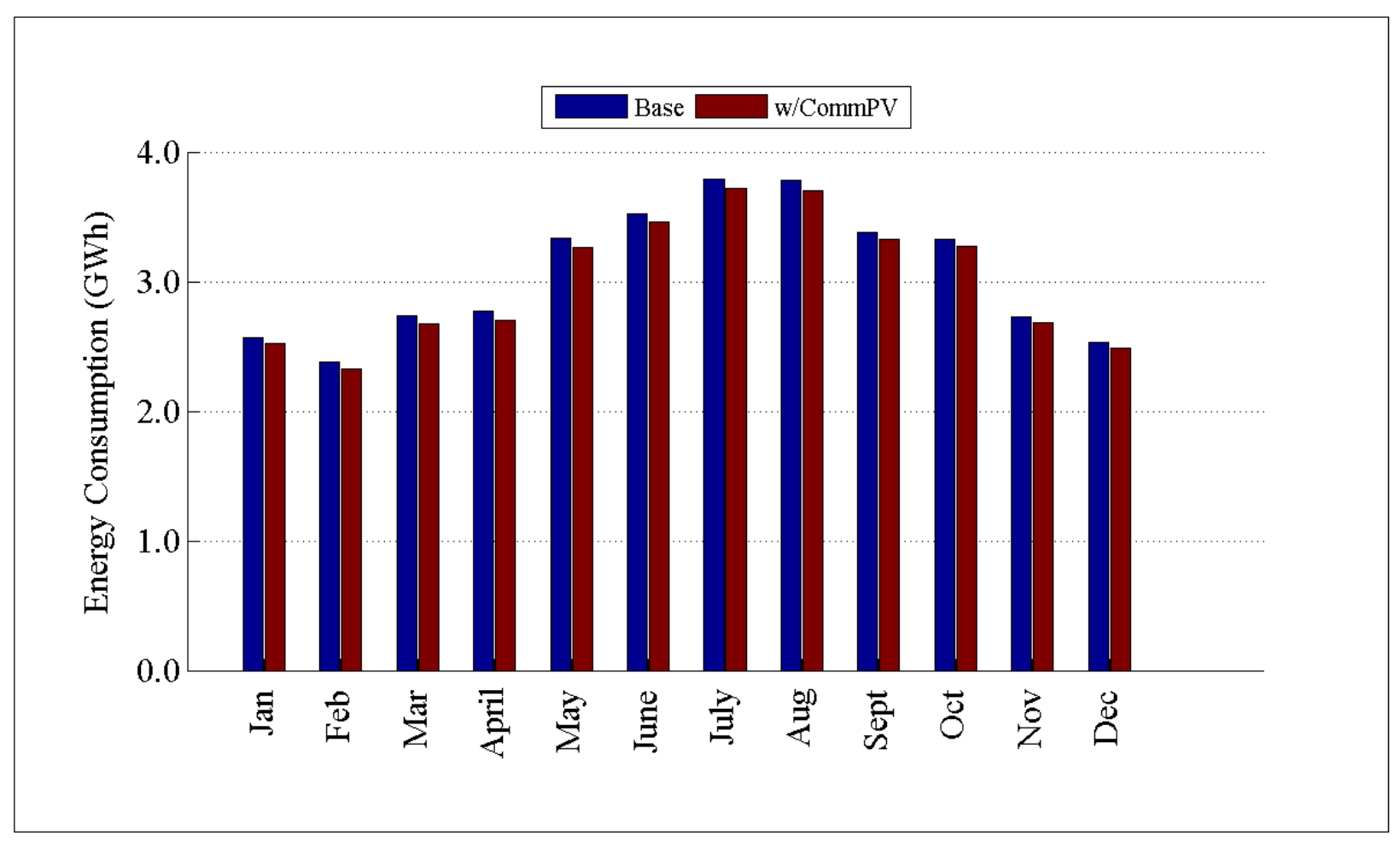

Figure D.222: Comparison of energy consumption by month for R5-12.47-5 


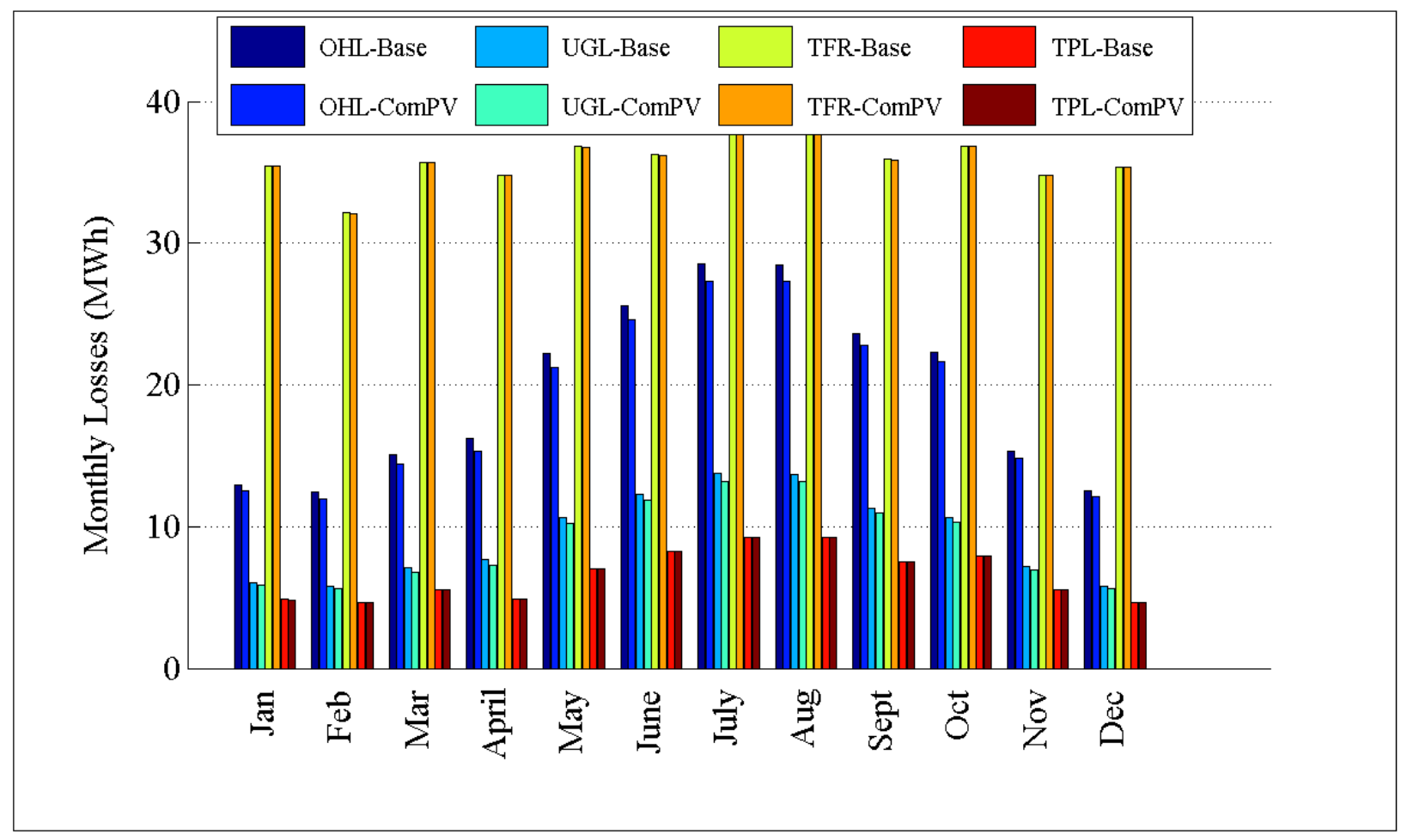

Figure D.223: Comparison of losses by month for R5-12.47-5

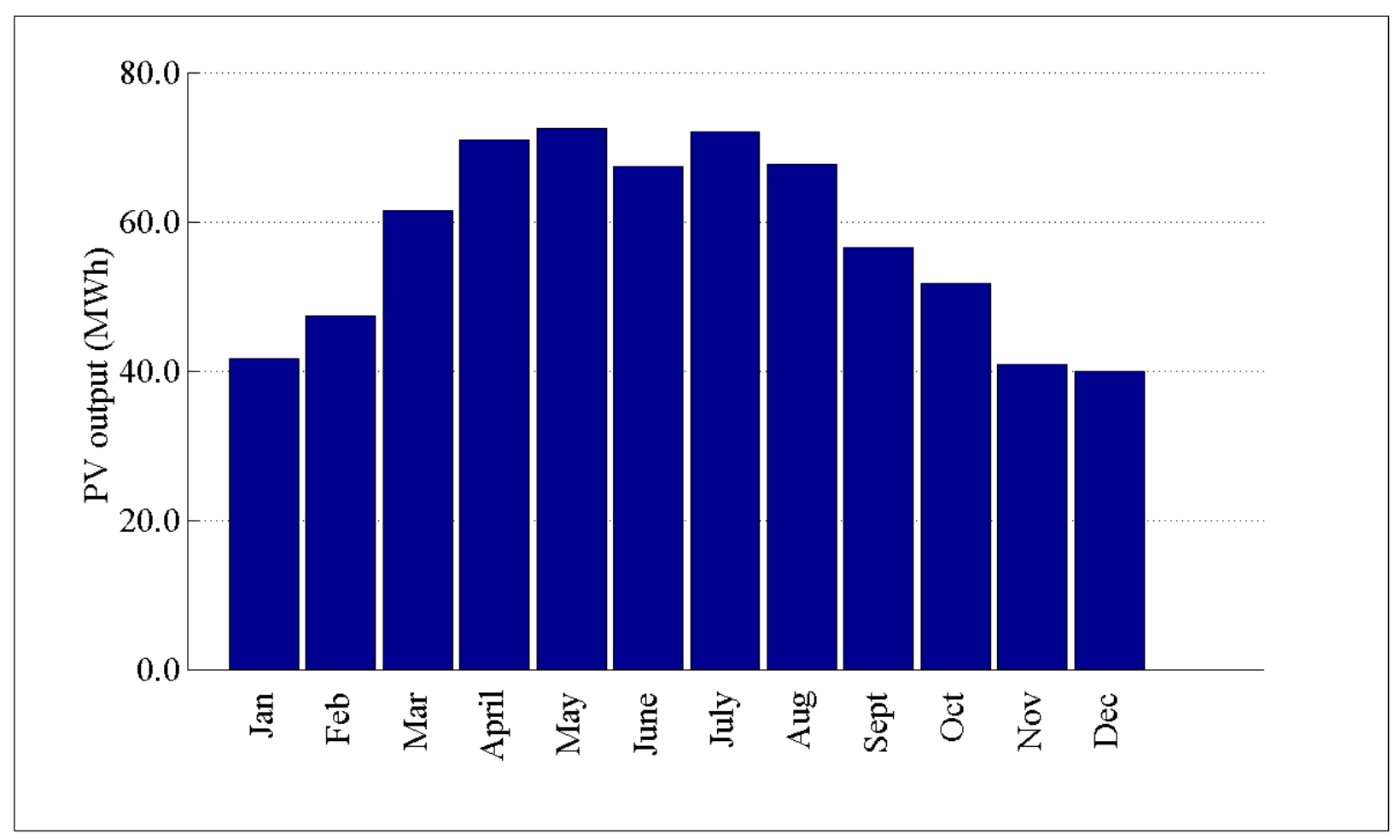

Figure D.224: PV output by month for R5-12.47-5 


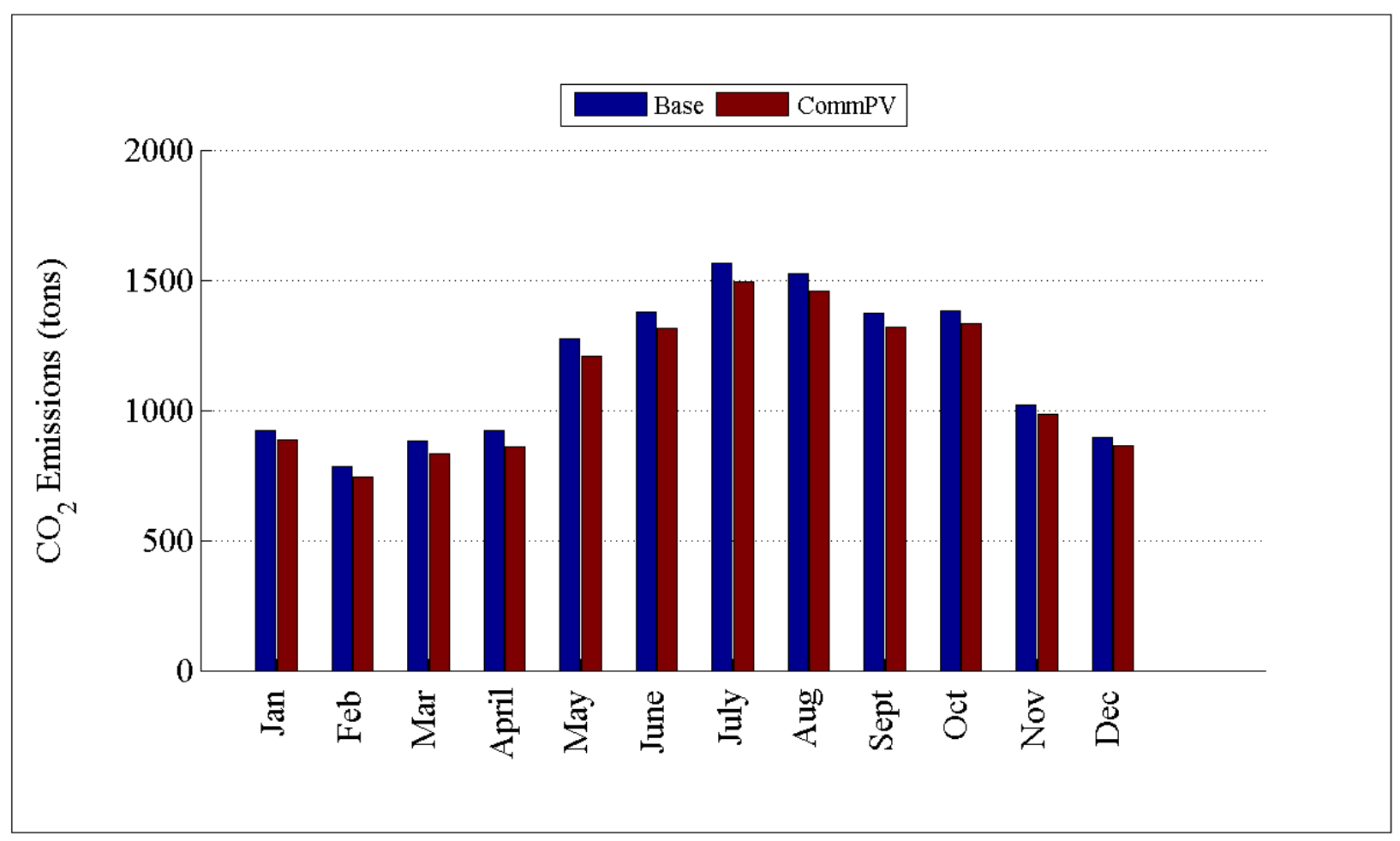

Figure D.225: Comparison of $\mathrm{CO}_{2}$ emissions by month for R5-12.47-5

D.2.26 Detailed Commercial PV Plots for R5-25.00-1 


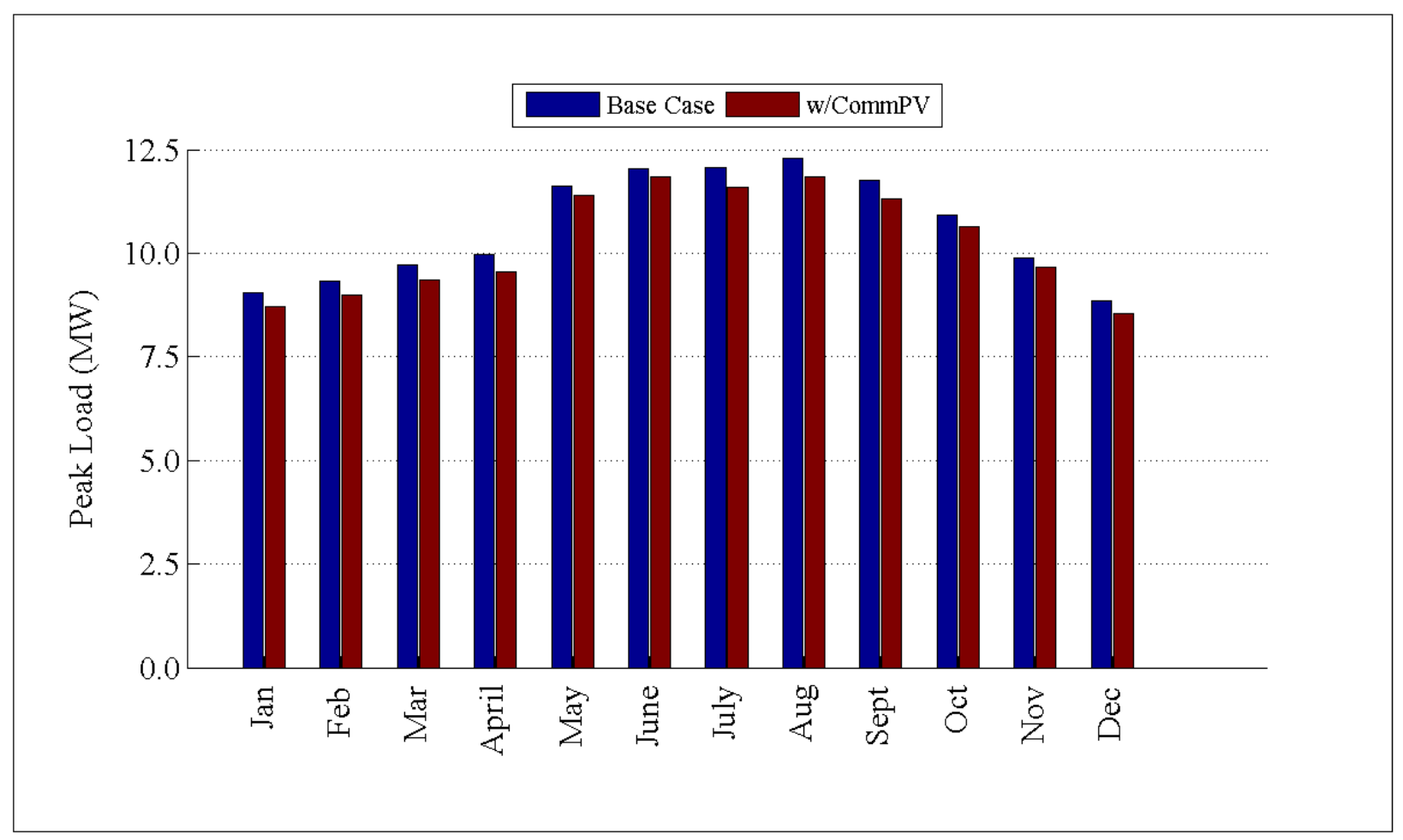

Figure D.226: Comparison of peak load by month for R5-25.00-1

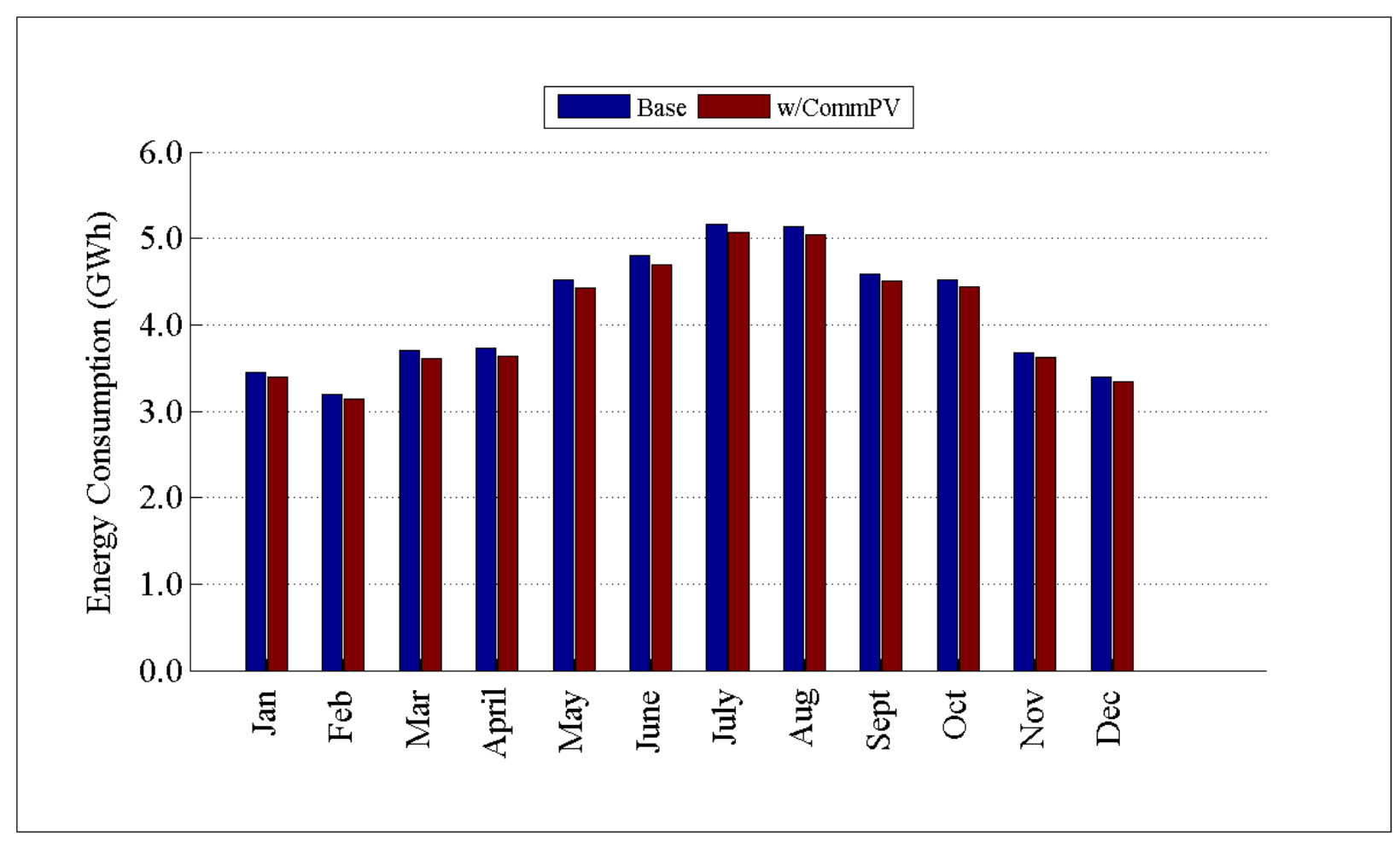

Figure D.227: Comparison of energy consumption by month for R5-25.00-1 


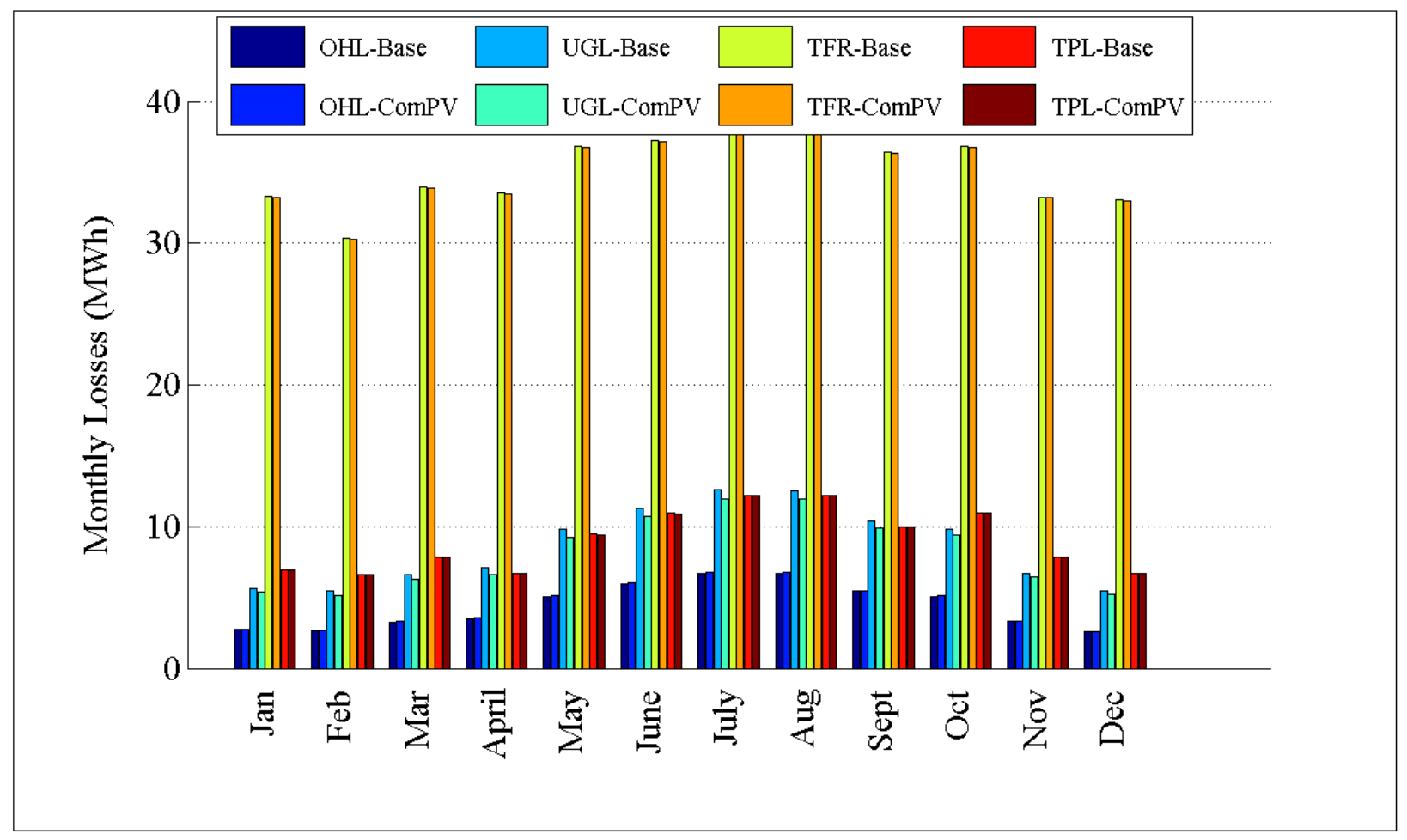

Figure D.228: Comparison of losses by month for R5-25.00-1

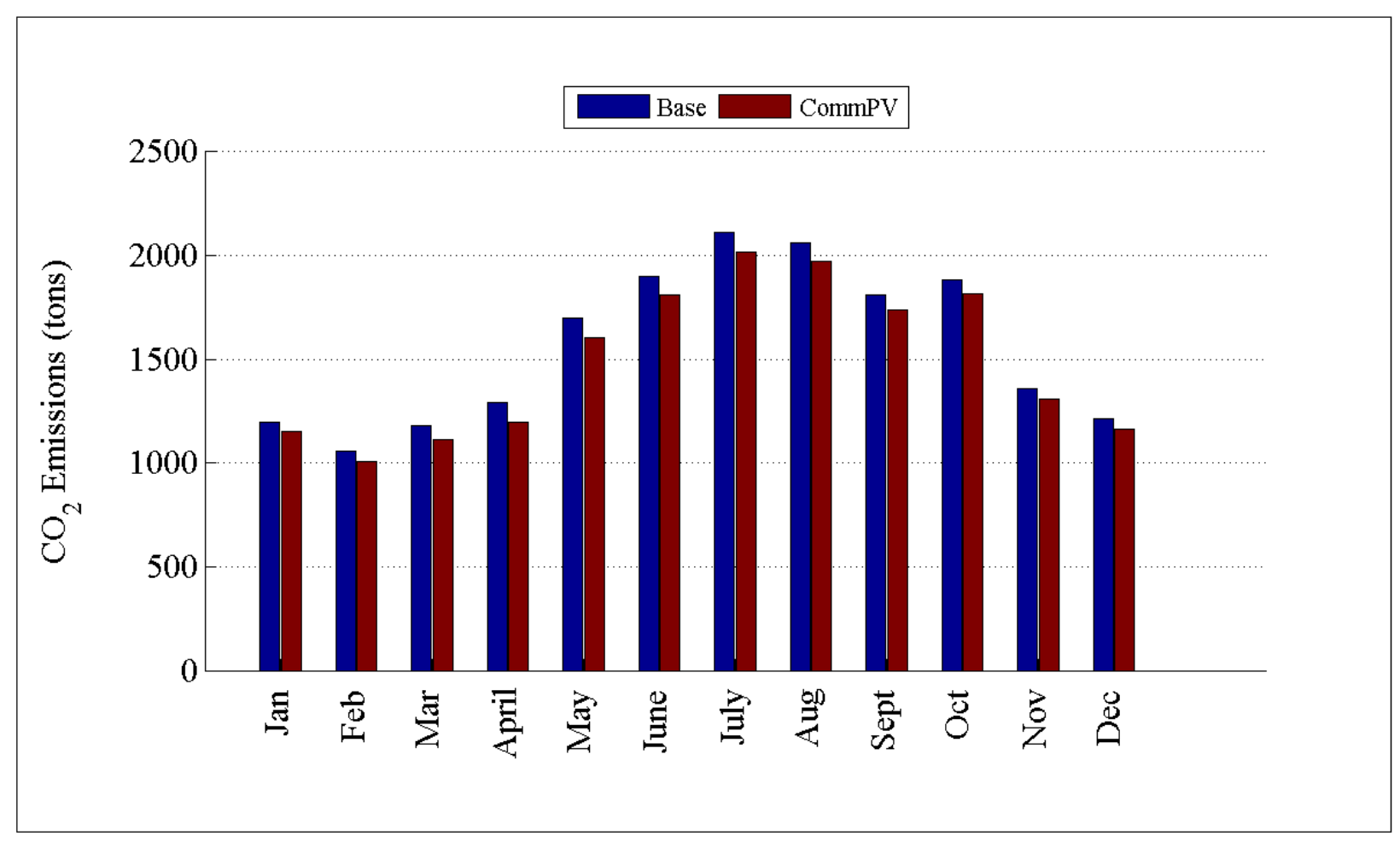

Figure D.229: Comparison of $\mathrm{CO}_{2}$ emissions by month for R5-25.00-1 


\section{D.2.27 Detailed Commercial PV Plots for R5-35.00-1}

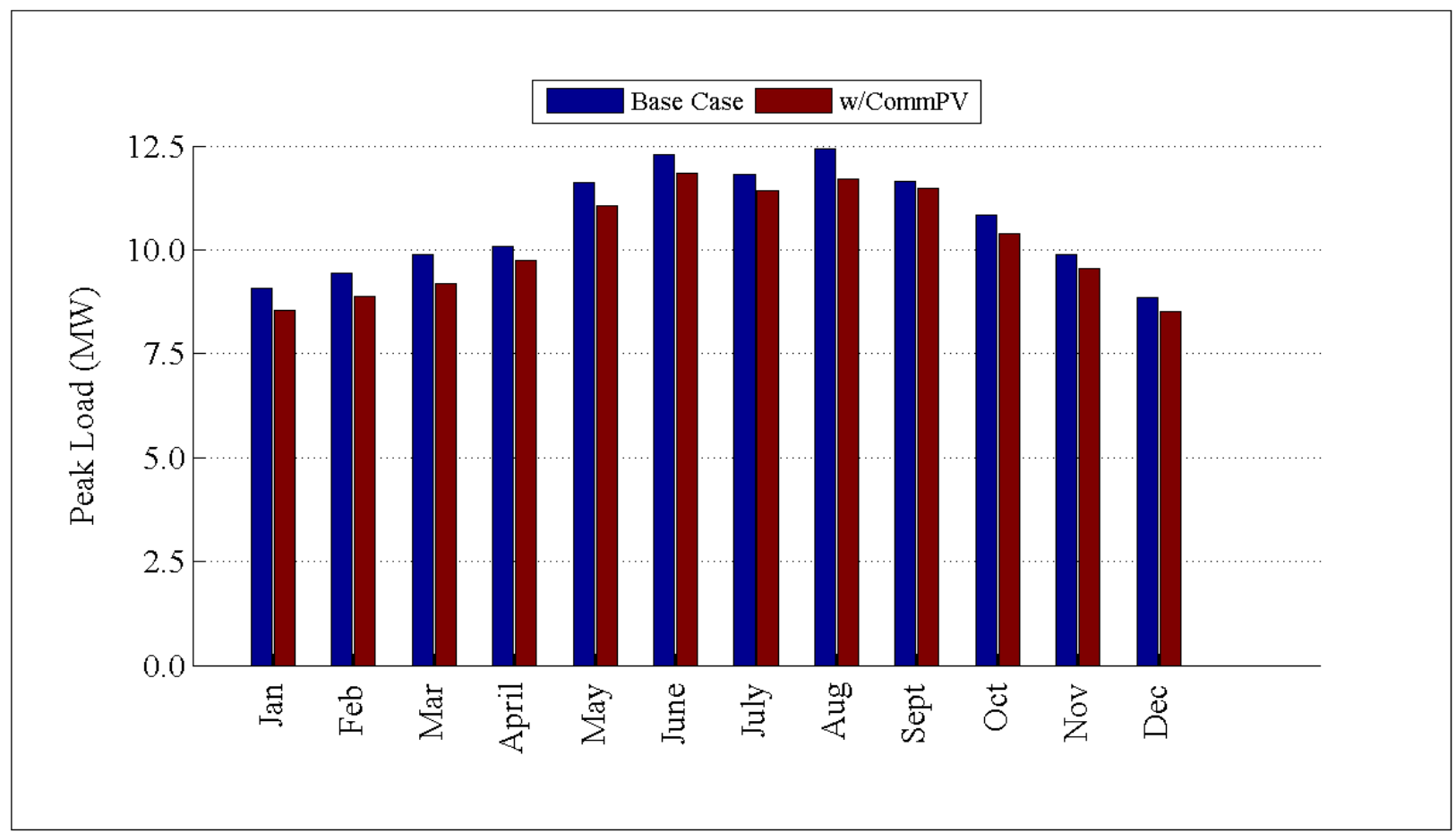

Figure D.230: Comparison of peak load by month for R5-35.00-1

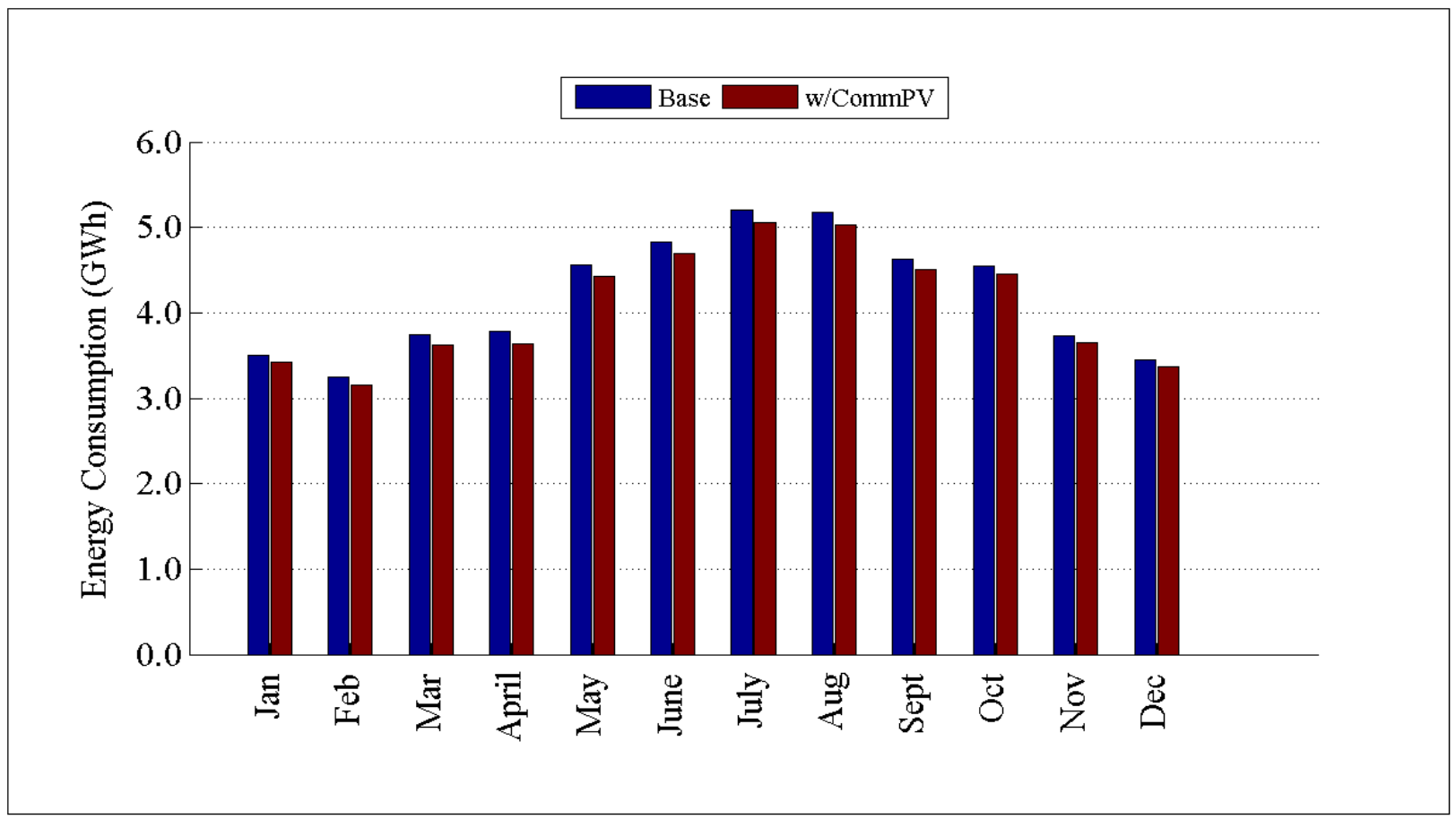

Figure D.231: Comparison of energy consumption by month for R5-35.00-1 


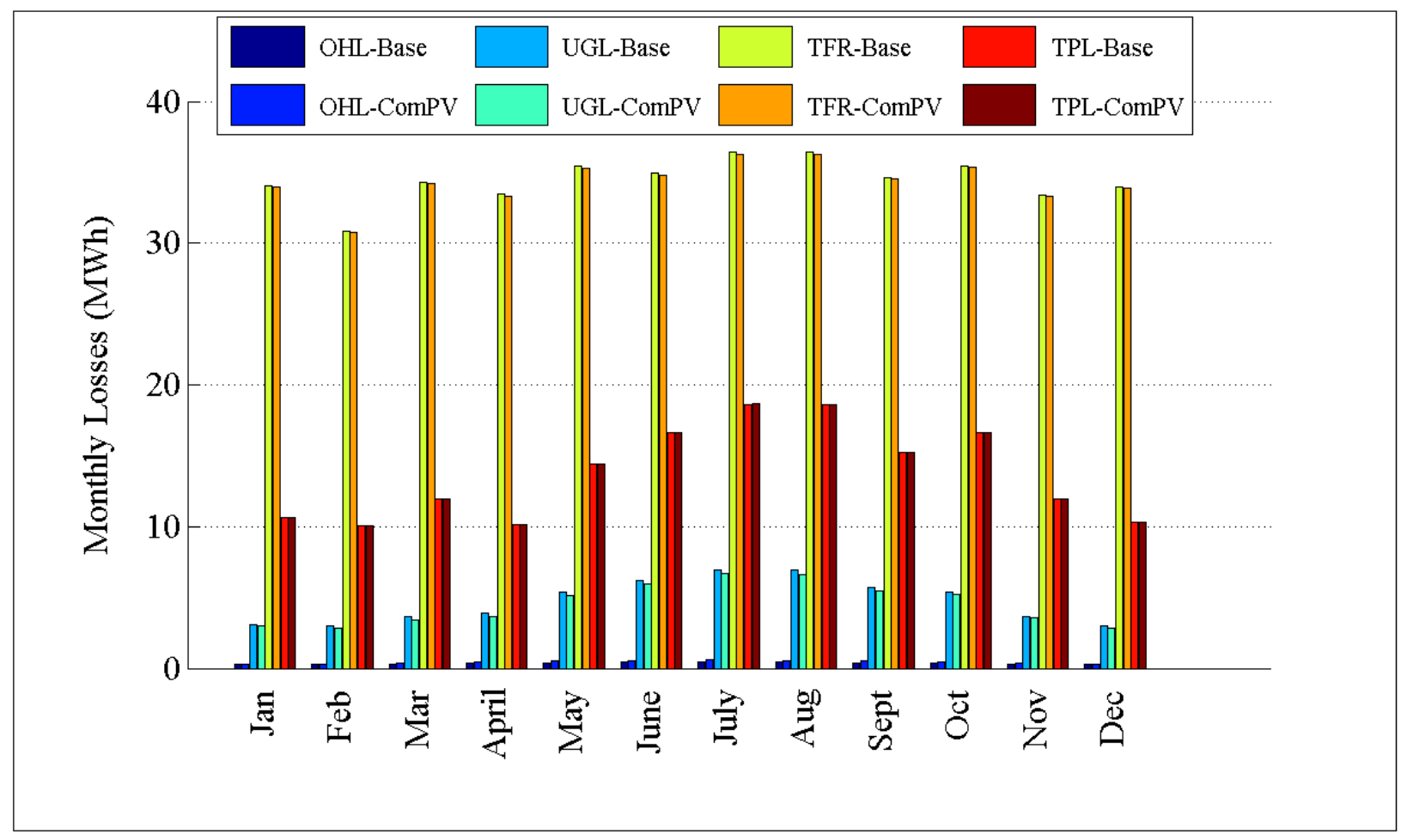

Figure D.232: Comparison of losses by month for R5-35.00-1

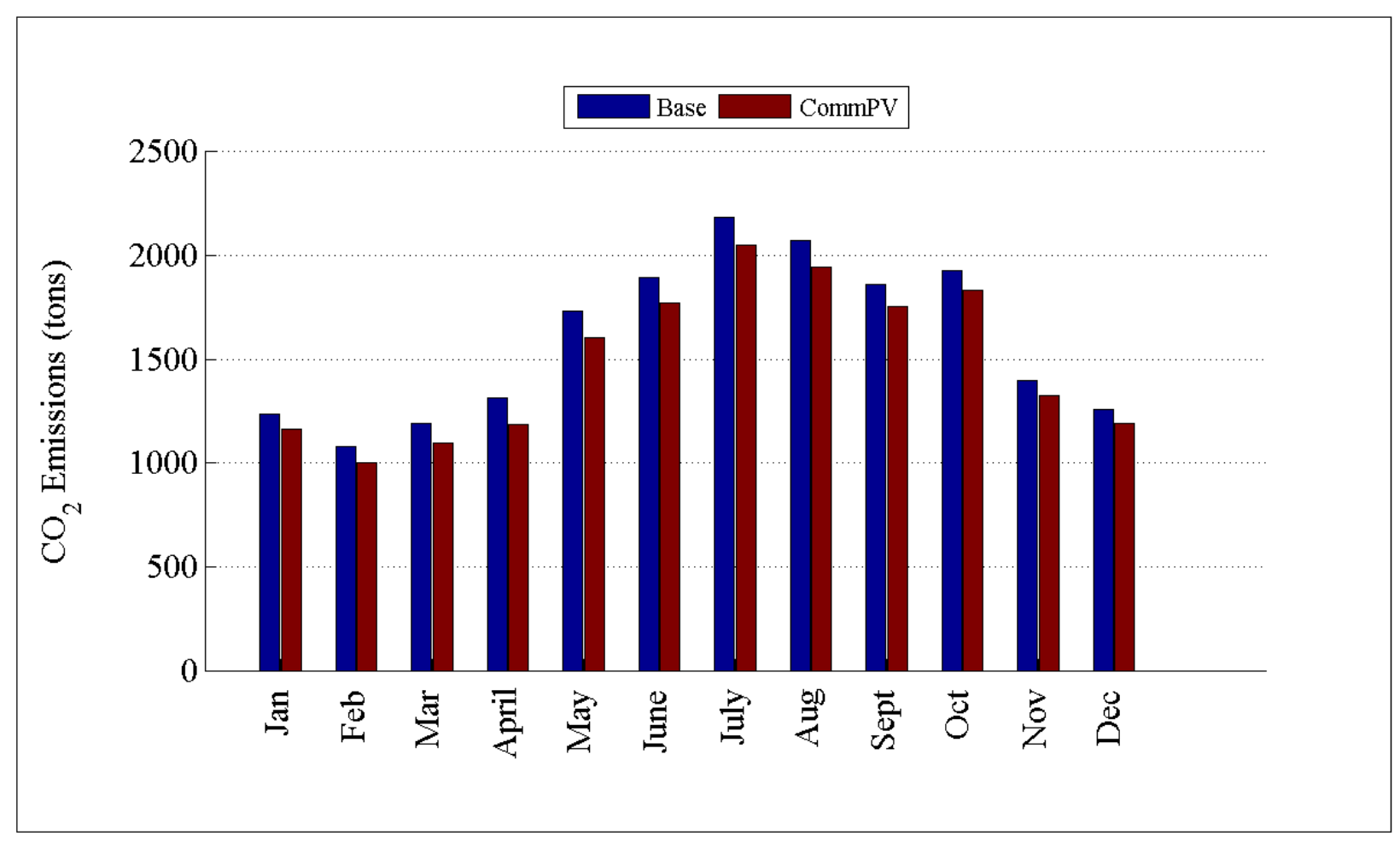

Figure D.233: Comparison of $\mathrm{CO}_{2}$ emissions by month for R5-35.00-1 


\section{D.3 Addition of Combined PV}

D.3.1 Detailed Combined PV Plots for R1-12.47-1

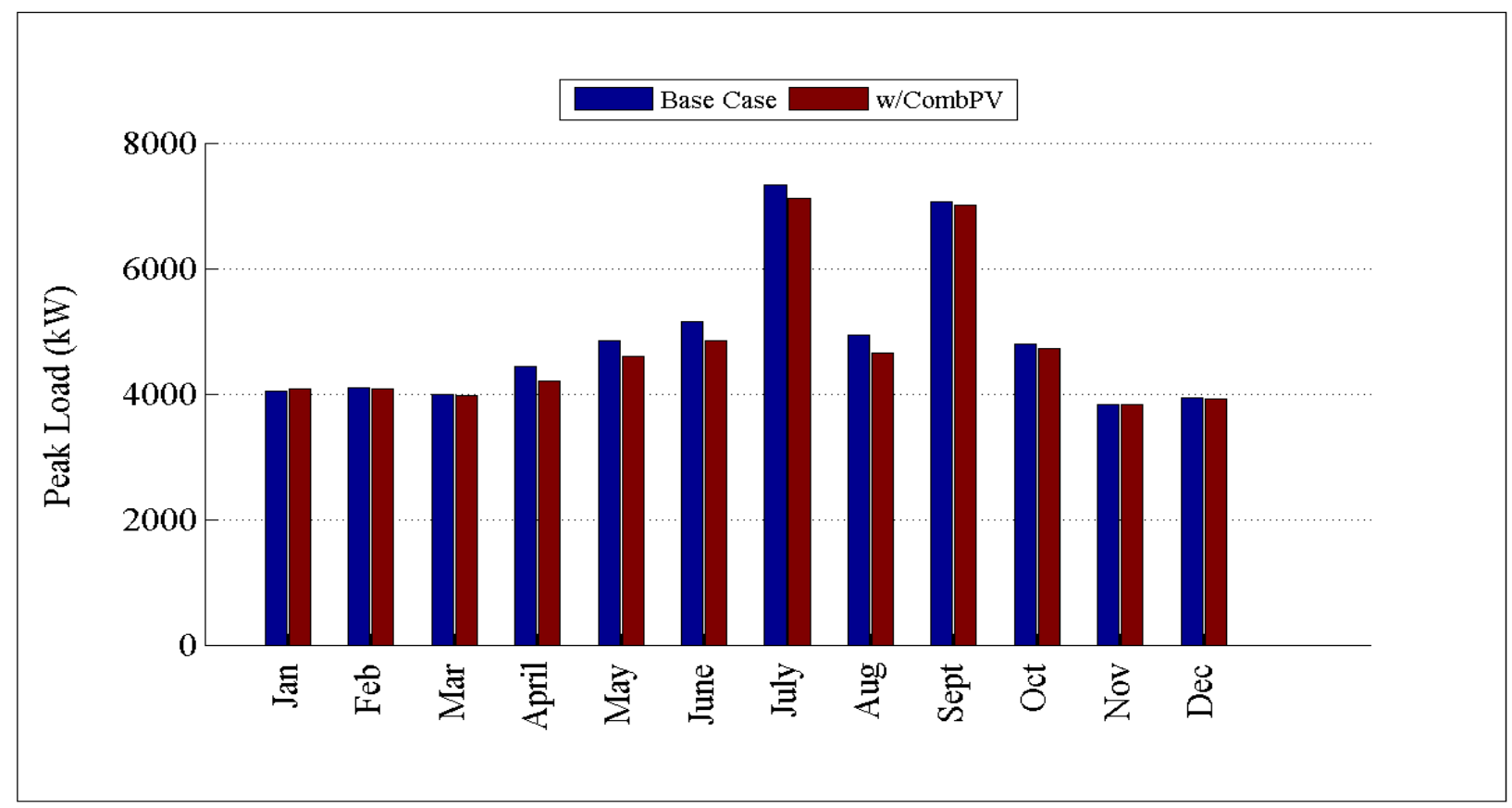

Figure D.234: Comparison of peak load by month for R1-12.47-1

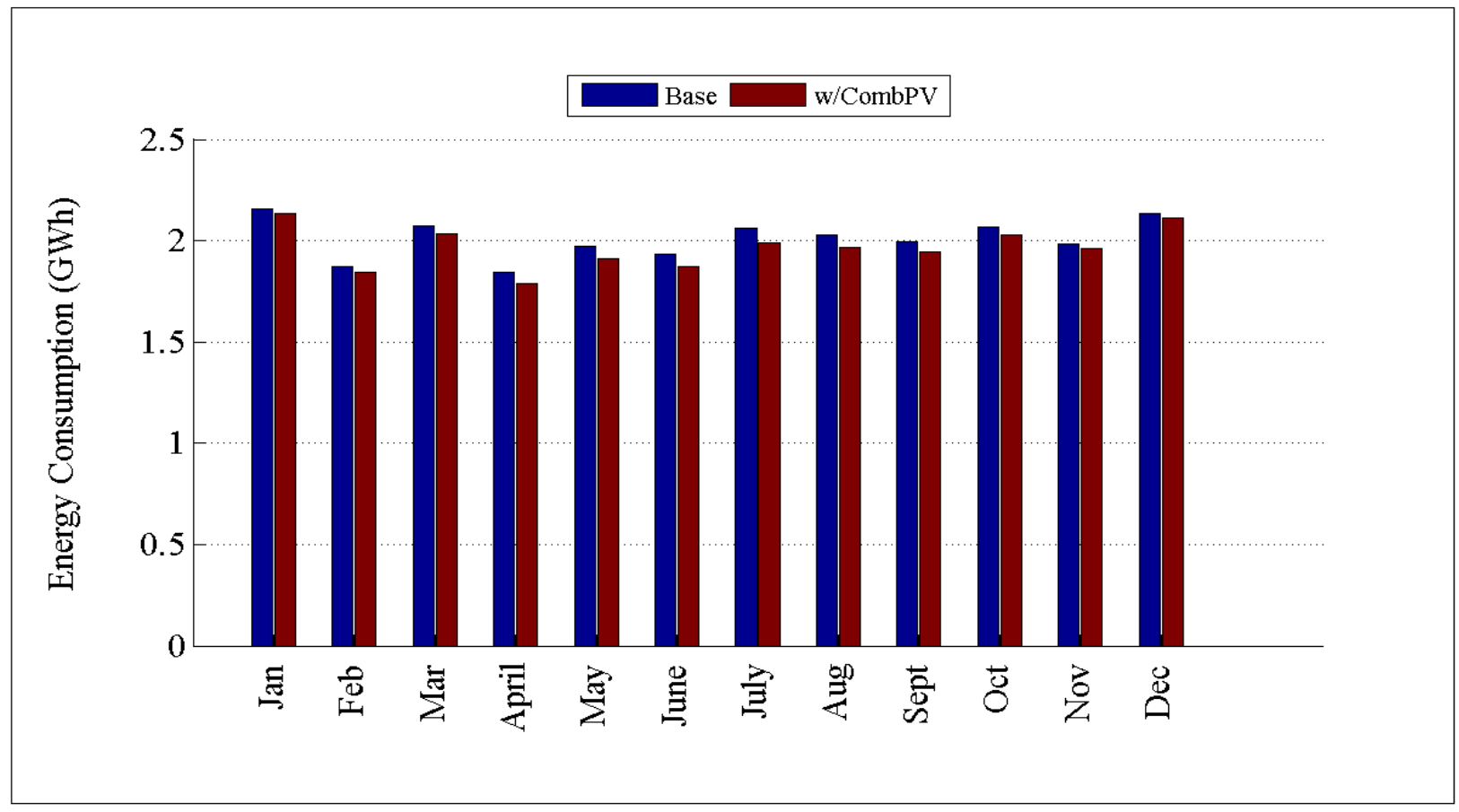

Figure D.235: Comparison of energy consumption by month for R1-12.47-1 


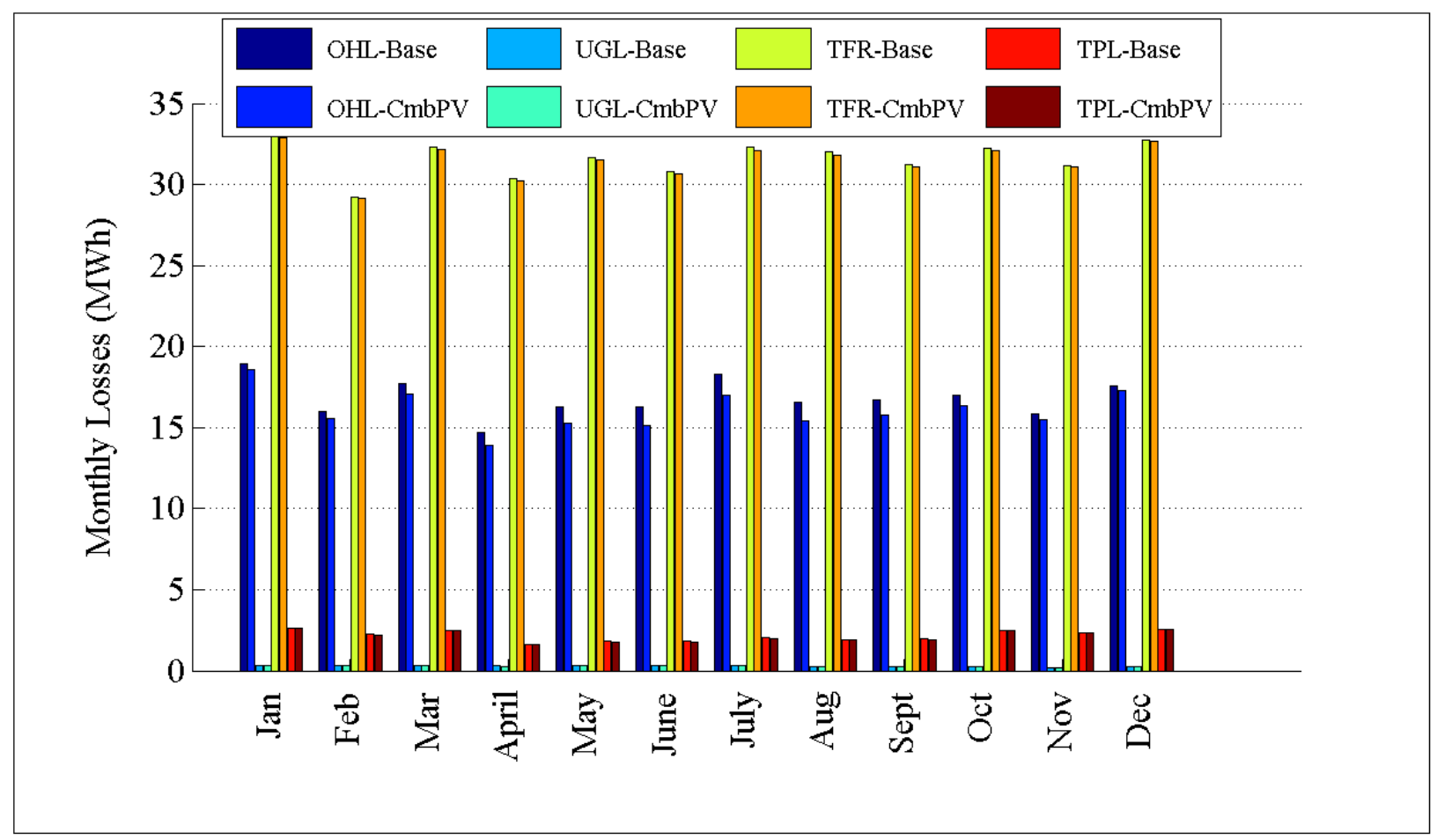

Figure D.236: Comparison of losses by month for R1-12.47-1

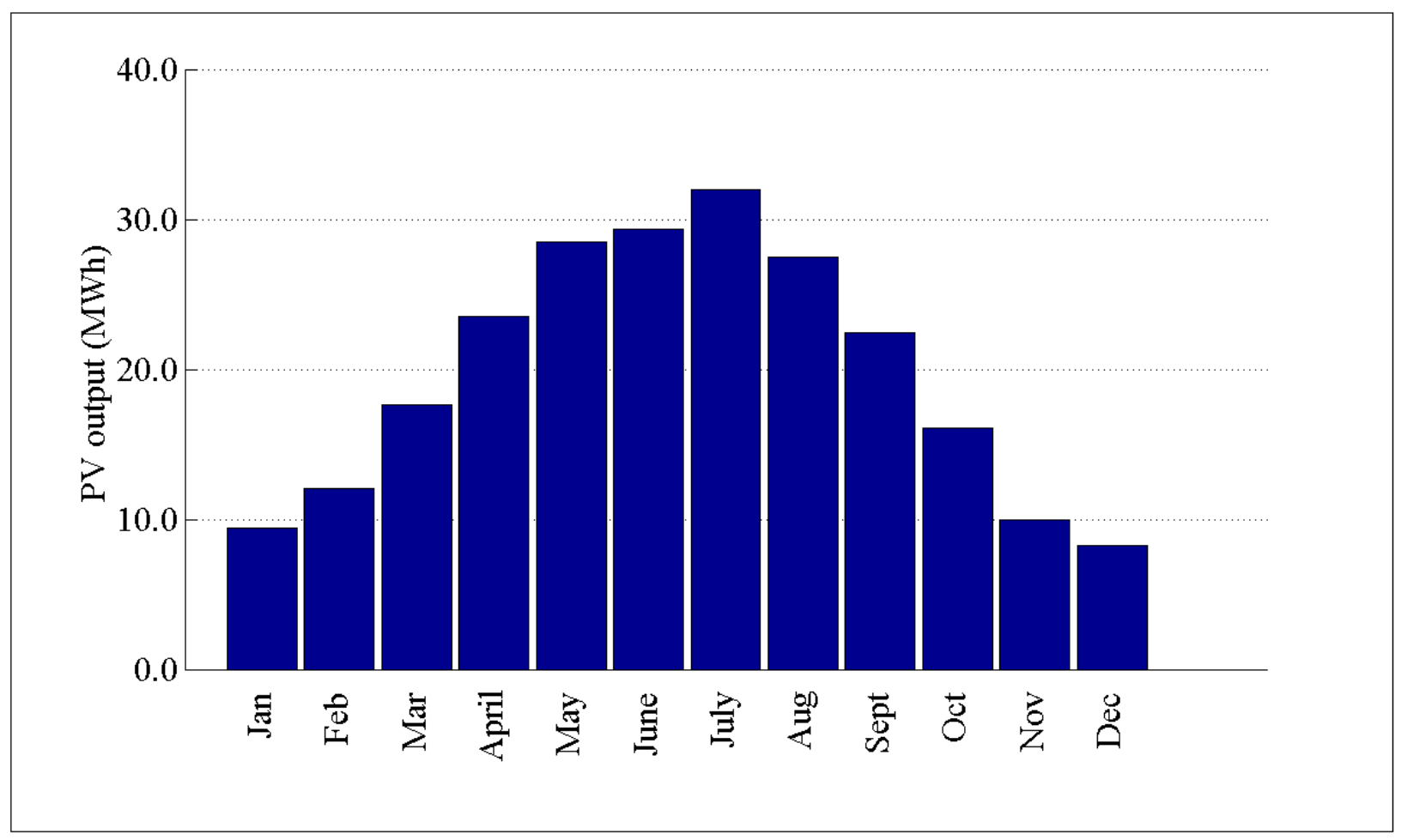

Figure D.237: PV output by month for R1-12.47-1 


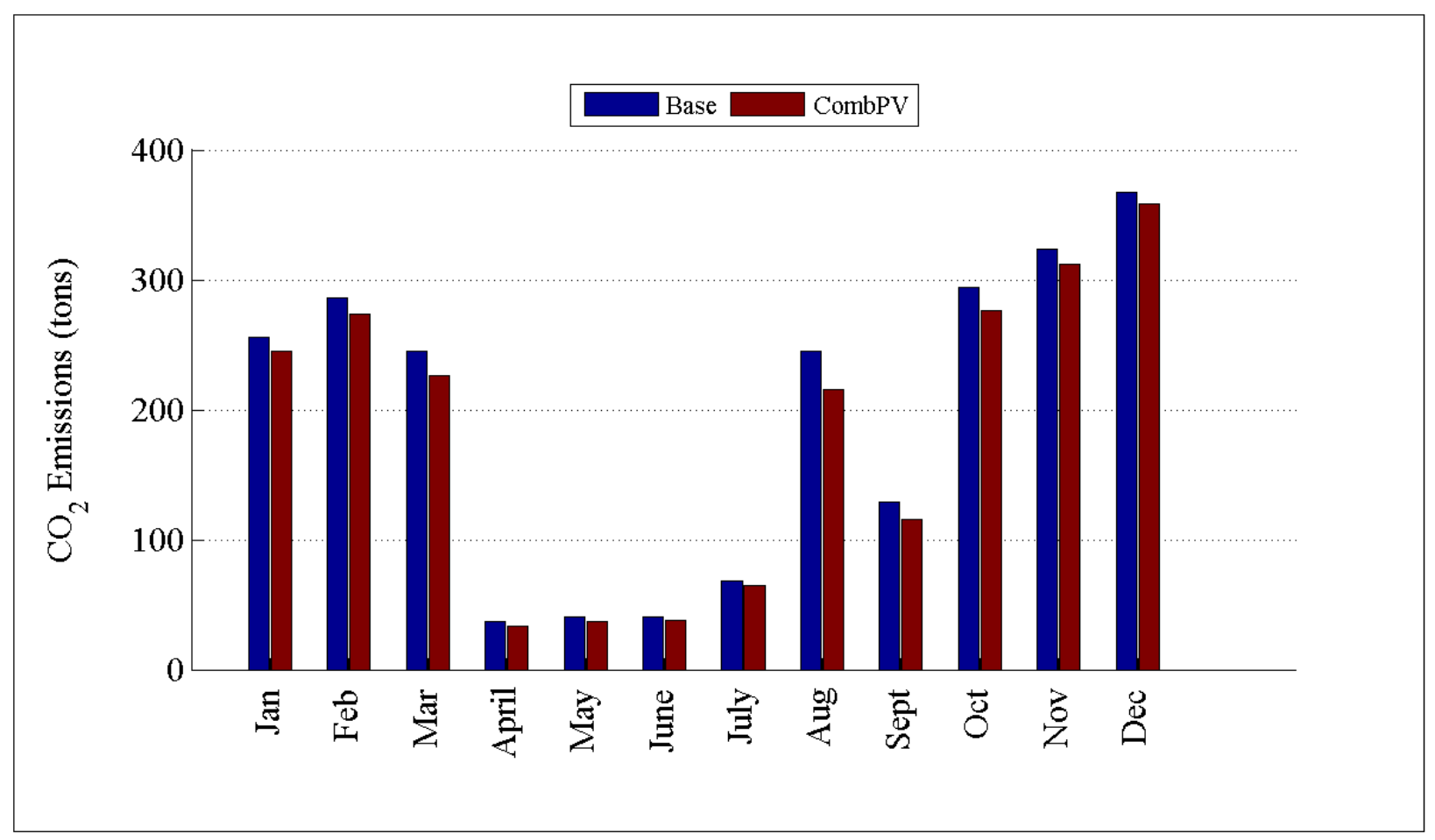

Figure D.238: Comparison of $\mathrm{CO}_{2}$ emissions by month for R1-12.47-1

\section{D.3.2 Detailed Combined PV Plots for R1-12.47-2}

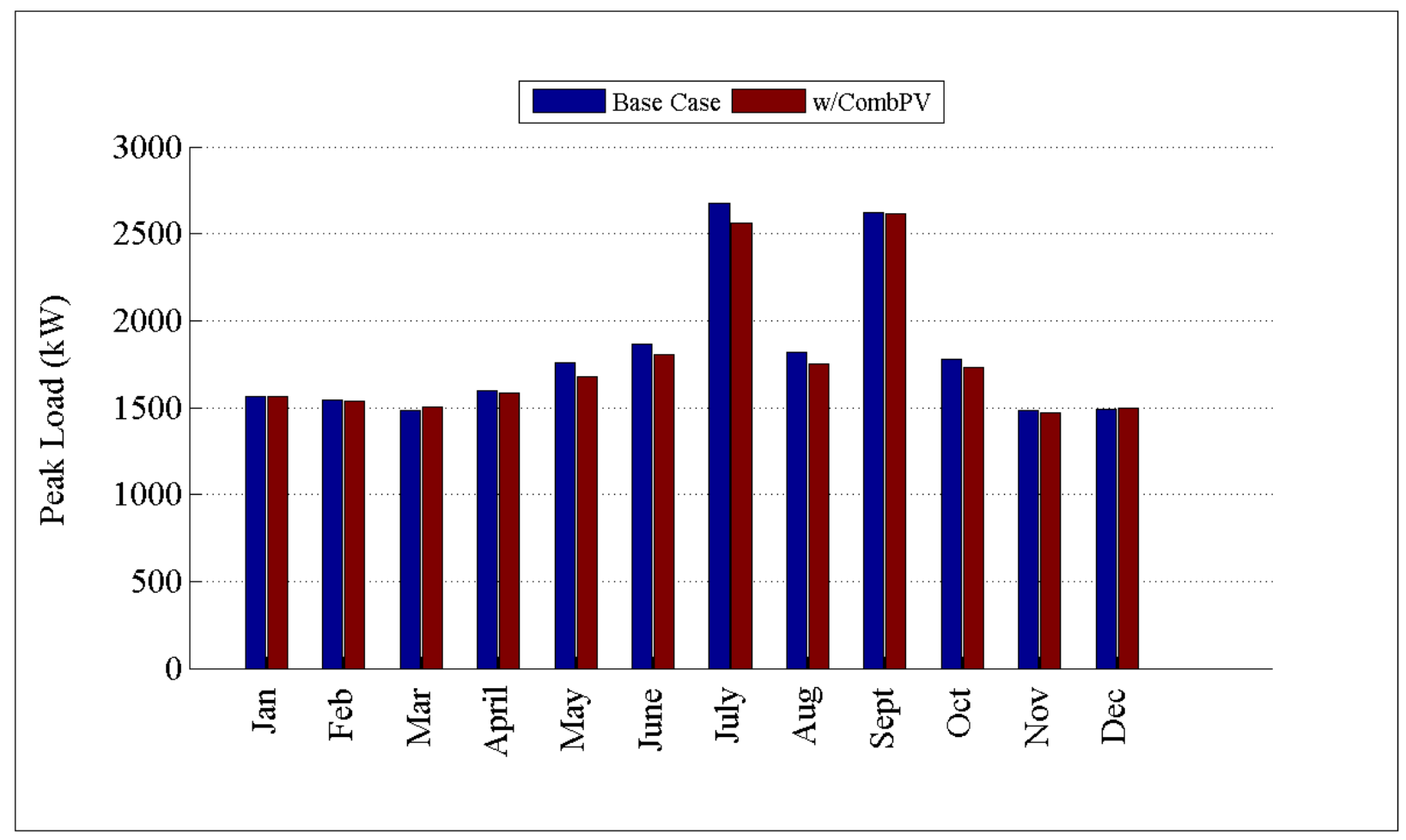

Figure D.239: Comparison of peak load by month for R1-12.47-2 


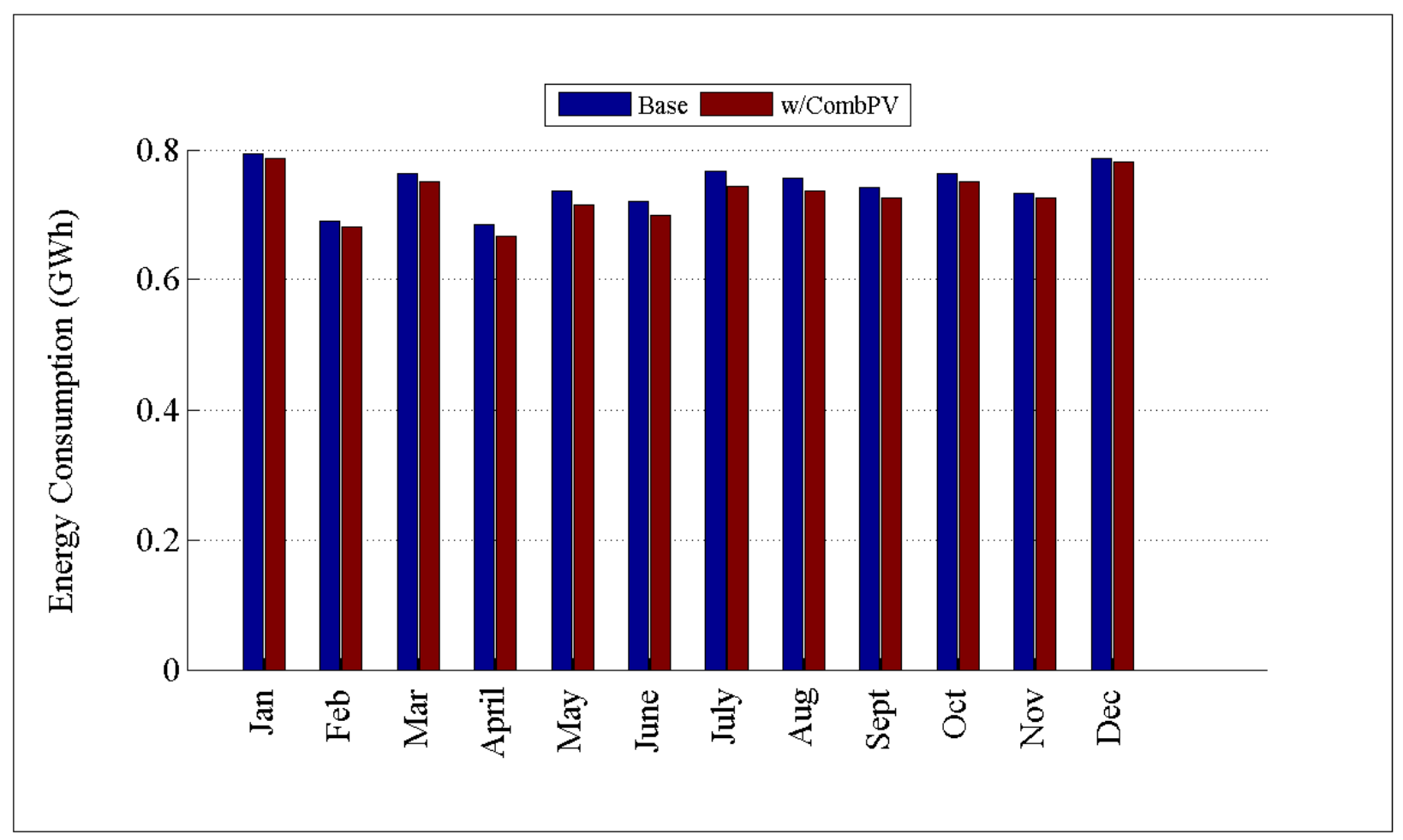

Figure D.240: Comparison of energy consumption by month for R1-12.47-2

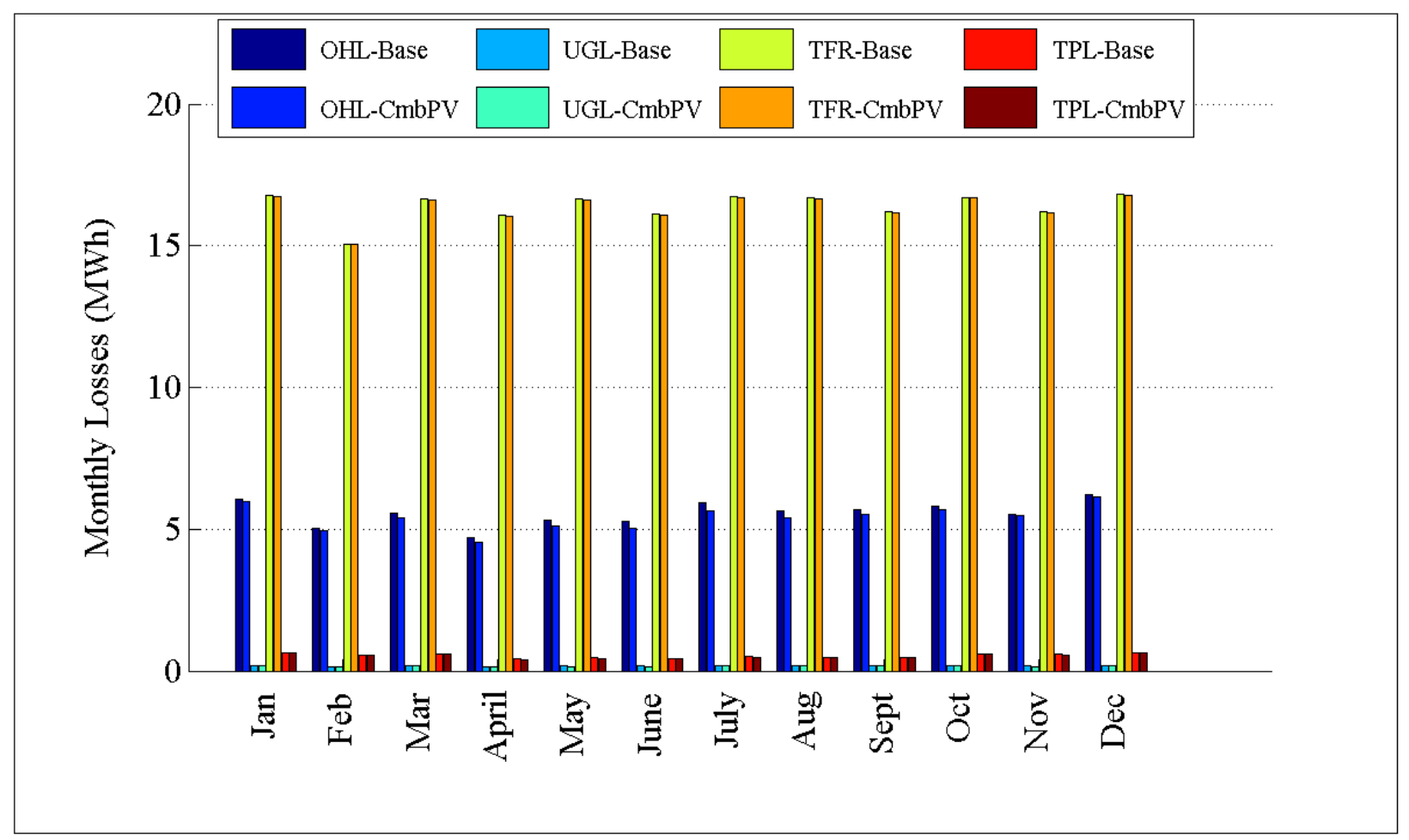

Figure D.241: Comparison of losses by month for R1-12.47-2 


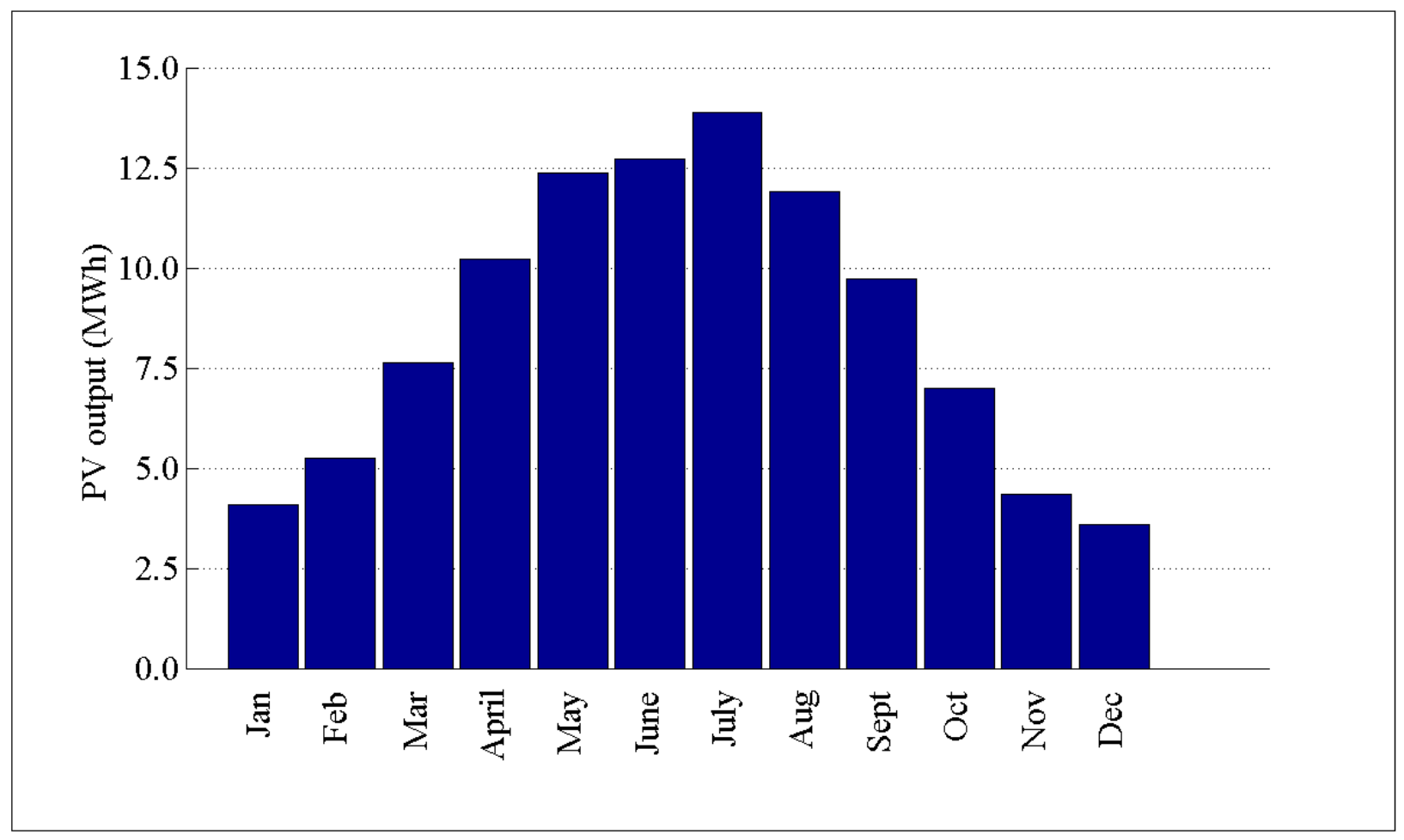

Figure D.242: PV output by month for R1-12.47-2

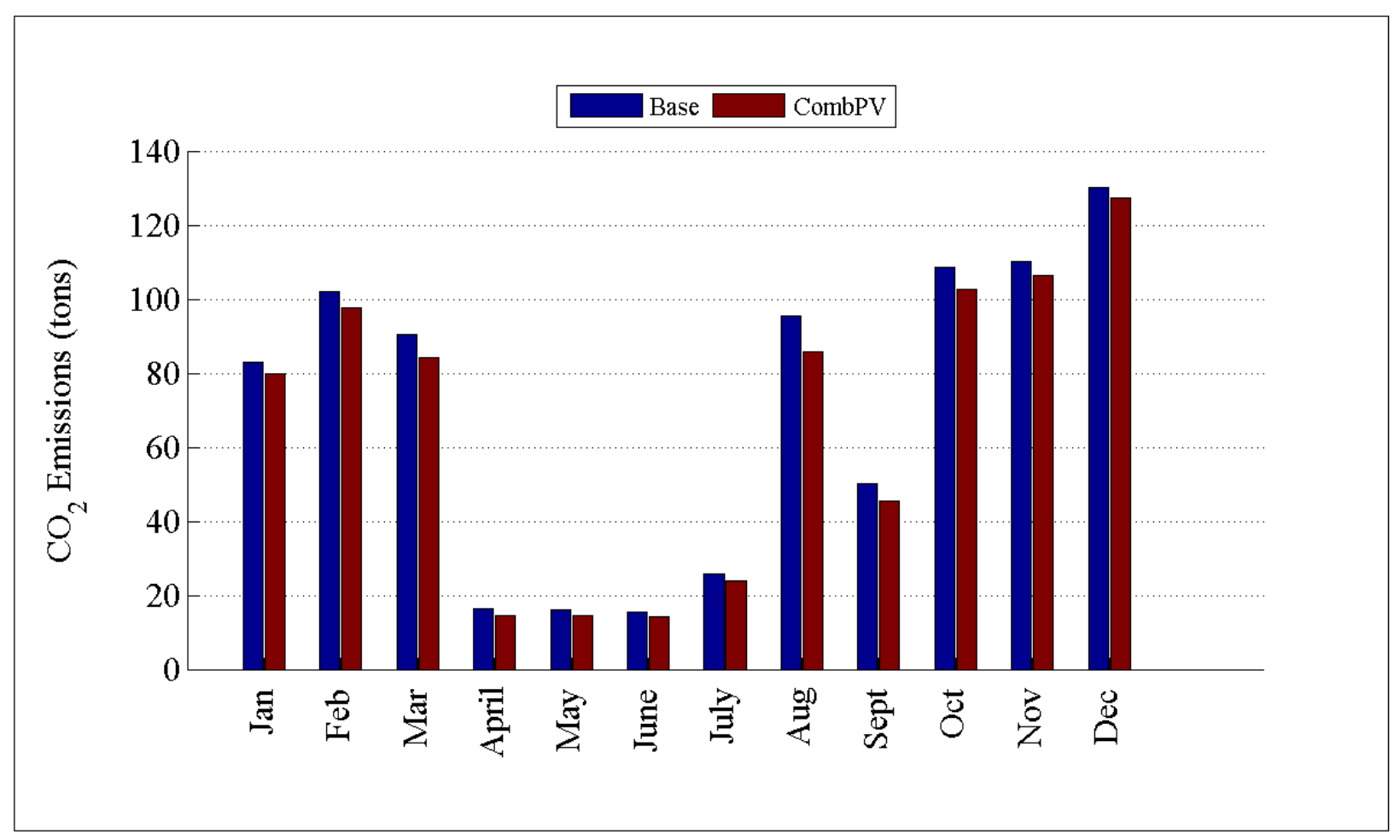

Figure D.243: Comparison of $\mathrm{CO}_{2}$ emissions by month for R1-12.47-2 
D.3.3 Detailed Combined PV Plots for R1-12.47-3

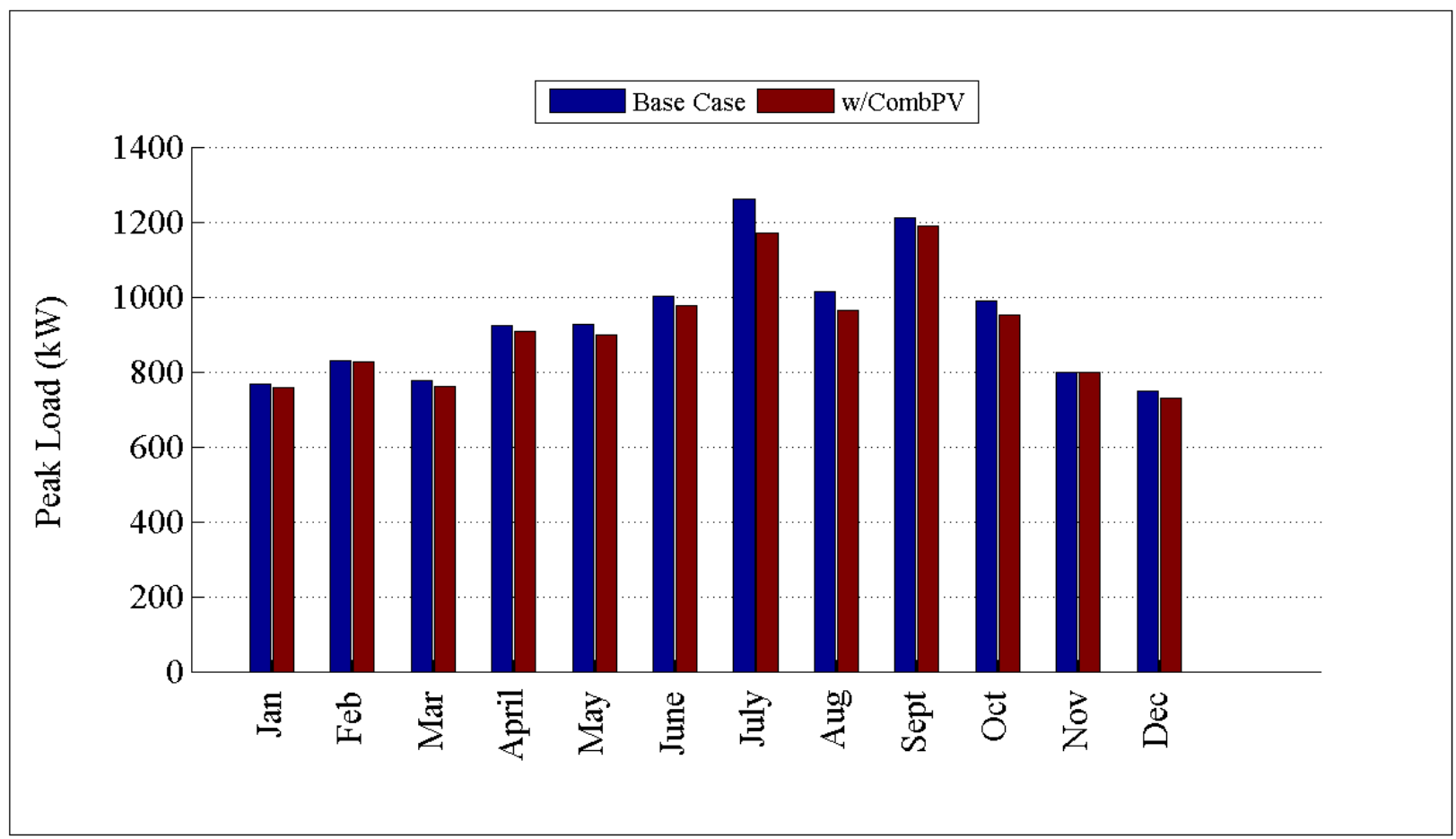

Figure D.244: Comparison of peak load by month for R1-12.47-3

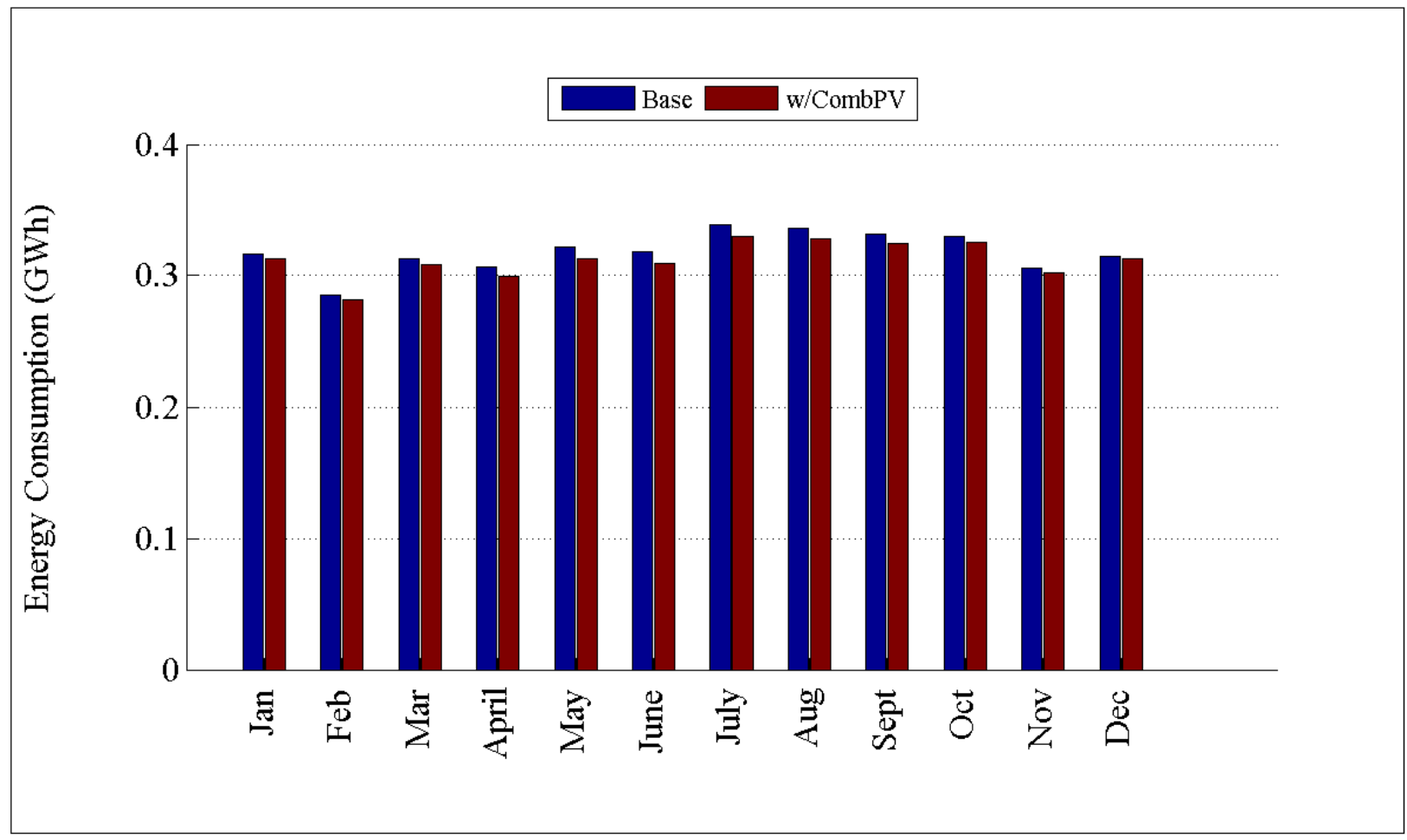

Figure D.245: Comparison of energy consumption by month for R1-12.47-3 


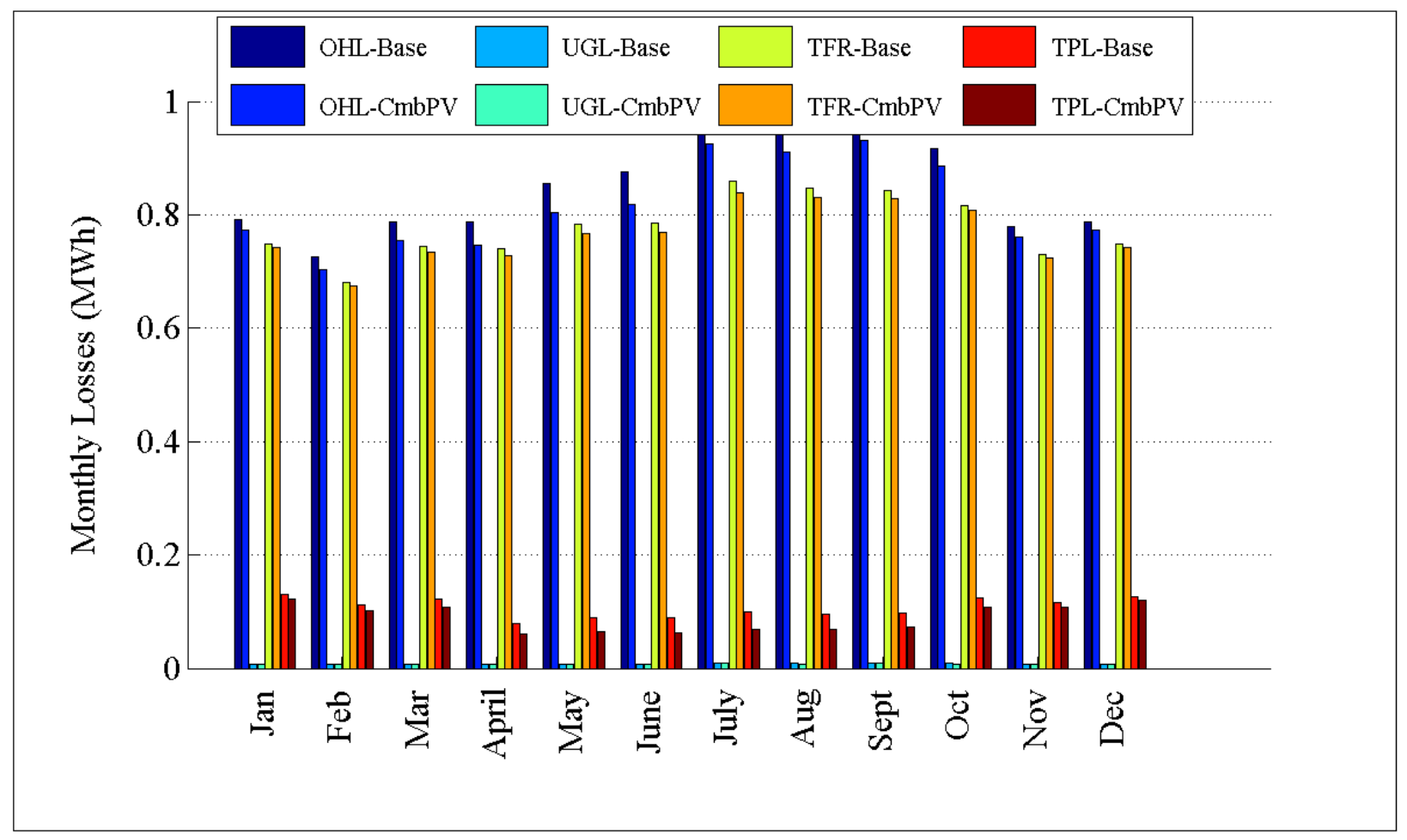

Figure D.246: Comparison of losses by month for R1-12.47-3

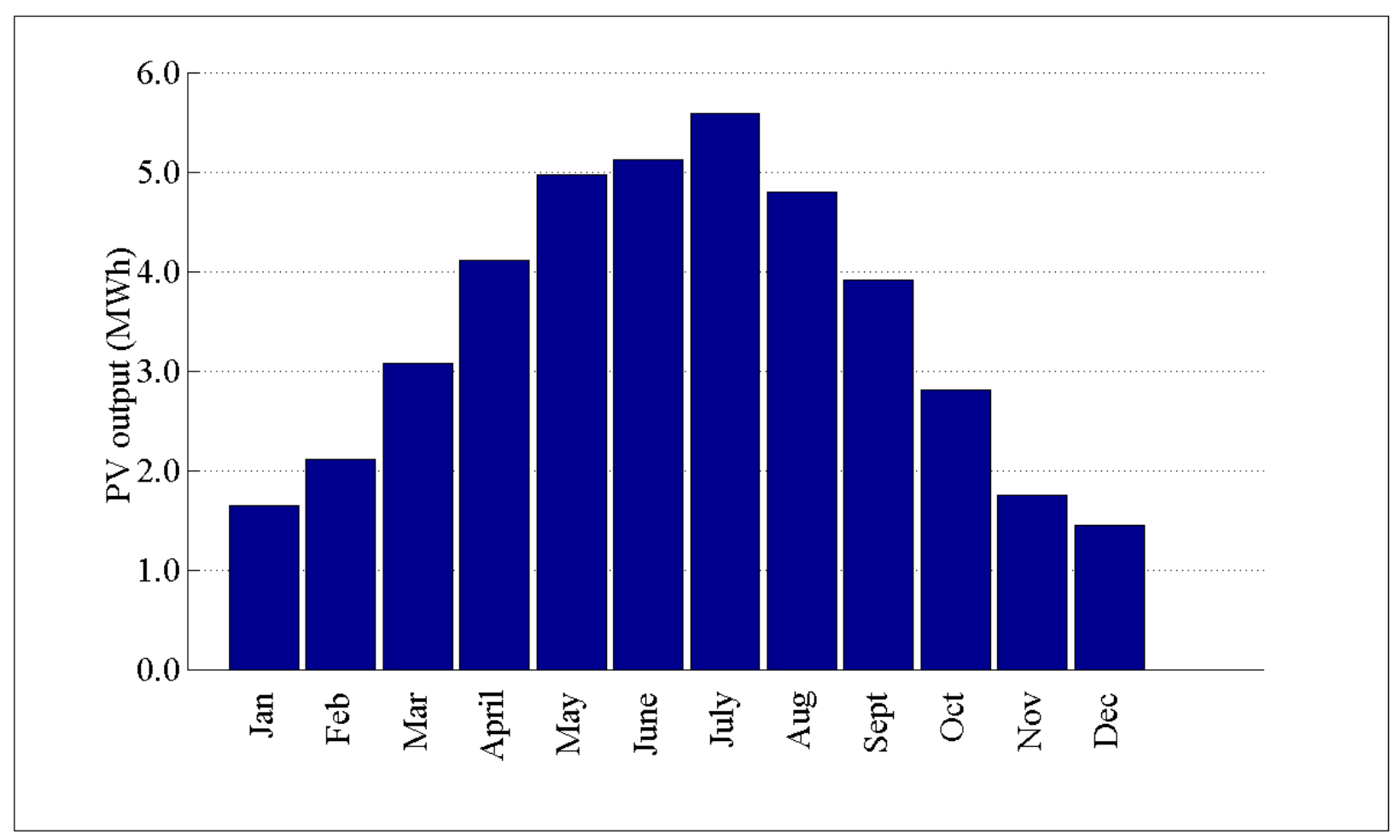

Figure D.247: PV output by month for R1-12.47-3 


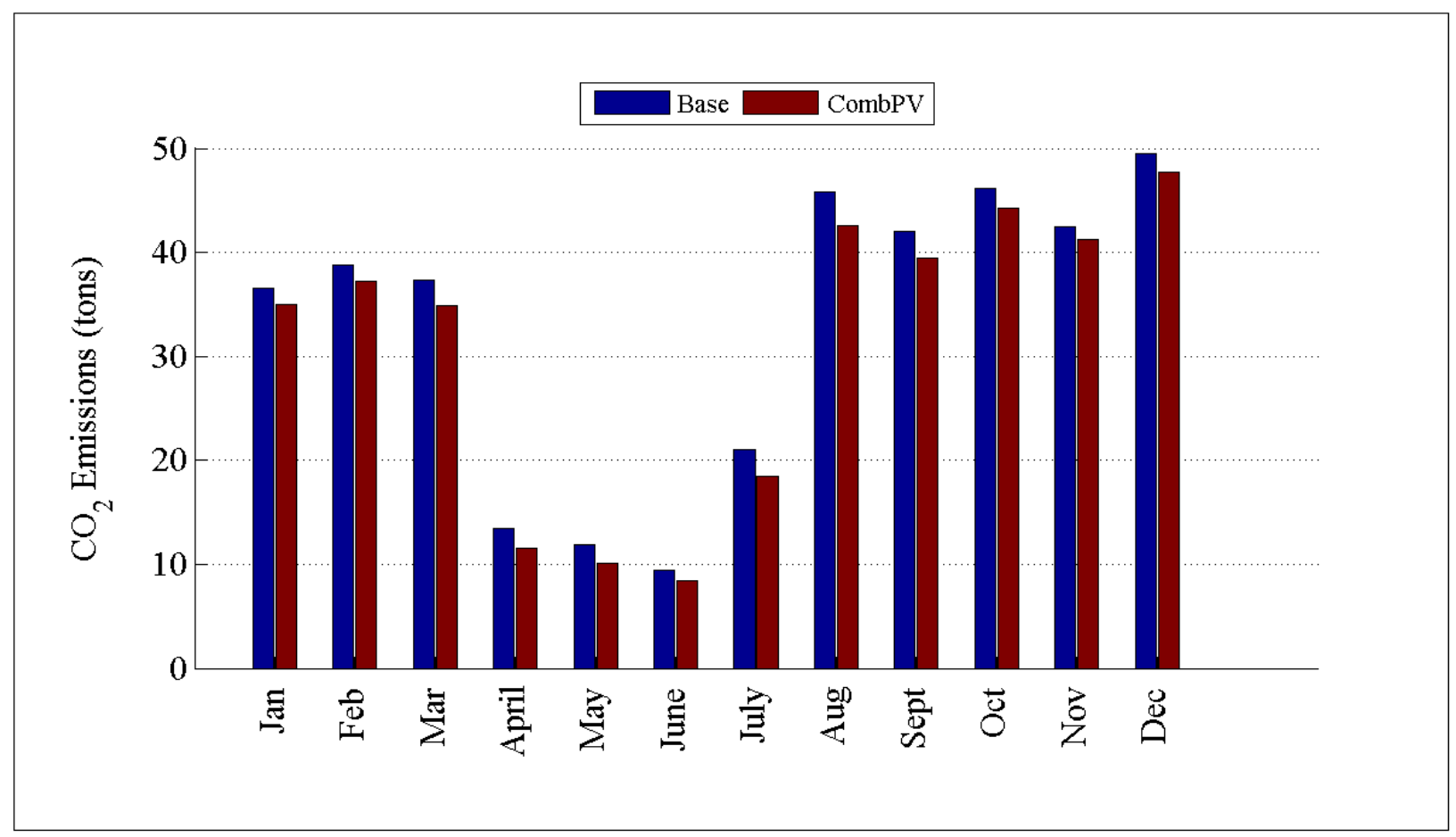

Figure D.248: Comparison of $\mathrm{CO}_{2}$ emissions by month for R1-12.47-3

D.3.4 Detailed Combined PV Plots for R1-12.47-4

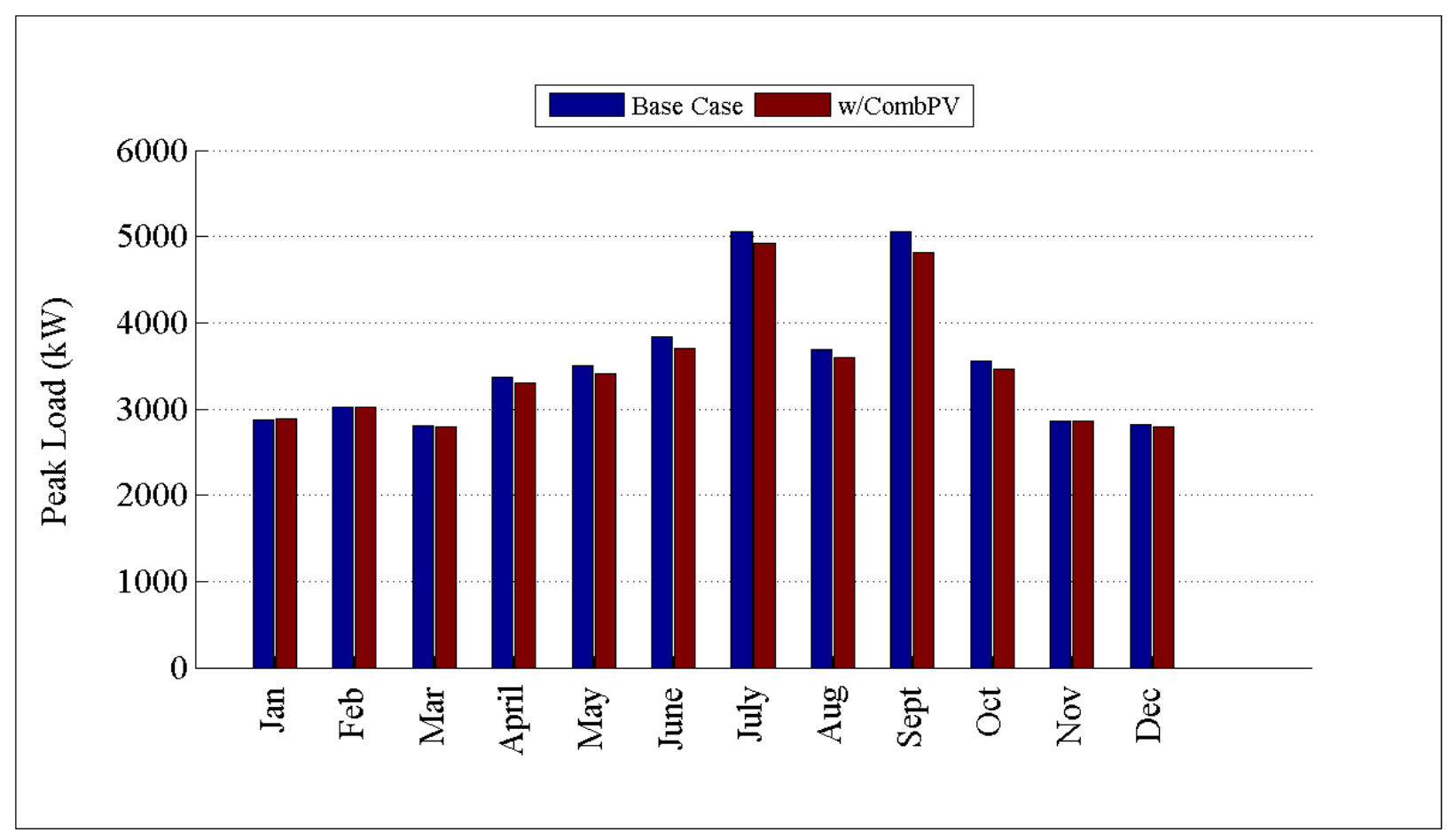

Figure D.249: Comparison of peak load by month for R1-12.47-4 


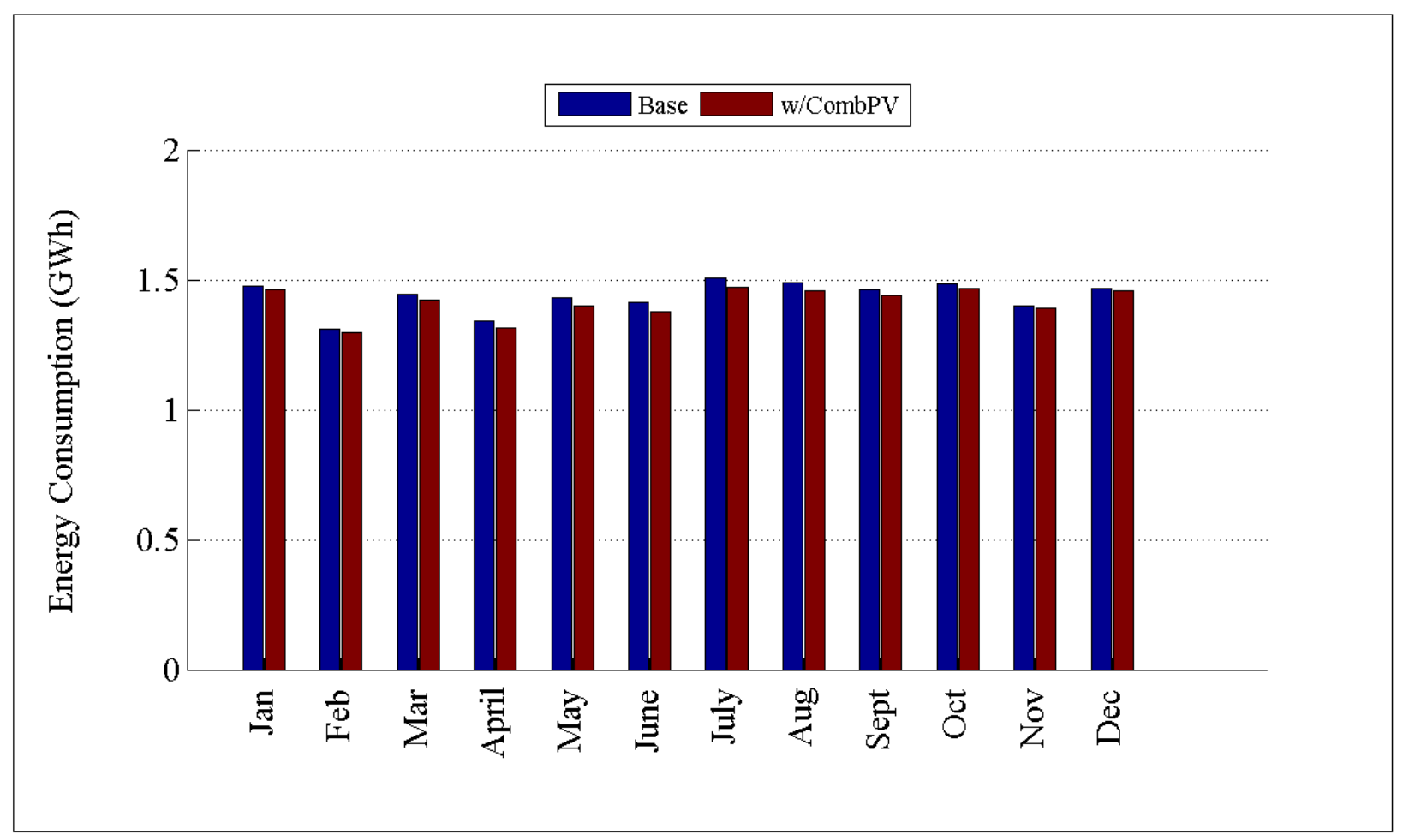

Figure D.250: Comparison of energy consumption by month for R1-12.47-4

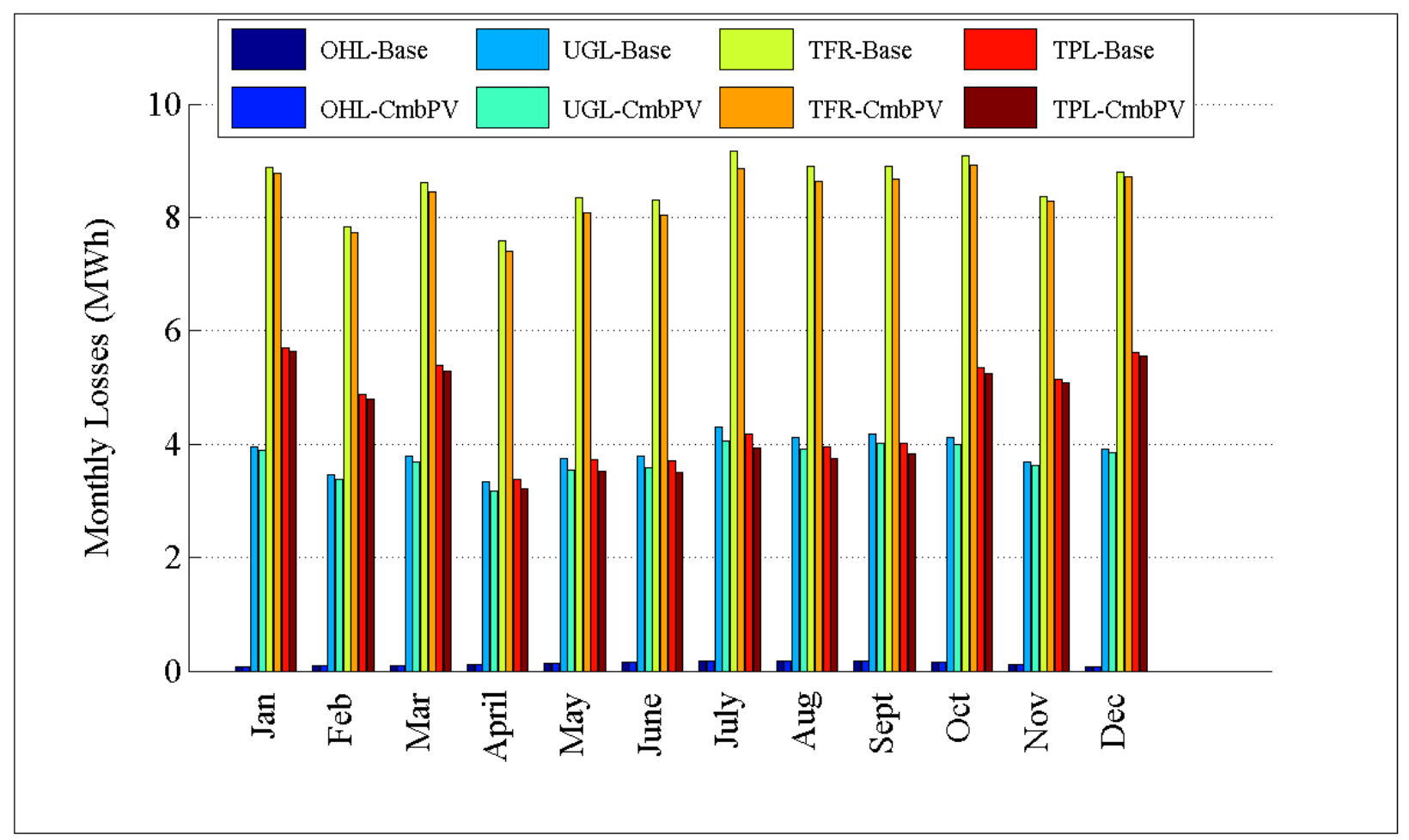

Figure D.251: Comparison of losses by month for R1-12.47-4 


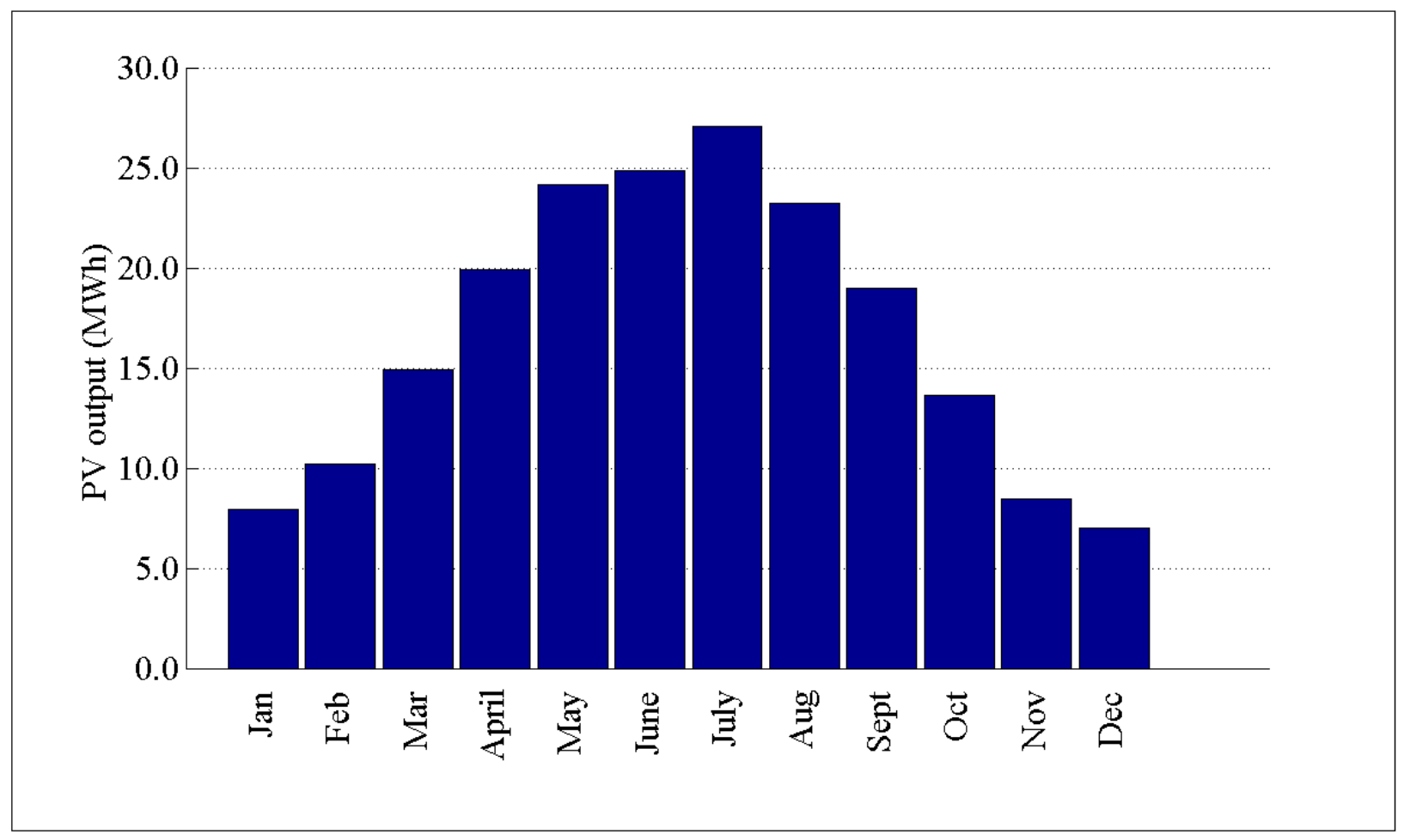

Figure D.252: PV output by month for R1-12.47-4

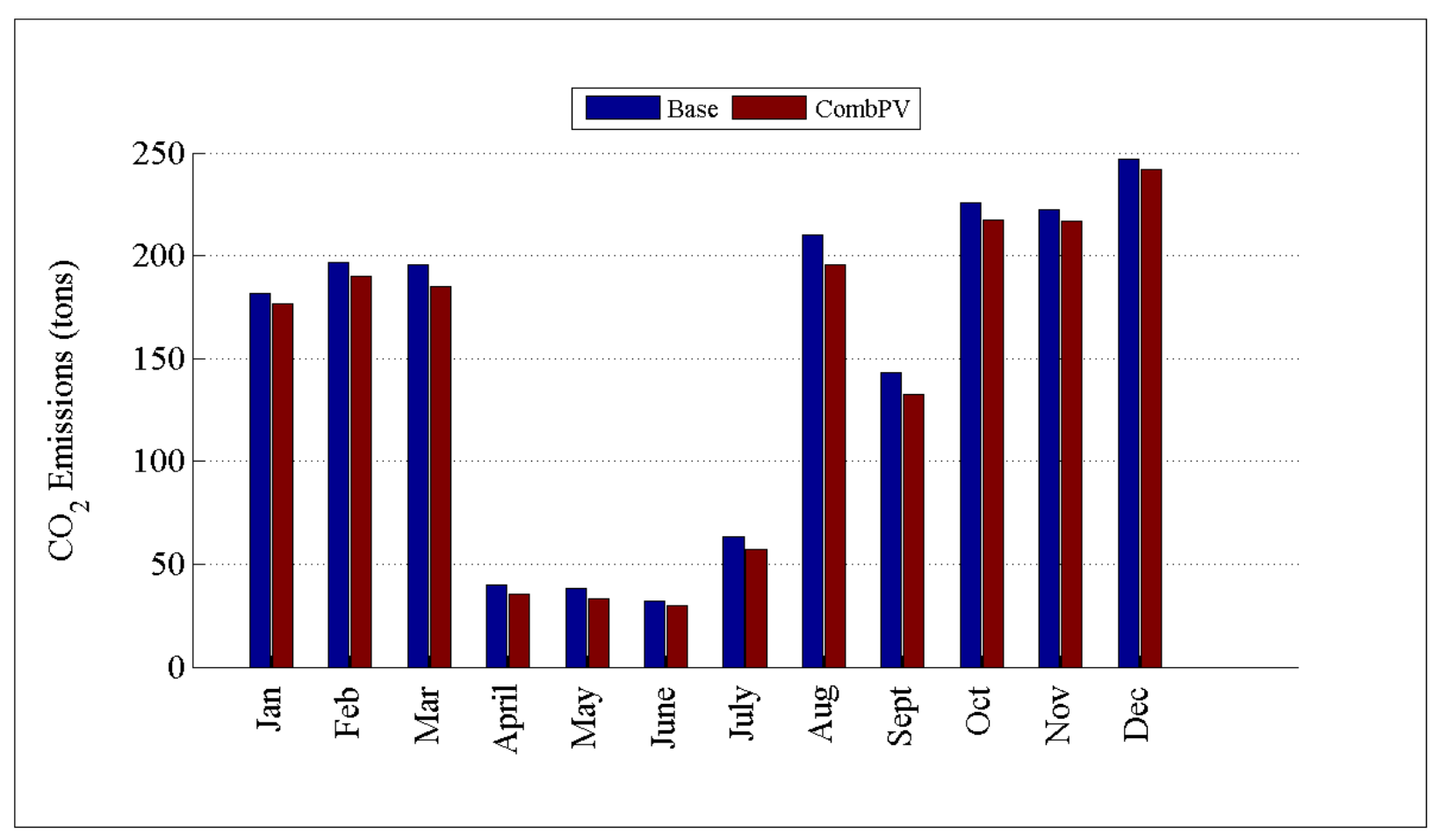

Figure D.253: Comparison of $\mathrm{CO}_{2}$ emissions by month for R1-12.47-4 
D.3.5 Detailed Combined PV Plots for R1-25.00-1

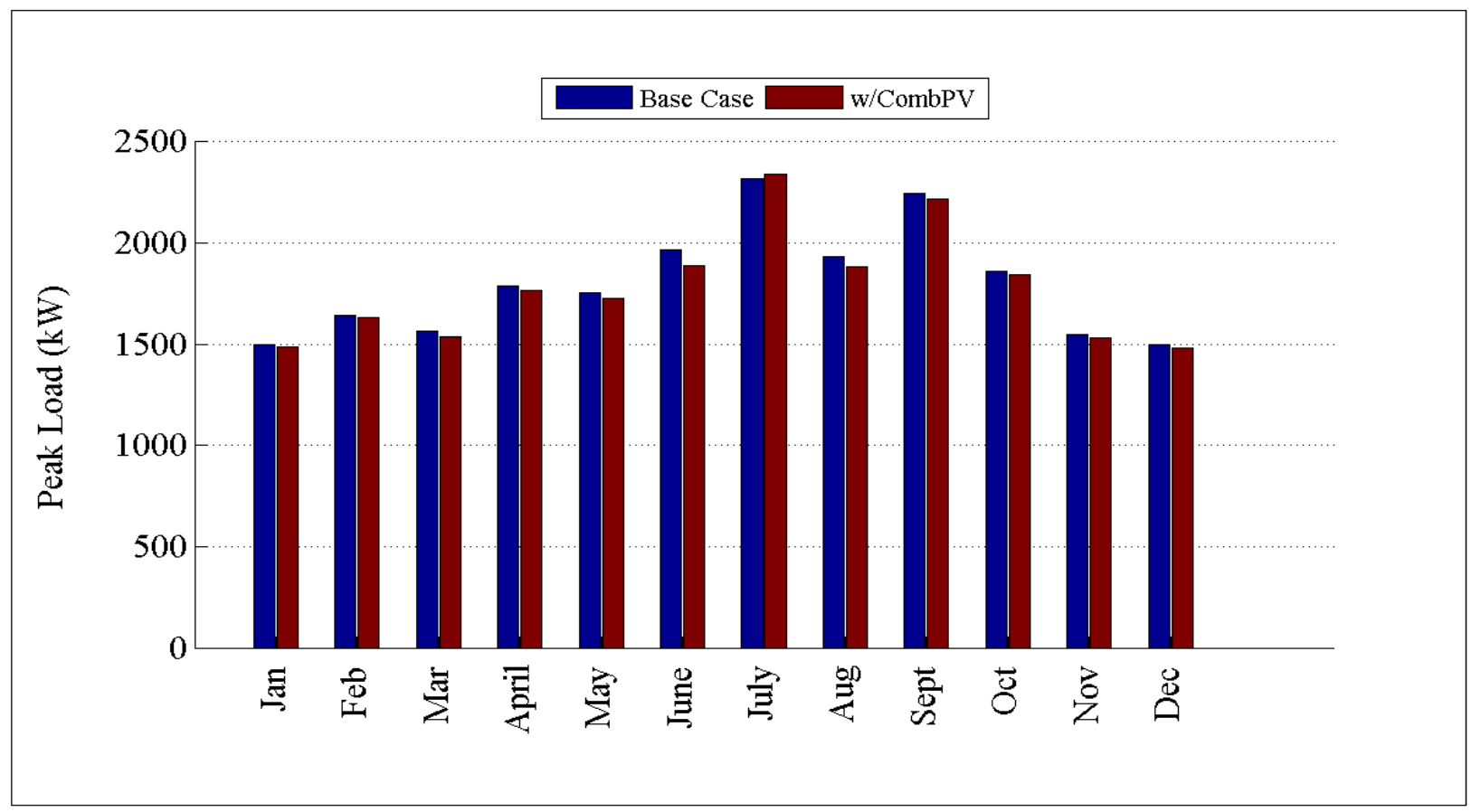

Figure D.254: Comparison of peak load by month for R1-25.00-1

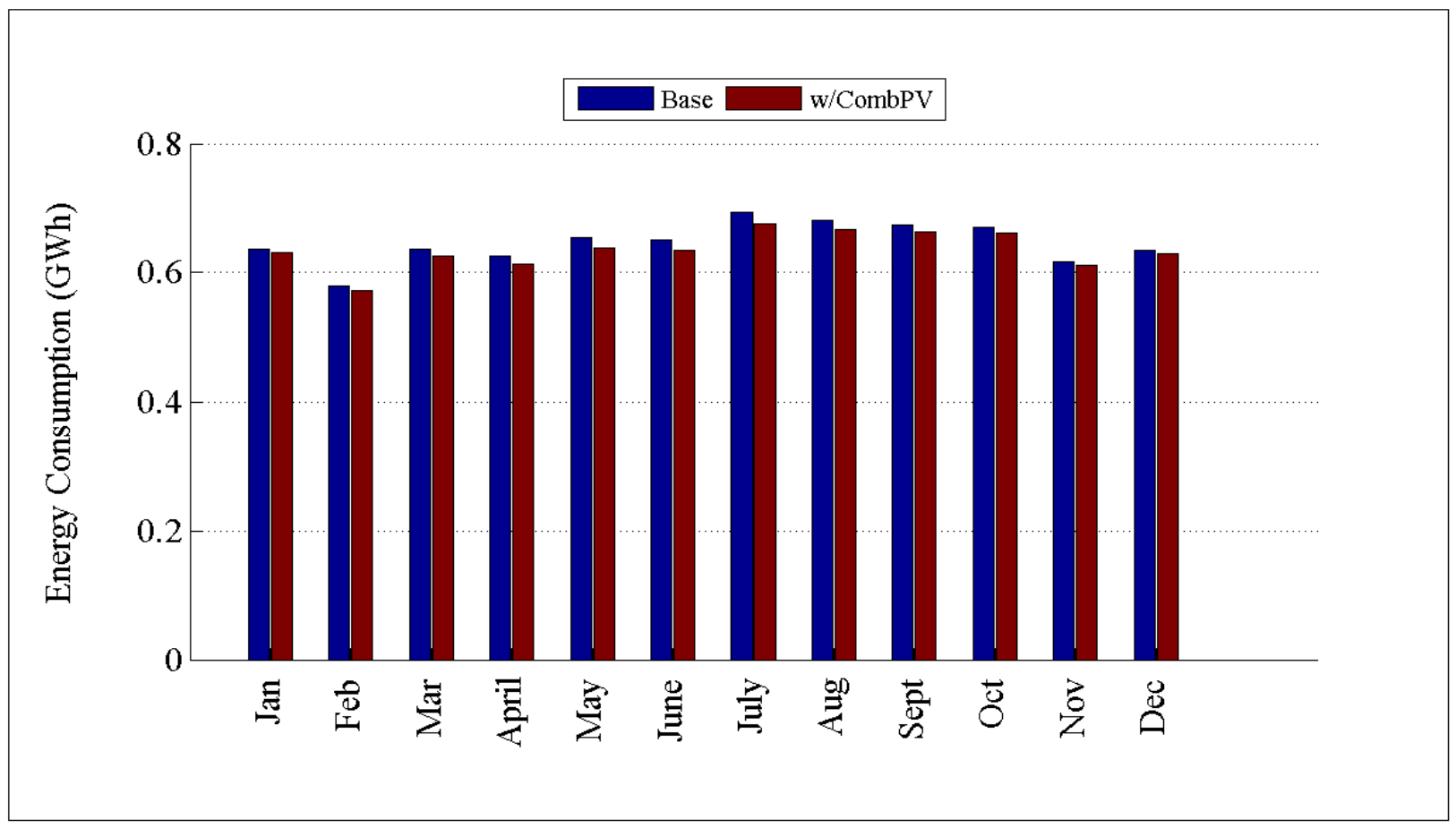

Figure D.255: Comparison of energy consumption by month for R1-25.00-1 


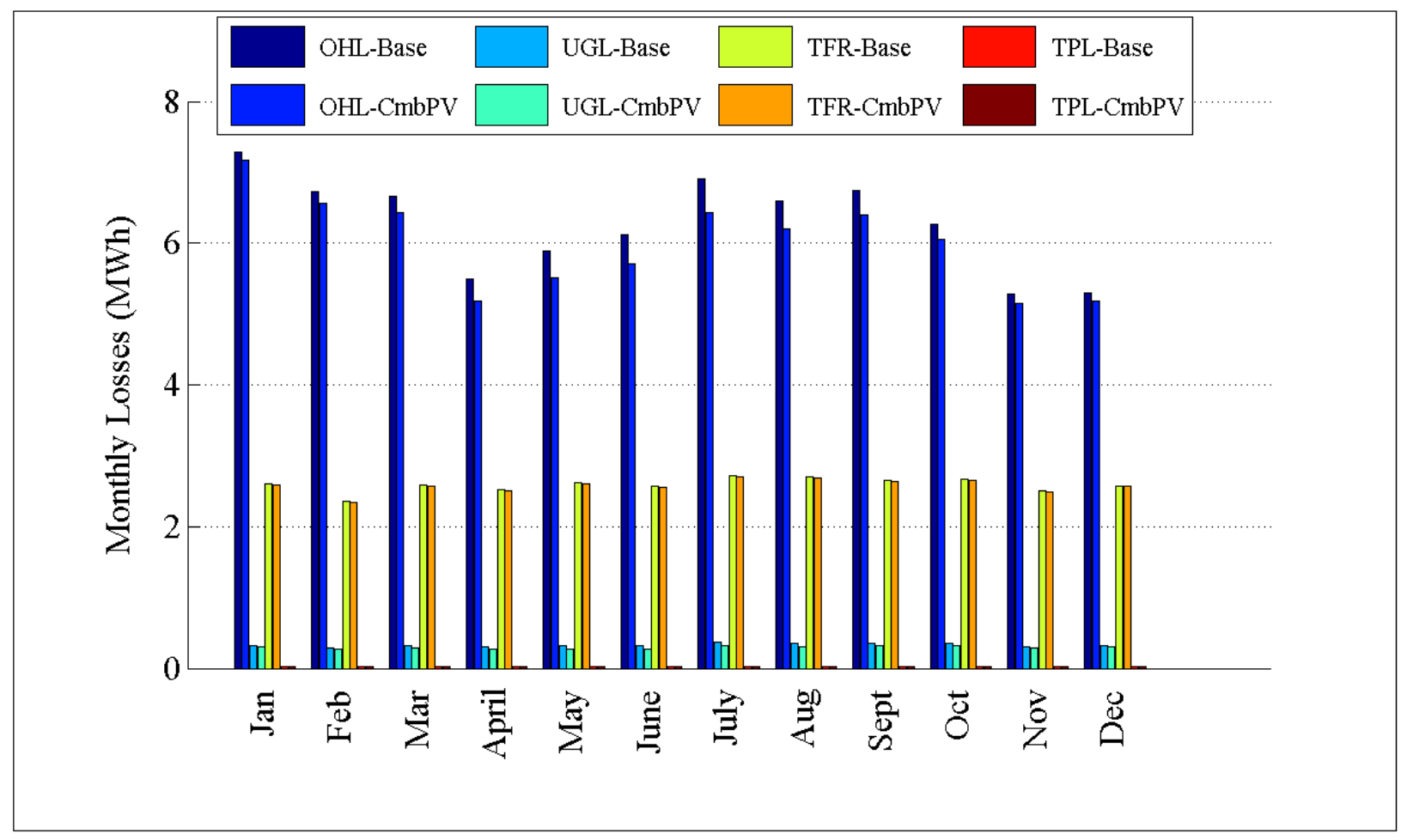

Figure D.256: Comparison of losses by month for R1-25.00-1

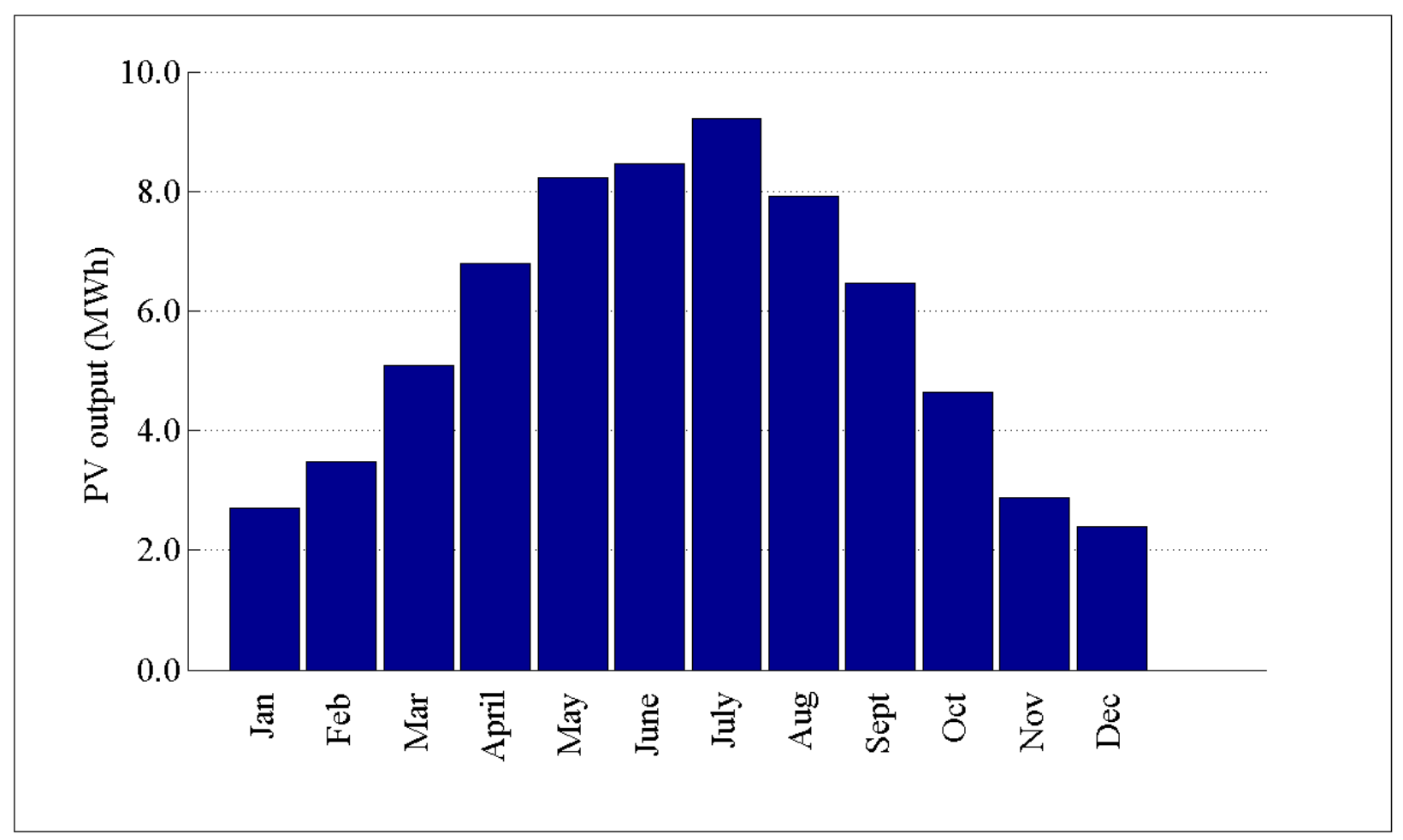

Figure D.257: PV output by month for R1-25.00-1 


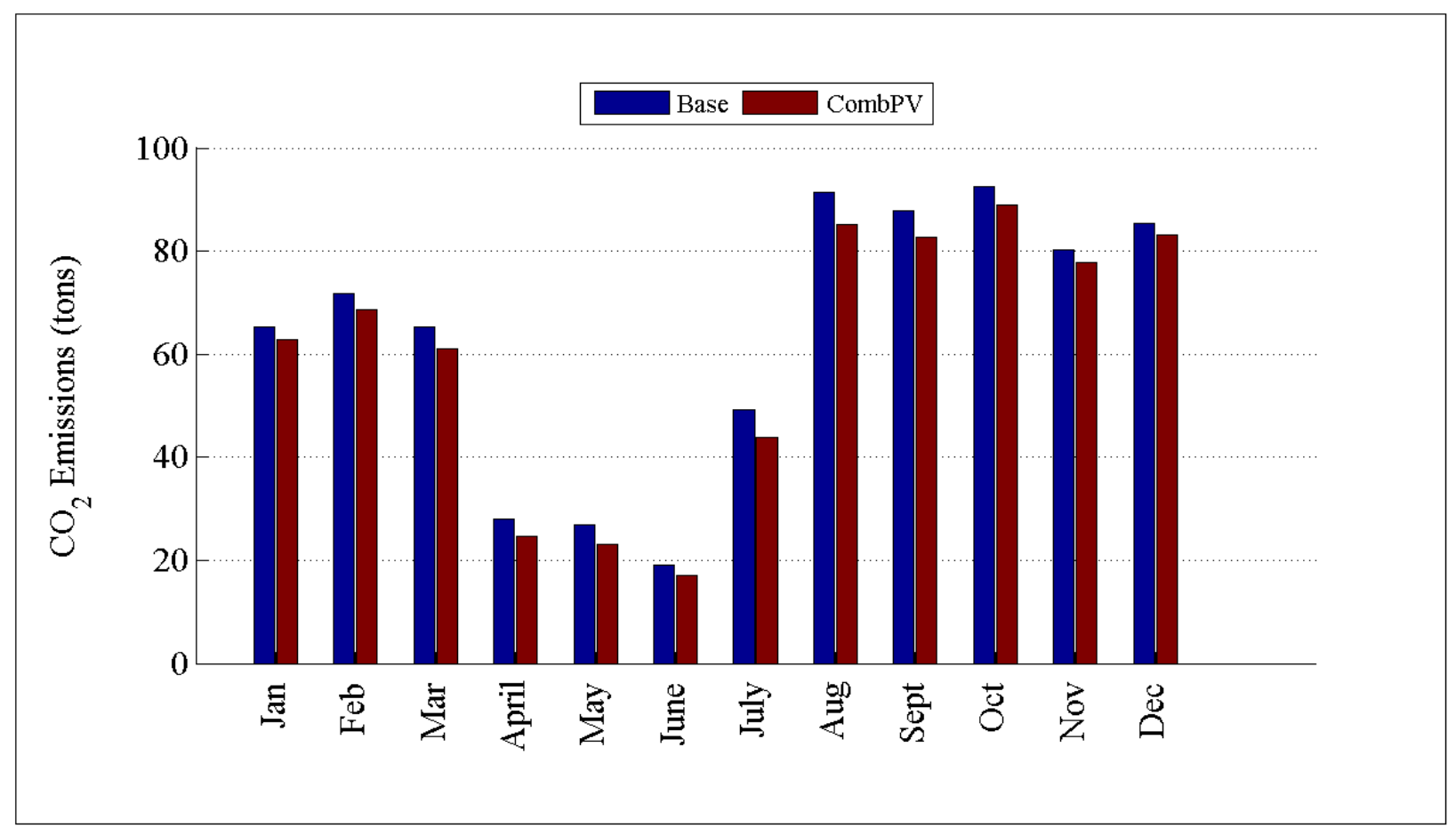

Figure D.258: Comparison of $\mathrm{CO}_{2}$ emissions by month for R1-25.00-1

D.3.6 Detailed Combined PV Plots for R2-12.47-1

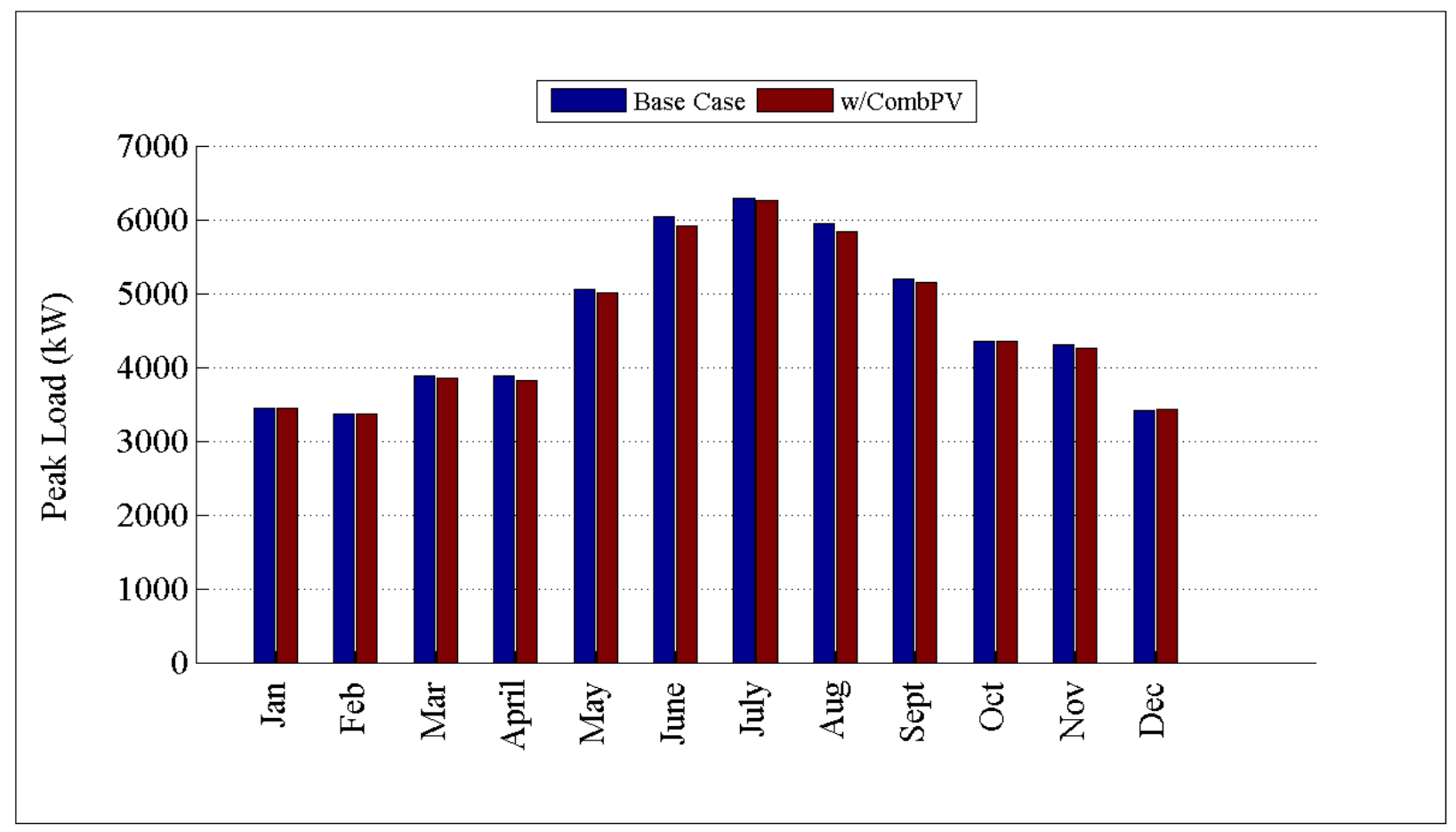

Figure D.259: Comparison of peak load by month for R2-12.47-1 


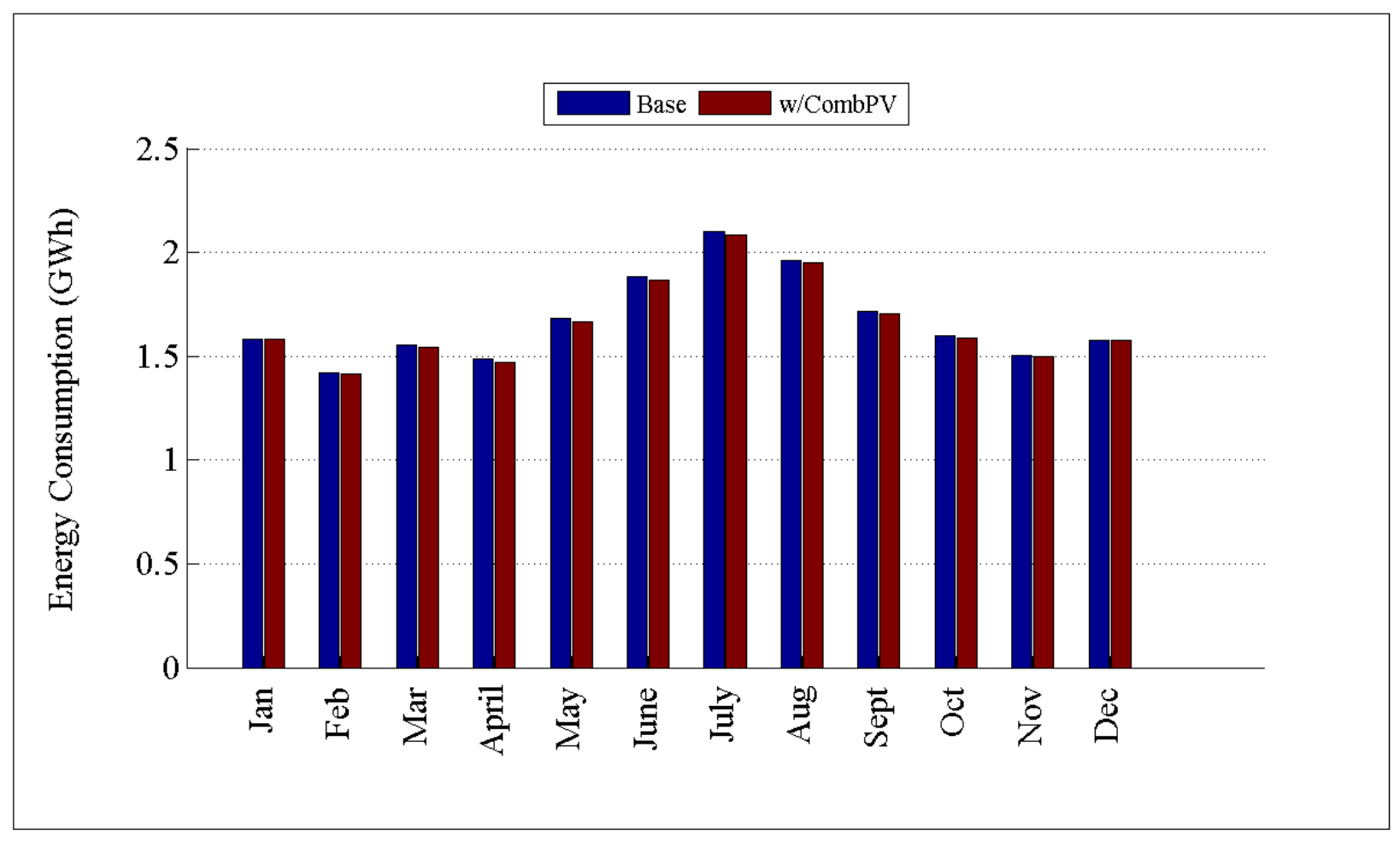

Figure D.260: Comparison of energy consumption by month for R2-12.47-1

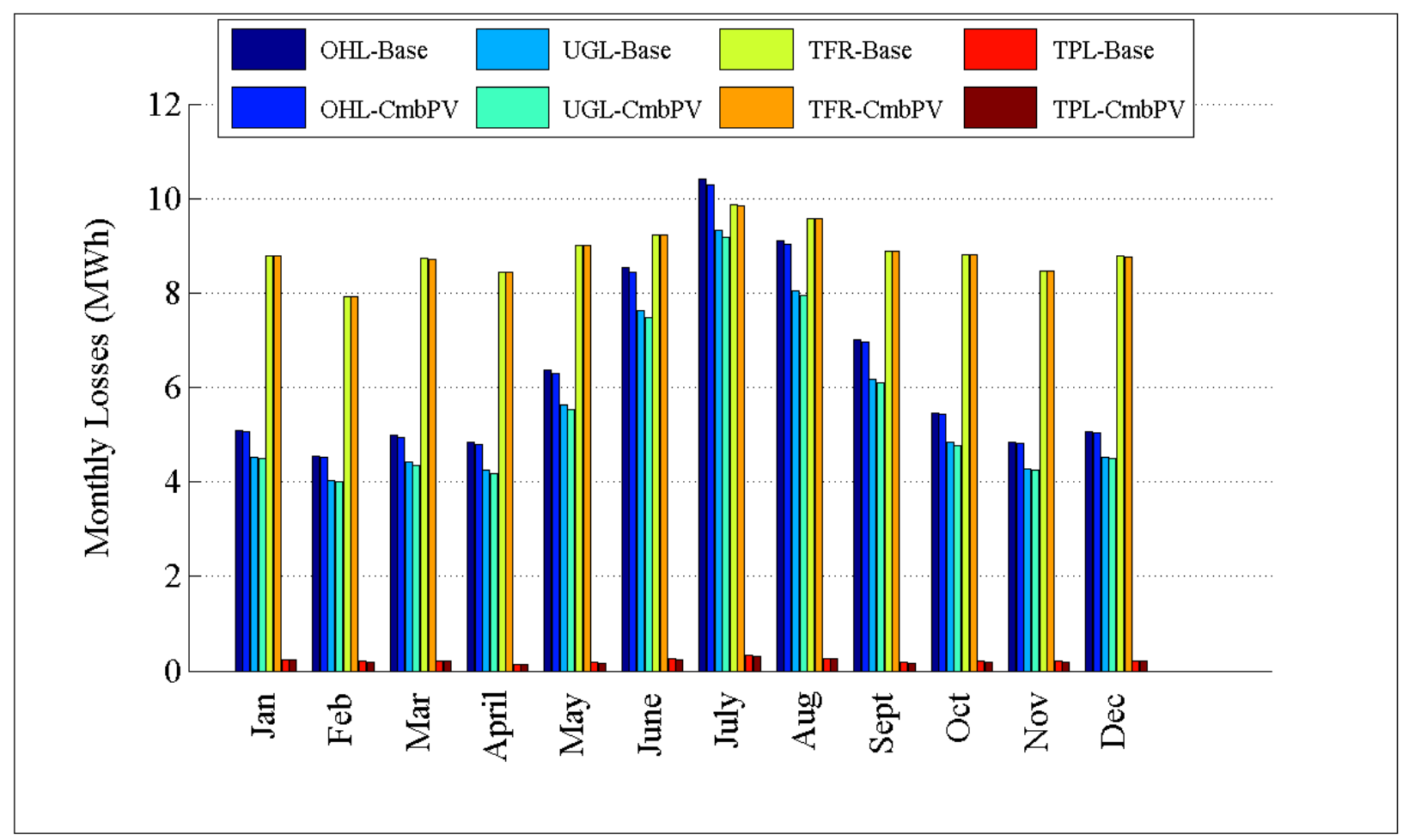

Figure D.261: Comparison of losses by month for R2-12.47-1 


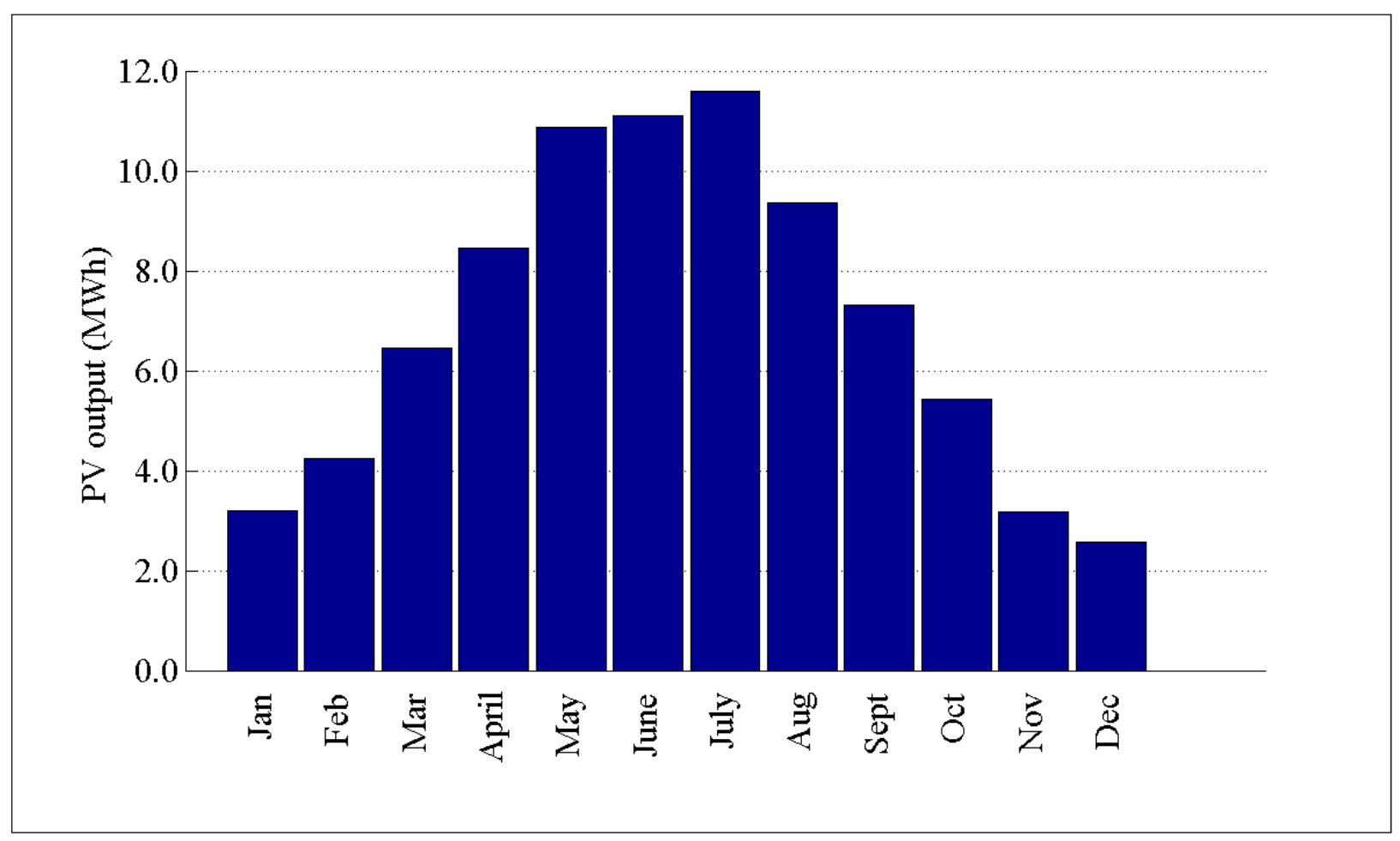

Figure D.262: PV output by month for R2-12.47-1

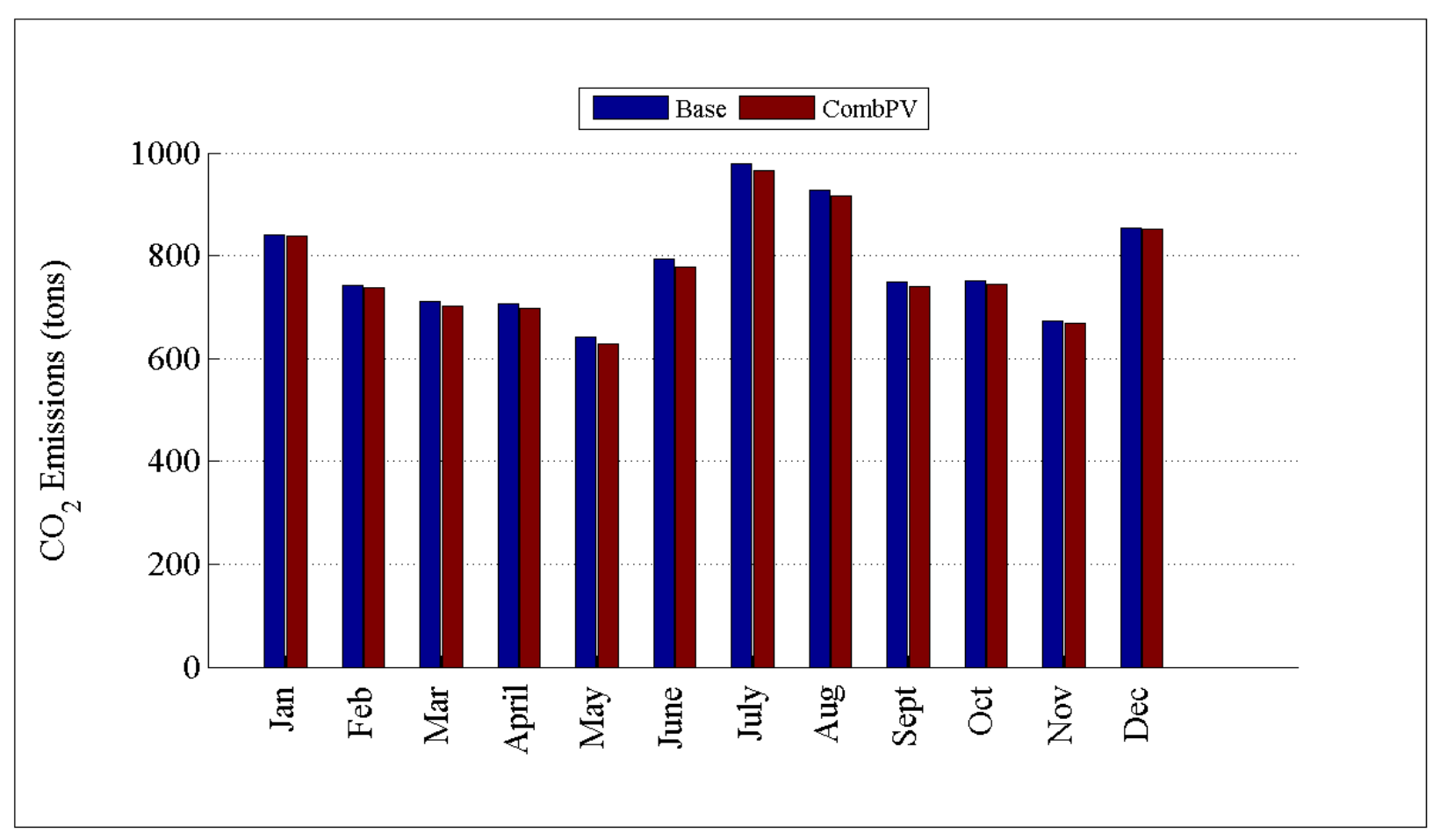

Figure D.263: Comparison of $\mathrm{CO}_{2}$ emissions by month for R2-12.47-1 
D.3.7 Detailed Combined PV Plots for R2-12.47-2

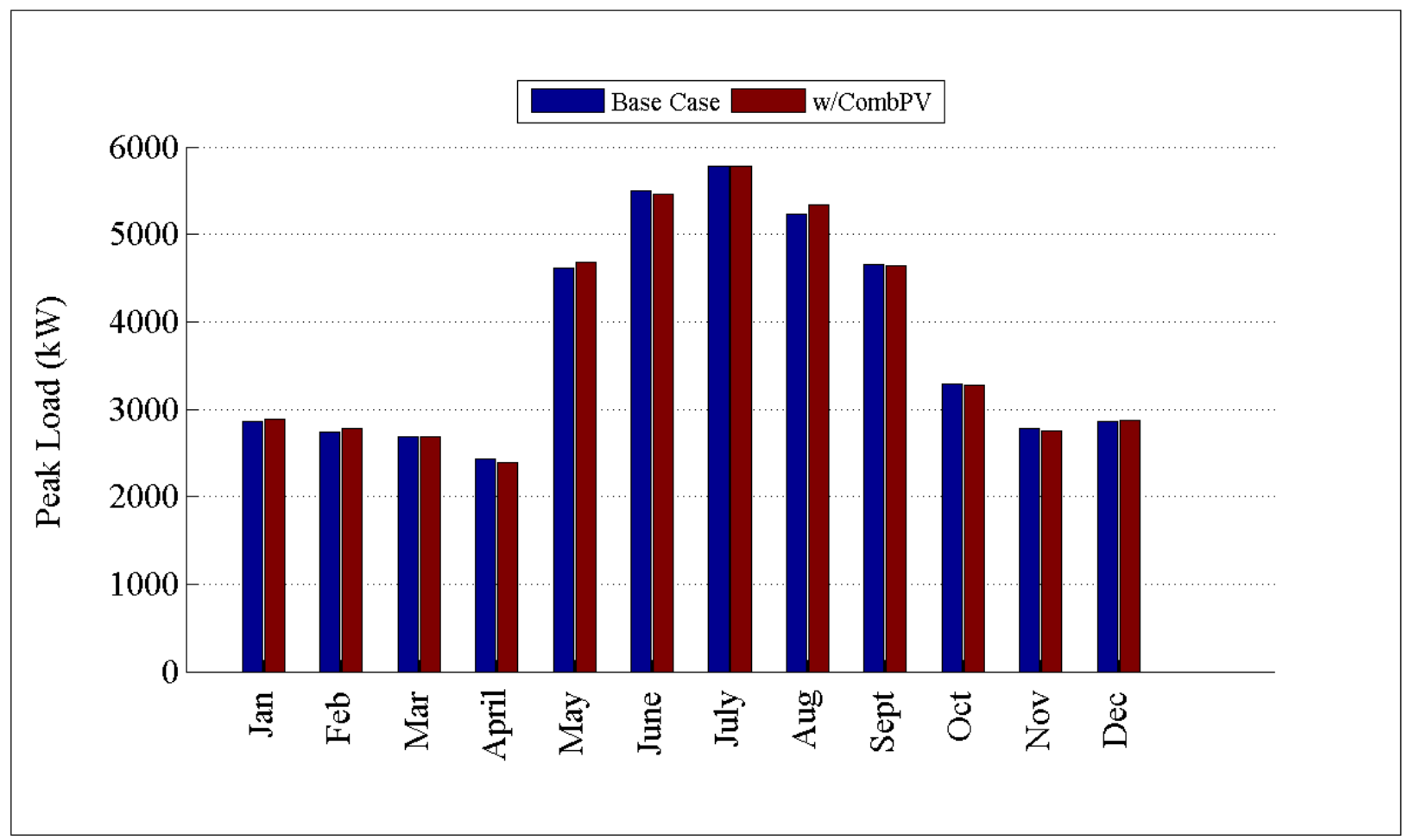

Figure D.264: Comparison of peak load by month for R2-12.47-2

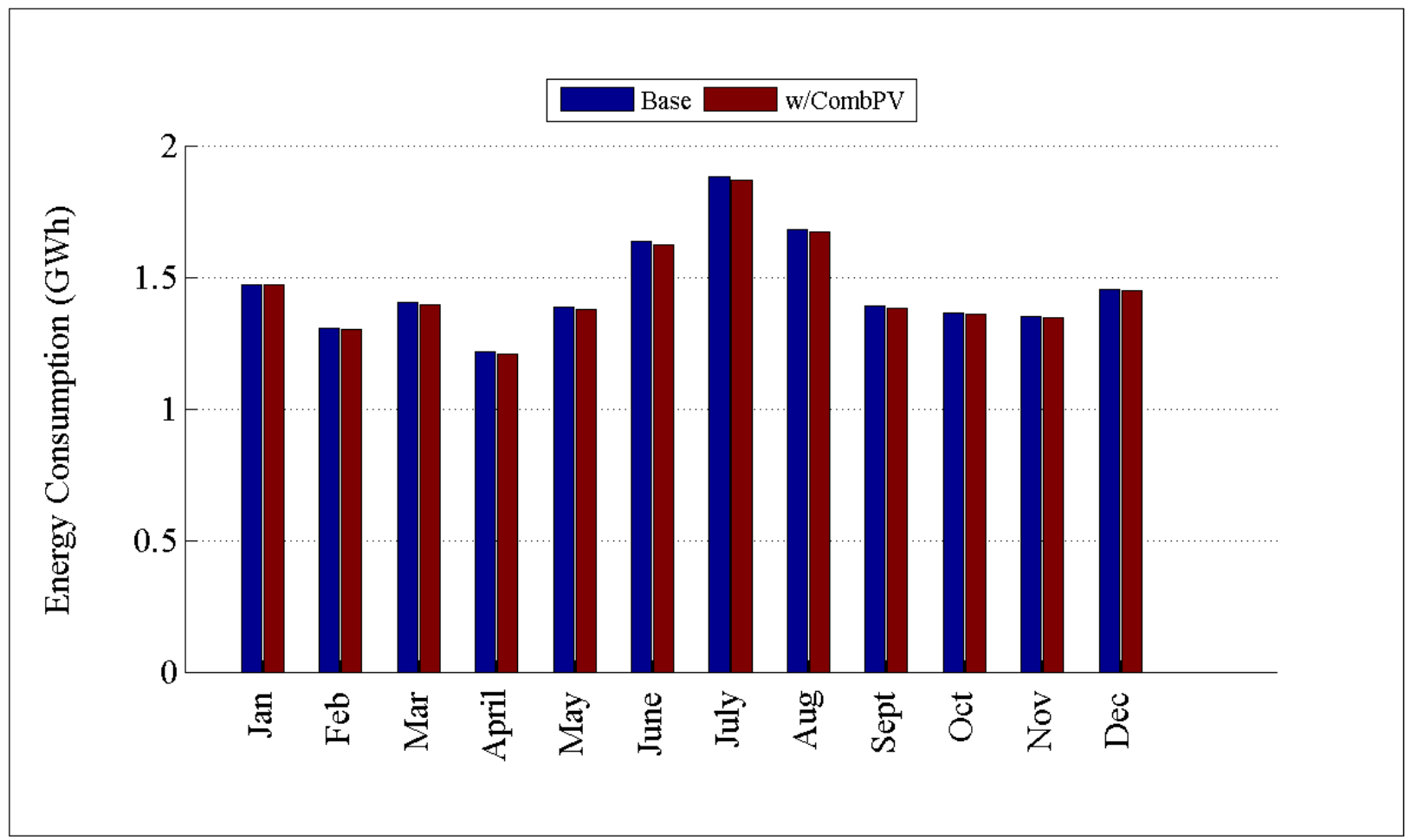

Figure D.265: Comparison of energy consumption by month for R2-12.47-2 


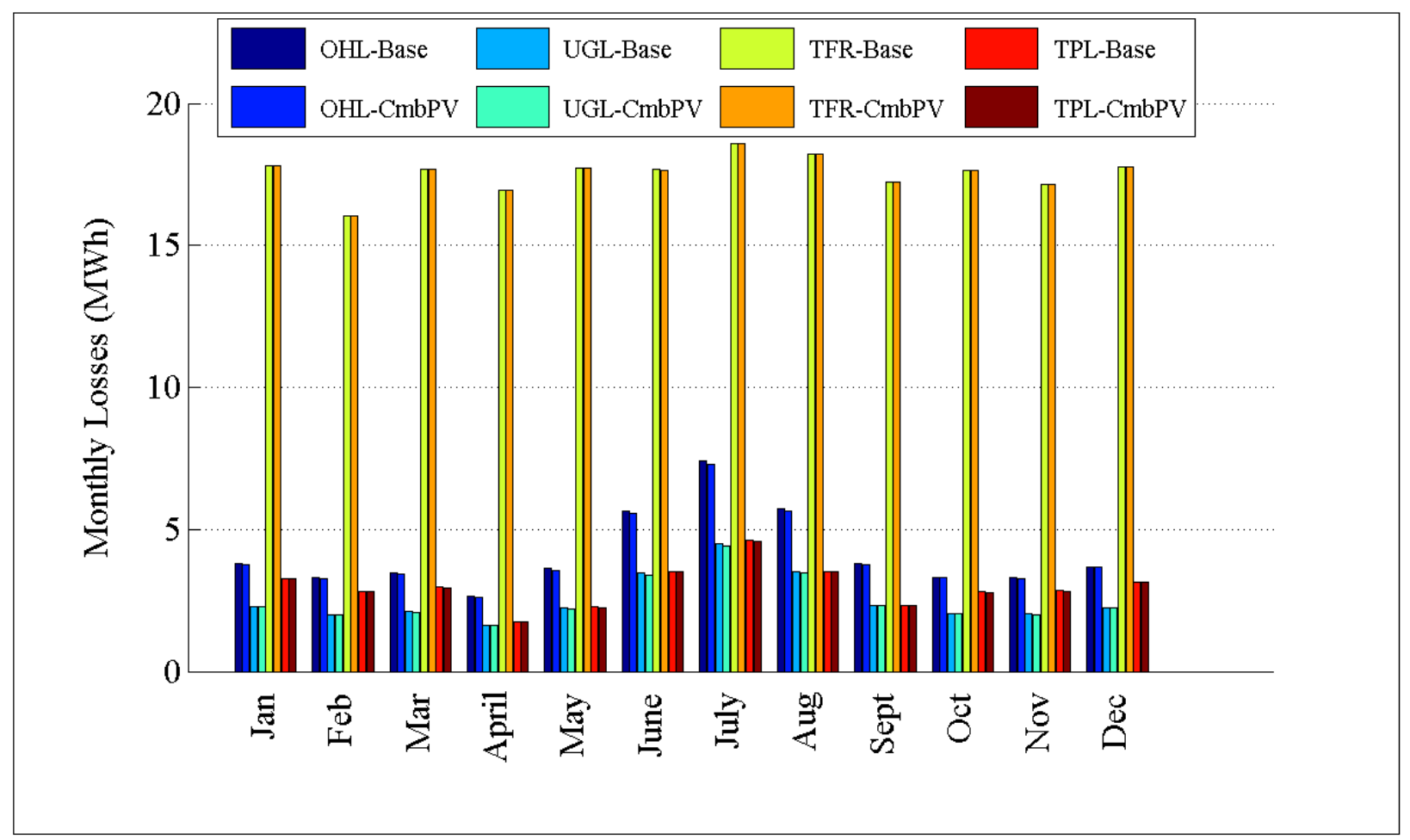

Figure D.266: Comparison of losses by month for R2-12.47-2

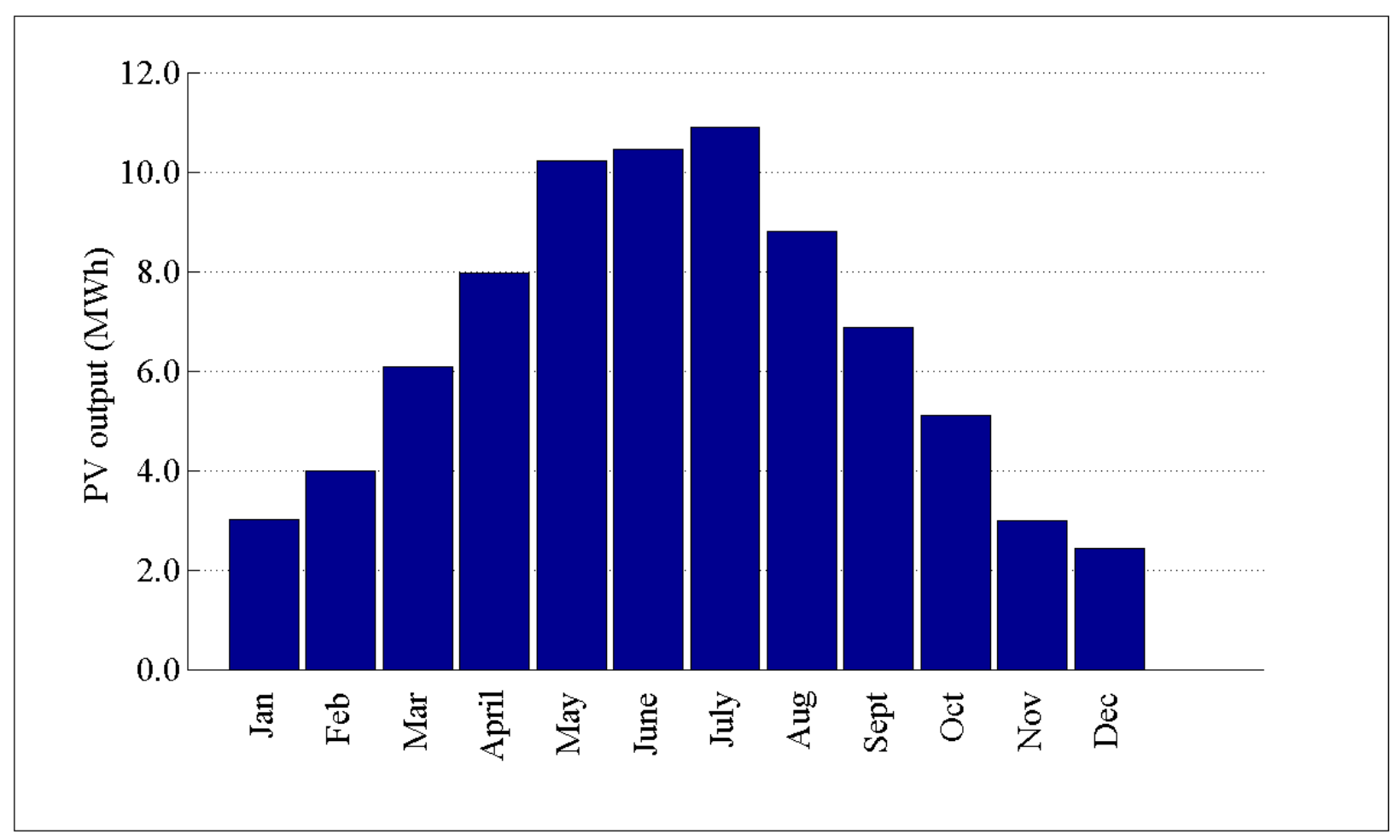

Figure D.267: PV output by month for R2-12.47-2 


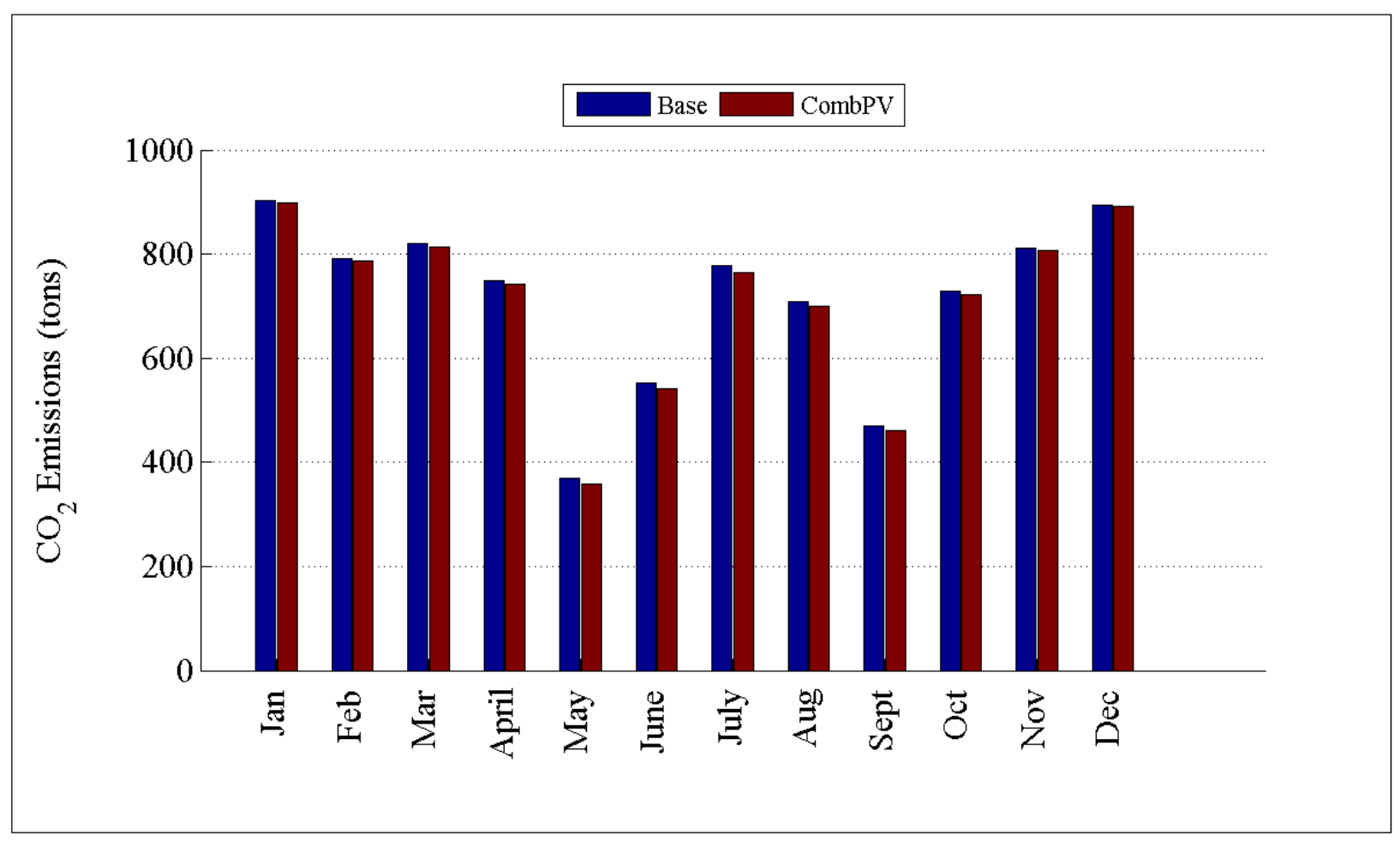

Figure D.268: Comparison of $\mathrm{CO}_{2}$ emissions by month for R2-12.47-2

\section{D.3.8 Detailed Combined PV Plots for R2-25.00-1}

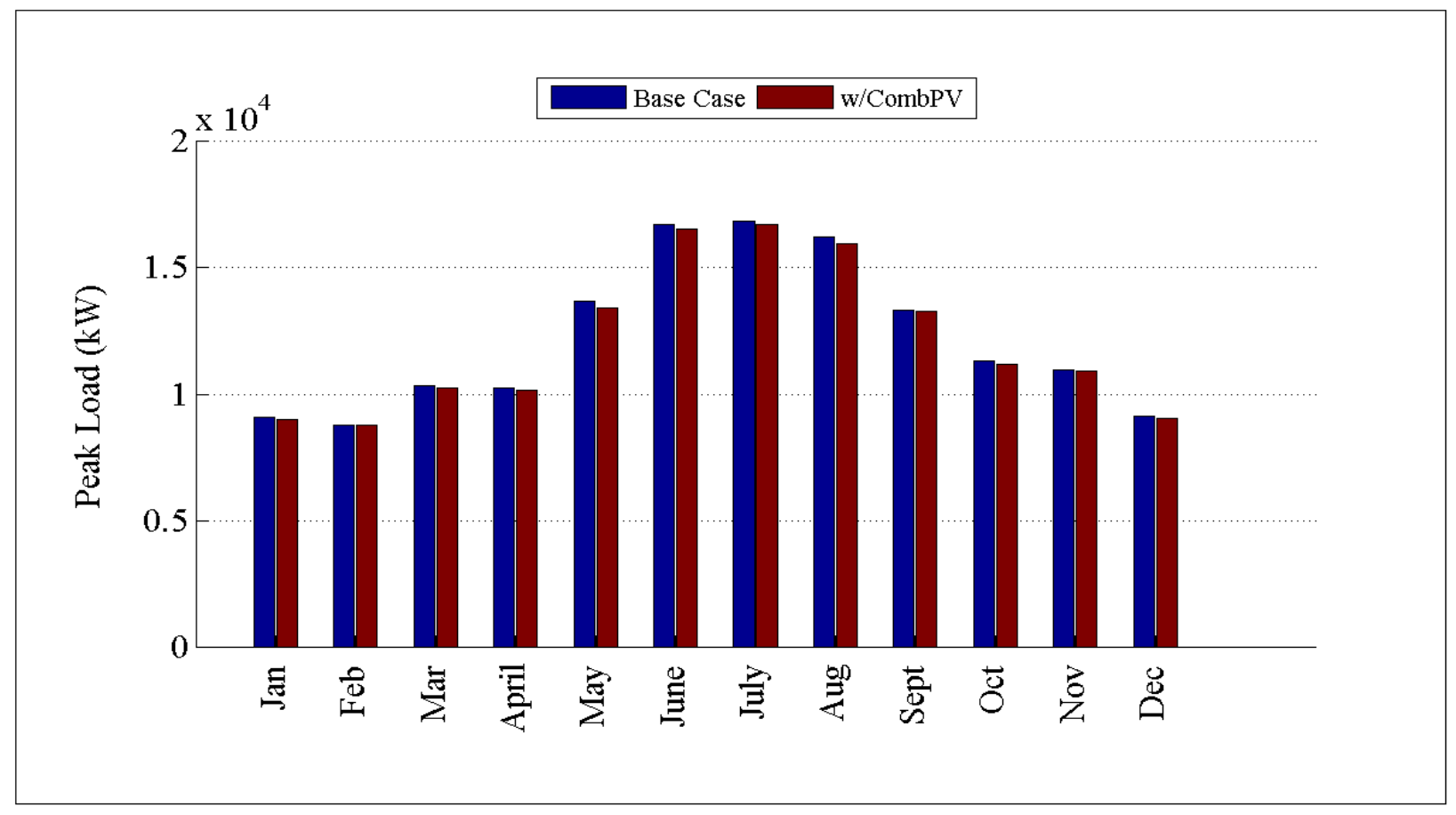

Figure D.269: Comparison of peak load by month for R2-25.00-1 


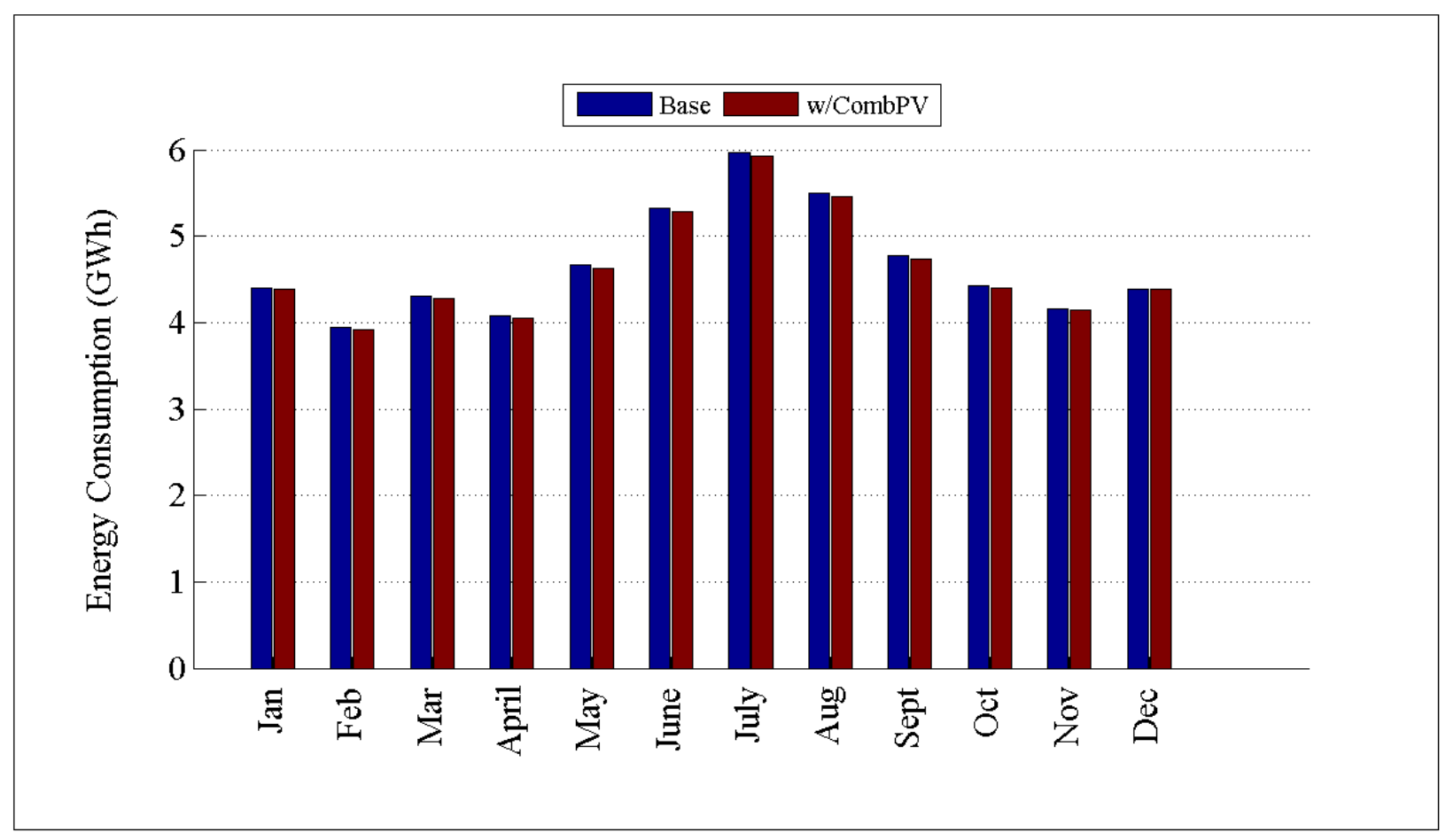

Figure D.270: Comparison of energy consumption by month for R2-25.00-1

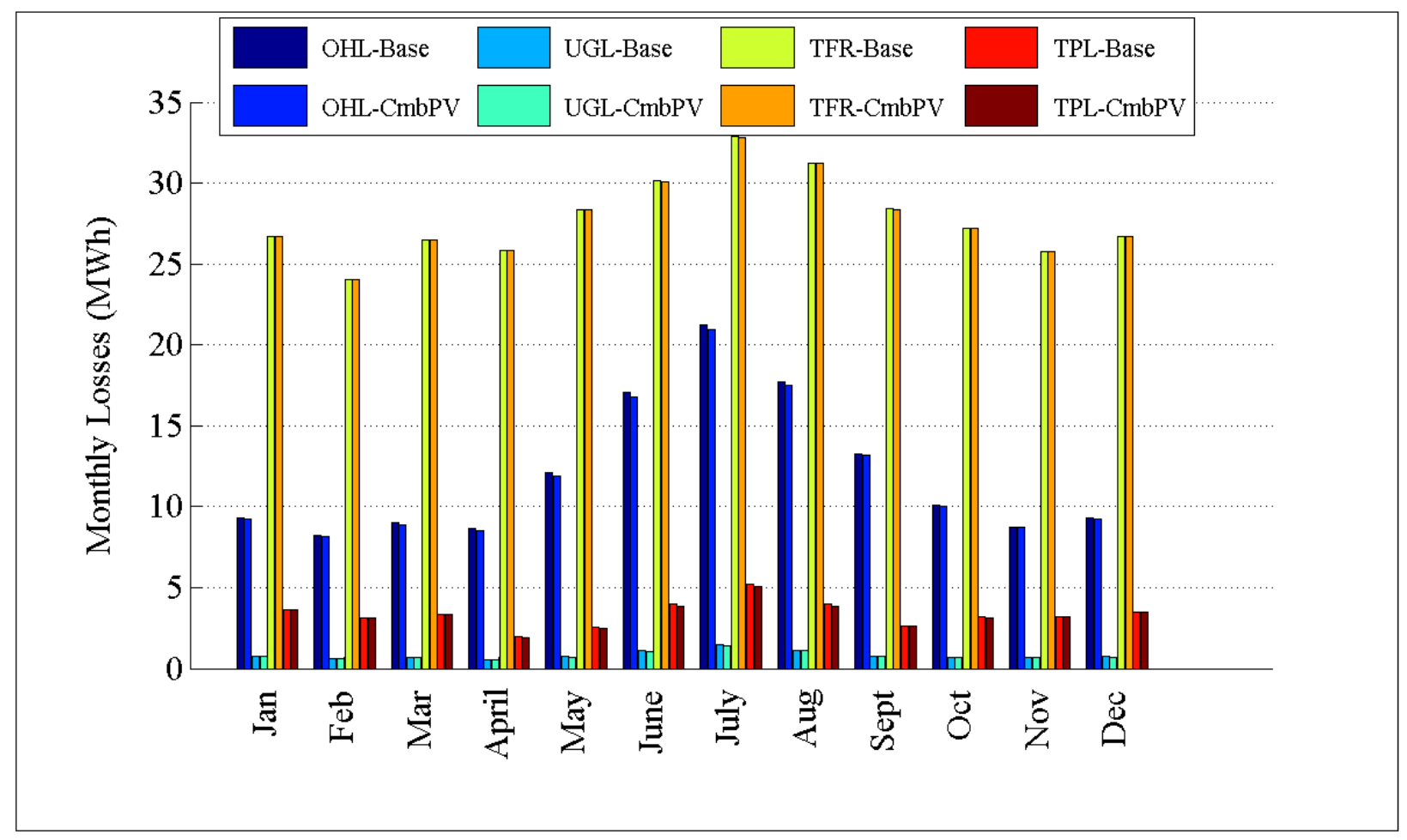

Figure D.271: Comparison of losses by month for R2-25.00-1 


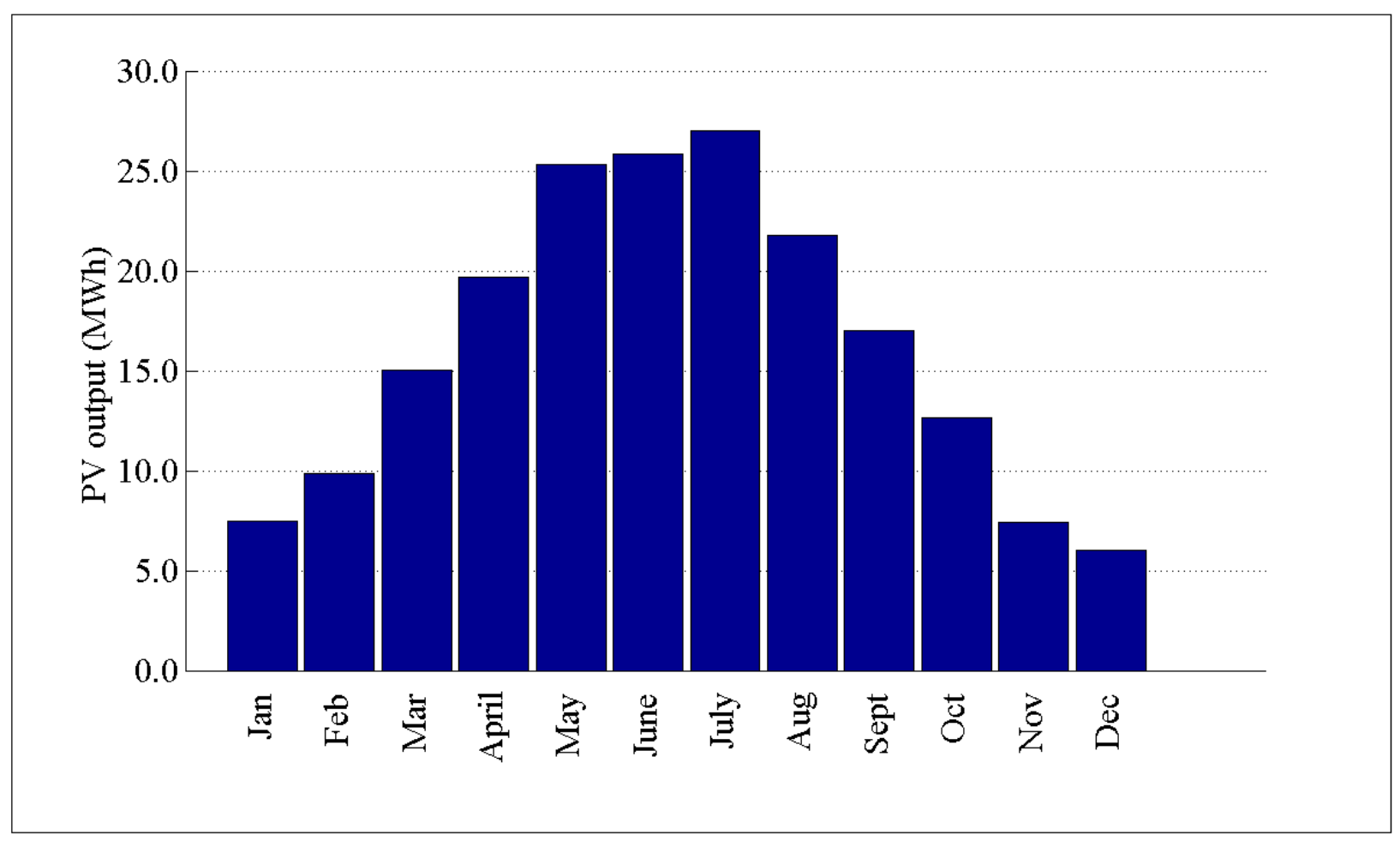

Figure D.272: PV output by month for R2-25.00-1

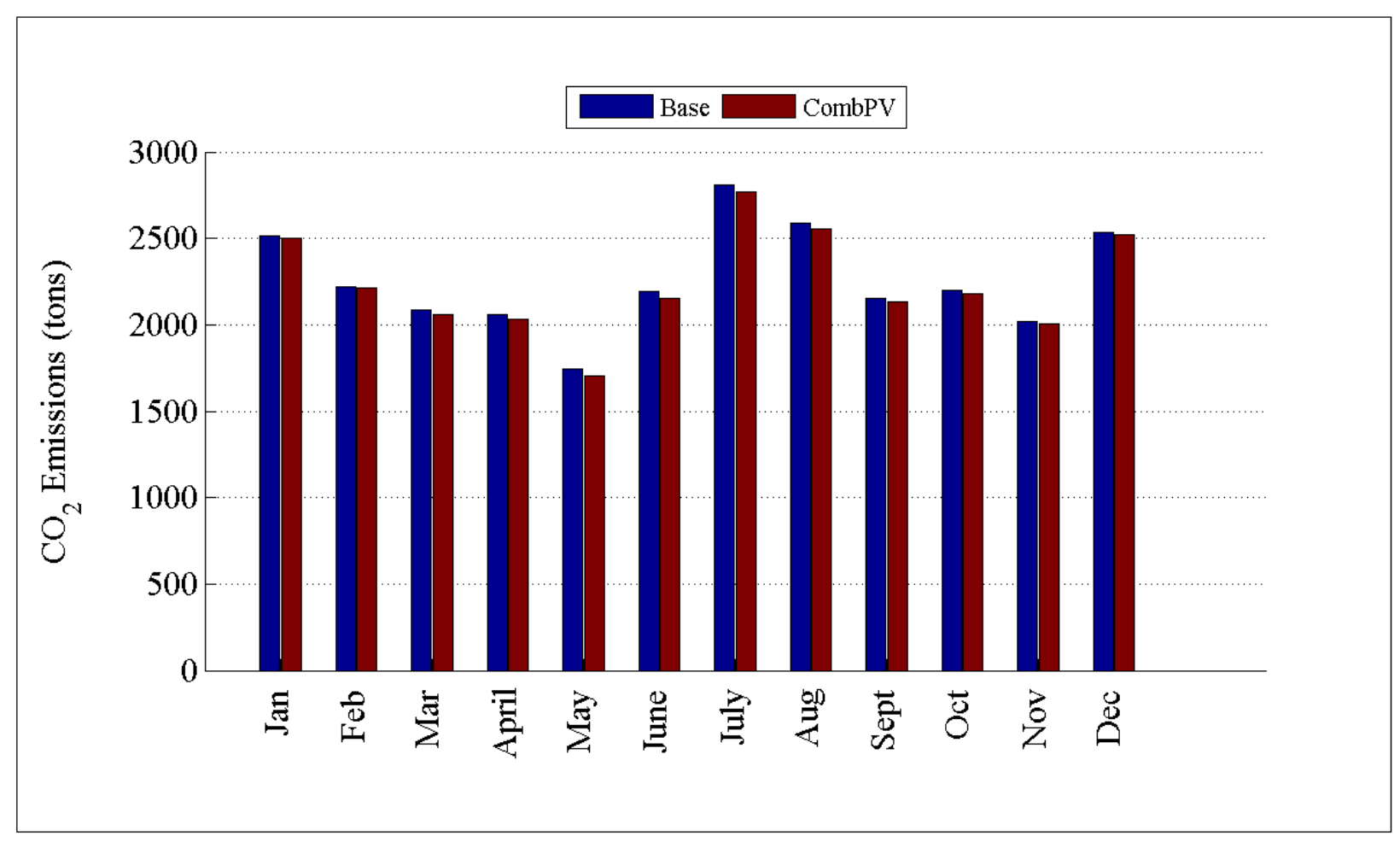

Figure D.273: Comparison of $\mathrm{CO}_{2}$ emissions by month for R2-25.00-1 


\section{D.3.9 Detailed Combined PV Plots for R2-35.00-1}

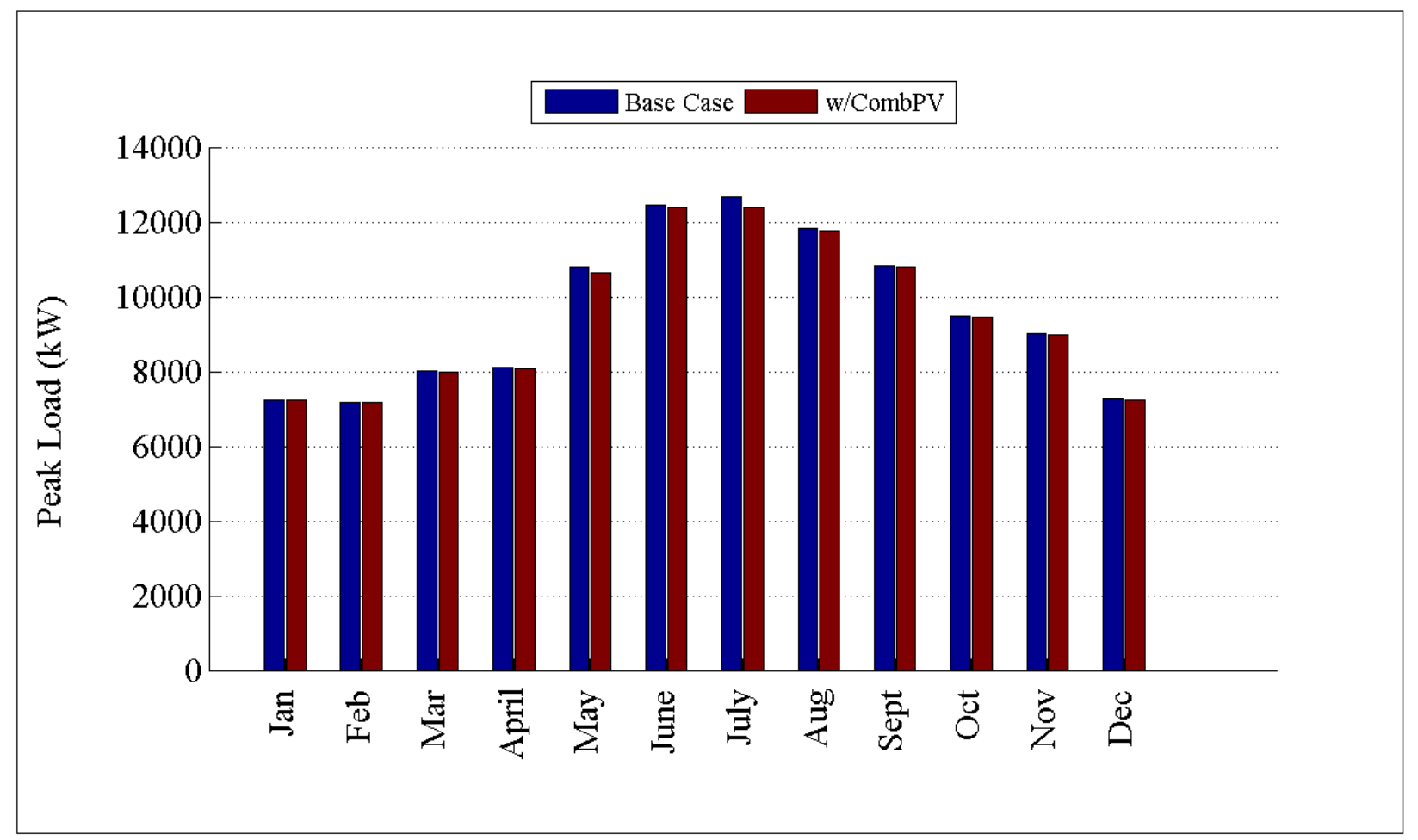

Figure D.274: Comparison of peak load by month for R2-35.00-1

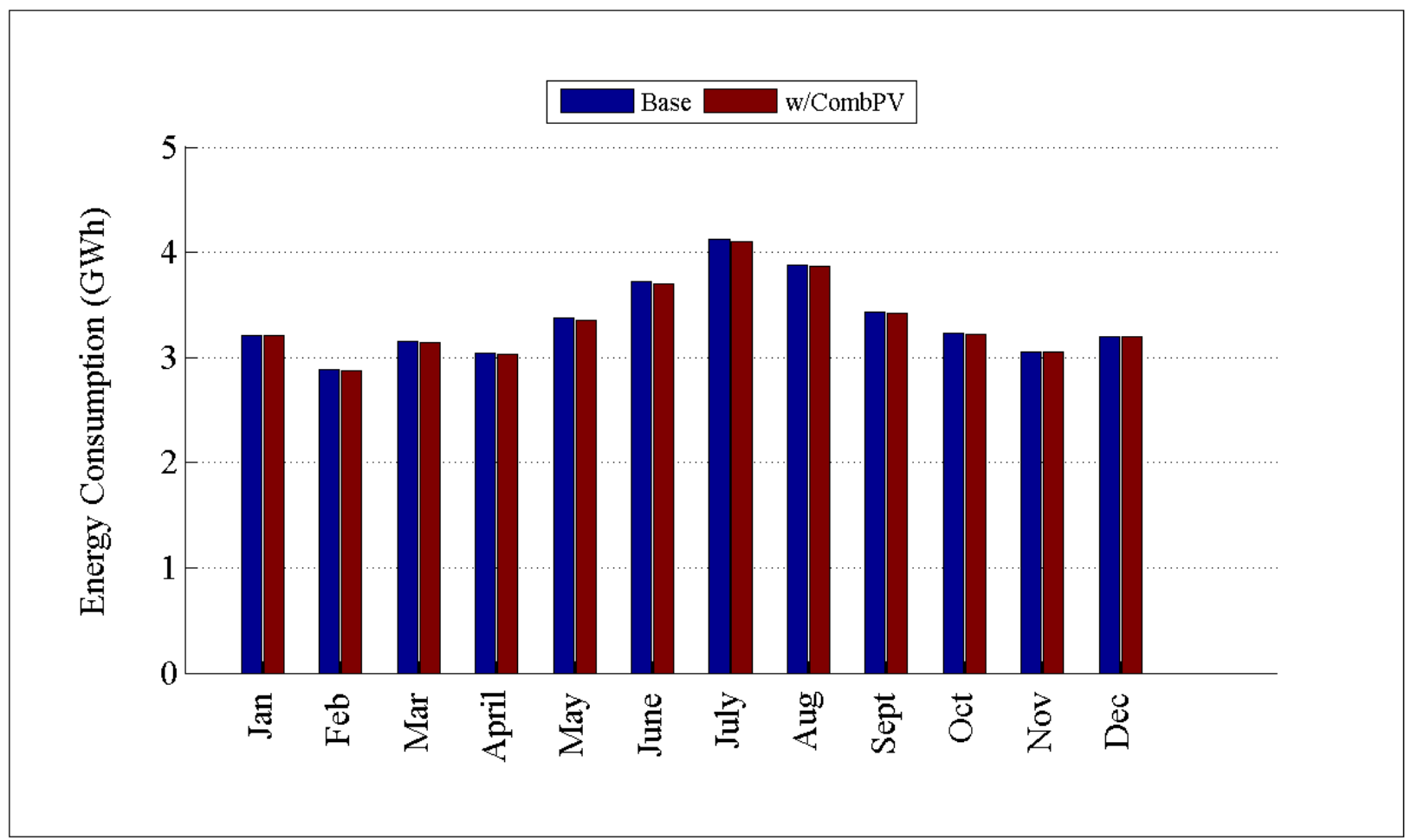

Figure D.275: Comparison of energy consumption by month for R2-35.00-1 


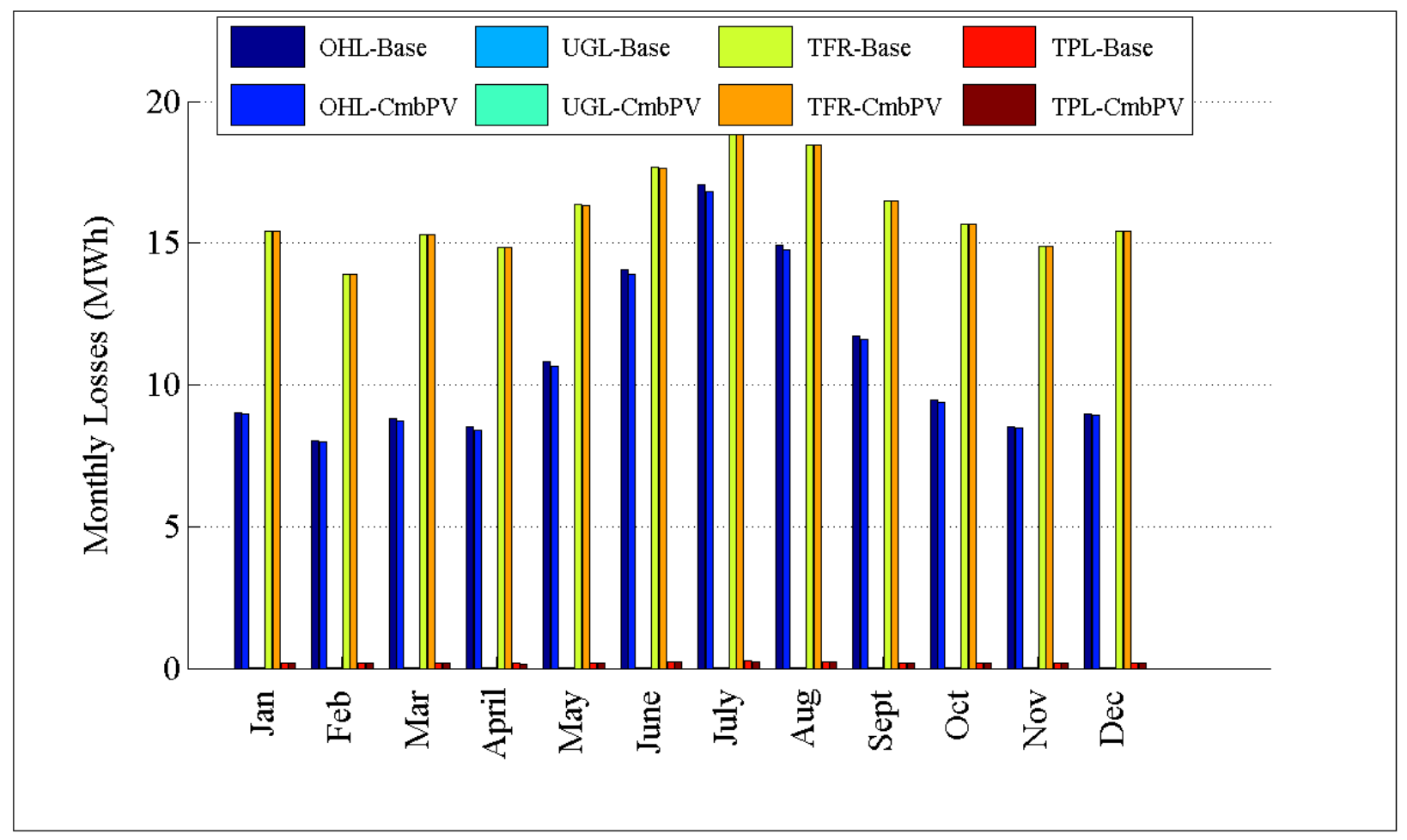

Figure D.276: Comparison of losses by month for R2-35.00-1

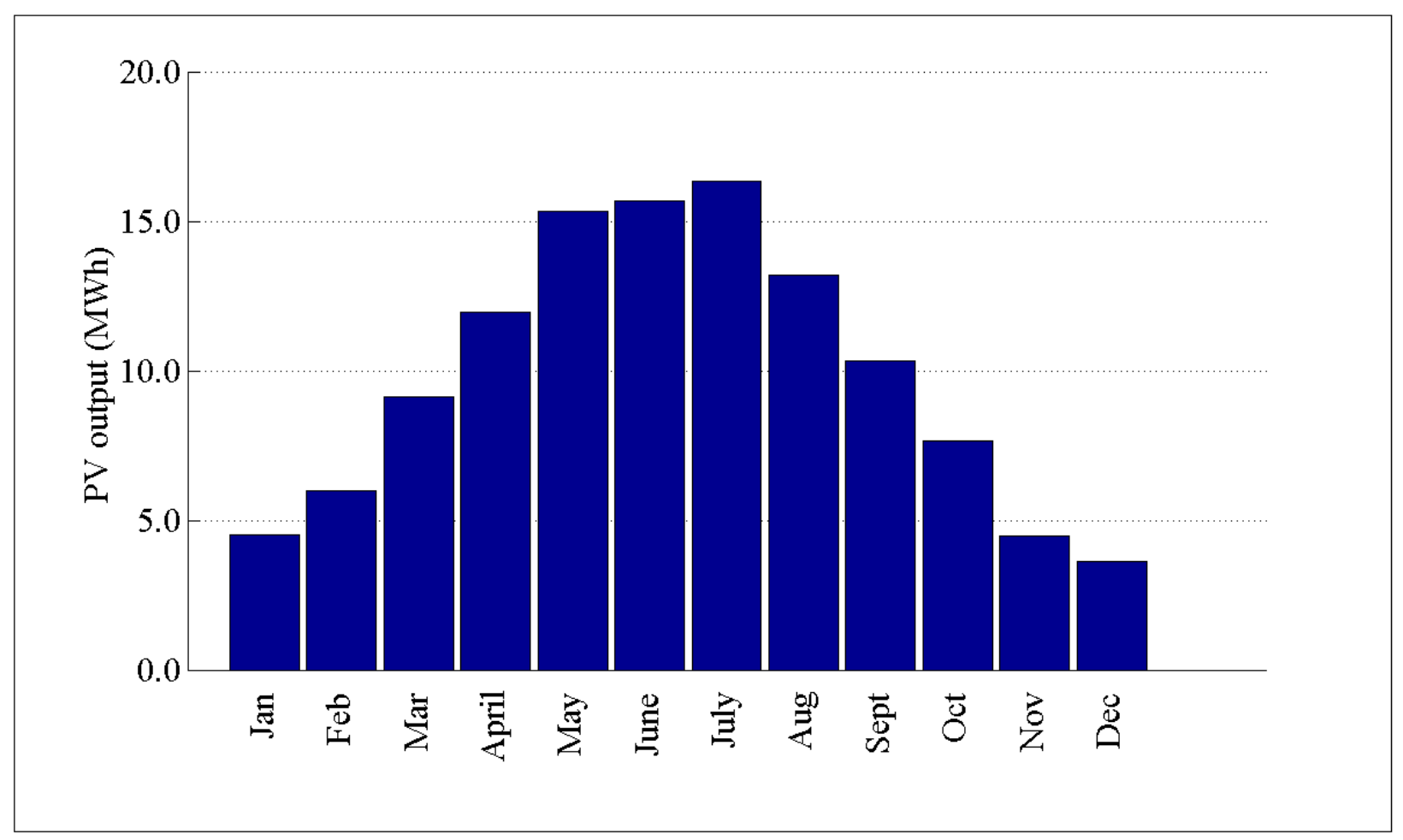

Figure D.277: PV output by month for R2-35.00-1 


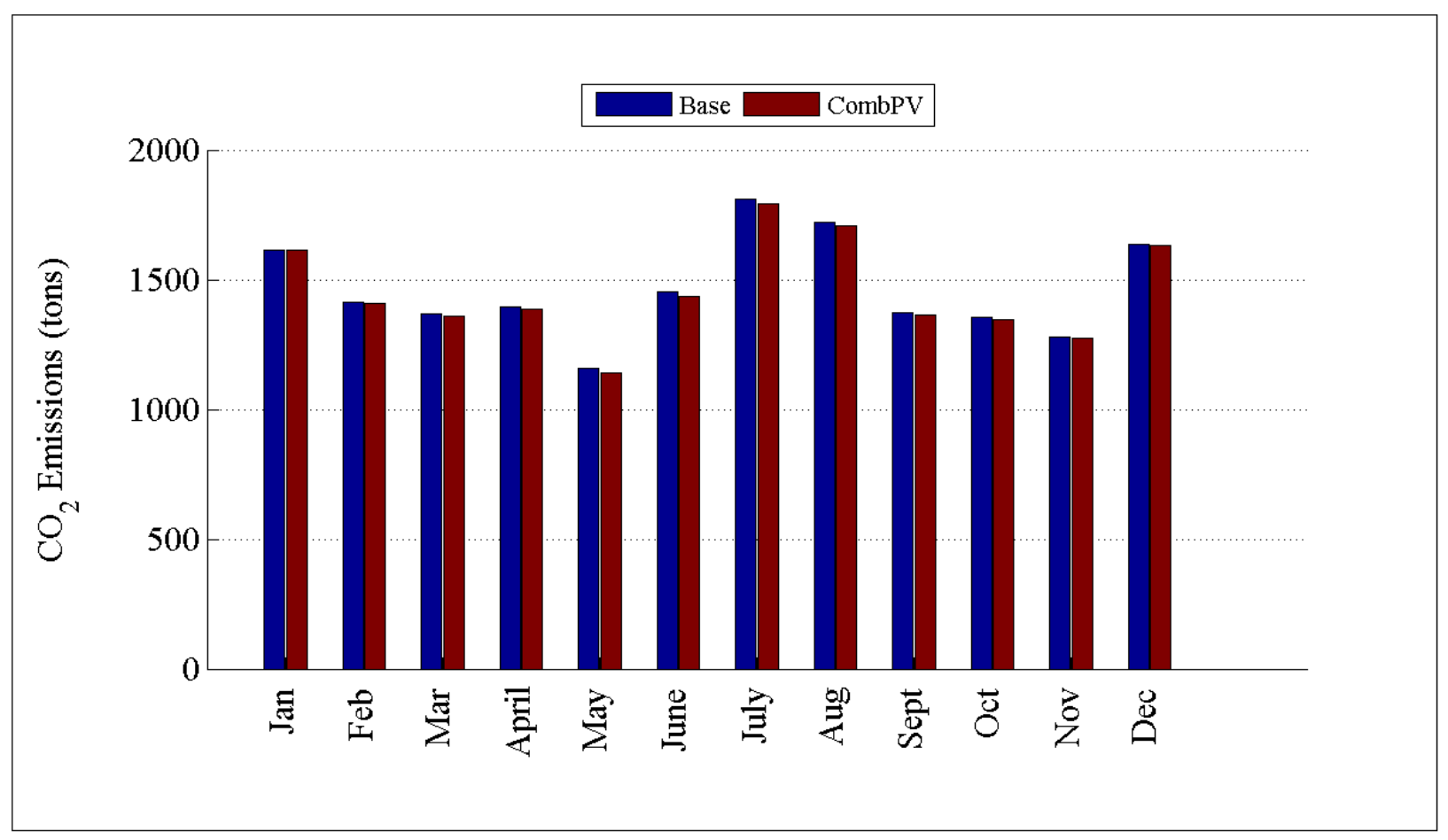

Figure D.278: Comparison of $\mathrm{CO}_{2}$ emissions by month for R2-35.00-1

\section{D.3.10 Detailed Combined PV Plots for R3-12.47-1}

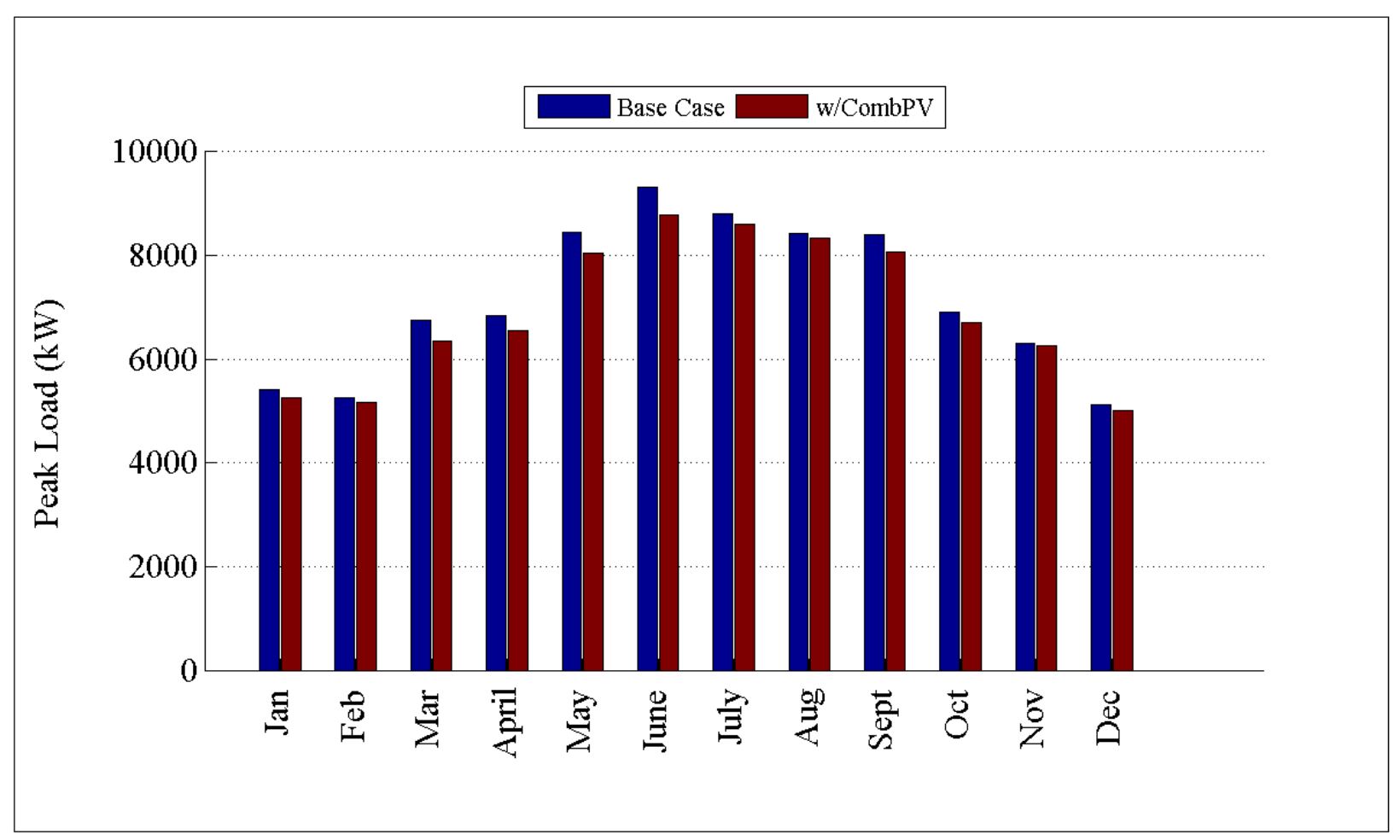

Figure D.279: Comparison of peak load by month for R3-12.47-1 


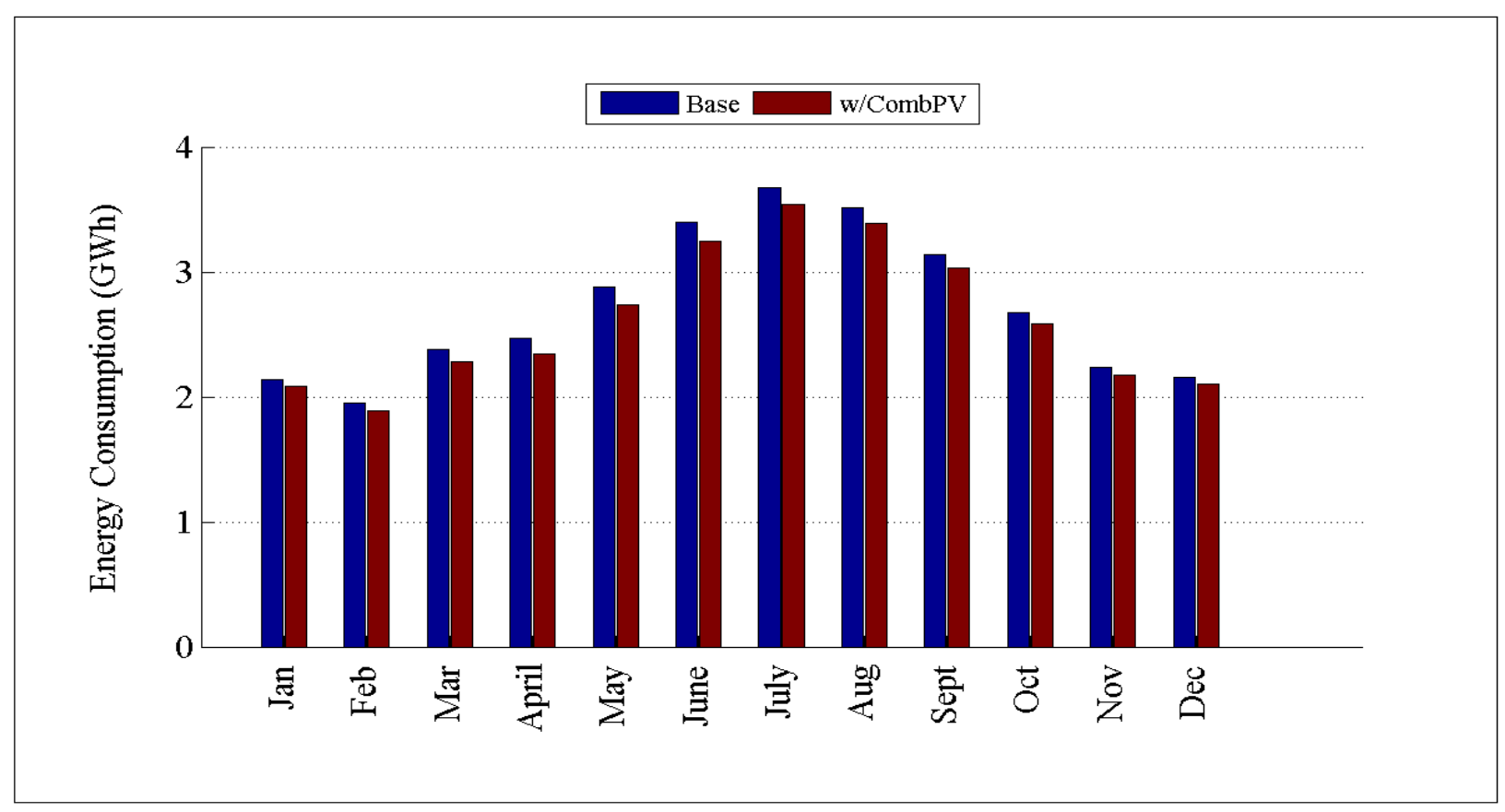

Figure D.280: Comparison of energy consumption by month for R3-12.47-1

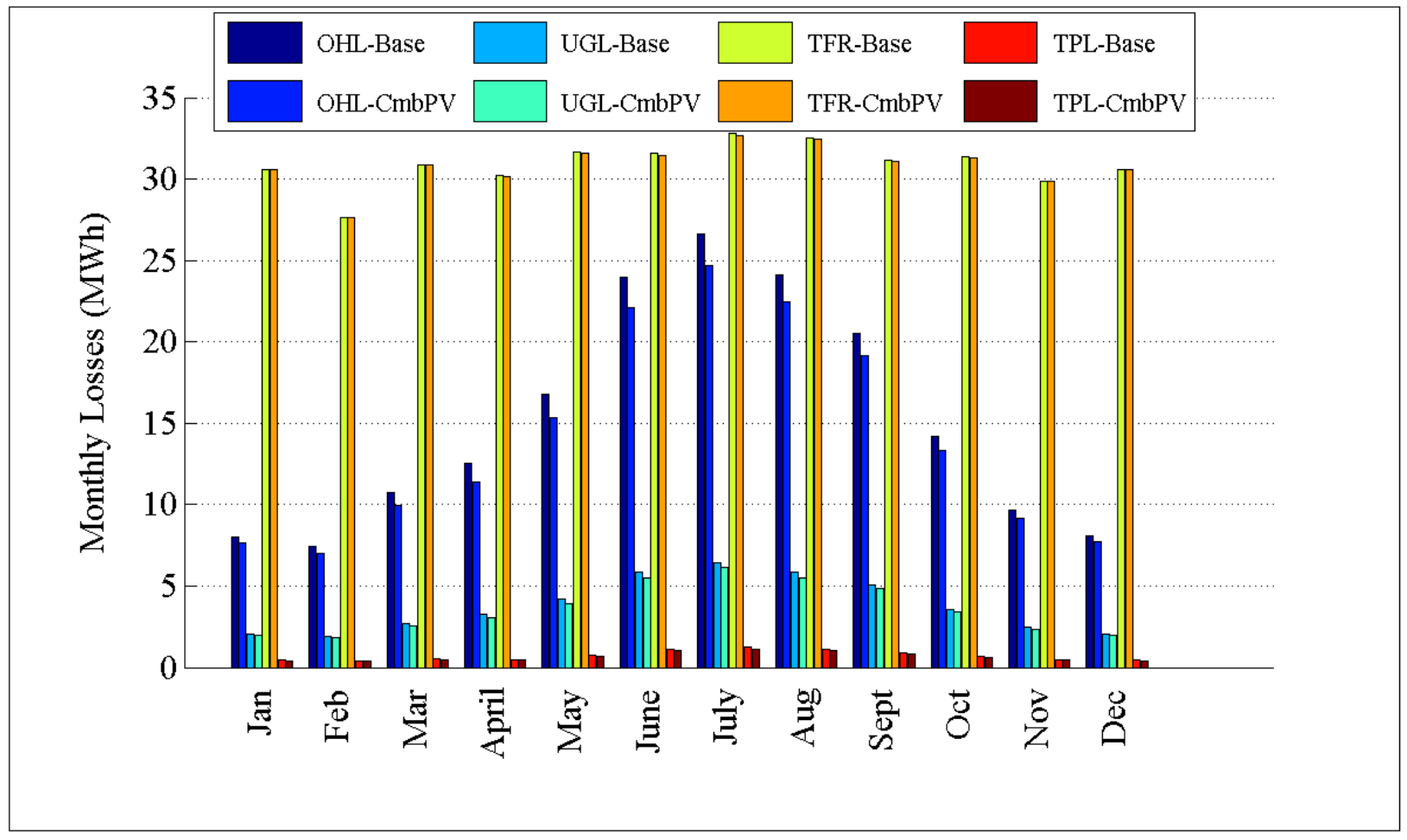

Figure D.281: Comparison of losses by month for R3-12.47-1 


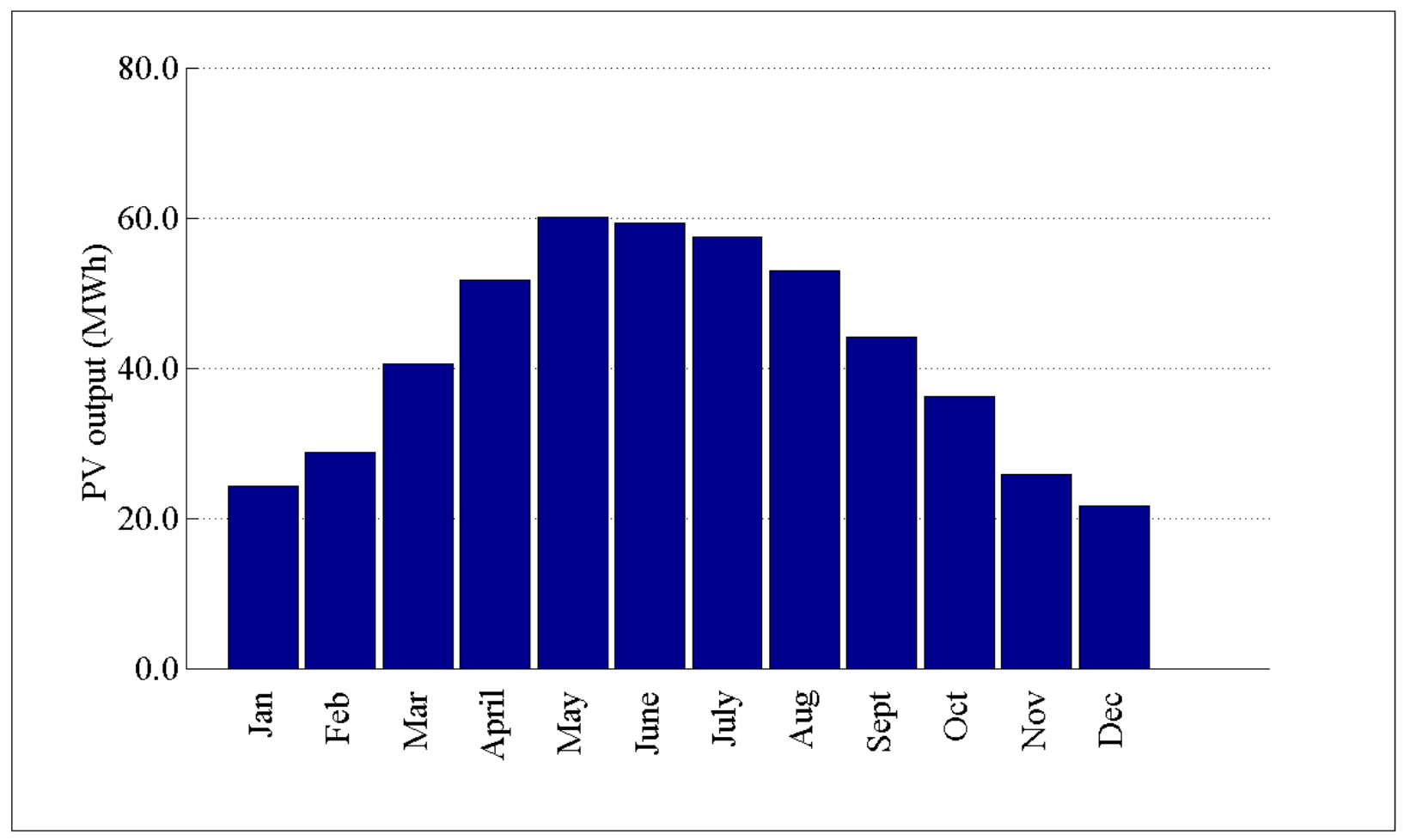

Figure D.282: PV output by month for R3-12.47-1

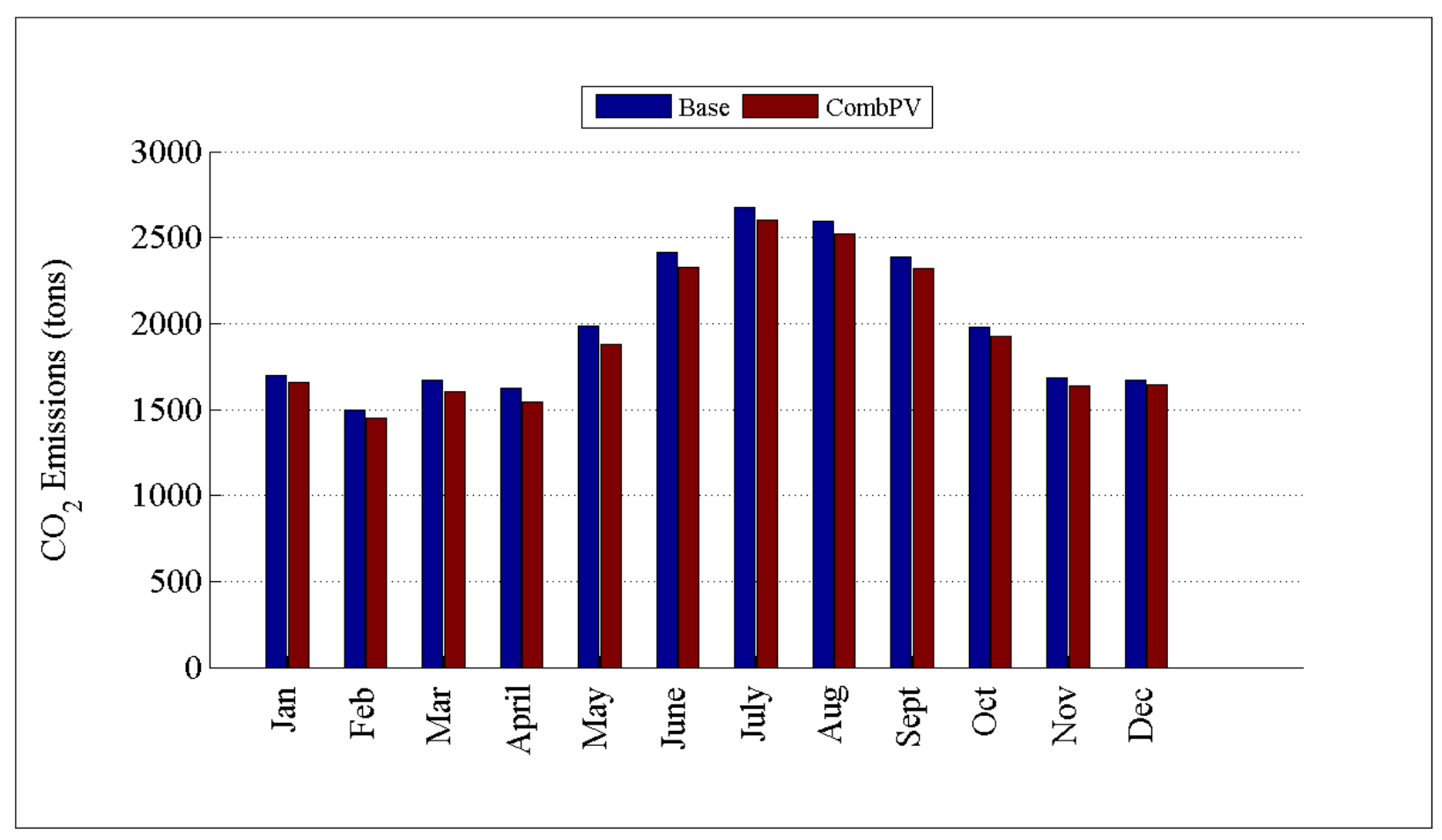

Figure D.283: Comparison of $\mathrm{CO}_{2}$ emissions by month for R3-12.47-1 
D.3.11 Detailed Combined PV Plots for R3-12.47-3

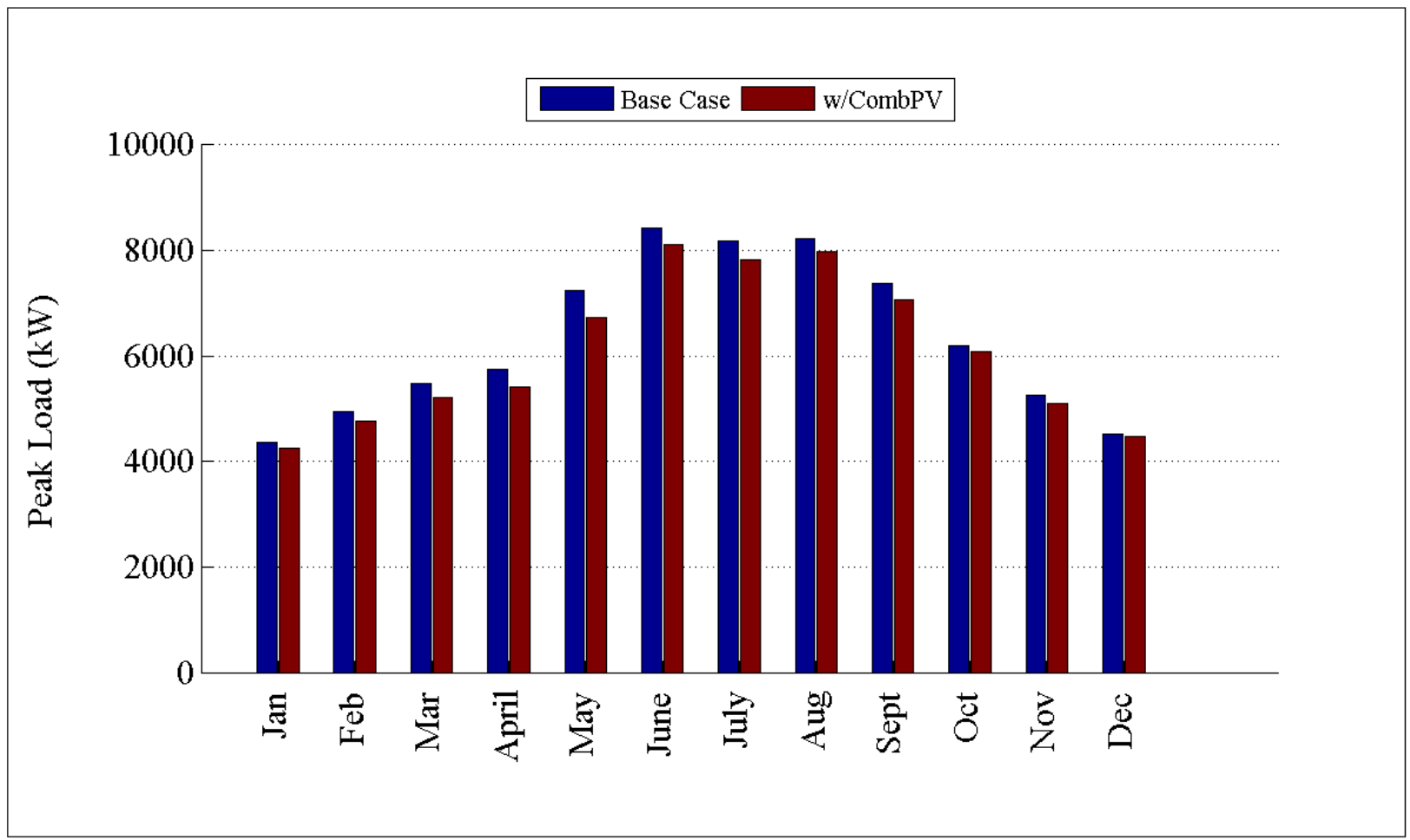

Figure D.284: Comparison of peak load by month for R3-12.47-3

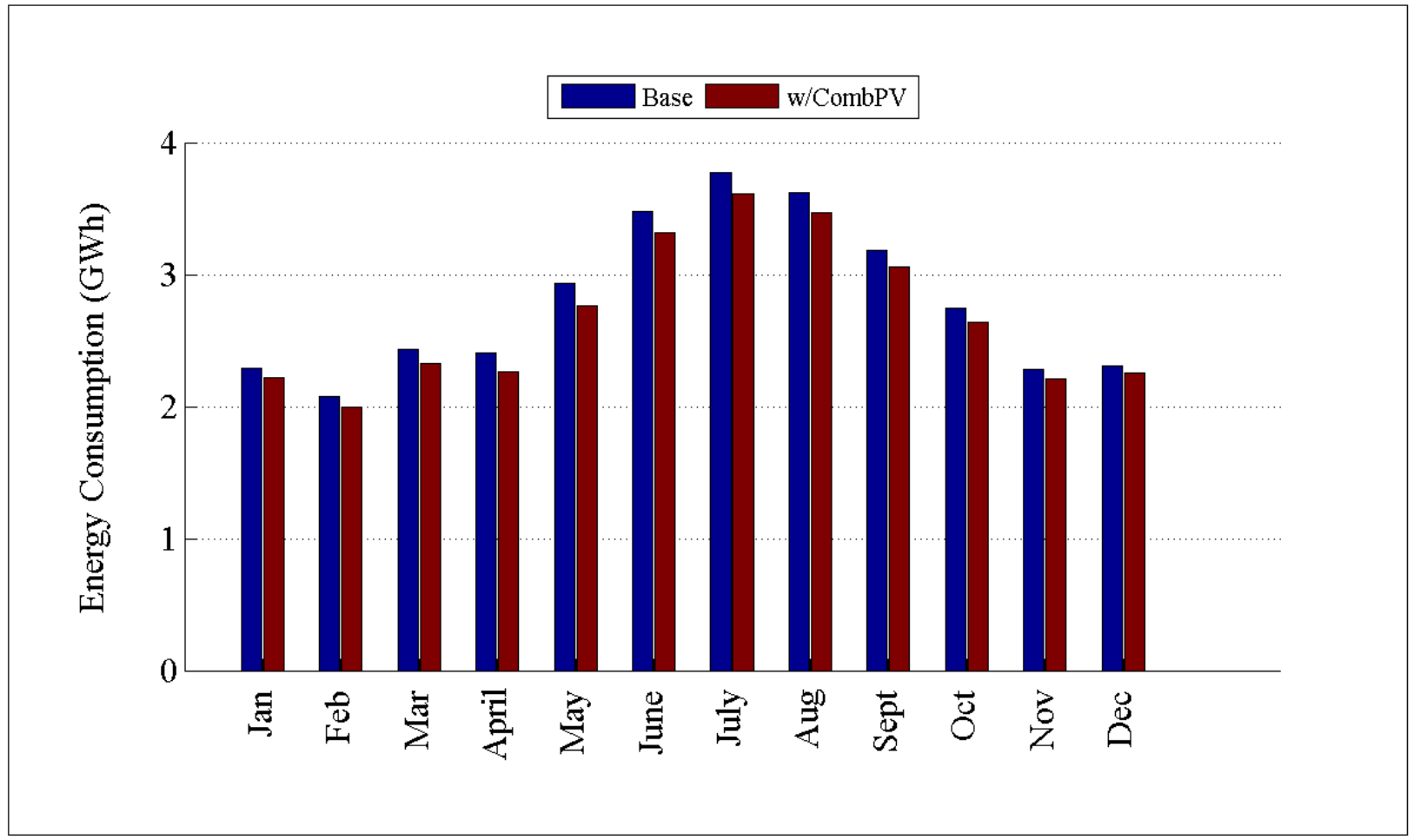

Figure D.285: Comparison of energy consumption by month for R3-12.47-3 


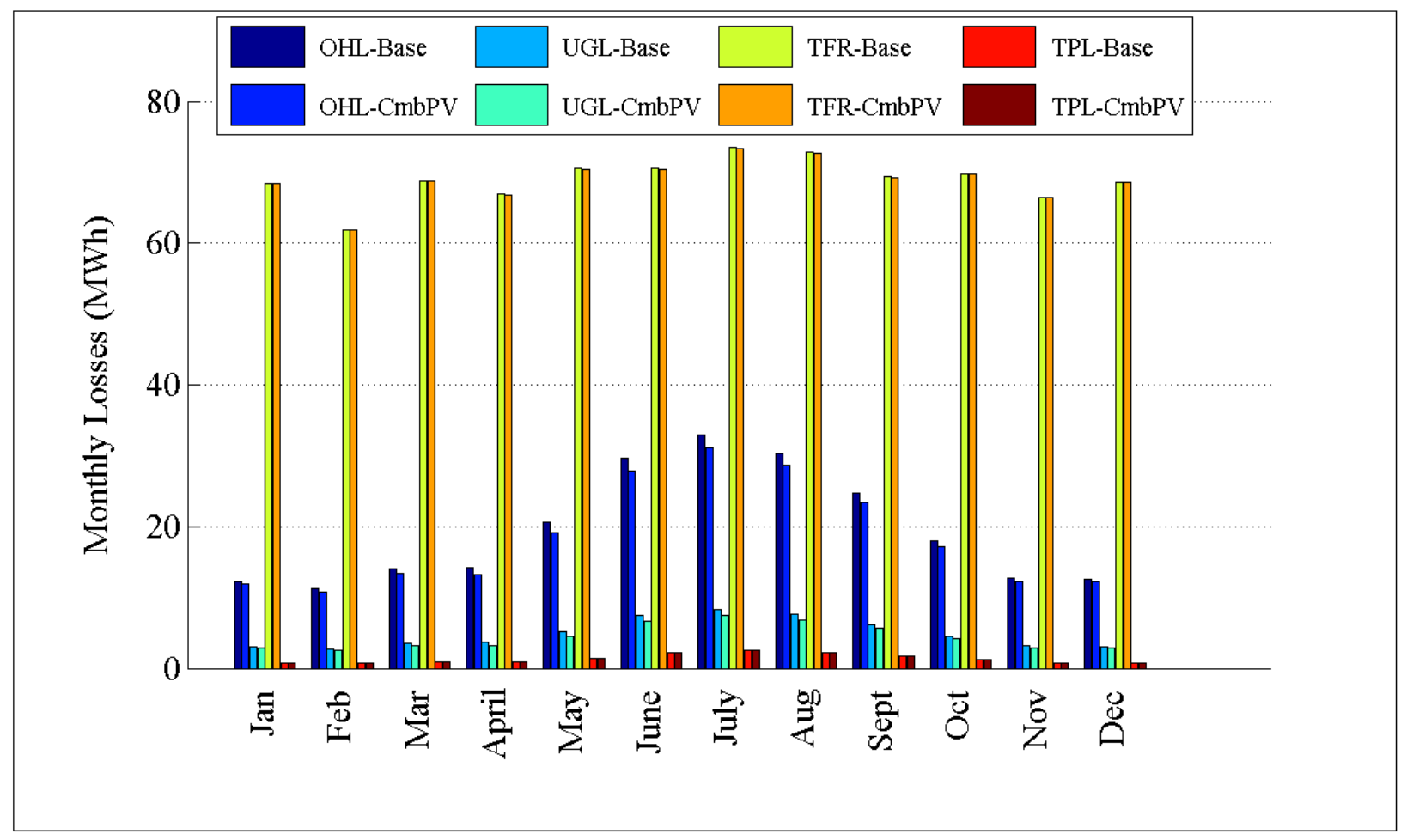

Figure D.286: Comparison of losses by month for R3-12.47-3

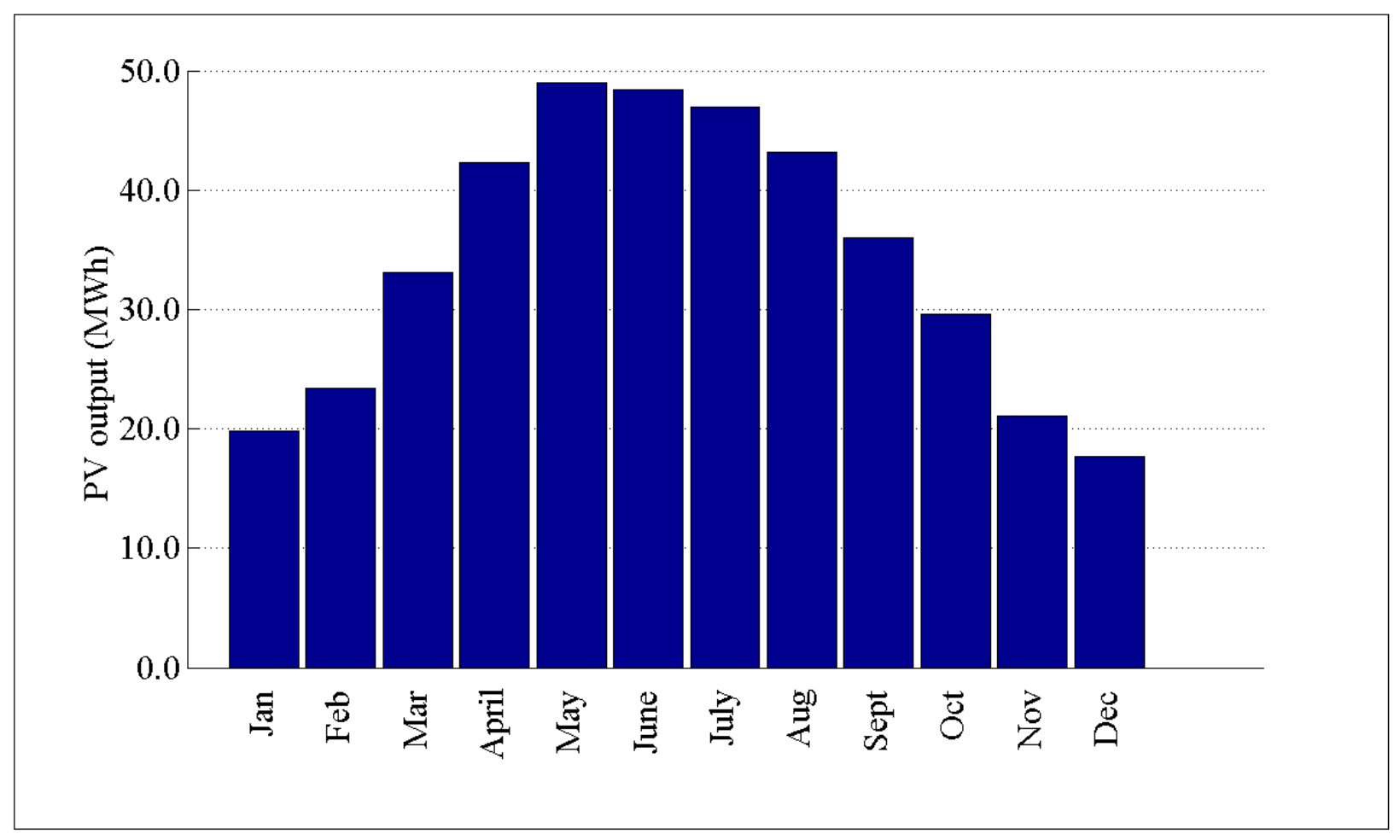

Figure D.287: PV output by month for R3-12.47-3 


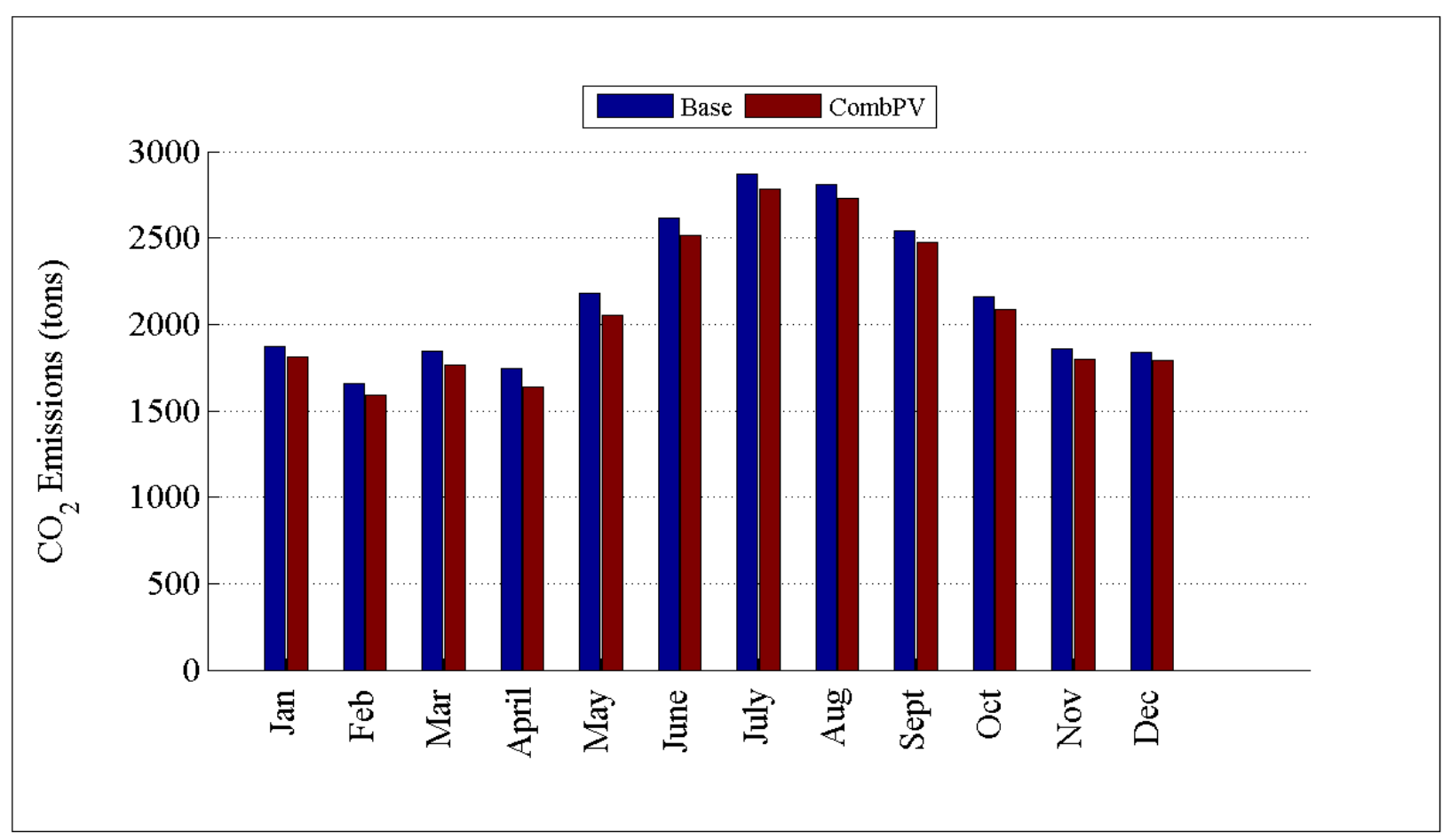

Figure D.288: Comparison of energy consumption by month for R3-12.47-3

D.3.12 Detailed Combined PV Plots for R4-12.47-1

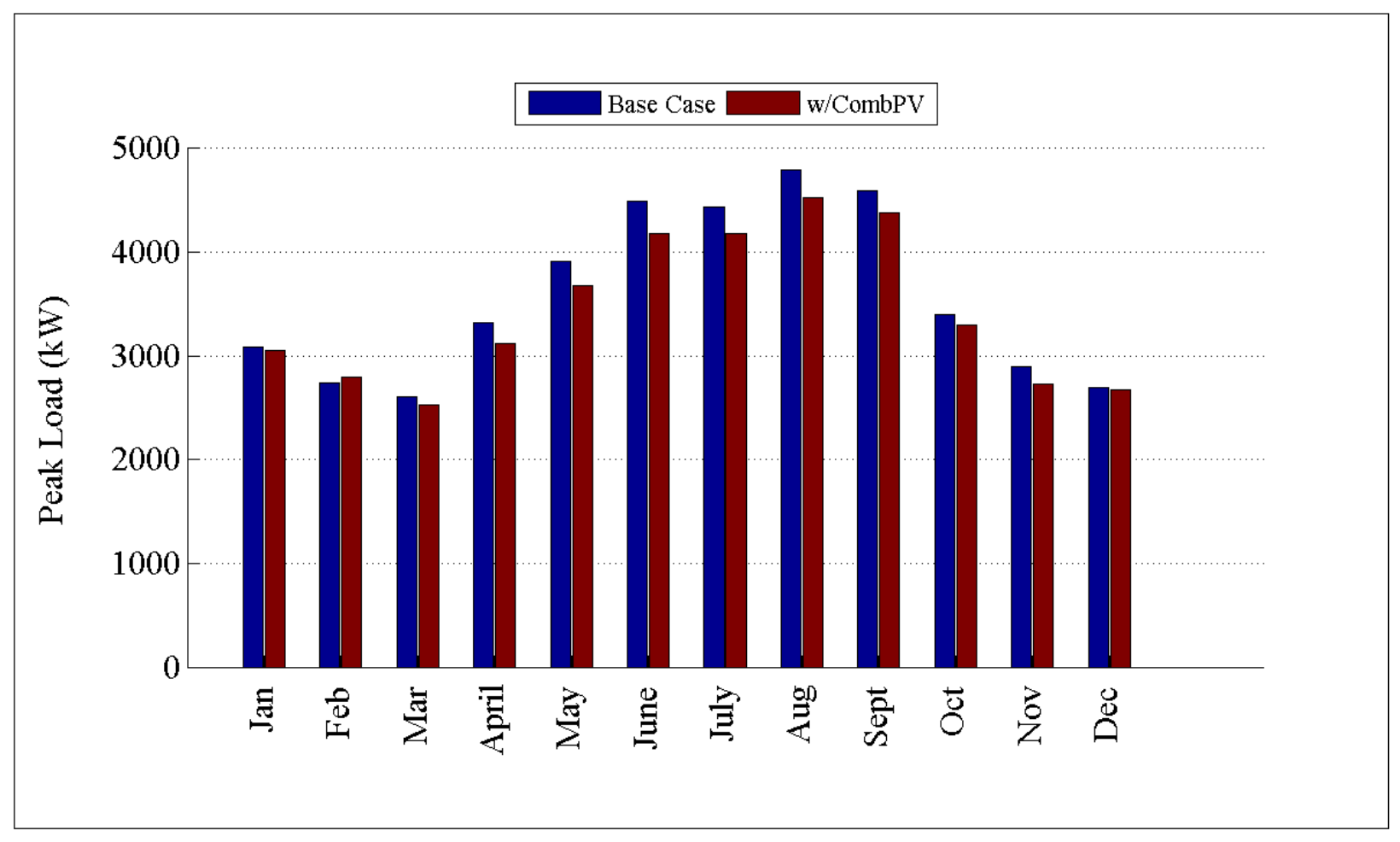

Figure D.289: Comparison of peak loadby month for R4-12.47-1 


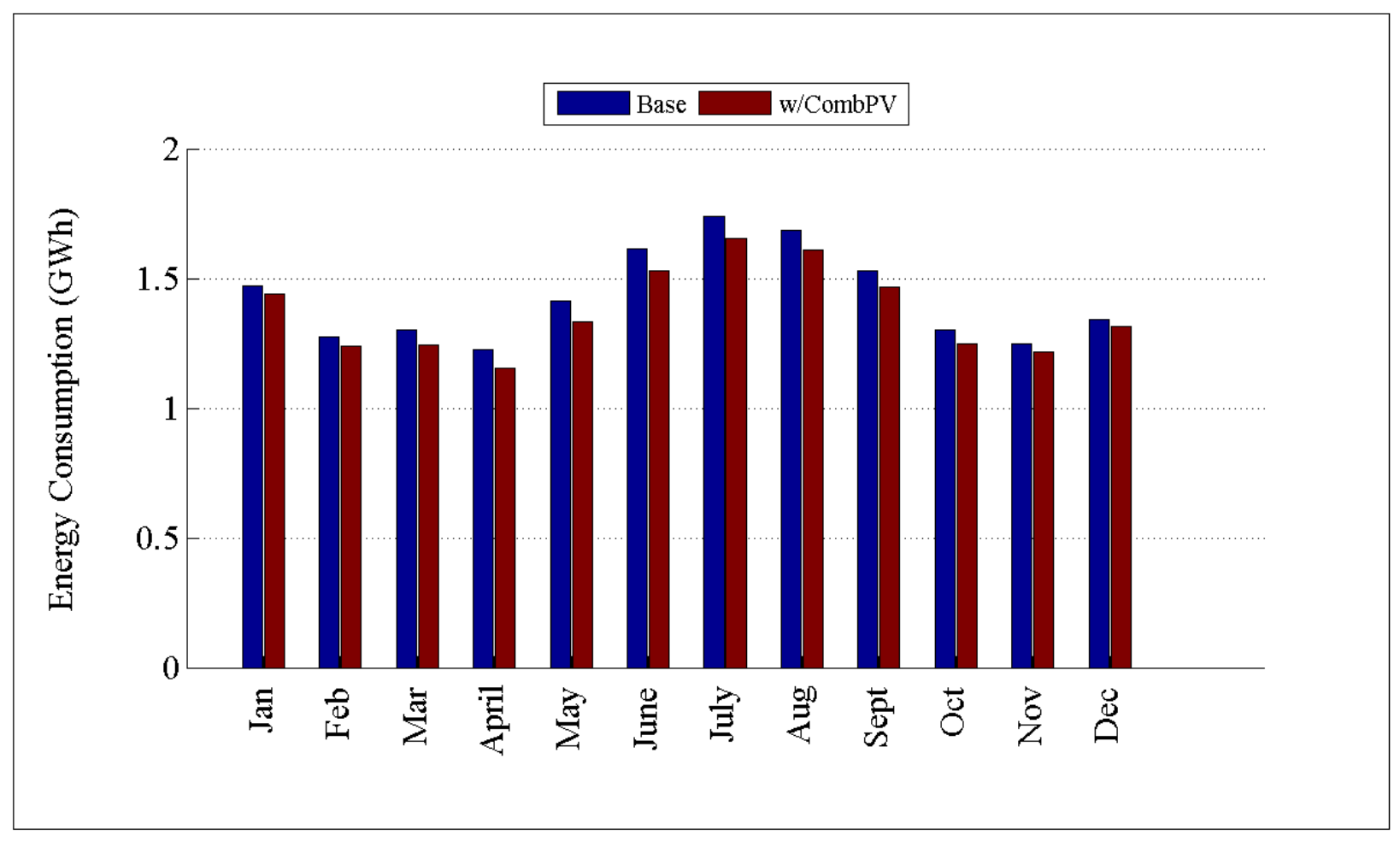

Figure D.290: Comparison of energy consumption by month for R4-12.47-1

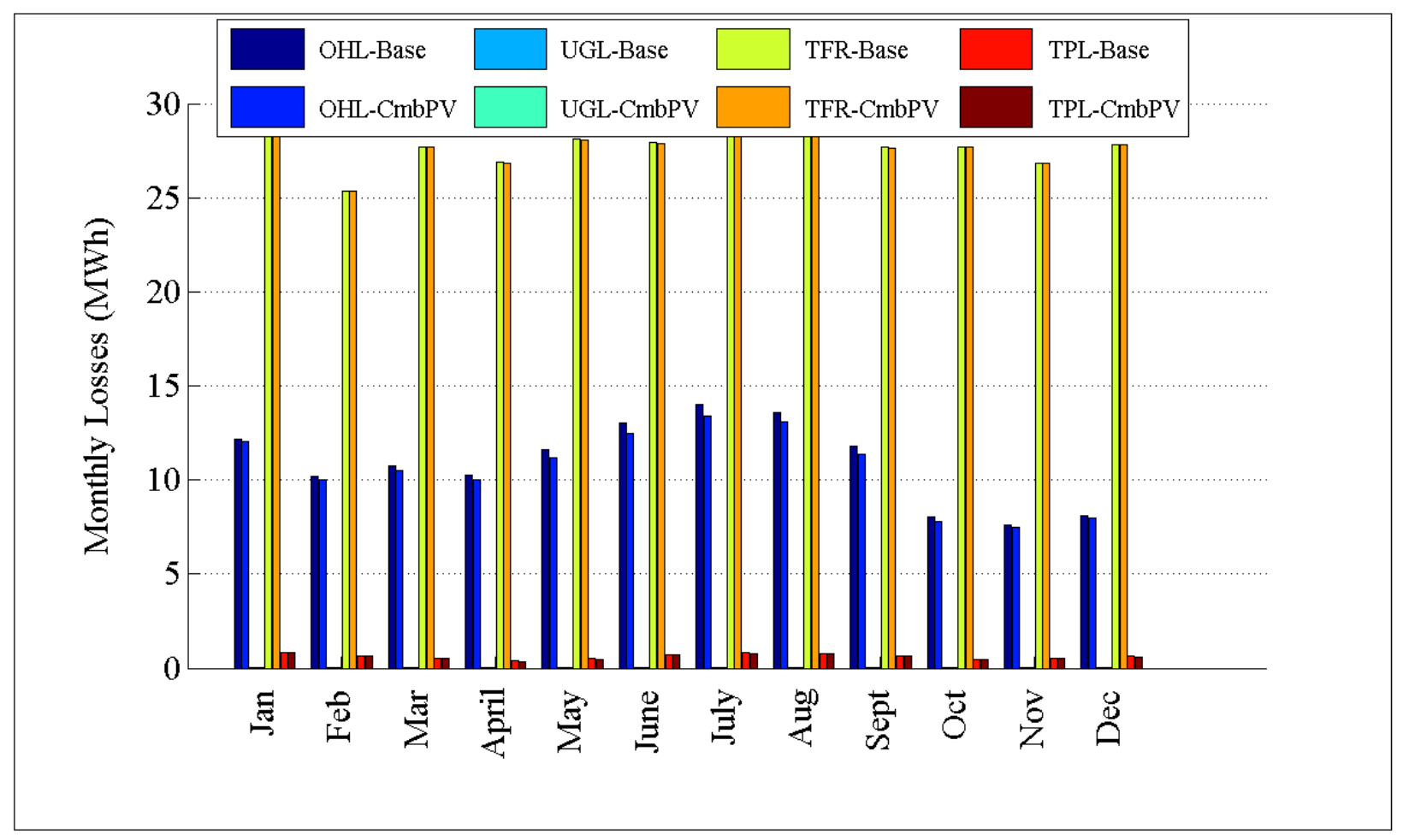

Figure D.291: Comparison of losses by month for R4-12.47-1 


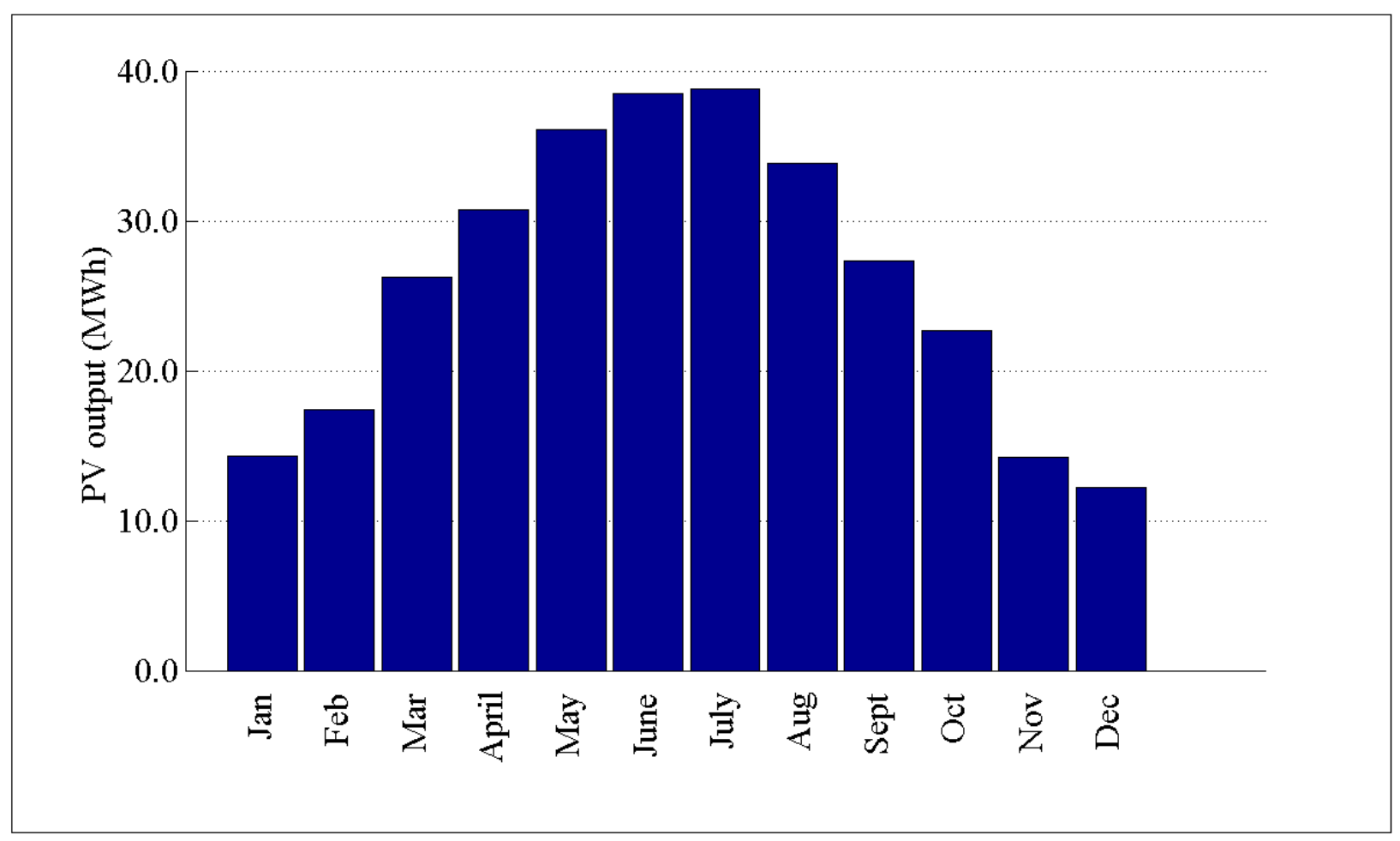

Figure D.292: PV output by month for R4-12.47-1

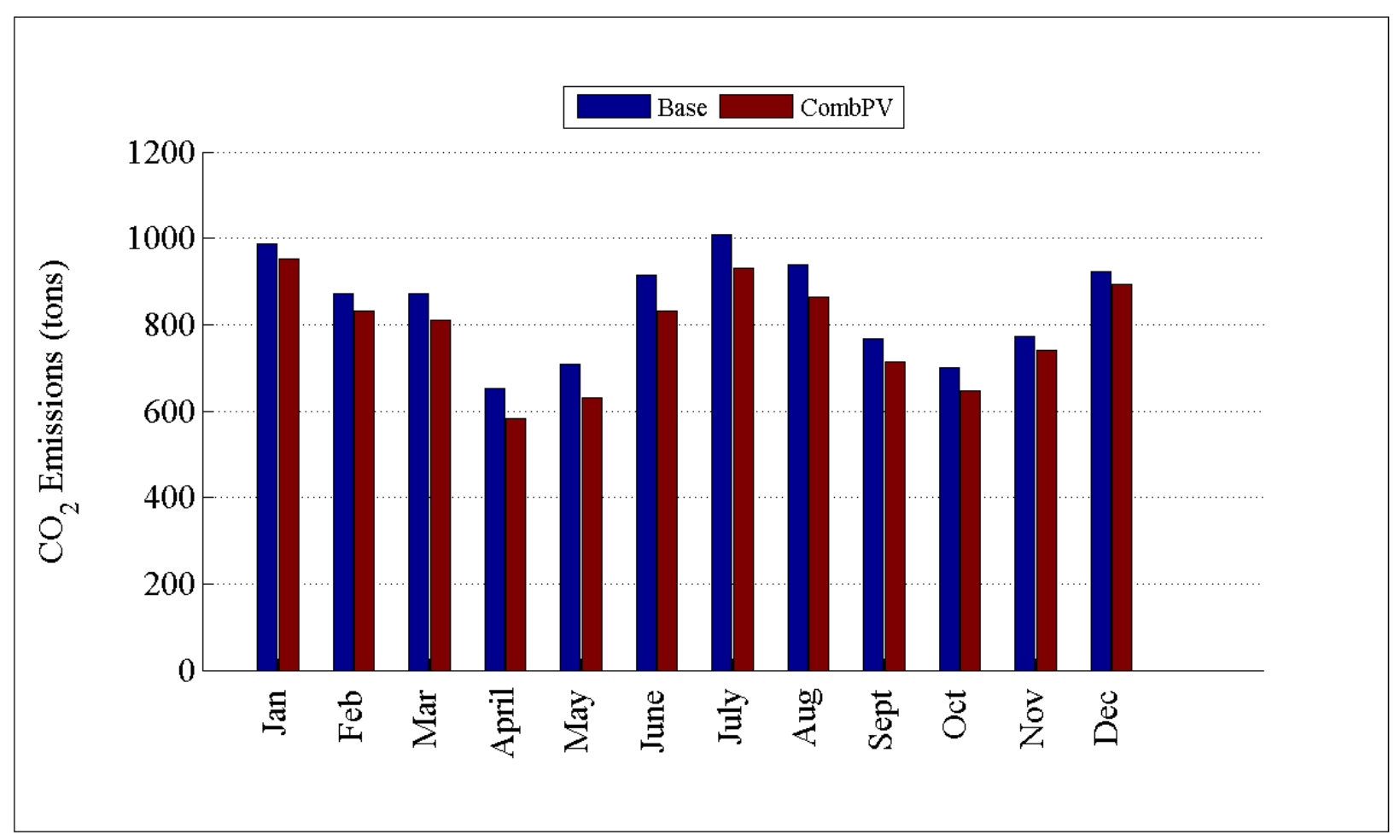

Figure D.293: Comparison of $\mathrm{CO}_{2}$ emissions by month for R4-12.47-1 
D.3.13 Detailed Combined PV Plots for R4-12.47-2

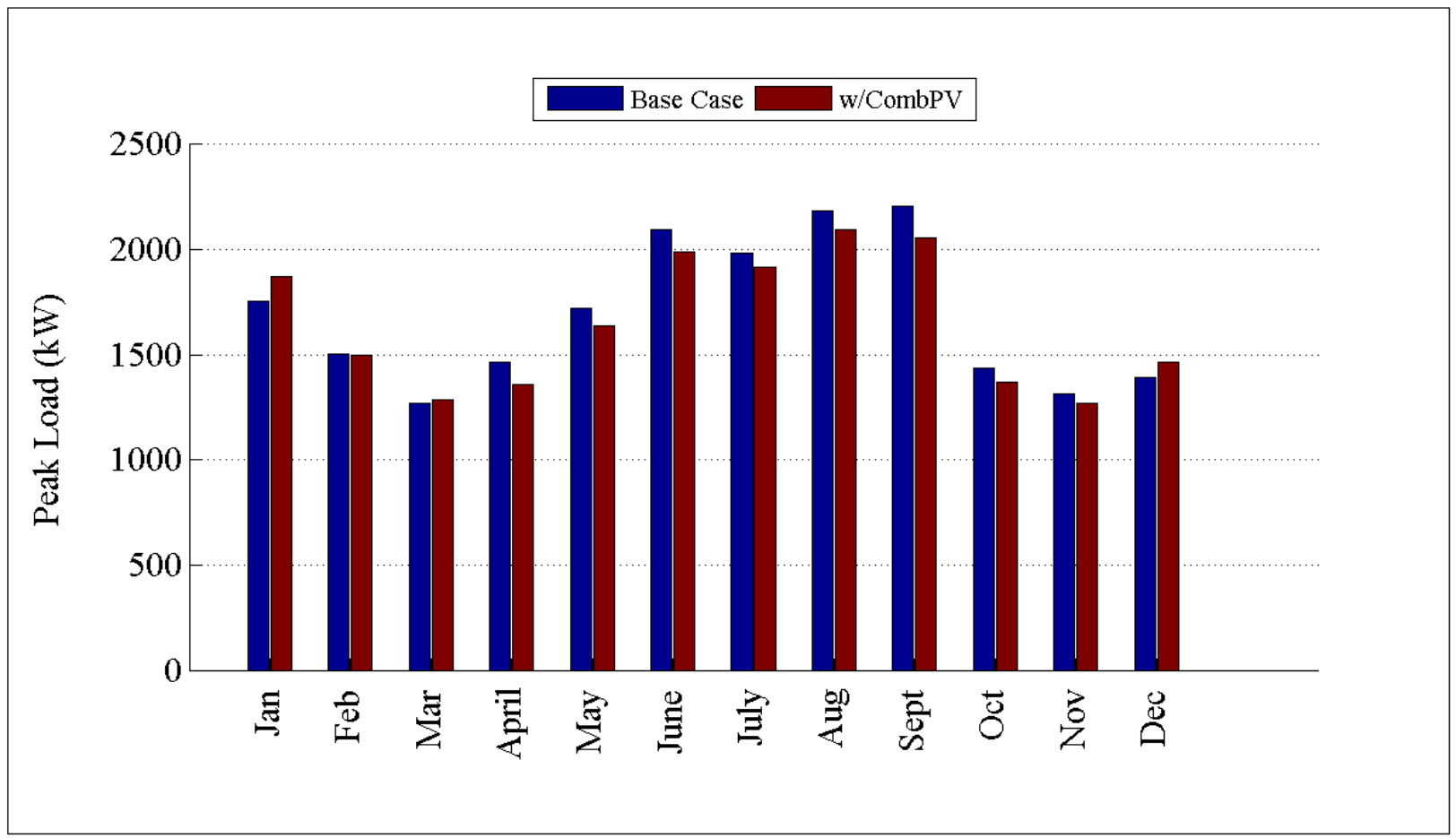

Figure D.294: Comparison of peak loadby month for R4-12.47-2

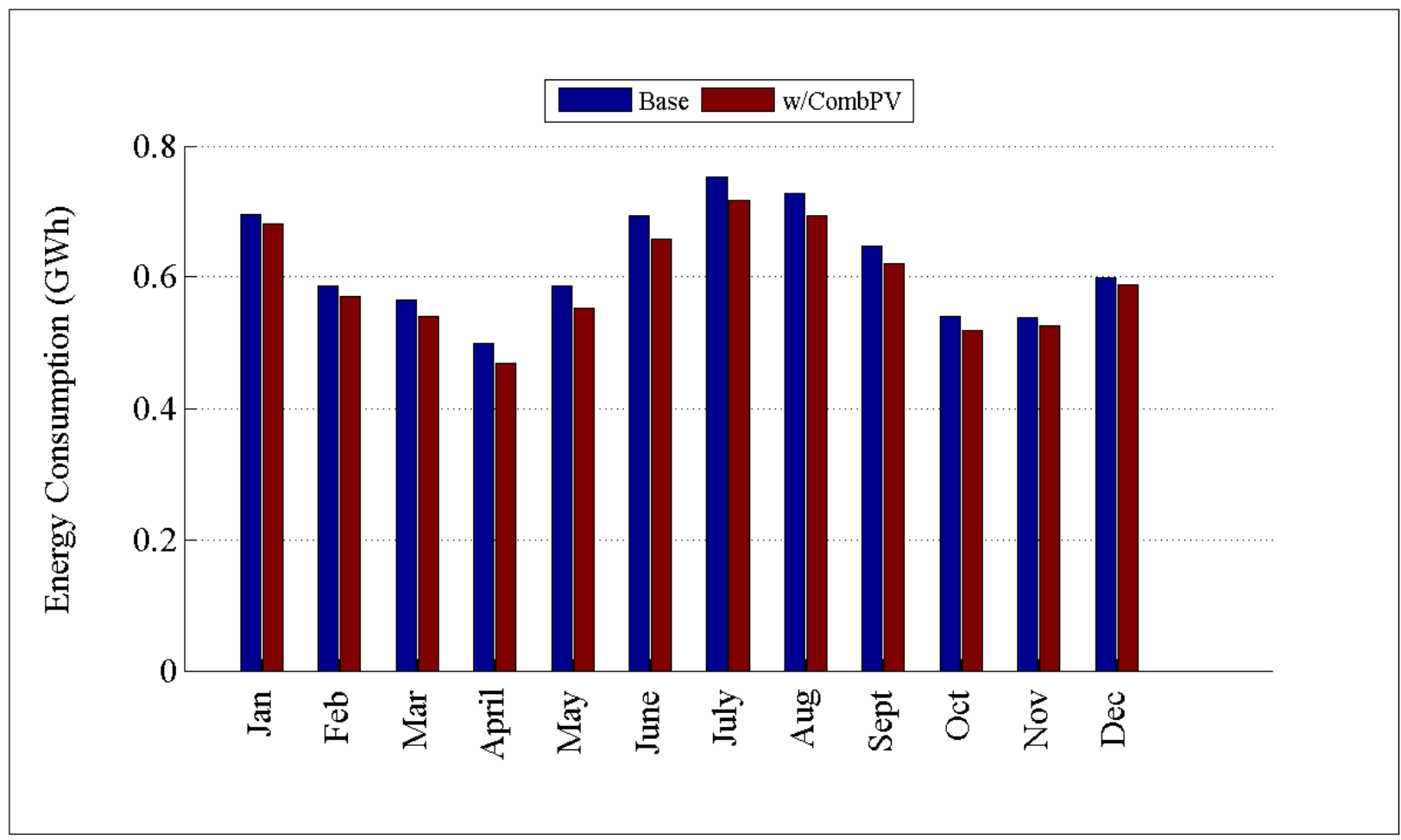

Figure D.295: Comparison of energy consumption by month for R4-12.47-2 


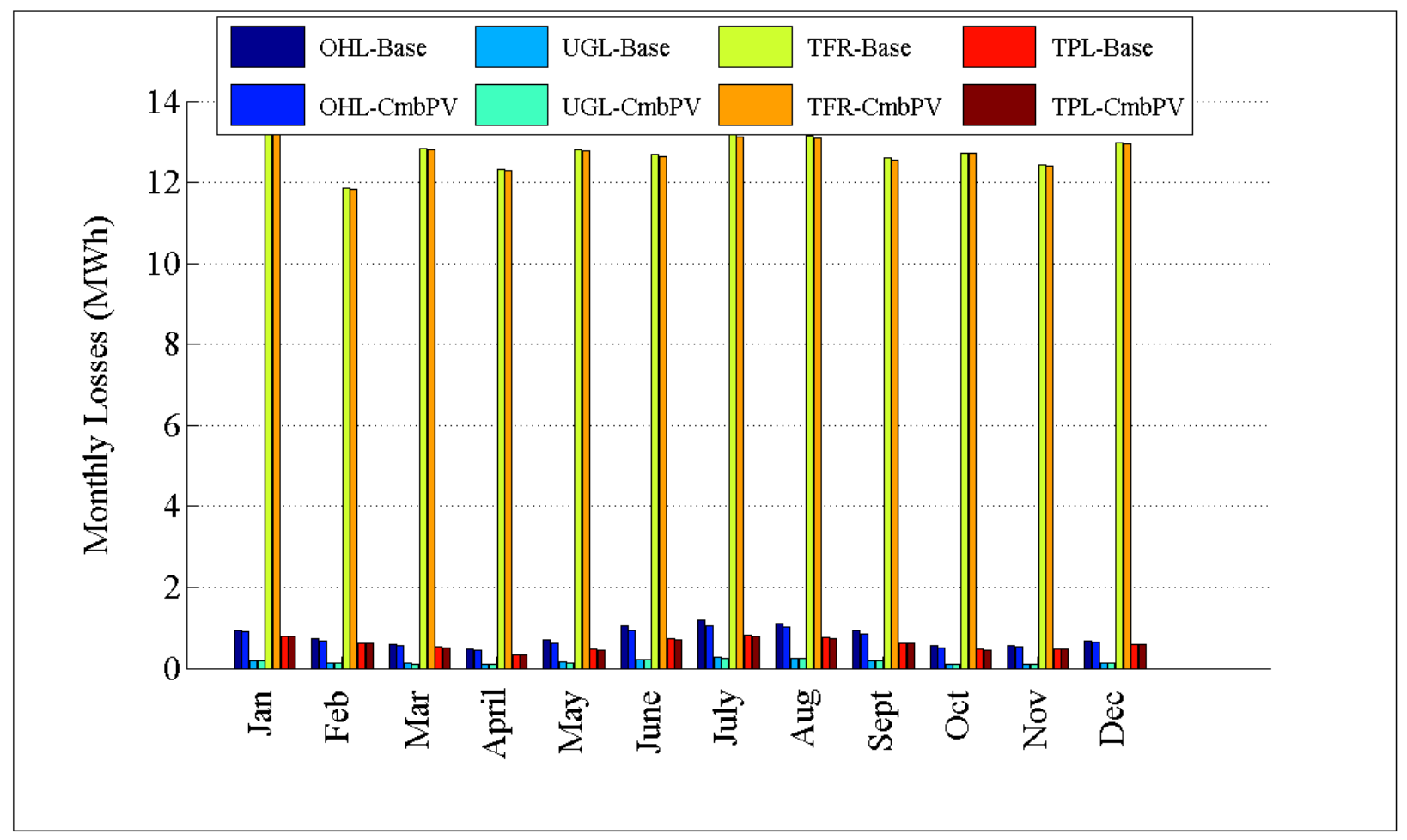

Figure D.296: Comparison of losses by month for R4-12.47-2

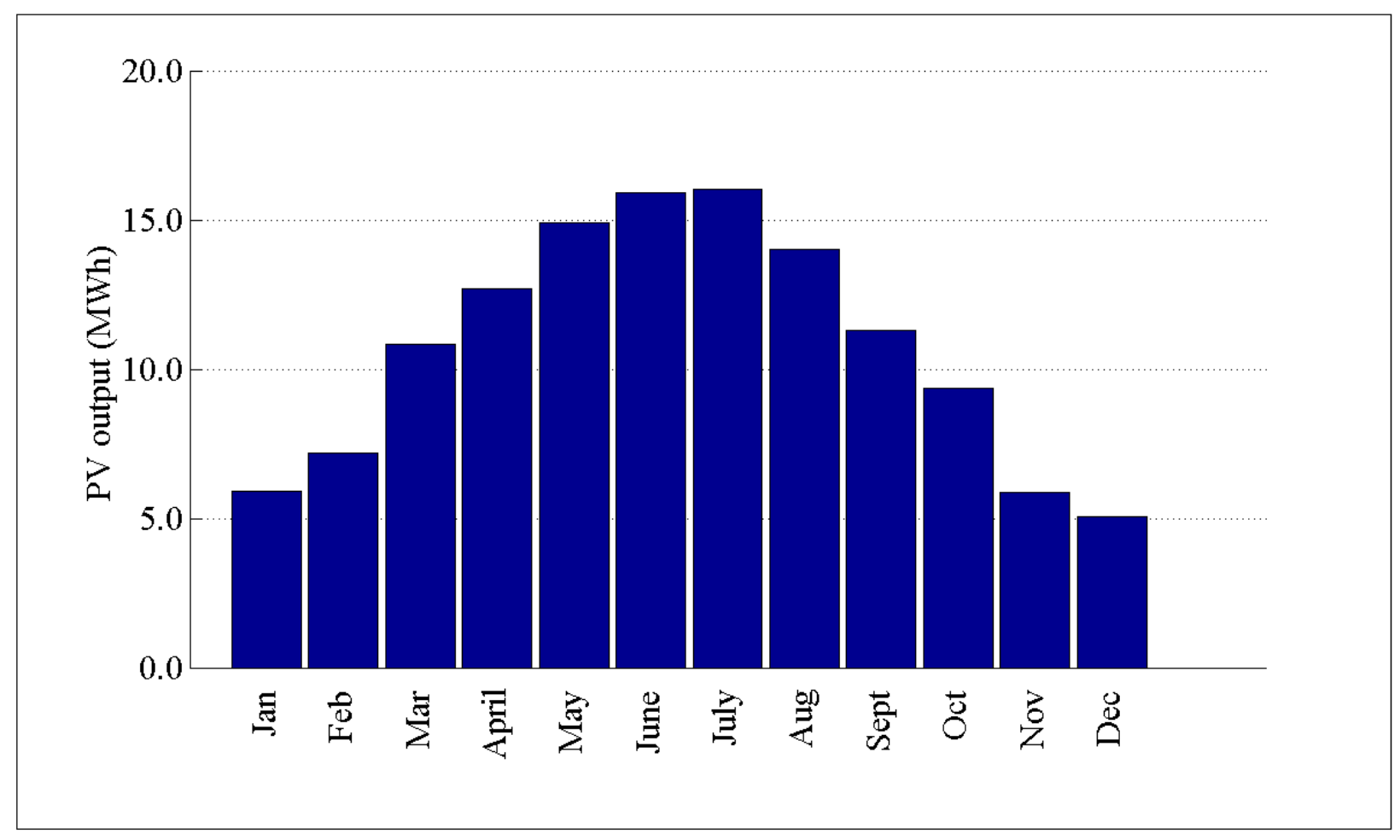

Figure D.297: PV output by month for R4-12.47-2 


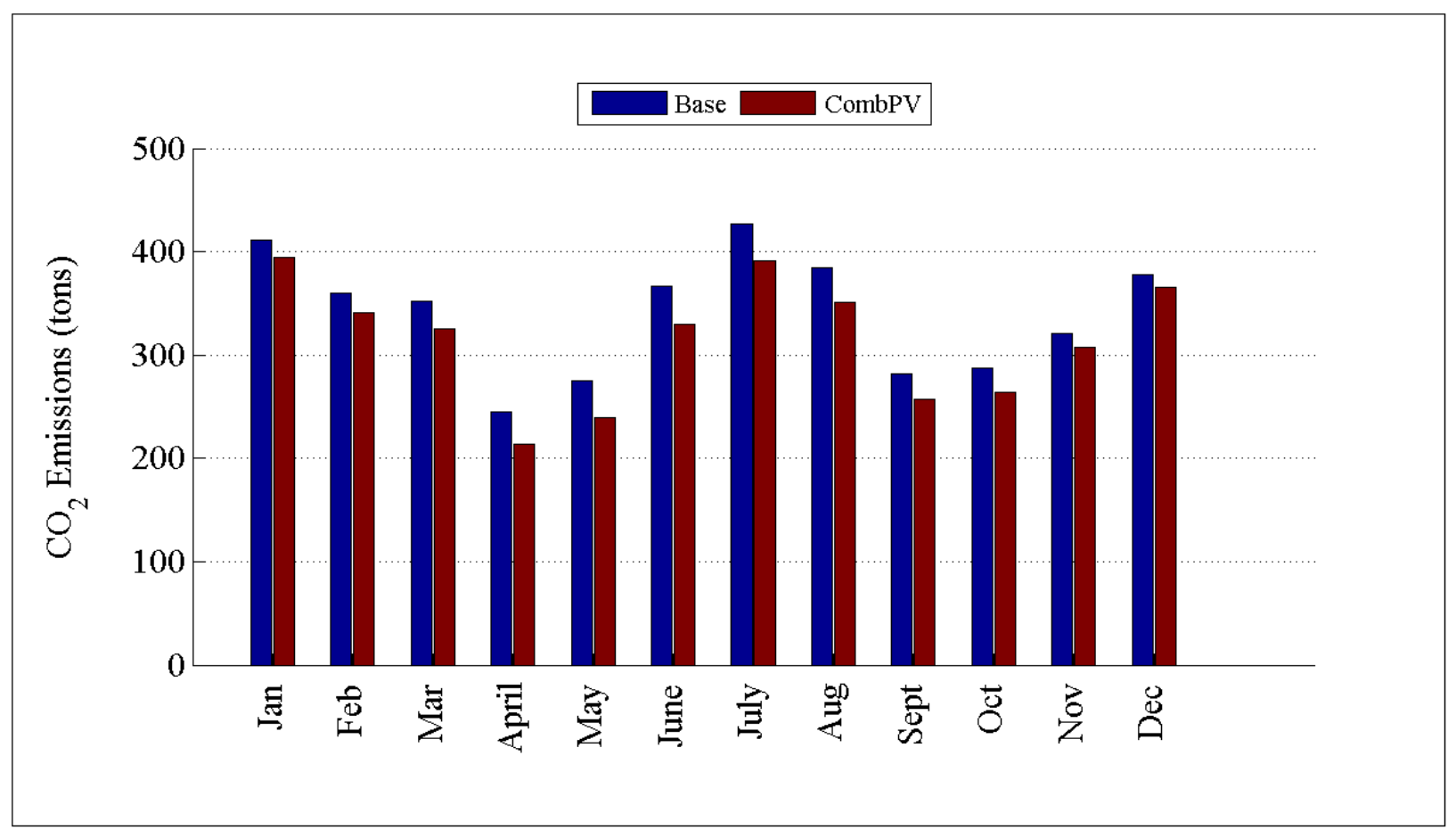

Figure D.298: Comparison of $\mathrm{CO}_{2}$ emissions by month for R4-12.47-2

\section{D.3.14 Detailed Combined PV Plots for R4-25.00-1}

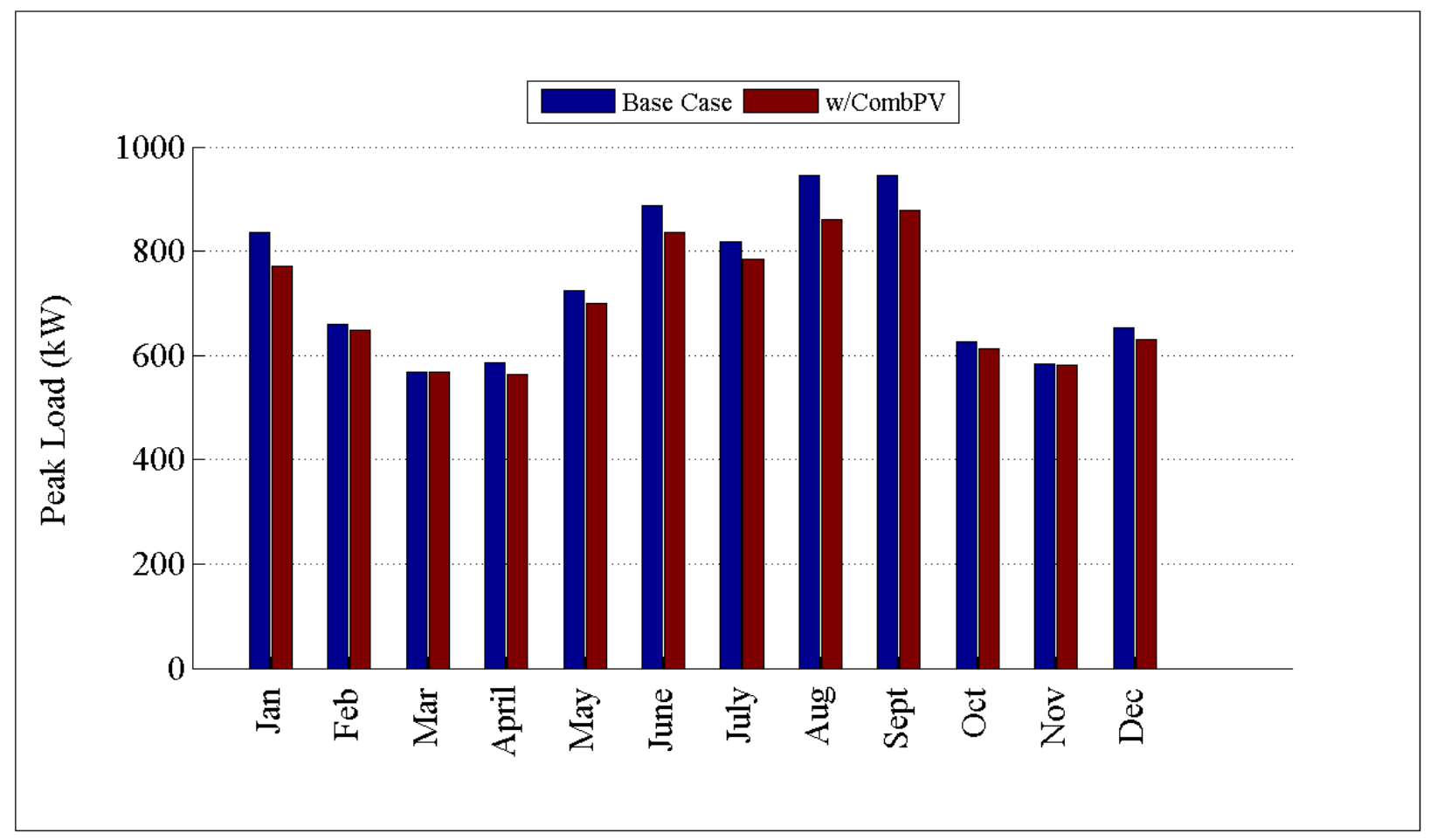

Figure D.299: Comparison of peak loadby month for R4-25.00-1 


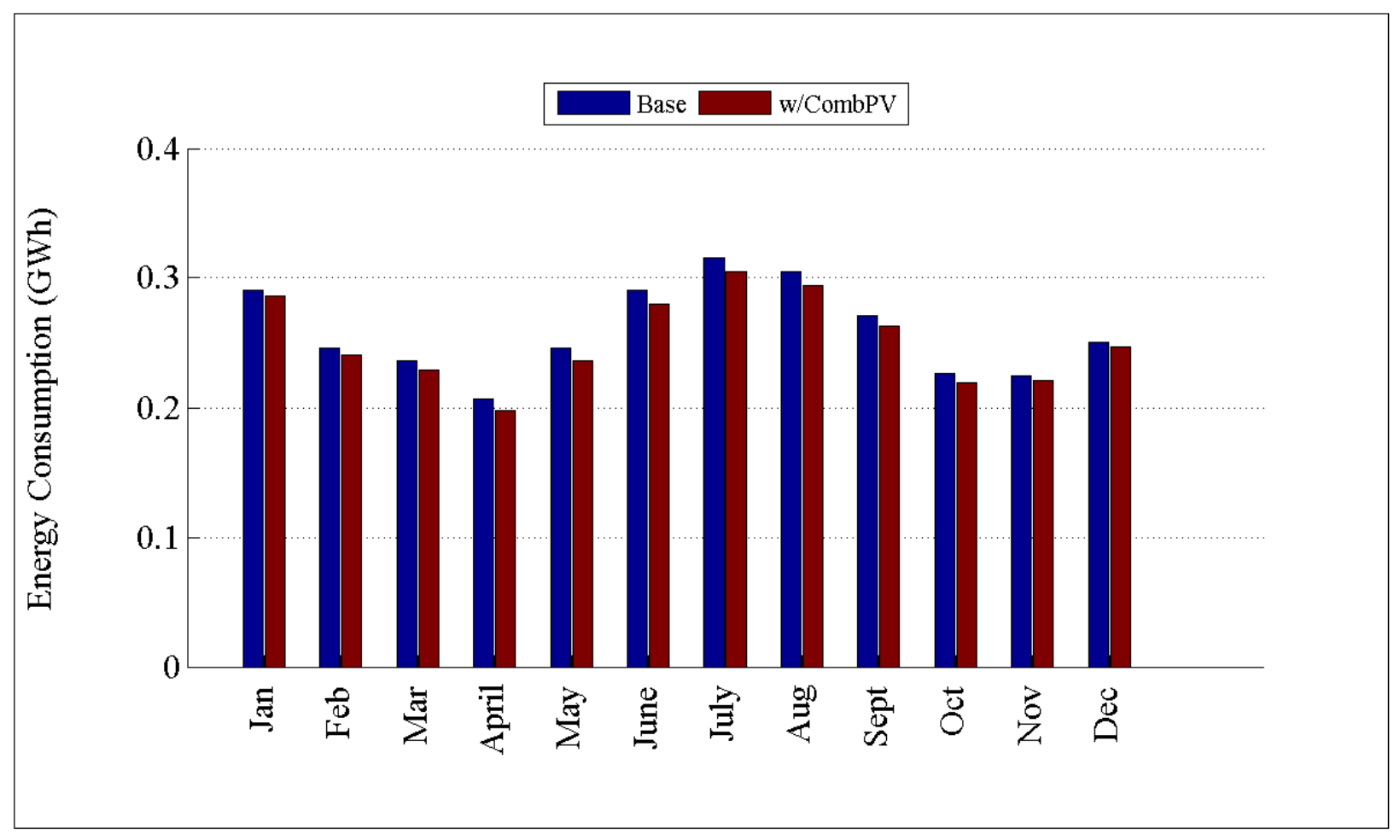

Figure D.300: Comparison of energy consumption by month for R4-25.00-1

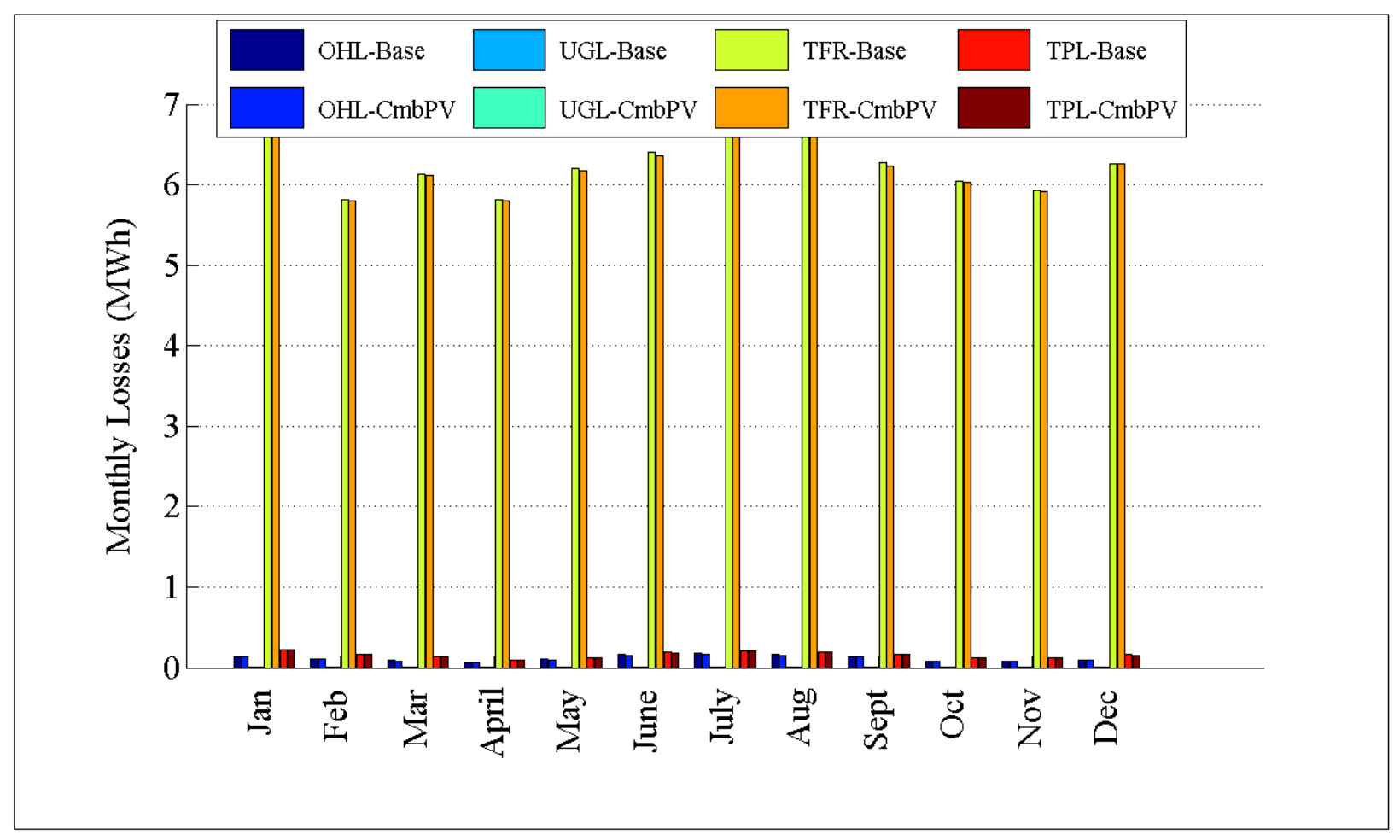

Figure D.301: Comparison of losses by month for R4-25.00-1 


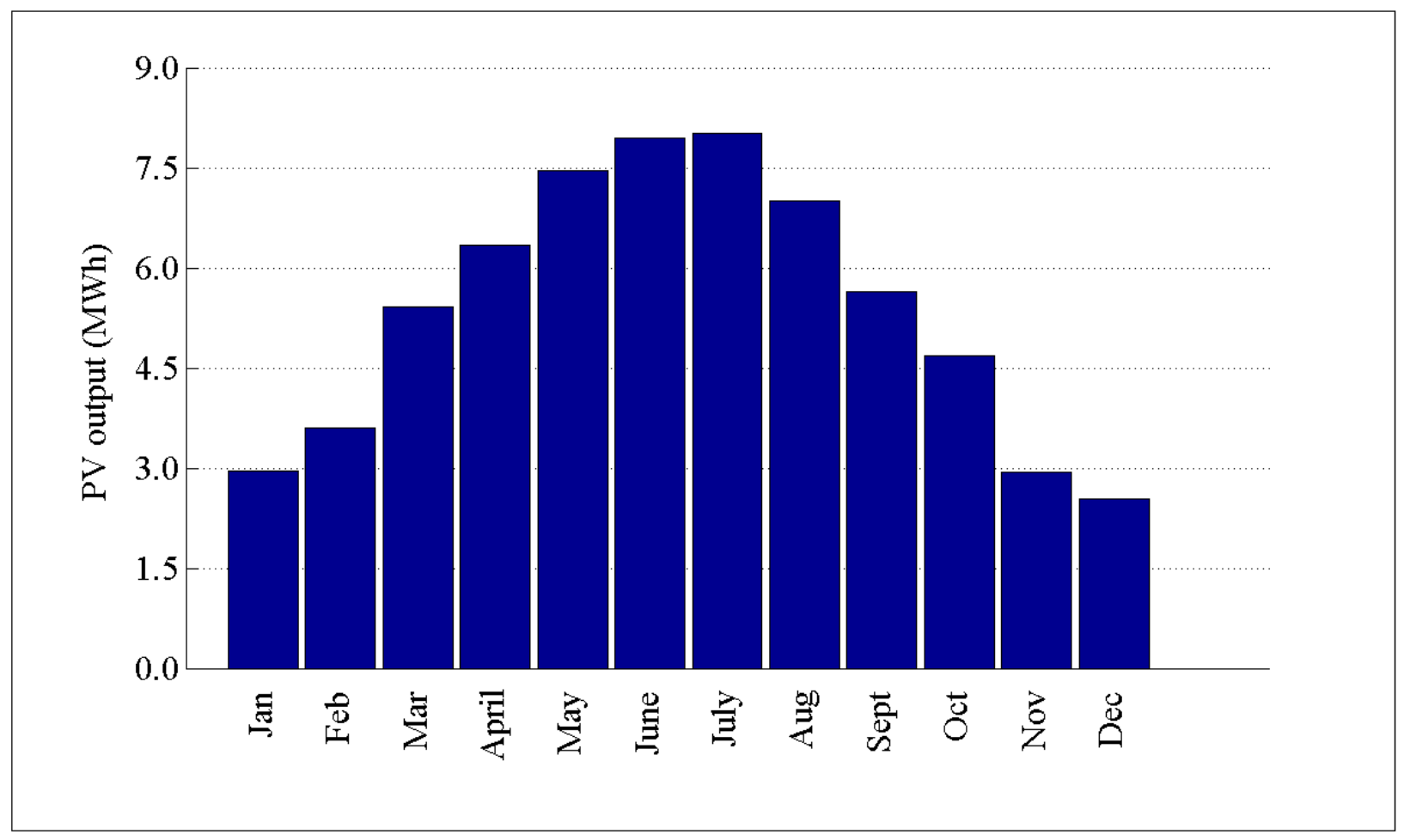

Figure D.302: PV output by month for R4-25.00-1

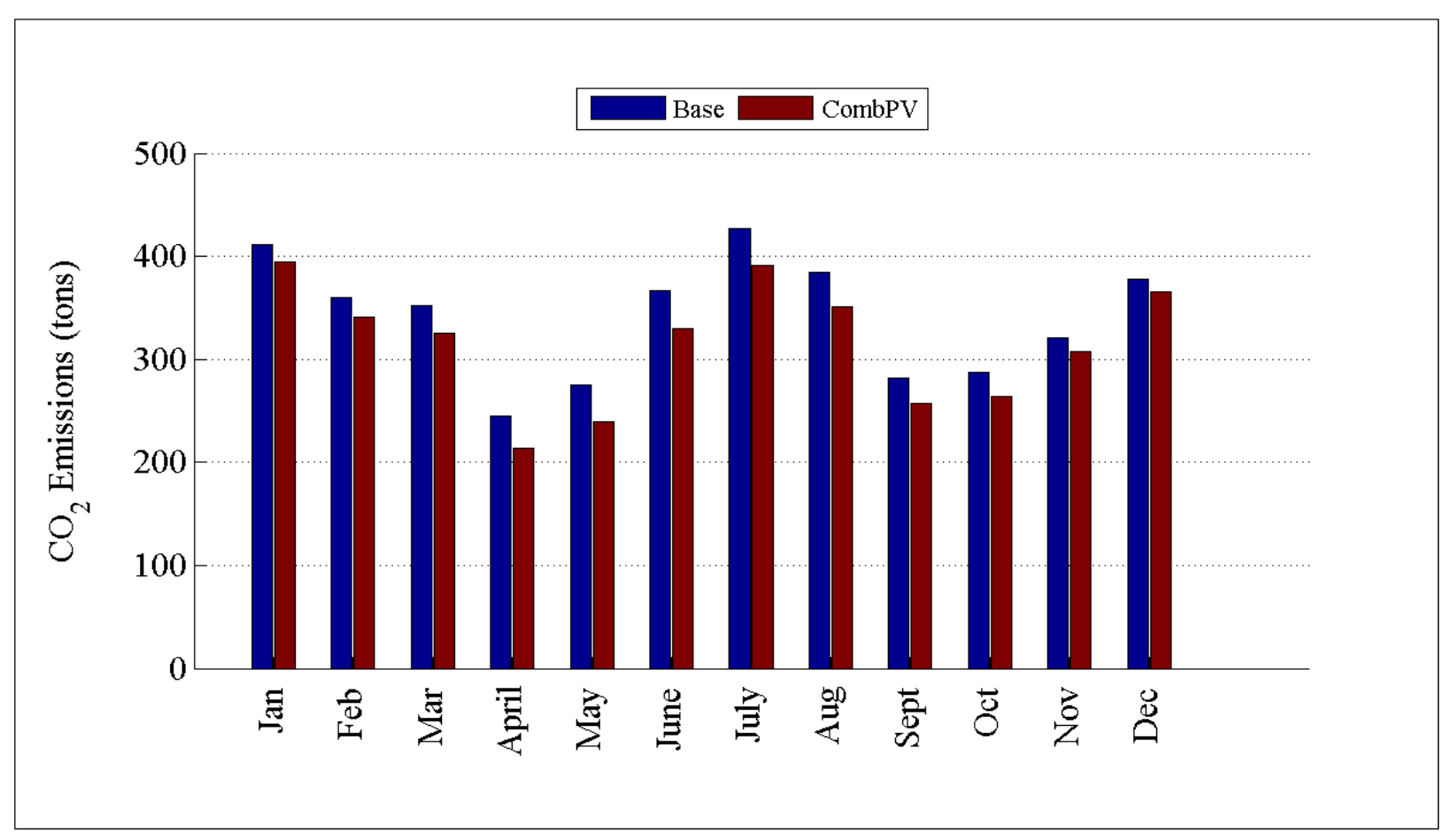

Figure D.303: Comparison of $\mathrm{CO}_{2}$ emissions by month for R4-25.00-1 
D.3.15 Detailed Combined PV Plots for R5-12.47-1

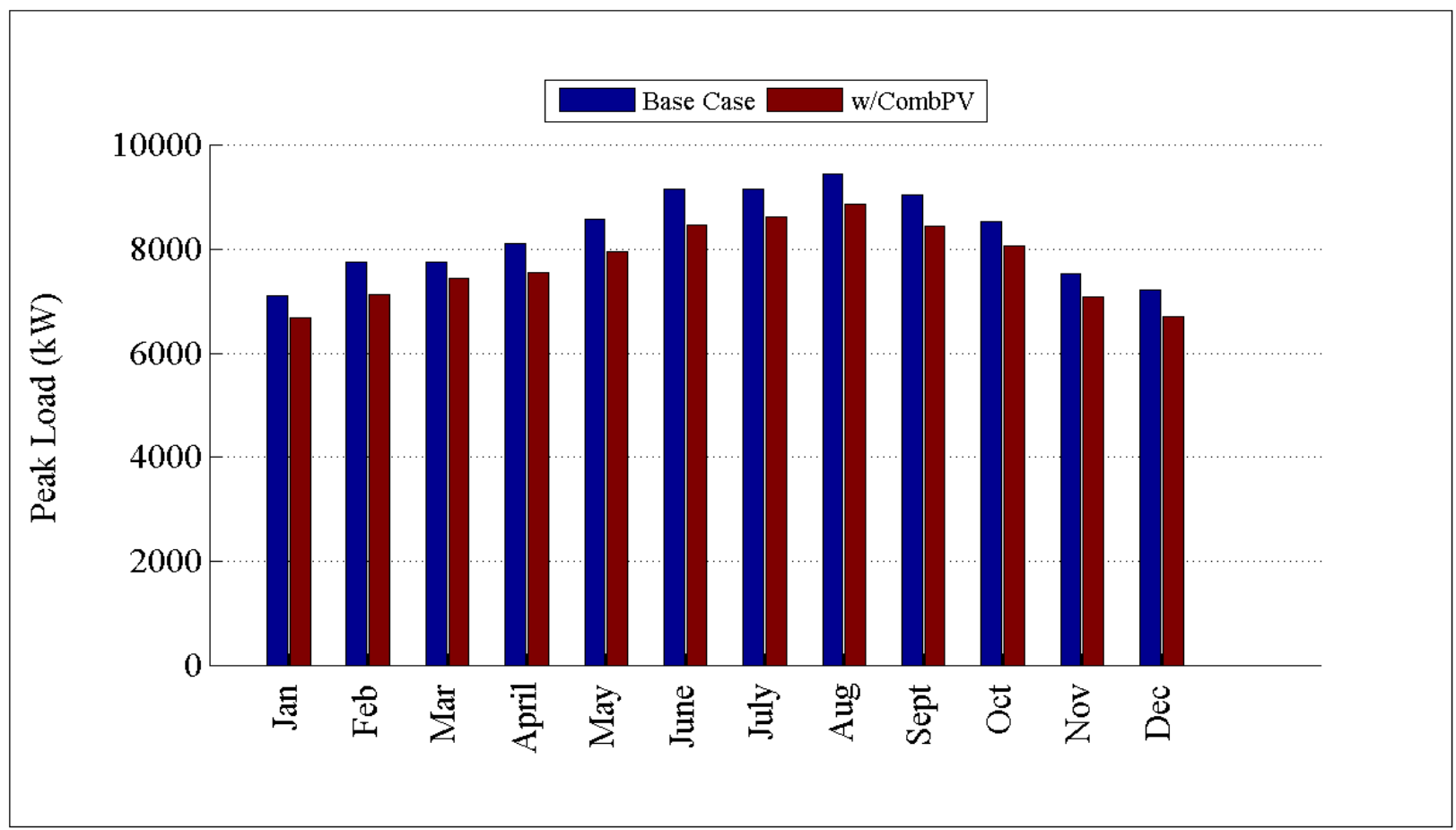

Figure D.304: Comparison of peak load by month for R5-12.47-1

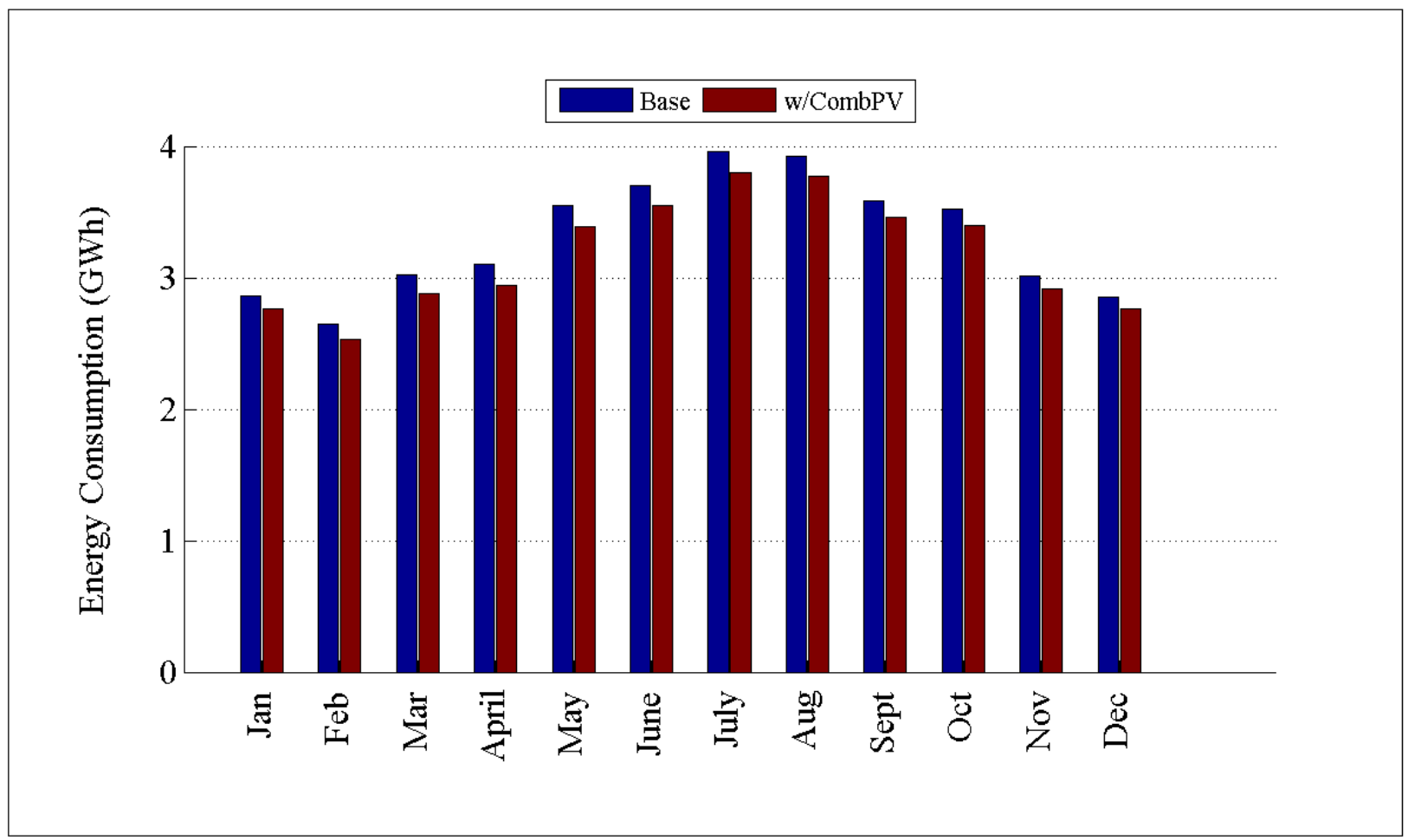

Figure D.305: Comparison of energy consumption by month for R5-12.47-1 


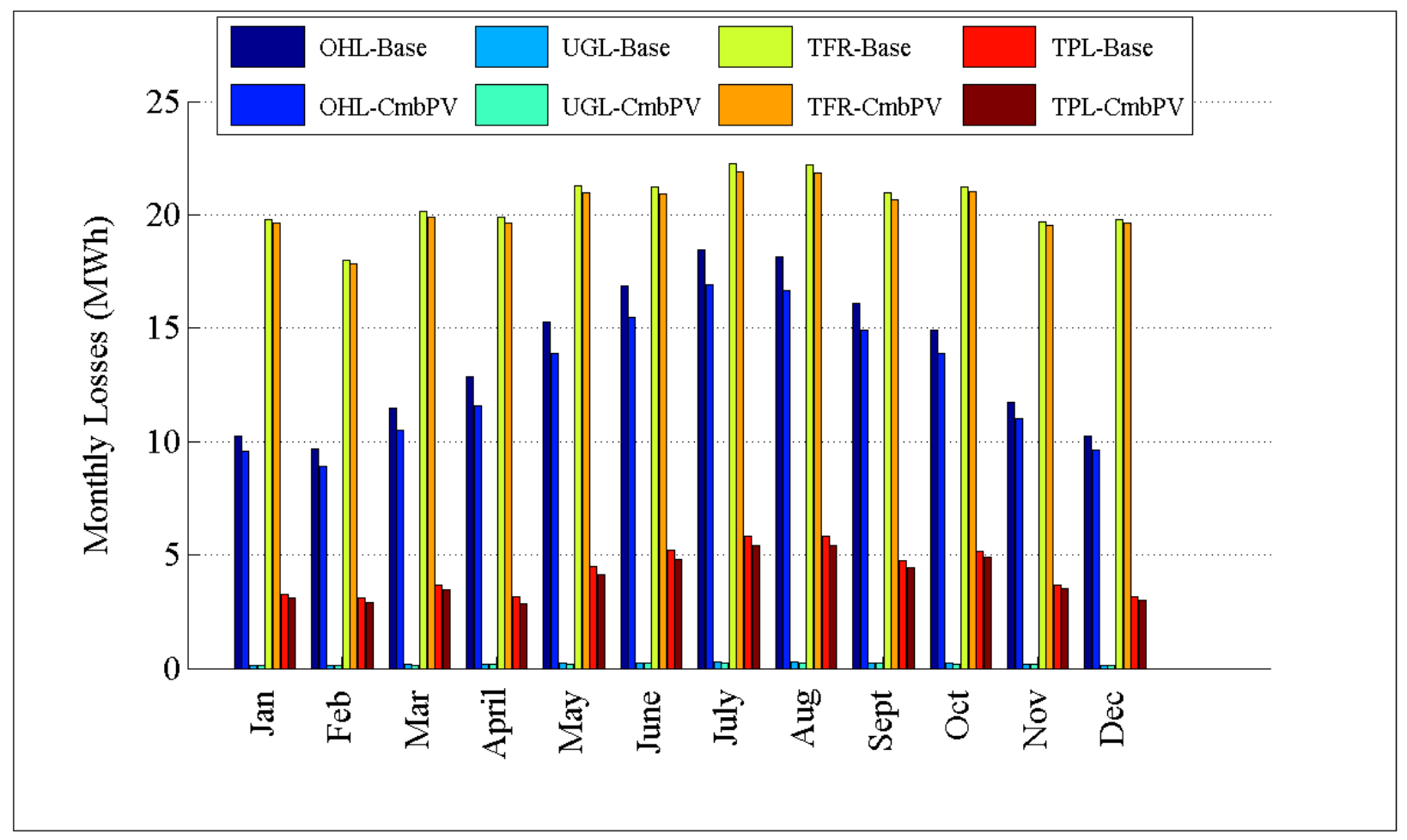

Figure D.306: Comparison of losses by month for R5-12.47-1

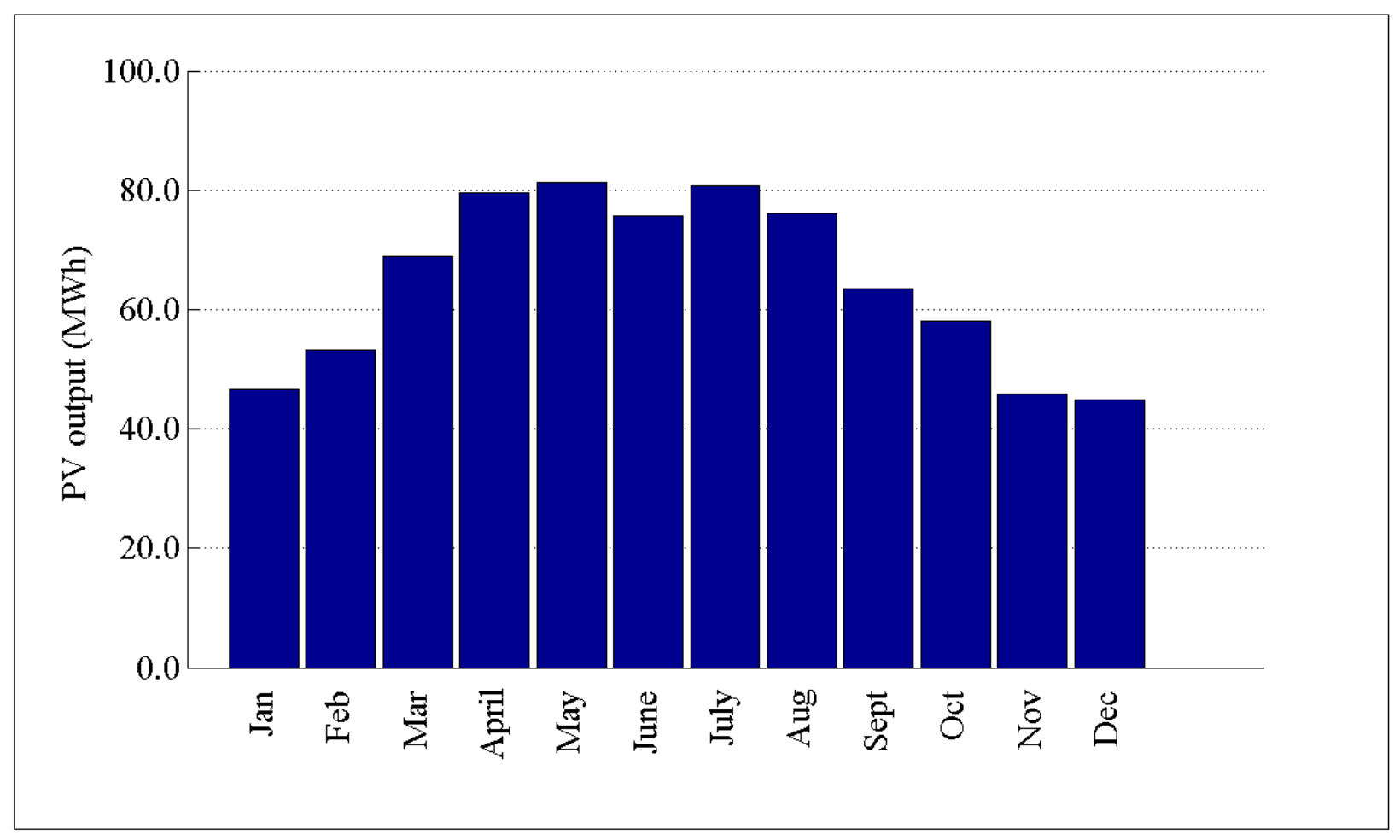

Figure D.307: PV output by month for R5-12.47-1 


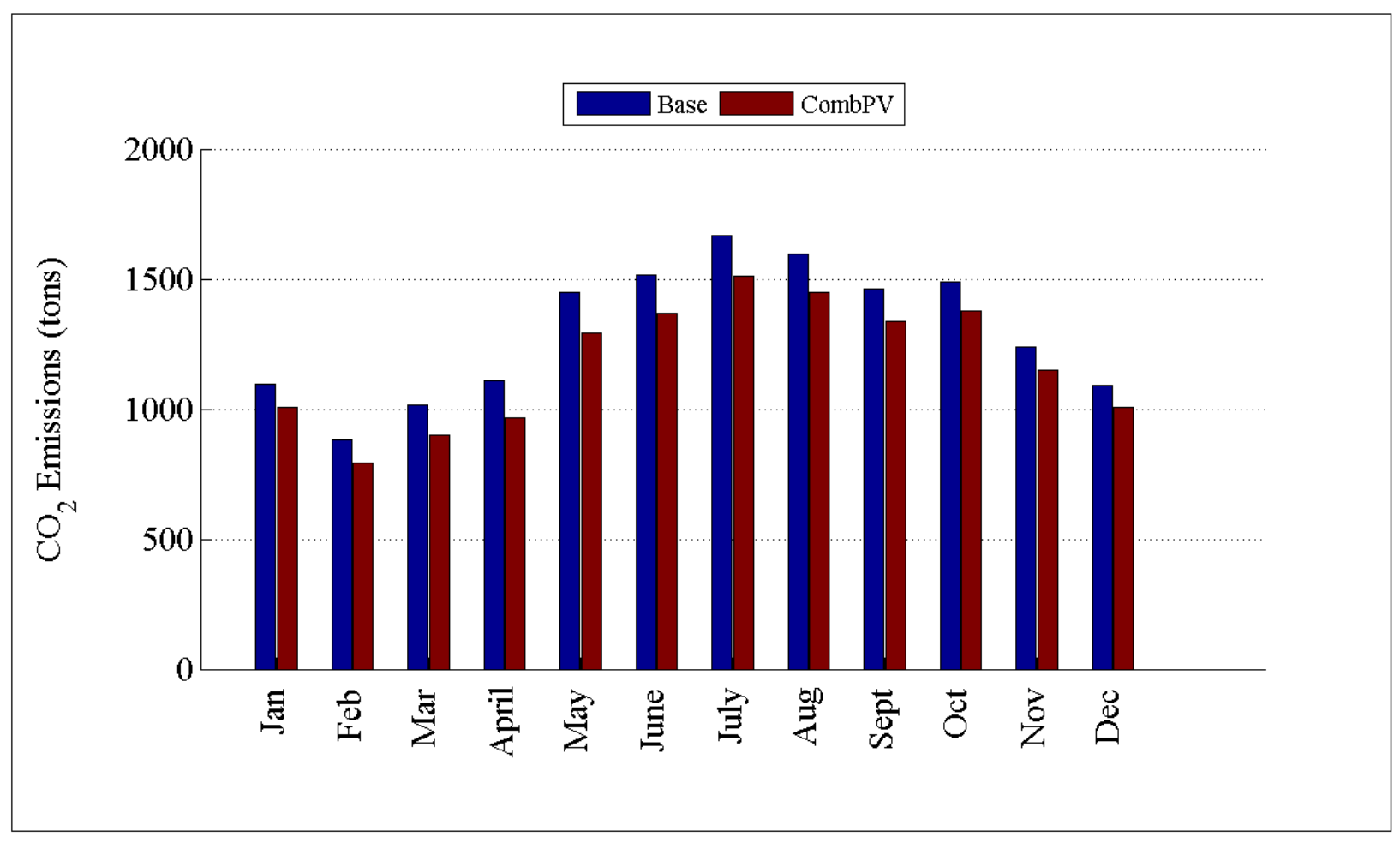

Figure D.308: Comparison of $\mathrm{CO}_{2}$ emissions by month for R5-12.47-1

D.3.16 Detailed Combined PV Plots for R5-12.47-2

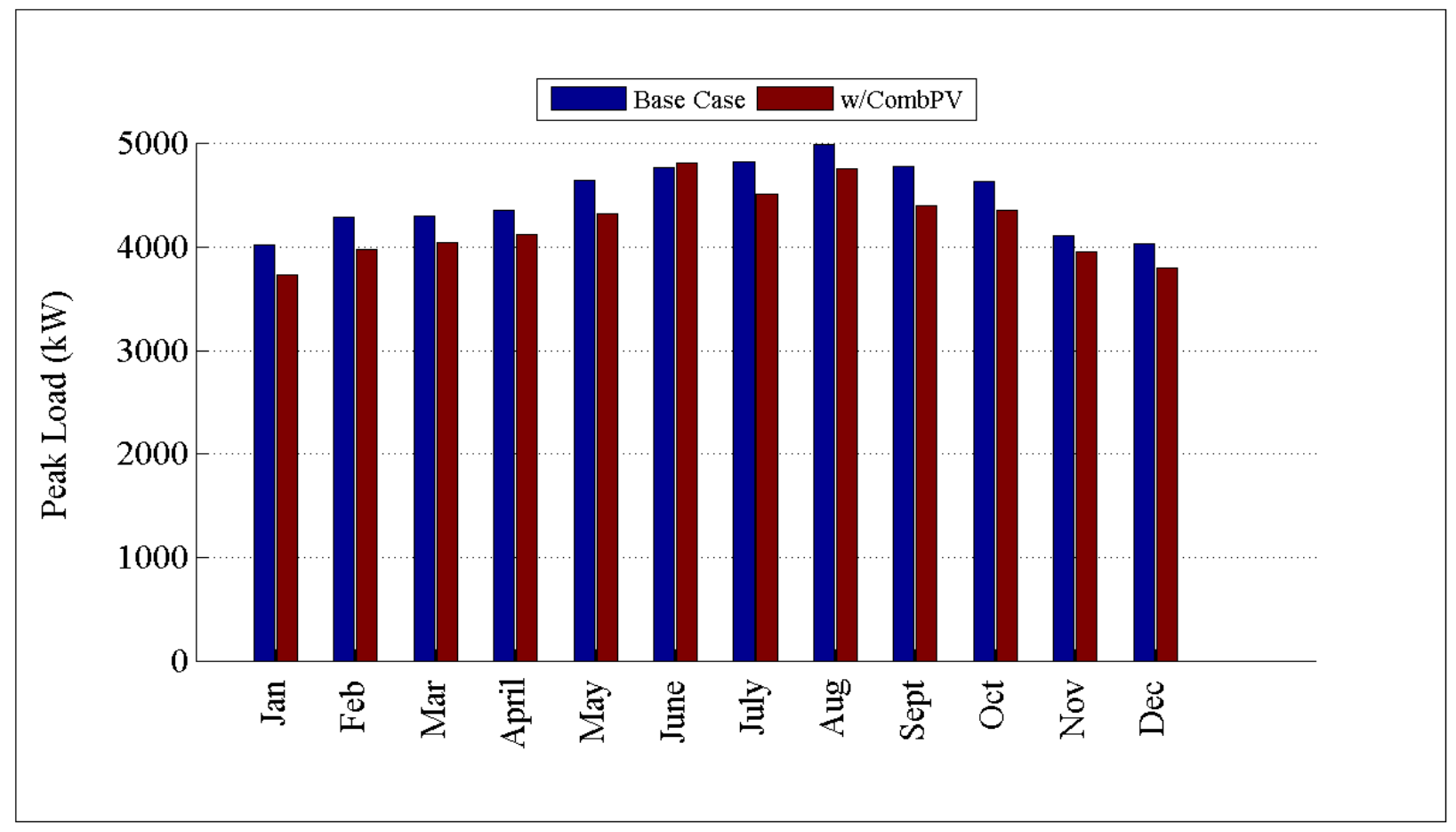

Figure D.309: Comparison of peak load by month for R5-12.47-2 


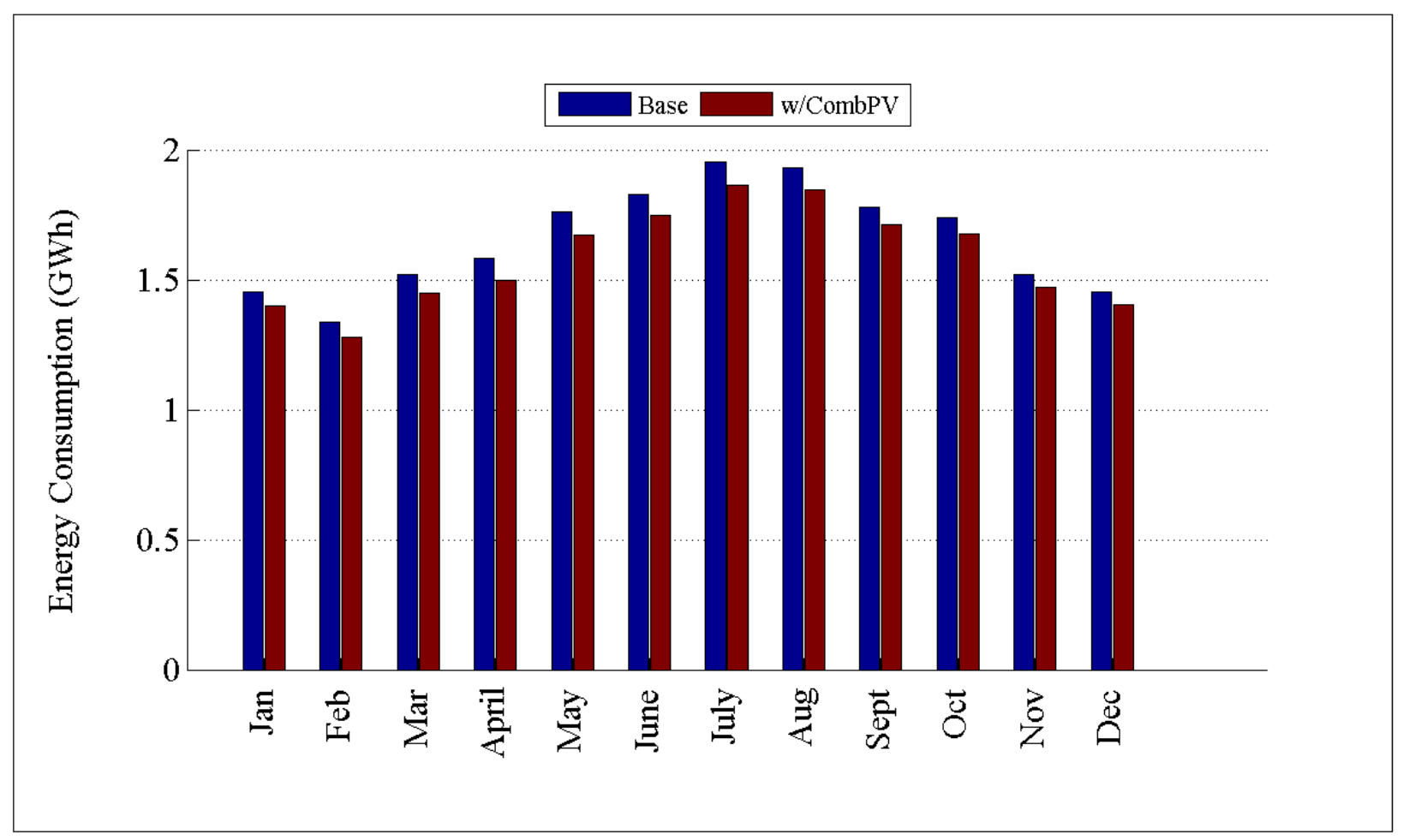

Figure D.310: Comparison of energy consumption by month for R5-12.47-2

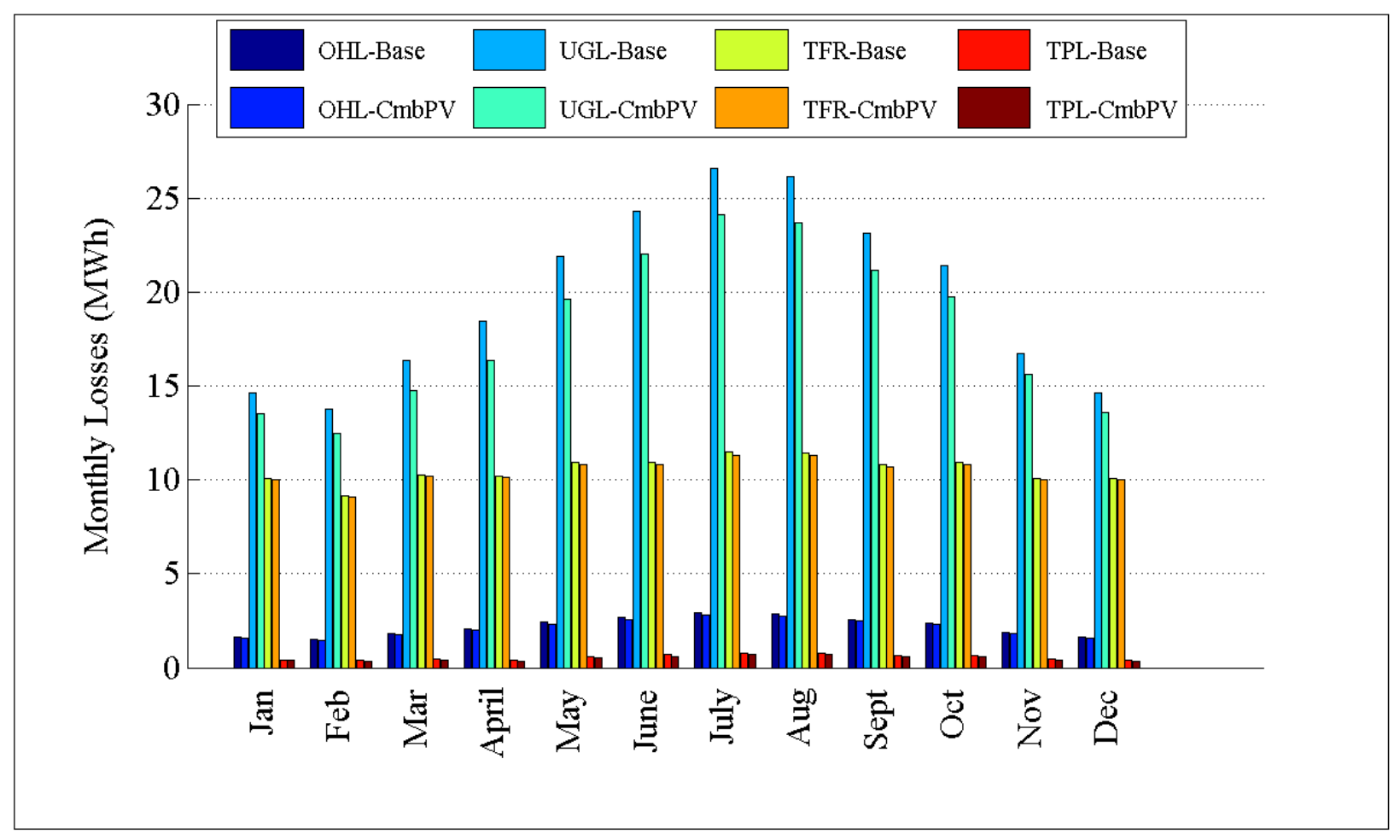

Figure D.311: Comparison of losses by month for R5-12.47-2 


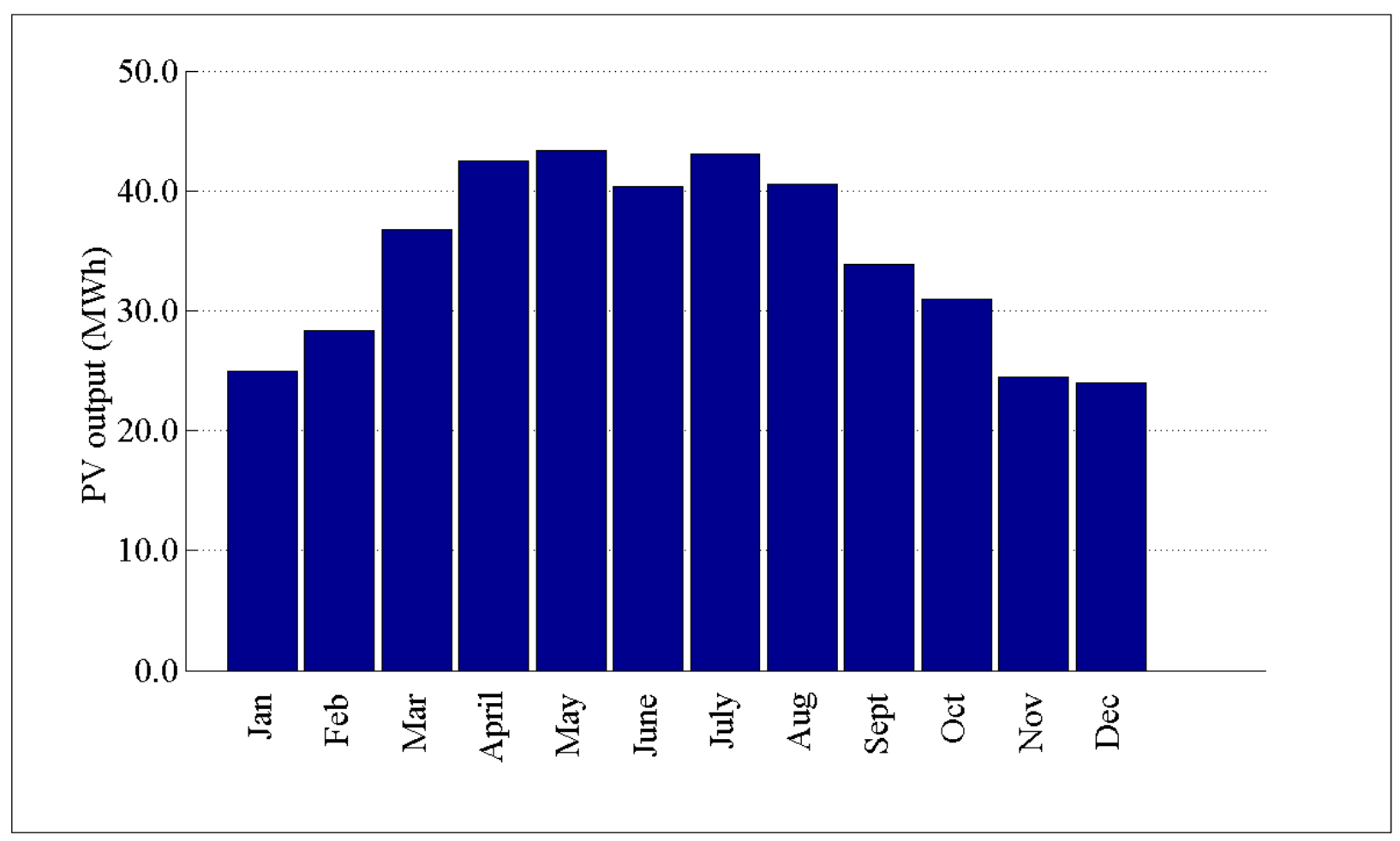

Figure D.312: PV output by month for R5-12.47-2

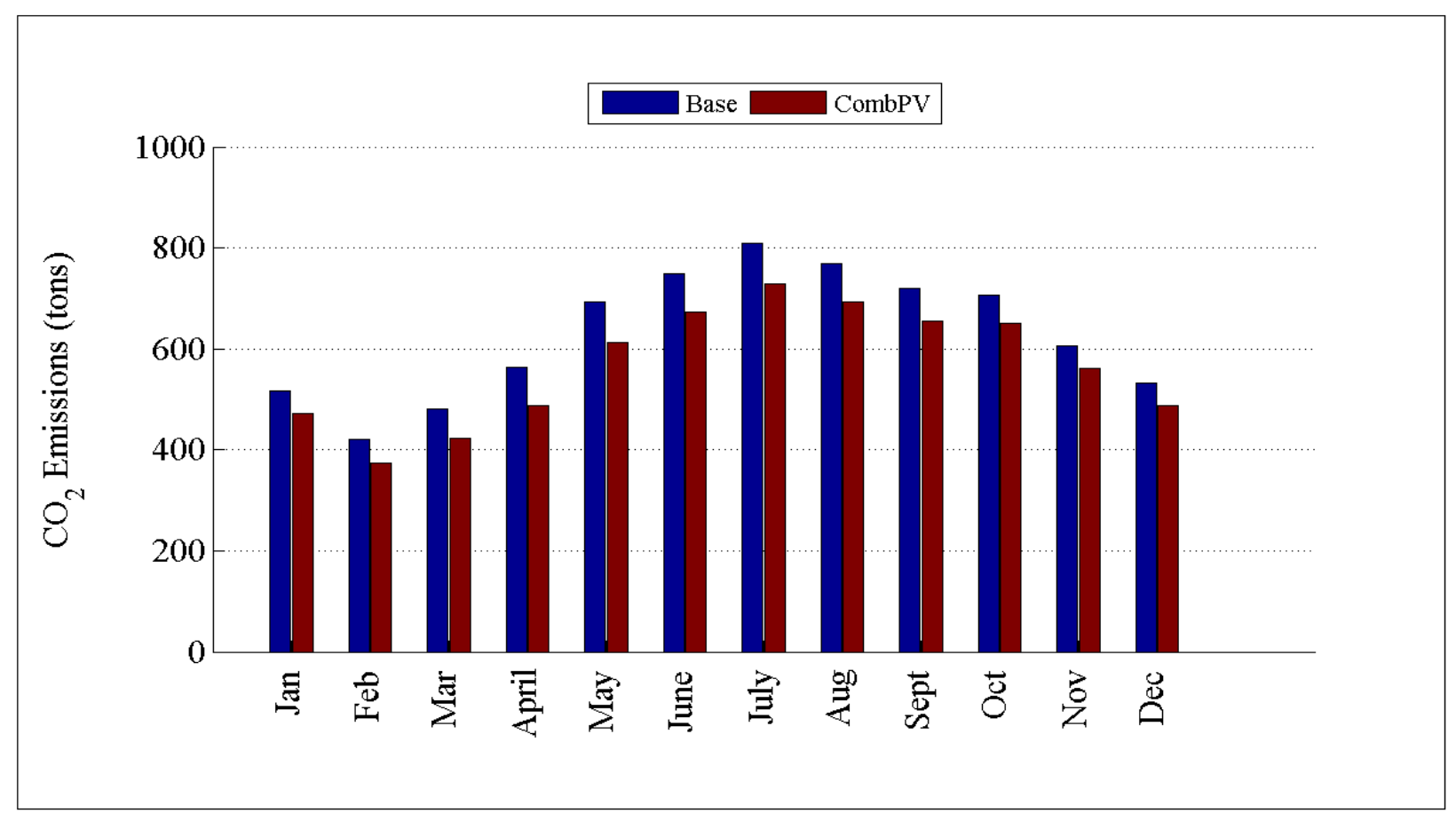

Figure D.313: Comparison of $\mathrm{CO}_{2}$ emissions by month for R5-12.47-2 
D.3.17 Detailed Combined PV Plots for R5-12.47-3

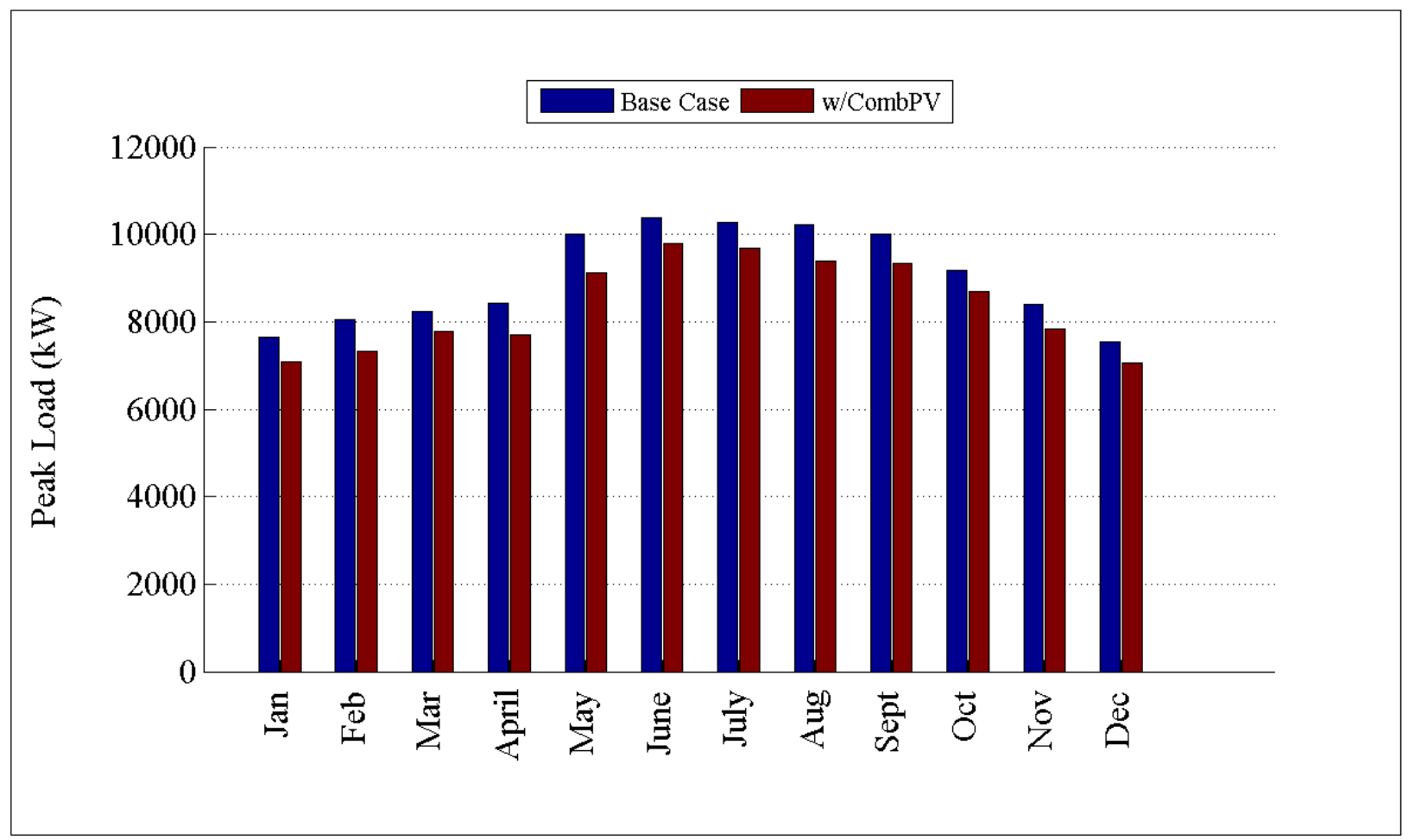

Figure D.314: Comparison of peak load by month for R5-12.47-3

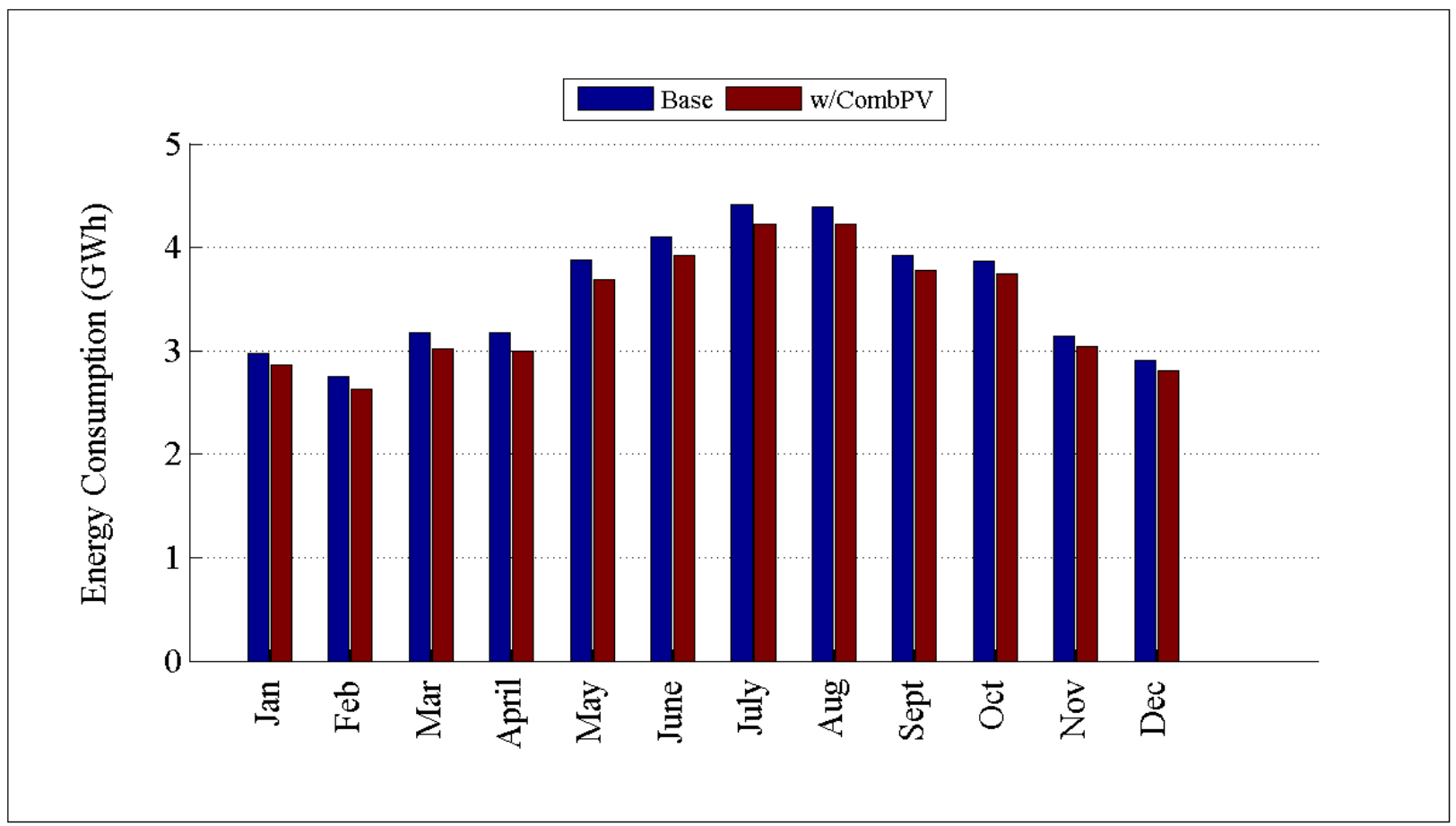

Figure D.315: Comparison of energy consumption by month for R5-12.47-3 


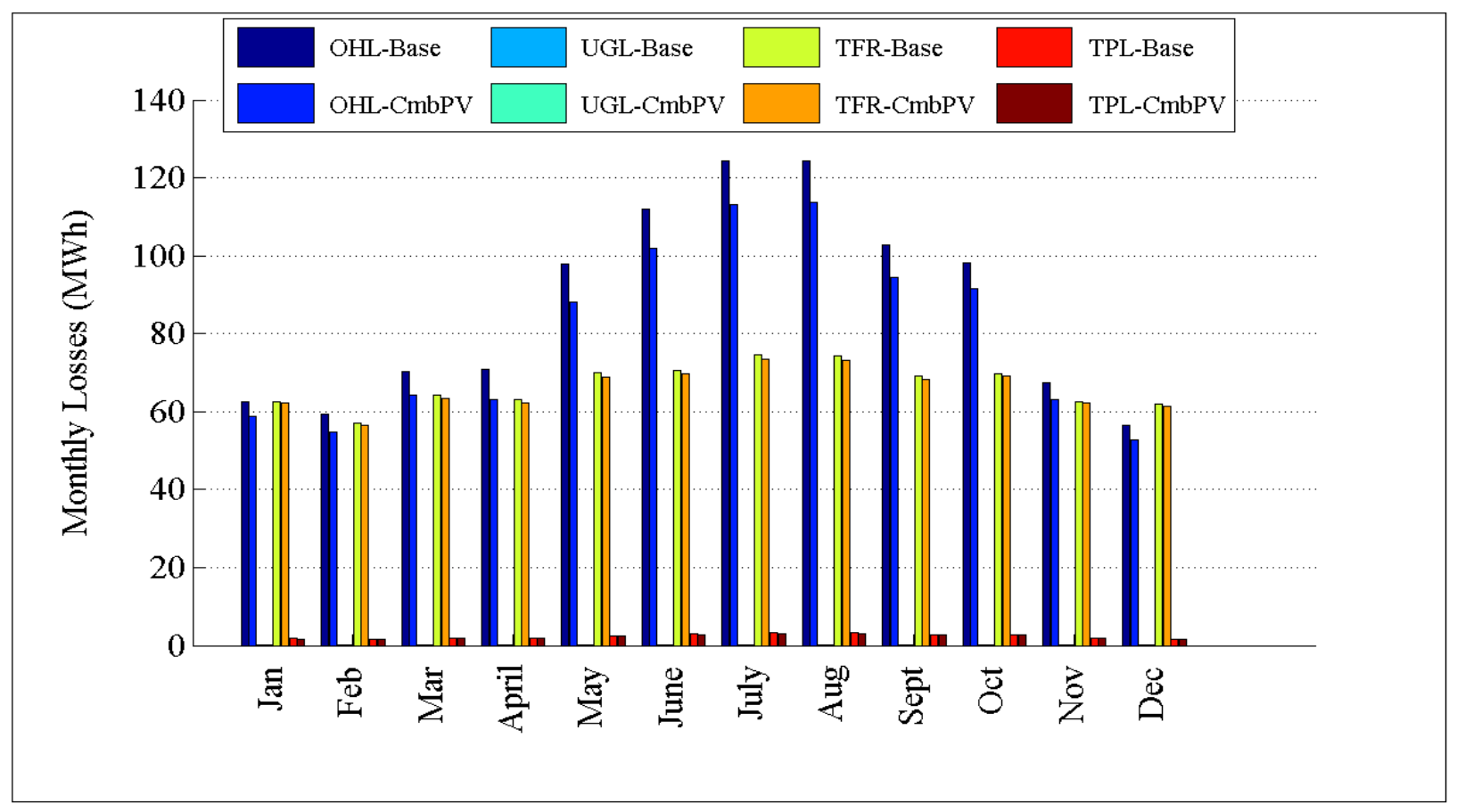

Figure D.316: Comparison of losses by month for R5-12.47-3

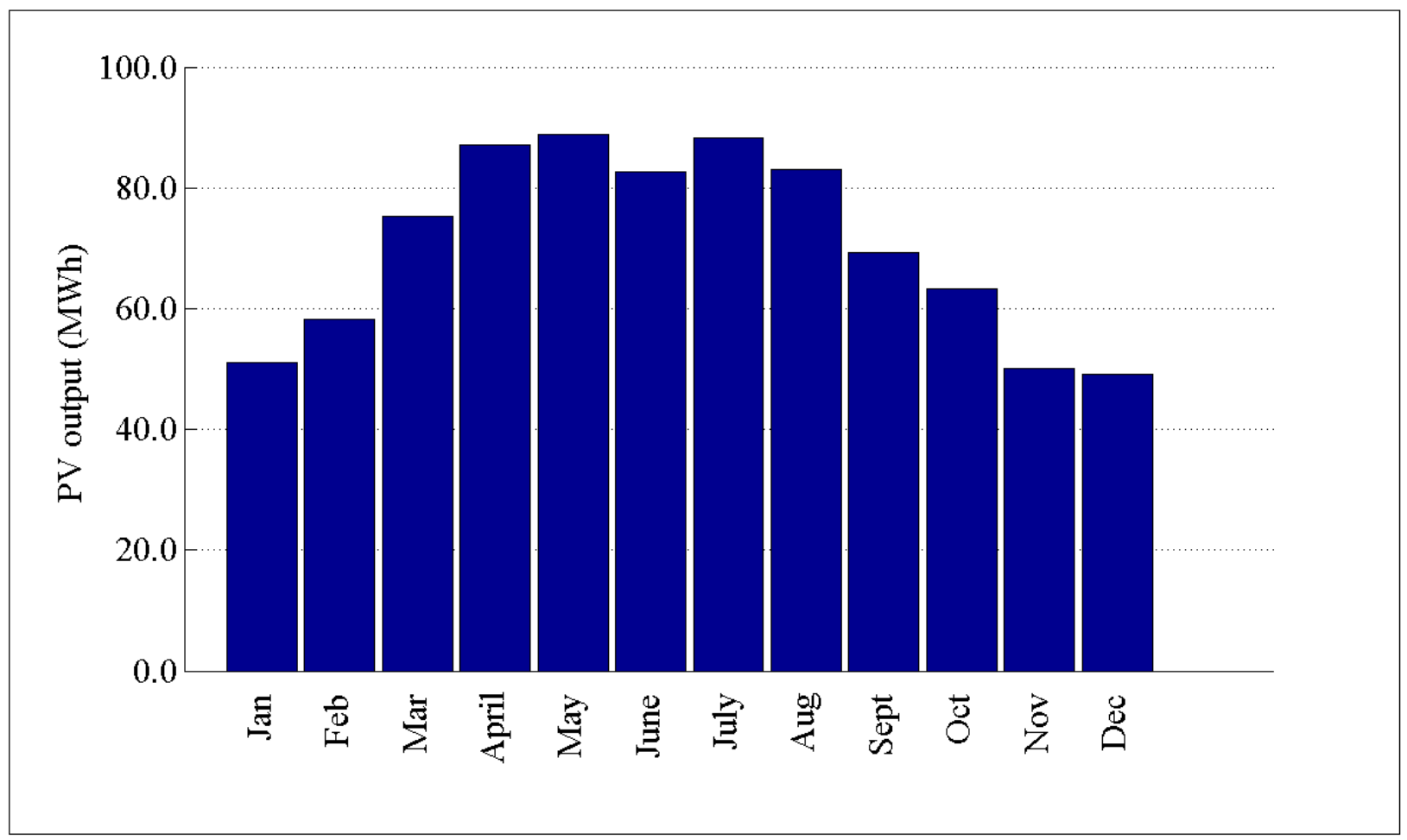

Figure D.317: PV output by month for R5-12.47-3 


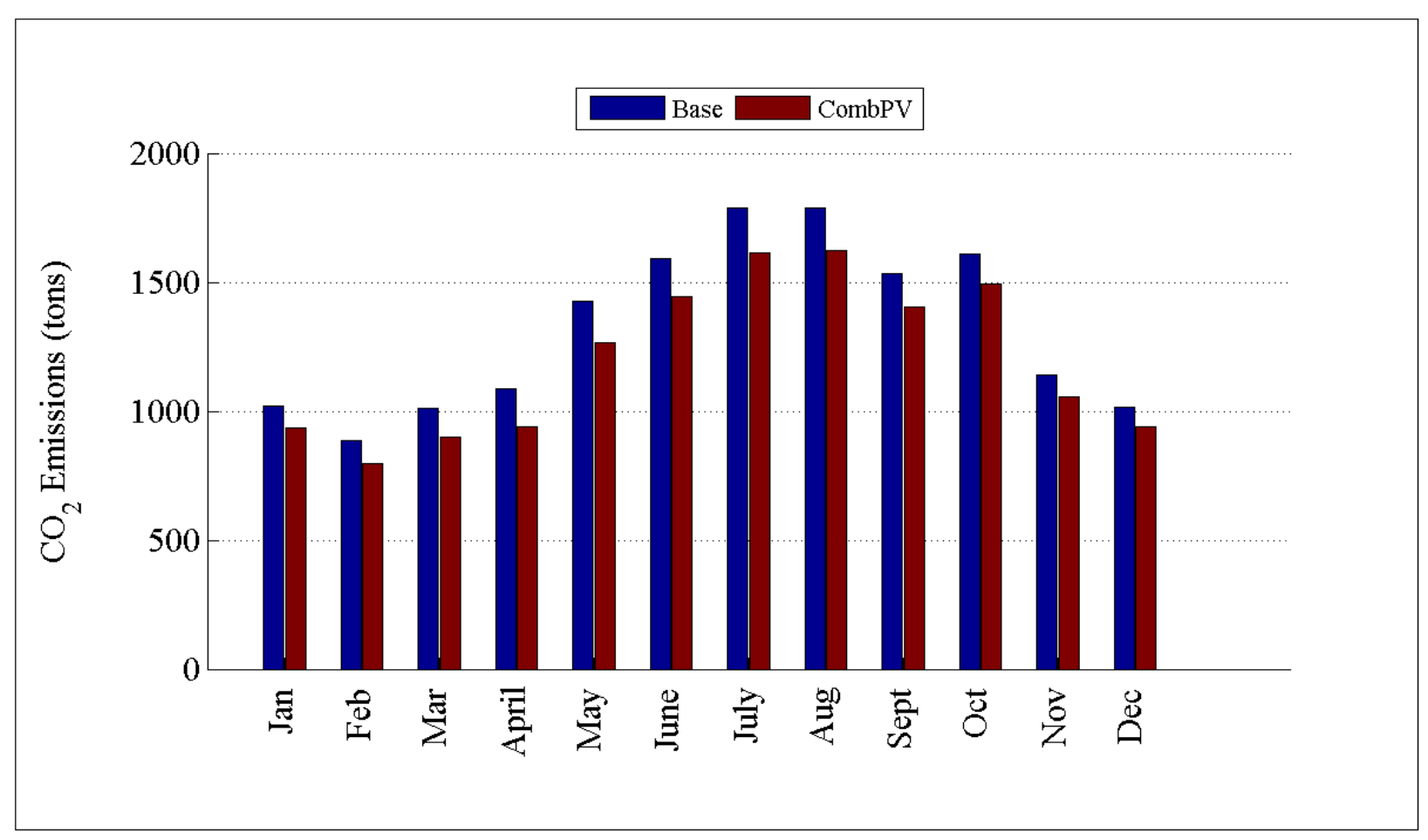

Figure D.318: Comparison of $\mathrm{CO}_{2}$ emissions by month for R5-12.47-3

D.3.18 Detailed Combined PV Plots for R5-12.47-4

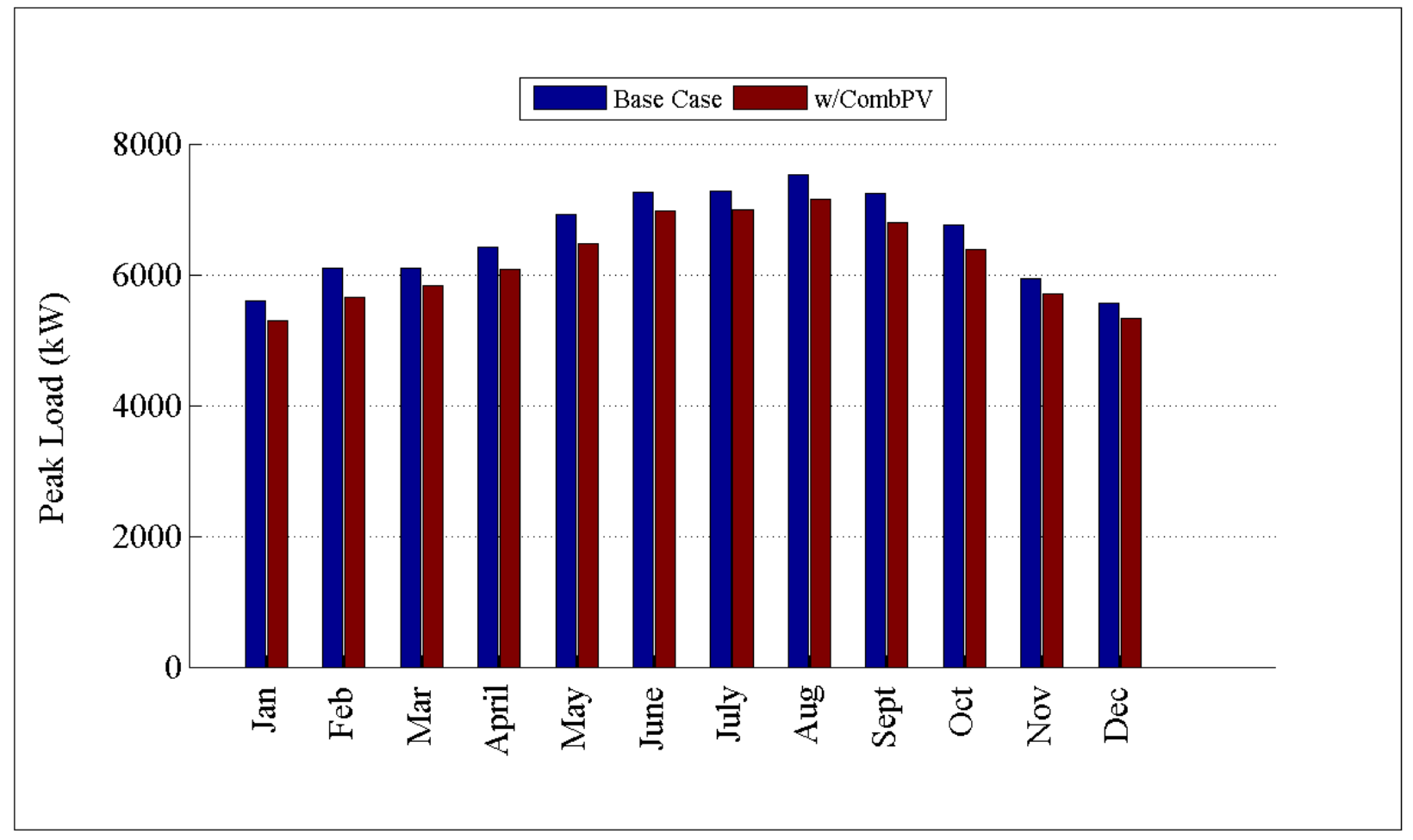

Figure D.319: Comparison of peak loadby month for R5-12.47-4 


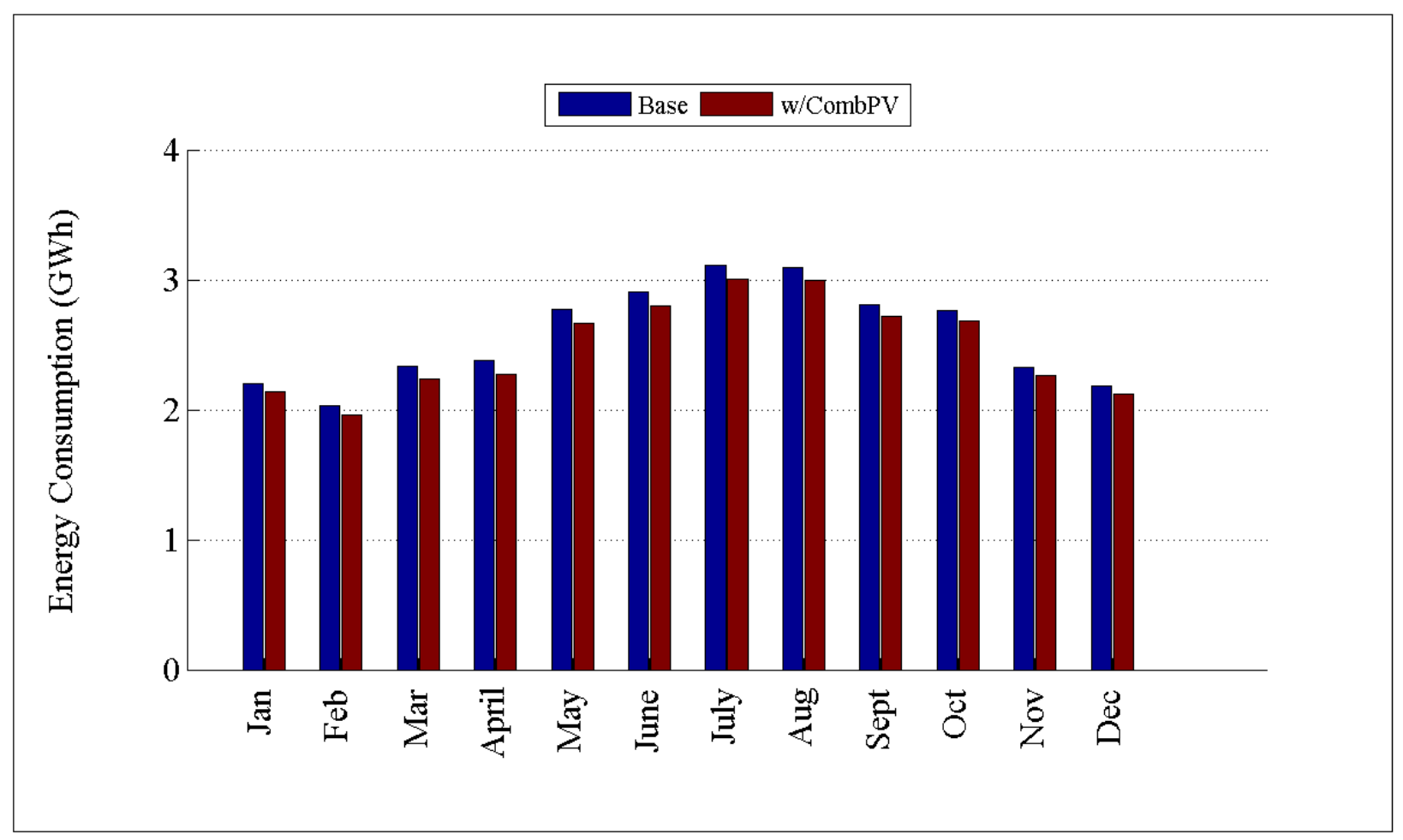

Figure D.320: Comparison of energy consumption by month for R5-12.47-4

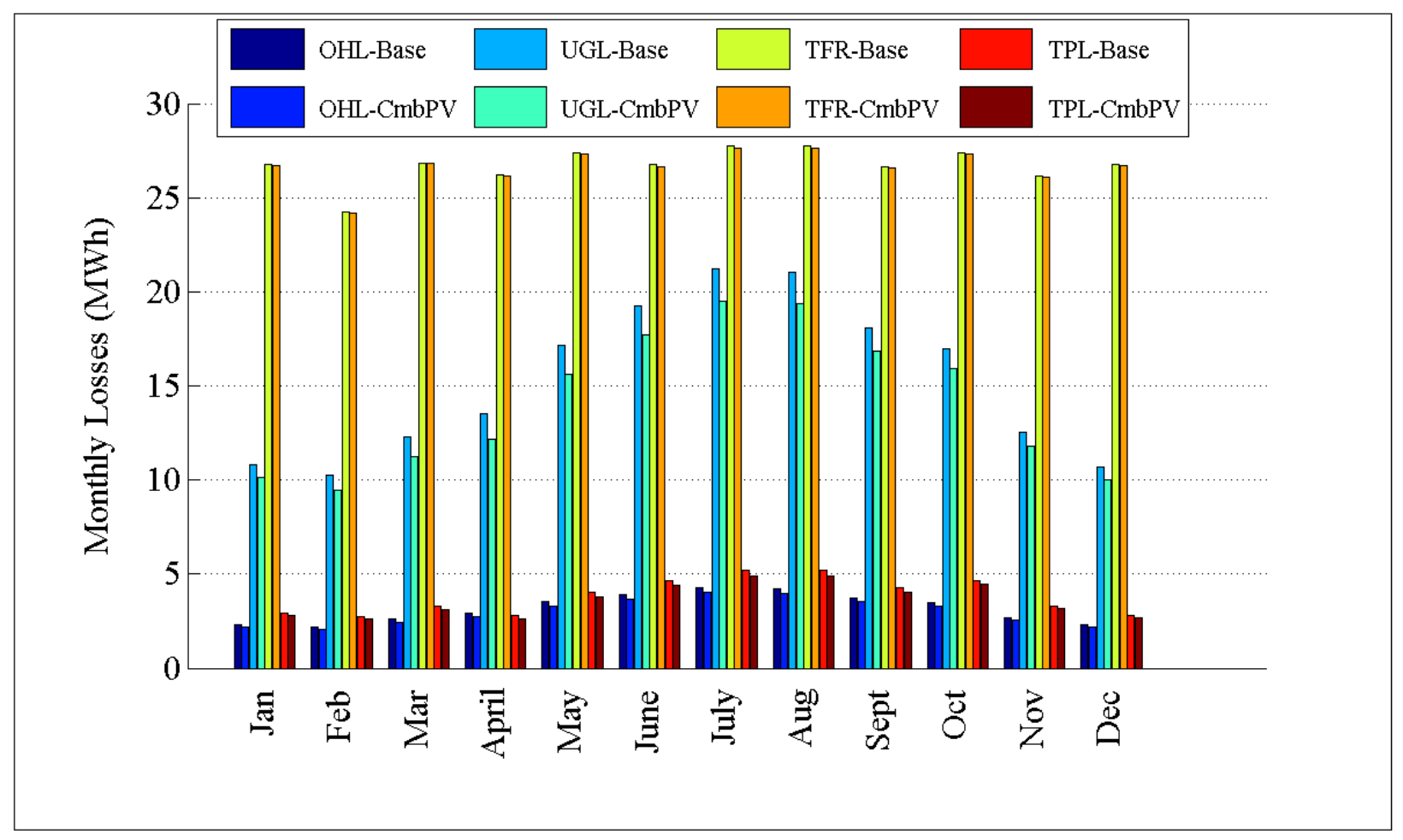

Figure D.321: Comparison of losses by month for R5-12.47-4 


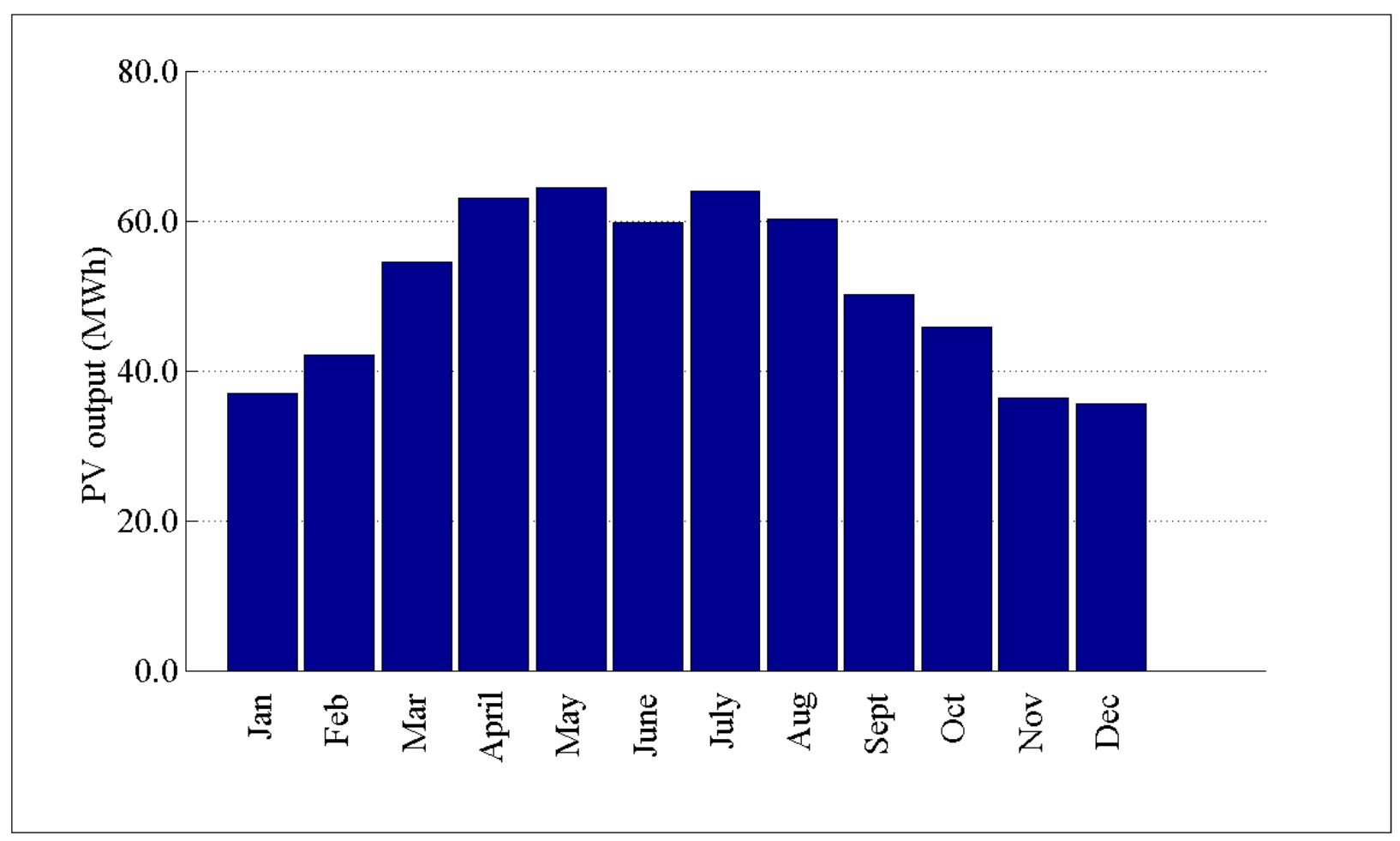

Figure D.322: PV output by month for R5-12.47-4

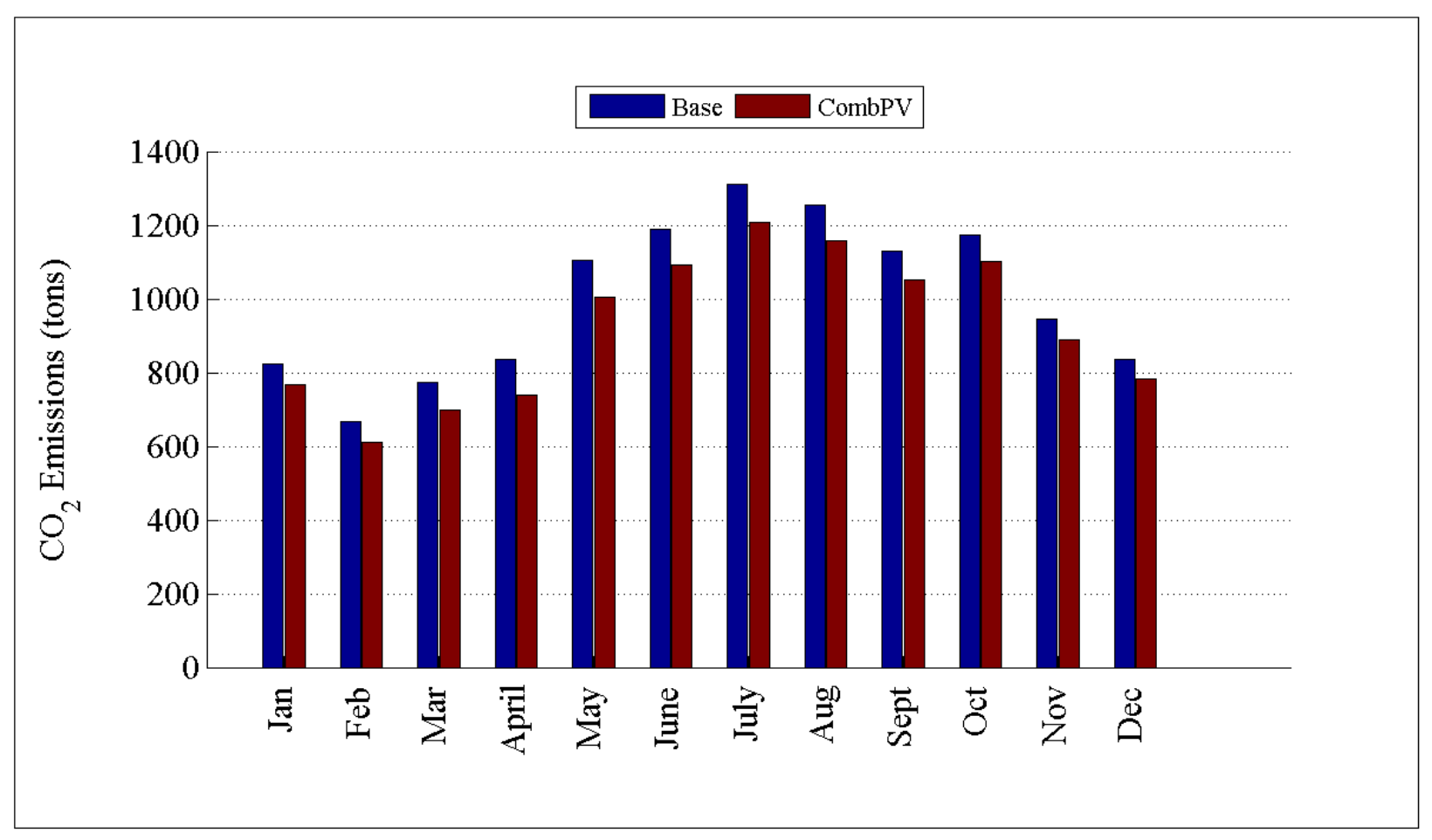

Figure D.323: Comparison of $\mathrm{CO}_{2}$ emissions by month for R5-12.47-4 
D.3.19 Detailed Combined PV Plots for R5-12.47-5

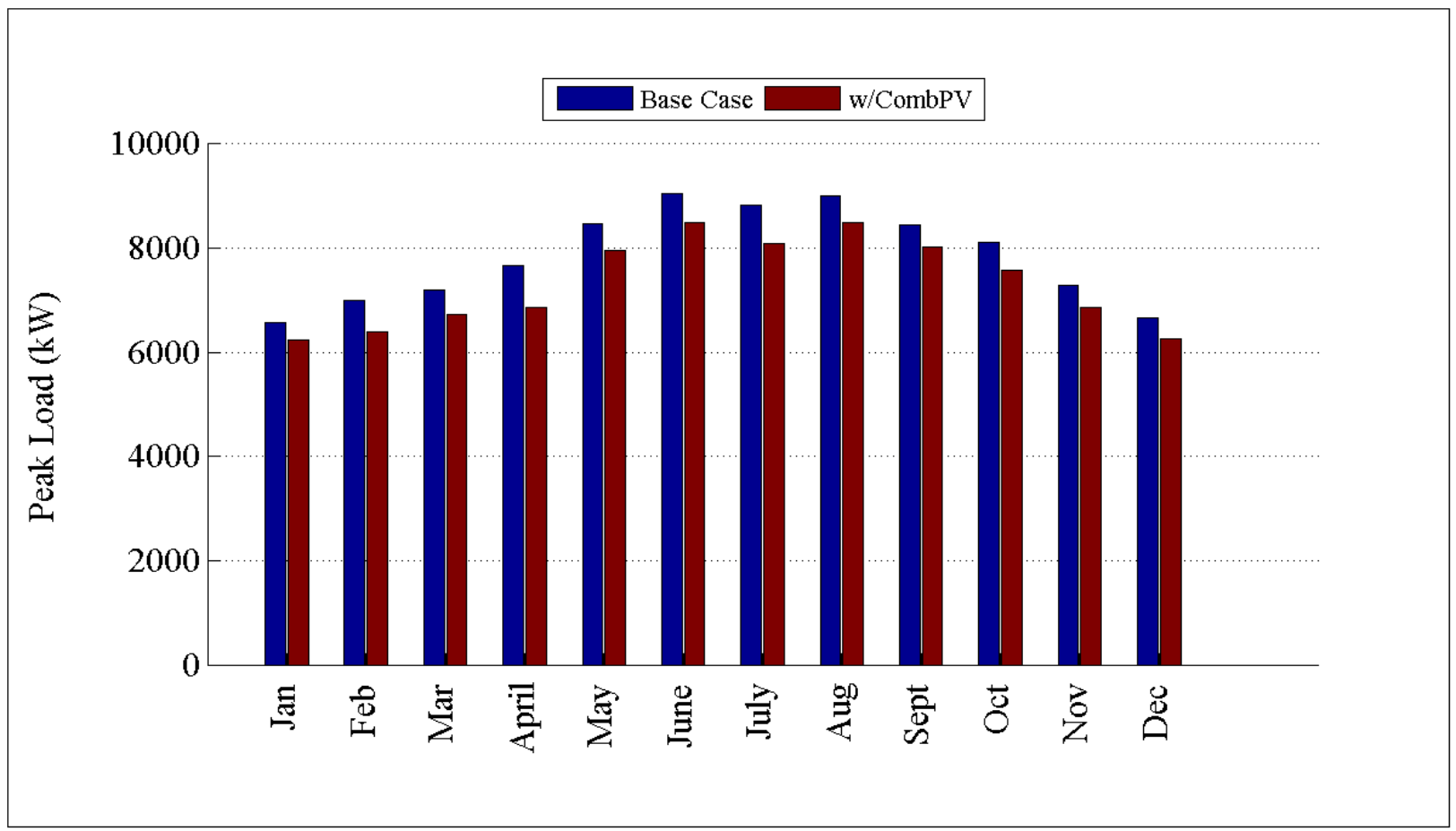

Figure D.324: Comparison of peak loadby month for R5-12.47-5

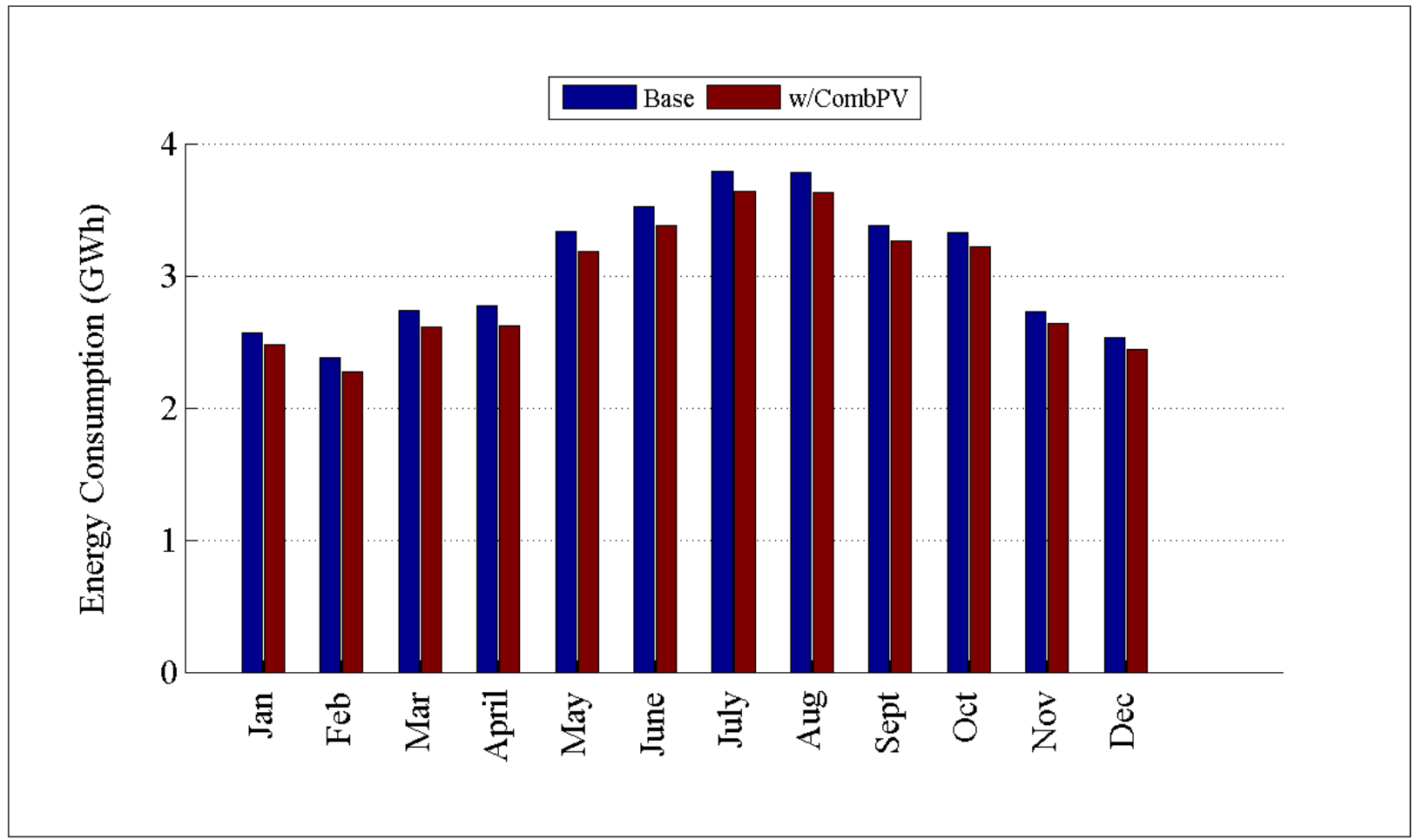

Figure D.325: Comparison of energy consumption by month for R5-12.47-5 


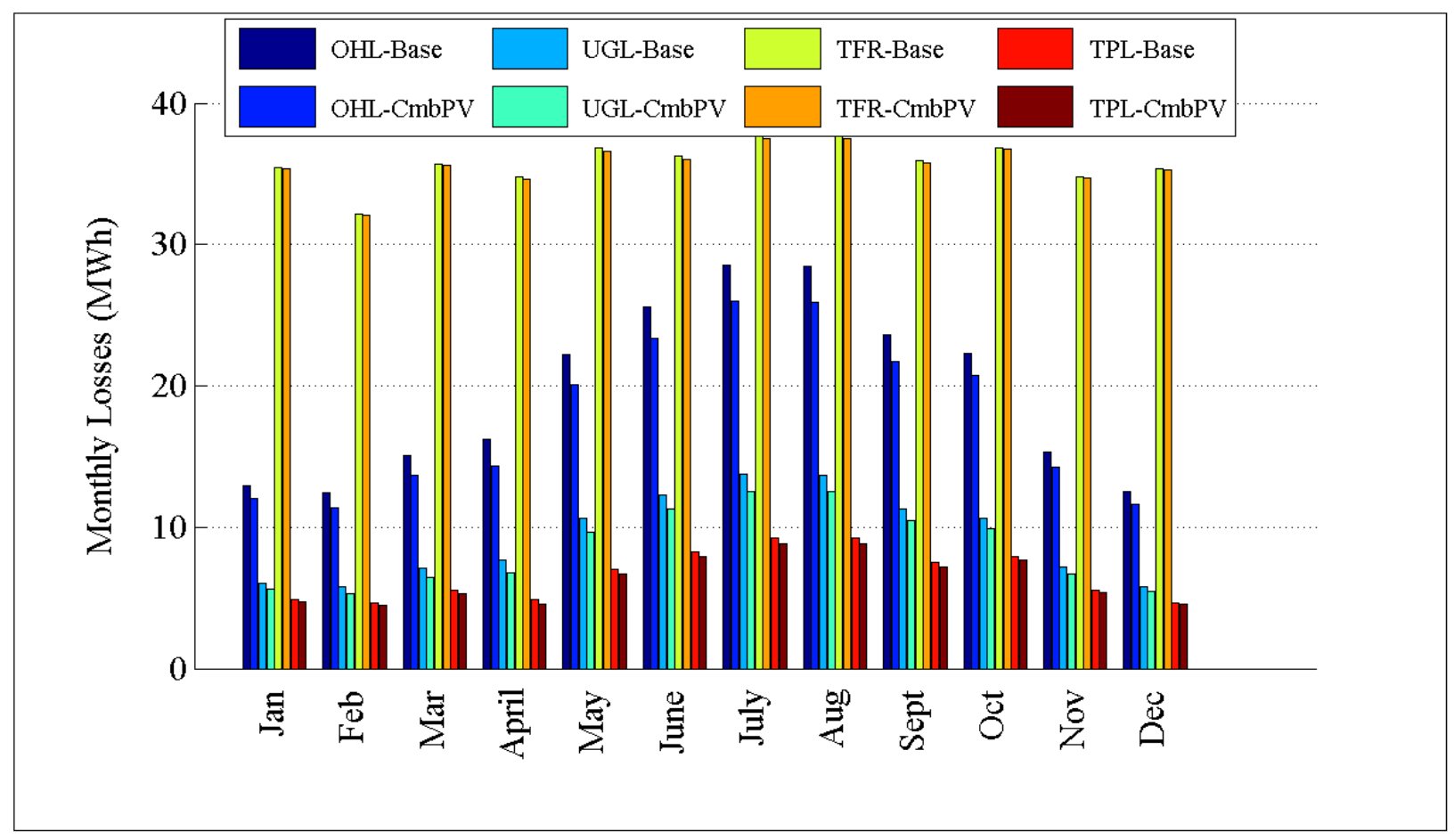

Figure D.326: Comparison of losses by month for R5-12.47-5

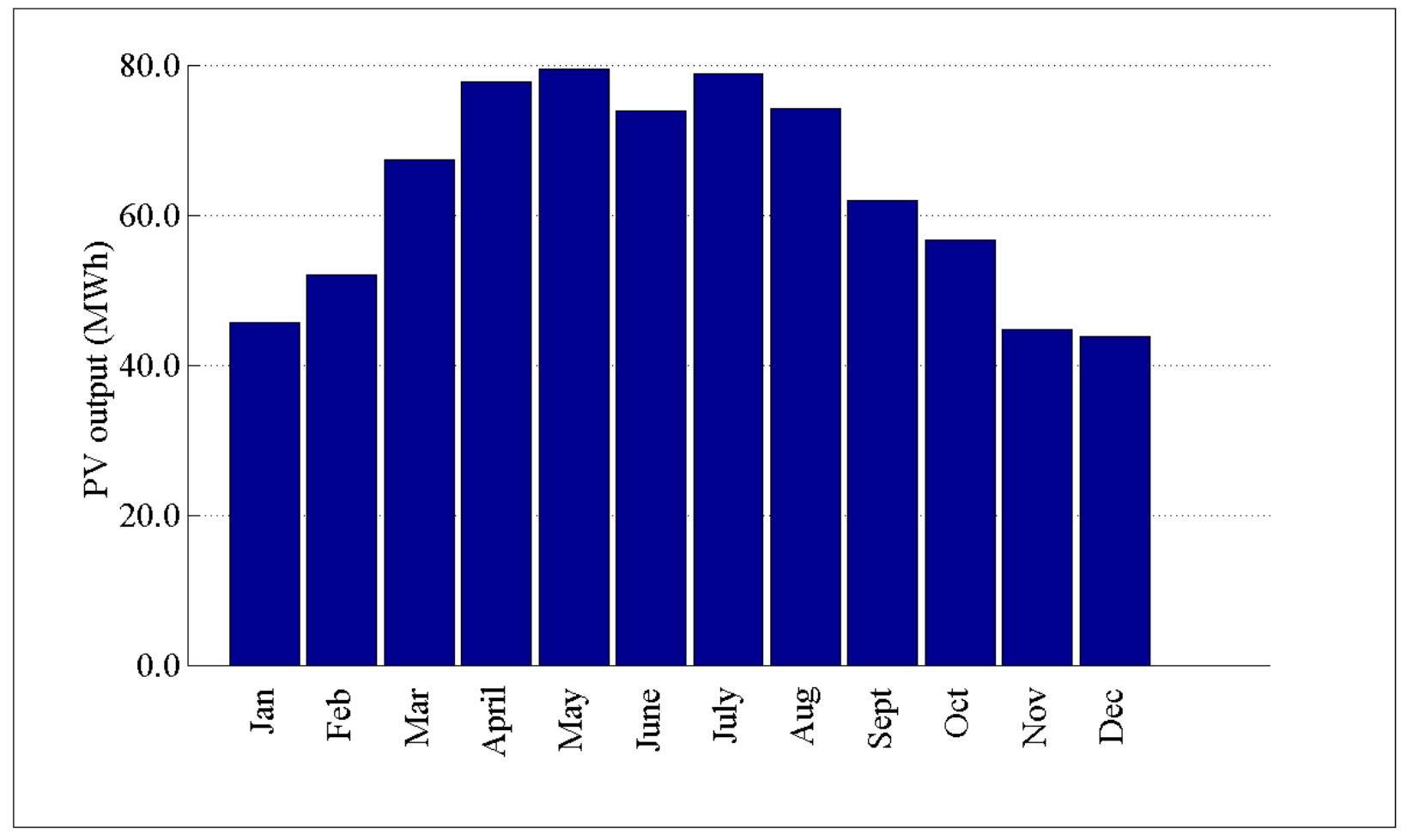

Figure D.327: PV output by month for R5-12.47-5 


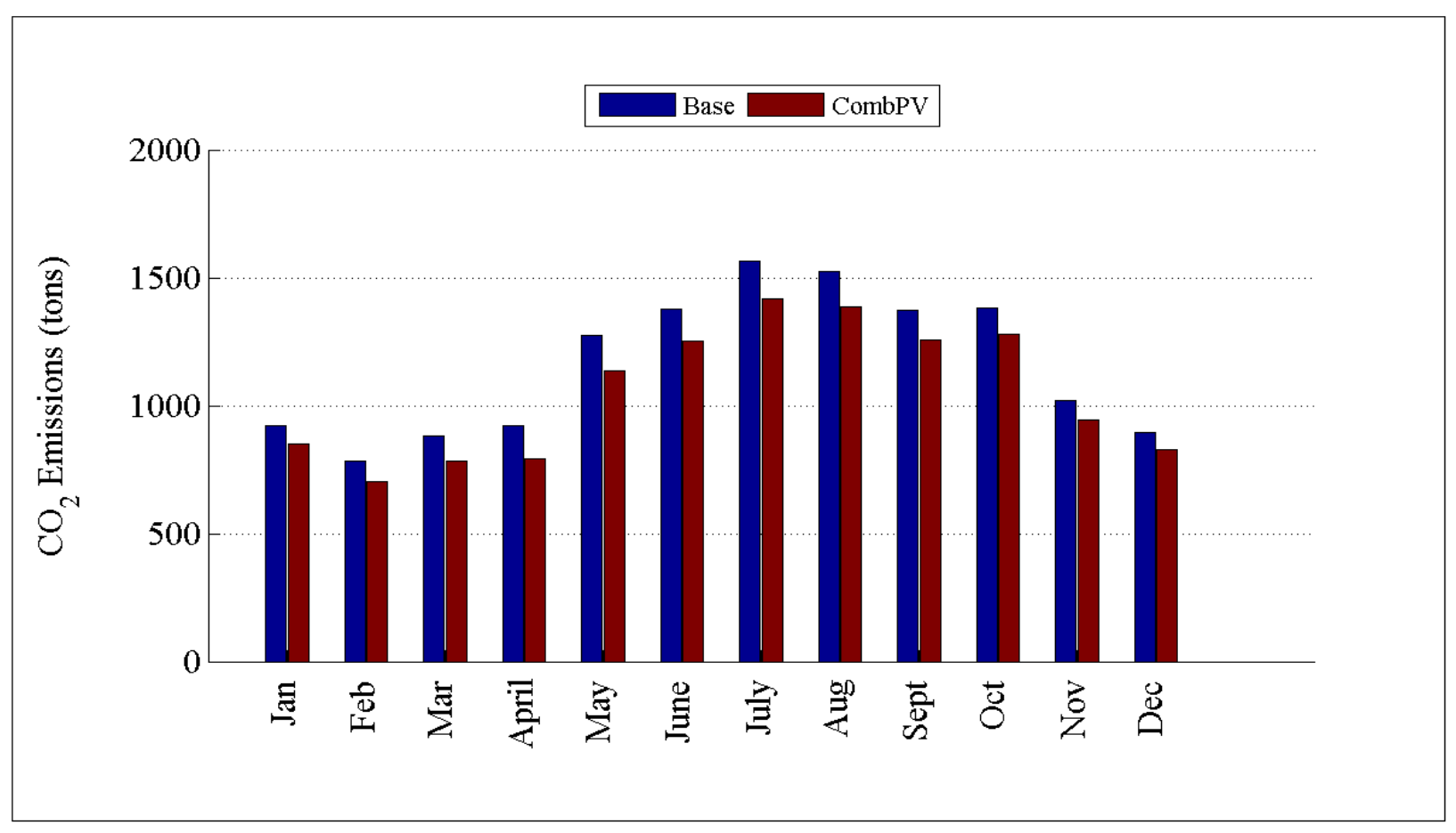

Figure D.328: Comparison of $\mathrm{CO}_{2}$ emissions by month for R5-12.47-5

\section{D.3.20 Detailed Combined PV Plots for R5-25.00-1}

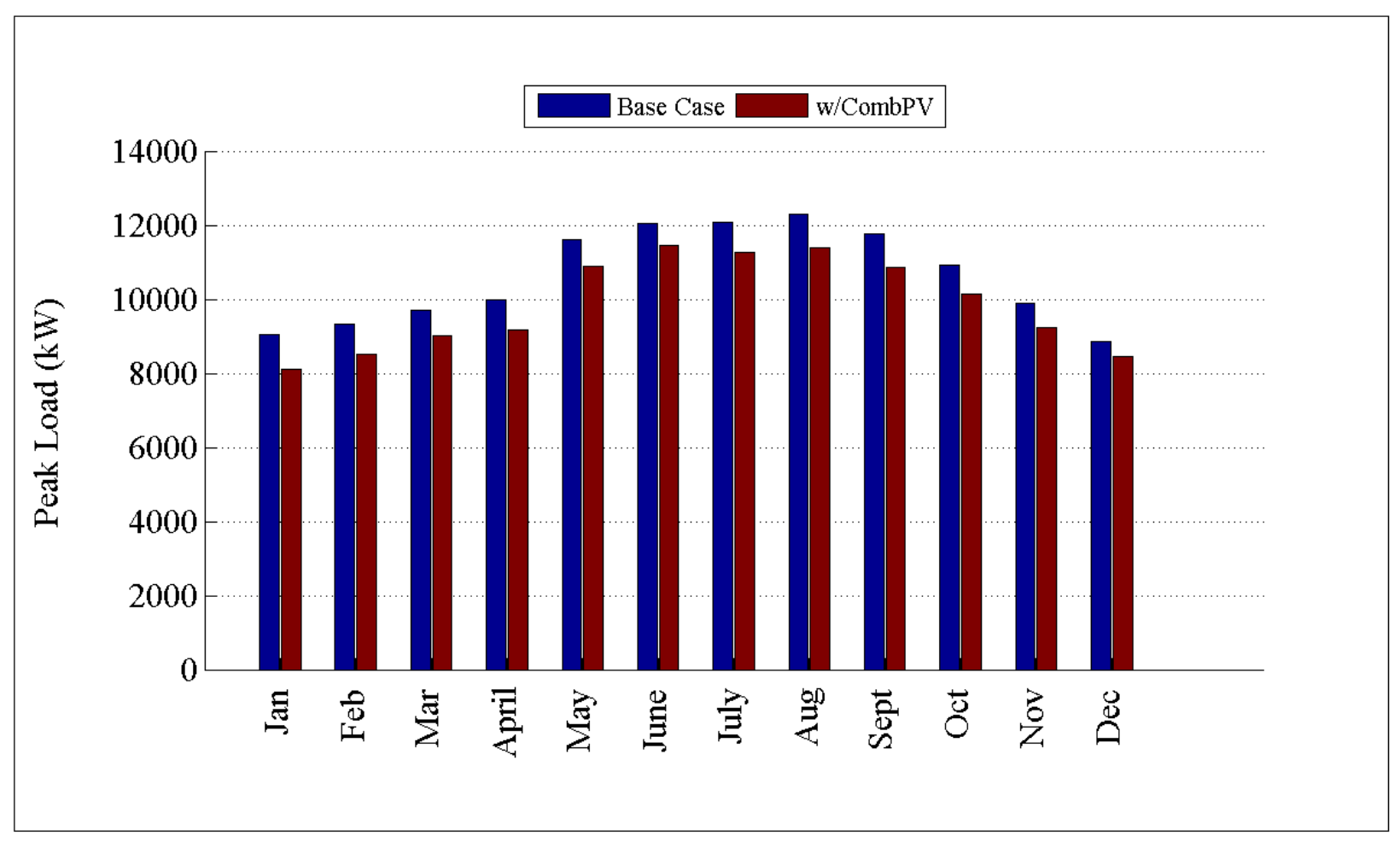

Figure D.329: Comparison of peak load by month for R5-25.00-1 


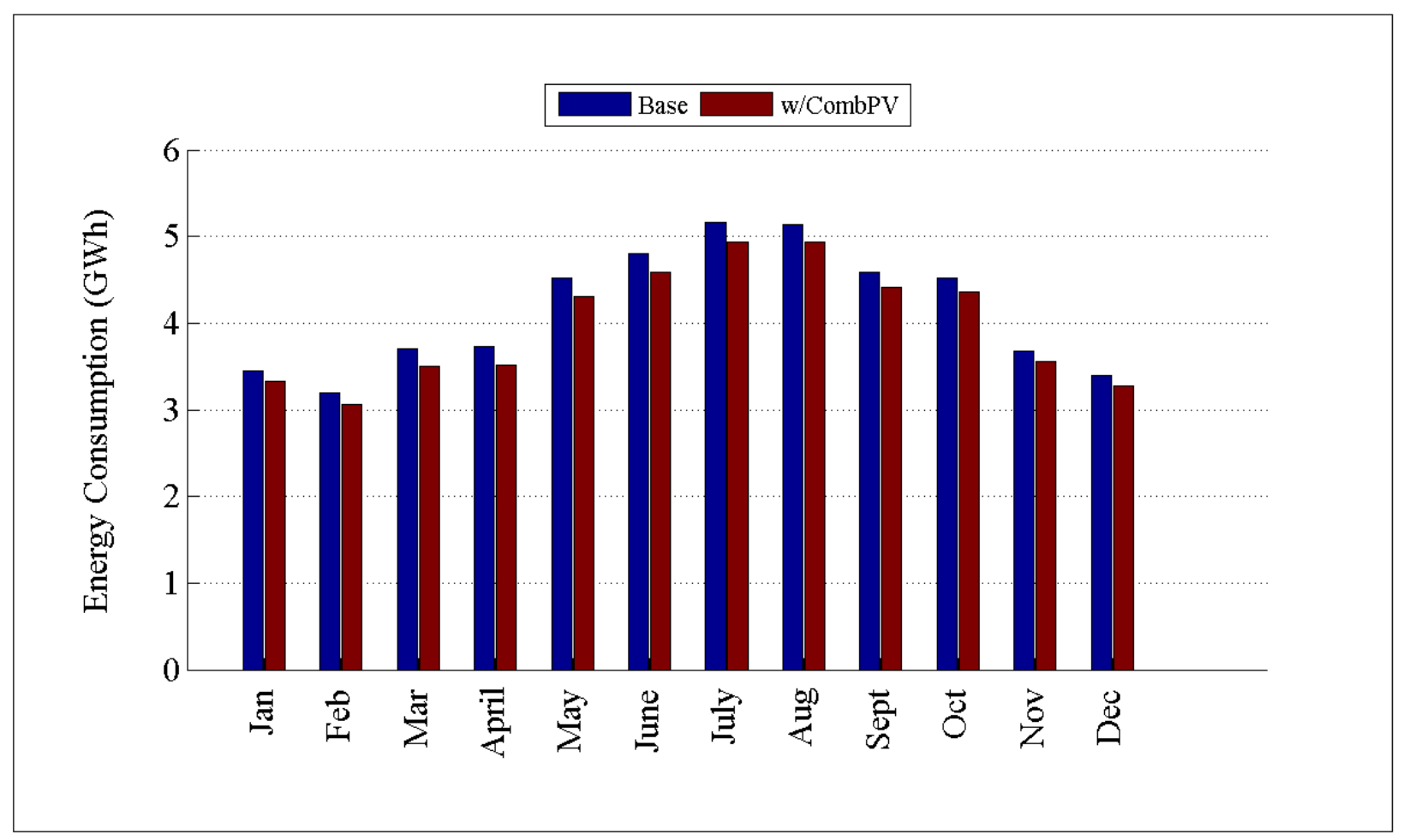

Figure D.330: Comparison of energy consumption by month for R5-25.00-1

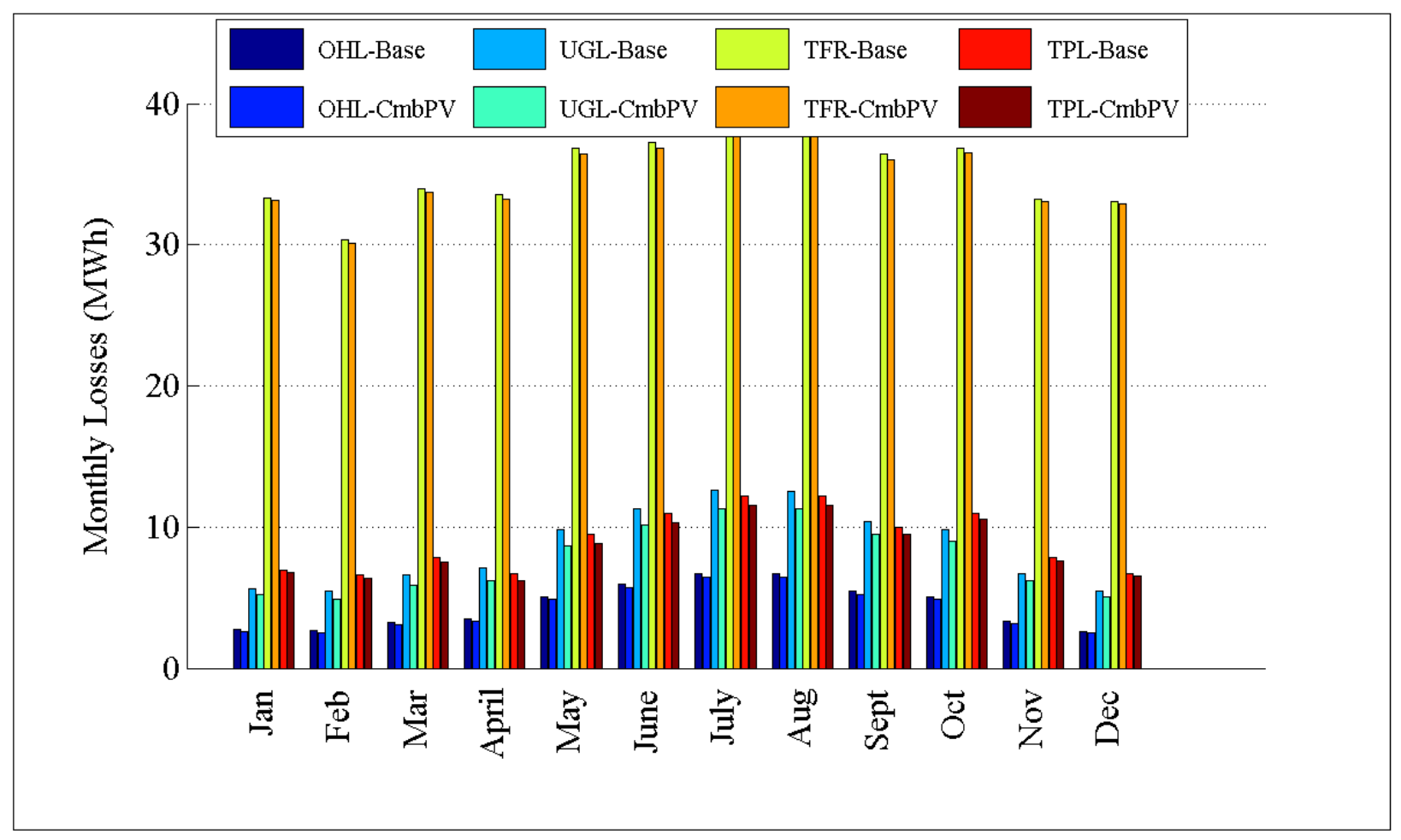

Figure D.331: Comparison of losses by month for R5-25.00-1 


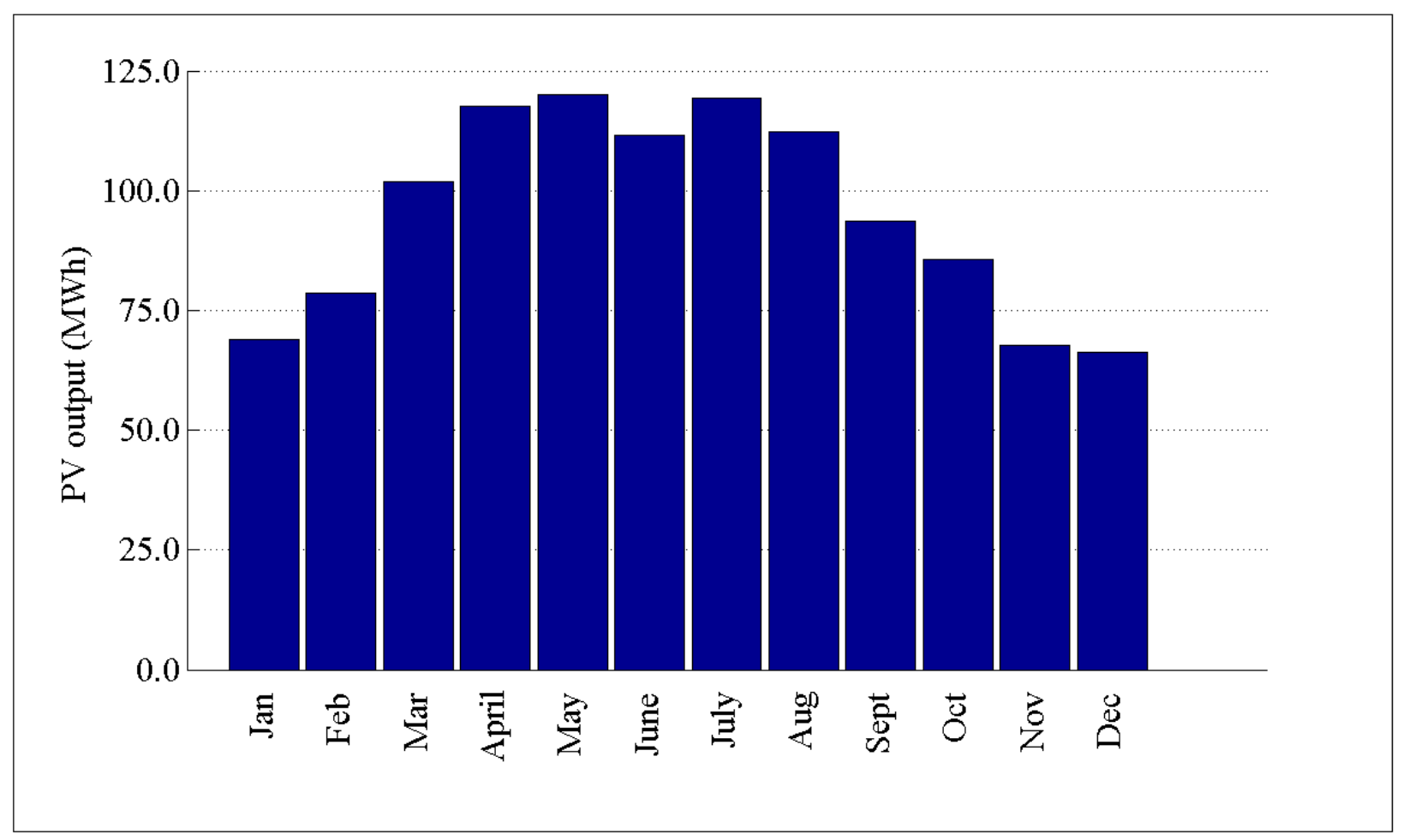

Figure D.332: PV output by month for R5-25.00-1

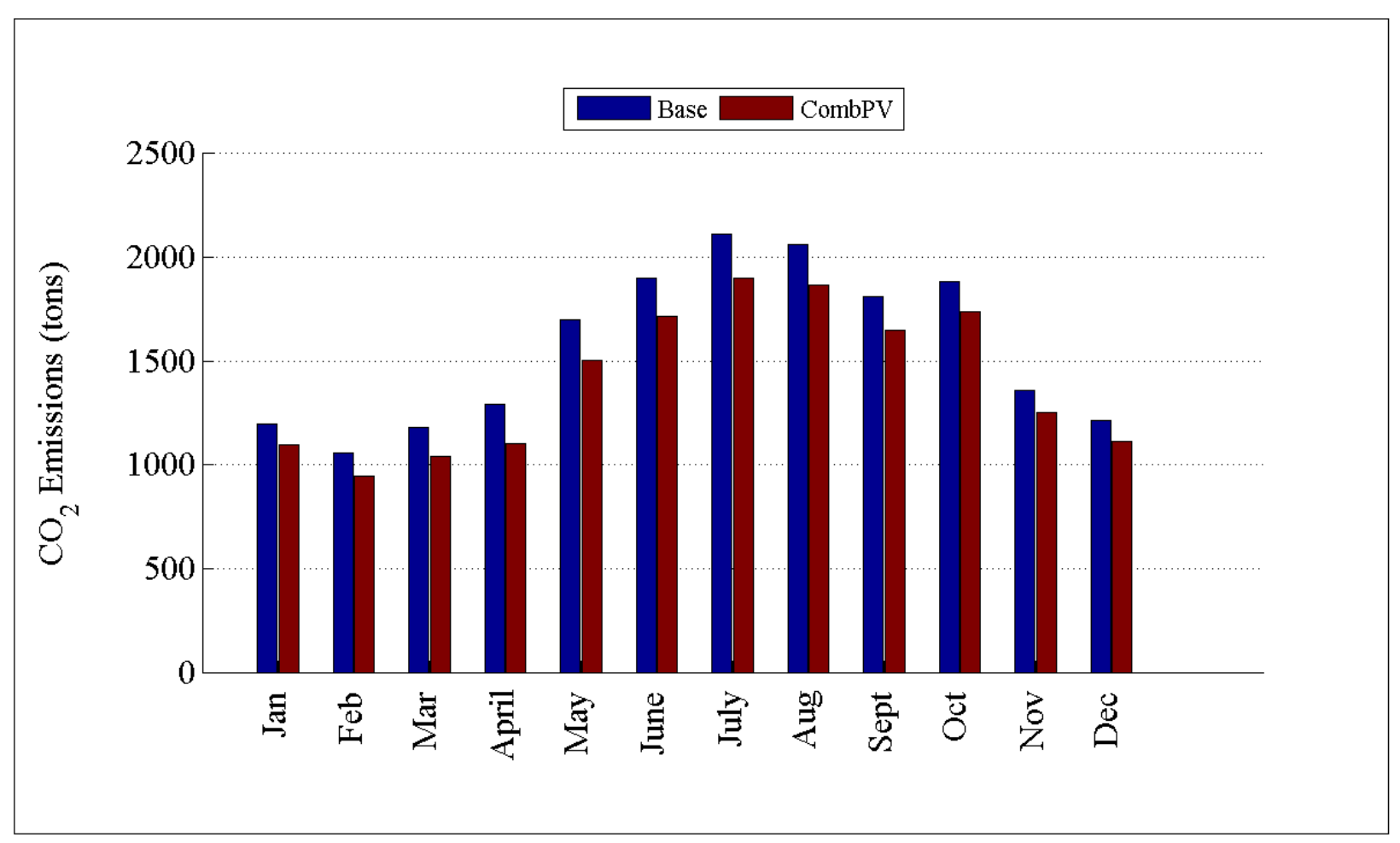

Figure D.333: Comparison of $\mathrm{CO}_{2}$ emissions by month for R5-25.00-1 


\section{D.3.21 Detailed Combined PV Plots for R5-35.00-1}

The detailed plots for this feeder is already given in Section

D.4 Addition of Commercial WTG

D.4.1 Detailed Commercial WTG plots for GC-12.47-1_R1

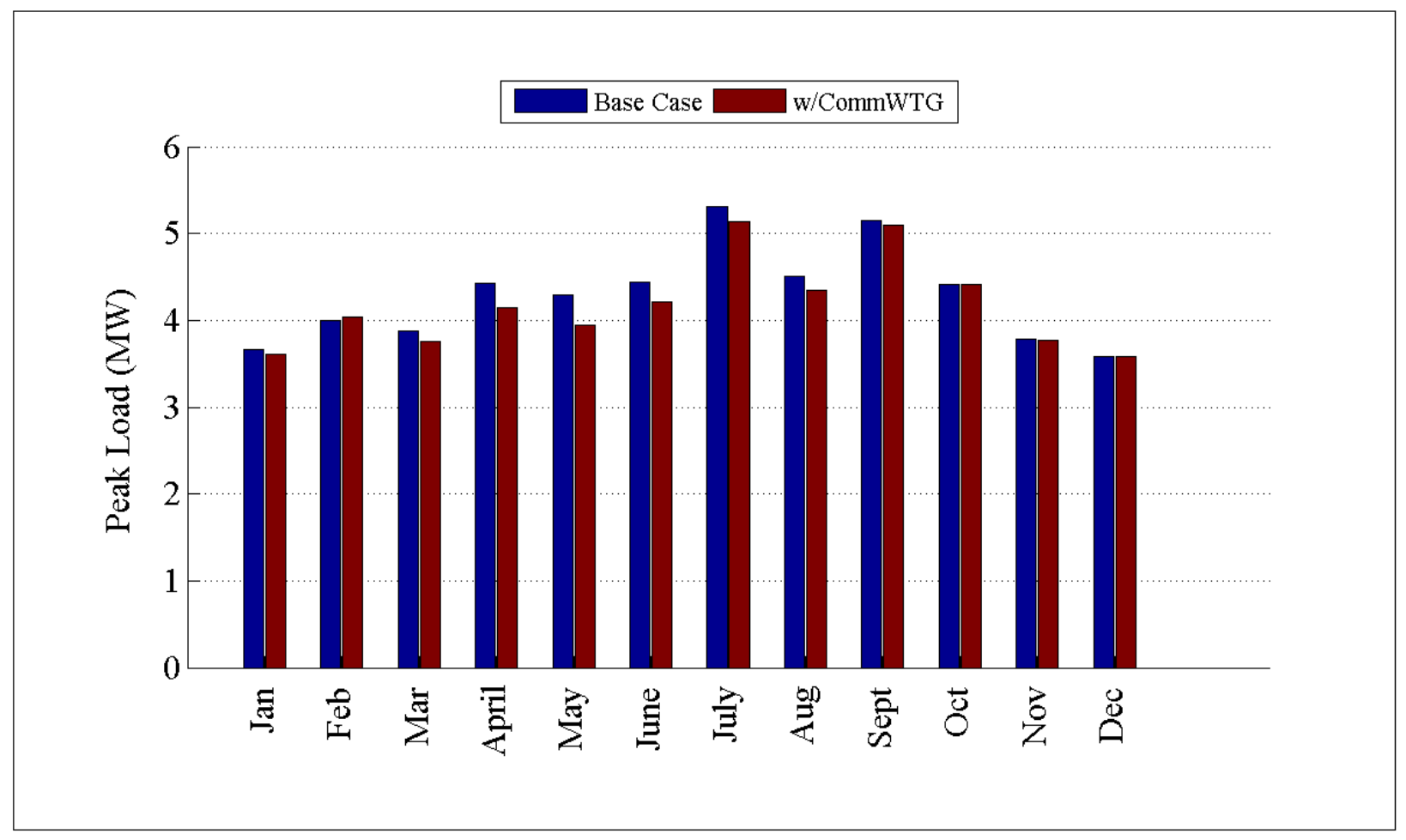

Figure D.334: Comparison of peak load by month for GC-12.47-1_R1 


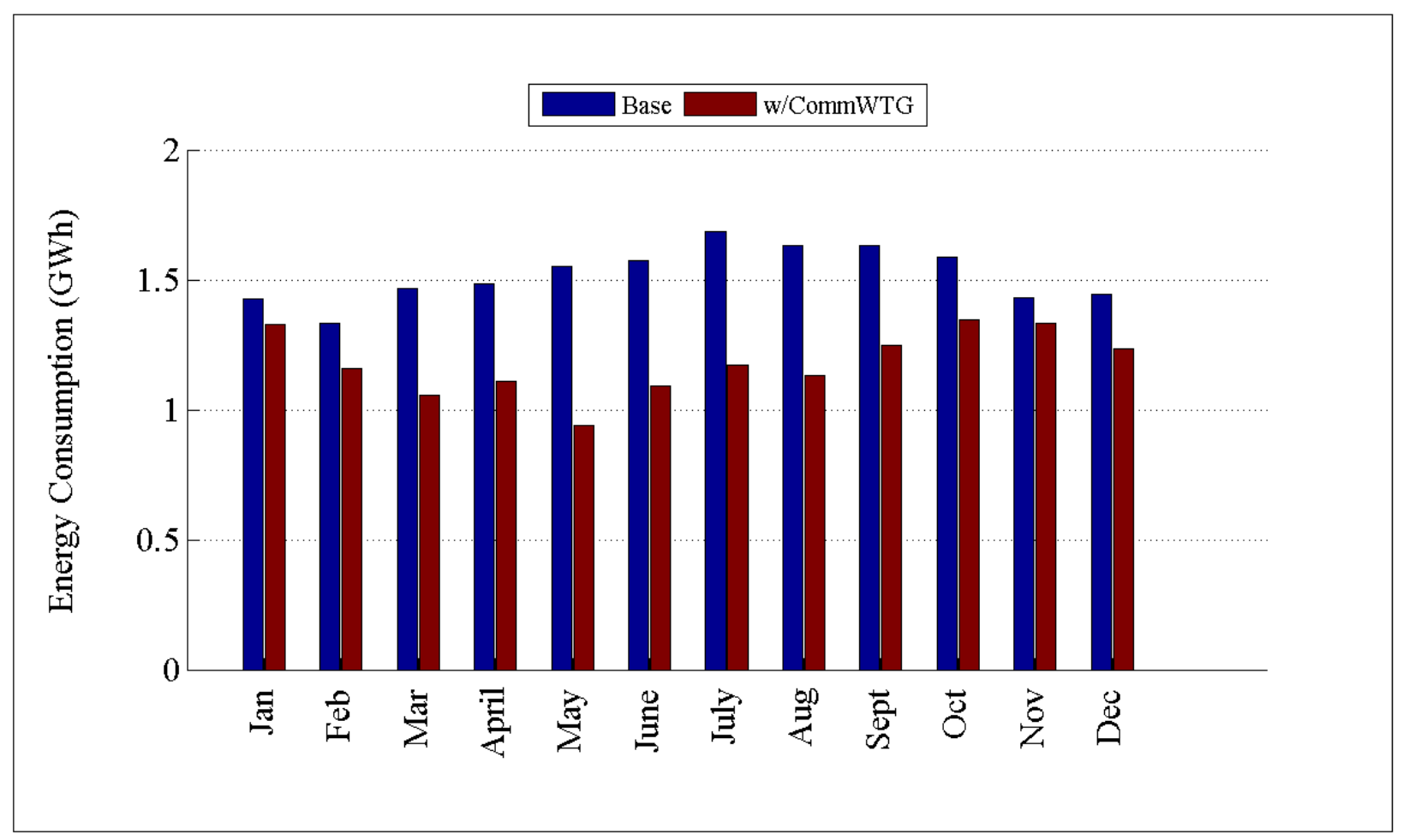

Figure D.335: Comparison of energy consumption by month for GC-12.47-1_R1

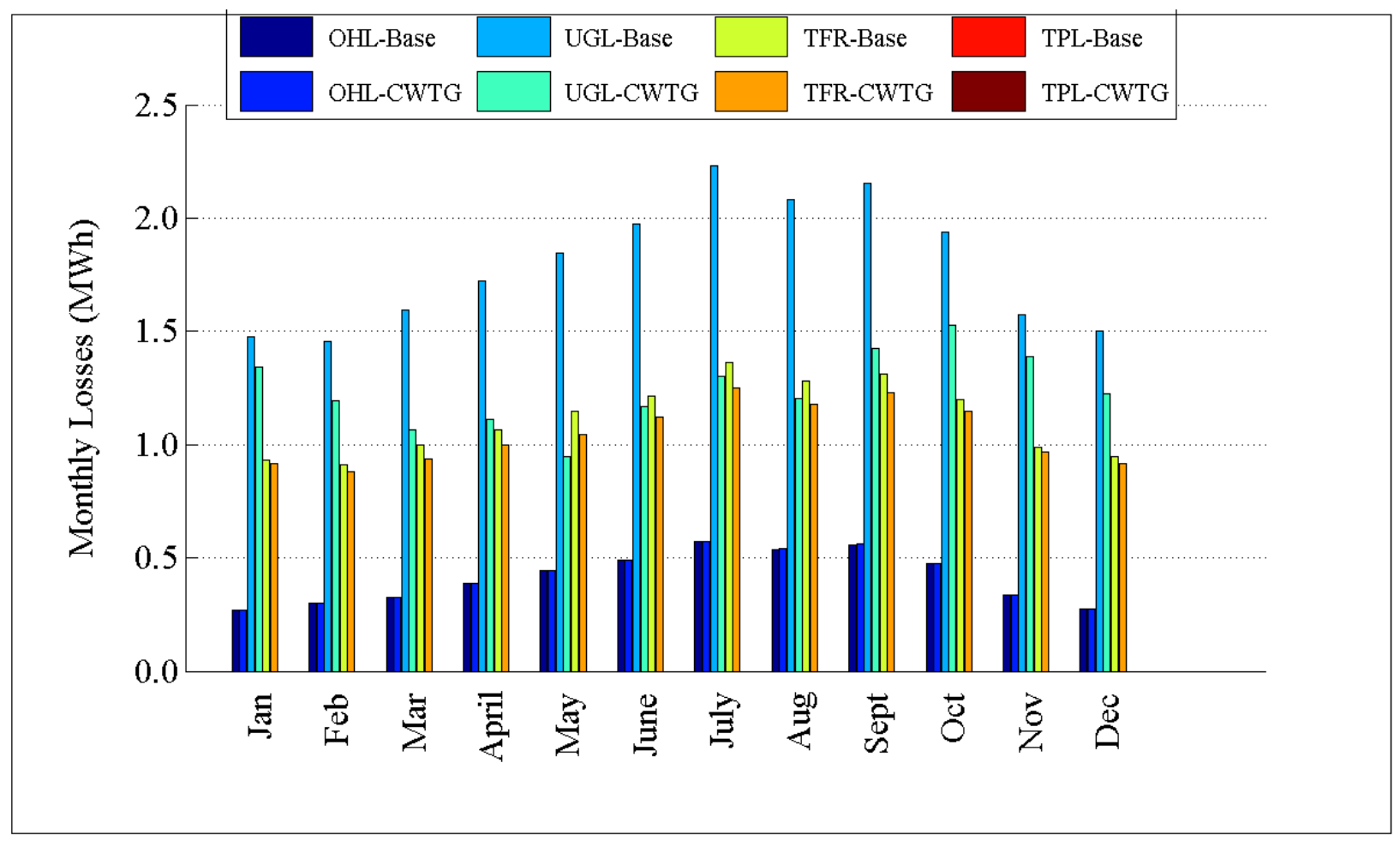

Figure D.336: Comparison of losses by month for GC-12.47-1_R1 


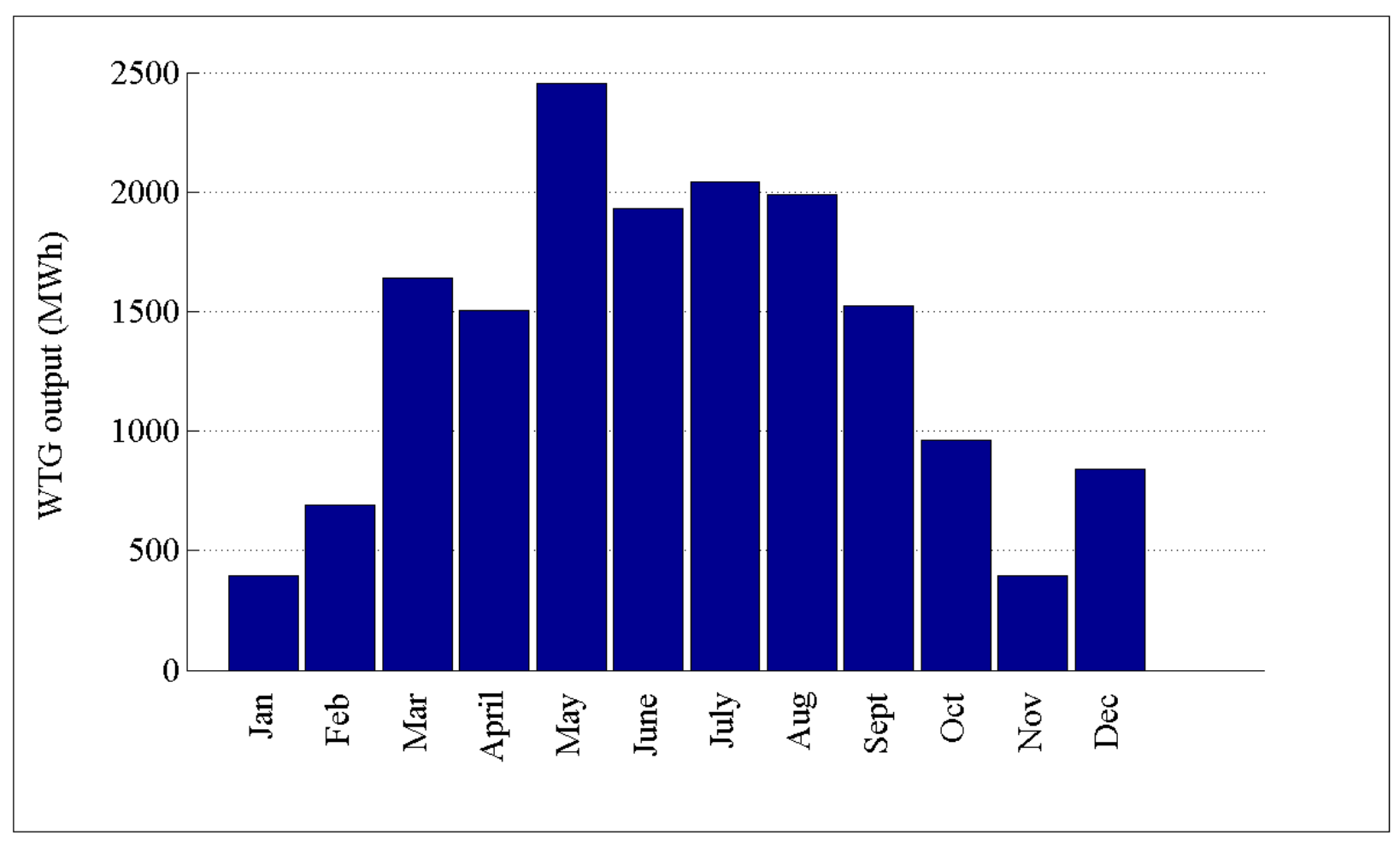

Figure D.337: Comparison of WTG output by month for GC-12.47-1_R1

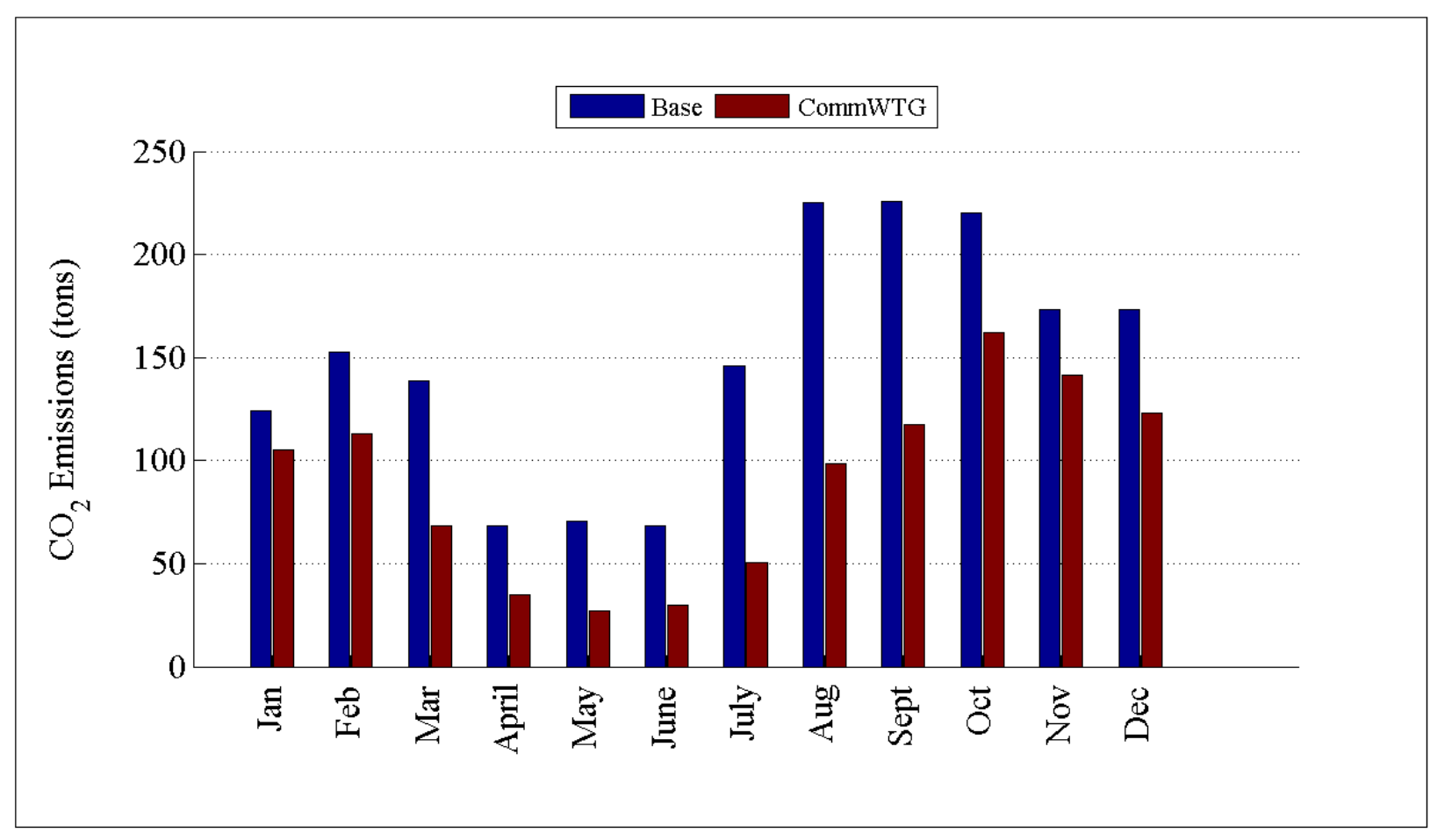

Figure D.338: Comparison of $\mathrm{CO}_{2}$ output by month for GC-12.47-1_R1 


\section{D.4.2 Detailed Commercial WTG plots for GC-12.47-1_R2}

The plots are already given in Section 3.

\section{D.4.3 Detailed Commercial WTG plots for GC-12.47-1_R3}

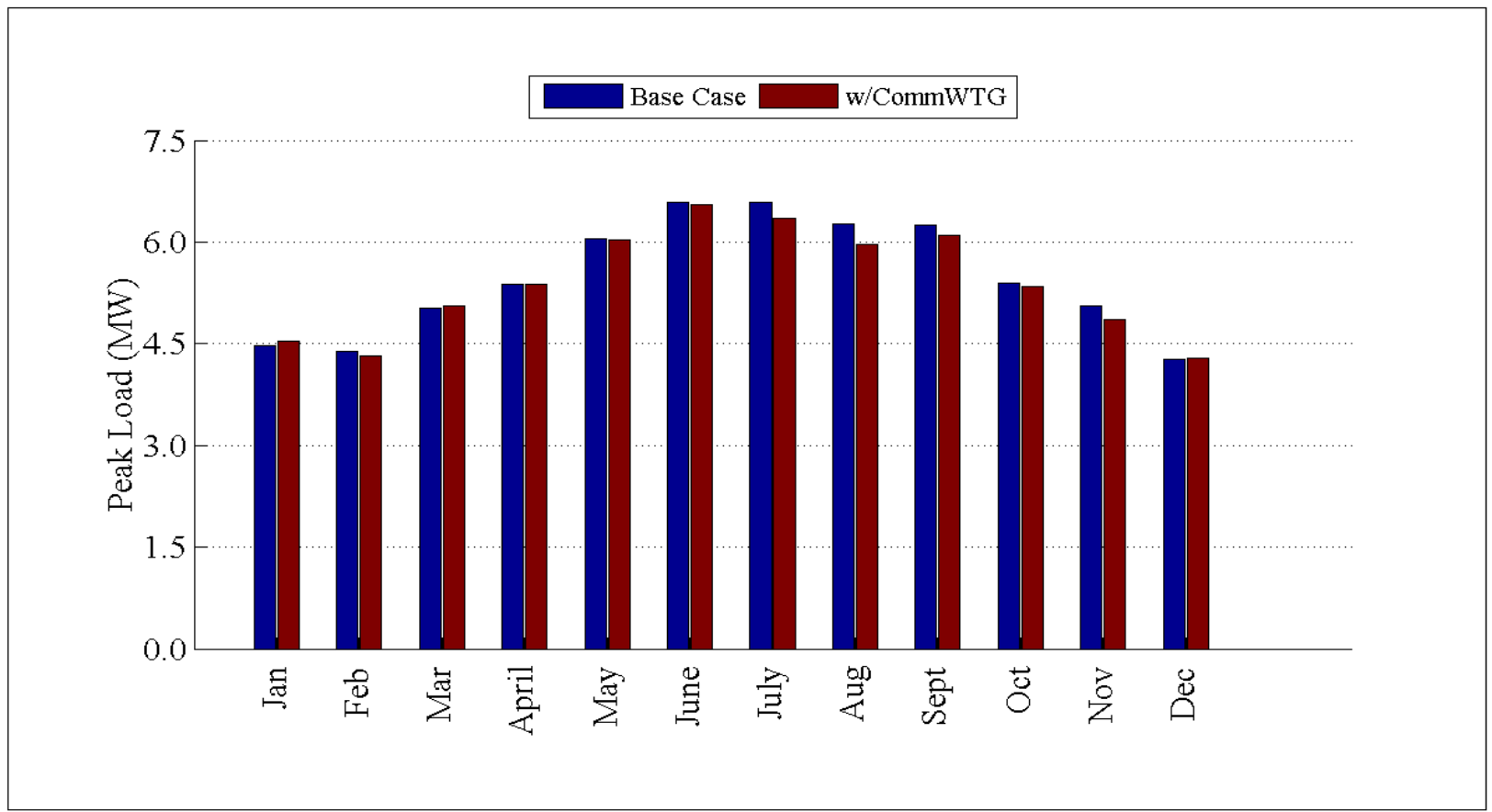

Figure D.339: Comparison of peak load by month for GC-12.47-1_R2

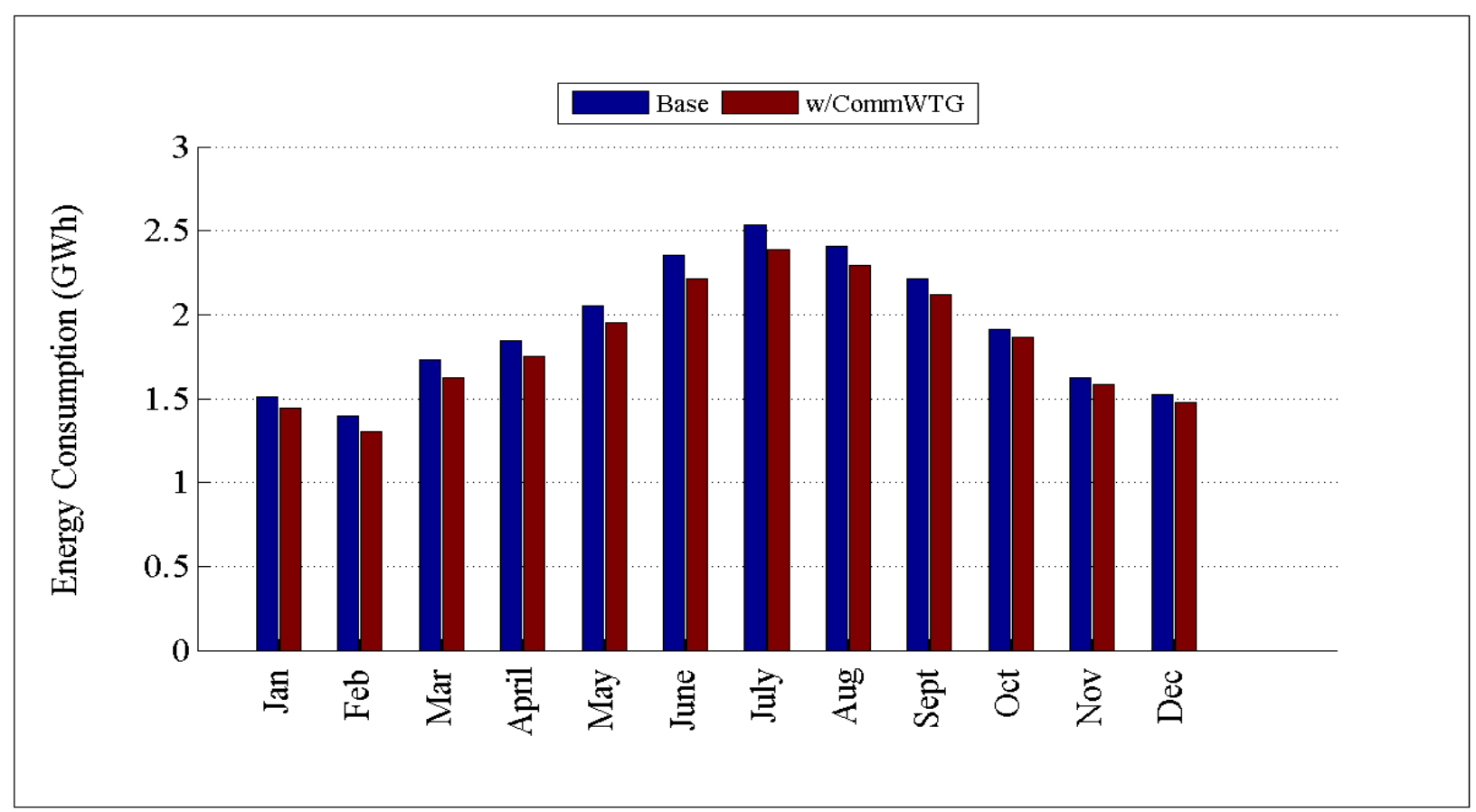

Figure D.340: Comparison of energy consumption by month for GC-12.47-1_R3 


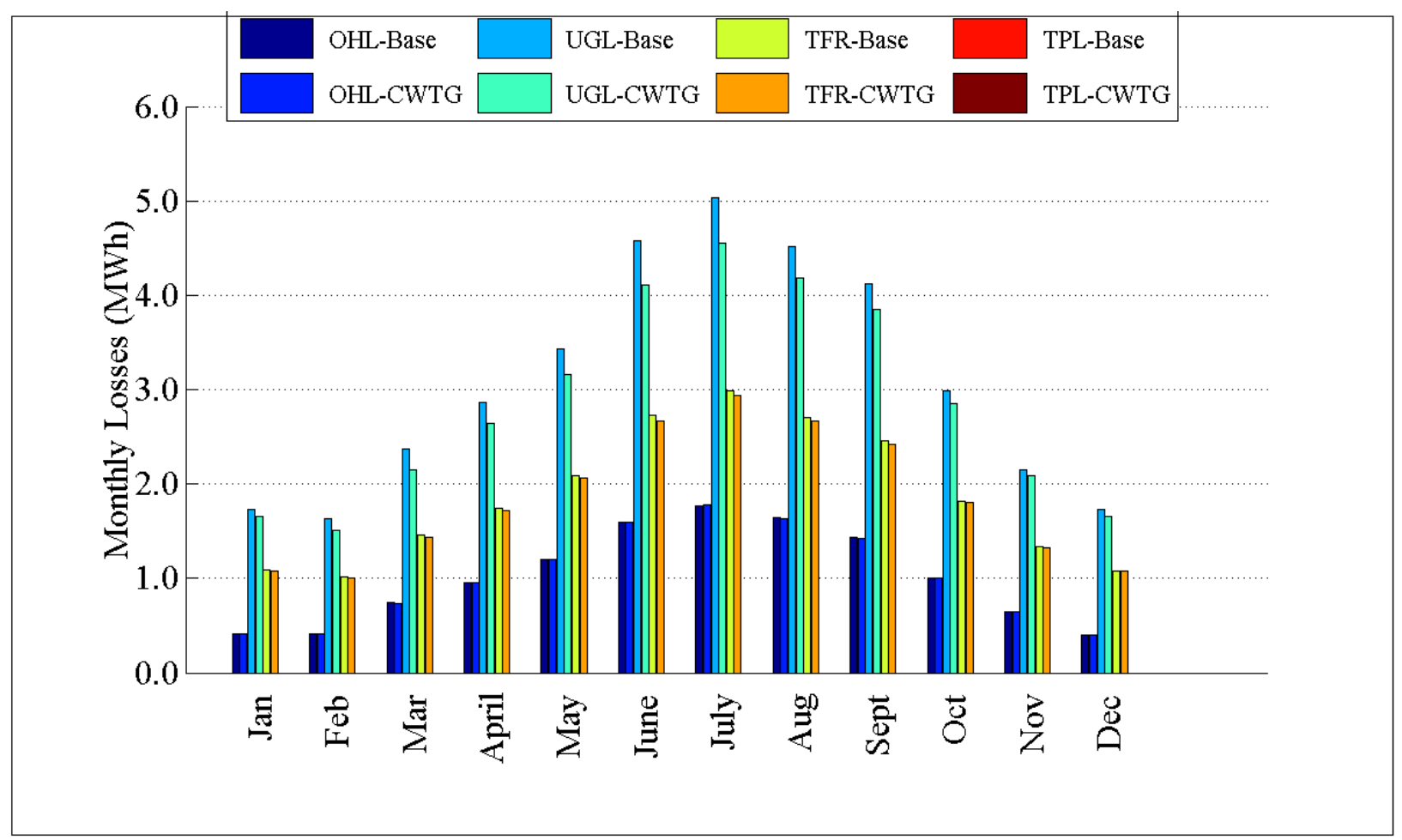

Figure D.341: Comparison of losses by month for GC-12.47-1_R3

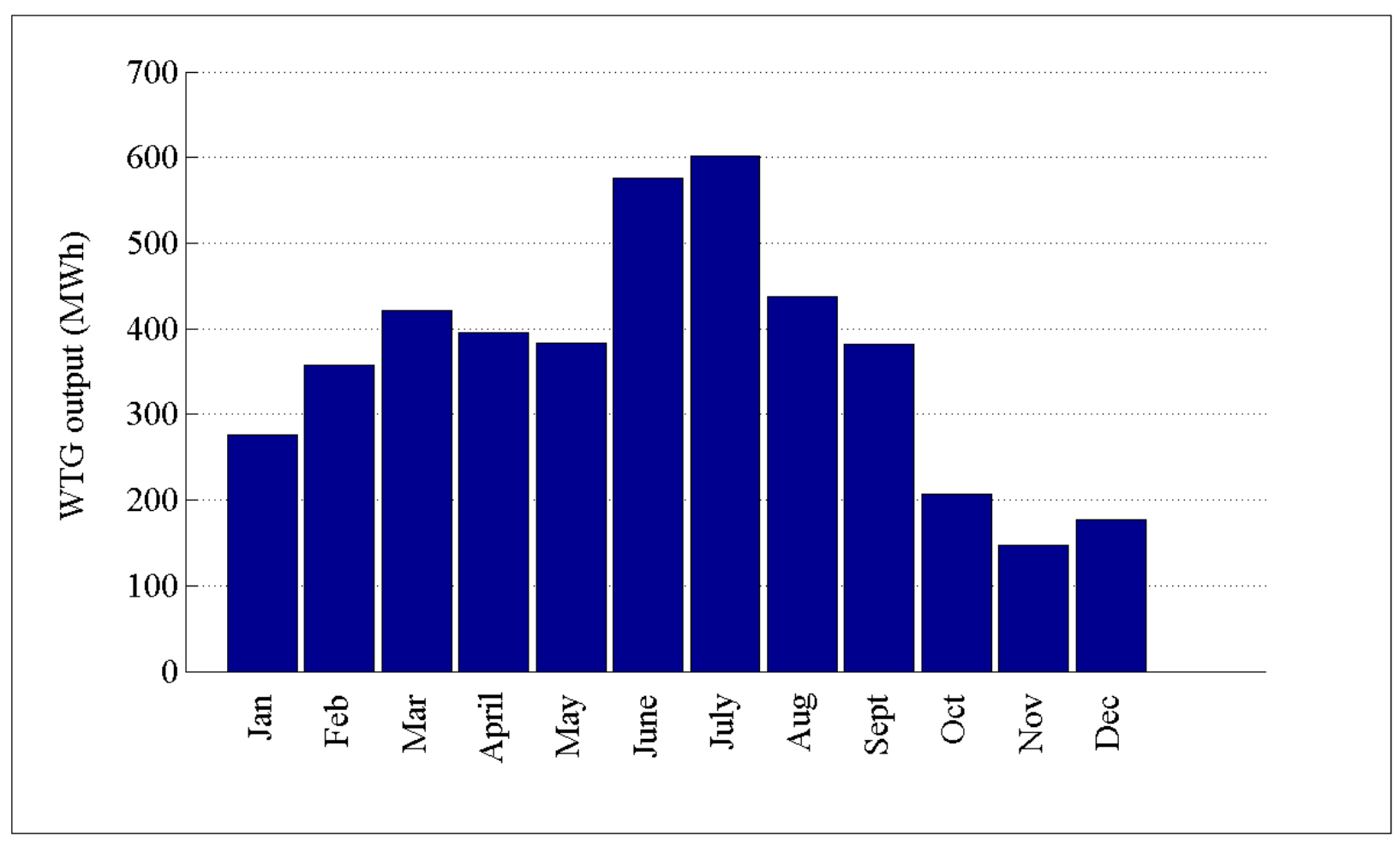

Figure D.342: Comparison of WTG output by month for GC-12.47-1_R3 


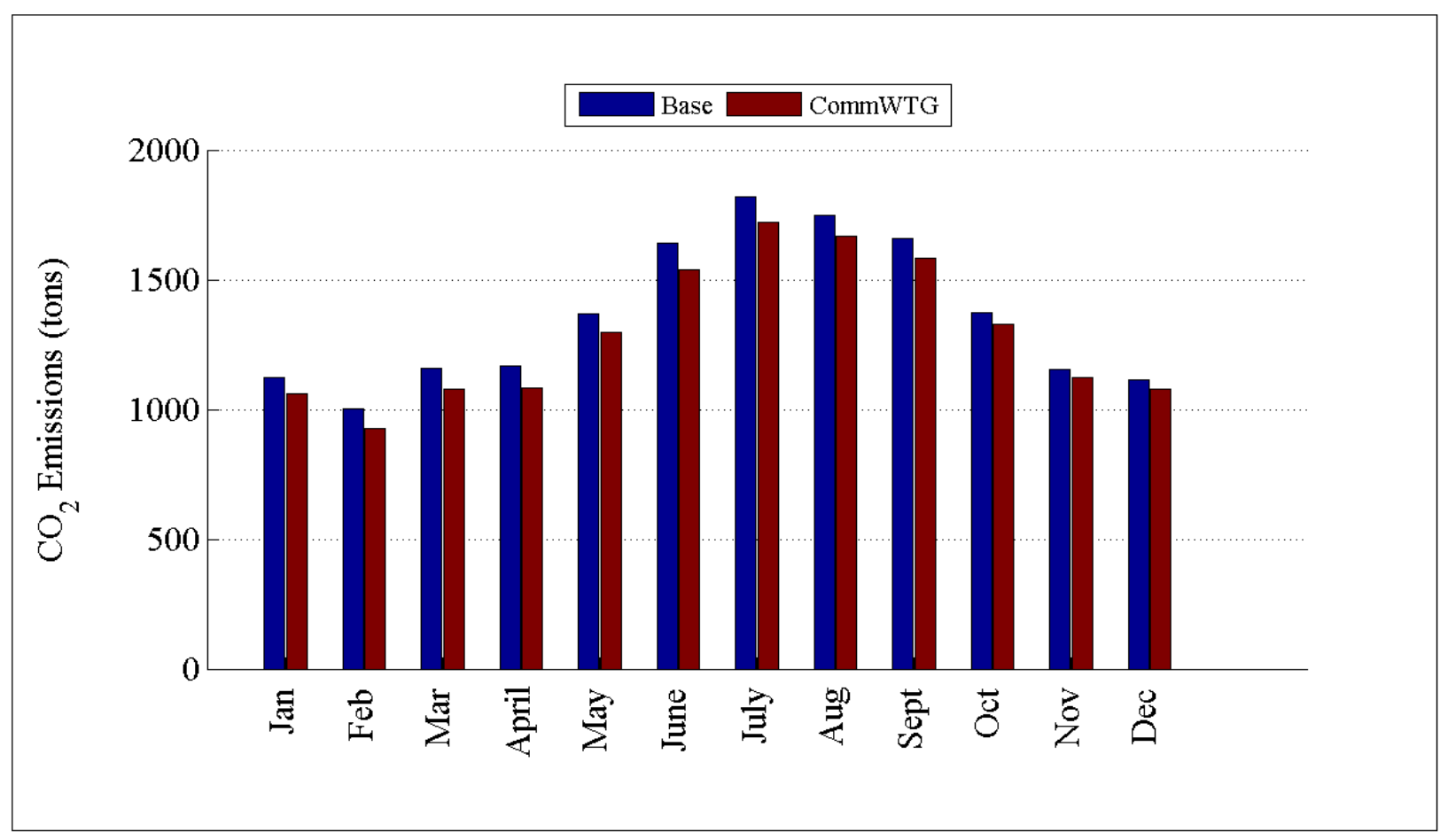

Figure D.343: Comparison of $\mathrm{CO}_{2}$ emissions by month for GC-12.47-1_R3

\section{D.4.4 Detailed Commercial WTG plots for GC-12.47-1_R4}

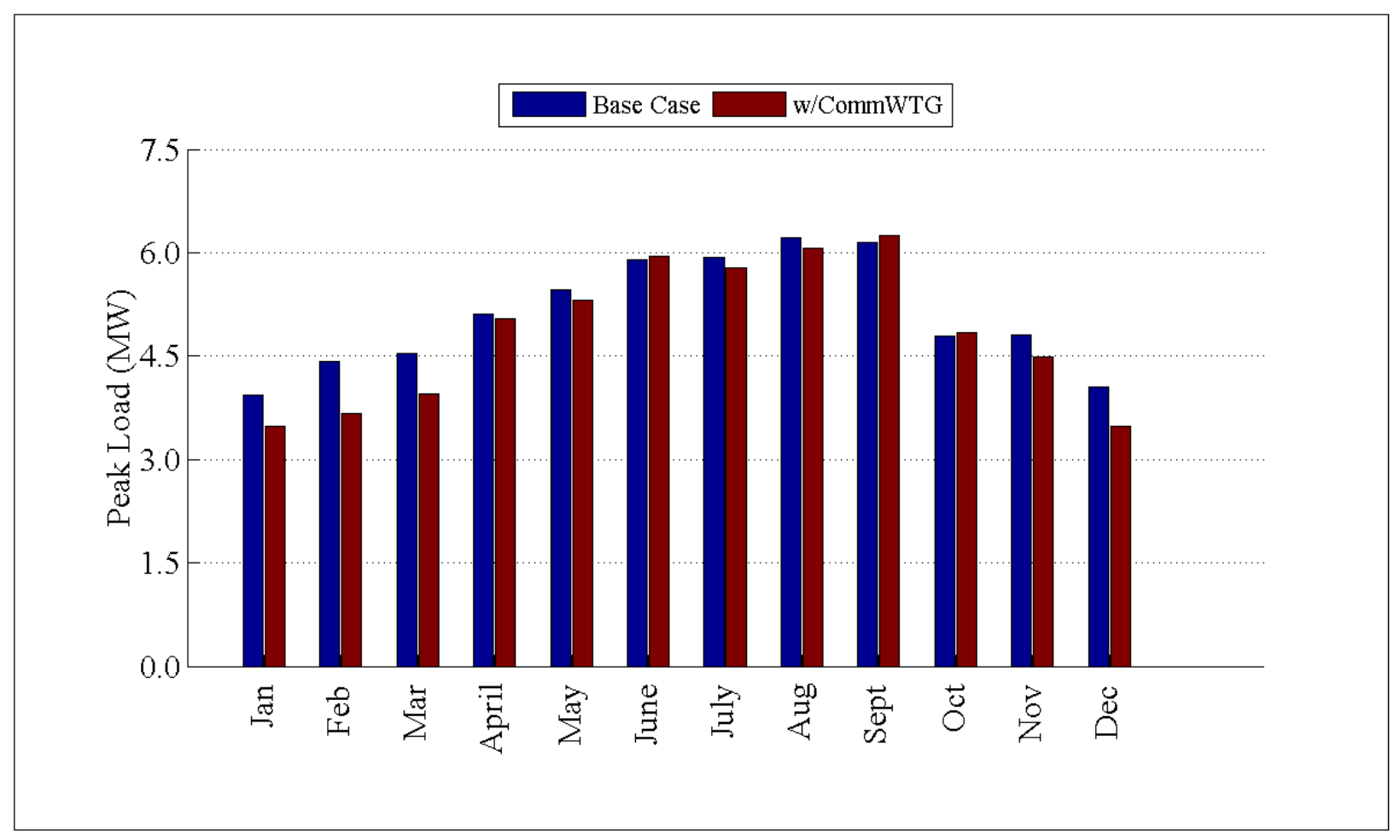

Figure D.344: Comparison of peak load by month for GC-12.47-1_R4 


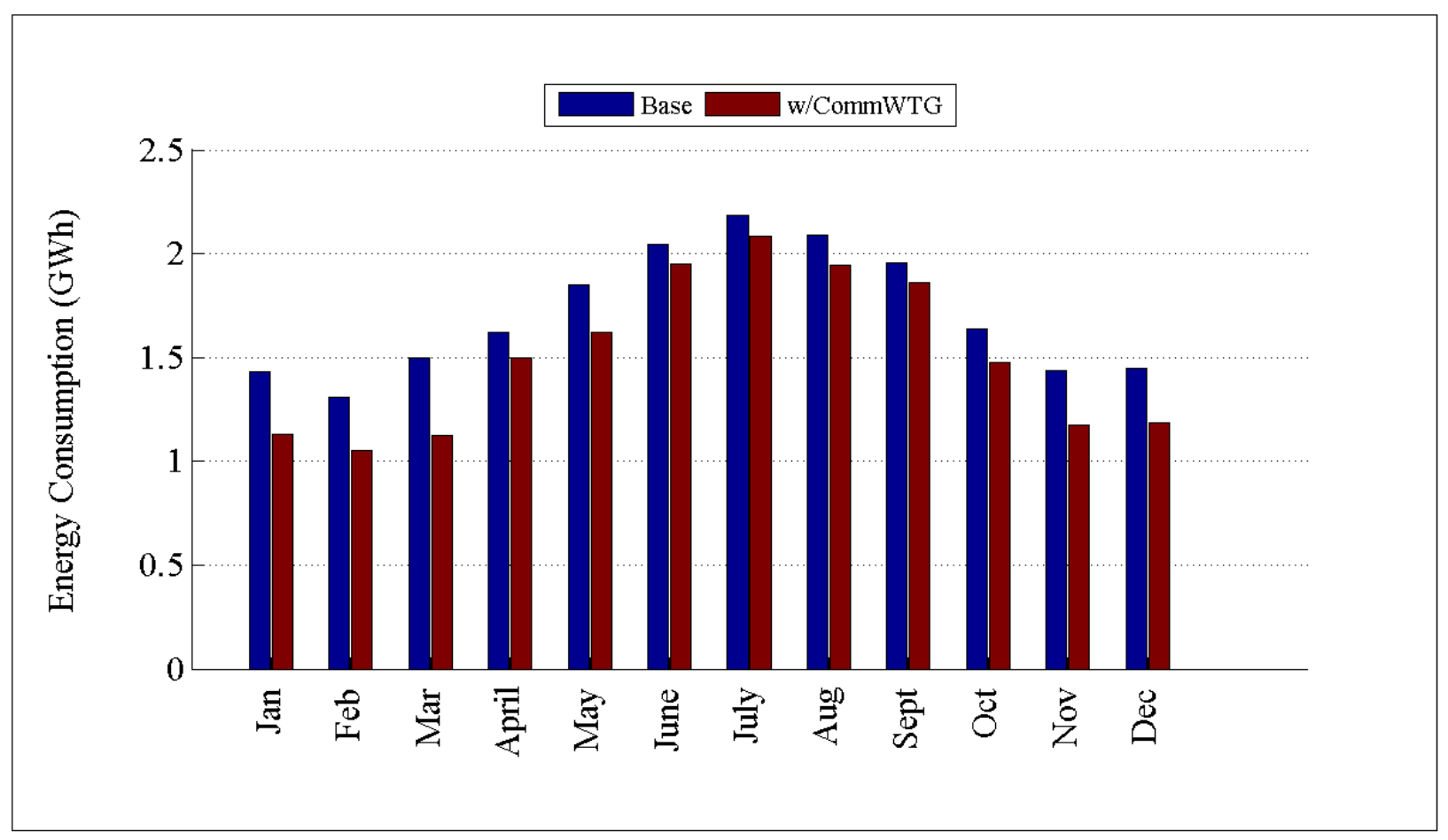

Figure D.345: Comparison of energy consumption by month for GC-12.47-1_R4

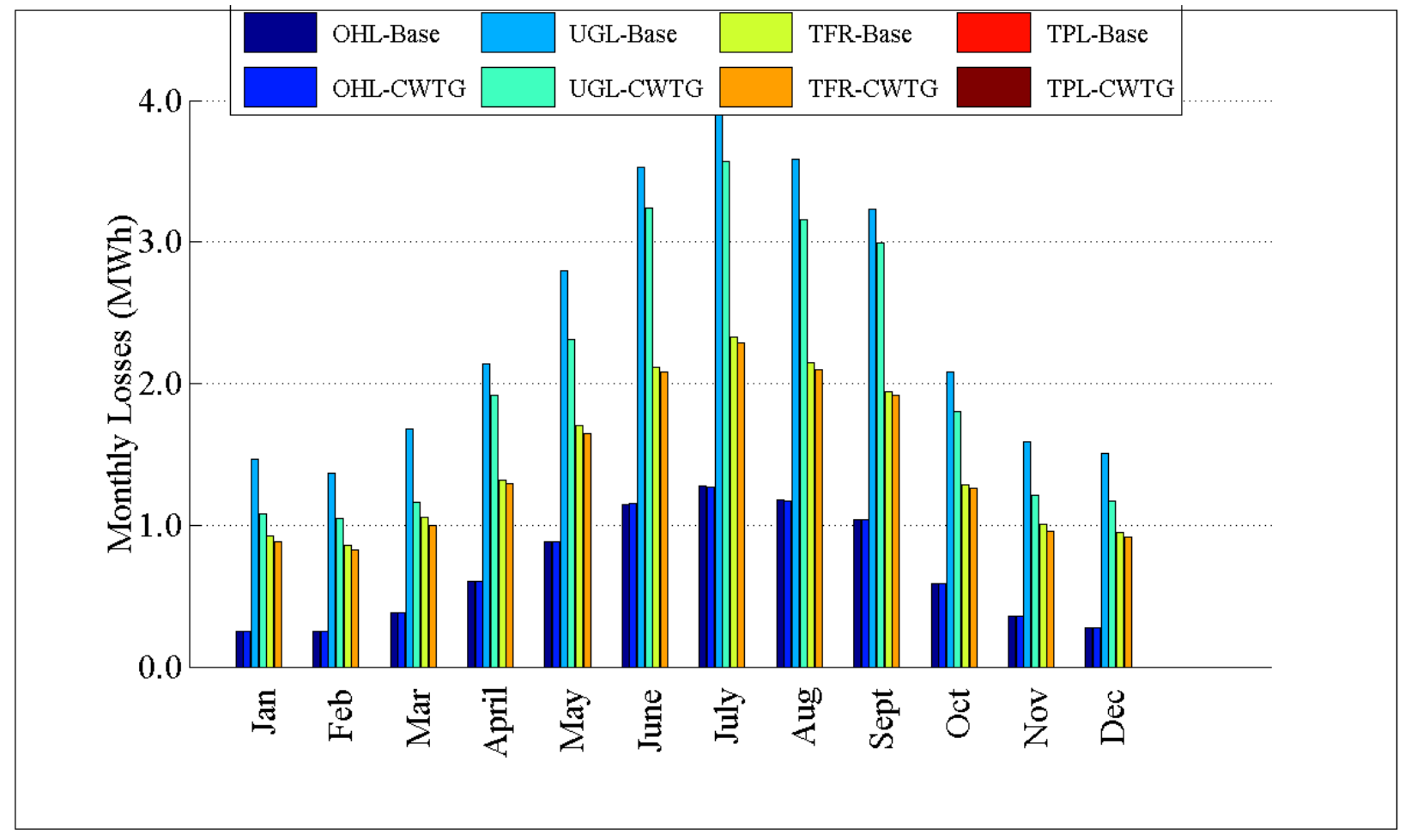

Figure D.346: Comparison of losses by month for GC-12.47-1_R4 


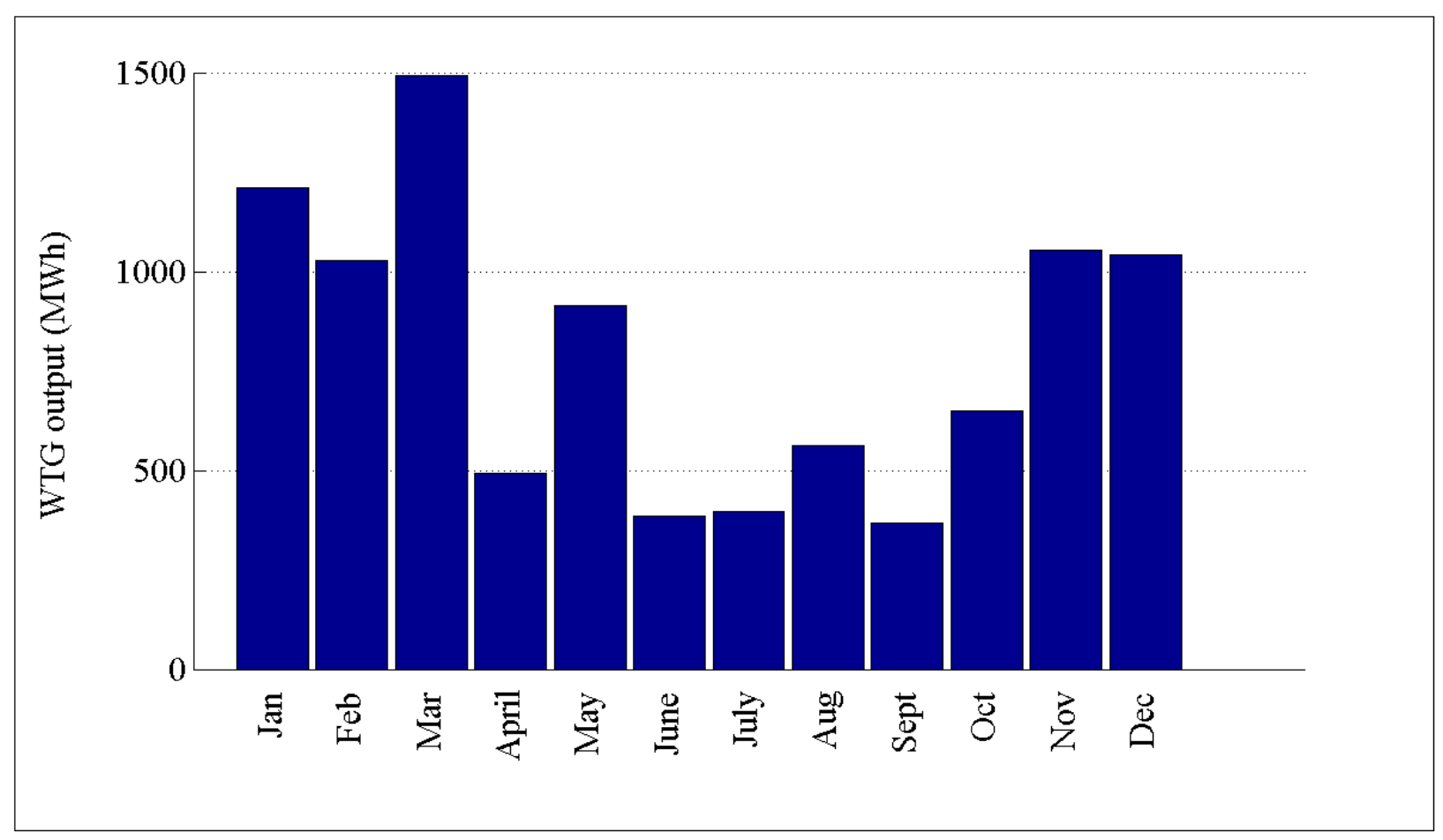

Figure D.347: Comparison of WTG output by month for GC-12.47-1_R4

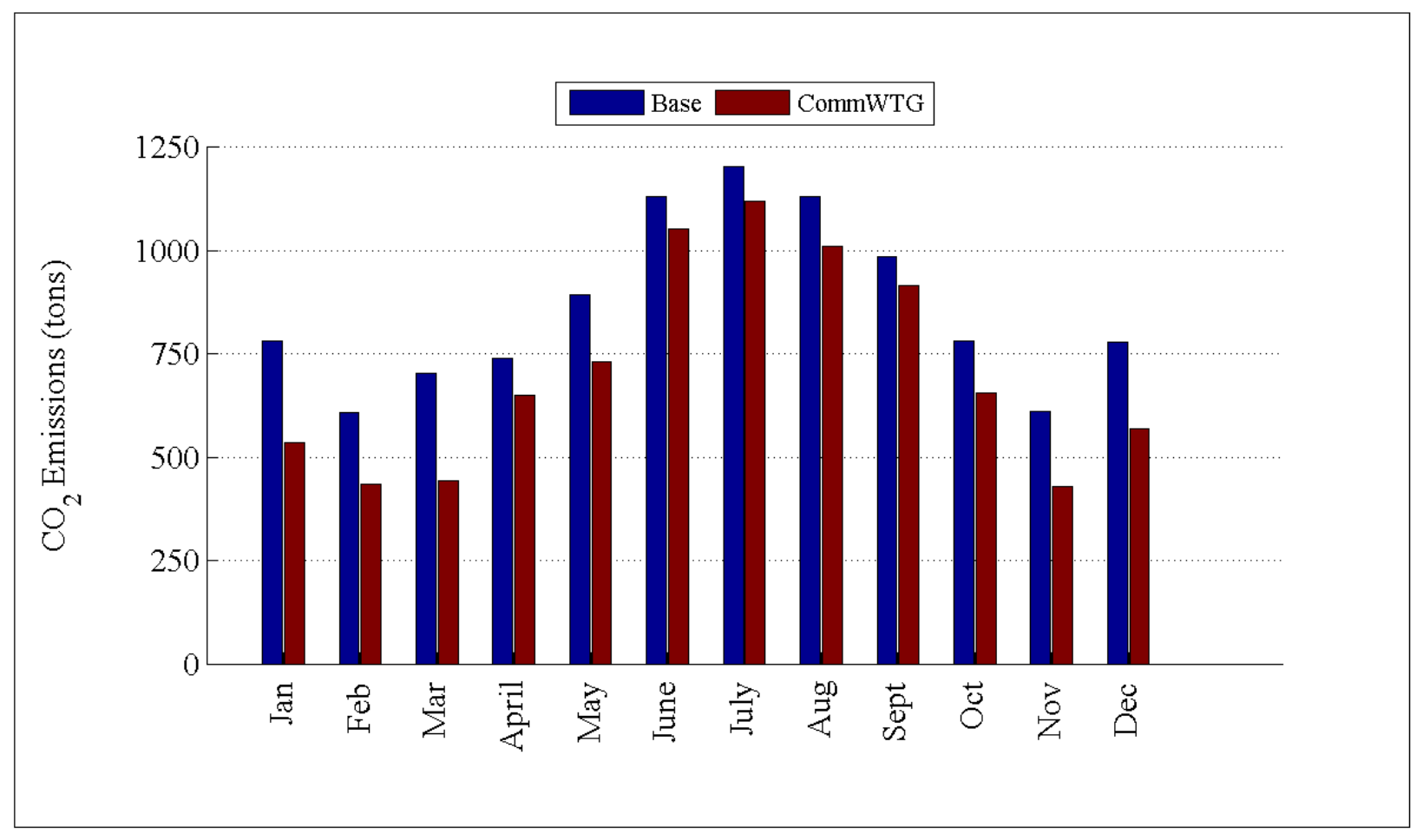

Figure D.348: Comparison of $\mathrm{CO}_{2}$ emissions by month for GC-12.47-1_R4 


\section{D.4.5 Detailed Commercial WTG plots for GC-12.47-1_R5}

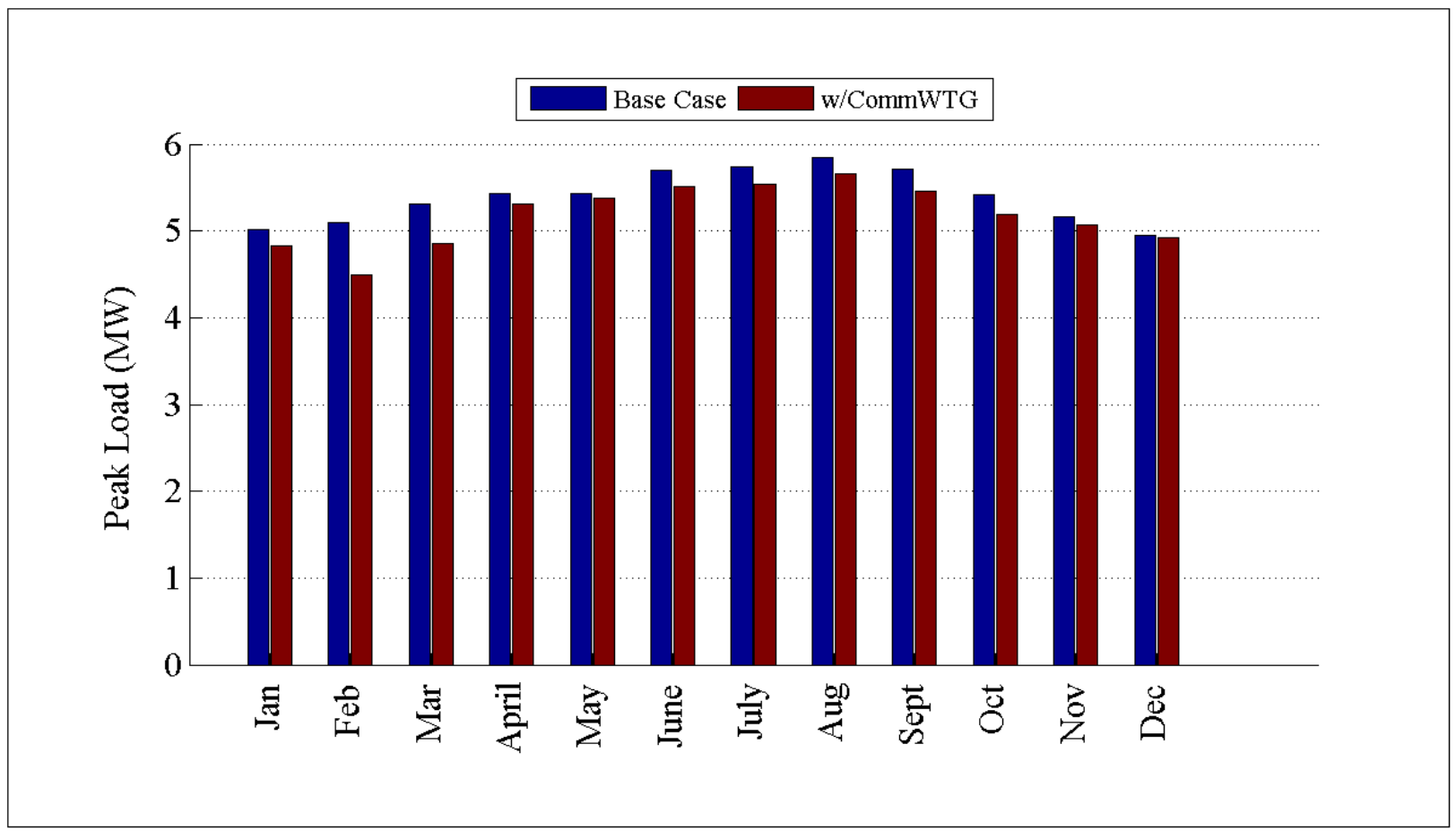

Figure D.349: Comparison of peak load by month for GC-12.47-1_R5

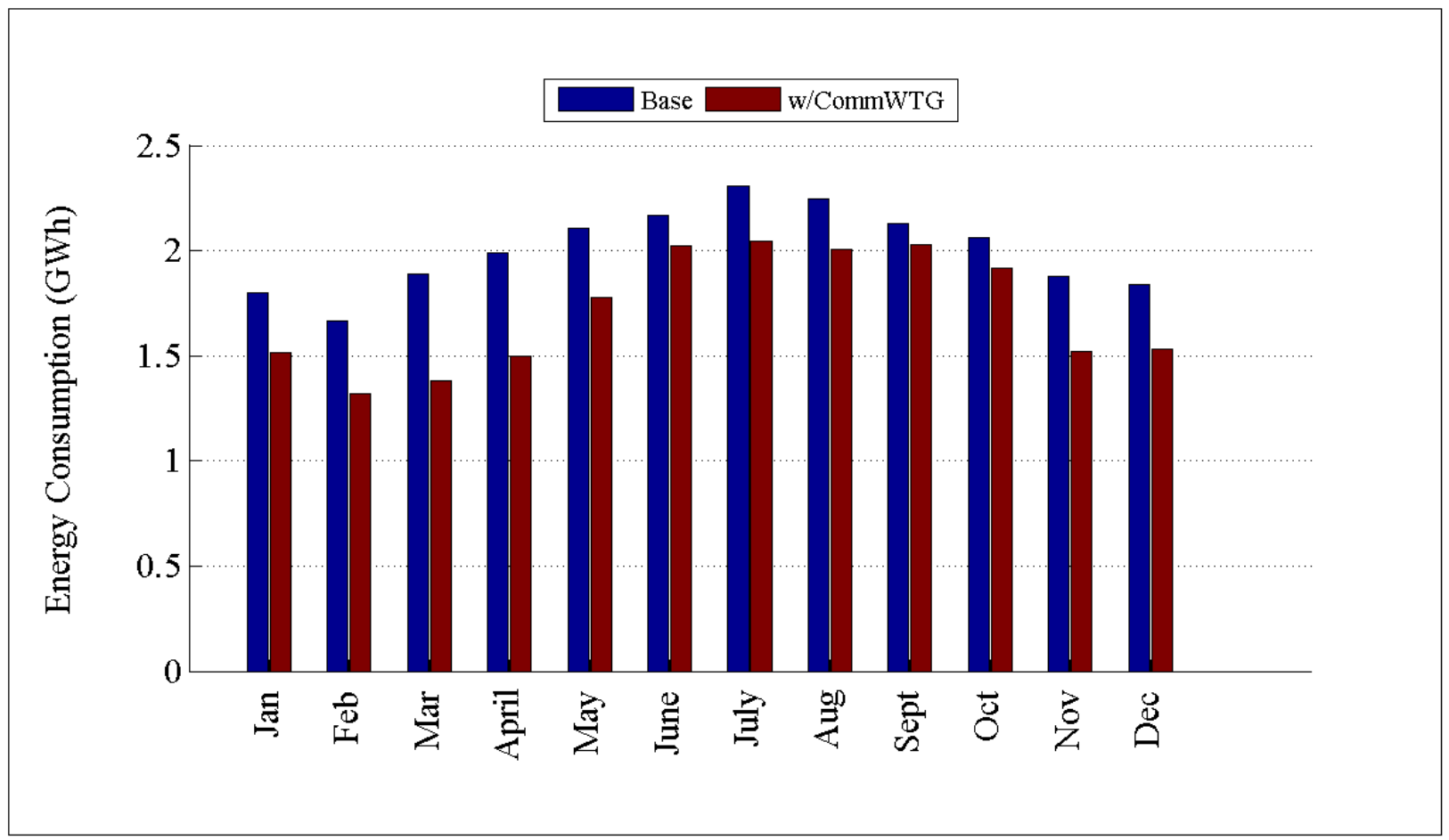

Figure D.350: Comparison of energy consumption by month for GC-12.47-1_R5 


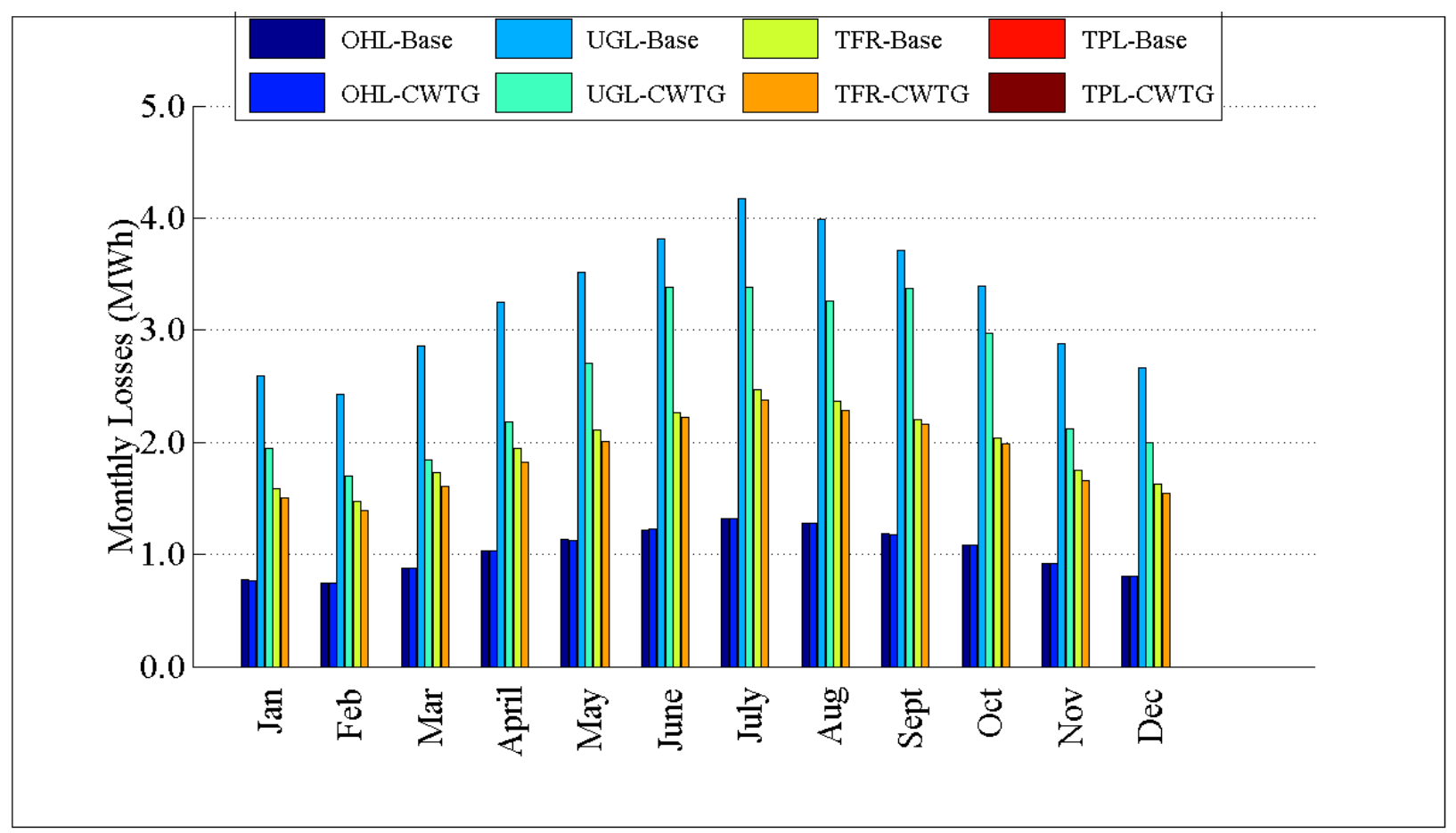

Figure D.351: Comparison of losses by month for GC-12.47-1_R5

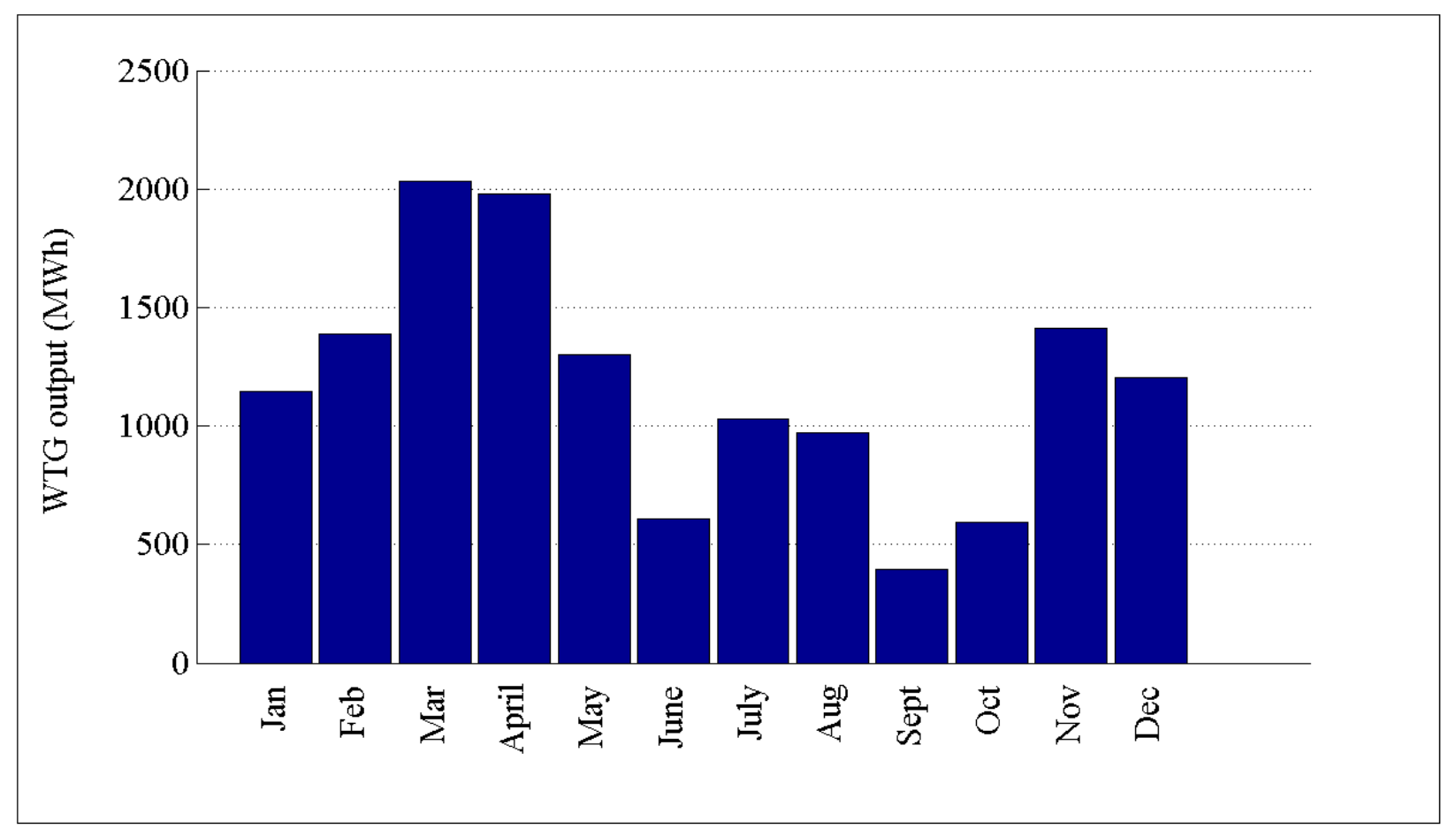

Figure D.352: Comparison of WTG output by month for GC-12.47-1_R5 


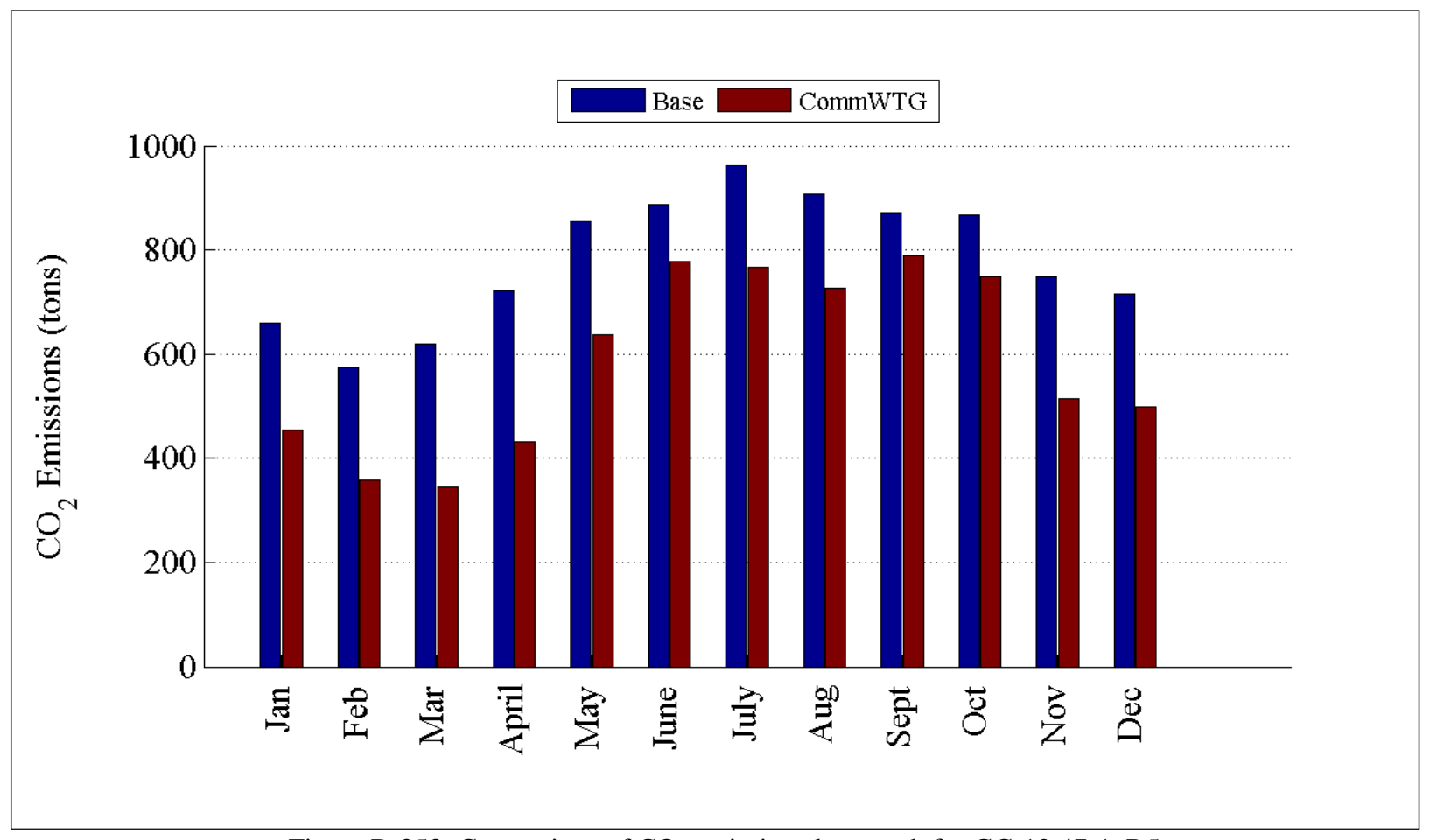

Figure D.353: Comparison of $\mathrm{CO}_{2}$ emissions by month for GC-12.47-1_R5 


\section{Appendix E: Individual Feeder Impact Metrics}

This appendix contains the raw performance metric values for each technology on each of the prototypical distribution feeders. The impact matrices in Section 4.1, 4.2, and 4.3 are calculated from the raw values in this appendix.

E.1 Individual Performance Metrics for Base Case 
Table E.1: Base case performance metrics for region 1

\begin{tabular}{|c|c|c|c|c|c|c|c|c|}
\hline Index & Metric & Units & 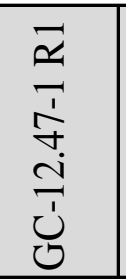 & 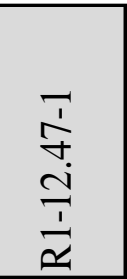 & 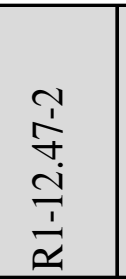 & 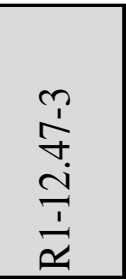 & 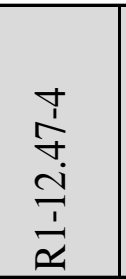 & 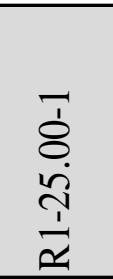 \\
\hline 1 & $\begin{array}{l}\text { Hourly Customer } \\
\text { Electricity Usage }\end{array}$ & $\mathrm{kWh}$ & 2,083 & 2,692 & 992 & 435 & 1,948 & 875 \\
\hline 2 & \begin{tabular}{|l|} 
Monthly Customer \\
Electricity Usage
\end{tabular} & MWh & 1,521 & 1,965 & 724 & 317 & 1,422 & 639 \\
\hline \multirow{12}{*}{3} & Peak Generation & $\mathrm{kW}$ & 5,313 & 7,329 & 2,675 & 1,261 & 5,050 & 2,317 \\
\hline & Nuclear & $\%$ & 10.68 & 10.68 & 10.68 & 10.68 & 10.09 & 10.68 \\
\hline & Solar & $\%$ & 0.25 & 0.25 & 0.25 & 0.25 & 0.21 & 0.25 \\
\hline & Bio & $\%$ & 0.67 & 0.67 & 0.67 & 0.67 & 0.72 & 0.67 \\
\hline & Wind & $\%$ & 4.07 & 4.07 & 4.07 & 4.07 & 3.55 & 4.07 \\
\hline & Coal & $\%$ & 2.88 & 2.88 & 2.88 & 2.88 & 4.38 & 2.88 \\
\hline & Hydroelectric & $\%$ & 36.88 & 36.88 & 36.88 & 36.88 & 26.32 & 36.88 \\
\hline & Natural Gas & $\%$ & 41.38 & 41.38 & 41.38 & 41.38 & 51.24 & 41.38 \\
\hline & Geothermal & $\%$ & 2.84 & 2.84 & 2.84 & 2.84 & 3.11 & 2.84 \\
\hline & Petroleum & $\%$ & 0.35 & 0.35 & 0.35 & 0.35 & 0.38 & 0.35 \\
\hline & Distributed Solar PV & $\%$ & 0.00 & 0.00 & 0.00 & 0.00 & 0.00 & 0.00 \\
\hline & Distributed Wind & $\%$ & 0.00 & 0.00 & 0.00 & 0.00 & 0.00 & 0.00 \\
\hline \multirow{2}{*}{4} & Peak Load & MW & 5,288 & 7,085 & 2,590 & 1,247 & 4,924 & 2,261 \\
\hline & Controllable load & $\%$ & 0.00 & 0.00 & 0.00 & 0.00 & 0.00 & 0.00 \\
\hline 7 & \begin{tabular}{|l|}
$\begin{array}{l}\text { Annual Electricity } \\
\text { Production }\end{array}$ \\
\end{tabular} & $\mathrm{MWh}$ & 18,290 & 24,196 & 8,964 & 3,829 & 17,276 & 7,776 \\
\hline 12 & $\mathrm{CO} 2$ Emis sions & Tons & 1,783 & 2,273 & 818 & 392 & 1,774 & 752 \\
\hline \multirow{3}{*}{13} & SOx Emis sions & Tons & 0.03 & 0.03 & 0.01 & 0.01 & 0.04 & 0.01 \\
\hline & NOx Emis sions & Tons & 0.24 & 0.28 & 0.10 & 0.05 & 0.22 & 0.10 \\
\hline & PM-10 Emis s ions & Tons & 0.25 & 0.32 & 0.12 & 0.06 & 0.25 & 0.11 \\
\hline 16 & Electricity Usage* & $\mathrm{kWh}$ & 0 & 0 & 0 & 0 & 0 & 0 \\
\hline 17 & Annual Storage Dispatch* & $\mathrm{kWh}$ & 0 & 0 & 0 & 0 & 0 & 0 \\
\hline 18 & $\begin{array}{l}\text { Average Energy Storage } \\
\text { Efficiency* }\end{array}$ & $\%$ & 0 & 0 & 0 & 0 & 0 & 0 \\
\hline \multirow{2}{*}{21} & Feeder Real Load & MW & 2,088 & 2,762 & 1,023 & 437 & 1,972 & 888 \\
\hline & Feeder Reactive Load & MVAR & 68 & -284 & -200 & 11 & 62 & -70 \\
\hline 29 & Distribution Losses & $\%$ & 0.23 & 2.54 & 3.05 & 0.56 & 1.21 & 1.44 \\
\hline 30 & Distribution Power Factor & $\mathrm{pf}$ & 0.9994 & 0.9925 & 0.9678 & 0.9997 & 0.9995 & 0.9666 \\
\hline 39 & $\mathrm{CO} 2$ Emissions & Tons & 1,787 & 2,332 & 844 & 394 & 1,796 & 763 \\
\hline \multirow{3}{*}{40} & SOx & Tons & 0.03 & 0.03 & 0.01 & 0.01 & 0.04 & 0.01 \\
\hline & NOx & Tons & 0.24 & 0.29 & 0.11 & 0.05 & 0.22 & 0.10 \\
\hline & PM-10 & Tons & 0.25 & 0.33 & 0.12 & 0.06 & 0.26 & 0.11 \\
\hline
\end{tabular}


Table E.2: Base case performance metrics for region 2

\begin{tabular}{|c|c|c|c|c|c|c|c|c|}
\hline Index & Metric & Units & 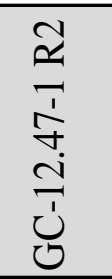 & 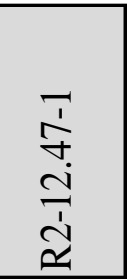 & 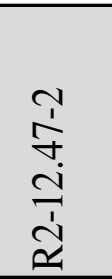 & $\begin{array}{l}\stackrel{1}{1} \\
\stackrel{+}{\sim} \\
\frac{1}{\tilde{d}}\end{array}$ & 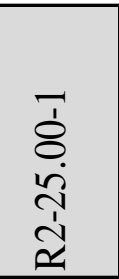 & $\begin{array}{l}\bar{\delta} \\
8 \\
\text { d. } \\
\dot{1} \\
\tilde{1}\end{array}$ \\
\hline 1 & $\begin{array}{l}\text { Hourly Customer } \\
\text { Electricity Usage }\end{array}$ & $\mathrm{kWh}$ & 2,169 & 2,268 & 1,970 & 2,975 & 6,342 & 4,576 \\
\hline 2 & \begin{tabular}{|l|} 
Monthly Customer \\
Electricity Usage
\end{tabular} & MWh & 1,584 & 1,656 & 1,438 & 2,171 & 4,630 & 3,340 \\
\hline \multirow{12}{*}{3} & Peak Generation & $\mathrm{kW}$ & 5,749 & 6,287 & 5,777 & 8,555 & 16,840 & 12,676 \\
\hline & Nuclear & $\%$ & 26.33 & 26.33 & 26.33 & 27.95 & 26.33 & 26.33 \\
\hline & Solar & $\%$ & 0.01 & 0.01 & 0.01 & 0.01 & 0.01 & 0.01 \\
\hline & Bio & $\%$ & 0.82 & 0.82 & 0.82 & 0.84 & 0.82 & 0.82 \\
\hline & Wind & $\%$ & 1.41 & 1.41 & 1.41 & 1.70 & 1.41 & 1.41 \\
\hline & Coal & $\%$ & 47.18 & 47.18 & 47.18 & 45.54 & 47.18 & 47.18 \\
\hline & Hydroelectric & $\%$ & 7.42 & 7.42 & 7.42 & 9.05 & 7.42 & 7.42 \\
\hline & Natural Gas & $\%$ & 16.33 & 16.33 & 16.33 & 14.47 & 16.33 & 16.33 \\
\hline & Geothermal & $\%$ & 0.07 & 0.07 & 0.07 & 0.07 & 0.07 & 0.07 \\
\hline & Petroleum & $\%$ & 0.43 & 0.43 & 0.43 & 0.37 & 0.43 & 0.43 \\
\hline & Distributed Solar PV & $\%$ & 0.00 & 0.00 & 0.00 & 0.00 & 0.00 & 0.00 \\
\hline & Distributed Wind & $\%$ & 0.00 & 0.00 & 0.00 & 0.00 & 0.00 & 0.00 \\
\hline \multirow{2}{*}{4} & Peak Load & MW & 5,720 & 6,166 & 5,647 & 8,360 & 16,622 & 12,533 \\
\hline & Controllable load & $\%$ & 0.00 & 0.00 & 0.00 & 0.00 & 0.00 & 0.00 \\
\hline 7 & \begin{tabular}{|l|}
$\begin{array}{l}\text { Annual Electricity } \\
\text { Production }\end{array}$ \\
\end{tabular} & $\mathrm{MWh}$ & 19,050 & 20,128 & 17,588 & 26,686 & 56,091 & 40,417 \\
\hline 12 & $\mathrm{CO} 2$ Emis sions & Tons & 8,419 & 9,246 & 8,417 & 12,627 & 26,866 & 17,434 \\
\hline \multirow{3}{*}{13} & SOx Emis sions & Tons & 3.81 & 4.21 & 3.88 & 5.82 & 12.33 & 7.86 \\
\hline & NOx Emis sions & Tons & 2.43 & 2.67 & 2.46 & 3.69 & 7.81 & 5.02 \\
\hline & PM-10 Emis s ions & Tons & 1.25 & 1.37 & 1.25 & 1.87 & 3.99 & 2.58 \\
\hline 16 & Electricity Usage* & $\mathrm{kWh}$ & 0 & 0 & 0 & 0 & 0 & 0 \\
\hline 17 & Annual Storage Dispatch* & $\mathrm{kWh}$ & 0 & 0 & 0 & 0 & 0 & 0 \\
\hline 18 & $\begin{array}{l}\text { Average Energy Storage } \\
\text { Efficiency* }\end{array}$ & $\%$ & 0 & 0 & 0 & 0 & 0 & 0 \\
\hline \multirow{2}{*}{21} & Feeder Real Load & MW & 2,175 & 2,298 & 2,008 & 3,046 & 6,403 & 4,614 \\
\hline & Feeder Reactive Load & MVAR & 92 & 116 & 146 & -130 & 333 & 69 \\
\hline 29 & Distribution Losses & $\%$ & 0.25 & 1.27 & 1.87 & 2.36 & 0.96 & 0.82 \\
\hline 30 & Distribution Power Factor & $\mathrm{pf}$ & 0.9989 & 0.9987 & 0.9973 & 0.9973 & 0.9986 & 0.9996 \\
\hline 39 & $\mathrm{CO} 2$ Emis sions & Tons & 8,440 & 9,365 & 8,578 & 12,932 & 27,125 & 17,579 \\
\hline \multirow{3}{*}{40} & SOx & Tons & 3.82 & 4.26 & 3.95 & 5.96 & 12.45 & 7.93 \\
\hline & NOx & Tons & 2.44 & 2.71 & 2.51 & 3.78 & 7.88 & 5.06 \\
\hline & PM-10 & Tons & 1.25 & 1.39 & 1.27 & 1.92 & 4.03 & 2.61 \\
\hline
\end{tabular}


Table E.3: Base case performance metrics for region 3

\begin{tabular}{|c|c|c|c|c|c|c|}
\hline Index & Metric & Units & 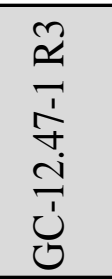 & $\begin{array}{l}\frac{1}{+} \\
\stackrel{+}{d} \\
\frac{1}{2}\end{array}$ & 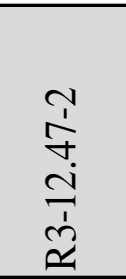 & 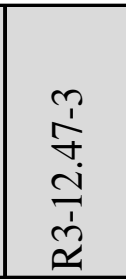 \\
\hline 1 & $\begin{array}{l}\text { Hourly Customer } \\
\text { Electricity Usage }\end{array}$ & $\mathrm{kWh}$ & 2,635 & 3,661 & 1,642 & 3,705 \\
\hline 2 & $\begin{array}{l}\text { Monthly Customer } \\
\text { Electricity Usage }\end{array}$ & MWh & 1,924 & 2,673 & 1,199 & 2,705 \\
\hline \multirow{12}{*}{3} & Peak Generation & $\mathrm{kW}$ & 6,594 & 9,315 & 4,422 & 8,417 \\
\hline & \begin{tabular}{|l} 
Nuclear \\
\end{tabular} & $\%$ & 8.65 & 9.72 & 9.72 & 9.72 \\
\hline & Solar & $\%$ & 0.13 & 0.13 & 0.13 & 0.13 \\
\hline & Bio & $\%$ & 0.23 & 0.25 & 0.25 & 0.25 \\
\hline & Wind & $\%$ & 2.05 & 2.45 & 2.45 & 2.45 \\
\hline & Coal & $\%$ & 40.24 & 41.52 & 41.52 & 41.52 \\
\hline & Hydroelectric & $\%$ & 5.58 & 6.40 & 6.40 & 6.40 \\
\hline & Natural Gas & $\%$ & 41.67 & 37.88 & 37.88 & 37.88 \\
\hline & Geothermal & $\%$ & 1.25 & 1.40 & 1.40 & 1.40 \\
\hline & Petroleum & $\%$ & 0.20 & 0.25 & 0.25 & 0.25 \\
\hline & Distributed Solar PV & $\%$ & 0.00 & 0.00 & 0.00 & 0.00 \\
\hline & Distributed Wind & $\%$ & 0.00 & 0.00 & 0.00 & 0.00 \\
\hline \multirow{2}{*}{4} & Peak Load & MW & 6,554 & 9,122 & 4,364 & 8,157 \\
\hline & Controllable load & $\%$ & 0.00 & 0.00 & 0.00 & 0.00 \\
\hline 7 & $\begin{array}{l}\text { Annual Electricity } \\
\text { Production }\end{array}$ & MWh & 23,160 & 32,687 & 14,483 & 33,603 \\
\hline 12 & $\mathrm{CO} 2$ Emis sions & Tons & 16,269 & 23,430 & 9,963 & 25,107 \\
\hline \multirow{3}{*}{13} & SOx Emissions & Tons & 7.03 & 10.24 & 4.25 & 11.14 \\
\hline & NOx Emissions & Tons & 4.38 & 6.36 & 2.66 & 6.88 \\
\hline & PM-10 Emis sions & Tons & 2.42 & 3.49 & 1.48 & 3.74 \\
\hline 16 & Electricity Usage* & $\mathrm{kWh}$ & 0 & 0 & 0 & 0 \\
\hline 17 & Annual Storage Dispatch* & $\mathrm{kWh}$ & 0 & 0 & 0 & 0 \\
\hline 18 & $\begin{array}{l}\text { Average Energy Storage } \\
\text { Efficiency* }\end{array}$ & $\%$ & 0 & 0 & 0 & 0 \\
\hline \multirow[t]{2}{*}{21} & Feeder Real Load & MW & 2,644 & 3,731 & 1,653 & 3,836 \\
\hline & Feeder Reactive Load & MVAR & 219 & 484 & 143 & 547 \\
\hline 29 & Distribution Losses & $\%$ & 0.33 & 1.87 & 0.69 & 3.40 \\
\hline 30 & Distribution Power Factor & $\mathrm{pf}$ & 0.9969 & 0.9904 & 0.99685 & 0.98973 \\
\hline 39 & $\mathrm{CO} 2$ Emis sions & Tons & 16,323 & 23,877 & 10,032 & 25,991 \\
\hline \multirow{3}{*}{40} & SOx & Tons & 7.05 & 10.44 & 4.28 & 11.53 \\
\hline & NOx & Tons & 4.39 & 6.48 & 2.67 & 7.12 \\
\hline & PM-10 & Tons & 2.43 & 3.56 & 1.49 & 3.87 \\
\hline
\end{tabular}


Table E.4: Base case performance metrics for region 4

\begin{tabular}{|c|c|c|c|c|c|c|}
\hline Index & Metric & Units & 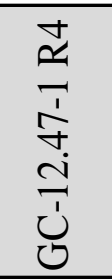 & 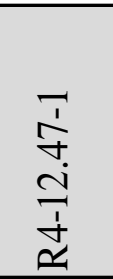 & 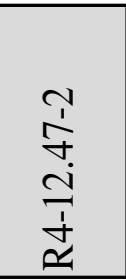 & 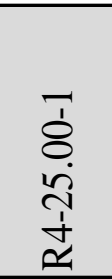 \\
\hline 1 & $\begin{array}{l}\text { Hourly Customer } \\
\text { Electricity Usage }\end{array}$ & $\mathrm{kWh}$ & 2,339 & 1,909 & 832 & 347 \\
\hline 2 & \begin{tabular}{|l|} 
Monthly Customer \\
Electricity Usage
\end{tabular} & MWh & 1,708 & 1,393 & 607 & 253 \\
\hline \multirow{12}{*}{3} & Peak Generation & $\mathrm{kW}$ & 6,221 & 4,798 & 2,205 & 945 \\
\hline & Nuclear & $\%$ & 21.91 & 21.91 & 23.58 & 23.58 \\
\hline & Solar & $\%$ & 0.00 & 0.00 & 0.00 & 0.00 \\
\hline & Bio & $\%$ & 0.18 & 0.18 & 0.21 & 0.21 \\
\hline & Wind & $\%$ & 0.60 & 0.60 & 0.59 & 0.59 \\
\hline & Coal & $\%$ & 57.14 & 57.14 & 56.06 & 56.06 \\
\hline & Hydroelectric & $\%$ & 2.20 & 2.20 & 3.09 & 3.09 \\
\hline & Natural Gas & $\%$ & 17.49 & 17.49 & 16.14 & 16.14 \\
\hline & Geothermal & $\%$ & 0.00 & 0.00 & 0.00 & 0.00 \\
\hline & Petroleum & $\%$ & 0.48 & 0.48 & 0.33 & 0.33 \\
\hline & Distributed Solar PV & $\%$ & 0.00 & 0.00 & 0.00 & 0.00 \\
\hline & Distributed Wind & $\%$ & 0.00 & 0.00 & 0.00 & 0.00 \\
\hline \multirow{2}{*}{4} & Peak Load & MW & 6,186 & 4,701 & 2,171 & 928 \\
\hline & Controllable load & $\%$ & 0.00 & 0.00 & 0.00 & 0.00 \\
\hline 7 & \begin{tabular}{|l|}
$\begin{array}{l}\text { Annual Electricity } \\
\text { Production }\end{array}$ \\
\end{tabular} & MWh & 20,550 & 17,195 & 7,457 & 3,118 \\
\hline 12 & $\mathrm{CO} 2$ Emis sions & Tons & 10,321 & 9,844 & 3,994 & 1,608 \\
\hline \multirow{3}{*}{13} & SOx Emissions & Tons & 4.91 & 4.72 & 1.92 & 0.77 \\
\hline & NOx Emis sions & Tons & 3.00 & 2.87 & 1.17 & 0.47 \\
\hline & PM-10 Emis sions & Tons & 1.54 & 1.47 & 0.60 & 0.24 \\
\hline 16 & Electricity Usage* & $\mathrm{kWh}$ & 0 & 0 & 0 & 0 \\
\hline 17 & Annual Storage Dispatch* & $\mathrm{kWh}$ & 0 & 0 & 0 & 0 \\
\hline 18 & $\begin{array}{l}\text { Average Energy Storage } \\
\text { Efficiency* }\end{array}$ & $\%$ & 0 & 0 & 0 & 0 \\
\hline \multirow{2}{*}{21} & Feeder Real Load & MW & 2,346 & 1,963 & 851 & 356 \\
\hline & Feeder Reactive Load & MVAR & 138 & -413 & 98 & 45 \\
\hline 29 & Distribution Losses & $\%$ & 0.28 & 2.76 & 2.32 & 2.53 \\
\hline 30 & Distribution Power Factor & $\mathrm{pf}$ & 0.9982 & 0.9666 & 0.9934 & 0.9920 \\
\hline 39 & $\mathrm{CO} 2$ Emis sions & Tons & 10,350 & 10,123 & 4,089 & 1,650 \\
\hline \multirow{3}{*}{40} & SOx & Tons & 4.93 & 4.86 & 1.96 & 0.79 \\
\hline & NOx & Tons & 3.00 & 2.95 & 1.19 & 0.48 \\
\hline & PM-10 & Tons & 1.54 & 1.51 & 0.61 & 0.25 \\
\hline
\end{tabular}


Table E.5: Base case performance metrics for region 5

\begin{tabular}{|c|c|c|c|c|c|c|c|c|c|c|}
\hline Index & Metric & Units & 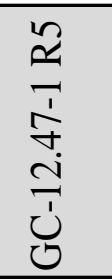 & 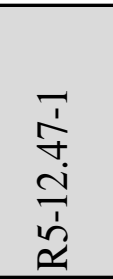 & 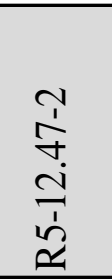 & 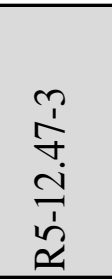 & 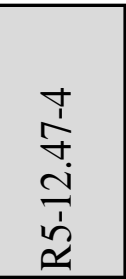 & $\begin{array}{l}\frac{r}{f} \\
\frac{1}{\sim} \\
\frac{1}{2}\end{array}$ & 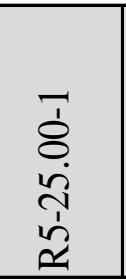 & $\begin{array}{l}\bar{\delta} \\
8 \\
\dot{\delta} \\
\tilde{n} \\
\dot{1}\end{array}$ \\
\hline 1 & $\begin{array}{l}\text { Hourly Customer } \\
\text { Electricity Usage }\end{array}$ & kWh & 2,747 & 4,490 & 2,226 & 4,669 & 3,468 & 4,116 & 5,627 & 5,689 \\
\hline 2 & $\begin{array}{l}\text { Monthly Customer } \\
\text { Electricity Usage }\end{array}$ & MWh & 2,005 & 3,278 & 1,625 & 3,408 & 2,532 & 3,005 & 4,108 & 4,153 \\
\hline \multirow{12}{*}{3} & Peak Generation & $\mathrm{kW}$ & 5,841 & 9,451 & 4,992 & 10,384 & 7,531 & 9,041 & 12,282 & 12,428 \\
\hline & \begin{tabular}{|l} 
Nuclear \\
\end{tabular} & $\%$ & 13.85 & 13.85 & 13.85 & 13.53 & 13.85 & 13.53 & 13.85 & 13.85 \\
\hline & Solar & $\%$ & 0.00 & 0.00 & 0.00 & 0.00 & 0.00 & 0.00 & 0.00 & 0.00 \\
\hline & Bio & $\%$ & 0.33 & 0.33 & 0.33 & 0.31 & 0.33 & 0.31 & 0.33 & 0.33 \\
\hline & Wind & $\%$ & 1.48 & 1.48 & 1.48 & 1.74 & 1.48 & 1.74 & 1.48 & 1.48 \\
\hline & Coal & $\%$ & 30.17 & 30.17 & 30.17 & 30.37 & 30.17 & 30.37 & 30.17 & 30.17 \\
\hline & Hydroelectric & $\%$ & 0.63 & 0.63 & 0.63 & 0.78 & 0.63 & 0.78 & 0.63 & 0.63 \\
\hline & Natural Gas & $\%$ & 51.68 & 51.68 & 51.68 & 51.29 & 51.68 & 51.29 & 51.68 & 51.68 \\
\hline & Geothermal & $\%$ & 0.00 & 0.00 & 0.00 & 0.00 & 0.00 & 0.00 & 0.00 & 0.00 \\
\hline & Petroleum & $\%$ & 1.86 & 1.86 & 1.86 & 1.98 & 1.86 & 1.98 & 1.86 & 1.86 \\
\hline & Distributed Solar PV & $\%$ & 0.00 & 0.00 & 0.00 & 0.00 & 0.00 & 0.00 & 0.00 & 0.00 \\
\hline & Dis tributed Wind & $\%$ & 0.00 & 0.00 & 0.00 & 0.00 & 0.00 & 0.00 & 0.00 & 0.00 \\
\hline \multirow{2}{*}{4} & Peak Load & MW & 5,810 & 9,319 & 4,848 & 9,772 & 7,373 & 8,784 & 12,088 & 12,270 \\
\hline & Controllable load & $\%$ & 0.00 & 0.00 & 0.00 & 0.00 & 0.00 & 0.00 & 0.00 & 0.00 \\
\hline 7 & \begin{tabular}{|l} 
Annual Electricity \\
Production
\end{tabular} & MWh & 24,144 & 39,806 & 19,900 & 42,781 & 30,976 & 36,921 & 49,992 & 50,486 \\
\hline 12 & $\mathrm{CO} 2$ Emissions & Tons & 9,364 & 15,419 & 7,414 & 15,195 & 11,809 & 13,594 & 18,504 & 18,904 \\
\hline \multirow{3}{*}{13} & SOx Emissions & Tons & 1.55 & 2.23 & 1.11 & 1.64 & 1.70 & 1.66 & 2.19 & 2.34 \\
\hline & NOx Emissions & Tons & 1.38 & 2.11 & 1.04 & 1.82 & 1.61 & 1.72 & 2.31 & 2.41 \\
\hline & PM-10 Emis sions & Tons & 1.37 & 2.26 & 1.09 & 2.23 & 1.73 & 1.99 & 2.71 & 2.77 \\
\hline 16 & Electricity Usage* & $\mathrm{kWh}$ & 0 & 0 & 0 & 0 & 0 & 0 & 0 & 0 \\
\hline 17 & Annual Storage Dis patch* & $\mathrm{kWh}$ & 0 & 0 & 0 & 0 & 0 & 0 & 0 & 0 \\
\hline 18 & $\begin{array}{l}\text { Average Energy Storage } \\
\text { Efficiency* }\end{array}$ & $\%$ & 0 & 0 & 0 & 0 & 0 & 0 & 0 & 0 \\
\hline \multirow{2}{*}{21} & Feeder Real Load & MW & 2,756 & 4,544 & 2,272 & 4,884 & 3,536 & 4,215 & 5,707 & 5,763 \\
\hline & Feeder Reactive Load & MVAR & 248 & 542 & 242 & -357 & 407 & 594 & 650 & 641 \\
\hline 29 & Distribution Losses & $\%$ & 0.33 & 1.19 & 2.02 & 4.41 & 1.92 & 2.34 & 1.39 & 1.28 \\
\hline 30 & Distribution Power Factor & $\mathrm{pf}$ & 0.9964 & 0.9937 & 0.9952 & 0.9779 & 0.9942 & 0.9913 & 0.9942 & 0.9944 \\
\hline 39 & $\mathrm{CO} 2$ Emissions & Tons & 9,395 & 15,605 & 7,567 & 15,895 & 12,040 & 13,919 & 18,766 & 19,150 \\
\hline \multirow{3}{*}{40} & SOx & Tons & 1.55 & 2.26 & 1.14 & 1.72 & 1.73 & 1.70 & 2.22 & 2.37 \\
\hline & NOx & Tons & 1.39 & 2.14 & 1.06 & 1.91 & 1.65 & 1.76 & 2.34 & 2.44 \\
\hline & PM-10 & Tons & 1.38 & 2.29 & 1.11 & 2.33 & 1.77 & 2.04 & 2.75 & 2.81 \\
\hline
\end{tabular}




\section{E.2 Individual Residential PV Performance Metrics}

Table E.6: Residential PV performance metrics for region 1

\begin{tabular}{|c|c|c|c|c|c|c|c|}
\hline Index & Metric & Units & 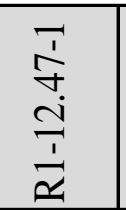 & 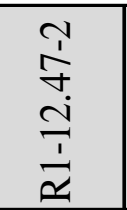 & 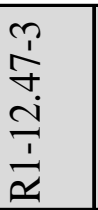 & 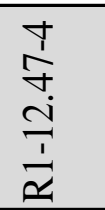 & 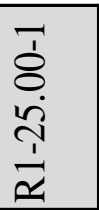 \\
\hline 1 & \begin{tabular}{|l|}
$\begin{array}{l}\text { Hourly Customer } \\
\text { Electricity Usage }\end{array}$ \\
\end{tabular} & $\mathrm{kWh}$ & 2,665 & 981 & 427 & 1,923 & 866 \\
\hline 2 & $\begin{array}{l}\text { Monthly Customer } \\
\text { Electricity Usage }\end{array}$ & MWh & 1,945 & 716 & 312 & 1,404 & 632 \\
\hline \multirow{12}{*}{3} & Peak Generation & $\mathrm{kW}$ & 7,398 & 2,662 & 1,176 & 4,916 & 2,360 \\
\hline & Nuclear & $\%$ & 10.56 & 9.96 & 10.14 & 10.74 & 10.49 \\
\hline & Solar & $\%$ & 0.25 & 0.21 & 0.21 & 0.25 & 0.25 \\
\hline & Bio & $\%$ & 0.66 & 0.71 & 0.72 & 0.67 & 0.66 \\
\hline & Wind & $\%$ & 4.02 & 3.51 & 3.57 & 4.09 & 4.00 \\
\hline & Coal & $\%$ & 2.85 & 4.33 & 4.40 & 2.90 & 2.83 \\
\hline & Hydroelectric & $\%$ & 36.47 & 25.99 & 26.44 & 37.09 & 36.21 \\
\hline & Natural Gas & $\%$ & 40.92 & 50.60 & 51.48 & 41.61 & 40.63 \\
\hline & Geothermal & $\%$ & 2.81 & 3.07 & 1.20 & 1.10 & 2.79 \\
\hline & Petroleum & $\%$ & 0.17 & 0.69 & 0.00 & 0.00 & 0.34 \\
\hline & Distributed Solar PV & $\%$ & 1.30 & 0.93 & 1.84 & 1.55 & 1.81 \\
\hline & Distributed Wind & $\%$ & 0.00 & 0.00 & 0.00 & 0.00 & 0.00 \\
\hline 4 & Peak Load & MW & 7,072 & 2,544 & 1,168 & 4,817 & 2,261 \\
\hline 7 & \begin{tabular}{|l} 
Annual Electricity \\
Production
\end{tabular} & MWh & 23,952 & 8,862 & 3,765 & 17,049 & 7,698 \\
\hline 12 & $\mathrm{CO} 2$ Emis sions & Tons & 2,211 & 791 & 371 & 1,705 & 725 \\
\hline \multirow{3}{*}{13} & SOx Emis sions & Tons & 0.03 & 0.01 & 0.00 & 0.03 & 0.01 \\
\hline & NOx Emis sions & Tons & 0.28 & 0.10 & 0.05 & 0.21 & 0.10 \\
\hline & PM-10 Emissions & Tons & 0.31 & 0.11 & 0.05 & 0.24 & 0.10 \\
\hline \multirow{2}{*}{21} & Feeder Real Load & MW & 2,734 & 1,012 & 430 & 1,946 & 879 \\
\hline & Feeder Reactive Load & MVAR & -284.80 & -199.79 & 10.46 & 61.47 & -70.59 \\
\hline 29 & Distribution Losses & $\%$ & 2.55 & 3.07 & 0.55 & 1.19 & 1.43 \\
\hline 30 & Distribution Power Factor & $\mathrm{pf}$ & 0.99 & 0.97 & 1.00 & 1.00 & 0.97 \\
\hline 39 & $\mathrm{CO} 2$ Emissions & Tons & 2,269 & 816 & 373 & 1,726 & 736 \\
\hline \multirow{3}{*}{40} & SOx & Tons & 0.03 & 0.01 & 0.00 & 0.03 & 0.01 \\
\hline & NOx & Tons & 0.28 & 0.10 & 0.05 & 0.22 & 0.10 \\
\hline & PM-10 & Tons & 0.32 & 0.12 & 0.05 & 0.24 & 0.10 \\
\hline
\end{tabular}


Table E.7: Residential PV performance metrics for region 2

\begin{tabular}{|c|c|c|c|c|c|c|c|}
\hline Index & Metric & Units & 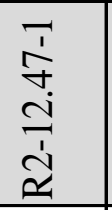 & 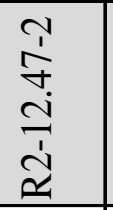 & 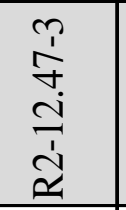 & 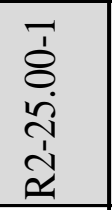 & $\begin{array}{l}7 \\
\delta \\
\dot{\delta} \\
\tilde{d} \\
\dot{v} \\
\tilde{c}\end{array}$ \\
\hline 1 & $\begin{array}{l}\text { Hourly Customer } \\
\text { Electricity Usage }\end{array}$ & $\mathrm{kWh}$ & 2,260 & 1,962 & 2,971 & 6,321 & 4,560 \\
\hline 2 & $\begin{array}{l}\text { Monthly Customer } \\
\text { Electricity Usage }\end{array}$ & MWh & 1,649 & 1,432 & 2,169 & 4,614 & 3,329 \\
\hline \multirow{12}{*}{3} & Peak Generation & $\mathrm{kW}$ & 6,094 & 5,968 & 8,464 & 16,871 & 12,382 \\
\hline & Nuclear & $\%$ & 26.67 & 25.84 & 26.41 & 26.24 & 27.95 \\
\hline & Solar & $\%$ & 0.01 & 0.01 & 0.01 & 0.01 & 0.01 \\
\hline & Bio & $\%$ & 0.83 & 0.80 & 0.82 & 0.82 & 0.84 \\
\hline & Wind & $\%$ & 1.43 & 1.38 & 1.41 & 1.41 & 1.70 \\
\hline & Coal & $\%$ & 47.78 & 46.30 & 47.33 & 47.02 & 45.54 \\
\hline & Hydroelectric & $\%$ & 6.18 & 7.28 & 7.44 & 7.39 & 8.94 \\
\hline & Natural Gas & $\%$ & 16.54 & 16.03 & 16.38 & 16.27 & 14.47 \\
\hline & Geothermal & $\%$ & 0.00 & 0.07 & 0.00 & 0.07 & 0.00 \\
\hline & Petroleum & $\%$ & 0.00 & 1.79 & 0.00 & 0.27 & 0.00 \\
\hline & Distributed Solar PV & $\%$ & 0.56 & 0.50 & 0.18 & 0.50 & 0.54 \\
\hline & Distributed Wind & $\%$ & 0.00 & 0.00 & 0.00 & 0.00 & 0.00 \\
\hline \multirow[b]{2}{*}{4} & Peak Load & MW & 6,051 & 5,727 & 8,297 & 16,596 & 12,241 \\
\hline & $\begin{array}{l}\text { Annual Electricity } \\
\text { Production }\end{array}$ & MWh & 20,049 & 17,513 & 26,651 & 55,904 & 40,275 \\
\hline 12 & $\mathrm{CO} 2$ Emis sions & Tons & 9,187 & 8,347 & 12,595 & 26,709 & 17,338 \\
\hline \multirow{3}{*}{13} & SOx Emis sions & Tons & 4.18 & 3.85 & 5.81 & 12.26 & 7.82 \\
\hline & NOx Emis sions & Tons & 2.66 & 2.44 & 3.68 & 7.77 & 4.99 \\
\hline & PM-10 Emis sions & Tons & 1.36 & 1.24 & 1.87 & 3.96 & 2.57 \\
\hline \multirow{2}{*}{21} & Feeder Real Load & MW & 2,289 & 1,999 & 3,042 & 6,382 & 4,598 \\
\hline & Feeder Reactive Load & MVAR & 116.29 & 146.10 & -130.05 & 332.65 & 68.90 \\
\hline 29 & Distribution Losses & $\%$ & 1.27 & 1.87 & 2.36 & 0.96 & 0.82 \\
\hline 30 & Distribution Power Factor & $\mathrm{pf}$ & 1.00 & 1.00 & 1.00 & 1.00 & 1.00 \\
\hline 39 & $\mathrm{CO} 2$ Emis sions & Tons & 9,305 & 8,506 & 12,899 & 26,967 & 17,481 \\
\hline \multirow{3}{*}{40} & SOx & Tons & 4.24 & 3.92 & 5.95 & 12.38 & 7.89 \\
\hline & $\mathrm{NOx}$ & Tons & 2.69 & 2.49 & 3.77 & 7.84 & 5.04 \\
\hline & PM-10 & Tons & 1.38 & 1.26 & 1.91 & 4.00 & 2.59 \\
\hline
\end{tabular}


Table E.8: Residential PV performance metrics for region 3

\begin{tabular}{|c|c|c|c|c|c|}
\hline Index & Metric & Units & 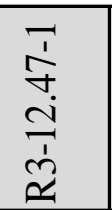 & 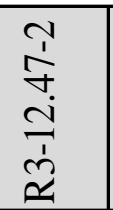 & 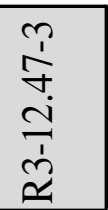 \\
\hline 1 & $\begin{array}{l}\text { Hourly Customer } \\
\text { Electricity Usage }\end{array}$ & $\mathrm{kWh}$ & 3,597 & 1,642 & 3,657 \\
\hline 2 & $\begin{array}{l}\text { Monthly Customer } \\
\text { Electricity Usage }\end{array}$ & MWh & 2,626 & 1,199 & 2,669 \\
\hline \multirow{12}{*}{3} & Peak Generation & $\mathrm{kW}$ & 8,985 & 4,422 & 8,338 \\
\hline & Nuclear & $\%$ & 9.78 & 9.72 & 9.67 \\
\hline & Solar & $\%$ & 0.13 & 0.13 & 0.13 \\
\hline & Bio & $\%$ & 0.25 & 0.25 & 0.25 \\
\hline & Wind & $\%$ & 2.47 & 2.45 & 2.44 \\
\hline & Coal & $\%$ & 41.78 & 41.52 & 41.32 \\
\hline & Hydroelectric & $\%$ & 5.15 & 6.40 & 6.37 \\
\hline & Natural Gas & $\%$ & 38.12 & 37.88 & 37.70 \\
\hline & Geothermal & $\%$ & 0.00 & 1.40 & 0.24 \\
\hline & Petroleum & $\%$ & 0.00 & 0.25 & 0.00 \\
\hline & Distributed Solar PV & $\%$ & 2.32 & 0.00 & 1.87 \\
\hline & Distributed Wind & $\%$ & 0.00 & 0.00 & 0.00 \\
\hline \multirow[b]{2}{*}{4} & Peak Load & MW & 8,848 & 4,364 & 8,038 \\
\hline & $\begin{array}{l}\text { Annual Electricity } \\
\text { Production }\end{array}$ & MWh & 32,110 & 14,483 & 33,168 \\
\hline 12 & $\mathrm{CO} 2$ Emissions & Tons & 23,080 & 9,963 & 24,830 \\
\hline \multirow{3}{*}{13} & SOx Emis sions & Tons & 10.17 & 4.25 & 11.07 \\
\hline & NOx Emis sions & Tons & 6.30 & 2.66 & 6.83 \\
\hline & PM-10 Emis sions & Tons & 3.44 & 1.48 & 3.70 \\
\hline \multirow{2}{*}{21} & Feeder Real Load & MW & 3,666 & 1,653 & 3,786 \\
\hline & Feeder Reactive Load & MVAR & 482.96 & 142.77 & 546.53 \\
\hline 29 & Distribution Losses & $\%$ & 1.88 & 0.69 & 3.42 \\
\hline 30 & Distribution Power Factor & $\mathrm{pf}$ & 0.99 & 1.00 & 0.99 \\
\hline 39 & $\mathrm{CO} 2$ Emis sions & Tons & 23,523 & 10,032 & 25,710 \\
\hline \multirow{3}{*}{40} & SOx & Tons & 10.36 & 4.28 & 11.46 \\
\hline & NOx & Tons & 6.42 & 2.67 & 7.07 \\
\hline & PM-10 & Tons & 3.51 & 1.49 & 3.83 \\
\hline
\end{tabular}


Table E.9: Residential PV performance metrics for region 4

\begin{tabular}{|c|c|c|c|c|c|}
\hline Index & Metric & Units & 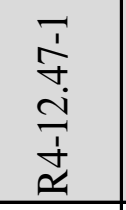 & 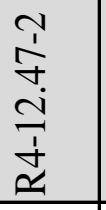 & 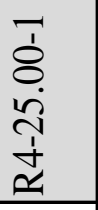 \\
\hline 1 & $\begin{array}{l}\text { Hourly Customer } \\
\text { Electricity Usage }\end{array}$ & $\mathrm{kWh}$ & 1,871 & 816 & 339 \\
\hline 2 & $\begin{array}{l}\text { Monthly Customer } \\
\text { Electricity Usage } \\
\end{array}$ & MWh & 1,366 & 596 & 248 \\
\hline \multirow{12}{*}{3} & Peak Generation & $\mathrm{kW}$ & 4,607 & 2,175 & 892 \\
\hline & Nuclear & $\%$ & 21.99 & 21.62 & 23.96 \\
\hline & Solar & $\%$ & 0.00 & 0.00 & 0.00 \\
\hline & Bio & $\%$ & 0.18 & 0.18 & 0.21 \\
\hline & Wind & $\%$ & 0.60 & 0.59 & 0.60 \\
\hline & Coal & $\%$ & 57.34 & 56.38 & 56.96 \\
\hline & Hydroelectric & $\%$ & 0.00 & 0.93 & 0.00 \\
\hline & Natural Gas & $\%$ & 16.59 & 17.26 & 15.71 \\
\hline & Geothermal & $\%$ & 0.00 & 0.00 & 0.00 \\
\hline & Petroleum & $\%$ & 0.00 & 0.00 & 0.00 \\
\hline & Distributed Solar PV & $\%$ & 3.30 & 3.03 & 2.56 \\
\hline & Distributed Wind & $\%$ & 0.00 & 0.00 & 0.00 \\
\hline \multirow[b]{2}{*}{4} & Peak Load & MW & 4,527 & 2,112 & 889 \\
\hline & $\begin{array}{l}\text { Annual Electricity } \\
\text { Production }\end{array}$ & MWh & 16,859 & 7,324 & 3,050 \\
\hline 12 & $\mathrm{CO} 2$ Emissions & Tons & 9,521 & 3,861 & 1,539 \\
\hline \multirow{3}{*}{13} & SOx Emis sions & Tons & 4.58 & 1.86 & 0.74 \\
\hline & NOx Emis sions & Tons & 2.78 & 1.13 & 0.45 \\
\hline & PM-10 Emissions & Tons & 1.42 & 0.58 & 0.23 \\
\hline \multirow{2}{*}{21} & Feeder Real Load & MW & 1,925 & 836 & 348 \\
\hline & Feeder Reactive Load & MVAR & -413.97 & 97.85 & 44.67 \\
\hline 29 & Distribution Losses & $\%$ & 2.79 & 2.35 & 2.58 \\
\hline 30 & Distribution Power Factor & $\mathrm{pf}$ & 0.96 & 0.99 & 0.99 \\
\hline 39 & $\mathrm{CO} 2$ Emis sions & Tons & 9,795 & 3,954 & 1,580 \\
\hline \multirow{3}{*}{40} & SOx & Tons & 4.71 & 1.90 & 0.76 \\
\hline & NOx & Tons & 2.86 & 1.16 & 0.46 \\
\hline & PM-10 & Tons & 1.46 & 0.59 & 0.24 \\
\hline
\end{tabular}


Table E.10: Residential PV performance metrics for region 5

\begin{tabular}{|c|c|c|c|c|c|c|c|c|c|}
\hline Index & Metric & Units & 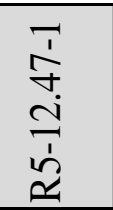 & 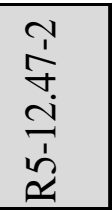 & 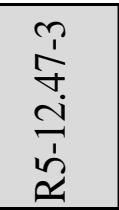 & 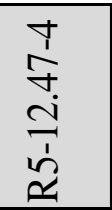 & 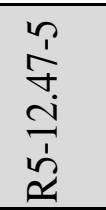 & 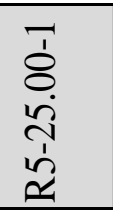 & 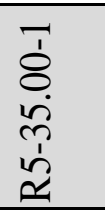 \\
\hline 1 & $\begin{array}{l}\text { Hourly Customer } \\
\text { Electricity Usage }\end{array}$ & $\mathrm{kWh}$ & 4,408 & 2,177 & 4,574 & 3,401 & 4,034 & 5,506 & 5,568 \\
\hline 2 & $\begin{array}{l}\text { Monthly Customer } \\
\text { Electricity Usage }\end{array}$ & MWh & 3,218 & 1,589 & 3,339 & 2,483 & 2,945 & 4,020 & 4,065 \\
\hline \multirow{12}{*}{3} & Peak Generation & $\mathrm{kW}$ & 9,224 & 4,979 & 10,502 & 7,232 & 8,887 & 11,791 & 11,849 \\
\hline & Nuclear & $\%$ & 13.82 & 13.56 & 13.27 & 13.93 & 13.72 & 13.88 & 13.96 \\
\hline & Solar & $\%$ & 0.00 & 0.00 & 0.00 & 0.00 & 0.00 & 0.00 & 0.00 \\
\hline & Bio & $\%$ & 0.33 & 0.32 & 0.30 & 0.33 & 0.33 & 0.33 & 0.33 \\
\hline & Wind & $\%$ & 1.48 & 1.45 & 1.71 & 1.49 & 1.47 & 1.48 & 1.49 \\
\hline & Coal & $\%$ & 30.01 & 29.55 & 29.79 & 29.40 & 29.89 & 28.97 & 28.96 \\
\hline & Hydroelectric & $\%$ & 0.00 & 0.17 & 0.77 & 0.00 & 0.19 & 0.00 & 0.00 \\
\hline & Natural Gas & $\%$ & 51.58 & 50.61 & 50.32 & 51.97 & 51.21 & 51.80 & 52.08 \\
\hline & Geothermal & $\%$ & 0.00 & 0.00 & 0.00 & 0.00 & 0.00 & 0.00 & 0.00 \\
\hline & Petroleum & $\%$ & 0.00 & 0.00 & 1.17 & 0.00 & 0.00 & 0.00 & 0.00 \\
\hline & Distributed Solar PV & $\%$ & 2.78 & 4.34 & 2.67 & 2.88 & 3.20 & 3.53 & 3.17 \\
\hline & Distributed Wind & $\%$ & 0.00 & 0.00 & 0.00 & 0.00 & 0.00 & 0.00 & 0.00 \\
\hline \multirow[b]{2}{*}{4} & Peak Load & MW & 9,074 & 4,732 & 9,691 & 7,115 & 8,549 & 11,626 & 11,783 \\
\hline & $\begin{array}{l}\text { Annual Electricity } \\
\text { Production } \\
\end{array}$ & MWh & 39,077 & 19,452 & 41,907 & 30,377 & 36,180 & 48,918 & 49,411 \\
\hline 12 & $\mathrm{CO} 2$ Emis sions & Tons & 14,749 & 7,020 & 14,475 & 11,271 & 12,956 & 17,573 & 17,955 \\
\hline \multirow{3}{*}{13} & SOx Emis sions & Tons & 1.94 & 0.95 & 1.36 & 1.47 & 1.40 & 1.81 & 1.95 \\
\hline & NOx Emis sions & Tons & 1.94 & 0.94 & 1.64 & 1.47 & 1.56 & 2.08 & 2.17 \\
\hline & PM-10 Emissions & Tons & 2.16 & 1.03 & 2.12 & 1.65 & 1.90 & 2.57 & 2.63 \\
\hline \multirow{2}{*}{21} & Feeder Real Load & MW & 4,461 & 2,221 & 4,784 & 3,468 & 4,130 & 5,584 & 5,640 \\
\hline & Feeder Reactive Load & MVAR & 540.52 & 239.98 & -372.28 & 405.36 & 588.54 & 648.93 & 640.81 \\
\hline 29 & Distribution Losses & $\%$ & 1.19 & 1.98 & 4.38 & 1.92 & 2.33 & 1.39 & 1.29 \\
\hline 30 & Distribution Power Factor & $\mathrm{pf}$ & 0.99 & 0.99 & 0.98 & 0.99 & 0.99 & 0.99 & 0.99 \\
\hline 39 & $\mathrm{CO} 2$ Emis sions & Tons & 14,926 & 7,161 & 15,138 & 11,492 & 13,265 & 17,821 & 18,189 \\
\hline \multirow{3}{*}{40} & SOx & Tons & 1.97 & 0.97 & 1.42 & 1.50 & 1.44 & 1.84 & 1.98 \\
\hline & NOx & Tons & 1.96 & 0.96 & 1.72 & 1.50 & 1.60 & 2.11 & 2.19 \\
\hline & PM-10 & Tons & 2.19 & 1.05 & 2.22 & 1.69 & 1.94 & 2.61 & 2.66 \\
\hline
\end{tabular}

\section{E.3 Individual Commercial PV Performance Metrics}


Table E.11: Commercial PV performance metrics for region 1

\begin{tabular}{|c|c|c|c|c|c|c|c|c|}
\hline Index & Metric & Units & 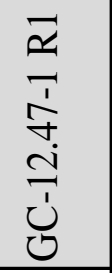 & 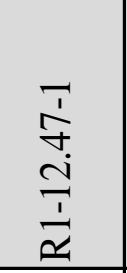 & 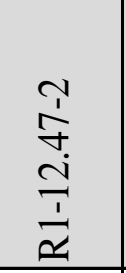 & 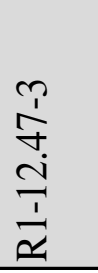 & 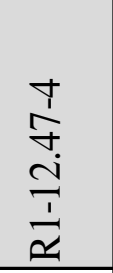 & 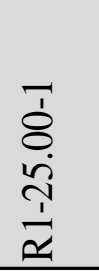 \\
\hline 1 & $\begin{array}{l}\text { Hourly Customer } \\
\text { Electricity Usage }\end{array}$ & $\mathrm{kWh}$ & 2,067 & 2,659 & 984 & 431 & 1,940 & 869 \\
\hline 2 & $\begin{array}{l}\text { Monthly Customer } \\
\text { Electricity Usage }\end{array}$ & MWh & 1,509 & 1,941 & 718 & 315 & 1,417 & 634 \\
\hline \multirow{12}{*}{3} & Peak Generation & $\mathrm{kW}$ & 5,215 & 7,257 & 2,620 & 1,205 & 5,027 & 2,313 \\
\hline & Nuclear & $\%$ & 10.71 & 10.64 & 10.73 & 10.86 & 10.09 & 10.62 \\
\hline & Solar & $\%$ & 0.25 & 0.25 & 0.25 & 0.25 & 0.21 & 0.25 \\
\hline & Bio & $\%$ & 0.67 & 0.67 & 0.67 & 0.68 & 0.72 & 0.67 \\
\hline & Wind & $\%$ & 4.08 & 4.06 & 4.09 & 4.14 & 3.55 & 4.05 \\
\hline & Coal & $\%$ & 2.89 & 2.87 & 2.89 & 2.93 & 4.38 & 2.86 \\
\hline & Hydroelectric & $\%$ & 37.00 & 36.74 & 37.06 & 37.49 & 26.33 & 36.66 \\
\hline & Natural Gas & $\%$ & 41.51 & 41.23 & 41.58 & 42.07 & 51.25 & 41.14 \\
\hline & Geothermal & $\%$ & 1.68 & 1.84 & 1.64 & 0.32 & 3.06 & 2.42 \\
\hline & Petroleum & $\%$ & 0.00 & 0.00 & 0.00 & 0.00 & 0.00 & 0.00 \\
\hline & Distributed Solar PV & $\%$ & 1.20 & 1.71 & 1.07 & 1.26 & 0.41 & 1.33 \\
\hline & Distributed Wind & $\%$ & 0.00 & 0.00 & 0.00 & 0.00 & 0.00 & 0.00 \\
\hline 4 & Peak Load & MW & 5,207 & 6,987 & 2,549 & 1,211 & 4,902 & 2,244 \\
\hline 7 & $\begin{array}{l}\text { Annual Electricity } \\
\text { Production }\end{array}$ & MWh & 18,153 & 23,902 & 8,894 & 3,801 & 17,206 & 7,720 \\
\hline 12 & $\mathrm{CO} 2$ Emis sions & Tons & 1,737 & 2,198 & 799 & 382 & 1,752 & 732 \\
\hline \multirow{3}{*}{13} & SOx Emis sions & Tons & 0.02 & 0.03 & 0.01 & 0.01 & 0.03 & 0.01 \\
\hline & NOx Emis sions & Tons & 0.23 & 0.28 & 0.10 & 0.05 & 0.22 & 0.10 \\
\hline & PM-10 Emis sions & Tons & 0.24 & 0.31 & 0.11 & 0.05 & 0.25 & 0.10 \\
\hline \multirow{2}{*}{21} & Feeder Real Load & MW & 2,072 & 2,729 & 1,015 & 434 & 1,964 & 881 \\
\hline & Feeder Reactive Load & MVAR & 67.76 & -285.64 & -199.74 & 10.42 & 61.56 & -70.68 \\
\hline 29 & Dis tribution Losses & $\%$ & 0.23 & 2.55 & 3.07 & 0.56 & 1.21 & 1.42 \\
\hline 30 & Distribution Power Factor & $\mathrm{pf}$ & 1.00 & 0.99 & 0.97 & 1.00 & 1.00 & 0.97 \\
\hline 39 & $\mathrm{CO} 2$ Emis sions & Tons & 1,741 & 2,255 & 824 & 385 & 1,773 & 743 \\
\hline \multirow{3}{*}{40} & SOx & Tons & 0.02 & 0.03 & 0.01 & 0.01 & 0.03 & 0.01 \\
\hline & NOx & Tons & 0.23 & 0.28 & 0.10 & 0.05 & 0.22 & 0.10 \\
\hline & PM-10 & Tons & 0.25 & 0.32 & 0.12 & 0.05 & 0.25 & 0.10 \\
\hline
\end{tabular}


Table E.12: Commercial PV performance metrics for region 2

\begin{tabular}{|c|c|c|c|c|c|c|c|c|}
\hline Index & Metric & Units & 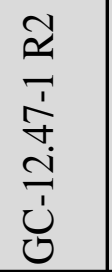 & 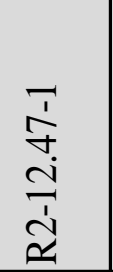 & 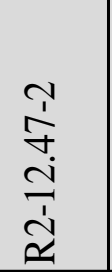 & 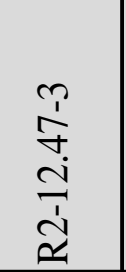 & 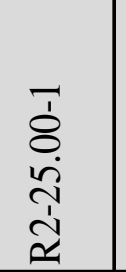 & $\begin{array}{l}\bar{\delta} \\
\tilde{\delta} \\
\tilde{n} \\
\tilde{1} \\
\tilde{\alpha}\end{array}$ \\
\hline 1 & $\begin{array}{l}\text { Hourly Customer } \\
\text { Electricity Usage }\end{array}$ & $\mathrm{kWh}$ & 2,156 & 2,263 & 1,969 & 2,975 & 6,325 & 4,571 \\
\hline 2 & \begin{tabular}{|l} 
Monthly Customer \\
Electricity Usage
\end{tabular} & $\mathrm{MWh}$ & 1,574 & 1,652 & 1,437 & 2,171 & 4,617 & 3,337 \\
\hline \multirow{12}{*}{3} & Peak Generation & $\mathrm{kW}$ & 5,880 & 6,232 & 5,880 & 8,555 & 17,192 & 12,699 \\
\hline & Nuclear & $\%$ & 25.88 & 26.40 & 26.09 & 27.95 & 27.52 & 27.65 \\
\hline & Solar & $\%$ & 0.01 & 0.01 & 0.01 & 0.01 & 0.01 & 0.01 \\
\hline & Bio & $\%$ & 0.81 & 0.82 & 0.81 & 0.84 & 0.83 & 0.83 \\
\hline & Wind & $\%$ & 1.39 & 1.41 & 1.40 & 1.70 & 1.67 & 1.68 \\
\hline & Coal & $\%$ & 46.38 & 47.31 & 46.74 & 45.54 & 44.84 & 45.06 \\
\hline & Hydroelectric & $\%$ & 7.29 & 7.35 & 7.35 & 9.05 & 8.91 & 8.95 \\
\hline & Natural Gas & $\%$ & 16.05 & 16.38 & 16.18 & 14.47 & 14.25 & 14.32 \\
\hline & Geothermal & $\%$ & 0.07 & 0.00 & 0.07 & 0.07 & 0.07 & 0.07 \\
\hline & Petroleum & $\%$ & 0.96 & 0.00 & 1.26 & 0.37 & 1.52 & 1.26 \\
\hline & Distributed Solar PV & $\%$ & 1.16 & 0.31 & 0.09 & 0.00 & 0.37 & 0.17 \\
\hline & Distributed Wind & $\%$ & 0.00 & 0.00 & 0.00 & 0.00 & 0.00 & 0.00 \\
\hline \multirow[b]{2}{*}{4} & Peak Load & MW & 5,751 & 6,128 & 5,696 & 8,360 & 16,711 & 12,421 \\
\hline & $\begin{array}{l}\text { Annual Electricity } \\
\text { Production }\end{array}$ & MWh & 18,933 & 20,081 & 17,575 & 26,686 & 55,943 & 40,371 \\
\hline 12 & $\mathrm{CO} 2$ Emis sions & Tons & 8,330 & 9,212 & 8,405 & 12,627 & 26,740 & 17,404 \\
\hline \multirow{3}{*}{13} & SOx Emis sions & Tons & 3.77 & 4.19 & 3.88 & 5.82 & 12.27 & 7.85 \\
\hline & NOx Emis sions & Tons & 2.41 & 2.66 & 2.46 & 3.69 & 7.77 & 5.01 \\
\hline & PM-10 Emis sions & Tons & 1.24 & 1.37 & 1.25 & 1.87 & 3.97 & 2.58 \\
\hline \multirow{2}{*}{21} & Feeder Real Load & MW & 2,161 & 2,292 & 2,006 & 3,046 & 6,386 & 4,609 \\
\hline & Feeder Reactive Load & MVAR & 91.50 & 116.25 & 146.32 & -129.98 & 332.72 & 69.09 \\
\hline 29 & Distribution Losses & $\%$ & 0.25 & 1.27 & 1.87 & 2.36 & 0.96 & 0.82 \\
\hline 30 & Distribution Power Factor & $\mathrm{pf}$ & 1.00 & 1.00 & 1.00 & 1.00 & 1.00 & 1.00 \\
\hline 39 & $\mathrm{CO} 2$ Emissions & Tons & 8,350 & 9,331 & 8,565 & 12,932 & 26,999 & 17,548 \\
\hline \multirow{3}{*}{40} & SOx & Tons & 3.78 & 4.25 & 3.95 & 5.96 & 12.39 & 7.91 \\
\hline & NOx & Tons & 2.41 & 2.70 & 2.50 & 3.78 & 7.85 & 5.05 \\
\hline & PM-10 & Tons & 1.24 & 1.38 & 1.27 & 1.92 & 4.01 & 2.60 \\
\hline
\end{tabular}


Table E.13: Commercial PV performance metrics for region 3

\begin{tabular}{|c|c|c|c|c|c|c|}
\hline Index & Metric & Units & 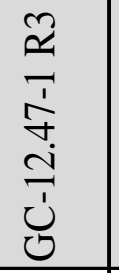 & 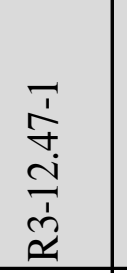 & 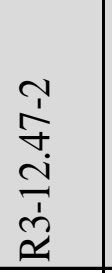 & 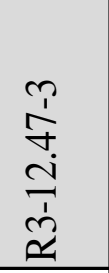 \\
\hline 1 & $\begin{array}{l}\text { Hourly Customer } \\
\text { Electricity Usage }\end{array}$ & $\mathrm{kWh}$ & 2,615 & 3,580 & 1,629 & 3,594 \\
\hline 2 & \begin{tabular}{|l} 
Monthly Customer \\
Electricity Usage \\
\end{tabular} & MWh & 1,909 & 2,614 & 1,189 & 2,624 \\
\hline \multirow{12}{*}{3} & Peak Generation & $\mathrm{kW}$ & 6,700 & 8,785 & 4,200 & 8,421 \\
\hline & Nuclear & $\%$ & 9.58 & 9.85 & 9.93 & 8.26 \\
\hline & Solar & $\%$ & 0.13 & 0.13 & 0.13 & 0.14 \\
\hline & Bio & $\%$ & 0.25 & 0.25 & 0.26 & 0.20 \\
\hline & Wind & $\%$ & 2.42 & 2.48 & 2.50 & 2.14 \\
\hline & Coal & $\%$ & 40.94 & 42.07 & 42.40 & 40.26 \\
\hline & Hydroelectric & $\%$ & 6.31 & 3.64 & 5.15 & 4.46 \\
\hline & Natural Gas & $\%$ & 37.35 & 38.38 & 38.68 & 40.31 \\
\hline & Geothermal & $\%$ & 1.38 & 0.00 & 0.00 & 0.81 \\
\hline & Petroleum & $\%$ & 0.52 & 0.00 & 0.00 & 0.00 \\
\hline & Distributed Solar PV & $\%$ & 1.12 & 3.20 & 0.96 & 3.42 \\
\hline & Distributed Wind & $\%$ & 0.00 & 0.00 & 0.00 & 0.00 \\
\hline \multirow[b]{2}{*}{4} & Peak Load & MW & 6,567 & 8,707 & 4,231 & 7,923 \\
\hline & \begin{tabular}{|l} 
Annual Electricity \\
Production
\end{tabular} & MWh & 22,987 & 31,968 & 14,367 & 32,614 \\
\hline 12 & $\mathrm{CO} 2$ Emis sions & Tons & 16,162 & 22,992 & 9,895 & 24,453 \\
\hline \multirow{3}{*}{13} & SOx Emis sions & Tons & 7.00 & 10.15 & 4.23 & 10.97 \\
\hline & NOx Emis sions & Tons & 4.36 & 6.29 & 2.65 & 6.75 \\
\hline & PM-10 Emis sions & Tons & 2.41 & 3.43 & 1.47 & 3.65 \\
\hline \multirow{2}{*}{21} & Feeder Real Load & MW & 2,624 & 3,649 & 1,640 & 3,723 \\
\hline & Feeder Reactive Load & MVAR & 218.30 & 482.33 & 142.52 & 545.26 \\
\hline 29 & Distribution Losses & $\%$ & 0.33 & 1.89 & 0.69 & 3.47 \\
\hline 30 & Distribution Power Factor & $\mathrm{pf}$ & 1.00 & 0.99 & 1.00 & 0.99 \\
\hline 39 & $\mathrm{CO} 2$ Emis sions & Tons & 16,215 & 23,435 & 9,964 & 25,332 \\
\hline \multirow{3}{*}{40} & SOx & Tons & 7.02 & 10.34 & 4.26 & 11.36 \\
\hline & NOx & Tons & 4.38 & 6.41 & 2.66 & 7.00 \\
\hline & PM-10 & Tons & 2.41 & 3.49 & 1.48 & 3.78 \\
\hline
\end{tabular}


Table E.14: Commercial PV performance metrics for region 4

\begin{tabular}{|c|c|c|c|c|c|c|}
\hline Index & Metric & Units & 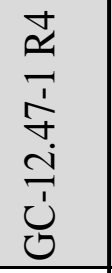 & 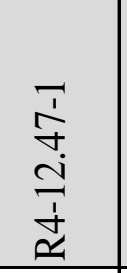 & 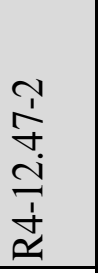 & 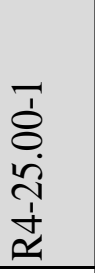 \\
\hline 1 & $\begin{array}{l}\text { Hourly Customer } \\
\text { Electricity Usage }\end{array}$ & $\mathrm{kWh}$ & 2,310 & 1,864 & 812 & 344 \\
\hline 2 & $\begin{array}{l}\text { Monthly Customer } \\
\text { Electricity Usage } \\
\end{array}$ & MWh & 1,686 & 1,361 & 593 & 251 \\
\hline \multirow{12}{*}{3} & Peak Generation & $\mathrm{kW}$ & 6,067 & 4,530 & 2,063 & 943 \\
\hline & Nuclear & $\%$ & 21.98 & 22.10 & 23.83 & 23.44 \\
\hline & Solar & $\%$ & 0.00 & 0.00 & 0.00 & 0.00 \\
\hline & Bio & $\%$ & 0.18 & 0.18 & 0.21 & 0.21 \\
\hline & Wind & $\%$ & 0.60 & 0.61 & 0.60 & 0.59 \\
\hline & Coal & $\%$ & 57.32 & 57.63 & 56.65 & 55.72 \\
\hline & Hydroelectric & $\%$ & 0.52 & 0.00 & 0.00 & 2.57 \\
\hline & Natural Gas & $\%$ & 17.55 & 15.54 & 14.26 & 16.04 \\
\hline & Geothermal & $\%$ & 0.00 & 0.00 & 0.00 & 0.00 \\
\hline & Petroleum & $\%$ & 0.00 & 0.00 & 0.00 & 0.00 \\
\hline & Distributed Solar PV & $\%$ & 1.85 & 3.95 & 4.46 & 1.44 \\
\hline & Distributed Wind & $\%$ & 0.00 & 0.00 & 0.00 & 0.00 \\
\hline \multirow[b]{2}{*}{4} & Peak Load & MW & 6,052 & 4,472 & 2,050 & 920 \\
\hline & \begin{tabular}{|l|} 
Annual Electricity \\
Production
\end{tabular} & MWh & 20,292 & 16,804 & 7,286 & 3,093 \\
\hline 12 & $\mathrm{CO} 2$ Emis sions & Tons & 10,090 & 9,467 & 3,822 & 1,583 \\
\hline \multirow{3}{*}{13} & SOx Emis sions & Tons & 4.81 & 4.55 & 1.84 & 0.76 \\
\hline & NOx Emis sions & Tons & 2.93 & 2.76 & 1.12 & 0.46 \\
\hline & PM-10 Emis sions & Tons & 1.51 & 1.41 & 0.57 & 0.24 \\
\hline \multirow{2}{*}{21} & Feeder Real Load & MW & 2,316 & 1,918 & 832 & 353 \\
\hline & Feeder Reactive Load & MVAR & 137.82 & -413.75 & 97.67 & 44.73 \\
\hline 29 & Distribution Losses & $\%$ & 0.28 & 2.81 & 2.36 & 2.55 \\
\hline 30 & Distribution Power Factor & $\mathrm{pf}$ & 1.00 & 0.96 & 0.99 & 0.99 \\
\hline 39 & $\mathrm{CO} 2$ Emis sions & Tons & 10,119 & 9,741 & 3,915 & 1,624 \\
\hline \multirow{3}{*}{40} & SOx & Tons & 4.83 & 4.68 & 1.88 & 0.78 \\
\hline & NOx & Tons & 2.94 & 2.84 & 1.14 & 0.48 \\
\hline & PM-10 & Tons & 1.51 & 1.45 & 0.58 & 0.24 \\
\hline
\end{tabular}


Table E.15: Commercial PV performance metrics for region 5

\begin{tabular}{|c|c|c|c|c|c|c|c|c|c|c|}
\hline Index & Metric & Units & 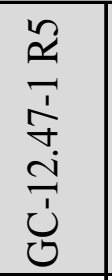 & 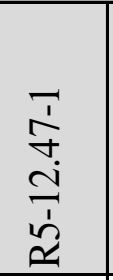 & 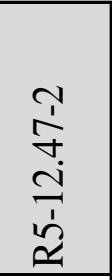 & 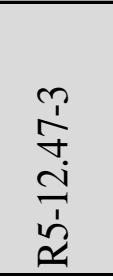 & 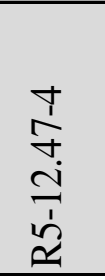 & 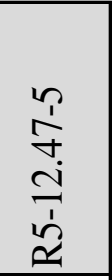 & 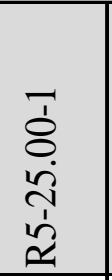 & 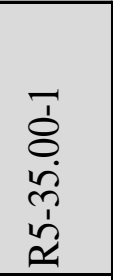 \\
\hline 1 & $\begin{array}{l}\text { Hourly Customer } \\
\text { Electricity Usage }\end{array}$ & $\mathrm{kWh}$ & 2,698 & 4,400 & 2,180 & 4,576 & 3,422 & 4,038 & 5,516 & 5,532 \\
\hline 2 & \begin{tabular}{|l|} 
Monthly Customer \\
Electricity Usage \\
\end{tabular} & MWh & 1,970 & 3,212 & 1,592 & 3,340 & 2,498 & 2,948 & 4,027 & 4,038 \\
\hline \multirow{12}{*}{3} & Peak Generation & $\mathrm{kW}$ & 5,975 & 9,110 & 4,951 & 9,981 & 7,457 & 8,849 & 11,978 & 11,909 \\
\hline & Nuclear & $\%$ & 13.05 & 13.89 & 13.72 & 13.61 & 13.75 & 13.81 & 13.38 & 13.47 \\
\hline & Solar & $\%$ & 0.00 & 0.00 & 0.00 & 0.00 & 0.00 & 0.00 & 0.00 & 0.00 \\
\hline & Bio & $\%$ & 0.30 & 0.33 & 0.33 & 0.31 & 0.33 & 0.33 & 0.31 & 0.31 \\
\hline & Wind & $\%$ & 1.68 & 1.48 & 1.47 & 1.75 & 1.47 & 1.48 & 1.72 & 1.73 \\
\hline & Coal & $\%$ & 29.30 & 29.40 & 29.88 & 30.00 & 29.95 & 30.07 & 30.04 & 29.57 \\
\hline & Hydroelectric & $\%$ & 0.75 & 0.00 & 0.62 & 0.00 & 0.63 & 0.36 & 0.77 & 0.00 \\
\hline & Natural Gas & $\%$ & 49.48 & 51.82 & 51.19 & 51.60 & 51.30 & 51.52 & 50.73 & 51.06 \\
\hline & Geothermal & $\%$ & 0.00 & 0.00 & 0.00 & 0.00 & 0.00 & 0.00 & 0.00 & 0.00 \\
\hline & Petroleum & $\%$ & 2.97 & 0.00 & 0.09 & 0.00 & 0.16 & 0.00 & 0.31 & 0.00 \\
\hline & Distributed Solar PV & $\%$ & 2.48 & 3.07 & 2.71 & 2.73 & 2.41 & 2.44 & 2.74 & 3.86 \\
\hline & Distributed Wind & $\%$ & 0.00 & 0.00 & 0.00 & 0.00 & 0.00 & 0.00 & 0.00 & 0.00 \\
\hline \multirow[b]{2}{*}{4} & Peak Load & MW & 5,733 & 9,003 & 4,759 & 9,429 & 7,245 & 8,565 & 11,655 & 11,698 \\
\hline & \begin{tabular}{|l|} 
Annual Electricity \\
Production
\end{tabular} & MWh & 23,715 & 39,011 & 19,491 & 41,922 & 30,565 & 36,219 & 49,012 & 49,104 \\
\hline 12 & $\mathrm{CO} 2$ Emis sions & Tons & 9,001 & 14,689 & 7,051 & 14,484 & 11,439 & 12,987 & 17,652 & 17,689 \\
\hline \multirow{3}{*}{13} & SOx Emis sions & Tons & 1.41 & 1.92 & 0.96 & 1.36 & 1.54 & 1.42 & 1.85 & 1.85 \\
\hline & NOx Emis sions & Tons & 1.29 & 1.92 & 0.95 & 1.65 & 1.52 & 1.57 & 2.10 & 2.10 \\
\hline & PM-10 Emis sions & Tons & 1.32 & 2.15 & 1.03 & 2.12 & 1.68 & 1.90 & 2.58 & 2.59 \\
\hline \multirow{2}{*}{21} & Feeder Real Load & MW & 2,707 & 4,453 & 2,225 & 4,786 & 3,489 & 4,135 & 5,595 & 5,605 \\
\hline & Feeder Reactive Load & MVAR & 247.51 & 538.14 & 240.55 & -373.84 & 405.20 & 588.64 & 649.44 & 640.42 \\
\hline 29 & Distribution Losses & $\%$ & 0.33 & 1.19 & 2.01 & 4.39 & 1.92 & 2.34 & 1.41 & 1.31 \\
\hline 30 & Distribution Power Factor & $\mathrm{pf}$ & 1.00 & 0.99 & 0.99 & 0.98 & 0.99 & 0.99 & 0.99 & 0.99 \\
\hline 39 & $\mathrm{CO} 2$ Emis sions & Tons & 9,030 & 14,865 & 7,196 & 15,149 & 11,663 & 13,298 & 17,904 & 17,925 \\
\hline \multirow{3}{*}{40} & SOx & Tons & 1.41 & 1.94 & 0.98 & 1.42 & 1.57 & 1.45 & 1.87 & 1.87 \\
\hline & NOx & Tons & 1.30 & 1.94 & 0.97 & 1.72 & 1.55 & 1.61 & 2.13 & 2.13 \\
\hline & PM-10 & Tons & 1.33 & 2.18 & 1.05 & 2.22 & 1.71 & 1.95 & 2.62 & 2.62 \\
\hline
\end{tabular}

\section{E.4 Individual Combined PV Performance Metrics}


Table E.16: Combined PV performance metrics for region 1

\begin{tabular}{|c|c|c|c|c|c|c|c|c|}
\hline Index & Metric & Units & 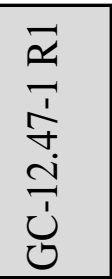 & 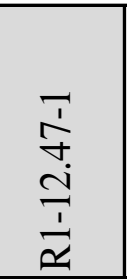 & 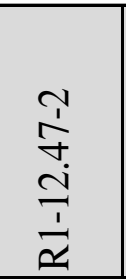 & 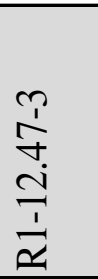 & 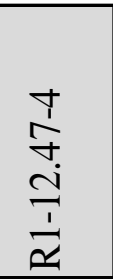 & 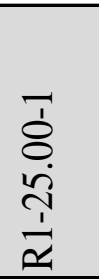 \\
\hline 1 & $\begin{array}{l}\text { Hourly Customer } \\
\text { Electricity Usage }\end{array}$ & $\mathrm{kWh}$ & 2,083 & 2,632 & 972 & 427 & 1,918 & 861 \\
\hline 2 & $\begin{array}{l}\text { Monthly Customer } \\
\text { Electricity Usage }\end{array}$ & $\mathrm{MWh}$ & 1,521 & 1,921 & 710 & 312 & 1,400 & 628 \\
\hline \multirow{12}{*}{3} & Peak Generation & $\mathrm{kW}$ & 5,313 & 7,108 & 2,652 & 1,182 & 4,889 & 2,422 \\
\hline & Nuclear & $\%$ & 10.68 & 10.68 & 9.94 & 10.15 & 10.75 & 10.33 \\
\hline & Solar & $\%$ & 0.25 & 0.25 & 0.21 & 0.21 & 0.25 & 0.24 \\
\hline & Bio & $\%$ & 0.67 & 0.67 & 0.71 & 0.72 & 0.67 & 0.65 \\
\hline & Wind & $\%$ & 4.07 & 4.07 & 3.50 & 3.57 & 4.10 & 3.93 \\
\hline & Coal & $\%$ & 2.88 & 2.88 & 4.32 & 4.41 & 2.90 & 2.78 \\
\hline & Hydroelectric & $\%$ & 36.88 & 36.89 & 25.93 & 26.48 & 37.11 & 35.66 \\
\hline & \begin{tabular}{|l} 
Natural Gas \\
\end{tabular} & $\%$ & 41.38 & 41.39 & 50.48 & 51.55 & 41.64 & 40.01 \\
\hline & Geothermal & $\%$ & 2.84 & 0.19 & 3.06 & 1.79 & 0.62 & 2.75 \\
\hline & Petroleum & $\%$ & 0.35 & 0.00 & 0.10 & 0.00 & 0.00 & 1.36 \\
\hline & Distributed Solar PV & $\%$ & 0.00 & 2.98 & 1.75 & 1.12 & 1.97 & 2.30 \\
\hline & Distributed Wind & $\%$ & 0.00 & 0.00 & 0.00 & 0.00 & 0.00 & 0.00 \\
\hline 4 & Peak Load & MW & 5,288 & 6,865 & 2,529 & 1,175 & 4,793 & 2,286 \\
\hline 7 & $\begin{array}{l}\text { Annual Electricity } \\
\text { Production }\end{array}$ & MWh & 18,290 & 23,661 & 8,790 & 3,759 & 17,001 & 7,649 \\
\hline 12 & $\mathrm{CO} 2$ Emis sions & Tons & 1,783 & 2,139 & 772 & 369 & 1,691 & 709 \\
\hline \multirow{3}{*}{13} & SOx Emis sions & Tons & 0.03 & 0.03 & 0.01 & 0.00 & 0.03 & 0.01 \\
\hline & NOx Emis sions & Tons & 0.24 & 0.27 & 0.10 & 0.05 & 0.21 & 0.10 \\
\hline & PM-10 Emis sions & Tons & 0.25 & 0.30 & 0.11 & 0.05 & 0.24 & 0.10 \\
\hline \multirow{2}{*}{21} & Feeder Real Load & MW & 2,088 & 2,701 & 1,003 & 429 & 1,941 & 873 \\
\hline & Feeder Reactive Load & MVAR & 67.75 & -286.67 & -199.94 & 10.38 & 61.25 & -70.99 \\
\hline 29 & Dis tribution Losses & $\%$ & 0.23 & 2.55 & 3.09 & 0.55 & 1.19 & 1.41 \\
\hline 30 & Distribution Power Factor & $\mathrm{pf}$ & 1.00 & 0.99 & 0.97 & 1.00 & 1.00 & 0.97 \\
\hline 39 & $\mathrm{CO} 2$ Emis sions & Tons & 1,787 & 2,195 & 797 & 371 & 1,711 & 719 \\
\hline \multirow{3}{*}{40} & SOx & Tons & 0.03 & 0.03 & 0.01 & 0.00 & 0.03 & 0.01 \\
\hline & NOx & Tons & 0.24 & 0.28 & 0.10 & 0.05 & 0.22 & 0.10 \\
\hline & PM-10 & Tons & 0.25 & 0.31 & 0.11 & 0.05 & 0.24 & 0.10 \\
\hline
\end{tabular}


Table E.17: Combined PV performance metrics for region 2

\begin{tabular}{|c|c|c|c|c|c|c|c|c|}
\hline Index & Metric & Units & 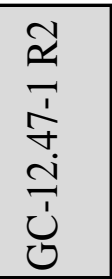 & 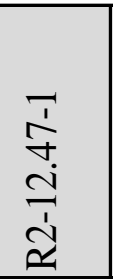 & 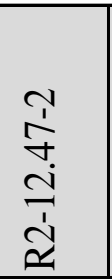 & 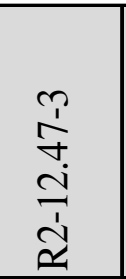 & 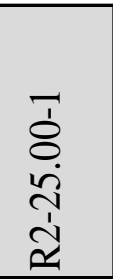 & 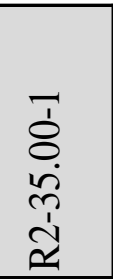 \\
\hline 1 & $\begin{array}{l}\text { Hourly Customer } \\
\text { Electricity Usage }\end{array}$ & $\mathrm{kWh}$ & 2,169 & 2,254 & 1,960 & 2,975 & 6,302 & 4,557 \\
\hline 2 & $\begin{array}{l}\text { Monthly Customer } \\
\text { Electricity Usage }\end{array}$ & $\mathrm{MWh}$ & 1,584 & 1,645 & 1,431 & 2,171 & 4,601 & 3,327 \\
\hline \multirow{12}{*}{3} & Peak Generation & $\mathrm{kW}$ & 5,749 & 6,290 & 5,802 & 8,555 & 16,766 & 12,215 \\
\hline & Nuclear & $\%$ & 26.33 & 26.22 & 26.20 & 27.95 & 26.23 & 26.74 \\
\hline & Solar & $\%$ & 0.01 & 0.01 & 0.01 & 0.01 & 0.01 & 0.01 \\
\hline & Bio & $\%$ & 0.82 & 0.82 & 0.82 & 0.84 & 0.82 & 0.83 \\
\hline & Wind & $\%$ & 1.41 & 1.40 & 1.40 & 1.70 & 1.40 & 1.43 \\
\hline & Coal & $\%$ & 47.18 & 46.98 & 46.96 & 45.54 & 47.00 & 47.91 \\
\hline & Hydroelectric & $\%$ & 7.42 & 7.39 & 7.38 & 9.05 & 7.08 & 5.87 \\
\hline & \begin{tabular}{|l} 
Natural Gas \\
\end{tabular} & $\%$ & 16.33 & 16.26 & 16.25 & 14.47 & 16.27 & 16.58 \\
\hline & Geothermal & $\%$ & 0.07 & 0.07 & 0.07 & 0.07 & 0.00 & 0.00 \\
\hline & Petroleum & $\%$ & 0.43 & 0.06 & 0.37 & 0.37 & 0.00 & 0.00 \\
\hline & Distributed Solar PV & $\%$ & 0.00 & 0.79 & 0.53 & 0.00 & 1.19 & 0.62 \\
\hline & Distributed Wind & $\%$ & 0.00 & 0.00 & 0.00 & 0.00 & 0.00 & 0.00 \\
\hline \multirow[b]{2}{*}{4} & Peak Load & MW & 5,720 & 6,142 & 5,644 & 8,360 & 16,485 & 12,262 \\
\hline & \begin{tabular}{|l|} 
Annual Electricity \\
Production
\end{tabular} & MWh & 19,050 & 19,997 & 17,498 & 26,686 & 55,743 & 40,253 \\
\hline 12 & $\mathrm{CO} 2$ Emis sions & Tons & 8,419 & 9,149 & 8,333 & 12,627 & 26,572 & 17,322 \\
\hline \multirow{3}{*}{13} & SOx Emis sions & Tons & 3.81 & 4.17 & 3.84 & 5.82 & 12.20 & 7.82 \\
\hline & NOx Emis sions & Tons & 2.43 & 2.65 & 2.44 & 3.69 & 7.73 & 4.99 \\
\hline & PM-10 Emis sions & Tons & 1.25 & 1.36 & 1.24 & 1.87 & 3.94 & 2.57 \\
\hline \multirow{2}{*}{21} & Feeder Real Load & MW & 2,175 & 2,283 & 1,997 & 3,046 & 6,363 & 4,595 \\
\hline & Feeder Reactive Load & MVAR & 91.62 & 116.11 & 146.06 & -129.98 & 332.38 & 68.83 \\
\hline 29 & Dis tribution Losses & $\%$ & 0.25 & 1.27 & 1.87 & 2.36 & 0.96 & 0.82 \\
\hline 30 & Distribution Power Factor & $\mathrm{pf}$ & 1.00 & 1.00 & 1.00 & 1.00 & 1.00 & 1.00 \\
\hline 39 & $\mathrm{CO} 2$ Emis sions & Tons & 8,440 & 9,266 & 8,492 & 12,932 & 26,829 & 17,465 \\
\hline \multirow{3}{*}{40} & SOx & Tons & 3.82 & 4.22 & 3.92 & 5.96 & 12.32 & 7.88 \\
\hline & NOx & Tons & 2.44 & 2.68 & 2.48 & 3.78 & 7.81 & 5.03 \\
\hline & PM-10 & Tons & 1.25 & 1.37 & 1.26 & 1.92 & 3.98 & 2.59 \\
\hline
\end{tabular}


Table E.18: Combined PV performance metrics for region 3

\begin{tabular}{|c|c|c|c|c|c|c|}
\hline Index & Metric & Units & 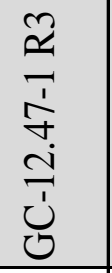 & 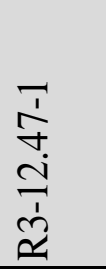 & 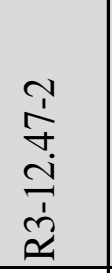 & 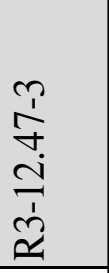 \\
\hline 1 & $\begin{array}{l}\text { Hourly Customer } \\
\text { Electricity Usage }\end{array}$ & $\mathrm{kWh}$ & 2,635 & 3,523 & 1,642 & 3,547 \\
\hline 2 & $\begin{array}{l}\text { Monthly Customer } \\
\text { Electricity Usage } \\
\end{array}$ & MWh & 1,924 & 2,572 & 1,199 & 2,590 \\
\hline \multirow{12}{*}{3} & Peak Generation & $\mathrm{kW}$ & 6,594 & 8,775 & 4,422 & 8,081 \\
\hline & Nuclear & $\%$ & 8.65 & 9.74 & 9.72 & 9.76 \\
\hline & Solar & $\%$ & 0.13 & 0.13 & 0.13 & 0.13 \\
\hline & Bio & $\%$ & 0.23 & 0.25 & 0.25 & 0.25 \\
\hline & Wind & $\%$ & 2.05 & 2.45 & 2.45 & 2.46 \\
\hline & Coal & $\%$ & 40.24 & 41.59 & 41.52 & 41.71 \\
\hline & Hydroelectric & $\%$ & 5.58 & 2.42 & 6.40 & 4.51 \\
\hline & Natural Gas & $\%$ & 41.67 & 37.94 & 37.88 & 38.05 \\
\hline & Geothermal & $\%$ & 1.25 & 0.00 & 1.40 & 0.00 \\
\hline & Petroleum & $\%$ & 0.20 & 0.00 & 0.25 & 0.00 \\
\hline & Dis tributed Solar PV & $\%$ & 0.00 & 5.48 & 0.00 & 3.12 \\
\hline & Distributed Wind & $\%$ & 0.00 & 0.00 & 0.00 & 0.00 \\
\hline \multirow[b]{2}{*}{4} & Peak Load & MW & 6,554 & 8,597 & 4,364 & 7,857 \\
\hline & $\begin{array}{l}\text { Annual Electricity } \\
\text { Production }\end{array}$ & MWh & 23,160 & 31,462 & 14,483 & 32,198 \\
\hline 12 & $\mathrm{CO} 2$ Emis sions & Tons & 16,269 & 22,668 & 9,963 & 24,162 \\
\hline \multirow{3}{*}{13} & SOx Emis sions & Tons & 7.03 & 10.07 & 4.25 & 10.88 \\
\hline & NOx Emis sions & Tons & 4.38 & 6.23 & 2.66 & 6.70 \\
\hline & PM-10 Emis sions & Tons & 2.42 & 3.38 & 1.48 & 3.60 \\
\hline \multirow{2}{*}{21} & Feeder Real Load & MW & 2,644 & 3,592 & 1,653 & 3,676 \\
\hline & Feeder Reactive Load & MVAR & 218.51 & 480.97 & 142.77 & 544.25 \\
\hline 29 & Distribution Losses & $\%$ & 0.33 & 1.89 & 0.69 & 3.49 \\
\hline 30 & Distribution Power Factor & $\mathrm{pf}$ & 1.00 & 0.99 & 1.00 & 0.99 \\
\hline 39 & $\mathrm{CO} 2$ Emis sions & Tons & 16,323 & 23,105 & 10,032 & 25,035 \\
\hline \multirow{3}{*}{40} & SOx & Tons & 7.05 & 10.26 & 4.28 & 11.27 \\
\hline & NOx & Tons & 4.39 & 6.35 & 2.67 & 6.94 \\
\hline & PM-10 & Tons & 2.43 & 3.44 & 1.49 & 3.73 \\
\hline
\end{tabular}


Table E.19: Combined PV performance metrics for region 4

\begin{tabular}{|c|c|c|c|c|c|c|}
\hline Index & Metric & Units & 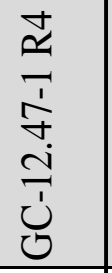 & 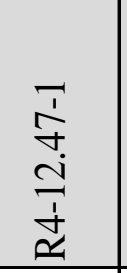 & 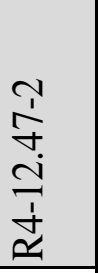 & 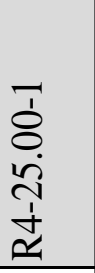 \\
\hline 1 & $\begin{array}{l}\text { Hourly Customer } \\
\text { Electricity Usage }\end{array}$ & $\mathrm{kWh}$ & 2,339 & 1,829 & 797 & 337 \\
\hline 2 & $\begin{array}{l}\text { Monthly Customer } \\
\text { Electricity Usage } \\
\end{array}$ & MWh & 1,708 & 1,335 & 582 & 246 \\
\hline \multirow{12}{*}{3} & Peak Generation & $\mathrm{kW}$ & 6,221 & 4,488 & 2,149 & 860 \\
\hline & Nuclear & $\%$ & 21.91 & 22.10 & 21.39 & 24.12 \\
\hline & Solar & $\%$ & 0.00 & 0.00 & 0.00 & 0.00 \\
\hline & Bio & $\%$ & 0.18 & 0.18 & 0.18 & 0.21 \\
\hline & Wind & $\%$ & 0.60 & 0.61 & 0.59 & 0.60 \\
\hline & Coal & $\%$ & 57.14 & 57.65 & 55.78 & 57.33 \\
\hline & Hydroelectric & $\%$ & 2.20 & 0.00 & 0.00 & 0.00 \\
\hline & Natural Gas & $\%$ & 17.49 & 14.67 & 15.82 & 12.94 \\
\hline & Geothermal & $\%$ & 0.00 & 0.00 & 0.00 & 0.00 \\
\hline & Petroleum & $\%$ & 0.48 & 0.00 & 0.00 & 0.00 \\
\hline & Distributed Solar PV & $\%$ & 0.00 & 4.80 & 6.25 & 4.79 \\
\hline & Distributed Wind & $\%$ & 0.00 & 0.00 & 0.00 & 0.00 \\
\hline \multirow[b]{2}{*}{4} & Peak Load & MW & 6,186 & 4,431 & 2,064 & 863 \\
\hline & $\begin{array}{l}\text { Annual Electricity } \\
\text { Production }\end{array}$ & MWh & 20,550 & 16,491 & 7,156 & 3,028 \\
\hline 12 & $\mathrm{CO} 2$ Emis sions & Tons & 10,321 & 9,162 & 3,692 & 1,517 \\
\hline \multirow{3}{*}{13} & SOx Emis sions & Tons & 4.91 & 4.41 & 1.77 & 0.73 \\
\hline & NOx Emis sions & Tons & 3.00 & 2.68 & 1.08 & 0.44 \\
\hline & PM-10 Emis sions & Tons & 1.54 & 1.37 & 0.55 & 0.23 \\
\hline \multirow{2}{*}{21} & Feeder Real Load & MW & 2,346 & 1,883 & 817 & 346 \\
\hline & Feeder Reactive Load & MVAR & 137.98 & -414.39 & 97.59 & 44.70 \\
\hline 29 & Distribution Losses & $\%$ & 0.28 & 2.85 & 2.40 & 2.59 \\
\hline 30 & Distribution Power Factor & $\mathrm{pf}$ & 1.00 & 0.96 & 0.99 & 0.99 \\
\hline 39 & $\mathrm{CO} 2$ Emis sions & Tons & 10,350 & 9,431 & 3,782 & 1,557 \\
\hline \multirow{3}{*}{40} & SOx & Tons & 4.93 & 4.54 & 1.82 & 0.75 \\
\hline & NOx & Tons & 3.00 & 2.76 & 1.11 & 0.46 \\
\hline & PM-10 & Tons & 1.54 & 1.41 & 0.56 & 0.23 \\
\hline
\end{tabular}


Table E.20: Combined PV performance metrics for region 5

\begin{tabular}{|c|c|c|c|c|c|c|c|c|c|c|}
\hline Index & Metric & Units & 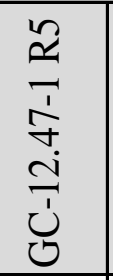 & 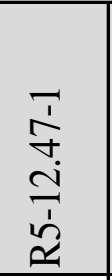 & 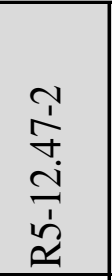 & 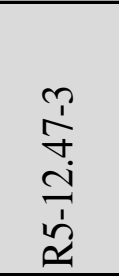 & 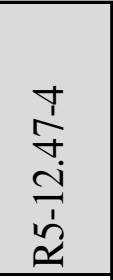 & 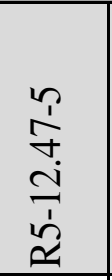 & 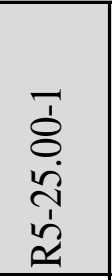 & $\begin{array}{l}7 \\
8 \\
\ddot{b} \\
\hat{n} \\
\dot{n}\end{array}$ \\
\hline 1 & $\begin{array}{l}\text { Hourly Customer } \\
\text { Electricity Usage }\end{array}$ & $\mathrm{kWh}$ & 2,747 & 4,313 & 2,133 & 4,480 & 3,353 & 3,952 & 5,386 & 5,410 \\
\hline 2 & $\begin{array}{l}\text { Monthly Customer } \\
\text { Electricity Usage }\end{array}$ & MWh & 2,005 & 3,148 & 1,557 & 3,271 & 2,447 & 2,885 & 3,932 & 3,949 \\
\hline \multirow{12}{*}{3} & Peak Generation & $\mathrm{kW}$ & 5,841 & 8,898 & 5,014 & 9,786 & 7,263 & 8,486 & 11,554 & 11,480 \\
\hline & Nuclear & $\%$ & 13.85 & 13.82 & 13.00 & 13.52 & 13.63 & 13.56 & 13.41 & 13.86 \\
\hline & Solar & $\%$ & 0.00 & 0.00 & 0.00 & 0.00 & 0.00 & 0.00 & 0.00 & 0.00 \\
\hline & Bio & $\%$ & 0.33 & 0.33 & 0.30 & 0.31 & 0.32 & 0.31 & 0.31 & 0.33 \\
\hline & Wind & $\%$ & 1.48 & 1.48 & 1.67 & 1.74 & 1.46 & 1.74 & 1.72 & 1.48 \\
\hline & Coal & $\%$ & 30.17 & 26.58 & 29.17 & 27.29 & 27.17 & 27.24 & 27.89 & 25.12 \\
\hline & Hydroelectric & $\%$ & 0.63 & 0.00 & 0.75 & 0.00 & 0.00 & 0.00 & 0.00 & 0.00 \\
\hline & Natural Gas & $\%$ & 51.68 & 51.59 & 49.26 & 51.25 & 50.87 & 51.39 & 50.82 & 51.72 \\
\hline & Geothermal & $\%$ & 0.00 & 0.00 & 0.00 & 0.00 & 0.00 & 0.00 & 0.00 & 0.00 \\
\hline & Petroleum & $\%$ & 1.86 & 0.00 & 2.69 & 0.00 & 0.00 & 0.00 & 0.00 & 0.00 \\
\hline & Distributed Solar PV & $\%$ & 0.00 & 6.20 & 3.16 & 5.89 & 6.54 & 5.76 & 5.85 & 7.49 \\
\hline & Distributed Wind & $\%$ & 0.00 & 0.00 & 0.00 & 0.00 & 0.00 & 0.00 & 0.00 & 0.00 \\
\hline \multirow[b]{2}{*}{4} & Peak Load & MW & 5,810 & 8,749 & 4,671 & 9,168 & 6,992 & 8,247 & 11,255 & 11,331 \\
\hline & \begin{tabular}{|l|} 
Annual Electricity \\
Production
\end{tabular} & MWh & 24,144 & 38,232 & 19,065 & 41,035 & 29,943 & 35,446 & 47,857 & 48,026 \\
\hline 12 & $\mathrm{CO} 2$ Emis sions & Tons & 9,364 & 13,992 & 6,686 & 13,778 & 10,891 & 12,341 & 16,683 & 16,783 \\
\hline \multirow{3}{*}{13} & SOx Emis sions & Tons & 1.55 & 1.63 & 0.81 & 1.09 & 1.31 & 1.16 & 1.47 & 1.50 \\
\hline & NOx Emis sions & Tons & 1.38 & 1.74 & 0.86 & 1.48 & 1.38 & 1.41 & 1.86 & 1.88 \\
\hline & PM-10 Emissions & Tons & 1.37 & 2.05 & 0.98 & 2.01 & 1.60 & 1.81 & 2.44 & 2.46 \\
\hline \multirow{2}{*}{21} & Feeder Real Load & MW & 2,756 & 4,364 & 2,176 & 4,684 & 3,418 & 4,046 & 5,463 & 5,482 \\
\hline & Feeder Reactive Load & MVAR & 247.93 & 535.92 & 239.07 & -390.03 & 404.02 & 583.07 & 648.06 & 639.82 \\
\hline 29 & Distribution Losses & $\%$ & 0.33 & 1.19 & 1.98 & 4.36 & 1.92 & 2.34 & 1.41 & 1.32 \\
\hline 30 & Distribution Power Factor & $\mathrm{pf}$ & 1.00 & 0.99 & 0.99 & 0.98 & 0.99 & 0.99 & 0.99 & 0.99 \\
\hline 39 & $\mathrm{CO} 2$ Emis sions & Tons & 9,395 & 14,160 & 6,821 & 14,406 & 11,104 & 12,636 & 16,921 & 17,007 \\
\hline \multirow{3}{*}{40} & SOx & Tons & 1.55 & 1.65 & 0.83 & 1.14 & 1.34 & 1.19 & 1.49 & 1.52 \\
\hline & NOx & Tons & 1.39 & 1.76 & 0.87 & 1.54 & 1.40 & 1.44 & 1.89 & 1.90 \\
\hline & PM-10 & Tons & 1.38 & 2.07 & 1.00 & 2.11 & 1.63 & 1.85 & 2.48 & 2.49 \\
\hline
\end{tabular}

\section{E.5 Individual Commercial WTG Performance Metrics}


Table E.21: Commercial WTG performance metrics for region 1

\begin{tabular}{|c|c|c|c|}
\hline Index & Metric & Units & 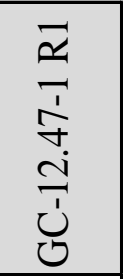 \\
\hline 1 & $\begin{array}{l}\text { Hourly Customer } \\
\text { Electricity Usage }\end{array}$ & $\mathrm{kWh}$ & 1,617 \\
\hline 2 & $\begin{array}{l}\text { Monthly Customer } \\
\text { Electricity Usage } \\
\end{array}$ & MWh & 1,180 \\
\hline \multirow{12}{*}{3} & Peak Generation & $\mathrm{kW}$ & 5,258 \\
\hline & Nuclear & $\%$ & 10.43 \\
\hline & Solar & $\%$ & 0.24 \\
\hline & Bio & $\%$ & 0.65 \\
\hline & Wind & $\%$ & 3.98 \\
\hline & Coal & $\%$ & 2.68 \\
\hline & Hydroelectric & $\%$ & 36.02 \\
\hline & Natural Gas & $\%$ & 40.42 \\
\hline & Geothermal & $\%$ & 0.00 \\
\hline & Petroleum & $\%$ & 0.00 \\
\hline & Distributed Solar PV & $\%$ & 0.00 \\
\hline & Distributed Wind & $\%$ & 5.57 \\
\hline 4 & Peak Load & MW & 5,111 \\
\hline 7 & $\begin{array}{l}\text { Annual Electricity } \\
\text { Production }\end{array}$ & MWh & 14,200 \\
\hline 12 & $\mathrm{CO} 2$ Emis sions & Tons & 1,069 \\
\hline \multirow{3}{*}{13} & SOx Emis sions & Tons & 0.01 \\
\hline & NOx Emis sions & Tons & 0.18 \\
\hline & PM-10 Emis sions & Tons & 0.15 \\
\hline \multirow{2}{*}{21} & Feeder Real Load & MW & 1620.95 \\
\hline & Feeder Reactive Load & MVAR & -126.92 \\
\hline 29 & Distribution Losses & $\%$ & 0.24 \\
\hline 30 & Distribution Power Factor & $\mathrm{pf}$ & 0.95 \\
\hline 39 & $\mathrm{CO} 2$ Emissions & Tons & 1,072 \\
\hline \multirow{3}{*}{40} & SOx & Tons & 0.01 \\
\hline & NOx & Tons & 0.18 \\
\hline & PM-10 & Tons & 0.15 \\
\hline
\end{tabular}


Table E.22: Commercial WTG performance metrics for region 2

\begin{tabular}{|c|c|c|c|}
\hline Index & Metric & Units & 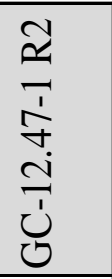 \\
\hline 1 & $\begin{array}{l}\text { Hourly Customer } \\
\text { Electricity Usage }\end{array}$ & $\mathrm{kWh}$ & 1,718 \\
\hline 2 & $\begin{array}{l}\text { Monthly Customer } \\
\text { Electricity Usage }\end{array}$ & $\mathrm{MWh}$ & 1,254 \\
\hline \multirow{12}{*}{3} & Peak Generation & $\mathrm{kW}$ & 5,460 \\
\hline & Nuclear & $\%$ & 26.61 \\
\hline & Solar & $\%$ & 0.01 \\
\hline & Bio & $\%$ & 0.83 \\
\hline & Wind & $\%$ & 1.42 \\
\hline & Coal & $\%$ & 47.67 \\
\hline & Hydroelectric & $\%$ & 3.93 \\
\hline & Natural Gas & $\%$ & 16.50 \\
\hline & Geothermal & $\%$ & 0.00 \\
\hline & Petroleum & $\%$ & 0.00 \\
\hline & Distributed Solar PV & $\%$ & 0.00 \\
\hline & Dis tributed Wind & $\%$ & 3.03 \\
\hline \multirow[b]{2}{*}{4} & Peak Load & MW & 5,488 \\
\hline & $\begin{array}{l}\text { Annual Electricity } \\
\text { Production }\end{array}$ & $\mathrm{MWh}$ & 15,094 \\
\hline 12 & $\mathrm{CO} 2$ Emis sions & Tons & 5,939 \\
\hline \multirow{3}{*}{13} & SOx Emis sions & Tons & 2.72 \\
\hline & NOx Emis sions & Tons & 1.74 \\
\hline & PM-10 Emis sions & Tons & 0.88 \\
\hline \multirow{2}{*}{21} & Feeder Real Load & MW & 1,723 \\
\hline & Feeder Reactive Load & MVAR & -96.54 \\
\hline 29 & Distribution Losses & $\%$ & 0.26 \\
\hline 30 & Distribution Power Factor & $\mathrm{pf}$ & 0.93 \\
\hline 39 & $\mathrm{CO} 2$ Emiss ions & Tons & 5,954 \\
\hline \multirow{3}{*}{40} & SOx & Tons & 2.72 \\
\hline & NOx & Tons & 1.74 \\
\hline & PM-10 & Tons & 0.88 \\
\hline
\end{tabular}


Table E.23: Commercial WTG performance metrics for region 3

\begin{tabular}{|c|c|c|c|}
\hline Index & Metric & Units & 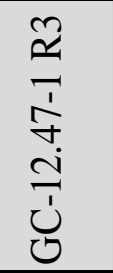 \\
\hline 1 & $\begin{array}{l}\text { Hourly Customer } \\
\text { Electricity Usage }\end{array}$ & $\mathrm{kWh}$ & 2,511 \\
\hline 2 & $\begin{array}{l}\text { Monthly Customer } \\
\text { Electricity Usage } \\
\end{array}$ & MWh & 1,833 \\
\hline \multirow{12}{*}{3} & Peak Generation & $\mathrm{kW}$ & 6,519 \\
\hline & Nuclear & $\%$ & 9.76 \\
\hline & Solar & $\%$ & 0.13 \\
\hline & Bio & $\%$ & 0.25 \\
\hline & Wind & $\%$ & 2.46 \\
\hline & Coal & $\%$ & 41.71 \\
\hline & Hydroelectric & $\%$ & 6.43 \\
\hline & Natural Gas & $\%$ & 38.05 \\
\hline & Geothermal & $\%$ & 1.07 \\
\hline & Petroleum & $\%$ & 0.00 \\
\hline & Distributed Solar PV & $\%$ & 0.00 \\
\hline & Distributed Wind & $\%$ & 0.12 \\
\hline \multirow[b]{2}{*}{4} & Peak Load & MW & 6,510 \\
\hline & $\begin{array}{l}\text { Annual Electricity } \\
\text { Production }\end{array}$ & MWh & 22,065 \\
\hline 12 & $\mathrm{CO} 2$ Emissions & Tons & 15,425 \\
\hline \multirow{3}{*}{13} & SOx Emis sions & Tons & 6.73 \\
\hline & NOx Emis sions & Tons & 4.18 \\
\hline & PM-10 Emis sions & Tons & 2.30 \\
\hline \multirow{2}{*}{21} & Feeder Real Load & MW & 2,519 \\
\hline & Feeder Reactive Load & MVAR & 166.36 \\
\hline 29 & Distribution Losses & $\%$ & 0.33 \\
\hline 30 & Distribution Power Factor & $\mathrm{pf}$ & 1.00 \\
\hline 39 & $\mathrm{CO} 2$ Emissions & Tons & 15,476 \\
\hline \multirow{3}{*}{40} & SOx & Tons & 6.75 \\
\hline & NOx & Tons & 4.20 \\
\hline & PM-10 & Tons & 2.30 \\
\hline
\end{tabular}


Table E.24: Commercial WTG performance metrics for region 4

\begin{tabular}{|c|c|c|c|}
\hline Index & Metric & Units & 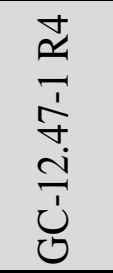 \\
\hline 1 & $\begin{array}{l}\text { Hourly Customer } \\
\text { Electricity Usage }\end{array}$ & $\mathrm{kWh}$ & 2,066 \\
\hline 2 & $\begin{array}{l}\text { Monthly Customer } \\
\text { Electricity Usage } \\
\end{array}$ & MWh & 1,508 \\
\hline \multirow{12}{*}{3} & Peak Generation & $\mathrm{kW}$ & 6,564 \\
\hline & Nuclear & $\%$ & 22.43 \\
\hline & Solar & $\%$ & 0.00 \\
\hline & Bio & $\%$ & 0.20 \\
\hline & Wind & $\%$ & 0.56 \\
\hline & Coal & $\%$ & 53.33 \\
\hline & Hydroelectric & $\%$ & 2.94 \\
\hline & Natural Gas & $\%$ & 15.35 \\
\hline & Geothermal & $\%$ & 0.00 \\
\hline & Petroleum & $\%$ & 1.88 \\
\hline & Distributed Solar PV & $\%$ & 0.00 \\
\hline & Distributed Wind & $\%$ & 3.31 \\
\hline \multirow[b]{2}{*}{4} & Peak Load & MW & 6,210 \\
\hline & $\begin{array}{l}\text { Annual Electricity } \\
\text { Production }\end{array}$ & MWh & 18,147 \\
\hline 12 & $\mathrm{CO} 2$ Emissions & Tons & 8,528 \\
\hline \multirow{3}{*}{13} & SOx Emis sions & Tons & 4.08 \\
\hline & NOx Emis sions & Tons & 2.49 \\
\hline & PM-10 Emis sions & Tons & 1.27 \\
\hline \multirow{2}{*}{21} & Feeder Real Load & MW & 2,072 \\
\hline & Feeder Reactive Load & MVAR & 23.58 \\
\hline 29 & Distribution Losses & $\%$ & 0.29 \\
\hline 30 & Distribution Power Factor & $\mathrm{pf}$ & 0.97 \\
\hline 39 & $\mathrm{CO} 2$ Emissions & Tons & 8553.05 \\
\hline \multirow{3}{*}{40} & SOx & Tons & 4.09 \\
\hline & NOx & Tons & 2.49 \\
\hline & PM-10 & Tons & 1.28 \\
\hline
\end{tabular}


Table E.25: Commercial WTG performance metrics for region 5

\begin{tabular}{|c|c|c|c|}
\hline Index & Metric & Units & 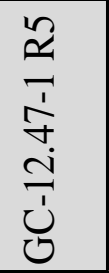 \\
\hline 1 & $\begin{array}{l}\text { Hourly Customer } \\
\text { Electricity Usage }\end{array}$ & $\mathrm{kWh}$ & 2,345 \\
\hline 2 & $\begin{array}{l}\text { Monthly Customer } \\
\text { Electricity Usage } \\
\end{array}$ & MWh & 1,712 \\
\hline \multirow{12}{*}{3} & Peak Generation & $\mathrm{kW}$ & 5,784 \\
\hline & Nuclear & $\%$ & 13.54 \\
\hline & Solar & $\%$ & 0.00 \\
\hline & Bio & $\%$ & 0.32 \\
\hline & Wind & $\%$ & 1.45 \\
\hline & Coal & $\%$ & 28.83 \\
\hline & Hydroelectric & $\%$ & 0.00 \\
\hline & Natural Gas & $\%$ & 50.53 \\
\hline & Geothermal & $\%$ & 0.00 \\
\hline & Petroleum & $\%$ & 0.00 \\
\hline & Distributed Solar PV & $\%$ & 0.00 \\
\hline & Distributed Wind & $\%$ & 5.33 \\
\hline \multirow[b]{2}{*}{4} & Peak Load & MW & 5,624 \\
\hline & $\begin{array}{l}\text { Annual Electricity } \\
\text { Production }\end{array}$ & MWh & 20,610 \\
\hline 12 & $\mathrm{CO} 2$ Emissions & Tons & 7,022 \\
\hline \multirow{3}{*}{13} & SOx Emis sions & Tons & 0.81 \\
\hline & NOx Emis sions & Tons & 0.88 \\
\hline & PM-10 Emis sions & Tons & 1.03 \\
\hline \multirow{2}{*}{21} & Feeder Real Load & MW & 2,353 \\
\hline & Feeder Reactive Load & MVAR & 79.49 \\
\hline 29 & Distribution Losses & $\%$ & 0.33 \\
\hline 30 & Distribution Power Factor & $\mathrm{pf}$ & 0.98 \\
\hline 39 & $\mathrm{CO} 2$ Emis sions & Tons & 7,045 \\
\hline \multirow{3}{*}{40} & SOx & Tons & 0.81 \\
\hline & NOx & Tons & 0.88 \\
\hline & PM-10 & Tons & 1.03 \\
\hline
\end{tabular}




\section{References}

[1] http://www.oe.energy.gov/american_recovery_reinvestment_act.htm

[2] http://www.smartgrid.gov/sites/default/files/pdfs/metrics_guidebook.pdf

[3] K. Schneider, Y. Chen, D. Chassin, R. Pratt, D. Engel, and S. Thompson, "Modern Grid Initiative Distribution Taxonomy Final Report", PNNL-18035, Pacific Northwest National Laboratory, Richland, Washington, 2008

[4] T.Ackermann, G.Anderson, L.Soder, "Distributed Generation: a definition", Electric Power Systems Research, 2010, Elseiver publications

[5] R.H.Lasseter, Control of distributed resources, in: L H. Fink, C.D. Vournas (Eds.), Proceedings: Bulk Power Systems Dynamics and Control IV, Restructuring, organised by IREP and National Technical University of Athens, Santorini, Greece, August 23-28, 1998, pp. 323-329.

[6] http://apps1.eere.energy.gov/states/maps/renewable_portfolio_states.cfm

[7] R.Singh, F.Tuffner, J.Fuller, K.Schneider, "Effects of Distributed Energy Resources on Conservation Voltage Reduction (CVR)", IEEE PES General Meeting, Detroit MI, July 2011.

[8] http://www.nrel.gov/gis/

[9] http://www.solardirect.com/pv/inverters/inverters.htm

[10] P.A.Basore, J.M.Gee, "Crystalline-Silicon Photovoltaics- Necessary and Sufficient", IEEE First World Conference on Photovoltaics Energy Conversion - IEEE photovoltaics Specialists Conference, December, 1994

[11] M.C.Russell, E.C.Kern, “ Lessons learned with residential photovoltaic systems”, IEEE Photovoltaic Specialists Conference, 1990

[12] "High Penetration of Photovoltaic (PV) Systems into the Distribution Grid", Workshop Report, Sponsored by U.S. Department of Energy, Office of Energy Efficiency \& Renewable Energy, Solar Energy Technologies Program, Systems Integration Subprogram, Ontario, CA, 2009

[13] B. Mather, "Analysis of High-Penetration Levels of PV into the Distribution Grid in California”, CSI Solar R\&D program, High Penetration Solar forum, March 2011

[14] http://www.nrel.gov/rredc/pvwatts/changing_parameters.html

[15] http://www.eia.gov/cneaf/solar.renewables/page/rea_data/rea_sum.html

[16] http://openpv.nrel.gov/gallery

[17] http://pdf.directindustry.com/pdf/vestas/v90-18-and-20-mw-brochure/20680-536065.html

[18] http://sourceforge.net/projects/gridlab-d/

[19] "Guidebook for ARRA Smart Grid Program Metrics and Benefits", June 2010, http://www.smartgrid.gov/federal_initiatives/featured_initiatives/smart-grid-metrics 
[20] K. Schneider, Y. Chen, D. Chassin, R. Pratt, D. Engel, and S. Thompson, "Modern Grid Initiative Distribution Taxonomy Final Report", PNNL-18035.

[21] R. S. Briggs, R. G. Lucus, Z. T. Taylor, "Climate Classification for Building Energy Codes and Standards", ASHRAE Winter Meeting, Chicago, IL, January, 2003

[22] K. Schneider, J. Fuller, F. Tuffner, and R. Singh, "Evaluation of Conservation Voltage Reduction (CVR) on a National Level), PNNL-19596.

[23] W. H. Kersting, "Distribution System Modeling and Analysis, 2nd Edition", CRC Press, New York, 2007.

[24] K. Schneider, J. Fuller, and D. Chassin, "Multi-State Load Models for Distribution System Analysis", Accepted IEEE Transactions on Power Systems.

[25] http://www.eia.gov/ 